

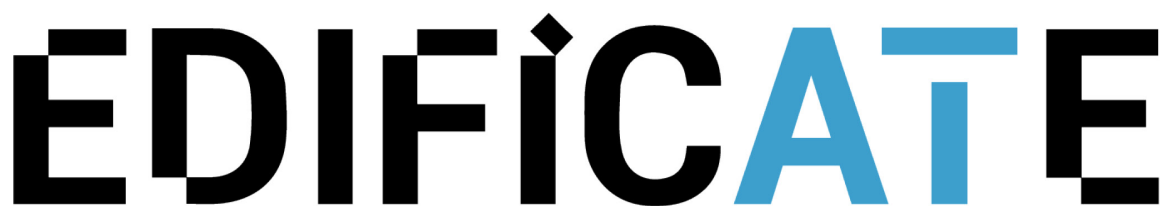

\title{
“ I CONGRESO DE ESCUELAS DE EDIFICACIÓN Y ARQUITECTURA TÉCNICA DE ESPAÑA"
}

\author{
Editores \\ Fernando Cos-Gayón López \\ José Manuel Gandía Romero
}

UNIVERSITAT
POLITÉCNICA
DE VALĖNCIA

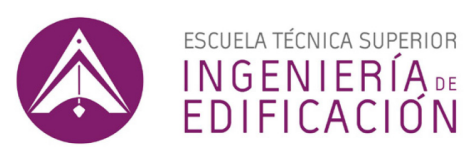




\section{Colección Congresos UPV}

Los contenidos de esta publicación han sido evaluados por el Comité Científico que en ella se relaciona y según el procedimiento que se recoge en

http://ocs.editorial.upv.es/index.php/EDIFICATe/EDIFICATe2021/about/editorialPolicies

\section{Editores}

Fernando Cos-Gayón López

José Manuel Gandía Romero

\section{Editado por}

Editorial Universitat Politècnica de València, 2021

www.lalibreria.upv.es / Ref.: 6684_01_01_01

ISBN: 978-84-9048-409-8 (versión impresa)

DOI: https://doi.org/10.4995/EDIFICATe2021.2021.13987

\section{(c) $(1) \Theta \Theta$}

I Congreso de Escuelas de Edificación y Arquitectura Técnica de España se distribuye bajo una licencia de Creative Commons Reconocimiento-NoComercial-SinObraDerivada 4.0 Internacional. Basada en una obra en http://ocs.editorial.upv.es/index.php/ EDIFICATe/EDIFICATe2021 


\section{EDIFICATE}

I CONGRESO DE ESCUELAS DE EDIFICACIÓN Y ARQUITECTURA TÉCNICA DE ESPAÑA

Editores

Comité Organizador

Chairs de las sesiones

Ponentes Invitados

Comité Científico

Patrocinadores

Prólogos

Indice de comunicaciones
III

III

III

IV

IV

V

VII

XV 


\section{EDIFICATE}

\section{CONGRESO DE ESCUELAS DE EDIFICACIÓN Y ARQUITECTURA TÉCNICA DE ESPAÑA}

\section{EDIFICATE 2021 Valencia, 4 y 5 de Noviembre de 2021}

\section{Editors / Editores}

Fernando Cos-Gayón López

José Manuel Gandía Romero

\section{Organization Committee / Comité Organizador}

Fernando Cos-Gayón López (Director), Universitat Politècnica de València Jose Manuel Gandía Romero (Coordinador), Universitat Politècnica de València Juan Manuel Santiago Zaragoza, Universidad de Granada María Segarra Cañamares, Universidad de Castilla-La Mancha Jose Ramón Albiol Ibáñez, Universitat Politècnica de València Paloma Arrué Burillo, Universitat Politècnica de València Maria Luisa Collado López, Universitat Politècnica de València Igor Fernández Plazaola, Universitat Politècnica de València Teresa Gil Piqueras, Universitat Politècnica de València Milagro Iborra Lucas, Universitat Politècnica de València M. Carmen Llinares Millán, Universitat Politècnica de València Pablo Rodríguez Navarro, Universitat Politècnica de València Pedro Gerardo Salinas Martínez, Universitat Politècnica de València

\section{Chairs of program committee I Presidentes del comité de programa}

M. Luisa Collado López Pablo Rodríguez Navarro

José Ramón Albiol Ibáñez 


\section{EDIFICATE}

\section{CONGRESO DE ESCUELAS DE EDIFICACIÓN Y ARQUITECTURA TÉCNICA DE ESPAÑA}

\section{Ponentes Invitados}

Fernando Cos-Gayon, Planes de estudio para una profesión de vanguardia Juan Manuel Santiago Zaragoza, La profesión desde la Academia Joaquín Manuel Durán Álvarez, Profesión vs Investigación. Jano o la transformación en Arquitectura Técnica e Ingeniería de Edificación

\section{Moderadores de las sesiones}

Fernando Cos-Gayón López

José Manuel Gandía Romero

\section{Scientific Committee / Comité Científico}

Carolina Aparicio Fernández, Universitat Politècnica de València Eduardo Bolufer Catalá, Universitat Politècnica de València Montserrat Bosch González, Universitat Politècnica de Catalunya Juana Cerdán Soriano, Universitat Politècnica de València Fernando da Casa Martín, Universidad de Alcalá Javier Garabito López, Universidad de Burgos Jorge Luis García Valldecabres, Universitat Politècnica de València Kàtia Gaspar Fabregas, Universitat Politècnica de Catalunya Jesús González Arteaga, Universidad de Castilla-La Mancha Francisco Hidalgo Delgado, Universitat Politècnica de València Susana Hormigos Jiménez, Universitat de les Illes Balears $M^{a}$ Concepción López González, Universitat Politècnica de València Jaime Llinares Millán, Universitat Politècnica de València Rafael Marín Sánchez, Universitat Politècnica de València Rosa María Martínez Sala, Universitat Politècnica de València Beatriz Montalbán Pozas, Universidad de Extremadura Raúl Tomás Mora García, Universidad de Alicante Elena Navarro Astor, Universitat Politècnica de València Martín Orna Carmona, Universidad de Zaragoza Luis Palmero Iglesias, Universitat Politècnica de València Ruth Pino Suárez, Universidad de La Laguna Ángel Pitarch Roig, Universitat Jaume I Castellón Susana Robles Sánchez, Universidade da Coruña 


\section{EDIFICATE}

\section{CONGRESO DE ESCUELAS DE EDIFICACIÓN Y ARQUITECTURA TÉCNICA DE ESPAÑA}

Ma Ascensión Rodríguez, Esteban Universidad de Salamanca

$M^{a}$ Jesús Romero Aloy, Universitat Politècnica de València

Josefa Ros Torres, Universidad Politécnica de Cartagena

Adela Rueda Márquez de la Plata, Universidad de Extremadura

Ma Paz Sáez Pérez, Universidad de Granada

Mercedes Valiente López, Universidad Politécnica de Madrid

Eloísa González Ponce, Universidad Católica de Murcia

Margarita Cámara Pérez, Universidad de Sevilla

Rosa Ma Domínguez Caballero, Universidad de Sevilla

\section{Patrocinadores}

Escuela Técnica Superior de Ingeniería de Edificación

CODATIE-Conferencia de Directores de Arquitectura Técnica e Ingeniería de Edificación

Consejo General de la Arquitectura Técnica de España

Universitat Politècnica de Valéncia

Cátedras Patrocinadoras

Cátedra UPV Observatorio de la Vivienda

Cátedra UPV Bertolín

Cátedra UPV CAATIE Valencia 


\section{EDIFICATE \\ I CONGRESO DE ESCUELAS DE EDIFICACIÓN Y ARQUITECTURA TÉCNICA DE ESPAÑA}

EI 50 aniversario de la Escuela Técnica Superior de Ingeniería de Edificación (ETSIE) es un momento clave que invita a reflexionar sobre una historia de éxito que ha sentado las bases de un brillante presente y de un prometedor futuro. La excelente dedicación con la que la Escuela ha formado profesionales de la Arquitectura Técnica y de la Ingeniería de Edificación es innegable. Más aún lo es la notable contribución que sus egresados han hecho a la construcción de las ciudades y los edificios que conforman la sociedad en la que vivimos, y todo ello con un alto y reconocido desempeño.

Este período se ha construido bajo una perspectiva de mejora continua, como lo demuestra la adecuación de los conocimientos, herramientas y planteamientos formativos que desde la Escuela se han desarrollado todos estos años. La Universidad puede afirmar con orgullo que cuenta con centros como la ETSIE que están a la vanguardia del conocimiento. Todo ello redunda en beneficio de nuestros estudiantes que, además de contar con una formación del máximo nivel, pueden beneficiarse de las oportunidades que genera un entorno único como el de la Universitat Politècnica de València.

La ETSIE tiene la peculiaridad de conjugar en perfecta armonía lo local con la necesaria generalidad de un mundo interconectado. Es por ello que es para mí un honor presentar el congreso EDIFÍCATE_2021, donde se da precisamente esta circunstancia. Este evento es un lugar de encuentro para expertos de 22 universidades españolas que, durante unas intensas jornadas abordarán cuestiones del máximo interés para nuestros futuros egresados: oferta educativa, planes de estudio, empleabilidad o sostenibilidad.

Así pues, felicito a los organizadores de este congreso, y estoy plenamente convencido de que de él surgirán sinergias que ahondarán en la colaboración interuniversitaria del profesorado y en la generación de participaciones conjuntas en proyectos de investigación e iniciativas docentes compartidas.

José E. Capilla Romá

Rector de la Universitat Politècnica de València 


\section{EDIFICATE \\ I CONGRESO DE ESCUELAS DE EDIFICACIÓN Y ARQUITECTURA TÉCNICA DE ESPAÑA}

"La mayoría de las personas son otras: sus pensamientos, las opiniones de otros; su vida, una imitación; sus pasiones, una cita."

Óscar Wilde

En tiempos donde la escueta inmediatez de un tweet mueve opiniones, acciones y reacciones, la oportunidad de reflexionar acerca de lo que somos se torna cada vez más compleja, preñada de distracciones que aturden y laminan. Como dejó escrito Wilde desde la soledad de Reading, quizás no son nuestros pensamientos, vida o pasiones lo que vivimos; quizás el vértigo que nos azota no nos deja pensar, vivir y apasionarnos, y todo ello no sea más que una burda imitación.

La urgencia que nos reclama es, ya no buscar quiénes somos, sino decidir quiénes queremos ser. Y lo hemos de hacer mientras todo cambia, signo de nuestros tiempos. La Edificación se enfrenta a un momento crucial, donde digitalización, industrialización y sostenibilidad van a transformar absolutamente el sector de la construcción de edificios. Se abren nuevos perfiles profesionales, nuevos procesos que liderar, nuevas herramientas que implementar, y el Arquitecto Técnico como agente legitimado para ello debe ser actor principal en este cambio.

La construcción industrializada -con su fabricación deslocalizada de la obra-, los nuevos agentes que lideran la promoción inmobiliaria, una acuciante falta de mano de obra cualificada, el incremento de los costes de construcción, la eficiencia energética, la conservación del patrimonio, la aparición de nuevos productos inmobiliarios, etc. Todo ello está requiriendo un técnico diversificado, con conocimientos y herramientas de gestión de última generación, capacidad de análisis y de adaptación, que le permitan actuar en cualquier entorno profesional.

Es por ello una necesidad -y una oportunidad- repensar y homogeneizar nuestros planes de estudios conducentes a la habilitación como Arquitecto Técnico. Hemos de aprovechar estos vientos favorables para el sector y ofrecer al estudiantado, presente y futuro, un grado universitario de alta capacitación, dotarle de herramientas sofisticadas, trasladándoles nítidamente que serán unos profesionales de reconocido prestigio, orientados a un futuro sostenible, preparados para liderar equipos motivados y solventes.

Esa es la esencia que ha inspirado este encuentro entre las Escuelas de España, y el nombre de nuestro congreso EDIFÍCATe: construyamos, edifiquemos juntos cómo será la Arquitectura Técnica que necesita la sociedad, la Ingeniería de Edificación que precisa nuestro alumnado; debatamos acerca de todo, de la enseñanza, de nuestra identidad, junto a nuestros colegios profesionales, pero con la urgencia del acuerdo que precisamos para avanzar juntos y que merece esta profesión centenaria, con un futuro envidiable. Pensemos, vivamos y apasionémonos juntos.

Fernando Cos-Gayón López

Director del Congreso Edifícate

Universitat Politècnica de València 


\section{EDIFICATE \\ I CONGRESO DE ESCUELAS DE EDIFICACIÓN Y ARQUITECTURA TÉCNICA DE ESPAÑA}

Quiero felicitar a la ETS de Ingeniería de Edificación de la Universitat Politècnica de València, y en especial a su director, el Dr. Fernando Cos-Gayón, por la iniciativa tomada para que este Congreso sea posible.

Hacer extensiva mi felicitación a los distintos autores que hacen que este libro de actas, que el lector tiene en sus manos, pulcramente editado, sea riguroso en su contenido y una ventana transparente al quehacer de las escuelas.

La variedad de temáticas habla de nuestra idiosincrasia y singularidad académica, como universidades ocupadas de su presente y, sobre todo, de su futuro: desde la docencia y su mejora, a los planes de estudio. Una base común, los 180 créditos homologables de la Orden $\mathrm{ECl}$, nos prepara para un mundo profesional diverso, y son la antesala de una ampliación de competencias, con los restantes 60 créditos del Grado, pero también con los Másteres y Doctorados, profundizando en materias y complejos ámbitos de interés de cada uno de los centros y de los egresados. Los sistemas de gestión y organización y la transversalidad de las materias completan un rico panorama.

Nuestro encaje en la estructura universitaria es sólido y actualmente disfrutamos de condiciones análogas al resto de titulaciones. Tenemos autonomía y capacidad de participar, de forma permanente, en los órganos de decisión que nos afectan.

Y nuestra apuesta es que, en las relaciones interprofesionales, este progreso sea análogo. En los países de nuestro entorno, los ingenieros de edificación actúan y cooperan en esferas y equipos multidisciplinares, en un plano de justa correspondencia, basada en el reconocimiento y el respeto de la diversidad, y también de la capacidad de cada uno. Así que, en tanto la peculiar normativa española se moderniza, debemos alejarnos de viejos y falsos estereotipos locales, que ya no se pueden sostener -ahora menos que nunca-, ni por la formación recibida, ni por la capacitación demostrada. Algo que ya les ocurre a nuestros titulados, cuando han de ejercer en otros países donde, verdaderamente, las atribuciones son las competencias.

Juan Manuel Santiago Zaragoza

Presidente de la Conferencia de Directores de Arquitectura

Técnica e Ingeniería de Edificación (CODATIE) 


\section{EDIFICATE \\ I CONGRESO DE ESCUELAS DE EDIFICACIÓN Y ARQUITECTURA TÉCNICA DE ESPAÑA}

Estimados congresistas

Sirvan estas palabras para daros la mas calurosa bienvenida.

Celebro muy especialmente la vuelta a mi escuela, que aún conserva entre sus aulas los recuerdos de una juventud inmersa en la construcción de un yo. Celebro también la iniciativa de su director de materializar una estupenda idea, que juzgo necesaria y conveniente.

Nuestra profesión tiene menos prestigio social del que merece, y es tarea de todos los estamentos, desde el docente hasta los representantes de los colegios profesionales, situarla en su verdadero lugar.

Especialmente importante es encontrar dentro de la autonomía universitaria un nosotros que sea la suma de los yo. Unificar en la medida de lo posible objetivos, atender a las oportunidades de demanda, agilizar las estructuras de manera que posibiliten el aprovechamiento de oportunidades, en un mundo que cada vez cambia mas rápido.

Como responsables de nuestras escuelas, estáis formando a futuros profesionales que deben contribuir a resolver los problemas de la sociedad en el ámbito de sus competencias. Ello nos sitúa en un espacio de responsabilidad compartida.

El allegro que vivimos nos invita a actuar rápido pensando despacio, y toca hacer uso de un sentido común refinado.

Inmersos en una trayectoria que transforma los prototipos que constituyen hasta ahora la edificación de una obra, en elementos seriados producidos en taller, debemos adaptar nuestra aportación al proceso, descartando prejuicios, que no son como dice el filósofo Marina, sino fracasos de la inteligencia.

Un congreso, es un buen lugar para reconocer trayectorias y proyectar itinerarios. No hay otro futuro posible que el futuro común. Por ello, os lo deseo y nos lo deseo.

Gracias por vuestro trabajo.

Alfredo Sanz

Presidente del Consejo General de la Arquitectura Técnica de España (CGATE) 


\section{EDIFICATE}

I CONGRESO DE ESCUELAS DE EDIFICACIÓN Y ARQUITECTURA TÉCNICA DE ESPAÑA

\section{ÍNDICE DE COMUNICACIONES}

\section{MATERIAS}

\section{Fundamentos científicos}

Implementación de recursos digitales para la formación a distancia en las asignaturas prácticas de la construcción

Jorge Arturo Gutiérrez Camarena, Fabiola Colmenero Fonseca, Luis Manuel Palmero Iglesias, Graziella Bernardo y Francisco Javier Carcel Carrasco

Adaptación metodológica de la docencia de la asignatura Matemáticas II del Grado en Arquitectura Técnica de la UPV debida a la Pandemia

Juana Cerdán Soriano, Màrius Fullana Alfonso y David Soler fernández

Investigación aplicada a la formación en nuevos materiales de construcción

Jesús Gadea Sáinz, Verónica Calderón Carpintero, Carlos Junco Petrement, Sara Gutiérrez-González, Ángel Rodríguez Saiz y Javier Garabito López

\section{Expresión Gráfica}

El método Flipped Classroom en asignaturas gráficas

Concepción López González, Jorge Luis García Valldecabres y Jorge Girbés Pérez

La Exposición de trabajos de clase como motivación para estudiantes de Expresión Gráfica

Ruth Pino Suárez y Juan Alejandro Melián Melián 


\section{EDIFICATE}

\section{CONGRESO DE ESCUELAS DE EDIFICACIÓN Y ARQUITECTURA TÉCNICA DE ESPAÑA}

Introducción de nuevas estrategias para el aprendizaje autónomo en alumnos de primer curso

María Isabel Giner-García y Ángeles Rodrigo-Molina

La metodología BIM como elemento vehicular en la docencia de Grado en Ingeniería de Edificación

David Valverde Cantero

\section{Técnicas y Tecnología de la Edificación}

Historia de la construcción, construcciones históricas y construcción tradicional en los planes de Grado de Edificación

Francisco Javier Castilla Pascual

Aprendizaje del proceso constructivo, basado en proyectos, mediante el empleo de BIM

Susana Hormigos-Jiménez, Gabriel Horrach Sastre, Joan Muñoz Gomila, Cristian Carmona Gómez y Francesc Masdeu Mayans

La importancia del marcado CE para el Director de Ejecución de Obra. Aspectos destacados en la formación de los futuros profesionales

Susana Robles Sánchez y María Paz Sáez Pérez

Estrategias docentes en el proceso de enseñanza y aprendizaje sobre sostenibilidad en el Grado en Arquitectura Técnica de la Universidad de Burgos

Javier Garabito López, Ángel Rodríguez Saiz, Verónica Calderón Carpintero, Sara Gutiérrez González, Francisco Fiol Oliván y Carmelo Muñoz Ruipérez

Metodología y recursos didácticos claves en el proceso de enseñanza-aprendizaje de las asignaturas de Construcción II y III del Grado de Arquitectura Técnica José Manuel Gandía Romero, Milagro Iborra Lucas y Ana Martínez Ibernón 


\section{EDIFICATE}

\section{CONGRESO DE ESCUELAS DE EDIFICACIÓN Y ARQUITECTURA TÉCNICA DE ESPAÑA}

La influencia de la presencialidad del alumnado en los resultados de evaluación en la UCAM

Eloísa González Ponce, Nuria Rosa Roca, Mercedes Galiana Agulló

Innovación pedagógica y aprendizajes en las asignaturas de Construcción en el Grado en Arquitectura Técnica de la Universidad de Burgos

Carmelo Muñoz Ruiperez, Marina Muñoz-Arranz y Francisco

Fiol Olivan

Instrumentación real de edificios para docencia en la asignatura de Patología y Restauración

Jesús González-Arteaga

Repositorio de términos constructivos

Luis Damián Ramos Pereira

Experiencias en docencia en inglés

María-Isabel Giner-García y Ángeles Rodrigo-Molina

Metodologías para la enseñanza de la Construcción en Edificación. Flip Teaching

Milagro Iborra Lucas y Jose Manuel Gandía Romero

\section{Estructuras e Instalaciones en edificación}

Diagnóstico de la ventilación natural, concentración de $\mathrm{CO}$, temperatura y humedad relativa de un aula docente con motivo del SARS-CoV-2. Caso de las aulas de la ETSIE de la UPV

Antonio Manuel Romero Sedó, Paloma Arrué Burillo, Carolina Aparicio Fernández y Milagro Iborra Lucas 


\section{EDIFICATE}

\section{CONGRESO DE ESCUELAS DE EDIFICACIÓN Y ARQUITECTURA TÉCNICA DE ESPAÑA}

\section{Gestión del Proceso}

Prevención y Seguridad en el Grado de Edificación, transversalidad y experiencia docente

Francisco José Forteza Oliver y Bárbara Estudillo Gil

Convalidación de la formación en materia de Prevención de Riesgos Laborales del Sector de la Construcción establecida en Convenio a los titulados de las Escuelas de Edificación y Arquitectura Técnica de España

María Segarra Cañamares

Guía de recomendaciones para la Gestión y tratamiento de RESIDUOS generados por las medidas de prevención ante la COVID-19 en obras de construcción

Francisco J. Sánchez Medrano, Salvador Aledo Guerao y Jesús H. Alcañíz Martínez

Encuesta de las medidas de prevención y protección frente a la COVID-19 añadidas a la Seguridad y Salud de las obras Francisco J. Sánchez Medrano, Salvador Aledo Guerao, Enrique Mínguez Martínez y Verónica Nadal Jiménez

\section{Proyectos Técnicos}

Desglose y sistematización de ítems para las labores de supervisión formal de proyectos de edificación

Manuel J. Carretero-Ayuso

Implantación de la metodología del Aprendizaje basado en Proyectos en la asignatura de Taller de Proyecto de Interiores Teresa Gil Piqueras y Pablo Rodríguez Navarro

\section{Derecho y Economía aplicados}

Evolución del plan de empresa en edificación como metodología docente de Aprendizaje basado en Proyectos Igor Fernández-Plazaola

La inserción de las asignaturas de carácter legal en la titulación de arquitecto técnico $M^{a}$ Jesús Romero Aloy 


\section{EDIFICATE}

\section{CONGRESO DE ESCUELAS DE EDIFICACIÓN Y ARQUITECTURA TÉCNICA DE ESPAÑA}

\section{Proyecto Final de Grado}

EI PFG como herramienta para la especialización en análisis integral y difusión del Patrimonio Arquitectónico

Pedro Enrique Collado Espejo

Innovación docente en el Trabajo Final de Grado de Arquitectura Técnica y Edificación. La oportunidad del Aprendizaje participativo sobre casos reales

Fernando da Casa Martín, Antonio Baño Nieva y Jorge Carlos

Delgado García

Aplicación Ebrón para la gestión de los Trabajos Fin de Grado y Fin de Máster en la UPV

Pedro Gerardo Salinas Martínez

\section{PLAN DE ESTUDIOS Y MODELOS DE GESTIÓN}

Convergencia de Títulos de Grado conforme a la Orden ECI $3855 / 2015$

Juan Manuel Santiago Zaragoza y María Segarra Cañamares

Modificación del plan de estudios del grado en Arquitectura Técnica y Edificación de la UPC

Inma Rodríguez Cantalapiedra y Juan Rodríguez Jordana

La incorporación de los ODS en el plan de estudios de Arquitectura Técnica y Edificación (2021) de la Universidad de Alcalá

Fernando da Casa Martín, Antonio Baño Nieva, Juan Manuel Vega Ballesteros, Ignacio Delgado Conde, Francisco Maza Vázquez, Enrique José Fernandez Tapia, Javier Temiño Vela, Ernesto Enrique Echeverría Valiente, Flavio Celis D'Amico, Enrique Castaño Perea y Mónica Martinez Martinez

La ingeniería de edificación. Una apuesta de futuro Juan Manuel Santiago Zaragoza, Fabián García Carrillo y Joaquín Passolas Colmenero, Emilio Gómez Cobos 


\section{EDIFICATE}

\section{CONGRESO DE ESCUELAS DE EDIFICACIÓN Y ARQUITECTURA TÉCNICA DE ESPAÑA}

Radiografía del Grado en Arquitectura Técnica de la EPS de Zamora (Universidad de Salamanca)

María Ascensión Rodríguez-Esteban, María Almudena FrechiIla-Alonso, Ana Belén González-Rogado y Ana Belén RamosGavilán

Propuesta de modificación de las Competencias de la asignatura Construcción VI de la Escuela Técnica Superior de Ingeniería de Edificación de la Universitat Politècnica de València

459

Jaime Llinares Millán, Jose Miguel Molines Cano y José María Bravo Plana-Sala

\section{TRANSVERSALIDAD}

La Inteligencia Artificial y su contribución a la optimización de la atención y memoria de los estudiantes a través del diseño del aula

Adrián Colomer Granero, Juan Luis Higuera Trujillo, Valeriana Naranjo Ornedo y Carmen Llinares Millan

La dificultad como oportunidad de cambio: mejoras docentes tras una experiencia íntegramente online

Lucía Reig-Cerdá, María José Ruá Aguilar, Àngel Miguel Pitarch Roig y Joaquín Angel Martínez Moya

RIARTE. EI repositorio científico y profesional de la Arquitectura e Ingeniería. Contenidos y avances

Joaquín Manuel Durán Álvarez, Juan López-Asiain Martínez y Alejandro Payán de Tejada Alonso

Innovación tecnológica de productos de la construcción en las enseñanzas técnicas de la Edificación

María Fernández Alconchel, Jose David Bienvenido Huertas, Juan José Moyano Campos 


\section{EDIFICATE}

\section{CONGRESO DE ESCUELAS DE EDIFICACIÓN Y ARQUITECTURA TÉCNICA DE ESPAÑA}

Equipo docente para la Docencia Digital y la Coordinación Transversal de las asignaturas del Módulo de Gestión del Proceso del Grado de Edificación. Universidad de Granada 523

Antonio J. Aguilar, Carlos Benavides de la Fuente, Gloria Cuenca-Moyano, Lourdes Gutiérrez-Carrillo, María L. de la Hoz-Torres, María Martín-Morales, María D. Martínez-Aires, Manuel Martínez Carrillo y Raquel Nieto-Álvarez

Ingeniería para las nuevas generaciones: contruyendo con bambú

Alba Fernández Sánchez, Ana María Cruz Valdivieso y Juan Manuel Santiago Zaragoza

Internacionalización en el Grado de Arquitectura Técnica Juan Villarroya Gaudó, Rafael Adé Beltrán e Inmaculada Urriés Ortiz

Competencias digitales, sí o sí 569

Montserrat Bosch González y Blas Echebarria Domínguez

Formación e investigación en rehabilitación: un campo para la colaboración interuniversitaria 581 Montserrat Bosch González y Joan Ramon Rosell Amigó

Implantación de la evaluación de Competencias Transversales en la titulación de Grado en Arquitectura Técnica de la Escuela Técnica Superior de Ingeniería de Edificación de la Universitat Politècnica de València

María Luisa Collado López y Paloma Arrué Burillo

Prácticas curriculares de estudiantes en empresas y despachos profesionales en el Grado de Ingeniería de Edificación

Julián Pérez Navarro y Josefa Ros Torres

Una aproximación al desarrollo de un índice neurofisiológico capaz de pre-decir el rendimiento cognitivo de un alumno a partir del diseño del aula

Juan Luis Higuera Trujillo, Adrián Colomer Granero, Valeriana Naranjo Ornedo, Carmen Llinares Millan 


\section{EDIFICATE}

\section{CONGRESO DE ESCUELAS DE EDIFICACIÓN Y ARQUITECTURA TÉCNICA DE ESPAÑA}

Observatorio 2020 de la producción científica de la Arquitectura Técnica en España. Análisis de la evolución de la Investigación en Arquitectura Técnica en la Universidad española

Joaquín Manuel Durán Álvarez

Proyecto Tetuán como espacio de aprendizaje. Investigación y docencia en Conservación del Patrimonio Edificado

Lorenzo Jurina, Carlo Manfredi, Carmen Campra García de

Viguera, Antonio Jiménez-Delgado

Movilidad de los estudiantes de Arquitectura Técnica y Edificación: diagnóstico y oportunidades

Laia Haurie Ibarra y Chantal Alastruey Martin 


\section{EDIFICATE}

I CONGRESO DE ESCUELAS DE EDIFICACIÓN Y ARQUITECTURA TÉCNICA DE ESPAÑA

\section{ENTIDADES COLABORADORAS}
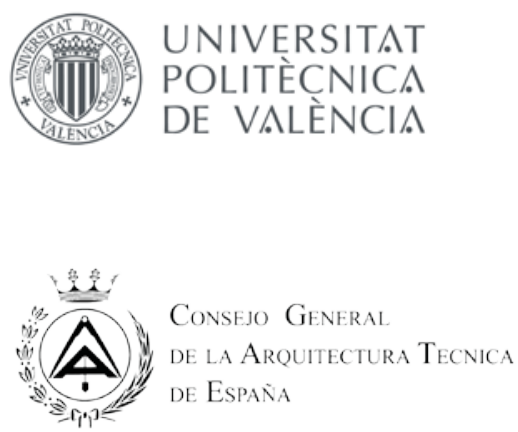

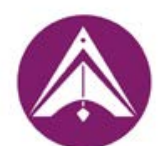

ESCUELA TÉCNICA SUPERIOR INGENIERÍA EDIFICACIÓN

\section{CODATIE}

| Conferencia de Directores de Arquitectura Técnica e Ingeniería de Edificación

PATROCINAN

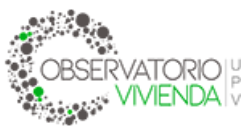




\title{
EDIFICATE
}

I Congreso de Escuelas de Edificación y Arquitectura Técnica de España

València, 4 y 5 de noviembre de 2021

Escuela Técnica Superior de Ingeniería de Edificación

Universitat Politècnica de València

Doi: https://doi.org/10.4995/EDIFICATE2021.2021.13292

\section{Implementación de recursos digitales para la formación a distancia en las asignaturas prácticas de la construcción Implementation of digital resources for distance learning in the practical subjects of construction}

\author{
Jorge Arturo Gutiérrez Camarena ${ }^{a}$, Fabiola Colmenero Fonseca ${ }^{b}$, Luis Manuel \\ Palmero Iglesias ${ }^{c}, G^{\prime}$ raziella Bernardo y ${ }^{d}$ Francisco Javier Carcel Carrasco ${ }^{e}$ \\ a Universidad de Guanajuato, Guanajuato, México; gutierrezja@ugto.mx ${ }^{\mathrm{b}}$ Departamento del Hábitat y \\ Desarrollo Urbano, Instituto Tecnológico y de Estudios Superiores de Occidente (ITESO), Jalisco, \\ México; fcolmenero@iteso.mx y ${ }^{\mathrm{C}}$ Departamento de Construcciones Arquitectónicas; \\ Ipalmero@csa.upv.es dUniversità degli Studi della Basilicata, Italia; graziella.bernardo@unibas.it \\ eDepartamento de Construcciones Arquitectónicas, Área Edificación, Universitat Politècnica de \\ València,España; fracarc1@csa.upv.es
}

\begin{abstract}
Due to the current contingency caused by the COVID-19 pandemic, in several universities around the world, it has been necessary to resort to distance learning to avoid the number of infections.

Some subjects have represented a challenge in the teaching-learning relationship because, although the cognitive knowledge of the subjects is unquestionable, the procedural knowledge is not easily communicated in the virtual modality. For example, in practical construction subjects, it is possible to show the theoretical foundations, but it is considered necessary to be accompanied by the advisor to ensure correct execution of the different mathematical problems presented.
\end{abstract}

Therefore, it is necessary to align the didactic resources available with the specific competencies of the subjects and considering the context in which we are immersed.

Currently, there are different digital tools available and the implementation of some of them is presented below according to analysis concerning the Didactic Guide of the subject itself.

Keywords: technological resources, practical construction subjects, distance mode. 


\section{Resumen}

Debido a la actual contingencia por la pandemia de COVID-19, en varias Universidades del mundo ha sido necesario recurrir a la educación no presencial para evitar el número de contagios.

Algunas materias han representado un desafío en la relación enseñanza aprendizaje pues, aunque el saber cognitivo de los temas es incuestionable, los saberes procedimentales no son fácilmente comunicables en la modalidad virtual. Por ejemplo, en asignaturas prácticas de la contrucción, es posible mostrar los fundamentos teóricos, pero se considera necesario el acompañamiento por parte del asesor para así asegurar una correcta ejecución de los diferentes problemas matemáticos presentados.

Por ello, se ve necesario alinear los recursos didácticos disponibles con las competencias especificas de las asignaturas y considerando a la vez el contexto en que nos encontramos inmersos.

En la actualidad existen diferentes herramientas digitales disponibles y se presenta a continuación la implementación de algunas de ellas conforme a un análisis con respecto a la Guía Didáctica de la materia.

Palabras clave: recursos tecnológicos, asignaturas prácticas de la construcción, modalidad a distancia. 


\section{Introducción}

La educación a distancia no es una actividad reciente pues basta señalar que entre los años 1960 a 1975 tan sólo en África ya existían 20 instituciones de este tipo (Hernández, 2006). Por ejemplo, algunas instituciones se basaban en el uso de cintas magnéticas y, posteriormente usaban casettes de formato VHS con los que comunicaban los conceptos principales de cada materia en particular.

No fue sino hasta el desarrollo de las telecomunicaciones y la necesidad de una educación que se adapte a las necesidades contemporáneas lo que ha permitido que la modalidad a distancia vea reforzada su razón de ser (Hernández, 2006). Mientras que, el surgimiento y mejora de recursos didácticos de naturaleza digital han facilitado la experiencia de aprendizaje de los individuos, quienes pueden obtener conocimientos incluso de manera autodidacta.

Debido a la actual contingencia ocasionada por la pandemia COVID-19, varias universidades, de carácter presencial, se vieron obligadas a cerrar sus espacios físicos. De igual manera se vieron forzadas a implementar el uso de recursos digitales y ambientes virtuales de aprendizaje, en un intento improvisado de continuar los ciclos escolares respectivos, donde, la información y conocimientos pudieron transmitirse en mayor o menor medida.

Sin embargo, recordemos que las competencias didácticas no sólo se componen de conocimientos (saberes cognitivos), sino también de forma integrada tanto de habilidades y destrezas (saberes procedimentales) así como de actitudes y valores (saberes conductuales) (Tigelaar, 2004).

Dicho lo anterior, se observa que el conocimiento o saber cognitivo es fácilmente asequible en una educación no presencial; pero, existen más dificultades para la transmisión de saberes procedimentales y conductuales. Es decir, el desarrollo de habilidades y actitudes ha tenido más factibilidad durante las clases tradicionales cara a cara.

Es cierto que se ha visto implementado a nivel mundial el uso de laboratorios remotos para poder realizar prácticas tal como lo señala Ariza y otros en el año 2008 y ejemplifican con el caso de la Universidad Militar Nueva Granada (Ariza, 2008). Pero, debe considerarse que estas tecnologías no existen para todas las universidades ni para todos los Programas Académicos, por lo que, mientras se obtienen dichas mejoras, será necesario que el docente evalúe los recursos didácticos con los cuales dispone y seleccione los que más se ajusten en su contexto.

Es bien conocido que la actividad docente influye y se retroalimenta sustancialmente del contexto social. Por ejemplo, Elton, Filomena y Teresa (2019), en su estudio llevado a cabo en la ciudad de Tete en Mozambique, ya mencionan la importancia de la labor docente en la formación de ciudadanos activos con su entorno; así como con la formación de ciudadanos conscientes del contexto global, pero sin perder de vista la realidad local. Y de igual manera podemos hablar de contextos virtuales. 
Asimismo, como menciona Ramírez y Montoya (2018), la buena docencia se asocia a la capacidad que tiene el profesor para motivar a los estudiantes, ofrecer un ambiente de aprendizaje estimulante, conectar a los estudiantes con la profesión, crear escuela y aportar al logro de la misión institucional. Una de las labores docentes que coadyuvan a esta buena docencia descrita anteriormente está en función de las creencias del profesor.

Es importante señalar que a la par del desarrollo tecnológico ha surgido un cambio de paradigma en la actividad docente. Anteriormente se partía de una postura basada en la enseñanza y ahora se dirige a una educación enfocada en el aprendizaje (Barry R. y Tagg J., 1995). Asimismo, sigue siendo válido el argumento de que el aprendizaje no se limita sólo por las características intrínsecas del alumno (motivación, capacidades, etc.) definidas en el enfoque centrado en el estudiante; ni tampoco se limita al profesor y los recursos didácticos disponibles definidos. Más bien, importa el contexto en conjunto y permitiendo que el alumno desarrolle sus capacidades más que limitarse a recibir la información (Biggs, 2006). Lo anterior independientemente de que hablemos de un espacio físico o virtual.

Del mismo modo, ya se ha investigado la importancia de renovar las formas de evaluación, porque tal como indican Dochy, Segers y Dierick (2002) y Vallés, Ureña y Ruiz (2011), los estudiantes lo encuentran más interesante y motivador. Dicha habilidad también se ve influenciada por las creencias, dado que al ser elementos dinámicos, nos permiten renovar y adaptarnos a diferentes contextos dentro y fuera del aula.

Se añade también que la educación a distancia por modalidad virtual conlleva algunos elementos particulares tal como la capacitación de los docentes encargados de impartir la materia en el uso de las Tecnologías de la Información (López y Darío, 2005) y el consumo de recursos didácticos existentes para establecer conexiones entre contenidos mediáticos dispersos (Benassini, 2014)

Finalmente, como expresan López y Darío en el año 2005, la educación mediada por tecnologías de la información y comunicación llegó para quedarse.

\section{Objetivos}

El objetivo principal de este trabajo fue que:

- El alumno adquiera los saberes procedimentales de las asignaturas prácticas de la construcción mediante la modalidad de clases virtuales.

Para ello como objetivo secundario se propuso:

- Implementar herramientas digitales para la enseñanza, evaluación y retroalimentación de los alumnos. 


\section{Desarrollo de la innovación}

Las estrategias y recursos didácticos de esta sección fueron implementadas para los grupos de las asignaturas prácticas de la construcción correspondiente a los periodos:

- Primavera 2020

- Otoño 2020

- Primavera 2021.

La plataforma virtual seleccionada fue Microsoft Teams.

Como pasos fundamentales se describen los siguientes:

- Definición del objetivo principal de la asignatura

- Definición de las competencias generales y específicas de la Guía de Aprendizaje.

- División del curso en momentos de aprendizaje

- Selección de recursos didácticos congruentes con las competencias

- Asignación de actividades digitales

- Evaluación y retroalimentación del alumnado

A partir de la Guía docente se determinó que la competencia específica esperada para el estudiante es que éste aplique las técnicas del cálculo aplicadas a la construcción para resolver problemas que representan situaciones propias de la Edificación, buscando la certeza en sus resultados bajo los principios éticos, formalidad y responsabilidad.

Del mismo modo se aprecia que el contenido de los diferentes Programas Académicos se resume en el siguiente temario:

- Introducción a fórmulas aplicadas al cálculo de estructuras

- Ecuaciones Lineales

- Espacios Vectoriales

- Ortogonalidad

- Determinantes

- Valores y Vectores Propios

- Transformaciones Lineales

Los tópicos anteriores se dividieron en momentos de aprendizaje conforme a la Guía docente donde, además del objetivo de la materia y las competencias específicas, se obtiene el tiempo efectivo de sesiones.

Se aplicó la ruta de enseñanza - aprendizaje mediante los 9 pasos de Gagné y el modelo ARCS y se definen las siguientes estrategias generales: 
Tabla 1. Ruta de enseñanza - aprendizaje

\begin{tabular}{|c|c|}
\hline Etapa & Recomendación \\
\hline Atraer la atención & $\begin{array}{l}\text { Se propone adjuntar videos e imágenes llamativas (colores } \\
\text { contrastantes y armónicos) }\end{array}$ \\
\hline $\begin{array}{l}\text { Informar a los alumnos } \\
\text { de los resultados de } \\
\text { aprendizaje }\end{array}$ & $\begin{array}{l}\text { Inicialmente se plantea la bienvenida y los criterios de } \\
\text { evaluación en formatos pdf con diseño formal para definir el } \\
\text { proceso y el resultado de aprendizaje. }\end{array}$ \\
\hline $\begin{array}{l}\text { Evocar los } \\
\text { conocimientos previos }\end{array}$ & $\begin{array}{l}\text { Adjuntar documentos en modalidad de anexos que se refieran } \\
\text { a saberes previos y que recurrentes en la Unidad de } \\
\text { Aprendizaje. }\end{array}$ \\
\hline $\begin{array}{l}\text { Presentar el Contenido } \\
\text { (nueva información) }\end{array}$ & $\begin{array}{l}\text { Aplicar recursos didácticos de diagramas de llaves y otros } \\
\text { organizadores gráficos para mantener un panorama general de } \\
\text { las clasificaciones de Ecuaciones Diferenciales. }\end{array}$ \\
\hline $\begin{array}{l}\text { Guiar, orientar y } \\
\text { acompañar a los } \\
\text { alumnos }\end{array}$ & $\begin{array}{l}\text { Videollamadas para aclaración de dudas y comentarios. } \\
\text { Asimismo, se propone un canal privado (chat de Microsoft } \\
\text { Teams) para facilitar la comunicación de los alumnos. }\end{array}$ \\
\hline Practicar & $\begin{array}{l}\text { Actividades mediante la pestaña de "Tareas" que se realizarán } \\
\text { de manera asíncrona por parte del alumno. La calificación } \\
\text { forma parte de la evaluación final. }\end{array}$ \\
\hline Retroalimentar & $\begin{array}{l}\text { Repasar en videollamadas los conceptos vistos con } \\
\text { anterioridad y aclarar dudas (y errores) que hayan surgido en } \\
\text { trabajos, siempre bajo el anonimato del alumno, salvo que éste } \\
\text { expresase lo contrario. }\end{array}$ \\
\hline Evaluar & $\begin{array}{l}\text { Calificación mediante rúbricas, prestando atención a los } \\
\text { componentes de uso de datos correctos (variar los datos por } \\
\text { alumno para mitigar las copias de trabajos), el proceso y el } \\
\text { resultado final. }\end{array}$ \\
\hline Reforzar el aprendizaje & $\begin{array}{l}\text { Se prefiere una ruta confidencial a través del chat privado de } \\
\text { Microsoft Teams donde se adjunte un documento elaborado } \\
\text { formalmente con la calificación y la rúbrica de evaluación de } \\
\text { cada parcial. }\end{array}$ \\
\hline
\end{tabular}


Tabla 2. Modelo ARCS

\begin{tabular}{ll}
\hline Categoría & \multicolumn{1}{c}{ Estrategias y recursos didácticos propuestos } \\
\hline Atención & $\begin{array}{l}\text { Curiosidad inicial por parte del alumno: Inicialmente los alumnos prestarán } \\
\text { atención por la curiosidad de los criterios de evaluación (o el miedo a ser } \\
\text { reprobados). Así que la idea es aprovechar esta etapa para formalizar los } \\
\text { criterios relevantes de la evaluación y las reglas principales del curso. }\end{array}$
\end{tabular}

Contraste: Uso de imágenes asociadas al tema, pero de colores armónicos y contrastantes. Se puede a su vez utilizar grabaciones y vídeos que se diferencien de los demás elementos / archivos del curso.

Relavancia Resumir: definir la competencia fundamental y sintetizar en el primer apartado del archivo los puntos esenciales. Desglosar más adelante los elementos secundarios para quienes deseen profundizar en el tema.

Añadir más peso en la evaluación de los temas esenciales: asociado al punto anterior, los conocimientos importantes para la Guía de aprendizaje se definen en los criterios de evaluación y durante la explicación del contenido (por videollamada o documento escrito) mencionar cuáles conocimientos son secundarios (útiles pero que no se considerarán en la evaluación).

Confianza Propiciar la participación del grupo: todos los comentarios asociados a la materia son bienvenidos durante las videollamadas. En caso de alguna discrepancia, agradecer la participación y a su vez comentar los puntos que pueden mejorarse.

Facilitar los canales de comunicación: algunos alumnos no se sienten cómodos con la participación ante otras personas. Por ello recomiendo permitir canales de comunicación privados (tal como el chat de Microsoft Teams) para permitir expresar sus dudas y comentarios.

Satisfacción Permitir el uso de "emoticonos" en las publicaciones: por medio de estos pequeños símbolos es posible definir indicadores de bienestar/malestar por parte de los alumnos para reforzar en su caso los puntos necesarios.

Flexibilidad en aprendizaje del alumno: se recomienda ser flexible en cuanto a la sincronía / asincronía del curso, pues algunos individuos aprenden mejor cuando perciben al maestro y otros son más autodidactas, quienes prefieren leer y acudir al maestro sólo como orientación.

A partir de las estrategias planteadas y de la plataforma virtual utilizada (Microsoft Teams) se analizaron los recursos didácticos utilizados en sus siguientes puntos:

- Momento de aplicación 
- Proceso cognitivo atendido

- Uso

- Contenido presentado

- Diseño y aplicación

- Concordancia entre los propósitos de aprendizaje, los procesos cognitivos y los momentos de aplicación

\section{Resultados}

La plataforma virtual utilizada fue Microsoft Teams que consta de herramientas digitales útiles para la educación virtual:

- Videollamada

- Pizarra electrónica

- Carpeta de archivos

- Organizador de tareas

- Pestaña de publicaciones

- Aplicaciones varias (Forms, Kahoot, One Note)

Los recursos didácticos utilizados en ellos fueron los siguientes:

- Objetivos e intenciones: .- Se avisó sobre el fin de la clase al principio de cada videollamada y el fin esperado.

Tabla 3. Estrategia utilizada de objetivos e intenciones

\begin{tabular}{ccccc}
\hline $\begin{array}{c}\text { Momento } \\
\text { de } \\
\text { aplicación }\end{array}$ & $\begin{array}{c}\text { Proceso } \\
\text { cognitivo } \\
\text { atendido }\end{array}$ & Para qué la utilizo & $\begin{array}{c}\text { Contenido } \\
\text { presentado }\end{array}$ & Concordancia \\
\hline $\begin{array}{c}\text { Pre- } \\
\text { instruccional }\end{array}$ & $\begin{array}{c}\text { Activar o } \\
\text { generar } \\
\text { conocimientos } \\
\text { previos }\end{array}$ & $\begin{array}{c}\text { Enunciar la actividad } \\
\text { de aprendizaje y los } \\
\text { efectos esperados }\end{array}$ & Objetivo & Sí \\
& & & & \\
& & & \\
\end{tabular}

- Señalizaciones: .- Se remarcaron conceptos y elementos clave tanto en el discurso como en las presentaciones. 
Gutiérrez Camarena, Colmenero Fonseca, Palmero Iglesias, Bernardo, Carcel Carrasco

Tabla 4. Estrategia utilizada de Señalizaciones (tanto en el texto como en el discurso)

\begin{tabular}{ccccc}
\hline $\begin{array}{c}\text { Momento } \\
\text { de } \\
\text { aplicación }\end{array}$ & $\begin{array}{c}\text { Proceso } \\
\text { cognitivo } \\
\text { atendido }\end{array}$ & Para qué la utilizo & $\begin{array}{c}\text { Contenido } \\
\text { presentado }\end{array}$ & Concordancia \\
\hline $\begin{array}{c}\text { Co- } \\
\text { instruccional }\end{array}$ & Orientación & $\begin{array}{c}\text { Para orientar y guiar } \\
\text { a los aprendices } \\
\text { sobre aspectos } \\
\text { relevantes de los } \\
\text { contenidos de } \\
\text { aprendizaje }\end{array}$ & $\begin{array}{c}\text { Datos } \\
\text { relevantes }\end{array}$ & \\
& & & \\
& & \\
\end{tabular}

- Preguntas: .- Entre cada cápsula teórica se hacían preguntas generales que los alumnos contestaban para poder continuar la sesión.

Tabla 5. Estrategia utilizada de Preguntas

\begin{tabular}{ccccc}
\hline $\begin{array}{c}\text { Momento } \\
\text { de } \\
\text { aplicación }\end{array}$ & $\begin{array}{c}\text { Proceso } \\
\text { cognitivo } \\
\text { atendido }\end{array}$ & Para qué la utilizo & $\begin{array}{c}\text { Contenido } \\
\text { presentado }\end{array}$ & Concordancia \\
\hline $\begin{array}{c}\text { Co- } \\
\text { instruccional }\end{array}$ & Orientación & $\begin{array}{c}\text { Para obtener } \\
\text { conocimiento } \\
\text { relevante de los } \\
\text { alumnos }\end{array}$ & $\begin{array}{c}\text { Datos } \\
\text { relevantes }\end{array}$ & Sí \\
& & & \\
\hline
\end{tabular}

- Gráficas: .- Las representaciones matemáticas fueron utilizadas a medida que se mostraban conceptos.

Tabla 6. Estrategia utilizada de Gráficas

\begin{tabular}{ccccc}
\hline $\begin{array}{c}\text { Momento } \\
\text { de } \\
\text { aplicación }\end{array}$ & $\begin{array}{c}\text { Proceso } \\
\text { cognitivo } \\
\text { atendido }\end{array}$ & Para qué la utilizo & $\begin{array}{c}\text { Contenido } \\
\text { presentado }\end{array}$ & Concordancia \\
\hline $\begin{array}{c}\text { Co- } \\
\text { instruccional }\end{array}$ & Codificación & $\begin{array}{c}\text { Mejorar la } \\
\text { codificación de la } \\
\text { información por } \\
\text { aprender }\end{array}$ & Ejemplos & \\
& & & \\
\hline
\end{tabular}


- Diagrama de llaves: .- Se presentó un diagrama de llaves con los tipos de sistemas de ecuaciones. Posteriormente, se dio una breve descripción sobre los elementos particulares, haciendo énfasis que a lo largo del curso serían comunes estos conceptos.

Tabla 7. Estrategia utilizada de Organizador Gráfico (Diagrama de llaves)

\begin{tabular}{ccccc}
\hline $\begin{array}{c}\text { Momento } \\
\text { de } \\
\text { aplicación }\end{array}$ & $\begin{array}{c}\text { Proceso } \\
\text { cognitivo } \\
\text { atendido }\end{array}$ & Para qué la utilizo & $\begin{array}{c}\text { Contenido } \\
\text { presentado }\end{array}$ & Concordancia \\
\hline $\begin{array}{c}\text { Co- } \\
\text { instruccional }\end{array}$ & $\begin{array}{c}\text { Organizar } \\
\text { información } \\
\text { nueva por }\end{array}$ & $\begin{array}{c}\text { Introducción al tema } \\
\text { general. Relación de } \\
\text { los subtemas entre sí } \\
\end{array}$ & $\begin{array}{c}\text { Clasificación } \\
\text { del concepto }\end{array}$ & Sí \\
& & con el nivel general. & & \\
& & & & \\
& & &
\end{tabular}

\section{1.- Videollamada}

La videollamada (figura 1) y su función de compartir pantalla (figura 2) permitió el uso de varios recursos didácticos:

- Objetivos e intenciones

- Señalizaciones:

- En el texto de las presentaciones (ver recuadros verdes en figura 2)

- En el discurso

Gráficas

- Preguntas

- Organizador gráfico 


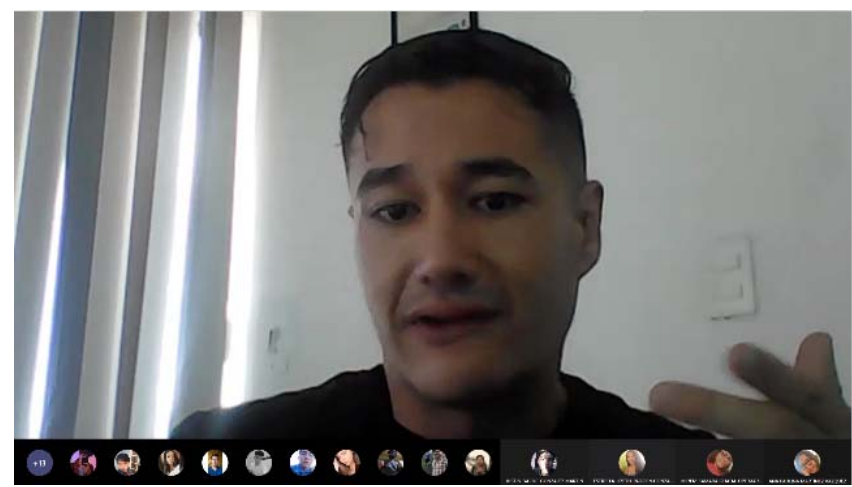

Fig. 1 Videollamada

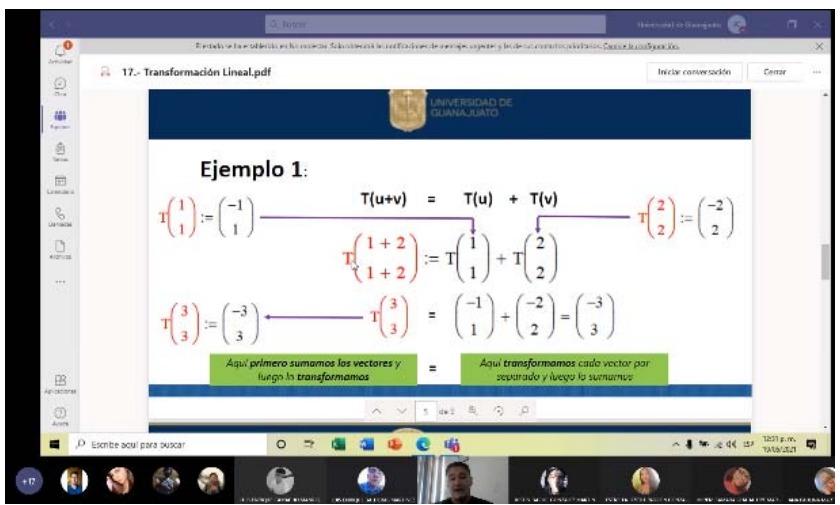

Fig. 2 Función de compartir pantalla

\section{2.- Pizarra electrónica}

Los recursos didácticos usados mediante la pizarra electrónica (figura 3) son:

- Señalizaciones:

- En el texto de las presentaciones (ver recuadros verdes en figura 2)

- En el discurso

- Preguntas

- Gráficas

- Organizador gráfico 
Implementación de recursos digitales para la formación a distancia en las actividades de las asignaturas de ámbito de la construcción - Implementation of digital resources for distance learning in the activities of subjects in the field of construction.

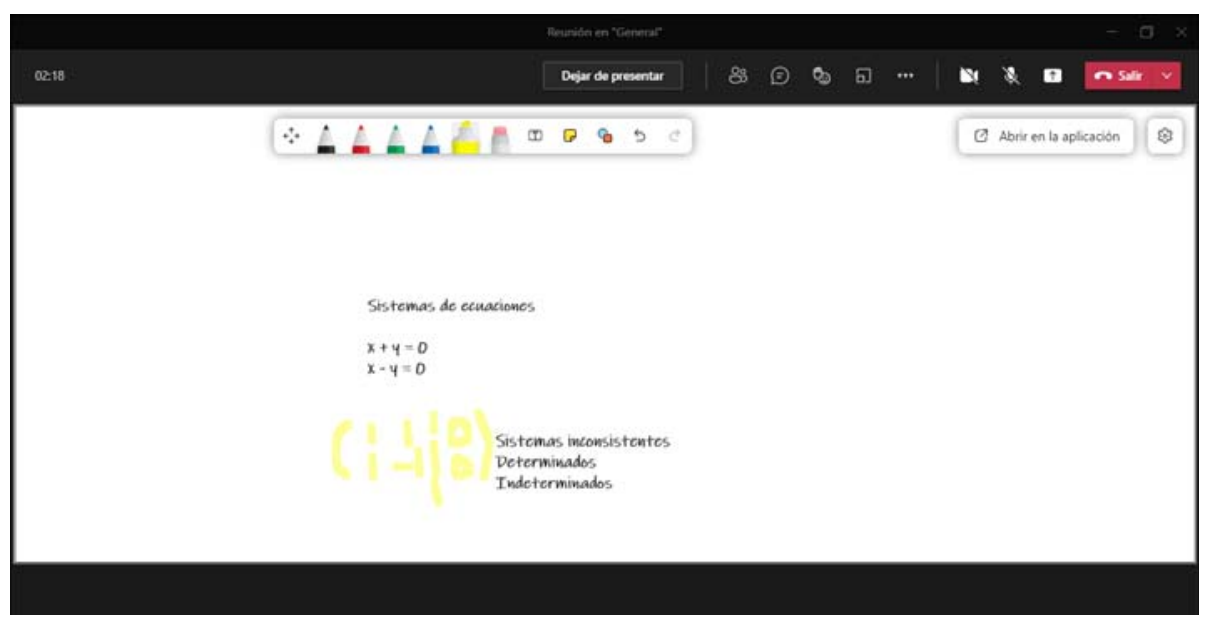

Fig. 3 Pizarra electrónica

\section{3.- Carpeta de archivos}

La carpeta de archivos (figura 4) contiene la información gráfica del curso facilitando el aprendizaje asincrónico del alumno.

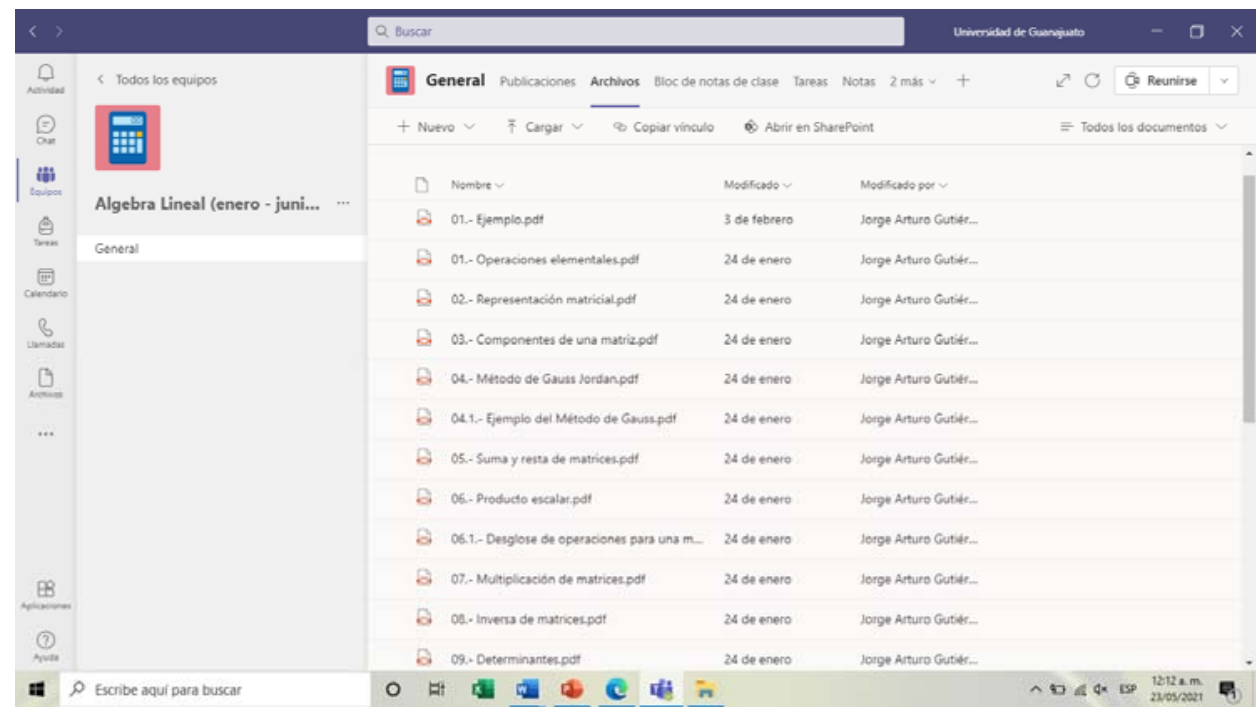

Fig. 4 Carpeta de archivos 


\section{4.- Organizador de tareas}

El organizador de tareas (figura 5) facilita la asignación de actividades al alumno mediante rúbricas, encuestas y ejercicios varios, así como la evaluación y retroalimentación.

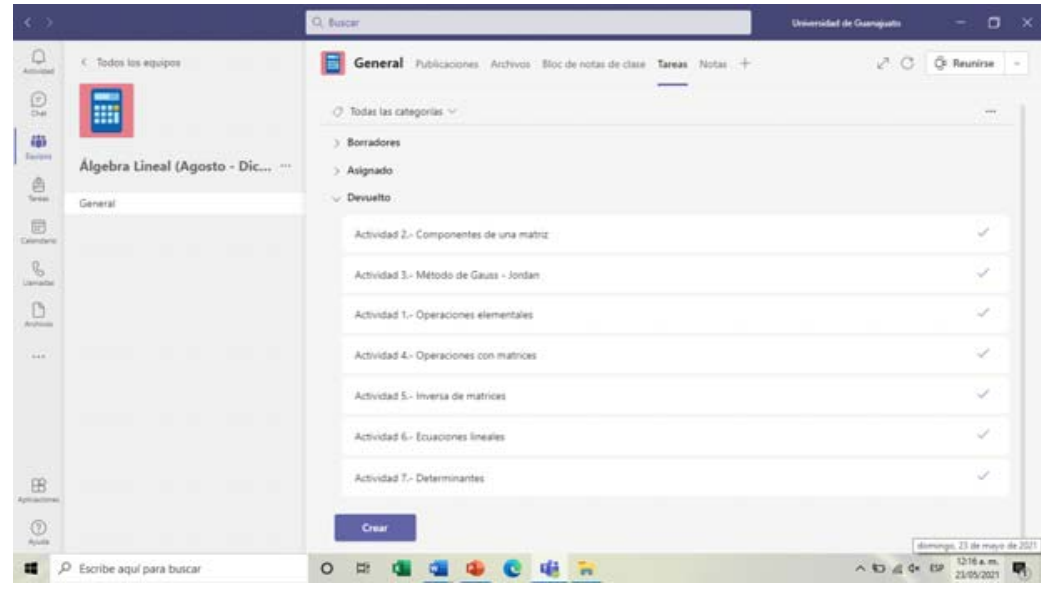

Fig. 5 Organizador de tareas

\section{5.- Pestaña de publicaciones}

En la pestaña de publicaciones (figura 6) se dan señalizaciones, indicaciones y recordatorios.

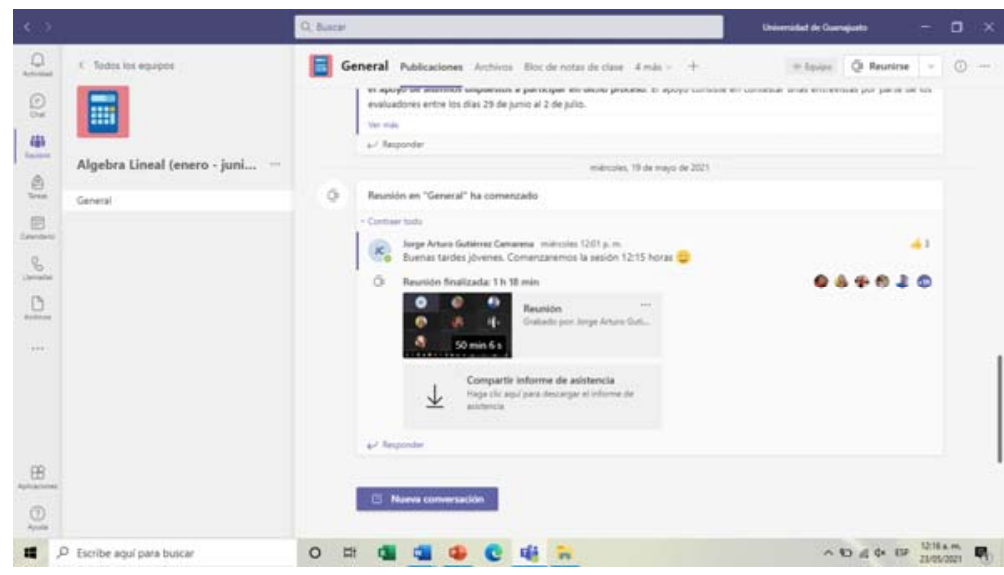

Fig. 6 Pestaña de publicaciones 


\section{6.- Aplicaciones varias}

Las diferentes aplicaciones de la plataforma permiten un proceso de enseñanza más dinámico. Por ejemplo, Kahoot (figura 7) vuelve las preguntas en una interesante combinación de juego con autoevaluación del conocimiento adquirido. La plataforma de Forms facilita el proceso de evaluación del mismo modo.

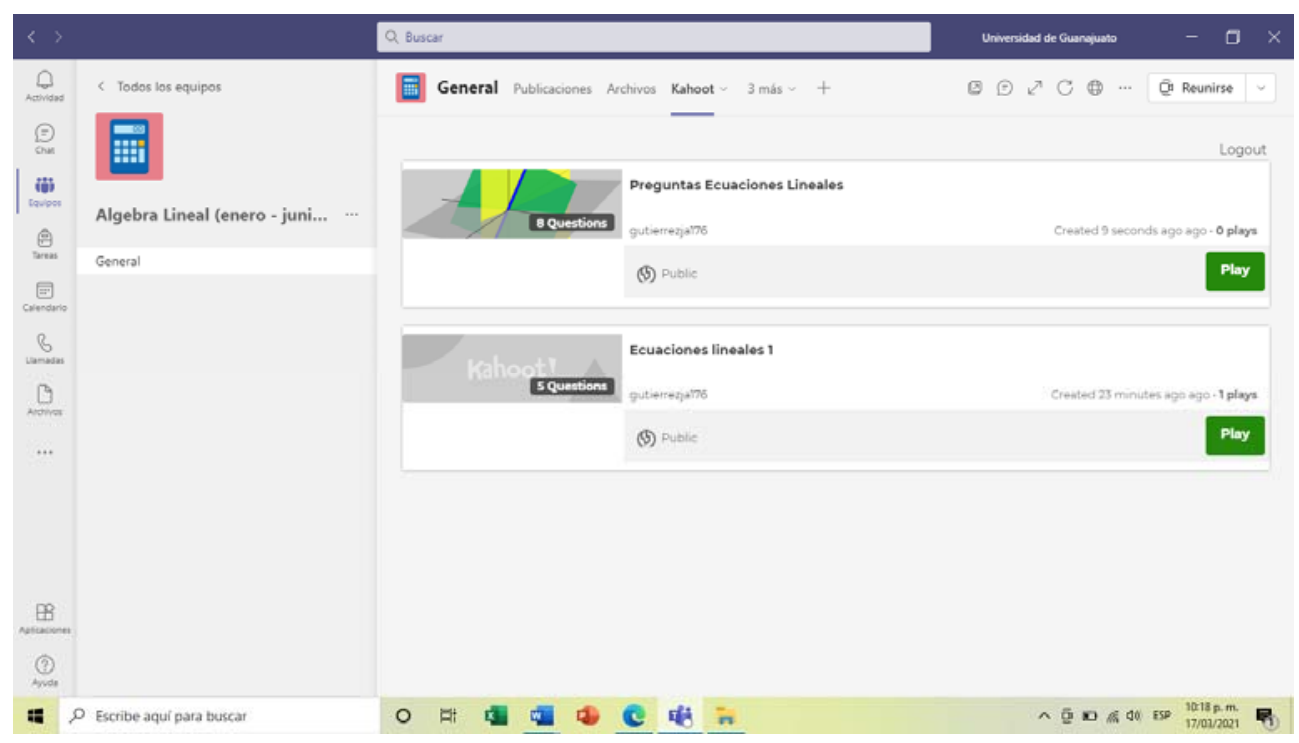

Fig. 7 Aplicación Kahoot

\section{Conclusiones}

Aunque la educación a distancia ya existía desde hace varios años, fue durante el periodo actual debido a la pandemia por COVID-19 que se hicieron notorias sus ventajas. El desarrollo de plataformas que facilitan los ambientes virtuales de aprendizaje facilitaron en gran medida la transmisión de saberes, (tanto cognitivos, como procedimentales y conductuales), hacia los alumnos.

Los retos siguen presentes tanto para profesores como estudiantes, en particular, para los profesores es un desafío conocer más sobre entornos virtuales y el desarrollo de habilidades para el diseño de situaciones de aprendizaje a través de herramientas tecnológicas. Es así como se ofreció la ruta de diseño de asignaturas en línea, como por ejemplo algunos cursos impartidos en el ITESO,(Instituto Tecnológico y de Estudios Superiores de Occidente), para 
apoyar a los profesores a reconocer las características de los entornos virtuales de enseñanza aprendizaje y diseñar estrategias didácticas para sus asignaturas en línea.

Es importante resaltar que el curso es flexible y cada participante determina el tiempo de trabajo que dedicará a la semana en función de los temas que quiera profundizar, aunque se recomienda que al menos se disponga de dos horas semanales para llevar a cabo las actividades del curso; se debe tomar en cuenta las habilidades de lectura y escritura que cada participante posea, lo cual puede afectar positiva o negativamente este tiempo estimado.

De igual manera se comprobó que, independientemente de la modalidad de enseñanza (a distancia o presencial), es posible alinear los diferentes recursos didácticos disponibles con respecto a la competencia específica a lograr para cada materia. Para este trabajo se analizó el curso de algunas asignaturas prácticas, así como diferentes actividades de la construcción y se observa que, aunque la dinámica virtual es diferente a la tradicional (cara a cara), sí existen herramientas disponibles para utilizar los recursos didácticos necesarios para impartirlo. Finalmente, como expresan López y Darío en el año 2005, la educación mediada por tecnologías de la información y comunicación llegó para quedarse.

Es importante partir de una situación de aprendizaje, en donde se establezca una relación académica con problemáticas actuales que aquejan a la sociedad actual desde el área de aprendizaje requerido y/o campo de estudio. Es saber cómo se nos presentan las situaciones en la vida cotidiana y poder dar una solución real y de manera práctica. Fomentando la creatividad y la reflexión desde una exploración emocional a distintos niveles.

Es poder romper paradigmas de "todo lo establecido" a como se ha trabajado anteriormente, es poder relacionar.

Claves de una Situación de Aprendizaje

1. Parte de un Propósito(s) de aprendizaje definido(s)

2. Parte de una situacion problemática y compleja (incluye ejercitación en diálogo con la realidad)

3. Es un reto que implica una serie de actividades evidentemente articuladas para lograr un propósito de aprendizaje.

4. El reto genera en el estudiante emocionalidad (le demanda el manejo de sus conductas) y conflicto cognitivo (le demanda aprender cosas nuevas para solucionar lo que no sabe).

5. Demanda un resultado y conclusión.

6. Para que sea significativo para el alumno éste tiene que tener claro el sentido de la situación de aprendizaje. 
Implementación de recursos digitales para la formación a distancia en las actividades de las asignaturas de ámbito de la construcción - Implementation of digital resources for distance learning in the activities of subjects in the field of construction.

7. Implica colaboración de varios actores (alumnos, docente, expertos externos, clientes, beneficiarios, etc.)

8. Aunque es flexible, posee rigor: demanda del estudiante disciplina, orden, responsabilidad.

9. Mete al alumno en una experiencia real (puede incluso ser una simulación siempre y cuando incluya elementos lo más similares posibles a la realidad)

10. Puede incluir SABERES MULTIDISCIPLINARIOS para ser resuelta.

11. Se administra, guía y controla mediante un alto grado de confianza por parte del docente, lo cual rompe con la codependencia del alumno hacia éste.

12. Implica la reflexión constante por parte del alumno, lo invita a tomar decisiones pensadas y acepta y valora el error como parte del proceso de aprendizaje.

13. Implica un diálogo abierto guiado y acompañado por el docente donde el alumno es el protagonista del proceso de aprendizaje.

14. El rol del docente es de facilitador y/o tutor.

No es:

1. Un listado de temas a cubrir aislados y estáticos

2. Actividades desarticuladas

3. Una actividad atractiva de una sola sesión

4. Acciones genéricas

5. Cátedra

\section{Referencias}

ARIZA, C, Y AMAYA, D. (2008). "Laboratorio remoto aplicado a la educación a distancia“ en Ciencia e Ingeniería Neogranadina $(18,2)$

BARRY, R. Y TAGG, J. (1995). "Teaching to Learning. A New Paradigmfor Undergraduate Educaction" en Revista Changer $(27,6)$

BENASSINI, C. (2014). "De audiencias a prosumidores. Acercamiento conceptual“ en Revista Luciérnaga $(6,12$, pps. 16-29) 
BIGGS, J. (2006). Calidad del Aprendizaje Universitario. Madrid, España: Narcea, S.A. de Ediciones

DOCHY, F., SEGERS, M Y SLUIJSMANS, D. (1999). "The use of self, peer and coassessm ent in Higer Education: a review. " en Studies in Higher Education, (24, 3, pps. 331-350).

ELTON L., FILOMENA A. Y TERESA M. (2019). "Reflexão teórica sobre o papel da docência universitária e da investigação na formação de uma cidadania sustentável em Tete (Moçambique)“ en Finisterra (LIV, 112, pps. 163-176. doi: 10.18055/finis18637).

HERNÁNDEZ, M. (2006). "Modelo Pedagógico del Sistema de Unidades Académicas de Educación a Distancia“ en en CienciaUAT (1, 2, pps. 55-60)

LÓPEZ R. Y DARÍO N.(2005), "Formación continua del talento humano para una docencia virtual integral“ en Revista Virtual Universidad Católica del Norte (15, pps. 1-16)

RAMIREZ G., MONTOYA V. (2018). "La buena docencia y su evaluación desde el punto de vista de las disciplinas en la Universidad“ en Revista de Docencia Universitaria (16, 1 , pps. 69-85. 10.4995/redu.2018.6073).

TIGELAAR, D., DOLMANS, D., WOFHAGEN, I. Y VAN DER VLEUTEN, C. (2004). "The Development and Validation of a Framework for Teaching Competencies in Higher Education. en Revista de Docencia Universitaria" en Higher Education (48, 2, pps. 253-268).

VALLES C., UREÑA N. Y RUIZ E. (2011). "La Evaluación Formativa en Docencia Universitaria. Resultados globales de 41 estudios de caso." en Revista de Docencia Universitaria, (9, 1, pps. 135158. doi: 10.4995/redu.2011.6184). 


\title{
EDIFICATE
}

I Congreso de Escuelas de Edificación y Arquitectura Técnica de España València, 4 y 5 de noviembre de 2021

Escuela Técnica Superior de Ingeniería de Edificación

Universitat Politècnica de València

Doi: https://doi.org/10.4995/EDIFICATE2021.2021.13441

\section{Adaptación metodológica de la docencia de la asignatura Matemáticas II del Grado en Arquitectura Técnica de la UPV debida a la Pandemia}

\section{Methodological adaptation of the teaching of Mathematics II subject in Technical Architecture Degree of the UPV due to the Pandemic}

\author{
Juana Cerdán Soriano ${ }^{a}$, Màrius Fullana Alfonso ${ }^{a}$ y David Soler Fernández ${ }^{a}$ \\ ${ }^{a}$ Dep. de Matemàtica Aplicada. Universitat Politècnica de València, Camí de Vera s/n 46022 València \\ jcerdan@mat.upv.es, mfullana@mat.upv.es, dsoler@mat.upv.es
}

\begin{abstract}
This article presents the work carried out to adapt the subject Mathematics II in the Technical Architecture degree of the Polytechnic University of València (UPV) to the confinement conditions due to the COVID-19 pandemic during the second semester of the 2019-20 academic year. Some conclusions and mechanisms used during this period that are considered useful in nonpandemic conditions are also presented.
\end{abstract}

Keywords: mathematics, teaching methodologies, online training, technological resources, evaluation

\section{Resumen}

En este artículo se expone el trabajo realizado para adaptar la asignatura Matemáticas II en el grado de Arquitectura Técnica de la Universitat Politècnica de València (UPV) a las condiciones de confinamiento por la pandemia de la COVID-19 durante el segundo cuatrimestre del curso 2019-20. Se presentan también algunas conclusiones y algunos mecanismos utilizados durante este período que se consideran útiles en condiciones sin pandemia.

Palabras clave: matemáticas, metodologías docentes, formación online, recursos tecnológicos, evaluación. 


\section{Introducción}

La asignatura Matemáticas II consta de 6 créditos repartidos en 3.5 créditos de teoría y 2.5 créditos de prácticas todos ellos impartidos de manera presencial en clases de: 1) teoría seminario, 2) teoría de aula, 3) práctica informática y 4) práctica de aula. A continuación, se detallan las nueve unidades didácticas en que se distribuye la materia impartida:

1. Cálculo diferencial en varias variables

2. Introducción a las ecuaciones diferenciales

3. Estadística descriptiva

4. Introducción a la probabilidad

5. Variables aleatorias discretas

6. Variables aleatorias continuas

7. Distribuciones muestrales

8. Estimación

9. Pruebas de hipótesis

La calificación de la asignatura Matemáticas II se obtiene mediante la media ponderada resultante de los cuatro actos de evaluación siguientes:

1. Primera prueba conjunta, escrita de respuesta abierta, con un peso entorno al $35 \%$, proporcionalmente a la materia impartida. Se entiende por conjunta el hecho de que todos los grupos realizan la misma prueba.

2. Segunda prueba conjunta, con un peso complementario del anterior hasta completar un $70 \%$. Esta prueba, como la primera conjunta, es escrita de respuesta abierta.

3. Pruebas de evaluación continua y/o trabajos académicos, con un peso del $30 \%$. Estas pruebas dependen del profesorado de cada grupo.

4. En caso de que la calificación de la asignatura sea inferior a 5 o tenga opción a evaluación curricular, el alumnado puede optar a realizar un examen de recuperación de una y solo una de las pruebas conjuntas.

La asignatura es impartida por los tres profesores firmantes de este artículo.

En el curso 2019/20 las clases de Matemáticas II del grado de Arquitectura Técnica en la UVP comenzaban el 27 de enero y acababan el 29 de mayo. Hasta el momento del confinamiento el 14 de marzo del 2020, se había impartido la mitad de la materia y el profesorado ya había realizado o propuesto parte de la evaluación continua. A partir del 14 de marzo la docencia pasó a ser virtual y el sistema de evaluación se ajustó a las nuevas circunstancias. Conviene expresar que se realizó un gran esfuerzo por parte de la comunidad educativa para seguir en esta línea, con adaptación inmediata tanto del alumnado como del profesorado, destacando el reto que esto supuso también para los autores, ya que el sistema presencial era diametralmente opuesto al nuevo y no se contaba con niguna experiencia. La coordinación del profesorado se realizó por videoconferencias constantes y exigió un sobreesfuerzo que se hizo con un alto sentido de responsabilidad y voluntad. 
En este trabajo se describe cómo se adecuó toda la docencia de Matemáticas II a esta situación de emergencia. Se realiza un análisis de su desarrollo y resultados. También se presentan las principales conclusiones y aquellas nuevas prácticas que se ha considerado oportuno implementar en el curso actual.

\section{Objetivos}

Tras el confinamiento el 14 de marzo de 2020, la docencia en la UPV pasó totalmente a modo virtual. Para la impartición de la materia ya se disponía de una plataforma virtual que proporciona la UPV Ilamada "PoliformaT". Cada asignatura tiene su propio espacio reservado en esta plataforma exclusivamente para el alumnado matriculado y el profesorado que la imparte. En la docencia presencial (anterior a la pandemia) ya se hacía un uso habitual del citado espacio virtual en esta asignatura, consistente en: 1) La publicación de material didáctico como apuntes, ejercicios resueltos, exámenes de cursos pasados, etc. 2) Anuncios de cualquier incidencia, convocatorias de exámenes, sus soluciones una vez realizados, publicación de notas, etc. 3) Comunicación con el alumnado. 4) Realización de tareas.

En la nueva fase creada por la situación del estado de emergencia y el confinamiento, el uso de las nuevas tecnologías, como ya se ha comentado, ha sido fundamental.

El objetivo de esta comunicación es la descripción del trabajo realizado en nuestra asignatura en la situación de emergencia y la exposición de todo lo aprendido. Se hace un análisis y se extraen unas conclusiones que sirven para hacer propuestas de cara al futuro, algunas de las cuáles ya se han implementado. Aprender de la experiencia y más en situaciones excepcionales es una de las características que nos definen como individuos y como seres sociales y así se constata en lo aquí expuesto.

\section{Desarrollo de la innovación}

Se describe ahora la adaptación de la docencia a esta situación. Se dedica una sección aparte al sistema de evaluación porque se tuvo que hacer un cambio radical que se sumó al gran esfuerzo que se realizó en el aspecto docente por no ser el sistema anterior virtual sino totalmente presencial.

\subsection{Las clases virtuales}

Se decidió utilizar la plataforma "PoliformaT" para explicar cada paso que se daba inmediatamente y de la manera más clara posible. De esta forma, el alumnado tenía claro qué hacer en cada momento y los medios de que disponía para ello. Así por ejemplo, al final de cada semana se publicaba un anuncio con la planificación de la semana siguiente. El Apéndice I muestra como ejemplo de comunicación el anuncio de una convocatoria de 
examen en que se puede apreciar cómo se intentó tener en cuenta cualquier mínimo detalle que pudiera ayudar y clarificar las dudas que pudiesen surgir.

En las carpetas de recursos de PoliformaT asociadas a los grupos de docencia se publicaron, nada más entrar en el estado de emergencia, ficheros pdf correspondientes a los temas que faltaban por impartir de la asignatura (versados sobre estadística). Cada fichero contenía tanto la teoría del tema (totalmente desarrollada y con ejemplos de cada concepto resueltos con todo detalle), como una colección de enunciados de problemas de consolidación junto con sus soluciones. El objetivo de esta publicación temprana era que el alumnado que lo desease pudiera avanzar en el estudio de la materia, según su programación en casa. Adicionalmente a los ficheros de los temas, se publicaron enlaces a vídeos en internet de corta duración donde se explicaban de manera sencilla conceptos puntuales de cada tema. Especial mención merecen los vídeos del repositorio de la UPV conocidos como polimedia, de los que, a modo de ejemplo, se citan dos: uno con la introducción de la variable aleatoria normal (UPV[Media]. Distribución normal) y otro con una explicación sencilla de la estimación, a través de un intervalo de confianza, de la media de una población conocida la desviación típica (UPV[Media]. Estimación).

Asimismo, previo aviso y de modo pautado y ajustado a los horarios de clase habituales (para dirigir el tiempo de aprendizaje de cada apartado), se publicaron en las carpetas de PoliformaT videos con voz en off, en los que se explicaban exhaustivamente todos los conceptos y se resolvían paso a paso los ejemplos correspondientes. Se pretendía que en el horario habitual de clase el alumnado visionase estos vídeos en su casa, pudiendo repetir las veces que considerase oportuno cualquier parte de la grabación para intentar entender todos los conceptos y pasos dados. Se puede considerar que las únicas diferencias con la clase presencial eran el no visionado del profesorado y la imposibilidad de realizar preguntas de forma inmediata al mismo. Pero esta segunda diferencia quedaba subsanada como se explica en el párrafo siguiente.

En los horarios habituales de clase, el profesorado estaba pendiente del correo electrónico corporativo, de manera que cualquier alumno/a o grupo de alumnado que quisiese realizar una consulta al profesorado, sólo tenía que enviarle un correo con el asunto CONSULTA DE invitada CLASE MAT-II, y automáticamente el profesorado invitaba a todo el grupo a conectarse a la plataforma TEAMS, para resolverle la duda de forma inmediata. Esta es una plataforma virtual de videoconferencias del soporte "MS Office" cuya licencia tiene contratada la UPV. Ello permitía al resto del alumnado que estuviera atento a la plataforma, por un lado escuchar e incluso participar de la conversación existente, aunque originalmente la consulta no fuera suya y, por otro, ponerse en "lista de espera", de manera que cuando acabara la consulta anterior, podía realizar la suya propia sin necesidad de escribir un correo previo.

Cuando se consideraba oportuno, según las consultas recibidas y particularmente para explicar resoluciones de problemas tipo, previo aviso con suficiente antelación, el profesorado usaba el horario de clase presencial para impartir una clase online a través de la plataforma TEAMS. Por la naturaleza de la materia, la resolución de problemas se iba exponiendo paso a paso a través de diapositivas en Powerpoint, de manera que se incitaba al alumnado a 
intervenir e indicar el paso siguiente en la resolución, así como a la búsqueda de datos en tablas o a la realización de cálculos sencillos, lo que permitía comprobar que se entendían los conceptos. El Apéndice II muestra una figura con la secuenciación de las diapositivas mostradas para la resolución de un problema tal como se visionaba por el alumnado durante la clase virtual por TEAMS.

Por último, en las carpetas de recursos de PoliformaT se fue publicando material adicional, como enunciados de exámenes anteriores, tablas y otros documentos que se consideraban convenientes según el desarrollo de la docencia y las necesidades particulares del alumnado.

\subsection{Las tutorías}

Puesto que la tutoría presencial era inviable (la UPV estaba cerrada para cualquier actividad no esencial), se optó por dos métodos de asistencia individual al alumnado.

- $\quad$ Si las dudas o preguntas eran concretas y breves se atendían por correo electrónico. Se recomendaba al alumnado que las hicieran llegar al profesorado por dicho medio, en días laborables de lunes a viernes, siendo atendidas lo antes posible en jornada laboral y por orden de recepción del correo. Las preguntas debían exponerse con la mayor claridad posible, y venir acompañadas, si resultaba necesario, de documentación (foto, docx, etc.).

- $\quad$ En caso contrario, se podía optar por tutorías, lo más parecido a las tradicionales, pero obviamente a través de la plataforma de vidoconferencia TEAMS. Una vez recibido el correo electrónico con la petición de tutoría por parte de un alumno, una alumna o un grupo del alumnado, el profesor concertaba día y hora en el grupo de TEAMS correspondiente.

\subsection{Cambio del sistema de evaluación}

Antes de presentar el método de evaluación propuesto cabe destacar que antes de pasar al sistema de enseñanza virtual ya se había impartido la mitad del contenido teórico y práctico de la asignatura. Los temas que quedaban de estadística no contenían conceptos teóricos de excesiva complejidad y sólo requerían de cálculos sencillos (con ayuda de calculadora) y el uso de tablas.

Se propuso el siguiente sistema de evaluación que fue aprobado por la Comisión Académica del Título de Grado y que anuló el que constaba hasta ese momento en la guía docente de la asignatura:

Una evaluación de clase con un peso del 10\%. Como ya se comentó en la Sección 1, a fecha de 14 de marzo ya se había realizado o propuesto en la asignatura parte de la evaluación continua correspondiente al $30 \%$ inicial de la nota, con lo que este peso del $10 \%$ se asignó a esta parte de la evaluación continua.

Una evaluación conjunta (todo el alumnado de la asignatura) con un peso del $90 \%$ repartido en 3 exámenes ( $30 \%$ cada uno) que se realizó a través de la plataforma PoliformaT con la 
herramienta "Exámenes". Cabe destacar que ello implicó una dedicación importante en horas por parte del profesorado de esta asignatura, sólo para el estudio y manejo de esta herramienta en la configuración de un examen, en las diferentes modalidades de preguntas (tipo test, con resultado numérico, subida de ficheros, etc.), y en lo que se refiere a la introducción de las preguntas en baterías, particularmente en esta asignatura, por la necesidad de incluir fórmulas y tablas en las mismas. Para este fin fue muy útil el curso de preparación de exámenes con esta herramienta a través de la página web habilitada por la UPV (Universitat Politècnica de València. Curso de Realización de Exámenes en PoliformaT).

\section{Estructura de los exámenes}

Antes de describir los exámenes realizados, destacar que al tener grupos de docencia en castellano, valenciano e inglés se tuvieron que redactar todas las preguntas en los 3 idiomas.

El primer examen se realizó el 22/04/2020. La materia evaluada se correspondía con la parte de cálculo (temas 1 y 2). Se optó por las preguntas de tipo test pues nos permitía utilizar LaTex [Lamport,L. 1994] para la introducción de las expresiones matemáticas tan necesarias en los temas de cálculo.

El examen constaba de 17 preguntas de tipo test con 4 opciones que se seleccionaban de forma aleatoria de una batería de 10 preguntas cada una de ellas. Además, se configuró de forma que las diferentes opciones de cada pregunta también se aleatorizaban. En la Figuras 1 y 2 se presenta un ejemplo de pregunta tipo test sobre la materia del primer y segundo tema, respectivamente. Además, en la Figura 1 puede verse parte de la configuración del examen. En la parte superior aparecía la información relativa al número de la pregunta y la puntuación de la misma y en la parte inferior aparecen 4 botones. Por una parte los botones de Anterior-Siguiente que le permiten avanzar y retroceder durante la realización del examen y por otra parte los botones de Guardar-Salir.

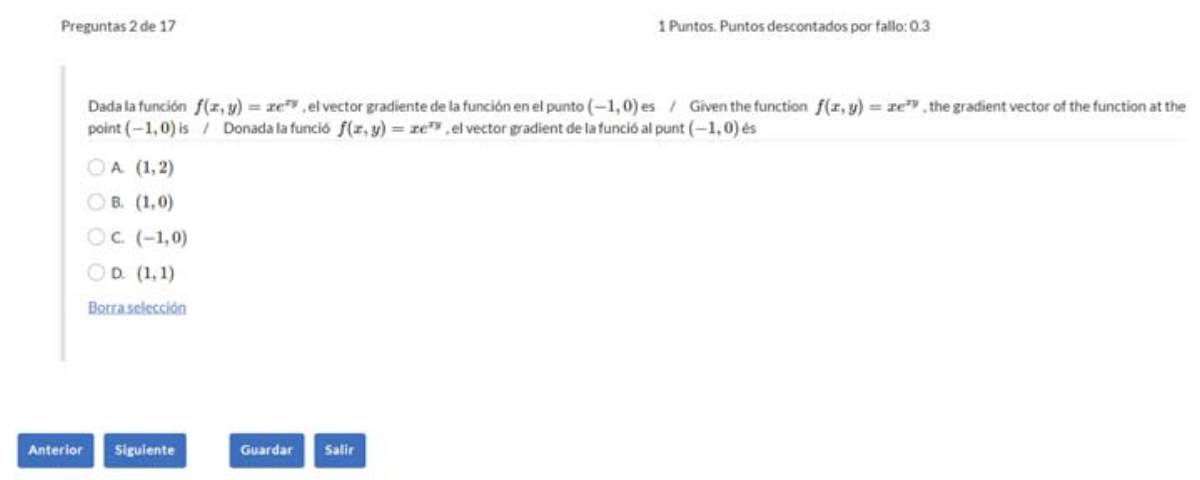

Fig. 1. Pregunta test Tema 1

La herramienta "Examen" no la habíamos utilizado hasta entonces. Se envió información a los alumnos sobre la ruta a seguir para acceder a los exámenes y se publicó una semana 
antes del examen oficial una prueba con preguntas tipo test para que los alumnos pudiesen practicar y así eliminar una parte del estrés del examen.

La duración del examen fue de 2 horas y se prepararon dos versiones del examen cambiando el orden. Tras realizar el examen el alumno recibía la nota y podía comparar su solución con la correcta como puede verse en la Figura 3.

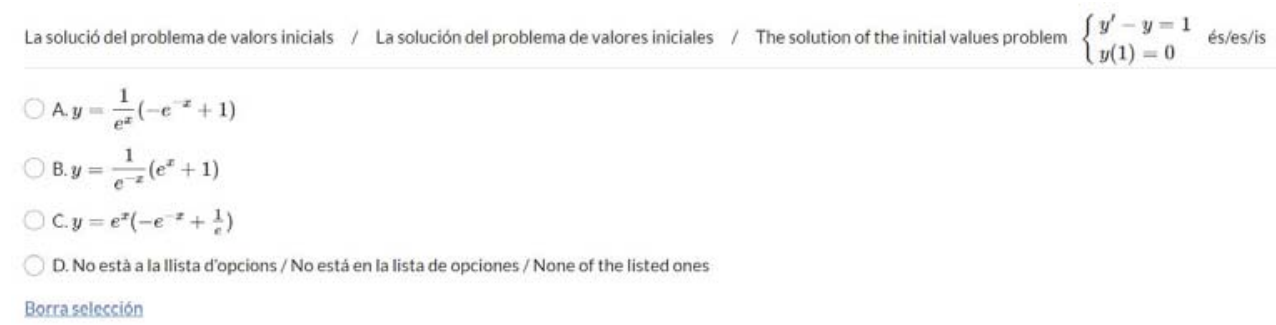

Fig. 2. Pregunta test Tema 2

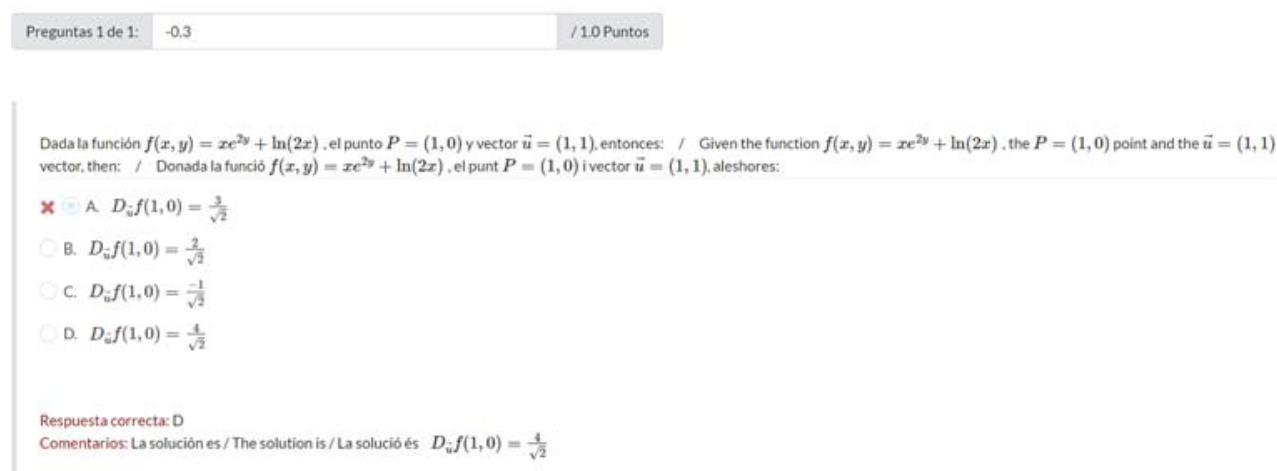

Fig. 3. Ejemplo de revisión de pregunta via PoliformaT.

El segundo examen se realizó el 20/05/2020. La materia evaluada se correspondía con los tres primeros temas de estadística. Este examen se configuró combinando preguntas de tipo numérico (hay que escribir la respuesta en un recuadro) y de tipo test (hay que marcar una opción de las cuatro posibles).

El examen se estructuró en 4 bloques:

$1^{\text {er }}$ bloque: Pregunta de tipo numérico con 4 apartados seleccionada de forma aleatoria de una batería de 20 preguntas

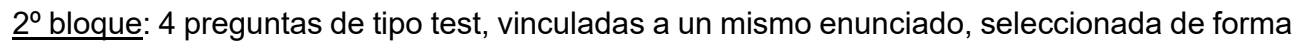
aleatoria de una batería de 20 preguntas 
$\underline{3^{e r} \text { bloque: }}$ Pregunta de tipo numérico seleccionada de forma aleatoria de una batería de 20 preguntas

$44^{\circ}$ bloque: Dos preguntas, una de tipo numérico y otra de tipo test seleccionadas de forma aleatoria baterías de 20 preguntas

La pregunta final de cada bloque consistía en subir el documento pdf (máximo 20MB cada fichero) resultado de escanear la foto del folio o folios donde aparecían desarrolladas las preguntas de dicho bloque. El objetivo, como se indicó al alumnado, era disponer del documento para una posible revisión para subsanar algún error como introducir mal la solución en el recuadro, error al marcar la opción en las preguntas tipo test, nunca por errores de cálculo. La falta del documento anulaba la pregunta.

Una diferencia importante respecto a la configuración del primer parcial es que en este examen no se permitió volver atrás en ninguna pregunta. Siempre hacia adelante. Se les informó de un procedimiento sencillo para convertir una foto en un documento pdf y, para que pudiesen practicar la subida de documentos y que valorasen el tiempo que tardaban, se publicó un simulacro de examen breve. La Figura 4 presenta un ejemplo de pregunta numérica del Tema 3. En cada recuadro el alumnado debía introducir la solución. Para evitar errores en la corrección debidos a que se podían realizar cálculos con diferente precisiones, en la configuración de la pregunta se establecía un intervalo de solución. En la Figura 5 se presenta una pregunta tipo numérico sobre la materia del Tema 5. La Figura 6 muestra la pregunta en la que se pedía que se subiese el fichero manuscrito de trabajo.

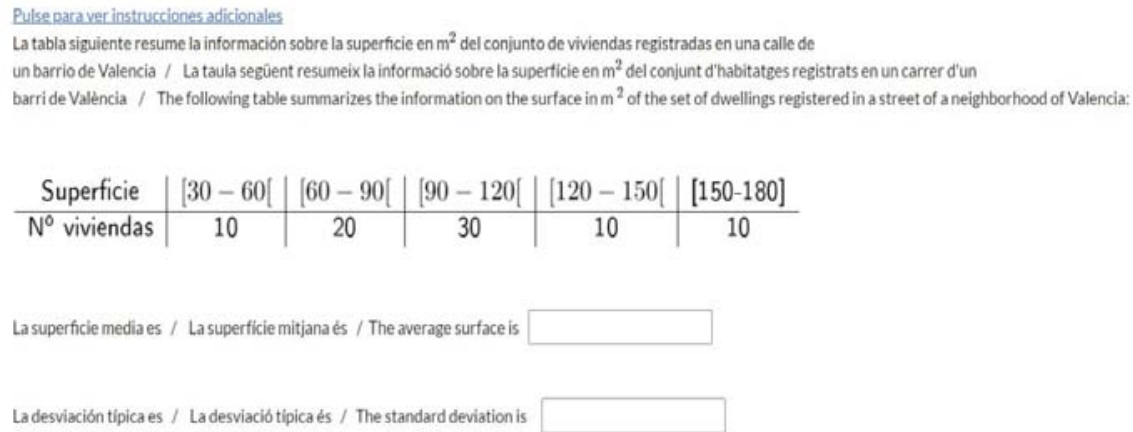

Si una inmobiliaria está interesada sólo en el 20 por ciento de las viviendas de mayor superficie de la calle, ¿cuál es la superficie minima de dichas viviendas? / Si una immobiliària está interessada només en el 20 per cent dels habitatges de major superficie del carrer, quina ès la superficie minima d'aquests habitatges? / If a real estate agency is interested in only 20 percent of the houses with the largest surface area on the street, what is the minimum surface of said houses?

Fig. 4. Pregunta test Tema 3 


\author{
Pulse para ver instrucciones adicionales \\ En una fàbrica de rajoles ixen 4 trencades de mitjana en 1 dia. Si la distribució que segueix és de Poisson, calcula la probabilitat que isquen trencades: \\ En una fábrica de ladrillos salen 4 rotos de media en 1 día. Si la distribución que sigue es de Poisson, calcula la probabilidad de que salgan rotos: \\ In a tile factory there are 4 breaks on average in 1 day. If the following distribution is from Poisson, calculate the probability that they will break: \\ 1) 7 en 2 dies / 7 en 2 días / 7 in 2 days: \\ 2) Com a màxim 10 en 2 dies / como máximo 10 en 2 días / maximum 10 in 2 days: \\ 3) Almenys 9 en 2 dies / al menos 9 en 2 días / at least 9 in 2 days: \\ 4) Més de 3 i menys de 6 en $1 \mathrm{dia} /$ más de 3 y menos de 6 en 1 día / more than 3 and less than 6 in 1 day:
}

Fig. 5. Pregunta test Tema 5

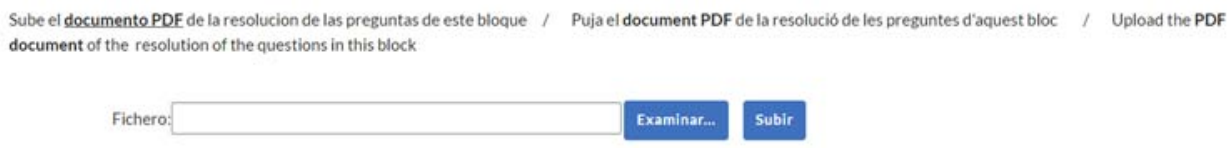

Fig. 6. Pregunta subir el fichero de trabajo

La duración del examen fue de 2 horas y se prepararon dos versiones del examen cambiando el orden de las preguntas. En este caso el proceso de corrección fue un poco más largo pues se tenía que comprobar que los ficheros con las resoluciones se habían subido y comprobar que se correspondía con las soluciones introducidas.

El tercer examen se realizó el día 08/06/2020. La materia evaluada se correspondía con los últimos temas de estadística. Este examen se configuró de forma similar al anterior, combinando preguntas de tipo numérico y de tipo test. Antes de cambiar de bloque debían subir el documento pdf que acreditaba la autoría de las soluciones introducidas.

El examen se estructuró en 3 bloques:

$\underline{1^{\text {er }} \text { bloque: }}$ Pregunta de tipo numérico con 4 apartados seleccionada de forma aleatoria de una batería de 18 preguntas

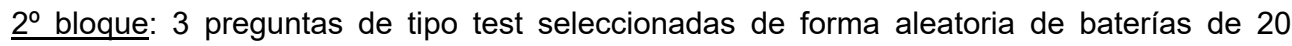
preguntas cada una

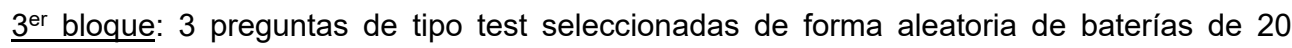
preguntas cada una

La Figura 7 muestra un ejemplo de pregunta numérica del tema 6 y la Figura 8 muestra una pregunta tipo test del tema 8. 


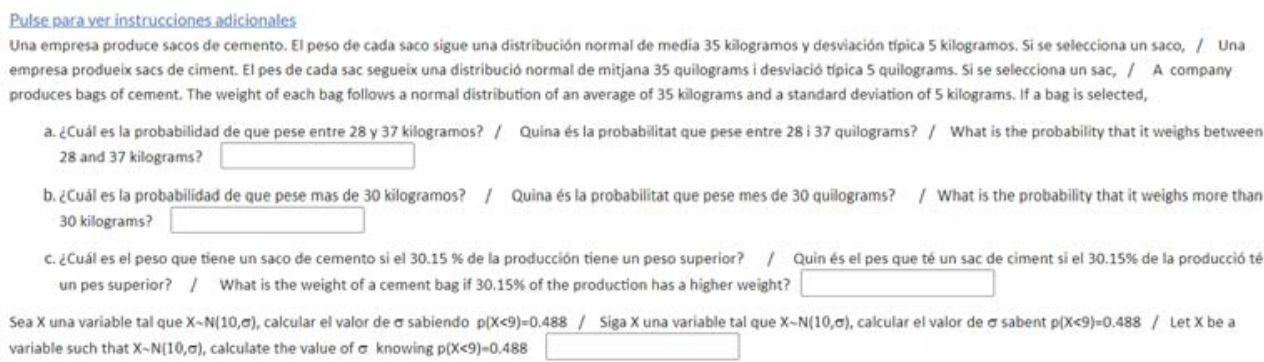

Fig. 7. Pregunta numérica Tema 6

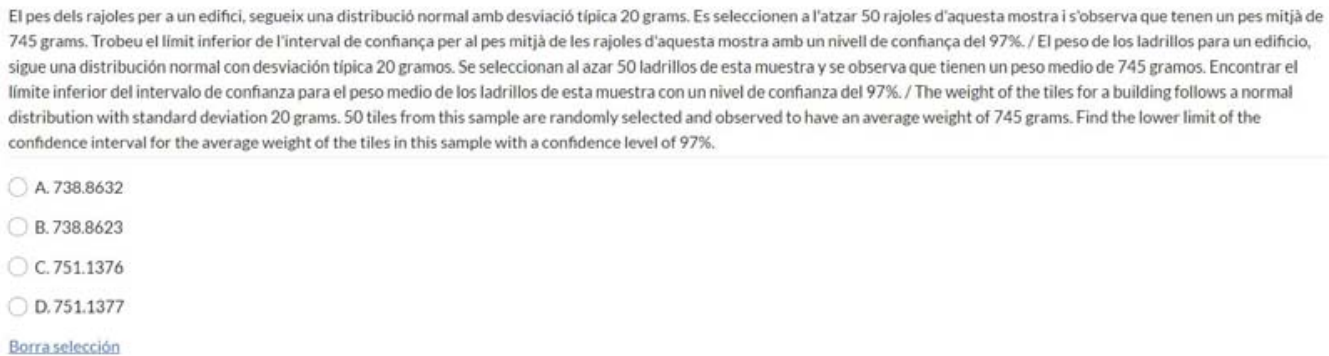

Fig. 8. Pregunta test Tema 8

La duración del examen fue de 1:30h y se prepararon dos versiones del examen cambiando el orden de las preguntas.

Como se indicó en el sistema de evaluación se programó un examen de recuperación. Podía optar a esta recuperación el alumnado cuya calificación de la asignatura fuese inferior a 5 y sólo se podía recuperar uno de los parciales. El examen se realizó el día 19/06/2020.

Se prepararon 3 exámenes de recuperación, uno por cada parcial, a los que se presentaron 2,6 y 21 alumnos, respectivamente. Se varió ligeramente la configuración y estructura de los exámenes. En los parciales 1 y 2 se reutilizaron las preguntas de las baterías y en el parcial 3 se crearon nuevas baterías. En concreto:

Recuperación $1^{\text {er }}$ parcial: Constaba de 12 preguntas tipo test y subir la resolución.

Recuperación $2^{\circ}$ parcial: Constaba de 4 bloques, cada uno de ellos con preguntas numéricas con 4 apartados. Debían subir la resolución.

Recuperación $3^{\text {er }}$ parcial: Constaba de 2 bloques. El primer bloque era un problema de 6 apartados y el segundo bloque estaba formado por 4 preguntas numéricas. Debían subir la resolución. 


\section{Resultados}

Se presentan resultados en dos aspectos diferentes. Por un lado en lo que concierne al número de aprobados y su comparativa con años anteriores y por otro, respecto de la aplicabilidad y aprovechamiento de la experiencia obtenida a una situación de no pandemia, con presencialidad total.

\subsection{Cambio del sistema de evaluación}

Los resultados obtenidos en cada parcial se presentan en la Tabla 1. En las primeras columnas se presentan los resultados de aprobados frente a presentados de cada parcial y la última columna recoge los resultados finales de la asignatura. Aquí se observa una mejora considerable de los resultados del segundo y tercer parcial respecto del primero. Esto puede ser debido a tres causas. La primera es que históricamente en la parte de cálculo se obtienen siempre peores resultados que en la parte de estadística. La segunda es que en la realización del primer examen los alumnos estaban confinados y no en los otros. La tercera es que por ser la primera vez que se realizaban este tipo de examen, quizás no supieron distribuir el tiempo de forma adecuada además de la dificultad de enfrentarse a un tipo de examen totalmente nuevo.

Tabla 1. Resultados de aprobados

\begin{tabular}{|l|c|c|c|c|}
\cline { 2 - 5 } \multicolumn{1}{c|}{} & 1 $^{\text {er }}$ parcial & $\mathbf{2}^{\mathbf{0}}$ parcial & 3 $^{\text {er }}$ parcial & Matemáticas II \\
\hline Presentados & 98 & 91 & 83 & 103 \\
\hline Aprobados & 26 & 53 & 45 & 60 \\
\hline$\%$ Aprobados & 26.53 & 58.24 & 54.21 & 58.25 \\
\hline
\end{tabular}

En la Figura 9 se muestra una comparativa del rendimiento del alumnado presentado el curso 2019-20 con los tres cursos anteriores. Como se observa en dicha figura, los medios informáticos disponibles y la responsabilidad y la voluntad de superación de toda la comunidad educativa de la asignatura de Matemáticas II ha hecho que los resultados docentes se hayan mantenido como en el nivel superior de los cursos anteriores, sin la emergencia social vivida. Este hecho pone en valor el inmenso trabajo realizado. 


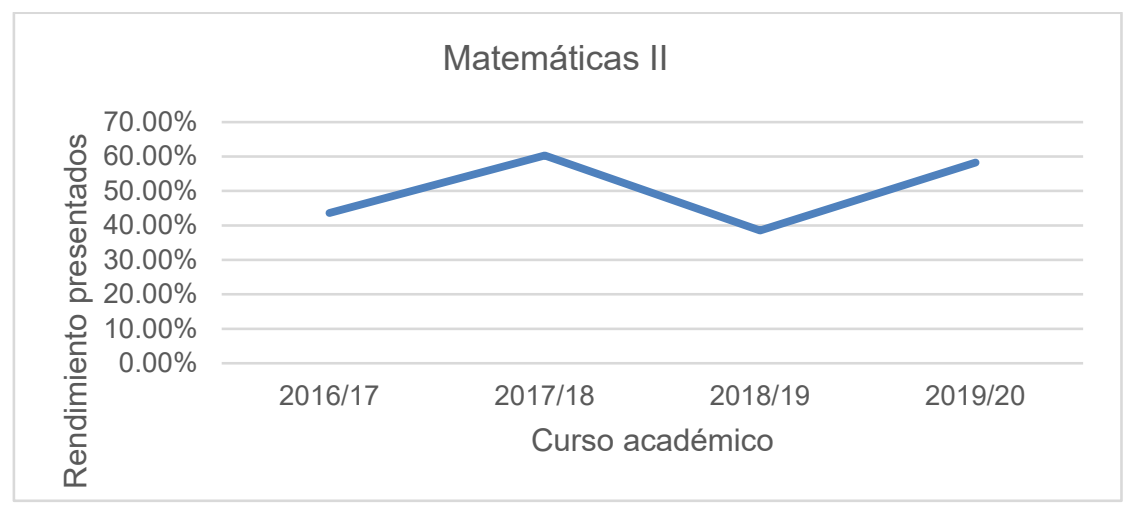

Fig. 9. Rendimiento del alumnado presentado

\subsection{Aplicabilidad de la experiencia en situación de normalidad}

Afortunadamente, la asignatura Matemáticas II se imparte en el segundo cuatrimestre, por lo que las condiciones de la pandemia en el curso 2020-21 en la Comunitat Valenciana o País Valencià han permitido que tanto el sistema de enseñanza como de evaluación en la escuela donde se imparte el grado de Arquitectura Técnica sea mayoritariamente presencial. Se ha vuelto por tanto al sistema de evaluar conjuntamente en prueba escrita y presencial el $70 \%$ de la asignatura y el otro $30 \%$ en evaluación continua grupal.

No obstante, la experiencia excepcional del curso pasado, y en particular la ingente cantidad de problemas acumulados en la herramienta "Exámenes" de la plataforma PoliformaT (ya detallada en la Sección 3) y que dieron lugar a millones de combinaciones de exámenes diferentes, ha permitido al profesorado de esta asignatura replantearse algunos aspectos en la impartición de la misma el curso 2020-21, y previsiblemente en cursos venideros. Notar que la herramienta Exámenes permite que los problemas puedan ser reagrupados o repartidos en diferentes baterías, de forma que se pueden generar exámenes de diferentes características o de diferente cantidad de materia a los realizados en curso 2019-20.

A continuación, se detallan algunas variaciones o aprovechamientos de la experiencia del curso anterior, respecto del sistema usado en cursos anteriores:

- $\quad$ Dado que la distancia social (1.5 metros) y el uso de mascarilla se ha seguido manteniendo durante todo el curso 2020-21, se ha combinado el sistema de tutoría tradicional presencial con el sistema usado el curso pasado a través de la plataforma TEAMS, así como con el uso de correo electrónico para dudas muy concretas. El objetivo de la tutoría solicitada, así como la cantidad de alumnado previsiblemente presente en dicha tutoría son la base para determinar si una tutoría debe ser presencial o vía TEAMS. En cualquier caso, por los comentarios recibidos, cabe destacar que el alumnado valora mucho el poder hablar con el profesorado viéndose las caras sin necesidad de desplazarse de su casa a propósito para una tutoría. Téngase en cuenta que las tutorías no deben solaparse con el horario de clases, y eso hace que, por ejemplo, alumnado del grupo de tarde deba en ciertas ocasiones acudir 
a la UPV a tutorías en horario de mañana. Así pues, el profesorado de esta asignatura considera que las tutorías a través de TEAMS son beneficiosas para los dos actores de éstas, previo acuerdo, por lo que su idea es seguir usándolas en cursos próximos.

- $\quad$ Algunos de los actos de evaluación no conjunta, que implican el 30\% de la nota, han sido realizados este curso 2020-2021 a través de la herramienta "Exámenes" de PoliformaT, aprovechando las baterías de problemas almacenadas el curso pasado. Por citar un ejemplo concreto, en la realización de un acto de evaluación de prácticas con ordenador con el programa Mathematica (Wolfram Mathematica), si tradicionalmente se ponía el mismo examen a todo el grupo, ahora cada estudiante es consciente de que tiene un examen diferente del resto, el cual realiza a través de PoliformaT, aunque de manera presencial en el aula. Ello facilita enormemente la labor de control de un examen en un aula de ordenadores y en el que todo tipo de apuntes está permitido, así como el poder realizar en casos justificados el examen desde fuera del aula, con control a través de TEAMS. Además, se añade la ventaja para el profesorado de que la ingente tarea de generación de problemas de examen el curso anterior hace que en este curso, y probablemente en algunos cursos venideros, no necesite generar nuevos exámenes.

- $\quad$ Conectando con el final del ítem anterior, incluso algunos de los problemas de los enunciados de los exámenes conjuntos han sido extraídos (y modificados si se consideró oportuno) de las baterías generadas el curso pasado. De alguna forma, se puede concluir que el profesorado "recupera" parte del tiempo extra invertido durante la situación excepcional del curso 2019-2020.

\section{Conclusiones}

De la adaptación metodológica de la docencia de la asignatura de Matemáticas II del Grado en Arquitectura Técnica de la UPV debida a la Pandemia se pueden extraer las siguientes conclusiones, detalladas en la Sección 4:

- Esta adaptación no supuso una variación sustancial en el porcentaje de aprobados del alumnado respecto de cursos anteriores. De hecho igualó práctimente al mejor porcentaje de los tres cursos anteriores.

- La experiencia adquirida por el profesorado y la ingente cantidad de material elaborado le ha hecho introducir cambios dentro del método de enseñanza presencial, que considera mejoras y comodidad tanto para el profesorado como para el alumnado, como son las tutorías vía TEAMS y la realización de exámenes individualizados vía PoliformaT, tanto dentro como fuera del aula, esto último espacialmente para alumnos con dispensa de asistencia y poca disponibilidad horaria. 


\section{Referencias}

Lamport, L. LaTeX: A Document Preparation System : User's Guide and Reference Manual. Addison Wesley, Reading, Mass., EUA, 2a edición, 1994

Universitat Politècnica de València. UPV[Media]. Distribución Normal. https://media.upv.es/\#/portal/video/8b2421d7-6fe4-834d-a555-a9037dc8e66c (Consulta: 13/06/2021).

Universitat Politècnica de València. UPV[Media]. Estimación de la media. https://media.upv.es/\#/portal/video/9a100389-37e3-174a-b229-4d1e7ea57c4b (Consulta: 13/06/2021).

Universitat Politècnica de València. Curso de Realización de Exámenes a través de

PoliformaT. http://personales.upv.es/sanvipui/eufol/eufol.html (último acceso 13/06/2021).

Wolfram, Mathematica. http://www.wolfram.com/mathematica. (Consulta: 02/06/2021).

\section{Apéndice I}

\section{Convocatoria del segundo parcial:}

Apreciados alumnos,

La evaluación del $2^{\circ}$ parcial de Matemáticas II se realizará mediante la herramienta Exámenes de PoliformaT. El examen se abrirá a las 18:30 h del 20 de mayo y constará de 4 bloques. La duración máxima del examen será de 105 minutos, por lo que el examen deberá ser enviado para su corrección antes de las 20:15 h. Todo examen enviado con posterioridad a esta hora será considerado por el sistema como "no presentado".

Hay preguntas de tipo numérico (hay que escribir la respuesta en un recuadro) y de tipo test (hay que marcar una opción de las cuatro posibles). Recordar que en las de tipo test cada pregunta incorrecta descuenta 1/3 de su valor, por lo que se aconseja contestar sólo si se tiene un alto grado de seguridad de acertar, nunca al azar.

En la última pregunta de cada bloque deberéis subir el documento PDF (máximo 20MB cada fichero) resultado de escanear la foto del folio o folios en los que hayáis resuelto las preguntas planteadas en dicha parte con el nombre Problema_1, Problema_2, etc. Es importante que se respete la denominación de los ficheros para que sepamos qué contiene cada uno de 
ellos. Si no se sube el fichero de una parte la puntuación en dicha parte será de 0 y no se admitirán envíos de ficheros por otros medios.

Como se especificó en el primer parcial, necesariamente deberéis realizar el documento manuscrito sobre folio/s blanco, a una cara y con tinta azul o negra, nunca con lápiz (no se lee bien). No importan los tachones. Puesto que disponéis de todo el material incluyendo fórmulas y tablas, la revisión en base a los documentos PDF subidos solo se realizará en casos excepcionales debidamente justificados y no por errores de cálculo.

Importante: durante la realización del examen, una vez contestada una pregunta (o en su defecto, pasando a la siguiente pregunta sin contestar la actual) no se podrá volver a contestar, ni revisar, ni cambiar preguntas anteriores. La configuración del examen/test no permitirá volver atrás en ninguna pregunta. Siempre hacia adelante. Así pues, deberéis gestionar el tiempo que dedicáis a cada bloque para poder acceder con suficiente tiempo a todas ellas. Por razones del sistema, no deberéis estar más de 44 minutos en una misma parte sin guardar la pregunta y pasar a la siguiente, ya que el sistema dará por caducada la sesión, no responsabilizándose el sistema de posibles fallos en la reconexión. Recordar guardar a medida que vayáis contestando las preguntas.

Respecto del uso de decimales, cuando se pida una probabilidad, ésta siempre se calculará usando las tablas que se os ha proporcionado, y por tanto manteniendo siempre los 4 decimales, no aceptándose resultados con truncamientos o redondeos a menos de 4 decimales. Por otro lado, si en otras operaciones no relacionadas con las tablas de variables aleatorias, la calculadora proporciona más de 4 decimales, se deberán mantener como mínimo 4 decimales a lo largo de todas las operaciones, de manera que, como mucho, el error cometido en el resultado sea de unas diezmilésimas. Dicho de otro modo, si estáis seguros de que habéis realizado las operaciones correctamente y vuestro resultado difiere sólo en el cuarto decimal respecto de una de las respuestas y se aleja mucho de las restantes, lo lógico es que esa sea la respuesta correcta.

Para que podáis practicar la subida de documentos vamos a abrir un simulacro de examen breve (nada que ver con el oficial) que constará de 2 bloques y que estará activo durante el lunes día 18 de mayo de $9 \mathrm{~h}$ a $13 \mathrm{~h}$.

Saludos

Juana Cerdán

Profesora responsable de Matemáticas II 


\section{Apéndice II}

Figura con la secuenciación de las diapositivas mostradas para la resolución de un problema a través de la plataforma TEAMS:

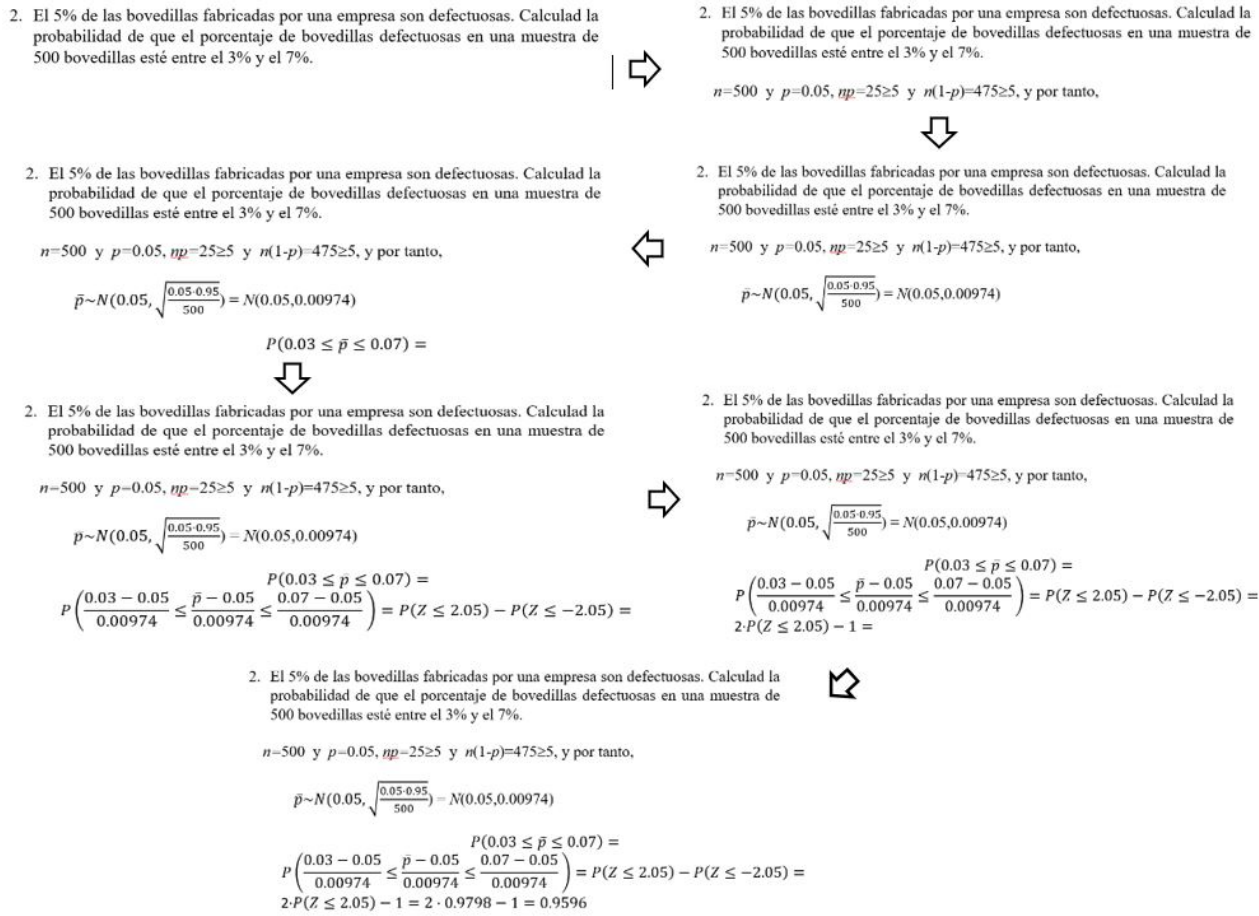




\title{
EDIFICATE
}

I Congreso de Escuelas de Edificación y Arquitectura Técnica de España

València, 4 y 5 de noviembre de 2021

Escuela Técnica Superior de Ingeniería de Edificación

Universitat Politècnica de València

Doi: https://doi.org/10.4995/EDIFICATE2021.2021.13531

\section{Investigación aplicada a la formación en nuevos materiales de construcción}

\section{Applied research to new construction materials subject}

\author{
Jesús Gadea Sáinz a , Verónica Calderón Carpinterob ${ }^{b}$ Carlos Junco Petrement c, Sara \\ Gutiérrez-González $^{\mathrm{d}}$, Ángel Rodríguez Saiz ${ }^{\mathrm{e}}$, Javier Garabito López ${ }^{\mathrm{f}}$ \\ Departamento de Construcciones Arquitectónicas e Ingeniería de la Construcción y del Terreno, \\ Escuela Politécnica Superior de la Universidad de Burgos \\ ajgadeamc@ubu.es, bvcalderon@ubu.es, ccjunco@ubu.es, dsggonzalez@ubu.es, \\ earsaizmc@ubu.es, fjgarabito@ubu.es
}

\begin{abstract}
The degree in Building Engineering at the University of Burgos has been included the Bologna System 10 years ago, implemented simultaneously in the 2010-2011 academic year the entire degree - four courses. According with the initial strategies, the acquisition of competences through project research work in the construction materials subjects has been one of the elements developed and consolidated, especially in the elective subjects of higher courses where training of the student already allows this type of resources. However, the work begins the first year with specific classes to introduce the investigation within the subjects of construction materials, with agenda reflected in the educational guide. One of them, for example, is an intensive course of advanced searches in international scientific databases, which must be used in a practical way to test what has been learned, and which can be extrapolated to the rest of the subjects of the degree.
\end{abstract}

Keywords: Project management skills, new construction materials, applied research tools, transferable' skills. 


\section{Resumen}

El grado en Arquitectura Técnica de la Universidad de Burgos lleva un recorrido de 10 años en el Plan Bolonia, que implantó de manera simultánea en el curso 2010-2011 para los cuatro cursos del grado. Dentro de las estrategias iniciales del Grado, la adquisición de competencias a través del trabajo por proyectos en las asignaturas de materiales de construcción ha sido uno de los factores que se ha desarrollado y afianzado, especialmente en la asignaturas optativas de cursos más altos donde la formación del estudiante ya permite este tipo de recursos. No obstante, se comienza desde primer curso con clases específicas de introducción a la investigación dentro de las asignaturas de materiales de construcción, con temario contemplado en la guía docente. Una de ellas, por ejemplo, es un curso internsivo de búsquedas avanzadas en bases de datos científicas internacionales, que debe ser utilizado de manera práctica para poner a prueba lo aprendido, y que puede ser extrapolado al resto de asignaturas de la titulación.

Palabras clave: Competencias de gestión de proyectos, nuevos materiales de construcción, herramientas de investigación aplicada, competencias transferibles. 


\section{Introducción}

La investigación aplicada se utiliza en alguna de las asignaturas de Materiales de Construcción como un proceso pedagógico que complementa el resto de métodos de enseñanza y aprendizaje, siendo especialmente útil en los últimos cursos de la Titulación. También se utiliza para abordar diferentes problemas asociados con los paradigmas de enseñanza y la dinámica del aula para una mejor experiencia de aprendizaje, aplicando muchos de los conocimientos previos adquiridos y otros que se consiguen durante este proceso formativo específico.

Elaborar e implementar un modelo para el desarrollo de la investigación aplicada en carreras técnicas desde la implantación de Bolonia ha sido un factor clave para determinar la calidad del curriculum en la formación teórico-práctica, y en el grado de especialización del mismo. No en vano, el paso de la diplomatura (180 créditos ECTS) a grado (240 créditos ECTS) en los estudios de Arquitectura Técnica supuso un gran desafío, pero también significó significó la apertura y la posibilidad de acceso directo a la carrera investigadora, dado el alcance académico de los estudios de grado en comparación con los títulos técnicos anteriores.

Además de la investigación aplicada dentro del taller y laboratorios de las asignaturas de Materiales de Construcción, se utilizan los entornos virtuales de aprendizaje como recurso didáctico, lo que incluye el empleo, entre otras cosas, de la plataforma educativa UBUVirtual y la biblioteca digital, desde la que se gestionan las bases de datos científicas, buscadores de patentes y registros de propiedad, y normativa nacional e internacional aplicable a los materiales de construcción, fortaleciendo el trabajo teórico y practico para el desarrollo del sector.

Esta innovación docente se enmarca dentro de la formación a través de la investigación basada en el conocimiento y la comprensión de cómo aplicar ese conocimiento en el ejercicio futuro de la profesión. Algunos estudios derivados de la aplicación de los principios propuestos a través de la aplicación aplicada afirman, a través de las conclusiones de sus docentes, que los estudiantes suelen conventirse en egresados con mejores capacidades para resolver problemas inesperados, que se benefician de la evaluación formativa y se vuelven más conscientes del objeto de aprendizaje que luego puede conducir a un mejor traslado profesional.

Promover este tipo de aprendizaje es una manera de impulsar la cultura de investigación en la formación universitaria en titulaciones tradicionalmente técnicas, puesto que se comprueba la utilidad inmediata de la aplicación, al mismo tiempo que se incentiva la capacidad investigadora y crítica. 


\section{Objetivos}

El aprendizaje basado en proyectos es una forma de instrucción centrada en el estudiante que se basa en tres principios: el aprendizaje es específico del contexto, la participación activa del aprendizaje y la interacción social mediante el intercambio de conocimientos. Además de las competencias propias del conocimiento académico y formal de las asignaturas de Materiales de Construcción, se busca alcanzar cinco de las seis categorías de las que se ocupan de las habilidades interpersonales: habilidades de comunicación, habilidades organizativas, habilidades de formación de equipos, habilidades de liderazgo y habilidades para abordar situaciones novedosas.

Por todo lo anterior, el objetivo principal de este proyecto de innovación docente se basa en la aplicación del aprendizaje por proyectos de investigación como respuesta a una demanda y necesidad de las nuevas metodologías en la enseñanza, especialmente en los cursos más avanzados de la titulación.

\section{Metodología}

Las asignaturas de Materiales en la Titulación de Arquitectura Técnica en la Universidad de Burgos se corresponden con el primer, segundo y cuarto curso, y son cuatro: Fundamentos de Materiales (primer curso, primer semestre), Materiales I (primer curso, segundo semestre), Materiales I (segundo curso, primer semestre) y Nuevos Materiales de Aplicación en Construcción (cuarto curso, segundo semeste). Todas ellas son materiales de 6 créditos.

Para poder aplicar los conocimientos previos adquiridos al respecto de estas asignaturas relacionadas con los Materiales de Construcción, se incide específicamente en la innovación docente llevada a cabo en la asignatura de Nuevos Materiales de Aplicación en Construcción. Este curso se presta especialmente a este tipo de aprendizaje, donde se combina la enseñanza propia del temario con la gestión de la investigación aplicada al desarrollo de un proyecto real de materiales novedosos aplicados en obra real. Además, surgen otros problemas inesperados a medida que el proyecto se desarrolla, de modo que la lista de temas siempre se expande más allá del conjunto tradicional.

El curso está estructurado para proporcionar a los estudiantes el conocimiento que será necesario para planificar y gestionar el trabajo de investigación aplicado, incluyendo el aprendizaje de herramientas complementarias como son búsqueda bibliográfica en bases de datos internación.ales, en buscadores mundiales de patentes y modelos de utilidad y en revistas técnicas especializadas.

Además del trabajo colaborativo por grupos generalmente de dos o tres personas, se asignan a cada estudiante tareas individuales, lo que asegura que todos los miembros del equipo dominen el material técnico.

Los estudiantes eligen, bajo supervisión del profesor, el material de construcción novedoso sobre el que van a trabajar, (fase de elección) lo que repercute positivamente en la 
implicación a lo largo del proyecto. Dar asignaciones de proyectos grupales a los estudiantes desarrolla las habilidades sociales de los estudiantes, como por ejemplo el liderazgo, la comunicación, el trabajo en equipo y los problemas habilidades para resolver, además de fortalecer la mentalidad adecuada para enfrentarse a las realidades de la vida al ejecutar proyectos. La identificación de las fuentes fiables y de la búsqueda y empleo de los recursos científico-técnicos, también son partes relevantes del proyecto (fase de preparación y planificación)

Durante el desarrollo del trabajo, también se llevan a cabo prácticas en el laboratorio químico y en el taller de materiales o de grandes estructuras. La finalidad consiste en dotar a los estudiantes de una visión global y multidisciplinar del funcionamiento de un material de construcción, y la incidencia de la microestructura en las propiedades finales a largo plazo. La idea es que ese conocimiento pueda ser trasladado también a cada trabajo concreto de investigación (fase de ejecución).

Una vez concluido el desarrollo colaborativo, se defienden y evalúan los trabajos en clase de manera expositiva. Finalmente, se sacan las conclusiones correspondientes del tema elegido, tanto de manera individual como de manera colectiva en la sesión expositiva, de manera que se decide si la solución tecnológica o científica al problema o proyecto planteado ha sido adecuada (fase de evaluación).

\section{Resultados de la innovación}

Los resultados obtenidos con esta metodología de investigación aplicada, comparados con los del método tradicional, indican que, aunque los estudiantes tienden a adoptar una actitud pasiva y son reacios a aumentar el grado de trabajo autónomo en un principio, el procedimiento contribuye a mejorar la aplicación de los conceptos teóricos en el diseño y la realización del proyecto.

Los estudiantes tienen el desafío de pensar críticamente sobre el trabajo realizado, vincular sus observaciones con los conceptos del curso, y discutir cómo pueden aplicar lo que aprendieron a proyectos futuros. Estas actividades de evaluación posteriores al proyecto resultan útiles porque animan a los estudiantes a reflexionar,aumentando así la calidad de los resultados del aprendizaje.

Aunque la fase de planificación del curso es relativamente estructurado, los proyectos trabajados, los factores contextuales, y la combinación de estudiantes involucrados determina en última instancia las lecciones adicionales que han ido surgiendo hasta el momento.

Se valoran los trabajos en función de las competencias adquiridas, como son la adquisición significativa de contenidos, la responsabilidad por el propio aprendizaje, las habilidades de comunicación oral y escrita, el autoaprendizaje, el pensamiento reflexivo y las habilidades para el trabajo en equipo. Los resultados indican que este proyecto ha contribuido claramente a la mejora de la adquisición de todas las competencias, a excepción del pensamiento reflexivo, que parece que se ha reforzado en las asignaturas cursadas en su 
plan de estudios. Estos resultados nos sirven para continuar en esta línea de trabajo, puesto que confirman que realmente es posible lograr la implicación activa de los estudiantes y mejorar el aprendizaje.

\section{Responsabilidad social de los profesionales de la construcción}

En lo que concierne a la responsabilidad social universitaria en general, y dentro de la docencia en particular, capacitar a los docentes y a los estudiantes en las especialidades del Aprendizaje Basado en Proyectos, abriendo las aulas hacia la comunidad como fuente de enseñanza significativa y práctica aplicada a la solución de problemas reales es algo fundamental. Se buscan de cómo el estudiante puede aprender lo que tiene aprender formándose como ciudadano informado y responsable. Esto fomenta la creación de talleres de aprendizaje, mayor articulación entre las disciplinas (por la necesidad de un enfoque multi e interdisciplinario para tratar los proyectos), y mayor articulación entre la docencia, la investigación y la proyección social.

Se debe garantizar la responsabilidad social de la profesión de Arquitecto Técnico, y por extrapolación a todo lo que tiene relación con el mundo de la edificación. Debemos reconocer que, hasta ahora, después de siglos de desarrollo de los materiales de construcción, hemos fracasado en controlar el impacto ambiental y energético del sector, lo que nos ha conducido entre otros a los problemas ecológicos globales que todo el mundo conoce. Es por lo tanto necesario someter la actividad a un control social y político, entendiendo la responsabilidad individual y trasladándola a los profesionales del futuro, que son nuestros estudiantes del presente.

El lugar estratégico para instituir y promover la responsabilidad social de la ciencia y la tecnología, en todos sus ámbitos, es justamente la Universidad, porque es el lugar de convergencia entre la producción del saber científico (la investigación), la reproducción de este saber (transmisión de los conocimientos y formación de los profesionales que socializan las ciencias y tecnologías) y la información de la ciudadanía sobre los avances científicos y tecnológicos (la Universidad es un espacio social abierto al debate público).

La Universidad tiene la responsabilidad social de promover el debate, facilitarlo, conducirlo y enriquecerlo, dando al estudiante los medios para informarse, reflexionar y juzgar y a las empresas los conocimientos adecuados para aplicar su propia Responsabilidad Social. En este sentido, la aplicación de la investigación a la Titulación de Arquitectura Técnica, así como el trabajo pro proyectos, es una de las acciones que contribuyen a ese fin.

\section{Conclusiones}

Como conclusión principal se extrae la necesidad de implantar procesos de esta índole, y de asumir la esta práctica como objeto de análisis, reflexión e intervención, con responsabilidad ética y profesional. Más allá de la implantación de esta metodología en la asignatura y de los resultados de aprendizaje obtenidos, la respuesta estudiantil ha sido muy positiva. Es decir, el trabajo por proyectos ha tenido un impacto muy positivo en el 
rendimiento y los aprendizajes de los estudiantes así como el incremento de la satisfacción para con la experiencia educativa.

Por tanto, se debe favorecer el análisis de los resultados obtenidos para extraer conclusiones con los aspectos aplicables para la situación problema en una realidad contextual. El poder trabajar con criterios claros sobre la propia acción del estudiante, favorece la fundamentación científica, e impulsa la formación constante y permanente del buen hacer en el gremio profesional de los arquitectos técnicos.

\section{REFERENCIAS}

BROWN K.A. (2000). "Developing Project Management Skills: A Service Learning Approach". Project Management Institute, vol. 31, issue 4, p. 53-58.

GARCIA ARENAS C, CANO PALACIOS M, VEGA BORRERO F, LOUISE NILSSON S, VILCHES ARENAS L.F, LEIVA FERNANDEZ C. (2014) "Nueva metodología de aprendizaje autónomo aplicada a una práctica de Ingeniería Química mediante técnicas de investigación-acción". Revista d'innovació educativa, vol. 13, p. 97-103.

GARCÍA RUIZ R., GONZALEZ N, CONTRERAS P. (2014). "La formación en competencias en la universidad a través de proyectos de trabajo y herramientas 2.0. Análisis de una experiencia". Revista de Universidad y Sociedad del Conocimiento (RUSC). vol. 11, p.. 49-60.

KOKOTSAKI D, MENZIES V, WIGGINS A. (2016). "Project-based learning: A review of the literature". Improving Schools, vol. 19, issue 3, p. 267-277.

KINKUS J. (2007). "Project Management Skills: A Literature Review and Content Analysis of Librarian Position Announcements", College \& Research Libraries, vol. 363.

RUIZ G. (2002). "La sociedad del conocimiento y la educación superior universitaria". Revista Mexicana de Ciencias Políticas y Sociales, vol. 45, issue 185, p. 109-124.

SARIWATI M.S, ZAIMY J.J. NORINA A.J. (2013). "Assessment of Project Management Skills and Learning Outcomes in Students' Projects". Procedia - Social and Behavioral Sciences, vol. 90, p. $745-754$.

VITERI BRIONES T.A, VAZQUEZ CEDEÑO S. (2015). "Formación de habilidades de investigación formativa en los estudiantes de la carrera de ingeniería comercial de la Facultad de Ciencias Administrativas de la Universidad de Guayaquil". Revista Universidad y Sociedad, vol. 8, p. 36-44. 


\title{
EDIFİCATE
}

I Congreso de Escuelas de Edificación y Arquitectura Técnica de España València, 4 y 5 de noviembre de 2021

Escuela Técnica Superior de Ingeniería de Edificación

Universitat Politècnica de València

Doi: https://doi.org/10.4995/EDIFICATE2021.2021.13273

\section{El método Flipped Classroom en asignaturas gráficas The Flipped Classroom method in graphic subjects}

\author{
Concepción López González ${ }^{a}$, Jorge Luis García Valldecabres ${ }^{b}$ y Jorge Girbés Pérez \\ aUniversitat Politècnica de València. Centro de Investigación en Arquitectura, Patrimonio y Gestión para \\ el Desarrollo Sostenible (PEGASO), 'Universitat Politècnica de València. Centro de Investigación en \\ Arquitectura, Patrimonio y Gestión para el Desarrollo Sostenible (PEGASO) y 'Universitat Politècnica \\ de València. Departamento de Expresión Gráfica Arquitectónica.
}

\begin{abstract}
One of the problems detected in the first years of university education is the demotivation of the students and the lack of interest in learning, which inevitably triggers school failure and dropout. In this framework, in the School of Building Engineering of the Polytechnic University of Valencia, the teaching methodology called "reverse teaching" has been tested in the field of Architectural Drawing. The main objective has been to achieve a greater interaction of the students, leading to an increase in performance. The methodology is based on the "Flipped Classroom" and "Blended Learning" and the contribution of virtual teaching content. This material is consulted and analyzed by the student prior to the face-to-face class, so that during it, it is discussed and applied to practical examples. To strengthen knowledge, the student, after class in the classroom, continues to learn through autonomous work. The results imply a greater follow-up of the student, an increase in motivation and an improvement in the acquisition of transversal skills. In this way, the teacher becomes a learning guide and leaves behind the role of a simple transmitter of knowledge.
\end{abstract}

Keywords: teaching methodologies, educational innovation, reverse teaching, transversal skills, Blended Learning 


\section{Resumen}

Uno de los problemas detectados en los primeros cursos de la enseñanza universitaria es la desmotivación del alumnado y la falta de interés por el aprendizaje, lo que irremediablemente desencadena el fracaso escolar y el abandono. En este marco, en la Escuela de Ingeniería de Edificación de la Universitat Politècnica de València, se ha ensayado en la materia de Dibujo Arquitectónico la metodología docente denominada "docencia inversa". El objetivo principal ha sido conseguir una mayor interacción del alumnado conducente al aumento del rendimiento. La metodología se basa en el "Flipped Classroom" y "Blended Learning" y el aporte de contenidos docentes virtuales. Este material es consultado y analizado por el alumno previamente a la clase presencial, de forma que durante la misma, se debate y se aplica sobre ejemplos prácticos. Para afianzar los conocimientos el alumno, tras la clase en el aula, continúa aprendiendo a través del trabajo autónomo. Los resultados implican un mayor seguimiento del alumno, un aumento motivacional y una mejora en la adquisición de competencias transversales. De este modo, el profesor se convierte en un orientador del aprendizaje y deja atrás el rol de simple transmisor de conocimiento

Palabras clave: metodologías docentes, innovación educativa, docencia inversa, competencias transversales, Blended Learning 


\section{Introducción}

Desde comienzos de la década anterior, cuando los efectos de la crisis económica e inmobiliaria se hicieron notar en la afluencia de alumnos a las Escuelas donde se imparte el grado de Arquitectura Técnica o Ingeniería de Edificación, se ha venido detectando un grave problema en la actitud de estudiantes de nuevo acceso: existe una desmotivación generalizada y una falta de interés por el aprendizaje. Esta desidia viene provocada por diversos factores: 1) La falta de expectativas de trabajo al finalizar los estudios redunda en una actitud pasiva frente a los estímulos que el aprendizaje debería proporcionar; 2) La disminución en el número de alumnos en las aulas, contrariamente a lo que pudiera pensarse, ralentiza el aprendizaje ya que promueve la desidia colectiva de los pequeños grupos; 3) La afluencia de alumnos extranjeros, con desconocimiento del idioma, desequilibra el ritmo de las clases; 4) La mayoría de los alumnos no han escogido esta carrera en primera opción, por lo que su preparación en el área de la expresión gráfica es muy escasa y, consecuentemente, el aprendizaje es mucho más lento de los esperado. Todo ello colabora de forma definitiva para que se produzca el fracaso escolar $y$, consecuentemente, el abandono.

El origen de la desmotivación no sólo hay que buscarla en los factores anteriormente señalados relativos al entorno estudiantil. También la falta de ilusión de los profesores por renovar las técnicas didácticas adaptándolas a las nuevas tecnologías influye en gran medida en los desfavorables resultados obtenidos en la última década. La falta de estímulos acordes con las dinámicas interoperacionales provocan un conflicto educativo conducente a la desmotivación y al fracaso del proceso enseñanza-aprendizaje. (Fg. 1)

Los modelos educativos que basan su estrategia didáctica úncamente en la clase magistral y en la práctica de aula están quedando obsoletos (Bergmann y Sams, 2012) ante una población estudiantil que interacciona ante los mensajes cortos y directos las imágenes altamente comunicativas, las redes sociales y la inmediatez en la información (López, García y Girbés, 2021).

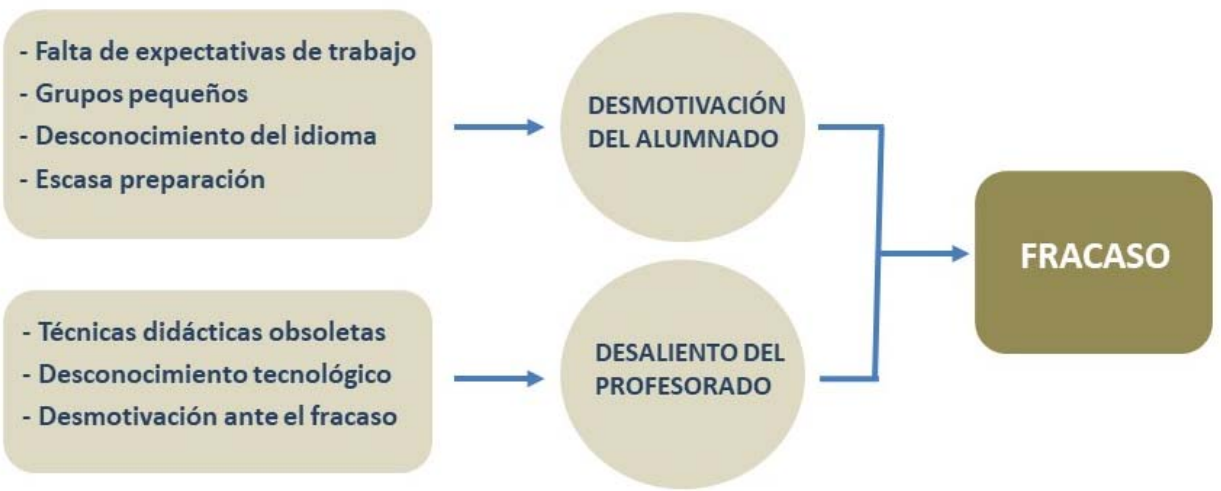

Fig. 1 Causa-Efecto del fracaso escolar. Fuente propia 
Cada vez se hace más necesario cambiar las estrategias didácticas y proponer modelos educativos más acordes con las exigencias marcadas por la sociedad. Despertar la curiosidad del alumnado y desarrollar la motivación de aprender son objetivos que necesariamente pasan por la incorporación de herramientas y técnicas de aprendizaje enmarcadas en el ámbito tecnológico-educativo que el alumnado utiliza en su vida cotidiana. En este sentido, la Tecnología de la Comunicación y de la Información (TIC) puede contribuir en gran manera a la mejora del proceso enseñanza-aprendizaje, especialmente cuando las aplicaciones informáticas y las herramientas de la Web 2.0 han abierto un abanico de posibilidades en el proceso de enseñanza en entornos abiertos y flexibles (Tucker, 2012)

\section{Objetivos y metodología de la experiencia}

Ante este panorama de desaliento del profesorado y desmotivación del alumnado, la Universitat Poitécnica de València, a través de sus vicerrectorados de Recursos Digitales y Documentación (VRED) y Estudios, Calidad y Acreditación (VECA), inició el curso 2018-19 un plan conjunto de innovación educativa, bajo la denominación "Aprendizaje y Docencia" $(A+D)$, que agrupaba algunas de las distintas acciones de innovación educativa que estaban desarrollándose en la universidad entre los que se encontraba la "Docencia Inversa". EI objetivo principal de esta iniciativa la estimulación del alumnado y a la preparación del profesorado en TIC's. Todo ello en aras de la mejora de la calidad docente y del éxito en el proceso de enseñanza-aprendizaje.

En la asignatura de Dibujo Arquitectónico 1, que se imparte en el primer curso de la carrera con una duración anual y 9 créditos de carga docente, se ha implementado una de las estrategias didácticas propuesta por la UPV: La Docencia Inversa. Se trata de un método que se está experimentando con buenos resultados en otras áreas temáticas. Este método, también denominado "aula invertida" o "flipped classroom" basa su estrategia en la inversión del método tradicional: Antes de impartir la clase presencial, el profesor facilita al alumno/a el material necesario para que el estudiante pueda preparar, ampliar y estudiar los contenidos del tema que se desarrollará posteriormente en la clase. De este modo, en el aula se debaten y analizan los conceptos que el alumno ha trabajado de forma autónoma con anterioridad a través de una práctica dirigida y guiada por el profesor. (fig. 2)

Con este proceso "inverso" se consigue que el alumno/a asuma un rol mucho más activo en su proceso de aprendizaje que el que venía ocupando tradicionalmente (Berenguer, 2016). Cuanto más activo sea el papel del alumnado, mayor será la conservación de lo aprendido (Sánchez, Ruiz y Sánchez, 2017)

El objetivo principal de la puesta en marcha de esta experiencia en la asignatura de Dibujo Arquitectónico 1 ha sido conseguir mejorar la enseñanza a través de la estimulación del alumno: se trata de involucrar al estudiante en su propio proceso formativo, haciéndolo responsable de su aprendizaje. 
Esta estrategia pretende despertar la motivación por aprender y por adquirir competencias específicas y transversales que necesitará para ser un buen profesional cuando acceda al mundo laboral.

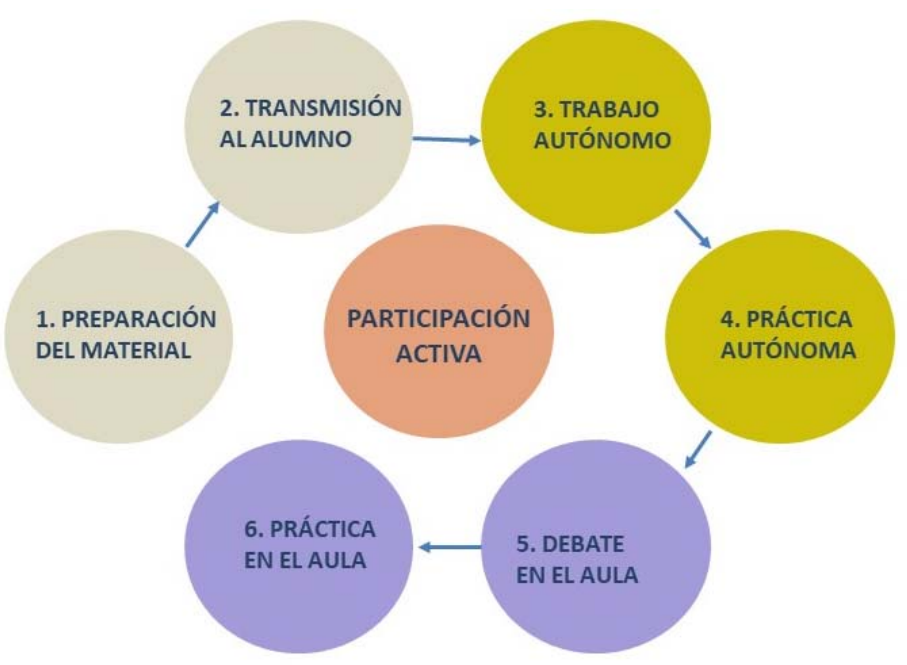

Fig. 2 Fases del proceso de Docencia Inversa. Fuente propia

Fases 1 y 2 realizadas por el profesor. Fases 3 y 4 por el alumno. Fases 5 y 6 de forma conjunta

La experiencia de docencia inversa en la asignatura de Dibujo Arquitectónico 1 se ha llevado a cabo estableciendo un protocolo de actuación que favoreciese la correcta identificación y el adecuado progreso de las etapas de trabajo. Para ello se han seguido tres estadios de trabajo: 1) Identificación y análisis del estado actual; 2) Elaboración de los recursos y del material didáctico; 3) Diseño de los ejercicios de autoevaluación y de las prácticas de aula (Sánchez, Ruiz y Sánchez, 2014)

\subsection{Identificación y análisis del estado actual}

Para la identificación del "estado de la cuestión" se tuvieron en consideración los tres agentes que intervienen en el proceso de enseñanza-aprendizaje: los alumnos, el profesorado y los medios disponibles, tanto los relativos a material docente como los medios tecnológicos y de infraestructuras que pueden ser utilizados. En muchos casos se olvida la importancia que puede tener el diseño del aula, las instalaciones y la tecnología disponible (Sánchez, Ruiz y Sánchez, 2017).

\subsubsection{Los alumnos}

El alumnado que accede a los estudios de Arquitectura Técnica en los últimos diez años ha experimentado un giro de $180^{\circ}$ respecto a la década anterior tanto por su número como por su procedencia. El número de alumnos extranjeros supone un $30 \%$ del total (48 de 166). La 
mayoría proceden de países del norte de África, de Latinoamérica y también, en menor número, del este de Europa y del continente asiático especialmente de China. Este misceláneo conjugado con el escaso conocimiento del idioma español agrava doblemente el problema ya que, a la diferente preparación con la que acceden a la Universidad respecto a los alumnos españoles hay que añadir la casi ausencia de comunicación efectiva.

Por otro lado, la mayoría de los alumnos españoles no han seleccionado la Arquitectura Técnica como primera opción en su acceso a la Universidad procediendo, en muchos casos, de un bachillerato no afín al tecnológico por lo que su preparación en materias enmarcadas en el área de la expresión gráfica es nula o muy precaria. Esta falta de conocimientos previos contribuye al incremento del desánimo.

Esta dispersión del alumnado hace necesaria la implementación de nuevos planteamientos docentes que faciliten la integración y la motivación basándose en la máxima de Aristóteles: Así nos hacemos constructores construyendo casas, y citaristas tocando la cítara (Aristóteles. Traducción Calvo, 2001) en la que se basó la implantación del proceso de Bolonia: aprender aprendiendo.

\subsubsection{Los profesores}

La drástica disminución del número de alumnos en la última década debido, fundamentalmente, a la falta de expectativas de trabajo al finalizar los estudios, consecuencia de la crisis económica acaecida en 2008, ha supuesto una considerable disminución del número de profesores. Este hecho que, aparentemente, resulta inocuo, sin embargo, ha tenido efectos adversos en calidad de la enseñanza. La Universidad ha prescindido mayoritariamente del profesorado asociado. Estos docentes suelen caracterizarse por tratarse de profesores jóvenes, dinámicos, emprendedores y afines a las nuevas tecnologías.

El profesorado que ha quedado a cargo de la docencia de la asignatura dispone de un mayor recorrido docente, con una larga experiencia educacional en diversas asignaturas, tanto del grado como de postgrado, acumulando visiones y enfoques diversos en diferentes materias. Esta experiencia ha sido afianzada a través de la docencia en universidades extranjeras y manteniendo vivo el binomio docencia-investigación mediante el desarrollo de proyectos de investigación, cuyos métodos y resultados han sido proyectados a las aulas.

La dilatada experiencia profesional de este profesorado "senior" también contribuye al desarrollo de una docencia más aplicada. Todo ello se manifiesta en la transmisión al alumnado del modo de pensar y razonar con criterio crítico sobre los aspectos aparentemente contradictorios que se presentan en torno a la edificación (Prunuske, Batzli, Howell, y Miller, 2012). Sin embargo, se trata de un profesorado que precisa mejorar su formación en el ámbito de las TIC's y en el uso de herramientas tecnológicas que facilitan, favorecen y optimizan el aprendizaje.

Esta limitación implica un nuevo desafío en el que la formación en el manejo de nuevos sistemas y herramientas de elaboración de recursos didácticos acordes con los modelos comunicativos del alumnado se hace necesari, sobre todo, ante un alumnado tan diverso. 


\subsubsection{Los medios disponibles}

Como ya se anticipaba al comienzo de este apartado, es necesario establecer la diferenciación entre las infraestructuras e instalaciones disponibles para impartir la docencia y los recursos y materiales didácticos.

Dentro del primer grupo cabe destacar el empeño de la Universitat Politècnica de València por poner a disposición de profesores y alumnos plataformas y herramientas que facilitan la gestión de la docencia. PoliformaT es una plataforma de de teleformación donde los alumnos y profesores comparten la información utilizando herramientas destinadas a la reposición de contenidos, tareas, exámenes, chat, etc. Con motivo de la pandemia ocasionada por la COVID-19, se ha puesto a disposición de toda la comunidad universitaria el acceso a la licencia educativa Microsoft Office 365 que facilita la docencia online para los estudiantes y personal. También las aulas han sido acondicionadas para posibilitar la videoconferencia. Además de las instalaciones e infraestructuras hay que añadir el uso gratuito de software especializado como es AutoCAD Autodesk 3ds Max Design y el programa Revit.

En el segundo grupo también habría que diferenciar entre el material didáctico tradicional consistente en la publicación de libros sobre la materia, apuntes, cuadernos de ejercicios y presentaciones en power point que contribuyen a la transmisión del conocimiento mediante la imagen y los nuevos materiales didácticos más acordes con las nuevas herramientas. La asignatura ha ido acumulando una gran cantidad de material didáctico tradicional a lo largo de los años: manuales, memorias de curso, libros, apuntes y presentaciones, así como exposiciones de trabajos comentados realizados por los alumnos. Material todo este, que los alumnos utilizaban y consultaban con gran interés. Sin embargo, en un momento donde existe un problema de desmotivación y abandono, la asignatura se encontraba deficitaria en materiales didácticos más comunicativos, participativos e interoperables. Es evidente que se hacía necesaria la revisión del material didáctico y su renovación atendiendo a las nuevas herramientas tecnológicas ya que se había detectado un gran desafecto por parte de los estudiantes hacia este material tradicional.

\subsection{Elaboración de los recursos y del material didáctico}

Una vez clarificado el "estado actual" de la asignatura y detectada la problemática y el origen de la misma, se consideró en primer lugar, la necesidad de plantear un enfoque diferente a la asignatura, estableciendo nuevos objetivos en el ámbito docente. En Dibujo Arquitectónico 1 , los alumnos no sólo tienen que aprender a realizar un buen levantamiento de planos partiendo de la correspondiente toma de datos, sino que además deben de adquirir una serie de competencias transversales que contribuirán a que sea en el futuro un buen profesional. Concretamente se trata de las competencias relativas a la "aplicación y pensamiento práctico", "aprendizaje permanente" y "planificación y gestión del tiempo". Por ello, se plantea una reorientación de la asignatura dirigida al análisis del proyecto arquitectónico dado que el arquitecto técnico es el garante de que la ejecución material de un proyecto se realice correctamente. Se trata, por tanto, de que esté capacitado para interpretar y conocer perfectamente los documentos que integran un proyecto arquitectónico. Asimismo, el análisis del proyecto supone un factor motivador para el alumnado que, desde el comienzo de sus 
estudios, maneja una documentación y realiza tareas y ejercicios directamente relacionados con la profesión. Atendiendo a este planteamiento se rediseñó el contenido del nuevo material docente. Se establecieron tres niveles de recursos:

1) Los vídeos con contenidos teóricos destinados a ser vistos, analizados y ampliados por los alumnos con anterioridad a la clase presencial. Estos recursos didácticos son transmitidos al alumnado a través de la plataforma PoliformaT. Un total de 19 vídeos con enlaces a otros recursos tradicionales además de blocs, manuales y video tutoriales online. (Fig. 3)

2) Los enunciados de los ejercicios que hemos denominado de "autoevaluación" que el alumno realiza tras consultar los vídeos y que le sirve para comprobar si ha comprendido bien los conceptos expuestos. Estos enunciados se ubican siempre al finalizar el vídeo correspondiente a cada tema. En PoliformaT los alumnos poseen un repositorio personal para subir sus ejercicios y documentos. Se establecieron cuatro carpetas donde entregar y almacenar los ejercicios realizados: Trabajos de casa, Trabajos de aula, Ejercicios de examen y la denominada carpeta del Profesor en la que se les incorporan los informes personalizados y las evaluaciones de cada uno de los ejercicios entregados.

3) Los enunciados de los ejercicios que alumno realizará en clase con la presencia del profesor y que le ayudarán a debatir y afianzar los conceptos aprendidos. Estas prácticas deben ser entendidas como un documento gráfico e interpretativo del proyecto arquitectónico y como toma de datos del edificio existente para la posterior elaboración del proyecto de ejecución. En este capítulo se preparó también la estrategia del debate posterior en el aula con el fin de elevar la participación del mayor número de alumnos. Asimismo, se elaboró la solución gráfica de cada una de las prácticas para que el alumno pudiera realizar su propia autoevaluación. Esta estrategia facilita en gran manera la comprensión de los errores y contribuye al buen entendimiento del resultado obtenido en la evaluación del ejercicio.

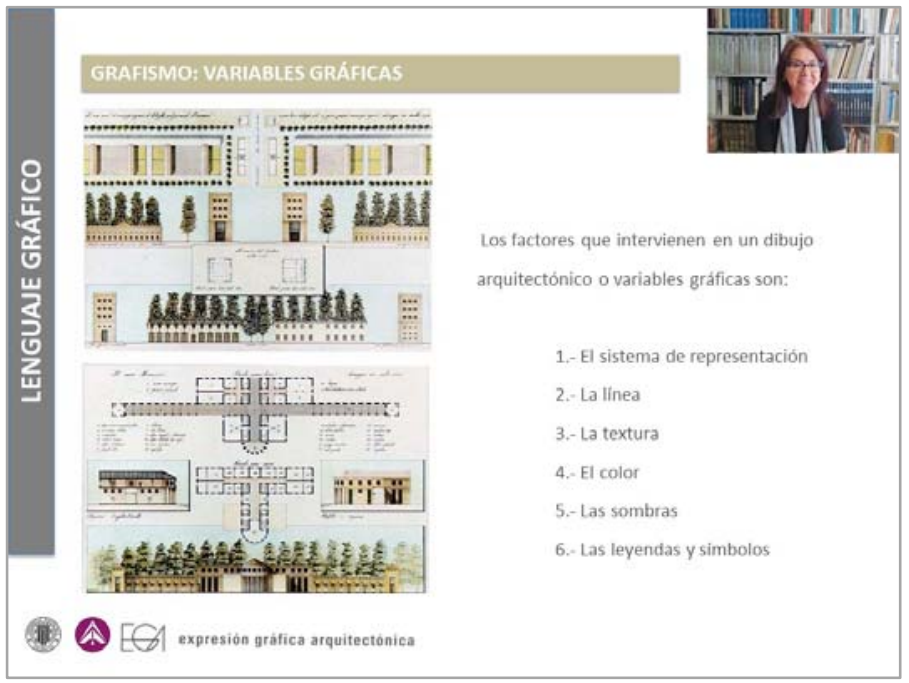

Fig. 3 Captura de un recurso de vídeo-apunte. Fuente propia 


\subsection{Diseño de los ejercicios de autoevaluación y de las prácticas de aula}

Siguiendo con el criterio de reorientación de la asignatura hacia el análisis del proyecto arquitectónico, se diseñaron los ejercicios autónomos y las prácticas de aula atendiendo a las operaciones que se realizan para interpretar el proyecto arquitectónico. Simultáneamente se establecieron manuales para la adquisición de las habilidades necesarias para su desarrollo.

El dibujo arquitectónico encierra un carácter analítico que contribuye a que el alumno se familiarice con las leyes de los sistemas de representación y con las variables gráficas que lo constituyen. Por ello, los primeros ejercicios están basados en modelos que se corresponden con el entorno profesional: Edificios geométricamente compuestos y con control proporcional. (Fig. 4). De cada uno de ellos realizan la correspondiente autoevaluación (Fig. 5)

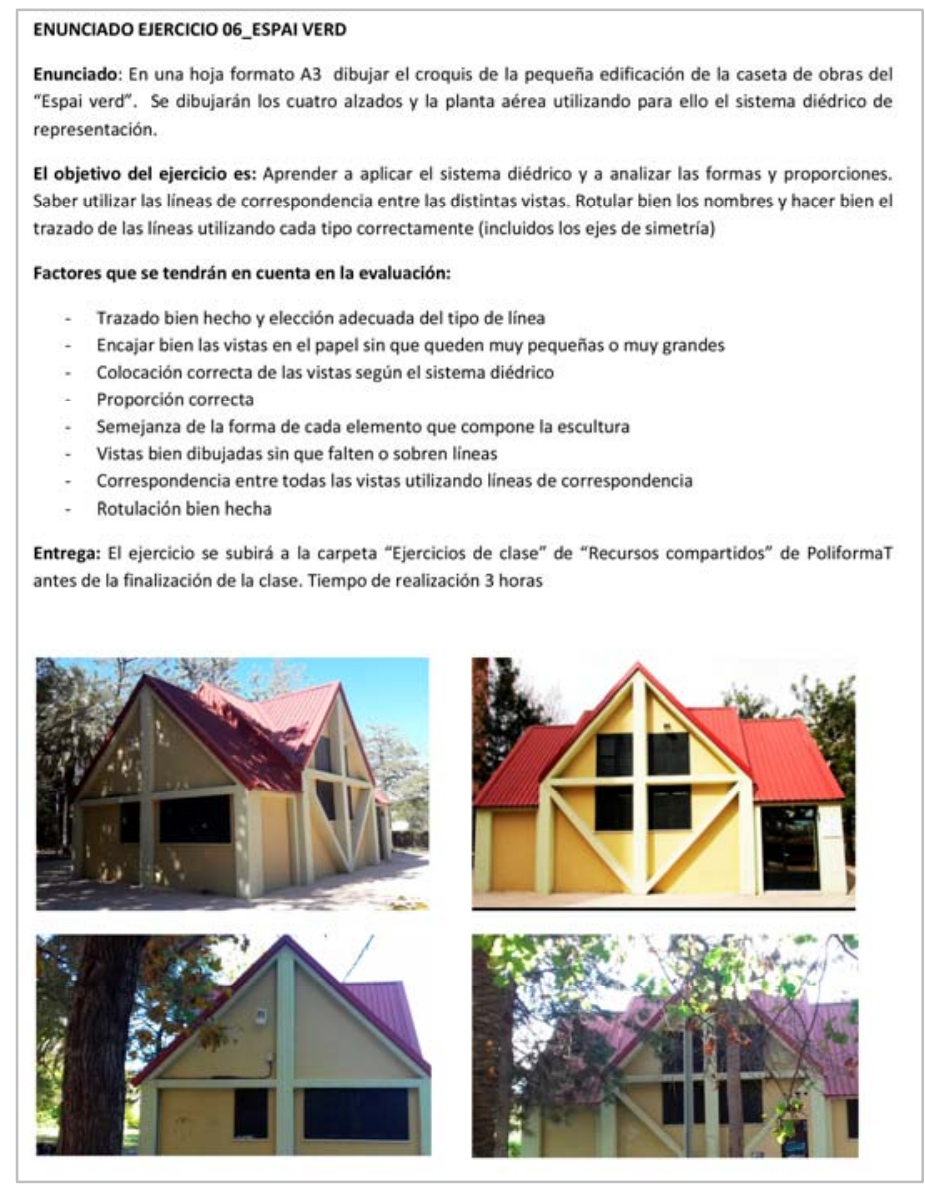

Fig. 4 Enunciado ejercicio destinado a fortalecer los conocimientos sobre el sistema diédrico. Fuente propia 


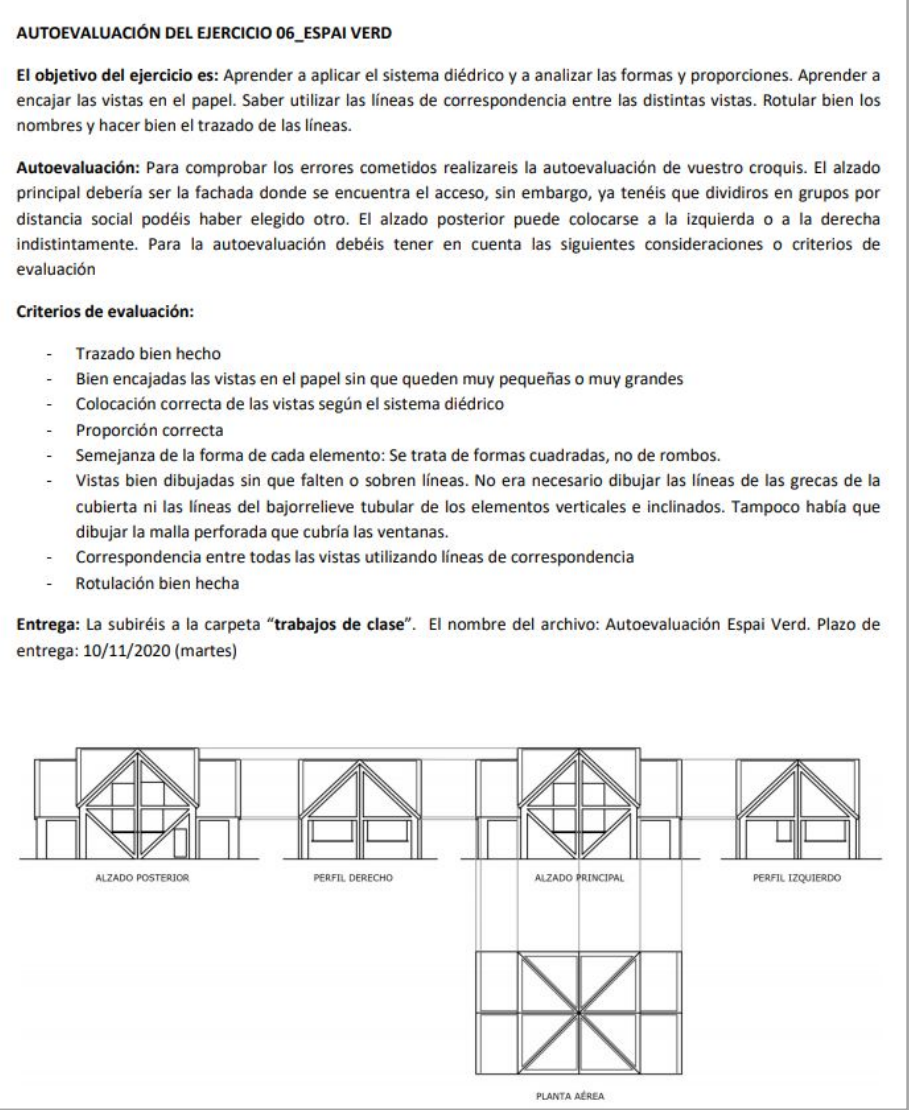

Fig. 5 Enunciado de autoevaluación destinado a analizar los errores cometidos. Fuente propia

Todos los ejercicios que se van realizando a lo largo del curso se fundamentan en temas arquitectónicos, tomando como modelos de representación algunas partes especialmente significativas de los edificios por su manifiesto interés constructivo o espacial. Es el caso de las escaleras, fachadas o galerías, hasta concluir en la representación completa de un edificio de reducidas dimensiones (Sams y Bergmann, 2013)

\section{Resultados de la experiencia}

Los resultados obtenidos se pueden clasificar en dos grandes grupos: Los relativos al proceso enseñanza aprendizaje y los concernientes al uso de nuevas técnicas comunicativas encaminadas a mejorar la docencia.

Respecto al primer bloque podemos afirmar tal y como expone Bromley (Bromley, 2013) que el método didáctico de docencia inversa ha incrementado notablemente la capacidad comunicativa, el arraigo del sentido de la responsabilidad y la estimulación del análisis crítico. 
Todo ello queda reflejado en la evidente mejora de los resultados de evaluación, en el aumento de las consultas, tanto presenciales como a través de Teams y en el gran número de ejercicios entregados en el plazo establecido. A todo ello ha contribuido sin duda la creación de video-apuntes porque, de algún modo, implica un acercamiento a las nuevas tecnologías de la comunicación a través de la imagen y del mensaje directo. Es precisamente el ámbito comunicativo en el que se desenvuelve el estudiante actual y por lo tanto, el alumno se vuelve más receptivo y más motivado ya que se trata de uno de los recursos más dinámicos que existen (Lara y Rivas, 2009).

El resultado más destacado ha sido la disminución de la tasa de absentismo. El ritmo constante marcado en la ejecución y entrega de los ejercicios así como la participación grupal han contribuido de forma notable a que el alumno se inmiscuya en el proceso didáctico y se sienta mucho más motivado a continuar con la docencia, pues comprende que el absentismo lo deja fuera de juego respecto a sus compañeros. La tasa de absentismo en la última década era aproximadamente del $30-35 \%$. La tasa de absentismo en el curso donde se ha implantado la docencia inversa es del $13 \%$. Este resultado cuantitativo refleja la eficacia del método.

Sin embargo, han existido excepciones, principalmente entre los alumnos de habla extranjera, que no han sido capaces de adaptarse a esta nueva estrategia didáctica. Son alumnos con un gran arraigo a los sistemas tradicionales, esperando trabajar con un nivel de comunicación inferior al necesario en este método. La falta de participación le ha producido incertidumbre y ha revertido en un menor aprovechamiento y en algunos casos en el abandono.

La experiencia también cuenta con resultados negativos en el marco de la elaboración del material docente. Para el profesorado ha supuesto una gran cantidad de trabajo adicional debido a los cambios sustanciales establecidos en la orientación de la asignatura, en el cambio del programa y, principalmente por la creación de recursos novedosos mediante el uso de nuevas técnicas que, en algunos casos, eran desconocidas.

\section{Conclusiones}

Para establecer las conclusiones de la experiencia tendremos en consideración los niveles de aprendizaje establecidos en la taxonomía de Bloom y su posterior revisión realizada en 2000 por sus discípulos Anderson y Krathwohl (Anderson y Krathwohl, 2001). Según esta revisión, "el proceso de aprendizaje se puede iniciar en cualquier punto y que los niveles taxonómicos más bajos estarán cubiertos por la estructura de la tarea de aprendizaje" (Churches, 2009).

Con el método de docencia inversa, el alumno dispone en primer lugar del material necesario para adquirir los conocimientos necesarios para realizar las tareas a desarrollar en casa como trabajo autónomo de autoevaluación basadas en el proceso cognitivo del proyecto gráfico arquitectónico. Por lo tanto se inicia el proceso a través del análisis y la aplicación a un caso práctico, es decir, el método docencia inversa altera el orden de los estadios establecidos por 
Bloom: Los niveles "analizar" y "aplicar" se sitúan en la primera etapa del proceso de aprendizaje. Con ello se consigue despertar en el alumnado la curiosidad y el deseo de conocer y profundizar en la materia que se está desarrollando en Dibujo Arquitectónico 1.

Este modo de plantear la docencia contribuye a que el docente pueda llevar un seguimiento más detallado del alumno/a; las clases presenciales planteadas según el método de aula invertida son más activas, más participativas y mucho más prácticas. Favorece la interacción con el alumno, cosa que no ocurre durante las clases magistrales. Este método, además, proporciona una cierta flexibilidad en el ritmo de aprendizaje permitiendo que cada alumno/a pueda mantener un recorrido independiente de trabajo acorde con sus capacidades y circunstancias lo que, finalmente, redunda en su rendimiento. Con esta experiencia se ha podido comprobar la afirmación de que "Los estudiantes mostrarán más interés y se sentirán más comprometidos. En definitiva, el individuo se convierte en el protagonista de su aprendizaje" (Aguilera et al., 2017)

A partir de los resultados de las encuestas realizadas en la Universitat Politècnica de València, y de las opiniones vertidas en las jornadas de seguimiento donde profesores y alumnos expusieron su visión de la experiencia, se puede concluir que tanto los docentes como los estudiantes entienden que la Docencia Inversa exige un mayor esfuerzo que se ve recompensado al redundar favorablemente en el proceso de enseñanza-aprendizaje. La experiencia ha favorecido la adquisición de competencias específicas de la y también ha contribuido a la obtención de competencias transversales, tan necesarias en el acceso al mundo laboral.

Se puede concluir que mediante la implementación de la estrategia didáctica basada en la docencia inversa en la asignatura de Dibujo arquitectónico 1, el alumno/a toma conciencia de su propio aprendizaje, de su autoaprendizaje obteniendo una formación más personalizada debido al rol de guía de aprendizaje que adquiere el profesor. La motivación y el interés del alumnado se ve incrementado debido, en gran medida al trabajo colaborativo y a la interacción alumno/profesor.

\section{Referencias}

aguilera-Ruiz C.; Manzano-león, A.; Martinez-Moreno, I.; Lozano-Segura, M.C. y Casiano YANICELLI, C. (2017). "EI modelo Flipper Classroom". En International Journal of Developmental and Educational Psychology INFAD Revista de Psicología, №1 - Monográfico 3, 261-266

ANDERSON, L.W., AND D. KRATHWOHL (Eds.) (2001). A Taxonomy for Learning, Teaching and Assessing: a Revision of Bloom's Taxonomy of Educational Objectives. New York: Longman

ARISTÓTELeS, Ética a Nicómaco. (s. IV a. C. Traducción, 2001). Traducción y Notas Calvo Martínez, J. L.; Madrid: Alianza Editorial.

BeRENGUeR, C. (2016). "Acerca de la utilidad del aula invertida o flipped classroom". M. Tortosa, S. Grau y J. Álvarez (Ed.), En XIV Jornadas de redes de investigación en docencia universitaria. Investigación, innovación y enseñanza universitaria: enfoques pluridisciplinares. Alicante, España: Universitat d'Alacant. 1466- 1480 
BergmanN, J. Y SAMS, A. (2012). Flip Your Classroom: Reach Every Student in Every Class Every Day. New York, NY: International Society for Technology in Education

BROMLEY, P. (2013). "Active Learning Strategies for Diverse Learning Styles: Simulations Are Only One Method”. En Ps-Political Science \& Politics, 46(4), 818-822. doi:10.1017/S1049096513001145

CHURCHES, A (2009) Taxonomía de Bloom para la era digital. http://www.eduteka.org/TaxonomiaBloomDigital.php:. [Consulta: 30 de abril de 2021]

LARA, S., Y RIVAS, S. (2009). "Aprendizaje autorregulado y fomento de competencias en dos asignaturas de Máster a través del empleo de plantillas de evaluación, método del caso, role-playing y vídeo digita"I En. Educación XX1, 12, pp. 67-96

Lopez Gonzalez, C, Garcia Valldecabres, J. y GiRbes Perez, J (2021). "Implantación de docencia inversa en asignaturas gráficas como estrategia de motivación” en Pino Suarez, R. Redrawing tfe future. La Laguna, Tirant lo Blanc

Prunuske, A. J., Batzli, J., Howell, E., y MilleR, S. (2012). "Using Online Lectures to Make Time for Active Learning". En Genetics, 192(1), 67-72.

SAmS, A., Y BergmanN, J. (2013). “Flip Your Students' Learning”. En Educational Leadership, 70(6), 1620.

SÁnCHEZ-RodrígueZ, J,; RUIZ-PALMERo, J. Y SÁNCHEZ-VegA, E. (2017) "Flipped classroom. Claves para su puesta en práctica". En Edmetic, Revista de educación mediática y TIC. 6 (2), pp.336-358. doi: https://doi.org/10.21071/edmetic.v6i2.5832

SÁNCHEZ, J.; RUIZ, J.; Y SÁNCHEZ, E. (2014). "Las clases invertidas: beneficios y estrategias para su puesta en práctica en la educación superior”. En M. C. Domínguez, M. L. Cacheiro, y J. Dulac (Eds.), Diálogo entre culturas: estrategias didácticas y tecnologías educativas. Pizarra digital. Madrid: UNED.

TUCKER, B. (2012) "The flipped classroom" En Education Next, 12 (1) 


\title{
EDIFİCATE
}

I Congreso de Escuelas de Edificación y Arquitectura Técnica de España València, 4 y 5 de noviembre de 2021

Escuela Técnica Superior de Ingeniería de Edificación

Universitat Politècnica de València

Doi: https://doi.org/10.4995/EDIFICATE2021.2021.13565

\section{La Exposición de trabajos de clase como motivación para estudiantes de Expresión Gráfica The Exhibition of class works as a motivation for Graphic Expression students.}

\author{
Ruth Pino Suárez y Juan Alejandro Melián Melián \\ Universidad de La Laguna, rpsuarez@ull.edu.es y Universidad de La Laguna, jamelian@ull.edu.es
}

\begin{abstract}
EDIGRÁFICA 2021 has recently been held, a Virtual Exhibition after a long trajectory as a traditional exhibition, with works by students and teachers of Graphic Expression subjects of degrees in the field of building and with international participation.

This is the first time that this exhibition has been carried out in a non-presential way, and this has allowed us to discover new possibilities for the relationship and exchange of learning results.

The experience of this form of exhibition has opened up an innovative way to encourage and promote the work of students in our degrees with a cross-cutting objective: to develop communicative, compositional and expressive skills while carrying out class work associated with the syllabus and/or research in the field of Graphic Expression.

But it also opens up the possibility of interacting with other participants from anywhere, exchanging information, organising on-line presentations within the room and using it as a multi-purpose classroom for teaching.
\end{abstract}

Keywords: Virtual exhibition, class work, research, exchange, interaction.

\section{Resumen}

Recientemente se ha celebrado EDIGRÁFICA 2021, una Exposición Virtual después de una larga trayectoria como exposición tradicional, con trabajos de estudiantes y profesores de asignaturas de Expresión Gráfica de titulaciones del ámbito de la edificación y con participación internacional.

Es la primera vez que se realiza esta exposición de manera no presencial, y esto ha permitido descubrir nuevas posibilidades para la relación y el intercambio de los resultados de aprendizaje.

La experiencia de esta forma de exponer ha abierto una vía innovadora para fomentar y promover la realización de los trabajos del alumnado de nuestras escuelas con un objetivo transversal: desarrollar la capacidad comunicativa, compositiva y expresiva a la vez que realizan trabajos de clase asociados a los temarios y/o a la investigación en materia de Expresión Gráfica. 
La Exposición de trabajos de clase como motivación para estudiantes de Expresión GráficaThe Exhibition of class Works as a motivation for Graphic Expression students.

Pero además abre la posibilidad de interactuar con otros participantes de cualquier lugar, intercambiar información, organizar presentaciones on-line dentro de la sala y usarla como aula multiusos para la docencia.

Palabras clave: Exposición virtual, trabajos de clase, investigación, intercambio, interacción. 


\section{Introducción}

La situación sociosanitaria del último año ha obligado a que tanto las clases como los congresos hayan tenido que adaptarse y encontrar el modo de no paralizarse. Con la exigencia de la no presencialidad, y venciendo múltiples resistencias, hemos descubierto herramientas y vehículos para la comunicación que parecen haber venido para quedarse.

A causa del imperativo de las circunstancias, lo que quizá hubiera tardado décadas en transformarse, se nos ha presentado de golpe, dando un salto sorprendente.

Esto nos ha permitido valorar aquellas herramientas que realmente nos han facilitado ciertos aspectos de la docencia así como las que, en muchos casos por casualidad o necesidad, hemos encontrado para desarrollar otros proyectos académicos y profesionales.

Hace dos años comenzamos a organizar el XV Congreso Internacional de Expresión Gráfica aplicada a la Edificación que, como todas las ediciones desde 1991, iba a ser presencial. Paralelamente al Congreso, siempre se organizaba una exposición denominada EDIGRÁFICA, donde los profesores de Expresión Gráfica de las Escuelas de Arquitectura Técnica e Ingeniería de Edificación presentaban los trabajos de sus estudiantes en paneles de cartón pluma que se colgaban y exponían en algún espacio de la sede del Congreso. En la mayoría de los casos los profesores cargaban con ellos desde sus escuelas de origen, de ahí que a veces sólo llegaran trabajos de ciudades cercanas.

Finalmente hemos celebrado dicho congreso de manera virtual, lo que ha obligado a que la exposición EDIGRÁFICA 2021, en Tenerife, del 27 de mayo al 30 de junio, también fuese virtual.

Del resultado de esta exposición nace esta propuesta docente gracias a la múltiples posibilidades que la aplicación nos abre hacia la interacción y el encuentro de estudiantes, profesores y participantes de otras nacionalidades.

\section{Objetivos}

A la vista del resultado de la Exposición Virtual que ha sido montada para EDIGRÁFICA 2021, analizando sus fortalezas y debilidades, se pretende proponer esta iniciativa participativa como un reto motivacional para profesores y estudiantes de estas materias.

La visita a la Exposición permite conocer los trabajos de otros estudiantes e investigadores, erigiéndose en sí misma como una herramienta de aprendizaje que pone en valor a la Expresión Gráfica y muestra una realidad profesional para futuros graduados.

Sin embargo, esta propuesta trata de promover la acción en cuanto a la participación en las futuras exposiciones, conociendo este objetivo en el momento de realizar los ejercicios prácticos de clase, añadiendo el reto expositivo al conjunto de competencias e integrando un aprendizaje basado en proyectos que sirva para impulsar la motivación de los estudiantes. 


\section{Desarrollo de la innovación. EDIGRÁFICA 2021}

Con motivo de la celebración del XV Congreso Internacional de Expresión Gráfica aplicada a la Edificación: Redibujando el Futuro - APEGA 2021, en Tenerife, se inauguró el pasado 27 de mayo la Exposición EDIGRÁFICA 2021.

Siendo la primera vez que se hace virtual y a la vista de las ventajas que han sobresalido tras esta experiencia, la Asociación de Profesores de Expresión Gráfica Aplicada a la Edificación tiene la convicción de que esta forma de exponer los trabajos de EDIGRÁFICA va a ser determinante en los Congresos futuros de APEGA.

\subsection{Antecedentes}

Los Congresos de APEGA comenzaron a organizarse en el año 1991 en las que se denominaron Primeras Jornadas de Expresión Gráfica Aplicada a la Edificación, en Sevilla, y desde entonces se vienen celebrando cada dos años ininterrumpidamente con carácter nacional hasta 2010 en que pasó a ser internacional y alcazó un hito de participación.

APEGA, como asociación, nació con el objetivo principal de fomentar la solidaridad y defensa de sus miembros, teniendo por objeto cuantas actividades tiendan a impulsar, potenciar, orientar, coordinar, desarrollar y promover en sus vertientes científicas y técnicas, la enseñanza y la divulgación de la Expresión Gráfica Arquitectónica en las Escuelas Técnicas Superiores de Ingeniería de Edificación, de Edificación, Politécnicas o con cualquier otra denominación, en las que se imparta la enseñanza de esta área de conocimiento y que impartan la titulación de grado que habilita a la profesión de Arquitecto Técnico (APEGA)

A partir de 1995, en el Congreso celebrado en La Coruña, se instauró EDIGRÁFICA, con el fin de exponer los trabajos de estudiantes y profesores de las diferentes escuelas de España, lo que contribuyó a la visibilidad de los resultados de docencia y aprendizaje en las diversas materias de la Expresión Gráfica.

La exposición EDIGRÁFICA pretende seguir conservando su espíritu inicial de constituir una muestra de logros conseguidos por el profesorado y alumnado vinculado a la Expresión Gráfica Arquitectónica e Ingeniería de la Edificación, perdurando en el tiempo y reafirmándose como instrumento de difusión nacional e internacional en todas sus dimensiones.

La historia de las quince ediciones de EDIGRÁFICA puede demostrar cómo la Expresión Gráfica aplicada a la Edificación ha ido evolucionando y adaptándose a los cambios que las nuevas tecnologías han ido imponiendo.

\subsection{Contexto Profesional}

Tanto los Congresos como las Exposiciones EDIGRÁFICA se enmarcan en el contexto de la docencia de Profesores de las áreas de Expresión Gráfica Arquitectónica que se constituyeron como Asociación en 1993, cuando la carrera y las asignaturas tenían el mismo nombre y mismo plan de estudios en casi todas la Universidades de España. 
La muestra de los trabajos de los estudiantes dirigidos por el profesorado de nuestras escuelas a través de EDIGRÁFICA ha permitido dar testimonio, y pretende seguir dándolo, de cómo se representa el mundo en construcción, el construido y el desaparecido, desde antes de la incorporación de los primeros dibujos asistidos por ordenador hasta las más novedosas metodologías actuales.

EDIGRÁFICA cuenta de forma visual la historia de la Expresión Gráfica aplicada a la Edificación y, por tanto, narra parte de la historia del mundo.

Profesionalmente los trabajos expuestos demuestran cómo los estudiantes aplican los conocimientos y los avances tecnológicos de aplicación en la topografía, levantamiento de planos, escaneados, modelado y recogida de datos, gestión de la información gráfica y de proyectos que tanta importancia tiene en el desarrollo posterior de nuestros egresados.

\subsection{Premios a los mejores trabajos}

Más tarde se establecieron los Premios a los mejores trabajos de EDIGRÁFICA que motivan y reconocen los méritos de los participantes en la Exposición.

En honor al Profesor D. Juan Manuel Raya Urbano, fallecido en 2008, estos premios comenzaron a llevar su nombre a partir del congreso de Alicante, en 2010.

Fue Catedrático de Dibujo Arquitectónico II de la Escuela Universitaria de Arquitectura Técnica de Sevilla y gran promotor e impulsor de la Asociación APEGA, así como de los congresos y actividades que ésta realiza.

Para EDIGRÁFICA 2021, observando que la realización virtual permitiría incluir en la exposición a un mayor número de participantes extranjeros, se abrió la posibilidad de abarcar trabajos docentes y de investigación que, sin salirse de la línea temática, tuvieran la visión y el desarrollo metodológico de otras latitudes. Los participantes en EDIGRÁFICA han presentado los trabajos con la debida antelación, siguiendo estrictamente instrucciones con el fin de garantizar la calidad de las imágenes y el anonimato de los autores para su valoración por parte del Jurado de los Premios Juan Manuel Raya.

El rigor de los trabajos ha permitico la realización de una Exposición y un Catálogo con excelente calidad de imagen tanto en la versión digitales como impresa. Del mismo modo, los premiados han podido figurar como tal en todos los documentos gráficos que se han publicado desde el mismo momento de la inauguración de EDIGRÁFICA 2021.

Estos premios y la visibilidad de los trabajos de todos lo participantes que les otorga su presencia en la web, así como su inclusión en el correspondiente Catálogo, son un aliciente y un mérito que pueden motivar a los futuros estudiantes de Expresión Gráfica y sus profesores a concursar en las próximas ediciones.

\subsection{Catálogo de la Exposición}

Es una publicación que recoge la totalidad de los trabajos que participan en EDIGRÁFICA, y donde además se destacan a los premiados por el jurado de los Premios Juan Manuel Raya, 
lo que supone un considerable mérito para los autores, en su mayoría grupos de estudiantes con sus respectivos profesores o tutores de trabajos de investigación.

Se ha iniciado una colección de Catálogos de EDIGRÁFICA gracias al impulso y la iniciativa de los comisarios que organizaron la Exposición para el XIV Congreso de APEGA que se celebró en Sevilla en 2019, siendo el primero de la colección y que lleva por título Catálogo de la Exposición EDIGRÁFICA 2019 (Rincón Millán y Díaz Cañete, 2020).

El Catálogo de la Exposición EDIGRÁFICA 2021, realizado en Tenerife, suma el segundo volumen de la incipiente colección (Pino Suárez y Melián Melián, 2021). Este catálogo está disponible en formato digital en el Repositorio Institucional de la Universidad de La Laguna (https://riull.ull.es/xmlui/handle/915/23955).

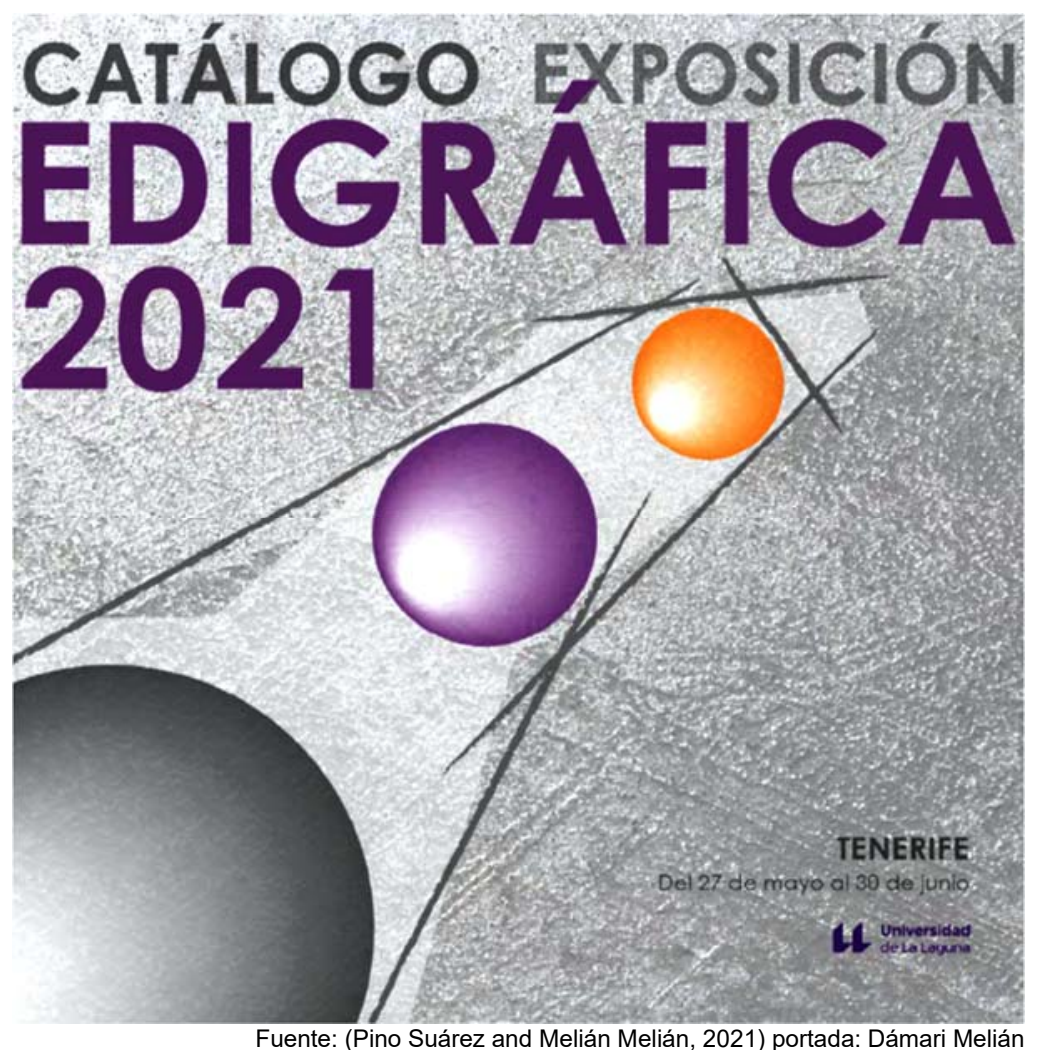

Fig. 1 Portada Catálogo Exposición EDIGRÁFICA 2021. 


\subsection{Exposición Virtual}

El 27 de mayo de 2021 se inauguró la Exposición EDIGRÁFICA 2021 de Tenerife, coincidiendo con el inicio del Congreso.

En la página web del congreso se preparó una exposición multimedia, mediante la cual se podían ver todos los trabajos pinchado alternativamente en cada título y accediendo a la información enlazada así como a cada uno de los paneles para ser visualizados en detalle con total calidad de imagen. Para esta muestra de EDIGRÁFICA se empleó la aplicación Genial.ly.

En la pantalla de inicio se encuentran los títulos de los trabajos presentados, siguiendo una numeración que, posteriormente se hizo coincidir tanto en la Exposición Virtual como en la edición del Catálogo.

Se puede observar la distinción entre las dos modalidades en que está dividida EDIGRÁFICA, docencia e investigación, de modo que los Premios Juan Manuel Raya otorgan un único galardón por modalidad y se reserva la opción de conceder dos accésits.

\section{EXPOSICIÓN EDIGRÁFICA 2021}

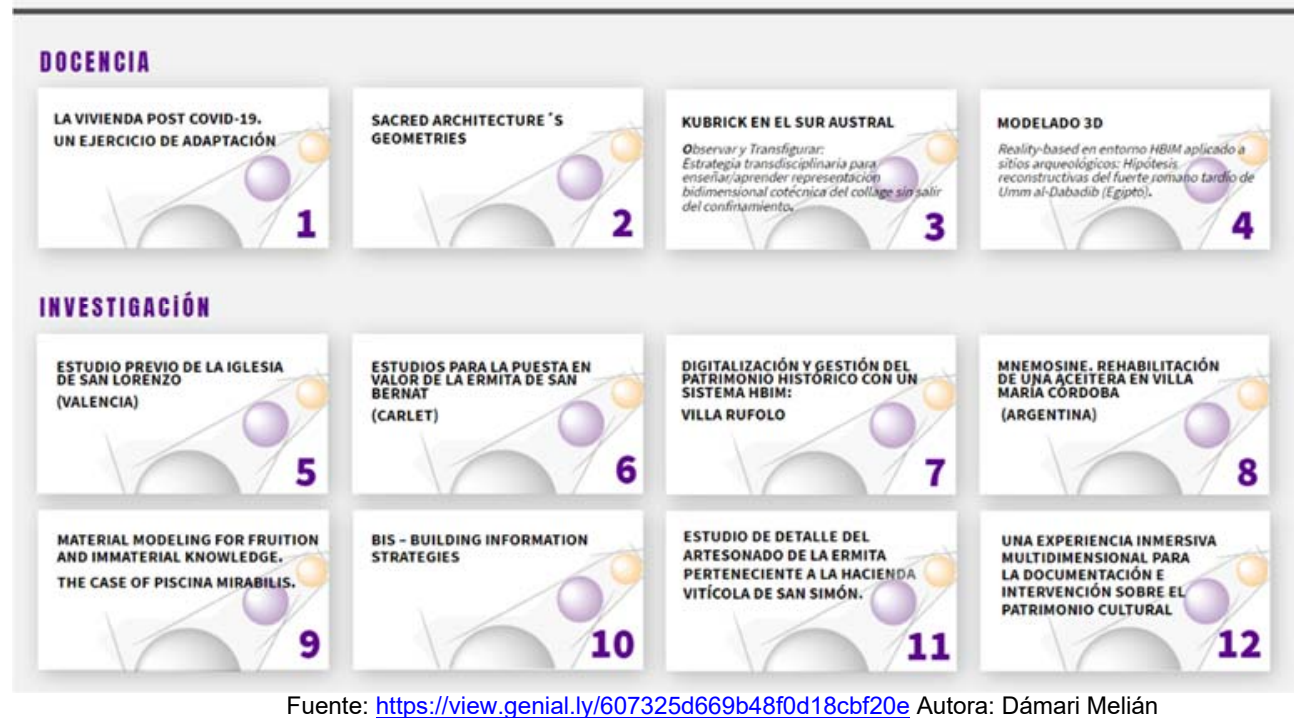

Fig. 2 Página de Inicio de EDIGRÁFICA donde figuran todos los trabajos presentados al concurso y expuestos en la sala virtual.

Pero la Exposición más dinámica y más atractiva ha sido la que finalmente ha permitido tener la posibilidad de pasear virtualmente por la Sala de Exposiciones donde se han colocado todos los paneles, enviados en formato jpeg y con resolución 600 ppp. 
Presentada y accesible desde la página web del Congreso, todo el público al que se le haya hecho llegar el enlace, puede visitarlo desde su ordenador y moverse con los mandos indicados, del mismo modo que un videojuego. Se incluye la posibilidad de que cada visitante pueda personalizar su propio "avatar", poner su nombre y encontrarse por la sala con otros avatares e interactuar con ellos como si se tratara de una visita real.

\subsubsection{Soporte técnico}

Para montar la exposición se ha utilizado la plataforma Mozilla Hubs (Hubs - Private, virtual 3D spaces in your browser). Es una plataforma gratuita que permite diseñar los entornos de forma bastante intuitiva, con la herramienta Spoke (Spoke by Mozilla) similar a muchos programas que se usan en Expresión Gráfica.

No obstante, usar Hubs de manera gratuita tiene sus limitaciones, ya que no se pueden personalizar numerosos aspectos de las salas, como por ejemplo la capacidad. Para la Exposición EDIGRÁFICA 2021 se han implementado algunas opciones para la personalización y se ha montado en una instancia de Amazon Web Services (AWS Cloud Computing - Servicios de informática en la nube), lo que ha requerido la ayuda de técnicos con conocimientos más avanzados. Además se ha sido necesario asumir los costes de todos los servicios asociados para que la instancia funcione lo que dure la exposición.

\section{EXPOSICIÓN EDIGRÁFICA 2021}

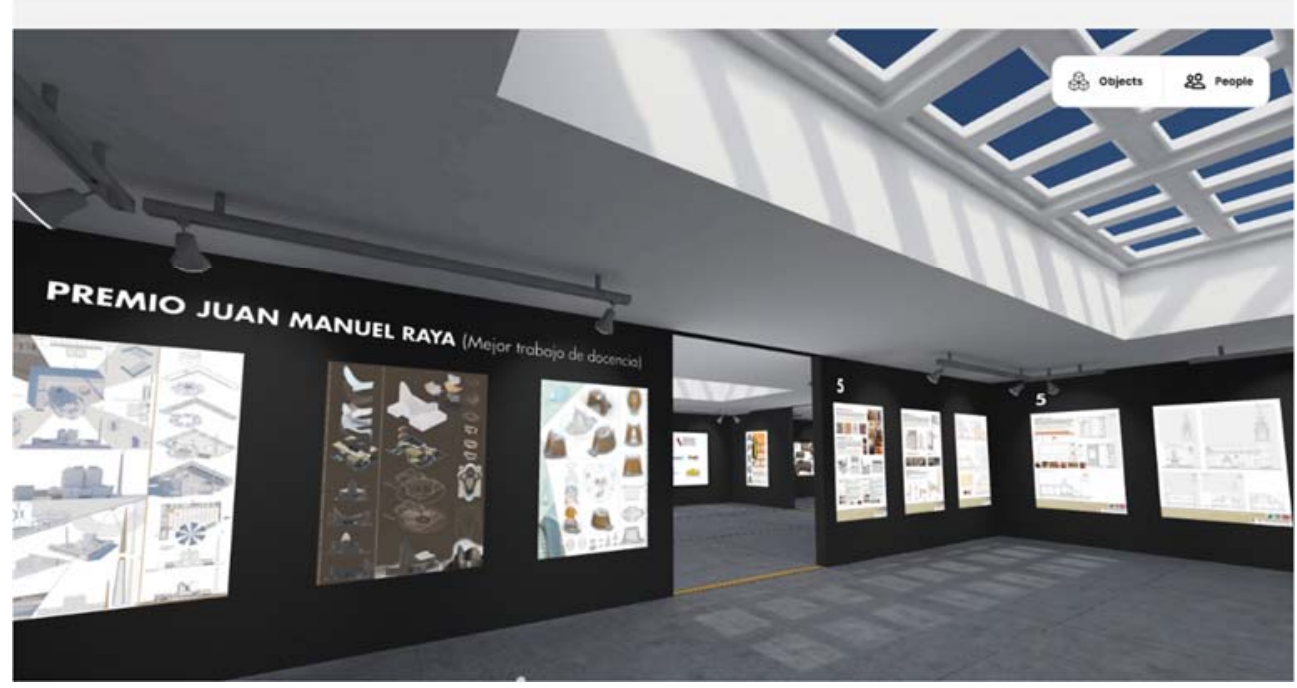




\section{EXPOSICIÓN EDIGRÁFICA 2021}

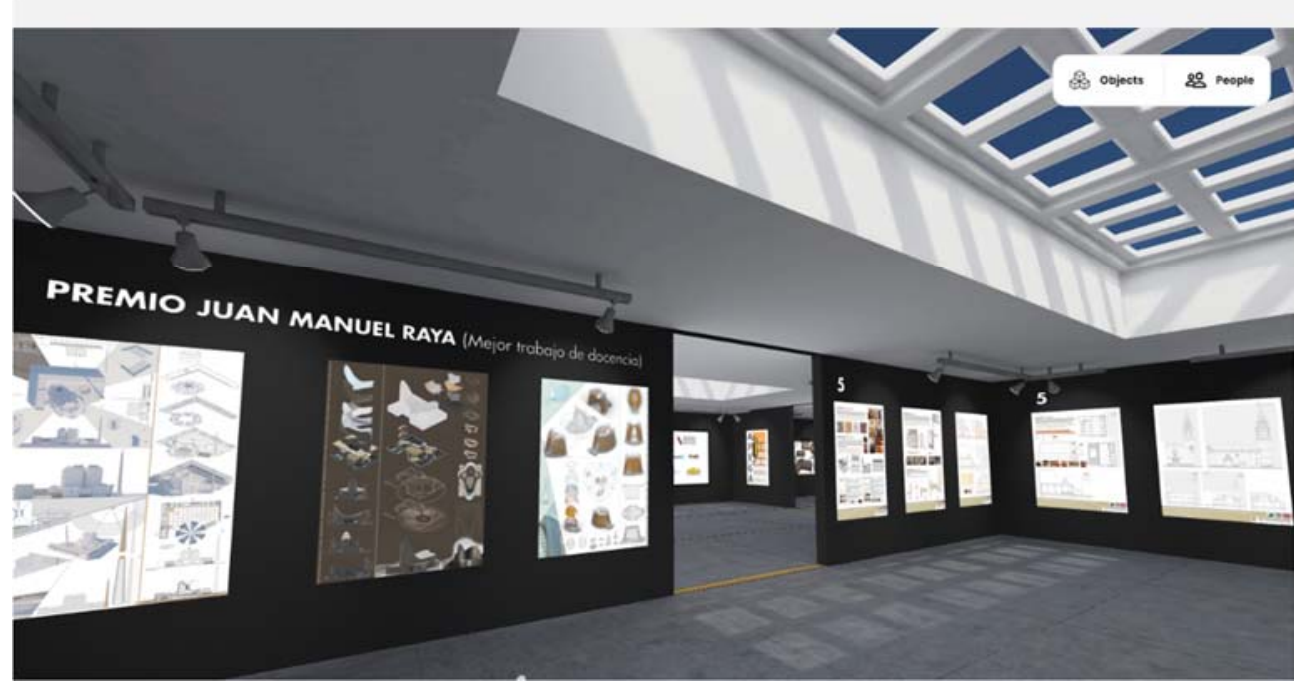

Fuente: elaboración propia

Fig. 3 Capturas de pantalla de la Exposición Virtual EDIGRÁFICA 2021-Tenerife, interactiva, accesible del 27 de mayo al 30 de junio de 2021

\subsubsection{Fortalezas}

A todos los efectos, esta Exposición Virtual, ha cumplido con la expectativas de una exposición al uso tradicional, teniendo en cuenta que los principales usuarios y visitantes iban a ser los propios participantes y los asistentes al Congreso.

Pero desde que se hiciera el llamamiento a la participación en EDIGRÁFICA 2021 a los diferentes colectivos de profesores y universidades incluyendo otros países europeos y latinoamericanos, se tomó conciencia de que al ser virtual sería muy fácil la participación internacional. Pero también la nacional, puesto que no se hacía necesario el envío de paneles en cartón pluma para su montaje y desmontje, ni tampoco prever lugares en Tenerife donde hacer las impresiones, etc.

Enumeramos a continuación todas las cualidades que han aflorado como fortalezas en esta modalidad expositiva:

- Hay cabida para un mayor número de trabajos sin necesidad de limitarlo a un espacio concreto.

- $\quad$ No hay que montar los paneles físicamente y desmontarla al finalizar.

- Se facilita la participación en la Exposición, sin costes de envío ni de impresión. Además los participantes no están obligados a asistir al Congreso. 
- Se promueve el intercambio de información y conocimiento entre los profesores y los estudiantes de diferentes países.

- La exposición resulta divertida de visitar y se asemeja a un juego, donde los participantes pueden interactuar unos con otros y dirigirse hacia un panel $u$ otro $y$ comentarlo.

- $\quad$ Los spónsors se pueden hacer más visibles y tener enlace a sus páginas web.

- El alcance y visibilidad de la Exposición a trevés de internet la convierte en potencialmente global.

- Se puede acceder a la sala en cualquier momento del día, noche o día de la semana y desde cualquier parte del mundo.

- Profesores y estudiantes de cualquier nacionalidad pueden citarse en la sala y realizar la visita en grupo guiados por el profesor. Se puede invitar a los autores de los trabajos a dar charlas dentro de la misma exposición.

- Los méritos de los participantes quedan igualmente acreditados con los certificados correspondientes y la publicación del Catálogo de la Exposición.

\subsubsection{Debilidades}

Es posible que las debilidades de este tipo de exposición sean las mismas que subyacen en todos los eventos que nos hemos ido viendo obligados a realizar on-line, como lo ha sido el propio Congreso de APEGA 2021.

Lo más destacable es la falta del contacto social y las relaciones humanas. No hay duda de que existe una frialdad y distancia entre las personas que se encuentran en cualquier reunión virtual. Pero más aun cuando la esencia de los congresos como los que organiza APEGA radica en conocer personalmente a los ponentes y prolongar los coloquios y discusiones de manera informal durante los momentos de ocio y descanso. Eso es insustituible.

Sin embargo, en el caso de EDIGRÁFICA como espacio expositivo, realmente en la modalidad presencial no representa un lugar de encuentro, sino más bien de paso o de paseo prácticamente individual, más que colectivo. Esta razón es una debilidad de la exposición tradicional, lo que se traduce en una fortaleza más de la exposición virtual.

No obstante, podemos decir que existen algunos puntos débiles:

- El montaje de la exposición virtual podría tener un coste muy bajo, sin embargo requiere destreza y soltura con las plataformas necesarias.

- Si se necesita ampliar capacidad o implementar servicios específicos así como un lugar donde alojar la exposición, hay que prever y asumir ciertos gastos y el apoyo de técnicos más experimentados.

- Puede resultar difícil acceder a visitantes que no estén familiarizados con el uso de estas plataformas o de internet.

- La exposición no está físicamente instalada en la Sede del Congreso, habitualmente es en el vestíbujo de la Escuela de Arquitectura Técnica a la que haya correspondido la organización, y el alumnado no se la encuentra cuando va a su clase mientras se 
celebra el un congreso de Expresión Gráfica en su centro, lo que se traduce en una alta visibilidad global en las redes, pero nula visibilidad local.

- La Exposición no se nutre tanto de los trabajos de profesores y estudiantes que pertenecen a la Universidad que acoge el congreso $y$, por extensión, a EDIGRÁFICA.

- Al abrir EDIGRÁFICA a la internacionalización también se produce un salto diferencial en el tipo de trabajos que se presentan desde otras universidades extranjeras, cuyos estudiantes son de doctorado o de carreras afines a la Arquitectura Técnica pero que han focalizado su aprendizaje en campos muy concretos y con disponibilidad de medios tecnológicos que los hacen diferenciarse.

- Esto puede resultar desmotivador y en ese sentido se apunta como una debilidad. Sin embargo, visto el resultado de esta primera exposición virtual, parece que también debe ser un estímulo para profundizar en otros modos de hacer e impulsar la excelencia de los trabajos de Expresión Gráfica de los futuros profesionales de la Edificación.

\section{Resultados. Propuesta Docente}

Por todo lo explicado, hemos considerado que un espacio expositivo virtual como EDIGRÁFICA 2021, se presenta como una oportunidad para desarrollar experiencias docentes con los estudiantes de Expresión Gráfica que se forman actualmente en nuestras escuelas.

Aprovechando que EDIGRÁFICA se celebra cada dos años, es posible organizar a los estudiantes desde segundo curso hasta el último, donde se preparan los Trabajos Fin de Grado, retándoles a que presenten sus trabajos en esta Exposición Virtual Internacional.

Las razones por las que esta propuesta podría ser de gran atractivo para los estudiantes se basan en objetivos de corto, medio y largo plazo, lo que requerirá poner en práctica diferentes fases de planificación y planteamientos del trabajo.

Pero lo que se busca realmente es que los estudiantes, dirigidos por el profesorado, asuman el reto y descubran una motivación más allá del resultado académico.

\subsection{La Motivación}

Una cuestion interesante a tener en cuenta por el profesorado, derivada de las recomendaciones tomadas de la investigación de Stipek (1988) para lograr la motivación de los alumnos al aprendizaje, hace referencia a que el profesor debe propiciar un contacto de los alumnos con el mundo real exponiendo casos reales de su ámbito profesional.

Los trabajos que se exponen en EDIGRÁFICA, especialmente los de investigación, son fieles reflejos de lo que se hace actualmente para realizar levantamientos de planos, topografías, análisis de patologías, comparaciones históricas del patrimonio, modelados con supuestos 
pasados y futuros, sistemas de información geográficos, combinaciones entre unos conocimientos y otros, etc.

Aunque sólo fuera para conocer en qué consiste la Exposición EDIGRÁFICA, los alumnos de cualquier curso que la visiten, estarían aprendiendo las cosas que se pueden hacer con la formación en Expresión Gráfica que reciben y con la que aún desconocen.

El profesor debe ser el primer implicado en el reto, y considerar qué motivación presenta su alumnado con el fin de estimular no sólo el logro de la recompensa externa como el aprobado del curso sino también la valoración social y el aumento de la capacidad y profundidad del conocimiento (Parrales Rodríguez y Solórzano Salas, 2014).

De modo que esta experiencia docente, que aún no se ha puesto en práctica, tiene que contar con la disposición de un profesor o grupo de profesores que mantenga el reto vivo entre su alumnado motivado.

Pese a que un elevado porcentaje de alumnos da más importancia al hecho de obtener los resultados académicos apetecidos que al hecho de aprender, existe la motivación intrínseca de los estudiantes, la que les nace de forma natural, que consigue mejor rendimiento y aprendizaje para el futuro. $\mathrm{Y}$, aunque requiere más esfuerzo y dedicación por parte de los estudiantes, repercute en una mejora del proceso de enseñanza-aprendizaje y sienta las bases para un aprendizaje significativo, lo que enlaza directamente con los principios educativos del EEES (Crespo Fernández y Martínez Lirola, 2008), además de aportar importantes ventajas en cuanto al rendimiento y la salud psíquica del estudiante (Mas Tous y Medinas Amorós, 2007).

El desarrollo por parte de los docentes de estrategias de motivación en sus actividades, generando simples desafíos vinculados con problemas reales que generen interés en los alumnos por llegar a una resolución satisfactoria y por aprender, redundará en el logro de un mayor nivel de compromiso por parte de dichos alumnos en la solución de los problemas planteados y en la construcción de sus propios conocimientos (Hector Ardisana, 2012).

Teniendo en cuenta las consideraciones de numerosos expertos en motivación, se puede entender que los estudiantes estén abiertos a preparar sus trabajos de clase para ser expuestos en una Exposición Virtual como EDIGRÁFICA con el fin de:

- Participar en una Exposición que convoca a otros estudiantes de carreras similares a nivel nacional e internacional.

- Optar a alguno de los Premios Juan Manuel Raya.

- Publicar sus trabajos en un Catálogo.

Para el profesorado, esta propuesta puede ser interesante a la hora de plantear trabajos en grupo y promover un aprendizaje basado en el Proyecto Expositiva, lo que obligaría a que los estudiantes desarrollaran sus competencias transversales en la línea de liderazgo, resolución de problemas, trabajo colaborativo, etc. 
Tendrán que seguir unas normas y plazos de presentación de los trabajos, organizar los paneles en los formatos exigidos con la información o los dibujos que quieran incluir, establecer el relato gráfico de su idea a transmitir, temática o secuencia de aprendizaje.

Finalizado el Proyecto tendrán la recompensa de ver el resultado de su trabajo en una publicación y una Exposición donde encontrarse e incluso divertirse como con un videojuego, a la vez que ellos mismos serán promotores y divulgadores tanto de su aprendizaje como del sentido de la Expresión Gráfica en la sociedad.

\subsection{El espacio expositivo: interactivo-docente-internacional}

Una vez que la Exposición está montada, se abre una nueva faceta que resulta de la versatilidad de la Sala Virtual de la Exposición.

- Es un espacio interactivo, abierto y global, ya que tiene libre acceso y funciona como una sala presencial excepto porque las personas que vemos son unos muñecos con un número asociado. Son visitantes que están viendo la exposición al mismo tiempo y que, si lo desean, pueden hablar mediante el micrófono que se activa al acceder a la sala.

- Es un espacio docente donde hacer reuniones o dar clases on-line, lo que permite salir de la rutina y mostrar a los demás estudiantes cómo se trabaja en otras universidades, fomentando el interés y la curiosidad por el conocimiento de las herramientas que se utilizan en Expresión Gráfica para lograr distintos objetivos en la representación arquitectónica.

- Es un espacio internacional, o pretende serlo en las sucesivas ediciones, ya que participan estudiantes y profesores del extranjero, especialmente de Italia, y alguno de Chile y Argentina. Este hecho, que confiere a EDIGRÁFICA un nuevo rasgo de internacionalización y apertura, supone una gran oportunidad para fomentar relaciones y contactos fuera de nuestras fronteras.

\section{Conclusión}

La experiencia llevada a cabo en EDIGRÁFICA 2021 como exposición virtual frente a la presencial, ha abierto una via innovadora que debe servir para fomentar y promover la realización de trabajos de los estudiantes de nuestras escuelas con un objetivo transversal: desarrollar la capacidad comunicativa, compositiva y expresiva a la vez que se les motiva para realizar trabajos de clase asociados a los temarios y/o a la investigación en materia de Expresión Gráfica.

Una buena oportunidad para poner en marcha esta propuesta didáctica entre los profesores y estudiantes de Expresión Gráfica de nuestras escuelas, sería la próxima Exposición EDIGRÁFICA 2023, aprovechando que tiene los medios y la infraestructura para que los trabajos de clase sean expuestos de una forma sostenible y global; más aún cuando las valoraciones de los usuarios de esta primera exposición virtual han sido altamente positivas. 
Esta experiencia docente se podrá completar con la organización interuniversitaria de encuentros en la Sala de Exposiciones, estableciendo un programa de eventos que también promuevan reuniones con estudiantes y profesores de otros países.

\section{Referencias}

APEGA Asociación de Profesores de Expresión Gráfica Aplicada a la Edificación, Objetivos. $<$ https://apega.blogs.upv.es/objetivos/> [Consulta: 28 de Junio de 2021]

AWS | CLOUD COMPUTING - Servicios de informática en la nube. <https://aws.amazon.com/es/> [Consulta: 28 de Junio de 2021]

CRESPO FERNÁNDEZ, E. y MARTÍNEZ LIROLA, M. (2008) "Convergencia Europea, motivación y actuación docente en el aula universitaria", en Revista de Enseñanza Universitaria, (31), pp. 416.

HECTOR ARDISANA, E. F. (2012) "La motivación como sustento indispensable del aprendizaje en los estudiantes universitarios.", en Pedagogía Universitaria, XVII(4), pp. 13-27.

HUBS. Private, virtual 3D spaces in your browser. <https://hubs.mozilla.com/> [Consulta: 28 de Junio de 2021]

MAS TOUS, C. y MEDINAS AMORÓS, M. (2007) "Motivaciones para el estudio en universitarios", en Anales de Psicología. Servicio de Publicaciones de la Universidad de Murcia, 23(1), pp. 17-24.

PARRALES RODRÍGUEZ, S. y SOLÓRZANO SALAS, J. (2014) "Motivación y estrategias de aprendizaje del estudiantado de la Escuela de Orientación y Educación Especial", en Revista electronica: Actualidades investigativas en educacion. Universidad de Costa Rica, 14(1), pp. 1-20.

PINO SUÁREZ, R. y MELIÁN MELIÁN, J. A. (2021) Catálogo Exposición EDIGRÁFICA 2021. Universidad de La Laguna. <http://riull.ull.es/xmlui/handle/915/23959> [Consulta: 29 de Junio de 2021]

RINCÓN MILLÁN, M. D. y DÍAZ CAÑETE, P. (2020) Catálogo Exposición EDIGRÁFICA 2019. Editorial Círculo Rojo. Sevilla, España.

SPOKE by Mozilla. <https://hubs.mozilla.com/spoke> [Consulta: 28 de Junio de 2021]

STIPEK, D. (1988) Motivation to learn: From theory to practice. E. Cliffs. New York, USA: Prentice Hall. 


\title{
EDIFİCATE
}

I Congreso de Escuelas de Edificación y Arquitectura Técnica de España

València, 4 y 5 de noviembre de 2021

Escuela Técnica Superior de Ingeniería de Edificación

Universitat Politècnica de València

Doi: https://doi.org/10.4995/EDIFICATE2021.2021.13585

\section{Introducción de nuevas estrategias para el aprendizaje autónomo en alumnos de primer curso}

\section{Implementating new strategies for autonomous learning in first-year students}

\author{
María-Isabel Giner-Garcíaa , Ángeles Rodrigo-Molina ${ }^{b}$ \\ ${ }^{a}$ Escuela Técnica Superior de Ingeniería de Edificación, Universitat Politècnica de València, Camino de \\ Vera s/n, 46022, Valencia (España). magigar@csa.upv.es. \\ ${ }^{\mathrm{b}}$ Escuela Técnica Superior de Ingeniería del Diseño, Universitat Politècnica de València, Camino de \\ Vera s/n, 46022, Valencia (España). arodrigo@ega.upv.es
}

\begin{abstract}
University training is more than the academic development of the student. The acquisition of certain competences, the know-how in specific situations applying knowledge, as well as skills and attitudes are also essential in the learning process. The paper shows the educational strategy implemented involving first-year students. The goal is that the students learn skills and resources destined to organise and to plan themselves facing the autonomous work. In addition, they improve their academic performance. Due mainly to the inexperience of these students, their difficulties for a project where they must work in an autonomous way and that it requires a planning in time have been evident. The proposed strategies set out a certain number of support guidelines for autonomous learning, which allow to improve the results. To this end, a work planning is carried out, and assessed tutorials are scheduled, where in each one of them the items marked in the calendar must be presented. Tools are used to analyse both the functioning and usefulness of the procedure, and the improvement in learning results.
\end{abstract}

Keywords: autonomous learning, educational strategies, planning, tutorial, architectural graphic expression, architectural drawing. 


\begin{abstract}
Resumen
La formación universitaria es algo más que el desarrollo académico del alumno. La adquisición de ciertas competencias, el saber hacer ante situaciones concretas aplicando conocimientos, así como las habilidades $y$ actitudes, son también esenciales en el proceso de aprendizaje. El trabajo que se expone muestra la estrategia educativa puesta en marcha con alumnos de primer curso. El objetivo es que aprendan habilidades y recursos destinados a organizarse y planificarse ante el trabajo autónomo, mejorando así su rendimiento académico. Debido principalmente a la inexperiencia de estos alumnos, se han evidenciado sus dificultades ante un proyecto donde deban trabajar de forma autónoma y que requiera una planificación en el tiempo. Las estrategias planteadas marcan una serie de pautas de apoyo para el aprendizaje autónomo, y permiten mejorar los resultados. Para ello se realiza una planificación del trabajo y se programan unas tutorías evaluables, donde en cada una de ellas se deben presentar los items marcados en calendario. Se utilizan herramientas de análisis tanto del funcionamiento $y$ utilidad del procedimiento, como de la mejora en los resultados aprendizaje.
\end{abstract}

Palabras clave: aprendizaje autónomo, estrategias educativas, planificación tutorias, expresión gráfica arquitectónica, dibujo arquitectónico. 


\section{Introducción}

Expresión Gráfica es una asignatura troncal, que se imparte en el primer curso de Grado de Arquitectura Técnica. En ella se introduce al alumno en el lenguaje gráfico y en el levantamiento arquitectónico. Es una asignatura anual, con tres horas de clase a la semana, en su mayoría prácticas que se realizan fuera del aula. Durante las nueve últimas semanas del curso se desarrolla un proyecto: levantamiento gráfico de un edificio o un conjunto arquitectónico de pequeñas dimensiones. Este proyecto se realiza fuera del horario lectivo, aunque se establece alguna sesión de trabajo en clase, y una serie de tutorías. El objetivo de la realización de este proyecto es fomentar el aprendizaje autónomo del alumno, trabajando en un caso real donde se deben aplicar los conocimientos adquiridos en el aula. El proyecto puede realizarse de forma individual, o por equipos (a elección de los propios alumnos).

El motivo de implantar una nueva estrategia de aplicación para el desarrollo del proyecto, fue el análisis de los resultados académicos de los últimos años. Se detectó una disminución de la calidad de los trabajos, así como un aumento en el número de trabajos no presentados. El porcentaje de trabajos no finalizados aumentó del $5 \%$ el primer año, al 6 ' $25 \%$ el segundo, y al 8 ' $10 \%$ en el último.

Igualmente se analizaron las posibles causas, y se evaluaron una serie de hipótesis:

La primera causa a considerar fue la dimensión del proyecto, probablemente demasiado extenso en cuanto al contenido en relación con el tiempo dado para su ejecución. No obstante, también existe un elevado porcentaje de alumnos que terminan puntualmente el trabajo con unos buenos e incluso excelentes resultados, por lo que se consideró que éste no era el factor principal de aumento de los malos resultados.

La segunda causa analizada fue el aumento del número de trabajos a realizar por el alumno en las diferentes asignaturas del curso académico. Esta cuestión requiere un análisis más profundo en cuanto a la transversalidad horizontal entre asignaturas de un mismo curso (Montes, 2011). Aún así, fue tomada en consideración, y se modificaron las fechas, tanto de inicio como de entrega final del proyecto, a fin de evitar la superposición excesiva de entregas.

Otro motivo que influiría en los malos resultados es la no utilización por parte del alumno de las tutorías. Todo trabajo autónomo requiere ser tutorizado, y aunque, en este caso, se establecen tres sesiones de clase para el seguimiento del mismo, es totalmente imprescindible el uso de las tutorías. La orientación del profesor a corto plazo ayuda al alumno a avanzar con mayor claridad y seguridad, y permite el desarrollo integral del alumno (Bisquerra, 2002). Por tanto, se consideran las tutorías uno de los puntos importantes a reflexionar.

Por último, otra problemática, que se viene observando durante los últimos años, es la carencia de destreza y las dificultades en las que se encuentran, sobretodo (los alumnos de primer curso) para organizarse y planificarse a medio y largo plazo. 
De todo lo anterior se obtiene como resultado que las dificultades más destacables surgen de la inexperiencia del alumnado a trabajar de forma autónoma, así como de la carencia de recursos para la planificación y organización frente a un trabajo de varios meses, agravado por la falta de uso de la tutoría para decibir el feedback del profesor. Por lo que, se decide profundizar en estos aspectos.

\section{Objetivos y resultados de aprendizaje}

Los objetivos de aprendizaje que se marcaron fueron: por un lado, impulsar estrategias y procedimientos que fomenten la motivación, la autonomía en el aprendizaje, y la participación del alumnado; por otro, asegurar la orientación personal que responda a las necesidades de los alumnos; y por último, promover estrategias que guíen al alumno para planificar sus trabajos.

En cuanto a los resultados de aprendizaje que se pretendían alcanzar utilizando estas estrategias fueron: ser capaz de planificar a medio-largo plazo un proyecto de relativa complejidad; identificar y describir los diferentes problemas que pueden surgir a la hora de realizar un levantamiento gráfico; y resolver, mediante los recursos adquiridos, cuestiones de la forma más conveniente.

Por ello, dichas estrategias se centraron en la incorporación de una planificación, corealizada alumno/profesor que permitiese alcanzar los ítems marcados en el trabajo, así como una serie de tutorías, obligatorias y evaluables, introducidas dentro de dicha planificación.

Con la incorporación de estas tutorías, se pretende incrementar y fortalecer las habilidades para consultar, analizar y seleccionar información aplicable a la enseñanza y aprendizaje del dibujo arquitectónico en contextos específicos. De este modo, se fortalece el desarrollo de hábitos de trabajo que favorezcan el crecimiento personal y el descubrimiento de nuevas formas de adquisición del conocimiento (Bisquerra, 2012). Se pretende trabajar tanto las estrategias cognitivas como las metacognitivas. Para las estrategias cognitivas, es importante tener claro el concepto de cognición, entendido como la acción de conocer, es decir recoger, organizar y utilizar el conocimiento (Gellalty, 1997). Las estrategias metacognitivas implican planificar qué se va aprender, y evaluar logros que les permitan concretar aprendizajes.

\section{Desarrollo de la innovación y metodología}

En consecuencia, se incorporó al proyecto una serie de recursos encaminados a conseguir los objetivos y resultados de aprendizaje. Una vez conocido el proyecto a desarrollar y el tiempo que se disponía para su ejecución, se procedió a la realización de un organigrama de trabajo (Tabla 1), incluyendo en él las tutorías evaluables. Dicha planificación, como se comentaba anteriormente, se trabajó conjuntamente con el alumnado. 
Tabla 1. Resumen del organigrama de trabajo

\begin{tabular}{|c|c|c|c|c|}
\hline Tareas & Descripción & Lugar & Duración & Responsable \\
\hline 1 & $\begin{array}{l}\text { Presentación proyecto, } \\
\text { metodologia de trabajo }\end{array}$ & Aula & $45 \mathrm{~min}$ & profesora \\
\hline 2 & $\begin{array}{l}\text { Visita edificio / trabajo de } \\
\text { campo }\end{array}$ & Edificio & $1 \mathrm{~h} 15 \mathrm{~min}$ & alumno/profesor \\
\hline 3 & Planificación/organigrama & Aula & $1 \mathrm{~h}$ & alumno/profesor \\
\hline 4 & Formacion de grupos & casa & $-\cdots$ & alumno \\
\hline 5 & Desarrollo ítem 1 & Edificio/casa & 3 semanas & alumno \\
\hline 6 & $\begin{array}{l}\text { 1a Sesión tutorías. Entrega } \\
\text { ficha seguimiento }\end{array}$ & Aula & $30 \mathrm{~min} /$ equipo & alumnos/profesor \\
\hline 7 & Desarrollo ítem 2 & Edificio/casa & 2 semanas & alumno \\
\hline 8 & Sesión aula & Aula & 3 horas & alumno/ tutor \\
\hline 9 & $\begin{array}{l}\text { 2a Sesión tutorías. Entrega } \\
\text { ficha seguimiento }\end{array}$ & Aula & $30 \mathrm{~min} /$ equipo & alumnos/profesor \\
\hline 10 & Desarrollo ítem 3 & Edificio/casa & 2,5 semanas & alumno \\
\hline 11 & Sesión aula & Aula & 3 horas & alumno/ tutor \\
\hline 12 & $\begin{array}{l}\text { 3a Sesión tutorías. Entrega } \\
\text { ficha seguimiento }\end{array}$ & Aula & $30 \mathrm{~min} /$ equipo & alumnos/profesor \\
\hline 13 & Entrega final & Aula & 2,5 semanas & alumnos/profesor \\
\hline 14 & Calificaciones & Web & 1 semana & profesor \\
\hline
\end{tabular}

Por otro lado, se integraron diversas herramientas de análisis de las tutorías (Badillo, 2007), con el fin de recoger evidencias que permitiesen detectar defectos de organización. Se plantearon herramientas como: el "registro de asistencia"; "informe tutor" -evalúa logro de ítem-; y "sondeo/encuesta", a completar por el alumno, donde se valoran aspectos positivos y negativos de factores como la organización y la eficacia de las tutorías, así como de la ayuda para su planificación. También se introdujeron herramientas de organización -"fichas de seguimiento" (Fig. 1)- a cumplimentar por el alumnado, y que permiten comprobar el cumplimiento de la planificación.

El proyecto consistió en el levantamiento gráfico de un edificio, donde se muestraban todas las formas reales y dimensiones, aplicando los criterios gráficos desarrollados en la asignatura y normativa vigente. Duración 9 semanas. La Metodología seguida para el desarrollo fue la siguiente: 
1.- Los alumnos optarán por trabajar de forma individual o en equipo ( $2 / 3$ alumnos por equipo). Si se decide trabajar en equipo (el trabajo es colaborativo), deberá haber una coordinación entre ellos para realizar la diferente planimetría.

2.- Se realizarán tres tutorías grupales evaluables, una al inicio, otro a mitad, y una última al final del trabajo. Si se trabaja en equipo deberán acudir conjuntamente todos los miembros.

3.- La planificación del proyecto, tiempos de trabajo, ítems a alcanzar...., se realizará de forma conjunta entre los alumnos y el profesor.

3.- En cada tutoría los alumnos deberán aportar, además de los planos a analizar y revisar, una ficha de seguimiento (Fig. 1) del trabajo acometido hasta el momento (ítems alcanzados, problemas surgidos y dudas).

\begin{tabular}{|l|l|}
\hline \multirow{2}{*}{ Nombre alumnos: } & Alumno 1: \\
\cline { 2 - 2 } & Alumno 2: \\
\hline
\end{tabular}

Rellena con una cruz los items alcanzados

\begin{tabular}{|r|c|l|l|}
\hline \multicolumn{1}{|c|}{ Ítems } & Distribución trabajo & Ítem resuelto en fecha & Observaciones/ dificultades encontradas \\
\hline Croquis entorno acotado la revisión: Jueves 25 de abril & $\begin{array}{c}\text { Alumno 1 } \\
\text { Alumno 2 }\end{array}$ & & \\
\hline Croquis planta baja & Alumno 1 & & \\
\hline Croquis planta primera & Alumno 2 & & \\
\hline Sección Vertical 1 & Alumno 1 & & \\
\hline Sección Vertical 2 & Alumno 2 & & \\
\hline Alzado principal & Alumno 1 & & \\
\hline Alzado Posterior & Alumno 2 & & \\
\hline Perfil izquierdo & Alumno 1 & & \\
\hline Perfil derecho & Alumno 2 & & \\
\hline Cuestiones a preguntar en la tutoria 1: & &
\end{tabular}

Fig. 1. Modelo de ficha de seguimiento.

4.- Se facilita a los alumnos la "ficha de autoevaluación" (Fig. 2) que permite la evaluación de cada uno de los ítems, y que será la misma que utilizará la profesora.

5.- Evaluación: - El trabajo supone un $20 \%$ de la nota final de curso. - Las tutorías, la asistencia, logro de ítems en fecha, cumplimentación de fichas de seguimiento, y modificación en plano de las correcciones hechas por la profesora, puntuarán $10 \%$ sobre la nota final.

En la primera sesión, una vez analizado el enunciado del proyecto, y conocido el edificio objeto de estudio, se realiza el organigrama de trabajo. Éste se realiza teniendo en cuenta el volumen de trabajo, tiempo para el desarrollo de cada de las partes del proyecto, y posibles contratiempos que los alumnos pudiesen tener. En él, además, se indica el calendario de las tutorías, y los ítems a alcanzar para cada una de ellas. Estas tutorías permiten marcar un ritmo de trabajo para lograr objetivos concretos, en un periodo de tiempo adecuado. Permiten observar el proyecto en actividades concretas alcanzables. 
Analiza cada una de las partes del ejercicio plantado atendiendo a los siguientes criterios:

\begin{tabular}{|l|l|}
\hline A: Muy bien & D: Regular \\
\hline B: Bastante bien & E: Mal \\
\hline C: Bien & F: No entiendo lo que me preguntan \\
\hline
\end{tabular}

\begin{tabular}{|c|c|c|c|c|c|c|}
\hline SISTEMA DIÉDRICO & A & B & C & D & E & $\mathbf{F}$ \\
\hline \multicolumn{7}{|l|}{ № de vistas necesarias para la definición completa del elemento } \\
\hline \multicolumn{7}{|l|}{ Proyección correcta de vistas } \\
\hline \multicolumn{7}{|l|}{ Abatimiento correcto de vistas } \\
\hline \multicolumn{7}{|l|}{ Correspondencia entre todas las vistas } \\
\hline \multicolumn{7}{|l|}{ Distribución correcta de las vistas dentro del papel } \\
\hline \multicolumn{7}{|l|}{ Definición (análisis) correcto de las vistas } \\
\hline \multicolumn{7}{|l|}{ Correcta denominación de cada vista } \\
\hline \multicolumn{7}{|l|}{ Valora de forma general el sistema diédrico de tu croquis } \\
\hline GRAFISMO - VALORACIÓN DE LÍNEAS - ROTULACIÓN & A & B & C & D & E & $\mathbf{F}$ \\
\hline \multicolumn{7}{|l|}{ Correcto dibujado de los trazos (precisos y uniformes) } \\
\hline \multicolumn{7}{|l|}{ Valoración de lineas auxiliares } \\
\hline \multicolumn{7}{|l|}{ Valoración de aristas proyectadas } \\
\hline \multicolumn{7}{|l|}{ Valoración de aristas seccionadas } \\
\hline \multicolumn{7}{|l|}{$\begin{array}{l}\text { Correcta ubicación y grafiado de los planos de corte/planos de } \\
\text { sección }\end{array}$} \\
\hline \multicolumn{7}{|l|}{ Correcta ubicación y grafiado de los ejes de simetria } \\
\hline \multicolumn{7}{|l|}{ Situación de la línea de tierra } \\
\hline \multicolumn{7}{|l|}{ Correcto grafismo de los límites del dibujo } \\
\hline \multicolumn{7}{|l|}{$\begin{array}{l}\text { Rotulación correcta del nombre de cada vista, homogénea y } \\
\text { proporcionada }\end{array}$} \\
\hline \multicolumn{7}{|l|}{$\begin{array}{l}\text { El cajetín está situado correctamente, y se han rellenado todos } \\
\text { sus apartados }\end{array}$} \\
\hline \multicolumn{7}{|l|}{ Correcta rotulación del cajetín } \\
\hline $\begin{array}{l}\text { Valora de forma general el grafismo, la valoración de líneas y la } \\
\text { rotulación de tu croquis. }\end{array}$ & & & & & & \\
\hline
\end{tabular}

Fig. 2. Ficha autoevaluación.

Tras cada tutoría y como evidencia de su desarrollo, la profesora realiza un informe (Fig. 3) de cada uno de los equipos de trabajo. En él se analizarán los ítems alcanzados, la calidad del trabajo, las dudas y soluciones aportadas.

\begin{tabular}{|c|c|c|c|}
\hline items REALIZADOS & st & NO & OBSERVACIONES \\
\hline \multicolumn{4}{|l|}{ Croquis entorno acotado } \\
\hline \multicolumn{4}{|l|}{ Croquis planta baja } \\
\hline \multicolumn{4}{|l|}{ Croquis planta primera } \\
\hline \multicolumn{4}{|l|}{ Sección Vertical 1} \\
\hline \multicolumn{4}{|l|}{ Sección Vertical 2} \\
\hline \multicolumn{4}{|l|}{ Alzado principal } \\
\hline \multicolumn{4}{|l|}{ Alzado Posterior } \\
\hline \multicolumn{4}{|l|}{ Perfil Izquierdo } \\
\hline Perfil derecho & & & \\
\hline Ficha de seguimiento & & & \\
\hline
\end{tabular}

\begin{tabular}{|l|l|}
\hline ANÁLISIS \\
\hline SISTEMA DIÉRRICO & \\
\hline $\begin{array}{l}\text { ANÁLSIS DE FORMAS/ } \\
\text { PROPORCION }\end{array}$ & \\
\hline VALORACIÓN DE LINEA & \\
\hline GRAFISMO & \\
\hline OTROS & \\
\hline
\end{tabular}

Fig. 3. Modelo para el informe del profesor donde se indican ítems alcanzados por cada equipo, análisis del trabajo realizado, funcionamiento y organización. 


\section{Resultados}

Tras la entrega, y antes de conocerse los resultados, se organizó una sesión a la cual asistieron la totalidad de los alumnos. En ella se plantea una encuesta con diferentes cuestiones a fin de conocer la opinión del alumnado (Fig. 4), ventajas e inconvenientes tanto de la planificación como de las tutorías llevadas a cabo.

En referencia a la planificación se valoró muy positivamente el poder alcanzar ítems parciales, por tanto metas a corto plazo asequibles en el tiempo. Esto les permitía trabajar de forma más sosegada, y aminorar la presión del proyecto íntegro. En su mayoría se ven capaces de enfrentarse a un trabajo de estas características, y planificar las tareas de forma adecuada en el tiempo. Por otro lado, si en un principio les pareció tedioso el desarrollo de la planificación, posteriormente la consideraron imprescindible para poder alcanzar los objetivos de un proyecto de estas características.

Por lo que respecta a las tutorías, se comentó que ayudaron a reflexionar acerca del progreso y desarrollo del proyecto. Les permitió mejorar y modificar errores importantes que mejoraran su calificación final. En cuanto a opiniones negativas, la obligatoriedad de las mismas por tener una fecha inamovible en el calendario.

De forma generalizada se continúa pensando que el proyecto es excesivamente extenso.

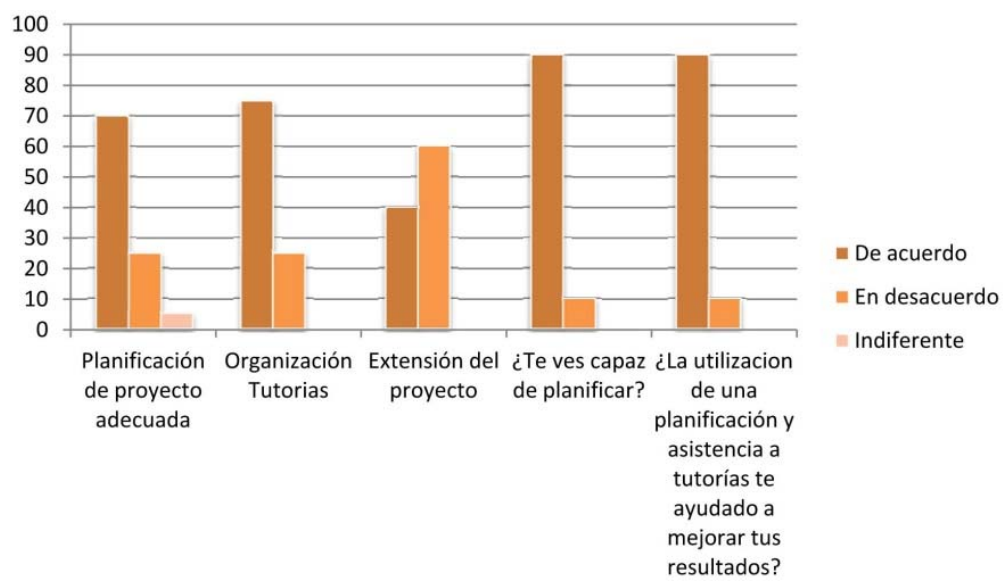

Fig. 4. Resultados de encuesta de opinión realizada a los alumnos.

Respecto a la colaboración y participación de los alumnos, y el trabajo en equipo. Informe del profesorado.

De los 15 alumnos, 7 decidieron trabajar de forma individual (1 abandonó la asignatura antes de empezar el trabajo), y los 8 restantes, decidieron trabajar en equipo de 2 (ninguno de 3 miembros, aconsejado por la profesora).

Los alumnos que trabajaron de forma individual en sus inicios se quejaron del volumen de trabajo, ya que era igual al realizado por los que trabajaban en equipo. Los alumnos que 
trabajaron en equipo, tuvieron problemas de coordinación, ya que en casi todas las tareas dependían de sus compañeros. De forma general, se considera muy satisfactoria la colaboración y participación entre los alumnos.

Respecto al funcionamiento de las tutorías. Informe del profesorado.

Problemas: Los días estaban establecidos en la planificación pero no hora exacta, ya que dependía del número de equipos que se formasen. Estas se difundieron a través del correo electrónico sin tener la confirmación de su lectura. Esto ocasionó que en la primera sesión algún grupo no se presentase, y se tuvo que fijar otra fecha. Evidentemente la solución pasa por asignar las horas en clase.

Por otro lado, el tiempo fijado para cada equipo de 30 minutos, en muchos casos se quedaba escaso. Muchos de los equipos demandaron más tutorías fuera de las establecidas como obligatorias.

Respecto a los resultados de aprendizaje. Informe del profesorado.

En las tutorías se pudo comprobar el avance de los alumnos a la hora de identificar problemas, analizarlos y solucionarlos de la mejor manera posible utilizando recursos gráficos adecuados. Por otro lado, durante el transcurso del proyecto algunos grupos tuvieron que modificar la planificación y adaptarla a sus necesidades. Si bien no tenemos posibilidad de comprobar de forma fehaciente si los alumnos son capaces de planificar otro proyecto de similares características, en esta asignatura, el hecho de saber acomodar, reorganizar y modificar la planificación a sus circunstancias es un indicador de su capacidad para realizarla.

Respeto a los resultados curriculares, el $100 \%$ de los alumnos aprobaron el trabajo en este grupo, y más de un $70 \%$ obtuvieron una nota superior a 7 .

\section{Conclusiones}

El problema principal surgido es la demanda del tiempo necesario para poder realizar correctamente todas las tutorías. Cierto es que, algunos equipos han necesitado más del doble del tiempo establecido. Esta problemática se podría solucionar de dos formas. Por un lado, simplemente centrando los temas a desarrollar durante la tutoría, y no desviándose de los mismos. Si surgieran dudas fuera de los ítems establecidos se podrían concertar tutorías particulares fuera de las establecidas en las tareas.

Por otro lado, otra solución sería aumentar el número de alumnos en cada tutoría. La experiencia ha demostrado que se podría hacer una revisión grupal con unos 6 alumnos, ya que los problemas que les surgen son comunes y muy repetitivos.

Por otro lado, además de resolver los problemas particulares de cada alumno, escuchar y solucionar las dudas y cuestiones que surgen a otros compañeros, también es muy ventajoso en su aprendizaje. Se podría incluso introducir la coevaluación (Lillo, 2013) dentro de las tutorías. 
De forma general, la experiencia ha sido muy positiva como muestra el $100 \%$ de aprobados. Esto demuestra que, aunque el aprendizaje autónomo en alumnos de primer curso es más complicado debido a su poca experiencia, los resultados son mejores con una correcta planificación donde se incluyan tutorías que permitan el feedback alumno/profesor.

\section{Referencias}

BADILLO J. (2007) "La tutoría como estrategia viable de mejoramiento de la calidad de la educación superior. Reflexiones en torno al curso" en CUP-e Revista de Investigación Educativa 5.

BISQUERRA, R. (2002). La práctica de la orientación y la tutoría. Barcelona: Praxis

BISQUERRA, R. (2012). Orientación, tutoría y educación emocional. Madrid: Síntesis.

GELLALTY, A (1997) La inteligencia hábil. El desarrollo de las capacidades cognitivas. Buenos Aires: Ainque.

LILLO S., PÉREZ M., RODRIGO A., FERRER J.A. (2013) "La evaluación entre iguales en el marco de la tutoría grupal, estrategia docente para la mejora del proceso de enseñanza-aprendizaje en alumnos de primeros curso s. Dibujo Arquitectónico I. Grado de Arquitectura Técnica",en Actas XXI Congreso Universitario de Innovación Educativa en las Enseñanzas Técnicas (2013 Valencia), 1069 .

MONTES N., MACHADO E.F. (2011). "Estrategias docentes y métodos de enseñanza-aprendizaje en la Educación Superior" en Humanidades Mededicas vol.11 no.3. 


\title{
EDIFİCATE
}

I Congreso de Escuelas de Edificación y Arquitectura Técnica de España

València, 4 y 5 de noviembre de 2021

Escuela Técnica Superior de Ingeniería de Edificación

Universitat Politècnica de València

Doi: https://doi.org/10.4995/EDIFICATE2021.2021.13592

\section{La metodología BIM como elemento vehicular en la docencia de Grado en Ingeniería de Edificación}

\section{BIM as a teaching tool in Building Engineering Degree}

\author{
David Valverde Cantero ${ }^{a}$ \\ aEscuela Politécnica de Cuenca, Universidad de Castilla-La Mancha, david.valverde@uclm.es
}

\begin{abstract}
Although, fortunately, we agree on the need to implement BIM methodology in university education effective strategies are still necessary to solve problems derived from such a big change. The strategy adopted by Escuela Politécnica de Cuenca was proposed with a transversal integration of BIM methodology and always based on the generosity of the agents -teachers and students-, in the absence of hierarchies and that seeks the motivation of the students.

The different experiences developed in recent years, an attempt has been made to promote collaborative work with challenges and joint workshops and overcoming the traditional teacher-student roles.
\end{abstract}

Keywords: BIM, teaching methodology, Building Engineering Degree, implementation, motivation, collaborative work.

\section{Resumen}

Aunque la necesidad de implementación de la metodología BIM en el ámbito de enseñanza universitaria ya parece, afortunadamente, un debate superado siguen siendo necesarias estrategias eficaces que solventen los problemas derivados de un cambio tan profundo. La estrategia de la Escuela Politécnica de Cuenca se planteó con una integración transversal en varios frentes, pero siempre basada en la generosidad de los intervinientes -profesores $y$ alumnos-, en la ausencia de jerarquías y en la motivación del alumnado.

En las distintas experiencias llevadas a cabo durante los últimos años se ha conseguido fomentar el trabajo colaborativo con retos y talleres conjuntos $y$ superando los roles tradicionales profesor-alumno.

Palabras clave: BIM, metodología docente, Ingeniería de Edificación, implementación, motivación, trabajo colaborativo. 


\section{Introducción}

La implementación de la metodología BIM ha sido interpretada en la Escuela Politécnica de Cuenca -EPCu- (Escuela Politécnica de Cuenca, 2021) como una oportunidad para organizar las acciones que en esta línea se venían realizando desde el curso 2017-2018 y proponer otras nuevas dentro del entorno del trabajo colaborativo, en un marco único para analizar y evaluar diferentes acciones para promover y profundizar en la filosofía BIM en el seno del Grado en Ingeniería de Edificación -GIE- (Oliver, 2015).

En este contexto destaca la iniciativa "aula BIM EPCu" (Fig. 1) como apoyo/afianzamiento a la implementación docente de BIM, pero desde un enfoque menos rígido que el propio de las asignaturas del plan de estudios (Valverde, 2019).

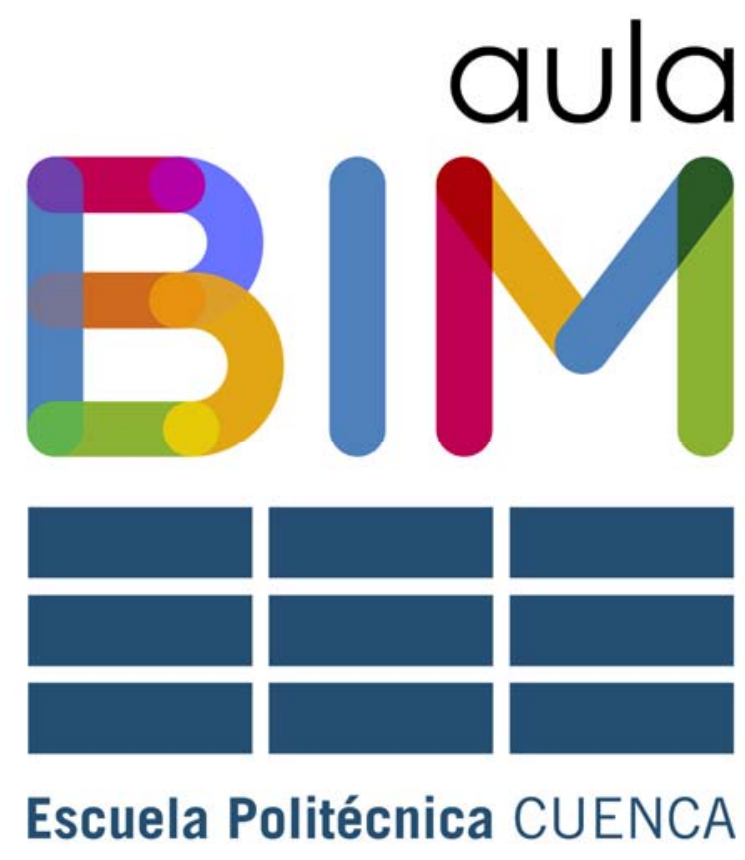

Fuente: Elaboración propia

Fig. 1 Logotipo aula BIM EPCu

Cabe destacar también que muchas de las acciones llevadas a cabo se recopilaron en un Proyecto de Innovación docente (Alfaro et al, 2018) que sirvió de base para plantear una serie de estrategias-recomendaciones prácticas centradas en adquirir destrezas "blandas" que aportan ayuda a ese otro $80 \%$ de metodología BIM que no está estrictamente vinculado con un manejo de software BIM. 


\section{Objetivos}

\subsection{Contenido y metodología docente clásica}

No se pretende cambiar los contenidos, pero sí la metodología. El principal objetivo es el de diseñar y poner en práctica un conjunto de acciones que permitan dotar de carácter integrador las técnicas de trabajo colaborativo BIM en el GIE. Se pretende con ello que las experiencias desarrolladas sirvan como ejercicios integradores de calado transversal dentro de la titulación, además de permitir la elaboración y desarrollo de prácticas docentes innovadoras que supongan la mejora y renovación del proceso enseñanza-aprendizaje de nuestros estudiantes.

\subsection{Metodología docente complementaria}

Admitiendo que efectuar un cambio completo y simultáneo no es viable apostamos por una vía paralela/complementaria que propone una metodología de trabajo colaborativa (AgullódeRueda, 2018) que esté coordinada entre las distintas asignaturas y/o materias interesadas.

Este entorno debe servir para recoger/filtrar/utilizar los avances/incidencias que, propuestos tanto por el profesorado como por los alumnos, estén relacionados con el desarrollo de cada una de las asignaturas y cristaliza en talleres/cursos específicos o en la participación de concursos BIM.

\section{Desarrollo de la innovación}

Centrándonos en las actividades desarrolladas bajo el concepto de aula BIM EPCu durante los últimos cuatro cursos podemos decir que las mismas han sido, preferentemente, presenciales. Aunque también han existido solicitudes/ensayos para la retransmisión de las mismas vía streaming sólo durante el último curso y medio, y debido a la crisis sanitaria por COVID-19, se ha recurrido a esta modalidad ya que entendemos que carece de las posibilidades de las sesiones presenciales.

Además, la demanda de actividades ha sido fundamentalmente bajo el formato de ASESORÍAS puntuales atendidas por el becario del aula BIM sobre temas muy concretos y a grupos reducidos.

Por otro lado, los TALLERES han sido propuestos/ programados mayoritariamente por los responsables de la iniciativa intentando no coincidir con otras actividades -ciclo de conferencias, periodos de exámenes, reuniones de carácter general...- e intentando garantizar unas asistencias mínimas. Para estos TALLERES se ha contado tanto con el personal docente de la EPCu o del resto de la UCLM, como con antiguos alumnos y con otros profesionales de reconocido prestigio que han accedido a compartir sus conocimientos en un entorno abierto a la participación de los asistentes. 


\section{Resultados}

De manera paralela a la realización de las actividades del aula BIM EPCu se ha llevado un minucioso registro y monitorización, mediante encuestas anónimas, donde los asistentes pudieran valorar la iniciativa. Los datos recopilados se cruzaron con los registros de asistencias para arrojar los datos que se muestran a continuación.

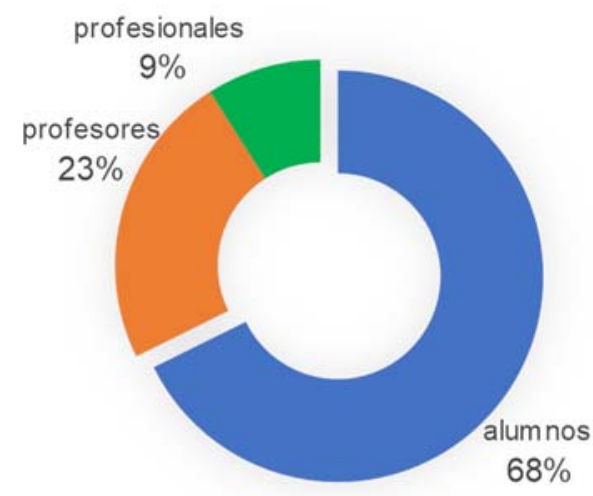

Fuente: Elaboración propia

Fig. 2 Perfil de asistente al aula BIM EPCu 2017-2021

En la primera gráfica (Fig. 2) se puede observar el perfil de acceso de los asistentes a las distintas sesiones, con un total de 869 asistentes, incluidos recurrentes, en los cuatro cursos de vida de aula BIM EPCu.

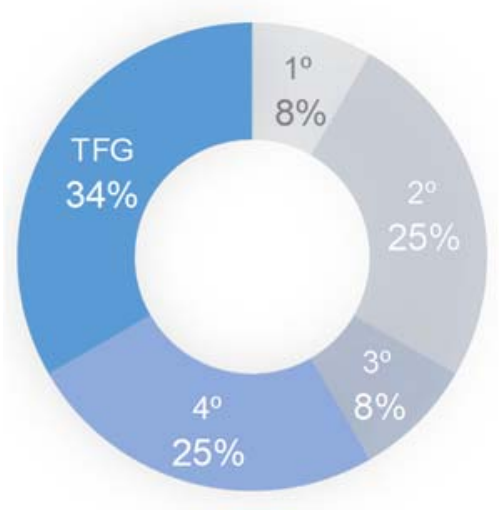

Fuente: Elaboración propia

Fig. 3 Perfil de alumnos asistentes al aula BIM EPCu 2017-2021

Si desglosamos los datos de asistencia general para los 591 alumnos participantes (Fig. 3) vemos que los estudiantes que hacen uso del aula se encuentran distribuidos de manera homogénea a lo largo de todos los cursos -aclarando que la baja asistencia de alumnos de $1^{\circ}$ se debe a la baja matriculación en el mismo durante los últimos años-. 
En cuanto a los profesores asistentes cabe destacar que fundamentalmente han sido respaldados por el aula BIM mediante el formato de ASESORÍAS. En ellas han podido desdoblar sus clases y hacer que los alumnos se inicien en herramientas BIM con las que poner en práctica los conocimientos adquiridos en clase. Los TALLERES también han servido para que profesores de otras áreas hayan entrado en contacto con los diferentes enfoques que propone la metodología BIM.

Por último, bajo el epígrafe de profesionales la EPCu también ha dado cabida a perfiles con mayor experiencia laboral/aplicada -antiguos alumnos en su mayoría- que ha aprovechado la iniciativa para compartir su experiencia con el resto de los asistentes y/o comenzar su reciclaje profesional bajo esta nueva metodología BIM.

\section{Conclusiones}

Aunque se trata de una iniciativa que ha ido puliéndose año a año, cabe resaltar la predisposición/buena acogida por parte del alumnado -con una nota media de 4,6 sobre 5y también, al menos en parte, entre el profesorado. Iniciativas como esta, esperamos, deben ejercer de dinamizadoras en el proceso de adopción de metodología BIM en el plan de estudios de GIE.

También entendemos que el progreso de contenidos/adhesiones por parte de alumnos/ profesores no puede ni debe ser impositivo, sino que más bien se trata de una "imparable expansión en mancha de aceite". La evolución de los índices de asistencia así lo demuestra y la ampliación de contenidos, diversidad de ponentes y participación de antiguos alumnos y profesionales, puede hacer de esta iniciativa una fuente de difusión, aprendizaje y testado de conocimientos, necesaria y complementaria a la formación reglada.

Nuestra iniciativa, supone una voluntad de implementación de la metodología BIM que, afortunadamente, es ajena a las voluntades de los responsables de las asignaturas. Estamos extendiendo una metodología aplicable en cualquiera de las asignaturas, lo deseable sería un entorno en el que todos estuvieran a favor y la colaboración y la participación fueran algo natural. Pero, entendiendo que esto puede que no siempre sea así, hemos diseñado un procedimiento que, sin estorbar ni imponer, permita la implementación por convencimiento y experimentación.

Queda claro también que es imposible afrontar problemas complejos en un entorno colaborativo si no se ha participado previamente en talleres y simulacros durante el proceso de aprendizaje. El profesor y el alumno deben ser conscientes cuanto antes de esa mentalidad y de adecuación de la metodología BIM a la misma. 


\section{Referencias}

ESCUELA POLITÉCNICA DE CUENCA. Grado en Ingeniería de Edificación. $<$ https://www.uclm.es/cuenca/epc/gradoedificacion > [Consulta: 30 de junio de 2021]

OLIVER FAUBEL, I. (2015). Integración de la metodología BIM en la programación curricular de los estudios de Grado en Arquitectura Técnica/Ingeniería de Edificación. Diseño de una propuesta. Tesis Doctoral. Valencia: Universitat Politècnica de València, < https://riunet.upv.es/handle/10251/61294> [Consulta: 30 de junio de 2021]

VALVERDE CANTERO, D, PÉREZ GONZÁLEZ, PE y ALFARO GONZÁleZ, J. (2019). "La implementación BIM mediante el aula BIM en la Escuela Politécnica de Cuenca" En: XIV Congreso Internacional de Expresión Gráfica Aplicada a la Edificación APEGA 2019. Sevilla: Editorial Círculo rojo. $48-50$.

ALFARO GONZÁLEZ, J, VALVERDE CANTERO, D, CAÑIZARES MONTÓN, JM, MARTíNEZ CARPINTERO, JA y PÉREZ GONZÁLEZ, PE. (2018). "EI BIM-LaB como aglutinador de la experiencia de implantación BIM académica y científica para profesores, alumnos y exalumnos de la Escuela Politécnica de Cuenca. UCLM" En: The international BIM conference, EUBIM 2018. Valencia: Editorial Universitat Politècnica de València. 57-66.

AGULLÓ-DERUEDA, J, JURADO-EGEA, J, INGLÉS-GOSÁLBEZ, B. (2018). "Trabajos colaborativos BIM en enseñanzas de grado" En: The international BIM conference, EUBIM 2018. Valencia: Editorial Universitat Politècnica de València. 35-46. 


\title{
EDIFICATE
}

I Congreso de Escuelas de Edificación y Arquitectura Técnica de España València, 4 y 5 de noviembre de 2021

Escuela Técnica Superior de Ingeniería de Edificación

Universitat Politècnica de València

Doi: https://doi.org/10.4995/EDIFICATE2021.2021.13299

\section{Historia de la construcción, construcciones históricas y construcción tradicional en los planes de Grado de Edificación \\ Construction history, historical heritage and vernacular construction in building degree}

\author{
Francisco Javier Castilla Pascual \\ Universidad de Castilla-La Mancha. Departamento de Ingeniería Civil y de la Edificación \\ fcojavier.castilla@ucml.es
}

\begin{abstract}
This communication carries out an analysis of the teaching of construction history and historical constructions in the undergraduate studies of the 23 existing degrees in our country. For this purpose, a comparative study of the teaching guides of the subjects related to the topic has been made. A statistical analysis of aspects related to the objectives, methodology and documentary sources are carried out. As conclusions, the need to establish guidelines and a consensual documentary corpus according to the consideration of this academic discipline of growing interest and development during this century is detected. Some proposals are made to achieve this goal
\end{abstract}

Keywords: curriculum, teaching methodologies, documentary resources, practical teaching, construction history

\section{Resumen}

Esta comunicación realiza un análisis de la enseñanza de la historia de la construcción y las construcciones históricas en los estudios de grado de las 23 titulaciones existentes en nuestro país. Para ello se realiza un estudio comparativo de las guías docentes de las asignaturas relacionadas con la materia y se realizan análisis estadísticos de aspectos relacionados con los objetivos, metodología y fuentes documentales. Como conclusiones se detecta la necesidad de establecer unas directrices y un corpus documental consensuado acorde a la consideración de esta disciplina académica de creciente interés y desarrollo durante este siglo. Se realizan algunas propuestas para su consecución

Palabras clave: plan de estudios, metodologías docentes, recursos documentales, enseñanza práctica, historia de la construcción 


\section{Introducción y objetivos}

Esta ponencia pretende establecer un espacio de reflexión, que es lo que debería producirse en un congreso de estas características, más allá de una simple exposición de un tema supuestamente innovador para ser revisado. El objeto es el análisis comparativo de la enseñanza de la historia de la construcción en los actuales planes de estudio y su discusión para valorar la adecuación de esta a la realidad de esta disciplina, así como la eficacia y procedencia de las metodologías y recursos docentes utilizados.

En esta primera fase se ha revisado y analizado la información relativa a las asignaturas relacionadas con la Historia de la Construcción en los 23 grados de Arquitectura Técnica/Edificación ${ }^{1}$ existentes en España, a partir de las guías docentes publicadas entre los cursos $19-20$ y $20-21$.

La competencia específica relacionada con esta materia, recogida en la ORDEN $\mathrm{ECl} / 3855 / 2007$, de 27 de diciembre (España 2007), por la que se establecen los requisitos para la verificación de los títulos universitarios oficiales que habiliten para el ejercicio de la profesión de Arquitecto Técnico, es el:

Conocimiento de la evolución histórica de las técnicas y elementos constructivos y los sistemas estructurales que han dado origen a las formas estilísticas. ${ }^{2}$

En la actualidad existen 15 titulaciones que recogen en el título o contenido de alguna asignatura la denominación de HISTORIA DE LA CONSTRUCCIÓN: 12 con el propio nombre y otros 4 con la denominación de CONSTRUCCION I (dedicando el temario total o parcialmente a esta cuestión), 2 que lo incluyen como HISTORIA DE LA ARQUITECTURA, 1 como CONSTRUCCIONES HISTÓRICAS y 5 que no la recogen y tienen sólo algún tema puntual en otras asignaturas (donde se incluye la competencia).

Se han contrastado por tanto las guías docentes de estas 19 asignaturas, comparando el número de créditos, objetivos, contenidos, metodología y la bibliografía disponible en todas ellas. Los resultados se analizan a modo de cuestiones abiertas para su discusión que confiamos puedan ser respondidas de forma interactiva por los participantes durante la celebración del congreso.

\footnotetext{
1 El listado de escuelas de arquitectura técnica y edificación (23) se ha obtenido de https://www.codatie.es/escuelas

2 A partir de esto se plantea ya una primera discusión, pues se asume que son las técnicas constructivas las que dan origen a los estilos, frente a otras hipótesis que contemplan una evolución de estilos no necesariamente asociada a grandes cambios tecnológicos, como ocurre entre los siglos XVII y XIX. Por otro lado, dicha variedad estilística resulta en la mayoría de los casos de una adaptación al contexto local de elementos constructivos similares, más que a una evolución tecnológica
} 


\section{Análisis comparativo de planes de estudios y asignaturas}

En la Tabla 1 se recogen las titulaciones y asignaturas que se han considerado en el estudio comparativo, con la reserva de haber cometido algún posible error de interpretación del contenido de los planes de estudio en los que la Historia de la construcción no aparece de un modo evidente ${ }^{3}$. En todos los casos se trata de asignaturas Obligatorias o Básicas.

Tabla 1. Tabla de asignaturas por titulaciones

\begin{tabular}{|c|c|c|c|c|c|}
\hline Univ & Titulo & Escuela & Materia específica & Curso & ECTS \\
\hline $\begin{array}{l}\text { Universidad de Castila-La } \\
\text { Mancha }\end{array}$ & $\begin{array}{l}\text { Grado en Ingeniería de } \\
\text { Edificación }\end{array}$ & Escuela Politécnica de Cuenca & CONSTRUCCION I & & 6 \\
\hline Universitat de Lleida & $\begin{array}{l}\text { Grado arquitectura técnica y } \\
\text { Edificación }\end{array}$ & & HISTORIA DE LA CONSTRUCION & 1 & 6 \\
\hline Universidad de Granada & Grado en edificación & ETS. Ingeniería de Edificación & $\begin{array}{l}\text { CONSTRUCCIÓN I. HISTORIA, TIPOLOGÍAS Y FUNDAMENTOS DE LA } \\
\text { EDIFICACIÓN }\end{array}$ & 1 & 6 \\
\hline $\begin{array}{l}\text { Universitat Politècnica de } \\
\text { Catalunya }\end{array}$ & $\begin{array}{l}\text { GRADO EN ARQUITECTURA } \\
\text { TÉCNICA Y EDIFICACIÓ }\end{array}$ & $\begin{array}{l}\text { Escuela Politécnica Superior de Edificación de } \\
\text { Barcelona }\end{array}$ & Arquitectura, Construcción y Ciudad en laHistoria de Occidente & 1 & 4.5 \\
\hline \begin{tabular}{|l|} 
Universidad de \\
Extremadura
\end{tabular} & GRADO EN EDIFICACIÓN & Escuela Politécnica de Cáceres & CONSTRUCCION I & 1 & 6 \\
\hline Universidad Zaragoza & $\begin{array}{l}\text { Grado en Arquitectura } \\
\text { Técnica }\end{array}$ & $\begin{array}{l}\text { Escuela Universitaria Politécnica_ La } \\
\text { Almunia }\end{array}$ & Historia de la construcción & 1 & 6 \\
\hline Universidad Ramón Llull & \begin{tabular}{|l|} 
Grado en Arquitectura \\
Técnica y Edificación
\end{tabular} & La Salle & Arquitectura del siglo XX & 2 & 3 \\
\hline Universidad de Alicante & $\begin{array}{l}\text { GRADO EN ARQUITECTURA } \\
\text { TÉCNICA }\end{array}$ & Escuela Politécnica Superior & Historia de la construcción & 1 & 6 \\
\hline $\begin{array}{l}\text { Universitat de les Illes } \\
\text { Balears }\end{array}$ & Grado en Edificación & Escuela Politécnica Superior & Construcción I. Historia de laConstrucción & 1 & 6 \\
\hline $\begin{array}{l}\text { Universitat Politècnica de } \\
\text { Valencia }\end{array}$ & $\begin{array}{l}\text { Grado en Arquitectura } \\
\text { Técnica }\end{array}$ & $\begin{array}{l}\text { Escuela Técnica Superior de Ingeniería } \\
\text { de Edificación }\end{array}$ & Construcciones Históricas & 3 & 4.5 \\
\hline Universidad de Salamanca & $\begin{array}{l}\text { Grado en Arquitectura } \\
\text { Técnica }\end{array}$ & Escuela Politécnica Superior de Zamora & Historia de la construcción & 3 & 4.5 \\
\hline Universidad de Sevilla & Grado en Edificación & $\begin{array}{l}\text { Escuela Técnica Superior de Ingeniería } \\
\text { de Edificación }\end{array}$ & Historia de la Construcción e Introducción a la Construcción & 1 & 6 \\
\hline Universidad del País Vasco & $\begin{array}{l}\text { Grado en Arquitectura } \\
\text { Técnica }\end{array}$ & Escuela de Ingeniería de Gipuzkoa & Historia de la construcción & 2 & 6 \\
\hline Universidad Jaime I & Arquitectura Técnica & $\begin{array}{l}\text { Escuela Superior de Tecnología y } \\
\text { Ciencias Experimentales }\end{array}$ & Construcción I: Fundamentos & 1 & 6 \\
\hline \begin{tabular}{|l|} 
Univerisdad Politécnica de \\
Madrid
\end{tabular} & Grado en Edificación & Escuela Técnica Superior de Edificación & Historia de la construcción & 3 & 3 \\
\hline Universidad de Alcalá & \begin{tabular}{|l|} 
Grado en Ciencia y \\
Tecnología de la Edificación \\
\end{tabular} & Escuela de Arquitectura & CONSTRUCCION I & 1 & 6 \\
\hline $\begin{array}{l}\text { Universidad Politécnica de } \\
\text { Cartagena }\end{array}$ & $\begin{array}{l}\text { Grado en Ingeniería de } \\
\text { Edificación }\end{array}$ & $\begin{array}{l}\text { Escuela Técnica Superior de } \\
\text { Arquitectura e Ingeniería de Edificación }\end{array}$ & Historia de la construcción & 2 & 3 \\
\hline Universitat de Girona & $\begin{array}{l}\text { Grau en Arquitectura } \\
\text { Tècnica i Edificació }\end{array}$ & Escola Politècnica Superior & Història de la construcción & 2 & 3 \\
\hline \begin{tabular}{|l|} 
Universidad Católica San \\
Antonio de Murcia \\
\end{tabular} & $\begin{array}{l}\text { Grado en Ingeniería de } \\
\text { Edificación }\end{array}$ & Murcia & Historia de la Construcción & 1 & 3 \\
\hline
\end{tabular}

Como se puede apreciar, las asignaturas abarcan de 3 a $6 \mathrm{cr}$, todas ellas entre primer y segundo curso. Como dato significativo, 2 de las 3 asignaturas de $4.5 \mathrm{cr}$ se imparten en segundo curso y la otra en tercero. Las figuras 1 y 2 recogen estos datos de forma más clara. Todas las asignaturas de $3 \mathrm{cr}$ son específicas de Historia de la construcción

\footnotetext{
${ }^{3}$ Por ejemplo, en la titulación de Grado en arquitectura Técnica de la Coruña, aparece asociada a la asignatura OPTATIVA "Patrimonio Arquitectónico galego" de cuarto curso con $6 \mathrm{cr}$ o en la Laguna en la asignatura de "Rehabilitación de edificios" también de cuarto curso
} 

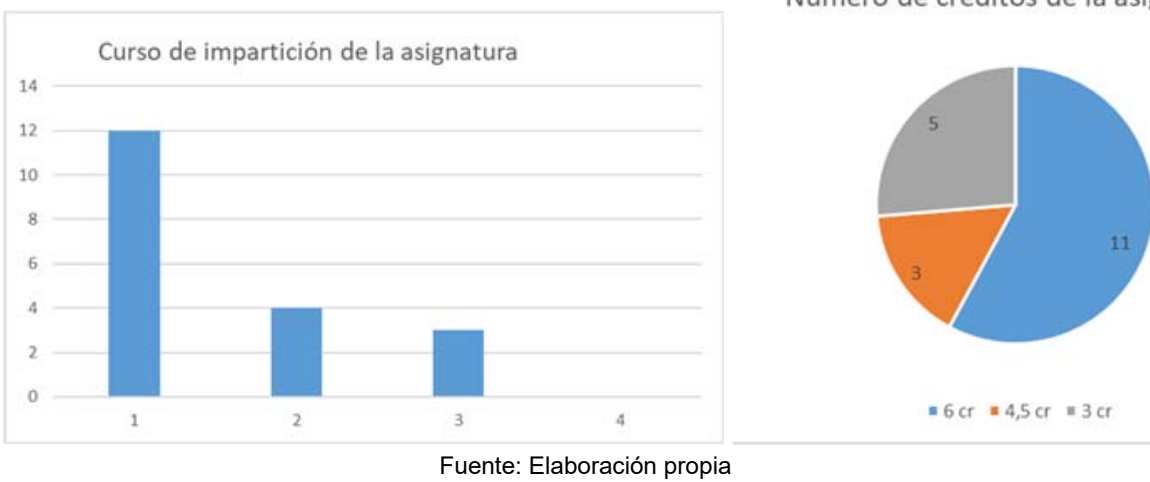

Fig. 1 Distribución de las asignaturas por curso y número de créditos

La primera cuestión que se nos suscita por tanto es: ¿en qué momento debe abordarse la enseñanza de la historia de la construcción dentro de un plan de estudios? ¿Debe tratarse como una disciplina (materia/asignatura) independiente como análisis previo para entender los sistemas constructivos actuales?, ¿debe asociarse a la enseñanza de intervención en construcciones históricas y referirse exclusivamente al conocimiento de aquellos sistemas en las asignaturas de patología y rehabilitación?, ¿debe formar parte, como algo complementario, del escaso bagaje humanista que caracteriza a las enseñanzas técnicas en nuestro país?

En este sentido, es necesario destacar que, tan solo la UCAM presenta una asignatura de Humanidades en su plan de estudios además de la mencionada de Historia de la construcción.

\subsection{Análisis de objetivos y competencias}

En la mayoría de los casos, en las guías docentes los objetivos aparecen superpuestos con algunas competencias. Los más repetidos, aunque formulados de distintos modos, hacen referencia a:

Reconocer las principales características de la construcción en los diferentes periodos históricos y áreas

Relacionar el contexto cronológico, social y geográfico con las construcciones.

Utilizar un vocabulario especializado adecuado.

Asimismo, es habitual encontrar en varias de las asignaturas recogidas las competencias de la orden $\mathrm{ECI}$ relativas a:

Conocimiento de los materiales y sistemas constructivos tradicionales o prefabricados empleados en la edificación, sus variedades y las características físicas y mecánicas que los definen. 
Aptitud para intervenir en la rehabilitación de edificios y en la restauración y conservación del patrimonio construido.

En el programa de estudios del grado en edificación, la historia de la construcción ¿debería centrarse más en las relaciones o interacciones entre la sociedad y la tecnología en los proyectos de construcción a lo largo de la historia que en los cambios en las tecnologías de la construcción? Cuestiones como el impacto de las obras de construcción en el medio ambiente, el consenso sobre los proyectos y la evolución de estos, incluidos los aspectos financieros y la evaluación por parte de la sociedad, deberían formar parte del discurso, junto con los aspectos más técnicos.

¿Debemos cambiar el enfoque del objetivo del aprendizaje? Algunos autores apuntan igualmente como objetivo que los ingenieros de construcción/edificación, desde un punto de vista ético, deben entender que la tecnología y la ingeniería tienen el poder de cambiar la forma de la naturaleza, aprender el concepto de simbiosis de la naturaleza y la existencia humana y los métodos para lograr esto, analizándolo desde una perspectiva histórica (Hisohata, 2006).

Para ello, ¿se estudia suficientemente la influencia de la organización socioeconómica en la evolución de las técnicas constructivas a lo largo de la historia y su repercusión en el contexto local? (especialmente en la era industrial).

\subsection{Análisis de temarios y contenidos}

Los temarios son bastante parejos, la mayoría se organizan de forma cronológica, según periodos históricos asociados a culturas o estilos arquitectónicos, especialmente en aquellas asignaturas de $3 \mathrm{cr}$, y en algunas de $6 \mathrm{cr}$. En otras tantas el temario se organiza parcialmente por sistemas constructivos, incluyendo en cada tema referencias a la evolución o contextualización histórica de distintos elementos (figura 2).

\section{Organización del contenido de la asignatura}

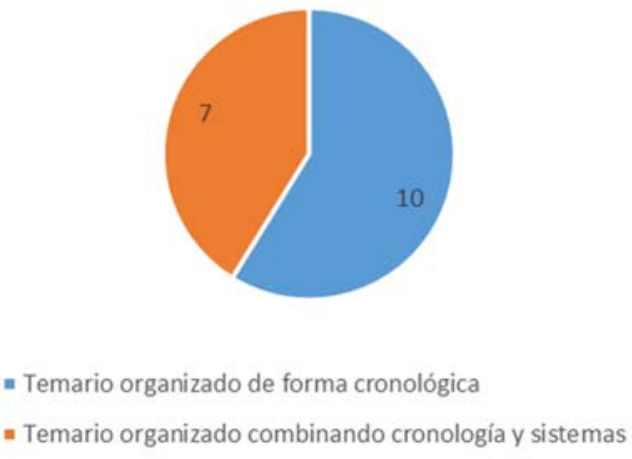

Fig. 2 Organización de los contenidos de las asignaturas analizadas, según guía docente 
En casi todos estos casos la asignatura corresponde con CONSTRUCCION I, compartiendo la enseñanza con principios básicos o fundamentales de organización de los elementos constructivos.

La cuestión planteada en este caso es: ¿debe enseñarse de forma cronológica, asociada a la historia de la arquitectura o referida a la evolución de los sistemas constructivos por si mismos? Por ejemplo, tiene sentido hablar de la construcción abovedada, sus tipos y su evolución/adaptación a lo largo de la historia en distintos contextos geográficos y culturales o es preferible estudiar los distintos periodos históricos cronológicamente y en cada uno de ellos incluir la referencia el uso de bóvedas. Esto nos lleva a la siguiente cuestión,

¿a qué tipo de edificios debemos referirnos en esos periodos históricos? Edificios singulares, representativos de hitos o avances en la tecnología de la época o edificios representativos de la construcción convencional.

A menudo la estructuración de la enseñanza a partir de periodos históricos asociados a los estilos arquitectónicos tiene poca relevancia, pues salvo en casos muy concretos no llevan asociados paralelamente una evolución significativa de las técnicas constructivas. En este sentido, se ha observado que algunos de los temarios agrupan varios periodos en base a estas cuestiones.

¿el estudio de la historia de la construcción se realiza de forma equilibrada atendiendo a distintos factores? Aparición y difusión de nuevos materiales, aspectos sociales en el desarrollo industrial, procesos constructivos, análisis de edificios completos como hecho arquitectónico, tendencias estéticas y estilos de diseño del momento.

¿cómo diferenciamos entonces la historia de la arquitectura de la historia de la construcción?

Estas cuestiones ya han sido tratadas en otras publicaciones (Huerta y Gil-Crespo, 2015) aunque referidas a su inclusión en los estudios de grado de arquitectura. En la citada publicación el profesor Huerta expone su propuesta de programa para las asignaturas optativas de cuarto y quinto curso, estructurado de forma cronológica en periodos históricos. La diferencia fundamental con las enseñanzas de edificación en la actualidad es el conocimiento previo por parte de los estudiantes, que permite una enseñanza más especializada y próxima a la investigación.

\subsection{Análisis de las actividades y métodos de enseñanza}

En todos los casos las actividades planteadas implican una parte importante del uso de clases magistrales, combinadas con trabajo de campo (visitas a edificios), desarrollo de casos prácticos en aula o laboratorio, lectura de información complementaria y elaboración de memorias. Es difícil deducir de las propias guías las herramientas y software utilizados por los estudiantes para realizar estos trabajos. En la mayoría de los programas se plantean actividades prácticas, pero tan solo en tres de ellos se habla de laboratorios o se menciona expresamente la construcción de modelos a escala como actividad obligatoria. 
Parece clara la necesidad de realización de trabajos prácticos, en los que el edificio debe entenderse como un todo y el estudio de los sistemas constructivos debe contextualizarse en el propio edificio al que pertenecen, no estudiarse de forma aislada. Pero por otro lado se necesita una comprensión previa del funcionamiento de los elementos constructivos presentes y no visibles íntegramente en los edificios a analizar.

La primera pregunta por tanto en este sentido es: ¿Cuál es el grado de profundidad con el que debe abordarse el conocimiento de las técnicas constructivas históricas para comprender su evolución o su variedad tipológica (más allá del formalismo)? ¿debemos enseñar los principios de diseño estructural (por ejemplo) como algo independiente a las cuestiones culturales y tecnológicas, para abordar el análisis histórico de las construcciones adecuadamente? ¿es suficiente en la actualidad una aproximación teórica o audiovisual (mediante distintos recursos) al conocimiento de las técnicas constructivas históricas?

Respecto a los sistemas de evaluación, salvo en tres casos, la ponderación entre el trabajo práctico (personal o en grupo) realizado por los estudiantes y las pruebas de evaluación personales (escritas en la mayoría de los casos) oscila entre el 40\%/60\%, 50\%/50\% o $60 \% / 40 \%$, pero ¿en qué consiste enseñar/aprender la historia de la construcción o los sistemas constructivos históricos de forma práctica?

\subsection{Análisis de Fuentes documentales y referencias bibliográficas}

En una primera aproximación, llama la atención que aun hoy en día, la "bibliografía" siga contando exclusivamente con recursos documentales impresos y generalmente de acceso bastante restringido. Tan sólo en uno de los casos se hace referencia a documentos audiovisuales en la bibliografía (aunque la mayoría de los docentes los usamos en la práctica y los incluimos como material docente posteriormente).

En cualquier caso, ¿existen suficientes textos o manuales de referencia para poder entender la historia de la construcción como una disciplina? Esta cuestión nace del convencimiento de que el conocimiento académico debe ser sistematizado y estructurado para poder ser transmitido de manera adecuada. Nadie pone en duda la existencia de diferentes alternativas docentes, pero en otras disciplinas la existencia de manuales (construcción, estructuras, instalaciones) parece ofrecer una visión conjunta más clara y ordenada del objeto de aprendizaje, que luego puede ser seleccionada o interpretada por el docente.

El análisis de las principales fuentes documentales citadas en las guías docentes se resume en la figura $3^{4}$. En ella se aprecia como la mayoría de las referencias corresponden a autores fuera del ámbito nacional (aunque los textos referidos han sido traducidos al castellano) y una buena parte corresponden a textos redactados en épocas preindustriales (Vitrubio, Choisy, Viollet). Se aprecia también la preponderancia de los textos de Choisy y Adam específicos del estudio de la construcción de época clásica romana y bizantina. Los textos de

\footnotetext{
${ }^{4}$ Se han incluido aquellos textos que aparecen mencionados en 4 guías docentes o más. La referencia completa de los textos recogidos en la tabla se encuentra en la base de datos completa, accesible a través del enlace incluido en el apartado "referencias"
} 
Ortega Andrade y Magro-Marín abarcan ámbitos históricos igualmente preindustriales, y el texto de Castro Villalba quizás es el más citado por su sencillez, abarcando un espectro más amplio. Creo que ninguno de estos textos puede considerarse un manual (o libro de texto) al uso y por tanto surge la necesidad de generar textos docentes más completos y mejor estructurados que cubran el espectro completo del temario que la mayoría abordamos, así como otro tipo de recursos documentales audiovisuales más acordes con las tendencias actuales. Sólo 5 de los docentes tienen textos incluidos en las bibliografías, y como se puede apreciar, escasamente citados, salvo los de Magro-Marín ${ }^{5}$.

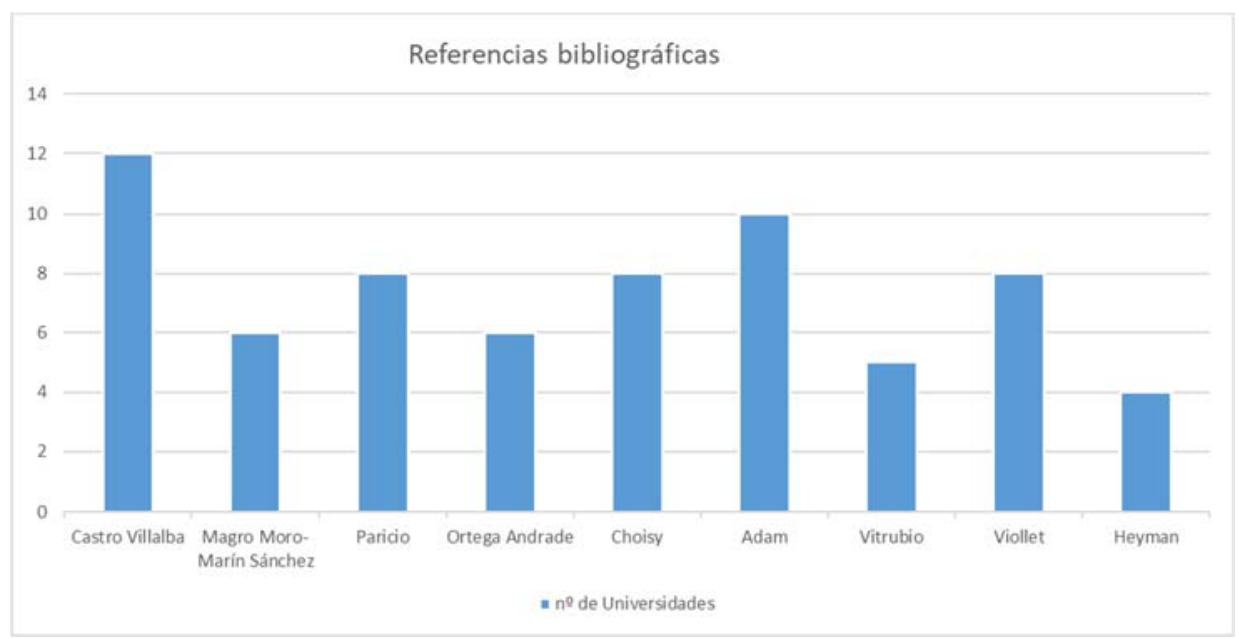

Fig. 3 Textos (identificados por nombre del autor) y numero de asignaturas en que aparecen incluidos como referencia bibliográfica

También es notoria la escasa concreción de las bibliografías, en las que alguna guía incluye casi 50 referencias, y la media es de 20 (gracias a la escasez en otras) lo que pone de manifiesto una vez más la dificultad para encontrar recursos adecuados acordes a la docencia.

Hay mucha información disponible como material didáctico de historia de la construcción en los archivos, los repositorios institucionales y en textos generados por la SEdHC ${ }^{6}$. Lo necesario es reunirla en libros, folletos, películas, colecciones de fotos o dibujos en formato digital, adaptados al nivel requerido en la docencia del grado de edificación ${ }^{7}$. La SEdHC

\footnotetext{
${ }^{5}$ Aunque su uso es mayoritario principalmente en las escuelas de Levante (Castellón, Valencia, Alicante, Cartagena)

${ }^{6}$ Sociedad Española de Historia de la Construcción

${ }^{7}$ Hay que destacar como posible referencia la "Breve guía de Recursos electrónicos para la investigación en Historia de la Construcción” propuesta por José Calvo, a través del Grupo de investigación Historia de la Construcción de la Universidad Politécnica de Cartagena (Calvo, 2012)
} 
podría participar activamente en este proyecto como parte de sus fines de promoción y difusión de los estudios de Historia de la Construcción en la ingeniería civil, edificación y las obras públicas. La importante labor de recopilación bibliográfica realizada por otros autores (Huerta, 2015) y sociedades (the Construction Hístory Society, 2014) así como los documentos disponibles en la biblioteca digital de la SEdHC resultan de gran interés para los trabajos de investigación, pero de difícil aplicación a la docencia a nivel de grado.

Como cuestiones complementarias a este tema se plantean las siguientes: ¿se pueden estudiar las técnicas de construcción históricas a partir del análisis de documentos históricos?

¿Qué vocabulario es el adecuado? ¿existe algún recurso que permita el contraste de la terminología utilizada para un mismo elemento constructivo a lo largo de la historia y en distintas zonas geográficas?

\section{Conclusiones y propuestas de actuación}

De lo expuesto anteriormente parece claro que sería conveniente una puesta en común y elaboración de unas directrices para la implantación adecuada de la enseñanza de la historia de la construcción, no tanto en los actuales planes de estudios, si no en las futuras reformas que parecen inminentes.

Creación de una web o repositorio documental (¿amparado por la SEdHC?) que incluya las siguientes secciones:

- Archivo de documentación gráfica constructiva de diversos ejemplos de construcciones históricas. En este sentido se han realizado ya algunas experiencias en otras universidades (Pilsitz, 2018)

- Ejemplos de prácticas sencillas a desarrollar en las aulas relacionadas con los elementos y técnicas constructivas históricas. En la figura 4 se muestran algunos ejemplos realizados en la Escuela Politécnica de Cuenca.

- $\quad$ Archivo de selección de trabajos de estudiantes sobre documentación y análisis de edificios históricos desarrollados en las asignaturas

- Desarrollo de Manual estructurado en unidades didácticas organizadas por elementos constructivos y periodos históricos.

Como propuesta para este último tema, el texto de Robert Mark: Tecnología arquitectónica hasta la revolución científica ${ }^{8}$ (que tiene versión en Castellano e inglés) citado en tres de las guías, tiene una estructura de doble entrada (figura 5) organizada por sistemas constructivos y periodos históricos, que resulta muy apropiada. En este texto, sin embargo, las referencias en el periodo medieval están muy vinculadas al ámbito del centro y norte de Europa y su alcance no va más allá del siglo XVIII, por lo que resultaría interesante una adaptación adecuada al contexto de la construcción en España.

\footnotetext{
${ }^{8}$ Edición en castellano. Akal, 2002
} 

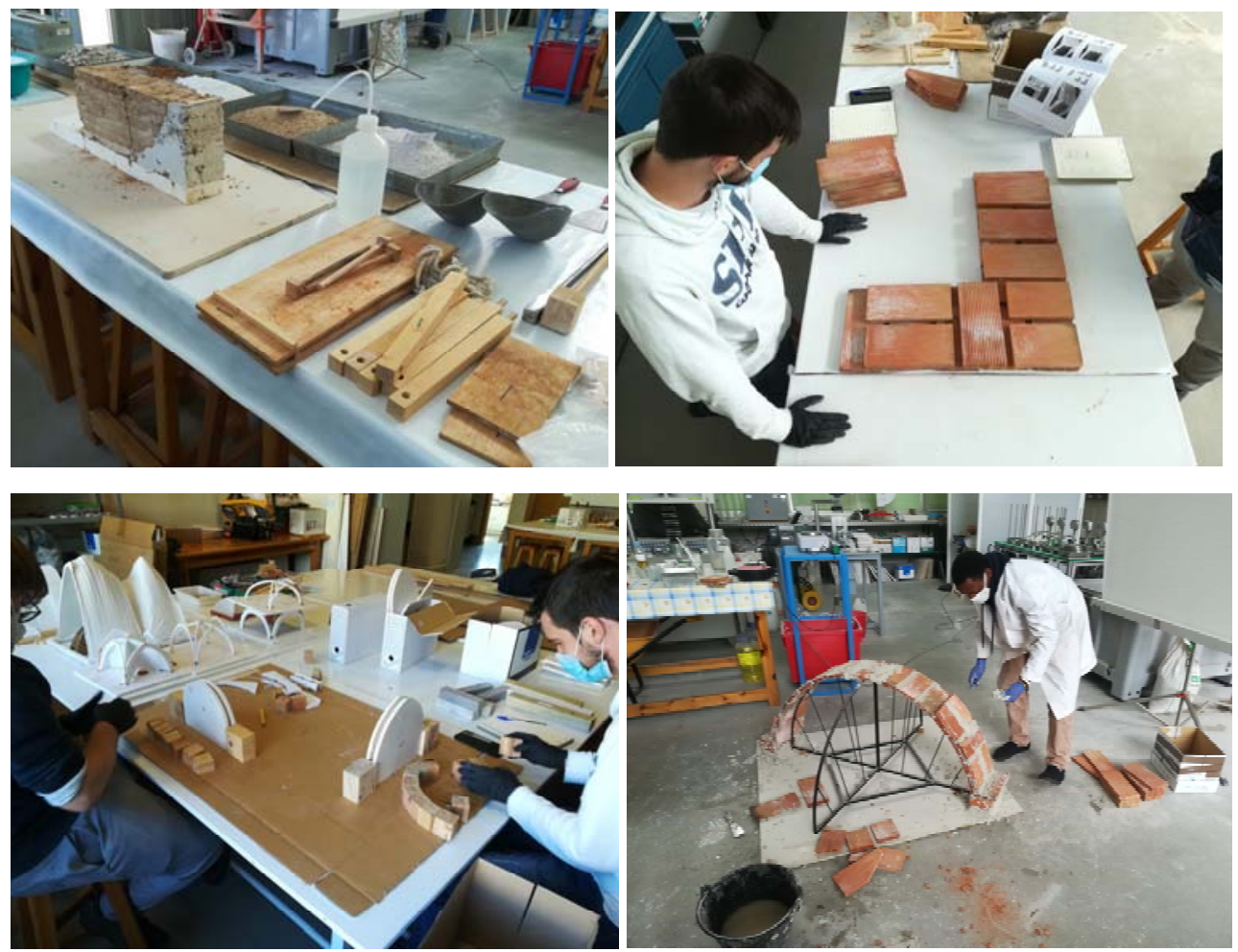

Fig. 4 a) construcción de tapial (1:5) b) aparejos de ladrillo (1:1) c) construcción de arcos (1:10) d) construcción de bóvedas (1:2)

Tabla 1

Índice de los componentes de edificios históricos

\begin{tabular}{|c|c|c|c|c|}
\hline \multicolumn{5}{|c|}{ Páginas del texto } \\
\hline 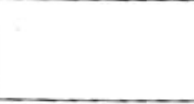 & $\begin{array}{c}\text { Suelos y } \\
\text { cimentaciones }\end{array}$ & $\begin{array}{c}\text { Muros y otros } \\
\text { elementos } \\
\text { verticales }\end{array}$ & $\begin{array}{l}\text { Bóvedas y } \\
\text { cúpulas }\end{array}$ & $\begin{array}{c}\text { Cubiertas de } \\
\text { madera } \\
\text { y chapiteles }\end{array}$ \\
\hline Introducción & 31 & 73 & 165 & 215 \\
\hline Antigüedad & 42 & 94 & 168 & 230 \\
\hline Roma Imperial & 45 & 101 & 169 & 234 \\
\hline Bizancio & 50 & 113 & 178 & 243 \\
\hline Alta Edad Media & 53 & 121 & 182 & 245 \\
\hline Románico & 54 & 124 & 184 & 249 \\
\hline Gótico & 59 & 131 & 190 & 254 \\
\hline Renacimiento & 67 & 154 & 203 & 264 \\
\hline
\end{tabular}

Fig. 5 Índice del libro "Tecnología arquitectónica hasta la revolución científica” (Mark, R. 2002. Akal, Ed) 
El texto de Bill Addis Building: 3000 Years of Design, Engineering and Construction, recomendado ya hace años por Santiago Huerta, como un excelente manual, utilizado y disponible en numerosas instituciones de ámbito anglosajón, no es de los más habituales en las referencias bibliográficas y quizás podría plantearse su edición en castellano.

Como cuestión adicional ¿podría ser la historia de la construcción una disciplina conjunta con las enseñanzas de ingeniería civil y arquitectura y compartir estos recursos? O cada una debe tener un perfil especializado acorde a los objetivos de cada grado. Para ello es necesario un análisis comparativo más detallado de la oferta académica actual en estos otros grados.

Finalmente, ¿en qué lugar queda la enseñanza y aprendizaje de la construcción tradicional asociada a la arquitectura popular? Dado que una de sus principales características es la escasa evolución de la misma a lo largo de la historia, parece no tener cabida en este ámbito y sin embargo tampoco tiene espacio en otras materias. Sería necesario incluir también su aprendizaje de forma específica y obligatoria en todos los planes de estudio, con referencia concreta al contexto local en cada una de las escuelas.

\section{Referencias}

Como documentación complementaria se adjunta enlace a una carpeta compartida en la que se encuentra el documento excel con la base de datos utilizada para el estudio y los documentos de todas las guias docentes de donde se ha extraido la información:

https://pruebasaluuclm-

my.sharepoint.com/:f:/g/personal/fcojavier castilla uclm es/EufgF6jPLGFHgfyLQ10TqxgBx JQhlsRZ5IM0X65fRZ-Tew?e=|z50Pe

CALVO LÓPEZ, J. (2012) Breve guía de recursos electrónicos para la investigación en historia de la construción <http://estereotomiadelapiedra.blogspot.com/2012/02/recursos-electronicos-parala 24.html> [Consulta: 30 de junio de 2021]

España. ORDEN ECI/3855/2007, de 27 de diciembre, por la que se establecen los requisitos para la verificación de los títulos universitarios oficiales que habiliten para el ejercicio de la profesión de Arquitecto Técnico. BOE núm. 312 Sábado 29 diciembre 2007 53739-53742

HUERTA, S. GIL CRESPO, I. (2015). "Construyendo la Historia de la Construcción". Huertas, S, Fuentes,P.. (coord.) En: Actas del Noveno Congreso Nacional y Primer Congreso Internacional Hispanoamericano de Historia de la Construcción (Segovia, 13 - 17 de octubre de 2015). Instituto Juan de Herrera. 41-59

ISOHATA, H. (2006) "Construction History in Education - Why and How It Should Be Learned". En The Construction History Society (United Kingdom) 2 1655-1672 Mar 27, 2006

PILSITZ, M. (2018) "Construction History in Theory and Teaching", Periodica Polytechnica Architecture, https://doi.org/10.3311/ PPar.13139

THE CONSTRUCTION HISTORY SOCIETY .(2014) < <http://www.constructionhistory.co.uk/wpcontent/uploads/2014/09/CH-bibliography-A.pdf > [Consulta: 30 de junio de 2021] 


\title{
EDIFICATEE
}

I Congreso de Escuelas de Edificación y Arquitectura Técnica de España

València, 4 y 5 de noviembre de 2021

Escuela Técnica Superior de Ingeniería de Edificación

Universitat Politècnica de València

Doi: https://doi.org/10.4995/EDIFICATE2021.2021.13325

\section{Aprendizaje del proceso constructivo, basado en proyectos, mediante el empleo de BIM}

\section{Construction process learning, by project-based methodology, using BIM}

\section{Susana Hormigos-Jiménez ${ }^{a}$, Gabriel Horrach Sastre ${ }^{b}$, Joan Munoz Gomilac ${ }^{c}$, Cristian Carmona Gómez ${ }^{\mathrm{d}}$ y Francesc Masdeu Mayans}

\footnotetext{
aProfesora Contratada Doctora Interina. Departamento de Ingeniería Industrial y Construcción.

Construcciones Arquitectónicas. Universitat de les Illes Balears. susana.hormigos@uib.es

bProfesor Contratado Doctor. Departamento de Ingeniería Industrial y Construcción. Construcciones Arquitectónicas. Universitat de les Illes Balears. gabriel.horrach@uib.es
}

'Profesor Contratado Doctor. Departamento de Ingeniería Industrial y Construcción. Construcciones Arquitectónicas. Universitat de les Illes Balears. joan.munoz@uib.es

dProfesor Asociado. Departamento de Ingeniería Industrial y Construcción. Construcciones Arquitectónicas. Universitat de les Illes Balears. cristian.carmona@uib.es

eProfesor Contratado Doctor Interino. Departamento de Ingeniería Industrial y Construcción. Construcciones Arquitectónicas. Universitat de les Illes Balears. francesc.masdeu@uib.es

\begin{abstract}
The use of BIM technology is increasingly widespread. To promote its implementation in the Construction IV course of the Degree in Construction at the University of the Balearic Islands, the project-based learning methodology is used. The main objectives of this research focus on favoring students' critical thinking, improving their spatial vision and graphic skills, and emphasizing their collaborative work. To do this, in the last three academic years, several group exercises have been proposed, having as case study a residential building (different in each course). There is also the option of developing the work individually. The resolution of the exercises must be developed in a written memory and in a 3D modeling carried out with Revit software. After completing the course, the students are very satisfied with learning the software, the constructive resolution of the structural elements of a building and with the work of teachers. It is observed, however, that, in order to obtain good results, it is essential to develop the work in group, with clear objectives per member, and that the students develop a continuous follow-up of the subject.
\end{abstract}



Construction process learning, by Project-based methodology, using BIM

Keywords: BIM technology, Revit software, project-based learning, construction, critial thinking, graphic skills, collaborative work.

\section{Resumen}

El uso de la tecnología BIM se encuentra cada vez más extendido. Para fomentar su implantación en la asignatura de Construcción IV del Grado en Edificación de la Universitat de les Illes Balears, se emplea la metodología del aprendizaje basado en proyectos. Los objetivos principales de esta investigación se centran en favorecer el pensamiento crítico de los alumnos, mejorar su visión espacial y sus competencias gráficas y enfatizar su trabajo colaborativo. Para ello, en los tres últimos cursos académicos se han propuesto varios ejercicios grupales, teniendo como objeto de estudio un edificio residencial (diferente en cada curso). También se da la opción de desarrollar el trabajo individualmente. La resolución de los ejercicios debe desarrollarse en una memoria escrita y en un modelado $3 D$ realizado con el software Revit. Tras la realización del curso, los alumnos se muestran muy satisfechos con el aprendizaje del software, de la resolución constructiva de los elementos estructurales de un edificio y con la labor del profesorado. Se observa, sin embargo, que para obtener buenos resultados es esencial que el trabajo se desarrolle en grupo, con objetivos claros por integrante, y que el alumnado desarrolle un seguimiento continuo de la asignatura.

Palabras clave: BIM, Revit, ABP, construcción, crítica, grafismo, colaboración. 


\section{Introducción}

El uso de la tecnología BIM (Building Information Modeling) en la industria AIC (Arquitectura, Ingeniería y Construcción) se encuentra en auge desde la última decáda (Clevenger, Glick, \& del Puerto, 2012; Forsythe, Jupp, \& Sawhney, 2013; Šadauskienė \& Pupeikis, 2018; Tsai, Chen, \& Chang, 2019). Dicha tecnología permite enfocar un proyecto como un proceso integrado, con un diseño eficiente a un almacenaje completo de información. Se realiza la toma de decisiones según un modelo visual y la comunicación con diferentes perfiles profesionales. Sin embargo, ante esta perspectiva, sigue habiendo carencia en la formación en BIM. Es por ello que resulta relevante fomentar el aprendizaje de dicha tecnología en los estudios del grado (Leite, 2016; Wu \& Luo, 2016).

En los último años, diversas instituciones académicas han empezado a incorporar BIM en diferentes cursos para dar respuesta a las necesidades de la industria AIC; sin embargo, la pedagogía no está aún consolidada (Ahn, Cho, \& Lee, 2013; Wang \& Leite, 2014). El almacenaje de datos en BIM permite que el modelo objeto de estudio no se ciña a una representación en 3D de la geometría, sino que facilite la estimación del coste, la simulación energética o la coordinación en el diseño. Es por ello que, además de enseñar el modelado en BIM, es igualmente importante poner en valor el potencial de la metodología a lo largo del ciclo de vida del proyecto (Forsythe et al., 2013; Leite, 2016).

Cabe destacar que el uso de BIM en una asignatura de pregrado requiere considerar varios aspectos que influyen directamente en la tarea docente (Leite, 2016):

(1) Resulta relevante que los estudiantes comprendan el funcionamiento y el objetivo último de la metodología BIM: agilizar el proceso colaborativo en un proyecto de construcción. Aunque no se profundice más allá del modelado, el objetivo último de esta metodología debe comprenderse.

(2) La tecnología de la información es altamente cambiante, por lo que la formación práctica en BIM del alumnado puede quedar obsoleta muy pronto. Por tanto, es esencial centrar el aprendizaje en el conocimiento autónomo.

(3) Además, dado que BIM aún está emergiendo en la industria AIC, se debe fomentar el pensamiento crítico.

Teniendo en cuenta estos 3 motivos, el aprendizaje basado en proyectos (ABP) es una metodología óptima a emplear para fomentar pensamiento crítico y aprendizaje autónomo. $\mathrm{ABP}$ es una metodología docente en la que el estudiante desarrolla un aprendizaje autodirigido mediante la resolución de uno o varios proyectos, facilitados por el docente. En estudios previos (Maida, 2011; Verma, 2011; Wang \& Leite, 2014) ha quedado patente la evaluación positiva de los estudiantes respecto a su aprendizaje con esta metodologías.

Los pasos a seguir para aplicar la metodología ABP pueden resumirse en:

(1) Se presenta una problemática que ha de ser resuelta, un proyecto a investigar.

(2) Los estudiantes proponen soluciones que ponen en común entre ellos y el docente, del cual obtenien propuestas de mejora y orientación. 
(3) La solución final se comparte con el resto de estudiantes, para hacer una puesta en común y enriquecer el conocimiento del grupo.

El valor de esta metodología, en el campo AIC, radica en la similitud con el ámbito profesional (Ahn et al., 2013; Clevenger et al., 2012; Šadauskienè \& Pupeikis, 2018). Adicionalmente, los proyectos pueden enfocarse desde un enfoque realista y colaborar con empresas que den su propio enfoque ante el problema concreto. En el ámbito concreto $\mathrm{AIC}$, según varias investigaciones desarrolladas en los últimos años (Johnson \& Johnson, 1985; Nembhard, Yip, \& Shtub, 2009; Slavin, 1989), la aplicación de la metodología ABP engloba las siguientes características:

(1) Los grupos de trabajo no superan los 6 integrantes. Al realizar un trabajo en equipo, mejora el rendimiento y la actitud de los estudiantes.

(2) Los objetivos del equipo quedan claramente definidos, teniendo cada integrante una responsabilidad concreta.

La aplicación de la metodología APB, para el docente, supone la inversión de tiempo adicional, acceso a empresas o a logística que, en ocasiones, puede resultar compleja (Ferreira \& Canedo, 2020; Leite, 2016; Wang \& Leite, 2014; Wu \& Luo, 2016). Sin embargo, teniendo en cuenta los beneficios de esta metodología ABP, centrada en el trabajo en equipo y en la resolución de un proyecto (problemática real a resolver), resulta esencial impulsar su uso en las asignaturas de pregrado en estudios del campo AIC, por la similitud con esta industria.

\section{Objetivos}

El presente artículo pretende describir la experiencia obtenida, durante los últimos tres cursos académicos, de la aplicación de la metodología de aprendizaje basada en proyectos, mediante el uso del software Revit en la asignatura obligatoria de Construcción IV, de tercer curso del Grado en Edificación de la Universitat de les Illes Balears.

Al tratarse de una experiencia de implantación inicial, el software se emplea, principalmente, como una herramienta de modelado, dejando el proceso colaborativo como un segundo paso en el desarrollo de la incorporación de este software en la metodología docente. La aplicación del aprendizaje basado en proyectos, empleando el software Revit, en este curso en concreto, se centra en:

(1) proporcionar a los alumnos experiencias que favorezcan su pensamiento crítico y el aprendizaje del proceso constructivo de un edificio, por medio del dimensionado de los elementos estructurales y de su ubicación dentro del conjunto;

(2) mejorar la visión espacial y las competencias gráficas del alumnado;

(3) enfatizar el trabajo colaborativo con los demás integrantes del grupo. 


\section{Desarrollo de la innovación}

En la asignatura de Construcción IV del Grado en Edificación de la Universitat de les Illes Balears, se aplica la organización docente mostrada en la tabla 1, que consiste en la realización de prácticas individuales, dos pruebas de evaluación y prácticas grupales, en estas últimas se centra el presente estudio.

Tabla 1. Organización docente de la asignatura de Construcción IV

\begin{tabular}{lc}
\hline Actividades & Horas \\
\hline Trabajos individuales & \\
Se realizan trabajos individuales relacionados con el contenido de la & 30 \\
asignatura. Los estudiantes disponen de los recursos necesarios para & \\
resolver los ejercicios (vídeos explicativos, apuntes en soporte digital) y las & \\
clases de teoría para exponer dudas. & \\
Trabajos grupales & 26 \\
A lo largo del curso se desarrolla un trabajo grupal, con dos entregas que \\
son evaluables. En dicho trabajo se ejercita el aprendizaje de los diferentes \\
$\quad$ contenidos del curso mediante la resolución constructiva de un proyecto \\
$\quad$ concreto. Se trabaja con el software Revit para crear un modelo en 3D \\
donde se integran los elementos estructurales del edificio.
\end{tabular}

Los contenidos temáticos de la asignatura se centran en los siguientes bloques:

1. Pilares, pantallas y vigas

2. Forjados unidireccionales y bidireccionales

3. Estructuras metálicas

4. Estructuras de madera

5. Interacción de las instalaciones con los elementos del edificio

6. Muros de contención

7. Muros de fábrica

8. Cimentaciones superficiales

9. Cimentaciones profundas

\subsection{Descripción de la organización de las prácticas grupales}

Desde el curso académico 2018-2019, se aplica la metodología docente ABP en la asignatura de Construcción IV del Grado en Edificación de la Universitat de les Illes Balears. En cada curso académico se propone un edificio residencial, plurifamiliar o unifamiliar, en el que los alumnos y alumnas deben proponer la disposición de pórticos, forjados unidireccionales y bidireccionales, incluir patinillos para el paso de instalaciones, disponer muros de contención, muros de fáblica y cimentaciones superficiales y profundas; todo ello según indicaciones del profesorado. 
Para resolver los proyectos propuestos, se les solicita el uso del software Revit. Los estudiantes deben entregar el modelo de Revit y una memoria, donde se presente el proceso desarrollado, los cálculos necesarios para la resolución del ejercicio y los planos que definan gráficamente la propuesta.

Para aplicar la metodología docente ABP en esta parte de la asignatura, se les indica a los estudiantes que deben formar grupos de 3 integrantes, como máximo.

\subsection{Objetivos de aprendizaje}

A través de la resolución de la práctica grupal, se pretende desarrollar los siguientes objetivos de aprendizaje:

- Específicos: capacidad para elaborar manuales y planes de mantenimiento y gestionar su implantación en el edificio; aptitud para el predimensionado, diseño, cálculo y comprobación de estructuras, para dirigir su ejecución material y aplicar la normativa específica: acero, madera y hormigón; mejora de la visión espacial y competencias de modelado 3D.

- Genéricos: que los estudiantes sepan aplicar sus conocimientos a su trabajo de forma profesional, que posean las competencias para la elaboración y defensa de argumentos y que demuestren la resolución de problemas en su área de estudio.

- Transversales: resolución de problemas; razonamiento crítico; trabajo en grupo.

Los alumnos y alumnas deben realizar dos entregas del trabajo en grupo, que son evaluables. El profesorado les devuelve el trabajo con la retroacción y evalúa si se están alcanzando los objetivos propuestos. Para la resolución de las prácticas, se dispone de las clases para la resolución de dudas y de un foro en la plataforma digital de la asignatura, al que tienen acceso tanto profesores como alumnos.

Adicionalmente, al final del curso, para comprobar si se alcanzan los objetivos de aprendizaje propuestos, se obtiene la opinión de los alumnos, los cuales, de forma voluntaria, responden a las siguientes cuestiones relacionadas con la aplicación de la metodología ABP:

- ¿Crees que con la resolución de la práctica en grupo has ampliado conocimientos en cuanto a la ejecución de los elementos estructurales de un edificio?

- ¿ ¿Crees que con la resolución de la práctica en grupo has ampliado conocimientos en cuanto al manejo del software Revit?

- ¿Consideras que los comentarios del profesorado sobre los trabajos entregados han favorecido tu aprendizaje y te han ayudado en prácticas posteriores?

- ¿Crees que los foros te han ayudado en la resolución de las prácticas?

\subsection{Prácticas y bloques de aprendizaje.}

En la figura 1 se muestra la planificación del curso, combinando los bloques temáticos con el desarrollo de la práctica en grupo en un diagrama de Gantt. La asignatura se cursa en el 
segundo semestre y consiste en 15 semanas de duración. Las clases tienen una duración de 2 horas y, normalmente, se imparten en días alternos (lunes y miércoles o martes y jueves); teniendo un total de 4 horas de clase semanales.

La práctica en grupo se desarrolla en dos partes. En la primera parte (P1) se dedica más tiempo ya que los estudiantes deben comprender el edificio y la problemática propuesta y, además, deben obtener unas sesiones explicativas del software Revit para poder afrontar el ejercicio. En la segunda parte (P2) se dedica un menor número de semanas, en comparación con $\mathrm{P} 1$, puesto que ya disponen de la base necesaria para manejar el software y, además, ya comprenden la organización arquitectónica del edificio.

ACTIVIDAD

P0. Presentación asignatura

A1. Tema 1: pilares y vigas

A2. Tema 2: forjados

A3. Tema 5: interacción instalaciones

A3. Tema 3 y 4: acero y madera

AX. Repaso general parte 1

E1. Entrega parte 1

B1. Tema 6: muros de contención

B2. Tema 7: muros de fábrica

B3. Tema 8: cimentaciones superficiales

B4. Tema 9: cimentaciones profundas

BX. Repaso general parte 2.

E2. Entrega parte 2

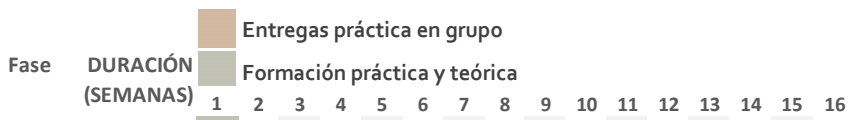

$\begin{array}{lllllllll}\text { (SEMANAS) } & 1 & 2 & 3 & 4 & 5 & 6 & 7 & 8\end{array}$

Fig. 1 Diagrama de Gantt. Bloques teóricos y entregas de la práctica grupal

\subsection{Enunciados, rúbrica y criterios de evaluación.}

El esquema principal de cada uno de los enunciados se mantiene en los diferentes cursos académicos, al igual que la rúbrica y los criterios de evaluación empleados, que se exponen a continuación:

\subsubsection{Enunciados}

La tabla 2 refleja los diferentes enunciados que se facilitan durante el curso, junto con las tareas a desarrollar en cada uno de ellos y las singularidades que varían y que se especifican en cada curso académico.

En todos los enunciados, se pide que su resolución se incorpore a una memoria, que recogerá la propuesta de cada grupo para cada uno de los ejercicios planteados, de la siguiente forma:

Debe realizarse una memoria que refleje el proceso y las decisiones, según la normativa de aplicación. El trabajo debe constar de dicha memoria y de toda la documentación gráfica necesaria para describir la resolución correctamente. Para el modelado de los elementos y la generación de la documentación gráfica debe emplearse el software REVIT. 
Tabla 2. Tareas a desarrollar según enunciados

\begin{tabular}{|c|c|c|}
\hline Enunciado & Tareas & Indicaciones según curso \\
\hline $\begin{array}{l}1(\mathrm{P} 1) \\
\text { Tema } 1\end{array}$ & $\begin{array}{l}\text { Modelado de los pilares de } \\
\text { hormigón armado (forjados } \\
\text { unidireccionales). } \\
\text { Modelado de las vigas de } \\
\text { hormigón armado de los } \\
\text { diferentes pórticos }\end{array}$ & $\begin{array}{l}\text { Sección de los pilares (cuadrada, circular, } \\
\text { rectangular). } \\
\text { Tipo de vigas a emplear. } \\
\text { Indicaciones para el cálculo del canto y ancho de las } \\
\text { vigas. } \\
\text { Singularidades del edificio. } \\
\text { Justificaciones: procesos constructivos. }\end{array}$ \\
\hline $\begin{array}{l}2(\mathrm{P} 1) \\
\text { Tema } 1\end{array}$ & $\begin{array}{l}\text { Cálculo y modelado del armado } \\
\text { de un pórtico }\end{array}$ & $\begin{array}{l}\text { Características geométricas del pórtico. Hormigón, } \\
\text { cemento, acero, características de armados de } \\
\text { positivos y negativos. } \\
\text { Justificaciones: cuantías mínimas y mecánicas, } \\
\text { longitudes de solape y anclaje, separación mínima } \\
\text { entre barras. }\end{array}$ \\
\hline $\begin{array}{l}3(\mathrm{P} 1) \\
\text { Tema } 2\end{array}$ & $\begin{array}{l}\text { Modelado de forjado } \\
\text { unidireccional, bidireccional, } \\
\text { escalera, losa. }\end{array}$ & $\begin{array}{l}\text { Singularidades del edificio. Ubicación de cada } \\
\text { elemento. } \\
\text { Características de los diferentes elementos. }\end{array}$ \\
\hline $\begin{array}{l}4(\mathrm{P} 1) \\
\text { Tema } 2\end{array}$ & $\begin{array}{l}\text { - Cálculo y modelado de los huecos } \\
\text { para las instalaciones }\end{array}$ & $\begin{array}{l}\text { Singularidades del edificio. } \\
\text { Dimensionado y ubicación de huecos }\end{array}$ \\
\hline $\begin{array}{l}5(\mathrm{P} 1) \\
\text { Temas } 3 \text { y } 4\end{array}$ & $\begin{array}{l}\text { Modelado, en una zona concreta } \\
\text { del edificio, elementos } \\
\text { estructurales de acero y de } \\
\text { madera. }\end{array}$ & $\begin{array}{l}\text { Zona del edificio donde ubicar los diferentes } \\
\text { elementos. } \\
\text { Tipo de elemento y tipo de material. } \\
\text { Justificaciones: uniones y procesos constructivos. }\end{array}$ \\
\hline $\begin{array}{l}6(\mathrm{P} 2) \\
\text { Tema } 8\end{array}$ & $\begin{array}{l}\text { Modelado de los elementos de } \\
\text { cimentación superficial y armados }\end{array}$ & $\begin{array}{l}\text { Singularidades del edificio. } \\
\text { Geometría y tipos de zapatas y vigas de atado o } \\
\text { centrado. }\end{array}$ \\
\hline $\begin{array}{l}7(\mathrm{P} 2) \\
\text { Temas } 6 \text { y } 7\end{array}$ & $\begin{array}{l}\text { Modelado de muros de fábrica, } \\
\text { muros de contención y armado }\end{array}$ & $\begin{array}{l}\text { Singularidades del edificio. } \\
\text { Geometría y tipo de muro. }\end{array}$ \\
\hline $\begin{array}{l}8(\mathrm{P} 2) \\
\text { Tema } 9\end{array}$ & $\begin{array}{l}\text { Cálculo y modelado de } \\
\text { cimentación profunda. }\end{array}$ & $\begin{array}{l}\text { Geometría y tipo de pilotes. } \\
\text { Indicaciones para el cálculo del encepado y armado. }\end{array}$ \\
\hline
\end{tabular}

\subsubsection{Criterios de evaluación}

Cada uno de los grupos obtiene una calificación numérica, con un decimal, comprendida entre 0 y 10 , de forma que, según la nota, se obtienen las siguientes calificaciones: $(0-4,9)$ suspenso; $(5-6,9)$ aprobado; $(7-8,9)$ notable; $(9-10)$ sobresaliente. 


\subsubsection{Rúbrica}

Para evaluar las competencias alcanzadas por los estudiantes, tanto en la primera entrega correspondiente a $\mathrm{P} 1$, como en la segunda entrega relativa a $\mathrm{P} 2$, se emplea la rúbrica que se muestra en la tabla 3.

Tabla 3. Rúbrica de evaluación

\begin{tabular}{|c|c|c|c|c|}
\hline $\begin{array}{l}\text { Criterios de } \\
\text { evaluación }\end{array}$ & Excelente & Satisfactorio & Mejorable & Deficiente \\
\hline $\begin{array}{l}\text { Expresión } \\
\text { escrita }\end{array}$ & $\begin{array}{l}\text { Sin faltas ortográficas o } \\
\text { con un número bajo de } \\
\text { faltas leves. } \\
\text { Redacción correcta, } \\
\text { con el empleo de los } \\
\text { signos de puntuación } \\
\text { pertinentes. }\end{array}$ & $\begin{array}{l}\text { Número elevado de } \\
\text { faltas ortográficas leves } \\
\text { o número bajo de faltas } \\
\text { ortográficas graves. } \\
\text { Mejoras en cuanto a } \\
\text { organización de } \\
\text { párrafos y signos de } \\
\text { puntuación. }\end{array}$ & $\begin{array}{l}\text { Número alto de faltas } \\
\text { sortográficas. } \\
\text { s Alto margen de mejora } \\
\text { en cuanto al empleo de } \\
\text { signos de puntuación y } \\
\text { desarrollo de la } \\
\text { redacción. }\end{array}$ & $\begin{array}{l}\text { Deficiencias graves } \\
\text { en cuanto al } \\
\text { desarrollo del texto. } \\
\text { Número elevado de } \\
\text { faltas ortográficas. }\end{array}$ \\
\hline $\begin{array}{l}\text { Desarrollo de } \\
\text { la memoria }\end{array}$ & $\begin{array}{l}\text { Organización correcta } \\
\text { de información. } \\
\text { Cálculos y } \\
\text { justificaciones } \\
\text { correctas. }\end{array}$ & $\begin{array}{l}\text { Mejoras mínimas en } \\
\text { la organización de la } \\
\text { memoria. Errores } \\
\text { leves en cálculos. } \\
\text { Falta de información } \\
\text { en algún punto que } \\
\text { deba justificarse. }\end{array}$ & $\begin{array}{l}\text { Mejoras acusadas en la } \\
\text { organización de la } \\
\text { memoria. } \\
\text { Errores graves en } \\
\text { cálculos. } \\
\text { Información necesaria } \\
\text { en varios puntos que } \\
\text { quedan sin justificar. }\end{array}$ & $\begin{array}{l}\text { Organización } \\
\text { definiciente de la } \\
\text { memoria. } \\
\text { Cálculos } \\
\text { incorrectos, con } \\
\text { errores muy } \\
\text { graves. } \\
\text { Sin justificación. }\end{array}$ \\
\hline $\begin{array}{l}\text { Definición } \\
\text { constructiva }\end{array}$ & $\begin{array}{l}\text { Resolución correcta } \\
\text { respecto a la } \\
\text { disposición de } \\
\text { elementos y } \\
\text { explicación del proceso } \\
\text { constructivo. }\end{array}$ & $\begin{array}{l}\text { Mínimas mejoras } \\
\text { respecto a la } \\
\text { disposición de } \\
\text { elementos y } \\
\text { pexplicación del } \\
\text { proceso constructivo. }\end{array}$ & $\begin{array}{l}\text { Errores en la } \\
\text { disposición de } \\
\text { elementos y en la } \\
\text { explicación del } \\
\text { proceso constructivo. }\end{array}$ & $\begin{array}{l}\text { Errores graves en } \\
\text { la disposición de } \\
\text { elementos y en la } \\
\text { explicación del } \\
\text { proceso } \\
\text { constructivo. }\end{array}$ \\
\hline $\begin{array}{l}\text { Definición } \\
\text { gráfica }\end{array}$ & $\begin{array}{l}\text { Se presenta la } \\
\text { información necesaria } \\
\text { para definir de forma } \\
\text { correcta el edificio. } \\
\text { Nivel alto en la } \\
\text { definición gráfica de } \\
\text { elementos y en la } \\
\text { composición de las } \\
\text { láminas. }\end{array}$ & $\begin{array}{l}\text { Mejoras en cuanto a la } \\
\text { información necesaria } \\
\text { para definir de forma } \\
\text { correcta el edificio. } \\
\text { Nivel medio en la } \\
\text { definición gráfica de } \\
\text { elementos y en la } \\
\text { composición de las } \\
\text { láminas. }\end{array}$ & $\begin{array}{l}\text { Mejoras importantes en } \\
\text { cuanto a la información } \\
\text { necesaria para definir } \\
\text { correctamente el } \\
\text { edificio. } \\
\text { Nivel bajo en la definicić } \\
\text { gráfica de elementos y } € \\
\text { la composición de las } \\
\text { láminas. }\end{array}$ & $\begin{array}{l}\text { No se presentan } \\
\text { hlos planos y hay } \\
\text { errores graves en } \\
\text { la definición gráfica } \\
\text { del ejercicio. } \\
\text { ć }\end{array}$ \\
\hline
\end{tabular}

\section{Resultados}

En los cursos académicos objetos de estudio, 2018-2019; 2019-2020; 2020-2021, se matricula el siguiente número de estudiantes: 37,36 y 32 , respectivamente

A continuación, en la tabla 4, se detalla el número de grupos e integrantes de cada uno de ellos, para cada curso académico. 
Tabla 4. Número de grupos e integrantes por cada curso académico

\begin{tabular}{|c|c|c|c|c|c|c|c|c|c|c|c|c|c|c|c|}
\hline \multicolumn{16}{|c|}{ 2018-2019 (a) } \\
\hline Grupos (Ga) & $1 a$ & $2 a$ & $3 a$ & $4 a$ & $5 a$ & $6 a$ & $7 a$ & $8 a$ & $9 a$ & $10 a$ & $11 a$ & $12 a$ & $13 a$ & $14 a$ & \\
\hline Integrantes & 3 & 3 & 3 & 3 & 2 & 3 & 3 & 3 & 3 & 3 & 3 & 1 & 2 & 1 & \\
\hline \multicolumn{16}{|c|}{$2019-2020$ (b) } \\
\hline Grupos (Gb) & $1 \mathrm{~b}$ & $2 b$ & $3 b$ & $4 b$ & $5 b$ & $6 b$ & $7 b$ & $8 b$ & $9 b$ & $10 \mathrm{~b}$ & $11 \mathrm{~b}$ & $12 b$ & $13 b$ & $14 \mathrm{~b}$ & $15 b$ \\
\hline Integrantes & 3 & 3 & 3 & 3 & 3 & 2 & 3 & 3 & 2 & 3 & 2 & 3 & 1 & 1 & 1 \\
\hline \multicolumn{16}{|c|}{ 2020-2021 (c) } \\
\hline Grupos (Gc) & 1c & $2 c$ & $3 c$ & 4c & $5 c$ & $6 c$ & 7c & $8 c$ & $9 c$ & $10 \mathrm{c}$ & $11 \mathrm{c}$ & & & & \\
\hline Integrantes & 3 & 3 & 3 & 3 & 3 & 3 & 3 & 3 & 3 & 3 & 2 & & & & \\
\hline
\end{tabular}

\subsection{Ejemplos del modelado en Revit para cada edificio propuesto por año académico}

Desde la implantación del software Revit en la asignatura, se observa un alto nivel de implicación de los alumnos en el desarrollo de los ejercicios, por varios motivos: (1) supone un reto para ellos aprender un software nuevo; (2), valoran la utilidad del programa en la visualización de elementos; y (3) comprenden la importancia de conocer el software para un futuro profesional próximo. La asignatura requiere constancia en el trabajo y es de gran importancia que los integrantes tengan objetivos claros y responsabilidades en el equipo.

Al alumnado se le proporciona información en 2D en formato dwg. Con dicha información y, con las indicaciones de los enunciados, deben ser capaces de proponer la resolución constructiva del edificio en 3D. A continuación, se muestran ejemplos del modelado solicitado (figura 2) para cada edificio propuesto en los 3 últimos cursos académicos.

(a)

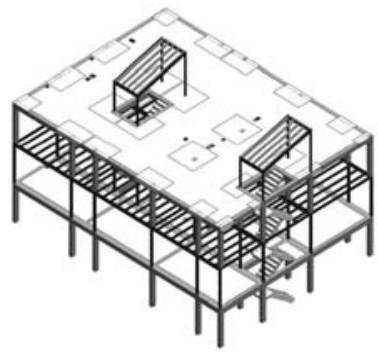

(b)

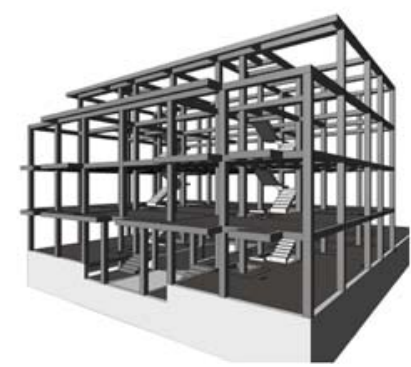

(c)

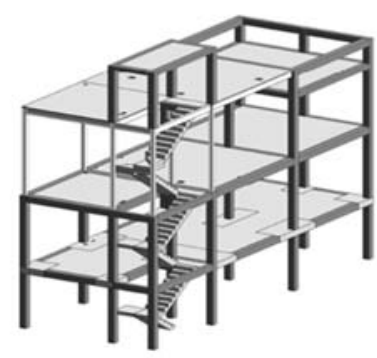

Fuente: propia

Fig. 2 Ejemplos de modelado solicitado para uno de los enunciados de la parte 1 de la asignatura, (a) curso 2018-2019; (b) curso 2019-2020; y (c) curso 2020-2021

\subsection{Satisfacción de los estudiantes}

Al finalizar el curso, los alumnos, de forma voluntaria, responden a una serie de preguntas (4.2.1. - 4.2.4) relativas a su aprendizaje tras aplicar la metodología APB. Los porcentajes de participación en el cuestionario, por año académico, son los siguientes: 86,5\% (2018-2019); 69,5\% (2019-2020); 71,9\% (2020-2021). 


\subsubsection{Conocimientos respecto a los elementos estructurales del edificio}

La figura 3 muestra la opinión de los alumnos sobre los conocimientos relativos a los elementos estructurales tras la realización de la práctica en grupo. Refleja las respuestas a la pregunta: ¿crees que con la resolución de la práctica en grupo has ampliado conocimientos en cuanto a la ejecución de los elementos estructurales de un edificio?

Se observa que, si se considera la suma entre las respuestas "totalmente de acuerdo" y "algo de acuerdo", la satisfacción va en aumento por cada curso académico $(75,1 \%, 88 \%$ y $91,3 \%$, respectivamente). Adicionalmente, las respuestas "totalmente de acuerdo" superan el $50 \%$ en los dos últimos cursos.
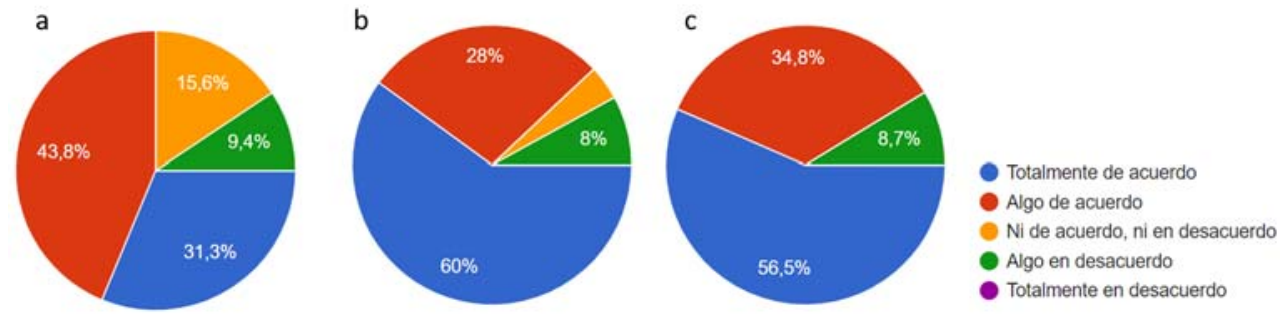

Fuente: propia. Formulario de Google

Fig. 3 Opinión del alumnado sobre sus conocimientos de los elementos estructurales del edificio tras la realización de la práctica grupal; (a) curso 18-19; (b) 19-20; y (c) 20-21

\subsubsection{Conocimientos respecto al manejo del software Revit}

La figura 4 muestra la opinión de los alumnos sobre los conocimientos relativos al manejo del software Revit tras la realización de la práctica en grupo. Refleja las respuestas a la pregunta: ¿crees que con la resolución de la práctica en grupo has ampliado conocimientos en cuanto al manejo del software Revit?

Se observa que, si se considera la suma entre las respuestas "totalmente de acuerdo" y "algo de acuerdo", la satisfacción supera el $90 \%$ en los 3 cursos académicos $(93,8 \%, 92 \%$ y $91,3 \%$, respectivamente). Adicionalmente, las respuestas "totalmente de acuerdo" superan el $50 \%$ en los tres últimos cursos.
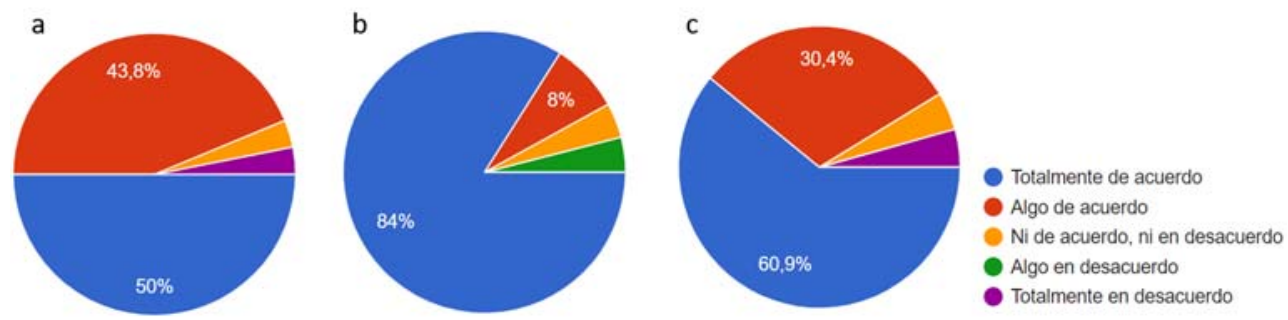

Fig. 4 Opinión del alumnado sobre sus conocimientos del manejo del software Revit tras la realización de la práctica grupal; (a) curso 18-19; (b) 19-20; y (c) 20-21 


\subsubsection{Utilidad de los comentarios del profesorado}

La figura 5 muestra la opinión de los alumnos sobre la utilidad de los comentarios proporcionados por el profesorado tras las entregas de la práctica grupal. Refleja las respuestas a la pregunta: ¿consideras que los comentarios de los profesores sobre los trabajos entregados han favorecido tu aprendizaje y te han ayudado en prácticas posteriores?

Se observa que, si se considera la suma entre las respuestas "totalmente de acuerdo" y "algo de acuerdo", la satisfacción supera el $75 \%$ en los 3 cursos académicos $(78,1 \%, 88 \%$ y $78,2 \%$, respectivamente).
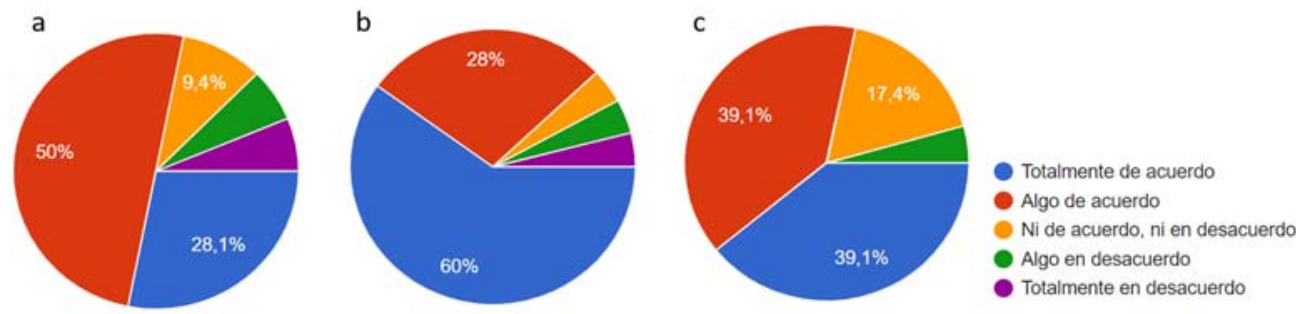

Fig. 5 Opinión del alumnado sobre la utilidad de los comentarios proporcionados por el profesorado tras las entregas de la práctica grupal; (a) curso 18-19; (b) 19-20; y (c) 20-21

\subsubsection{Utilidad de los foros en la resolución de la práctica grupal}

La figura 6 muestra la opinión de los alumnos sobre la utilidad de los foros para la solución de las dudas. Refleja las respuestas a la pregunta: ¿crees que los foros te han ayudado en la resolución de las prácticas?

Se observa que, si se considera la suma entre las respuestas "totalmente de acuerdo" y "algo de acuerdo", la satisfacción supera el $70 \%$ en los 2 primeros cursos académicos $(71,9 \%$ en 2018-2019 y $76 \%$ en 2019-2020). Sin embargo, en el curso académico 2020-2021 únicamente el $8,7 \%$ está totalmente de acuerdo (el mismo porcentaje que totalmente en desacuerdo) y el $4,3 \%$ está algo de acuerdo; adicionalmente, hay un alto porcentaje $(65,2 \%)$ que no está de acuerdo ni en desacuerdo. Se deduce de estos datos que es importante seguir fomentando el uso de los foros, año tras año, puesto que deja de ser útil en el momento en el que el alumnado no hace uso de ellos.
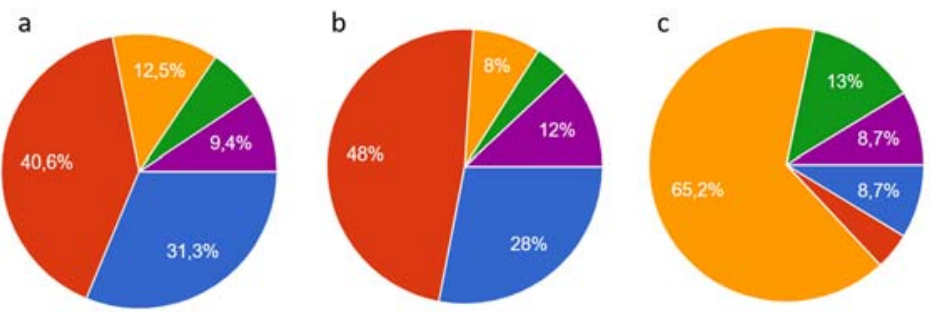

Totalmente de acuerdo

- Algo de acuerdo

Ni de acuerdo, ni en desacuerdo

- Algo en desacuerdo

- Totalmente en desacuerdo

Fig. 6 Opinión del alumnado sobre la utilidad de los foros para la resolución de dudas; (a) curso 2018-2019; (b) curso 2019-2020; y (c) curso 2020-2021 


\subsection{Calificación de las prácticas grupales}

En las siguientes figuras (7-9) se reflejan las calificaciones obtenidas por grupo, por cada año académico. Adicionalmente, en los gráficos se muestran, como área tras las barras, los integrantes del grupo indicados en el eje secundario. En el curso 2020-2021 no se disponen de datos de calificaciones de la segunda parte de la práctica grupal.

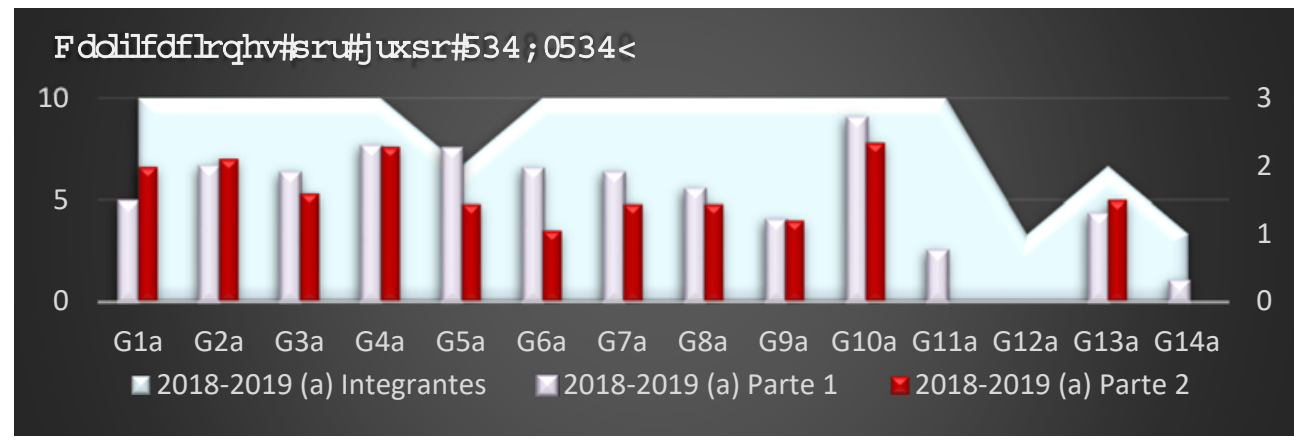

Fuente: propia

Fig. 7 Calificaciones de las 2 partes de la práctica grupal e integrantes del grupo, curso 18-19

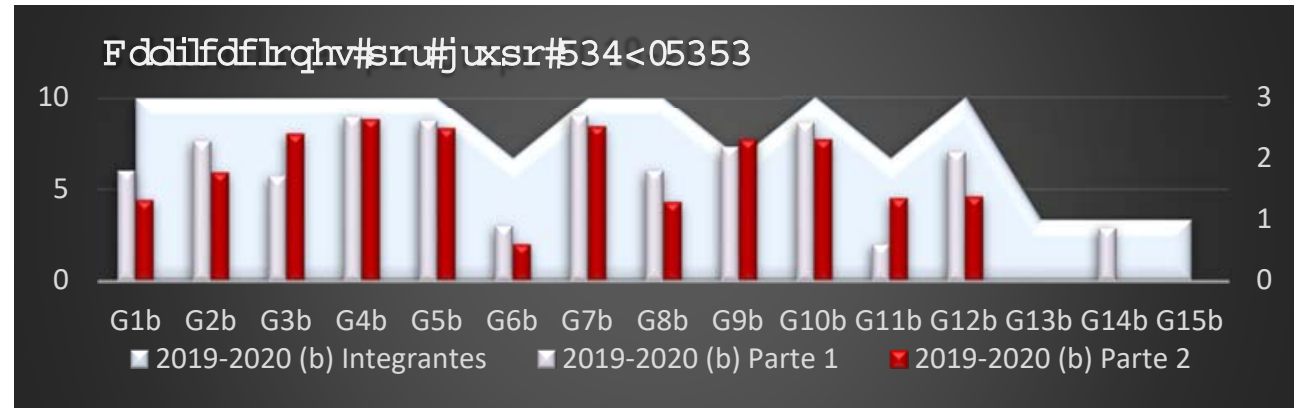

Fuente: propia

Fig. 8 Calificaciones de las 2 partes de la práctica grupal e integrantes del grupo, curso 19-20

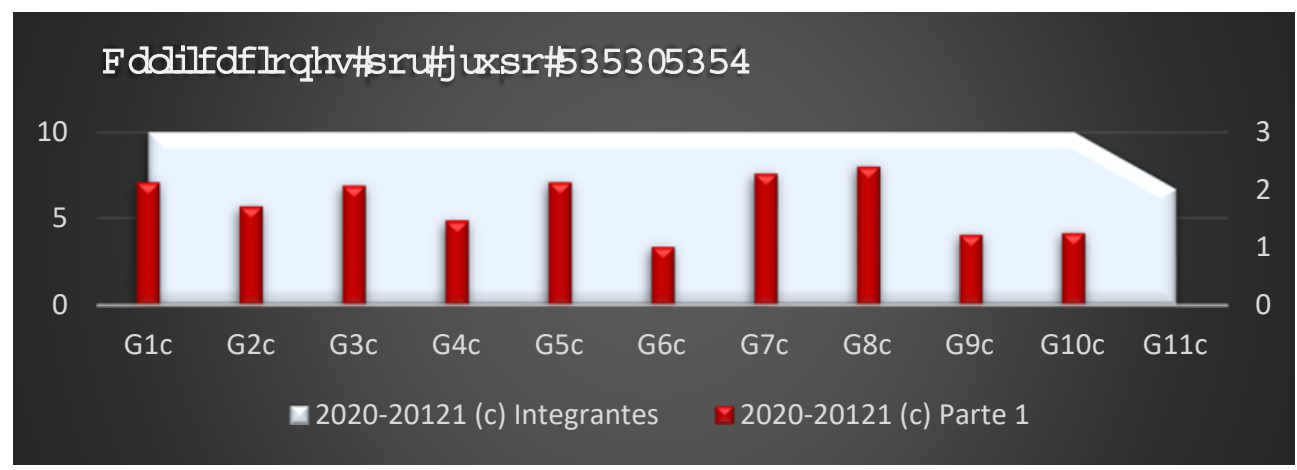

Fuente: propia

Fig. 9 Calificaciones de las 2 partes de la práctica grupal e integrantes del grupo, curso 20-21 
De los resultados obtenidos, se observa que la metodología ABP no resulta satisfactoria en aquellos grupos con un único integrante. Puesto que la calificación es, o bien inferior a 4, o bien no se ha presentado el trabajo. Por otro lado, pueden llegar a obtener buenas calificaciones los grupos formados por 2 integrantes. Sin embargo, las calificaciones más altas siempre las han obtenido los equipos de 3 integrantes.

El porcentaje de no presentados por curso académico es de $7 \%, 13,3 \%$ y $9,1 \%$ en 2018 $2019,2019-2020$ y 2020-2021, respectivamente. Por último, respecto a la tasa de éxito (aprobados/presentados) de la primera parte de la práctica es de 5,5 (2018-2019); 6,4 (20192020) y 5,9 (2020-2021). Por otro lado, la tasa de éxito de la segunda parte de la práctica es de 5,6 (2018-2019) y 5,7 (2019-2020).

\section{Conclusiones}

El presente trabajo pretende mostrar y evaluar las lecciones aprendidas tras la incorporación de la metodología ABP en la asignatura de Construcción IV del Grado en Edificación de la Universitat de les Illes Balears. Para la resolución de proyectos, se solicita el empleo del software Revit. Tras 3 cursos académicos de aplicación de esta metodología, se obtienen las siguientes conclusiones:

- Tras la realización de las prácticas, los alumnos consideran (en más de un $90 \%$ de las respestas obtenidas) que han ampliado sus conocimientos sobre el software Revit; y que mejoran sus conocimientos sobre los elementos estructurales (en más de un $75 \%$ de las respuestas obtenidas).

- Aquellos grupos con 2 o 3 integrantes obtienen mejores resultados que quienes realizan el trabajo de manera individual, siendo grupos de 3 los que han obtenido las mejores calificaciones.

- El empleo del software Revit despierta el interés del alumnado y la gran mayoría considera que, tras el curso, mejoran ampliamente sus conocimientos respecto al software.

\section{Referencias}

AHN, Y. H., CHO, C. S., \& LEE, N. (2013). "Building information modeling: Systematic course development for undergraduate construction students" en Journal of Professional Issues in Engineering Education and Practice, vol. 139, issue 4, p. 290-300.

CLEVENGER, C., GLICK, S., \& DEL PUERTO, C. L. (2012). "Interoperable Learning Leveraging Building Information Modeling (BIM) in Construction Education" en International Journal of Construction Education and Research, vol. 8, issue 2, p. 101-118.

FERREIRA, V. G., \& CANEDO, E. D. (2020). "Design sprint in classroom : exploring new active learning tools for project - based learning approach" en Journal of Ambient Intelligence and Humanized Computing, (August 2019), vol. 11, issue 3, p. 1191-1212.

FORSYTHE, P., JUPP, J., \& SAWHNEY, A. (2013). "Building Information Modelling in Tertiary Construction Project Management Education: A Programme-wide Implementation Strategy" en Journal for Education in the Built Environment, vol. 8, no 1, p. 16-34. 
JOHNSON, D. W., \& JOHNSON, R. T. (1985). "The Internal Dynamics of Cooperative Learning Groups" en Learning to Cooperate, Cooperating to Learn. Springer, Boston, MA, 1985. p. 103-124.

LEITE, F. (2016). "Project-based learning in a building information modeling for construction management course" en Journal of Information Technology in Construction, vol. 21, p. 164-176.

MAIDA, C. A. (2011). "Project-based learning: A critical pedagogy for the twenty-first century" en Policy Futures in Education, vol. 9, no 6, p. 759-768.

NEMBHARD, D., YIP, K., \& SHTUB, A. (2009). "Comparing competitive and cooperative strategies for learning project management" en Journal of Engineering Education, vol. 98, no 2, p. 181-192.

ŠADAUSKIENĖ, J., \& PUPEIKIS, D. (2018). "Review of BIM Implementation in Higher Education" en Journal of Sustainable Architecture and Civil Engineering, vol. 22, no 1.

SLAVIN, R. E. (1989). "Research on Cooperative Learning: An international perspective" en Scandinavian Journal of Educational Research, vol. 33, no 4, p. 231-243.

TSAI, M., CHEN, K., \& CHANG, Y. (2019). "Development of a Project-Based Online Course for BIM Learning" en Sustainability, vol. 11, no 20, p. 5772.

VERMA, A. K. (2011). "Impact of project based learning in Introduction to Engineering /Technology class" en ASEE Annual Conference and Exposition, Conference Proceedings.

WANG, L., \& Leite, F. (2014). "Process-oriented approach of teaching building information modeling in construction management" en Journal of Professional Issues in Engineering Education and Practice, vol. 140, no 4, p. 04014004.

WU, W., \& LUO, Y. (2016). "Pedagogy and assessment of student learning in BIM and sustainable design and construction" en Journal of Information Technology in Construction, vol. 21, no 15, p. 218-232. 


\title{
EDIFICATE
}

I Congreso de Escuelas de Edificación y Arquitectura Técnica de España València, 4 y 5 de noviembre de 2021

Escuela Técnica Superior de Ingeniería de Edificación

Universitat Politècnica de València

Doi: https://doi.org/10.4995/EDIFICATE2021.2021.13475

\section{La importancia del marcado CE para el Director de Ejecución de Obra. Aspectos destacados en la formación de los futuros profesionales.}

\section{The importance of the CE marking for the Director of Works Execution. Highlights in the teaching of future professionals.}

\author{
Susana Robles Sánchez ${ }^{a}$, María Paz Sáez Pérez ${ }^{\text {b }}$ \\ a UDC, Construcciones y Estructuras Arquitectónicas, Civiles y Aeronáuticas, Calle de la Fraga, $n^{\circ} 27$, \\ 15008, La Coruña, España, susana.robles@udc.es b UGR, Construcciones Arquitectónicas, Campus \\ Fuentenueva, c/ Severo Ochoa, s/n, 18071, Granada, España, mpsaez@ugr.es
}

\begin{abstract}
The CE marking is a system by which it is certified that construction products have certain essential characteristics that guarantee compliance with the basic requirements that works must meet during an economically reasonable period of life. The adaptation to the intended use of said products is not automatic, and requires the review of the Director of Execution of the Work, as provided by Spanish regulations.
\end{abstract}

The Building Planning Law and the Building Technical Code are the provisions that regulate the responsibilities of the Director of Work Execution in the field of quality control, within which the mandatory CE marking is framed.

The aim of this communication is to inform future professionals of the tasks that the Director of Execution of the Work must carry out when a construction product must bear the CE marking, establishing a procedure that facilitates the revision task imposed by the regulations.

The agents involved in the process define everything related to the essential characteristics that the manufactured product must have, and the Director of Work Execution is, in turn, responsible for checking that these characteristics meet those required in the building project. in which the product will be integrated.

Not always all the elements are available to carry out this task.

Keywords: CE marking, Director of Work Execution, construction products, quality control, professional attributions. 


\section{Resumen}

El marcado CE es un sistema por el cual se certifica que los productos de construcción poseen determinadas características esenciales que garantizan el cumplimiento de los requisitos básicos que las obras deben cumplir durante un período de vida económicamente razonable. La adecuación al uso previsto de dichos productos no es automática, y precisa de la revisión del Director de Ejecución de la Obra, tal y como lo dispone la reglamentación española.

La Ley de Ordenación de la Edificación y el Código Técnico de la Edificación son las disposiciones que regulan las responsabilidades del Director de Ejecución de la Obra en el campo del control de calidad, dentro del que se enmarca el preceptivo marcado CE.

El objetivo de esta comunicación es dar a conocer a los futuros profesionales las labores que debe realizar el Director de Ejeucción de la Obra cuando un producto de construcción debe ostentar el marcado CE, estableciendo un procedimiento que facilite la tarea de revisión impuesta por la reglamentación.

Los agentes implicados en el proceso definen todo lo relativo a las características esenciales que debe poseer el producto fabricado, y el Director de Ejecución de la Obra es, a su vez, el responsable de cotejar que dichas características alcanzan las requeridas en el proyecto de edificación en el que se vaya a integrar el producto.

No siempre se dispone de todos los elementos para realizar dicha tarea.

Palabras clave: marcado CE, Director de Ejecución de Obra, productos de construcción, control de calidad, atribuciones profesionales. 


\section{Introducción}

La comprobación de la idoneidad de los productos usados en las obras de construcción ha sido históricamente una responsabilidad asignada a la profesión del Aparejador (hoy Arquitectura Técnica) legalmente establecida desde el Decreto de 16 de julio de 1935, de Regulación de las atribuciones de la carrera de Aparejador (Gaceta de Madrid, 1935), hasta la vigente Ley 38/1999, de 5 de noviembre, de Ordenación de la Edificación (en adelante LOE) (LOE, 1998). Es por ello que la formación en materia de control de calidad y, específicamente de las actuaciones a llevar a cabo por el Director de Ejecución de la Obra (en adelante DEO) frente a productos que ostenten el marcado CE, es de vital importancia para los futuros arquitectos técnicos, debiendo tener conocimiento tanto de la teoría como de la práctica.

Garantizar la idoneidad de los productos fabricados o de los importados de otros países, para su incorporación a la obra, así como las responsabilidades derivadas de los posibles perjuicios causados por una fabricación deficiente, obliga - necesariamente - a normalizar las especificaciones que los productos deben cumplir de forma que se garantice la seguridad y salud del usuario, de lo que se derivan otros factores vitales como son el libre comercio y, por lo tanto, la competitividad y mejora de la calidad de los productos utilizados.

La norma ISO 9000:2015 (AENOR, 2015) define calidad como: "grado en el que un conjunto de características inherentes a un objeto (producto, servicio, proceso, persona, organización, sistema o recurso) cumple con los requisitos», pudiéndose ampliar esta definición estableciendo el concepto de calidad como el grado de cumplimiento del conjunto de prestaciones que debe reunir un bien o servicio para satisfacer las necesidades del usuario durante su vida útil prevista, lo que conlleva, necesariamente, la acreditación del cumplimiento de las citadas prestaciones.

Por otra parte con la creación de la Unión Europea (UE en adelante) se pretendió, entre otros objetivos, la implantación de un libre mercado de forma que cualquier fabricante de productos de construcción (no necesariamente de la UE) pudiera comercializar sus productos en todo el territorio de la UE, siempre que éstos cumplieran determinados requisitos. Esto implicó, además de la eliminación de las fronteras entre los Estados Miembros, consensuar determinados requisitos esenciales para los productos de construcción que garantizaran el cumplimiento de los requisitos básicos que las obras deben cumplir durante un período de vida económicamente razonable. Esto se materializó mediante la armonización de las disposiciones técnicas en todo el territorio europeo mediante la creación de "normas armonizadas", un procedimiento que permitiera evaluar la conformidad de los productos fabricados a través de un sistema de evaluación de la conformidad certificado, y una estructura de vigilancia del mercado constituyendo, todo ello, el sistema del marcado CE, tal y como se esquematiza en la figura 1. 


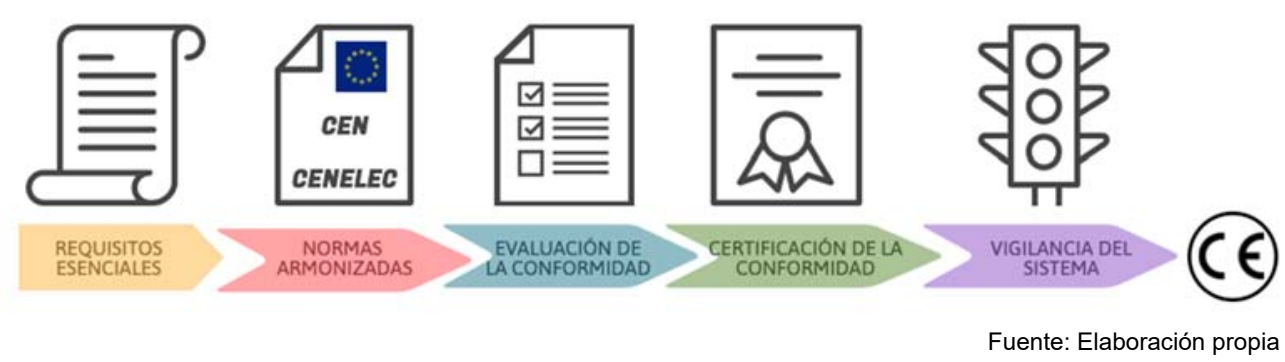

Fig. 1 Funcionamiento del sistema del marcado CE en los productos de construcción

Actualmente existen aproximadamente unas 500 familias de productos de construcción sujetas a normas armonizadas, cuyos fabricantes están obligados a seguir el procedimiento establecido que los productos resultantes ostenten el marcado CE.

La puesta en marcha del marcado CE implica a varios agentes que tienen que completar una serie de pasos para que finalmente el marcado CE cumpla su cometido: garantizar que las características esenciales que posee el producto, y que aparecen plasmadas en la preceptiva documentación que acompañará al producto, son las adecuadas para el uso previsto en el proyecto de edificación.

Como ya se ha indicado, el DEO es responsable dentro de sus atribuciones profesionales de comprobar la adecuación al uso de los productos con marcado CE recibidos en la obra, lo que comporta tener conocimiento del reglamento y de las tareas a realizar en el ámbito profesional.

Estas cuestiones relacionadas con la adecuación al uso y al cumplimiento de las prestaciones de los productos de construcción, entre las que se incluye todo lo relacionado con el marcado $\mathrm{CE}$, es materia fundamental de los planes de estudios de los grados habilitantes para ejercer la profesión de arquitecto técnico, siendo por lo tanto contenido que se puede impartir en las asignaturas del grado relacionadas tanto con los materiales de construcción como con las de control de calidad.

\section{Reglamentación específica relacionada con el marcado CE para el DEO}

Son varias las disposiciones en España que regulan las atribuciones del DEO relacionadas con las labores de control de calidad del proceso edificatorio y que afectan en su mayoría a la figura del DEO. De hecho, la LOE define al DEO como -art. 13.1-: «El director de la ejecución de la obra es el agente que, formando parte de la dirección facultativa, asume la función técnica de dirigir la ejecución material de la obra y de controlar cualitativa y cuantitativamente la construcción y la calidad de lo edificado», estableciendo que, para todas las obras de edificación -art. 2- en las que sea preceptiva la presencia del DEO, será obligación de éste, entre otras, art. 13.2.b: «Verificar la recepción en obra de los productos de construcción, ordenando la realización de ensayos y pruebas precisas" y art. 13.2.f: 
"Colaborar con los restantes agentes en la elaboración de la documentación de la obra ejecutada, aportando los resultados del control realizado».

Es el Código Técnico de la Edificación (en adelante CTE) (CTE, 2006), en el artículo 5.2.1 el que determina que: «Los productos de construcción que se incorporen con carácter permanente a los edificios, en función de su uso previsto, llevarán el marcado CE, de conformidad con la Directiva 89/106/CEE de productos de construcción, transpuesta por el Real Decreto 1630/1992 de 29 de diciembre, modificado por el Real Decreto 1329/1995 de 28 de julio, y disposiciones de desarrollo, u otras Directivas europeas que les sean de aplicación». Como se puede observar, todavía no se ha realizado la actualización del articulado del CTE, sustituyendo el ya derogado Real Decreto 1630/1992, trasposición de la derogada Directiva de Productos de la Construcción (DPC, 1989), por el vigente Reglamento de Productos de Construcción (en adelante RPC) (RPC, 2011).

Respecto a la forma de proceder, en el artículo 7.1.2 del CTE se indica que durante la construcción de la obra se elaborará la «documentación de la obra», que incluirá Documentación del Control de la obra, la cual está definida en el Anejo II.2:

«1. El control de calidad de las obras realizado incluirá el control de recepción de productos, los controles de la ejecución y de la obra terminada. Para ello:

a. el director de la ejecución de la obra recopilará la documentación del control realizado, verificando que es conforme con lo establecido en el proyecto, sus anejos y modificaciones;

b. el constructor recabará de los suministradores de productos y facilitará al director de obra y al director de la ejecución de la obra la documentación de los productos anteriormente señalada así como sus instrucciones de uso y mantenimiento, y las garantías correspondientes cuando proceda; y

c. la documentación de calidad preparada por el constructor sobre cada una de las unidades de obra podrá servir, si así lo autorizara el director de la ejecución de la obra, como parte del control de calidad de la obra.»

Por lo tanto el constructor deberá requerir al suministrador la documentación de los productos de construcción que sea preceptiva, dentro de la que estará, en el caso de que el producto esté regulado por una norma armonizada, la del marcado CE. El constructor, para reclamar dicha documentación, se puede acoger al artículo 7.2.1.1.c del CTE, que dice lo siguiente: «Los suministradores entregarán al constructor, quien los facilitará al director de ejecución de la obra, los documentos de identificación del producto exigidos por la normativa de obligado cumplimiento y, en su caso, por el proyecto o por la dirección facultativa. Esta documentación comprenderá, al menos, los siguientes documentos:

a) los documentos de origen, hoja de suministro y etiquetado;

b) el certificado de garantía del fabricante, firmado por persona física; y

c) los documentos de conformidad o autorizaciones administrativas exigidas reglamentariamente, incluida la documentación correspondiente al 
marcado CE de los productos de construcción, cuando sea pertinente, de acuerdo con las disposiciones que sean transposición de las Directivas Europeas que afecten a los productos suministrados.»

Por último respecto a las resposabilidades del DEO, por el Anejo II.2.2 del CTE: "Una vez finalizada la obra, la documentación del seguimiento del control será depositada por el director de la ejecución de la obra en el Colegio Profesional correspondiente o, en su caso, en la Administración Publica competente, que asegure su tutela y se comprometa a emitir certificaciones de su contenido a quienes acrediten un interés legítimo."

\section{Objetivos}

La reglamentación citada en el anterior apartado establece cuáles son las funciones del DEO respecto al control de calidad de los productos de construcción recepcionados en la obra, que, entre otras, implica que el DEO deberá revisar la documentación que acompaña a los productos de construcción que se incorporen a la obra para comprobar si cumplen los requisitos que deberán estar indicados en el preceptivo Plan de Control de Calidad de la Obra (Anejo I, Memoria I, Anejos a la Memoria del CTE).

Respecto a la recepción de productos, dentro de la documentación que debe acompañar a la que se incorpore permanentemente a la obra, está la particularidad de los productos que ostenten el marcado $\mathrm{CE}$, que merecen un análisis en detalle.

Los objetivos propuestos en esta comunicación son dos:

En primer lugar, desde el punto de vista académico y de formación, dar a conocer a los futuros profesionales la necesidad de adquirir los conocimentos de los procedimientos establecidos para dar cumplimiento a la recepción de los productos con marcado CE, así como todo lo relacionado con la aplicación práctica y con las responsabilidades resultantes.

Y en segundo lugar, desde el punto de vista profesional, analizar las labores que debe realizar el DEO cuando se recepciona en la obra un producto de construcción debe ostentar el marcado $\mathrm{CE}$, estableciendo un procedimiento que facilite la tarea de revisión impuesta por la reglamentación.

\section{Procedimiento del marcado CE}

El proceso del marcado CE de los productos de construcción, regulado por el RPC, contiene varias etapas, comenzando por la fabricación del producto en sí, durante la cual el fabricante deberá seguir una serie de procedimientos y documentarlos, declarando las características técnicas resultantes a través de la Declaración de Prestaciones (en adelante DdP) y colocando el marcado CE en el producto. Paralelamente, el proyectista deberá indicar en el proyecto cuáles son las características técnicas exigidas a cada producto para el uso para el que haya sido destinado, puesto que, dependiendo del uso, el mismo producto podrá poseer diferentes características. Una vez finalizada la redacción del proyecto y comenzada la obra, el DEO deberá verificar que el producto de construcción que el contratista ha comprado 
cumple con los requisitos indicados en el proyecto, por lo que deberá contrastar las características técnicas indicadas en el proyecto con la Declaración de Prestaciones que debe acompañar al producto de construcción y que el contratista tendrá que entregarle. Finalmente, el DEO deberá depositar en su Colegio Profesional la documentación resultante del seguimiento del control de la obra, de forma que éste pueda emitir certificaciones de su contenido. Todo el proceso se resume en la figura 2:

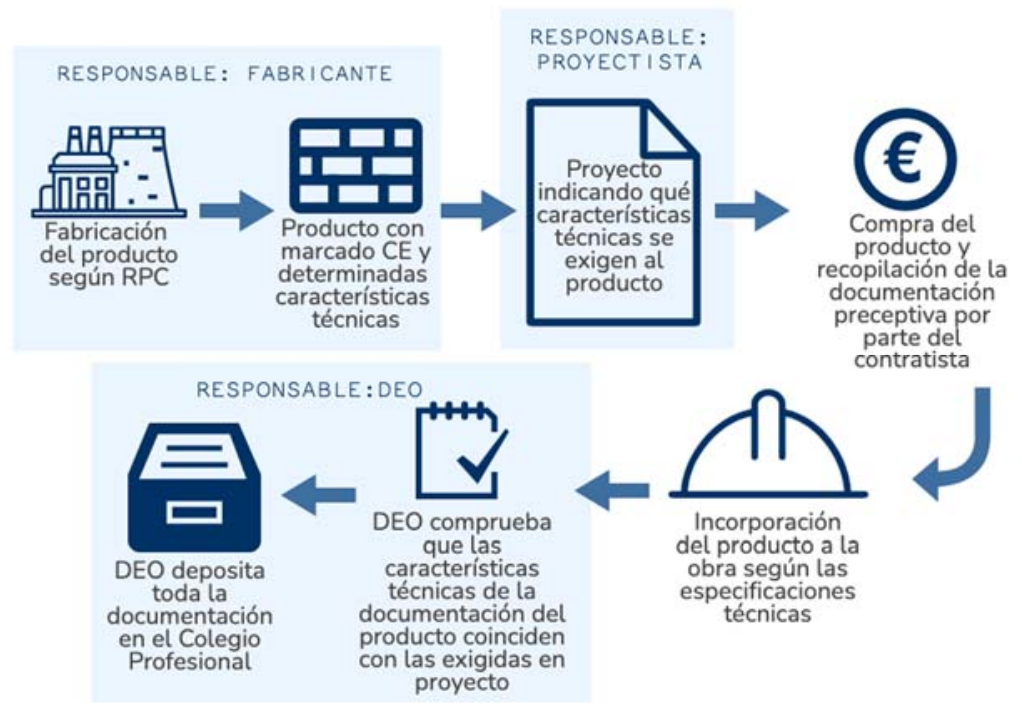

Fuente: Elaboración propia

Fig. 2 Procedimiento a seguir por el DEO para productos que deban ostentar marcado CE

El proceso de fabricación de los productos de construcción y su control será diferente según lo indique la norma armonizada que afecte al producto de construcción, de forma que hay procesos que deben ser más exigentes que otros. EI RPC, con la modificación introducida por el Reglamento Delegado (UE) № 568/2014, especifica cuáles son los sistemas de evaluación y verificación de la constancia de las prestaciones, en base a los que el fabricante redactará la preceptiva Declaración de Prestaciones (según el Reglamento Delegado (UE) $n^{\circ}$ 574/2014). Existen actualmente cinco sistemas de evaluación y verificación de la constancia de las prestaciones, que se resumen en la siguiente figura: 


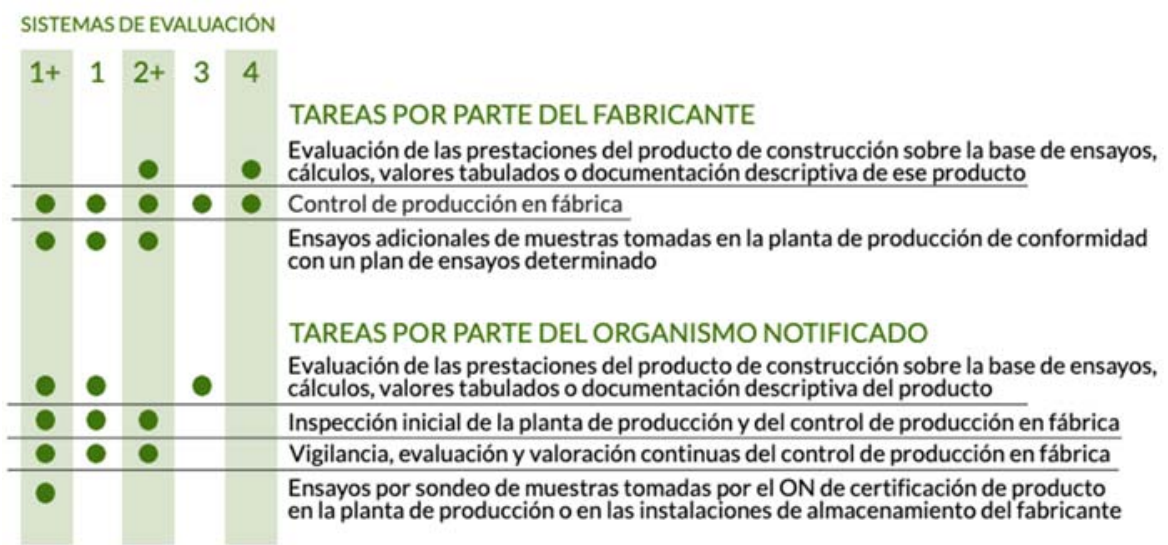

Fuente: Elaboración propia

Fig. 3 Sistemas de Evaluación y Verificación de la constancia de las prestaciones según el vigente RPC

El sistema de marcado CE implica que el fabricante deberá, dependiendo del Sistema de Evaluación indicado en la norma armnonizada al que esté sometido el producto a fabricar, contratar en algunos casos organismos externos -llamados Organismos Notificados, ON- que deberán ser ajenos al fabricante y estar certificados por la ENAC, para realizar las correspondientes tareas.

Una vez evaluadas las características esenciales del producto concreto que el fabricante desee declarar y documentados los resultados, éste deberá recopilar y custodiar toda la documentación resultante del proceso denominada "documentación técnica". Al cliente se le entregará la siguiente documentación (Artículo 11.6 del RPC), resumida en la figura 4:

- Declaración de prestaciones del producto

- Marcado CE del producto e información asociada al mismo

- Instrucciones e información sobre seguridad (sólo si procede)

- Información sobre sustancias peligrosas (sólo si procede)

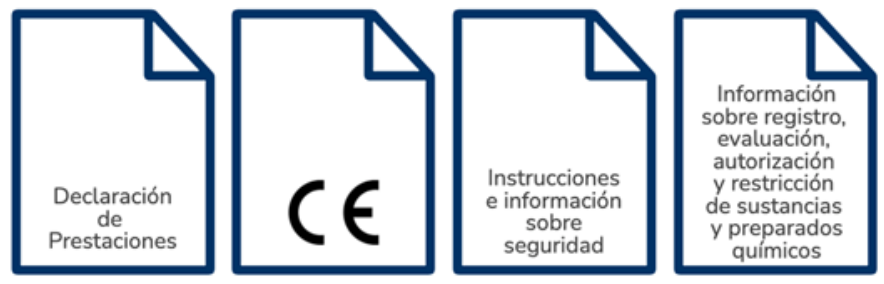

Fuente: Elaboración propia.

Fig. 4 Documentación preceptiva que el fabricante deberá entregar al cliente. 
La responsabilidad de redactar la DdP es del fabricante, que se ceñirá al Reglamento Delegado (UE) N $N^{\circ} 574 / 2014$ de La Comisión, en donde se detalla el modelo utilizado para emitir la DdP. Esta versión se publicará en el idioma oficial del país donde el producto se vaya a comercializar (Artículo 7.4 del RPC), y se deberá mantener durante diez años que contarán tras la puesta en venta del producto. Podrá estar disponible gratuitamente para su descarga a través de una página web (según el Reglamento Delegado (UE) N N 157/2014 de La Comisión) o el cliente la puede solicitar en papel (Artículo 7.1 y 7.2 del RPC).

Tomando como base la DdP, el fabricante elaborará la etiqueta del marcado CE, cuyo contenido se detalla en el artículo 9 del RPC, que se deberá colocar en un lugar visible, siendo legible e indeleble. El marcado se colocará siempre antes de la introducción del producto en el mercado (Artículo 9.3 del RPC).

Toda esta documentación deberá acompañar al producto desde su salida de fábrica hasta la entrega final de la obra, que quedará en manos del usuario final de la construcción.

\section{Actuación del DEO}

Como consecuencia del proceso, el DEO deberá:

Comprobar si, en el Plan de Control de Calidad del Proyecto de Edificación de la obra que dirigirá, hay productos que estén regulados por el marcado CE. En caso de que no exista dicho Plan, deberá comprobar en el Pliego de Condiciones Técnicas Particulares qué productos intervienen en la obra, y verificará cuáles están regulados por una norma armonizada. Para comprobarlo, deberá acceder a la página oficial de La Comisión Europea (https://ec.europa.eu/docsroom/documents/38863) en donde se puede consultar el listado actualizado (a fecha noviembre de 2019) de los productos que están regulados por norma armonizada.

Una vez localizados, deberá solicitar al contratista que le entregue la documentación que éste debe haber recopilado del suministrador. La documentación debe ser la indicada en le anterior apartado, dentro de la cual, la más relevante es la DdP.

Antes de la colocación del producto en la obra, el DEO deberá confirmar que las características técnicas contenidas en la DdP de dicho producto se cumplen los valores exigidos en el Plan de Control de Calidad del proyecto de edificación y la reglamentación nacional. Una vez comprobado, el producto se aceptará, la documentación se archivará y el producto podrá colocarse en obra.

En cualquier caso, hay que comprobar los valores exigidos, tanto en la reglamentación como en el proyecto, con los declarados en el marcado CE. Puede darse el caso de que un valor exigido por la reglamentación nacional no haya sido ensayado por el fabricante y su valor aparezca como NPD ("No Performance Determined" o prestación no determinada, según se detalla con posterioridad) En este caso, el producto no debería admitirse pudiéndose, a juicio de la Dirección Facultativa, solicitar la determinación de esa característica mediante algún 
otro procedimiento. Por ejemplo, en el caso de la resbaladicidad, característica exigida por el Documento Básico de Seguridad de Utilización y Accesibilidad del CTE (sección 1), no suele estar contemplada entre las características técnicas de la DdP de los productos de solados.

Finalmente el DEO deberá depositar toda la documentación recopilada, junto con la restante concerniente al control de calidad, en su colegio profesional para que éste pueda emitir certificaciones a quien acredite un interés legítimo.

\section{Conclusiones}

La formación actual de los futuros titulados debe incluir tanto los conocimientos teóricos como aquellos aspectos prácticos relacionados con el desarrollo real de la profesión, lo que implica conocer previamente las labores que como DEO deben ejercer durante su vida profesional. Esto obliga al conocimiento de la realidad de la obra, por lo que en esta ponencia se han puesto de manifiesto los aspectos más destacados de la parte del proceso que el DEO debe desarrollar respecto de los materiales que ostenten marcado CE que sean recepcionados en la obra.

En relación con esa realidad profesional, es sabido que no siempre el proyecto de edificación contiene el preceptivo Plan de Control de Calidad, lo que complica la tarea de localicación de productos que estén regulados por norma armonizada y por lo tanto con marcado CE. Por lo tanto, el DEO se verá obligado a consultar en la página oficial de la UE para localizar cuáles de los productos están sometidos a normas armonizadas.

Resulta extremadamente difícil y laborioso recopilar toda la documentación de estos productos con marcado CE, que muchas veces los contratistas no poseen porque ni siquiera el suministrador se la ha facilitado. Toda la que el contratista haya recopilado se la entregará al DEO, y no siempre antes de la colocación del producto.

Una vez conseguida la documentación, el DEO deberá cotejar que las características técnicas que contiene la DdP del producto sean las requeridas tanto en el proyecto de edificación como las de la reglamentación nacional, de forma que pueda recepcionar el producto correctamente. Aunque la documentación exista, muchas veces no se encuentran las características exigidas en el proyecto de edificación, por lo que hay que recurrir a reglamentación nacional y comprobar que el producto es válido.

Para que la recepción sea válida y el producto se pueda incorporar a la unidad de obra correspondiente, esta comprobación debería realizarse siempre antes de la incorporación del producto a la obra, pues de otro modo, el rechazo o sustitución del producto será harto complicada o imposible. Si la comprobación se realiza a posteriori se invalida todo el sistema.

Las tareas que implica el sistema redundarían en una presencia prácticamente constante del DEO en la obra, lo que no está contemplado en los honorarios o tiempos que se manejan en la obra realmente. 
Tratando de aportar soluciones, en algunos colegios profesionales, para velar por el cumplimiento de la ley, requieren al DEO el depósito previo de la documentación del control de obra para poder expedir el Certificado Final de Obra.

Todo lo comentado permite confirmar que el proceso conforma conocimientos fundamentales que derivan en responsabilidades que recaen exclusivamente en los profesionales de la arquitectura técnica, $y$, tanto el conocimiento del proceso como su aplicación en la obra debe formar parte del aprendizaje y de la formación académica de los estudiantes de los grados habilitantes para la profesión de arquitectura técnica.

\section{Referencias}

\section{Legislación y normas}

España. CTE. Real Decreto 314/2006, de 17 de marzo, por el que se aprueba el Código Técnico de la Edificación. BOE, 28 de marzo de 2006, núm. 74, p. 11816-11831.

España. ENAC. Real Decreto 1715/2010, de 17 de diciembre, por el que se designa a la Entidad Nacional de Acreditación (ENAC) como organismo nacional de acreditación de acuerdo con lo establecido en el Reglamento (CE) n $n^{\circ}$ 765/2008 del Parlamento Europeo y el Consejo, de 9 de julio de 2008, por el que se establecen los requisitos de acreditación y vigilancia del mercado relativos a la comercialización de los productos y por el que se deroga el Reglamento (CEE) n 339/93. BOE, 8 de enero de 2011, núm.7, p. 1670-1673.

España. ISO 9000:2015, Sistemas de gestión de la calidad, fundamentos y vocabulario. AENOR, septiembre de 2015.

España. LOE. Ley de Ordenación de la Edificación. BOE, 6 de noviembre de 1999, núm. 266, p. 3892538934.

España. Decreto 16 de julio de 1935 de Regulación de las atribuciones de la carrera de aparejador. Gaceta de Madrid, 18 de julio de 1935.

Unión Europea. DPC. Directiva 89/106/CEE del Consejo de 21 de diciembre de 1988 relativa a la aproximación de las disposiciones legales, reglamentarias y administrativas de los Estados Miembros sobre los productos de construcción. DOCE, 11 de febrero de 1989, nújm. L40.

Unión Europea. Reglamento Delegado (UE) No 568/2014 DE LA COMISIÓN de 18 de febrero de 2014 por el que se modifica el anexo V del Reglamento (UE) no 305/2011 del Parlamento Europeo y del Consejo en lo relativo a la evaluación y verificación de la constancia de las prestaciones de los productos de construcción. DOUE, 27 de mayo de 2014, núm. L157/76.

Unión Europea. Reglamento Delegado (UE) No 574/2014 DE LA COMISIÓN de 21 de febrero de 2014 que modifica el anexo III del Reglamento (UE) no 305/2011 del Parlamento Europeo y del Consejo en lo relativo al modelo que debe utilizarse para emitir una declaración de prestaciones de productos de construcción. DOUE, 28 de mayo de 2014, núm. L159/41.

Unión Europea. RPC. Reglamento (UE) n ³05/2011 del Parlamento Europeo y del Consejo, de 9 de marzo de 2011, por el que se establecen condiciones armonizadas para la comercialización de 
productos de construcción y se deroga la Directiva 89/106/CEE del Consejo. DOUE, 4 de abril de 2011, núm. L88/5.

\section{Páginas web}

EUROPEAN COMMISSION. Regulation (EU) No 305/2011 for Construction Products - Summary list as pdf document. < https://ec.europa.eu/docsroom/documents/38863> [Consulta: 9 de junio de 2021] 


\title{
EDIFİCATE
}

I Congreso de Escuelas de Edificación y Arquitectura Técnica de España València, 4 y 5 de noviembre de 2021

Escuela Técnica Superior de Ingeniería de Edificación

Universitat Politècnica de València

Doi:https://doi.org/10.4995/EDIFICATE2021.2021.13497

\section{Estrategias docentes en el proceso de enseñanza y aprendizaje sobre sostenibilidad en el Grado en Arquitectura Técnica de la Universidad de Burgos}

\section{Strategies in teaching and learning process on sustainability in the Degree in Technical Architecture of the University of Burgos}

\author{
Javier Garabito López ${ }^{\mathrm{a}}$, Ángel Rodríguez Saiz ${ }^{\mathrm{b}}$, Verónica Calderón Carpinteroc, Sara \\ Gutiérrez González $^{\mathrm{d}}$, Francisco Fiol Oliváne y Carmelo Muñoz Ruipérez ${ }^{\mathrm{f}}$ \\ Departamento de Construcciones Arquitectónicas e Ingeniería de la Construcción y del Terreno, \\ Escuela Politécnica Superior de la Universidad de Burgos \\ a jgarabito@ubu.es, barsaizmc@ubu.es, cvcalderon@ubu.es, ${ }^{\mathrm{d}}$ sggonzalez@ubu.es, effiol@ubu.es y \\ 'cmruip@ubu.es
}

\begin{abstract}
The University of Burgos faced the 2010-2011 academic year the challenge of starting a new Degree in Technical Architecture, which was the adaptation of the technical architecture studies in Spain according to Bologna System. One of the goals was to introduce sustainability criteria in this academic qualification, so new subjects were taught: Sustainable Construction and Energy Efficiency. As a novelty the programs of these subjects include such important topics as: Life Cycle Assessment, Sustainability Assessment Tools, sustainability criteria... This new approach to the studies has not limited only to the new subjects. Materials Fundamentals, as an example, raise new issues, such as waste management or recycling. A methodology used in Sustainable Construction is the cooperative teaching-learning method, through the critical study of existing sustainable buildings to later transform a conventional building into a sustainable one.
\end{abstract}

Keywords: Teaching methodology, skills, cooperative work, sustainability, Sustainable Construction, Materials

\section{Resumen}

La Universidad de Burgos afrontó el curso 2010-2011 el reto de iniciar un nuevo Grado en Arquitectura Técnica, que consistía en la adecuación de los estudios de Arquitectura Técnica en España según el Sistema de Bolonia. Uno de los objetivos era introducir criterios de sostenibilidad en esta titulación académica, por lo que se impartieron nuevas materias: Construcción Sostenible y 
Estrategias docentes en el proceso de enseñanza y aprendizaje sobre sostenibilidad en el Grado en Arquitectura Técnica de la Universidad de Burgos - Strategies in teaching and learning process on sustainability in the Degree in Technical Architecture of the University of Burgos

Eficiencia Energética. Como novedad los programas de estas asignaturas incluyen temas tan importantes como: Evaluación del Ciclo de Vida, Herramientas de Evaluación de la Sostenibilidad, criterios de sostenibilidad ... Este nuevo enfoque de los estudios no se ha limitado solo a las nuevas asignaturas. Fundamentos de los Materiales, por ejemplo, plantea nuevos contenidos, como la gestión de residuos o el reciclaje. En la asignatura de Construcción Sostenible como metodología se emplea el método de enseñanza-aprendizaje cooperativo, mediante el estudio crítico de edificios sostenibles existentes para, posteriormente, transformar un edificio convencional en uno sostenible.

Palabras clave: Metodología docente, competencias, trabajo cooperativo, sostenibilidad, Construcción Sostenible, Materiales. 


\section{Implantación del concepto de sostenibilidad en el Grado en Arquitectura Técnica.}

\subsection{Antecedentes}

Los estudios de Arquitectura Técnica de la Universidad de Burgos tienen una larga tradición universitaria, ya que la escuela es una de las más antiguas de España. Los estudios de Aparejadores se iniciaron en Burgos el curso académico 1962-1963, dependiendo de la Escuela Técnica Superior de Arquitectura de Madrid.

El 26 de mayo de 1994 se crea la Universidad de Burgos, mediante la Ley 12/94. De este modo, estos estudios universitarios pertenecen a la Universidad de Burgos desde ese año.

La Escuela Politécnica Superior de la Universidad de Burgos se crea en 1998 (RD 210/98 BOCy L. 6 oct. 6) como transformación de la Escuela Politécnica.

El 19 de junio de 1999, 29 ministros de educación europeos firmaron la Declaración de Bolonia, que da el nombre al proceso y en el que se basan los fundamentos del Espacio Europeo de Educación Superior (EEES).

En el año 2004 la Agencia Nacional de Evaluación de la Calidad y Acreditación, ANECA, crea el Libro Blanco del título universitario de Grado en Ingeniería de Edificación - Grsdo en Arquitectura Técnica, estableciendo una estructura de primer nivel o Grado de cuatro cursos lectivos anuales de 240 ECTS.

\subsection{El Grado en Arquitectura Técnica.}

Con el proceso de convergencia europea se propuso adaptar la titulación al Grado en Arquitectura Técnica, siguiendo las directrices de Bolonia. En la Universidad de Burgos aprovechamos la necesidad de la acreditación para renovar y actualizar los programas con el fin de adaptarlos a las necesidades del mundo profesional, más competitivo y en constante cambio.

Entre las nuevas competencias que se recogen en la memoria para la verificación del título podemos destacar:

- Gestionar las nuevas tecnologías edificatorias y participar en los procesos de gestión de la calidad en la edificación.

- Realizar análisis, evaluaciones y certificaciones de eficiencia energética, así como estudios de sostenibilidad en los edificios.

- Dirigir y gestionar el uso, conservación y mantenimiento de los edificios, redactando los documentos técnicos necesarios;

- Elaborar estudios del ciclo de vida útil de los materiales, sistemas constructivos y edificios.

- Gestionar el tratamiento de los residuos de demolición y de la construcción. 
Y como nuevas Competencias Específicas:

- Capacidad para el análisis del ciclo de vida útil de los elementos y sistemas constructivos.

- Conocimiento de la evaluación del impacto ambiental de los procesos de edificación y demolición, sostenibilidad en edificación y de los procedimientos y técnicas para evaluar la eficiencia energética de los edificios.

- Procedimientos y técnicas para evaluar la eficiencia energética de los edificios.

- Conocimiento y aplicaciones de las Energías Renovables aplicadas a la Edificación que se establecen en el artículo 15 de la Parte I del Código Técnico de la Edificación y de otras fuentes de Energías Renovables innovadoras aplicadas a la Edificación.

Así, uno de los objetivos de la adaptación de la titulación fue introducir criterios de sostenibilidad (Edwards, 2008) para el Grado, de modo que se ofertaron dos nuevas asignaturas: Construcción Sostenible y Eficiencia Energética.

La introducción de la Asignatura de Eficiencia Energética, de 3 créditos ECTS, en el Plan formativo de la Titulación del Grado en Arquitectura Técnica, ha supuesto un cambio cualitativo en la formación del profesional Arquitecto Técnico, dotándole de conocimiento relativo a los aspectos de demanda energética de los edificios y capacidad de decisión para aportar soluciones que fomenten el ahorro energético a través de soluciones de rentabilidad energética, introduciendo criterios de arquitectura bioclimática en las fases de diseño, ejecución y uso de los edificios.

La asignatura de Construcción Sostenible se analiza en el apartado 2.

Este nuevo enfoque en la titulación no se ha limitado a estas nuevas asignaturas, ya que las asignaturas tradicionales desarrollan competencias directamente relacionadas con la sostenibilidad. Las disciplinas de materiales de construcción consideran la sostenibilidad ambiental como un valor a fomentar.

El curso Fundamentos de los Materiales, figura 1, ha incorporado la Unidad Docente Impacto Ambiental, Gestión y Residuos de los Materiales de Construcción. Su ubicación como última Unidad Docente en la asignatura responde a que los alumnos ya tienen una noción general del concepto de material de construcción y esta Unidad aporta conocimiento sobre aspectos de sostenibilidad que después podrán aplicar en materiales más avanzados estudiados en asignaturas de cursos superiores. 


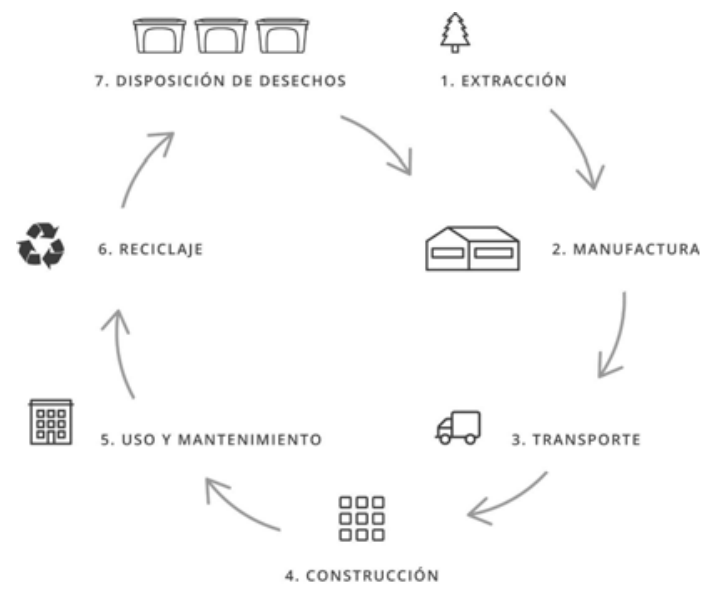

Fig. 1 Fundamentos de Materiales, un ejemplo de presentación

El sector de la Edificación en Europa y en España es responsable de gran parte de la contaminación atmosférica y de aproximadamente el $25 \%$ - $30 \%$ de los residuos de la industria en general. La construcción de los edificios comporta unos impactos ambientales por el uso de materiales que provienen de recursos naturales, la utilización de grandes cantidades de energía tanto en la construcción como a lo largo de su vida y el impacto ocasionado en el emplazamiento. El material, fuertemente manipulado, utilizado en el campo de la construcción tiene unos efectos medioambientales muy importantes, con un gasto muy elevado de energía. No se pueden olvidar los costes ecológicos que suponen tanto la extracción de los recursos minerales (canteras, minas, etc.) como la deposición de los residuos originados, en la construcción o en el derribo, que abarcan desde las emisiones tóxicas al envenenamiento de las aguas subterráneas por parte de los vertedores.

El reciclaje y la reutilización de los residuos de demolición y de la construcción es una solución que mitigará el importante impacto ambiental que genera el vertido y la incineración. La aplicación de los criterios de sostenibilidad y de una utilización racional de los recursos naturales disponibles en la construcción requerirá realizar unos cambios importantes en los valores que ésta tiene como cultura propia. Estos criterios o, más correctamente, principios de sostenibilidad llevarán hacia una conservación de los recursos naturales, una maximización en la reutilización de los recursos, una gestión del ciclo de vida, así como reducciones de la energía utilizada.

\section{La asignatura de Construcción Sostenible}

La Asignatura de Construcción Sostenible, de 3 créditos ECTS, aparece por primera vez en los estudios del Grado en Arquitectura Técnica de la Universidad de Burgos con la adaptación del Plan de Estudios a Bolonia. 
En el programa de Construcción Sostenible se enseñaron por primera vez en Arquitectura Técnica conceptos tan relevantes como: análisis del ciclo de vida, herramientas para evaluar la sostenibilidad como LEED, BREEAM o VERDE, criterios de sostenibilidad, ...

Las competencias específicas que deben adquirir los alumnos en esta asignatura son:

- ETE.04 - Conocimiento de la normativa técnica al proceso de edificación

- ETE.08 - Capacidad para generar documentos de especificación técnica de los procedimientos y métodos constructivos de edificios. Plantear y resolver soluciones constructivas

- $\quad$ ETE.10 - Conocimiento de la evaluación del impacto ambiental de los procesos de edificación y demolición, sostenibilidad en edificación y de los procedimientos y técnicas para evaluar la eficiencia energética de los edificios.

Esta asignatura aporta a los alumnos la sensibilidad por los nuevos valores sociales de la construcción, como el urbanismo respetuoso con el entorno, la utilización de nuevas tecnologías energéticas, la incorporación de nuevos métodos constructivos, el uso de materiales sostenibles, mantenimiento y la rehabilitación de edificios, entre otros. De este modo con el nuevo Plan de Estudios la Universidad de Burgos se incorpora a la vanguardia de la formación universitaria de Técnicos Especialistas en Construcción y Edificación capaces de adaptarse a la evolución social y técnica de nuestra sociedad.

Es una asignatura muy relevante para incentivar la creatividad de los alumnos, ya que el concepto de sostenibilidad es un valor social unido al progreso científico y tecnológico, con constantes avances técnicos de aplicación a la arquitectura, la ingeniería y la construcción.

Como objetico básico, la metodología de trabajo seguida en la asignatura ha tratado de motivar a los alumnos a establecer criterios sobre la aplicación de materiales de construcción respetuosos con el Medio Ambiente, la utilización de instalaciones fáciles de mantener y con un consumo razonable de energía y la configuración de nuevos diseños y soluciones constructivas, más ventajosas para la sostenibilidad y cuidadosas con el medio natural. Por ello, se incentiva el conocimiento de sistemas y procedimientos constructivos sostenibles, energías renovables no contaminantes y materiales reciclados a partir de residuos valorizados, todo ello orientado a la economía circular.

\subsection{Planteamiento de la asignatura de Construcción Sostenible.}

La asignatura, obligatoria, se imparte en el $4^{\circ}$ Curso del Grado en la Universidad de Burgos. A la hora de plantear la asignatura se tuvo en consideración lo siguiente:

- Es una asignatura del Plan de Bolonia, lo que implicaba que la evaluación fuese continua y que el alumno adquiriese competencias específicas y transversales. 
- $\quad$ Aunque los egresados en el Grado en Arquitectura Técnica tienen unas atribuciones limitadas en urbanismo y diseño arquitectónico no se consideraba correcto limitar el contenido a la construcción, ya que si la arquitectura no es sostenible o el urbanismo no plantea criterios de sostenibilidad es prácticamente imposible alcanzar un estándar de calidad.

- Dado que la industria de la construcción está en permanente evolución y se está adaptando a criterios de sostenibilidad, o al menos determinados productos quieren vender esta etiqueta, se consideraba pertinente que el objetivo de las clases teóricas fuese dotar a los alumnos de criterios y conocimientos para que en su labor profesional pudiesen determinar en cada circunstancia qué materiales o procesos constructivos son los más sostenibles y adecuados, mientras que en las clases prácticas los alumnos tendrían que emplear sus conocimientos constructivos en supuestos reales para obtener edificios sostenibles, eficientes y confortables.

- Como metodología educativa consideramos emplear el trabajo cooperativo en los trabajos prácticos, ya que es muy apropiada para desarrollar las habilidades personales de los alumnos, al mismo tiempo que se fomenta la colaboración interactiva con otros compañeros en la realización de proyectos y trabajos conjuntos.

De este modo la asignatura se estructura en dos grandes bloques temáticos formativos complementarios:

- Formación Teórica en conceptos relacionados con la sostenibilidad en construcción, tanto desde el punto de vista urbanístico, de diseño, de procedimientos y técnicas constructivas, así como el empleo de energías renovables y sistemas pasivos.

- Formación Práctica, mediante el desarrollo de dos trabajos específicos de grupo evaluables y con actuación profesional como técnicos expertos, que sirven para poner en valor los conocimientos adquiridos en la formación teórica.

\subsection{Contenidos de la asignatura de Construcción Sostenible.}

El programa de la asignatura está dividido en tres bloques.

En el primer bloque planteamos qué es sostenibilidad y por qué debemos aplicar los criterios de sostenibilidad en la construcción. También definimos cuales pueden ser los criterios de una construcción sostenible. Así mismo se define cual es el marco legislativo y normativo en España. Es un bloque de concienciación del alumno en temas sostenibilidad.

En el segundo bloque explicamos conceptos de urbanismo sostenible, haciendo hincapié en las consecuencias que tiene la urbanización sobre el territorio, desarrollando conceptos como la huella ecológica. También se definen principios del urbanismo sostenible.

El tercer bloque es el más extenso. Este apartado trata sobre arquitectura y construcción sostenible (Hernandez Pezzi, 2007, Reyes et al, 2007). Estudiamos en qué consiste la 
arquitectura sostenible, la importancia de analizar el entorno de las edificaciones, los sistemas pasivos en condiciones de verano e invierno, el análisis de ciclo de vida de materiales o sistemas constructivos. En este bloque finalmente exponemos diferentes sistemas de certificación de la sostenibilidad: LEED, BREEAM y VERDE.

\subsubsection{Formación práctica}

Paralelamente a las clases de teoría, los profesores de la asignatura plantean dos prácticas para su desarrollo en grupo, con no más de tres alumnos. Uno de los objetivos del proceso de enseñanza y aprendizaje es apostar por fomentar el espíritu crítico de los alumnos y crear espacios de diálogo como forma de adquirir conocimientos (De la Torre y Violant, 2001).

Por ello, en la asignatura se ha apostado por utilizar el Estudio de Proyectos de Edificación que han logrado unos niveles relevantes de sostenibilidad, como puede ser una Certificación Sostenible, utilizando los indicadores de calidad de las diferentes entidades de acreditación ambiental. De esta forma, los alumnos se familiarizan con los procedimientos que miden y evalúan el grado de sostenibilidad de un entorno urbanístico o de edificio, así como analizan las carencias y proponen mejoras con criterios de sostenibilidad.

Por otra parte, el segundo trabajo consiste en estudiar y aplicar criterios de sostenibilidad en proyectos de edificación convencionales, es decir, que cumplen estrictamente la normativa. Consideramos que es un excelente modo de enfrentar al alumno al reto de proponer mejoras para alcanzar unos estándares de sostenibilidad en la construcción que logren edificios más confortables, saludables y seguros para sus usuarios.

De este modo, en la asignatura se propone el desarrollo de dos trabajos sobre construcción sostenible, con planteamientos metodológicos totalmente distintos:

1. Estudio de un Proyecto de Edificación Construido con técnicas de sostenibilidad, que dispongan de alguna de Certificación Medioambiental (LEED, BREEAM, HQE, DGNB, VERDE) o un reconocimiento público. Figura 2. 


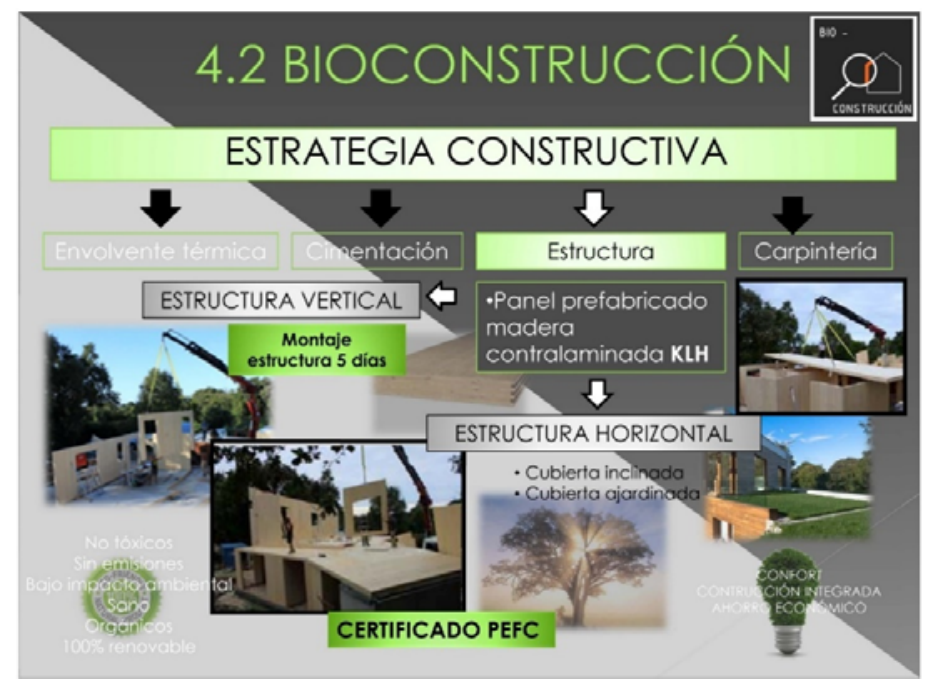

Fig. 2 Construcción Sostenible. Ejemplo de exposición de trabajo práctico 1

2. Desarrollo de un Proyecto de Edificación Sostenible, figura 3: El trabajo consiste en transformar un proyecto de edificación convencional en uno sostenible, aplicando los conocimientos adquiridos en la asignatura (Heywood, 2017). Los alumnos tienen libertad para actuar con un criterio personal, justificando y documentando todos los cambios y razonando por qué han adoptado las soluciones que proponen.

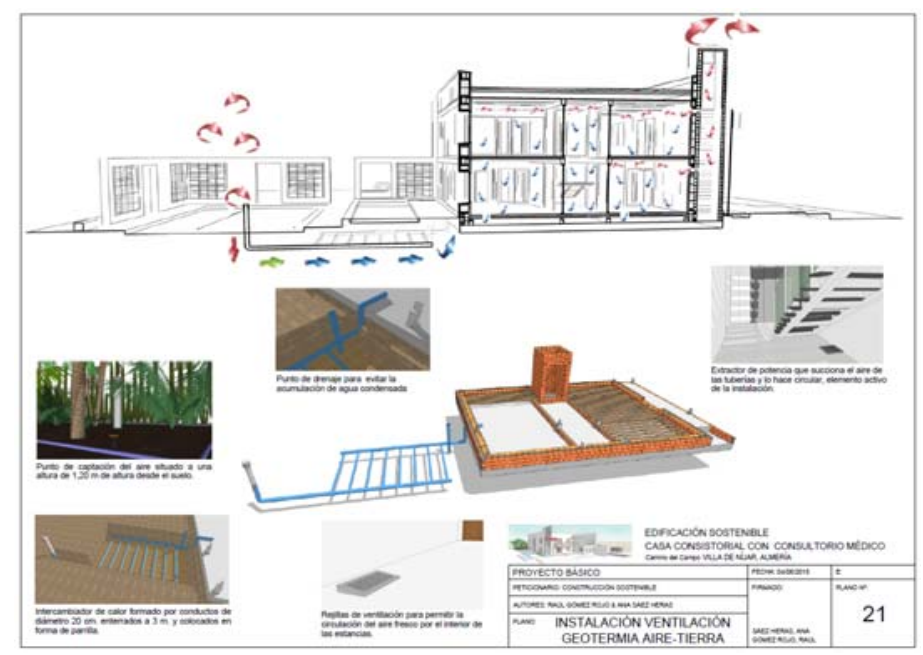

Fig. 3 Construcción Sostenible. Ejemplo de trabajo práctico 2 


\subsubsection{El trabajo cooperativo}

En el nuevo contexto mundial, el éxito de las empresas se basa en configurar equipos de trabajo eficaces, en los que sus miembros puedan aportar sus conocimientos y capacidades de forma complementaria, adaptándose a los requerimientos y necesidades cada vez más flexibles e inciertas del mercado de trabajo. El trabajo en equipo supone una ventaja competitiva sobre los sistemas de organización individuales, menos eficaces y carentes de una visión de conjunto en las estrategias y objetivos empresariales.

Trabajar en grupo no es fácil y requiere el aprendizaje de habilidades y competencias específicas, por lo que desde la Universidad se debe ser sensible a esta nueva realidad social, para formaralumnos bienpreparados y con una alta competencia profesional, pero también personas capaces de crear espacios de interacción personal para trabajar en grupo, compartiendo el conocimiento y comprometidos en conseguir alcanzar el éxito en la gestión de objetivos comunes (Saiz y Gómez, 2011; Marín et. al., 2014).

El trabajo cooperativo en grupo es una metodología educativa apropiada para desarrollar las habilidades personales de los alumnos, al mismo tiempo que se fomenta la colaboración interactiva con otros compañeros para realizar proyectos y trabajos conjuntos. Figura 4.

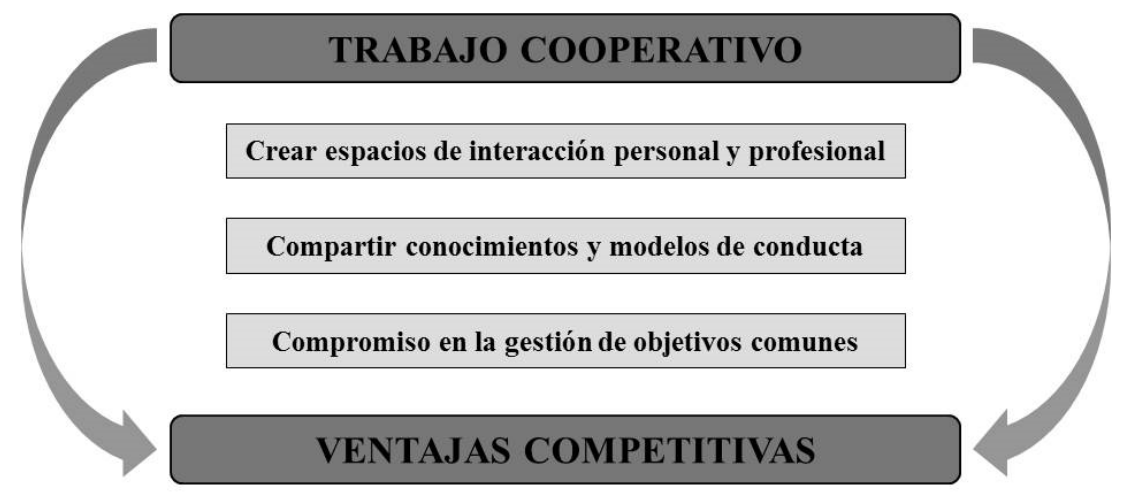

Figura 4. Ventajas del Trabajo Cooperativo en grupo

Una de las potencialidades de esta metodología de trabajo es la heterogeneidad de los componentes del grupo, que lejos de ser un problema se convierte en una ventaja competitiva al crearse un marco de convivencia activa, en el que los participantes se ayudan unos a otros y se responsabilizan del resultado final.

Si bien el planteamiento metodológico se muestra como un sistema perfectamente cerrado, en el que cada miembro del grupo sabe lo que debe hacer y se responsabiliza del resultado final común, existen peligros potenciales que pueden hacer ineficaz esta forma de trabajar. Por una parte, es posible que el grado de implicación de los miembros del grupo no sea el 
mismo ni tampoco el deseado, o que aparezcan rivalidades y problemas de convivencia y sociabilidad por las distintas personalidades y sensibilidades que confluyen (Poveda, 2006). Todo esto es posible y ocurre, pero el trabajo cooperativo implica también a los docentes, que deben posicionarse activamente orientando y dinamizando el grupo de trabajo y mediando en los conflictos que pudieran surgir. Los docentes deben obrar con diligencia buscando un equilibrio entre las exigencias individuales y los compromisos del grupo, analizando previamente las capacidades de cada uno de los miembros que lo forman. (Viles et al, 2010; León et al., 20011; Mesa, 2012)

\subsubsection{Competencias transversales}

El planteamiento de las clases prácticas se ha realizado para que los alumnos adquieran las competencias transversales que relaciona la guía docente. En las clases teóricas también se consideran estas competencias, pero es en las prácticas cuando se interactúa constantemente con los alumnos.

Los dos trabajos prácticos se realizan en grupo por lo que implican capacidad de trabajo en equipo, desarrollo de habilidades en las relaciones personales, capacidad de liderazgo,...

Los alumnos tienen que buscar y analizar información sobre los edificios existentes o las soluciones que planteen en el segundo trabajo, empleando competencias como aprendizaje autónomo, creatividad, análisis y síntesis, razonamiento crítico, capacidad de gestión de la información, actitud positiva frente a las innovaciones sociales y culturales, ...

El primer trabajo se expone en público, de manera aleatoria por uno de los miembros del grupo, evaluándose la exposición, por lo que el alumno debe tener un compromiso con sus compañeros y desarrollar las competencias de comunicación oral y capacidad de comunicación a través de la palabra y la imagen.

En el segundo trabajo desarrolla competencias tales como orientación al cliente (en este caso el docente), capacidad de organización y planificación, resolución de problemas, toma de decisiones, motivación por la calidad, ...

\subsubsection{Desarrollo de los trabajos prácticos}

La asignatura se imparte en un semestre, con trece sesiones prácticas de una hora. El primer trabajo se plantea el día de la presentación y se desarrollará las tres primeras semanas, destinando una o dos clases para la exposición en público de este. Los días de la exposición se explica el contenido del segundo trabajo, que se entregará el último día de las clases prácticas. Para los trabajos prácticos se diseñan grupos de trabajo formados con un máximo de tres alumnos, estableciendo unas normas de organización del trabajo consensuadas entre sus miembros, así como un compromiso de corresponsabilidad en el resultado final. 

sustainability in the Degree in Technical Architecture of the University of Burgos

El objetivo es formar a los alumnos en las técnicas de construcción sostenible utilizadas en edificación y fomentar su interacción personal formando parte de un grupo de trabajo en la consecución de un objetivo común. Con ello se quiere conseguir:

- Contribuir a mejorar el proceso de enseñanza y aprendizaje mediante el trabajo cooperativo.

- Fomentar la creatividad de los alumnos y el interés por nuevas tecnologías sostenibles.

- Socializar al alumno para que perciba y valore las potencialidades del trabajo en grupo y sepa integrarse en los equipos de trabajo de las empresas.

- Adquirir criterios de opinión y de elección para optar por soluciones sostenibles ventajosas en construcción (economía circular).

- Capacidad de contraponer opiniones con argumentos fundamentados en el conocimiento

Como primer trabajo cada grupo elige un edificio que disponga de Certificación de Sostenibilidad o un reconocimiento como tal, para estudiar todos los elementos diferenciadores respecto de un edificio convencional. Se realiza un análisis del diseño arquitectónico sostenible, de los sistemas constructivos, materiales e instalaciones (figura 5), sistemas pasivos, integración en el entorno, empleo de energías renovables...analizando sus puntos fuertes y sus debilidades, tanto en la fase diseño como en el proceso de ejecución y en su mantenimiento, teniendo en cuenta su tipología de uso.

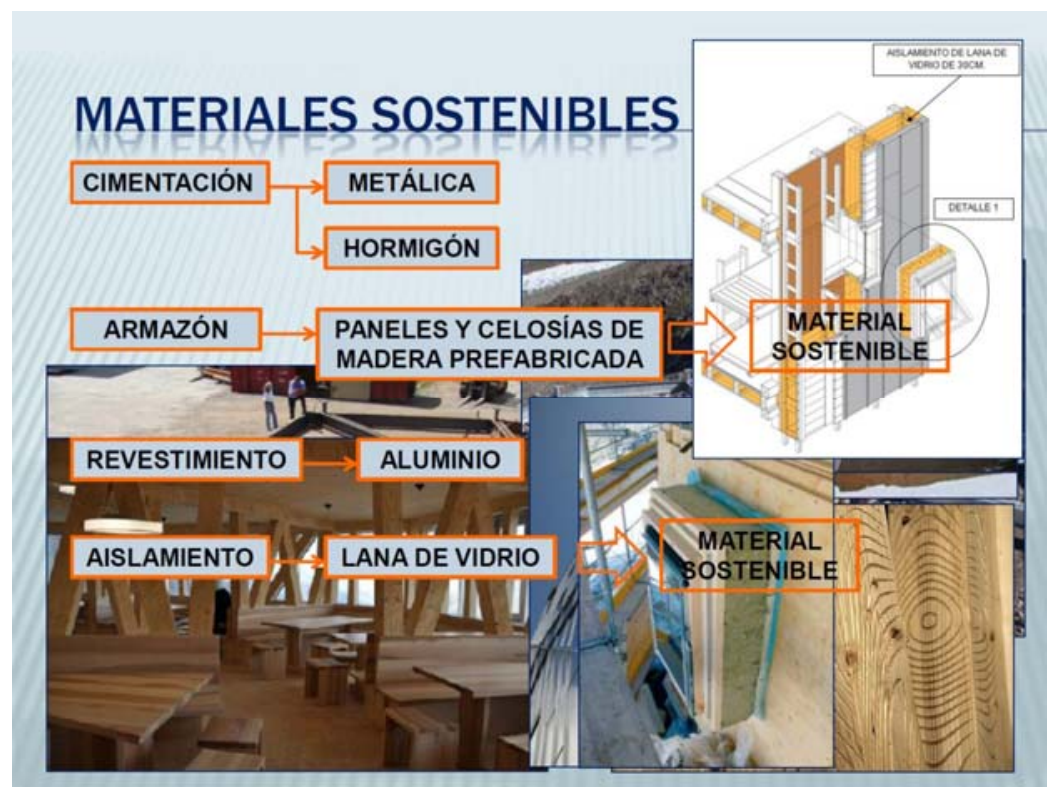

Fig. 5 Construcción Sostenible. Ejemplo de trabajo práctico 1. Estudio de materiales 
Cada grupo de trabajo debe realizar un informe técnico completo que posteriormente se expone en grupo, utilizando técnicas de exposición gráficas basadas en TIC, de este modo se transmite toda la información al resto de la clase. La exposición se realiza de manera similar a un congreso, con tiempos medidos y abriéndose un debate al final de la presentación en el que pueden y deben participar los alumnos.

Como segundo trabajo se entrega a los alumnos un proyecto de edificación convencional para que apliquen los criterios y conocimientos adquiridos en la asignatura y lo transformen en un proyecto de edificación sostenible, figura 6. Para ello pueden modificar todos los elementos constructivos (estructura y cimentación, fachada, cubiertas, particiones, carpinterías, revestimientos...) y las instalaciones, emplear sistemas pasivos (Muro Trombe, tubos canadienses, muro parietodinámico, chimenea solar, etc..) (Neila, 2014, Rodriguez, 2002), y actuar en el entorno que le rodea, ya sea con vegetación o con sistemas de soleamiento. La única limitación es no variar la distribución interior de la edificación, ya que no es objeto de la asignatura.

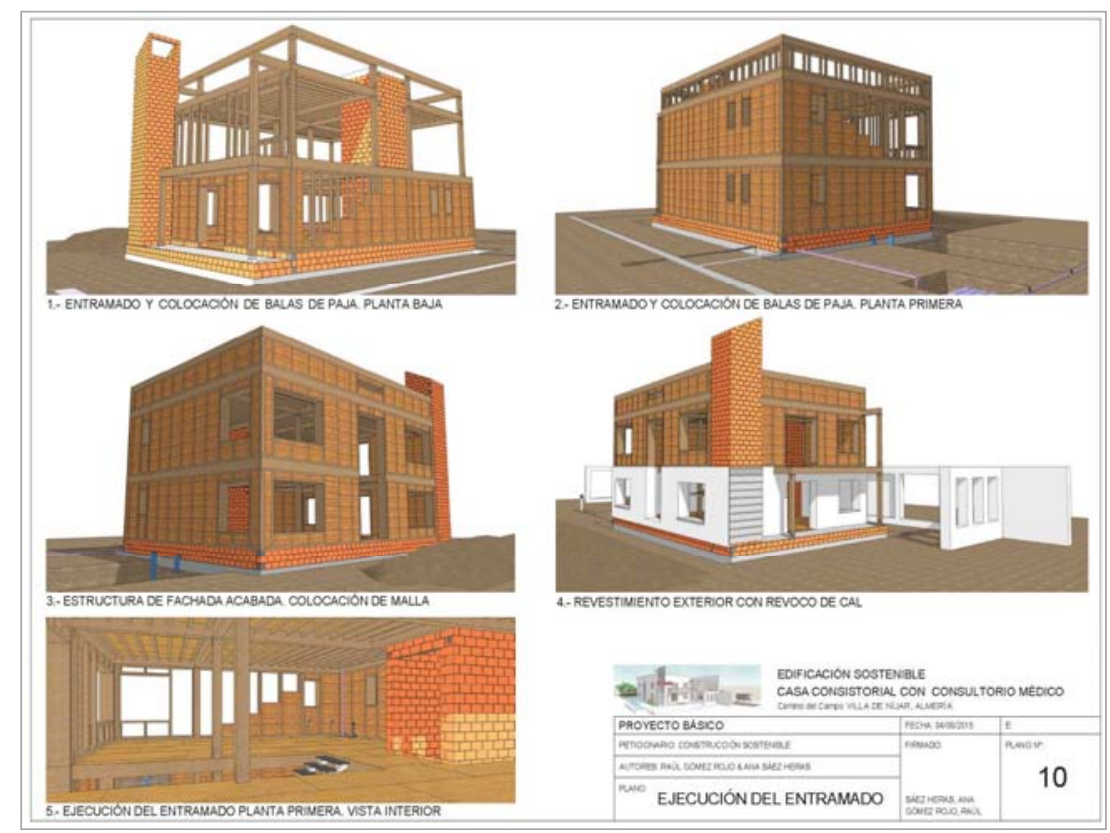

Fig. 6 Construcción Sostenible. Ejemplo de trabajo práctico 2. Desarrollo constructivo

Para que las soluciones propuestas por los alumnos en los trabajos sean más heterogéneas y abarquen diferentes tipologías innovadoras, se plantean diferentes emplazamientos, con climatologías diferenciadas (D’Amico, 2014). Suelen ser cornisa cantábrica, Burgos y Andalucía interior. 
El desarrollo de esta segunda actividad se organiza con los mismos grupos de trabajo establecidos en la primera fase. De igual forma, el protocolo de actuaciones es común para todos los grupos, tomando como referencia los siguientes criterios y planteamientos:

- Análisis del entorno del edificio, estudio del clima, soleamiento, viento y especies vegetales naturales, con el objetivo de poder detectar tanto los beneficios como los factores adversos a la hora de plantear las soluciones arquitectónicas elegidas.

- Análisis del programa de necesidades del edificio y de sus ocupantes, así como de la orientación óptima del mismo, de acuerdo con los factores climatológicos.

- Estudio de las características constructivas y de diseño, de las medidas pasivas y activas, y de las energías renovables del entorno, en función de su uso, y posterior examen crítico mediante el análisis de los indicadores medioambientales.

- Puesta en común y debate sobre las posibles actuaciones para introducir mejoras, de acuerdo con los conocimientos transmitidos en las clases magistrales de la asignatura.

- Debate y puesta en común de las opciones técnicas de aplicación, eligiendo de forma consensuada las propuestas más ventajosas elegidas por cada grupo de trabajo.

- Capacidad de contraponer opiniones con argumentos fundamentados en el conocimiento, con el objetivo de aportar mejoras que sean técnicamente viables.

- Elección de las soluciones constructivas y de las instalaciones de los edificios, indicando las diferentes opciones y tipologías. El documento final del trabajo debe contener una memoria descriptiva razonada, complementada con un estudio gráfico. De igual forma, se establecerá un análisis comparativo entre las diferentes alternativas estudiadas, detallando sus ventajas y defectos.

\section{Conclusiones sobre las estrategias docentes}

La puesta en práctica de esta metodología educativa, basada en el trabajo cooperativo, muestra un alto compromiso de los alumnos y una gran implicación en el desarrollo de los trabajos, así como un elevado interés del alumno por experimentar otras formas de trabajar. La propuesta educativa ayuda a que los alumnos interioricen el trabajo en grupo, ya que experimentan una forma de trabajar real y profesional, tal y como sucede en el ámbito empresarial. A modo de referencia, se pueden aportar las siguientes reflexiones:

- Se percibe que los alumnos asumen el trabajo en grupo como una experiencia profesional, semejante a la que experimentarán en las empresas, una vez concluidos sus estudios.

- La exposición de los trabajos permite desarrollar otras competencias personales, como la capacidad de comunicar, de explicar un proyecto, de fundamentar y defender con argumentos las soluciones adoptadas y de convencer a la audiencia. 
- Son capaces de comparar su trabajo con el del resto de compañeros, lo que motiva su interés por mejorar y conseguir la excelencia del grupo.

- El alumno valora y respeta el trabajo del resto de compañeros, aceptando la existencia de otros puntos de vista y opiniones, lo que contribuye a enriquecer el nivel colectivo de los trabajos.

\section{Referencias}

D'AMICO, F. C. (2014). Arquitectura bioclimática, conceptos básicos y panorama actual. Boletín CF+ S, (14). http://habitat.aq.upm.es/boletin/n14/afcel.html

DE LA TORRE, S. ; VIOLANt, V. (2001). Estrategias creativas en la enseñanza universitaria. Creatividad y sociedad, 3, 10-35.

EDWARDS, B. (2008) Guía básica de la sostenibilidad, Editorial Gustavo Gili, Barcelona.

HERNANDEZ PEZZI, C. (2007) Un Vitruvio ecológico: Principios y práctica del proyecto arquitectónico sostenible, Editorial Gustavo Gili, Barcelona.

HEYWOOD, H. (2017) 101 reglas básicas para edificios y ciudades sostenibles , Gustavo Gili, Barcelona.

LEON, B., Felipe, E., Iglesias, D. y Latas, C. (2011). El aprendizaje cooperativo en la formación inicial del profesorado. Revista de Educación, 354.

MARIN, V. ; NEGRE, F. ; PEREZ, A. (2014). Entornos y redes personales de aprendizaje (PLE-PLN) para el aprendizaje colaborativo. Comunicar, 21(42).

MESA, L. M. (2011). El trabajo colaborativo del profesorado como oportunidad formativa. Los docentes, conciencia educativa de la sociedad, 69.

NEILA, J. (2014). Arquitectura bioclimática en un entorno sostenible: buenas prácticas edificatorias. Boletín CF+ S, (14). http://habitat.aq.upm.es/boletin/n14/afcel.html

POVEDA SERRA, P. (2006). Implicaciones del aprendizaje de tipo cooperativo en las relaciones interpersonales y en el rendimiento académico. Universidad de Alicante.

REYES, C.; BARAHONA, E.; PIRILLO, C. (2007) Arquitectura sostenible, Editorial Pensil, Valencia.

RODRIGUEZ, M. (2002) Introducción a la arquitectura bioclimática, Limusa, México,

SAIZ, M. S. I. ; GOMEZ, G. R. (2011). Aprendizaje autónomo y trabajo en equipo: reflexiones desde la competencia percibida por los estudiantes universitarios. Revista Electrónica Interuniversitaria de Formación del Profesorado (REIFOP), 73

VILES, E., Jaca, C., Campos, J., Serrano, N., \& Santos, J. (2012). Evaluación de la competencia de trabajo en equipo en los grados de ingeniería. Dirección y Organización, (46), 67-75. 


\title{
EDIFICATE
}

I Congreso de Escuelas de Edificación y Arquitectura Técnica de España València, 4 y 5 de noviembre de 2021

Escuela Técnica Superior de Ingeniería de Edificación

Universitat Politècnica de València

Doi: https://doi.org/10.4995/EDIFICATE2021.2021.13537

\section{Metodología y recursos didácticos claves en el proceso de enseñanza-aprendizaje de las asignaturas de Construcción II y III del Grado de Arquitectura Técnica.}

\section{Methodology and key didactic resources used in teaching- learning process in the subjects of Construction II and III on Bachelor's Degree in Technical Architecture.}

\footnotetext{
José Manuel Gandía-Romeroa, Milagro lborra Lucas ${ }^{b}$, Ana Martínez lbernón ${ }^{c}$

a Universitat Politècnica de València, Depto. de Construcciones Arquitectónicas, joganro@csa.upv.es

b Universitat Politècnica de València, Depto. de Construcciones Arquitectónicas, miborra1@csa.upv.es b Universitat Politècnica de València (IDM), anmarib@arqt.upv.es
}

\begin{abstract}
Construction II (Flat roofs and sloped roofs) and Construction III (Facades, partitions and claddings) are two mandatoy subjects of second-year courses. The new European Higher Education Area and the competence-based learning approach required a global and integrated approach. This paper describes key methodological aspects used in both subjects and exposes those didactic resources considered essential to achieve the learning outcomes and the competences defined in the teaching guide. In addition, promoting the acquisition of transversal competences has been a key factor in the design of activities and for the selection of teaching resources. At the end of the work, the student's perception of the usefulness of the resources used is analyzed.
\end{abstract}

Keywords: Construction, resources, didactic metodology competences.

\footnotetext{
Resumen

Las asignaturas de Construcción II (Cubiertas planas y cubiertas inclinadas) y de Construcción III (Fachadas, particiones y revestimientos) son dos asignaturas obligatorias de segundo curso. El nuevo espacio europeo para la educación superior y el aprendizaje basado en competencias requirieron de un enfoque global e integrado. En el presente trabajo se describen aspectos metodológicos y se exponen aquellos recursos didácticos considerados
} 
Metodología y recursos didácticos claves el proceso de enseñanza-aprendizaje de las asignaturas de

Construcción II y III del Grado de Arq. Técnica - Methodology and key didactic resources used in teaching-learning process in the subjects of C II and III on Bachelor's Degree in Technical Architecture.

imprescindibles para alcanzar los resultados de aprendizaje $y$ las competencias definidas en la guía docente. El enfoque de la asignatura hacia la adquisición de competencias ha sido clave en el diseño de actividades y en la selección de los recursos. Al final del trabajo se analiza la percepción del alumno sobre la utilidad de los recursos empleados.

Palabras clave: Construcción, recursos, metodología didáctica, competencias. 


\section{Introducción}

El nuevo Espacio Europeo de Educación Superior (EEES) generó profundos cambios metodológicos en el sistema universitario (Benito, 2005). Se hizo necesaria una reformulación de los métodos de enseñanza-aprendizaje, pasando del "saber" y "aprender" al "saber hacer" y "aprender a aprender".

Actualmente, los resultados de aprendizaje no los entendemos como elementos aislados, deben además fomentar la adquisición de competencias. La competencia se puede definir como una capacidad para movilizar diversos recursos cognitivos para hacer frente a un tipo de situaciones (Perrenoud, 2007). Éstas, deben permitir al alumnado abordar con éxito los restos futuros desde una perspectiva profesional y personal (Goñi Zabala, 2005; Poumay, 2017). Se pasa, por tanto, de un modelo basado, casi exclusivamente en contenidos, a otro donde se hace necesario un enfoque global desde el punto de vista metodológico que promueva la adquisición de competencias profesionales y transversales. En la Universitat Politècnica de València (UPV) se consideran claves estas competencias $y$, es por ello que, son evaluadas y reflejadas en los expedientes académicos.

Por tanto, debe de darse importancia no solo a lo que se enseña sino también a cómo lo enseñamos. Una de las claves del nuevo modelo de educación es el método docente, lo que nos obliga como profesores a tener una visión global. Se debe guiar al alumnado y abrirle nuevos caminos, adquiriendo así la labor tutorial y de acompañamiento adquiere un gran valor. Por otro lado, al alumnado se le debe exigir una actitud claramente activa y una implicación decidida y responsable en su propia formación.

En la UPV, ya en el año 2002 se creó el Proyecto EUROPA que tenía como objetivos favorecer sinergias entre cada Centro y los Departamentos que imparten docencia en él, mejorar la cualificación del profesorado e incentivar la implantación de nuevos métodos de enseñanza y evaluación. Se hacía una propuesta de un nuevo método docente que suponía un cambio en la actividad del profesorado. Al diseñar la metodología en las asignaturas de CII y III también se tuvieron en cuenta las directrices del Plan de Acciones para la Convergencia Europea (PACE) y las de Plan Estratégico 2007-2014. En este último plan y dentro del primer eje estratégico, como objetivo I.3 se indicaba la necesidad de mejorar el rendimiento académico de los estudiantes, desarrollando algunas líneas estratégicas y planes de acción orientadas a la adecuación de las metodologías como el "Método Activa" que buscaba potenciar el uso de las metodologías activas que mejorasen la capacidad de aprendizaje y el rendimiento académico de los estudiantes y la "Docencia en Red" que buscaba desarrollar una completa oferta formativa con metodología específica TIC (cursos on-line, ejercicios prácticos, foros de aprendizaje, blogs, documentación bibliográfica,...). Finalmente, indicar también que en el Plan estratégico UPV 2015-2020, uno de los retos estratégicos es "Ser un referente en formación de calidad orientada a las necesidades de la sociedad y tiene como objetivo... avanzar hacia modelos de formación que logren que sus estudiantes adquieran las competencias necesarias para poder tener una adecuada inserción laboral. Esta formación debe verse desde una perspectiva amplia, ligada al ciclo formativo 
Metodología y recursos didácticos claves el proceso de enseñanza-aprendizaje de las asignaturas de

Construcción II y III del Grado de Arq. Técnica - Methodology and key didactic resources used in

teaching-learning process in the subjects of C II and III on Bachelor's Degree in Technical Architecture.

integral de las personas, que abarca tanto el grado como el posgrado, lo que implica un esfuerzo continuado en la renovación y mejora de la metodología".

Por todo lo expuesto, desde el punto de vista metodológico la organización e integración de los recursos didácticos en las asignaturas de Cll y CIII ha sido para los profesores un aspecto fundamental para satisfacer los resultados de aprendizaje fomentando que este aprendizaje sea significativo y que favorezca también la adquisición de competencias. El análisis de la percepción del alumnado sobre la metodología empleada y la adecuación de los recursos es clave de cara a establecer futuras acciones.

\section{Objetivos}

El objetivo principal del presente trabajo es analizar la percepción que tienen actualmente los alumnos del empleo de los recursos didácticos en las asignaturas de Cll y CIII para poder establecer futuras estrategias de mejora y/o consolidación.

Para poder contextualizar dicho análisis se han establecido los siguientes objetivos operativos: (i) Describir de forma general la organización y metodología empleada actualmente en las asignaturas de Cll y CII, (ii) identificar los recursos didácticos empleados durante el proceso de enseñanza aprendizaje y (iii) analizar las encuestas de los alumnos.

\section{Las asignaturas de Cll y CIII del grado de Arquitectura Técnica en la UPV}

\subsection{Enfoque, competencias y contenidos en las asignaturas de Construcción II y III}

Antes de comenzar a describir la metodología se considera interesante dar un enfoque general de las asignaturas en el grado de Arquitectura Técnica (GAT). Las asignaturas de Construcción II (cubiertas planas e inclinadas) y III (fachadas, particiones y revestimientos), tienen asignados 4,5 ECTS cada una y son asignaturas obligatorias de segundo curso que tienen como objetivos comunes hacer que los alumnos consoliden la aplicación de los principios constructivos estudiados en la asignatura de Construcción I (Introducción a la construcción) y sobre todo que profundicen en los sistemas específicos de las asignaturas de Cll y III, esto es, identificando los materiales que componen los sistemas y las relaciones entre los diferentes elementos constructivos. Se pretende que el alumnado sea capaz de evaluar y concretar las soluciones, secuencias constructivas y puestas en obra. Se potencian las capacidades de análisis y el uso de la expresión gráfica como medio eficaz para comunicar ideas. El análisis de la normativa y la adecuación de las soluciones es otro aspecto que tiene mucha importancia. En definitiva, las asignaturas aportan el conocimiento necesario para resolver de forma correcta las cubiertas, fachadas, particiones y revestimientos, teniendo en cuenta la problemática de cada una de las tipologías y siendo capaz de tomar, con conocimiento técnico, las decisiones adecuadas para su correcta ejecución. Tanto ClI como CIII comparten profesores y metodología, Cll se imparte en el primer semestre y CIII en el segundo semestre si bien ambas asignaturas en el anterior plan de estudios estaban integradas en una asignatura anual común de tercer curso. 
La competencias definidas en la guía docente son las siguientes:

Tabla 1. Competencias específicas (CE) y transversales (CT) en Cll y CIII

\section{Competencias}

(CE01) Aptitud para identificar los elementos, sistemas y tipologías constructivas, definir su función, idoneidad relativa y compatibilidad en el proceso constructivo. Aptitud para plantear y resolver detalles constructivos.

(CE02) Conocimiento de los procedimientos específicos de control de la ejecución material de obras de edificación.

(CE03) Conocimiento de los equipos, instalaciones provisionales y medios auxiliares empleados en las obras de edificación, sus características y normativa de aplicación.

(CE04) Capacidad para evaluar las necesidades y establecer criterios para la selección de los equipos, instalaciones provisionales y medios auxiliares.

(CE05) Saber aplicar sus conocimientos a su trabajo o vocación de una forma profesional y poseer las competencias que suelen demostrarse por medio de la elaboración y defensa de argumentos y resolución de problemas dentro del área de estudio.

(CE06) Poseer habilidades de aprendizaje necesarias para emprender estudios posteriores con un alto grado de autonomía.

(CE07) Capacidad para aplicar la normativa técnica al proceso de la edificación y generar documentos de especificación técnica que determinen los procedimientos y métodos constructivos de edificios.

(CE08) Poseer y comprender conocimientos en un área de estudio que parte de la base de la educación secundaria general, y se suele encontrar a un nivel, que si bien se apoya en libros de texto avanzados, incluye también algunos aspectos que implican conocimientos procedentes de la vanguardia de su campo de estudio.

(CE09) Capacidad de transmitir información oral y escrita en la lengua nativa: ideas, problemas y soluciones a un público tanto especializado como no especializado.

(CE10) Conducta ética en ingeniería. Capacidad crítica y autocrítica. Conciencia de la necesidad de calidad y alto nivel profesional y de su aplicación al continuo perfeccionamiento.

(CE11) Conocimiento de los elementos, sistemas y tipologías constructivas, tradicionales y prefabricados empleados en la edificación y sus variedades.

(CE12) Capacidad para dictaminar sobre las causas y manifestaciones de las lesiones en los edificios, y proponer soluciones para evitar o subsanar su patología.

(CE13) Conocimiento de los procedimientos y técnicas de evaluación de la eficiencia energética de los edificios.

(CE14) Aptitud para diseñar y materializar soluciones de acondicionamiento acústico, térmico y lumínico de los mismos.

(CT02) Aplicación y pensamiento práctico

(CT03) Análisis y resolución de problemas

(CT09) Pensamiento crítico

Hay dos bloques de contenidos en CII (tejados y azoteas) y tres grandes bloques en CIII (fachadas, particiones y revestimientos). Los bloques de contenidos se estructuran en las siguientes unidades didácticas:

Tabla 2. Desglose de Unidades Didácticas en las asignaturas de Cll y CIII

\section{Construcción II}

TJ-01. Cubiertas. Introducción.

TJ-02.Tejados. Generalidades, Exigencias Básicas y Clasificación según CTE

TJ-03.Tejados de Teja. Cerámica y de Hormigón 
Metodología y recursos didácticos claves el proceso de enseñanza-aprendizaje de las asignaturas de

Construcción II y III del Grado de Arq. Técnica - Methodology and key didactic resources used in

teaching-learning process in the subjects of C II and III on Bachelor's Degree in Technical Architecture.

TJ-04. Tejados de Teja. Pizarra.

TJ-05. Tejados. Placas y Perfiles. Cubiertas Ligeras no Metálicas.

TJ-06. Tejados. Placas y Perfiles. Cubiertas Ligeras Metálicas.

AZ-07. Azoteas. Generalidades

AZ-08. Azoteas Transitables

AZ-09. Azoteas no Transitables

Construcción III

FA-01. Fachadas. Generalidades

FA-02. Fachadas. Fabrica de ladrillo

FA-03. Fachadas. Fabrica de bloque

FA-04. Fachadas. Carpintería de vidrio

FA-05. Fachadas. Muros cortina

FA-06. Fachadas. Ventiladas

FA-07. Fachadas. Otros tipos

PT-08. Particiones. Generalidades

PT-09. Particiones. Fabricas de ladrillo y bloque

PT-10. Particiones. Entramados de yeso laminado

PT-11. Particiones. Carpintería interior

$\mathrm{RV}$-12. Revestimientos verticales

RV-13. Revestimientos horizontales

\subsection{Principales actividades desarrolladas y recursos empleados en las asignaturas de Construcción II y III}

Algunos aspectos clave que se han tenido en cuenta en el diseño metodológico de las asignaturas de Construcción II y III son los siguientes:

- Diseñar actividades y procedimientos para favorecer la construcción de los aprendizajes de una forma más efectiva utilizando metodologías activas, buscando que el aprendizaje sea significativo y que se construya sobre los conocimientos previos.

- Establecer una evaluación continua del proceso, que permita obtener información y modificar o mejorar aquellos aspectos que se consideren necesarios.

- Proporcionar un feed-back en las actividades para que puedan conocer la forma de resolver las prácticas, es decir, aquellos aspectos determinantes y condicionantes de la solución.

- Explicar cuáles son los criterios de evaluación, el alumno debe conocerlos, no solo en los actos de evaluación sino en el desarrollo de prácticas y teoría.

- Favorecer el trabajo cooperativo y evaluar también aspectos relacionados con la adquisición competencias transversales.

- Motivar al alumnado con actividades que puedan resultarles más atractivas y aplicables a su futura actividad profesional. 
- Canalizar y orientar correctamente los trabajos que se plantean a lo largo del curso de modo que puedan servir como apoyo en las prácticas, en las tutorías y en el propio desarrollo de los contenidos de clase en teoría de aula.

- Fomentar el uso del laboratorio de Construcción como espacio de aprendizaje y espacio tutorial.

- Facilitar el acceso a los espacios de modo que los alumnos puedan trabajar individualmente, reflexionar y tener contacto con los recursos disponibles, ver trabajos de años anteriores seleccionados por los profesores, elaborar las maquetas...

- Incrementar los recursos materiales y de apoyo que proporcionados a los alumnos, incorporando documentación gráfica y facilitándole los criterios de selección de información para que pueda de utilidad en el estudio y en el desarrollo de las actividades planteadas en la asignatura.

- Incrementar el número de estudiantes que hacen uso de la tutoría.

Las actividades más relevantes que quedan recogidas en la guía docente de la asignatura y los recursos empleados se describirán a continuación teniendo en cuenta aspectos significativos desde el punto de vista metodológico. Debe tenerse en cuenta que las actividades no deben entenderse como elementos independientes sino que se conectan incluso en una misma sesión, por ejemplo, es habitual integrar sesiones de teoría de aula con prácticas de aula o incluso con prácticas de laboratorio.

\subsubsection{TA: Teoría de Aula.}

La clase magistral expositiva la consideramos muy útil si, desde un enfoque participativo, se da la oportunidad al alumnado de preguntar, reflexionar a partir de los contenidos teóricos, ejercicios o de preguntas abiertas. Esta metodología la empleamos fundamentalmente en las clases de TA ya que, aunque la materia de construcción tiene un carácter aplicado, se requiere de unos conocimientos básicos previos para poderse llevar a la práctica. Es importante obtener feedback de los alumnos a partir de preguntas abiertas ya que eso nos permitirá adoptar estrategias correctoras y reorientar aspectos en caso de ser necesarios. En este tipo de clases, la pizarra desempeña un papel fundamental, ya que permite la "construcción" del detalle, e incorporar su "ejecución" en un orden lógico (Ver Figura 1). Por otro lado, empleamos el proyector y el retroproyector, apuntes, publicaciones docentes, videos e imágenes de obras. Es habitual combinar la teoría de aula con prácticas de aula de corta duración. 


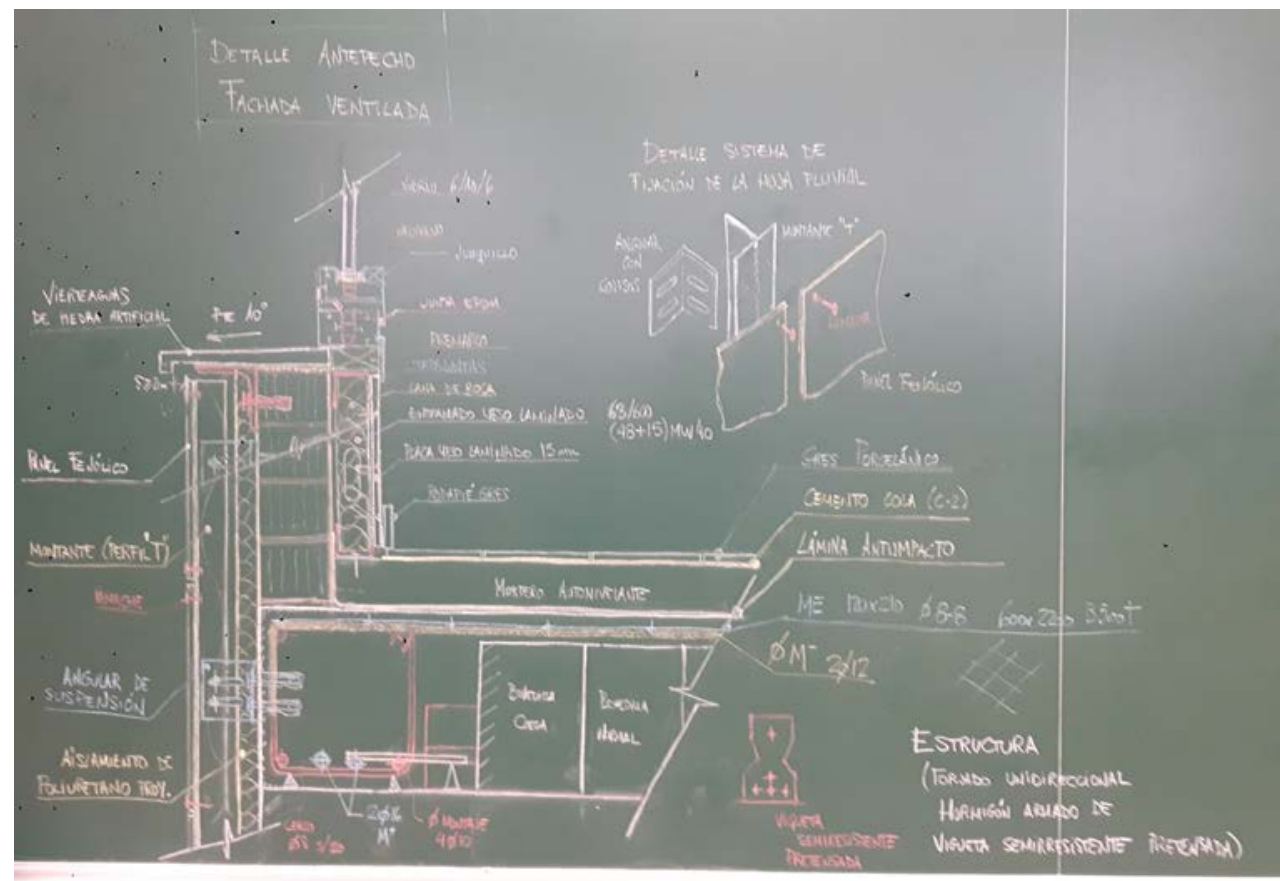

Fuente: Elaboración propia. J.M Gandía

Fig. 1 Representación en la pizarra de un detalle constructivo de CIII elaborado en clase (fachada ventilada)

\subsubsection{PA: Práctica de Aula.}

Las prácticas de aula son una de las actividades más relevantes ya que contribuyen a la adquisición de las competencias transversales y también de las específicas al estar conectadas directamente con las clases de teoría. Permiten consolidar los conocimientos, reforzar las ideas básicas, fomentar la capacidad de análisis y propiciar el acercamiento a situaciones reales. Los materiales y recursos empleados deben enfocarse a ese tipo de actividad. En este sentido, para el trabajo de las prácticas de aula se dispone de los "cuadernos de prácticas" que son documentos elaborados por el profesorado de la asignatura. Estos cuadernos son el soporte básico de muchos de los problemas que se plantean y son además un material que permite al alumnado trabajar de forma autónoma y recibir un feed-back en tutorías. 

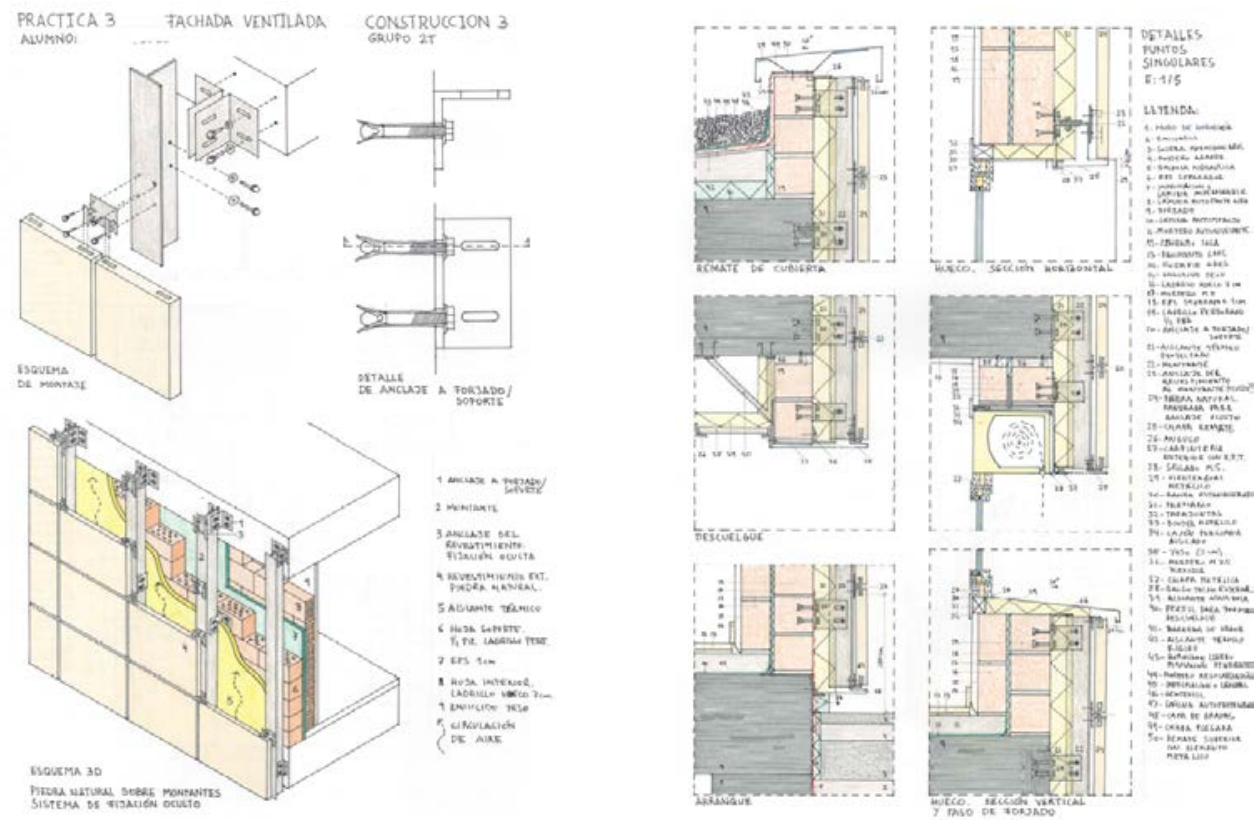

Alumno J. Saiz

Fig. 2 Práctica de Aula de CIII resuelta por un alumno del curso 20-21.

Se utilizan metodologías de aprendizaje basado en problemas (ABP) y métodos del caso mediante lo que denominamos visitas virtuales a obras. En las prácticas de aula, aparte de los cuadernos de prácticas y las lecciones publicadas, el recurso de las maquetas es clave de cara a fomentar la visión y comprensión espacial ya que todavía hay alumnos que tienen dificultades. Destacar también la metodología flip teaching que se ha implementado en los grupos de inglés (muy reducidos en cuanto a número de estudiantes) donde las clases son esencialmente prácticas y el alumnado dispone de un material específico que debe estudiar en casa,quedando la Teoría de Aula queda muy reducida en pro de la Práctica de Aula .

\subsubsection{PL: Práctica de Laboratorio}

Se desarrollan en el laboratorio de Construcción II-III Se hacen teniendo en cuenta unos objetivos muy concretos. El alumnado experimenta en primera persona ya que preferentemente tienen un carácter manipulativo. La finalidad es poner en contacto al alumno con materiales y analizar elementos constructivos, sistemas o tipologías. Se trabajan con recursos a escala y/o tamaño real y con materiales "reales" ya que los profesores hemos ido incorporando y renovando constantemente. También se dispone de muchos materiales disponibles gracias a la colaboración de empresas de referencia del sector que en determinados momentos son expuestos en la ETSIE. También se emplean maquetas realizadas por el alumnado de cursos previos de forma habitual en este tipo de actividades. 
Metodología y recursos didácticos claves el proceso de enseñanza-aprendizaje de las asignaturas de

Construcción II y III del Grado de Arq. Técnica - Methodology and key didactic resources used in teaching-learning process in the subjects of C II and III on Bachelor's Degree in Technical Architecture. En determinadas prácticas de laboratorio se realizan sesiones en colaboración con empresas del sector a modo de taller.

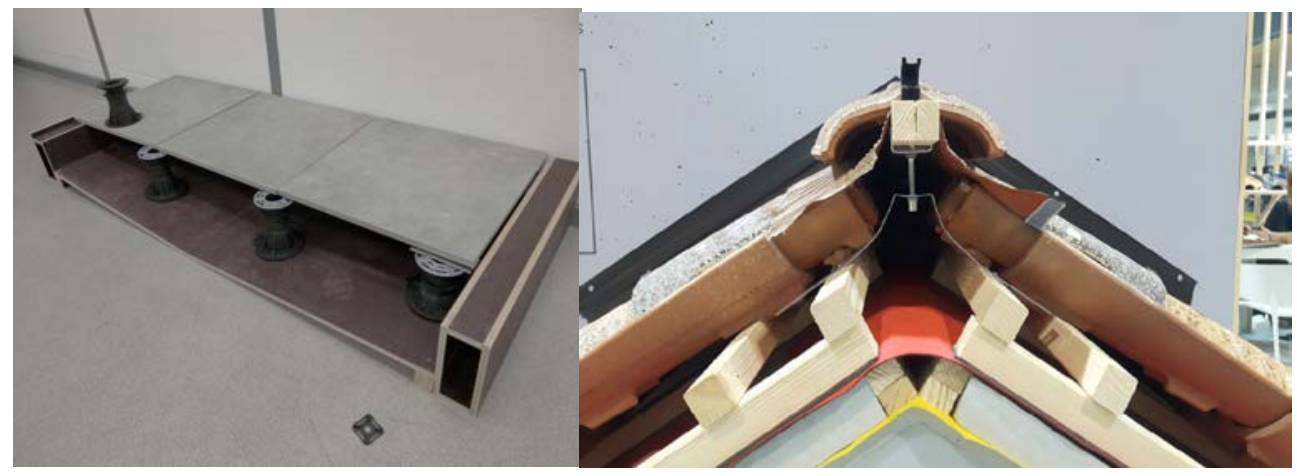

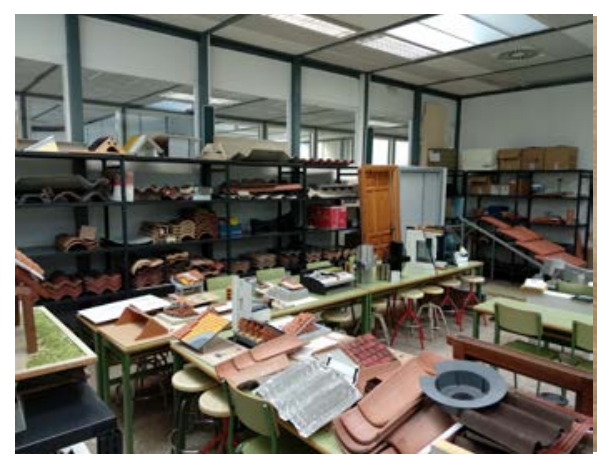

Fig. 3. Ejemplos de materiales y maquetas empleadas durante las prácticas de laboratorio

\subsubsection{PC: Práctica de Campo}

Como actividad tienen gran interés pedagógico, no hay que olvidar que la profesión de arquitecto técnico es eminentemente práctica, de hecho, en su origen nos encontramos con una profesión donde el aprendizaje se hacía de forma práctica. Las visitas a obras permiten que se pongan en relación conceptos, contenidos de distintas materias y que se contextualice en situación real, con sus interrelaciones constructivas, etc. Por otro lado, los talleres desarrollados en colaboración con empresas permiten profundizar en aspectos teóricoprácticos y ver "ejecuciones reales" que dan respuesta a numerosas cuestiones. Para las visitas a obra o talleres externos se rellena un formulario en la escuela y se proporciona un registro de participantes para tener cobertura con el seguro escolar. Por otro lado, cada vez es más frecuente que las grandes empresas de materiales tengan aulas de formación para aplicadores donde es posible orientar actividades a modo de taller. Un aspecto importante para nosotros es facilitar a los alumnos información de la visita/taller ya sea a partir de la plataforma PoliformaT de la UPV. 

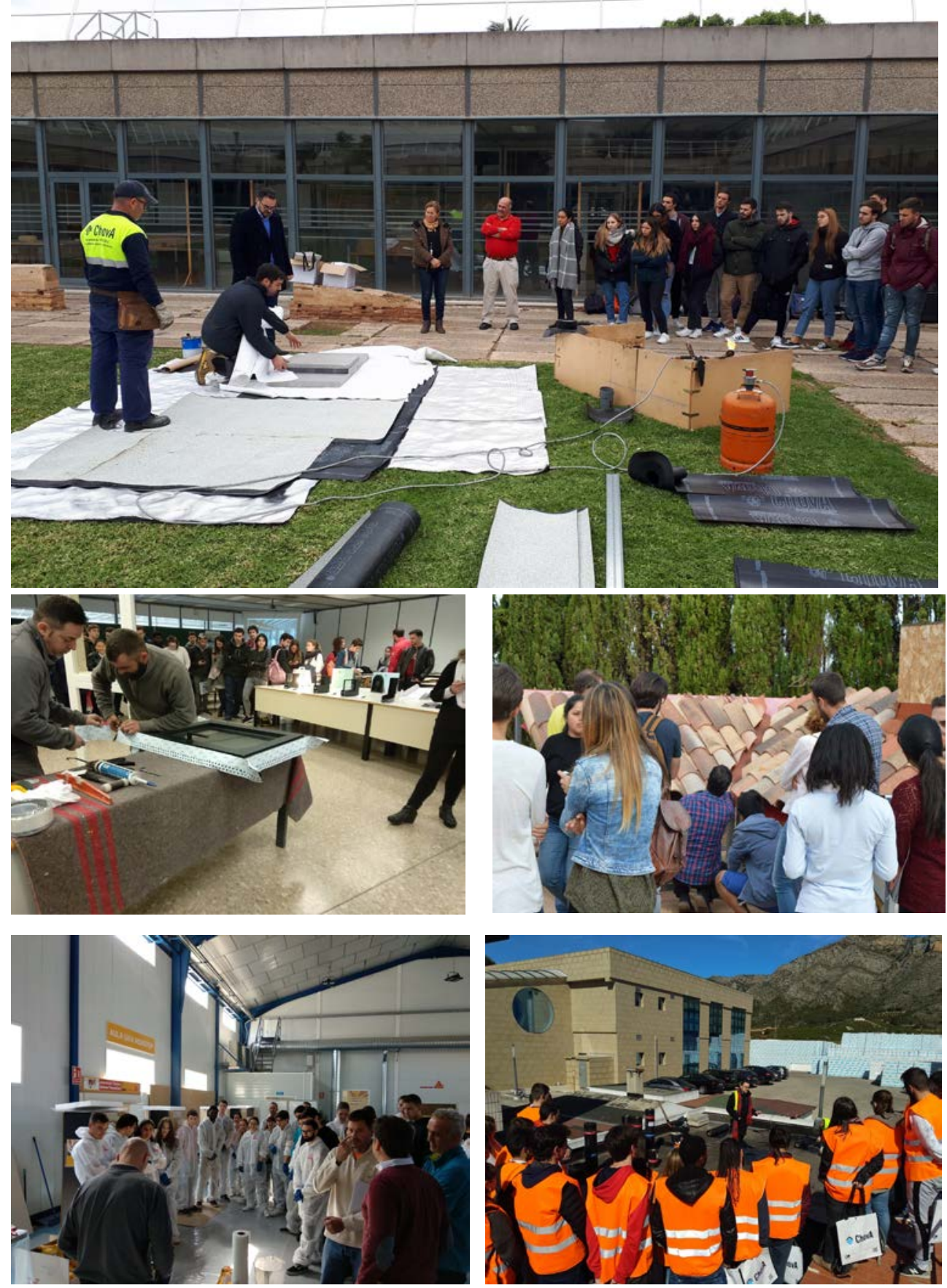

Fuente: Elaboración propia

Fig. 4. Talleres desarrollados con alumnos en colaboración con empresas. 
En la Figura 4 se incluyen algunos ejemplos de talleres realizados. Arriba el taller de instalación de laminas asfálticas realizado con la colaboración de Chova en la ETSIE; en medio a la izquierda: el taller de instalación de carpinterías para Passive House desarrollado en colaboración con VicenteTorres en la ETSIE; en medio a la derecha: el taller desarrollado en las instalaciones de Tejas Borja en Llíria sobre tejados ventilados y microventilados; abajo a la izquierda el taller realizado en colaboración con la empresa Sika en Quart de Poblet sobre instalación del sistema Sikatherm y abajo a la derecha el taller sobre puntos singulares en azoteas y visita a fábrica de XPS desaqrrollado en colaboración con Chova en Tavernes.
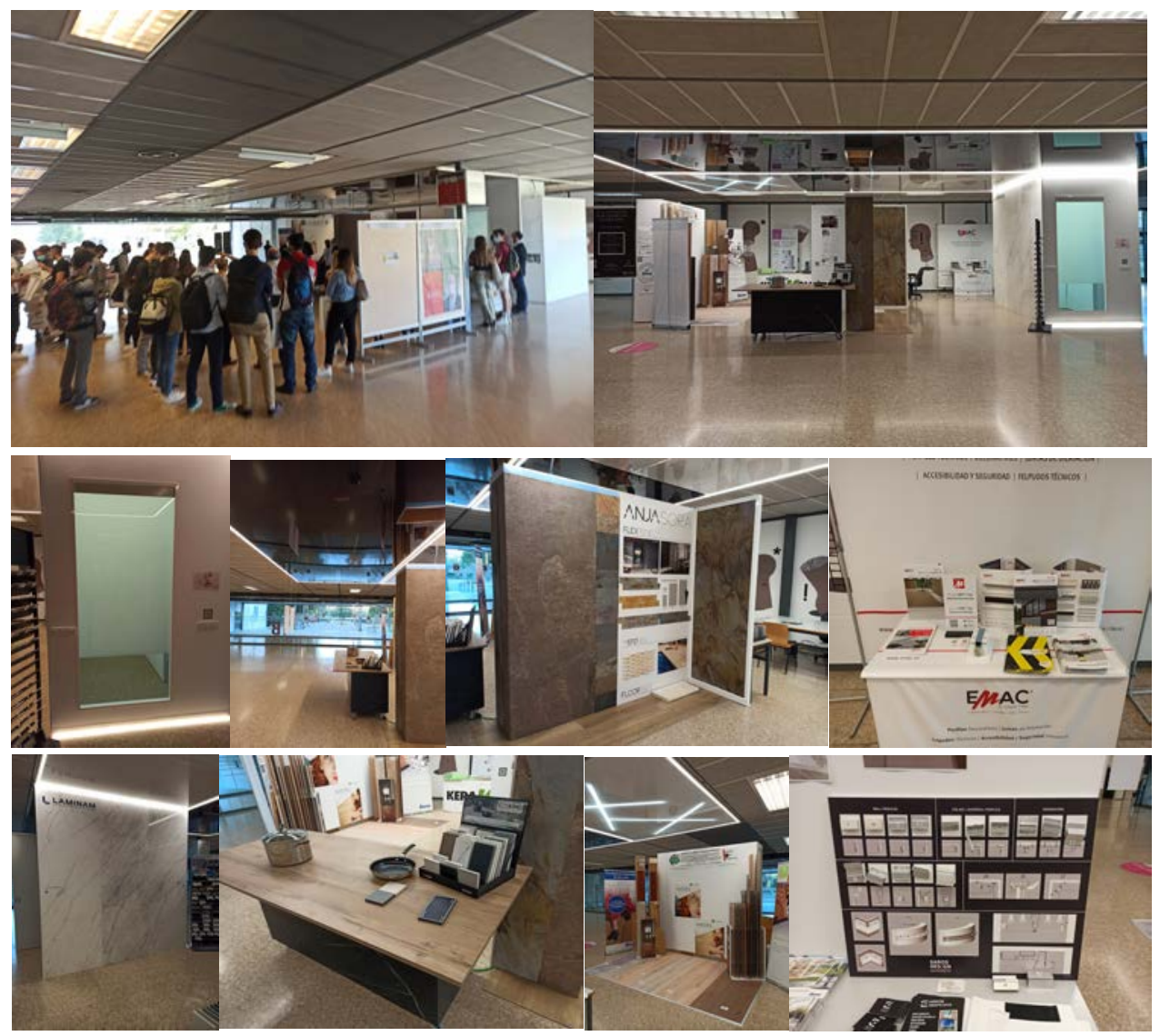

Fuente: Elaboración propia

Fig. 5. Exposición realizada en el Hall de la ETSIE sobre revestimientos y nuevos materiales.

Este año como novedad hemos introducido en la ETSIE la realización de una exposición (Figura 5) que permitiese a los alumnos profundizar en el bloque de revestimientos y ha sido 
muy interesante ya que se han expuesto materiales de varias empresas de forma temporal en el hall de la escuela y se han realizado varias charlas-seminario cortas en ese mismo espacio. Se han expuesto techos tensados, grandes formatos cerámicos, revestimientos pétreos naturales flexibles, soluciones de aislamiento acústico, nuevas soluciones de cocina, perfiles para pavimentos, adhesivos y materiales de rejuntado entre otros.

\subsubsection{TNP: Trabajo no presencial}

Como actividad tutorizada se plantea trabajar la metodología del aprendizaje por proyectos para que el alumno ponga en práctica los conocimientos y los aprendizajes adquiridos aplicándolos a una simulación de un proyecto real. Se busca la adquisición de competencias específicas y generales a través del aprendizaje cooperativo. Es una de las actividades donde más se fomenta la adquisición de habilidades de síntesis, de aplicación de los aprendizajes, de pensamiento práctico, de trabajo en equipo o de su creatividad por lo que potencian de una forma clara las competencias transversales. Los trabajos se desarrollarán en grupo, de 3 personas como máximo y el trabajo es tutorizado por el profesorado durante todo el semestre. Se les definen claramente los objetivos y se les orienta en los enfoques, la materialización, se resuelven las dudas y se asegurará que se cumple con los requisitos establecidos para su presentación.

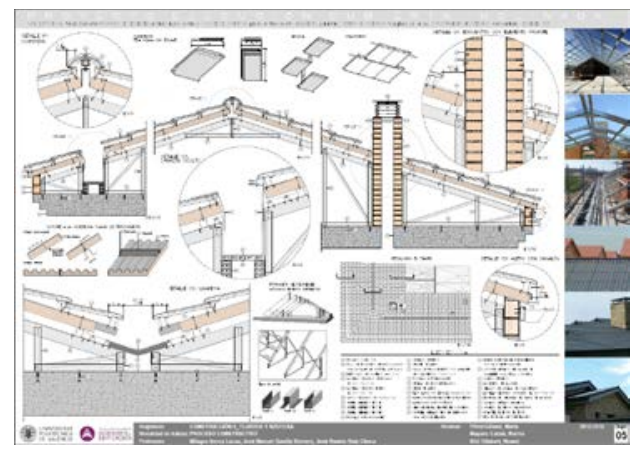

Fig. 6 Ejemplo de trabajo entregado por un grupo en la asignatura de CII en el curso 2018-2019.

\subsubsection{EVA: Actividades de evaluación}

Se realiza una evaluación continua multicriterio que permite evaluar al alumno teniendo en cuenta todas las actividades que llevan a cabodurante el curso (trabajos, examen, prácticas, problemas...) con lo que se consigue valorar de forma integral la asignatura. Los valores porcentuales de los actos de evaluación en Construcción II y III están reflejados en la guía docente. 
Metodología y recursos didácticos claves el proceso de enseñanza-aprendizaje de las asignaturas de

Construcción II y III del Grado de Arq. Técnica - Methodology and key didactic resources used in teaching-learning process in the subjects of C II and III on Bachelor's Degree in Technical Architecture.

\subsection{Análisis de la percepción del alumnado respecto al empleo de recursos didácticos}

A partir de las encuestas que periódicamente se emplean para evaluar el proceso de enseñanza-aprendizaje es posible tener un feedback sobre la percepción del alumnado respecto a la metodología y recursos ya que hay varias preguntas que evalúan esos aspectos.

En la Tabla 3 se incluyen los resultados de las encuestas de los últimos 5 años. Al analizar los resultados se puede observar que la valoración es alta.

Al preguntar si la recepción de la información al inicio de curso es adecuada, la valoración es es alta, con valor un promedio en las encuestas (s/10) de los últimos 5 años de 8.78 en Cll y 9.14 en CIII. En la pregunta que hace referencia a la metodología y actividades realizadas se obtienen promedios de 9.01 y 8.92. Cuando se les pregunta acerca de si los materiales recomendados a nivel de bibliografía y documentación són útiles para el aprendizaje se obtienen promedios de 8.51 y 8.76. En cuanto a la coherencia y utilidad de los recursos accesibles a través de la plataforma UPV (PoliformaT) la nota es de 8.33 y 8.67 .

Tabla 3. Resultados de las encuestas UPV durante los últimos 5 años en Cll y CIII referidas a metodologías y empleo de recursos

\begin{tabular}{|c|c|c|c|c|c|c|c|c|c|c|c|}
\hline & & \multicolumn{2}{|c|}{ 2016-2017 } & \multicolumn{2}{|c|}{$2016-2017$} & \multicolumn{2}{|c|}{ 2017-2018 } & \multicolumn{2}{|c|}{$2018-2019$} & \multicolumn{2}{|c|}{$2019-2020$} \\
\hline & & Nota $s / 10$ & $\frac{\text { desviación }}{\text { típica }}$ & $\underline{\text { Nota } s / 10}$ & $\frac{\text { desviación }}{\text { típica }}$ & $\underline{\text { Nota } s / 10}$ & $\frac{\text { desviación }}{\text { típica }}$ & Nota s/11 & $\frac{\text { desviación }}{\text { típica }}$ & $\underline{\text { Nota } s / 10}$ & $\begin{array}{c}\frac{\text { desviación }}{\text { típica }} \\
\end{array}$ \\
\hline \multirow{4}{*}{ ClI } & $\begin{array}{l}\text { AL INICIO DEL CURSO PROPORCIONA } \\
\text { INFORMACIÓN CLARA SOBRE LA } \\
\text { ASIGNATURA: OBJETIVOS, PROGRAMA, } \\
\text { METODOLOGÍA Y CRITERIOS DE } \\
\text { EVALUACIÓN }\end{array}$ & - & - & 8.33 & 1.86 & 9.22 & 1.92 & 9.04 & 1.61 & 8.56 & 1.42 \\
\hline & $\begin{array}{l}\text { LA METODOLOGÍA EMPLEADA Y LAS } \\
\text { ACTIVIDADES REALIZADAS EN LA } \\
\text { ASIGNATURA AYUDAN A APRENDER AL } \\
\text { ALUMNADO }\end{array}$ & - & - & 8.58 & 1.24 & 9.11 & 1.5 & 9.34 & 1.64 & 9.04 & 1.4 \\
\hline & $\begin{array}{l}\text { LOS MATERIALES UTILIZADOS Y/O } \\
\text { RECOMENDADOS (BIBLIOGRAFÍA, } \\
\text { DOCUMENTOS, RECURSOS DIDÁCTICOS, } \\
\text { ETC.) SON DE GRAN AYUDA PARA EL } \\
\text { APRENDIZAJE DE LA ASIGNATURA }\end{array}$ & - & - & 7.9 & 1.69 & 9.03 & 1.76 & 9.04 & 1.49 & 8.08 & 1.44 \\
\hline & $\begin{array}{l}\text { LOS MATERIALES DOCENTES HABILITADOS } \\
\text { ON-LINE (POLIFORMAT U OTROS ESPACIOS } \\
\text { ON-LINE OFICIALES EN LA UPV) POR ESTA } \\
\text { ASIGNATURA SON COHERENTES CON LOS } \\
\text { CONTENIDOS DEL PROGRAMA, } \\
\text { REPRESENTAN UNA IMPORTANTE AYUDA } \\
\text { PARA SU APRENDIZAJE Y PARA ALCANZAR } \\
\text { LOS OBJETIVOS DE LA ASIGNATURA. }\end{array}$ & - & - & 7.67 & 1.82 & 9.08 & 1.77 & 8.31 & 1.79 & 8.26 & 1.67 \\
\hline \multirow{4}{*}{ CIII } & $\begin{array}{l}\text { AL INICIO DEL CURSO PROPORCIONA } \\
\text { INFORMACIÓN CLARA SOBRE LA } \\
\text { ASIGNATURA: OBJETIVOS, PROGRAMA, } \\
\text { METODOLOGÍA Y CRITERIOS DE } \\
\text { EVALUACIÓN }\end{array}$ & 8.2 & 2.18 & 8.89 & 1.24 & 9.63 & 0.88 & 8.82 & 1.63 & 9.25 & 1.21 \\
\hline & $\begin{array}{l}\text { LA METODOLOGÍA EMPLEADA Y LAS } \\
\text { ACTIVIDADES REALIZADAS EN LA } \\
\text { ASIGNATURA AYUDAN A APRENDER AL } \\
\text { ALUMNADO }\end{array}$ & 8.9 & 2.13 & 8.75 & 1.5 & 9.88 & 0.54 & 8.82 & 2.03 & 8.25 & 2.65 \\
\hline & $\begin{array}{l}\text { LOS MATERIALES UTILIZADOS Y/O } \\
\text { RECOMENDADOS (BIBLIOGRAFÍA, } \\
\text { DOCUMENTOS, RECURSOS DIDÁCTICOS, } \\
\text { ETC.) SON DE GRAN AYUDA PARA EL } \\
\text { APRENDIZAJE DE LA ASIGNATURA }\end{array}$ & 7.7 & 2.64 & 8.06 & 2.13 & 9.31 & 1.48 & 8.55 & 2.36 & 9.15 & 1.59 \\
\hline & $\begin{array}{l}\text { LOS MATERIALES DOCENTES HABILITADOS } \\
\text { ON-LINE (POLIFORMAT U OTROS ESPACIOS } \\
\text { ON-LINE OFICIALES EN LA UPV) POR ESTA } \\
\text { ASIGNATURA SON COHERENTES CON LOS } \\
\text { CONTENIDOS DEL PROGRAMA, } \\
\text { REPRESENTAN UNA IMPORTANTE AYUDA } \\
\text { PARA SU APRENDIZAJE Y PARA ALCANZAR } \\
\text { LOS OBJETIVOS DE LA ASIGNATURA. }\end{array}$ & 7.6 & 2.4 & 8.82 & 1.94 & 8.82 & 2.42 & 7.79 & 2.41 & 9.25 & 1.69 \\
\hline
\end{tabular}

${ }^{*}$ En color azul: Periodo Covid 100\% Docencia online 
Dado que de este curso activo no se disponía de encuestas y al considerar necesario explorar de una forma más particularizada la percepción del alumnado sobre la utilidad de los recursos y sobre su adecuación al contexto de aprendizaje, se preparó una encuesta a través de la plataforma PolifoprmaT que ha sido respondida por 41 estudiantes de los 57 alumnos correspondientes a los grupos A y $\mathrm{T}$.

En ningún caso se ha obtenido una puntuación inferior a 8.5 puntos como se puede observar en la Tabla 4 donde incluimos los resultados derivados de la valoración de los estudiantes del curso 2020-2021.

Tabla 4. Resultados de las encuestas realizadas por los profesores en el curso 2020-2021

\begin{tabular}{|c|c|c|c|c|c|c|c|}
\hline & $\begin{array}{c}\text { Muy } \\
\text { insatisfecho } \\
\text { (1) }\end{array}$ & $\begin{array}{c}\text { Insatisfecho } \\
\text { (2) }\end{array}$ & Neutral (3) & $\begin{array}{l}\text { Satisfecho } \\
\text { (4) }\end{array}$ & $\begin{array}{c}\text { Muy } \\
\text { satisfecho (5) }\end{array}$ & Nota $s / 10$ & $\begin{array}{l}\text { desviación } \\
\text { típica }\end{array}$ \\
\hline $\begin{array}{l}\text { Considero que el uso de recursos materiales } \\
\text { desempeña (maquetas, muestras de material, } \\
\text { videos...) es clave en el proceso de enseñanza- } \\
\text { aprendizaje de las asignaturas de CII - CIII }\end{array}$ & 1 & 0 & 0 & 8 & 32 & 9.41 & 1.43 \\
\hline $\begin{array}{l}\text { Creo que asistir presencialmente a clase y el } \\
\text { contacto con los recursos es clave de cara a } \\
\text { abordar los procedimientos evaluables }\end{array}$ & 0 & 0 & 1 & 6 & 34 & 9.85 & 0.69 \\
\hline $\begin{array}{l}\text { El uso de maquetas en el aula es clave para el } \\
\text { aprendizaje de procedimientos y soluciones } \\
\text { constructivas }\end{array}$ & 0 & 0 & 1 & 17 & 23 & 9.07 & 1.10 \\
\hline $\begin{array}{l}\text { El uso de maquetas en el aula ha sido adecuado } \\
\text { para apoyar los contenidos }\end{array}$ & 1 & 0 & 1 & 5 & 34 & 9.51 & 0.98 \\
\hline $\begin{array}{l}\text { El uso de materiales de construcción en el aula es } \\
\text { clave para el aprendizaje de procedimientos y } \\
\text { soluciones constructivas }\end{array}$ & 0 & 0 & 1 & 11 & 29 & 9.37 & 1.04 \\
\hline $\begin{array}{l}\text { El uso de materiales de construcción en el aula ha } \\
\text { sido adecuado para apoyar los contenidos }\end{array}$ & 1 & 0 & 1 & 7 & 32 & 9.37 & 1.51 \\
\hline $\begin{array}{l}\text { El uso de fotografias y videos reales de obras en } \\
\text { ejecución en el aula es clave para el aprendizaje } \\
\text { de procedimientos y soluciones constructivas }\end{array}$ & 0 & 1 & 0 & 10 & 30 & 9.37 & 1.22 \\
\hline $\begin{array}{l}\text { El uso de fotografias y videos reales de obras en } \\
\text { ejecución en el aula ha sido adecuado para el } \\
\text { aprendizaje de procedimientos y soluciones } \\
\text { constructivas }\end{array}$ & 0 & 1 & 2 & 10 & 28 & 9.17 & 1.41 \\
\hline $\begin{array}{l}\text { Los detalles constructivos elaborados en la pizarra } \\
\text { son clave para el aprendizaje de procedimientos y } \\
\text { soluciones constructivas }\end{array}$ & 1 & 0 & 1 & 6 & 33 & 9.41 & 1.50 \\
\hline $\begin{array}{l}\text { El número y selección de los detalles elaborados } \\
\text { en la pizarra ha sido adecuado para el aprendizaje } \\
\text { de procedimientos y soluciones constructivas }\end{array}$ & 0 & 0 & 5 & 10 & 26 & 8.93 & 1.42 \\
\hline $\begin{array}{l}\text { Los apuntes de PoliformaT son un recurso clave } \\
\text { como apoyo a los apuntes de clase y de cara al } \\
\text { aprendizaje de la asignatura }\end{array}$ & 0 & 0 & 2 & 17 & 22 & 9.07 & 1.10 \\
\hline $\begin{array}{l}\text { Los apuntes de PoliformaT se pueden considerar } \\
\text { adecuados como complemento de los contenidos } \\
\text { desarrollados en las clases. Se consideran bien } \\
\text { estructurados }\end{array}$ & 0 & 2 & 6 & 12 & 21 & 8.54 & 1.79 \\
\hline $\begin{array}{l}\text { La realización de actividades como la Exposición } \\
\text { de Materiales con empresas del sector me ha } \\
\text { parecido interesante y motivadora. Es útil de cara } \\
\text { al aprendizaje }\end{array}$ & 0 & 0 & 3 & 16 & 22 & 8.93 & 1.27 \\
\hline $\begin{array}{l}\text { La realización de actividades como la Exposición } \\
\text { de Materiales con empresas del sector me ha } \\
\text { parecido interesante y motivadora. Es útil de cara } \\
\text { al aprendizaje }\end{array}$ & 0 & 1 & 3 & 10 & 27 & 9.07 & 1.49 \\
\hline $\begin{array}{l}\text { De forma general, se puede considerar que } \\
\text { metodológicamente y a nivel de recursos la } \\
\text { asignatura de Construcción III está bien } \\
\text { planificada }\end{array}$ & 0 & 0 & 3 & 8 & 30 & 9.17 & 1.67 \\
\hline
\end{tabular}




\section{Conclusiones}

En el presente trabajo se ha realizado una contextualización metodológica de las asignaturas de segundo curso de Construcción II y III en el grado de Arquitectura Técnica de la ETSIE. Se han realizado encuestas y, de forma general, se puede indicar que el grado de satisfacción por parte del alumnado es alto teniendo una percepción positiva sobre la utilidad de los recursos y los planteamientos metodológicos utilizados. Por otro lado, se ha podido observar que la base de recursos disponible ha permitido que en el periodo en el que la docencia pasó a la modalidad $100 \%$ no presencial por COVID se haya mantenido el nivel de satisfacción de los alumnos.

Aunque no se detectan carencias que puedan requerir de acciones correctivas a corto plazo si se considera al analizar en detalle los resultados, la conveniencia de planificar las acciones siguientes:

- Actualizar y mejorar los apuntes de Poliformat y de la bibliografía

- Analizar los detalles en pizarra con el fin de optimizar su selección y número

- Introducir herramientas de autoevaluación y tutoriales en determinadas actividades para reforzar el aprendizaje.

\section{Referencias}

BENITO, A., CRUZ, A. (2005). Nuevas claves para la docencia universitaria en el Espacio Europeo de Educación Superior. Madrid: Narcea.

GOÑI ZABALA, J.M. (2005). El Espacio Europeo de Educación Superior, un reto para la universidad. Barcelona: Octaedro / ICE Universidad de Barcelona

PERRENOUD , P (2007). Diez nuevas competencias Para enseñar. Invitación al viaje, Graõ, Colofón, México

POUMAY, M., TARDIF, J. ET GEORGES, F. (2017). Organiser la formation à partir des compétences : un pari gagnant pour l'apprentissage dans le supérieur. Louvain-laNeuve, Belgique : De Boeck Supérieur.

UNIVERSITAT POLITĖCNICA DE VALÈNCIA. Competencias Transversales <http://www.upv.es/contenidos/COMPTRAN/ > [Consulta: 20 de junio de 2021]

UNIVERSITAT POLITÈCNICA DE VALÈNCIA. Proyecto Europa < http://www.upv.es/europa/documen2.html> [Consulta: 26 de junio de 2021]

UNIVERSITAT POLITĖCNICA DE VALÈNCIA. Proyecto Europa <https://www.upv.es/entidades/ICE/info/638057normalc.html> [Consulta: 10 de junio de 2020]. 


\title{
EDIFİCATE
}

I Congreso de Escuelas de Edificación y Arquitectura Técnica de España

València, 4 y 5 de noviembre de 2021

Escuela Técnica Superior de Ingeniería de Edificación

Universitat Politècnica de València

Doi: https://doi.org/10.4995/EDIFICATE2021.2021.13542

\section{La influencia de la presencialidad del alumnado en los resultados de evaluación en la UCAM}

\section{The influence of the presence of students in the evaluation results at UCAM}

\author{
Eloísa González Ponce ${ }^{a}$, Nuria Rosa Roca ${ }^{b}$, Mercedes Galiana Agullóc \\ aUCAM Universidad Católica de Murcia egonzalez@ucam.edu, aUCAM Universidad Católica de Murcia \\ nrosa@ucam.edu, cUCAM Universidad Católica de Murcia mgaliana@ucam.edu
}

\begin{abstract}
Due to the state of alarm decreed in Spain and the confinement of the population by COVID-19, in the second semester of the 2019-2020 academic year, Spanish universities had to suspend face-to-face teaching and change their teaching modality. As of March 14, 2020, at UCAM we adapt to teaching online classes and in this course to an adapted face-to-face modality. This study analyzes the academic performance of the students, in 5 subjects of the Degree in Building Engineering, comparing the results of the evaluation in the last three years, that is, in face-to-face, online and adapted mode. From the analysis it is derived that not being present does not influence the pass rate, but does influence the percentage of failures and no-shows.
\end{abstract}

\section{Keywords:}

Evaluation, adapted face-to-face, videoconference, virtual methodology and bimodal teaching. Building Engineering

\footnotetext{
Resumen

Debido al estado de alarma decretado en España y al confinamiento de la población por la COVID-19, en el segundo semestre del curso académico 2019-2020, las universidades españolas, tuvieron que suspender la docencia presencial y cambiar su modalidad de enseñanza. A partir del 14 de marzo de 2020, en la UCAM nos adaptamos a impartir las clases online y en el presente curso a una modalidad de presencialidad adaptada. Este estudio analiza el
} 
rendimiento académico de los alumnos, en 5 asignaturas del Grado en Ingeniería de Edificación, comparando los resultados de la evaluación en los tres últimos años, es decir, en modalidad presencial, online y adaptada. Del análisis se deriva que la no presencialidad no influye en el índice de aprobados, pero sí en el porcentaje de suspensos y de no presentados.

\section{Palabras clave:}

Evaluación, presencialidad adaptada, videoconferencia, metodología virtual y enseñanza bimodal. Ingeniería de Edificación 


\section{Introducción}

Las universidades españolas, por el estado de alarma decretado en España y el confinamiento de la población debido a la COVID-19, sucedido a principios del segundo semestre del curso académico 2019-2020, tuvieron que suspender la docencia presencial y cambiar de la noche a la mañana su modalidad de enseñanza.

La UCAM, a partir del 14 de marzo de 2020 en las asignaturas del segundo semestre del 2019-2020, pasó de impartir sus clases presenciales a la modalidad virtual, es decir, con metodologías para la educación a distancia, retransmitiendo en remoto y a tiempo real a través del Campus Virtual por Videoconferencia, circunstancia a la que el profesorado tuvo que adaptarse con rapidez. Gracias al fácil manejo de la herramienta se realizó sin dificultades. También la evaluación del alumnado tuvo que adaptarse a la modalidad no presencial.

Durante el curso académico 2020-2021 continúa la crisis sanitaria derivada de la pandemia y se ha optado por la enseñanza bimodal o presencialidad adaptada, que combina metodologías virtuales y presenciales, incidiendo en los grupos de clase reducidos, principalmente en las actividades formativas prácticas. Se trata de facilitar el seguimiento de las clases de tipo teórico o teórico/práctico a aquella parte del alumnado que, por circunstancias derivadas de la situación sanitaria, no puedan acudir presencialmente a las clases, retransmitiendo en directo con la instalación de cámaras en el aula.

Dado este panorama, parece interesante analizar si el cambio en la modalidad de enseñanza ha tenido repercusión en los resultados académicos de los alumnos, estudiando los 3 últimos cursos académicos: 2018-2020, antes de la pandemia, con presencialidad total; 2019-2020, online debido al confinamiento; y 2020-2021, enseñanza bimodal o presencialidad adaptada (Figura 1).

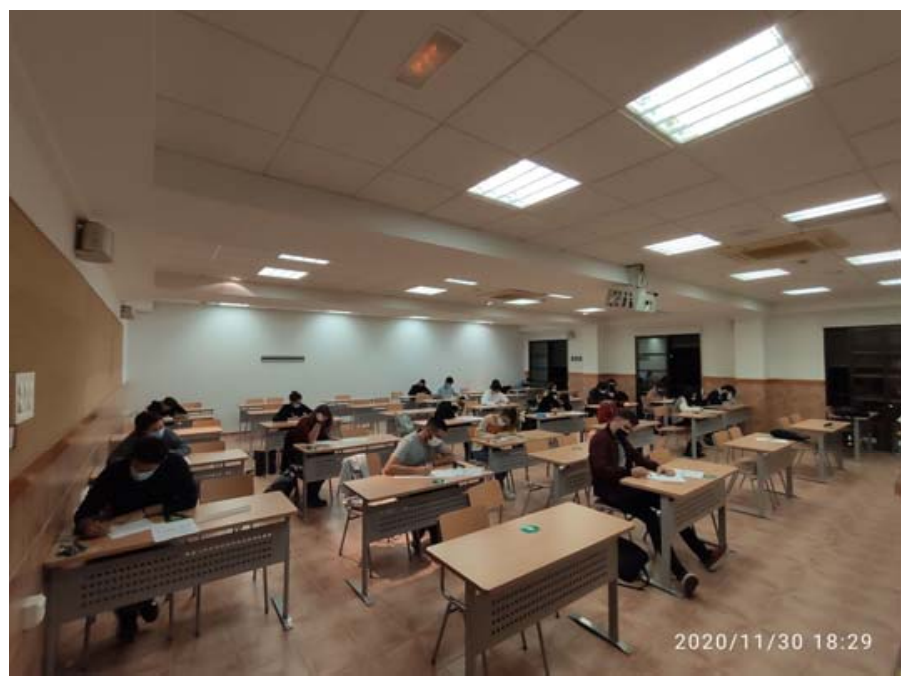

Figura 1. Alumnos con presencialidad adaptada

Fuente: Elaboración propia 


\section{Objetivos}

Los objetivos pretendidos son:

- Comparar los resultados de la evaluación en varias asignaturas del 2 semestre de la titulación de Ingeniería de Edificación de la UCAM, en la convocatoria de mayo/junio, que fue la convocatoria afectada en el curso 2019-20 por el confinamiento de la población, frente a la del curso anterior y posterior.

- Conocer si la presencialidad ha tenido influencia en el porcentaje de presentados y de aprobados.

\section{La enseñanza online y la presencialidad adaptada}

El Plan de Estudios del Grado en Ingeniería de Edificación que imparte la UCAM fue evaluado positivamente por la Agencia Nacional de Evaluación de la Calidad y Acreditación (ANECA) el 06 de mayo de 2008, verificado por el Consejo de Universidades el 28 de mayo de 2008, autorizada su implantación por parte de la Comunidad Autónoma de la Región de Murcia (CARM) y publicada en el Boletín Oficial de la Región de Murcia (BORM) mediante el Decreto n. ${ }^{\circ}$ 206/2008 de 11 de julio de 2008, publicado en el Boletín Oficial del Estado (BOE) del 26 septiembre 2008 para su inscripción en el Registro de Universidades, Centros y Títulos. La acreditación fue renovada el 27 de abril de 2016.

En la Memoria Verificada aprobada consta que el tipo o modalidad de enseñanza es presencial, con una carga lectiva total en el Grado de 240 créditos ECTS. Con carácter general, se ha considerado que cada crédito ECTS conlleva 25 horas de trabajo para el estudiante, repartidas en un $40 \%$ para las actividades presenciales y un $60 \%$ no presencial, para el trabajo que el alumno debe invertir en la realización de tareas y/o estudio. Todo esto se estima para un estudiante de capacidad media, calculando el esfuerzo que debe dedicar para superar cada crédito ECTS. Con estas premisas se consideró que el Grado en Ingeniería de Edificación precisa de una dedicación presencial del alumno de 2455 horas, de un total de 6000 horas (UCAM, 2015).

Las actividades formativas presenciales son especificadas por el profesor responsable en cada una de las Guía Docentes de la titulación, dando respuesta a las que enumera la Memoria Verificada para cada materia del Plan de Estudios. Estas actividades pueden ser: clase teórica participativa, clase práctica participativa, tutorías personalizadas y de grupo, seminarios y la evaluación en el aula.

Una vez sobrevenido el estado de alarma y el confinamiento de la población en marzo de 2020, la UCAM puso en marcha un plan de contingencia, para abordar la situación y determinar los protocolos de actuación para la adaptación en el curso 2019-2020 (UCAM, 2020 a), en base a las recomendaciones del Ministerio de Universidades y la CRUE, tal como hicieron la gran mayoría de universidades españolas (Area-Moreira, 2020). Posteriormente, la UCAM también estableció el protocolo para el curso 2020-2021 (UCAM, 2020 b). Cabe 
destacar que la planificación académica prevista inicialmente para el segundo semestre del curso 2019-2020 no se alteró ni en los horarios de impartición de las clases ni en las convocatorias de evaluación.

Ante esta nueva situación excepcional, las actividades formativas presenciales, incluida la evaluación en el aula, tuvieron que adaptarse a la modalidad online. Gracias a que el Campus Virtual disponía de la infraestructura necesaria, las clases teóricas y prácticas participativas se impartieron, en su mismo horario, por la herramienta de Videoconferencia BLACKBOARD disponible en el Campus Virtual de cada asignatura, y, además, fueron grabadas para su posterior visionado, dando flexibilidad a los alumnos que no pudieron asistir.

Para la rápida adaptación al cambio de modalidad que requería la situación, los servicios centrales de la UCAM, concretamente el Vicerrectorado de Enseñanzas Virtuales, realizó un Plan de Formación con varias sesiones formativas y de asistencia técnica en metodologías docentes y recursos técnicos on-line, con diverso material de apoyo, video tutoriales y manuales dirigidos al PDI (Personal Docente e Investigador). También se asignó un equipo PAS (Personal de Administración y Servicios) de personal técnico a cada titulación, con conocimiento en el funcionamiento de las herramientas a utilizar, disponible permanentemente para asistencia técnica y de apoyo, así como para la resolución de las posibles incidencias. Paralelamente y de forma similar, también se realizó el Plan de Formación y asistencia técnica al estudiantado.

En la impartición de las clases online, el profesor compartía la presentación y/o el material didáctico necesario con los alumnos a través de la herramienta. Los alumnos podían participar activando su micrófono o poniendo sus preguntas o consultas en el chat para que el profesor pudiera atenderlas en el periodo que destinara a las dudas o debate. En las clases más prácticas se utilizaron programas, como los de dibujo, mediante los cuales el profesor iba realizando, por ejemplo, los detalles constructivos mediante tarjeta gráfica y el alumno iba siguiendo la explicación, viendo el trazado del dibujo del profesor, e incluso podía ir realizando al mismo tiempo su propia práctica en su ordenador o tablet (Figura 2).

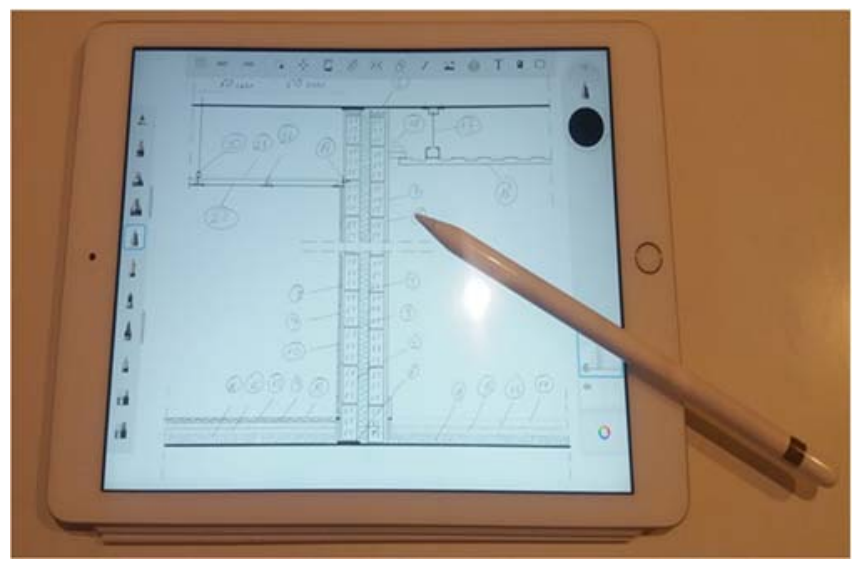

Figura 2. Prácticas de construcción en tablet

Fuente: Elaboración propia 
También se utilizaron videos grabados en cursos anteriores o de internet para suplir las prácticas presenciales de laboratorio o las visitas a obras y/o empresas externas. Otra metodología que se empleó fue dar permiso al alumno como presentador en la Videoconferencia, para que pudiera compartir su pantalla y así poder ver el trabajo realizado en sus tareas o prácticas y poder comentar y/o corregir, como si fuera una revisión en el aula, en grupo o individualmente alumno/profesor.

EI Campus Virtual UCAM está habilitado con diversas herramientas para la comunicación entre el profesor o profesores con los alumnos, incluso pueden utilizarlas para interactuar los alumnos entre sí, como pueden ser los Foros o el Chat. Todas las herramientas se muestran en la Figura 3.

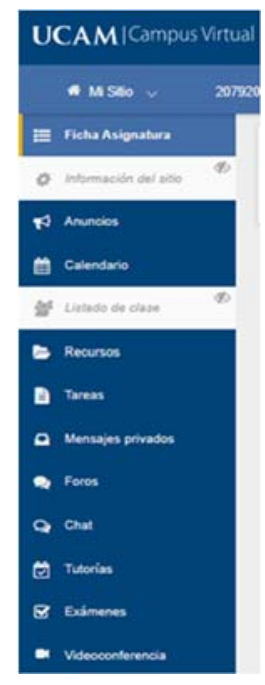

Figura 3. Herramientas CV UCAM

Fuente: Elaboración propia

La "Normativa de Evaluación UCAM" (UCAM, 2020 c), para mantener el carácter eliminatorio de los exámenes parciales, exige al alumnado un porcentaje mínimo de presencialidad. Desde el estado de alarma hasta el presente curso, en el cómputo de asistencia a las clases se han tenido en cuenta tanto las asistidas por el alumno de forma presencial como aquellas seguidas virtualmente, estas las contabiliza la herramienta al detectar la entrada del alumno a la Videoconferencia cuando la clase está siendo retransmitida en streaming.

En cuanto al sistema de evaluación siempre se ha respetado el especificado en la Memoria de Verificación y en la "Normativa de Evaluación Ucam", cambiando la modalidad presencial por la online. Para ello, en la plataforma del Campus Virtual se habilitó la herramienta Exámenes, con una serie de opciones para crear y programar exámenes tipo test de opción múltiple, por plantilla o por batería de preguntas y generando registros de eventos e informe de actividad. También se podía utilizar la herramienta de Tareas para la entrega de ficheros por parte del alumno, con los trabajos, prácticas, resolución de problemas, análisis de casos o respuestas a preguntas planteadas por el profesor. Se contaba con la opción de poder 
diseñar las tareas específicas asignándolas a un alumno o grupo de alumnos para evitar las copias, y también, para detectar porcentajes elevados de coincidencias, permitía activar el sistema Turnitin de antiplagio. Además, el profesor, para asegurar la autoría, podía precisar al estudiante una breve explicación o defensa de la tarea realizada a través de la herramienta Videoconferencia. Otra modalidad de examen era el examen oral, a través también de esa herramienta. Siempre, para la realización de los exámenes, todos los alumnos tenían que tener activada su webcam del ordenador, dispositivo móvil o Tablet. Durante las sesiones de evaluación se contaba con el apoyo del personal técnico para la solución de posibles incidentes.

Para que el alumno fuera conocedor de los detalles de la evaluación, el profesor debía anunciar previamente la convocatoria de examen, pormenorizando la metodología a seguir, además de la fecha y el horario. La decisión de aplicar un tipo de examen, modelo evaluatorio o instrumento de evaluación era decisión del profesor responsable de cada asignatura, para poder garantizar la adquisición de competencias y determinar el grado de aprendizaje de contenidos por parte del estudiante.

Durante el presente curso 2020-2021 se ha facilitado la presencialidad adaptada en la impartición de la docencia. Las clases y las tutorías han sido impartidas en el aula, pero retransmitidas también por Videoconferencia en tiempo real, compartiendo pantalla y activando la cámara del aula, para aquellos alumnos que no podían acudir presencialmente. Los exámenes, este curso, han sido presenciales respetando todas las medidas higiénicas en las instalaciones de la universidad y facilitando el cambio de fecha a aquellos alumnos confinados por el COVID-19.

\section{Resultados}

Para realizar la comparativa de resultados en la evaluación del alumnado en las 3 modalidades de enseñanza de estos 3 cursos académicos, se han tomado como muestra 5 asignaturas del segundo semestre del Grado en Ingeniería de Edificación, como son: Historia de la Construcción; Patología de la Edificación; Estudios, Planes y Coordinación de Seguridad; Gestión y Aseguramiento de la Calidad y Construcción IV, teniendo en cuenta sólo los datos de la convocatoria de mayo/junio de los cursos 2018-2019, 2019-20 y 20202021. No se han podido utilizar los datos de la convocatoria de recuperación, ya que del curso actual aún no se tienen resultados.

Los resultados se presentan en forma de porcentaje, sobre el total de alumnos matriculados, de aprobados, suspensos y no presentados para cada una de las 5 asignaturas (Tabla 1).

También se realiza una comparativa entre los resultados en su conjunto por curso académico, para tener una visión más global (Tabla 2). 
La influencia de la presencialidad del alumnado en los resultados de evaluación en la UCAM The influence of the presence of students in the evaluation results at UCAM

Tabla 1. Resultados por asignaturas

\begin{tabular}{l}
\hline \multicolumn{4}{|c|}{ Porcentajes asignaturas } \\
\begin{tabular}{|l|c|c|c|}
\hline $\begin{array}{l}\text { HISTORIA DE LA } \\
\text { CONSTRUCCIÓN }\end{array}$ & $18-19$ & $19-20$ & $20-21$ \\
\hline Aprobados & $100 \%$ & $20 \%$ & $71,4 \%$ \\
\hline Suspensos & $0 \%$ & $60 \%$ & $0 \%$ \\
\hline No presentados & $0 \%$ & $20 \%$ & $28,6 \%$ \\
\hline
\end{tabular}
\end{tabular}

\begin{tabular}{|l|c|c|c|}
\hline \multicolumn{1}{|c|}{ PATOLOGÍA } & $18-19$ & $19-20$ & $20-21$ \\
\hline Aprobados & $60 \%$ & $100 \%$ & $50 \%$ \\
\hline Suspensos & $0 \%$ & $0 \%$ & $0 \%$ \\
\hline No presentados & $40 \%$ & $0 \%$ & $50 \%$ \\
\hline
\end{tabular}
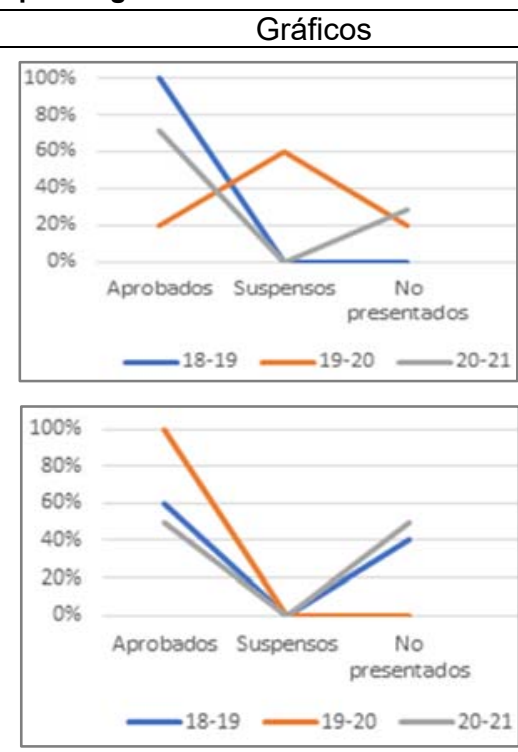

\begin{tabular}{|l|c|c|c|}
\hline $\begin{array}{c}\text { ESTUDIOS Y } \\
\text { PLANES }\end{array}$ & $18-19$ & $19-20$ & $20-21$ \\
\hline Aprobados & $\mathbf{9 1 , 7 \%}$ & $90 \%$ & $83,3 \%$ \\
\hline Suspensos & $\mathbf{8 , 3} \%$ & $0 \%$ & $16,7 \%$ \\
\hline No presentados & $\mathbf{0} \%$ & $10 \%$ & $0 \%$ \\
\hline
\end{tabular}

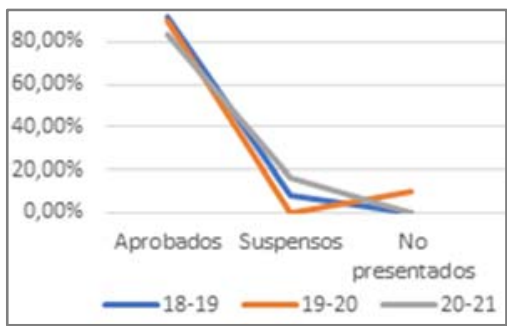

\begin{tabular}{|c|c|c|c|}
\hline $\begin{array}{c}\text { GESTIÓN Y } \\
\text { ASEG.CALIDAD } \\
\end{array}$ & $18-19$ & $19-20$ & $20-21$ \\
\hline Aprobados & $64,3 \%$ & $60 \%$ & $37,5 \%$ \\
\hline Suspensos & $35,7 \%$ & $40 \%$ & $50 \%$ \\
\hline No presentados & $0 \%$ & $0 \%$ & $12,5 \%$ \\
\hline
\end{tabular}

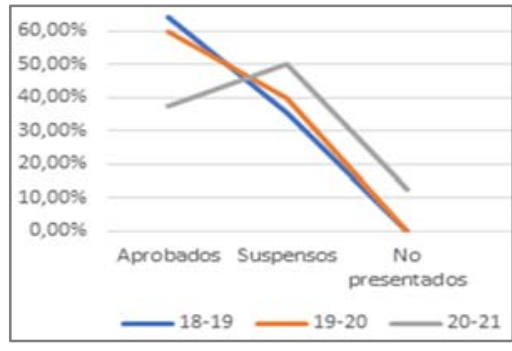

\begin{tabular}{|l|c|c|c|}
\hline $\begin{array}{c}\text { CONSTRUCCIÓN } \\
\text { IV }\end{array}$ & $18-19$ & $19-20$ & $20-21$ \\
\hline Aprobados & $12,5 \%$ & $27,3 \%$ & $20 \%$ \\
\hline Suspensos & $25,0 \%$ & $36,4 \%$ & $60 \%$ \\
\hline No presentados & $62,5 \%$ & $36,4 \%$ & $20 \%$ \\
\hline
\end{tabular}

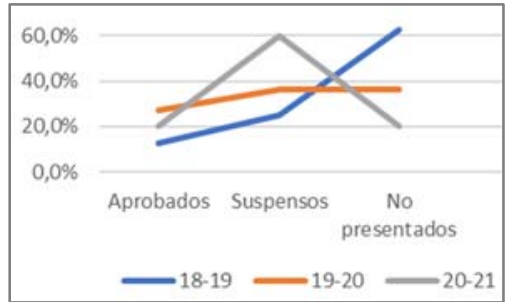


Tabla 2. Resultados por cursos académicos

\begin{tabular}{l}
\hline \multicolumn{4}{|c|}{ Medias por curso académico } \\
\begin{tabular}{|l|c|c|c|}
\hline $2018-2019$ & Aprobados & Suspensos & $\begin{array}{c}\text { No } \\
\text { presentados }\end{array}$ \\
\hline HISTORIA & $100 \%$ & $0 \%$ & $0 \%$ \\
\hline PATOLOGIA & $60 \%$ & $0 \%$ & $40 \%$ \\
\hline ESTUDIOS P & $91,7 \%$ & $8,3 \%$ & $0 \%$ \\
\hline GESTIÓN & $64,3 \%$ & $35,7 \%$ & $0 \%$ \\
\hline CONST.IV & $12,5 \%$ & $25,0 \%$ & $62,5 \%$ \\
\hline
\end{tabular}
\end{tabular}

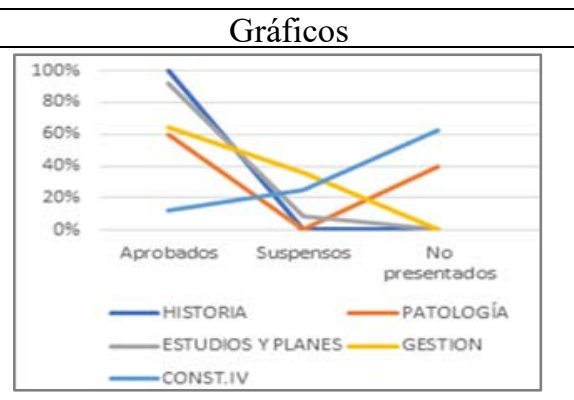

\begin{tabular}{|l|c|c|c|}
\hline 2019-2020 & Aprobados & Suspensos & $\begin{array}{c}\text { No } \\
\text { presentados }\end{array}$ \\
\hline HISTORIA & $20 \%$ & $60 \%$ & $20 \%$ \\
\hline PATOLOGIA & $100 \%$ & $0 \%$ & $0 \%$ \\
\hline ESTUDIOS P & $90 \%$ & $0 \%$ & $10 \%$ \\
\hline GESTIÓN & $60 \%$ & $40 \%$ & $0 \%$ \\
\hline CONST.IV & $27,3 \%$ & $36,4 \%$ & $36,4 \%$ \\
\hline
\end{tabular}

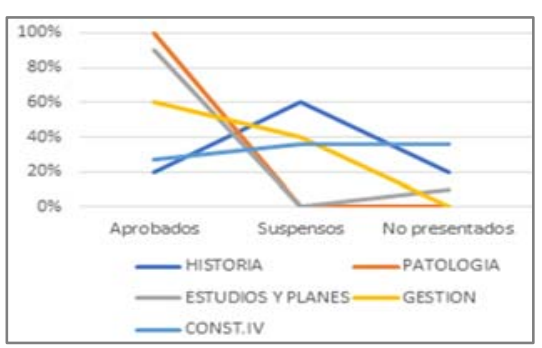

\begin{tabular}{|l|c|c|c|}
\hline 2020-2021 & Aprobados & Suspensos & $\begin{array}{c}\text { No } \\
\text { presentados }\end{array}$ \\
\hline HISTORIA & $\mathbf{7 1 , 4} \%$ & $\mathbf{0} \%$ & $\mathbf{2 8 , 6} \%$ \\
\hline PATOLOGÍA & $\mathbf{5 0 \%}$ & $\mathbf{0} \%$ & $\mathbf{5 0 \%}$ \\
\hline ESTUDIOS P & $83,3 \%$ & $16,7 \%$ & $\mathbf{0} \%$ \\
\hline GESTIÓN & $37,5 \%$ & $50 \%$ & $12,5 \%$ \\
\hline CONST.IV & $20 \%$ & $60 \%$ & $20 \%$ \\
\hline
\end{tabular}

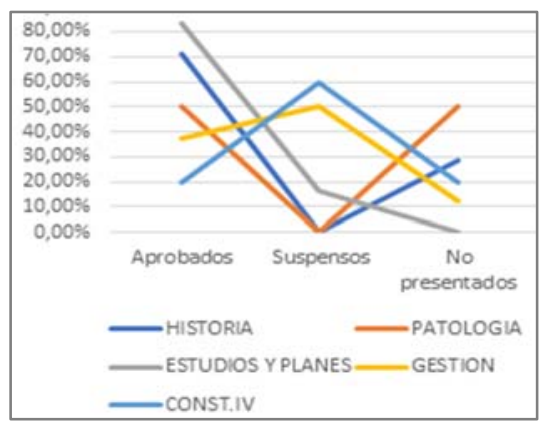

\begin{tabular}{|l|c|c|c|}
\hline \multicolumn{1}{|c|}{ MEDIA } & $2018-2019$ & $2019-2020$ & $2020-2021$ \\
\hline Aprobados & $65,7 \%$ & $59,4 \%$ & $52,5 \%$ \\
\hline Suspensos & $13,8 \%$ & $27,3 \%$ & $25,3 \%$ \\
\hline No presentados & $20,5 \%$ & $13,3 \%$ & $22,2 \%$ \\
\hline
\end{tabular}

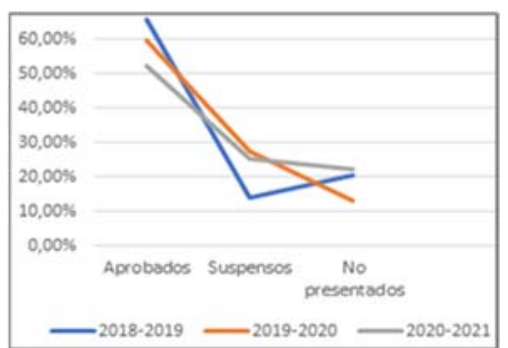


Del análisis de cada una de las asignaturas (Tabla 1) se obtienen los siguientes resultados:

- En la asignatura de Historia de la Construcción en el curso 2019-2020, cuando las clases tuvieron que ser online y con respecto al curso anterior con presencialidad obligatoria, el porcentaje de aprobados descendió considerablemente en un $80 \%$, el porcentaje de suspensos subió en un $60 \%$ y el de no presentados ascendió en un $20 \%$. En cambio, con respecto al presente curso, cuando la presencialidad es adaptada, el porcentaje de aprobados ha aumentado en más del $50 \%$, no hubo suspensos y el porcentaje de no presentados ascendió a un $8,6 \%$. Los resultados del curso 20-21 con respecto al 2018-2019 tienen un 28,6\% menos de aprobados y más de no presentados.

- En la asignatura de Patología, en el curso 2019-2020, cuando las clases no pudieron ser presenciales, el porcentaje de aprobados aumentó respecto al año anterior y fue del $100 \%$. En cambio, cuando la presencialidad ha tenido que ser adaptada en este curso 2020-2021, el porcentaje de aprobados ha bajado, siendo de un $50 \%$, y el porcentaje de no presentados ha aumentado un 50\%. Comparando el curso presente con el 2018-2019, los aprobados han descendido un $10 \%$ y los no presentados han aumentado otro $10 \%$.

- En la asignatura de Estudios y Planes, el porcentaje de aprobados ha ido disminuyendo desde el curso 2018-2019, el porcentaje más alto se producía cuando las clases eran presenciales. Cabe destacar que en el curso 2019-2020 el porcentaje de suspensos fue nulo, ya que se debió al $10 \%$ de no presentados. En cambio, en los cursos 2018-2019 y 2020-2021 no hubo no presentados.

- En la asignatura de Gestión y Aseguramiento de la Calidad, el porcentaje de aprobados ha ido descendiendo, en un 4,3\%, al pasar de presencial a online, y en un $22,5 \%$ en el paso del online a la modalidad adaptada. En cambio, es en esta modalidad cuando esta asignatura tiene índice de no presentados, concretamente de un $12,5 \%$.

- En la asignatura Construcción IV, el mayor índice de aprobados se obtuvo en el curso 2019-2020, con las clases online, y el mayor índice de suspensos se ha producido en este curso de presencialidad adaptada con un $60 \%$. Por otro lado, el índice de no presentados ha ido mejorando paulatinamente con respecto al curso $2018-2019$, bajando hasta un $20 \%$ en el curso $2020-2021$ con respecto al $62,5 \%$ del 2018-2019.

De la comparativa de lo acaecido en los diferentes cursos académicos analizados (Tabla 2) se obtienen los siguientes resultados:

- $\quad$ En el curso 2018-2019, que fue el curso de modalidad presencialidad, el porcentaje de aprobados fue mayor que el de suspensos en la mayoría de las asignaturas.

- En el curso 2019-2020, el curso donde las clases tuvieron que ser online, en la mayoría de las asignaturas fue mayor el número de aprobados respecto al de suspensos y no presentados. 
- En el curso 2020-2021, el curso donde hemos tenido presencialidad adaptada, el porcentaje de aprobados fue mayor que el de suspensos en la mayoría de las asignaturas.

- Las asignaturas que aumentaron sus aprobados en el curso 2019-2020 con respecto al año anterior y posterior fueron Patología y Construcción IV, asignaturas con más carga práctica que el resto en la resolución de casos reales y detalles constructivos.

- Analizando las medias de todas las asignaturas y cursos académicos, el porcentaje de aprobados ha ido descendiendo curso a curso desde el 2018-2019 hasta el 20202021. Por lo que, los aprobados del curso 2019-2020 aumentaron respecto al 20182019, pero son menores que los del curso 2020-2021. En cambio, el porcentaje de suspensos aumentó en 2019-2020 hasta el 27,3\%, y descendió al 25,3\% en este curso. Respecto a los no presentados, el curso 2019-2020 fue el de menor índice.

\section{Conclusiones}

Para hacer frente al cambio forzoso de la modalidad de enseñanza, los espacios virtuales y las nuevas tecnologías son un escenario que favorece a las nuevas formas de enseñanza y de aprendizaje colaborativo, a los que las universidades y los docentes tienen que adaptarse por las demandas sociales, laborales e incluso sanitarias.

En la experiencia vivida en la UCAM durante el curso 2019-2020 y con los datos analizados, no parece que la no presencialidad haya influido en el índice de aprobados, pues este fue menor que en el curso anterior, pero mayor que en el presente. Donde parece que sí ha influido es en el porcentaje de suspensos, que fue más elevado en ese curso, y en el de no presentados, que bajó de media un $8 \%$.

Hay que tener en cuenta que, un modelo de educación semipresencial o no presencial puede ser la transformación estratégica digital que tanto demanda la sociedad a las universidades, sin que esta deje de ser una enseñanza de calidad. Para ello debe haber un gran esfuerzo docente e inversión en infraestructuras, medios técnicos y personal (García-Peñalvo,2020), (Corel, 2021).

\section{Referencias}

AREA-MOREIRA, M., BETHENCOURT-AGUILAR, A., MARTÍN-GÓMEZ, S. Y SAN NICOLÁS-SANTOS, B. (2020). Análisis de las políticas de enseñanza universitaria en España en tiempos de Covid-19. $\mathrm{La}$ presencialidad adaptada. RED. Revista Educación a Distancia, 21(65). https://doi.org/10.6018/red.450461

CORELL, A. Y GARCÍA PEÑALVO, F. J. (2021) COVID-19: La encerrona que transformó las universidades en virtuales. Gaceta Cultural (91)

GARCÍA-PEÑALVO, F. J. (2020). Modelo de referencia para la enseñanza no presencial en universidades presenciales. Campus Virtuales, 9(1), 41-56. (www.revistacampusvirtuales.es)
UCAM Memoria Verificada tras el proceso de acreditación
$<$ https://www.ucam.edu/sites/default/files/estudios/grados/grado-edificacion/presencial/plan-de-
estudios/memoriaiev13conalegoct15.pdf> Murcia, 2015 [Consulta: 24 de junio 2021]

(2015) 
La influencia de la presencialidad del alumnado en los resultados de evaluación en la UCAM The influence of the presence of students in the evaluation results at UCAM

UCAM Protocolo COVID -19 para la Adaptación de las Enseñanzas Presenciales a Modalidad a-Distancia Curso 2019/2020 $<$ https://www.ucam.edu/sites/default/files/public/launiversidad/normativa/protocolo covid-19.pdf??ucam> Murcia, abril 2020 [Consulta: 24 de junio 2021]

UCAM Protocolo para la aplicación de un modelo universitario de presencialidad adaptada Curso 2020/21. <https://www.ucam.edu/sites/default/files/public/la-universidad/normativa/protocolo-parala-aplicacion-de-un-modelo-universitario-de-presencialidad-adaptada-2020-21.pdf> Murcia, julio 2020 [Consulta: 24 de junio 2021]

UCAM Normativa de Evaluación de la Universidad Católica de Murcia Curso 2020/2021 $<$ https://www.ucam.edu/sites/default/files/public/la-universidad/normativa/normativa-deevaluacion.pdf??ucam> Murcia, septiembre 2020 [Consulta: 24 de junio 2021] 


\title{
EDIFİCATE
}

I Congreso de Escuelas de Edificación y Arquitectura Técnica de España

València, 4 y 5 de noviembre de 2021

Escuela Técnica Superior de Ingeniería de Edificación

Universitat Politècnica de València

Doi: https://doi.org/10.4995/EDIFICATE2021.2021.13553

\section{Innovación pedagógica y aprendizajes en las asignaturas de Construcción en el Grado en Arquitectura Técnica de la Universidad de Burgos}

\section{Pedagogical innovation and learning in Construction subjets in the Degree in Technical Architecture of the University of Burgos}

\author{
Carmelo Muñoz Ruiperez ${ }^{a}$, Marina Muñoz-Arranz ${ }^{\mathrm{b}}$; Javier Garabito López ${ }^{\mathrm{c}}$; Francisco \\ Fiol Olivand \\ Universidad de Burgos \\ a cmruip@ubu.es, b munozarranz@gmail.com , cjgarabito@ubu.es, ${ }^{d}$ ffiol@ubu.es
}

\begin{abstract}
One of the main challenges of higher education is knowing how to adapt the training of students to the continuous need for innovation and research, a fundamental pillar in our education, being used as a differentiating and valuable element. The arrival of the Bologna plan provided new changes in university management and planning, achieving classes with a higher practical percentage, thus complementing the scientific or regulatory and technical aspects. In Construction subjects, the cooperative teaching-learning method is used, providing the student with a greater degree of autonomy, involvement and responsibility. Working cooperatively with students in construction subjects is mainly focused on practical classes where study cases are presented in which a simulation of real problems is carried out before which the student must propose and select solutions among which consider more appropriate
\end{abstract}

Keywords: Innovation, research, teaching methodology, teaching-learning.

\section{Resumen}

Uno de los principales desafíos de la educación superior es saber adaptar la formación del alumnado a la continua necesidad de innovación e investigación, un pilar fundamental en nuestra educación, empleándose como elemento diferenciador y de valor. La llegada del plan Bolonia proporcionó nuevos cambios en la gestión y planificación universitaria, logrando clases con mayor porcentaje práctico, consiguiendo de esta manera complementar el aspecto científico o normativo y el técnico. En las asignaturas de Construcción se emplea el método de enseñanza-aprendizaje cooperativo, proporcionando al 
alumnado un mayor grado de autonomía, implicación y responsabilidad. El trabajo con los estudiantes de manera cooperativa en las asignaturas de construcción se materializa sobre todo en las clases prácticas donde se plantean casos de estudio en los que se realiza una simulación de problemas reales ante los que el estudiante debe plantear y seleccionar soluciones entre las que considere más apropiada.

Palabras clave: Innovación, investigación, metodología docente, enseñanzaaprendizaje. 


\section{Introducción}

\subsection{El concepto de innovación en la Universidad}

Uno de los principales desafíos de la educación superior es saber adaptar la formación del alumnado a la continua necesidad de innovación e investigación (Rué, 2007), un pilar fundamental en nuestra educación, empleándose como elemento diferenciador y de valor.

Es fundamental describir, analizar y concretar el concepto de innovación educativa, dado que este ha ido evolucionando a medida que lo hacia la sociedad, adaptándose a las necesidades y a los constantes cambios de esta.

El concepto de innovación surge en el ámbito industrial, y poco a poco, se ha ido adaptando a la sociedad de la información (Margalef y Arenas, 2006), llegando a convertirse en un elemento propio dentro de las universidades a nivel mundial (Gairín, 2001; Quizhpe, Gómez y Aguilar, 2016).

Actualmente se habla de innovación más que nunca, pero, estas innovaciones deben consolidarse, evaluarse y adaptarse a las nuevas necesidades, siendo necesario un cambio de mentalidad por parte de todos los agentes principales en la educación, profesorado y alumnado (López-Martín, Días y Tiana, 2017).

El cambio de actitudes debe ir acompañado de un cambio en la forma de pensar y actuar, y que se fundamenta en nuevos objetivos, competencias, metodologías y estrategias de evaluación.

El alumnado debe convertirse en el principal agente en los procesos de enseñanzaaprendizaje, donde el docente actua de guía de los conocimientos y anima a los estudiantes a involucrarse en la educación, alentándoles a transformar el aprendizaje, cambiándolo, acomodándolo, mejorándolo, modificándose uno en el mismo proceso, convirtiéndose en líderes del cambio (García-Retamero, 2010; Salinas, 2004).

Nosotros como docentes, debemos valorar la innovación, la exploración, la creatividad... convirtiendo el proceso de enseñanza-aprendizaje en la comprensión, experimentación, resolución de problemas e indagación.

Como decía Piaget, debemos dejar que los estudiantes aprendan, que sean ellos quienes descubran, porque de esta manera, lograremos un mayor aprendizaje, una mayor autonomía, un mayor desarrollo de habilidades y un mayor crecimiento personal.

Podemos definir como innovación al proceso orientado a la mejora de un curso, un departamento o la persona que conlleva una planificación, una organización y un esfuerzo en busca del cambio (Gros y Lara, 2009), convirtiéndose en la llave para lograr una cohesión 
dentro de la educación, la formación y el crecimiento como docentes, y como consecuencia del alumnado.

\subsection{Innovación en las asignaturas de Construcción del Grado de Arquitectura Técnica en la Universidad de Burgos}

Desde la implantación en el curso 2010-2011 del Grado de Arquitectura Técnica, en las asignaturas de Construcción, hemos buscado la mejora y el aprendizaje, adaptando las guías docentes y los programas de las asignaturas a los cambios que surgían en la normativa, así como a las necesidades de los estudiantes.

Todo ello, teniendo en cuenta la relación entre sociedad-empresa-universidad, pilar fundamental para lograr un proceso enseñanza-aprendizaje y una formación más práctica integral y funcional.

La llegada del plan Bolonia proporcionó nuevos cambios en la gestión y planificación universitaria, logrando clases con mayor porcentaje práctico, consiguiendo de esta manera complementar el aspecto científico o normativo y el técnico.

Tabla 1: Asignaturas de Construcción en el Grado de Arquitectura Técnica en UBU

\begin{tabular}{|c|c|c|c|c|}
\hline ASIGNATURAS & CURSO & SEMESTRE & CRÉDITOS & CONTENIDOS \\
\hline Construcción I & $1^{a}$ & 1 & 6 & $\begin{array}{l}\text { Iniciación al conocimiento básico de los procesos constructivos. } \\
\text { Terreno. Técnicas y sistemas constructivos en cimentacione. } \\
\text { Sistemas de contención. }\end{array}$ \\
\hline Construcción II & $1^{\circ}$ & 2 & 6 & $\begin{array}{l}\text { Evolución histórica de las técnicas de construcción. Obras de } \\
\text { fábrica (resistentes y particiones). Introducción a las cubiertas }\end{array}$ \\
\hline Construcción III & $2^{\circ}$ & 1 & 6 & $\begin{array}{l}\text { Elementos constructivos realizados con hormigón. Cimentaciones. } \\
\text { Muros. Estructuras a base de muros. Entramados. Escaleras. } \\
\text { Prefabricación. EHE08. }\end{array}$ \\
\hline Construcción IV & $2^{a}$ & 2 & 6 & Canteria. Carpinteria de armar. Estructuras de acero y mixtas. EAE \\
\hline Construcción V & $3^{a}$ & 1 & 6 & Cubiertas. Fachadas. Revestimientos. Acabados \\
\hline
\end{tabular}

La implicación e intervención del alumnado en las sesiones también tomo un papel mucho más importante, logrando que fueran ellos quienes a través de continuas retroalimentaciones fueran indicando las necesidades de mejora y repaso en ciertos contenidos.

Es por ello, que desde las asignaturas de Construcción del Grado de Arquitectura Técnica nos planteamos seguir la siguiente estructura en la realización, programación y desarrollo del curso académico.

Como metodología docente, las asignaturas de Construcción cuentan con horas teóricas y prácticas, dividiéndose estas en prácticas de pizarra y prácticas en el taller de construcción, 
de forma que se complementa el aspecto científico o normativo y el técnico, posibilitando al estudiante una mejor comprensión de lo explicado, ya que en construcción la realidad teórica y práctica van indisolublemente unidas.

Para el desarrollo de las asignaturas de Construcción del grado Arquitectura Técnica se han elaborado unos materiales que se publican en la plataforma Moodle y que están a disposición de los estudiantes. Estos contenidos se van actualizado en virtud de las cambios normativos o nuevas técnicas constructivas que aparecen en el mercado. La normativa vigente y videos de construcción forman parte de su aprendizaje, y están a disposición de los estudiantes a través de la plataforma. Se pretende con todos estos materiales fomentar la actitud investigadora y que los estudiantes usen de forma correcta las tecnologías de la información que se disponen.

En las asignaturas de Construcción durante las presentaciones que se realizan el primer día de clase se les proporciona a los estudiantes un programa completo con toda la información necesaria para el desarrollo de estas, se les plantean los objetivos generales, la planificación con las clases teóricas, clases prácticas y de taller, la bibliografía seleccionada, el calendario de entrega de las prácticas y los controles que se efectuarán. Es importante que el estudiante conozca de antemano todos los aspectos de la asignatura.

La función de las tutorías es la de consulta y orientación académica, clarificando las dudas sobre la materia impartida y permitiendo afrontar la enseñanza de forma individualizada según las necesidades personales de cada estudiante, este recurso didáctico permite el intercambio de ideas entre el estudiante y el profesor, ofreciéndole retroalimentación sobre su trabajo. Las tutorías se realizan tanto de forma presencial como online.

La formación de las asignaturas de Construcción se complementa con la realización de conferencias, estas son impartidas por empresas del sector de la construcción donde se pretende que el estudiante conozca la realidad de la vida profesional, y fomentar y motivar el interés del estudiante por determinadas materias.

La realización de controles cada 3-4 semanas y que el contenido de estos sea propugnado por los estudiantes intenta fomentar la motivación de los estudiantes promoviendo el protagonismo de estos y la obtención de la recompensa de no tener que presentarse al examen final en función de la calificación de los controles.

Otra de las bases del aprendizaje es la inmersión tecnológica, que aumenta con la adaptación de escenario educativo que hemos tenido que realizar con la llegada de la pandemia, lo que nos ha permitido integrar aún más las nuevas tecnologías en el aula, convirtiendo las TICs en nuestro nuevo aliado en la educación.

Como dice Salinas (2004), la innovación docente va de la mano con las tecnologías de la información y la comunicación, las cuales, se encuentran integradas en los procesos de 
formación, dando acceso a nuevos usuarios, apoyando los cambios en los procesos de enseñanza-aprendizaje y haciendo estos aún más flexibles.

\section{Objetivos}

Los principales objetivos que se pretenden lograr introduciendo la innovación y las metodologías pedagógicas en las asignaturas de Construcción del Grado de Arquitectura Técnica en la Universidad de Burgos son los siguientes:

- Lograr una mayor autonómica, resolución de problemas, creatividad, formación en el alumnado.

- Proporcionar mayor importancia a la figura del estudiante en el desarrollo de las clases y las asignaturas.

- Reflexionar sobre el cambio de metodología pedagógica que estamos implantando en las asignaturas de Construcción.

- Cambiar la mentalidad de los agentes educativos en el proceso de enseñanzaaprendizaje

- Apoyar la importancia de la formación permanente del profesorado universitario.

- Aumentar la motivación docente por un aprendizaje teórico-práctico, activo y significativo

- Mejora de las tasas de éxito

\section{Desarrollo de la innovación}

En el desarrollo de los cursos, asignaturas y sesiones pretendemos que los estudiantes adquieran una serie de competencias, habilidades y contenidos, pero siempre bajo el objetivo de lograr futuros profesionales.

Se considera metodología pedagógica activa o innovadora a aquellas actividades o conjuntos de procesos que obligan al cambio de mentalidad tradicional, poniendo el enfoque en los procesos de enseñanza-aprendizaje y proporcionando una mayor importancia e implicación del alumnado en el desarrollo de estas (Silva y Maturana, 2017).

Las diferentes metodologías innovadoras se basan en el modelo centrado en el aprendizaje, que nos permiten lograr una mayor adquisición de los procesos de enseñanza-aprendizaje y un mayor grado de autonomía, implicación y responsabilidad del alumnado (Gallardo, Morara y García, 2015).

La propuesta de metodologías activas en las asignaturas de Construcción propicia un cambio de paradigma tradicional, incorporando enseñanzas participativas, planteando problemas en donde se involucran diferentes áreas de conocimiento de manera interdisciplinar, buscando un proceso dinámico de aprendizaje. 


\subsection{Aprendizaje cooperativo e interdisciplinar}

El trabajo en equipo es uno de los pilares en nuestra sociedad, y más en la educación, es por ello, que debemos aprender a trabajar en grupo, siendo aplicable tanto al alumnado como al profesorado.

La estrategia de aprendizaje cooperativo nos permite llevar a cabo actividades tanto dentro como fuera del aula convirtiéndolas en experiencias de crecimiento tanto social como de aprendizaje, en la que los diferentes integrantes buscan un objetivo común aportando lo mejor de ellos (García Ruiz y González, 2013).

El trabajo con los estudiantes de manera cooperativa en las asignaturas de construcción se centra sobre todo en las clases prácticas donde se plantean casos de estudio en los que se realiza una simulación de problemas reales ante los que el estudiante debe plantear y seleccionar soluciones entre las que considere más apropiadas.

Las prácticas deben ser presentadas y defendidas por grupos de trabajo (máximo 3 personas por grupo), debiendo los otros grupos formular cuestiones sobre aspectos del trabajo presentado, logrando una heteroevaluación entre los propios estudiantes, aprendiendo los unos de los otros. Se promueve el espíritu emprendedor del estudiante, el pensamiento crítico y su autonomía, ya que son ellos, quienes deben defender sus presentaciones e ideas.

En las prácticas los estudiantes comparten sus dudas y aplican lo aprendido como de lluvia de ideas, logrando una cohesión grupal y una mayor satisfacción en los resultados.

Esta técnica también les proporciona habilidades de trabajo en grupo, resolución de conflictos, interdependencia positiva, y valores como la responsabilidad, el respeto y la confianza.

El trabajo del profesorado es multidisciplinar, es decir, que involucra el trabajo de diferentes profesionales de diferentes disciplinas y departamentos. Logrando así una mayor amplitud de conocimientos y perspectivas a la hora de transmitir las clases y de desarrollar las guías docentes (López, Corrales, Corchuelo y Blanco, 2015).

\subsection{Educación práctica}

Con esta metodología se pretende acercar al estudiante la realidad de las empresas, de la vida profesional, haciendo que los estudiantes sean conscientes de las necesidades laborales de estas.

A nuestro juicio una de las funciones principales de un profesor es la de proporcionar-entrenar nuevas estrategias que ayuden en la adquisición de conocimientos, este aspecto se ve materializado en las prácticas donde se plantean casos de estudio en los que se realiza una 
simulación de problemas reales ante los que el estudiante debe plantear y seleccionar soluciones entre las que considere más apropiadas. Las prácticas se desarrollan mediante trabajo colaborativo, estas deben ser presentadas y defendidas por los grupos de trabajo (máximo 3 personas por grupo), debiendo los otros grupos formular cuestiones sobre aspectos del trabajo presentado, logrando una heteroevaluación entre los propios estudiantes, aprendiendo los unos de los otros. Se promueve el espíritu emprendedor del estudiante, el pensamiento crítico y su autonomía, ya que son ellos, quienes deben defender sus presentaciones e ideas.

Los profesores que impartimos las asignaturas de construcción contamos con una amplia experiencia profesional, proporcionando a los estudiantes una imagen realista de los problemas que se pueden plantear en un futuro, así como fomentar habilidades en cuanto a la resolución de problemas de la vida real.

\subsection{Aprendizaje activo}

La metodología activa pretende la integración activa de los estudiantes en la planificación y desarrollo de las sesión y en la adquisición de aprendizajes.

La filosofía parte del cambio de papel del profesor, quien actúa como guía y orienta en el desarrollo de los aprendizajes, aportando mayor importancia a los estudiantes, y en donde se fomenta su aprendizaje autónomo, la resolución de problemas y la adquisición de habilidades y competencias pedagógicas (Morera et al, 2013).

Este cambio también repercute en los estudiantes, quienes deben cambiar la mentalidad de receptores de conocimiento, convirtiéndose en investigadores e indagadores de información constante, es decir, en sujetos activos de aprendizaje.

En las asignaturas de Construcción del Grado de Arquitectura Técnica pretendemos que nuestro estudiantes sean los protagonistas del aprendizaje, es por ello, que en la primera clase se dedica a la explicación de lo que se va a impartir en cada asignatura, cómo se estructura esta, los objetivos, habilidades y competencias que se pretende que adquieran, cómo se va a impartir la docencia (teóricas, prácticas, taller), los profesores que van a impartirla, los criterios de evaluación, para que el estudiante tenga una idea global de la asignatura y puedan reflexionar en cuanto a su progreso y planificación.

Durante el desarrollo de todas sesiones, los estudiantes tienen un papel activo, siguiendo la filosofía "aprendiendo a hacer", donde tanto profesores y estudiantes nos encontramos en un continuo feedback de aprendizajes.

Dedicamos la última clase a departir con los estudiantes todos aquellos aspectos de la asignatura que les han parecido más o menos interesantes, en resumen, determinar el grado de satisfacción de estos con la asignatura, realizando una autoevaluación que permite posteriormente junto con las encuentas regladas que realiza la Universidad de Burgos 
mejorar y complementar o trabajar respecto a ello, lo que nos ha permitido introducir cambios en las asignaturas que han hecho que estas evolucionen.

Las tutorías con los estudiantes son fundamentales en el proceso enseñanza-aprendizaje, y muy enriquecedoras tanto para los estudiantes como para nosotros como profesores. La figura del docente debe ir más allá de ser un mero transmisor de conocimientos, sirviendo las tutorías como una labor de apoyo y asesoramiento para desarrollar una actividad complementaria a la didáctica del aula.

\section{Resultados}

Los cambios que se han ido realizando (prácticas en grupo, heteroevaluación de las mismas por los propios estudiantes, realización de controles formulados por ellos mismos, etc..) han sido del agrado de los estudiantes que han respondido con entusiasmo a los mismos en las reflexiones que se han realizado con ellos, siendo los resultados académicos muy elocuentes, con tasas de éxito muy satisfactorias.

Tabla 2: Tasas de éxito en los últimos 4 cursos en Construcción III y IV

\begin{tabular}{|l|c|c|c|c|}
\hline \multirow{2}{*}{ ASIGNATURAS } & \multicolumn{4}{|c|}{ TASA DE ÉXIIO } \\
\cline { 2 - 5 } & Curso 17-18 & Curso 18-19 & Curso 19-20 & Curso 20-21 \\
\hline Construcción III & $62,50 \%$ & $60 \%$ & $100 \%$ & $72,70 \%$ \\
\hline Construcción IV & $81 \%$ & $87,50 \%$ & $100 \%$ & $95 \%$ \\
\hline
\end{tabular}

Pero todavía existen factores que en nuestra opinión influyen negativamente en los resultados académicos de alguna asignatura, como en el caso de la asignatura de Construcción III, que se imparte el primer semestre en el segundo curso, y determinados contenidos fundamentales para el desarrollo de esta asignatura se imparten en el siguiente semestre, este aspecto ha sido sancionado por estudiantes repetidores, en las reflexiones que se mantienen con los estudiantes.

\section{Conclusiones y aprendizajes}

La llegada de la innovación a la educación superior trae consigo un necesario cambio de ideologías y paradigmas, así como la necesaria reformulación pedagógica dentro del Grado de Arquitectura Técnica.

En la formación de nuestros estudiantes es necesario el aprendizaje de fórmulas, técnicas, procedimientos... pero también debemos tener la perspectiva humanística, somos personas que tratamos con personas y formamos a personas. 
Lo que nos lleva un cambio necesario de las guías docentes, en los contenidos de las asignaturas, y en las guías docente que en muchas ocasiones se han estacado en la tradicionalidad.

Nosotros como docentes debemos propiciar la innovación dentro de nuestros propios estudios, en nuestras aulas y en nuestros estudiantes. Para ello, debemos realizar un cambio en las metodologías, haciéndolas más innovadoras y pedagógicas.

La figura del docente debe estar en continua formación y crecimiento, adaptándose a los avances de la sociedad, generando una necesidad continua de evolución y crecimiento.

Debemos cambiar el enfoque de enseñanza por el enfoque de enseñanza-aprendizaje, centrándonos más en el aprendizaje de los estudiantes, dándoles mayor importancia, responsabilidad y autonomía, generando futuros profesionales cualificados con gran cantidad de recursos, cualidades y habilidades.

Estos nuevos cambios han supuesto grandes dificultades, haciéndonos volver a aprender, y proporcionándonos esa necesidad de seguir avanzando, aunque todavía nos queda mucho por aprender. El conocimiento de estas nuevas técnicas y metodologías por parte de los docentes nos permiten influir positivamente en la calidad educativa e incentivar en los estudiantes la construcción del conocimiento con reflexión, análisis y creatividad.

Las nuevas metodologías han proporcionado a las asignaturas de construcción donde se han aplicado un nuevo aire de adaptación, de crecimiento y de evolución. Permitiéndonos reflexionar sobre la necesidad de cambio en la práctica docente.

\section{Bibliografía}

GAIRÍN, J. (2001). "La innovación en la Universidad” en Revista de Investigación Educativa, vol 19, issue 2, p 635-640.

GALLARDO, B., MORERA, I., \& GARCÍA, E. (2015). "Metodología innovadora en la universidad. Sus efectos sobre los procesos de aprendizaje de los estudiantes universitarios" en Anales de Psicología, vol 31, issues 3, p 901-915.

GARCÍA-RETAMERO, J. (2010). "De profesor tradicional a profesor innovador" en Revista digital para profesionales de la enseñanza, issue 11.

GARCÍA-RUIZ, R.M. \& GONZÁLEZ, N. (2013). "El aprendizaje cooperativo en la universidad. Valoración de los estudiantes respecto a su potencialidad para desarrollar competencias" en Revista Iberoamérica para la Investigación y el Desarrollo Educativo, vol 4, issue 7, p 106-128.

GROS, B. \& LARA, P. (2009). "Estrategias de innovación en la educación superior: el caso de la Universitat Oberta de Catalunya" en Revista Iberoamericana de Educación, issues 49, p 223-245. 
LÓPEZ, M.J., CORRALES, N.M., CORCHUELO, B. \& BLANCO, M.A. (2015). "Interdisciplinariedad a través del aprendizaje cooperativo para adquisición de competencias" en Campo Abierto, vol 34, issue $1, \mathrm{p} 103-121$.

LÓPEZ-MARTíN, R., DIAS, P. \& TIANA, A. (2017).(Eds.), “ E-Innovación en la educación superior” en Comunicar, vol 51 , issue 2.

MARGALEF, L. \& ARENAS, A. (2006). “¿Qué entendemos por innovación educativa?. A propósito del desarrollo curricular” en Perspectiva Educacional, Formación de profesores, issue 47 p 13-31.

MORERA, \&. et al. (2013). Metodología innovadora y estrategias de aprendizaje en la Universidad. GIMA. Valencia: Universidad Politécnica de Valencia. http://doi.org/10.13140/2.1.1228.9609

QUIZHPE, L.A., GÓMEZ, O.A. \& AGUILAR, R.P. (2016). "La innovación educativa en la Educación Superior Ecuatoriana y el portafolio docente: instrumentos de desarrollo" en Revista Cubana de Reumatología, vol 18, issue 3, p 297-303.

RUÉ, J. (2007). Enseñar en la universidad. El EEES como reto para la educación superior. Madrid, ES: Narcea.

SALINAS, J. (2004). "Innovación docente y uso de las Tic en la enseñanza universitaria" en universities y Knowledge Society Journal, vol 1, issue 1.

SILVA, J. \& MATURANA, D. (2017). "Una propuesta de modelo para introducir las metodologías activas en la educación superior" en Innovación Educativa, vol 16, issues 73, p 117-131. 


\title{
EDIFİCATE
}

I Congreso de Escuelas de Edificación y Arquitectura Técnica de España

València, 4 y 5 de noviembre de 2021

Escuela Técnica Superior de Ingeniería de Edificación

Universitat Politècnica de València

Doi: https://doi.org/10.4995/EDIFICATE2021.2021.13575

\section{Instrumentación real de edificios para docencia en la asignatura de Patología y Restauración \\ Instrumentation of buildings for teaching in the subject of Pathology and Restoration}

\author{
Jesús González-Arteaga ${ }^{a}$ \\ a Escuela Politécnica de Cuenca, Universidad de Castilla-La Mancha, jesus.garteaga@uclm.es.
}

\begin{abstract}
The pathology and restoration subject seeks to train future technicians to diagnose problems in buildings. This course shows the procedures and methodologies that technicians use in their work for data collection and validation of hypotheses about the causes of pathologies. In the practice works that students perform during the course it is not possible to monitor the evolution over time of the lesions, treating this aspect only in a theoretical way. To solve this deficiency, it has been proposed the use of monitoring equipment installed in buildings of the university itself in which students can track them during the semester, which data taken previously can be added, thus being able to develop the ability to identify expected trends and identify problems based on values obtained in a real case.
\end{abstract}

Keywords: Pathology, Instrumentation, Follow-up, Teaching resources

\section{Resumen}

La asignatura de patología y restauración busca capacitar a los futuros técnicos para el diagnóstico de problemas en las edificaciones. En esta asignatura se muestran los procedimientos y metodologías que los técnicos utilizan en su trabajo para la toma de datos y validación de hipótesis sobre las causas de las patologías. En las prácticas que realizan los alumnos durante el curso no es posible realizar un seguimiento de la evolución en el tiempo de las lesiones, tratando este aspecto solo de forma teórica. Para solventar esta carencia se ha propuesto la utilización de equipos de monitorización instalados en edificios de la propia universidad en los cuales los alumnos puedan hacer el seguimiento de estos durante el semestre en el que se imparte la asignatura, a los que se pueden añadir datos tomados con anterioridad, pudiendo asi desarrollar la capacidad de identificar tendencias 
Instrumentación real de edificios para docencia en la asignatura de Patología y RestauraciónInstrumentation of buildings for teaching in the subject of Pathology and Restoration

esperadas e identificar problemas en base a valores obtenidos en un caso real.

Palabras clave: Patología, Instrumentación, Seguimiento de lesiones, Recursos docentes 


\section{Introducción}

En el Grado de Ingeniería de Edificación que se imparte en la Escuela Politécnica de Cuenca, Universidad de Castilla-La Mancha, los estudiantes se preparan para poder trabajar como técnicos del sector de la edificación.

En su plan de estudios, publicado en el Boletín Oficial del Estado en marzo de 2010 (España, 2010), se establece dentro de la formación específica en el módulo de Técnicas y Tecnología de la Edificación, en la materia de Construcción la asignatura obligatoria de 6 créditos ECTS Patología y Restauración.

Los resultados de aprendizaje esperados propios de la asignatura son:

- Elaboración de manuales y planes de mantenimiento. Gestionar su implantación en los edificios.

- Dictaminar sobre las causas y manifestaciones de las lesiones en los edificios.

- Intervención en la rehabilitación de edificios y la restauración y conservación del patrimonio construido.

- Plantear y resolver detalles constructivos adecuados a requerimientos previos.

- Comprensión de la forma de trabajo de los elementos constructivos, definir su función y compatibilidad.

- Propuesta de soluciones de reparación de las lesiones.

- Puesta en obra de los elementos y sistemas constructivos.

- Analizar el ciclo de vida útil de los elementos y sistemas constructivos.

Para poder alcanzar estos objetivos se han venido desarrollando durante cursos pasados, junto a las clases teóricas, diversas prácticas de dos tipologías diferentes. Por un lado, trabajos que se inician en clase presencial junto a los profesores y que se finalizan de forma individual, centrados en los distintos bloques que componen la asignatura. En ellos los alumnos localizan lesiones, elaboran mapas de lesiones, realizan fichas patológicas, determina causas y proponen actuaciones. Se usan para ello casos reales aprovechando, bien edificaciones existentes en la ciudad, bien casos estudiados por los profesores (ver fig. 1) siendo necesario realizar simplificaciones para que los alumnos puedan abordar las prácticas.

A su vez se realiza sobre un edificio real que presenta lesiones significativas, un estudio patológico que se va completando conforme se desarrolla la asignatura realizándose diversas sesiones de seguimiento en la que los alumnos exponen sus avances completándose la práctica con una presentación final. Para la elección del inmueble objeto de esta práctica de curso se busca que se tenga la mayor accesibilidad para que los alumnos puedan realizar más visitas adicionales a la de inicio que se realiza junto con los profesores. Cuando se ha detectado una necesidad general por parte de los alumnos se han organizado visitas posteriores en grupo. Este caso de estudio debe presentar lesiones 
que permitan la determinación de unas hipótesis sobre su origen sin la necesidad de ensayos ni cálculos que impliquen tener que determinar las capacidades portantes específicas, ya que por un lado generalmente el propietario del edificio no permite realizar ensayos destructivos, y por otro el tiempo de visita y la duración de la asignatura no permite hacer un seguimiento significativo de las lesiones e introducir cálculos completos llevaría a dedicar tiempos elevados que se corresponden más con las asignaturas de cálculo.

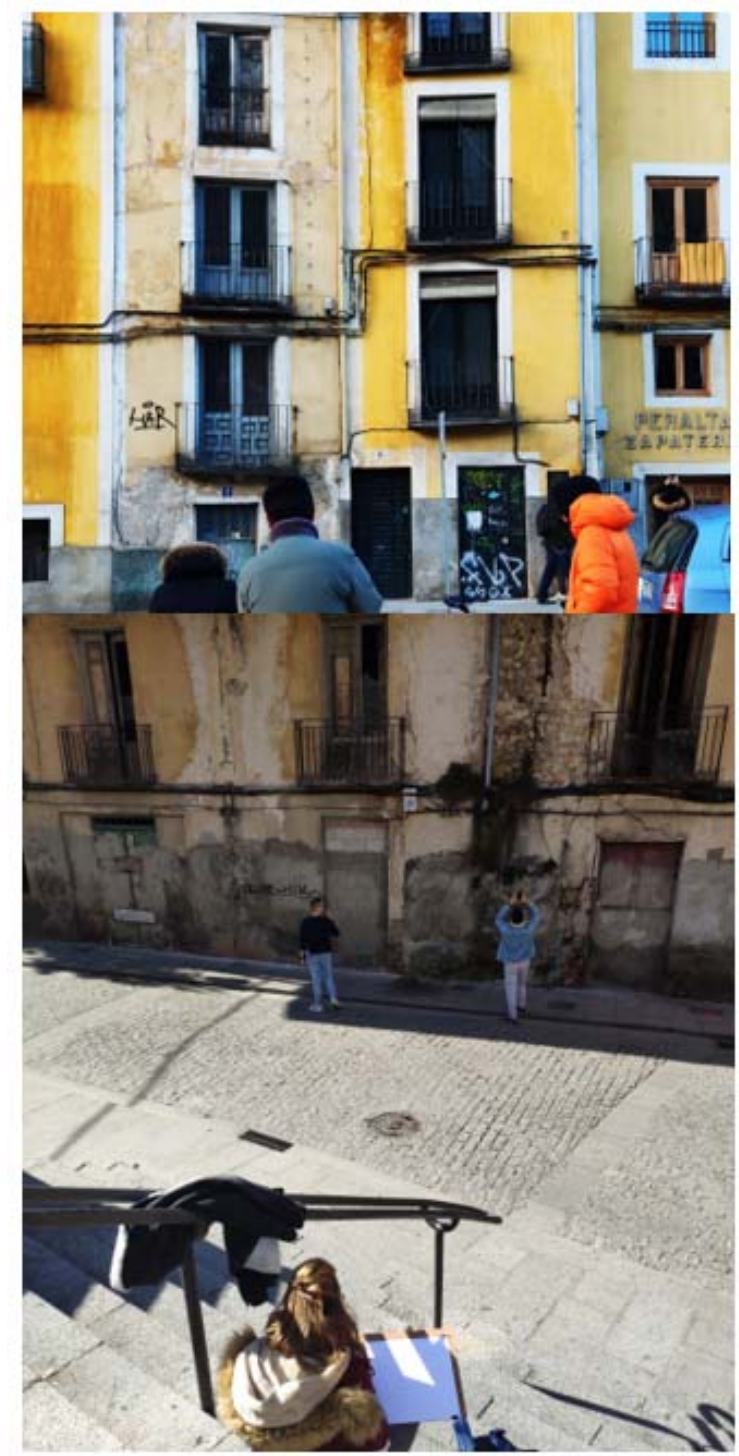

Fuente: Elaboración propia.

Fig. 1 Ejemplos de tomas de datos en casos reales para para prácticas de la asignatura de patología. 
Se debe indicar que la monitorización es una tendencia actualmente (Meyer et al., 2013; la Manna, 2015; Noel et al., 2017; Wang et al., 2018), que sirve para mejorar el conocimiento de los edificios, controlar su estado de conservación y permite realizar estudios patológicos basados en datos que aportan certeza y seguridad a los técnicos.

\section{Objetivos}

Dado que el futuro técnico debe tener capacidad para poder realizar un seguimiento en el tiempo de la evolución de las lesiones se plantea el problema de poder hacer tomas de datos en los meses de docencia (de febrero a mayo) que permitan desarrollar esas capacidades y que les sirvan para respaldar o descartar hipótesis sobre las causas que originan los problemas de patología en los edificios y casos estudiados.

A su vez se plantea el poder hacer que estos futuros técnicos conozcan equipos de instrumentación y seguimiento que pueden emplear para el estudio de lesiones o para una monitorización que sirva para un adecuado control del estado de salud de las edificaciones. Se quiere que el alumno sea el que establezca la frecuencia de lectura y realice las tomas de datos o descargue los archivos con los valores medidos en bruto, pudiendo aplicar metodologías de trabajo que permitan su interpretación.

Se quiere también que los alumnos adquieran nociones sobre las horquillas de valores habituales en las variables que se pueden monitorizar para conocer el comportamiento estructural por medio de mediciones de deformación o los cambios que se producen en las lesiones como por ejemplo la variación de apertura de una grieta.

Finalmente se plantea como objetivo que estos trabajos de seguimiento no supongan una carga extra sobre el alumno que suponga una dedicación por encima de la requerida por los créditos establecidos, buscando además generar un interés despertando la curiosidad sobre cómo va el problema o la variable monitorizada.

\section{Desarrollo de la innovación}

Para que los alumnos puedan trabajar con equipos de seguimiento se han utilizado las mediciones de los equipos de monitorización del Instituto de Tecnología Construcción y Telecomunicaciones de la UCLM, que se sitúa junto al edificio donde se imparte la docencia de la asignatura, instalados inicialmente para realizar labores de investigación sobre interacción suelo estructura y la influencia de las cargas ambientales (González-Arteaga, 2019; González-Arteaga, 2020). Aquí se han dispuesto diversos sistemas de medición de variables ambientales como temperatura, humedad, condiciones climáticas y de movimientos en la estructura por medio de sensores y equipos de medida. Son especialmente interesantes los clinómetros ((Durham Geo Slope Indicator, 2010)) instalados sobre diversas soluciones estructurales (figura 2) que permiten ver el diferente comportamiento de una tipología estructural frente a otra. 


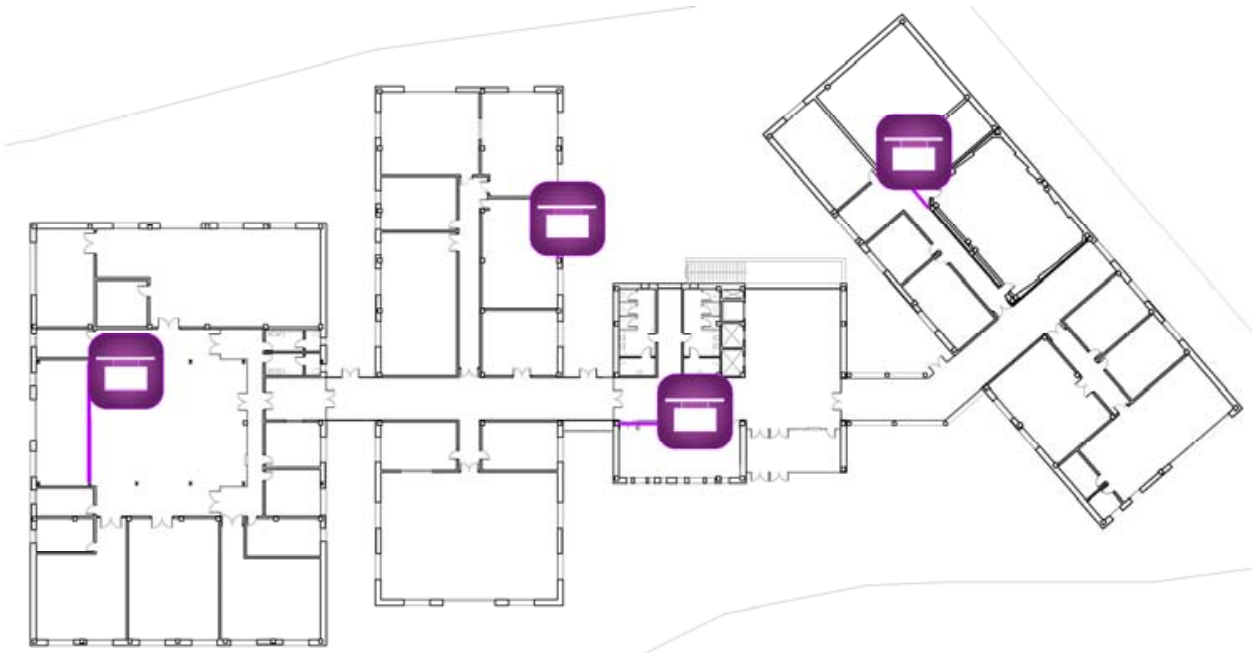

Fuente: Elaboración propia.

Fig. 2 Disposición de los clinómetros (icono morado) en el Instituto de Tecnología Construcción y Telecomunicaciones de la Universidad de Castilla-La Mancha.

Estos resultados de toma de datos se han expuesto en clase durante dos cursos (figura 3), explicando los valores y tendencias obtenidas, sin llegar a establecer una dinámica de trabajo con ellos, pero consiguiendo despertar un interés en el alumnado sobre esos sistemas de instrumentación, queriendo conocer más sobre su funcionamiento, frecuencias, rangos y métodos de interpretación.

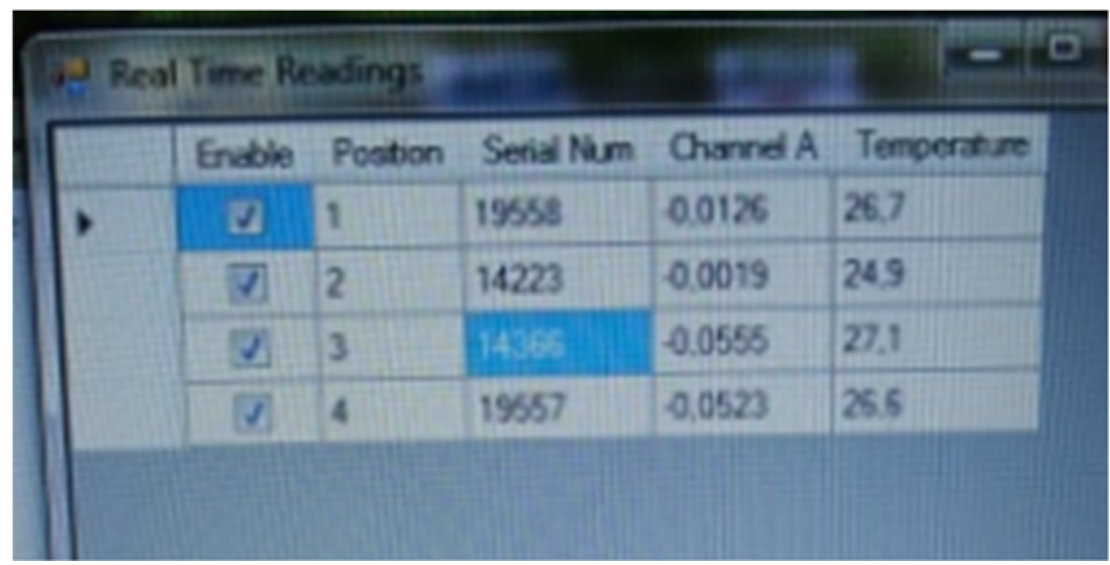




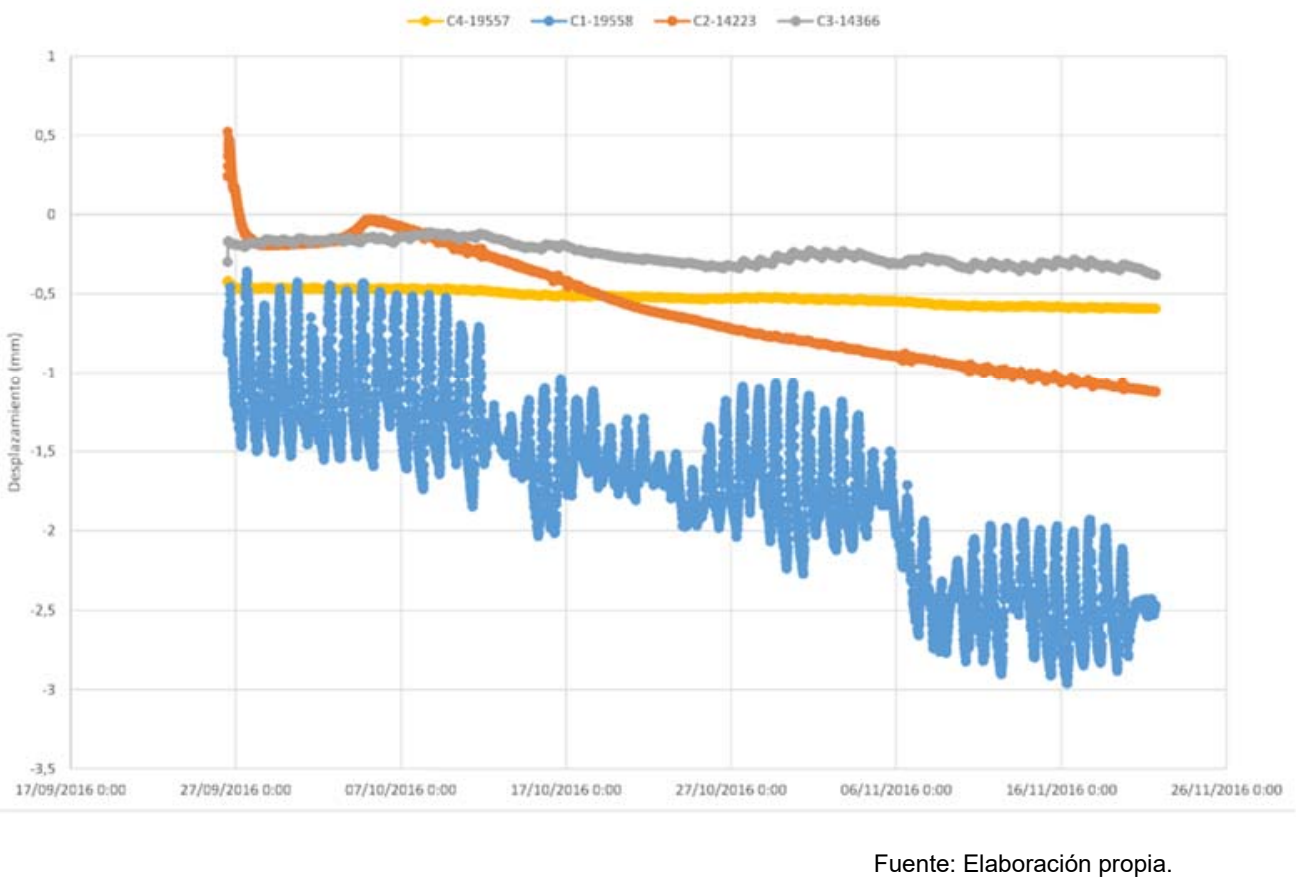

Fig. 3 Captura de pantalla de la descarga de datos y comparativa de resultados obtenidos en los 4 clinómetros dispuestos.

Además, durante el curso 2020-21 se dispusieron en una grieta existente muy próxima al aula unos equipos de medición de espesor de grieta tipo crackmeter, más concretamente los sensores VW Displacement Sensor fabricado por Slope Indicator de rango $60 \mathrm{~mm}$. (Slope Indicator Company, 2003), que pueden verse en la figura 4, que han servido para que los alumnos conociesen estos sistemas de medición interesándose por la evolución de algunas grietas y fisuras existentes en el edificio demandando conocer más sobre sus lecturas y su interpretación. 


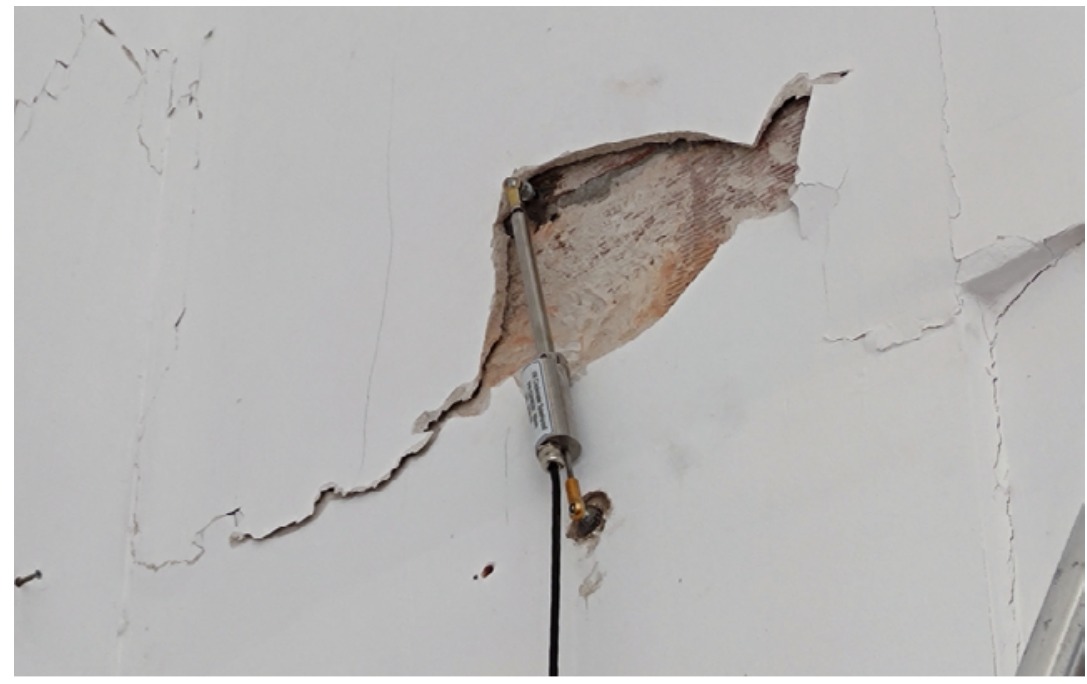

Fuente Elaboración propia.

Fig. 4 Crackmeter VW Displacement Sensor, instalado junto a aula de la asignatura.

\section{Resultados}

El resultado de mostrar a los alumnos el seguimiento realizado en un edificio que conocen y enseñarles los equipos de instrumentación y sus lecturas ha despertado un interés en el estudio de las patologías, aumentando su participación en clase, y ha permitido conocer técnicas para el diagnóstico de las patologías, que es uno de los objetivos de la asignatura. Han sido los propios alumnos los que han solicitado a los profesores poder trabajar con estos equipos durante el curso.

Por ello y con el fin de paliar la problemática indicada sobre la falta de trabajo en seguimiento de lesiones para el curso próximo se va a implementar un trabajo práctico en el cual los alumnos además de investigar en técnicas para el estudio de la evolución de las lesiones comprobarán las lecturas de los equipos instalados descargando cada mes los datos registrados por los clinómetros y crackmeter. Trabajarán por medio de hojas de cálculo en su análisis y se implantará este seguimiento dentro de la metodología BIM, que 
se trabaja en el Grado de Ingeniería de Edificación, en este caso dentro del 7D, gestión del ciclo de vida, realizando un informe final del seguimiento al concluir el semestre.

Se plantea como complemento facilitar datos de la monitorización previa en casos en que los cuatro meses de docencia no aporten resultados relevantes.

Se espera que puedan seguir aumentando en número de sensores, utilizando equipos de menor coste, que ampliarán las posibilidades de trabajo de los alumnos y ofrecerán mayor variedad de casos para el estudio.

\section{Conclusiones}

Como se ha indicado la monitorización es tendencia actualmente y por ello es importante que los futuros profesionales de la arquitectura técnica puedan trabajar en el seguimiento de las lesiones, interpretar los resultados que les ofrecen los equipos de monitorización junto con los datos tomados por ellos a lo largo del tiempo de estudio y poder así adquirir las capacidades necesarias para hacerlo de forma satisfactoria en sus futuros trabajos.

Solo con unas menciones puntuales durante el desarrollo de las clases a los equipos utilizados para investigación en la propia escuela.

Con la inclusión de tecnología se consigue aumentar el interés de nuestros alumnos, permitiendo que desarrollen sus prácticas en entornos que conocen y vislumbrando la tecnificación de la profesión.

\section{Referencias}

DURHAM GEO SLOPE INDICATOR. (2010). EL Tilt Sensor, (For Tilt and Beam Sensors) Standard \& SC Versions, 56802198. Washington: Mukilteo.

España. Resolución de 17 de febrero de 2010, de la Universidad de Castilla-La Mancha, por la que se publica el plan de estudios de Graduado en Ingeniería de Edificación. BOE,4 de marzo de 2010, núm. 55 , p. 22292-22294

GONZALEZ-ARTEAGA, J., MOYA, M., YUSTRES, A., ALONSO, J., MERLO, O. y NAVARRO, V. (2019). "Characterisation of the water content distribution beneath building foundations" en Measurement, vol. 136, p. 82-92.

GONZÁLEZ-ARTEAGA, J. ALONSO,J., MOYA, M., MERLO, O., NAVARRO, V. y YUSTRES, A. (2020). "Long-term monitoring of the distribution of a building's settlements: Sectorization and study of the underlying factors" en Engineering Structures, vol. 205, p. 110111.

LA MANNA, M. (2015). "Monitoring and control of urban critical infrastructures. 6th International Multi-Conference on Complexity" en Orlando: A., Tremante, H.W., Chu, B. y Sanchez, N.C. Informatics and Cybernetics, IMCIC 2015 and 6th International Conference on Society and Information Technologies, ICSIT 2015 - Proceedings Volume 1. Florid: Callaos. P. 74-75). 
MEYER, C., CUCINO, P., ECCHER, G. y ULRICH, D. (2013). "The Florence High-Speed Railway Hub: 4D monitoring - innovations in data acquisition and data management for tunnelling projects in sensitive urban areas" en Anagnostou G. y Ehrbar H. World Tunnel Congress 2013. Geneva: CRC Press 2013. p. 1403-10.

NOEL, A. B., ABDAOUI, A., ELFOULY, T., AHMED, M. H., BADAWY, A. y SHEHATA, M. S. (2017). "Structural Health Monitoring Using Wireless Sensor Networks: A Comprehensive Survey" en IEEE Communications Surveys and Tutorials, vol.19, n³, p. 1403-1423.

SLOPE INDICATOR COMPANY. (2003) VW Crackmeter 52636099. Washington: Mukilteo.

WANG, T., BHUIYAN, M., WANG, G., RAHMAN, M. A., WU, J. y CAO, J. (2018). "Big Data Reduction for a Smart City's Critical Infrastructural Health Monitoring" en IEEE Communications Magazine, 56, p. 128-133. 


\title{
EDIFİCATE
}

I Congreso de Escuelas de Edificación y Arquitectura Técnica de España

València, 4 y 5 de noviembre de 2021

Escuela Técnica Superior de Ingeniería de Edificación

Universitat Politècnica de València

Doi: https://doi.org/10.4995/EDIFICATE2021.2021.13577

\section{Repositorio de términos constructivos}

\section{Repository of constructive terms}

\author{
Luis Damián Ramos Pereira
}

Escuela Politécnica Superior de Zamora - Universidad de Salamanca, Idramos@usal.es

\begin{abstract}
The Repository of Constructive Terms was born as an academic activity aimed at improving the knowledge of constructive terminology for first-year students of the Degree in Technical Architecture. Within the virtual space of the Construction I subject, a digital repository of construction terms has been generated, which grows every week with the contributions, in the form of individual practices, of the students through the analysis of different buildings, in order to that students begin in the knowledge of the elements and constructive terms in their first year of university studies, acquiring an extensive vocabulary in a collaborative way
\end{abstract}

\section{Keywords:}

Repository, Construction Terms, Vocabulary, Online Training, Language Skills

\section{Resumen}

El Repositorio de Términos Constructivos nació como una actividad académica dirigida a mejorar el conocimiento de la terminología constructiva a los alumnos de primer curso del Grado de Arquitectura Técnica. Dentro del espacio virtual de la asignatura de Construcción I se ha generado un repositorio digital de términos constructivos, que va creciendo cada semana con las aportaciones, en forma de prácticas individuales, de los alumnos a través del análisis de distintas edificaciones, con el fin de que los alumnos se inicien en el conocimiento de los elementos y términos constructivos en su primer curso de estudios universitario, adquiriendo un extenso vocabulario de forma colaborativa.

Palabras clave: Repositorio, Términos Constructivos, Vocabulario, Formación On-line, Competencias Lingüísticas 


\section{Introducción}

Durante casi catorce años, hasta el curso 2015/2016 impartí docencia de Prevención de Riesgos en la Escuela Politécnica de la Universidad de Extremadura, los últimos años en el último curso del Grado y anteriormente en $3^{\circ}$ de Arquitectura Técnica. Eran tiempos con muchos alumnos en clase y en los que las dinámicas de trabajo individual eran muy complicadas de llevar a cabo, al igual que llegar a cumplir con el programa de la asignatura, por lo que primaba el trabajo en grupo frente al individual. En el trabajo grupal las carencias en cuanto a las competencias lingüísticas no afloraban como si lo hacían a la hora de tener que componer un documento técnico individualmente, como era la práctica final de curso de componer un estudio de seguridad y salud de forma individual.

En el curso 2016/2017 me incorporé como profesor asociado a la Escuela Politécnica Superior de Zamora de la Universidad de Salamanca (USAL), para impartir la asignatura de Construcción I en el Grado de Arquitectura Técnica. Al enfrentarme al reto de impartir docencia en la que considero la asignaturas que debe ser más ilusionante para los alumnos recién incorporados, me acordé de mis quejas como docente al tener que corregir los trabajos de los alumnos de último curso, y justo me fije en una de las últimas incorporaciones en mi librería en ese año 2016, una de las publicaciones de la Fundación MUSAAT el "Compendio Visual de Términos Constructivos-Arquitectónicos" de Juan López Cantos, tomando la idea del autor de un encargo que recibió de los Servicios Jurídicos de MUSAAT para que sus letrados colaboradores se familiarizaran con los términos constructivos y arquitectónicos que debían utilizar en las demandas y pleitos "El propósito era difundirlo a otros profesionales que, careciendo de conocimientos técnicos en la materia, pudieran estar en contacto con el sector de la construcción y más concretamente de la edificación y, por tanto, interesados en conocer y comprender la terminología técnica que los profesionales de este sector utilizamos habitualmente". Curiosamente justo lo que yo quería conseguir con mis alumnos, que futuros profesionales carentes de conocimientos técnicos en la materia conozcan y comprendan la terminología técnica utilizada habitualmente por los profesionales del sector. Se me ocurrió aprovechar la idea al considerarla ser muy interesante para conseguir la mejora de las competencias lingüísticas de mis alumnos, había un pero, ¿cómo llevarlo a cabo?

\section{Objetivos}

Como ya he señalado en la introducción, el objetivo principal del repositorio nació de la idea de mejorar las competencias lingüísticas del alumnado de arquitectura técnica en cuanto al conocimiento y comprensión de la terminología utilizada en nuestro sector de la edificación.

Todos los textos, figuras y tablas estarán incluidas dentro de los márgenes que tiene la plantilla. 


\section{Desarrollo de la innovación}

Una vez que el objetivo estaba claro y la forma de plasmarlo era a través de la visualización de imágenes en las que cada alumno reflejara términos constructivos arquitectónicos, quedaba por diseñar cómo construir ese compendio visual a través del trabajo práctico individual de los alumnos junto con la autorización del campus virtual como herramienta para el seguimiento y evaluación de la docencia.

Al contrario que pasaba en los años del boom académico de alumnos en nuestras escuelas de arquitectura técnica al día de hoy son pocos los alumnos que eligen nuestra titulación frente al ingente número de egresados de la primera década de este siglo. Esto hace que sea más fácil para el docente el seguimiento individualizado de la evaluación continua y el progreso académico de cada uno de sus alumnos, máxime si hablamos ya grupos de entre diez a quince alumnos.

Dentro de las prácticas de la asignatura se establecen una serie prácticas individuales, en torno a siete u ocho (Fig. 1), en las que el alumno tiene que hacer entrega de un documento en el que se incluyan cinco fotografías de edificios y en cada fotografía se localizarán cinco elementos constructivos diferentes, de los que se dará su definición con la ayuda de diccionarios especializados o monografías con temática de arquitectura o construcción.

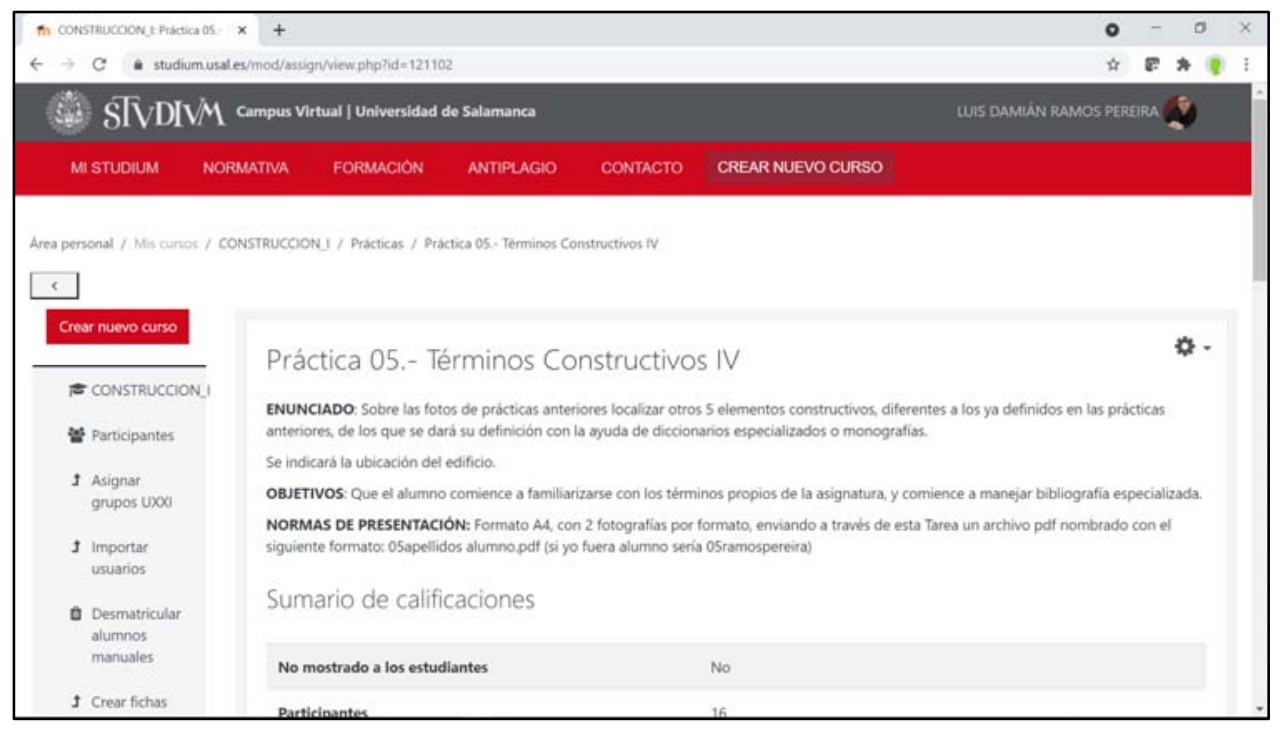

Fuente: Studium USAL

Fig. 1 Enunciado práctica 05.- Términos Constructivos

Los alumnos deberán utilizar fotografías de:

- Tres edificios ya construidos, uno de los cuales ha de ser uno de los dos pabellones que conforman la escuela Politécnica Superior de Zamora, junto con otro obligatorio 
que es el Edificio Aulario de la misma Escuela, dónde se imparte la docencia de la asignatura de construcción I, señalar en este punto qué la Escuela Politécnica Superior de Zamora se localiza en unos antiguos pabellones militares del antiguo Cuartel Viriato, actualmente Campus Viriato que comparte con la Facultada de Educación que utiliza el tercer pabellón del cuartel, todos con fachada a base de unas magníficas fábricas de ladrillos (Fig. 2) y el edificio aulario (Fig. 3) de reciente construcción con fachada a base de piedra caliza con un muro cortina en el desarrollo de los huecos de escaleras.

El último de los tres debe ser un edificio catalogado como BIC, con el fin de tener que utilizar términos de edificios antiguos, pudiendo elegir el alumno el mismo referenciando situación y año de construcción.

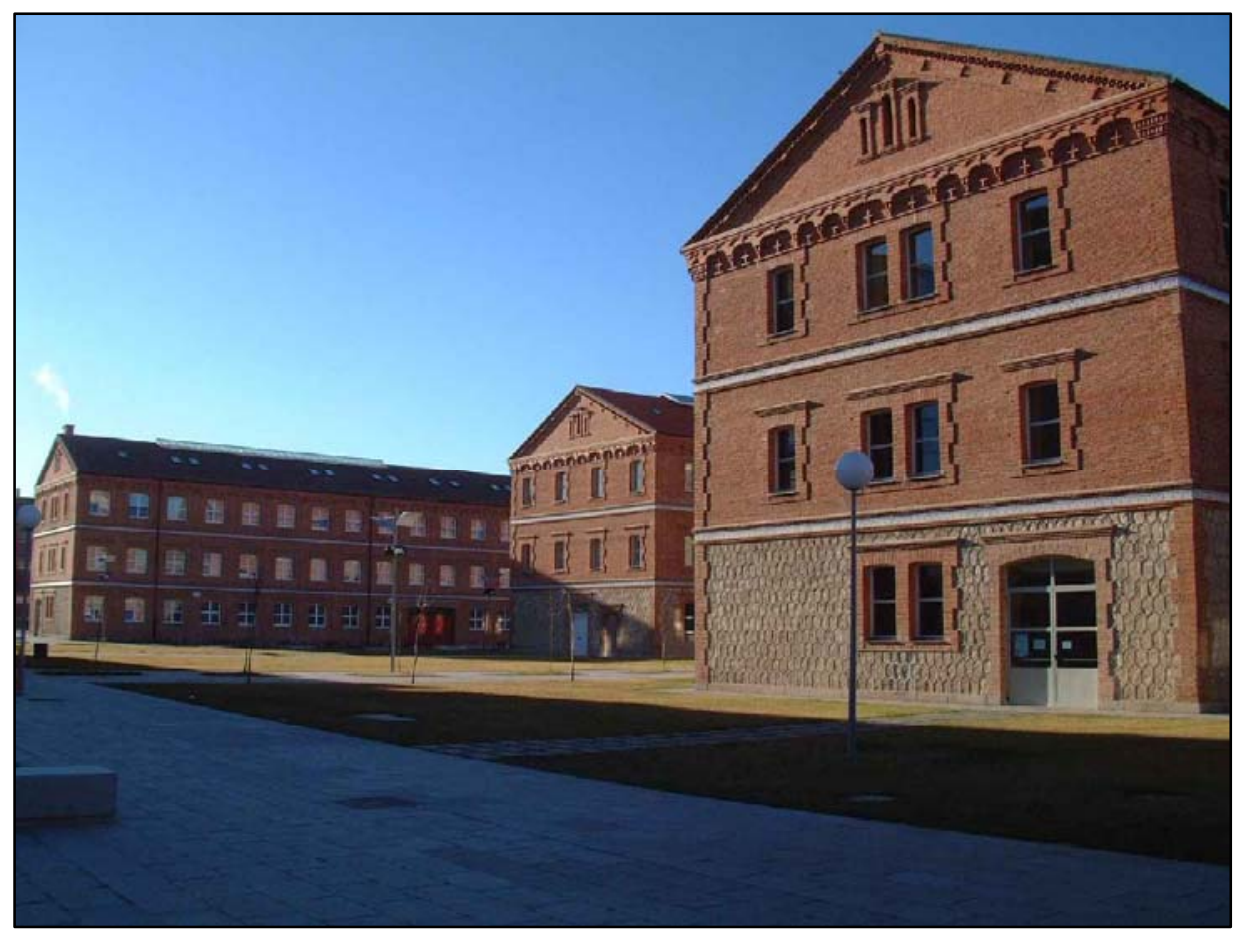

Fuente: https://poliz.usal.es/

Fig. 2 Pabellones Militares - Escuela Politécnica Superior de Zamora 


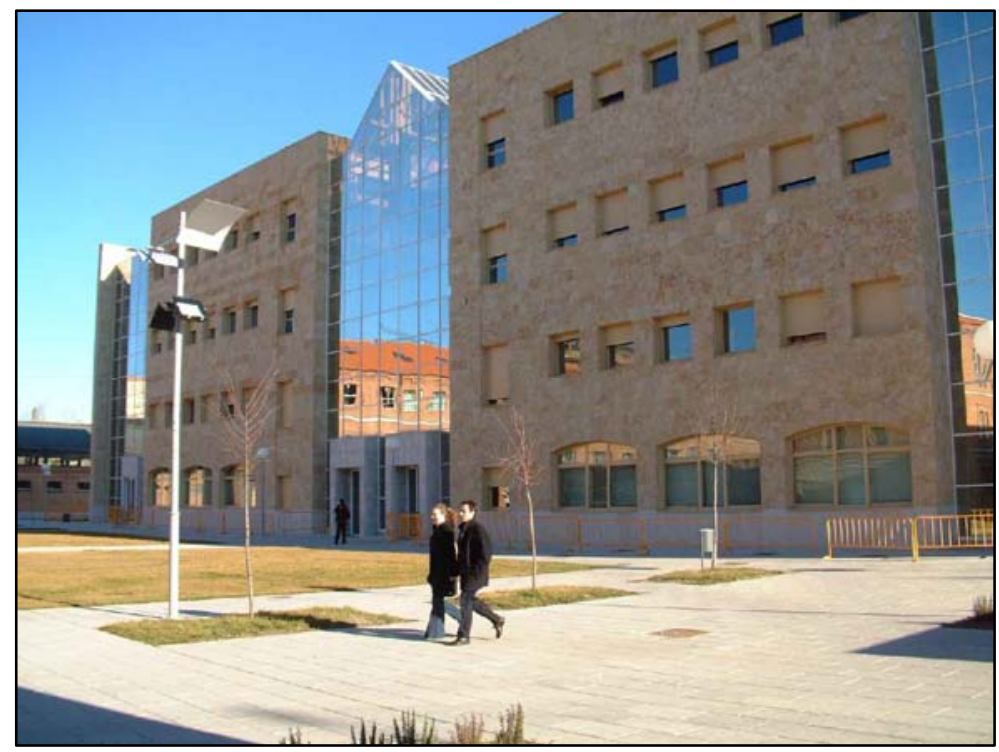

Fig. 3 Pabellones Militares - Escuela Politécnica Superior de Zamora

- Dos edificios en construcción, en cualquiera de las fases de edificación; indicando al alumno que una vez elegidos los edificios para la primera práctica, éstos no podrán cambiarse por otros en las siguientes.

En total en cada práctica, con un grupo de doce alumnos, tenemos 300 términos distintos y cada alumno tiene que localizar y definir 25 términos constructivos.

Ahora falta plantear cómo vamos a conseguir que no se repitan términos y que cada alumno pueda comprobar que sus términos no hayan sido utilizados por un compañero en su entrega. Para ello utilizamos una "actividad" de Moodle en el espacio de la asignatura del Campus Virtual (Studium) de la USAL, la creación de una "Base de datos" a modo de repositorio de los términos que define individualmente cada alumnos en sus prácticas (Fig. 4).

Información de ayuda sobre la actividad "Base de datos" en Moodle: https://docs.moodle.org/all/es/M\%C3\%B3dulo de actividad BasedeDatos

El módulo de actividad de base de datos permite a los participantes crear, mantener y buscar información en un repositorio de registros. La estructura de las entradas la define el profesor según una lista de campos. Los tipos de campo incluyen casilla de verificación, botones de radio, menú desplegable, área de texto, URL, imagen y archivo cargado.

La presentación visual de la información al listar, ver o editar las entradas de la base de datos se controla mediante plantillas de base de datos. Las actividades de base de datos 
pueden ser compartidos entre los cursos como opción preestablecida de manera que un profesor también puede importar y exportar las entradas de base de datos.

Un profesor puede permitir comentarios en las entradas. Las entradas también pueden ser calificadas por profesores $u$ otros estudiantes (evaluación por pares). Las calificaciones se agregarán para formar una calificación final que se registrará en el libro de calificaciones.

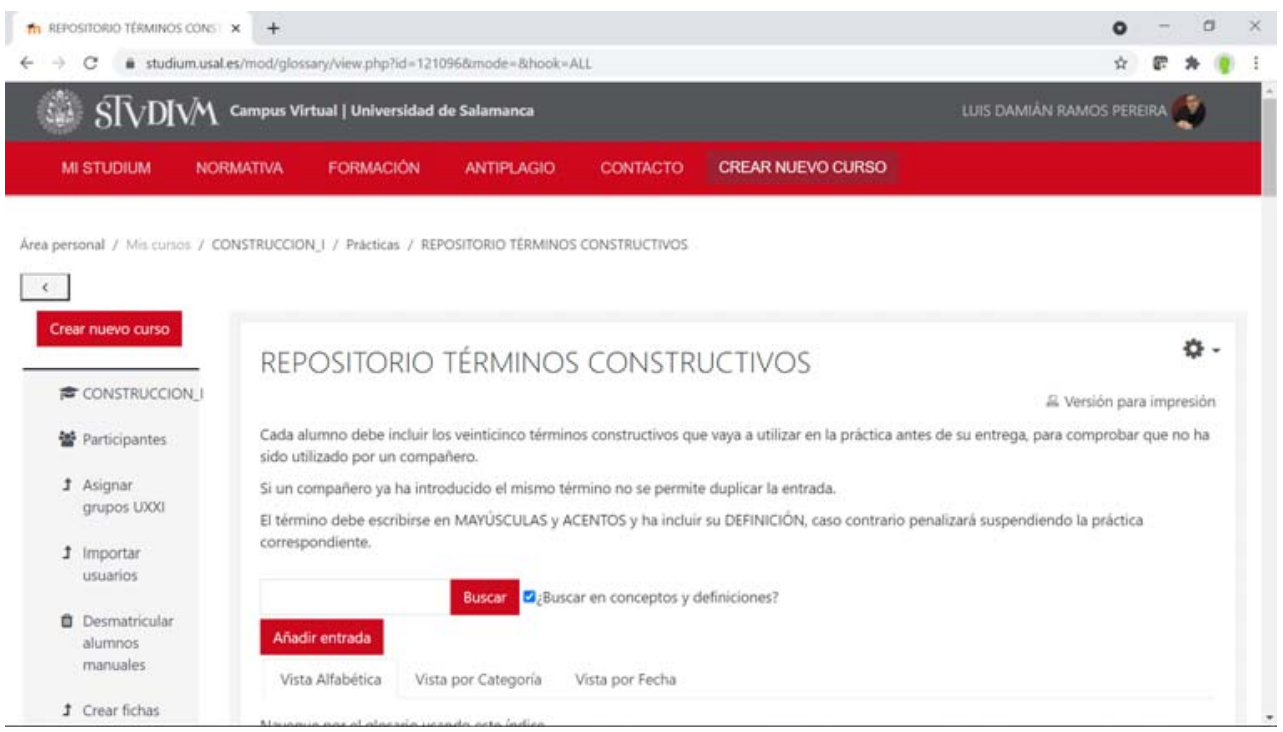

Fig. 4 Repositorio Términos Constructivos

Fuente: Studium USAL

Los alumnos deben agregar a la base de datos únicamente los veinticinco términos que van a incluir en el pdf de la práctica a entregar como "tarea" dentro de los plazos establecidos en el campus virtual (Fig. 5). Para evitar repeticiones en el enunciado de la actividad se señala que:

"Cada alumno debe incluir los veinticinco términos constructivos que vaya a utilizar en la práctica antes de su entrega, para comprobar que no ha sido utilizado por un compañero.

Si un compañero ya ha introducido el mismo término no se permite duplicar la entrada.

El término debe escribirse en MAYÚSCULAS y ACENTOS y ha incluir su DEFINICIÓN, caso contrario penalizará suspendiendo la práctica correspondiente.

Tampoco se podrán incluir términos fuera de los plazos de entrega de la práctica donde se incluyen los términos, para evitar que se haga acopio de términos para siguientes entregas adelantando su inclusión en el Respositorio." 


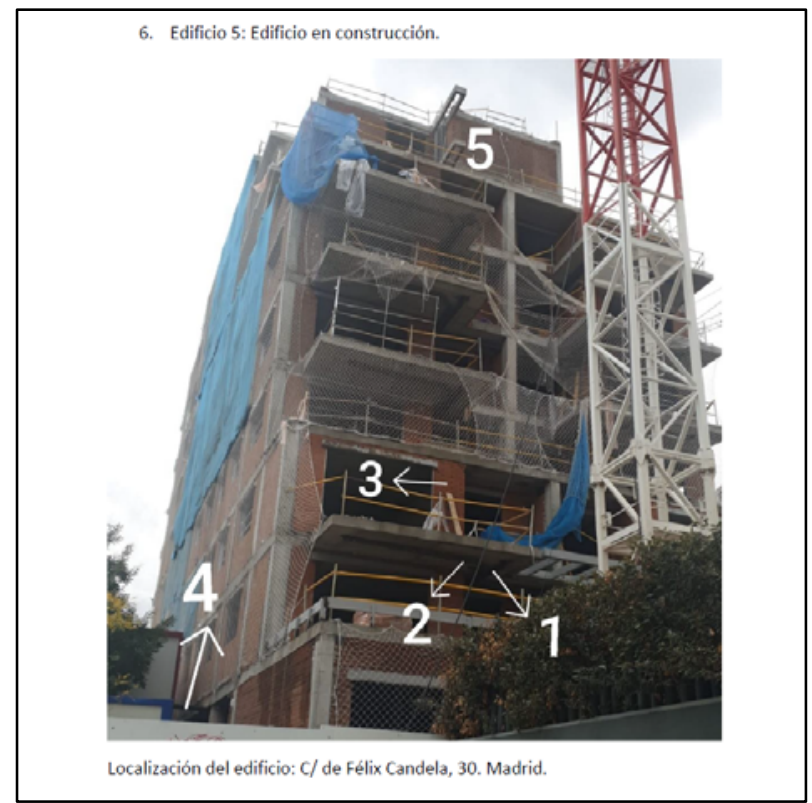

Fig. 5 Entrega práctica 03.- Términos Constructivos

Fuente: Studium USAL

La entrega de la práctica completa y que al menos quince de los vienticinco términos se hayan calificado sin errores en la base de datos se califica con un 5 sobre 10 puntos. 90 puntos es máximo que corresponde a la calificación de las 9 prácticas que se realizan en la evaluación continua de la asignatura, con un peso del $40 \%$ de la nota; siendo el otro $60 \%$ la media de las dos pruebas tipo test que se realizan para calificar el conocimiento de los contenidos teóricos de la asignatura.

\section{Resultados}

Si bien los resultados los podemos calificar de muy buenos en cuanto a la adquisición de la competencia descrita en el objetivo principal, hay que tener en cuenta las pequeñas dificultades que se encuentran los alumnos a partir de la cuarta práctica de Términos Cosntructivos; es a partir de esta cuando empiezan a tener mayores problemas en la localización de nuevos términos constructivos, excepto los que son claramente ayudados por familiares y amigos. Hay que considerar que en tres primeras prácticas el Repositorio contiene alrededor de 900 entradas y a partir de aquí comienzan las solicitudes de cambio de edificios, normalmente en los dos en construcción pues les resulta más difícil a los alumnos la localización y definición de nuevos términos.

Personalmente estoy muy conforme con el resultado obtenido desde que he incorporado esta metodología en la asignatura de Construcción I, con un $100 \%$ de aprobados en la evaluación continua, junto con el grado de satisfacción transmitido por los alumnos al terminar el semestre y creo que se ha logrado conseguir que futuros profesionales carentes 
de conocimientos técnicos en la materia conozcan y comprendan la terminología técnica utilizada habitualmente por los profesionales del sector mejorando sus competencias lingüísticas y el desarrollo de otras competencias transversales relacionadas con el manejo de la información.

\section{Referencias}

LOPEZ CANTOS, JUAN. (2016) "Compendio Visual de Términos Constructivos-Arquitectónicos". Madrid. Fundación MUSAAT

UNIVERSIDAD DE SALAMANCA. Studium - Campus Virtual de la Universidad de Salamanca. $<$ https://studium.usal.es/my/> [Consulta: 30 de junio de 2021]

UNIVERSIDAD DE SALAMANCA. Escuela Politécnica Superior de Zamora de la Universidad de Salamanca. <https://poliz.usal.es/> [Consulta: 30 de junio de 2021] 


\title{
EDIFİCATE
}

I Congreso de Escuelas de Edificación y Arquitectura Técnica de España

València, 4 y 5 de noviembre de 2021

Escuela Técnica Superior de Ingeniería de Edificación

Universitat Politècnica de València

Doi: https://doi.org/10.4995/EDIFICATE2021.2021.13587

\section{Experiencias en docencia en inglés}

\section{English teaching experiences}

\section{María-Isabel Giner-García ${ }^{a}$, Ángeles Rodrigo-Molina ${ }^{b}$}

${ }^{a}$ Escuela Técnica Superior de Ingeniería de Edificación, Universitat Politècnica de València, Camino de Vera s/n, 46022, Valencia (España). magigar@csa.upv.es.

${ }^{\mathrm{b}}$ Escuela Técnica Superior de Ingeniería del Diseño, Universitat Politècnica de València, Camino de Vera s/n, 46022, Valencia (España). arodrigo@ega.upv.es

\begin{abstract}
In the 21st century University, and increasingly so, the knowledge and mastery of English as a first foreign language is necessary for the integral education of students, and has become essential for integration into the labour market. For this reason, the internationalisation strategies or language policy plans of the vast majority of Spanish universities include the introduction of teaching in English in their degree programmes, enabling them to attract international students as well.

In this line, the School of Building Engineering of the Polytechnic University of Valencia reached the point where English teaching was implemented in the entire Bachelor's Degree in Technical Architecture in the 2016-2017 academic year, although currently only a few subjects remain in the 2nd year. As a result, we became personally involved as lecturers in a total of 6 subjects, both in the Building Techniques and Technology module and in the Urban Management and Applied Economics module, as well as in the Bachelor's Degree Thesis.
\end{abstract}

The aim of this paper is to present the balance of the English teaching experiences in the aforementioned subjects of the Degree in Technical Architecture of the School of Building Engineering of the Polytechnic University of Valencia.

Keywords: Bachelor's Degree Thesis; Budget and Economic Control topics; Building Techniques and Technology module; Construction topics; English teaching; Experts, Appraisals, and Valuations topics; Urban Management and Applied Economics module. 


\section{Resumen}

En la Universidad del siglo XXI, y cada vez más en auge, el conocimiento y el dominio del inglés como primera lengua extranjera es necesario en la formación integral del alumno, y se ha tornado imprescindible para la inserción en el mundo laboral. De ahí que las estrategias de internacionalización o planes de política lingüística de la gran mayoría de universidades españolas pase por introducir la docencia en inglés en sus titulaciones, permitiendo además atraer al alumno internacional.

En esta línea, la Escuela Técnica Superior de Ingeniería de Edificación de la Universitat Politécnica de València llegó a tener implantada la docencia en inglés en la totalidad del Grado en Arquitectura Técnica en el curso académico 2016-2017, aunque en la actualidad sólo quedan algunas asignaturas de $2^{\circ}$ curso. Como resultado se llegó a tener una implicación personal como docente en un total de 6 asignaturas, tanto del módulo de Técnicas y Tecnología de la Edificación, como del de Gestión Urbanística y Economía Aplicada, así como en el Trabajo Final de Grado.

El objetivo del presente trabajo, es dar a conocer el balance sobre las experiencias en docencia en inglés en el Grado de Arquitectura Técnica de la ETSIE de la UPV.

Palabras clave: docencia en inglés; materias de Construcción; materias de Presupuestos y Control Económico; materias de Peritaciones, Tasaciones y Valoraciones; módulo de Gestión Urbanística y Economía Aplicada; módulo de Técnicas y Tecnología de la Edificación; Trabajo Final de Grado. 


\section{Introducción}

En la Universidad del siglo XXI, y cada vez más en auge, el conocimiento y el dominio del inglés como primera lengua extranjera es necesario en la formación integral del alumno, y cada vez más resulta requisito impresciondible para la inserción en el mundo laboral.

Las estrategias de internacionalización o planes de política lingüística de la gran mayoría de universidades españolas pasa por introducir la docencia en inglés en sus titulaciones, permitiendo además atraer al alumno internacional.

Algunas universidades como la Universitat Politècnica de València (UPV) requieren a su estudiantado la acreditación del conocimiento de un idioma extranjero con un nivel mínimo de B2 para la obtención del título.

\section{Objetivos}

El objetivo es dar a conocer el balance sobre las experiencias en docencia en inglés en el Grado de Arquitectura Técnica de la Escuela Técnica Superior de Ingeniería de Edificación (ETSIE) de la UPV.

\section{Desarrollo de la Innovación}

\subsection{Importancia de conocimiento del inglés como idioma extranjero}

El conocimiento del inglés como idioma extranjero tiene importancia no sólo desde el punto de vista curricular, sino también en el no curricular.

Por normativa UPV (UPV Servei d'Alumnat, s.f.), todos los alumnos deben acreditar el conocimiento de una lengua extranjera, preferentemente el inglés, con un nivel correspondiente al B2 de los niveles comunes de referencia fijados por el "Marco Común Europeo de Referencia para las lenguas: aprendizaje, enseñanza, evaluación".

Es recomendable también la formación en lengua inglesa para el caso en que se desee participar en programas de intercambio internacional, debido a la necesidad de acreditar un nivel mínimo de B2 de inglés.

Según se desprende de la Convocatoria y Bases Específicas de Programa Erasmus+Estudios publicada como Anexo I por la OPII -Oficina de Programas Internacionales de Intercambio- de la UPV (UPV Oficina de Programes Internacionals d'Intercanvi, s.f.), y específicamente para las titulaciones de Grado en Arquitectura Técnica y Máster en Edificación cursadas en la ETSIE (ETSIE, s.f.-a), la docencia en inglés representa un $5 \%$ de la puntuación total. Así mismo, permite la obtención de puntos adicionales para optar a las mencionadas becas Erasmus+, obteniendo 2 puntos por cada asignatura técnica cursada (y superada) en inglés durante los estudios de grado y hasta un máximo de 10 puntos, frente a los 4 puntos que se alcanzarian según la tabla de equivalencias con respecto al Marco Europeo de Referencia. 
A tener en cuenta la doble ventaja que, desde el punto de vista curricular, presenta la oferta realizada por la ETSIE de recibir docencia en inglés en el Grado en Arquitectura Técnica. Por un lado, permite al alumnado la obtención de créditos para convalidación o reconocimiento académico del nivel B2 de lengua extranjera necesario para la obtención del título. Y por otro, la obtención de puntos adicionales para el acceso a becas de intercambio internacional (ETSIE, s.f.-b).

Con la docencia en inglés, se adquieren y desarrollan competencias que identifican elementos compartidos comunes a cualquier titulación, como la competencia transversal número 009, en la que se considera la apreciación de la diversidad y multiculturalidad. Habilidad para trabajar en un contexto internacional. Capacidad para adaptarse a nuevas situaciones. Asímismo, también se alcanzan competencias específicas, como la número 062, en la que se destaca la capacidad para comunicarse oralmente en un segundo idioma en un entorno profesional o académico...Competencias estas, marcadas por la Memoria de Solicitud de Verificación del Título de Mayo de 2010, especificadas en el Libro Blanco, y debiendo ser garantizada su adquisición por el Plan de Estudios.

\subsection{Situación de docencia en inglés en la Escuela Técnica Superior de Ingeniería de Edificación de la UPV}

La línea de docencia en inglés impartida en la titulación de Grado en Arquitectura Técnica de la ETSIE de la UPV se inició en el curso académico 2013-2014, implantándose de forma progresiva anualmente en cada uno de los cursos. De tal forma que, en el curso académico 2016-2017 la línea en inglés ya se impartía completamente en todo el Grado. Sin embargo, por decisiones políticas, a partir del curso 2019-2020 la mencionada línea empezó a desaparecer, iniciándose en las asignaturas de $4^{\circ}$ curso, y continuando con las asignaturas de $1^{\circ}$ y $3^{\circ}$ curso en el curso académico 2020-2021. En la actualidad únicamente queda docencia en inglés en algunas asignaturas de segundo curso (Instalaciones I y II, Materiales III, Construcción II, Construcción III, y Dibujo Arquitectónico II) (ETSIE, s.f.-c).

La docencia en inglés ha formado parte también del programa de movilidad internacional que oferta el Centro para sus estudiantes. Este programa de movilidad permite a los alumnos cursar asignaturas o desarrollar el Trabajo Final de Grado, pudiendo realizarse estancias en distintas universidades (UPV Titulaciones, s.f.) de algunos países europeos como Alemania, Dinamarca, Finlandia, Francia, Gales, Holanda, Hungría, Inglaterra, Italia, Lituania, Polonia, Portugal, República Checa, y Suecia, asícomo países de otros continentes como Cuba, Chile, China, etc.

La Escuela también ha promovido la matriculación de asignaturas con docencia en inglés, haciendo excepciones a la normativa de progreso y permanencia de la UPV, permitiendo el acceso a dichas asignaturas de cursos superiores desde el primer curso.

\subsection{Implicación personal en docencia en inglés}

El antecedente a la implicación docente se fraguó durante la época de estudiante, gracias a resultar beneficiada por una beca del Programa de movilidad de estudiantes ERASMUS 
(European Exchange Programme) en el curso 1996-1997, por un periodo de 6 meses para la realización del Proyecto Final de Carrera en HORSENS POLYTECHNIC (Denmark).

La experiencia de recibir como estudiante docencia en inglés resultó ser dura, pero muy positiva y enriquecedora, no sólo desde el punto de vista curricular sino también personal. La movilidad a otro país, con una cultura completamente diferente, y la convivencia con personas no sólo del país de destino sino también de otros países, aportaron un valor extra a la educación académica y evolución personal.

Desde la perspectiva curricular, aprender y desarrollar formas diferentes de entender la profesión (incluso, en ciertos aspectos, mucho más avanzados), ampliaron los conocimientos adquiridos durante la formación académica en el país de origen, que incluso se han podido aplicar durante el ejercicio profesional. La hicieron especialmente dura la combinación de varios factores como: el uso de una normativa diferente y específica del país de destino; un desarrollo tecnológico completamente distinto al estudiado durante la carrera; y el idioma. Es necesario reseñar que esta dificultad se pudo resistir y sobrellevar gracias a la ayuda y apoyo prestado tanto por el personal docente como por los compañeros. También mencionar la importancia y papel relevante que tuvo la existencia en inglés tanto de la normativa como de la bibliografía a consultar.

\section{Resultados}

\subsection{Implicación en docencia en inglés}

La implicación docente como profesora inició durante el curso académico 2005-2006, casualmente con la misma asignatura con la que finalizó la etapa de estudiante, y con el mismo centro de destino. Esto es, con la asignatura de Trabajo Final de Grado (en plan anterior Proyecto Final de Carrera), pero en este caso como tutora académica del alumnado de intercambio entre ambas escuelas _ETSIE_UNIVERSITAT POLITĖCNICA DE VALĖNCIA (España) y HORSENS POLYTECHNIC (Denmark)-.

La tabla 1 muestra un resumen de la implicación personal en docencia en inglés tanto como tutora académica como profesora. Tal y como se observa, a partir del curso 2015-2016 la implicación docente ha sido mayor, debido a la implantación de la línea de inglés en todo el Grado en Arquitectura Técnica, perdurando en el tiempo hasta la fecha. La docencia se ha llevado a cabo en distintas asignaturas, todas ellas de carácter troncal/obligatorio, y con una duración diferente en cada una de ellas, principalmente en el Grado en Arquitectura Técnica de la ETSIE, aunque también en el último curso académico ha implicado al Grado en Fundamentos de Arquitectura de la ETSA. 
Tabla 1. Resumen de la implicación personal en docencia en inglés tanto como tutora académica como profesora

\begin{tabular}{|c|c|c|c|c|c|}
\hline Asignatura & Curso & Semestre & Créditos & Tipo de materia & $\begin{array}{l}\text { Cursos } \\
\text { impartidos }\end{array}$ \\
\hline \multicolumn{6}{|l|}{$\begin{array}{l}\text { Grado en Arquitectura } \\
\text { Técnica }\end{array}$} \\
\hline Trabajo Final Grado & $4^{\circ}$ & 2 & 12 & $\begin{array}{l}\text { Proyecto Fin de } \\
\text { Grado }\end{array}$ & $\begin{array}{c}\text { Desde } \\
\text { 2005-2006 } \\
\text { Hasta la } \\
\text { actualidad }\end{array}$ \\
\hline Construcción IV & $3^{\circ}$ & 1 & 4,5 & Construcción & $\begin{array}{l}2015-2016 \\
2016-2017\end{array}$ \\
\hline Construcción V & $3^{\circ}$ & 2 & 6 & Construcción & $\begin{array}{l}2018-2019 \\
2019-2020\end{array}$ \\
\hline Construcciones Históricas & $3^{\circ}$ & 1 & 4,5 & Construcción & $2018-2019$ \\
\hline $\begin{array}{l}\text { Técnicas de Gestión } \\
\text { Presupuestaria }\end{array}$ & $3^{\circ}$ & 2 & 6 & $\begin{array}{l}\text { Presupuestos y } \\
\text { Control } \\
\text { Económico }\end{array}$ & $\begin{array}{l}2018-2019 \\
2019-2020\end{array}$ \\
\hline $\begin{array}{l}\text { Tasaciones, Peritaciones y } \\
\text { Valoraciones }\end{array}$ & $4^{\circ}$ & 1 & 4,5 & $\begin{array}{l}\text { Peritaciones, } \\
\text { Tasaciones y } \\
\text { Valoraciones }\end{array}$ & $\begin{array}{l}2016-2017 \\
2017-2018 \\
2018-2019 \\
\end{array}$ \\
\hline \multicolumn{6}{|l|}{$\begin{array}{l}\text { Grado en Fundamentos de } \\
\text { la Arquitectura }\end{array}$} \\
\hline Introducción a la Construcción & $1^{\circ}$ & 1 & 4,5 & Construcción & $2020-2021$ \\
\hline
\end{tabular}

\subsection{Perfil del alumnado}

El perfil de acceso del alumnado al Grado en Arquitectura Técnica en la línea en inglés es tanto español como extranjero. El estudiante extranjero procede tanto de Europa como de otros continentes, especialmente Asia. Los países mayoritarios son: Italia, Francia, Bélgica, Holanda, Alemania, Dinamarca, Suecia, Noruega, Finlandia, Polonia, Lituania, Hungría, Ucrania, República Checa, Eslovaquia, y China. Y los minoritarios han sido: Turquía, y Australia.

Sin embargo, la procedencia del alumnado extranjero para el Grado en Fundamentos en Arquitectura ha sido mayoritariamente de los países del Norte de África (en especial Marruecos y Argelia), y muy puntual países del Sur de América (como Venezuela, y Curaçao), y de Europa (Italia y Ucrania).

La demanda de la docencia en inglés, en el Grado en Arquitectura Técnica, históricamente ha sido moderada (en torno a los 25 alumnos máximo en el grupo entre españoles y extranjeros), y variable dependiendo del curso académico, semestre y asignaturas. Sin embargo, esta demanda, contrasta con la asignatura de Grado en Fundamentos de Arquitectura, es justamente a la inversa, tanto en procedencia del alumnado como en número total de alumnos en el grupo, llegando incluso a duplicarla. 
Tabla 2. Procedencia del alumnado demandante de docencia en inglés

\begin{tabular}{|c|c|c|c|c|c|c|c|c|c|c|c|c|}
\hline \multirow{3}{*}{$\begin{array}{l}\text { Asignaturas } \\
\text { Grado en } \\
\text { Arquitectura } \\
\text { Técnica }\end{array}$} & \multicolumn{2}{|c|}{$2015-2016$} & \multicolumn{2}{|c|}{$2016-2017$} & \multicolumn{2}{|c|}{$2017-2018$} & \multicolumn{2}{|c|}{$2018-2019$} & \multicolumn{2}{|c|}{$2019-2020$} & \multicolumn{2}{|c|}{$2020-2021$} \\
\hline & Esp. & Otros & Esp. & Otros & Esp. & Otros & Esp. & Otros & Esp. & Otros & Esp. & Otros \\
\hline & & & & & & & & & & & & \\
\hline Const. IV & $100 \%$ & $0 \%$ & $23 \%$ & $77 \%$ & $11 \%$ & $89 \%$ & $21 \%$ & $79 \%$ & $0 \%$ & $100 \%$ & & \\
\hline Const. V & $80 \%$ & $20 \%$ & $44 \%$ & $56 \%$ & $23 \%$ & $77 \%$ & $80 \%$ & $20 \%$ & $0 \%$ & $100 \%$ & & \\
\hline Const. Históricas & & & & & & & $10 \%$ & $90 \%$ & & & & \\
\hline TGP & & & & & & & $17 \%$ & $83 \%$ & $0 \%$ & $100 \%$ & & \\
\hline Tasac., Val. y Perit. & & & $37 \%$ & $63 \%$ & $16 \%$ & $84 \%$ & $0 \%$ & $100 \%$ & & & & \\
\hline $\begin{array}{l}\text { Fundamentos } \\
\text { en Arquitectura }\end{array}$ & & & & & & & & & & & & \\
\hline $\mathrm{ICO}$ & & & & & & & & & $60 \%$ & $40 \%$ & $56 \%$ & $44 \%$ \\
\hline
\end{tabular}

Habría que preguntarse el porqué de la baja demanda de alumnos españoles que hay en el Grado en Arquitectura Técnica frente a la que se produce en el Grado en Fundamentos en Arquitectura. Las razones podrían atender a varios factores: el nivel de inglés del alumnado; el nivel de inglés del profesorado; la escasez de bibliografía y material de estudio de las asignaturas; y el esfuerzo adicional que supone estudiar materias en lenguas diferentes a la lengua materna/nativa.

La heterogeneidad y variedad de procedencia del alumnado, no sólo se hacía patente en las nacionalidades, sino también en los Grados, con la consiguiente dispersión en cuanto a conocimientos previos de las materias objeto de estudio.

\subsection{Recursos}

Una característica común y generalizada para todas las asignaturas ha sido la inexistencia de material docente propio en inglés, y en la mayoría de los casos incluso escasa bibliografía en inglés para poder consultar. En otros casos, teniendo en cuenta la selección y estructuración de las unidades didácticas de las asignaturas hubiera sido posible facilitar al alumno bibliografía, sin embargo, los temas eran tan variados que la bibliografía a consultar hubiese tenido que ser de igual modo muy diversa, y se hubiera causado la dispersión del alumno.

Con respecto al material docente de las asignaturas impartidas, se daban casos de diversa índole: asignaturas cuyo material docente en español era escaso o nulo, por lo que ha sido necesaria una preparación de material previa a su traducción; asignaturas que contaban con presentaciones en power point en español, por lo que se ha procedido a traducir dichas presentaciones; $y$, asignaturas que ya contaban con presentaciones traducidas por otros profesores, procediendo en este caso a su revisión.

La traducción académica especializada ha sido propia en la mayoría de los casos. Unicamente se ha contado con una colaboración puntual en una de las asignaturas por otro 
profesor de la asignatura. Así mismo, en otra asignatura ha sido necesario recurrir a la contratación externa para la traducción de parte de la materia.

Como se ha mencionado, las traducciones de español a inglés en general han sido propias, por lo que se han realizado sin estar sometidas a control de calidad en lo referente a la revisión terminológica y gramatical. Es decir, no ha habido traductores/revisores nativos con formación en la especialidad o área de conocimiento, y por supuesto sin experiencia en la traducción, en particular la especializada.

A pesar de no haber contado en general con ayuda o apoyo para la traducción, se hace necesario mencionar que puntualmente y durante cierto tiempo, el Centro de Lenguas de la UPV ha puesto a disposición de los profesores con docencia en inglés sesiones para la revisión del material docente. Las sesiones eran individuales de una hora semanal o cada dos semanas, durante las cuales se repasaban las diapositivas que el profesor ya había confeccionado en inglés, y se resolvían dudas sobre vocabulario, pronunciación, etc. No obstante, debido a la gran cantidad de material docente que supervisar, el tiempo dedicado a ello resultó ser insuficiente. También destacar que aunque los revisores eran nativos no contaban con formación especializada en el área de conocimiento, lo cual representaba un obstáculo a la hora de aportar más rigor a la terminología específica.

\subsection{Resultados académicos del alumnado}

A modo de ejemplo, se muestran los resultados académicos obtenidos en el curso 20182019 para dos de las asignaturas, representativas a su vez de cada uno de los módulos en los que se ha impartido docencia: Construcciones Históricas (Tabla 3) del módulo de Técnicas y Tecnología de la Edificación, y Técnicas de Gestión Presupuestaria (Tabla 4) del módulo de Gestión Urbanística y Economía Aplicada.

Se muestra en las tablas el número de alumnos matriculados tanto en los grupos con docencia en español (DE) como en el grupo con docencia en inglés (DI), así como de este último grupo cuántos alumnos eran de procedencia extranjera y cuántos españoles. Además, se exponen los resultados académicos, diferenciando no sólo los grupos con DE con respecto al grupo con DI, sino también del grupo con DI el alumnado español del alumnado extranjero.

De la Tabla 3 correspondiente a la asignatura de Construcciones Históricas, se deduce que: el número de alumnos matriculados en el grupo con DI representa el $27 \%$ del total de alumnos matriculados en la asignatura, de los cuales sólo el $10 \%$ es alumnado con procedencia española (tal y como muestra también la tabla 2); prácticamente el mismo porcentaje (en torno al 5-6\%) de alumnos, tanto del grupo con DE como con DI, han obtenido una nota de notable, y de éste último grupo todos son extranjeros; el porcentaje de alumnos con una nota aprobada es mucho mayor en DI ( $70 \%$ del grupo, de los cuales el $85,7 \%$ son extranjeros) que en DE (el $55,5 \%$ del grupo); el porcentaje de alumnos suspensos, con respecto al total matriculados en la asignatura, en DI (10\%, todos extranjeros) es mucho más bajo que en DE (37\%); y por último, el porcentaje de alumnos 
no presentados es relativamente superior en DI ( $5 \%$ del grupo, de los cuales el $100 \%$ era extranjero) que en DE (3,7\% del grupo).

Tabla 3. Número de alumnos matriculados y resultados académicos obtenidos en la asignatura de Construcciones Históricas durante el curso 2018-2019

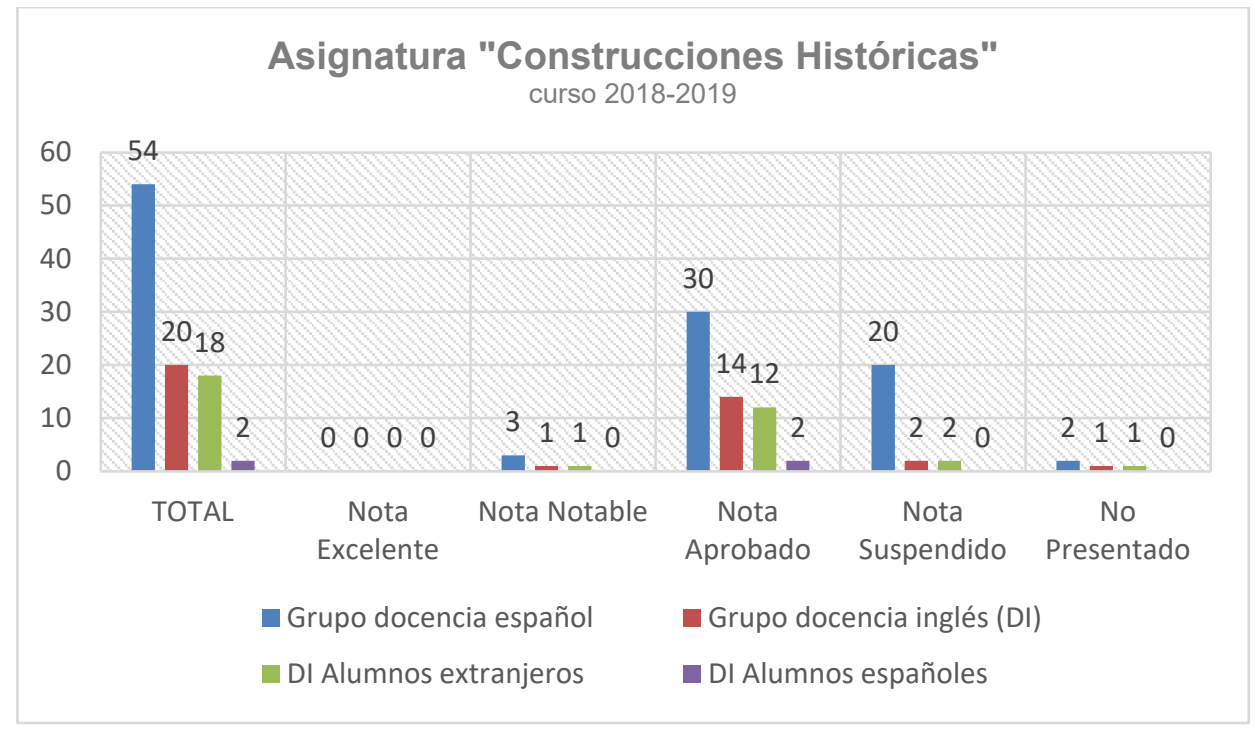

Tabla 4. Número de alumnos matriculados y resultados académicos obtenidos en la asignatura de Técnicas de Gestión presupuestaria durante el curso 2018-2019.

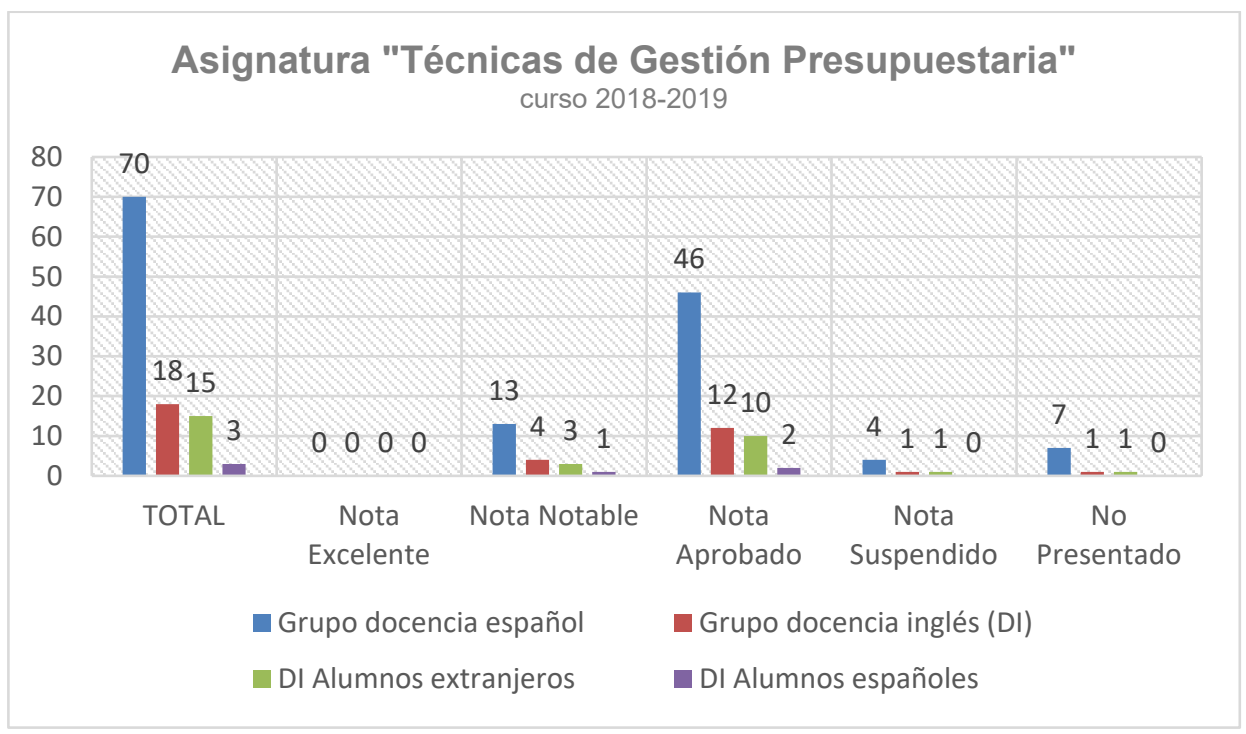


De la Tabla 4 correspondiente a la asignatura de Técnicas de Gestión Presupuestaria, se desprende que: el número de alumnos matriculados en el grupo con DI representa el 20,5\% del total de alumnos matriculados en la asignatura, de los cuales sólo el $17 \%$ es alumnado con procedencia española (tal y como muestra también la tabla 2); han obtenido una nota de notable un porcentaje relativamente mayor de alumnos del grupo con DI $(22,2 \%$, de los cuales el $75 \%$ es extranjero) que el grupo con DE (18,6\%); el porcentaje de alumnos con una nota aprobada es prácticamente igual (en torno al 65\%) en DI (el 83,3\% son extranjeros); el porcentaje de alumnos suspensos, con respecto al total matriculados en la asignatura, podría decirse que es igual tanto en DE como en DI (5,6\%, todos extranjeros); y por último, el porcentaje de alumnos no presentados es superior en DE ( $10 \%$ del grupo) que en DI (5,6\% del grupo, de los cuales el $100 \%$ era extranjero).

\section{Conclusiones}

Se ha podido comprobar que el nivel de inglés por parte del alumnado de otras nacionalidades ha sido sobradamente suficiente. Sin embargo, en el caso del alumnado español no lo ha sido tanto. Aún así, hay que decir que se ha visto un esfuerzo añadido por parte de este último para suplir esta carencia.

De la comparativa en las experiencias entre asignaturas impartidas y años académicos mostrados en la tabla 2, se desprende que en el Grado en Arquitectura Técnica la demanda de alumnos procedentes de otros países es mucho mayor frente a la demanda de alumnos españoles, aunque en el primer año básicamente sólo había alumnos españoles.

La casi total desaparición de la línea de inglés en la Escuela Técnica Superior de Ingeniería de Edificación de la UPV ha supuesto un retroceso en cuanto a la proyección internacional y calidad del Grado conseguidos durante los años en los que estuvo vigente.

La ampliación del léxico español a través de la gran cantidad de terminología específica que aparece durante la titulación del Grado en Arquitectura Técnica ya de por sí presenta ciertas dificultades para el alumnado. Además, si a esto se le suma la necesidad de hacerlo en un idioma extranjero, la dificultad es aún mayor. Del mismo modo, hay algunos casos con elevada complejidad de comprensión de la materia, debido al lenguaje tan concreto y completamente diferente del área de conocimiento, como es el caso de la asignatura de Tasaciones, Valoraciones y Peritaciones.

Del mismo modo, para facilitar y contribuir al aprendizaje del alumnado, se considera relevante la necesidad de disponer de un glosario o diccionario que desarrolle y contemple toda la terminología específica en español y su traducción a inglés, especialmente la concerniente a las asignaturas propias del módulo de Técnicas y Tecnologías de la Edificación. Esta bibliografía se podría hacerse extensiva también a las que corresponden a otros módulos, pero que igualmente pertenecen al mismo departamento.

La evolución del alumnado y los resultados de aprendizaje del grupo con DI han sido en general mejores que los grupos con DE en la mayoría de los casos. Lo cierto es que, 
incluso parece haber una mayor motivación e implicación por parte del alumnado. Así mismo, los buenos resultados académicos del grupo con DI han sido de alumnos de procedencia extranjera, tal y como muestran las tablas 3 y 4.

Se considera imprescindible y completamente justificada, para facilitar la comunicación con el estudiantado, la exigencia del nivel mínimo B2 de inglés no sólo al propio alumnado, sino también al profesorado. Sin embargo, y a pesar de que el profesorado tenga buen nivel de inglés, en ocasiones se presentan limitaciones por parte del alumno en la recepción de la información transmitida, bien debido al desconocimiento del idioma por no ser nativo, o bien por la materia objeto de estudio en sí misma, por ser completamente nueva y diferente de la formación recibida en los Grados que cursan en su lugar de origen.

Restablecer la línea de inglés en todo el Grado en Arquitectura Técnica en la Escuela Técnica Superior de Ingeniería de Edificación de la UPV, supondría recuperar no sólo ese nivel de calidad que le hace diferenciarse de otros centros nacionales, sino también convertirse en destino deseado por estudiantes de otros centros de ámbito internacional.

La baja demanda del alumnado español por la docencia en inglés, parece justificar la necesidad de promover entre este alumnado las ventajas académicas de recibir docencia en inglés en el Grado en Arquitectura Técnica. Se hace extensiva también la promoción hacia la faceta no curricular, ya que quizás pueda resultar incluso más atractiva.

La diversidad de nacionalidades y el moderado número de alumnos, reporta beneficios al grupo no sólo desde el punto de vista curricular por los resultados de aprendizaje, sino también desde la perspectiva no curricular. Ésta última debido el enriquecimiento personal, ya que el alumno prospera y aumenta sus habilidades personales, independientemente del Grado, por compartir docencia y trabajar con compañeros de otros países.

Es indispensable dotar de recursos al profesorado para la traducción del material docente, más aún si se desea dotar de cierto rigor y calidad al Grado. En este último caso, se hace necesaria la revisión terminológica por parte de traductores nativos con formación en la especialidad.

El prácticamente inexistente apoyo y ayuda para la traducción del material docente, ha implicado la realización de un importantísimo esfuerzo, que finalmente no ha sido reconocido ni valorado, resultando en definitiva desmotivador para el profesorado.

Destacar también que la dedicación académica del profesorado que imparte docencia en una lengua extranjera es mayor al que lo hace en la lengua de origen. De ahí la necesidad de dotar de reconocimiento docente al profesorado, como así lo muestran ciertas universidades españolas. Igualmente, y con el objetivo tanto de rentabilizar la labor desempeñada por el profesorado, como de mantener el estímulo de éste, se debe garantizar la continuidad de la docencia en inglés.

Por último, a pesar del sobreesfuerzo que ha supuesto y representa impartir la dociencia en inglés, y todo lo que ello conlleva, cabe decir que, como experiencia personal ha resultado una tarea muy interesante y enriquecedora. 


\section{Referencias}

Escuela Técnica Superior de Ingeniería de Edificación (s.f.-a). Convocatoria programa erasmus+ estudios. Curso 2021-2022. Anexo Khttps://www.etsie.upv.es/wp-content/uploads/2021/05/Anexo-IBases-especificas-ERASMUS-2021-2022.pdf> [Consulta: 16 de junio de 2021] [sin autoría reconocida]

Escuela Técnica Superior de Ingeniería de Edificación (s.f.-b). Erasmus 2021-2022. Programa de Intercambio para estudiantes ETSIE-UPVhttps://www.etsie.upv.es/internacional/estudiantesetsie/programas-de-intercambio-estudiantes-salientes/erasmus/> [Consulta: 16 de junio de 2021] [sin autoría reconocida]

Escuela Técnica Superior de Ingeniería de Edificación (s.f.-c)Estudiantes intercambio (Incomings). Asignaturas en inglés. <https://www.etsie.upv.es/wpcontent/uploads/2021/05/UPV_ETSIE_English_courses_2020-2021-r1.pdf> [Consulta: 16 de junio de 2021] [sin autoría reconocida]

Universitat Politècnica de València, Grado en Arquitectura Técnica (s.f.-a). Ficha informativa del Grado. <http://www.upv.es/titulaciones/GIE/indexc.html>. [Consulta: 16 de junio de 2021] [sin autoría reconocida]

Universitat Politècnica de València, Oficina de Programes Internacionals d'Intercanvi (s.f.-b). Convocatoria programa erasmust estudios. Curso 2020-2021. <http://www.upv.es/entidades/OPII/infoweb/pi/info/Anexo_I_20-21.pdf> [Consulta: 16 de junio de 2021] [sin autoría reconocida]

Universitat Politècnica de València, Servei d'Alumnat (s.f.-c). Información sobre la acreditacion del conocimiento de lenguas extranjeras, nivel B2, en los nuevos planes de estudio de grado. <https://www.upv.es/entidades/SA/ciclos/U0677392.pdf> [Consulta: 16 de junio de 2021] [sin autoría reconocida] 


\title{
EDIFICATE
}

I Congreso de Escuelas de Edificación y Arquitectura Técnica de España València, 4 y 5 de noviembre de 2021

Escuela Técnica Superior de Ingeniería de Edificación

Universitat Politècnica de València

Doi: https://doi.org/10.4995/EDIFICATE2021.2021.13600

\section{Metodologías para la enseñanza de la Construcción en Edificación. Flip Teaching. \\ Methodologies for teaching Building Construction. Flipped Teaching.}

\author{
Milagro Iborra-Lucasa ${ }^{a}$, José Manuel Gandía-Romerob \\ Universitat Politècnica de València, Depto. de Construcciones Arquitectónicas, \\ amiborra1@csa.upv.es, bjoganro@csa.upv.es
}

\begin{abstract}
Traditional classes develop a passive attitude of students to their learning, which contradicts expectations in the final assessment where students are expected to demonstrate the practical skills they have been developed in the course. Construction Technology II and Construction Technology III, both are second-year undergraduate courses in the Bachelor of Building Engineering program, (Universitat Politècnica de València), subjects primarily treat the building envelope and its constructive and hydrothermal behavior. Construction Technology II and Construction Technology II, both are second-year undergraduate subjects in the Bachelor of Building Engineering program. Inside this program, we have conducted a new experiment applying Reverse Methodology, also called Flipped Teaching, in order to encourage more active students in their learning. Flipped Teaching Methodology is carried out within the aforementioned Bachelor's cited program, specifically in the English Group, composed mainly by students of the Erasmus Program. Experimental course design is presented here, which included learning activities to greater interaction student-professor and student-student during classroom activities through Individual and Group Projects and Collaborative Learning.
\end{abstract}

Keywords: Construction Technology, Learning Methodologies, Flipped Learning. 


\section{Resumen}

Las clases tradicionales desarrollan una actitud pasiva de los estudiantes hacia su aprendizaje, lo que contradice las expectativas en la evaluación final donde se espera que los alumnos demuestren las habilidades prácticas que han desarrollado en el curso. Construcción II y Construcción III, son asignaturas que se imparten en Segundo curso del Grado en Arquitectura Técnica, en la Escuela Técnica Superior de Ingeniería de Edificación, en la Universitat Politècnica de València, tratando principalmente el estudio constructivo y el comportamiento higrotérmico de la envolvente del edificio. Dentro de este programa, hemos realizado un nuevo experimento aplicando la Metodología de Docencia Inversa, también llamada Flipped Teaching, con el fin de incentivar a los estudiantes de forma mas activa en su aprendizaje. La Metodología, se lleva a cabo dentro del citado programa de Grado, concretamente en el grupo de inglés, integrado principalmente por alumnos del Programa Erasmus. A continuación, se presenta el diseño del curso experimental, que incluyó actividades de aprendizaje con el objeto de fomentar una mayor interacción entre alumno-profesor y alumno-alumno, a través de Proyectos Individuales y Grupales y Aprendizaje Colaborativo.

Palabras clave: Construcción en Edificación, Metodologias de Aprendizaje, Enseñanza Inversa. 


\section{Introducción}

El Proceso de Bolonia y el Espacio Europeo de Educación Superior (EEES), están promoviendo cambios en el sistema de educación universitario existente, suponiendo ello la introducción de nuevas metodologías de enseñanza (Cruz, 2005). Con la introducción del sistema de transferencia de créditos europeo, ECTS (European Credit Transfer System), el entorno de aprendizaje está cambiando, se ha facilitado la movilidad de los estudiantes haciendo necesario nuevas metodologías de aprendizaje, más globales, que integren la diversidad cultural, que desarrollen una mejor formación en competencias y que mejore el rendimiento de los estudiantes.

Los nuevos avances tecnológicos involucran desarrollos cognitivos que deben ser internalizados por ellos. La universidad debe ir de la mano y participar activamente en el desarrollo de nuevas metodologías de enseñanza, con el fin de incrementar la participación activa de los estudiantes en el proceso de aprendizaje, teniendo en cuenta el Real Decreto 1393/2007, estableciendo los requisitos para la verificación de títulos universitarios oficiales que habiliten para el ejercicio de la profesión de Arquitecto Técnico (Real Decreto 1393/2007, ORDEN ECI/3855/2007). La Escuela Técnica Superior de Ingeniera de Edificación (ETSIE) de la Universitat Politècnica de València (UPV) ha realizado un experimento aplicando la metodología de Clase Inversa también denominada Flip Teaching o Flipped Classroom o Docencia Inversa.

Tras la revisión bibliográfica existente sobre la práctica de esta metodología de enseñanza en la educación superior, se observa que después de 2012, la Clase Inversa o Flip Teaching ganó en popularidad entre los profesores de disciplinas relacionadas con los estudios de ingenierías (Karabulut-llgu, 2018).

Las asignaturas seleccionadas para la realización de este estudio, Construcción II y Construcción III, están relacionadas con los sistemas de construcción utilizados en la envolvente del edificio, incluyendo también parte de particiones y revestimientos interiores. Las asignaturas se imparten en segundo curso del Grado de Arquitectura Técnica y el grupo seleccionado fue el de docencia en inglés, por el carácter multicultural, de multidisciplinaridad y la diversidad de conocimiento de base del grupo. El principal objetivo de las asignaturas es implicar a los alumnos en los procesos técnicos reales de la construcción del edificio, permitiéndoles formar parte de la toma de decisiones en la calidad, en la viabilidad constructiva y seguridad durante el proceso de construcción, paralelamente también se busca desarrollar habilidades de trabajo en grupo.

Cuatro son los aspectos que se involucran principalmente en la docencia invertida. En primer lugar, la flexibilidad. Un entorno flexible es esencial para permitir que los estudiantes decidan cuándo, dónde y a qué ritmo aprenderán, lo que requiere cambios y adaptación en la orientación del profesor para una conveniente enseñanza y un adecuado aprendizaje. En segundo lugar, se necesita fomentar la cultura del aprendizaje, que el alumno se encuentre activamente envuelto en su propio proceso de formación de conocimiento, para lo cual el profesor necesita diseñar actividades de aprendizaje significativas. En tercer lugar, es necesario diseñar un curso con un contenido intencionado, premeditado, pensado, ex 
profeso, de forma que se seleccionen los conceptos relevantes y estudios de casos relevantes para aprender y determinar cuáles pueden ser estudiados de forma autónoma por los estudiantes y cuales deben ser reforzados en clase. Finalmente, en cuarto lugar, el profesor debe actuar como un educador profesional, dando soporte a los alumnos y proporcionando feedback en su proceso de aprendizaje (Cáceres, 2017).

La metodología Flip Teaching, entendida como una sistemática en la cual el profesor pasa de ser un mero transmisor de información a un facilitador y un modelo para el aprendizaje de los estudiantes, es lo que ha motivado su aplicación en las asignaturas de Construcción II y Construcción III, además por la alta carga de contenido práctico que implica el desarrollo de habilidades específicas para su comprensión, tales como el dibujo, visión espacial, etc. Además, la metodología inversa de aprendizaje favorece otros métodos que refuerzan los resultados tales como, el aprendizaje colaborativo, por su mayor interacción durante el desarrollo de las actividades en clase o grupales a través de Proyectos.

\section{Objetivos}

El objetivo del presente documento es mostrar la experiencia llevada a cabo en la implantación de la metodología Flip Teaching en las asignaturas de Construcción II y Construcción III impartidas en el Grado de Arquitectura Técnica de la ETSIE de la UPV. Para ello, aparte de la traducción total al inglés, se hizo una reestructuración del programa de la asignatura en la que se incluyeron Lecciones Teóricas, Actividades y Cuestionarios relacionados con las lecciones teóricas y estudios de Casos. Además, se llevó a cabo en diversos espacios y entornos de trabajo y aprendizaje, tales como las tradicionales aulas, el laboratorio de las asignaturas, donde se exponen prototipos de sistemas constructivos objeto de estudio y visitas guiadas a construcciones reales, todo ello con el propósito de reforzar los conocimientos adquiridos en clase, durante el estudio autónomo y el trabajo grupal.

\section{Metodología}

Fueron tomados en cuenta diversos aspectos en la definición del marco metodológico a implementar, teniendo en cuenta las competencias a alcanzar por medio de la metodología Flip Teaching. De una parte, el proyecto institucional de la UPV, que tiene como objetivos capacitar y evaluar a los estudiantes en competencias genéricas y transversales, dada la importancia de estas habilidades en su actuación profesional (http://www.upv.es: Proyecto Competencias Transversales). Por otra parte, la ETS de Ingeniería de Edificación ha establecido las competencias transversales particulares para Construcción II y CIII en su Guía Docente. Ambos aspectos fueron considerados para desarrollar nuevos recursos materiales, crear actividades específicas para cada clase, promover el aula como un espacio para el aprendizaje, potenciar el trabajo en equipo para cambiar el rol docente, en general, aumentar la motivación del alumno mediante la mejora del proceso de enseñanza-aprendizaje. 
Tabla 1. Competencias Transversales en Guía Docente de Construcción, ETSIE.UPV.

\begin{tabular}{|l|l|}
\hline \multicolumn{1}{|c|}{ ASIGNATURAS } & COMPETENCIAS TRANSVERSALES \\
\hline \multirow{3}{*}{ CONSTRUCCIÓN II Y CONSTRUCCIÓN III } & (2) Aplicación y pensamiento crítico \\
\cline { 2 - 2 } & (3) Análisis y resolución de problemas \\
\cline { 2 - 2 } & (9) Pensamiento crítico \\
\hline
\end{tabular}

Fuente: Propia

La metodología se ha aplicado a un grupo de Segundo curso del Grado en Arquitectura Técnica, cuya docencia se imparte en inglés, en su mayoría son estudiantes acogidos al programa ERASMUS, de diferentes nacionalidades (chinos, alemanes, franceses, holandeses y españoles) procedentes de estudios diversos. En algunos casos, desconocen la disciplina de la construcción e incluso no han desarrollado habilidades de dibujo en las universidades de origen, ambos aspectos imprescindibles para iniciar adecuadamente el curso.

Se utiliza la plataforma Poliformat, para poner a disposición de los alumnos todos los recursos elaborados para el desarrollo del curso y el proceso de aprendizaje tales como, lecciones, planos, actividades, cuestionarios, información adicional o complementaria, vídeos, etc. Tradicionalmente, en las asignaturas de Construcción, se han ido desarrollando prototipos o maquetas de modelos reales de sistemas constructivos, que los profesores utilizamos para reforzar las clases teóricas y prácticas. Por ello, el Laboratorio es considerado uno de los mejores espacios para introducir las nuevas técnicas de enseñanza. Después de muchos años impartiendo las asignaturas de construcción, los profesores hemos concluido que los prototipos son realmente un soporte muy didáctico, independientemente de las metodologías aplicables, reforzando la visión espacial y ayudando a una mejora de la comprensión de los procesos constructivos durante su elaboración.

Se plantearon dos tipos de actividades, atendiendo a si la forma de trabajo era grupal o individual. En primer lugar se incluyen las actividades diseñadas para ser trabajadas de forma individual en casa, para evaluar la adquisición de contenidos de forma autónoma. Por otra parte, se proponen unas actividades para desarrollar en lase de forma grupal, crear discusión, analizar, etc. 


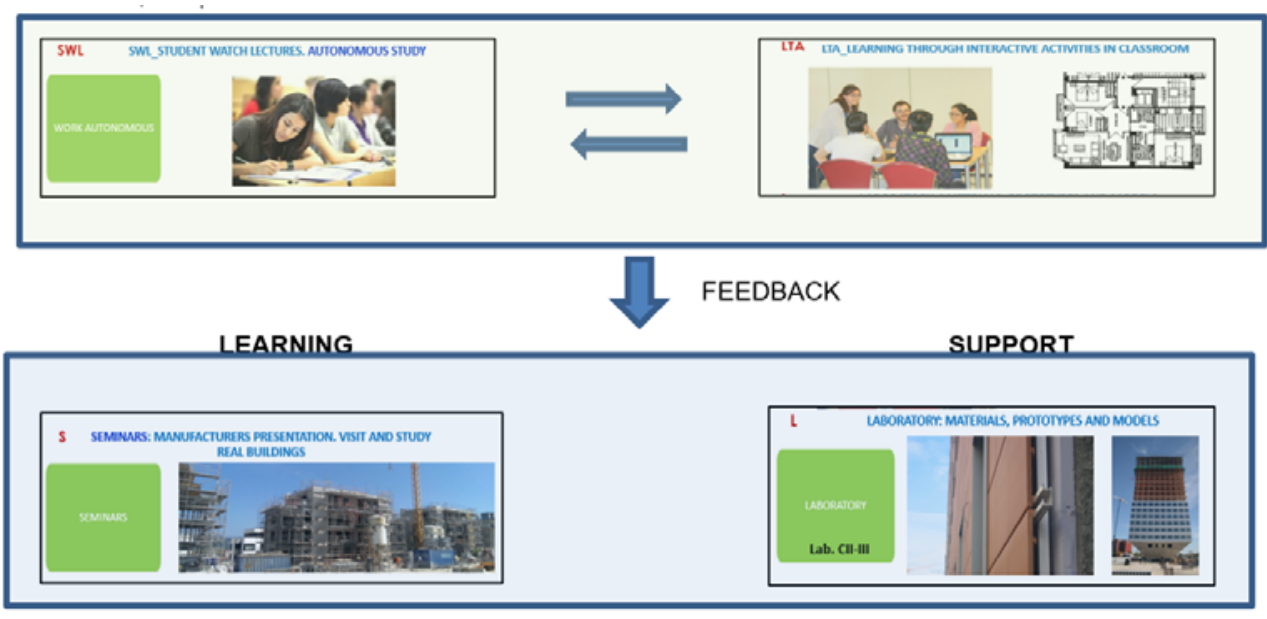

Fuente: Propia

Fig. 1 Metodología FT

Todas las actividades, cuestionarios, estudio de casos, etc, formarán parte de un portfolio que se incluye en la evaluación final, junto con dos pruebas de evaluación individuales.

La metodología propuesta Fig. 1, se estructura en 4 bloques principales. El primer bloque consiste en un trabajo autónomo e individual por parte del alumno, el alumno tiene que estudiar las lecciones que están disponibles en la plataforma Poliformat de forma autónoma, previa la asistencia a clase, anotando las dudas que se le presenten en dicho estudio. No se le requiere ningún aprendizaje memorístico, sino el objetivo es más sencillo y simple, se trata de alcanzar un nivel previo necesario para avanzar en clase.

El segundo bloque consiste en un aprendizaje a través de las actividades programadas, dichas actividades constan de un breve cuestionario y la resolución de un caso práctico relacionado con lo estudiado en el Bloque 1. El caso práctico permite desarrollar el análisis crítico de los sistemas constructivos estudiados, desarrollo de habilidades gráficas para transmitir conceptos constructivos. Estas actividades son introducidas y desarrolladas en clase y finalizadas de forma individual por cada alumno. El éxito de las actividades depende del trabajo autónomo del alumno, si el alumno no ha preparado adecuadamente el Bloque 1, en este segundo Bloque puede presentar dificultades para su avance en clase. Durante la clase, el profesor revisa conceptos, apoya individualmente y utiliza como soporte la pizarra para aclarar colectivamente dudas. Este bloque trata de resolver cuestiones complejas y de mayor nivel cognitivo, que el alumno debe alcanzar guiado por el profesor y en trabajo colaborativo con sus compañeros. Posteriormente a la sesión del aula, en casa, el alumno debe profundizar en aspectos que lo requieran, así como finalizar y reflexionar sobre el trabajo realizado en el aula. 
El alumno dispone de unas fichas de trabajo por semana que le permiten hacer un seguimiento de la actividad en la asignatura, donde se refleja el resultado de aprendizaje, el trabajo previo en casa, el trabajo de aula y el trabajo posterior en casa.

Tabla 2. Ficha Plan de Trabajo Semanal Metodología FT.

SEMANA 1 - [Clases lunes y miércoles]

\begin{tabular}{|c|c|c|c|c|c|c|}
\hline \multirow{3}{*}{ 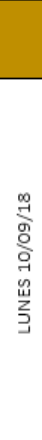 } & \multirow{2}{*}{\begin{tabular}{|l} 
RESULTADO DE APRENDIZAJE \\
$\begin{array}{l}\text { 1. Localizar en un microscopio } \\
\text { óptico los elementos que lo } \\
\text { integran. }\end{array}$
\end{tabular}} & \multicolumn{2}{|c|}{ 合 TRABAJO PREVIO EN CASA } & \multicolumn{2}{|c|}{$\therefore$ TRABAJO EN EL AULA } & $\begin{array}{c}\text { TRABAJO POSTERIOR EN } \\
\text { CASA }\end{array}$ \\
\hline & & $\begin{array}{|lr|}\text { Visualización del } \\
\text { video (URL) con } \\
\text { preguntas insertadas } \\
\text { (20 minutos) }\end{array}$ & $\begin{array}{|lr|}\text { Cuestionario } & 1 \\
\text { poliformat } & \text { ubicado } \\
\text { en } & \text { EXAMENES } \\
\text { titulado } & \\
\text { (VINCULADO) } & (10 \\
\text { minutos) } & \\
\end{array}$ & \begin{tabular}{|l|} 
Kahoot grupal \\
(1 hora)
\end{tabular} & & \\
\hline & $\begin{array}{l}\text { 2. Clasificar los elementos de un } \\
\text { microscopio óptico según la } \\
\text { función que desempeñan. }\end{array}$ & $\begin{array}{|ll|}\text { Visualización } & \text { del } \\
\text { video (URL) } & (20 \\
\text { minutos) } & \\
\end{array}$ & $\begin{array}{|lr|}\text { Cuestionario } & 2 \\
\text { poliformat } & \text { ubicado } \\
\text { en } & \text { EXAMENES } \\
\text { titulado } & \\
\text { (VINCULADO) } & (10 \\
\text { minutos) } & \\
\end{array}$ & $\begin{array}{|lr|}\text { Debate en clase } \\
\text { sobre los } \\
\text { resultados del } \\
\text { cuestionario }\end{array}$ & $\begin{array}{|lr|}\text { Cuestionario r } & 3 \\
\text { poliformat } \quad(50 \\
\text { minutos) } \\
\text { PUNTUABLE }\end{array}$ & \\
\hline 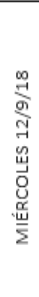 & $\begin{array}{l}\text { 3. Realizar muestras pictóricas } \\
\text { utilizando un microscopio } \\
\text { óptico. } \\
\text { 4. Seleccionar la información } \\
\text { relevante y ordenarla de } \\
\text { forma lógica para elaborar un } \\
\text { documento que sea } \\
\text { comprensible, utilizando los } \\
\text { recursos adecuados (CT-8. } \\
\text { COMUNICACIÓN EFECTIVA) }\end{array}$ & & & $\begin{array}{|ll|}\text { Práctica } & \text { de } \\
\text { laboratorio } & (2 \\
\text { horas }) & \\
\end{array}$ & $\begin{array}{l}\text { Cuaderno de } \\
\text { laboratorio con } \\
\text { los resultados de } \\
\text { la práctica }\end{array}$ & $\begin{array}{l}\text { Redacción punto } 3 \text { memoria de } \\
\text { prácticas a través de TAREAS en } \\
\text { PoliformaT (1 } \quad \text { hora) } \\
\text { PUNTUABLE }\end{array}$ \\
\hline
\end{tabular}

Fuente: Guia de implantación de la DOCENCIA INVERSA UPV. ICE

La experiencia durante varios cursos impartiendo la metodología Flip Teaching en Construcción II y III, ha supuesto en algunos casos, el requerimiento de una planificación intermedia de la asignatura, de modo que ha ido adaptándose en función de los resultados de aprendizaje a alcanzar por los alumnos, reestructurando contenidos y tiempos, con el objetivo de facilitar y guiar en el aprendizaje del alumno, no siendo un mero transmisor de conocimientos.

Paralelamente al Bloque 1 y 2, se organizan visitas al laboratorio de las asignaturas para estudiar los prototipos relacionados con la lección objeto de estudio Fig. 2 y también se organizan seminarios y visitas a edificios en construcción, Fig. 3. 


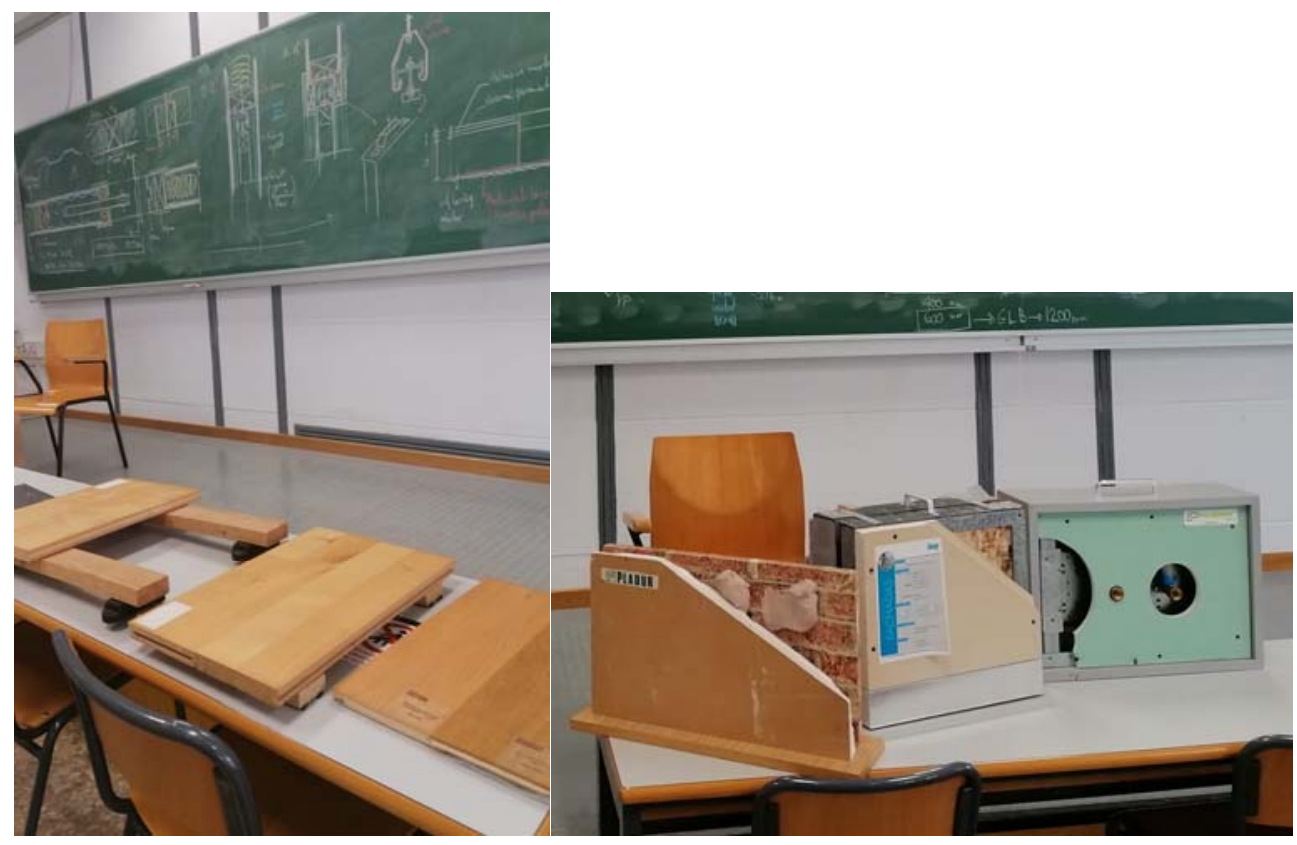

Fig. 2 Prototipos y soporte feedback en clase

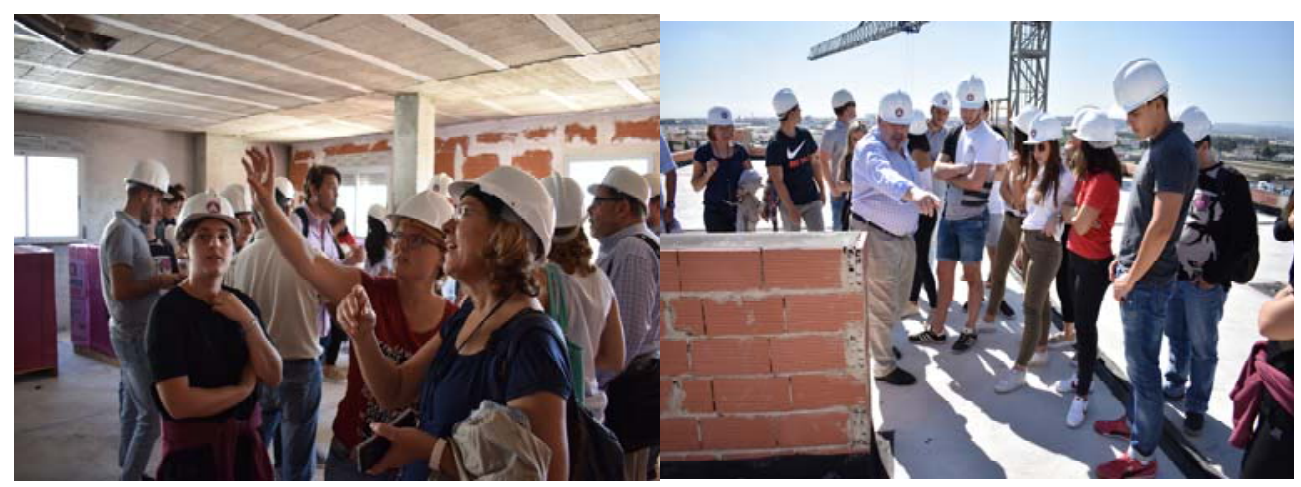

Fig. 3 Seminarios. Visita y estudio de edificios en construcción

Todas las Actividades, Cuestionarios, Seminarios, Visitas, quedan integradas en un Cronograma, Tabla 2, acorde a las semanas que componen el semestre, donde se interrelacionan con las Lecciones teóricas, y a su vez con el calendario académico de la ETSIE-UPV. Toda la información está disponible desde el primer día de clase para el alumno, de forma que le permita al alumno aventajado, pueda trabajar a su ritmo. 
Tabla 3. Cronograma de Lecciones, Actividades, Cuestionarios y otros con la metodología FT.

\begin{tabular}{|c|c|c|c|c|c|c|}
\hline \multicolumn{7}{|l|}{ ETSIE_UPV } \\
\hline \multicolumn{7}{|c|}{ CONSTRUCTION TECHNOLOGY II. SLOPED AND FLAT ROOFS } \\
\hline & \multicolumn{6}{|c|}{ SCHEDULE (course 19-20) } \\
\hline & & & & \multicolumn{3}{|c|}{ FLP TEACHING METHODOLOGY } \\
\hline & WEEK & LESSONS & IMPORTANT DATE & Activities & QUESTIONNAIRE & CASESTUDY \\
\hline \multirow{6}{*}{ SEPTEMBER } & 4 & RF. L1. SLOPED ROOFS. GENERALITIES & 4 SEPTEMBER START SEMESTER1 & A1.SR & & \\
\hline & & & & & & \\
\hline & 9 & RF. L1. SLOPED ROOFS. GENERALITIES & & A1.SR & Q1-2.5R & \\
\hline & 16 & RF. L2. TILE ROOFS & 17 SEP. DELIVERY OF COURSE WORK PROPOSAL & A2.SR & & \\
\hline & & & & & & \\
\hline & 23 & RF. L2. TILE ROOFS & & A2.SR & & \\
\hline & & & & & & \\
\hline \multirow{9}{*}{ OCTOBER } & 30 & RF. L2. TILE ROOFS & & A2-SR & Q1-2.SR & \\
\hline & & & & & & \\
\hline & 7 & RF. L3. SLATE ROOFS & 9Y12 OCTUBRENON CLASS & A3-SR & Q3.SR & \\
\hline & & & 8OCTOBERR (TUUSDAYY) CLASS WEDNESDAY & & & \\
\hline & 14 & RF. L4. LIGHTWEIGHT ROOFS & & A4.SR & Q4.SR & \\
\hline & & & & & & \\
\hline & 21 & RF. L5. METAL ROOFS & & A5-SR & Q5.5R & \\
\hline & 28 & FR. L6. FLAT ROOFS. GENERALITES & 31 OCT. DELIVERY OF COURSE WORK. PARTI(5\%) & A6-FR & Q6.5R & WC1-SR \\
\hline & & & 1 NOVEMBER NON CLASS & & & \\
\hline & & & & & & \\
\hline \multirow{6}{*}{ NOVEMBER } & 4 & & & & & \\
\hline & & & & & & \\
\hline & 11 & FR. L7. TRANSITABLE ROOFS & & A7FR & Q7.SR & \\
\hline & & & & & & \\
\hline & 18 & FR. L7. TRANSITABLE ROOFS & & A7 FR & Q7.5R & \\
\hline & 25 & FR. L7. TRANSITABLE ROOFS & & A7FR & Q7.SR & \\
\hline & 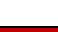 & & & & & \\
\hline \multirow{9}{*}{ DECEMBER } & 2 & FR. L8. NON-TRANSITABLE ROOFS & 5 NOV (THURSDAY) CLASS FRIDAY & $A 8-F R$ & Q8.5R & \\
\hline & & & 6 DECEMBER NON CLASS & & & \\
\hline & 9 & FR. L8. NON-TRANSITABLE ROOFS & & A8.FR & Q8.5R & \\
\hline & & & & & & \\
\hline & 16 & FR. L8. NON-TRANSITABLE ROOFS & & AB.FR & Q8.5R & \\
\hline & & & 20 DEC DELIVERY OF COURSE WORK. PARTII & & & WC2-FR \\
\hline & & & 20 DECEMBER FINAL LEMESTER 1 & & & \\
\hline & & & & & & \\
\hline & & & Evaluaton & $70 \%$ & $20 \%$ & $10 \%$ \\
\hline \multirow{3}{*}{ JANUARY } & & & & & & \\
\hline & & EXAM RECC & ANUARY 16:00H & & & \\
\hline & & & & & & 0 \\
\hline
\end{tabular}

Fuente: Propia

Finalmente, teniendo como referencia un cuestionario desarrollado por la UPV, se ha creado un modelo adaptado, considerando que se trata de un grupo con nacionalidades variadas, procedentes de programas académicos particulares y disciplinas diversas. Las cuestiones están relacionadas con, el uso de los recursos que tienen disponibles en la plataforma Poliformat, qué tipo de actividades de las propuestas les parecen más interesantes, su opinión sobre la metodología Flip Teaching, qué parte de la metodología ven más interesante, 
su opinión general sobre la metodología, y finalmente una cuestión basada en la experiencia personal del estudiante con la metodología.

Tabla 4. Cuestionario de evaluación de la experiencia de los estudiantes con la metodología FT.

\begin{tabular}{|c|c|c|}
\hline \multicolumn{3}{|c|}{ QUESTIONNAIRE ABOUT NEW METHODOLGIES IN UPV-ETSIE. FLIPPED CLASSROOM } \\
\hline IDENTIFICATION & $\begin{array}{ll}\text { Subject: } & \text { Construction Technology II } \\
\text { Course: } & 2019 / 20 . \\
\text { Group: } & \text { English Group (national and international students) }\end{array}$ & \\
\hline \multirow{28}{*}{$\begin{array}{l}\text { FLIPPED } \\
\text { CLASSROOM } \\
\text { METHODOLOGY }\end{array}$} & Resources to be used previously to class: & Rate 1-5 \\
\hline & 1: Videos Screencast & \\
\hline & 2: Vídeos Polimedia & \\
\hline & 3: Documentation in Poliformat & \\
\hline & What kind of classroom activities do you find most interesting: & Rate 1-5 \\
\hline & 4: Review and resolution of doubts in the classroom & \\
\hline & 5: Practical deepening exercises & \\
\hline & 6: Explanation of addition theoretical & \\
\hline & 7: Project development & \\
\hline & 8: Exhibitions and presentations of students in the class & \\
\hline & About methodology Flipped Classroom: & Rate 1-5 \\
\hline & 9: I went to class regularly with a previous work done & \\
\hline & 10: The methodology has helped to increase my involvement & \\
\hline & 11: I found it rewarding & \\
\hline & 12: It has taken a long time for me & \\
\hline & 13: It has allowed the teacher had more time in class to questions & \\
\hline & 14: It has helped me to get better prepared for the exams & \\
\hline & What do you like the most?: & Rate 1-5 \\
\hline & 15: The materials provided by the teacher & \\
\hline & 16: The work done in class (classroom activities) & \\
\hline & 17: Work done at home necessary to follow the classes & \\
\hline & 18: The relationship with the teacher, closer and work together & \\
\hline & 19: The relationship with my classmates & \\
\hline & 20: The organization and planning of the subject & \\
\hline & General opinion about Flipped Classroom: & Rate 1-5 \\
\hline & 21: I am satisfied with the methodological experience & \\
\hline & 22: I recommend this methodology to my fellow & \\
\hline & 23: I would like this methodology to be applied to the rest subjects & \\
\hline \multirow{6}{*}{$\begin{array}{l}\text { ABOUT } \\
\text { STUDENT'S } \\
\text { SITUATION }\end{array}$} & Answer based on your experience as a student & Rate 1-5 \\
\hline & 24: I consider myself a student who always carry the subjects a day & \\
\hline & 25: I leave the most difficult points for the last minute & \\
\hline & 26: I study only the days before examinations or deliveries work & \\
\hline & 27: I attend class regularly. & \\
\hline & 28: I prefer to attend traditional classroom classes & \\
\hline
\end{tabular}

\section{Resultados}

En este apartado se presentan resultados correspondientes a las cuestiones planteadas en la Tabla 4 y los resultados correspondientes a las encuestas acádemicas. 
Los resultados de la encuesta propuesta en la Tabla 4, manifiestan que, los recursos dispuestos en la plataforma Poliformat resultan de gran interés, mientras que otros recursos como screencast videos no fueron demasiado relevante para ellos, sin embargo sí lo fueron para los estudiantes de nacionalidad china. Con respecto a las actividades específicas desarrolladas para trabajar en clase, todos los estudiantes mostraron un gran interés en su desarrollo y feedback durante las clases, sumado al apoyo teórico de las lecciones sitas en Poliformat. Esto pone de relevancia la importancia de las actividades paralelas propuestas en cada una de las lecciones o conceptos específicos de especial relevancia a trabajar. En general, la metodología Flip Teaching fue gratificante para aquellos alumnos que asistían con regularidad a clase y realizaban las actividades planteadas, en cambio para aquellos alumnos con una baja asistencia a clase o falta de seguimiento de las actividades, les resultaba una carga excesiva de trabajo, una metodología poco atractiva. Cabe destacar como aspecto valorado positivamente por los alumnos, la relación interpersonal estudiante-profesor, estudiante-estudiante.

En el segundo caso, se presentan los resultados de las encuestas académicas realizadas en la UPV, correspondientes a los cuatro años en los que se lleva implantando la metodología Flip Teaching en las asignaturas Construction Technology II and III, docencia en ingles. En las encuestas se hace una valoración del profesorado con respecto a cinco dimensiones principales establecidas, siendo, conocimiento de la materia; organización y planificación, desarrollo y metodología docente; motivación e intereacción y ayuda y finalmente la satisfacción general.

Según muestra la Fig.4, atendiendo a la dimensión de desarrollo y metodología docente, los valores resultaron notables siendo los más bajos los que se presentaron en la docencia no presencial que se llevó a cabo en el curso 19-20 durante el segundo cuatrimestre (donde se imparte la asignatura de Construcción II), presentando valores muy bajos con respecto a los años en que se impartió docencia presencial. Ello pone de manifiesto que, la no presencialidad, evitó la fluidez en la comunicación entre estudiantes y con el profesor, aunque se dispusiera de tecnologías como el Teams y otras para impartir las clases, reuniones grupales y otras actividades, demostrando esto no ser lo bastante eficaz para llevar una metodología de Docencia Inversa adecuadamente. A la penalización de esta dimensión se suma que tampoco se pudo hacer uso del laboratorio, donde el alumno interactúa con protopos/maquetas de apoyo, así como tampoco se llevaron a cabo los seminarios, workshops y visitas a obras que se realizan en el transcurso del cuatrimestre, todo ello repercutiendo en la valoración final. 


\section{TODOS LOS CURSOS}

\section{DESARROLO/METODOLOGÍA DOCENTE}

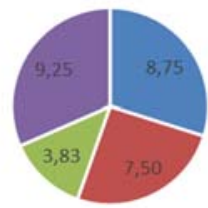

- PRESENCIAL 20-21 CII - PRESENCIAL 19-20 CII $=$ ONLINE $19-20 \mathrm{CIII}$ - PRESENCIAL. 18-19 CII

Fig. 4 Resultados MFT

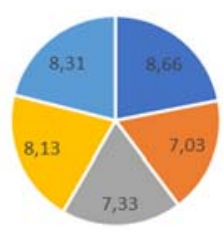

- CONOCIMIENTO DE LA MATERIA = ORganización Y PLANIFICACION - DEARROLO/METODOLOGLA DOCENTE = MOTNACION/INTERACCION AYUDA - SATISFACCION GRAL.

Fig. 5 Resultados MFT

No obstante, y pese a ciertas limitaciones, según muestran los datos de la Fig. 5., la valoración en el resto de las dimensiones y la satisfacción general de los alumnos en la docencia de la asignatura con la metodología Flip Teaching, es buena, penalizando la no presencialidad en el resultado medio del valor de la dimensión relacionada con la metodología docente. Todo ello pese a, como ya se ha indicado en apartados anteriores, ser grupos muy diversos en cuanto a, cultura, idioma y estudios de procedencia, lo cual implica por parte del profesor encontrar el equilibrio para crear un buen ambiente de trabajo y gran esfuerzo para conseguir su motivación, aparte de una adecuada adaptación del material académico.

\section{Resultados Encuestas Metodología Flip Teaching}

SATISFACCION GRAL

MOTIVACION/INTERACCION AYUDA

DEARROLO/METODOLOGIA DOCENTE

ORGANIZACIÓN Y PLANIFICACION

CONOCIMIENTO DE LA MATERIA

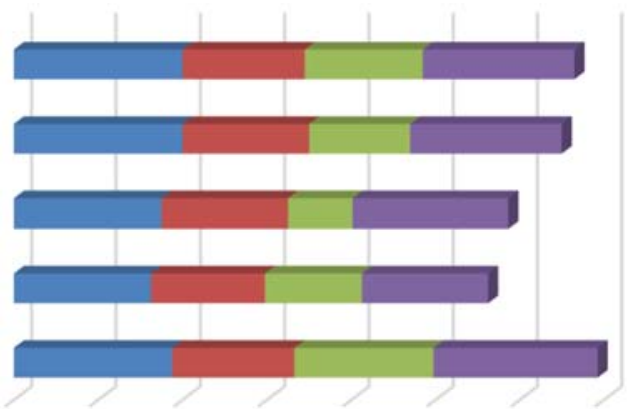

$0.00 \quad 5.0010 .0015 .0020 .0025 .0030 .0035 .00$

$$
\begin{aligned}
& \square \text { PRESENCIAL 20-21 CII } \square \text { PRESENCIAL 19-20 CII } \\
& \square \text { ONLINE 19-20 CIII } \quad \text { PRESENCIAL 18-19 CII }
\end{aligned}
$$

Fig. 7 Resultados MFT

Los alumnos tienen una satisfacción general positiva ante la experiencia en la metodología Flip Teaching, reconociendo el grado de implicación, compromiso y carga de trabajo que 
exige para un correcto seguimiento de la asignatura. Como profesor, la metodología ha supuesto una carga adicional de coordinación del grupo, organización y planificación, como consecuencia de falta de regularidad en el comportamiento del grupo (respuesta irregular ante las actividades propuestas que impide el avance unifome del grupo), tal como lo refleja la Fig 7 en la valoración de la dimensión de la organización y planificación.

\section{Conclusiones}

Alguno de los aspectos positivos a destacar como docentes en la aplicación de la metodología de la clase invertida es que, requiere que los educadores tengan una adecuada programación de clases, coordinada con unos recursos teóricos y prácticos detallados, evitando el paso hacia la improvisación. Desde el punto de vista de los alumnos, se sienten más involucrados y motivados cuando tienen una asistencia regular a clase, se preocupan por resolver las actividades propuestas y promover la discusión y el feedback en clase. También, cuando las actividades propuestas son variadas, implicando cambios de escenario, conexión con el mundo real, el alumno entiende la realidad de la profesión, incrementando su motivación. En general, la metodología supone una mayor interacción entre los profesores y alumnos, de forma que reporta en una mejora del aprendizaje.

Tras la experiencia de la implantación de la metodología Flip Teaching en las asignaturas de Construcción, se propone como trabajos futuros, propuestas de evaluación alternativas, así como revisión de las actividades con diferentes cargas de trabajo, pero sobre todo, incrementar la motivación del alumno que ve la metodología como una carga de trabajo y no como un camino hacia un aprendizaje autónomo.

\section{Referencias}

CRUZ, A Y BENITO, A (2005), Nuevas claves para la docencia universitaria en el Espacio Europeo de Educación Superior. Madrid: Narcea

KARABULUT-ILGU, A ET AL (2018) "A systematic review of research on the flipped learning method in engineering education"en British Journal of Educational Technology. Vol 49, Issue 3, p. 398411.

UPV < http://www.upv.es/contenidos/COMPTRAN/info/955689normalc.html. $>$ [Consulta 15 de Julio de 2021]

CÁCERES, P.A. Y MARTíNEZ, S. Proyecto Flip Teaching en la UPV. Cómo invertir nuestras clases a través de las herramientas tecnológicas. ICE-ASIC.

REAL DECRETO 1393/2007 de 29 de Octubre.

ORDEN ECI/3855/2007 de 27 de Diciembre 2007. 


\title{
EDIFICATE
}

I Congreso de Escuelas de Edificación y Arquitectura Técnica de España València, 4 y 5 de noviembre de 2021

Escuela Técnica Superior de Ingeniería de Edificación

Universitat Politècnica de València

Doi: https://doi.org/10.4995/EDIFICATE2021.2021.13552

\section{Diagnóstico de la ventilación natural, concentración de $\mathrm{CO}_{2}$, temperatura y humedad relativa de un aula docente con motivo del SARS-CoV-2. Caso de las aulas de la ETSIE de la UPV.}

\section{Diagnosis of natural ventilation, $\mathrm{CO}_{2}$ concentration, temperature and relative humidity of a teaching classroom due to SARS- CoV-2: The case of classrooms of the ETSIE of the UPV.}

\author{
Antonio M. Romero Sedóa, Paloma Arrué Burillo ${ }^{b}$, Carolina Aparicio Fernández ${ }^{c} y$ \\ Milagro Iborra Lucas ${ }^{d}$ \\ Universitat Politècnica de València, ${ }^{a}$ aromeros@csa.upv.es, ${ }^{b}$ paarbu@csa.upv.es, ${ }^{b}$ caap@csa.upv.es, ${ }^{b}$ \\ miborra1@csa.upv.es
}

\begin{abstract}
This article aims to give a broad vision of how to manage and quantify safe states inside the classrooms, based on compliance with administrative regulations and recommendations. Compliance verification is carried out through computational fluid dynamics (CFD) simulations, as a preliminary study to determine the location of the air vortices and renewals, to locate the security occupation zones and that it is this aspect that determines the maximum capacity. Subsequently, an experimental measurement of the $\mathrm{CO}_{2}$ concentration is carried out, analyzing the regulatory effect of the rest intervals, obtaining the reduction speeds and the recommended times.
\end{abstract}

Keywords: SARS-CoV-2, ventilation, concentration of $\mathrm{CO}_{2}$, teaching.

\section{Resumen}

Este artículo pretende dar una visión amplia de cómo gestionar y cuantificar los estados seguros en el interior de las aulas, partiendo del cumpliendo de las normativas y recomendaciones administrativas. Se realiza la comprobación del cumplimiento mediante simulaciones por dinámica de fluidos computacional (CFD), como un estudio previo que determine la localización de los vórtices de aire y las renovaciones, para localizar las zonas de ocupación de seguridad y que sea este aspecto el que determine el aforo máximo. Se realiza una medición experimental de la concentración de $\mathrm{CO}_{2}$, analizando el efecto regulador de los intervalos de descansos obteniendo las velocidades de reducción y los tiempos recomendables.

Palabras clave: SARS-CoV-2, Ventilación, concentración de $\mathrm{CO}_{2}$, docencia. 


\section{Introducción}

Desde el inicio de la pandemia como consecuencia del SAR-CoV-2, y por recomendaciones administrativas se obligó a partir del 16 de marzo en el curso 2019-2020 a impartir las clases de forma telemática en toda la Universitat Politècnica de València. Así mismo, en el curso 2020-2021 se han impartido la mayoría de las clases de forma presencial, para ello, se ha tenido que tomar medidas de carácter preventivo en toda la universidad con la finalidad de evitar en la medida de lo posible los contagios en la comunidad educativa.

Bien es cierto que una de las vías de contagio del virus es a través de los aerosoles dispersos en el aire y que pueden ser inhalados tanto por los docentes como por los estudiantes en las aulas que no estén debidamente ventiladas (Santarpia et. al, 2020). Por ello se planteó al inicio del curso 2020-2021 un estudio de la ventilación natural de algunas aulas y su modelización por dinámica de fluidos computacional (CFD) de una de ellas, con ello se perseguía saber varios parámetros: caudal y velocidad del aire, dirección y sentido de las líneas de corriente en el aula, número de renovaciones del aire, etc. Esto permitió cuantificar el aforo máximo de las aulas, ubicaciones más adecuadas de los estudiantes y docentes, evitando cualquier zona del aula que tuviese remansos del aire provocados por vórtices.

Además, durante el transcurso de la docencia, se planteó la medición de uno de los gases como el dióxido de carbono $\mathrm{CO}_{2}$, también llamado anhidrido carbónico, emanado este por la actividad humana en las aulas, que, aun siendo un gas incoloro e inodoro y no tóxico ni nocivo para la salud humana desplaza el aire obteniéndose sensaciones térmicas poco confortables haciendo que la respiración sea fatigosa. Las altas concentraciones de $\mathrm{CO}_{2}$ en el aire son un indicador de falta de ventilación y de alto riesgo de posible contagio. El objetivo era conseguir junto con la temperatura y humedad relativa, estados de confort para la comunidad docente, y tener un indicador de la falta de ventilación, para ello se implantaron en la mayoría de las aulas medidores digitales para conocer y saber cuál era el estado de confort en las aulas.

\section{Objetivos}

El primer objetivo antes de iniciar las clases del curso 2020-2021 fue realizar una evaluación de la ventilación natural mediante dinámica de fluidos computacional (CFD), para ubicar de forma segura a los docentes y al estudiantado en el interior del aula, y el segundo objetivo fue la medición de la concentración de $\mathrm{CO}_{2}$, temperatura y humedad relativa, para determinar el grado de confortabilidad de las aulas donde se imparte docencia. Las aulas a estudio fueron la JB2 y C1 de la ETSIE de la Universitat Politècnica de València.

\section{Desarrollo de la Innovación}

Con motivo de la pandemia se redactó normativa hasta la fecha inexistente para gestionar los espacios arquitectónicos, con la finalidad de aportar una cierta seguridad a las personas para no ser contagiadas por los aerosoles disueltos en el aire. Las normativas y recomendaciones que se publicaron fueron redactadas por las administraciones, 

docente con motivo del SARS-CoV-2. Caso de las aulas de la ETSIE de la UPV.

Diagnosis of natural ventilation, $\mathrm{CO}_{2}$ concentration, temperature and relative humidity of a teaching classroom due to SARS-CoV-2: The case of classrooms of the ETSIE of the UPV.

obedeciendo a criterios establecidos por otros países, posiblemente contrastados con modelos específicos en materia de aerosoles, pero no a nivel específico en docencia.

No obstante, existe normativa a nivel Nacional en España como es el Reglamento de Instalaciones Térmicas de los Edificios (RITE), (BOE, 2007), que establece criterios muy severos para su cumplimiento, tanto es así, que las medidas que establece en la calidad del aire, renovaciones y confortabilidad supera con creces a las normativas aparecidas durante la pandemia. Cabe destacar, que el RITE es uno de los reglamentos que ha perdurado con el tiempo y que dado su nivel de exigencia no ha sido absorbido por el Código Técnico de la Edificación (CTE), (BOE, 2006).

La innovación de este artículo radica no solo en el cumplimiento de la normativa y recomendaciones establecidas por las administraciones como consecuencia del SARS-CoV2, y el RITE, sino además su comprobación mediante cálculo numérico computacional de la ventilación natural, y de las variables que establecen los grados de confort en las aulas.

\subsection{Estudio mediante dinámica de fluidos computacional (CFD).}

El rango de velocidad de aire adecuada a la altura de la mesa y la cabeza de los estudiantes es de 0.12 y $0.35 \mathrm{~m} / \mathrm{s}$ (BOE, 2007), como valores más empleados en los proyectos de climatización de zonas arquitectónicas ocupadas. Las características del aire están definidas por la presión barométrica es de $101204.92 \mathrm{~Pa}$, (Harrison, 1965; U.S. Standard atmosphere, 1976; Hyland y Wexler, 1983), y considerando el aire en unas condiciones de confortabilidad (Carrier Air Conditioning Company, 2009), de temperatura seca de $22^{\circ} \mathrm{C}$ y humedad relativa del $50 \%$.

El caudal de aire en el interior del aula se puede obtener variando los valores de la ecuación diferencial aplicable para fluidos compresibles en un sistema isotérmico, ecuación 1.

$$
\mathrm{P} \cdot \mathrm{dP}+\frac{\mathrm{PM}}{\mathrm{R} \cdot \mathrm{T} \cdot \mathrm{Z}} \cdot \mathrm{g} \cdot \mathrm{P}^{2} \cdot \mathrm{dz}+\rho^{2} \cdot \frac{\mathrm{R} \cdot \mathrm{T} \cdot \mathrm{Z}}{\mathrm{PM}} \cdot \lambda \cdot \frac{1}{\mathrm{D}^{5}} \cdot \frac{8 \cdot \mathrm{Q}_{\mathrm{o}}^{2}}{\pi^{2}} \cdot \mathrm{dx}=0
$$

Para comprobar el comportamiento del aire en el interior del aula se han utilizado las ecuaciones de Navier-Stokes, mediante la dinámica de fluidos computacional (CFD), (Temam, 1979), (Zienkiewicz \& Taylor, 2000), considerando el aire como un fluido real y compresible, ecuación 2. Los cálculos se han realizado mediante aplicación informática comercial (Systems, S. D., 2019).

$$
\frac{\partial \Phi}{\partial \mathrm{t}}+\nabla \mathrm{F}+\nabla \mathrm{G}+\mathrm{Q}=0
$$

El estudio se ha realizado en las aulas JB2 y C1 de la Escuela Técnica Superior de Ingeniería de Edificación. 
El aula JB2 se describe en la figura 1 y 2, y el aula C1 en la figura 3. En ambas aulas se ha mantenido la separación mínima de 1.5 metros entre las mesas de los estudiantes y 2 metros entre estudiantes, siguiendo las recomendaciones de seguridad.

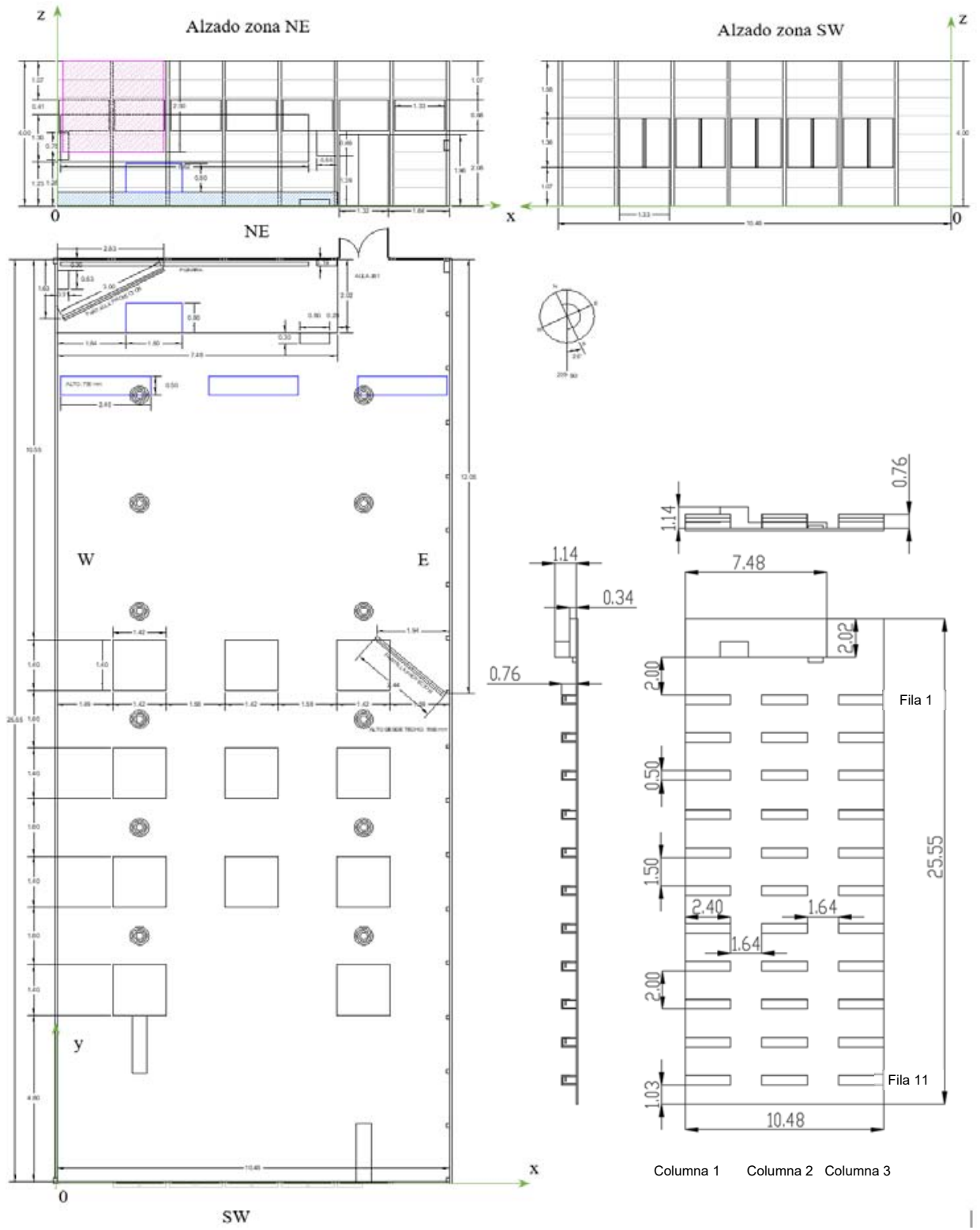

Fig. 1.- Aula docente JB2. Distribución de mesas, cotas en metros. 

docente con motivo del SARS-CoV-2. Caso de las aulas de la ETSIE de la UPV.

Diagnosis of natural ventilation, $\mathrm{CO}_{2}$ concentration, temperature and relative humidity of a teaching classroom due to SARS-CoV-2: The case of classrooms of the ETSIE of the UPV.
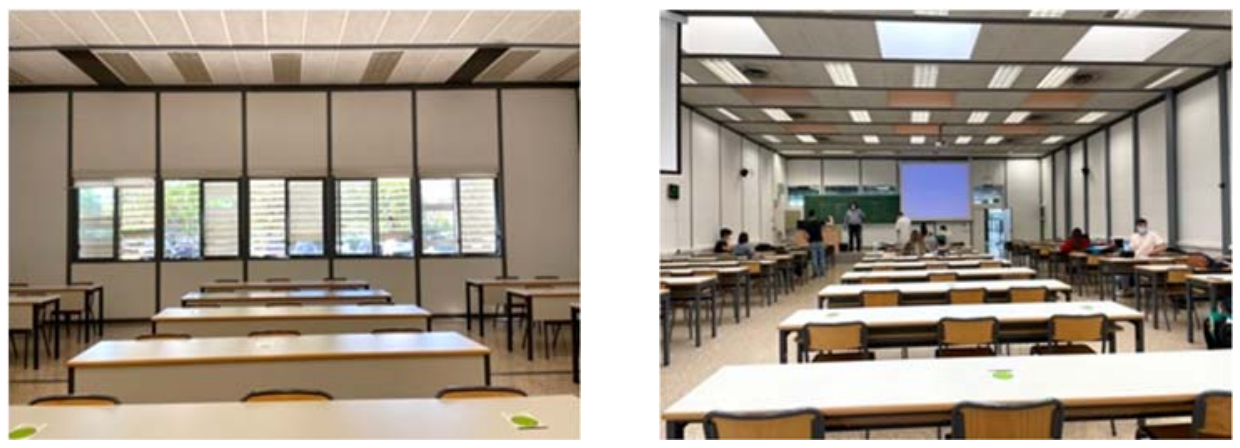

Fig. 2. Aula JB2 de la ETSIE de la UPV
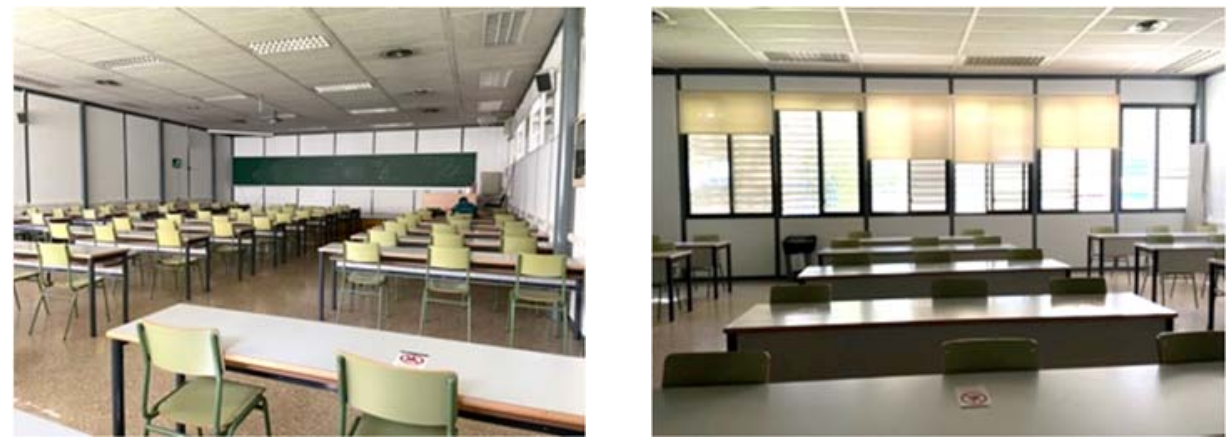

Fig. 3. Aula C1 de la ETSIE de la UPV

\subsection{Obtención de las variables de confort, monóxido de carbono $\mathrm{CO}_{2}$, temperatura y humedad relativa.}

Para la obtención de las variables de $\mathrm{CO}_{2}$, temperatura y humedad relativa, se ha utilizado un equipo de medición portátil modelo CDP-H2008, figura 4. Las mediciones se han realizado en las zonas donde los resultados del cálculo de la ventilación natural por CFD indica la formación de vórtices en el aire, es decir, en las zonas donde el aire posee remansos y en consecuencia la renovación del aire se produce con dificultad.

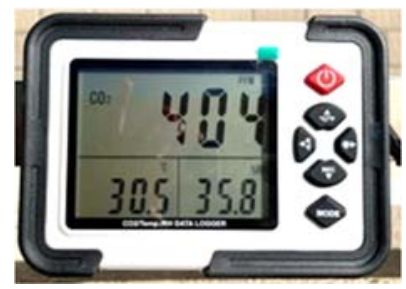

Fig. 4. Equipo de medición portátil, modelo CDP-H2008. 
En la tabla 1 se indican las mediciones realizadas en el exterior del edificio y en la tabla 2 la programación de las mediciones interiores, aforo y ventilación natural de las aulas.

Tabla 1. Mediciones exteriores en el año 2021.

\begin{tabular}{cccccc}
\hline Aula & Dia & Hora & $\mathbf{C O}_{\mathbf{2}}(\mathbf{p p m})$ & $\mathbf{T}\left({ }^{\circ} \mathbf{C}\right)$ & $\mathbf{e ~ ( \% )}$ \\
\hline \multirow{2}{*}{ JB2 } & \multirow{2}{*}{ 24-May } & $12: 30$ & 431 & 24.0 & 42.2 \\
& & $17: 00$ & 427 & 29.4 & 30.0 \\
\multirow{2}{*}{ C1 } & $20: 00$ & 418 & 28.0 & 30.3 \\
& \multirow{2}{*}{ 25-May } & $8: 00$ & 414 & 20.6 & 57.8 \\
& & $20: 00$ & 420 & 20.9 & 73.2 \\
\hline
\end{tabular}

Tabla 2. Programación de las mediciones interiores de las aulas en el año 2021.

\begin{tabular}{|c|c|c|c|c|c|c|}
\hline \multirow{2}{*}{ Aula } & \multirow{2}{*}{ Dia } & \multirow{2}{*}{ Hora } & \multirow{2}{*}{$\begin{array}{c}\mathbf{N}^{\circ} \\
\text { Personas }\end{array}$} & \multicolumn{3}{|c|}{ Ventilación Natural, Sup $\left(m^{2}\right)$} \\
\hline & & & & Huecos ext. & Huecos int. & Puerta int. \\
\hline \multirow{5}{*}{ JB2 } & & $8: 00-10: 35$ & 13 & 9.04 & 2.28 & 2.59 \\
\hline & & 10:35-12:30 & 28 & 9.04 & 2.28 & 2.59 \\
\hline & 24 May & $12: 30-14: 00$ & 36 & 9.04 & 2.28 & 2.59 \\
\hline & & $15: 00-17: 00$ & 12 & 9.04 & 2.28 & 2.59 \\
\hline & & $17: 00-20: 00$ & 12 & 9.04 & 2.28 & 2.59 \\
\hline \multirow[t]{2}{*}{ JB2 } & 17-Jun & 16:00-19:00 & 62 & 9.04 & 2.28 & 2.59 \\
\hline & & $8: 00-11: 30$ & 22 & 5.42 & 2.28 & 2.59 \\
\hline \multirow[t]{2}{*}{$\mathrm{C} 1$} & 25 May & $11: 30-15: 00$ & 17 & 5.42 & 2.28 & 2.59 \\
\hline & & $15: 00-18: 00$ & 35 & 5.42 & 2.28 & 2.59 \\
\hline
\end{tabular}

\section{Resultados}

\section{1.- Resultados de la ventilación natural por CFD en el aula JB2.}

Los resultados por ventilación natural por CFD, se representan en la perspectiva con las líneas de corriente en el interior del aula JB2, figura 5.

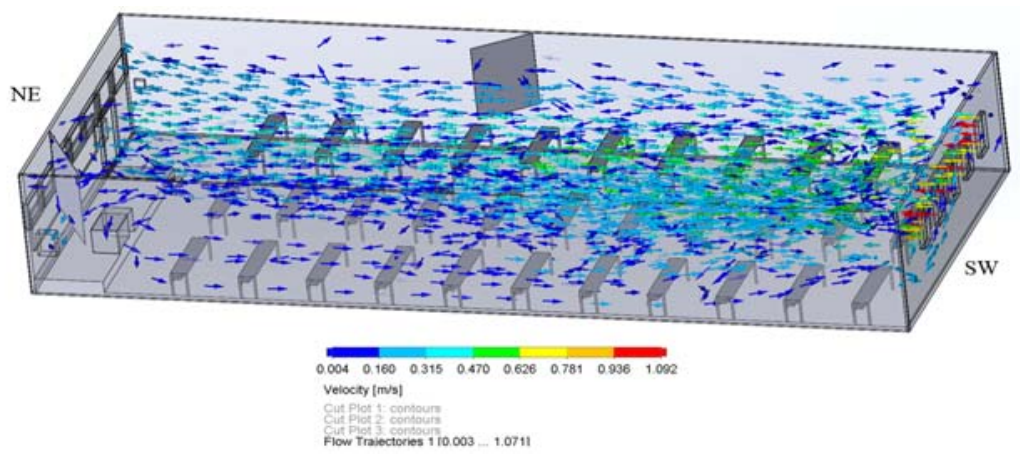

Fig. 5.- Perspectiva de las líneas de corriente en el interior del aula JB2. 
Diagnóstico de la ventilación natural, concentración de $\mathrm{CO}_{2}$, temperatura y humedad relativa de un aula docente con motivo del SARS-CoV-2. Caso de las aulas de la ETSIE de la UPV.

Diagnosis of natural ventilation, $\mathrm{CO}_{2}$ concentration, temperature and relative humidity of a teaching classroom due to SARS-CoV-2: The case of classrooms of the ETSIE of the UPV.

La velocidad mínima y máxima es de 0.004 y $0.955 \mathrm{~m} / \mathrm{s}$ respectivamente. La velocidad máxima se encuentra situada en la entrada del aire a través de las ventanas de la cara SW, mientras que la mínima es variable. En la figura 6, se representa la ventilación en planta.

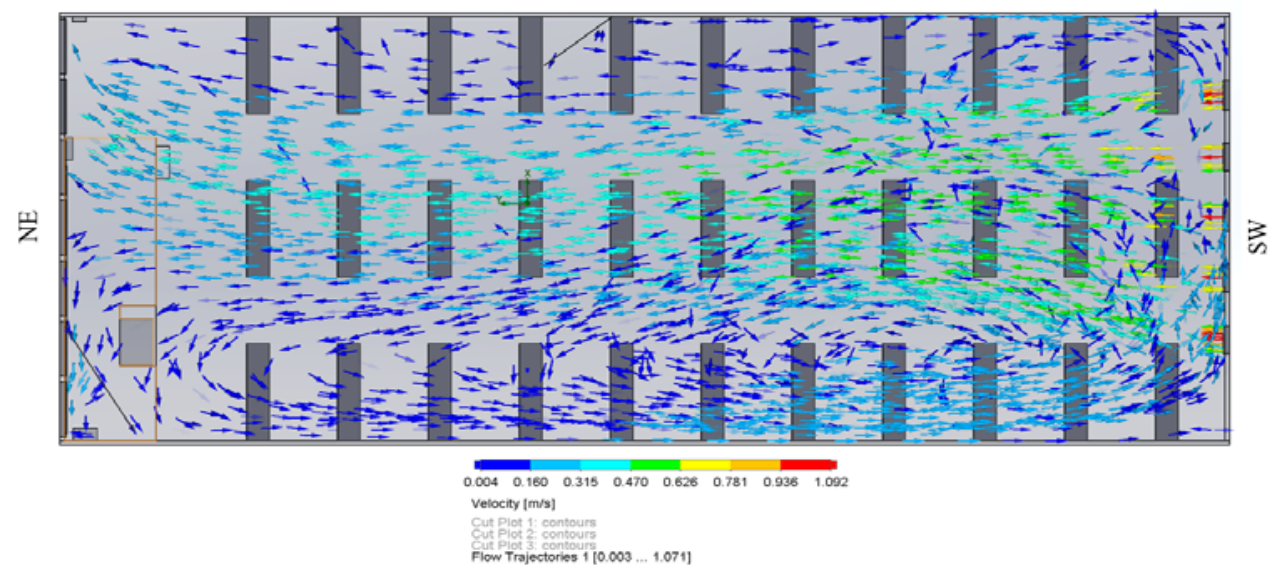

Fig. 6.- Planta de las líneas de corriente, velocidad, sentido y dirección del aire en el aula JB2.

Se puede observar que se produce un vórtice de aire cercano a la cara oeste de dimensiones aproximadas de 4.04 metros de anchura y 23.78 metros de longitud cuya superficie es de $96.07 \mathrm{~m}^{2}$, correspondiente a un $35.88 \%$ de la superficie total del aula. La existencia de este vórtice es preocupante dado que en el supuesto de que el aula se encuentre totalmente ocupada el aire del vórtice es compartido por al menos 22 estudiantes, lo que supone un $32.84 \%$ del aforo total máximo, y dado que en este espacio el aire no se renueva adecuadamente el contagio es inevitable.

La parte del aula más segura con mayor renovación de aire, así como la velocidad del aire más aconsejable, se sitúa sobre la columna central 2, figura 7 . La velocidad mínima se encuentra situada sobre la columna 3 con un valor de $0.005 \mathrm{~m} / \mathrm{s}$ y la máxima en la entrada del aire por las ventanas SW, con un valor de $1.082 \mathrm{~m} / \mathrm{s}$ en la columna central 2 .

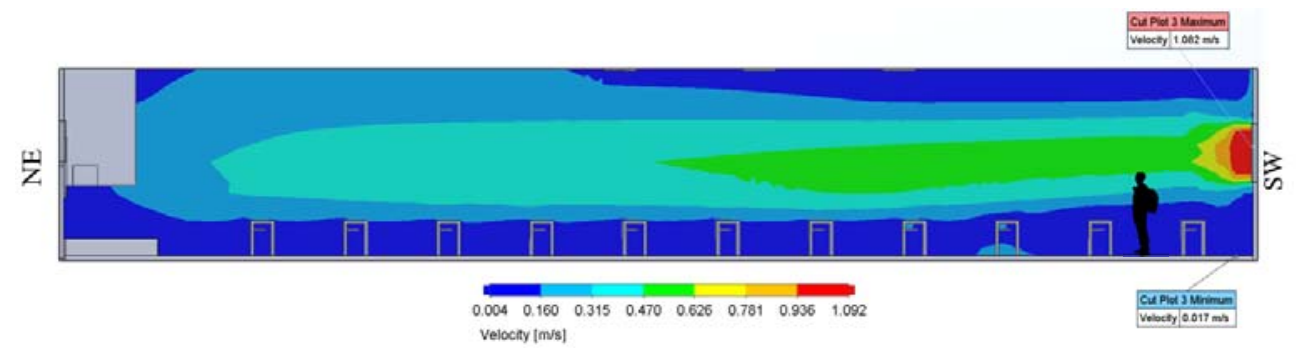

Fig. 7.- Ventilación natural columna 2. Sección vertical en sentido longitudinal del aula. 
Los resultados obtenidos de las secciones transversales del aula en las filas 1, 6 y 11, por la parte central de las mesas de los estudiantes, viene dado por las figuras 8,9 y 10 . El rango de velocidades se encuentra entre los valores de 0.001 y $0.526 \mathrm{~m} / \mathrm{s}$.

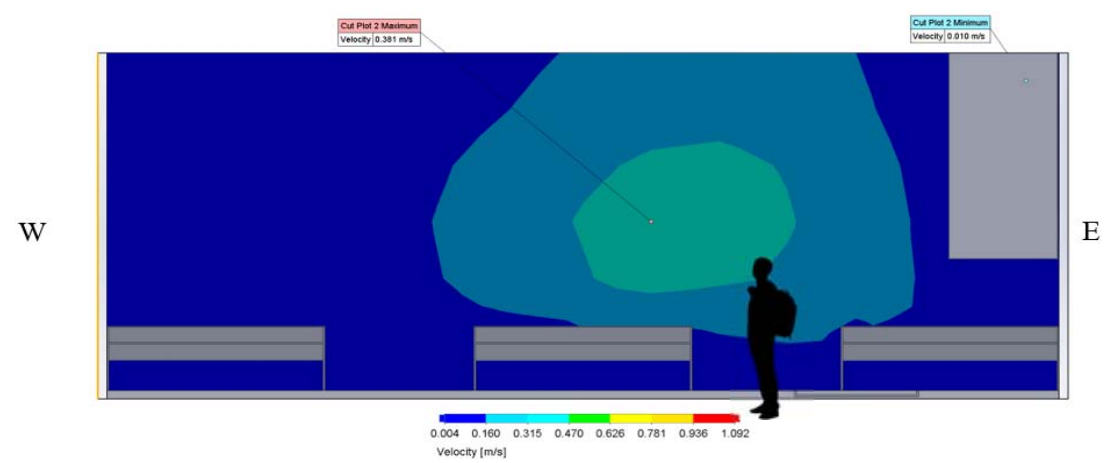

Fig. 8.- Ventilación natural (central), fila 1. Sección vertical en sentido transversal del aula.

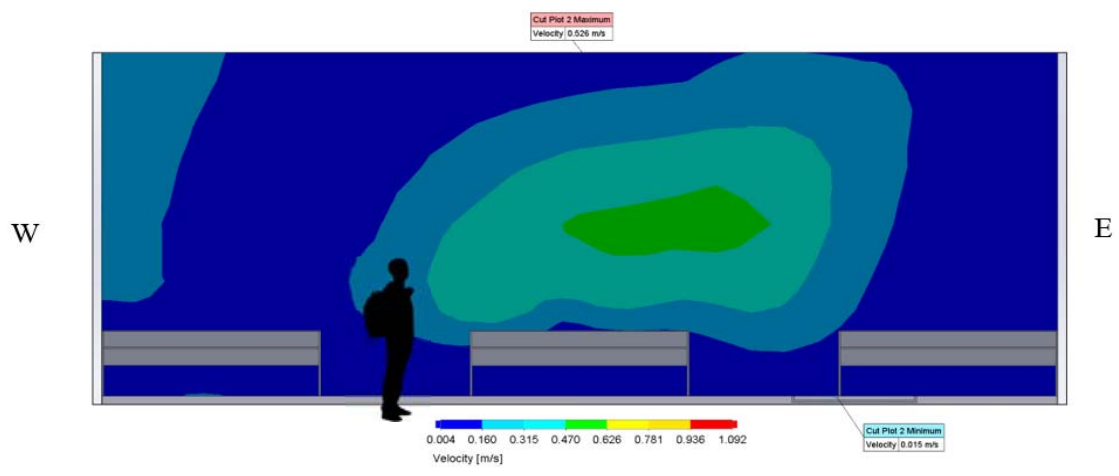

Fig. 9.- Ventilación natural (central), fila 6. Sección vertical en sentido transversal del aula.

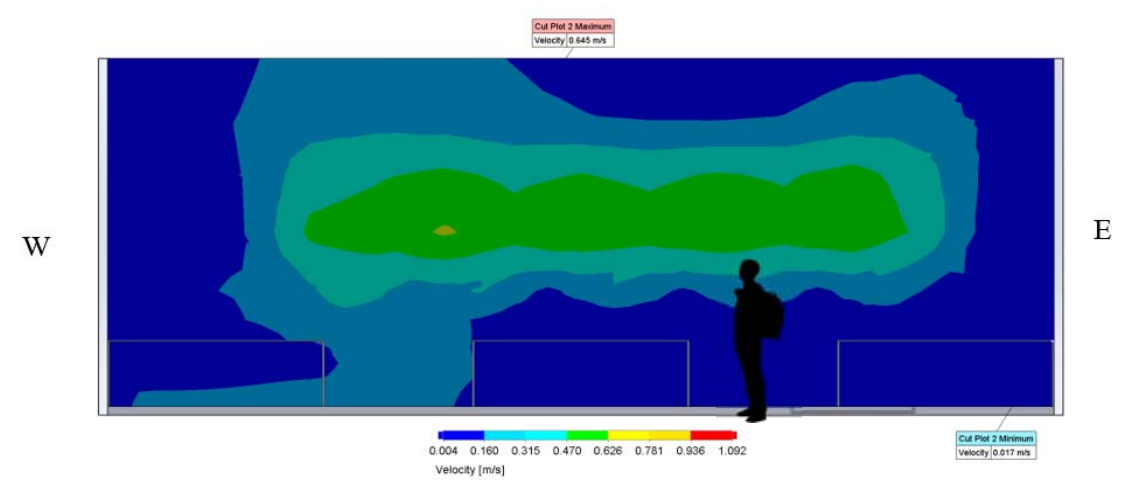

Fig. 10.- Ventilación natural, fila 11. Sección vertical en sentido transversal del aula.

Y, por último, los resultados obtenidos de las secciones cenitales a la altura de las de la cabeza del alumno sentado viene dado por la figura 11 . 
Diagnóstico de la ventilación natural, concentración de $\mathrm{CO}_{2}$, temperatura y humedad relativa de un aula docente con motivo del SARS-CoV-2. Caso de las aulas de la ETSIE de la UPV.

Diagnosis of natural ventilation, $\mathrm{CO}_{2}$ concentration, temperature and relative humidity of a teaching classroom due to SARS-CoV-2: The case of classrooms of the ETSIE of the UPV.

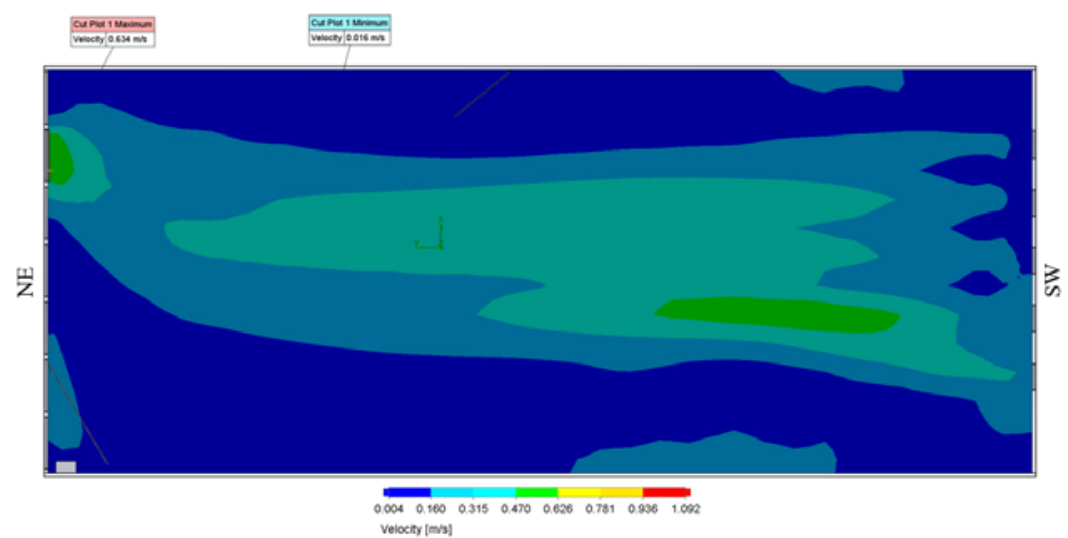

Fig. 11.- Ventilación natural. Planta a la altura de la cabeza alumno sentado

Como se ha indicado en los resultados obtenidos, es recomendable que el aula sea ocupada por todas las filas de la columna 2 central, más la mitad de las filas de la columna 3 que dan al pasillo. Por tanto, el aforo sería de 33 estudiantes más 1 profesor, siendo un total de 34 personas, cuyo esquema de ubicación de estudiantes y profesor viene dado por la figura 12. En base a estos datos los resultados son el $\mathrm{t}=3.73 \mathrm{~min}, \mathrm{n}=16.07$ renovaciones/hora y considerando las 34 personas, $q=140.63$ litros $\cdot \mathrm{s}^{-1} \cdot$ persona $^{-1}$.

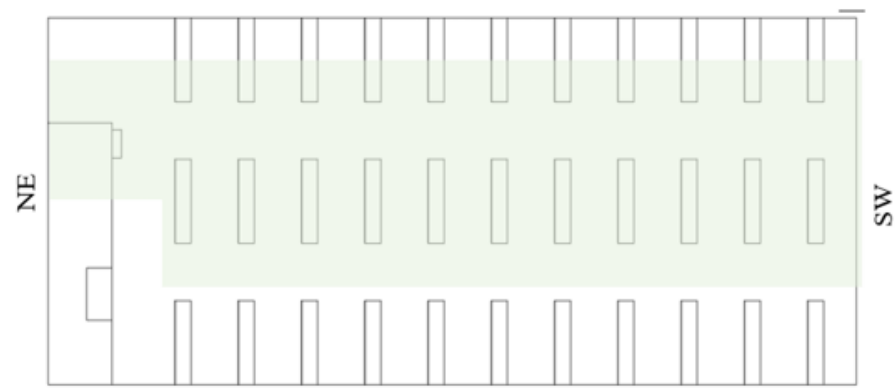

Fig. 12.- Ventilación natural, planta de la zona de ocupación de seguridad, color verde claro.

Se plantean las siguientes recomendaciones, es imprescindible que en todo momento las ventanas situadas en la cara SW, los huecos practicados en la cara NE y la puerta de acceso al aula se encuentren totalmente abiertas. La velocidad del aire en la tarima del profesor puede ser inferior al mínimo de $0.12 \mathrm{~m} / \mathrm{s}$, se recomienda permanecer en ella el menor tiempo posible. Se aconseja no sobrepasar el aforo máximo en el aula de 34 personas. Y no es aconseja utilizar para la docencia la columna 1 por razones de formación de vórtice y escasa velocidad del aire, ni en la columna 3 en los asientos cercanos a la pared de la cara este. 


\subsection{Resultados de las mediciones de monóxido de carbono $\mathrm{CO}_{2}$, temperatura y humedad relativa.}

4.2.1.- Estudio del aula JB2 el día 24 de mayo de 8:00 a 20:00h.

El aforo fue de 13 personas de 8:00 a 10:35, de 28 personas de 10:35 a 12:30 y de 36 personas de $12: 30$ a $14: 00 h$.

De la evolución de la concentración de $\mathrm{CO}_{2}$ en ppm, figura 13, se puede observar que la concentración máxima registrada fue de $592 \mathrm{ppm}$ a las $12: 51 \mathrm{~h}$, aproximadamente cinco horas tras el comienzo de la docencia. Se observa una evolución claramente ascendente a lo largo de la mañana, produciéndose descensos en los momentos coincidentes con los descansos entre las distintas sesiones de aula, donde se produce el movimiento de los estudiantes en el aula y la salida a los pasillos para volver a acceder al aula al comienzo de la siguiente clase. Se puede observar que un descanso de 19 minutos con un aforo de 13 personas produjo un descenso de $37 \mathrm{ppm}, 1.94 \mathrm{ppm} / \mathrm{min}$. Mientras que un descanso de menor tiempo (13 $\mathrm{min}$ ) pero con un mayor aforo (28 personas) produjo un descenso de $71 \mathrm{ppm}, 5.46$ $\mathrm{ppm} / \mathrm{min}$, aproximadamente tres veces superior.

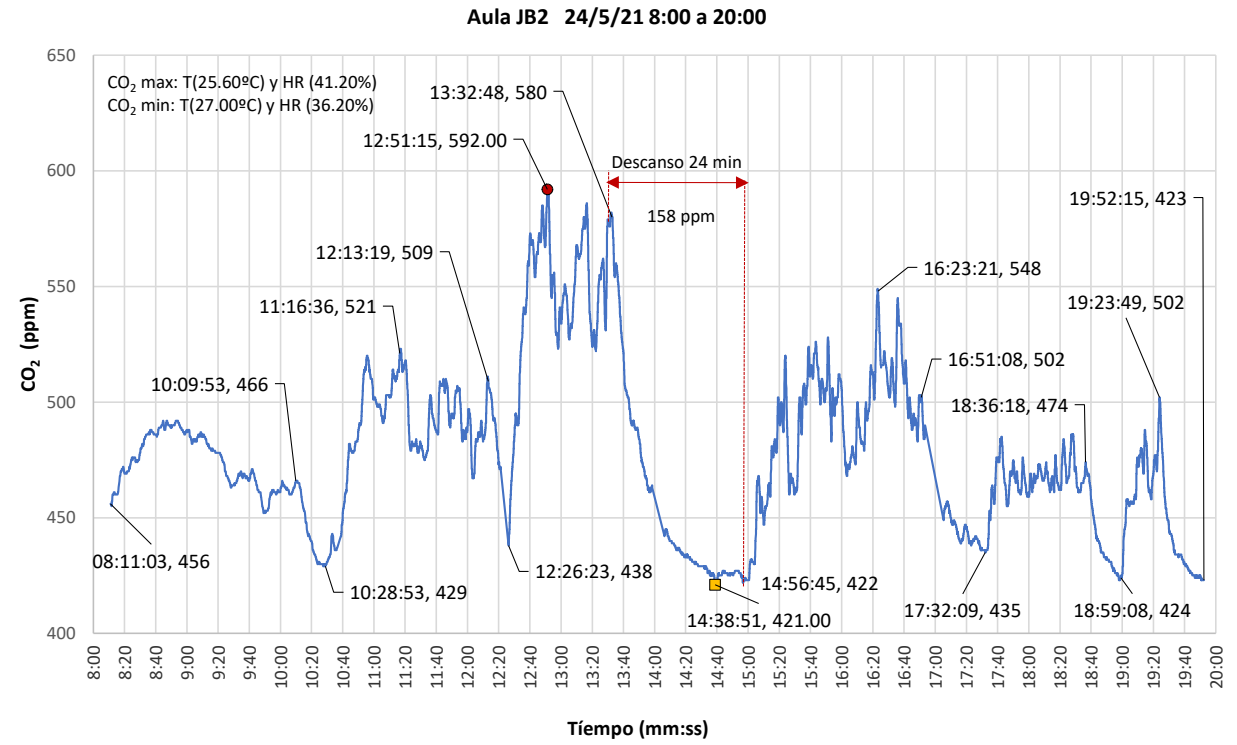

Fig. 13. Concentración de CO2 (ppm) en aula JB2 el 24/5/2021 de 8:00 a 20:00

Al finalizar la docencia de la mañana se pasó de un registro de 580 ppm, el segundo más alto de la mañana a 463 ppm, es decir 117 ppm en $26 \mathrm{~min}, 4.5 \mathrm{ppm} / \mathrm{min}$, cuando el aforo era de 36 personas.

Al finalizar la docencia de la mañana se redujo la concentración de $\mathrm{CO}_{2}$ en 117 ppm en 26 $\mathrm{min}, 4.5 \mathrm{ppm} / \mathrm{min}$, hasta que el aforo pasó de 36 personas a ser nulo. Ya con el aforo nulo, el descenso fue mucho más lento hasta alcanzar un mínimo de $421 \mathrm{ppm}$ en $41 \mathrm{~min}, 1.05$ 
Diagnóstico de la ventilación natural, concentración de $\mathrm{CO}_{2}$, temperatura y humedad relativa de un aula docente con motivo del SARS-CoV-2. Caso de las aulas de la ETSIE de la UPV.

Diagnosis of natural ventilation, $\mathrm{CO}_{2}$ concentration, temperature and relative humidity of a teaching classroom due to SARS-CoV-2: The case of classrooms of the ETSIE of the UPV.

ppm/min. Considerándose el valor mínimo y estable dado que la medición del exterior del edificio fue de $431 \mathrm{ppm}$.

En la sesión de tarde el aforo fue de 12 personas de 15:00 a 20:00h. En este caso el valor máximo registrado fue de 548 ppm a las $16 \mathrm{~h} 22 \mathrm{~min}$, obtenido en sentido ascendente a 1.38 $\mathrm{ppm} / \mathrm{min}$.

El primer descanso de la tarde redujo $67 \mathrm{ppm}$ en $41 \mathrm{~min}, 1.64 \mathrm{ppm} / \mathrm{min}$ y el segundo $50 \mathrm{ppm}$ en $23 \mathrm{~min}, 2.17 \mathrm{ppm} / \mathrm{min}$, con el aforo de 12 personas. Al finalizar la docencia se redujo 79 ppm en $29 \mathrm{~min}, 2.72 \mathrm{ppm} / \mathrm{min}$, hasta alcanzar el mínimo de 423 ppm cuando el exterior del edificio registro $418 \mathrm{ppm}$.

Puede observarse que los descanso permiten controlar la concentración descendiendo momentáneamente, pero creando un proceso acumulativo en los valores mínimos y máximos de las mediciones. Estando la velocidad de descenso relacionada con el aforo existente.

Los valores de la temperatura registrados oscilaron desde 29.20 a $20.30^{\circ} \mathrm{C}$ y la humedad relativa claramente descendiente a lo largo de la mañana pasó de un $60.00 \%$ a un $29.40 \%$, figura 14.

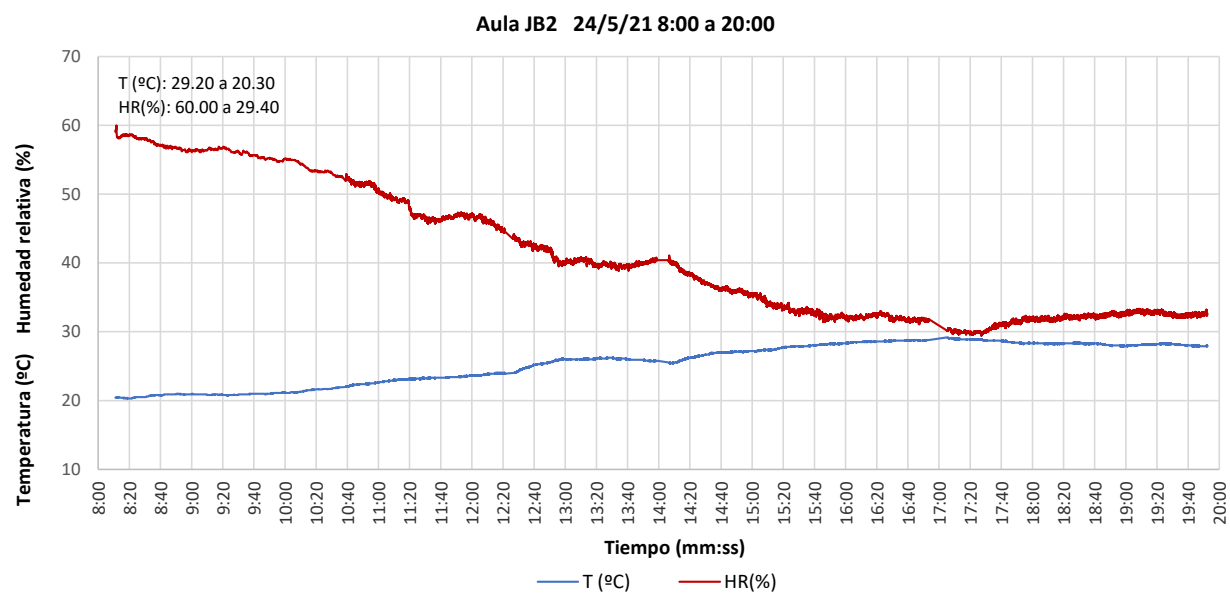

Fig. 14. Temperatura $\left({ }^{\circ} \mathrm{C}\right)$ y Humedad relativa $(\%)$ en aula JB2 el 24/5/2021 de 8:00 a 20:00

\subsection{2.- Estudio del aula JB2 el día 17 de junio de 16:00 a 19:00h.}

El aforo fue de 62 personas de 16:00 a 19:00h debido a la realización de un examen. Este aforo generó una concentración de $\mathrm{CO}_{2}$ que alcanzó un máximo de 688 ppm a las 18:52h, aproximadamente 3 horas tras el comienzo del examen, figura 15.

Destacó el rápido aumento al inicio que incrementó 214 ppm en $15 \mathrm{~min}, 14,26$ ppm/min. En el primer descanso se redujo en 98 ppm en $27 \mathrm{~min}, 3.63 \mathrm{ppm} / \mathrm{min}$ y en el segundo descanso 
se redujo 96 ppm en $17 \mathrm{~min}, 5.65$ ppm/min. Y la finalización del examen redujo en 90 ppm en $6 \mathrm{~min}, 15.00 \mathrm{ppm} / \mathrm{min}$.

Los descansos facilitan el control de la acumulación de $\mathrm{CO}_{2}$, pero se mantiene un crecimiento sostenido. Es destacable que la velocidad de reducción de la concentración es mayor cuando más elevado ha sido el aforo. En la figura 16 se representa la evolución de la temperatura y humedad relativa.

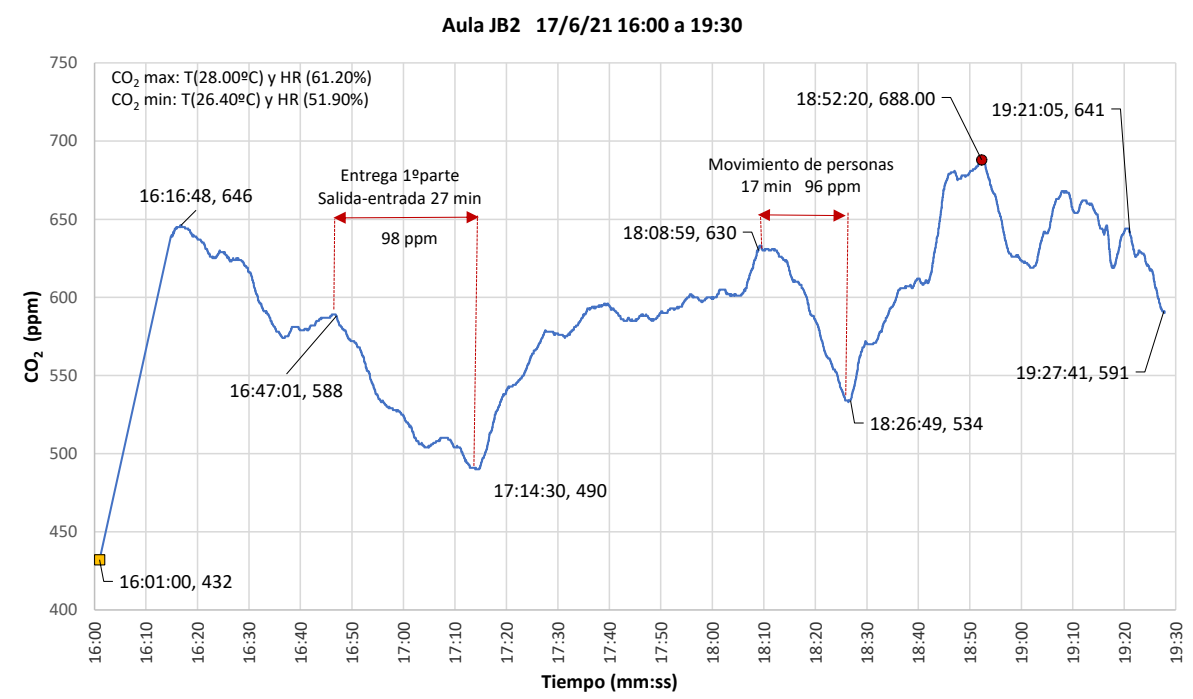

Fig. 15. Concentración de CO2 en aula JB2 el 17/6/2021 de 16:00 a 19:30

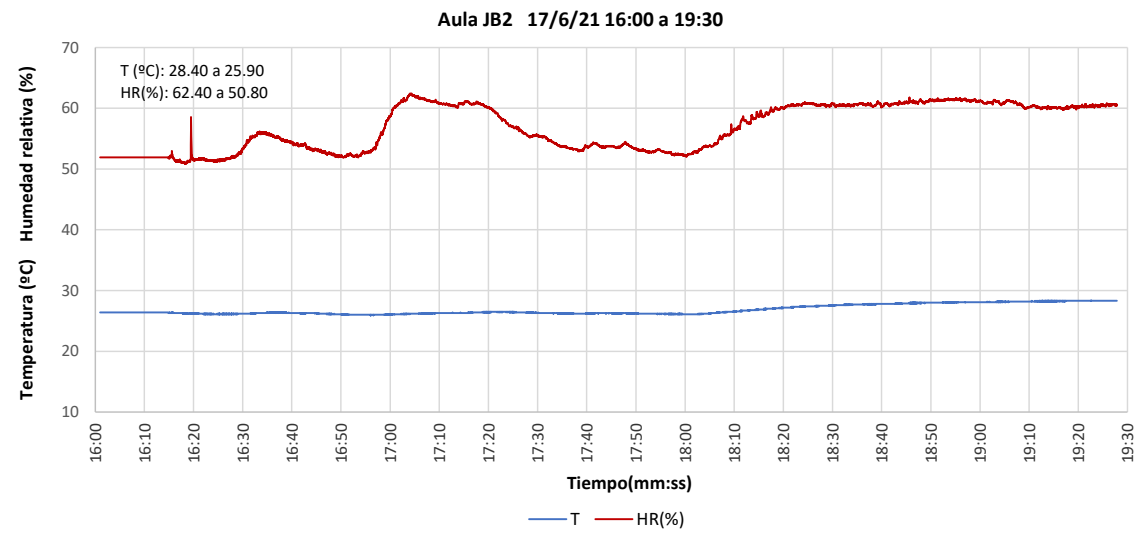

Fig. 16. Temperatura $\left({ }^{\circ} \mathrm{C}\right)$ y Humedad relativa $(\%)$ en aula JB2 el 17/6/2021 de 16:00 a 19:30 
Diagnóstico de la ventilación natural, concentración de $\mathrm{CO}_{2}$, temperatura y humedad relativa de un aula docente con motivo del SARS-CoV-2. Caso de las aulas de la ETSIE de la UPV.

Diagnosis of natural ventilation, $\mathrm{CO}_{2}$ concentration, temperature and relative humidity of a teaching classroom due to SARS-CoV-2: The case of classrooms of the ETSIE of the UPV.

4.2.3.- Estudio del aula C1 el día 25 de mayo de 8:00 a 20:15h.

El aforo fue de 22 personas de 8:00 a 11:30, de 17 de 11:30 a 15:00 y de 35 de 15:00 a 19:00h. En este caso se generó una concentración de $\mathrm{CO}_{2}$ que alcanzó un máximo de 556 ppm a las 12:08h, aproximadamente 4 horas tras el comienzo de las clases, figura 17 y 18.

El incremento inicial fue de 71 ppm en $35 \mathrm{~min}, 2.03$ ppm/min. La finalización de las clases de la mañana se redujo en $94 \mathrm{ppm}$ en $53 \mathrm{~min}, 1.77 \mathrm{ppm} / \mathrm{min}$. El primer descanso de la tarde redujo $37 \mathrm{ppm}$ en $33 \mathrm{~min}, 1.12 \mathrm{ppm} / \mathrm{min}$, el segundo descanso de $15 \mathrm{ppm}$ en $10 \mathrm{~min}$, $1.5 \mathrm{ppm} / \mathrm{min}$ y la finalización de las clases en $70 \mathrm{ppm}$ en $45 \mathrm{~min}, 1.55 \mathrm{ppm} / \mathrm{min}$.

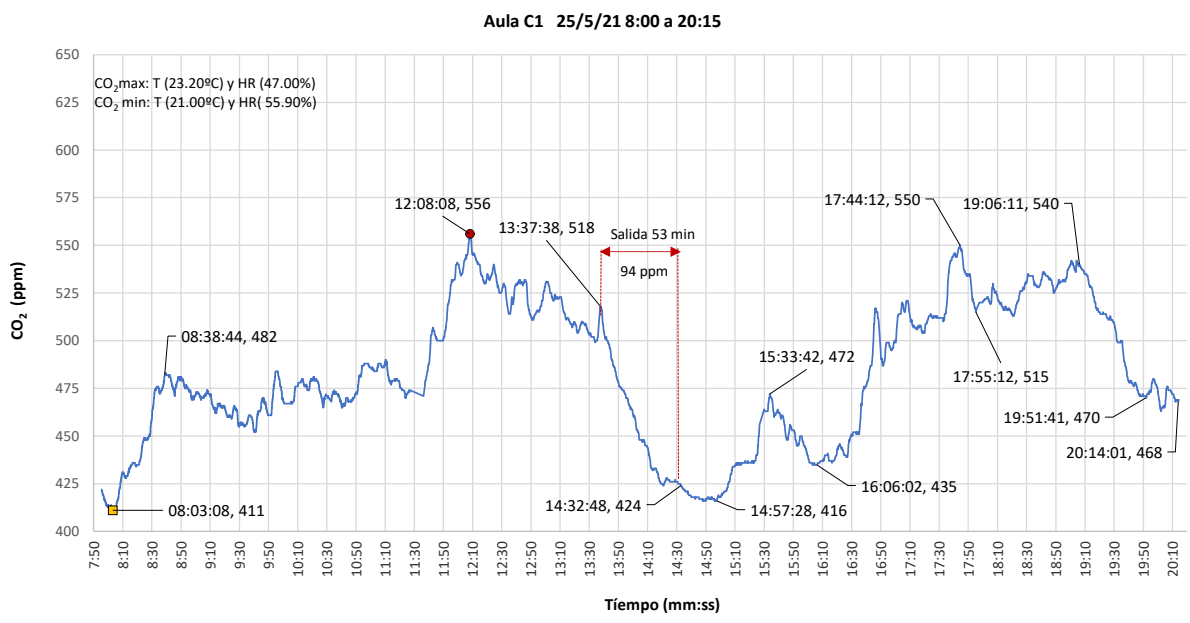

Fig. 17. CO2 en aula C1 el 25/5/2021 de 8:00 a 20:15

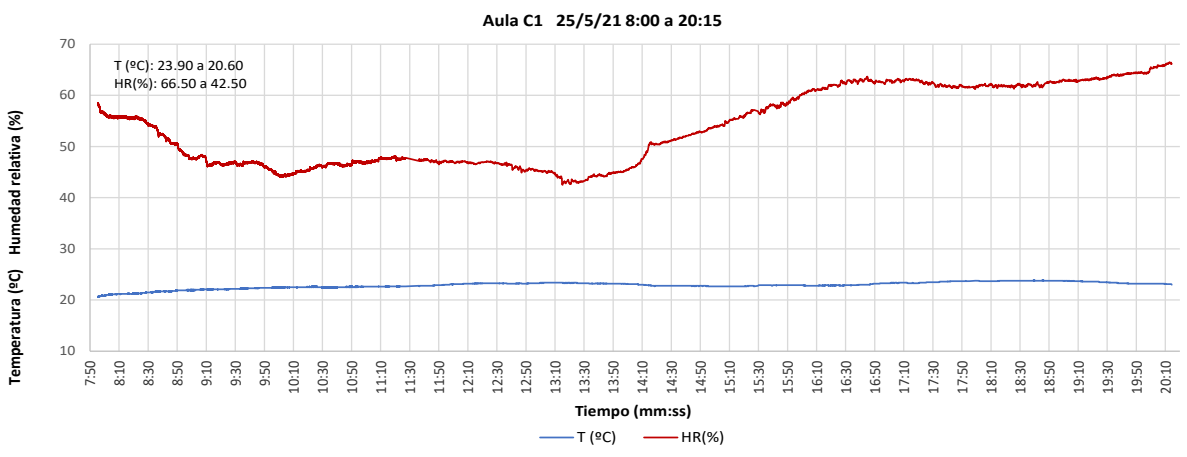

Fig. 18. Temperatura $\left({ }^{\circ} \mathrm{C}\right)$ y Humedad relativa $(\%)$ en aula $\mathrm{C} 1$ el 25/5/2021 de 8:00 a 20:15

En la tabla 3 se indican los resultados de las concentraciones máximas registradas de $\mathrm{CO}_{2}$, y las velocidades de reducción de esta, por unidad de tiempo y por persona, producidas en 
los descansos y finalización de la docencia, observándose velocidades mayores con mayores aforos.

Tabla 3. Concentración de CO2 máximo y velocidad de reducción de $\mathrm{CO}$ (ppm/min y $\mathrm{ppm} / \mathrm{min} \cdot$ persona), año 2021.

\begin{tabular}{|c|c|c|c|c|c|c|c|}
\hline \multirow{2}{*}{ Aula } & \multirow{2}{*}{ Dia } & \multirow{2}{*}{ Hora } & \multirow{2}{*}{$\begin{array}{c}\mathbf{N}^{\circ} \\
\text { Personas }\end{array}$} & \multirow{2}{*}{$\begin{array}{l}\text { CO2 máximo } \\
(p p m)\end{array}$} & \multicolumn{3}{|c|}{$\begin{array}{l}\text { Velocidad de reducción de } \mathrm{CO}_{2} \\
\text { (ppm/min) -- (ppm/min/personas) }\end{array}$} \\
\hline & & & & & $1^{\circ}$ Descanso & $2^{\circ}$ Descanso & Finalización \\
\hline \multirow{6}{*}{ JB2 } & & $8: 00-10: 35$ & 13 & 491 & $1.94-0.15$ & - & - \\
\hline & & $10: 35-12: 30$ & 28 & 521 & - & $5.46-0.20$ & - \\
\hline & 24-May & $12: 30-14: 00$ & 36 & 592 & - & - & $4.50-0.13$ \\
\hline & & $15: 00-17: 00$ & 12 & 548 & $1.64-0.14$ & - & - \\
\hline & & $17: 00-20: 00$ & 12 & 502 & - & $2.17-0.18$ & $2.72-0.23$ \\
\hline & 17-Jun & $16: 00-19: 00$ & 62 & 688 & $3.63-0.06$ & $13.71-0.22$ & $15.00-0.24$ \\
\hline \multirow{3}{*}{ C1 } & & $8: 00-11: 30$ & 22 & 482 & - & - & - \\
\hline & 25-May & $11: 30-15: 00$ & 17 & 556 & - & - & $1.77-0.10$ \\
\hline & & $15: 00-19: 00$ & 35 & 550 & $1.12-0.03$ & $1.50-0.04$ & $1.55-0.04$ \\
\hline
\end{tabular}

Dada la recomendación de no sobrepasar una concentración de $\mathrm{CO}_{2}$ de entre 700 y 900 ppm, Puede considerarse que el aforo de la JB2 no debería sobrepasar de 62 personas, sin embargo, en comparación con los resultados del cálculo por CFD que permite localizar las zonas no seguras por formación de vórtices se limita el aforo a 34 personas.

\section{Conclusiones}

Para poder afirmar que una ventilación es adecuada, desde el punto de vista de la seguridad, no basta con cumplir la normativa oficial o recomendaciones, es necesario realizar simulaciones mediante dinámica de fluidos computacional para comprobar la dirección de las líneas de corriente, velocidad del aire, caudales, número de renovaciones del aire, existencia de vórtices, remanso, eficiencia del sistema, etc. Cualquier aplicación de ecuaciones simples de tipo lineal que propone la normativa hay que adoptarla como sugerencia, debiendo demostrar mediante la mecánica de fluidos que el sistema funciona correctamente.

Por simplificación en todas las simulaciones por dinámica de fluidos computacional, no se ha tenido en cuenta la pérdida de carga o de presión producido por las lamas exteriores de las ventanas y por la ocupación tanto de estudiantes como del profesor. Es por ello por lo que los resultados de cálculo deben de adoptarse como valores mínimos.

Es necesaria una medición experimental que aporte la seguridad cuantitativa de la concentración de $\mathrm{CO}_{2}$ como medida inmediata, pero siempre acompañada de un estudio previo que determine la localización de los vórtices de aire y las renovaciones, para localizar las zonas de ocupación de seguridad y que sea este aspecto el que determine el aforo máximo. La ocupación de las zonas donde se producen los vórtices es sensible a la propagación de contagios. 
Diagnóstico de la ventilación natural, concentración de $\mathrm{CO}_{2}$, temperatura y humedad relativa de un aula docente con motivo del SARS-CoV-2. Caso de las aulas de la ETSIE de la UPV.

Diagnosis of natural ventilation, $\mathrm{CO}_{2}$ concentration, temperature and relative humidity of a teaching classroom due to SARS-CoV-2: The case of classrooms of the ETSIE of the UPV.

Es recomendable establecer un tiempo entre 10 a 15 minutos entre clases para que exista una renovación completa del aire del aula. Esto se ha visto claramente reflejado en el estudio experimental realizado, como elemento regulador de la concentración de $\mathrm{CO}_{2}$.

Dado que el sistema posee gran variedad de variables como la presión barométrica, humedad relativa y específica, entalpía, temperatura seca y húmeda, presión del vapor de agua, volumen específico, densidad, viscosidad cinemática, grado de compresibilidad del aire, pérdidas de carga o de presión provocada por las personas, condiciones de confortabilidad, etc., es muy complejo establecer una única solución válida. Por ello se recomienda de forma práctica para asegurar la renovación del aire que los huecos del aula, incluido ventanas y puertas estén en todo momento abiertas.

\section{Referencias}

España. Acuerdo, de 19 de junio, sobre las medidas de prevención frente a la covid 19. Diario Oficial de la Generalitat Valenciana, 20 de junio de 2020, núm. 8841, pp. 24259-24277.

España. Real Decreto 314/2006, de 17 de marzo y corrección de errores, por el que se aprueba el Código Técnico de la Edificación. Aplicación de la exigencia HS 3 Calidad del aire interior. Boletín Oficial del Estado, 28 de marzo de 2006, núm. 74, pp. 11816-11831.

España. Real Decreto 1027/2007, de 20 de julio, por el que se aprueba el reglamento de Instalaciones térmicas en los Edificios. Boletín Oficial del Estado, 29 de agosto de 2007, núm. 207, pp. 3593135984.

HARRISON, L. P. (1965). Fundamental Concepts and Definitions Relating to Humidity and Moisture Measurement and Control in Science and Industry. Proc. Int. Symp. On Humidity and Moisture, Vol.3 Fundamentals and Standards, Reinhold, New York, 3-256.

HYLAND, R.W., AND WEXLER, A. 1983. Formulations for the thermodynamic properties of the saturated phases of $\mathrm{H} 2 \mathrm{O}$ from 173.15K to 473.15K. ASHRAE Trans. 89, 500-519.

Carrier Air Conditioning Company. (2009). Manual de aire acondicionado. Marcombo.

SANTARPIA, J. L., RIVERA, D. N., HERRERA, V., MORWITZER, M. J., CREAGER, H., SANTARPIA, G. W., ... \& LOWE, J. J. (2020). Aerosol and surface transmission potential of SARS-CoV-2. MedRxiv.

SYSTEMS, S. D. (2019). SolidWorks Education Edition . http://www.solidworks.es

TEMAM, R. (1979). Navier-Stokes equations : Theory and numerical analysis (Ed. rev.). Amsterdam, etc. : North-Holland.

U.S. Standard atmosphere. 1976. National Oceanic and Atmospheric Administration (NOAA), National Aeronautics and Space Administration (NASA), and the United States Air Force. Available from National Geophysical Data Center, Boulder, CO. Washington DC. EEUU.

ZIENKIEWICZ, O. C., \& TAYLOR, R. L. (2000). The finite element method. Volume 3, Fluid dynamics (5th ed..). Oxford [etc.]: Butterworth-Heinemann. 


\title{
EDIFICATE
}

I Congreso de Escuelas de Edificación y Arquitectura Técnica de España València, 4 y 5 de noviembre de 2021

Escuela Técnica Superior de Ingeniería de Edificación

Universitat Politècnica de València

Doi: https://doi.org/10.4995/EDIFICATE2021.2021.13507

\section{Prevención y Seguridad en el Grado de Edificación, transversalidad y experiencia docente \\ Prevention and Safety in Building Degree, transversally and teaching experience}

\author{
Francisco J. Forteza Oliver ${ }^{\mathrm{a}}$ Bárbara Estudillo Gil ${ }^{\mathrm{a}}$ \\ aUIB, departamento Ingeniería industrial y Construcción (francisco.forteza@uib.es), \\ barbara.estudillo@uib.cat
}

\begin{abstract}
The subject of Prevention and Safety (P\&S) is key for Building studies due to the breadth of skills and knowledge that should allow students to develop and the specificity of content, often developed by this single subject. On the other hand, assimilating these contents and skills requires prior knowledge and skills that are assimilated through other subjects. Drawing, construction or measurements are key tools that the student must handle to develop specific skills in P\&S.
\end{abstract}

To make these objectives possible, over the years we have developed a teaching methodology that aims to complete in a subject the minimum requirements that the student needs in preventive matters. The subject is structured in two modules. The first is more theoretical, with a part of lectures and another of applied practices, and another module, of writing Security Studies in which students first develop a Basic Study (EBS) in a group, followed by a Security Study and Health (ESS) individually. The course is completed with group visits to works in different phases and with laboratory practices. This organization of the subject allows us to achieve the objectives set.

Keywords: Prevention and Safety, teaching experience, degree of construction, construction process and prevention, transversality. 


\section{Resumen}

La asignatura de Prevención y Seguridad (P\&S) es clave para los estudios de Edificación debido a la amplitud de competencias y conocimientos que debe permitir desarrollar a los alumnos y la especificidad de contenidos, muchas veces desarrollados por esta única asignatura. Por otra parte, asimilar estos contenidos y competencias requiere de conocimientos y habilidades previas que se asimilan a través de otras asignaturas. Dibujo, construcción o mediciones, son herramientas clave que el alumno debe manejar para desarrollar las habilidades especificas en P\&S.

Para hacer posibles estos objetivos, a lo largo de los años hemos desarrollado una metodología docente que pretende completar en una asignatura los requerimientos mínimos que el alumno necesita en materia preventiva. La asignatura se estructura en dos módulos. El primero más teórico, con una parte de clases magistrales y otra de prácticas aplicadas, y otro módulo, de redacción de Estudios de seguridad en la que los alumnos desarrollan primero un Estudio Básico (EBS) en grupo, seguido de un Estudio de Seguridad y Salud (ESS) de manera individual. La asignatura se completa con visitas en grupos a obras en diferentes fases y con prácticas de laboratorios. Esta organización de la asignatura nos permite alcanzar los objetivos planteados.

Palabras clave: Prevención y Seguridad, experiencia docente, grado edificación, proceso constructivo y prevención, transversalidad. 


\section{Introducción}

Los estudios de Edificación se caracterizan por formar a un técnico de manera global para el desarrollo de funciones muy amplias en el sector de la construcción. Esta amplitud en la formación engloba conocimientos y habilidades muy diversas, entre otras, expresión gráfica, construcción, mediciones y presupuestos, instalaciones, estructuras y Prevención y Salud (P\&S) aplicada al sector.

Esta última asignatura requiere del manejo de conocimientos previos de otras materias para poder aplicarlos al estudio de la prevención. Los estudiantes deben conocer los procesos constructivos, entenderlos, ser capaces de secuenciarlos, para poder aplicar las medidas de seguridad. Por otra parte, se requiere de un amplio conocimiento de la normativa aplicable y de las obligaciones de carácter preventivo que deben atender las empresas. Estamos ante un reto muy importante ya que los estudiantes, que todavía no tienen muy asentados sus competencias en materia constructiva, deben manejarlas de manera solvente para identificar los riesgos y adoptar las medidas preventivas adecuadas.

\section{Objetivos}

Impartir la asignatura de prevención y seguridad en un curso académico de Edificación capaz de alcanzar por el estudiante la base de los conocimientos, competencias y habilidades necesarias para el futuro ejercicio profesional del perfil del Graduado en Edificación y su profesión regulada de Arquitecto Técnico. Todo ello en el entorno del Espacio Europeo de Educación Superior, en el que desarrollan los actuales estudios de Grado, caracterizados por centrarse en el estudiante como foco principal, en torno al que se deben desarrollar todos los esfuerzos.

Para ello, se estructura la asignatura de manera que el alumno pueda adquirir y practicar estas habilidades, siguiendo diversos estudios que verifican que la inclusión de prácticas en la formación aumentando la participación activa de los alumnos, mejora los resultados de aprendizaje y retención de contenidos para su mejor aplicación y resolución de problemas reales (Burke et al., 2011; Reiman et al., 2019). Se integran en la asignatura, entre otras, las visitas guiadas y las prácticas en clase, en grupo e individuales, donde el alumno se enfrenta a la redacción de los contenidos de un Estudio Básico de Seguridad (EBS) y un Estudio de Seguridad y Salud (ESS) con la guía del profesor y colaboración entre compañeros.

\section{Desarrollo de la innovación}

La estructura de las clases difiere de la clásica de lecciones magistrales. En este caso únicamente se aplican clases magistrales al 25 por ciento de las horas lectivas. Otro 15 por ciento corresponde a prácticas de clase en la que el alumno debe manejar y aplicar la normativa y complementos teóricos a ejemplos prácticos aplicados. Otro 40 por ciento se utiliza para el desarrollo de casos aplicados de EBS y ESS, que se redactan en clase y se completan en casa con trabajo en grupo e individual. Finalmente se complementa todo ello 
con visitas de campo y prácticas de laboratorio, en la que los alumnos pueden ver en condiciones reales los conocimientos adquiridos en el aula.

\subsection{Clases magistrales}

Las clases magistrales se desarrollan con ayuda de material audiovisual de manera que sean lo más comprensibles y amenas para los alumnos. Tarea ardua en ocasiones, ya que se trata de asimilar mucha normativa y compleja. Para poder hacer un seguimiento del grado de asimilación de contenidos que hacen los alumnos, se introdujo la realización de prácticas en el aula donde se realizan casos prácticos de aplicación de los conocimientos adquiridos.

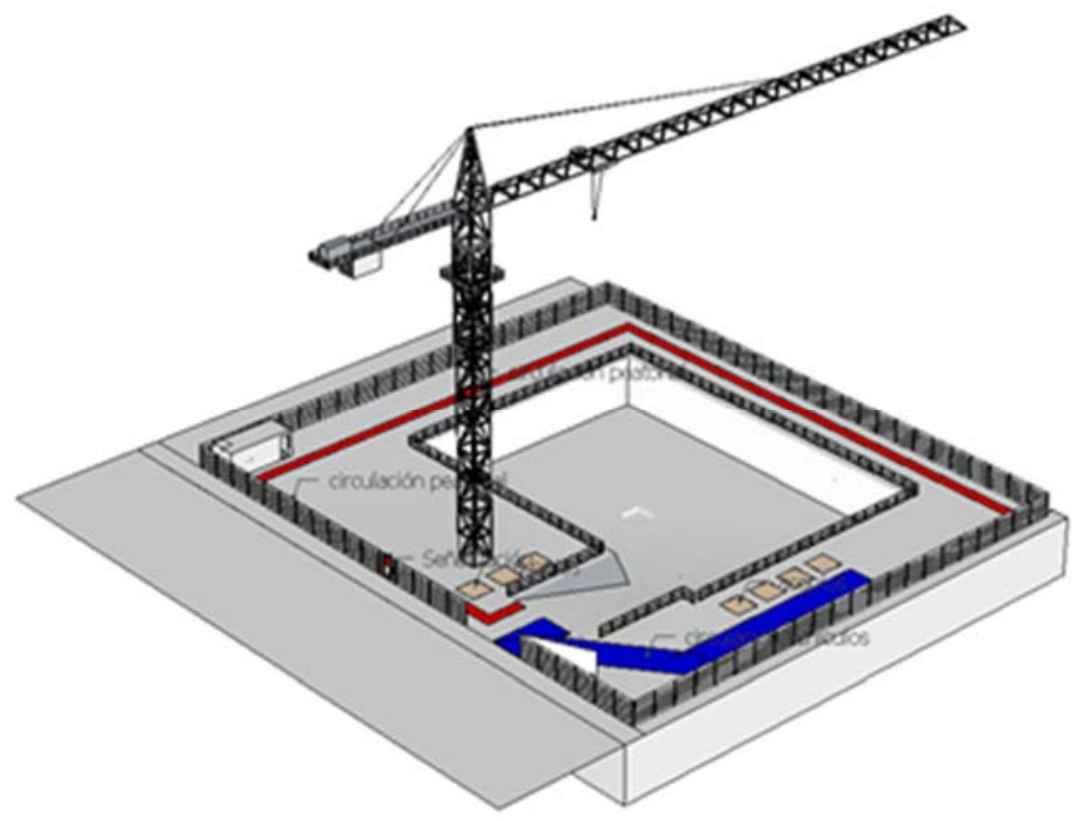

Fig. 1 Animación 3D Implantación de obra.

Fuente: Elaboración propia

Además de los recursos cásicos de presentaciones, vídeos, fotografías, etc., se utilizan imágenes $3 \mathrm{D}$ animadas en sketckup procedentes de un proyecto de innovación docente realizado con colaboración de los alumnos. Según algunos estudios recientes, como el de Gao et al. (2019), los métodos de impartición más innovadores (incluyendo material gráfico con el uso de las nuevas tecnologías) hacen más efectivo el aprendizaje por parte de los alumnos que con los métodos tradicionales. 


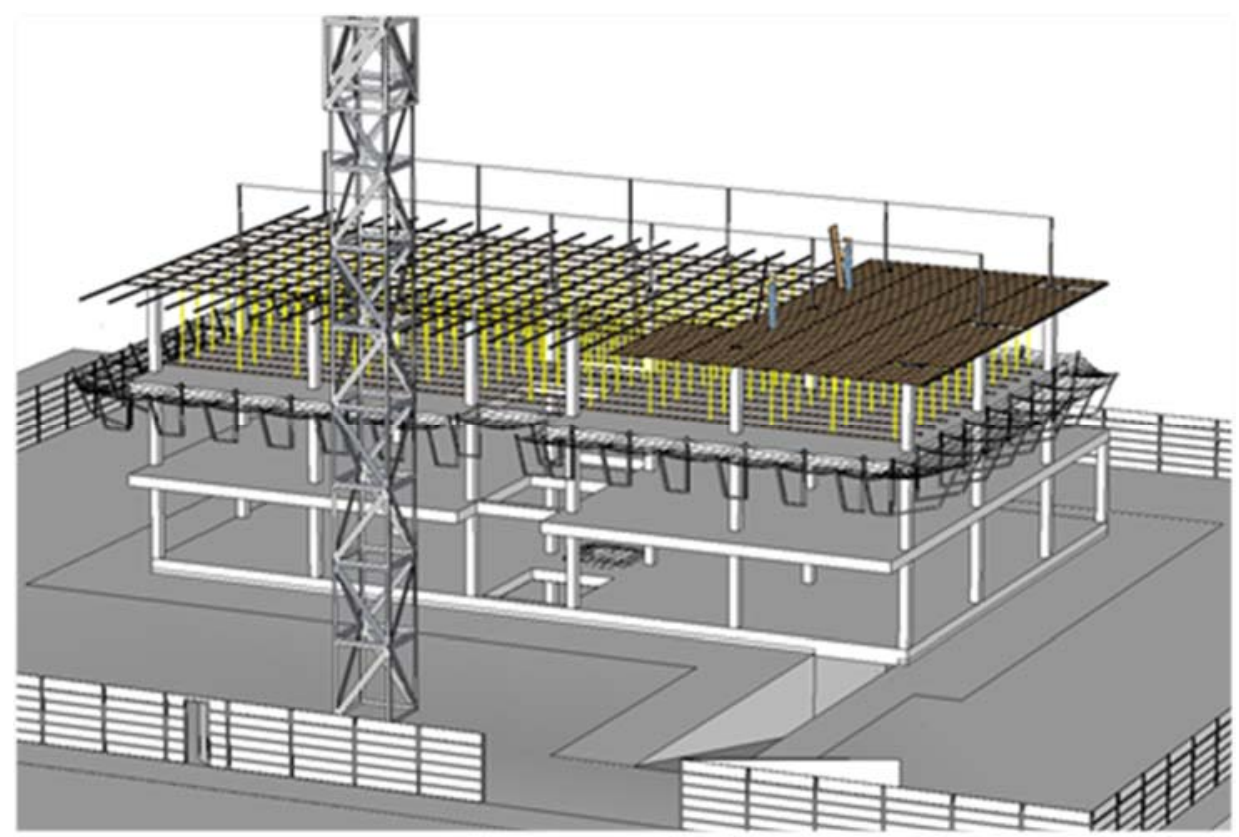

Fuente: Elaboración propia

Fig. 2 Animación 3D Encofrado estructura.

Estos recursos nos permiten transmitir de manera gráfica lo más amena e interactiva posible los procesos y secuencia de actividades en obra, con la identificación de riesgos y las diferentes medidas preventivas disponibles en obra.

\subsection{Prácticas aplicadas a las clases magistrales}

El seguimiento de la asimilación de contenidos y la capacidad para tomar decisiones a partir de las exposiciones realizadas en las clases magistrales se realiza mediante prácticas de clase realizadas después de cada tema. Las prácticas se realizan con apoyo del profesor y la interacción de los alumnos del grupo. Son objeto de valoración para la nota final de la asignatura. Tienen una buena acogida entre los alumnos ya que les permite poder aplicar la teoría expuesta a contextos prácticos concretos. Por otra parte, refuerzan el seguimiento de la asignatura, evitando que los alumnos la dejen debido al carácter más teórico de algunas partes de la materia que hace su seguimiento más arduo.

En la figura $\mathrm{n}^{\circ} 2$ tenemos un ejemplo de aplicación de una práctica de clase. Podemos ver como el alumno debe proponer las protecciones adecuadas para una fase concreta en la ejecución de una estructura, así como el proceso y la secuencia de colocación de las protecciones propuestas. 


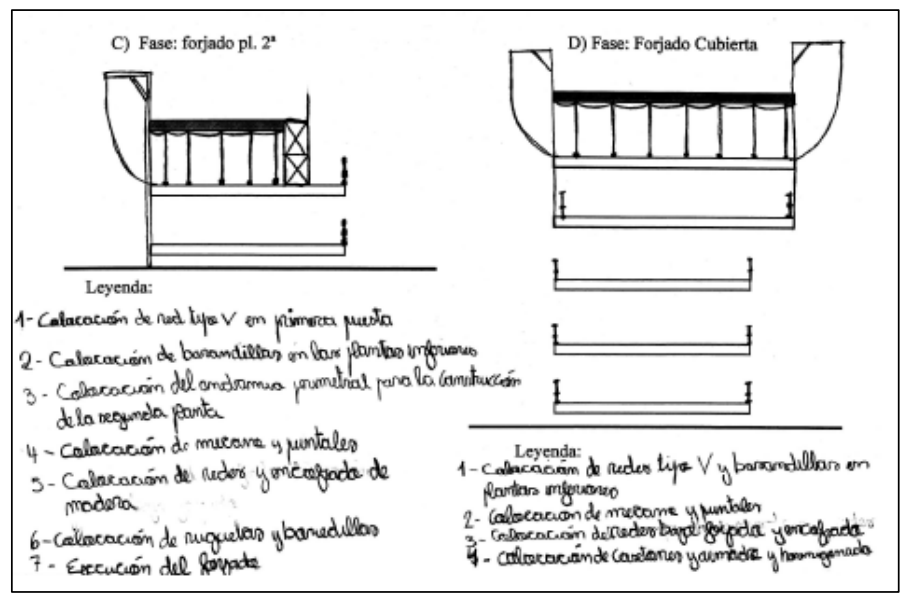

Fuente: Práctica alumno

Fig. 2 Ejemplo de práctica de clase.

\subsection{Seminarios para redacción de EBS y ESS}

Los seminarios para la redacción del EBS y ESS son una parte fundamental de la asignatura, en el desarrollo de las clases y que está dirigida a que los alumnos integren los principios preventivos junto al proceso constructivo y sean capaces de enfrentarse con la redacción de los documentos indicados. En estos seminarios el profesor expone, para cada fase de obra, la secuencia, los materiales, maquinaria y medios necesarios, así como las diferentes posibles localizaciones de los trabajadores. Todo ello, con el fin de que se identifiquen los riesgos específicos de la fase y se propongan las medidas preventivas vistas con anterioridad en las clases magistrales. Se trata de la fase previa para que el alumno se enfrente a la redacción de la memoria y planos del EBS y ESS, sin programas informáticos que se consideran demasiado generales para la adquisición de las competencias necesarias que se persiguen en este apartado.

\subsection{Redacción en el aula de un EBS y un ESS}

Una vez analizados en detalle los procesos constructivos relacionados con la fase de obra pertinente, identificados los riesgos y comentadas las posibilidades de protección, el estudiante debe enfrentarse por primera vez con la redacción de una memoria de un EBS/ESS. La tarea es ardua y puede ser una barrera compleja enfrentarse al papel en blanco. Para ayudar a superar esta dificultad el desarrollo de la práctica se desarrolla en clase de manera grupal y con el seguimiento del profesor. De este modo se produce un primer nivel de foro de discusión entre los compañeros del grupo y un segundo nivel de discusión con el profesor, cuando el nivel de duda no se soluciona a nivel del grupo. De esta manera, el estudiante se enfrenta a una nueva tarea que pretende dotarle de los principios básicos para que posteriormente pueda desarrollar un ESS de manera individual $\mathrm{y}$, con ello, adquirir las competencias para el desarrollo posterior de trabajos profesionales de este tipo. 
Además de la memoria, el estudiante debe enfrentarse a transmitir la información gráfica necesaria para que el documento final sea comprensible a la empresa que va dirigido y recoja la información necesaria para redactar el Plan de Seguridad y Salud (PSS).

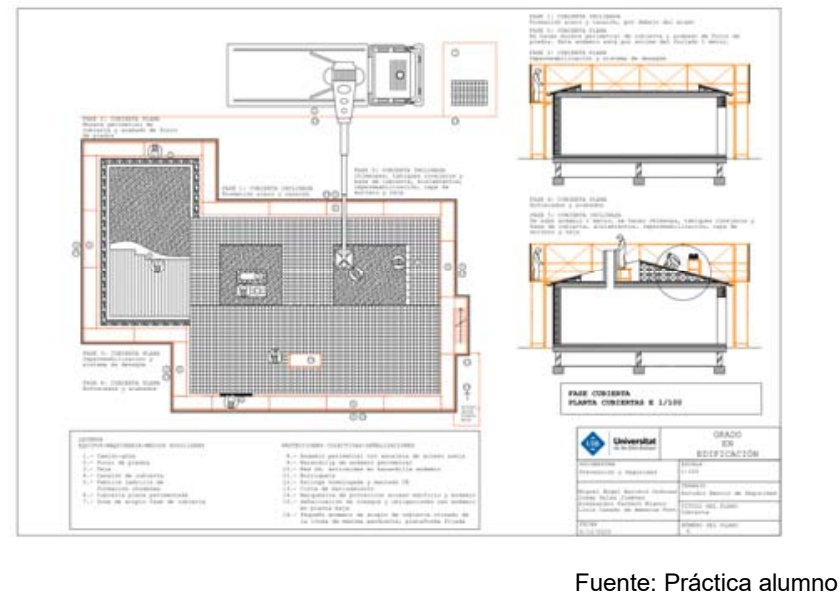

Fig. 3 Ejemplo de entrega final de un plano de un EBS.

En la figura $n^{\circ} 3$ podemos ver un ejemplo de la documentación gráfica final de un EBS realizado por los estudiantes en grupo. El ejemplo forma parte de una secuencia en la que se grafía la secuencia de los diferentes trabajos que comportan cada una de las fases y los medios necesarios para cada fase. Este documento es complementario de la memoria escrita desarrollada.

\subsection{Visitas de obra y prácticas de laboratorio}

Las actividades anteriores en el aula están complementadas con dos actividades que permiten una experiencia del estudiante más próxima a la aplicación práctica. De este modo se intenta resolver la falta de experiencia cuando deben iniciar su andadura profesional en materia de P\&S (Ros et al, 2013). Por una parte, las visitas de obra permiten ver in situ situaciones reales explicadas en el aula, así como la aplicación práctica de documentos también vistos en el desarrollo teórico. El libro de Incidencias, el PSS, o el libro de subcontratación, por ejemplo, cobran protagonismo al poderlos revisar en obra en relación con unas condiciones y entrono concreto que el estudiante puede experimentar y relacionar, complementando y reforzando los conocimientos adquiridos en el aula. De manera similar en el laboratorio, el alumno experimenta con protecciones que puede seleccionar u usar para un cometido específico que se le propone. Con ello se consiguen experiencias similares a las visitas de obra.

\section{Resultados}

Los resultados obtenidos medidos en base a las encuestas de satisfacción de los alumnos son favorables. Las medias de las valoraciones de la asignatura se sitúan los últimos cinco 
años entorno al 7.5 sobre 10. Los estudiantes valoran globalmente la asignatura con esta cualificación, a pesar de que también indican que la carga de trabajo es elevada en relación a los créditos de la asignatura (9 créditos ETS).

Por otra parte, el seguimiento es mayoritario, produciéndose muy pocos abandonos. El porcentaje de alumnos que supera la asignatura oscila entre el 60 y el $70 \%$, por lo que, en el contexto de los estudios de grado de edificación, se puede considerar adecuado.

\section{Conclusiones}

EL grado de Edificación debe formar un perfil técnico muy versátil, en un entorno centrado en el estudiante y con unos objetivos muy amplios. La formación en Prevención y Seguridad debe dar al estudiante las competencias necesarias para poder enfrentarse a los requisitos de desarrollo de la profesión. Mediante un itinerario muy completo en el que se utilizan diferentes técnicas docentes se alcanzan los objetivos deseados, alcanzando unas competencias adecuadas en la materia, a base de desarrollar los conocimientos específicos y desarrollarlos en el contexto de los conocimientos generales adquiridos durante los estudios y su relación entre ambos.

En este contexto la transversalidad y la capacidad de relación se revelan como los elementos fundamentales para el desarrollo de las competencias del estudiante. El trabajo en grupo, el posterior trabajo individual, con seguimiento y tutoría del profesor se han revelado herramientas exitosas. La reducción de las clases magistrales y el aumento de prácticas aplicadas, en su lugar, también son elementos que facilitan el seguimiento del estudiante y evitan el abandono.

\section{Referencias}

Burke, M., Salvador, R., Smith-Crowe, K., Chan Serafin, S., Smith, A., \& Sonesh, S. (2011). The dread factor: How hazards and safety training influence learning and performance. Journal ofApplied Psychology, 96(1), 46-70.

Gao, Y., Gonzalez, V.A., Yiu, T.W., 2019. The effectiveness of traditional tools and computer-aided technologies for health and safety training in the construction sector: A systematic review. Computers and Education, 138, pp.101-115.

Reiman, A. ( 1 ), Väyrynen, S. ( 1 ), Haapasalo, H. ( 1 ), Pedersen, L. M. ( 2 ), Sormunen, E. ( 3 ), Räsänen, T. ( 3 ), \& Airaksinen, O. ( 4 ). (n.d.). Safety Training Parks-Cooperative Contribution to Safety and Health Trainings. International Journal of Construction Education and Research, 15(1), 19-41. https://0-doi-org.llull.uib.es/10.1080/15578771.2017.1325793

Antonio, R. S., Isabel, O. M., Gabriel, P. S. J., \& Angel, U. C. (2013). A proposal for improving safety in construction projects by strengthening coordinators' competencies in health and safety issues. Safety Science, 54, 92-103. https://doi.org/10.1016/j.ssci.2012.12.004 


\title{
EDIFICATE
}

I Congreso de Escuelas de Edificación y Arquitectura Técnica de España València, 4 y 5 de noviembre de 2021

Escuela Técnica Superior de Ingeniería de Edificación

Universitat Politècnica de València

Doi: https://doi.org/10.4995/EDIFICATE2021.2021.13511

\section{Convalidación de la formación en materia de Prevención de Riesgos Laborales del Sector de la Construcción establecida en el Convenio a los titulados de las Escuelas de Edificación y Arquitectura Técnica de España}

\section{Validation of the training in Occupational Risk Prevention in the Construction Sector established in the Agreement for graduates of the Spanish Schools of Building and Technical Architecture.}

\author{
María Segarra Cañamares ${ }^{a}$
}

aEscuela Politécnica de Cuenca. Universidad de Castilla-La Mancha. Maria.segarra@uclm.es

\begin{abstract}
Article 146 of the General Collective Bargaining Agreement for the construction sector, on training provided in university degrees, establishes that workers who hold university degrees which provide training in occupational risk prevention equivalent to that specified in this Agreement will have it recognized, as appropriate in each case, by agreement of the Board of Trustees of the Construction Labor Foundation.

Graduates of the Spanish Schools of Building and Technical Architecture receive training in occupational risk prevention that exceeds in content and competences that established in the agreement, which should lead to a direct and generally agreed validation, for all our Schools, of the Second cycle of training in Occupational Risk Prevention in the Construction Sector: Training by work post and the Basic Level of prevention in construction.
\end{abstract}

Keywords: Risk prevention training, construction, university, validation.

\section{Resumen}

El Convenio colectivo general del sector de la construcción establece en su artículo 146, sobre la formación impartida en títulos universitarios, que los trabajadores que estén en posesión de títulos universitarios en los que se imparta una formación en materia de prevención de riesgos laborales equivalente a la especificada en el presente Convenio, se procederá a su 
Convalidación de la formación en materia de Prevención de Riesgos Laborales del Sector de la Construcción establecida en el Convenio a los titulados de las Escuelas de Edificación y Arquitectura Técnica de España - Validation of the training in Occupational Risk Prevention in the Construction Sector established in the Agreement for graduates of the Spanish Schools of Building and Technical Architecture.

convalidación, según proceda en cada caso, mediante acuerdo del Patronato de la Fundación Laboral de la Construcción.

Los titulados de las Escuelas de Edificación y Arquitectura Técnica de España reciben una formación en prevención de riesgos laborales que excede en contenido y competencias la establecida en convenio, lo que debería suponer una convalidación directa y acordada, con carácter general, para todas nuestra Escuelas, del Segundo ciclo de formación en materia de Prevención de Riesgos Laborales del Sector de la Construcción: Formación por puesto de trabajo y del Nivel básico de prevención en construcción.

Palabras clave: Formación en prevención de riesgos, construcción, universidad, convalidación. 


\section{Introducción}

El Convenio colectivo general del sector de la construcción (CCGSC) (RDGE, de 21 de septiembre) establece en su artículo 146, sobre la formación impartida en títulos universitarios, que los trabajadores que estén en posesión de títulos universitarios en los que se imparta una formación en materia de prevención de riesgos laborales equivalente a la especificada en el presente Convenio, se procederá a su convalidación, según proceda en cada caso, mediante acuerdo del Patronato de la Fundación Laboral de la Construcción (FLC).

Actualmente algunas escuelas han optado por realizar convenios con la FLC, para que la formación impartida en la titulación le sea reconocida por la correspondiente al nivel básico de prevención en la construcción, a los efectos previstos en el CCGSC.

Dichos convenios establecen la necesidad de que los contenidos de las asignaturas se correspondan con los establecidos en el convenio, sin margen alguno a que dichos contenidos se impartan bajo otros epígrafes distintos a los indicados. Esto obligaría a las escuelas a tener que adaptar sus epígrafes a los marcados en el convenio, teniendo por tanto que modificar sus guías docentes, con lo que esto supone a efectos de la planificación y programación de unas asignaturas que han de dar cabida a unos contenidos mucho más amplios para cubrir a las competencias que el alumno debe adquirir.

La Orden ECl/3855/2007, por la que se establecen los requisitos para la verificación de los títulos universitarios oficiales que habiliten para el ejercicio de la profesión de Arquitecto Técnico (Orden ECl) (O.ECl, de 27 de diciembre), establece las competencias que el estudiante debe adquirir y entre estas se encuentra en su artículo 3 apartado 2 la de "Redactar estudios y planes de seguridad y salud laboral y coordinar la actividad de las empresas en materia de seguridad y salud laboral en obras de construcción, tanto en fase de proyecto como de ejecución".

La adquisición de estas competencias, dando cumplimiento a lo establecido en el Real Decreto 1627/1997, por el que se establecen disposiciones mínimas de seguridad y de salud en las obras de construcción (RD 1627/97, de 24 de octubre), conlleva un conocimiento profundo del proceso constructivo y de los procedimientos preventivos a aplicar en dicho proceso. Es por ello que la formación que reciben estos técnicos excede en gran medida de la contenida en el Segundo ciclo de formación en materia de Prevención de Riesgos Laborales del Sector de la Construcción: Formación por puesto de trabajo, y en el Nivel básico de prevención en construcción.

\section{Objetivos}

Se busca poder trasladar información relevante, a todas las escuelas que imparten los grados universitarios habilitantes para el ejercicio profesional de la Arquitectura Técnica, que permita realizar una propuesta conjunta, para el reconocimiento de la formación en materia de prevención de riesgos en obras de construcción conforme al CCGSC. 


\section{Desarrollo}

\section{1 Ámbito académico}

El Arquitecto Técnico ocupa hoy, por razón de los conocimientos adquiridos en la carrera, un papel muy importante en el sector de la edificación como generalista que conoce y aplica las técnicas al proceso constructivo.

La vinculación y el compromiso de la profesión con la Seguridad y Salud de los trabajadores en la Construcción no es reciente y es un hecho sobradamente conocido por todas las entidades y organismos relacionadas con el sector. Quizás sea fruto de esta circunstancia, amén de la especial preparación profesional de los arquitectos técnicos, el hecho de que la mayoría de los "Coordinadores de Seguridad y Salud" ejercientes en las obras de edificación en España sean Arquitectos Técnicos (Merino, 2012).

Los conocimientos que en materia de seguridad y salud adquieren los Arquitectos Técnicos en su carrera se formulan como competencias en la Orden ECl, la cual establece en su artículo 3 Objetivos, las competencias que los estudiantes deben adquirir:

1. Dirigir la ejecución material de las obras de edificación, de sus instalaciones y elementos, llevando a cabo el control cualitativo y cuantitativo de lo construido mediante el establecimiento y gestión de los planes de control de materiales, sistemas y ejecución de obra, elaborando los correspondientes registros para su incorporación al Libro del Edificio. Llevar el control económico de la obra elaborando las certificaciones y la liquidación de la obra ejecutada.

2. Redactar estudios y planes de seguridad y salud laboral y coordinar la actividad de las empresas en materia de seguridad y salud laboral en obras de construcción, tanto en fase de proyecto como de ejecución.

3. Llevar a cabo actividades técnicas de cálculo, mediciones, valoraciones, tasaciones y estudios de viabilidad económica; realizar peritaciones, inspecciones, análisis de patología y otros análogos y redactar los informes, dictámenes y documentos técnicos correspondientes; efectuar levantamientos de planos en solares y edificios.

4. Elaborar los proyectos técnicos y desempeñar la dirección de obras de edificación en el ámbito de su habilitación legal.

5. Gestionar las nuevas tecnologías edificatorias y participar en los procesos de gestión de la calidad en la edificación; realizar análisis, evaluaciones y certificaciones de eficiencia energética, así como estudios de sostenibilidad en los edificios.

6. Dirigir y gestionar el uso, conservación y mantenimiento de los edificios, redactando los documentos técnicos necesarios. Elaborar estudios del ciclo de vida útil de los materiales, 
sistemas constructivos y edificios. Gestionar el tratamiento de los residuos de demolición y de la construcción.

7. Asesorar técnicamente en los procesos de fabricación de materiales y elementos utilizados en la construcción de edificios.

8. Gestionar el proceso inmobiliario en su conjunto. Ostentar la representación técnica de las empresas constructoras en las obras de edificación.

Dichas competencias quedan reguladas por la Orden ECl conforme al Plan de Estudios dentro del módulo de Gestión, donde se fijan como competencias que deben adquirirse:

- Capacidad para programar y organizar los procesos constructivos, los equipos de obra, y los medios técnicos y humanos para su ejecución y mantenimiento.

- Conocimiento del derecho de la construcción y de las relaciones contractuales que se producen en las distintas fases del proceso de edificación, así como de la legislación, reglamentación y normativas específicas de la prevención y coordinación en materia de seguridad y salud laboral en la edificación.

- Aptitud para redactar estudios, estudios básicos y planes de seguridad y salud laboral, y coordinar la seguridad en fase de proyecto o en fase de ejecución de obra.

Añadir que aun siendo este el módulo donde se abordan de una forma concreta las competencias en el ámbito de la seguridad y salud, el resto de los módulos específicos tales como el de Expresión Gráfica, Técnicas y Tecnología de la Edificación, Estructuras e Instalaciones de la Edificación, Gestión del proceso, Gestión Urbanística y Economía aplicadas y Proyectos Técnicos lo abordan de forma transversal.

\section{2 Ámbito profesional}

Profesionalmente y en relación a dichas competencias, el Arquitecto Técnico es considerado por la Ley 38/1999 de Ordenación de la Edificación (LOE) (L38/1999 de 5 de noviembre) el técnico competente al que hace mención el RD 1627/1997 conforme a lo que establece su Guía Técnica, la cual:

Considera "técnico competente" aquella persona que posee titulaciones académicas y profesionales habilitantes, así como conocimientos en actividades de construcción y de prevención de riesgos laborales acordes con las funciones a desempeñar según el RD $1627 / 1997$.

A este respecto, la disposición adicional cuarta de la LOE señala que "las titulaciones académicas y profesionales habilitantes para desempeñar la función de coordinador de seguridad y salud en obras de edificación, durante la elaboración del proyecto y la ejecución de la obra, serán las de arquitecto, arquitecto técnico, ingeniero o ingeniero técnico, de acuerdo con sus competencias y especialidades".

Para las obras de construcción excluidas del ámbito de aplicación de la LOE, así como para las obras de ingeniería civil, a los efectos de delimitar la figura de técnico competente, cabe 
interpretar que las titulaciones académicas y profesionales que habilitan para desempeñar las funciones de coordinador en materia de seguridad y salud durante la elaboración del proyecto y la ejecución de este tipo de obras serán las que estén facultadas, con arreglo a las competencias propias de sus específicas titulaciones, para proyectar y dirigir dichas obras a la vista de las disposiciones legales vigentes para cada profesión.

En base a las competencias adquiridas en el título de Grado, el Arquitecto Técnico es competente para llevar a cabo el encargo global en materia de seguridad y salud, que comprende la coordinación de seguridad durante la elaboración del proyecto, con redacción de Estudio o Estudio básico de seguridad y salud y la coordinación de seguridad en fase de ejecución de la obra, junto a la aprobación de los Planes de Seguridad y Salud en el trabajo

Como coordinación de seguridad y salud durante la elaboración del proyecto se encargará de:

- Coordinar que se tengan en cuenta los principios generales de prevención en materia de seguridad y salud durante las fases de concepción, estudio y elaboración del proyecto y las previsiones contenidas en el Estudio o en el Estudio Básico de seguridad y salud. Y elaborar o hacer que se elabore, bajo su responsabilidad, el Estudio o Estudio Básico de seguridad y salud.

Como coordinación en materia de seguridad y salud durante la ejecución de la obra sus funciones son:

- Coordinar la aplicación de los principios generales de prevención.

- Coordinar las actividades a desarrollar en la obra para garantizar que se aplique la acción preventiva por parte de las empresas intervinientes, así como de los trabajadores autónomos.

- Aprobar el Plan de seguridad y salud en el trabajo.

- Organizar la coordinación de las actividades empresariales.

- Coordinar la aplicación correcta de los métodos de trabajo.

- Adoptar medidas de control de acceso a la obra.

- Ser depositario del Libro de Incidencias y hacer anotaciones en el mismo.

- Formular al contratista instrucciones en materia de seguridad y salud.

- Remitir copia de las anotaciones del Libro de Incidencias a la Inspección Provincial de Trabajo y Seguridad Social.

- Paralizar los trabajos en caso de observarse incumplimiento de las medidas de seguridad y salud. 
Sirve todo lo anterior para fijar los contenidos que, desde las distintas Universidades, y para los Grados que habilitan para el ejercicio de la profesión de Arquitecto Técnico, se imparten como asignatura troncal de al menos 6 ECTS (60 horas presenciales, equivalentes a 150 horas de trabajo del alumno), llegando a alcanzar los 9 ECTS (90 horas presenciales, equivalentes a 225 horas de trabajo del alumno) en la mayoría de las Escuelas, tal y como puede comprobarse en los planes de estudio.

\subsection{Contenidos conforme al Convenio}

El Capítulo III del VI CGSC relativo a la formación desarrolla, en su Sección Primera y Segunda a través de los artículos 139 y 140, el Segundo ciclo de formación en materia de prevención de riesgos laborales: formación por puesto de trabajo y el Nivel básico de prevención en la construcción. Dicha formación en relación con la formación inicial, los puestos de trabajo de personal directivo, responsables de obra y técnicos de ejecución, mandos intermedios, delegados de prevención y nivel básico de prevención en construcción, desarrollan contenidos que pueden ser considerados equivalentes a los impartidos en los títulos universitarios oficiales que habilitan para el ejercicio de la profesión de Arquitecto Técnico.

Si marcamos en dichos contenidos los no comunes entre sí, tal y como aparecen en la tabla 1 , podemos determinar cuáles son los epígrafes a desarrollar. 
Convalidación de la formación en materia de Prevención de Riesgos Laborales del Sector de la Construcción establecida en el Convenio a los titulados de las Escuelas de Edificación y Arquitectura

Técnica de España - Validation of the training in Occupational Risk Prevention in the Construction Sector established in the Agreement for graduates of the Spanish Schools of Building and Technical Architecture.

\section{Tabla 1. Contenidos formación anexo XII VI CGSC}

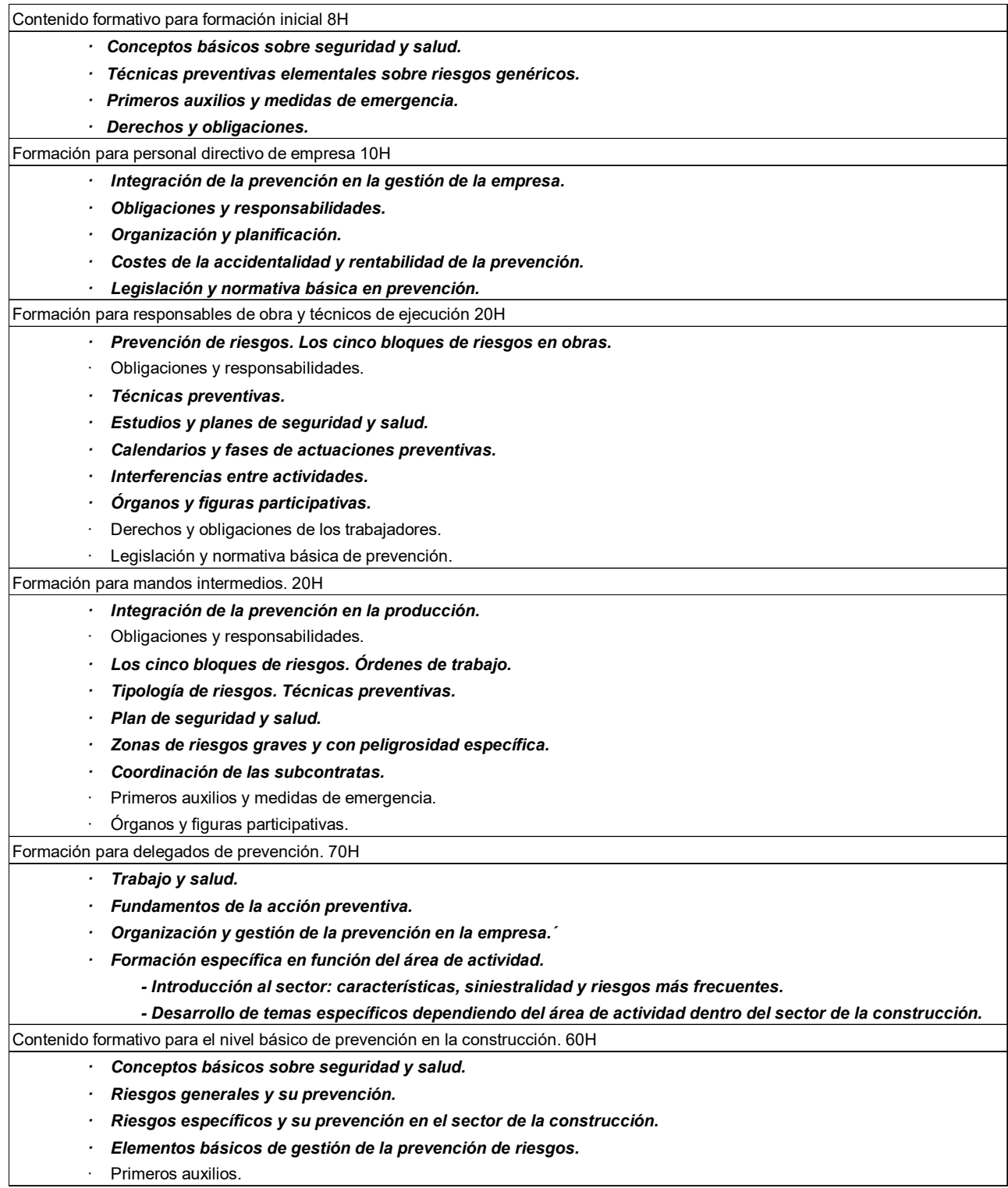


Los epígrafes serían:

- Conceptos básicos sobre seguridad y salud. (Trabajo y salud, fundamentos de la acción preventiva)

- Técnicas preventivas elementales sobre riesgos genéricos.

- Primeros auxilios y medidas de emergencia.

- Derechos y obligaciones.

- Integración de la prevención en la gestión de la empresa.

- Obligaciones y responsabilidades.

- Organización y planificación.

- Costes de la accidentalidad y rentabilidad de la prevención.

- Legislación y normativa básica en prevención.

- Prevención de riesgos. Los cinco bloques de riesgos en obras.

- Técnicas preventivas.

- Estudios y planes de seguridad y salud.

- Calendarios y fases de actuaciones preventivas.

- Interferencias entre actividades.

- Órganos y figuras participativas.

- Los cinco bloques de riesgos. Órdenes de trabajo.

- Tipología de riesgos.

- Zonas de riesgos graves y con peligrosidad específica.

- Coordinación de las subcontratas.

- Organización y gestión de la prevención en la empresa.

- Formación específica en función del área de actividad.

- Riesgos generales y su prevención.

- Riesgos específicos y su prevención en el sector de la construcción.

- Elementos básicos de gestión de la prevención de riesgos.

Todos y cada uno de estos epígrafes, son objeto de desarrollo en los contenidos impartidos en los títulos universitarios oficiales que habilitan para el ejercicio de la profesión de Arquitecto Técnico, tal y como puede comprobarse en las guías docentes de las asignaturas correspondientes a la materia de prevención y seguridad.

\section{Resultado y conclusiones}

El Arquitecto Técnico asume como técnico competente actuaciones en materia de seguridad y salud que conllevan la necesidad de tener un conocimiento profundo del proceso productivo y preventivo.

Esta necesidad se contempla tanto el la Orden $\mathrm{ECl}$, donde se establecen las competencias en la materia, como en los planes de estudios, donde se incluyen créditos en asignaturas troncales donde se imparten los contenidos de la materia de prevención y seguridad y se asumen dichas competencias.

Profesionalmente se asumen responsabilidades que sólo desde un conocimiento profundo del proceso productivo pueden abordarse. Conocimientos que los profesionales de la Arquitectura Técnica poseen en mayor nivel que los Titulados de formación profesional o los adquiridos en Certificados de profesionalidad 
Convalidación de la formación en materia de Prevención de Riesgos Laborales del Sector de la Construcción establecida en el Convenio a los titulados de las Escuelas de Edificación y Arquitectura

Técnica de España - Validation of the training in Occupational Risk Prevention in the Construction

Sector established in the Agreement for graduates of the Spanish Schools of Building and Technical Architecture.

No se trata de cuestionar si los contenidos impartidos son los mismos que los que marca el CCGSC sino de reconocer que la formación recibida excede de la requerida.

Vistas las competencias de la Orden $\mathrm{ECl}$, los créditos asignados para su adquisición en los planes de estudio, la actividad relacionada en el ejercicio profesional, así como los contenidos que se establecen en el CCGSC, la formación en materia de prevención de riesgos en obras de construcción de los Arquitectos Técnicos debe poder obtener el reconocimiento.

Según el artículo 146 del Convenio General del Sector de la Construcción, sobre formación impartida en Títulos Universitarios, en relación con los trabajadores que estén en posesión de títulos universitarios en los que se imparta una formación en materia de prevención de riesgos laborales equivalente a la especificada en el presente Convenio, se procederá a su convalidación, según proceda en cada caso, mediante acuerdo del Patronato de la FLC.

EI Anexo XIII del CGCC en su apartado 2 recoge un cuadro resumen de reconocimientos con Títulos de formación profesional y Certificados de profesional en las ramas de edificación y obra civil.

Dicho reconocimiento puede por tanto realizarse por la vía de un acuerdo por el patronato, o por la del establecimiento de dichos reconocimientos de forma directa en el Convenio, siendo este último el medio mediante el cual deberían poder incluirse todas las titulaciones universitarias oficiales que habilitan para el ejercicio de la profesión de Arquitecto Técnico.

\section{Referencias}

España. Ley 38/1999, de 5 de noviembre, de Ordenación de la Edificación. BOE, 6 de noviembre de 1999, núm. 266, p. 38925 a 38934.

España. Orden ECI/3855/2007, de 27 de diciembre, por la que se establecen los requisitos para la verificación de los títulos universitarios oficiales que habiliten para el ejercicio de la profesión de Arquitecto Técnico. BOE, 29 de diciembre de 2007, núm. 312, p. 53739 a 53742.

España. Real Decreto 1627/1997, de 24 de octubre, por el que se establecen disposiciones mínimas de seguridad y de salud en las obras de construcción. BOE, 25 de octubre de 1997, núm. 256, p.30875 a 30886 .

España. Resolución de 21 de septiembre de 2017, de la Dirección General de Empleo, por la que se registra y publica el Convenio colectivo general del sector de la construcción. BOE, 26 de septiembre de 2017, núm. 232, p. 94090 a 94253.

MERINO VELASCO, F. (2012). Competencias y atribuciones del arquitecto técnico en Europa : estudio específico en Italia, Austria y Polonia. Trabajo Final de Grado. Valencia: Universitat Politècnica de València, < https://riunet.upv.es/handle/10251/17769> [Consulta: 1 de mayo 2021] 


\title{
EDIFICATE
}

I Congreso de Escuelas de Edificación y Arquitectura Técnica de España València, 4 y 5 de noviembre de 2021

Escuela Técnica Superior de Ingeniería de Edificación

Universitat Politècnica de València

Doi: https://doi.org/10.4995/EDIFICATE2021.2021.13249

\section{Guía de recomendaciones para la Gestión y tratamiento de RESIDUOS generados por las medidas de prevención ante la COVID-19 en obras de construcción}

\section{Recommendations guide for the Management and treatment of WASTE generated by prevention measures against COVID-19 in construction sites}

\footnotetext{
Francisco J. Sánchez Medrano ${ }^{a}$, Salvador Aledo Guerao ${ }^{b}$ y Jesús H. Alcañiz Martínez ${ }^{\mathrm{c}}$ aDr. Arquitecto, profesor UCAM, fjsanchez@ucam.edu, bDr. Ingeniero de Edificación, profesor UCAM, saledo@ucam.edu y Dr. Ingeniero de Edificación, profesor UCAM, jalcaniz@ucam.edu.
}

\begin{abstract}
The COVID-19 pandemic crisis has affected all areas of society, from production to classrooms. As teachers and researchers, and given the emergence of new elements of disease prevention, and therefore new waste in construction, we have been participants in the profusion of news, rules and recommendations that have fallen on all of us.

The need to live with the health threat, and to continue economic activity, required a clear and concise structure for the management of these wastes so that they do not become another source of added risk.

We have worked for several months in collaboration with more than 20 construction companies, to give an answer in the form of a Guide of recommendations for the management of these elements, also involving the students of Health and Safety and Construction Process Management, of the importance of incorporating changes into the development of a work, because the context is an inseparable part of our task.
\end{abstract}

Keywords: Health and Safety, Risk prevention, incorporation of new challenges, process disturbances 


\section{Resumen}

La crisis de la pandemia del COVID-19 ha afectado a todos los ámbitos de la sociedad, desde la producción hasta las aulas. Como docentes e investigadores, $y$ ante el surgimiento de nuevos elementos de prevención de la enfermadad, y por tanto, de nuevos residuos en la construcción, hemos sido partícipes de la profusión de noticias, reglas y recomendaciones que han caído sobre todos nosotros.

La necesidad de convivir con la amenaza sanitaria, y de proseguir la actividad económica, precisaba de una estructura clara y concisa del manejo de estos residuos para que no se conviertan en una fuente más de riesgo añadida.

Hemos trabajado varios meses en colaboración con más de 20 empresas constructoras, para dar una respuesta en forma de Guía de recomendaciones para la gestión de estos elementos, haciendo partícipes también a los alumnos de Seguridad y Salud y Gestión del Proceso constructivo, de la importancia de incorporar los cambios al desarrollo de una obra, porque el contexto forma parte inseparable de nuestro trabajo.

Palabras clave: Seguridad y Salud, Prevención de riesgos, incorporación de nuevos retos, alteraciones del proceso. 


\section{Introducción}

La declaración de pandemia de COVID-19 el 11 de marzo de 2020 por la Organización Mundial de la Salud elevó la situación de emergencia sanitaria. En este contexto y tras la grave incidencia de la enfermedad en nuestro país, el 14 de marzo se declaró el estado de alarma por medio del Real Decreto 463/2020, tras el que se han aprobado sucesivas regulaciones en todos los sectores productivos, entre ellos el de la construcción.

Como consecuencia de ello, han sido numerosas las instituciones que han desarrollado recomendaciones y protocolos de actuación en materia de seguridad y salud en las obras de construcción con el objetivo de adaptar el sector a la situación sanitaria actual. Estas guías contienen, entre otras, medidas de distanciamiento de los trabajadores, pero apuntan también a la necesidad de extremar las condiciones de limpieza de los centros de trabajo y al uso de equipos de protección individual (EPI), en muchos casos desechables, cuando las condiciones del trabajo lo requieran

Ha aparecido en las obras de construcción, un nuevo tipo de residuo, relacionado con la prevención de la COVID-19, cuya gestión, almacenamiento y reciclaje o destrucción requiere de unos ciertos protocolos de actuación. Se trata de una alteración contextual que afecta a la Seguridad y Salud en obra e introduce un nuevo factor en la gestión del proceso constructivo. Para que estas alteraciones fueran rápidamente asimiladas en obra, hemos procurado que estas nuevas indicaciones se expusieran de forma concisa y práctica en un documento con formato de Guía.

\section{Objetivos}

El grupo de investigación ARIES (Arquitectura, Ingeniería de Edificación y Sostenibilidad), está constituido por un conjunto de técnicos del ámbito de la construcción, con el objetivo principal de buscar soluciones sostenibles a los problemas que se plantean en la edificación del s. XXI.

En este sentido, y también como docentes, la presencia en la sociedad de la COVID-19 ha supuesto un importante reto para adaptar las medidas de prevención y delimitación de riesgos, que ha merecido nuestra atención, centrándonos en el tratamiento de un nuevo conjunto de residuos añadidos a los tradicionales del sector.

Con el patrocinio de la UCAM, en convocatoria de financiación propia, hemos estado trabajando durante varios meses, en contacto con más de 20 empresas constructoras, para extractar la abundante información vertida desde distintos organismos, y aplicar una metodología de funcionamiento que resuma en un decálogo los procedimientos a seguir con este nuevo peligro biológico con el que deberemos acompasar nuestras tareas.

Como no se ha interrumpido la docencia, sino que se ha trasladado a una presencialidad adaptada a las circunstancias y al soporte digital, los avances del proyecto de investigación han sido compartidos con los alumnos de Seguridad y Salud y de las diversas materias de 
Gestión del Proceso Constructivo, a modo de ejemplo de la incorporación de elementos externos obligatorios y necesarios para la continuidad de los trabajos.

La responsabilidad sobre las medidas de salud, en este caso, opera como alteración imprevista en la organización de los tajos (distancias de seguridad), accesos de obra, incremento de bajas por enfermedad, provision de nuevos elementos EPI y generación de residuos. Cuestión real e insoslayable que supera la virtualidad de ejemplos prácticos y obliga a una revisión de los supuestos económicos fundamentales de obra (plazo y precio).

\section{Desarrollo de la investigación}

Una obra de construcción es cualquier obra, pública o privada, en la que se efectúen trabajos de construcción o ingeniería civil cuya relación no exhaustiva figura en el anexo I del Real Decreto 1627/1997, de 24 de octubre, por el que se establecen disposiciones mínimas de seguridad y de salud en las obras de construcción.

En ellas, actúa una o varias empresas contratistas que actúan como titulares del centro de trabajo. Las medidas preventivas a aplicar respecto a la protección de los trabajadores frente a la COVID-19 en obra son, de forma general, las que indique el Ministerio de Sanidad o Ministerio de Trabajo para cualquier centro de trabajo (siendo el RD 463/2020 de aplicación, por tanto, en las obras de construcción).

El contratista, titular del centro de trabajo, deberá establecer un procedimiento de actuación en cada obra, siguiendo el "Procedimiento de actuación para los servicios de prevención de riesgos laborales frente a la exposición al SARS-CoV- 2", publicado por el Ministerio de Sanidad, o cualquier normativa análoga del ámbito territorial que sea pertinente.

El documento que se ha elaborado es el resultado de un Proyecto de Investigación del programa PMAFI-COVID 19, convocatoria de financiación propia de la Universidad Católica de Murcia, desarrollado por el Grupo de Investigación Arquitectura Ingeniería de Edificación y Sostenibilidad (ARIES); tiene carácter informativo y preventivo de carácter general, recogiéndose una selección no exhaustiva de recomendaciones y medidas de tipo sanitario e higiene en las obras.

Como se ha expuesto, su formulación se ha producido a lo largo del curso 20-21, y ha estado cimentado en una encuesta en la que han participado más 20 empresas constructoras $\mathrm{Ha}$ servido como ejemplo real en sesiones prácticas de alumnos de los últimos niveles de Ingeniería de Edificación/Arquitectura Técnica, trasladando las circunstancias impuestas al desarrollo de las obras, evaluando los efectos producidos, y reafirmando la conveniencia de dotar con un sistema ordenado y práctico de medidas a seguir. 


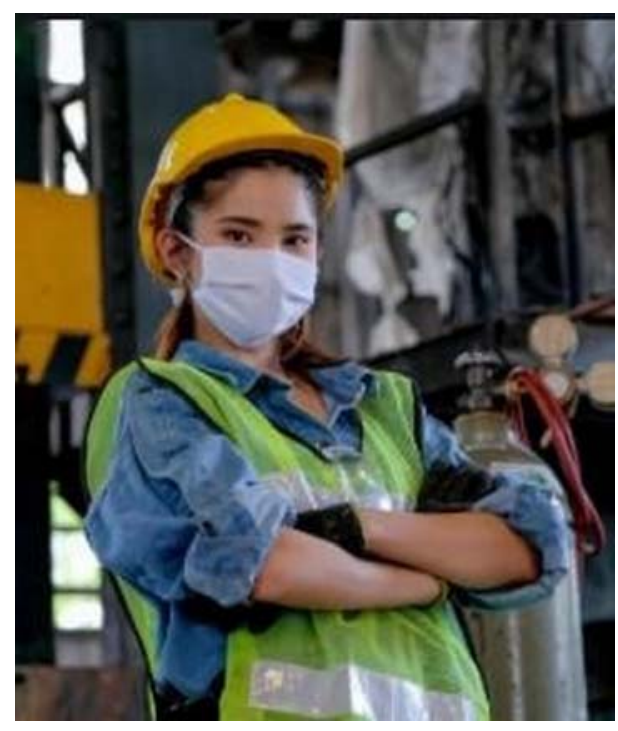

Fig. 1 Trabajadora con mascarilla de protección

\section{Resultados/conclusiones: Gestión de los nuevos residuos en la obra}

(Mascarillas, guantes, pantallas faciales, cubrezapatos, felpudos desinfectantes, toallas de papel, pañuelos, botes de desinfección, etc.)

1. La gestión de los residuos ordinarios continuará realizándose del modo habitual, respetando los protocolos de separación de residuos.

2. Se recomienda que los pañuelos desechables que el personal emplee para el secado de manos o para el cumplimiento de la "etiqueta respiratoria" sean desechados en papeleras o contenedores protegidos con tapa y, a ser posible, accionados por pedal.
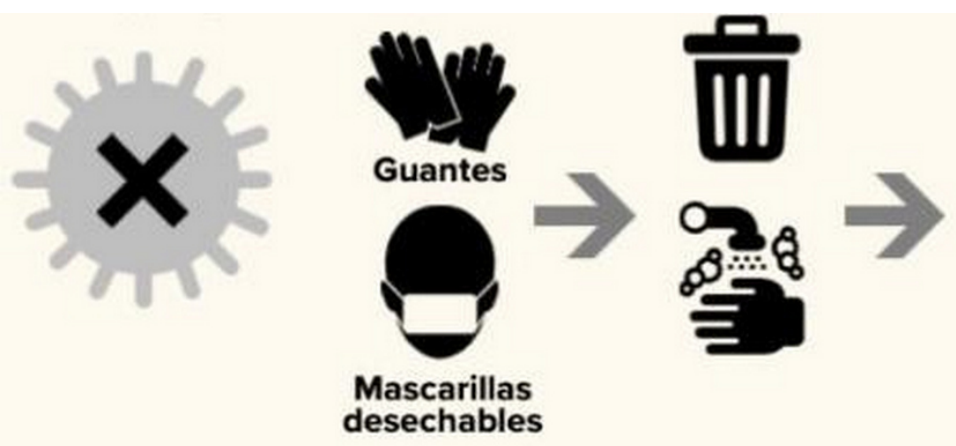

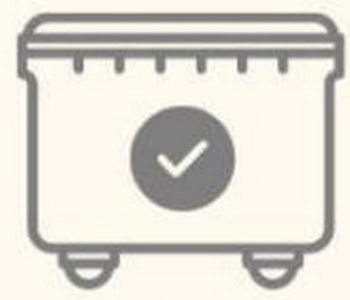

Fracción resto

Fig. 2 Esquema de depósito de protecciones sin contagio 

prevención ante la COVID-19 en obras de construcción. Recommendations guide for the Management and treatment of WASTE generated by prevention measures against COVID-19 in construction sites

3. Hay que facilitar en las zonas comunes (Vestuarios, aseos), y en las proximidades de los puestos de trabajo geles hidroalcohólicos, toallas de papel desechables y papeleras de pedal con tapa para depositar residuos.

4. Para una mejor toma de responsabilidad se recomienda que junto a los contenedores se dispongan expendedores de bolsas desechables para depositar en ellas los residuos personales envueltos.

5. Todo material de higiene personal (pañuelos desechables, mascarillas, guantes de látex, etc.), debe depositarse en la fracción resto (agrupación de residuos de origen doméstico que se obtiene una vez efectuadas las recogidas separadas).

6. El contenedor o papelera tipo para este tipo de fracción es el de COLOR GRIS, y deberá ser sometido a un procedimiento de limpieza y desinfección, tanto por dentro como por fuera, cada vez que se eliminen la bolsa con los residuos.

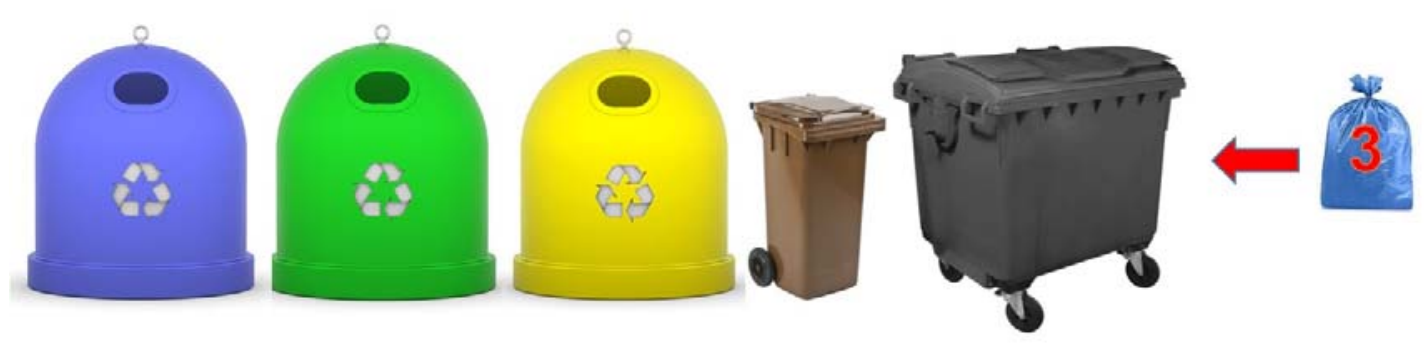

Fig. 3 Contenedor a utilizar

7. Para desinfectar el material utilizado para la limpieza (bayetas, trapos, fregonas, etc., si no son desechables) se deben sumergir en agua con un poco de lejía durante 10 minutos, aclarar y dejar secar bien.

8. No existe obligación legal de realizar la desinfección por una empresa autorizada. Se podrá realizar la desinfección por el propio personal de la empresa y utilizando detergentes habituales.

9. Sólo en el caso de que para la desinfección se decida utilizar productos virucidas cuya aplicación requiera de personal profesional especializado, las empresas que realizan estos tratamientos deberán ser empresas de servicios que estén expresamente registradas para ello en el Registro Oficial de Establecimientos y Servicios Biocidas de las Comunidades Autónomas.

10. En caso de que un trabajador presente síntomas mientras se encuentre en su puesto de trabajo, será preciso aislar el contenedor donde haya depositado pañuelos u otros 
productos usados. Esa bolsa de basura deberá ser extraída y colocada en una segunda bolsa de basura, con cierre, para su depósito en la fracción resto.

En algunas CCAA estos casos pueden ser tratados como residuos sanitarios tipo III, cuando se comprueba que se trata de un caso positivo de COVID-19. Con carácter general, los contenedores de fracción resto vacíos y las ubicaciones de los mismos en el propio centro de trabajo, serán limpiados interior y/o exteriormente y baldeados con productos desinfectantes con la mayor frecuencia posible, debiendo establecerse al efecto protocolos de limpieza y desinfección de estas zonas.

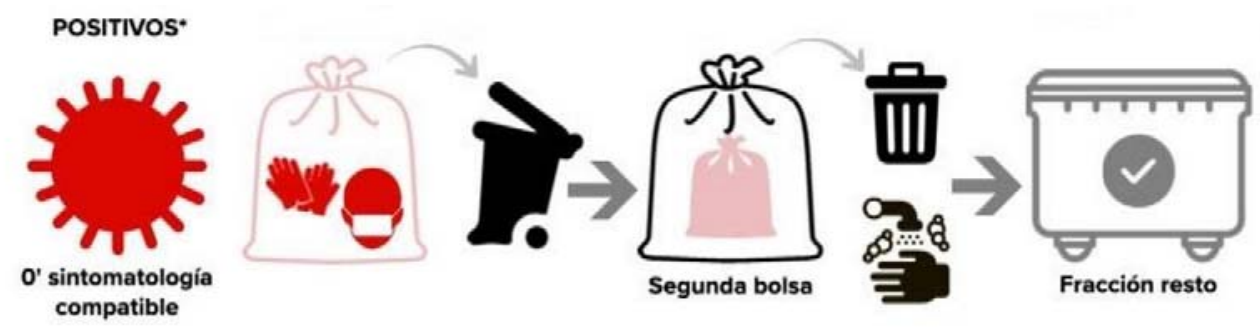

Fig. 4 Esquema de depósito de protecciones existiendo contagio

\section{RECOMENDACIONES SOBRE USO DE EQUIPOS DE PROTECIÓN INDIVIDUAL}

- En la medida de lo posible, evitar compartir los equipos de protección y, en ningún caso, compartir equipos de protección respiratoria.

- Mascarillas: la mayoría de estos equipos vienen marcados con las letras "NR" (no reutilizable), por lo que lo más recomendable es desecharlas tras su uso. En el caso de que el marcado de la misma sea "R" (reutilizable) es recomendable, tras su uso, dejarla en cuarentena durante 72 horas, ya que determinados métodos de lavado y desinfección pueden alterar su estructura filtrante, por lo que pierden eficacia. En algunos casos es posible sumergir la mascarilla en soluciones de hipoclorito sódico. Para estos casos, consultar en el libro de instrucciones o con el fabricante.

- Guantes: el sistema de desinfección variará en función del material del mismo.

- Látex o nitrilo: se desecharán siempre tras cada uso.

- Cuero: generalmente, no soportan el lavado, por lo que se pulverizarán con una solución hidroalcohólica al $70 \%$ dejando secar al aire. Otra opción sería mediante el calor seco.

- Goma o plástico: es necesario consultar el manual de instrucciones del equipo, aunque, en general, podrán limpiarse con una solución hidroalcohólica al $70 \%$.

- Textil: en general, se podrán lavar conforme se ha descrito anteriormente, consultar previamente instrucciones del fabricante. 

prevención ante la COVID-19 en obras de construcción. Recommendations guide for the Management and treatment of WASTE generated by prevention measures against COVID-19 in construction sites

- Calzado: se podrán desinfectar con una solución hidroalcohólica al 70\%.

- Arnés: no se deben utilizar productos químicos, ya que pueden deteriorar las fibras textiles y materiales plásticos. Un arnés que haya sido utilizado se dejará en cuarentena antes de su utilización por otro trabajador. Para determinar el tiempo que debe mantenerse sin uso, se tendrán en cuenta los materiales que componen el arnés, por ejemplo, en los metales puede permanecer hasta 96 horas, tiempo para determinar el periodo de cuarentena del arnés. Para su desinfección mediante cualquier otro procedimiento (lavado con agua caliente, uso de productos químicos, etc.), se deberá consultar con el fabricante.

- Gafas o pantallas faciales: se pueden limpiar con toallitas empapadas en desinfectantes y, tras su total secado, aclarar con una segunda toallita empapada con agua el exceso de producto restante para no entorpecer la visión. Como solución desinfectante puede usarse, de forma general, una solución hidroalcohólica.

\section{LIMPIEZA, DESINFECCIÓN E HIGIENE}

Practique la higiene de las manos, la higiene respiratoria y las normas de higiene para la tos, así como la limpieza y desinfección.

- Use agua y jabón para lavarse frecuentemente las manos (por al menos 20 segundos), y toallas de papel para secárselas.

- Use un desinfectante de manos con al menos un $60 \%$ de alcohol a menudo, cuando no sea fácil lavarse las manos.

- Cúbrase la nariz y la boca con un pañuelo desechable o la parte de arriba de la manga al toser o estornudar.

- Cuando sea posible, evite compartir objetos y equipos con otros empleados, incluidos los teléfonos, los escritorios u otras mesas de trabajo, herramientas y equipos.

- Lave y desinfecte los objetos y las superficies que se tocan frecuentemente, como herramientas compartidas, máquinas, vehículos y otros equipos, barandas, escaleras, manijas de puertas, y baños portátiles. Las superficies que estén visiblemente sucias deben limpiarse con agua y jabón antes de desinfectarlas.

\section{DISTANCIAMIENTO SOCIAL Y MASCARILLAS}

Siga las guías de distanciamiento social y uso de mascarillas:

- Mantenga al menos 2 metros de distancia (aproximadamente el largo de 2 brazos) entre trabajadores, siempre que sea posible.

- Mantenga el distanciamiento social durante los descansos y cuando coma.

- Evite las áreas cerradas, como casas móviles y espacios reducidos. 
- Póngase una mascarilla en los lugares de trabajo, especialmente cuando sea difícil mantener el distanciamiento social.

- Póngase una mascarilla que le cubra la nariz y la boca para lograr la máxima protección (no se ponga la mascarilla alrededor del cuello o sobre la frente).

- No toque la parte de afuera de la mascarilla cuando la tenga puesta; si lo hace, lávese las manos o use un desinfectante de manos con al menos un $60 \%$ de alcohol para desinfectarse.

- Tenga cuidado de no tocarse los ojos, la nariz ni la boca al quitarse la mascarilla, y lávese las manos de inmediato después de hacerlo, a menos de que se las haya lavado recientemente

\section{Referencias}

Ley 31/1995, de 8 de noviembre, de Prevención de Riesgos Laborales.

Real Decreto 646/2020, de 7 de julio, por el que se regula la eliminación de residuos mediante depósito en vertedero.

Real Decreto 773/1997, de 30 de mayo, sobre disposiciones mínimas de seguridad y salud relativas a la utilización por los trabajadores de equipos de protección individual.

Aparejadores Madrid: Resumen de los principales aspectos relacionados con la actuación de la INSPECCIÓN DE TRABAJO Y SEGURIDAD SOCIAL respecto de la VIGILANCIA del cumplimiento de las MEDIDAS PREVISTAS en el RD-Ley 21/2020, y analizadas en el CRITERIO TÉCNICO 103/2020 "Sobre actuaciones de la Inspección de Trabajo y seguridad social relativas a la habilitación contenida en el real decreto-ley 21/2020, de 9 de junio, en relación con las medidas de prevención e higiene para hacer frente a la crisis sanitaria ocasionada por la Covid-19 en los centros de trabajo

AA VV (2020): Estrategia de arquitectura y construcción sostenible. Consejería de Fomento e Infraestructuras. Di. Gral. De Territorio y Arquitectura. Murcia

AA VV (2016): Guía sobre gestión de residuos de construcción y demolición. AEDED.

Asociación Española de Empresarios de Demolición.

ADPR (Asociación de Descontaminación de Residuos Peligrosos) (2011): Residuos peligrosos en la Construcción y en la obra pública. Interempresas Media.

CDC (USA) Centros para el Control y la Prevención de Enfermedades.

CDCINFO: 1-800-CDC-INFO (1-800-232-4636) i TTY; 1-888-232-6348. Web: cdc.gov/info

prevencionygestionderesiduos_tcm30-509671

https://apps.who.int/iris/bitstream/handle/10665/331856/WHO-2019-nCoV 
Guía de recomendaciones para la Gestión y tratamiento de RESIDUOS generados por las medidas de prevención ante la COVID-19 en obras de construcción. Recommendations guide for the Management and treatment of WASTE generated by prevention measures against COVID-19 in construction sites

Food_Safety-2020.1-spa.pdf

CPWR The Center for Construction Reserach and Training

CSCAE. 09-04-2020: Recomendaciones de seguridad en obras de construcción por la crisis del Covid-19

Ecorys (2016): Protocolo de gestión de residuos de la construcción y demolición en la UE. Comisión Europea. Dir. Gral. Mercado Interior, Industria, Emprendimiento y Pymes.

Guía de medidas frente al CORONAVIRUS en obras de construcción (CNC, UGT, CCOO)

ICASST Orientaciones preventivas frente al covid-19 en obras de construcción

Instituto Nacional de Seguridad y Salud en el Trabajo. Prevención de riesgos laborales vs. COVID-19: compendio no exhaustivo de fuentes de información. INSST 2020. Disponible en: www.insst.es

Instituto de Salud Pública y Laboral de Navarra. Web oficial sobre el coronavirus https://coronavirus.navarra.es/es/

Instituto Valencià de Seguretat i Salut en el Treball: Gestión de residuos. medidas técnicas y organizativas preventivas frente a la exposición al coronavirus (Sars-Cov-2)

LEITE, Wolfgang (1981): la Química y la protección del medio ambiente. Ed. Paraninfo. Madrid.

Listado de virucidas autorizados en España para uso ambiental (PT2), industria alimentaria (PT4) e higiene humana (PT1) 26.03.2020. Ministerio de Sanidad Buenas prácticas en el centro de trabajo (PDF) Gobierno de España

Ministerio para la Transición Ecológica y el reto demográfico: Residuos Sanitarios.

https://www.miteco.gob.es/es/calidad-y-evaluacion-ambiental/temas/prevencion-y-gestionresiduos/flujos/residuos-sanitarios/

Ministerio de Sanidad (2020). Procedimiento de actuación para los servicios de prevención de riesgos laborales frente a la exposición al SARS-CoV-2, de 8 de abril de 2020.

Ministerio de Sanidad (2020). Procedimiento de actuación para los servicios de prevención de riesgos laborales frente a la exposición al nuevo coronavirus (SARS-COV-2).

Ministerio de Sanidad (2020). Estrategia de detección precoz, vigilancia y control de COVID-19.

Ministerio de Sanidad (2020). Medidas higiénicas para la prevención de contagios del COVID-19.

Ministerio de Sanidad (2020). Guía de buenas prácticas en centros de trabajo para prevenir los contagios del COVID19. 
OTERO DEL PERAL, Luis R. (1992): Residuos sólidos urbanos. Secretaría de Estado para las Políticas del Agua y el Medio Ambiente. Ministerio de obras Públicas y Transportes. Madrid

Protocolo Para la Gestion de Residuos Sanitarios Generados en los Centros Dependientes del Sescam.

https://www.chospab.es/enfermeria/Documentos/Protocolo_Residuos.pdf

PÉREZ DE LAMA, J. (2008): Ecología metropolitana: Arquitectura bioclimática, desarrollo sostenible, ecosofía. Composición Arquitectónica. Universidad de Sevilla.

http://htca.us.es/blogs/perezdelama

PÉREZ GUERRA, Alfonso (1991): Planificación de la Seguridad e Higiene en el Trabajo en Construcción y Conservación de Edificios. IFAS. Sección España. Barcelona

Servicio de PRL de la Generalitat www.prevencio.gva.es

VILLORIA SÁEZ, Paola (2014): Sistema de gestión de residuos de construcción y demolición en obras de edificación residencial. Buenas prácticas en la ejecución de obra. Tesis Doctoral. Univ. Politécnica de Madrid.

WHO-2019-nCoV-Workplace-actions-Policy-brief-2021.1-eng 


\title{
EDIFICATE
}

I Congreso de Escuelas de Edificación y Arquitectura Técnica de España

València, 4 y 5 de noviembre de 2021

Escuela Técnica Superior de Ingeniería de Edificación

Universitat Politècnica de València

Doi: https://doi.org/10.4995/EDIFICATE2021.2021.13271

\section{Encuesta de las medidas de prevención y protección frente a la COVID-19 añadidas a la Seguridad y Salud de las obras de edificación}

\section{Survey of prevention and protection measures against COVID- 19 added to the Health and Safety of building works}

\author{
Francisco Javier Sánchez Medranoa, Salvador Aledo Guerao ${ }^{b}$, Enrique Minguez \\ Martínez $^{c}$ y Verónica Nadal Jiménez ${ }^{\mathrm{d}}$ \\ ${ }^{a}$ Dr. Arquitecto, profesor UCAM, fjsanchez@ucam.edu, 'Dr. Ingeniero de Edificación, profesor UCAM, \\ saledo@ucam.edu, aDr. Arquitecto, profesor UCAM, eminguez@ucam.edu e Ingeniera de Edificación, \\ profesora UCAM, vnadal@ucam.edu.
}

\begin{abstract}
As an initial phase and prior to the drafting of a "Guide of recommendations for the management and treatment of waste generated by prevention measures against COVID-19 in construction works", we have worked for several months, in collaboration with more than 20 companies construction companies, to know what prevention and protection measures against COVID-19 have been added to the Health and Safety of building works with the approach based on using the information received to respond to the need to incorporate them into the procedures to continue incorporating them into the training given in university degrees leading to the professional qualification of Technical Architecture in the subjects of Prevention and Sauld of the curricula.
\end{abstract}

Keywords: Health and Safety, Risk prevention, incorporation of new challenges, process disturbances

\section{Resumen}

Como fase inicial y previa a la redacción de una "Guía de recomendaciones para la gestión y tratamiento de residuos generados por las medidas de prevención ante la COVID-19 en obras de construcción", hemos trabajado varios meses, en colaboración con más de 20 empresas constructoras, para conocer que medidas de prevención y protección frente a la COVID-19 han sido añadidas a la Seguridad y Salud de las obras de edificación con el planteamiento basado en utilizar la información recibida para dar una respuesta 
Encuesta de las medidas de prevención y protección frente a la COVID-19 añadidas a la Seguridad y Salud de las obras. Survey of prevention and protection measures against COVID-19 added to the Health and Safety of building works

a la necesidad de incorporarlas en los procedimientos a seguir incorporando los mismos a la formación impartida en los grados universitarios conducentes a la habilitación profesional de la Arquitectura Técnica en las asignaturas de Prevencion y Sauld de los planes de estudios.

Palabras clave: Seguridad y Salud, Prevención de riesgos, incorporación de nuevos retos, alteraciones del proceso. 


\section{Introducción}

La declaración de pandemia de COVID-19 el 11 de marzo de 2020 por la Organización Mundial de la Salud provocó la duda sobre qué medidas de prevención y protección frente a la COVID-19 era preciso adoptar en las obras.

En el inicio de esta investigación, desde el grupo de investigación ARIES (Arquitectura, Ingeniería de Edificación y Sostenibilidad), se planteó elaborar una guía o código de buenas prácticas para la gestión de los residuos peligrosos relacionados con la COVID-19 en las obras, la cual aportase recomendaciones a tener en cuenta pues se partía de una posible relación entre los residuos de protección personal y colectiva y los denominados "sanitarios", en concreto los clasificados como Residuos del Grupo III, que son residuos peligrosos tipificados específicamente por su riesgo biológico.

Previa a la redacción de la guía se optó que, como fase inicial y previa, era preciso conocer que medidas de prevención y protección frente a la COVID-19 han sido añadidas a la Seguridad y Salud de las obras.

Para realizar el planteamiento de la encuesta se procedió a analizar la legislación vigente y la posible normativa al respecto siendo en ambos casos muy reducida pues se disponía de:

- Real Decreto 1627/1997, de 24 de octubre, por el que se establecen disposiciones mínimas de seguridad y de salud en las obras de construcción.

- Procedimiento de actuación para los servicios de prevención de riesgos laborales frente a la exposición al nuevo coronavirus (SARS-COV-2).

\section{Objetivos}

En primer lugar, se plantea el objetivo de preparar y realizar una encuesta para obtener información fiable sobre las medidas de protección añadidas a la Seguridad y Salud de las obras.

Realizada la misma, analizar los resultados obtenidos en la encuesta para proceder a valorar la necesidad de establecer protocolos de gestión de los nuevos residuos generados por la COVID-19.

A continuación, se procedería con la confección de una "Guía de recomendaciones para la gestión y tratamiento de residuos generados por las medidas de prevención ante la COVID19 en obras de construcción".

\section{Desarrollo de la investigación}

Una obra de construcción, en el aspecto que nos ocupa, se regula por el Real Decreto 1627/1997, de 24 de octubre, por el que se establecen disposiciones mínimas de seguridad y de salud en las obras de construcción. Se puede dar el caso que la obra sea ejecutada por una o varias empresas contratistas que son titulares y responsables del centro de trabajo. 
El titular del centro de trabajo debe establecer el procedimiento de actuación en cada obra, siguiendo el "Procedimiento de actuación para los servicios de prevención de riesgos laborales frente a la exposición al SARS-CoV- 2", publicado por el Ministerio de Sanidad, o cualquier normativa análoga del ámbito territorial que sea pertinente.

En consecuencia hemos procedido a trabajar varios meses, en colaboración con más de 20 empresas constructoras, con el planteamiento basado en utilizar la información recibida para dar una respuesta a la necesidad de incorporarlas en los procedimientos a seguir.

Esta encuesta se integra en el Proyecto de Investigación del programa PMAFI-COVID 19, convocatoria de financiación propia de la Universidad Católica de Murcia, desarrollado por el Grupo de Investigación Arquitectura Ingeniería de Edificación y Sostenibilidad (ARIES).

\section{Estudio de la encuesta realizada sobre las medidas de prevención y protección añadidas a la Seguridad y Salud de las obras para la gestión de los nuevos residuos en la obra}

El tipo de construcción sobre el que se ha realizado la encuesta, abarca los sectores de Rehabilitación, Reformas, Reparación, Obra civil, Almacén, Equipamientos y Viviendas, y el tamaño de las obras ha sido diverso (Presupuestos de ejecución material de poco más de 24.000.- $€$ a más de $48 \mathrm{M}$ de $€$ ).

\section{Resultados de la encuesta realizada}

Comentamos los principales datos obtenidos:

a) No llega a un $20 \%$ los proyectos que incluyen medidas de protección frente al contagio de COVID-19 en sus Estudios de Seguridad y Salud, y tampoco llega a un $30 \%$ los Planes de Seguridad y Salud elaborados por las empresas constructoras que las incluyen.

Sin embargo, en casi los $2 / 3$ de las obras se han redactado anexos de medidas de prevención frente a la enfermedad lo cual se puede apreciar gráficamente en las figuras 1 y 2. 

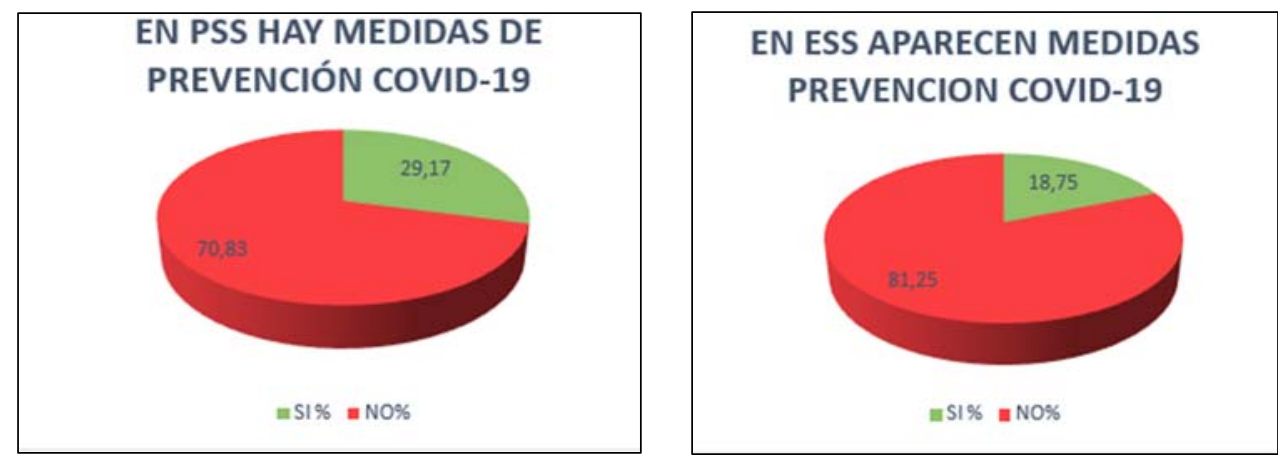

Figura 1. Análisis de las medidas incluidas en los ESS y PSS

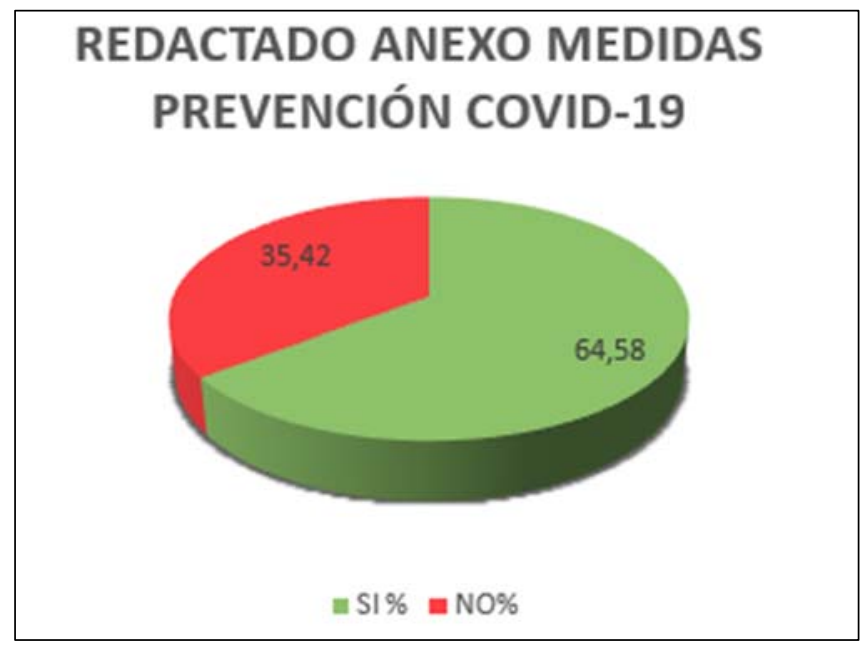

Figura 2.Análisis de los Anexos incorporados en los PSS

Esto puede tener explicación en el dilatado proceso que media entre la elaboración de la documentación técnica de una obra de construcción y la ejecución efectiva de la misma, en la que median autorizaciones administrativas (licencias, permisos, acometidas de servicios), y sistemas de adjudicación (concursos, subastas, comparativos de ofertas), que frecuentemente llegan a meses o años, siendo uno de los factores reales de desviaciones de coste de las mismas (subidas de precios de materiales, mano de obra y maquinaria, descatalogaciones, cambios de normativa a mayores prestaciones o estándares, etc.)

b) Hay una gran variabilidad de adopción de medidas para la protección frente la COVID-19, así mientras el uso de mascarillas ronda el $80 \%$ y la presencia de 
dispensadores supera el $70 \%$, el uso de felpudos desinfectantes es prácticamente nulo y hay muy poco empleo de mamparas de protección, señalizaciones y dotación de contenedores encontramos en algo más de la mitad de obras (Ver Tabla 1 y Figura 3).

Tabla 1. Resumen clasificado de datos obtenidos

\begin{tabular}{|c|c|c|c|c|}
\hline $\begin{array}{c}\text { MEDIDAS ADOPATADAS EN } \\
\text { OBRA }\end{array}$ & $\begin{array}{c}\mathrm{N}^{\circ} \text { CASOS } \\
\text { FAVORABLES }\end{array}$ & $\begin{array}{c}\mathrm{N}^{\circ} \text { CASOS } \\
\text { DESFAVORABLES }\end{array}$ & $\% \mathrm{SI}$ & $\% \mathrm{NO}$ \\
\hline $\begin{array}{l}\text { SEÑALIZACIÓN HORIZONTAL } \\
\text { (cintas, discos, flechas) }\end{array}$ & 23 & 25 & 47,92 & 52,08 \\
\hline $\begin{array}{ll}\text { SEÑALIZACIÓN } & \text { VERTICAL } \\
\text { (cartel, señales) } & \end{array}$ & 31 & 17 & 64,58 & 35,42 \\
\hline $\begin{array}{l}\text { BALIZAMIENTO } \\
\text { cintas, poste) }\end{array}$ & 21 & 27 & 43,75 & 56,25 \\
\hline $\begin{array}{l}\text { MAMPARA SEPARADORA DE } \\
\text { PROTECCIÓN }\end{array}$ & 13 & 35 & 27,08 & 72,92 \\
\hline ESTACIÓN DE HIGIENE & 20 & 28 & 41,67 & 58,33 \\
\hline $\begin{array}{ll}\text { PAPELERAS } & Y \\
\text { CONTENEDORES }\end{array}$ & 24 & 24 & 50,00 & 50,00 \\
\hline $\begin{array}{l}\text { GUANTES, } \quad \text { MASCARILLAS } \\
\text { PANTALLAS CUBREZAPATOS }\end{array}$ & 38 & 10 & 79,17 & 20,83 \\
\hline PRODUCTOS VIRUCIDAS & 14 & 34 & 29,17 & 70,83 \\
\hline $\begin{array}{ll}\text { DOSIFICADORES } & Y \\
\text { DISPENSADORES }\end{array}$ & 35 & 13 & 72,92 & 27,08 \\
\hline FELPUDOS DESINFECTANTES & 1 & 47 & 2,08 & 97,92 \\
\hline LIMPIEZAY DESINFECCIÓN & 32 & 16 & 66,67 & 33,33 \\
\hline $\begin{array}{l}\text { RECONOCIMIENTO } \\
\text { APLICACIÓN REAL EN OBRA }\end{array}$ & 37 & 11 & 77,08 & 22,92 \\
\hline
\end{tabular}




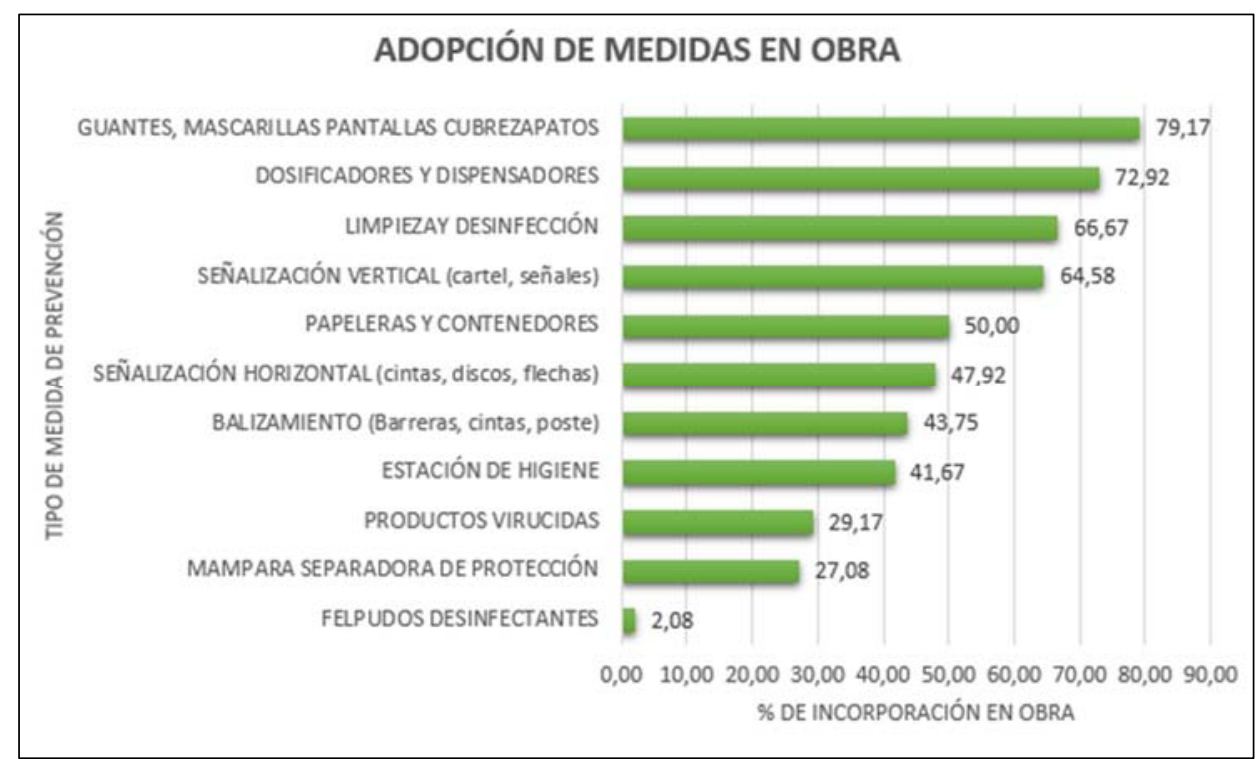

\section{Figura 3. Gráfica de datos obtenidos}

El tipo de trabajo que se realiza en las obras favorece la adopción de ciertas medidas personales (uso de guantes, mascarillas), y colectivas (carteles informativos, servicios higiénicos), mientras que dificulta otros (como las mamparas, más pensadas para trabajos estáticos o de oficina, que es donde en las obras pueden disponerse).

No obstante, quizás lo más significativo es la autocrítica de los propios encuestados, cuando reconoce que el cumplimiento de estas normas sanitarias tan publicitadas y exigidas a la población general, llega a poco más de las $3 / 4$ partes de los operarios (ver Figura 4).

En este sentido, en la lectura de artículos, blogs y comunicaciones sobre el caso, se alude a la dificultad de seguimiento individual y necesidad de una toma de conciencia del trabajador (no muy diferente de los porcentajes generales de la sociedad frente al seguimiento de dicha normativa).

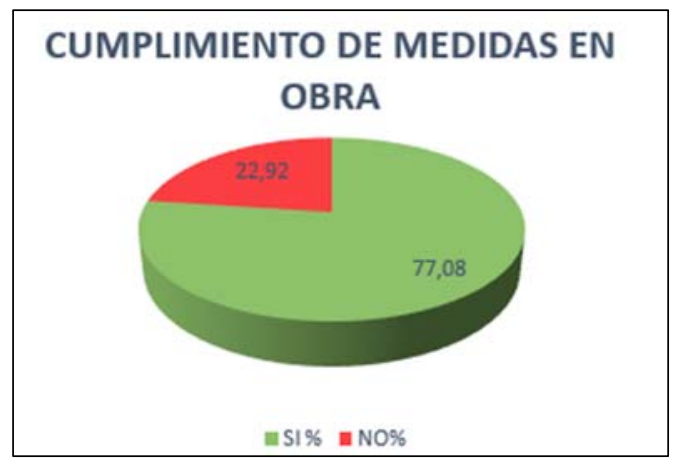

Figura 4. Gráfica del cumplimiento de medidas en obra 
c) En este apartado es donde se encuentra un menor esfuerzo: en la gestión adecuada de los residuos, donde la vigilancia de su peligrosidad o consideración del nivel de riesgo, se aprecia más bajo.

Apenas roza el $40 \%$ donde hay contenedores específicos y ronda en $30 \%$ de los mismos donde se señalan como "peligrosos" o "sanitarios" (ver Figuras 5) siendo recogidos por un gestor especializado lo cual queda reflejado en la Figura 6.

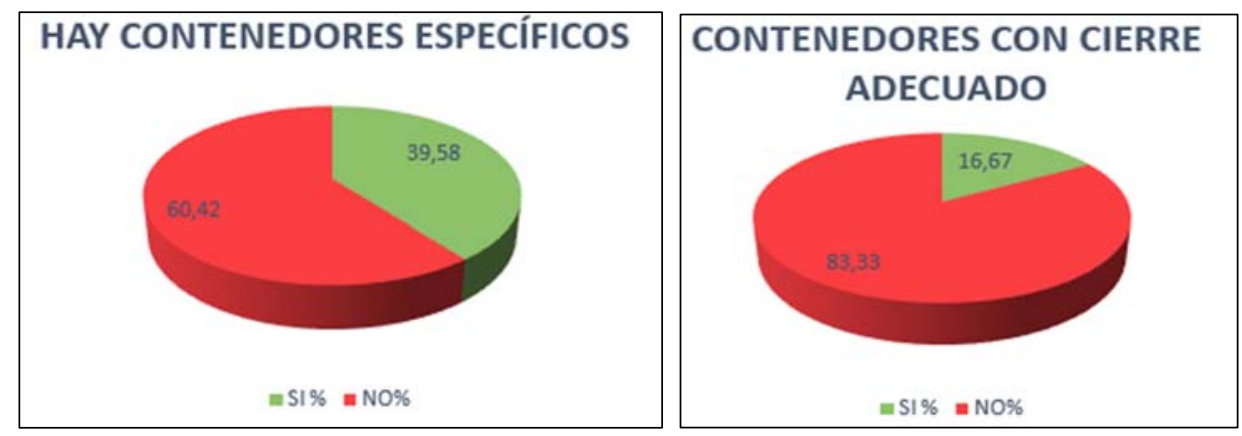

Figura 5. Gráfica de disponibilidad de contenedores

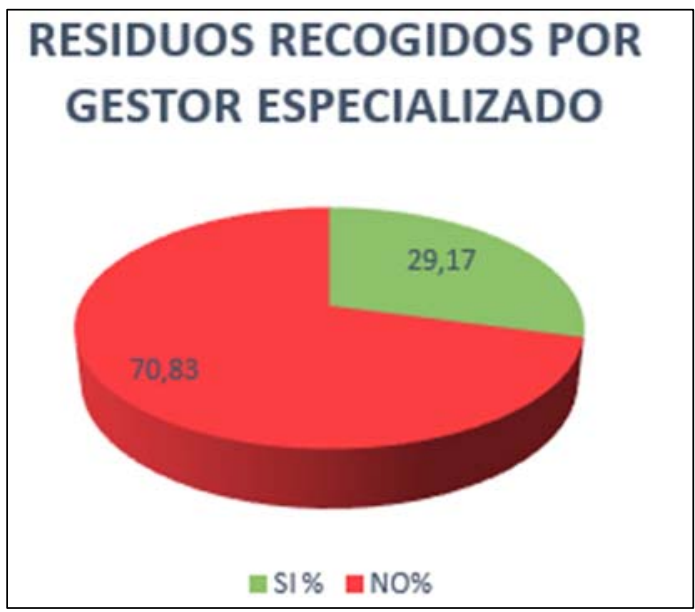

Figura 6. Gráfica del uso de gestores especializados en obras

Significar que las instrucciones y normativas de los organismos de la Administración, ver Figuras 7, han concluido que estos residuos (guantes, mascarillas, cubrezapatos, 
dispensadores, pañuelos o toallas de papel), deben ir a los contenedores de basura general (fracción "resto" una vez procedido a la separación), con la precaución de su manipulación y empleo de doble bolsa.
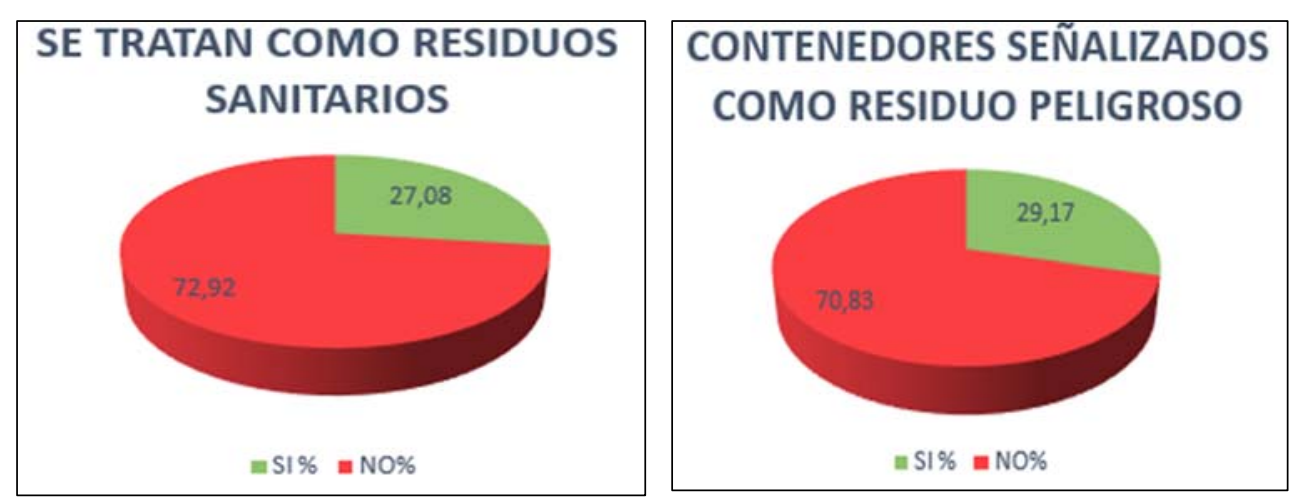

Figura 7. Gráfica del tratamiento de los residuos

\section{Conclusiones de la encuesta realizada sobre las medidas de prevención y protección añadidas a la Seguridad y Salud de las obras para la gestión de los nuevos residuos en la obra}

A la vista de los casos estudiados y lo resultados obtenidos, se pone de manifiesto la necesidad de incorporar los procedimientos a seguir para implantar las medidas de prevención y protección frente a la COVID-19, añadidas a la Seguridad y Salud de las obras obras de edificación y todo ello, con la ayuda de la formación a impartir en los grados universitarios conducentes a la habilitación profesional de la Arquitectura Técnica en las asignaturas relacionadas incluidas en los planes de estudios vigentes.

\section{Referencias}

Real Decreto 1627/1997, de 24 de octubre, por el que se establecen disposiciones mínimas de seguridad y de salud en las obras de construcción.

Procedimiento de actuación para los servicios de prevención de riesgos laborales frente a la exposición al nuevo coronavirus (SARS-COV-2). 


\title{
EDIFICATE
}

I Congreso de Escuelas de Edificación y Arquitectura Técnica de España València, 4 y 5 de noviembre de 2021

Escuela Técnica Superior de Ingeniería de Edificación

Universitat Politècnica de València

Doi: https://doi.org/10.4995/EDIFICATE2021.2021.13355

\section{Desglose y sistematización de ítems para las labores de supervisión formal de proyectos de edificación. Breakdown and systematisation of items for formal supervision of building projects}

\author{
Manuel J. Carretero-Ayuso \\ Universidad de Alcalá. \\ Profesor en el Grado de Arquitectura Técnica y Edificación, carreteroayuso@yahoo.es
}

\begin{abstract}
Graduates of technical architecture and construction have several work possibilities ahead of them. One is to join firms that carry out supervisory work of construction design projects, and their role in such firms is to perform an indepth and formal verification of the content of design documents. This paper presents a number of results obtained in practical activities with students, the objective of which was to understand how they would carry out the management of such supervisory tasks by means of a systematic process of item verification (through the creation of ad hoc tables). It is thus intended to hold an exercise of how they will eventually organise their professional duties and to prove that it is possible to manage the way in which this work task is produced by breaking down and standardizing the supervision process. The results are grouped into five fully systematised checklist tables, one for each of the component elements of design projects (description, attachments, plans, measurements and budgets, and terms and conditions). A total of 108 testing and control checks were envisaged, each of which is well suited to be used, as-is, in a real professional context..
\end{abstract}

Keywords: Design projects, document supervision, methodological systematisation, process management, breakdown of professional tasks 


\section{Resumen}

El graduado en arquitectura técnica y edificación tiene multitud de posibilidades laborales diferentes; una de ellas es la de pertenecer a gabinetes $u$ oficinas técnicas de supervisión de proyectos de edificación. En estas tareas es necesario realizar un chequeo del contenido formal y de fondo de dichos documentos. La comunicación expone los resultados obtenidos en las prácticas con alumnos, cuyo objetivo era trasladar cómo llevarían a cabo la gestión de estas labores de supervisión a un proceso sistematizado de ítems de control formal (mediante la creación de tablas ad hoc). De esta forma se pretende hacer un ejercicio de cómo éstos podrian secuenciar sus labores profesionales en este ámbito una vez estuvieran egresados y constatar que es posible gestionar la manera en que se produce esta tarea laboral desglosando y estandarizando el proceso de supervisión. El resultado obtenido son cinco tablas de verificación totalmente sistematizadas, sobre cada una de las partes que conforman conceptualmente los proyectos de ejecución (memoria, anejos, planos, mediciones y presupuestos, así como pliego de condiciones). En total se han implementado un total de 108 checks de testeo o control, que son perfectamente utilizables tal cual están, para ser utilizados directamente en un entorno profesional real.

Palabras clave: proyectos de ejecución, supervisión documental, sistematización metodológica, gestión de procesos, desglose de acciones profesionales. 


\section{Introducción}

Muchas veces se dice en diferentes ámbitos que bastantes estudios universitarios están desligados en mayor o menor medida de la realidad laboral, al menos, en ciertos enfoques y formas de plantear algunos aspectos. Esto es así en algunos países más que en otros, y en algunos grados de manera más leve que en otros.

Los cambios de todo tipo que están teniendo los estudios superiores en España en los últimos años, hace que se deban plantear nuevos escenarios que enfoquen las titulaciones a las necesidades reales que tiene nuestra sociedad.

Las faltas de habilidades lógicas dificultan el desarrollo posterior de capacidades fundamentales como la de síntesis, orientación y abstracción. Estas dificultades, tienen consecuencias negativas en el desarrollo de las competencias finales a adquirir (Desoete and Roeyers, 2006).

Una de las posibilidades para que los alumnos aprendan ciertas cuestiones, es llevar a cabo tareas mediante las cuales indirectamente se les seduzca en trabajos que no han realizado nunca. Estos trabajos deben llevar implícito competencias que deberán desarrollar (ANECA, 2003), y si es posble, sin que sean conscientes de ello durante el propio camino que han de transitar.

De esta forma, el proceso de aprendizaje del estudiante, debe tener en cuenta esas competencias laborales legalmente establecidas y extenderla a lo largo de toda la etapa de formación (Gobierno de España, 2007). Posteriormente, para ahondar más, deberán llevarse las especializaciones necesarias a través de postgrados y másteres (Parra et al., 2003).

Dentro del campo de análisis que esta comunicación analizará, este autor ha desarrollado algunos estudios de investigación que han puesto el acento en los procesos de sistematización del control de calidad de los proyectos (Carretero-Ayso et al., 2016; Carretero-Ayso et al., 2018). Las lecciones aprendidas pasan por que los técnicos sean más conscientes de la importancia -en diferentes ámbitos- de un proyecto de ejecución minuciosamente elaborado.

\section{Objetivo}

El objetivo de esta comunicación es constatar que es posible gestionar la forma en que se produce una tarea laboral de un arquitecto técnico, desglosándolo y sistematizándolo en pequeños ítems, dentro de una función técnica muy concreta. En el amplio abanico de competencias profesionales que tendrán los futuros egresados del Grado en Arquitectura Técnica y Edificación, están los relacionados con las Administraciones Públicas y los de las Entidades de Control de Calidad en la Edificación. En cada uno de estos nichos laborales hay una faceta que es la de actuar en el testeo y supervisión de proyectos de edificación, aunque desde perspectivas distintas. Esta tarea tiene amplios matices y envergaduras pues la 
extensión y profundidad de la misma es claramente diferente según el puesto laboral que se tenga y el encargo concreto que se le indique que hay que efectuar.

En este caso se trata de que los estudiantes del grado de arquitectura técnica y edificación puedan hacer una práctica en la que se intente desmenuzar cada una de las comprobaciones formales que debe llevar a cabo un técnico que supervise un proyecto edificatorio, de forma que siguiendo unas tablas ad hoc se camine por las comprobaciones clave que hay que verificar en dicho proyecto. Simultaneamente, consiguiendo todo esto se produce una constatación implícita de que es posible gestionar la manera en que se produce esta tarea laboral, estructurando y estandarizando el propio proceso de supervisión. En este caso, este chequeo a efectuar será solo desde el punto de vista formal, sin que se entren a valorar el contenido/adecuación de los cálculos y memorias en él presentes.

\section{Desarrollo de la innovación}

Hay que tener en cuenta que actualmente no existe un documento nacional de trabajo que sirva de base mínima y orientativa para estas tareas. Se trata pues de una innovación, pues a pesar de que hay muchos técnicos que actualmente están realizando estas funciones laborales, no hay normalmente unas guías procedimentales que lo sistematicen y planifiquen. Se trata de hacer una verificación secuenciada de todos los apartados y contenidos necesarios que debe tener un proyecto presentado a una Administración Pública en España.

Para hacer estas tablas de supervisión, los alumnos formaron grupos de 5 personas, de manera que cada uno de ellos fuera el responsable de cada uno de los 5 documentos/tablas a realizar, pero que al mismo tiempo, todo el equipo participara en la visión global de la práctica a llevar a cabo. Posteriormente, una vez acabado esta primera acción, los responsables de cada documento tuvieron reuniones transversales y sectoriales con los otros responsables de los equipos restantes para poner en común las dificultades y ver qué aspectos podrían mejorar en sus respectivas tareas.

Una vez puntuado el trabajo que presentó cada equipo, se hizo una asamblea general de toda la clase para consensuar un único conjunto de documentos finales (que es lo que aquí se presenta), de forma que se recogieran en éstos las mejores aportaciones de los alumnos.

\section{Resultados}

El resultado ha sido obtener 5 tablas. Una por cada documento que forma parte de un proyecto: Memoria (código de ítems: Mm) -Fig. 1-, Planos (código de ítems: Pn) -Fig. 3-, Mediciones y Presupuesto (código de ítems: Mp) -Fig. 4- y Pliego de Condiciones (código de ítems: Pc) -Fig. 5-. Así mismo hay otra que es para los Anejos y Documentos Adjuntos del proyecto (código de ítems: Aa) -Fig. 2-, como puedan ser: estudio de seguridad y salud, estudio geotécnico, estudio de gestión de residuos, plan de control de calidad, instrucciones de uso y mantenimiento, proyectos parciales de las instalaciones, memorias de cálculos, etc... 
Las fichas contienen una serie de indicaciones base que son los puntos de testeo que deben de verificarse durante la revisión de los proyectos. Cada uno de ellos está identificado mediante un código único que les hace totalmente reconocibles, de forma que, si entre el supervisor y el proyectista hubiera que hacer aclaraciones sobre alguno de ellos, estas referencias les hacen más fácil la comunicación para saber el ítem al que se refieren.

A parte de estas indicaciones base, se pueden incluir otras que libremente se deseen y que haga falta incluir, según las necesidades que se vayan dando. Además de ello, en ese informe que contendrá las citadas fichas, pueden expresarse otra serie de comentarios específicos, contextualizados y adaptados a la naturaleza y característica del caso en concreto que se esté revisando.

Hay que indicar, que no todos los textos redactados durante el proceso de revisión deben de entenderse como negativos, dado que habrá ocasiones que se incluyan algunos solamente para quedar reflejados ciertos aspectos o para hacer constatar ciertos términos. 
Desglose y sistematización de ítems para las labores de supervisión formal de proyectos de edificación. Breakdown and systematisation of items for formal supervision of building projects.

FICHA DE SUPERVISIÓN DEL PROYECTO
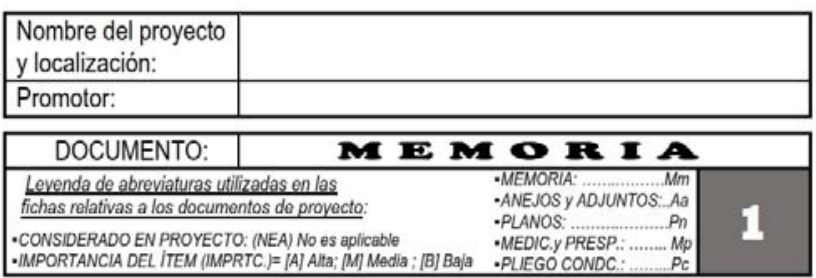

\begin{tabular}{|c|c|}
\hline \multirow{2}{*}{$\begin{array}{l}\text { 음 } \\
\text { 엉 }\end{array}$} & CONCEPTOS DE TESTEO \\
\hline & $\begin{array}{l}\text { ASPECTOS QUE SE VERIFICAN SOBRE LA DOCUMENTACION } \\
\text { ENTREGADA A LA OFICINA DE SUPERVISIÓN }\end{array}$ \\
\hline$M m 1$ & MEMORIA DESCRIPTIVA \\
\hline Mm 1.1 & Apartado de identificación del proyecto \\
\hline Mm 1.2 & Apartado de objeto del contrato \\
\hline Mm 1.3 & Apartado de agentes intervinientes* \\
\hline Mm 1.4 & Apartado de información previa* y situación actual \\
\hline Mm 1.5 & Apartado de condiciones urbanisticas y servicios afectados \\
\hline Mm 1.6 & Apartado de prestaciones del edificio" y descripción del proyecto* \\
\hline Mm 1.7 & Presupuesto de la obra y honorarios facultativos \\
\hline Mm 1.8 & Apartado de condiciones contractuales (incluido declaración obra completa) \\
\hline Mm 1.9 & Apartado relativo a pertenencia a planes específicos \\
\hline Mm 2 & MEMORIA CONSTRUCTIVA \\
\hline Mm 2.1 & Apartado de demoliciones y trabajos previos \\
\hline Mm 2.2 & Apartado sobre la sustentación del edificio* ${ }^{*}$ \\
\hline Mm 2.3 & Apartado sobre el sistema estructural \\
\hline Mm 2.4 & Apartado sobre el sistema envolvente \\
\hline Mm 2.5 & Apartado sobre el sistema de compartimentación \\
\hline Mm 2.6 & Apartado sobre el sistema de acabados \\
\hline Mm 2.7 & Apartado sobre sistemas de acondicionamiento e instalaciones \\
\hline Mm 2.8 & Apartado sobre equipamiento \\
\hline Mm 2.9 & Apartado sobre urbanización y otros \\
\hline $\mathrm{Mm} 3$ & CUMPLIMIENTO DEL CTE \\
\hline Mm 3.1 & Apartado relativo a la seguridad estructural (DB-SE) \\
\hline Mm 3.2 & Apartado relativo a la seguridad en caso de incendio (DB-SI) \\
\hline Mm 3.3 & Apartado relativo al ahorro de energia (DB-HE) \\
\hline Mm 3.4 & Apartado relativo a la seguridad de utilización y accesibilidad (DB-SUA) \\
\hline Mm 3.5 & Apartado relativo a la protección contra el ruido (DB-HR) \\
\hline Mm 3.6 & Apartado relativo a la salubridad (DB-HS) \\
\hline $\mathrm{Mm} 4$ & CUMPLIMIENTO DE OTRAS NORMATIVAS \\
\hline Mm 4.1 & Apartado sobre instrucciones estructurales \\
\hline Mm 4.2 & Apartado sobre electricidad y telecomunicación \\
\hline Mm 4.3 & Apartado sobre instalaciones térmicas \\
\hline Mm 4.4 & Apartado sobre condiciones regionales sobre accesibilidad \\
\hline Mm 4.5 & Apartado sobre ruidos y vibraciones \\
\hline Mm 4.6 & Apartado sobre gestión de residuos \\
\hline Mm 4.7 & Apartado sobre resto de reglamentos y disposiciones \\
\hline Mm 5 & ASPECTOS COMPLEMENTARIOS \\
\hline $\operatorname{Mm} 5.1$ & La memoria tiene indicada la fecha de emisión \\
\hline $\operatorname{Mm} 5.2$ & La memoria está firmada por el autor \\
\hline
\end{tabular}

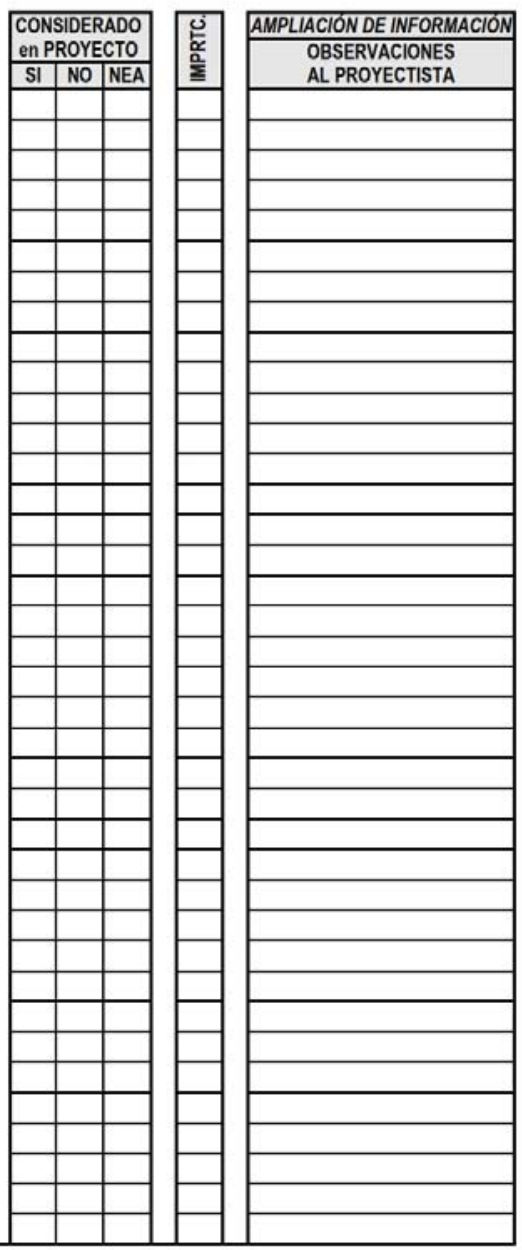

Fig. 1 Modelo diseñado de ficha para la supervisión de la Memoria

Las fichas de revisión de los documentos de proyecto tienen un tamaño A4 en sentido vertical. Poseen dos áreas diferenciadas: el área de encabezado/datos y el área de control.

En el diseño del área de encabezado/datos aparece el nombre de la ficha (sobre fondo negro) que dice: "Ficha de supervisión del proyecto". También hay unas áreas en la que hay espacio 
para hacer constar los siguientes datos de identificación: nombre el proyecto y localización, nombre del promotor, número del expediente, fecha de supervisión y nombre del supervisor.

Finalmente, hay otra zona que indica el nombre del documento del proyecto que se está verificando y el número de ficha (fondo gris y letra en blanco). Justo en la fila inferior, se incluye la relación de abreviaturas utilizadas posteriormente en el área de control.

\section{FICHA DE SUPERVISIÓN DEL PROYECTO}

\begin{tabular}{|c|l|}
\hline № de expediente: & \\
\hline Fecha supervisión: & \\
\hline $\begin{array}{c}\text { Nombre del } \\
\text { supervisor: }\end{array}$ & \\
\hline
\end{tabular}

\begin{tabular}{|c|c|}
\hline \multirow{2}{*}{$\begin{array}{l}\text { 엄 } \\
\text { 엉 }\end{array}$} & CONCEPTOS DE TESTEO \\
\hline & $\begin{array}{l}\text { ASPECTOS QUE SE VERIFICAN SOBRE LA DOCUMENTACIONN } \\
\text { ENTREGADA A LA OFICINA DE SUPERVISIÓN }\end{array}$ \\
\hline $\mathrm{Aa} 01$ & Documento de aceptación del proyecto \\
\hline $\mathrm{Aa02}$ & Temporalización y programación de la obra \\
\hline $\mathrm{Aa03}$ & Hay escrito de haber resuelto las incidencias detectadas anteriormente \\
\hline $\mathrm{Aa04}$ & Memoria de cálculo de estructuras \\
\hline Aa05 & Memoria de cálculo de instalaciones \\
\hline $\mathrm{Aa06}$ & Memoria de cálculo de sistemas constructivos \\
\hline Aa07 & Estudio de impacto ambiental \\
\hline Aa08 & Certificado de eficiencia energética \\
\hline $\mathrm{Aa09}$ & Estudio de gestión de residuos \\
\hline Aa10 & Estudio de seguridad y salud (o estudio básico) \\
\hline Aa11 & Plan de control de calidad \\
\hline Aa12 & Instrucciones de uso y mantenimiento \\
\hline Aa13 & Justificaciones especificas \\
\hline Aa14 & Autorizaciones y otras justificaciones \\
\hline Aa15 & Listado general de la legislación aplicable \\
\hline Aa16 & Estudio geotécnico \\
\hline Aa17 & Proyecto de derribo \\
\hline Aa18 & Proyectos parciales de instalaciones \\
\hline Aa19 & Estudio de inundabilidad \\
\hline Aa20 & Estudio histórico-artístico y/o arqueológico \\
\hline Aa21 & Tramitaciones sectoriales \\
\hline
\end{tabular}

\begin{tabular}{|l|l|}
\hline $\begin{array}{l}\text { Nombre del proyecto } \\
\text { y localización: }\end{array}$ & \\
\hline Promotor: & \\
\hline
\end{tabular}

\begin{tabular}{|c|c|c|c|}
\hline DOCUMENTO: & ANENOS & DOC. ADJUT & TOS \\
\hline \multirow{2}{*}{\multicolumn{2}{|c|}{ Levenda de abreviaturas utilizadas en las }} & -MEMORIA' & \\
\hline & & - ANEJOS y ADUUNTOS: Aa & \\
\hline \multicolumn{2}{|c|}{$\begin{array}{l}\text {-CONSIDERADO EN PROYECTO: (NEA) No es aplicable } \\
\text {-IMPORTANCIA DEL ITEM (IMPRTC.)= [A] Aita; [M] Medla ; [B] Baja }\end{array}$} & $\begin{array}{l}\text {-MEDIC y PRESP.: ..........Mp } \\
\text {-PLIEGO CONDC.: ........PC } \\
\end{array}$ & \\
\hline
\end{tabular}

Fig. 2 Modelo diseñado de ficha para la supervisión de los Anejos y Documentos Adjuntos

El área de control está formada por 4 subáreas. La primera subárea tiene dos cuerpos, siendo el primer cuerpo el que identifica (mediante un código) el aspecto que se verifica. Dicho código está compuesto por las abreviaturas que se han indicado antes, seguido de un número cardinal consecutivo de dos cifras. El segundo cuerpo dentro de esta primera subárea es el que contiene los conceptos de testeo propiamente dichos; es decir, los aspectos que el supervisor procede a verificar sobre la documentación que le ha sido entregada.

La segunda subárea contiene tres columnas denominadas SI, NO y NEA (abreviatura de 'no es aplicable') para que el técnico supervisor señale con una $X$ si se cumple el aspecto que se controla, que no se cumple o no aparece en la documentación que se ha entregado, o que en su caso este aspecto no es de aplicación al proyecto en cuestión. 
Desglose y sistematización de ítems para las labores de supervisión formal de proyectos de edificación. Breakdown and systematisation of items for formal supervision of building projects.

La tercera subárea es una única columna, identificada como 'IMPRTC' (abreviatura de 'importancia'), para que se haga una clasificación del grado de importancia que tiene cada aspecto que se controla, en función del criterio de quien hace la supervisión. Esta valoración dependerá de cómo se entienda el propio concepto para cada caso, en función de la extensión o envergadura que adquiera el mismo dentro del proyecto supervisado, o de cómo se entienda que puede repercutir el mismo. Se escribirá ' $A$ ' si tiene una importancia alta, se escribirá ' $M$ ' si tiene una importancia media, o se escribirá 'B' si se considera que es baja.

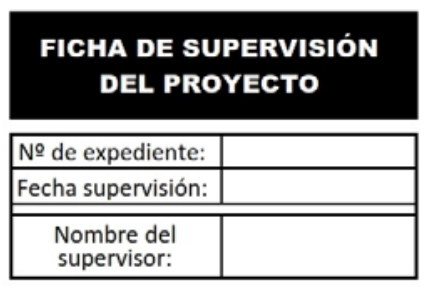

\begin{tabular}{|c|c|}
\hline 웅 & CONCEPTOS DE TESTEO \\
\hline 응 & $\begin{array}{c}\text { ASPECTOS QUE SE VERIFICAN SOBRE LA DOCUMENTACIONN } \\
\text { ENTREGADA A LA OFICINA DE SUPERVISIÓN }\end{array}$ \\
\hline Pn01 & Listado general de planos* \\
\hline Pn02 & Los planos están firmados por el proyectista* \\
\hline Pn03 & Los planos tienen señalados la fecha de emisión ${ }^{*}$ \\
\hline Pn04 & Plano de situación ${ }^{*}$ \\
\hline Pn05 & Plano de emplazamiento* \\
\hline Pn06 & Plano de urbanización* \\
\hline$P n 07$ & Plano topográfico \\
\hline Pn08 & Planos del estado actual ${ }^{*}$ \\
\hline Pn09 & Plano de demoliciones y trabajos previos* \\
\hline Pn10 & Planos de replanteo general y movimiento de tierras \\
\hline Pn11 & Plantas generales de arquitectura* \\
\hline Pn12 & Alzados generales* \\
\hline Pn13 & Secciones generales $^{*}$ \\
\hline Pn14 & Definición de alzados. Cotas* y acabados \\
\hline Pn15 & Definición de secciones. Cotas* y acabados \\
\hline Pn16 & Definición de plantas. Cotas* y acabados \\
\hline Pn17 & Definición de plantas. Albañileria, carpinteria y cubiertas ${ }^{*}$ \\
\hline Pn18 & Detalles constructivos y encuentros especiales \\
\hline Pn19 & Memoria gráfica y detalles de la carpintería exterior \\
\hline Pn20 & Memoria gráfica y detalles de la carpintería interior \\
\hline Pn21 & Memoria gráfica y detalles de la cerrajeria \\
\hline Pn22 & Cumplimiento normativo de protección contra incendios* \\
\hline Pn23 & Cumplimiento normativo de seguridad de utilización y accesibilidad ${ }^{*}$ \\
\hline Pn24 & Replanteo de estructuras e interconexiones \\
\hline Pn25 & Cimentación y cuadro de armados \\
\hline Pn26 & Estructura. Plantas \\
\hline Pn27 & Estructura. Pórticos \\
\hline Pn28 & Estructura. Detalles \\
\hline Pn29 & Fontaneria y saneamiento \\
\hline Pn30 & Electricidad \\
\hline Pn31 & Telecomunicaciones \\
\hline Pn31 & Climatización \\
\hline Pn32 & Contraincendios \\
\hline Pn33 & Solar térmica y fotovoltaica \\
\hline Pn34 & Otras instalaciones \\
\hline
\end{tabular}

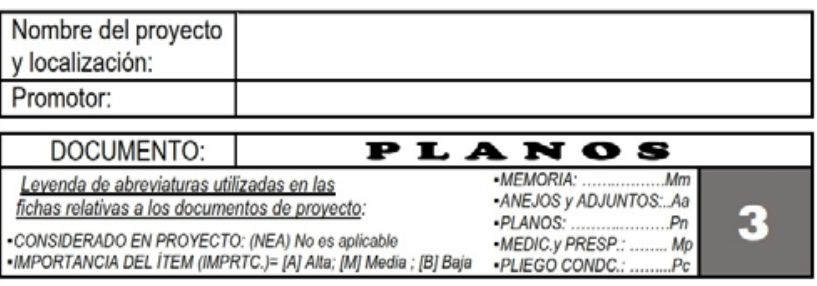
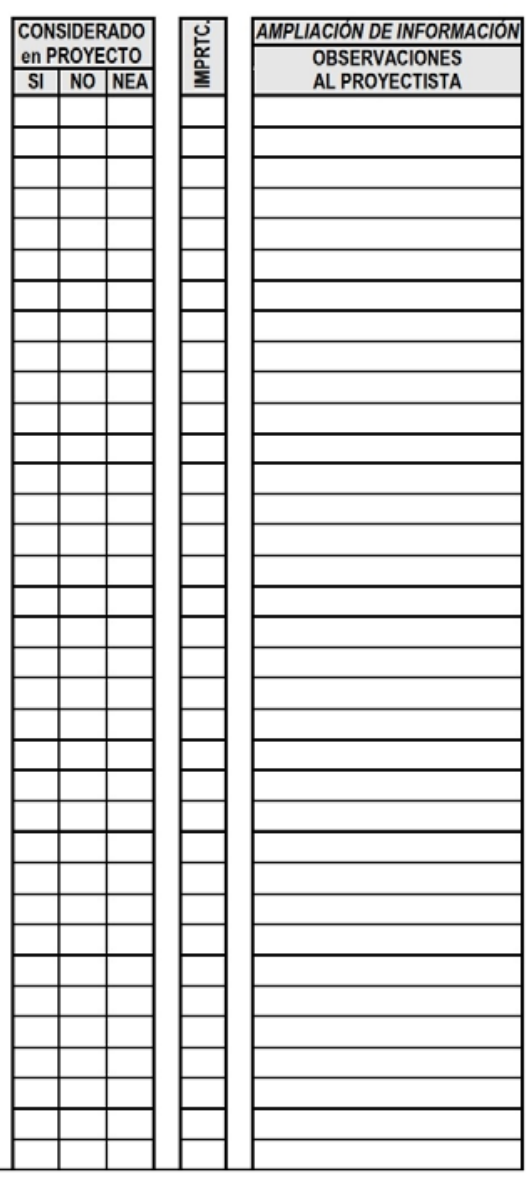

Fig. 3 Modelo diseñado de ficha para la supervisión de los Planos 
La cuarta subárea es también de una sola columna, y está pensada para que el supervisor escriba unas brevísimas palabras para resaltar alguna idea que desee hacer constar. Si fuera necesario, en el informe general de supervisión, se puede habilitar un apartado específico donde se pudieran incluir más aclaraciones, si fueran precisas.

\section{FICHA DE SUPERVISIÓN DEL PROYECTO}

\begin{tabular}{|c|l|}
\hline № de expediente: & \\
\hline Fecha supervisión: & \\
\hline $\begin{array}{c}\text { Nombre del } \\
\text { supervisor: }\end{array}$ & \\
\hline
\end{tabular}

\begin{tabular}{|l|l|}
\hline $\begin{array}{l}\text { Nombre del proyecto } \\
\text { y localización: }\end{array}$ & \\
\hline Promotor: & \\
\hline
\end{tabular}

\begin{tabular}{|c|c|c|c|}
\hline DOCUMENTO: & \multicolumn{3}{|c|}{ MEDICIONES $Y$ PRESUPUESTO } \\
\hline \multirow{2}{*}{\multicolumn{2}{|c|}{$\begin{array}{l}\text { Levenda de abreviaturas utilizadas en las } \\
\text { fichas relativas a los documentos de provecto: }\end{array}$}} & -MEMORIA: .......Mm & \\
\hline & & - ANEJOS Y ADJUNTOS: Aa & \\
\hline \multicolumn{2}{|c|}{$\begin{array}{l}\text {-CONSIDERADO EN PROYECTO: (NEA) No es aplicable } \\
\text {-IMPORTANCIA DEL iTEM (IMPRTC.)=[A] Alla; [M] Media ; [B] Baja }\end{array}$} & 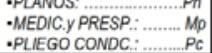 & \\
\hline
\end{tabular}

\begin{tabular}{|c|c|}
\hline 을 & CONCEPTOS DE TESTEO \\
\cline { 2 - 3 } Oे & \multicolumn{1}{|c|}{$\begin{array}{c}\text { ASPECTOS QUE SE VERIFICAN SOBRE LA DOCUMENTACION } \\
\text { ENTREGADA A LA OFICINA DE SUPERVISIÓN }\end{array}$} \\
\hline Mp00 & Existe un presupuesto aproximado* \\
\hline Mp01 & Las mediciones incluyen precios descompuestos \\
\hline Mp02 & Las mediciones incluyen listado de precios auxiliares \\
\hline Mp03 & Hay título abreviado de los epigrafes \\
\hline Mp04 & Hay un listado valorado de conceptos \\
\hline Mp05 & Existe un presupuesto general \\
\hline Mp06 & Se incluyen lineas numéricas de desglose de medición \\
\hline Mp07 & Cada una de las partidas incluye su precio \\
\hline Mp08 & Se considera el importe del estudio de Seguridad y Salud \\
\hline Mp09 & Se considera el importe del estudio de Gestión de Residuos \\
\hline Mp10 & Se considera el importe del Plan de Control de Calidad \\
\hline Mp11 & El importe del plan de control se incluye fuera del presupuesto \\
\hline Mp12 & Se especifica el PEM, el precio contrata y presupuesto licitación \\
\hline Mp13 & La hoja final del presupuesto está firmada por el proyectista \\
\hline Mp14 & Se hace constar el importe de los honorarios de los facultativos \\
\hline
\end{tabular}

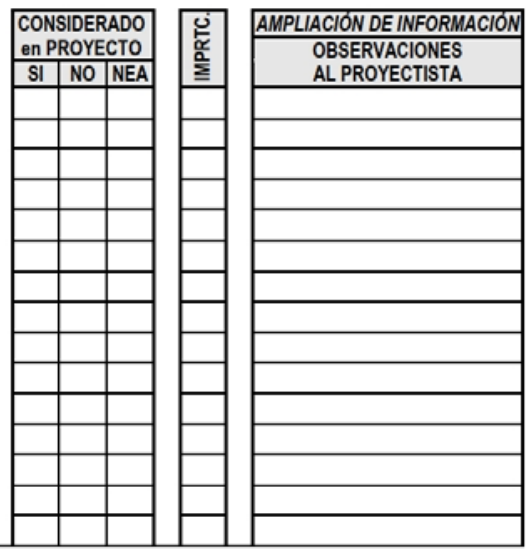

Fig. 4 Modelo diseñado de ficha para la supervisión de los las Mediciones y Presupuesto

\section{FICHA DE SUPERVISIÓN DEL PROYECTO}

\begin{tabular}{|c|l|}
\hline № de expediente: & \\
\hline Fecha supervisión: & \\
\hline \hline $\begin{array}{c}\text { Nombre del } \\
\text { supervisor: }\end{array}$ & \\
\hline
\end{tabular}

\begin{tabular}{|l|l|}
\hline $\begin{array}{l}\text { Nombre del proyecto } \\
\text { y localización: }\end{array}$ & \\
\hline Promotor: & \\
\hline
\end{tabular}

\begin{tabular}{|c|c|c|c|}
\hline DOCUMENTO: & PLIEGO DE & CONDICIO & Jes \\
\hline \multicolumn{2}{|c|}{$\begin{array}{l}\text { Levenda de abreviaturas utilizadas en las } \\
\text { fichas relativas a los documentos de provecto: }\end{array}$} & $\begin{array}{l}\text {-MEMORIA: } \quad . M m \\
\text {-ANEJOS Y ADJUNTOS:Aa }\end{array}$ & \multirow{2}{*}{5} \\
\hline $\begin{array}{l}\text { - CONSIDERADO EN PROYEC } \\
\text {-IMPORTANCIA DEL ITEM IIN }\end{array}$ & $\begin{array}{l}: \text { :NEA) No es aplicable } \\
T C .=[\text { [A] Alta; }[M] \text { Media ; }[B] \text { Baja }\end{array}$ & 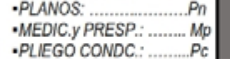 & \\
\hline
\end{tabular}

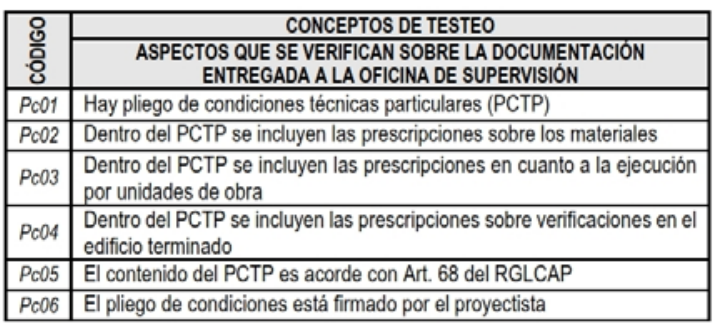
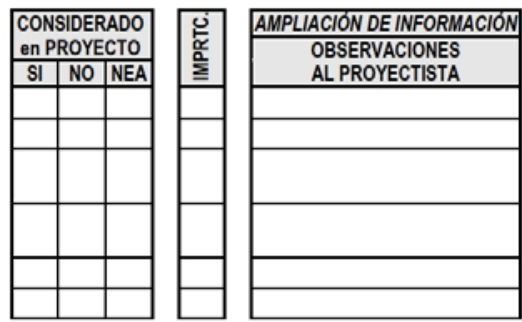

Fig. 5 Modelo diseñado de ficha para la supervisión del Pliego de Condiciones 
En las tablas se ha incluido todo lo previsto en la normativa de obligado cumplimiento, como el Código Técnico. En este sentido, incluso se ha referenciado con un asterico ( $\left.{ }^{*}\right)$ los aspectos que según dicha legislación debe incluirse previamente en los proyectos básicos. También están presentes otros aspectos formales que suelen pedir las oficinas de proyecto de algunas de las Administraciones Públicas consultadas.

\section{Discusión}

En caso de ser necesario la modificación de alguno de los documentos de proyecto, motivados por las indicaciones de la revisión sobre el mismo, es conveniente pedir a los proyectistas que emitan un escrito en el que se incluya un listado de los aspectos considerados.

A partir de la entrega de la nueva versión del proyecto, al técnico que realiza la revisión de éste, procederá al testeo de cada indicación emitida, al objeto de comprobar si éstas han sido subsanadas (total o parcialmente), o en caso contrario, no han sido tenidas en cuenta. En este momento, es posible que pudieran aparecer nuevas cuestiones que anteriormente no fueron indicadas, dado que las nuevas modificaciones introducidas pueden conllevar otras problemáticas.

Toda esta sistemática antes indicada, orientada por el profesor hacia los alumnos, es una forma de dar el conocimiento de primera mano a los alumnos de cómo se funciona en la vida real en estos aspectos. Por tanto, la experiencia resultar ser 'un simulacro' con todos los parámetros que intervienen verdaderamente en la vida profesional que les tocará vivir.

\section{Conclusiones}

Los egresados de la titulación del grado en arquitectura técnica y edificación, tienen un abanico importante para dirigir su faceta profesional: direcciones de obra, proyectos técnicos, informes, dictámenes, peritaciones, valoraciones, certificados, eficiencia energética, gestión medioambiental, seguridad y salud, docencia, etc. Esta comunicación se ha enfocado en aquellas labores que se deben desarrollar cuando estén en gabinetes u oficinas técnicas de supervisión de proyectos de edificación (como por ejemplo en Administraciones Públicas y en Entidades de Control de Calidad en la Edificación).

Dentro de los cometidos que se deben llevar a cabo en estos puestos laborales, está el realizar chequeos del contenido formal y de fondo de proyectos de ejecución. De esta manera, se ha trabajado para que los estudiantes del grado hagan una práctica para desmenuzar cada una de las comprobaciones formales que lleva a cabo un técnico que supervise un proyecto de estas características.

El resultado conjunto y aunado de todas estas prácticas se ha integrado en el mejor resumen de ítems a contextualizar, de manera que todo ello se ha resumido en 5 tablas sistematizadas. Cada una de estas tablas está en relación a los documentos proyectuales que conforman los 
proyectos de ejecución: memoria, anejos, planos, mediciones y presupuestos, así como pliego de condiciones.

Finalmente, este buen desarrollo de las prácticas ha conseguido implementar un total de 108 checks de testeo o control, que son perfectamente utilizables tal cual están, para ser utilizados directamente en un entorno profesional real.

Toda esta labor realizada por los alumnos bajo la supervisión del profesor, ha servido también para que ellos experimenten la forma en que se trabaja en equipo dentro de un grupo de técnicos, al tiempo que sepan expresar/defender sus ideas y plasmarlas en unos documentos conjuntos de consenso para emitir un único trabajo final como resultado de entrega.

\section{Referencias}

ANECA. (2003). Programa de convergencia europea: el crédito europeo: Agencia Nacional de Evaluación de la Calidad y Acreditación.

CARRETERO-AYUSO, M.J., GARCÍA-SANZ-CALCEDO, J., REYES-RODRÍGUEZ, A.M. (2016). Qualitative and Quantitative Analyses on Project Deficiencies in Flat-Roof Design in Extremadura, Spain. Journal of Construction Engineering and Management, 142 (11), 04016061.

CARRETERO-AYUSO, M.J., GARCÍA-SANZ-CALCEDO, J., RODRÍGUEZ-JIMÉNEZ, C.E. (2018). Characterization and Appraisal of Technical Specifications in Brick Façade Projects in Spain. Journal of Performance of Constructed Facilities, 32 (3), 04018012.

DESOETE, A, ROEYERS, H., (2006) Metacognitive macroevaluations in mathematical problem sol-ving, Learning and instruction, 16, 12-25.

GOBIERNO DE ESPAÑA. (2007). Real Decreto 1397/2007 de 29 de octubre, por el que se establece la ordenación de las enseñanzas universitarias. Boletín Oficial del Estado (Vol. 260, pp. 44037-44048).

PARRA, M. D. M. A., URIA, M. V. R., LOPEZ, M. J., AND TEROL, A. M. B. (2003). Matemáticas en los estudios de economía y gestión de empresas en el marco del acuerdo de Bolonia. Anales de economía aplicada. 


\title{
EDIFİCATE
}

I Congreso de Escuelas de Edificación y Arquitectura Técnica de España València, 4 y 5 de noviembre de 2021

Escuela Técnica Superior de Ingeniería de Edificación

Universitat Politècnica de València

Doi: https://doi.org/10.4995/EDIFICATE2021.2021.13609

\section{Implantación de la metodología del Aprendizaje basado en Proyectos en le asignatura de Taller de Proyecto de Interiores Implementation of the Projetc-based Learning methodology in
the Interior Projects Workshop lesson}

Teresa Gil-Piqueras ${ }^{a}$, Pablo Rodríguez-Navarro ${ }^{a}$

E.T.S: Ingeniería de Edificación, Universitat Politècnica de València, tgi@ega.upv.es ${ }^{a}$, rodríguez@upv.es ${ }^{\mathrm{b}}$

\begin{abstract}
In the last years, Project-Based Learning has been one of the priority lines of innovation at the Universitat Politécnica de València, already having an impact on institutional initiatives in schools, faculties and departments. In the Technical Architecture Degree of the Escuela Técnica Superior de Ingenieria de Edificación, the "Interior Projects Workshop" lesson is taught with this teaching methodology. The objective of this communication is to show how the lesson is designed, and how the methodology has influenced the results obtained by the students after the learning process.
\end{abstract}

Keywords: Interior Projects, Project-Based Learning, Technical Architecture.

\begin{abstract}
Resumen
En los últimos años, el Aprendizaje Basado en Proyectos ha sido una de las líneas prioritarias de innovación en la Universitat Politècnica de València, incidiendo ya en iniciativas institucionales en escuelas, facultades $y$ departamentos. En el Grado de Arquitectura Técnica de la Escuela Técnica Superior de Ingeniería de la Edificación se imparte la asignatura "Taller de Proyecto de Interiores" con esta metodología de enseñanza. El objetivo de esta comunicación es mostrar cómo está diseñada la asignatura, y como ha influido la metodología en los resultados obtenidos por los estudiantes tras el proceso de aprendizaje.
\end{abstract}

Palabras clave: Proyectos de Interiores, Aprendizaje Basado en Proyectos, Arquitectura Técnica. 


\section{Introducción}

La metodología en la que se basa el Aprendizaje Basado en Proyectos se remonta a mediados del siglo XVI cuando en diferentes escuelas de Arquitecta de Roma y París comienza a trabajarse esta técnica (Wilkinson, 1977). A partir de mediados del siglo XVIII esta metodología se expande como método de enseñanza habitual en las escuelas públicas de América. Desde entonces, el método sufre varias revisiones que hacen que se expanda cada vez con más fuerza: en la década de 1970 experimentó un notable renacimiento, especialmente en el norte y centro de Europa; a partir de entonces se difunde a nivel internacional (Knoll, 1997).

Podemos definir el Aprendizaje Basado en Proyectos (ABP) o Project-Based Learning $(\mathrm{PBL})$ como una estrategia de aprendizaje en la que el alumno adquiere conocimientos y competencias específicas y transversales, a través de la elaboración de un proyecto que da respuesta a un problema de la vida real (reto). El ABP fomenta el aprendizaje individual y autónomo del estudiante, dentro de un plan de trabajo definido a partir de unos objetivos y procedimientos establecidos por el profesor. En este proceso de aprendizaje, la adquisición del conocimiento es el resultado de un proceso de búsqueda y selección de la información, a partir de unas necesidades reales planteadas inicialmente, de manera que a partir de ellas y a través del debate y la discusión, los estudiantes van aplicando conocimientos y desarrollando habilidades, que les llevan a obtener resultados lógicos a los retos planteados.

De modo general el proceso de aprendizaje busca seguir el siguiente esquema (Blumenfeld y otros, 1991):

- Hacer y depurar preguntas.

- Debatir ideas.

- Hacer predicciones.

- Diseñar planes y/o experimentos.

- Recolectar y analizar datos.

- Establecer conclusiones.

- Comunicar sus ideas y descubrimientos a otros.

- Hacer nuevas preguntas.

- Crear artefactos.

En los últimos años el aprendizaje orientado a proyectos es una de las líneas prioritarias de innovación de la Universitat Politècnica de València (UPV), teniendo ya impacto en algunas iniciativas Institucionales de escuelas, facultades y departamentos. En la Escuela Técnica Superior de Ingeniería de Edificación (ETSIE) son varias las asignaturas que de modo autónomo, tienen implantado este sistema de aprendizaje, siendo actualmente el Taller de Proyecto de Interiores una de ellas.

En los últimos años esta asignatura se ha reestructurado, orientándose por completo al aprendizaje a través de proyectos basados en casos reales, impulsándose de esta manera 
el aprendizaje autónomo del alumno; la búsqueda, selección e interpretación de la información; el desarrollo de habilidades; el debate crítico; y la exposición en público de los resultados, todo ello bajo la dirección de los profesores de la materia, que son quienes establecen el ritmo de trabajo. Por tanto, el objetivo de esta comunicación es mostrar la metodología seguida en la asignatura Taller de Proyecto de Interiores, que se imparte en el Grado en Arquitectura Técnica de la ETSIE (UPV), así como los resultados obtenidos por los alumnos tras el proceso de aprendizaje.

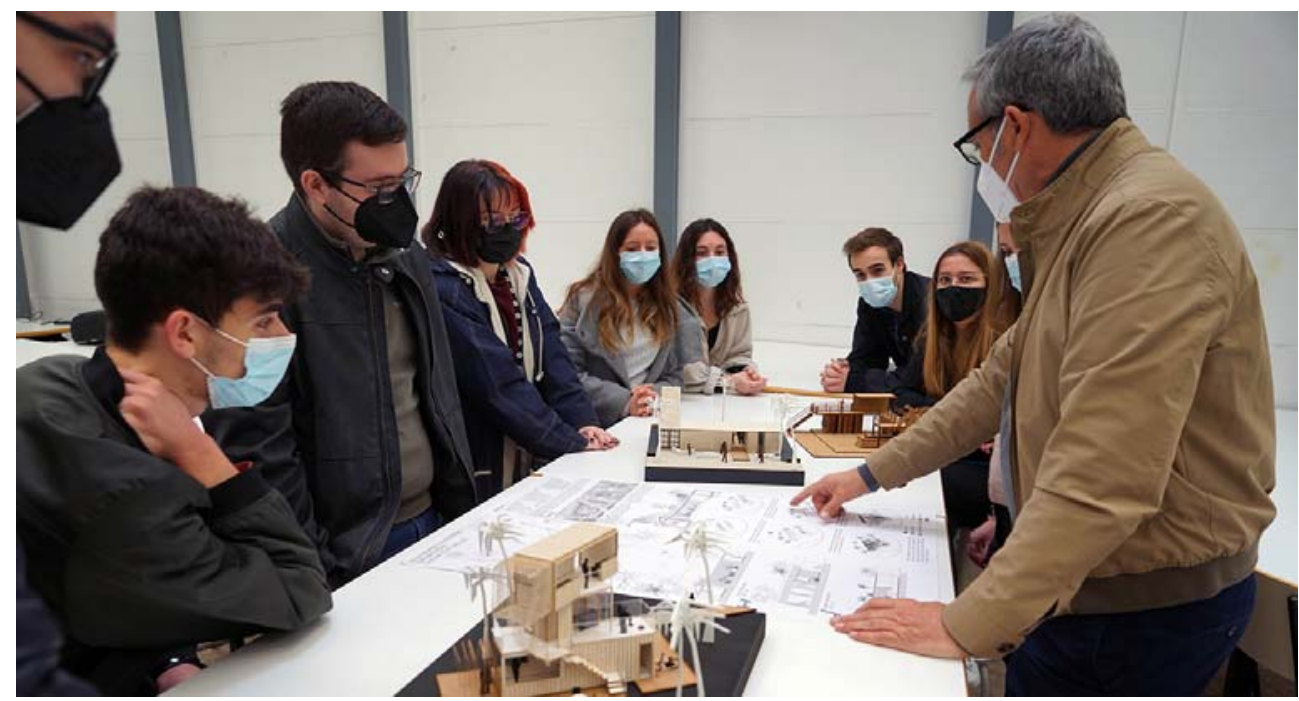

Fuente: Los autores (2020)

Fig. 1 Revisión y debate en el aula.

\section{El Taller de Proyecto de Interiores}

En el plan de estudios para la obtención del título de Arquitecto Técnico (UPV) de 1999 (BOE $n^{\circ} 235$, resolución de 2 de septiembre) aparece por primera vez la asignatura Arquitectura de Interiores. En su origen, se contempla como una materia optativa de 18 créditos ECTS, e incluye contenidos que se basan fundamentalmente en la elaboración de proyectos de diseño de interiores tanto en viviendas como en locales comerciales.

Tras la conversión a Bolonia de las titulaciones universitarias españolas, y con el paso al título de Grado en Arquitectura Técnica, esta materia se mantiene con carácter optativo como área de intensificación, con una carga docente de 12 créditos, de los cuales 6 son de tipo teórico y 6 práctico. La asignatura perteneciente al departamento de Expresión Gráfica Arquitectónica pasa a denominarse Taller de Proyecto de Interiores (TPI), impartiéndose en el octavo semestre de la titulación, junto al Trabajo Fin de Grado, situándose en el último semestre del Grado. En este sentido la formación constructiva y tecnológica adquirida en las distintas enseñanzas de los últimos cursos del Grado son una base fundamental para los estudiantes, aplicándolos de manera específica en el diseño de interiores. 
A través del Taller de Proyecto de Interiores se busca dar a conocer y poner en práctica los conocimientos y criterios de actuación que afectan a las competencias de la profesión regulada de Arquitecto Técnico, combinando para ello técnicas y procedimientos gráficos avanzados. El objetivo general de la asignatura es la optimización de las posibilidades funcionales, perceptivas y de confort para las diferentes formas de habitar, trabajar, relacionarse y comunicarse. El ámbito de aplicación contempla la intervención en el espacio arquitectónico tanto público como privado, y en esta última etapa de la asignatura también incluye el diseño de arquitecturas efímeras. La asignatura se estructura en seis unidades didácticas que son las siguientes:

1. Introducción al diseño de interiores.

2. El proyecto de interiores. Conceptos y procedimientos.

3. Metodología de representación.

4. Diseño de arquitecturas efímeras. Stands.

5. Diseño de espacios comerciales.

6. Diseño de reformas de viviendas.

En los últimos años la asignatura ha seguido una metodología activa centrada en el Aprendizaje Basado en Proyectos, en la que los estudiantes adquieren un rol activo, fomentándose la motivación académica. A lo largo del cuatrimestre y a partir del material generado por los profesores de la asignatura, se plantea la resolución de tres proyectos basados en casos reales, de manera que con su ejecución se garantice que los alumnos adquieren el conocimiento y las destrezas necesarias. Una vez planteado el caso a resolver, a lo largo de las siguientes sesiones se analizan y reflexionan en grupo las soluciones aportadas a medida que se avanza en el desarrollo del proyecto, relacionando conceptos que condicionan o determinan su funcionalidad y la percepción espacial del objeto proyectado en un lugar determinado por su contexto. En el ABP es fundamental la participación activa del alumnado, quien busca información, selecciona referentes, desarrolla sus ideas, las expone y las justifica, mientras que el profesorado, aunque orienta al alumno a lo largo del desarrollo del proyecto, adquiere un rol aparentemente menos activo, fomentando el debate y ayudando a alcanzar un consenso.

\subsection{Proyectos en los que se basa el aprendizaje en TPI.}

Desde el curso 2017-2018 en el Taller de Proyecto de interiores se vienen desarrollando tres proyectos. El primero de ellos busca introducir al alumno en el diseño de pequeñas estructuras, en las que tanto su función concreta como el material de construcción van a ser los principales requisitos que van a limitar su diseño. Para ello el proyecto contempla la construcción de una arquitectura efímera, que dará respuesta a las condiciones planteadas. La finalidad es fomentar la creatividad del alumno. El segundo proyecto consiste en el desarrollo de un proyecto de interiores para un espacio de uso comercial, en el que los alumnos que parten de un espacio definido por un elemento modular, deberán plantear su propuesta, diseñando todos los espacios necesarios para ello. En este caso, las limitaciones, además de por las necesidades del propio proyecto, vienen limitadas por el 
volumen del que se parte. Por último, el tercer proyecto plantea el proyecto de reforma interior de una vivienda. Aunque los ejemplos varían de unos años a otros, las condiciones generales se mantienen. En los siguientes apartados pasamos a describir cada uno de los tres proyectos.

\subsubsection{Proyecto 1. Arquitectura efímera}

En la primera tarea del Taller de Proyecto de Interiores el alumnado trabaja en el diseño de una arquitectura efímera, tridimensional y funcional. En este primer proyecto se ha venido planteando desde el diseño de un puesto de información turística con diferentes necesidades [Proyecto +INFO], hasta el diseño de un puesto de venta [Stand Market], o de un espacio expositivo [Proyecto 3D4EXPO]. Durante los cursos 2019-20 y 2020-21 se propuso esto último, el diseño de un espacio cuya finalidad era la de servir de expositor de los trabajos realizados por los propios alumnos, y que debía adaptarse a los entregables previstos, ya fueran en soporte papel (póster A1), como en formato tridimensional (maqueta). Por tanto, se trataba de un proyecto real, en el que todos los alumnos se involucraron con interés, puesto que en su proyecto se planteaba exponer su propio trabajo.
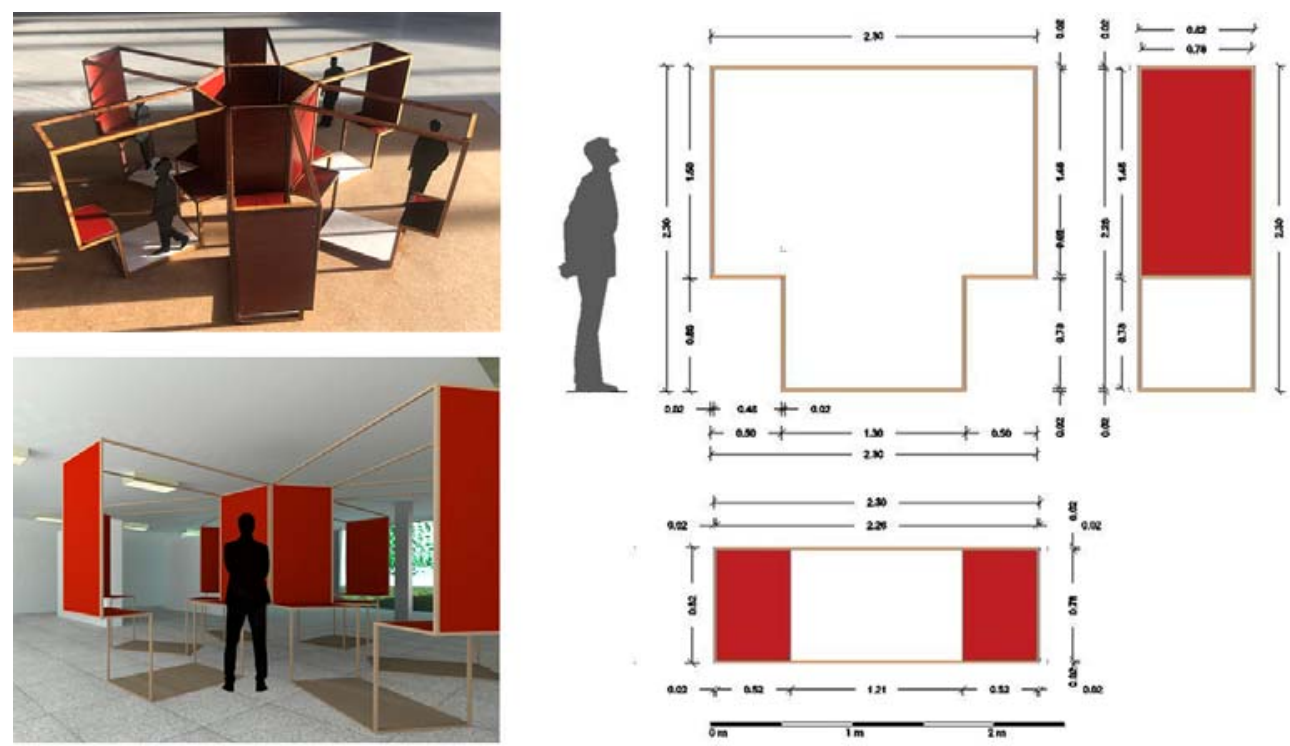

Fuente: Los autores (2020)

Fig. 2 Diseños de espacio expositivo. Proyecto "Tú decides", realizado por la alumna M. Chiara Fabbrica, curso 2019-20.

El proyecto se planteó a partir de una serie de objetivos que buscaban cumplir con un programa de necesidades determinado y que contemplaba entre otros, el número de exposiciones a determinar en función del número de proyectos realizados, el diseño del recorrido expositivo, así como el sistema de construcción, sujeción, o cualquier otro 
elemento necesario para llevarla a cabo. En todo momento se planteó la realización del diseño del proyecto empleando en su construcción materiales ligeros tales como paneles de madera contrachapada o DM, vigas y pies derechos de madera maciza, cartón, cajas, palets, lonas, cuerdas, cables, o moqueta en el suelo, a elección del alumno, primando en todo ello la economía de medios y el uso de material reciclado.

Una vez establecido el programa de necesidades y definido el material, se planteó la búsqueda de referentes de estilo. Para ello se partió del debate generado en clase a partir de algunas propuestas seleccionadas por los profesores y del dibujo de los primeros bocetos, a través de los que se iban plasmando las ideas. Las propuestas iniciales eran expuestas y debatidas por todos los participantes, valorando los pros y los contras a medida que se avanzaba en el desarrollo de la idea. A partir de la aceptación de la idea inicial, el alumno ya está en condiciones de preparar un anteproyecto, en el que la idea ya comienza a materializarse mediante software de diseño gráfico. En este sentido los alumnos son los que determinan qué herramientas quieren usar, eligiendo generalmente las más usadas; Autocad, Revit, Scketchup,... Las sesiones continúan todas ellas de tipo práctico, fomentándose el trabajo en equipo y la creación de sinergias entre los alumnos.

Despues de ser aceptado el anteproyecto se continua con la fase de desarrollo del proyecto, en la que el alumno va concretándolo tanto a nivel constructivo, como a nivel de materiales y despieces. Finalmente, el resultado incluye el desarrollo de la idea, la elección del material, la creación de los planos para su construcción (tanto bidimensionales como tridimensionales), y la construcción de una maqueta a escala 1:30. Todo el trabajo, desde la fase de la idea hasta el resultado final, se presenta resumido en un póster formato A1 que se entrega, junto a la maqueta, al finalizar el plazo establecido.

\subsubsection{Proyecto 2. Espacio comercial}

El segundo proyecto denominado STREET FOOD 2X40 es un proyecto de actividad, en el que se trabaja en esta ocasión con una estructura pre-existente. En este caso para la realización del proyecto se propone la reutilización de 2 contenedores marinos de tipo standard, de 40 pies equivalentes a 12 m., construidos en acero.
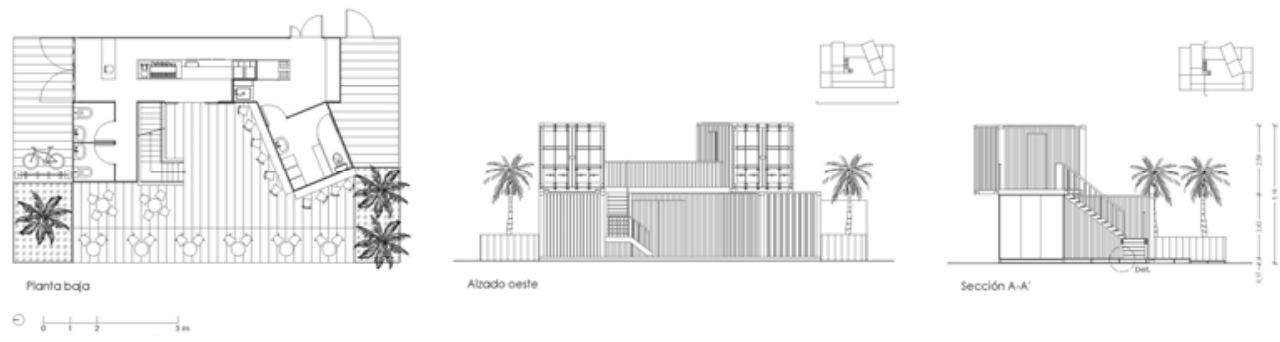

Fuente: Los autores (2020)

Fig. 3 Diseño de puesto de comida rápida. Proyecto "Street Food Arangina", realizado por el alumno Leandro Bontá, curso 2020-21. Planta baja, alzado principal y sección. 
A lo largo de los últimos cursos se han planteado diversas actividades, relacionadas todas ellas con la restauración. En el último proyecto se planteó el diseño de un Street Food que presumiblemente debía construirse en un lugar concreto de la ciudad de Valencia, estableciéndose de este modo la condición de su entorno.
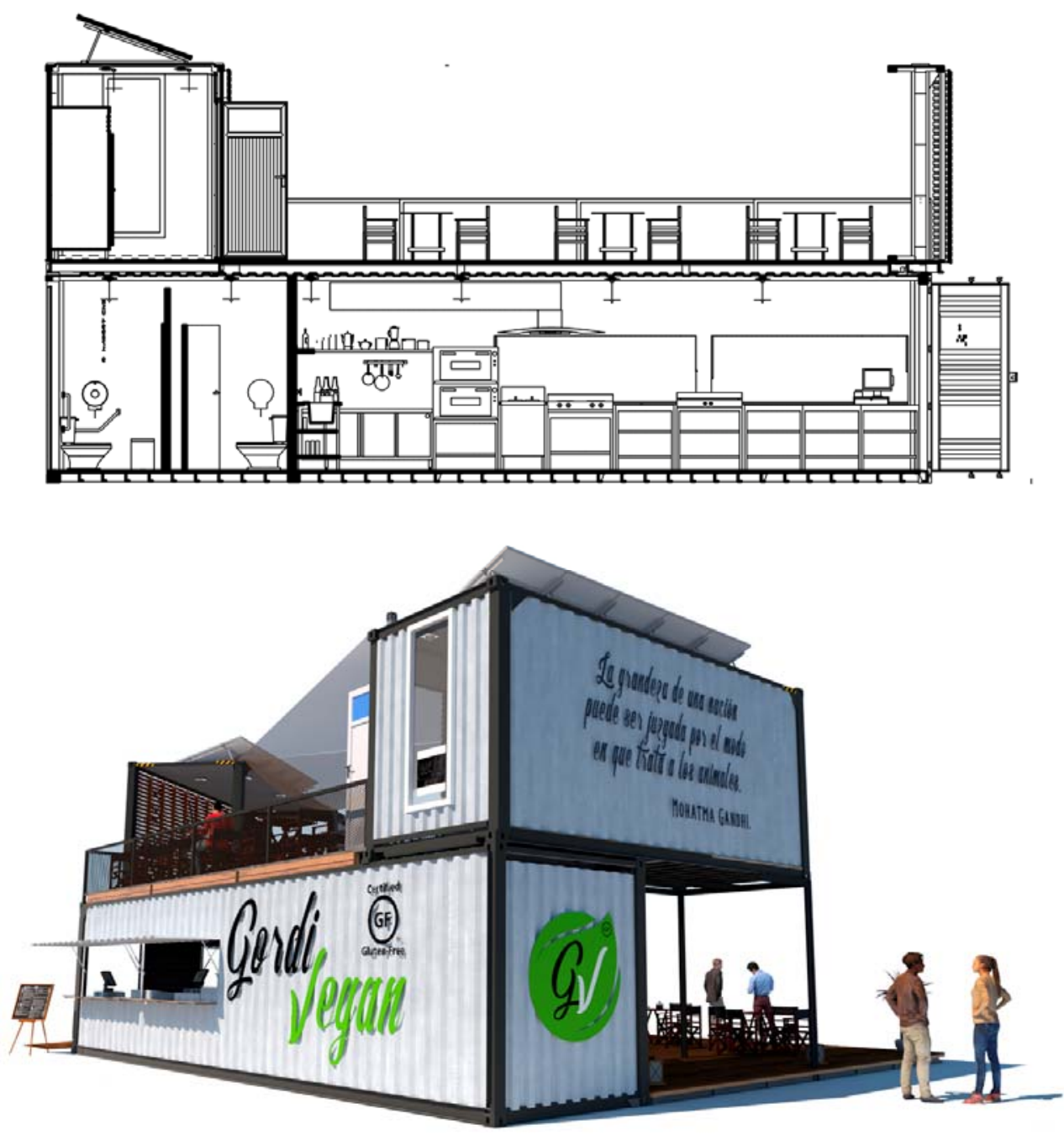

Fuente: Los autores (2020)

Fig. 4 Diseño de puesto de comida rápida. Proyecto "Street Food GV", realizado por el alumno Pablo Espinosa, curso 2019-20.

El objetivo del trabajo contemplaba desde la visita y análisis in situ del lugar donde se ubicaría el puesto de comida rápida, hasta el diseño de los diferentes espacios que 
cumplieran con el programa de necesidades previsto. Este programa, además de lo necesario para el Street Food, cuya tipología era establecida por el alumnado, debía contar con una barra de servicio, una cocina completa, dos aseos (que pueden ser químicos), un almacén y un vestuario con ducha. En la propuesta también se debía incluir la definición de la marca y la selección del emplazamiento idóneo para realizar la actividad, dentro del espacio fijado. Para la instalación del Street Food se permitía ocupar una superficie máxima de $175 \mathrm{~m}^{2}$. El proyecto de Street Food busca en todo momento la definición gráfica del puesto, tanto en lo referente al proceso creativo, como a los planos necesarios para su construcción, o las perspectivas necesarias para su correcta comprensión. Finalmente, este proyecto al igual que el anterior, contemplaba la entrega de un póster en formato A1 que recogiera el resumen del trabajo, y una maqueta a escala de la propuesta.

\subsubsection{Proyecto 3. Reforma de vivienda}

El tercer y último proyecto contempla la actuación sobre una vivienda existente. En el proyecto de interiores de la vivienda se plantean, además de la distribución de espacios, instalaciones, usos y el cumplimiento de las normas de habitabilidad, todo aquello que intervenga en el espacio interior: color, mobiliario, iluminación, revestimientos, materiales, acabados....

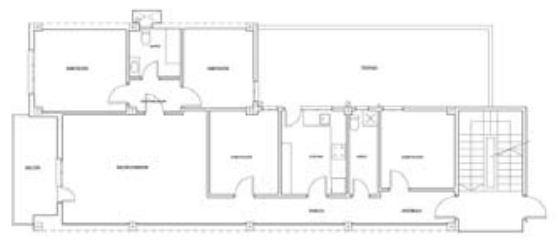

Estado actual

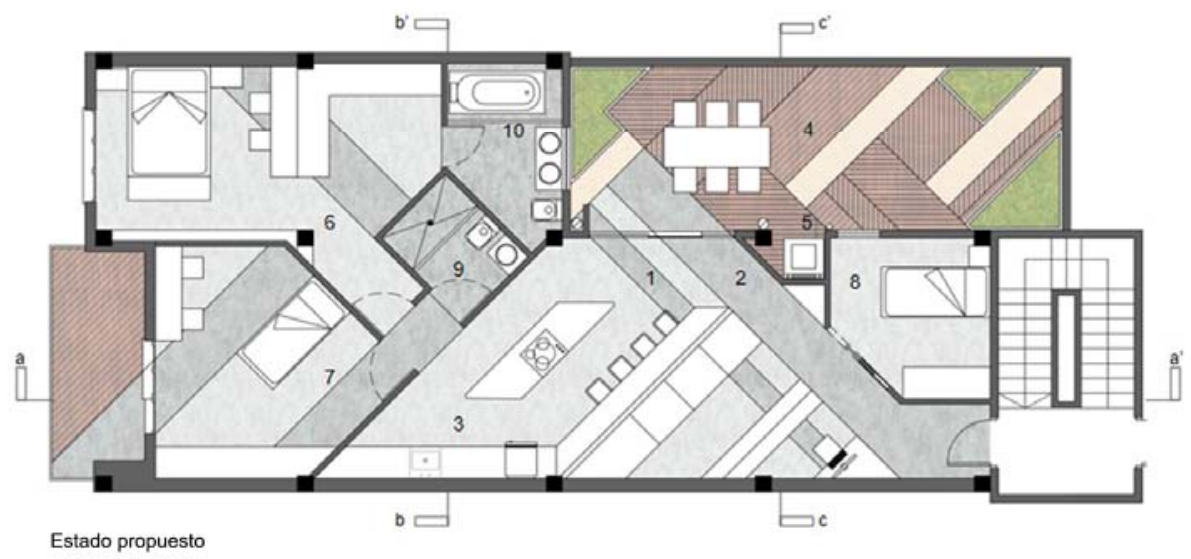

Fuente: Los autores (2020)

Fig. 5 Proyecto de interiores. Proyecto "Reforma 43", realizado por el alumno Aquiles Román Serrano, curso 2018-19. 
En este caso el objetivo fundamental del proyecto es aproximar al alumno al ámbito de los proyectos de reforma de interior de viviendas existentes. A partir de un programa de necesidades concreto el alumno debe elaborar un proyecto de reforma que incluye, en este caso, una breve memoria descriptiva, memoria constructiva, presupuesto y planos, además de alguna presentación gráfica tridimensional hiperrealista.
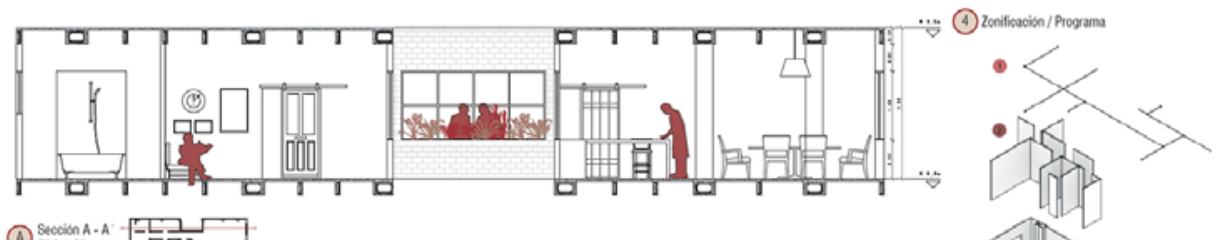

(A) ESC $1: 50^{-15}$ A
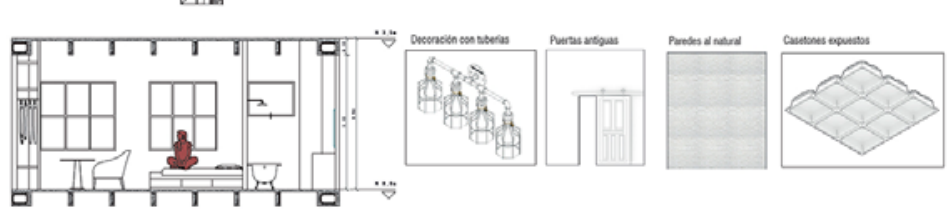

(B) Secoish B-8.
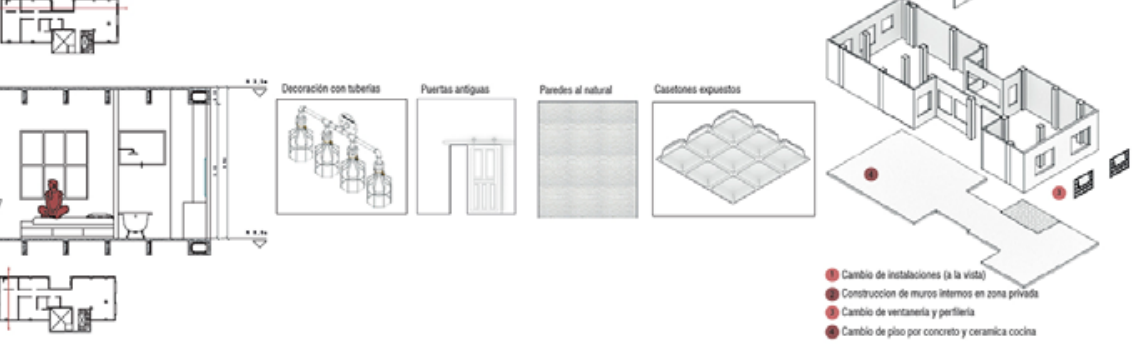

Fuente: Los autores (2020)

Fig. 6 Proyecto de interiores. Proyecto "Industrial Chic", realizado por la alumna Carolina Rojas Arbeláez, curso 2017-18. Secciones y propuesta de zonificación de espacios (derecha).

\section{Metodología y Evaluación}

En los tres casos el proceso a seguir en el estudio, análisis y elaboración del proyecto se basa en los siguientes ítems:

- Búsqueda de referentes.

- Concreción del programa de necesidades.

- Primeros bocetos.

- Propuesta. Anteproyecto. Es necesaria su aceptación para seguir con el proyecto.

- Desarrollo del proyecto. Concreción constructiva: materiales y despiece.

- Realización de planos (vistas bidimensionales y tridimensionales) y maqueta en su caso.

Semanalmente cada proyecto es revisado en clase llevando los profesores un seguimiento del trabajo realizado por el alumno. En las sesiones de clase se debate y se plantean propuestas, haciendo partícipe de este análisis a todos los alumnos.

Las entregas se organizan en tres fases:

$-1^{\text {a }}$ fase. Anteproyecto. Se revisa y se acepta. 
Implantación de la metodología del Aprendizaje Basado en Proyecto en la asignatura "Taller de Proyecto de Interiores" - Implementation of the Projetc-based Learning methodology in the "Interior Projects Workshop" lesson.

- $2^{a}$ fase. Entrega previa. Se presenta un póster $A 1$ en papel $(B N)$, que se revisará, corregirá y en su caso será aceptado para la siguiente fase.

- $3^{a}$ fase. Entrega definitiva, que comprende: maqueta a escala (según el proyecto) y un póster en formato $A 1$.

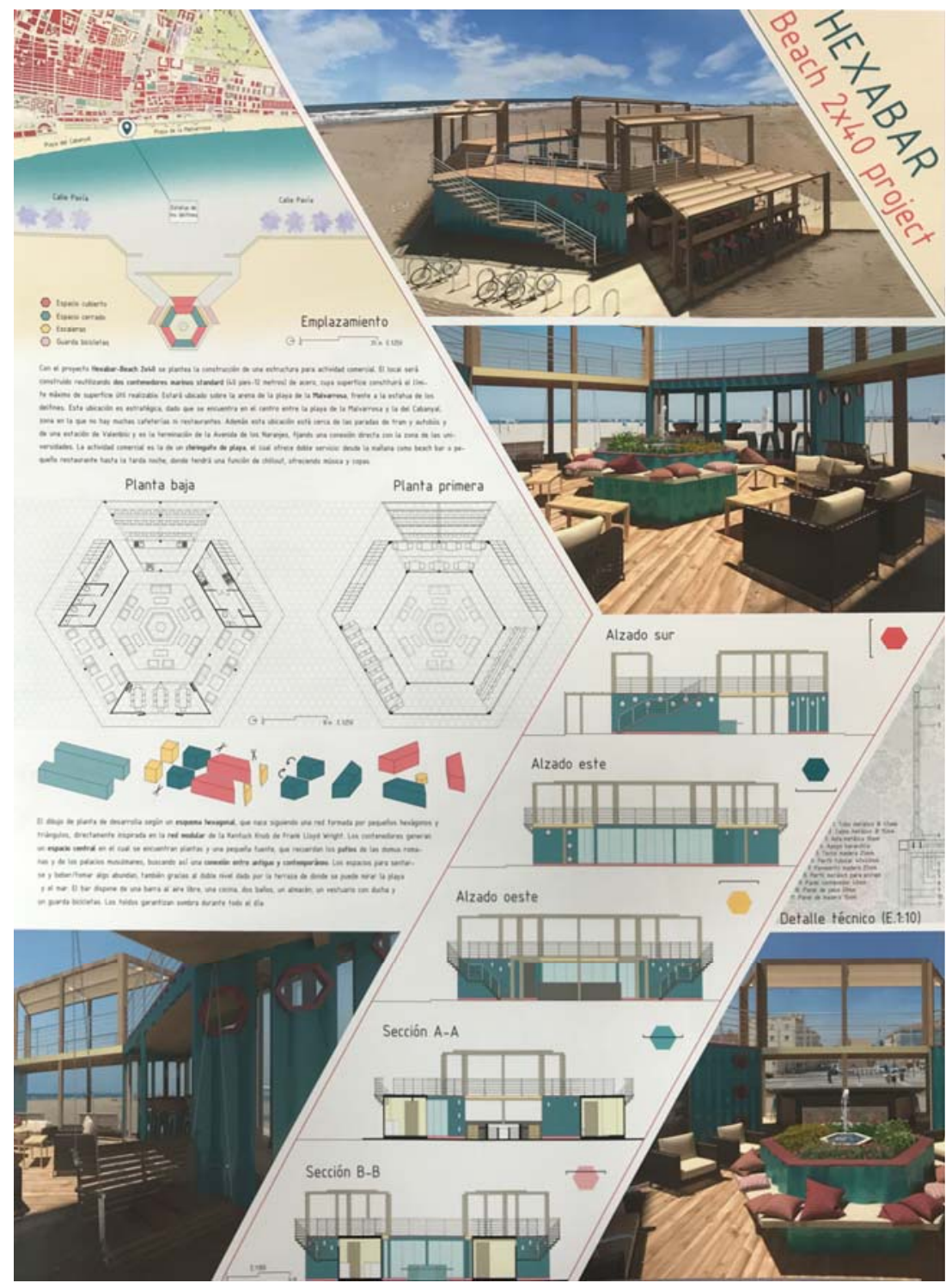

Fuente: Los autores (2020)

Fig. 7 Proyecto "Beach 2x40", realizado por el alumn Gianmarco Sartori, curso 2018-19. 


\section{[ +INFO ]}

$(+$ INFO $]$ er un pabellón ubicado en la marina de Valenoia que sirve ocomo puesto de

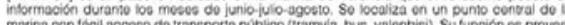

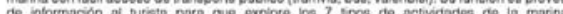
Gastronomia y Ocio, Nautica, Formación o innovación, Cultura y Creatividad, Patrimenio, Servicion nauticos y Actividades Náuticas.

\section{SITUACIÓN}

- liness de traneporte

$\frac{1}{2}$ Playe + info]

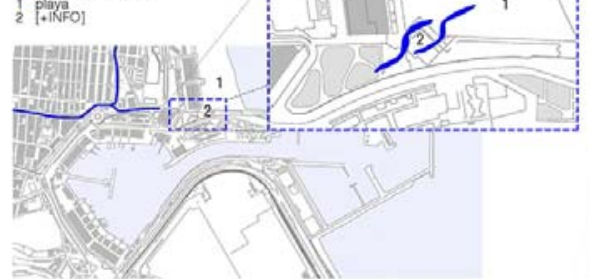

DISEÑO

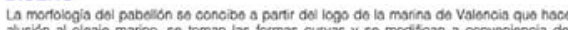

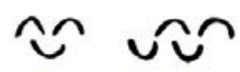

LOGO

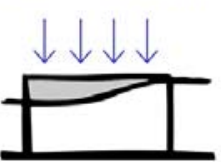

PLANTAS

El pabolibn ouanta con una zona interior y una oxtonior para quo $600 \mathrm{~s}$ cill las $24 \mathrm{hrs}$ dol dita

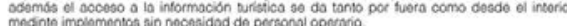
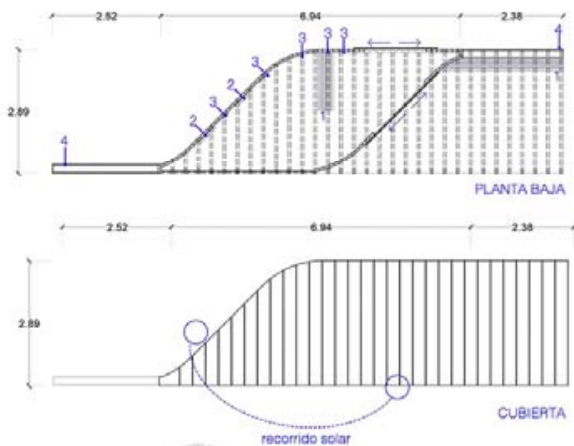

CUBIERTA
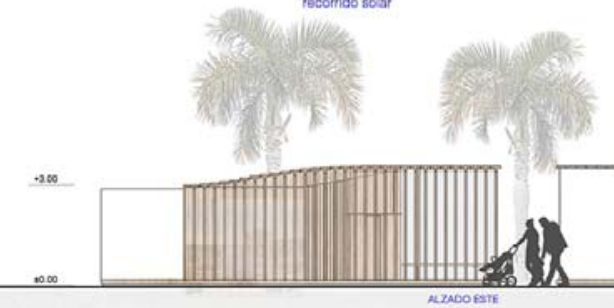

Fuente: Los autores (2020)

Fig. 8 Proyecto “+ INFO”, realizado por Denisse Andrea Reyes Álvarez, curso 2017-18. 
La evaluación de los proyectos se realiza a través de rúbricas diseñadas exprofeso para cada uno de los proyectos. En todos ellos se tienen en consideración los siguientes apartados:

- Criterios y conceptos generales de diseño.

- Criterios y conceptos tecnológicos: Viabilidad de la propuesta. Aspectos constructivos y normativos. Selección de materiales.

- Aspectos comunicativos y de presentación de la propuesta: Calidad gráfica de la representación. (Valores de línea, tramas / revestimientos, 3D, sombras, cotas, cuadro de carpinterías, superficies / renders.)

- Presentación oral de la propuesta.

\section{Resultados y conclusiones}

El ABP permite afrontar el estudio de la materia a través del desarrollo de proyectos diseñados para aproximar al alumno a la realidad profesional. La preparación del material de partida requiere de un diseño adecuado, que incluya todo lo necesario para que el alumno pueda desarrollar su proyecto con total garantía, evitando que caiga en el exceso de trabajo o incluso en la frustración por no alcanzar el resultado deseado en el tiempo previsto. El hecho de ser casos reales, y de trabajar por objetivos que han de desarrollar semanalmente, en los que es muy importante la puesta en común, hace que se active notablemente la participación y cooperación, despertando rápidamente un gran interés por la materia, y por mejorar la calidad de sus resultados. En este sentido hemos observado que la puesta en común de los trabajos y el hecho de comentarlos públicamente favorece el interés del alumnado por el uso de software avanzado de diseño gráfico, mejorando notablemente sus resultados individuales. Todo ello se ve favorecido por la comunicación transversal y por la obligatoriedad de la exposición y debate público final.

Quizá el mayor inconveniente es que para el correcto avance en el conocimiento de la materia es fundamental que los alumnos asistan a clase de manera continuada, ya que se trata de una metodología activa que se apoya en un aprendizaje continuo, fruto de la propia experiencia de los alumnos, de los debates y de las puestas en común, pero también de las explicaciones de los profesores que se van desarrollado a media que se van exponiendo las ideas y se van resolviendo las dudas.

Finalmente, desde que en el curso 2017-18 se implantara la metodología del ABP en la asignatura TPI hemos detectado un aumento en las calificaciones de los alumnos, tal y como se desprende del análisis del porcentaje de aprobados sobre los presentados que vemos en el gráfico 1, en el que se observa cómo en los últimos años el porcentaje de alumnos situados en el rango de calificaciones Matrícula de Honor- Excelente ha alcanzado sus valores mas altos, lo que demuestra la alta implicación y motivación de los alumnos por obtener unos buenos resultados. 


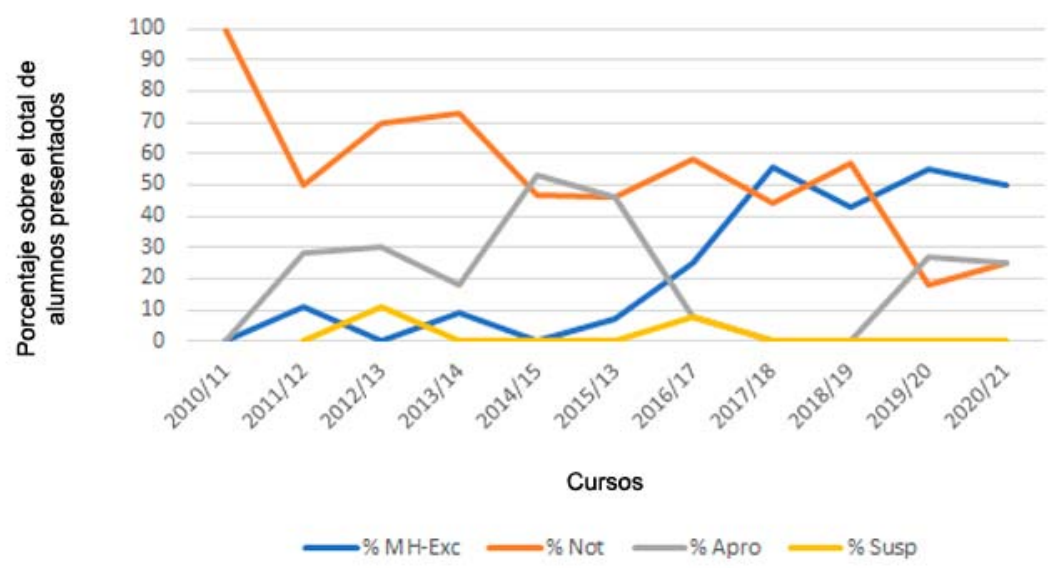

Fuente: Los autores (2020)

Fig. 9 Gráfico en donde se muestra el procentaje de calificaciones sobre el total de alumnos presentados desde el curso 2010-11 hasta el curso 2020-21.

\section{Referencias}

Aprendizaje orientado a proyectos. Servicio de Innovación Educativa. Universidad Politécnica de Madrid. Disponible en: https://innovacioneducativa.upm.es/guias/AP_PROYECTOS.pdf

Blumenfeld, Pc., Soloway, E., Marx, Rw., Krajcik, Js., Guzdial, M., y Palincsar, A. (1991). "Motivating Project Based Learning: sustaining the doing, supporting the learning" en Educational Psychologist. 1991, 26 (3 \& 4), pp. 369-398.

El método de proyectos como técnica didáctica. Dirección de Investigación y Desarrollo Educativo Vicerrectoría Académica, Instituto Tecnológico y de Estudios Superiores de Monterrey. Disponible en:http://sitios.itesm.mx/va/dide2/documentos/proyectos.PDF

Knoll, M. (1997). "The Project Method: Its Vocational Education Origin and International Development" en Journal of Industrial Teacher Education. 1997, v34, n 3 , p59-80.

La metodología del ABP como recurso didáctico. Disponible en: http://didactia.grupomasterd.es/blog/numero-12/metodologia-aprendizaje-basado-en-proyectos-abp

Wilkinson, C. (1977). "The new professionalism in the Renaissance" en Kostof, S. (Ed.), The architect. Chapters in the history of the profession. New York: Oxford University Press. pp. 124-160. 


\title{
EDIFİCATE
}

I Congreso de Escuelas de Edificación y Arquitectura Técnica de España

València, 4 y 5 de noviembre de 2021

Escuela Técnica Superior de Ingeniería de Edificación

Universitat Politècnica de València

Doi: https://doi.org/10.4995/EDIFICATE2021.2021.13566

\section{Evolución del plan de empresa en edificación como metodología docente de Aprendizaje basado en Proyectos. \\ Evolution of the building business plan as a Project-based Learning teaching methodology.}

\author{
Igor Fernández-Plazaola ${ }^{a}$ \\ aiplazaola@doe.upv.es, \\ Departamento de organización de empresas, Escuela Técnica Superior de Ingeniería de Edificación, \\ Universitat Politècnica de València.
}

\begin{abstract}
Getting and keeping the students of Educational Institutions (EI) committed and motivated constitutes a great challenge for teachers. Despite the idiosyncrasy and diversity of students and study plans, research shows that there are certain practices that encourage greater student participation. These practices encourage moving away from uniform mechanical and rote teaching to a more constructively focus with more intriguing, challenging, and complex tasks. Use an interdisciplinary approach rather than one per area or subject and encourage cooperative work. Project-based learning (PBL) incorporates all of these principles.

This article shows the integration and implementation of PBL in a case of specific application to the subject of "Economics" at Escuela Técnica Superior de Ingeniería de Edificación of the Universitat Politècnica de València. The work includes the methodology used to develop a complete project of "Business Plan" associated with the building sector, and the implementation of the knowledge acquired throughout the project process.

The results show that the use of PBL procedures and methodologies considering the student as the protagonist of their own learning, help to bring closer and focus the area of knowledge of economics to the intellectual affinities of students of the Building Engineering degree.
\end{abstract}

Keywords: Project based learning, Business plan, Economics 


\section{Resumen}

Motivar a los estudiantes constituye un gran reto para los docentes. A pesar de la diversidad de alumnos y planes de estudios, la investigación evidencia que existen ciertas prácticas que estimulan una mayor participación de los estudiantes. Estas prácticas fomentan dejar de lado la enseñanza mecánica y memorística uniforme para, de manera más constructivista, enfocarse en un trabajo más desafiante y complejo; utilizar un enfoque interdisciplinario en lugar de uno por área o asignatura y estimular el trabajo cooperativo. El aprendizaje basado en proyectos $(A B P)$ incorpora estos principios.

El presente artículo muestra la integración e implementación de $A B P$ en un caso de aplicación concreta a la asignatura de "Economía" en la Escuela Técnica Superior de Ingeniería de Edificación de la Universitat Politècnica de València. El trabajo recoge la metodología empleada para desarrollar un proyecto completo de "Plan de empresa" asociado al sector de la edificación, y la implementación de los conocimientos adquiridos a todo el proceso del proyecto.

Los resultados muestran que el uso de metodologías $A B P$ considerando al estudiante como protagonista de su propio aprendizaje, ayudan a acercar el área de conocimiento de economía a las afinidades intelectuales de los estudiantes del grado de Ingeniería de Edificación.

Palabras clave: Aprendizaje basado en projectos, Plan de empresa, economía. 


\section{Introducción}

En el proceso de adaptación de nuestro sistema educativo al Espacio Europeo de Educación Superior (EEES), un aspecto que cobra gran importancia es el cambio que se está impulsando desde modelos basados en la enseñanza hacia modelos basados en el aprendizaje (Carmiña, 2003) (Barrows, 1980), entre los que ocupa una posición destacada el aprendizaje basado en problemas o proyectos ABP. Mediante la metodología ABP, el aprendizaje se produce como resultado del diseño y desarrollo de proyectos por parte del alumnado. En este modelo lo fundamental es el aprendizaje que se produce en el proceso de elaboración del proyecto, y no tanto el resultado obtenido en términos de la calidad del proyecto realizado. La aplicación del método ABP requiere un exhaustivo diseño previo del programa de actividades que los estudiantes deben abordar, tanto dentro como fuera de clase, y permite realizar un adecuado seguimiento del grado de consecución de los objetivos formativos planteados, en términos de las habilidades y competencias adquiridas por el alumnado. Por ello resulta especialmente adecuado a la hora de adoptar el sistema European Credit Transfer System (ECTS) (Valero Garcia \& Navarro Guerrero, 2008) definido en el proyecto de convergencia europea para alcanzar el EEES.

Actualmente el ABP representa uno de los métodos docentes más adecuados para los nuevos modelos de educación superior basados en el aprendizaje (Woods, Felder, Rugarcia, \& Stice, 2000). En él, el alumnado, desempeñan un papel activo en su propio aprendizaje, asumiendo la responsabilidad de este y bajo la supervisión de un pre tutor. Mientras que en el modelo tradicional de enseñanza, el profesorado expone primero la información y posteriormente busca su aplicación en la resolución del problema, en el método ABP se presenta el problema, se identifican las necesidades de aprendizaje por parte del alumnado, se busca la información necesaria para la resolución del problema y finalmente el proyecto se soluciona. En este método tienen vital importancia tanto la adquisición de conocimientos como el desarrollo de habilidades, actitudes, valores y competencias.

La metodología ABP plantea las siguiente etapas:

- Lectura y análisis del escenario del problema.

- Realización de lluvias de ideas.

- Listado de los temas conocidos.

- Listado de los temas desconocidos.

- Listado de las tareas necesarias para resolver el problema

- Definición del problema.

- Obtención de la información.

- Presentación de resultados.

En el presente trabajo se va a mostrar la experiencia de implementación de la metodología ABP a la asignatura de "Economía" de la Escuela Técnica Superior de Ingeniería de Edificación (ETSIE) de la Universitat Politècnica de València (UPV). La evolución a nivel de plan de estudios que esta asignatura ha tenido se muestra en las tablas 1 y 2 . Estas indican 
su conversión de la antigua Arquitectura Técnica al actual Grado de Ingeniería de Edificación.

Tabla 1: Distribución de créditos de la asignatura de Economía.

\section{PLAN 2008/2009}

ECONOMÍA APLICADA 6 créditos (60 h presenciales)

Teoría de aula 4.2 créditos (42 h presenciales)

Prácticas 1.8 créditos (18 h presenciales)

Prácticas evaluables y no evaluables de base teórica.

Tabla 2: Distribución de créditos de la asignatura de Economía.

\begin{tabular}{c|c|c}
\hline \multicolumn{3}{c}{ PLAN 2009/2010 } \\
\hline ECONOMÍA 7.5 créditos ECTS $(206.25 \mathrm{~h})$ \\
\hline Teoría de aula 3.75 ECTS (103.125 h) & \multicolumn{2}{c}{ Prácticas 3.75 ECTS (103.125 h) } \\
\hline & $\begin{array}{c}\text { Prácticas Teóricas } \\
1.875 \text { ECTS }(51.56 \mathrm{~h})\end{array}$ & $\begin{array}{c}\text { Prácticas Tareas } \\
1.875 \text { ECTS }(51.56 \\
\mathrm{h})\end{array}$ \\
\cline { 2 - 3 } & $\begin{array}{c}\text { Evaluables y no } \\
\text { evaluables de base } \\
\text { teórica. }\end{array}$ & $\begin{array}{c}\text { Tareas prácticas } \\
\text { asociadas a la teoría } \\
\text { impartida }\end{array}$ \\
\cline { 2 - 3 }
\end{tabular}

El alumnado del grado en Arquitectura Técnica han considerado tradicionalmente esta asignatura, a pesar de ser troncal, lejana a su ámbito de actuación profesional, de aplicación efímera o incluso nula. Este posicionamiento del alumnado frente a la materia plantea una barrera inicial que hay que salvar. Es cierto que en estos últimos años y debido a la coyuntura económica el interés por la asignatura en el entorno Politécnico que nos rodea ha sido notablemente creciente y es algo que el profesorado vive día a día. Ahora bien, incluso de esta manera se detectaba una falta de interés inicial del alumando hacia este tipo de área de conocimiento la cual consideran periférica a sus futuras atribuciones.

En el presente trabajo vamos a describir el desarrollo de esta actividad en la ETSIE de la UPV durante el curso lectivo 2020/2021. El proyecto de implantación se realizó en el curso 2011/2012 con el alumnado de primero durante el primer semestre de docencia y desde entonces la asignatura ha ido realizando diversos ajustes para mejorar los resultados. Para alcanzar los objetivos propuestos se consideró interesante la utilización de la metodología del aprendizaje basado en proyectos, porque brinda unas herramientas a priori idóneas para los objetivos planteados. Por todo ello en el curso 2011/2012 se plantearon modificaciones en la asignatura, que pasaría de tener prácticas basadas en problemas teóricos consecuencia directa del temario impartido, a buscar una actividad que generara la posibilidad de alcanzar los objetivos iniciales. 


\section{Desarrollo}

\subsection{Bases y objetivos}

En el marco de todo lo expuesto anteriormente, la asignatura de "Economía" objeto del estudio, es una troncal de primero de la ETSIE de la UPV. La asignatura se inscribe en el primer cuatrimestre del primer curso de la titulación, y consta de 7.5 ECTS, lo cual implica que (según los criterios UPV) el alumnado tiene 206.25 horas de dedicación, tanto presencial como trabajo propio de toda índole tanto individual como grupal o bien tutorizado. La distribución y peso de cada una de las partes en las que se encuentra subdividida la asignatura lo podemos ver en la Tabla 3.

Tabla 3: Distribución de créditos de la asignatura de Economía.

\section{PLAN 2020/2021}

ECONOMÍA 7.5 créditos ECTS (206.25 h)

Teoría de aula 3.9 ECTS (107.25 h)

Prácticas 3.6 ECTS (99 h)

Prácticas Teóricas $\quad$ Prácticas Tareas

1.8 ECTS $(49.5 \mathrm{~h}) \quad 1.8$ ECTS $(49.5 \mathrm{~h})$

Evaluables y no Proyecto ABP evaluables de base teórica.

Siguiendo los preceptos del Libro Blanco de Ingeniero de Edificación (ANECA, 2005) y con la intención de conseguir las destrezas y competencias consensuadas en el mismo tanto para el ámbito académico como para el profesional, la unidad docente plantea los siguientes objetivos genéricos en la asignatura:

- Conocimiento adecuado del concepto de empresa, su marco institucional, modelos de organización, planificación, control y toma de decisiones estratégicas en ambientes de certeza, riesgo e incertidumbre; sistemas de producción, costes, planificación, fuentes de financiación y elaboración de planes financieros y presupuestos.

- Capacidad para organizar pequeñas empresas y de participar como miembro de equipos multidisciplinares en grandes empresas.

- Saber aplicar sus conocimientos a su trabajo o vocación de una forma profesional y poseer las competencias que suelen demostrarse por medio de la elaboración y defensa de argumentos y resolución de problemas dentro del área de estudio.

- Capacidad de reunir e interpretar datos relevantes para emitir juicios que incluyan una reflexión sobre temas relevantes de índole social, científica o ética.

- Capacidad de transmitir información oral y escrita en la lengua nativa: ideas, problemas y soluciones a un público tanto especializado como no especializado. 
Con todo ello y en la búsqueda de conseguir los objetivos anteriormente mostrados, la unidad docente se planteó la posibilidad de aplicación de las metodologías ABP. Se consideró que esta metodología resultaba apropiada para conseguir los objetivos planteados y para ayudar a la conversión de enfoques que el EEES y la declaración de Bolonia (European Ministers Responsible for Higher Education, 2012) exigían en la búsqueda del esfuerzo y aprendizaje del alumno para que desarrollen competencias que sustenten su empleabilidad.

En este ámbito se comenzó planteando los objetivos específicos perseguidos con la implantación de la nueva metodología consistentes en:

- Profundizar en los conocimientos teóricos de la asignatura.

- Conseguir una mayor afinidad hacia el área concreta de conocimiento por parte de los estudiantes.

- Acercamiento de los conceptos económico-teóricos a la realidad de la futura profesión.

- Conocimiento de la realidad empresarial del sector industrial afín a sus estudios.

- Fomentar el emprendedurismo.

- Capacidad de transformar la materia de lo teórico en palpable y funcional.

- Fomentar la capacidad de síntesis y organización de ideas.

- Favorecer el pensamiento creativo.

- Inculcar el trabajo en grupo y en equipo.

- Impulsar la búsqueda de información fiable y el aprendizaje pro-activo.

- Alcanzar un nivel óptimo de expresión y presentación de informes.

Las reflexiones mantenidas en la unidad docente plantearon una serie de actividades diversas que tuvieran la entidad de proyectos con la duración adecuada a la carga lectiva que la asignatura planteaba de 49.5 horas. Finalmente se tomó la decisión de plantear al alumando el desarrollo de un "Plan de Negocio" real y válido a nivel profesional. El único condicionante que se exigió a la hora de la realización del plan de negocio, fue que se tratara de la fundación de una empresa del sector de la edificación o con una vinculación directa con este. Con ello se pretendía fundir la teoría de aula con la aplicación práctica de los contenidos y enmarcarlo todo en el contexto del sector de la construcción en el que el alumno se iba a ver inmerso en un plazo de unos cuatro años.

\subsection{Estructura y bloques temáticos}

La estructura del plan de empresa ha ido variando a lo largo de los años desde su implantación en el año 2011. La tendencia ha sido reducir y focalizar el número de horas dedicadas al proyecto y concentrar su desarrollo temporalmente para evitar la dispersión del alumnado detectada los primeros años. En el presente curso lectivo 2020/2021 la asignatura se ha estructurado en 6 sesiones presenciales de 3 horas de duración. Esto supone que el alumnado tenía una carga presencial de 18 horas y el resto del trabajo tanto 
de grupo como individual o tutorizado debía responder a una carga de 31.5 horas. La evolución y distribución de las distintas sesiones ha sido la mostrada en la tabla 4.

Tabla 4: Planificación de sesiones del proyecto.

\begin{tabular}{|c|l|c|c|}
\hline \multicolumn{2}{|c|}{ PROYECTO PLAN DE NEGOCIO 2011/2012 } & \multicolumn{2}{c|}{ DEDICACIÓN (en horas) } \\
\cline { 2 - 3 } & PRESENCIAL & PROPIAS \\
\hline \multirow{5}{*}{} & Sesión 01 Introducción & 1.5 & 1 \\
\cline { 2 - 3 } & Sesión 02 El mercado de bienes inmuebles 01 & 1.5 & 1.5 \\
\cline { 2 - 4 } & Sesión 03 El mercado de bienes inmuebles 02 & 1.5 & 1.5 \\
\cline { 2 - 4 } PLAN DE & Sesión 04 Teoría Microeconómica construcción & 1.5 & 2 \\
\cline { 2 - 4 } & Sesión 05 Teoría Macroeconómica construcción & 1.5 & 2 \\
\cline { 2 - 4 } & Sesión 06 Idea de negocio & 1.5 & 2 \\
\cline { 2 - 4 } & Sesión 07 Plan de gestión & 1.5 & 2 \\
\cline { 2 - 4 } & Sesión 08 Análisis de mercado & 1.5 & 2 \\
\cline { 2 - 4 } & Sesión 09 Plan económico financiero & 1.5 & 2 \\
\cline { 2 - 4 } & Sesión 10 Plan de marketing & 1.5 & 2 \\
\cline { 2 - 4 } & Sesión 11 Trámites burocráticos & 1.5 & 2 \\
\cline { 2 - 4 } & Sesión 12 Revisión y normas de presentación & 1.5 & 3 \\
\cline { 2 - 4 } & Sesión 13 Exposición final & 1.5 & 3 \\
\cline { 2 - 4 } & Sesión 14 Entrega & 21 & 30 \\
\hline
\end{tabular}

\begin{tabular}{|c|l|c|c|}
\hline \multicolumn{2}{|c|}{ PROYECTO PLAN DE NEGOCIO 2020/2021 } & \multicolumn{2}{c|}{ DEDICACIÓN (en horas) } \\
\cline { 3 - 4 } & PRESENCIAL & PROPIAS \\
\hline \multirow{4}{*}{ PLAN DE } & Sesión 01 Introducción + Idea de negocio & 3 & 3 \\
\cline { 2 - 4 } EMPRESA & Sesión 02 Plan de gestión & 3 & 6 \\
\cline { 2 - 4 } & Sesión 03 Análisis de mercado & 3 & 6 \\
\cline { 2 - 4 } & Sesión 04 Plan de marketing & 3 & 6 \\
\cline { 2 - 4 } & Sesión 05 Plan económico financiero & 3 & 6 \\
\cline { 2 - 4 } & Sesión 06 Exposición final & $\mathbf{1 8}$ & $\mathbf{3 1 . 5}$ \\
\hline \multicolumn{2}{|c|}{ TOTALES } & & \multicolumn{2}{|c|}{} \\
\hline
\end{tabular}

Como se puede observar en la planificación de la tabla 4 el grueso del trabajo ha sufrido una evolución evidente, inicialmente se dividía en 2 bloques importantes bastante diferenciados. Un primer bloque denominado estudio del sector, y un segundo bloque denominado plan de empresa. El conjunto de los 2 bloques conjuga el proyecto completo de plan de negocio. El primer bloque de estudio del sector consistía en situar al alumno en el sector en el cual se enmarca su futuro ámbito de actuación profesional. El objetivo es que el alumno averiguase los condicionantes del sector, las grandes cifras económicas del mismo, los movimientos históricos y su importancia en el conjunto de la economía global y familiar. El segundo bloque consistía en el plan de empresa propiamente dicho en el que desarrollaban el proyecto de empresa que querían formar. Llegados a este punto, y tras haber acabado el estudio del sector y tener una idea global del mismo el alumnado debía elegir qué tipo de empresa querían fundar, los únicos condicionantes que se les imponían es que fueran empresas del sector específico de la construcción o afines. A la hora de 
elegir el tipo de empresa o negocio, no se imponía ningún otro condicionante de tamaño o localización o ni siquiera de tipo económico. Con el paso de los años el primer bloque ha sido integrado dentro de la parte teórica de la asignatura para conseguir un trabajo que no se dilatara tanto en el tiempo y que fuera un proyecto más puntual y no una actividad de todo el cuatrimestre.

Gran parte del éxito de la metodología consiste en conseguir el motor de inicio y enganche para el alumnado tal y como propone la metodología base (Stepien \& Gallagher, 1993). En el caso del presente trabajo se decidió plantear al alumnado que en la actual situación de incertidumbre, y teniendo en cuenta los históricos de las variables económicas más importantes del sector, así como la reciente y muy presente crisis económica mundial una posibilidad alentadora y cada vez más aceptada socialmente es la creación de empresas y el fomento del emprendedurismo. Todo ello planteó una situación de inicio muy favorecedor, ya que generó una discusión interna en el grupo y situó al alumno en predisposición de iniciar la actividad.

El tamaño medio de grupo con el que se realizaron las practicas es el mismo que el de la parte teórica de la asignatura, siendo aproximadamente de 40 alumnos. Para la realización de los proyectos el trabajo era en grupo y se permitían formaciones de 3 o 4 componentes. La formación del grupo y elección de los componentes era responsabilidad única y exclusiva del alumnado, lo que da pie a grupos por afinidad y amistad (contrario a la vida real), sin embargo les hace más responsables a la hora de conseguir un funcionamiento correcto y duradero del grupo de trabajo.

\subsection{Sesiones}

Las sesiones se desarrollaron en el mismo entorno de aula que las sesiones teóricas. Se trata de aulas con tarima elevada en la zona de pizarra y ordenador con todos los programas necesarios y conexión a internet, éste cuenta con un proyector y salidas de audio y video integradas en el aula. La zona del alumnado se compone de mesas para cuatro personas realmente pesadas con sillas individuales e independientes del resto del mobiliario. En algún caso las mesas se encontraban fijas al suelo, no permitiendo el libre movimiento de las mismas.

La planificación temporal del proyecto se encuentra en todo momento ligada a la parte teórica de la asignatura, de manera que todo el bagaje teórico pueda ser empleado para solucionar las dificultades del proyecto. De esta manera se consigue un mayor poso y aplicabilidad de los conocimientos. La teoría va en todo momento por delante de la práctica.

Durante la primera sesión se expuso toda la información necesaria para el desarrollo completo de la actividad. El alumnado no sólo recibe, sino que ellos mismos establecen que el emprededurismo y el auto-empleo resultan una alternativa muy interesante en su futuro cercano. Con esto conseguimos plantar una semilla inicial con fuerza que plantea retos y tiene la complejidad suficiente para la realización del proyecto, tal como plantean las teorías del ABP. En la primera sesión el alumno recibe también la completa metodología, 
seguimiento y control del proyecto completo y su integración con la parte teórica de la asignatura.

En el resto de sesiones la dinámica consiste en una primera parte teórica de duración variable de entre 20 a 60 minutos y una posterior puesta en común con cada uno de los grupos de manera individualizada entre el profesor y los componentes de cada grupo durante el resto de la clase. La teoría elegida para cada sesión se escoge en base a las necesidades previstas inicialmente por el profesorado, así como a las que el propio alumno plantea a lo largo del transcurso del proyecto. Las carencias teóricas que solicitó paliar el alumnado fue la falta de conocimientos del entorno y estructura del sector empresarial, el conocimiento de los agentes del mercado y la búsqueda de información de fuentes fiables.

De forma genérica, la metodología seguida para las clases fue:

- Recordatorio y resumen de la anterior clase.

- Presentación inicial del tema a tratar y establecimiento de los objetivos a conseguir en el día.

- Repaso de la teoría necesaria para su desarrollo.

- Muestra de ejemplos y búsqueda de información conjunta en la red.

- Trabajo propio de cada uno de los grupos en los objetivos propuestos para el día.

- Planteamiento conjunto de necesidades.

- Resolución de dudas.

- Resumen de la teoría impartida y conclusiones.

- Recogida del trabajo en caso de tratarse de un hito en el cronograma.

Para el trabajo posterior a cada una de las sesiones, los grupos traían sus ordenadores portátiles con los que trabajaban en la búsqueda de información. El uso de esta herramienta facilitaba el aprendizaje pro-activo y la tutorización personalizada de cada uno de los grupos en pos de sus propias necesidades.

La sesión 06 consistió en una exposición y defensa pública de su idea de negocio con explicación pormenorizada de su funcionamiento. El alumnado disponía de 10 minutos para exponer su idea utilizando los medios considerados oportunos (a su disposición tenían el aula, ordenador, proyector, megafonía y multimedia). Durante esta sesión el profesorado adoptó el rol de grupo inversor y el objetivo de los estudiantes era conseguir convencer al grupo inversor para que invirtiera en su negocio y que leyese el fruto de su proyecto, el plan de negocio con la máxima atención. Tras la exposición cualquier persona del público podía realizar las preguntas que estimase conveniente. En años anteriores se ha organizado fruto de un Proyecto de Innovación y Mejora Educativa (PIME) subvencionado la defensa final de los planes de empresa en modalidad de concurso con premios para los mejores trabajos expuestos, evaluados por parte del profesorado y empresarios invitados. 


\subsection{Evaluación}

El proyecto de negocio planteado en la presente comunicación ha tenido al igual que la estructura una evolución en su ponderación sobre la nota final. Inicialmente en su implementación tenía un peso del $25 \%$ en el total de la asignatura y actualmente ha aumentado su ponderación hasta un $30 \%$ del total de la asignatura. Con ello el proyecto tiene un peso importante en el total de la asignatura y el alumnado así lo interpretan. La evaluación del proyecto y plan de empresa evalua 2 aspectos del mismo, por un lado la defensa oral del proyecto empresarial y por otro el contenido esrito en la memoria por los estudiantes. De los 3 puntos sobre los 10 a los que opta el alumnado con el plan de empresa la defensa oral pesaba un $30 \%$, es decir 0,9 de los 3 y el contenido escrito de la memoria un $70 \%$ de los 3 puntos, es decir 2,1 puntos del total.

Los criterios de corrección establecidos se basan por un lado en aspectos formales, y por otro en los contenidos. En cuanto a estos se valora:

- $\quad$ Correcta exposición de la idea.

- Novedad en cuanto a contenido o tecnología de la idea aportada.

- Alcance del estudio realizado, no se han dejado cuestiones significativas por analizar o contemplar en el trabajo.

- Claridad de contenidos.

- Estructura uniforme del trabajo sin que parezca un collage de distintas partes cada una realizada por una persona distinta y sin una vertebración clara.

- Pensamiento original evidente.

- Fuentes de información variadas y de entidad: calidad de las citas y de las fuentes consultadas.

- Adecuación y cercanía a la realidad del proceso de creación de una empresa.

- Concatenación correcta y coherente de cada uno de los apartados basándose cada uno en el inmediato anterior.

Los criterios de evaluación para el aspecto formal del trabajo de desarrollo son:

- Introducción clara.

- Idea central expresada claramente.

- Buen apoyo de puntos principales de argumentación que sustentan la idea central.

- La estructura del trabajo es lógica e intuitiva para el lector.

- La conclusión es efectiva.

- $\quad$ El trabajo tiene entidad suficiente para ser considerado un trabajo de curso.

- El trabajo tiene un desarrollo formal, gráfico y compositivo adecuado a la calidad esperada.

Para el correcto desarrollo del proyecto además de las distintas sesiones teóricas y tutorías se estableció un espacio en la plataforma virtual de la universidad PoliformaT para el intercambio de información. En esta plataforma virtual se colgaban distintos documentos, 
recortes, prensa y direcciones webs que fueran de ayuda para la búsqueda de información y para la formación de la empresa de cada grupo. Dicha plataforma virtual ha servido también para establecer una comunicación fluida entre los distintos miembros del proyecto y el profesorado.

\section{Resultados}

Para evaluar los resultados obtenidos de la implementación de la metodología ABP en la asignatura y la mejora de afinidad de conocimientos hacia el área de conocimiento de la economía se han realizado dos tipos de ensayos. Las encuestas, útiles para un estudio y análisis cuantitativo fueron acompañadas de entrevistas en profundidad personalizadas a alumnos elegidos al azar para poder determinar resultados de manera cualitativa y extraer ciertos datos relevantes.

Como resultado de lo anterior y en base al estudio cualitativo se extrae que el alumno en una inmensa mayoría establece como fundamental la realización del proyecto de empresa. Tras la realización de este proyecto mejora su afinidad a un área de conocimiento a priori lejana a su idea de actividad y necesidad profesional. En cuanto a conseguir mejorar el entendimiento y asentamiento de los conceptos teóricos, en opinión del alumnado la realización del proyecto no les ha ayudado. Los conocimientos de la parte teórica de la asignatura no se vieron asentados por la realización del proyecto de plan de empresa, esto se ve refrendado porque las notas obtenidas en los últimos años no han sufrido variaciones significativas a pesar del cambio de la metodología.

La posición de inicio del planteamiento de la actividad ha resultado tremendamente importante para el arranque de la misma, porque ha contado con el beneplácito del alumnado en principio reacio. Para nuestra sorpresa esta actividad ha sido considerada desde el inicio de manera favorable, hecho que contrasta con el contenido teórico de la misma. Esta, como se ha comentado anteriormente, le resulta al alumnado de manera generalizada unos conocimientos lejanos a su interés inicial y a sus creencias de lo que la titulación les brindaría.

Se ha extraído de esta experiencia que a pesar de la familiaridad del alumno con las nuevas tecnologías de la información, y la cantidad de información de la que disponen, el alumnado muestra carencias en la búsqueda de información de fuentes fiables. Además este aspecto sale a relucir en la investigación cualitativa, del mismo modo presentan carencias en cuanto a conocimientos relativos a formas y normas de presentación y expresión oral, presentación y formalismos escritos, referenciación, falta de conocimiento del entorno empresarial, su estructuración y funcionamiento.

Es evidente que la actual coyuntura económica favorece un entorno empático hacia este proyecto, pero la introducción de esta metodología ha propiciado sin duda un acercamiento del alumno hacia la asignatura y los conocimientos de la teoría económica. La afinidad demostrada por el alumnado es mayor y eso lo podemos observar por los resultados que de manera cuantitativa han sido analizados y que se refleja como la diferencia en el número de 
"no presentados" (al examen final) entre el anterior sistema pedagógico y el actual en el que se han implementado metodologías ABP tabla 5.

Tabla 5. Alumnos presentados y no presentados a los actos de evaluación de "Economía"

\begin{tabular}{|l|c|c|c|c|c|c|c|c|}
\cline { 2 - 9 } \multicolumn{1}{c|}{} & \multicolumn{2}{c|}{$\begin{array}{c}\text { Curso } \\
\mathbf{2 0 0 8 / 2 0 0 9}\end{array}$} & \multicolumn{2}{c|}{\begin{tabular}{c} 
Curso \\
\multicolumn{1}{c|}{$\mathbf{2 0 0 9 / 2 0 1 0}$}
\end{tabular}} & \multicolumn{2}{c|}{$\begin{array}{c}\text { Curso } \\
\mathbf{2 0 1 0 / 2 0 1 1}\end{array}$} & \multicolumn{2}{c|}{$\begin{array}{c}\text { Curso } \\
\mathbf{2 0 1 1 / 2 0 1 2}\end{array}$} \\
\cline { 2 - 9 } & Número & $\%$ & Número & $\%$ & Número & $\%$ & Número & $\%$ \\
\hline Matriculados & 786 & & 476 & & 412 & & 315 & \\
\hline Presentados & 343 & 43.64 & 369 & 77.52 & 403 & 97.82 & 272 & 86.35 \\
\hline No presentado & 443 & 56.36 & 107 & 22.48 & 9 & 2.18 & 43 & 13.65 \\
\hline
\end{tabular}

\begin{tabular}{|l|c|c|c|c|c|c|c|c|}
\cline { 2 - 9 } \multicolumn{1}{c|}{} & \multicolumn{2}{c|}{\begin{tabular}{c} 
Curso \\
\multicolumn{1}{c|}{$\mathbf{2 0 1 2 / 2 0 1 3}$}
\end{tabular}} & \multicolumn{2}{c|}{$\begin{array}{c}\text { Curso } \\
\mathbf{2 0 1 3 / 2 0 1 4}\end{array}$} & \multicolumn{2}{c|}{$\begin{array}{c}\text { Curso } \\
\mathbf{2 0 1 4 / 2 0 1 5}\end{array}$} & \multicolumn{2}{c|}{$\begin{array}{c}\text { Curso } \\
\mathbf{2 0 1 5 / 2 0 1 6}\end{array}$} \\
\cline { 2 - 9 } & Número & \% & Número & \% & Número & \% & Número & $\%$ \\
\hline Matriculados & 196 & & 86 & & 86 & & 67 & \\
\hline Presentados & 188 & 95,91 & 86 & 100 & 86 & 100 & 65 & 97,01 \\
\hline No presentado & 8 & 4,09 & 0 & 0 & 0 & 0 & 2 & 2,99 \\
\hline
\end{tabular}

\begin{tabular}{|c|c|c|c|c|c|c|c|c|}
\hline & \multicolumn{2}{|c|}{$\begin{array}{c}\text { Curso } \\
2016 / 2017\end{array}$} & \multicolumn{2}{|c|}{$\begin{array}{c}\text { Curso } \\
2017 / 2018 \\
\end{array}$} & \multicolumn{2}{|c|}{$\begin{array}{l}\text { Curso } \\
2018 / 2019\end{array}$} & \multicolumn{2}{|c|}{$\begin{array}{l}\text { Curso } \\
2019 / 2020\end{array}$} \\
\hline & Número & $\%$ & Número & $\%$ & Número & $\%$ & Número & $\%$ \\
\hline Matriculados & 78 & & 74 & & 90 & & 116 & \\
\hline Presentados & 78 & 100 & 70 & 94,59 & 89 & 98,88 & 111 & 95,68 \\
\hline No presentado & 0 & 0 & 4 & 5,41 & 1 & 1,12 & 5 & 4,32 \\
\hline
\end{tabular}

\begin{tabular}{|l|c|c|c|c|c|c|c|c|}
\cline { 2 - 8 } \multicolumn{1}{c|}{} & \multicolumn{2}{c|}{ Curso } & \multicolumn{2}{c|}{} & \multicolumn{2}{c|}{} \\
\cline { 2 - 9 } \multicolumn{1}{c|}{202021} & Número & $\%$ & & & & & \\
\hline Matriculados & 148 & & & & & & & \\
\hline Presentados & 134 & 90,54 & & & & & & \\
\hline No presentado & 14 & 9,46 & & & & & & \\
\hline
\end{tabular}

Una gran mayoría del alumnado entrevistado y las encuestas realizadas determinan que para poder sacarle mayor partido a la materia, la asignatura completa debería estar emplazada en los últimos cursos del plan de estudios de la titulación. La metodología ABP a pesar de estar aconsejada en cursos avanzados de la titulación también arroja resultados positivos y prometedores desde el inicio. A pesar de ello cabe destacar que la realización de este proyecto con alumnado de primero plantea ciertos problemas. El alumnado desconoce los aspectos más básicos tanto del sector industrial del que en breve formarán parte como de las estructuras empresariales básicas.

En cuanto al apartado expositivo y de la defensa del negocio resultó llamativo que lo que a priori les parecía un reto difícil de asumir, a posterior les resultó más sencillo. En principio se veían incapaces de hablar en público durante 10 minutos y resultó que la gran mayoría 
de equipos suelen excederse del tiempo. En cuanto a las técnicas salvo contadas excepciones la mayoría carecía de iniciativa imaginativa.

\section{Conclusiones}

El proyecto planteado sugiere un reto útil y cercano tanto a las necesidades reales del alumno como a los objetivos de la asignatura, por tanto se considera muy acertada la implantación de la metodología ABP. El proyecto planteaba la complejidad suficiente como para convertirse en un aliciente para el alumnado.

En la implantación de la metodología y el proyecto en general ha resultado imprescindible fundamentar su necesidad de realización argumentándolo en base a criterios económicos y de emprendedurismo. Fomentar el auto empleo en la coyuntura económica actual supone una pieza de apoyo imprescindible para el proyecto que ha conseguido la implicación del alumnado desde el inicio. No obstante ha resultado que el interés ha ido en aumento a medida que se desarrollaba el proyecto, debido al propio descubrimiento que el alumnado realizaba de la materia.

En la evolución de los años desde que venimos aplicando la metodología el número reducido de alumnos favorece la implementación y aplicación de la metodología y predispone a la participación. También se ve favorecido el seguimiento y control de cada uno de los grupos respecto a la metodología tradicional de clases magistrales de la parte teórica de la asignatura.

Así como las instalaciones tecnológicas de la universidad con su red wifi, recursos y plataforma virtual fomentaron y favorecieron el trabajo al permitir trabajar al alumnado con sus portátiles en todas las sesiones. Sin embargo, un aspecto a mejorar es el mobiliario de las aulas. El existente en las instalaciones utilizadas no permitía fomentar el trabajo en grupo, las mesas y sillas impedían poder tener reuniones de trabajo fluidas.

\section{Futuras líneas de trabajo}

En base al éxito que la actividad y metodología utilizada muestran, el siguiente paso que nos planteamos es conseguir cierto grado de transversalidad del proyecto. Se pretende fusionar el proyecto con asignaturas afines con tal de tejer redes y sinergias que confluyan en la consecución de la interconexión de las distintas atribuciones que el alumnado va adquiriendo a lo largo de su desarrollo profesional.

Conseguir entornos facilitadores del trabajo grupal y la comunicación interactiva de los miembros para conseguir un aprendizaje pro-activo y enriquecedor. 
La limitación fundamental de todo este proceso es el hecho de que el alumnado es de primero y todavía carecen de un bagaje suficiente para el máximo aprovechamiento de las posibilidades que esta metodología nos presenta.

\section{Referencias}

ANECA. (2005). Libro Blanco del Título de Grado en Ingeniería de Edificación. Madrid: Agencia Nacional de Evaluación de la Calidad y Acreditación.

BARROWS, H. T. (1980). Problem Based Learning: An approach to medical education. New York: Springer publishing company.

CARMIÑA, C. B. (2003). "Mitos y realidades de la innovación educativa." Congreso Universitario de Innovación Educativa en las enseñanzas técnicas, Vilanova i La Geltrú.

EUROPEAN MINISTERS RESPONSIBLE FOR HIGHER EDUCATION. (13 de 01 de 2012). The official Bologna Process website (2010-2012): The Bologna Process 2020. Obtenido de The European Higher Education Area in the new decade. : http://www.eees.es/pdf/Leuven_Louvain-la-Neuve_Communique_April_2009.pdf

STEPIEN, W., \& GALLAGHER, S. (1993). "Problem based Learning: As authentic as it gets." Educational Leadreship, 25-28.

VALERO GARCIA, M., \& NAVARRO GUERRERO, J. (2008). "La planificación del trabajo del estudiante y el desarrollo de su autonomía en el aprendizaje basado en proyectos." El aprendizaje basado en problemas en la enseñanza universitaria (págs. 171-190). Murcia: Universidad de Murcia.

WOODS, D., FELDER, R., RUGARCIA, A., \& STICE, J. (2000). "The future of engineering education. Developing critical skills." Chemical Engineering Educatio, V34 108-117. 


\title{
EDIFİCATE
}

I Congreso de Escuelas de Edificación y Arquitectura Técnica de España

València, 4 y 5 de noviembre de 2021

Escuela Técnica Superior de Ingeniería de Edificación

Universitat Politècnica de València

Doi: https://doi.org/10.4995/EDIFICATE2021.2021.13608

\section{La inserción de las asignaturas de carácter legal en la titulación de arquitecto técnico}

\section{The insertion of legal subjects in the degree of technical architect}

\author{
$M^{\mathbf{a}}$ Jesús Romero Aloy \\ Profesora Titular de Universidad. Área de Derecho Administrativo del Departamento de Urbanismo. \\ Universitat Politècnica de Valencia, maroal1@urb.upv.es
}

\begin{abstract}
This communication presents the teaching experience during the last 20 years in the subjects of legal content taught at the Higher Technical School of Building Engineering of the Polytechnic University of Valencia. Teaching methodologies are proposed that, starting from the lecture, must necessarily give way to active methodologies based on guided practices, group work by students and the development of projects based on the knowledge acquired.
\end{abstract}

Keywords: teaching methodologies, legislation, urban management, projects.

\section{Resumen}

Esta comunicación presenta la experiencia docente durante los últimos 20 años en las asignaturas de contenido legal impartidas en la Escuela Técnica Superior de Ingeniería de la Edificación de la Universidad Politécnica de Valencia. Se proponen metodologías docentes que, partiendo de la lección magistral, necesariamente deben dar paso a metodologías activas basadas en las prácticas guiadas, los trabajos grupales de los alumnos y el desarrollo de proyectos basados en los conocimientos adquiridos.

Palabras clave: metodologías docentes, legislación, gestión urbanística, proyectos. 


\section{Introducción: la actitud inicial del alumnado y finalidad de esta comunicación}

En primer lugar, he de referirme a la actitud del alumnado ante las asignaturas de contenido legal en las escuelas técnicas, compartiendo mi experiencia adquirida a lo largo de veintidós años de enseñanza. En principio, puede decirse que el alumno acusa una cierta sorpresa al observar que en el plan de estudios tiene una asignatura llamada Legislación y otra denominada Gestión Urbanística, cursadas en segundo, cuyo contenido es eminentemente legal.

Esa desubicación inicial está en proporción a la madurez del alumnado. Así, se comprueba que en los grupos de la tarde a los que suelen acudir alumnos de mayor edad y con mayor experiencia que en los grupos de la mañana, aquéllos tienen una actitud de mayor aprecio y de positiva valoración que en los grupos de la mañana en los que el alumnado es generalmente de menor madurez.

En cualquier caso, a medida que se avanza en las explicaciones de las asignaturas, se observa un progresivo interés en la medida que el alumno capta la relación de la materia impartida con la vida real en la que se inserta el trabajo profesional.

Por tanto, el propósito de esta comunicación es poder hacer comprender al alumno desde el primer momento la necesidad que tiene de conocer bien el contenido de estas asignaturas, ya que de lo contrario el ejercicio profesional se verá afectado negativamente por fuertes limitaciones. Si esto se asimila desde el inicio de la asignatura, el alumno cursará las asignaturas desde una perspectiva mucho más favorable. Por el contrario, si mantiene una cierta nebulosa sobre la utilidad de lo que tiene que aprender, sin que se desvanezca su extrañeza sorpresa inicial evidentemente su actitud será de menor motivación e interés.

Este cometido que nos proponemos no es necesario en las otras materias que componen el plan de estudios de la carrera en las que el alumno no necesita de ninguna aclaración para comprender que debe conocerlas como puede ser el caso de la construcción o de las instalaciones.

\section{Visión histórica: el tronco común, la Arquitectura Legal}

Por el impacto social que produce la edificación, ha estado sometida a normas desde tiempos remotos. Algunas de las determinaciones hoy vigentes en el Código Civil sobre servidumbres y otras limitaciones de la propiedad tienen su origen en el Derecho Romano. Por referirnos a épocas menos antiguas, es significativo el Acuerdo que en el año 1759 adoptó la Real Academia de San Fernando ante el desorden que reinaba en las enseñanzas de la arquitectura, acordó nombrar una comisión que elaborara un plan de estudios, propuesta que después de diversas vicisitudes, cristalizó en la Real Orden de 8 de enero de 1850, por la que se formalizó el plan de estudios de la titulación de arquitecto donde, en el cuarto curso de la carrera, ya aparecía la asignatura de Arquitectura Legal, en 
la que se encuentra el núcleo de los contenidos legales que, desde hace casi dos siglos se vienen impartiendo en la titulaciones universitarias.

Desde el punto de vista académico, tempranamente aparecen tratados importantes que desarrollan las asignaturas de contenido legal. El primero de ellos es el Tratado de la Legislación de Arquitectura, Agrimensura y Caminos Vecinales de Marcial de la Cámara. En 1870, aparece el Tratado de Arquitectura Legal de Calvo y Pereira. Pocos años después de la publicación del Código Civil, se publica la obra de Martínez Ángel y Oyuelos Pérez, también titulado Tratado de Arquitectura Legal, obra muy sistemática ya que aprovecha el tratamiento que el Código Civil efectúa de las materias afectantes a la edificación.

Como puede comprobarse, a partir del momento en el que aparece publicado el primer plan de estudios de la titulación de Arquitecto, comienzan a publicarse importantes tratados sobre arquitectura legal que constituyen la base científica de la materia. Así pues en el siglo XIX, ya existe un importante cuerpo doctrinal que sirve de pilar para la enseñanza de estos contenidos.

\section{La relación de las asignaturas Legislación y Gestión Urbanística con las atribuciones profesionales}

Estas asignaturas sirven directamente a un importante grupo de competencias profesionales que, de no ser por estas disciplinas, el titulado saldría de la escuela siendo incapaz de atender tales trabajos. El temario impartido parte del análisis de las competencias profesionales del arquitecto técnico y sus correspondientes necesidades formativas en la materia.

La gran parte de atribuciones profesionales del arquitecto técnico se encuentran reguladas en la Ley 38/1999, de Ordenación de la Edificación y en la Ley 12/1986, de atribuciones profesionales de Ingenieros y Arquitectos Técnicos.

Concretamente, las competencias profesionales de los arquitectos técnicos se regulan en el Real Decreto 927/1992, de 17 de julio, por el que se establece el título universitario oficial de Arquitecto Técnico y la aprobación de las directrices generales propias de los planes de estudios conducentes a la obtención de aquél, y en la Orden ECl 3855/2007, de 27 de diciembre, por la que se establecen los requisitos para la verificación de los títulos universitarios oficiales que habiliten para el ejercicio de la profesión de Arquitecto Técnico.

Acudiendo a la citada Ley 12/1986, de 1 de abril, reguladora de las atribuciones de los arquitectos técnicos, podemos identificar aquellos trabajos profesionales para cuyo ejercicio resulta indispensable el contenido de las asignaturas que estamos tratando. Un superficial análisis nos lo demuestra:

1. Las atribuciones profesionales dentro del ámbito de los proyectos de intervención en la edificación necesitan del conocimiento de los planes de ordenación en los que figuran las determinaciones urbanísticas a las cuales el 
proyecto debe someterse. Si estas determinaciones se desconocen o se interpretan de modo erróneo, la intervención en el edificio no podrá realizarse. En las asignaturas se presta una considerable atención al conocimiento de las distintas figuras de planeamiento.

2. La gestión administrativa de las licencias de obra: todas las posibles intervenciones de edificación para poder realizarse, necesitan de la correspondiente licencia de obra. Si ésta no existe no se puede intervenir. El arquitecto técnico necesita conocer bien el contenido y estructura de la licencia de obra, no sólo para confeccionar la documentación correctamente, sino para ser capaz de intervenir como parte ante el ayuntamiento o en el proceso de tramitación, en el cual muchas veces es preciso subsanar deficiencias o aportar nuevos datos.

3. Como principal responsable de la técnica constructiva el profesional debe conocer lo que es un contrato de obra, ya que muchas veces será el responsable del seguimiento y correcta ejecución del mismo. Es el denominado proyect management o gestión del proyecto.

4. Las valoraciones inmobiliarias en las que el arquitecto técnico tiene cada vez un mayor protagonismo. Para valorar un solar o una parcela, es preciso conocer las determinaciones urbanísticas de las que depende su valor tales como la edificabilidad, aprovechamiento tipo, cesiones de suelo a realizar, obras pendientes de urbanización a cargo del propietario, previsiones temporales de gestión urbanística, etc. Por otra parte, es imprescindible conocer la calificación urbanística de suelo urbano, urbanizable o no urbanizable. Sin el conocimiento de estos elementos derivados del planeamiento y de la gestión urbanística es imposible realizar la valoración de un solar o de una parcela.

5. La responsabilidad profesional en el ejercicio de la profesión. En la práctica profesional del arquitecto técnico se depositan unos intereses económicos, en ocasiones importantes en cuantía y, respecto de su tarea como director de ejecución de obra, se le requerirá un resultado adecuado, por lo que el ejercicio de la profesión genera un importante impacto social cuyas responsabilidades civiles, penales y administrativas, tienen una gran importancia. Por tanto, resulta necesario que el alumno conozca las responsabilidades en las que puede incurrir durante el ejercicio de la profesión, ya sean civiles, penales, o meramente administrativas.

6. La tramitación de expedientes en las licencias ambientales (de apertura) de todo tipo de establecimientos. El alumno recibe la formación adecuada sobre los instrumentos de control administrativo ambiental que siguen la fiscalización de aquellas instalaciones y actividades susceptibles de producir molestias, alterar las condiciones de salubridad del medio ambiente u ocasionar daños o riesgos a las personas o el medio ambiente. 
7. La preparación que suponen estas asignaturas para quienes vayan a optar a algún puesto en la administración pública en los diferentes niveles de administración estatal, autonómica o municipal. Los temarios de estas oposiciones tienen una importante parte de materias legales (oposiciones para nombramientos interinos, bolsas de trabajo ...) por lo que el conocimiento de las materias legales a las que nos estamos refiriendo es imprescindible.

8. Todas las servidumbres que afectan a la edificación tales como las servidumbres de vistas, de luces, de paso, de medianería, etc. Es de capital importancia el conocimiento de estas limitaciones de la propiedad ya que, de no observarlas, el técnico incurre en la correspondiente responsabilidad.

9. Toda la normativa referente a las viviendas de protección pública en cuyos expedientes el arquitecto técnico tiene plena competencia para su tramitación y para la realización de determinadas intervenciones en este tipo de viviendas.

10. El conocimiento de las medidas de defensa a su alcance para defenderse ante posibles perjuicios en algún inmueble como son los juicios verbales de obra nueva o los de obra ruinosa.

\section{La visión de la panorámica global en la que se inserta la edificación y la asignatura de Gestión Urbanística}

Esta asignatura proporciona al estudiante una nueva visión de la edificación, ya que aparece insertada dentro de un complejo instrumento cual es el plan de ordenación, que contiene las alineaciones, los posibles usos del edificio, las alturas edificables, la tipología edificatoria, los condicionantes estéticos, etc..

El impacto de esta asignatura sobre la visión de la edificación y de la arquitectura es muy importante, ya que se le ofrece al alumno no la visión particular e individualizada, sino una visión total desde la cual se comprende y se justifica la edificación en cada caso particular.

La posible pieza se inserta, además, sobre un suelo que tiene una determinada clasificación urbanística de urbano, urbanizable o no urbanizable, lo cual supone que pueda edificarse en un breve periodo de tiempo, como es el caso del suelo urbano, tras la obtención de la correspondiente licencia de edificación, o bien que para poder edificarse haya de seguirse un largo periodo de gestión que puede durar años, después del cual el suelo contará con los correspondientes servicios urbanísticos, como es el caso del suelo urbanizable. O bien que no pueda edificarse en absoluto o sólo en situaciones muy particulares, como es el caso del suelo no urbanizable.

La construcción de la ciudad pasa inevitablemente por complejos procesos de gestión urbanística como resultado de los cuales se obtiene la urbanización de los viarios, abastecimiento de agua, desagües, alumbrado público y obtención de suelos dotacionales para zonas verdes, centros educativos, asistenciales, etc. Todo ello supone importantes desembolsos por parte de los propietarios para el pago de las obras de urbanización que, 
además, deben ceder gratuitamente la parte proporcional que les corresponde de suelo para viarios y dotaciones.

Esta compleja operación debe realizarse según unos criterios de reparto proporcional que exige la formulación de conceptos como son los de aprovechamiento tipo, coeficientes de homogenización, etc. Como resultado de los cuales se obtiene el aprovechamiento urbanístico que en cada caso corresponde al propietario.

Estos conceptos definen el valor del suelo y en consecuencia son de imprescindible conocimiento a la hora de que el profesional realice la valoración de un determinado suelo.

En este sentido, y con carácter global, cabe decir que el urbanismo es una ciencia multidisciplinar $^{1}$ que admite la intervención de numerosas ramas profesionales, lógicamente, todo ello, en función de las competencias que pueda ejercer cada titulación y, el arquitecto técnico goza de las competencias profesionales para ejercer su profesión en materia de urbanismo, ya sea dentro del ejercicio libre de la profesión o en su trabajo desde la administración pública dentro de los servicios técnicos de urbanismo. Pues bien, esta asignatura le otorga los conocimientos necesarios para que, en su ejercicio profesional, puedan desarollar exitosamente las labores en materia de urbanismo tales como: proyectos de reparcelación, segregación y agrupación de parcelas, instrumentos de planeamiento, proyectos de urbanización, expedientes de legalización de infracciones urbanísticas, etc. Dentro de los servicios técnicos de urbanismo en la administración, tendrán competencias para realizar informes técnicos urbanísticos en los expedientes de licencias de obras, informes para laconcesión de licencias de agrupación, segregación, reparcelación o modificación de linderos, informes de situación urbanística, informes de compatibilidad urbanística, apertura de expedientes de infracciones urbanísticas, etc

\section{La metodología docente}

Debemos partir de la idea de cambio del sistema de "enseñar" por el de "ayudar a aprender", donde los alumnos tengan una actitud activa en su tarea de conocer la materia propuesta (Santana, 2020) ${ }^{2}$, pero tal afirmación no se realiza en desdeño de la clase magistral, puesto que el docente debe enseñar el contenido de la asignatura. Quizás, el cambio con respecto a la clásica lección magistral es que, en las asignaturas de contenido legal, estas explicaciones se realizan desde un punto de vista eminentemente práctico

\footnotetext{
${ }^{1}$ GARCÍA ERVITI, F. et all ( 2013) "Herramientas de aprendizaje sobre regulación legal del ejercicio profesional del arquitecto". En XI Jornadas de Redes de Investigación en Docencia Universitaria. Alicante: Universidad de Alicante, 2659 p. "Las materias propias de la disciplina académica de Arquitectura Legal tienen un carácter pluridisciplinar y transversal en el contexto de las competencias que deben adquirirse para la obtención de los títulos universitarios oficiales que habiliten para el ejercicio de la profesión de Arquitecto, participando tanto del área técnica -con las disciplinas propias de la construcción, estructuras e instalaciones-, como del ámbito proyectual, que incorpora las materias de composición, proyectos y urbanismo”. 2273.

2 SANTANA RODRÍGUEZ, R.J., (2020). "El aprendizaje basado en la práctica profesional : metodologías activas". En Arquitectura v2020. Valencia: Universitat Politècnica de València. 56.
} 
enfocándolas a la práctica constructiva que les permitirá reflejar en la vida real los conceptos aprendidos.

En nuestras asignaturas, Legislación y Gestión Urbanística, se lleva a cabo una docencia presencial mediante clases magistrales; se plantean casos concretos y reales para ilustrar los contenidos teóricos y, se alternan con debates surgidos a partir de las preguntas y comentarios de los alumnos en relación al caso estudiado.

También se desarrollan talleres de trabajos en grupo sobre un caso práctico propuesto y tutelado por el profesor, con el análisis, exposición y discusión de los casos realizados por los alumnos, con una presentación oral de los trabajos con debate posterior y preguntas del resto de compañeros.

En concreto, la metodología docente se desarrolla del siguiente modo:

\subsection{Las clases teóricas}

Es muy importante conseguir una metodología docente que se corresponda con el perfil del alumnado que tiene una formación técnica. Por ello hay que acudir a una metodología con importantes dosis de aporte práctico que sirva para fijar y comprender los conceptos y determinaciones que vienen establecidos en las normas.

Al alumno puede resultarle ininteligible una formulación que se contiene en un determinado precepto legal. A modo de ejemplo, puede pensarse en la regulación de lo que es una actuación integrada o una actuación aislada. La expresión contenida en la norma hay que verla reflejada concretamente sobre un plano de cualquier ejemplo real. Entonces, el alumno pasa de una nebulosa inicial a una comprensión clara que, por estar reflejada en un plano y unas determinaciones anexas, resulta claramente asumible y enriquecedor. Por ello, las explicaciones teóricas deben ir siempre acompañadas del correspondiente reflejo práctico. Al alumno se le proporcionan ambos contenidos.

Además, tanto de la asignatura de Legislación, como de Gestión Urbanística, el gran equipo docente que imparte estas asignaturas, ha publicado dos libros docentes "Legislación, parte general" y "Legislación y gestión urbanística en la Comunidad Valenciana", que los alumnos pueden seguir durante las clases teóricas, junto con las correspondientes presentaciones disponibles en la plataforma Poliformat, lo que ha supuesto una sólida base para el seguimiento y estudio de la lección magistral y para la posterior realización de los trabajos prácticos y proyectos. 


\subsection{Los trabajos prácticos}

Para asegurar el éxito de estas asignaturas, la metodología activa se desarrolla mediante trabajos que se plantean desde una perspectiva de supuestos reales que implican el manejo de instrumentos de planeamiento o de gestión urbanística. Se realizan en clase por grupos de alumnos bajo la supervisión del Profesor pero dando cierta autonomía al alumnado. En general resultan muy atractivos para el alumnado ya que lo introducen en el mundo real bien manejando los distintos tipos de planes o bien los recursos y sistemas para la ejecución de los mismos.

El trabajo con proyectos grupales debe ser una parte predominante en el proceso de formación del alumno en las asignaturas de contenido legal al objeto de aprender aplicando la normativa y los conocimientos adquiridos a casos reales. Además, el trabajo en pequeños grupos crea un diálogo directo entre el profesor y los alumnos que debe ser el pilar en el periodo de aprendizaje. Con ello se pretende la integración del alumno en la actividad laboral.

Por ejemplificar uno de estos trabajos, se les plantea el siguiente supuesto a trabajar por grupos reducidos de 5 alumnos en los que debe existir plena coordinación para el desarrollo del trabajo:

A cada grupo se le asigna una parcela a partir de la cual deberán realizar un proyecto que recorrerá todos los aspectos legales que deberán tener en cuenta para la finalización del mismo con el siguiente desarrollo:

1. Identificación registral y catastral de la parcela.

2. Planeamiento aplicable a la parcela: clasificación y calificación del suelo, cumplimiento o no de la condición de solar, parámetros urbanísticos aplicables, usos pormenorizados permitidos en la parcela.

3. Posibles afecciones de la parcela que puedan condicionar la obra prevista: inundabilidad, carreteras, ferrocarriles, aeropuertos, patrimonio, cauces públicos, etc.

4. Análisis, si procede, de las obras de urbanización a realizar y las cesiones pendientes al Ayuntamiento.

5. Elaboración de un breve anteproyecto y estimación de los costes de urbanización de la actuación.

6. Elaboración de planos del estado actual de la parcela, distribución de la parcela resultante, Layout e imágenes fotorealísticas.

7. Lectura y análisis de uno de los contratos a firmar entre constructora y promotora.

Durante la realización del trabajo $\mathrm{y}$, después de las explicaciones teóricas correspondientes, los alumnos trabajan en el aula con una interacción constante entre el profesorado y los grupos de alumnos resolviendo dudas y aconsejando sobre la adopción de las mejores soluciones poniendo en práctica los conocimientos legales adquiridos en las clases magistrales. 

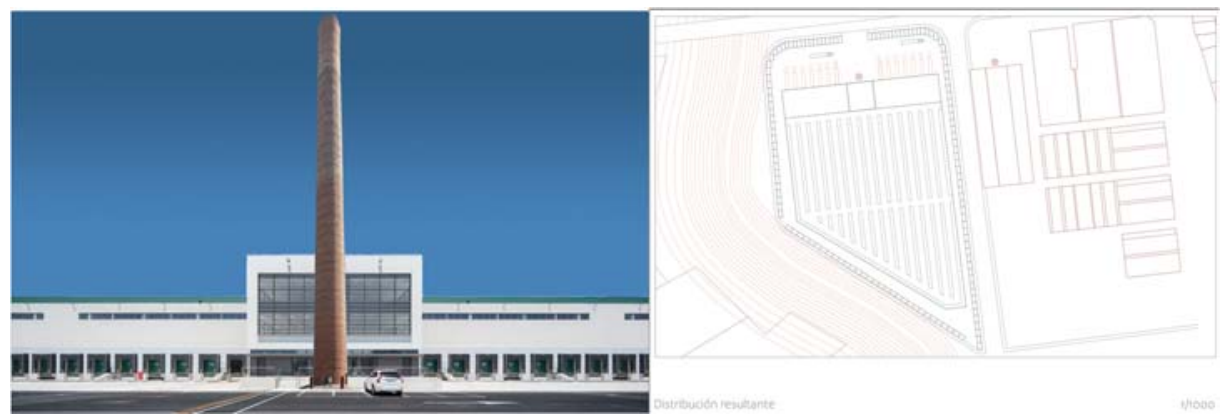

Fig. 1 Ejemplo de planos realizados por los alumnos

Otra de las actividades complementarias al trabajo grupal es, por una parte, la visita a los ayuntamientos de las parcelas asignadas al objeto de mantener una reunión con los técnicos municipales para poder recabar la información necesaria relativa a la parcela además de tener un contacto directo con la realidad del urbanismo en la administración; por otra parte, se realiza una visita guíada con un profesional junto con todos los alumnos a una de las parcelas asignadas que, en la realidad, ya está edificada para que puedan plasmar esa realidad en sus trabajos.

\section{Conclusiones}

Con esta metodología docente que se ha expuesto, realmente se han conseguido frutos muy importantes que despiertan el interés por estas asignaturas que, de otro modo, pueden resultar "ásperas" para los alumnos no acostumbrados a estudiar normativa. De este modo, los futuros arquitectos técnicos podrán aplicar la normativa correspondiente a cada una de las competencias profesionales en materia de urbanismo a través de los conocimientos adquiridos, a lo que se debe sumar la capacidad de trabajar en grupo y hablar en público con seguridad.

\section{Referencias bibliográficas}

GARCÍA ERVITI, F. et all ( 2013) " Herramientas de aprendizaje sobre regulación legal del ejercicio profesional del arquitecto". En XI Jornadas de Redes de Investigación en Docencia Universitaria. Alicante: Universidad de Alicante, $2659 \mathrm{p}$.

SANTANA RODRÍGUEZ, R.J., (2020). "El aprendizaje basado en la práctica profesional : metodologías activas". En Arquitectura v2020. Valencia: Universitat Politècnica de València. 56. 


\title{
EDIFICATE
}

I Congreso de Escuelas de Edificación y Arquitectura Técnica de España València, 4 y 5 de noviembre de 2021

Escuela Técnica Superior de Ingeniería de Edificación

UniversitatPolitècnica de València

Doi:https://doi.org/10.4995/EDIFICATE2021.2021.13396

\section{EI PFG como herramienta para la especialización en análisis integral y difusión del Patrimonio Arquitectónico}

\section{The PFG as a tool for specialization in comprehensive analysis and dissemination of Architectural Heritage}

\author{
Pedro Enrique Collado Espejo \\ ETS de Arquitectura y Edificación. Universidad Politécnica de Cartagena, pedroe.collado@upct.es
}

\begin{abstract}
The methodology developed in the ETS of Architecture and Building (ETSAE) of the Polytechnic University of Cartagena (UPCT), for the realization of Final Degree Projects (PFG) in the current Degree in Building Engineering is exposed, focused on architectural heritage. With the completion of the PFG the student shows how he has assimilated and integrated the training content received but it should also be an opportunity to enhance the specific and transversal competences of the degree. The text exposes the methodology, based on the motivation and involvement of the student, to develop the comprehensive analysis of the historic building and the dissemination of the PFG. The results obtained, after almost twenty years of experience and more than eighty PFG directed and focused on research, historical-constructive analysis and pathologies and the intervention proposal, for their future restoration and conservation, of historical buildings; show an effective methodology for the technical and human training of the student, especially in the field of Architectural Heritage. A successful experience if the awards that graduates have received in recognition of the quality of their PFG are taken into account.
\end{abstract}

Keywords: Final Degree Project, UPCT, Architectural Heritage, ETSAE, involvement, research, PFG methodology.

\section{Resumen}

Se expone la metodología desarrollada en la ETS de Arquitectura y Edificación (ETSAE) de la Universidad Politécnica de Cartagena (UPCT) para la realización de Proyectos Fin de Grado (PFG) en el actual Grado en 
Ingeniería de Edificación, centrados en el patrimonio arquitectónico. Con la realización del PFG el alumno muestra cómo ha asimilado e integrado los contenidos formativos recibidos pero también debe ser una oportunidad para potenciar las competencias específicas y transversales del título. El texto expone la metodología, basada en la motivación e implicación del estudiante, para desarrollar el análisis integral del edificio histórico y la difusión del PFG. Los resultados obtenidos, después de casi veinte años de experiencia y más de ochenta PFG dirigidos y enfocados a la investigación, el análisis históricoconstructivo y de patologías y la propuesta de intervención, para su futura restauración y conservación, de construcciones históricas; muestran una metodología eficaz para la formación técnica y humana del estudiante, especialmente en el ámbito del Patrimonio Arquitectónico. Una experiencia exitosa si se tienen en cuenta los premios que han recibidos los egresados en reconocimiento a la calidad de sus PFG.

Palabras clave: Proyecto Final de Grado, UPCT, Patrimonio Arquitectónico, ETSAE, implicación, investigación, metodología de PFG 


\section{Introducción}

A partir del curso académico 2000-2001, la Universidad Politécnica de Cartagena (en adelante UPCT), comienza a impartir la titulación de Arquitectura Técnica (diplomatura de tres cursos), integrando estos estudios en la Escuela Universitaria de Ingeniería Técnica Civil. En paralelo, la Declaración de Bolonia (1999) establecía el año 2010 como fecha para la implantación del llamado Espacio Europeo de Educación Superior (EEES), por lo que la UPCT aprobó, para el curso 2008-2009, implantar el Grado en Arquitectura y transformar el título de Arquitectura Técnica en el actual Grado en Ingeniería de Edificación (que comenzó a impartirse en el curso 2009-2010), además de crear la Escuela Técnica Superior de Arquitectura y Edificación (ETSAE), donde se integran, desde entonces, estas dos titulaciones (junto con el Máster en Patrimonio Arquitectónico y el Máster en Ciencia y Tecnología de la Edificación en Arquitectura).

Como se sabe, la implantación del EEES ha supuesto una profunda transformación de la Universidad, que se ha visto especialmente reflejada en los planes de estudios al pasar de diplomaturas de tres cursos a grados de cuatro, como en el caso de la titulación de Arquitectura Técnica/Ingeniería de Edificación. El modelo formativo y educativo que desarrolla el EEES sustituye el antiguo concepto de enseñanza, donde las clases magistrales y el libro de apuntes y prácticas formaban la base metodológica y modelo educativo (tanto en la enseñanza media como en el ámbito universitario), por el concepto de aprendizaje o, como también se ha definido, autogestión del aprendizaje. Un nuevo modelo que apuesta por la idea de "aprender a aprender" en lugar de la mera acumulación de conocimientos. Donde se incide en la evaluación contínua, la mayor tutorización del alumno, el aprendizaje autónomo..., y donde el profesor se convierte en un guía para el alumno y éste debe asumir gran parte de la responsabilidad de su proceso formativo (Collado, 2011). Y en este sentido, la elección del tipo de Proyecto Fin de Grado (genérico o específico, obra nueva o restauración, análisis teórico, realización de ensayos...), y cómo se afronte su realización, por parte del alumno y del profesor-tutor, es un ejemplo claro de las posibilidades de éxito o fracaso de lo que se persigue con la "autogestión del aprendizaje". Además, esta reforma del modelo de formación técnica y humana del alumno incluye la evaluación por adquisición de competencias. Es decir, los planes de estudios de las diferentes tutulaciones y las guías docentes de las asignaturas, establecen las competencias que el alumno debe alcanzar y el sistema de evaluación de éstas, dividiendo las competencias en específicas (del título y/o de la asignaturta) y genéricas o transversales, diferenciando estas últimas en tres bloques: instrumentales, personales y sistémicas, con sus correspondientes objetivos.

Por tanto, y teniendo en cuenta que el Reglamento de Trabajos Fin de Estudios en la UPCT establece que éste debe plantearse como "una herramienta fundamental para consolidar la adquisición de competencias por parte de los estudiantes, siendo en algunos casos la única actividad formativa en la que se puede abordar determinadas competencias trnasversales recogidas en los planes de estudios"; además de considerarlo como "un trabajo individual orientado a la aplicación y evaluación de competencias asociadas al título", la metodología de planificación y desarrollo del Proyecto Fin de Grado (PFG) en el actual Grado en 
Ingeniería de Edificación debe dar respuesta a estas necesidades. Es decir, el PFG debe enfocarse como un trabajo que integra y desarrolla la mayoría de contenidos formativos (técnicos y humanísticos) de la titulación y las competencias profesionales (específicas) y genéricas que se adquieren con, en nuestro caso, el título de Graduado en Ingeniería de Edificación (Collado, 2020). Así, tanto el Proyecto Fin de Carrera (en la antigua diplomatura de Arquitectura Técnica), como especialmente el actual PFG en Ingeniería de Edificación (IdE), debe planificarse y desarrollarse con una metodología adaptada a la consolidación y potenciación del máximo de competencias propias de la titulación, así como con un sistema que permita controlar y evaluar la calidad del trabajo y la adquisición de estas competencias por parte del autor del PFG. Además, la realización de este trabajo, como ocurre con el programa de prácticas, debe perseguir que el estudiante tenga una experiencia profesional que le ayude en su futura inserción en el mercado laboral (Raposo y Zabalza, 2011).

Este texto pretende exponer cómo se afronta y qué metodología se sigue en la UPCT para la realización de los PFG específicos, desde la época de la titulación de Arquitectura Técnica hasta la actual IdE, centrados en el análisis integral y propuestas de intervención en edificios que, básicamente, forman parte del Patrimonio Arquitectónico de la Región de Murcia, así como la evolución de esta metodología, con su adaptación a los nuevos requisitos de calidad, y los resultados obtenidos después de casi 20 años de experiencia.

\section{Objetivos. EI PFG como herramienta de conocimiento}

En general, las titulaciones técnicas tienen un enfoque técnico-científico muy acentuado y cuando se plantea un proyecto de anáilisis integral y propuesta de intervención en un edificio histórico se suele acometer desde ese rigor técnico y científico. Sin embargo, cuando estudiamos construcciones que forman parte del Patrimonio Arquitectónico o están protegidos como Monumento, no sólo tenemos que enfocar el análisis sobre la arquitectura y los materiales y sistemas constructivos propios del inmueble; también debemos tener muy presentes aspectos como el carácter histórico, simbólico, social y cultural de estos elementos; además de analizar y valorar su correcta integración y relevancia en el entorno urbano, natural y/o paisajístico en el que se ubican. Así mismo, tenemos que ser conscientes de que en las últimas décadas, términos como restauración, rehabilitación y conservación, están muy presentes en el debate social y cultural sobre cómo recuperar, adecuar e integrar los edificios antiguos en los actuales modos de vida. Un debate, más sociocultural que técnico, que persigue que estos edificios sigan en uso y en unas condiciones de habitabilidad acordes al momento actual, pero que no puede obviar la relevancia, singularidad e identidad de estas construcciones ni los variados e importantes valores que atesoran; valores históricos, arquitectónicos y constructivos evidentes, pero también valores sociales, documentales, simbólicos, culturales...

Por tanto, la formación y especialización del estudiante en el campo del Patrimonio Arquitectónico debe enfocarse, como mínimo, en un doble sentido: el técnico y el humanístico. Y el PFG puede convertirse en una herramienta muy eficaz para que el 
alumno de IdE desarrolle la mayoría de los conocimientos generales adquiridos y, en el campo de la arquitectura monumental, la formación específica en tipologías constructivas, metodologías de análisis, criterios y técnicas de intervención, los conceptos de autenticidad, legibilidad y reversibilidad, etc. Todo ello sin olvidar que, con la realización del TFG, y en cumplimiento de la Guía Docente, debemos estimular y potenciar en el alumno competencias instrumentales como: capacidad de análisis y síntesis, capacidad de organización y planificación del trabajo, capacidad de gestionar la variada y compleja información que se va generando, el razonamiento crítico-constructivo, la comunicación oral y escrita (el PFG debe estar bien redactado), y la capacidad y madurez para la toma de decisiones. En cuanto a las competencias personales, se afianzarán: el aprendizaje autónomo, las habilidades en las relaciones interpersonales y la capacidad de trabajar en equipo, que practican al tener que analizar las últimas intervenciones realizadas en el edificio y comentar éstas con el arquitecto director y/o con algún técnico de la empresa que las llevó a cabo. Igualmente, el PFG debe favorecer el impulso de las competencias sistémicas (creatividad e innovación en las propuestas de intervención, iniciativa y motivación por la calidad del trabajo), que serán muy valoradas por el tribunal evaluador del PFG al constituir el resultado final de todo el trabajo teórico-práctico realizado.

\section{Metodología para el desarrollo del PFG específico en Patrimonio}

Hasta hace unos años, el "levantamiento arquitectónico", general y en detalle, se consideraba la herramienta básica, habitual, para el conocimiento arquitectónico, material y constructivo de los edificios; conforme lo vamos dibujando, reconocemos y comprendemos, material y constructivamente, el edificio. Por ello, la realización y definición de los planos (en CAD a partir de principios de los 90), tenía una carga de trabajo y una valoración muy importante en los PFG, limitándose el análisis histórico y descriptivo del edificio a una pequeña memoria justificativa. Con el desarrollo de la metodología de trabajo que vamos a exponer se pretende conseguir un "conocimiento integral", completo y en profundidad, del edificio/conjunto arquitectónico. Este análisis no sólo debe permitir el conocimiento de su materialidad física, sino que abarca todo lo que concierne a su historia arquitectónica, social y cultural, su identidad, sus valores y significados (que pueden haber cambiado a lo largo del tiempo). Un conocimiento integral básico para poder asumir, con las mayores garantías, la complejidad de cualquier intervención en el Patrimonio Arquitectónico.

Como punto de partida, tenemos que tener muy en cuenta que los PFG los realizan alumnos que están en el final de su formación académica universitaria (por lo que disponen de amplios conocimientos teóricos y prácticos de su titulación), que serán tutorizados por un profesor (con más o menos experiencia en esta labor), pero que dependiendo de las circunstancias personales del estudiante, en muchos casos compaginando la realización del PFG con trabajos (Pérez et al., 2019), y no siempre relacionados con sus estudios universitarios, afrontarán este nuevo reto de muy diversas formas. Por tanto, y en base a nuestra experiencia, nos atrevemos a afirmar que el profesor-tutor de un PFG específico centrado en el análisis integral de un edificio histórico debe tener presente que: 
- Se trata de un trabajo original, que debe ser evaluado por un Tribunal y reflejar los conocimientos, habilidades y competencias (específicas y genéricas), que el alumno debe haber adquirido a lo largo de su formación universitaria.

- EI PFG tiene una carga de 12 ECTS, no es una Tesis Doctoral, pero sí debería servir para que el alumno adquiera un modelo correcto de investigación y referenciación documental y desarrolle su capacidad observadora, reflexiva y crítica.

- El profesor-tutor debe facilitar la realización del PFG, no "controlarlo"; debe ayudar en la evolución y aprendizaje del alumno que debe ser el que busque soluciones a los retos que se plantean con el desarrollo del trabajo.

- El profesor-tutor debe comportarse como un técnico experimentado que sirve de guía y apoyo en todo lo necesario para el correcto aprendizaje del estudiante, haciendo que esta experiencia sea lo más enriquecedora posible (Zabalza, 2011)

- Cuando las propuestas del alumno o la orientación del trabajo no es el adecuado, el tutor debe saber "canalizar" el PFG pero sin desmotivar al estudiante, éste debe sentir que su opinión, su participación es fundamental.

- La relación entre tutor y alumno ha de ser fluida, de confianza y abierta a plantear propuestas creativas e innovadoras. Por ello, las tutorías presenciales u online deben ajustarse a la evolución del trabajo pero nunca renunciar a ellas. En una situación de pandemia, plataformas como TEAMS facilitan la interacción tutor-alumno.

- La implicación y responsabilidad del estudiante depende de él mismo pero también de la actitud del tutor. El profesor debe favorecer e incentivar la participación del estudiante (Sánchez et al., 2015), su razonamiento crítico y toma de decisiones y su autoevaluación. Las tutorías son fundamentales para canalizar la implicación del estudiante en este proceso de compromiso con el aprendizaje.

- Los PFG específicos favorecen la implicación del alumno, especialmente cuando es éste el que elige el tema y los objetivos del trabajo a realizar.

- El análisis integral de un edificio histórico aumenta la sensibilidad hacia la conservación y correcta valoración del Patrimonio. El trabajo es una poderosa herramienta, didáctica y divulgativa, al servicio del Patrimonio Cultural.

- Manejar mucha información no es sinónimo de entenderla. El exceso puede "bloquear" al alumno. Éste debe aprender a seleccionar y procesar la información.

- La originalidad del PFG será comprobado con un programa antiplagio (Turnitin en el caso de la UPCT), lo que implica gestionar y procesar correctamente la información (sobre todo histórica y legislativa) que se maneja.

- Los alumnos se implican cuando se sienten respetados y valorados, por ello, se les debe tratar como profesionales. 
- Los alumnos motivados son más receptivos y aprenden más. La motivación tiene una influencia importantísima en el aprendizaje (Sancho, 2016).

- Establecer una metodología de desarrollo del PFG ayuda a planificar y controlar el trabajo pero debe ser flexible y adaptarse a la situación personal del estudiante (dedicación, horarios de trabajo, situación familiar...) y a las características y objetivos del trabajo específico a desarrollar.

- El alumno de PFG suele compaginar éste con un trabajo profesionalpor lo que, en ocasiones, no dispone de tiempo para finalizar el PFG en el plazo establecido (Pérez et al., 2019), lo que suele conllevar desmotivación. El profesor-tutor debe ser comprensivo pero también debe insistir en motivar y comprometer al estudiante.

- Analizar la/s última/s intervención/es realizada/s en el edificio origen del PFG implica que el estudiante debe contactar con la dirección facultativa, constructora y promotor de las obras. Compartir conocimientos con profesionales es una experiencia muy enriquecedora y motivadora para el estudiante, además de potenciar su capacidad de análisis y síntesis y sus habilidades en las relaciones interpersonales.

Además de todo esto, realizar un PFG sobre un edificio histórico, trabajar en el Patrimonio Cultural, se convierte en un proceso de sensibilización y compromiso ético hacia todo lo que representa el Patrimonio. Por tanto, este trabajo debe plantearse también como una oportunidad para el desarrollo emocional y la formación integral del estudiante hacia el conocimiento y respeto al Patrimonio Cultural, con todo lo que ello conlleva socialmente. Asi mismo, este tipo de PFG exige un alto grado de dedicación, compromiso y conocimientos por parte del profesor-tutor (Alfaro et al., 2012); sólo así podrá orientar y ayudar al alumno.

\section{Desarrollo del PFG específico en Patrimonio. Resultados}

A partir de estas premisas, el PFG se divide básicamente en tres bloques: análisis histórico, constructivo, sociocultural y de las intervenciones realizadas; análisis del estado actual de conservación; y propuesta razonada de intervención para la correcta conservación y uso. Estos tres bloques deben organizarse teniendo en cuenta que la originalidad del trabajo será comprobada con el programa antiplagio y éste no analiza documentación gráfica (planimetría) y cuando se analiza el cumplimiento de la normativa actual en Patrimonio Cultural, accesibilidad, protección, mantenimiento, ahorro energético, etc., el porcentaje de "similitud" puede ser alto, pues hay que hacer referencia a la normativa en cuestión. Por ello, la ETSAE aprobó que los PFG desarrollados en esta Escuela deben entregarse en tres archivos pdf independientes. Uno con los análisis histórico-constructivos, estado de conservación y propuesta de intervención; otro con la documentación planimétrica; y un tercero con al análisis del cumplimiento de la normativa y los correspondientes anexos. Sólo el primer archivo (el de los análisis teóricos) se analizará con el programa antiplagio.

El primer paso para desarrollar el PFG es que el/la alumno/a elija el edificio histórico sobre el que quiere trabajar. Los profesores podemos ofertar trabajos/edificios pero si es elección del estudiante la motivación e implicación de éste casi está garantizada. La busqueda del 
edificio ya forma parte del PFG, potenciando competencias como la iniciativa y espíritu emprendedor, el aprendizaje autónomo, capacidad de análisis, toma de decisiones... El edificio debe poder ser inspeccionado sin grandes inconvenientes y la publicación del PFG, en abierto (en el repositorio de la UPCT), también debería estar garantizada (los inmuebles gestionados por algunas administraciones no siempre cumplen estas premisas y los propietarios particulares también pueden poner objeciones a visitar la totalidad del edificio).

Elegido el edificio, el trabajo comienza con la elaboración del índice general. Un documento "abierto", que se irá adecuando al desarrollo del PFG pero que sirve para organizar y planificar los contenidos a desarrollar. El primer capítulo se centrará en exponer los objetivos que se persiguen y la metodología empleada. Desde el primer momento, el alumno debe saber qué objetivos tiene que alcanzar. Normalmente, el análisis del estado de conservación, junto con la memoria histório-cultural, indicará la propuesta de intervención, que debe ser valorada económicamente (no con un extenso presupuesto pero sí con una valoración global de las intervenciones propuestas). Por tanto, el objetivo suele ser la intervención sobre las patologías detectadas y la correcta adecuación del edificio al uso actual o a otro uso (respetuoso con los valores patrimoniales del edificio y cumpliendo las diferentes normativas que le afecten). La búsqueda, selección y procesado de la documentación escrita e información oral (debidamente contrastada), debe enfocarse al conocimiento integral del inmueble y a los objetivos que se persiguen.

Normalmente, el trabajo empieza con un breve análisis de la historia del municipio en el que se ubica el edificio y un estudio más amplio de la época histórica y sociocultural en que se construyó. Continúa con el estudio histórico-cultural del propio edificio (quién lo proyectó y construyó, por qué, cómo ha evolucionado el inmueble), el análisis descriptivo (volumétrico y compositivo, posibles añadidos y/o desmontajes/demoliciones, elementos artísticos y decorativos) y el estudio constructivo (materiales y sistemas constructivos tradicionales y/o contemporáneos, su compatibilidad). Así mismo, se analizan las diferentes intervenciones que el edificio ha tenido durante su vida, poniendo especial énfasis en las últimas. Como se ha comentado, es fundamental que el alumno contacte con la dirección facultativa, la constructora y el promotor de esas intervenciones para documentarlas correctamente y hacer un análisis crítico-constructivo, que le servirá para su propuesta razonada de intervención integral. Toda esta información es básica para entender el valor Patrimonial del inmueble, su evolución e influirá en la toma de decisiones para su conservación.

Lógicamente, la realización de planos generales y de detalle ayudarán a entender el edificio, por lo que se realizará un completo levantamiento gráfico y de precisión (en los últimos años con escáner láser 3D y fotogrametría digital), con planos de alzados, plantas, secciones y detalles constructivos. Al tratarse de construcciones antiguas, hay que buscar el patrón de medida con el que se proyectó y construyó el edificio, sabiendo que hasta 1849 no se implanta en España el Sistema Métrico Decimal (uniformidad metrológica con el metro como medida básica). Por tanto, los planos deben reflejar la escala y el patrón de medida que se usó originalmente (en el caso del antiguo Reino de Murcia solía ser la vara de Burgos o vara castellana) y su correspondencia con el patrón actual. 
El estudio del estado de conservación, con el análisis de las patologías detectadas (localización e identificación de deterioros y lesiones, grado de incidencia/peligro, hipótesis sobre las causas y su evolución, necesidad o no de apuntalamientos u otras medidas urgentes, planimetría específica de patologías, fichas de deterioros/lesiones por elementos constructivos, etc.), es fundamental para afrontar posteriormente la propuesta de intervención. Así mismo, este análisis es una de las grandes aportaciones que el estudiante hace a favor de la restauración y conservación del edificio en cuestión, pues una copia del PFG se suele entregar al propietario del inmueble y otra al Servicio de Patrimonio Histórico, dependiente de la Direcc. Gral. de Bienes Culturales de la CARM, con lo que esto conlleva.

Y como paso previo a la propuesta de intervención, se realiza un estudio del grado de protección del edificio (según el PGMO y la normativa en Patrimonio Cultural en vigor) y las repercusiones respecto al estado actual de conservación, así como el cumplimiento de otras normativas, como la de accesibilidad, si es un edificio de pública concurrencia, la de eficiencia y ahorro energético, seguridad, etc.

Por tanto, este amplio conocimiento del edifico capacita al estudiante para plantear una intervención adecuada a las características y singularidad del inmueble, que resuelva las patologías detectadas y que sirva para adaptarlo a un uso que siempre debe ser respetuoso con todos sus valores patrimoniales. Así mismo, el PFG incluye una estimación económica, un presupuesto no excesivamente desglosado pero que sí permite estimar, por fases, las diferentes intervenciones que se han propuesto. $Y$ todo ello tutorizado por un profesor pero desarrollado por el/la alumno/a y bajo las premisas de conocimiento, implicación, responsabilidad y calidad del trabajo expuestas anteriormente.

Finalmente, el PFG incluye un capítulo de conclusiones en el que se hace un resumen del trabajo realizado, se comenta cómo se ha planificado y desarrollado éste, los objetivos que se marcaron y los logros conseguidos. Se destaca la importancia de los estudios realizados y las propuestas de intervención, razonadas y justificadas, para la conservación integral del edificio histórico analizado. Así mismo, la última reforma del Reglamento de Trabajos Fin de Estudios de la ETSAE obliga a entregar al menos dos láminas, impresas en formato A2, "que muestren el trabajo realizado". Este ejercicio de concreción del PFG desarrolla y potencia competencias instrumentales como la capacidad de análisis y síntesis, la gestión de la información documental y oral, la comunicación escrita y el razonamiento crítico, entre otras; competencias que serán muy importantes en el futuro profesional del estudiante.

Con la defensa pública del PFG, ante un Tribunal compuesto por tres profesores de la ETSAE, el alumno estimula su capacidad de exponer y defender sus ideas y trabajo, y lo debe hacer de manera clara, eficaz y motivadora, y en un tiempo máximo de 20 minutos. Este ejercicio potencia sobremanera la capacidad de síntesis y comunicación del alumno, fortaleciendo su lenguaje verbal (vocalización, volumen, fluidez, entonación...), no verbal (vestimenta apropiada, posición corporal, gesticulación, tensión visual con el tribunal y el auditorio...), y las competencias de creatividad e innovación, al tener que elaborar una presentación que reafirme y complemente su discurso, a la vez que lo diferencia y distingue positivamente del resto de PFG (de los ya defendidos y de los que, seguramente, se 
defienden también en la misma sesión). Toda una experiencia vital que le ayudará en su futuro profesional como arquitecto técnico, especialmente como dirección facultativa.

La publicación en formato pdf en el repositorio de la UPCT, en abierto, de los numerosos PFG desarrollados con esta metodología de conocimiento integral permite difundir tanto la propia metodología como los resultados, dando a conocer y poniendo en valor los edificios analizados. Además, las Jornadas de Patrimonio Cultural de la Región de Murcia, organizadas conjuntamente por la Direcc. Gral. de Bienes Culturales de la CARM y la UPCT y que se celebran anualmente (en 2021 será la XXVII edición), incluyen un bloque temático para la exposición oral y publicación, en el Libro de Actas, de los mejores PFG de la UPCT defendidos en el año anterior a las Jornadas y relacionados con el análisis integral del Patrimonio Arquitectónico, con lo que los egresados también disponen de un evento, donde participan numerosos profesionales que trabajan en el Patrimonio Cultural, para mostrar sus conocimientos y especialización. Un motivo más para potenciar la implicación y motivación del estudiante en la realización, con calidad, de su PFG

Por último, destacar que en 2017 el Colegio Oficial de Aparejadores, Arquitectos Técnicos e Ingenieros de Edificación de la Región de Murcia creó los "Premios COAATIEMU a Trabajos Final de Grado y de Máster", con el objetico de "dar visibilidad y divulgar el importante trabajo de investigación que se hace en las Universidades por parte de los arquitectos técnicos, reconociéndoles el gran esfuerzo y dedicación invertidos, y premiando a aquellos cuyos trabajos destaquen, por el interés que representan para la profesión o bien por el planteamiento del tema tratado y las conclusiones aportadas". A estos premios puede concurrir cualquier colegiado/a o precolegiado/a del COAATIEMU así como cualquier recien egresado/a de la UPCT, Universidad Católica San Antonio (UCAM) u otras universidades politécnicas con PFG relacionados con la edificación en la Región de Murcia. Y en las tres primeras ediciones, el $1^{\circ}$ Premio ha recaído en PFG realizados por alumnos de IdE de la UPCT y desarrollados con la metodología de trabajo expuesta en este texto. En 2017, el $1^{\circ}$ Premio recayó en el PFG con título "Arquitectura tradicional en Cehegín. El Hospital de la Real Piedad. Análisis histórico, constructivo y de patologías. Propuesta de intervención", realizado por el egresado D. Francisco Jesús Ondoño Llorente. En 2018, en el trabajo "Balneario Floridablanca en San Pedro del Pinatar. Análisis histórico-constructivo y de patologías. Propuesta de intervención", de D. Francisco Javier Tárraga Martínez que, además, obtuvo un reconocimiento a nivel nacional al ser galardonado con el $3^{\circ}$ Premio en la "Primera Edición de los Premios a Trabajos de Fin de Grado que concede el Consejo General de la Arquitectura Técnica de España". Y en 2019, en el PFG con título "Rehabilitación de la arquitectura histórica. Análisis integral de los trabajos de rehabilitación de pabellones del Cuartel de Artillería en Murcia", desarrollado por D. Víctor San Bernardo Hernández. Así mismo, otros trabajos desarrollados con esta metodología han recibido también el reconocimiento del COAATIEMU. En la edición de 2017, el PFG "Las murallas medievales de Mula (Murcia). Estudio integral y propuesta de restauración de la muralla del albacar", realizado por D. Juan Fernández Del Toro, obtuvo el $3^{\circ}$ Premio; y en la edición de 2018, el PFG con título "Edificios ferroviarios en el término municipal de Mula. Análisis 
histórico-constructivo y de patologías. Propuesta de intervención", de D. Francisco José Huertas Fernández, obtuvo el $2^{\circ}$ Premio. Por tanto, unos reconocimientos también a la calidad de estos PFG y a su importancia como herramienta para desarrollar y potenciar competencias genéricas y específicas del graduado en IdE y como recurso para la especialización de los técnicos en el campo del Patrimonio Arquitectónico.

\section{Algunas conclusiones}

Desde el curso 2000-2001 se imparte la titulación de Arquitectura Técnica en la UPCT, que se adaptará al EEES en el curso 2009-2010, impartiéndose como Grado en Ingeniería de Edificación. El modelo formativo y educativo que se desarrolla con los criterios del EEES incide en el concepto de autogestión del aprendizaje, potenciando la evaluación contínua y por adquisición de competencias (genéricas y específicas), y el aprendizaje autónomo, con lo que el estudiante adquiere mucho más protagonismo y responsabilidad en todo este proceso. Por tanto, el PFG debe realizarse con una metodología que dé respuesta a todas estas cuestiones. Es decir, el trabajo tiene que planificarse y desarrollarse con una metodología y unos criterios técnico-científicos y de carácter teórico-práctico (muy acentuados en las carreras técniccas), complementados con conceptos y planteamientos más "humanísticos" (especialmente cuando se analizan edificios monumentales). Unos trabajos adaptados a la consolidación y potenciación del máximo de competencias propias del egresado en IdE, así como con una metodología que permita controlar y evaluar la calidad del trabajo y la adquisición de esas competencias.

En el caso de PFG específicos y enfocados al análisis de edificios protegidos, incluso monumentales, la formación y especialización del estudiante en este campo y con la premisa del conocimiento integral, debe convertirse en uno de los grandes objetivos.

La motivación, implicación y responsabilidad del estudiante son básicas para la correcta realización de un PFG. Estas actitudes dependen, básicamente, del estudiante pero también pueden y deben favorecerse y potenciarse con el compromiso positivo, flexible y colaborador del profesor-tutor. La tutorías presenciales (u online, si no son posibles las presenciales) son muy importantes en este proceso de gestión del aprendizaje y motivación del estudiante, y en ellas el estudiante debe sentirse escuchado, respetado y valorado por su tutor. El alumno puede ser impulsivo y plantear propuestas no justificables, por lo que la labor del tutor debe centrarse en canalizar esta situación, pero nunca cohibir al alumno.

La metodología que se ha implantado y se sigue en la ETS de Arquitectura y Edificación de la UPCT, para desarrollar los PFG del Grado en Ingeniería de Edificación enfocados al análisis y propuesta de conservación de construcciones históricas, se basa en la idea de que estos Proyectos sirvan para fomentar y potenciar las competencias específicas y genéricas del egresado en IdE, así como en convertirse en una herramienta y recurso eficaz para la especialización en el ámbito del Patrimonio Arquitectónico y Cultural. Los casi veinte años de experiencia permiten afirmar que la realización de un riguroso análisis integral (estudio histórico-constructivo, planimétrico y de patologías detectadas), junto con las propuestas técnicas de intervención del edificio histórico para su futura restauración y 
conservación, se ha mostrado como una muy buena herramienta para la formación técnica y humana del estudiante. Una experiencia exitosa si se tienen en cuenta los premios que han recibidos los egresados de IdE de la ETSAE en reconocimiento al esfuerzo realizado, la calidad de la investigación, su difusión y el interés que representan estos PFG para el ejercicio de la profesión de arquitect técnico/ingeniero de edificación.

Por último, insistir en que el PFG debe organizarse y desarrollarse para mostrar cómo el estudiante ha asimilado e integrado los contenidos formativos recibidos durante su formación universitaria, pero también debe plantearse como una oportunidad para potenciar las competencias específicas y transversales del título en Arquitectura Técnica/Ingeniería de Edificación. Y en el caso de trabajos específicos en Patrimonio Arquitectónico, el PFG debe abordarse también como una oportunidad para el desarrollo emocional y la formación técnica integral del estudiante hacia el conocimiento, respeto y difusión del Patrimonio Cultural, con todo lo que esto conlleva social y profesionalmente.

\section{Referencias}

ALFARO GONZÁLEZ, J.; ARTEAGA MARTÍNEZ, J.J.; y VALVERDE CANTERO, D. (2012). Competencias básicas y herramientas docentes para la tutorización de Proyectos Fin de Grado en la titulación de Grado en Ingeniería de Edificación. En Las competencias básicas. Competencias profesionales del docente. Universidad de Castilla-La Mancha; pp. 761-770.

COLLADO ESPEJO, P.E. (2011). Autogestión del aprendizaje en el estudio del Patrimoniuo Arquitectónico: la experiencia del Taller de Restauración Monumental en la UPCT. En Congreso Internacional de Innovación Docente 2011. Cartagena. CRAI-Biblioteca. Universidad Politécnica de Cartagena; pp. 330-331 (abstract)

COLLADO ESPEJO, P.E. (2020). El Trabajo Fin de Grado: una oportunidad para la especialización en el análisis y difusión del Patrimoniuo Arquitectónico. En Anuario 3. Colección Docencia, Innovación, Investigación. Cartagena. CRAI-Biblioteca. Universidad Politécnica de Cartagena; pp. 130-135.

UPCT. Reglamento de Trabajos Fin de Estudios (Grado y Máster) en la Universidad Politécnica de Cartagena. Aprobado en Consejo de Gobierno del 7 de febrero de 2020.

ETSAE. Reglamento de Trabajos Fin de Estudios en la ETSAE. Universidad Politécnica de Cartagena. Aprobado en Consejo de Gobierno del 26 de febrero de 2020.

PÉREZ SÁNCHEZ, J.C. et al. (2019). Análisis, discusión y propuestas de mejora en el desarrollo de la asignatura Proyecto Fin de Grado del Grado en Arquitectura Técnica. En Memoria del Programa de Redes-I3CE de calidad, innovación e investigación en docencia univeritaria. Convocatoria 2018-19. Universidad de Alicante; pp. 2749-2766.

RAPOSO RIVAS, M.; ZABALZA BERAZA, M.A. (2011) La formación práctica de estudiantes: repensando el Practicum. Revista de Educación, n³54. Madrid. Ministerio de Educación; pp. 17-20. 
SÁNCHEZ CARRACEDO et al. (2015). El método socrático como guía del Trabajo Fin de Grado. En ReVisión, vol 8, n¹. UPC. Barcelona; pp. 53-62.

SANCHO SÁEZ, J. (2019). Técnicas de enseñanza para mejorar la motivación de los estudiantes. Revista Virtual Educrea. Biblioteca Docente.

VALVERDE CANTERO, D.; ARTEAGA MARTínEZ, J.J. y ALFARO GONZÁLEZ, J. (2012). Coordinación multidiscipplinar de PFGS en la titulación de Grado en Ingeniería de Edificación. En XVI Congreso Internacional de Ingeniería de Proyectos. Valencia, AEIPRO. Universidad Politécnica de Valencia; pp. 2511-2519.

ZABALZA BERAZA, M.A. (2011). El prácticum en la formación universitaria: estado de la cuestión. Revista de Educación n³54. Madrid. Ministerio de Educación; pp. 21-43. 


\title{
EDIFICATE
}

I Congreso de Escuelas de Edificación y Arquitectura Técnica de España València, 4 y 5 de noviembre de 2021

Escuela Técnica Superior de Ingeniería de Edificación

Universitat Politècnica de València

Doi: https://doi.org/10.4995/EDIFICATE2021.2021.13540

\section{Innovación docente en el Trabajo Final de Grado de Arquitectura Técnica y Edificación. La oportunidad del Aprendizaje participativo sobre casos reales}

\section{Teaching innovation in the Final Degree Project of Technical Architecture and Building. The opportunity for participatory learning on real}

\begin{abstract}
Fernando da Casa Martín ${ }^{a}$, Antonio Baño Nieva ${ }^{b}$ y Jorge Carlos Delgado García ${ }^{c}$ aEscuela de Arquitectura,, Universidad de Alcalá. fernando.casa@uah, 'bscuela de Arquitectura, Universidad de Alcalá, antonio.banno@uah.es, 'Escuela de Arquitectura, Universidad de Alcalá, jorge.delgado@uah.es,
\end{abstract}

\begin{abstract}
The experience resulting from a Teaching Innovation Project of the University of Alcalá is presented, implementing a new teaching methodology, experienced since 2011. This subject will be endowed with the concept of a subject, in an academic year, under a collective development, with works in team, and based on the development of real cases, has allowed to achieve a high level of results in the TFG, in a limited time. It is obtained from the student who follows the process, a result that combines all the skills and abilities acquired in the degree, as well as others of a transversal nature, such as a capacity for exposing and defending their work in a professional way. The results in the case of degrees that are characterized by being professional, are even more relevant. In turn, the monitoring of the methodology has made it possible to establish a continuous Improvement Plan. Specific problems in development are analyzed both from the student's point of view and from the teacher's point of view, including cross-cutting aspects, such as those derived from the obligation of Defense before Court.
\end{abstract}

Keywords: Final Degree Project, transversality, real cases, teamwork, participatory learning, professional attributions, teaching efficiency. 


\section{Resumen}

Se presenta la experiencia fruto de un Proyecto de Innovación docente de la Universidad de Alcalá, implantando una nueva metodología docente, experimentada desde 2011. Se dota a esta materia del concepto de asignatura, en un curso académico, bajo un desarrollo colectivo, con trabajos en equipo, $y$ en base al desarrollo de caso reales. Esto ha permitido conseguir un alto nivel de resultados en el TFG, en un tiempo acotado (un curso). Se consigue del estudiante que sigue el proceso, un resultado que aúna todas las habilidades y capacidades adquiridas en la titulación, así como otras de carácter transversal, como una capacidad de exposición y defensa de su trabajo de forma profesional. Los resultados en el caso de titulaciones que están caracterizadas por ser profesionalizantes, son aún más relevantes. A su vez el seguimiento de la metodología, ha permitido establecer un continuo Plan de Mejora. Se analizan las problemáticas específicas en el desarrollo tanto desde el punto de vista del estudiante, como desde el punto de vista del profesor, incluyendo aspectos transversales, como los derivados de la obligación de Defensa ante Tribunal.

Palabras clave: Trabajo Final de Grado, transversalidad, casos reales, trabajo en equipo, aprendizaje participativo, atribuciones profesionales, eficiencia docente. 


\section{Introducción}

El Espacio Europeo de Enseñanza Superior, conocido como "plan Bolonia", se desarrolla en España, según el Real Decreto 1393/2007. En esta norma se ordenan las enseñanzas universitarias oficiales. Una novedad académica es que todas las enseñanzas oficiales de grado concluirán con la elaboración y defensa de un trabajo de fin de Grado, que ha de formar parte del plan de estudios.

Como se indica en la documentación base para el desarrollo de todas estas titulaciones (ANECA 2012), el Trabajo de Fin de Grado deberá realizarse en la fase final del plan de estudios, y estar bien diferenciado del resto de módulos o materias. Tendrá entre 6 y 30 créditos. Estará orientado a la evaluación de competencias asociadas al Título, y deberá ser defendido ante un Tribunal. Este trabajo no podrá ser reconocido o convalidado.

Este tipo de trabajos tienen un antecedente directo en los Trabajos o Proyectos Final de Carrera de las titulaciones técnicas, diferenciadas notablemente por su aspecto profesionalizante y técnico (da Casa, 2008), En otras titulaciones hay un precedente en la denominada "tesina", si bien en el resto no hay referencias previas.

La "tesina", se definía como un trabajo científico monográfico, breve y original (UNAV 2016), con una extensión que rondaba los 50-100 páginas, que era la alternativa al examen para la obtención de las Licenciaturas (UCM 2016), y que no era obligatoria, pero que daba créditos para el doctorado, por lo que en algunos modelos responde a las exigencias formales de una Tesis, pero sin el rigor de esta. Si bien se defendía públicamente lo cierto es que cada institución tenía su modalidad, que regía todos los aspectos de la misma, por lo que no es un modelo coherente como referencia.

También es de referir la necesidad de innovación en este marco. La evolución de los sistemas docentes relacionados con las enseñanzas técnicas tiene su propio paradigma. $Y$ el sector de la Edificación no es ajeno a ello. En 2021, las necesidades de un profesional, así como las oportunidades laborales, enfoques y todo lo que conlleva, han sufrido un gran cambio. Si como docentes no estamos a ello e incluso nos adelantamos a estos cambios, estaremos haciendo un flaco favor a nuestros estudiantes.

Se debe tener en cuenta una singularidad particular en el amplio espectro de otras enseñanzas de Grado, y es el carácter habilitante y la consecución, junto con el título universitario, de las correspondientes "atribuciones profesionales". Esta circunstancia obliga a que los métodos de evaluación final aplicados garanticen y comprueben que el alumno ha adquirido adecuadamente "todas" las competencias que profesionalmente se le van a exigir; es una obligación social de las Universidades. El establecimiento del trabajo fin de grado ha provocado importantes debates sobre cómo deben ser los procesos de tutorización o lo criterios de evaluación (Rullán, 2010).

Los nuevos métodos pedagógicos en el campo del aprendizaje (el Aprendizaje Activo, el Aprendizaje Cooperativo, así como el Aprendizaje Basado en Resolución de Problemas), desarrollado para materias específicas (Ojeda, 2019) (Aristizabal, 2018), aportan nuevos 
puntos de vista en cuya combinatoria puede encontrarse un proceso metodológico de aprendizaje de gran potencial en el ámbito de las Enseñanzas Técnicas.

Es a partir de esta situación en la que aparece la necesidad de buscar un modelo, y experimentarlo de modo que se conozcan las diferentes variantes y posibilidades de adaptar dicho modelo a cada titulación, más aún en la oportunidad que significa el momento con las primeras acreditaciones de los Grados que se implantaron en primer lugar.

\section{Objetivos}

El objetivo principal pues es la búsqueda de una metodología estratégica, como innovación docente, un método específico de desarrollo y evaluación de la adquisición de las competencias obtenidas por el alumno, en su proceso final de la titulación, considerando la viabilidad que el aprendizaje activo y participativo aplicado sobre casos reales.

Además, se plantean una serie de objetivos secundarios concretos, como son:

- Dotar al alumno de las habilidades y capacidades de carácter transversal, en base a una autonomía responsable, dentro de un trabajo colaborativo, multidisciplinar, en equipos, capaz de resolver problemas complejos y con capacidad de comunicar, transmitir y defender sus resultados.

- Determinar los procesos de coordinación que permitan el desarrollo en paralelo de las diferentes materias del mismo curso, y del resto de la titulación, y que favorezcan el apoyo mutuo del conocimiento a adquirir.

- Dotar a la metodología de un carácter flexible, de modo que permita ser aplicada en diferentes niveles, en función de la titulación, en el caso de otras ramas de conocimiento.

\section{Desarrollo de la innovación. Un cambio de concepto con los planteamientos clásicos de los PFC.}

EI TFG es un buen momento para poner en práctica la creación una dinámica de aprendizaje continua por parte del alumno. Es decir, iniciar a los alumnos en el autoaprendizaje, y como autogestionarlo, introduciéndoles en el cómo tendrán que hacerlo en su futuro profesional, en una sociedad más cambiante que nunca y que plantea nuevas necesidades.

Se plantea aquí, una propuesta para el desarrollo de los TFG, que modifica sustancialmente la forma de desarrollo más habitual, con la finalidad de realizar un ajuste más real de los trabajos a la finalidad de este tipo de materia, y permitir al estudiantado el desarrollo de su formación dentro de unos plazos concretos de tiempo (un curso).

Se plantea el TFG configurado como una asignatura colectiva de temporalidad anual, lo que da mayor margen para el "reposo" y reflexión para la fase de ideas, proceso de investigación, búsqueda de datos, toma de decisiones, con menor dedicación temporal semanal que si fuera 
cuatrimestral (al ser las mismas horas totales). De este modo se acota el plazo de ejecución, y el estudiante aprende al manejo de plazos parciales y totales.

El TFG debe tener una componente de realidad y relacionado con el ámbito de trabajo profesional, siendo capaz de desarrollar sus diferentes partes. Con un carácter eminentemente práctico, sin mayores aportaciones de conocimiento, de modo que permita interrelacionar los conocimientos adquiridos, acercando el mundo profesional.

El modo de trabajar es en conjunto. Con una distribución docente en grupos de 12 a 35 estudiantes, donde cada grupo desarrolla una misma temática establecida previamente por los tutores. Los trabajos dispondrán de dos fases fundamentales, una con carácter colectivo de inmersión en investigación en la temática objeto del TFG, y que servirá de base común para todo el alumnado, y su desarrollo posterior de propuestas, en equipos de 3 estudiantes, pero dentro del conjunto del grupo. Esto permite conocer el trabajo colectivo, la necesidad de los roles, la organización y responsabilidad de tareas. Se llega a profundizar en los temas hasta un nivel superior que el trabajo individual. Todo ello con dos o tres tutores por cada grupo, lo que permite al estudiante disponer de diferentes puntos de vista, lo que enriquece y obliga a generar una opinión propia.

Con el planteamiento de este nuevo modelo se plantean las siguientes prioridades:

- El contenido del trabajo y su desarrollo debe tener un carácter polivalente, su cronología debe ser clara y transparente para el estudiante y conocida de forma previa. Para ello se establece un dossier inicial de curso elaborado por los tutores.

- $\quad$ El TFG no debe ser solo un compendio de las habilidades y materias de la titulación. No se trata de aporta mayor nivel de conocimiento, sino de permitir demostrar el desarrollo simultáneo de las habilidades adquiridas durante el Grado.

- Se plantea complementar además otras competencias y habilidades, de carácter transversal (trabajo en equipo, capacidad de mostrar y defender el trabajo), que tendrán gran valor posterior en su desarrollo laboral.

- De este modo se cumplen, además de los objetivos fundamentales "oficiales" del TFG, respecto de mostrar las capacidades y habilidades adquiridas por el estudiante, aplicadas a la resolución de cuestiones reales y próximas a su desarrollo laboral, y dotar al estudiante de otras habilidades fundamentales en el mundo laboral actual.

- Podríamos considerarlo como el último paso del conocido estudio por competencias (proyecto Tuning), definido como la capacidad de movilizar recursos cognitivos para hacer frente a un tipo de situaciones (Perrenoud, 2004).

- Otro concepto del cambio propuesto es el de la presencialidad del profesorado. En el modelo propuesto al tratarse de la consideración de ser una materia, esta tiene implementada un número de horas de presencialidad por grupo, en la que además de tener incluidas la correspondiente al desarrollo de la materia se incluye la asistencia a los Tribunales. 


\subsection{El desarrollo de la propuesta en un curso}

Como se ha indicado se plantea que el TFG se desarrolle en un curso académico, con el siguiente tipo de actividades:

\subsubsection{Sesión Inicial}

Se establece con la totalidad de los estudiantes matriculados (asistencia obligatoria), y con representación de los tutores. Con las siguientes acciones:

Presentación del modelo de Trabajo, las temáticas previstas, los contenidos, finalidad y metodología a desarrollar, cronograma de acciones, y el proceso de evaluación.

Distribución de los estudiantes por grupos (caso de haber varias temáticas, según el número de estudiantes). En caso de haber una solicitud de estudiantes para un tema concreto mayor en número que las plazas disponibles, se establece un criterio de selección en función de la calificación obtenida en la materia afín a la temática elegida, o bien mejor expediente académico general.

Los estudiantes que desarrollan su TFG en estancias en el extranjero, o en otros Centros de Investigación o Universidades, se rigen por los mismos aspectos anteriores, si bien la presencialidad y seguimiento de su trabajo será especial.

\subsubsection{Sesiones de Grupo completo de estudiantes}

Una vez establecidos los grupos, los tutores establecen el método de desarrollo de la temática propuesta. A su vez se distribuyen los subtemas a desarrollar por cada equipo, así como los objetivos de cada uno de ellos. Se establecen las bases documentales y trabajos previos a realizar.

En una fase inicial se desarrolla una labor de investigación para tener un marco de referencia completo que permita un mejor conocimiento del tema al grupo y tener criterios y argumentos justificativos para la toma de decisiones en las fases siguientes.

Se planifica la asistencia periódica a las actividades y sesiones que se programen, y que tendrán su reflejo en el calendario del curso. Estas sesiones son de tres tipos:

Sesiones de Control o tutorización global, donde se analiza la evolución de cada trabajo y se establecen las premisas que con carácter general se aplican para todos los trabajos, así como las relaciones que deben existir de forma transversal entre todo el grupo. Se establece una periodicidad mínima de una al mes.

Sesiones de tutorización individual. Estas sesiones se dedican a la resolución de dudas por cada grupo de trabajo o estudiante. Dentro de las actividades de tutorización individual del profesor.

Sesiones de conferencia, visitas técnicas o charlas específicas de temas afines con el desarrollo del tema, a modo de seminarios. Se establecen de forma alterna con las sesiones de control. 
En la última sesión de control los tutores deben determinan si el trabajo desarrollado en el curso por el estudiante (o grupo) ha alcanzado el nivel suficiente, mediante una exposición a modo de "ensayo general" de la Defensa y la entrega de un dossier escrito. Si es superada se obtiene la autorización para ser presentado a su evaluación mediante Tribunal en sesión de Defensa Pública. Este paso implica la obtención del nivel mínimo de aprobado. En la fase siguiente se determina la calificación por encima de este valor. Se indican además las condiciones individuales para su presentación, recordando que es condición imprescindible tener aprobado el resto de los créditos de la titulación para proceder a la defensa del TFG. Caso de no ser así por parte de algún miembro de algún equipo se procede del modo más oportuno.

\subsubsection{La defensa pública ante Tribunal}

Una vez los estudiantes han obtenido el visto bueno de los tutores, la evaluación final se realiza ante Tribunal en sesión de Defensa Pública, con la entrega del dossier final definitivo, su exposición y defensa.

Cada Tribunal está formado por tres miembros, entre los profesores de la titulación que no han participado en el desarrollo del trabajo, y en caso de no haber quórum se incorporará al menos uno de los profesores tutores. No todos los trabajos tienen que ser evaluados por el mismo Tribunal.

Cada grupo debe entregar previo a su defensa, en formato digital, la presentación que se vaya a realizar ante el tribunal. Tiene un tiempo máximo de 30 minutos para presentar su defensa, y posteriormente estará a disposición del Tribunal para responder a las preguntas que se le hagan por otros 30 minutos.

Estas sesiones son públicas y abiertas a toda persona que quiera asistir, permitiendo el acceso a la sala, en los momentos previos a cada defensa, por respeto a los estudiantes que defienden su trabajo.

Finalizadas todas las sesiones de Tribunal, se reúne de forma conjunta la Comisión del TFG, formada por los Profesores que han conformado los Tribunales y los profesores tutores, junto con la Dirección del Centro, para proceder a la evaluación y establecimiento de calificaciones individuales de cada estudiante, teniendo en cuenta el proceso del Tribunal, junto con el desarrollo continuo del curso aportado por los tutores.

\subsection{La experiencia. TFG desde 2011-2012 a 2020-2021}

Para aprovechar la situación del grado de Ciencia y Tecnología de la Edificación, de ser el primer grado de la UAH en implantar el $4^{\circ}$ curso, y el primero en tener que implantar el nuevo modelo del Trabajo Final de Grado (TFG), con una carga de 12 ECTS, y un desarrollo previsto inicialmente en el segundo cuatrimestre de $4^{\circ}$ curso, se estableció el Proyecto de Innovación docente de la Universidad de Alcalá, con código UAH/EV358, que conllevaba una experiencia piloto (da Casa, 2012), iniciada el curso 2010/2011. En dicho curso no hubo estudiantes de TFG, pero se establecieron las bases, y planteamiento metodológico, sometido a debate en la comunidad universitaria de la Escuela. 
Desde el curso 2011/12 se ha mantenido el control experimental y la aplicación de mejoras continuadas, hasta la actualidad. Se debe indicar que se ha dejado fuera de este modelo lo correspondiente al Curso de Adaptación que se desarrolló en paralelo a la implantación de la titulación em los primeros años.

El número de estudiantes en estos cursos ha variado sustancialmente. Así en el curso 2011/12, hubo 32 estudiantes matriculados. En el curso 12/13, hubo 93 estudiantes. En el curso 13/14, hubo 79 estudiantes. Continuando el descenso progresivo hasya la actualidad, que en el curso 2020/21, han sido 25 los estudiantes matriculados.

Este descenso, está relacionado con la crisis económica de gran afección en el sector de la Construcción, y que ha repercutido en el interés por la titulación, si bien se debe indicar que se detecta una ligera recuperación en las matrículas de nuevo ingreso en nuestro grado.

\section{Resultados de la experiencia}

\subsection{Respecto de los contenidos desarrollados}

Los estudiantes consiguen durante el curso, una gran vinculación con la temática, a través de una primera fase de investigación y toma de datos, que permite conocer y poder disponer de criterios propios en la toma de decisiones posteriores, y por tanto el nivel de asimilación y desarrollo es muy alto, lo que se traduce en una gran implicación en todo el proceso. La posibilidad de realizar propuestas innovadoras, conociendo las consecuencias, consigue un resultado muy efectivo del trabajo, con una alta capacidad de defender sus argumentos por parte de los autores. El nivel alcanzado supera las expectativas iniciales de cada curso.

Es de significar que muchos estudiantes utilizan el dossier del TFG, a modo de ejemplarizar su capacidad de trabajo profesional, presentándolo en diferentes entrevistas de recursos humanos. Estos Departamentos nos han comunicado la gran visibilidad que para ellos tienen en dichos trabajos, los aspectos fundamentales que ellos buscan en sus procesos de selección.

Se presenta a continuación un breve resumen de los trabajos realizados en la experiencia en estos cursos:

4.1.1. Curso 11/12. Tema: La ciudad como laboratorio de la escuela. Estudio para la implantación de un campus universitario en Guadalajara

Se realiza un estudio del estado actual del funcionamiento de la ciudad de Guadalajara, para un análisis de la implantación de un campus universitario, en la ubicación que se determinara más adecuada. Se analizan los condicionantes y cómo influyen en la ciudad. Se analizan los factores de influencia de la nueva implantación y las consecuencias directas e indirectas, así como la modificación del funcionamiento actual de la ciudad en caso de implantación. Se analizan las posibles ubicaciones en la ciudad y tras un análisis comparativo se opta por una ubicación. Se determinan las necesidades del nuevo campus y se analizan las alternativas 
de organización, de acciones y su cronograma (fig 1). Todo ello se completa con el estudio económico de la implantación.

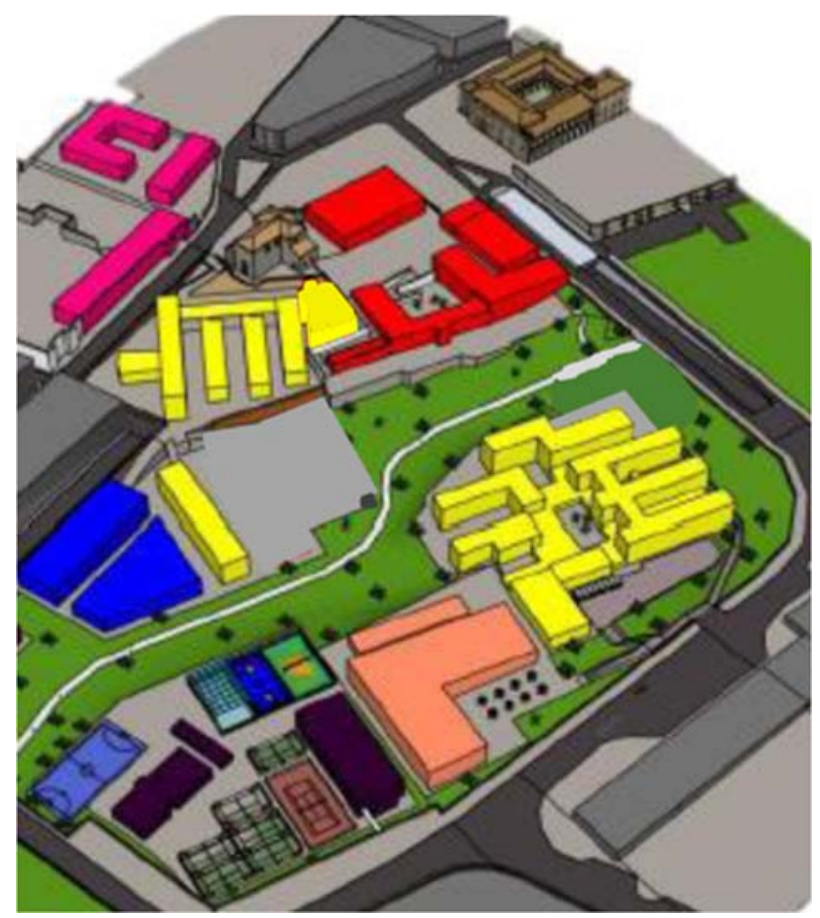

Fuente: Elaboración propia del curso

Fig. 1 Representación 3D del análisis de una de las propuestas. Fuente: Elaboración propia del curso.

\subsubsection{Curso 13/14. Tema: La gestión del Patrimonio Mundial. Aplicación en la Universidad de Alcalá}

El trabajo plantea realizar una aproximación interdisciplinar a diferentes modelos y fórmulas de planificación de la gestión del patrimonio histórico mundial. La Gestión es una herramienta fundamental, y más en el caso del Patrimonio Mundial. Se trata de integrar en un único proceso todos los factores, aspectos, o planes que suelen disponerse de forma individualizada para tener una visión de conjunto, coordinada y práctica, detectando y resolviendo las carencias y contradicciones, y aportando nuevas ideas para su desarrollo, optimización y puesta en valor (fig 2). El papel del técnico-gestor es fundamental.

El objetivo es enfocar todo el planteamiento al caso concreto de la Universidad de Alcalá, como parte del Patrimonio Mundial desde 1998. 
Se da una visión del tema enfocada al papel de la gestión como parte de la labor profesional en edificación, cada grupo de estudiantes plantea una propuesta concreta para poner en valor el Patrimonio de Alcalá en relación con la Universidad
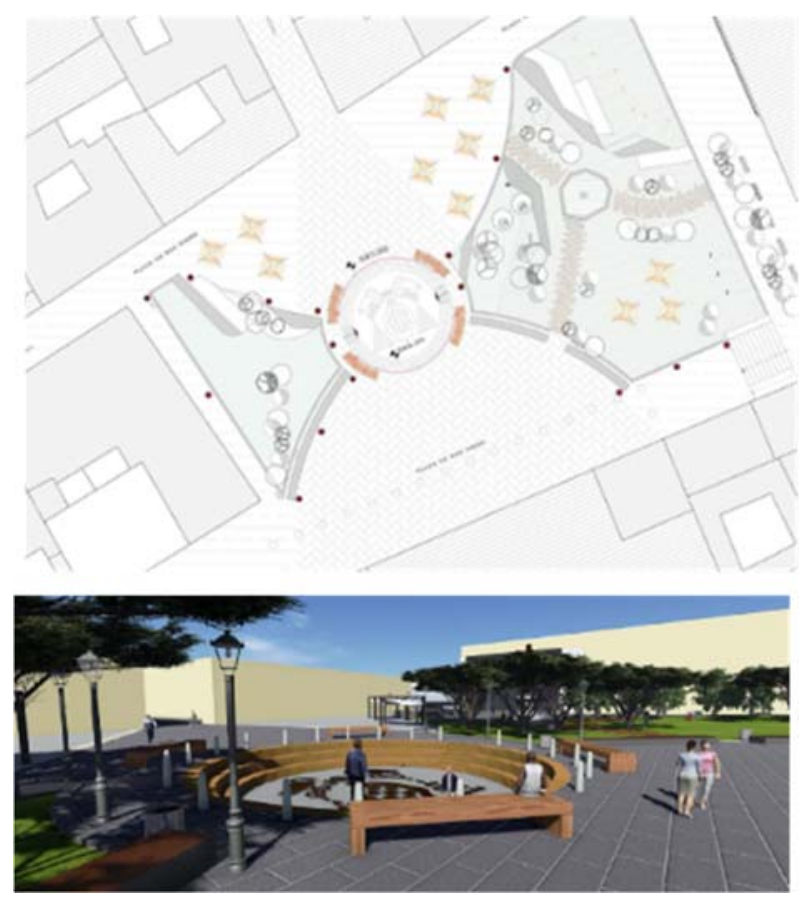

Fuente: Elaboración propia del curso

Fig. 2 Representación en planta y en 3D del análisis de una de las propuestas.

\subsubsection{Curso 15/16. Tema: La innovación aplicada a la edificación. Intervención en edificios} para su adecuación a un nuevo campus universitario del siglo XXI en Guadalajara”

La creación de un campus universitario acorde al siglo XXI, suponía integrar dicho campus con el entorno de la ciudad y adaptarlo a las necesidades que éste requería, respetando en todo momento el impacto que podría tener en la zona de intervención, considerando el análisis minucioso de la situación, junto con la fusión de la eficiencia energética y las energías renovables, para así poder alcanzar una sustentabilidad sólida e importante. Es una evolución del trabajo realizado en el curso 11/12, que se toma como referencia de partida.

Los aspectos de organización del campus, contribuyen a fomentar la participación e interrelación social con personas de diferentes formaciones académicas y experiencias profesionales, consiguiendo así una ampliación de perspectiva de trabajos y análisis, los cuales se deberán aplicar posteriormente en la vida laboral, en la cual se trabajará en equipos multidisciplinares (fig 3). 


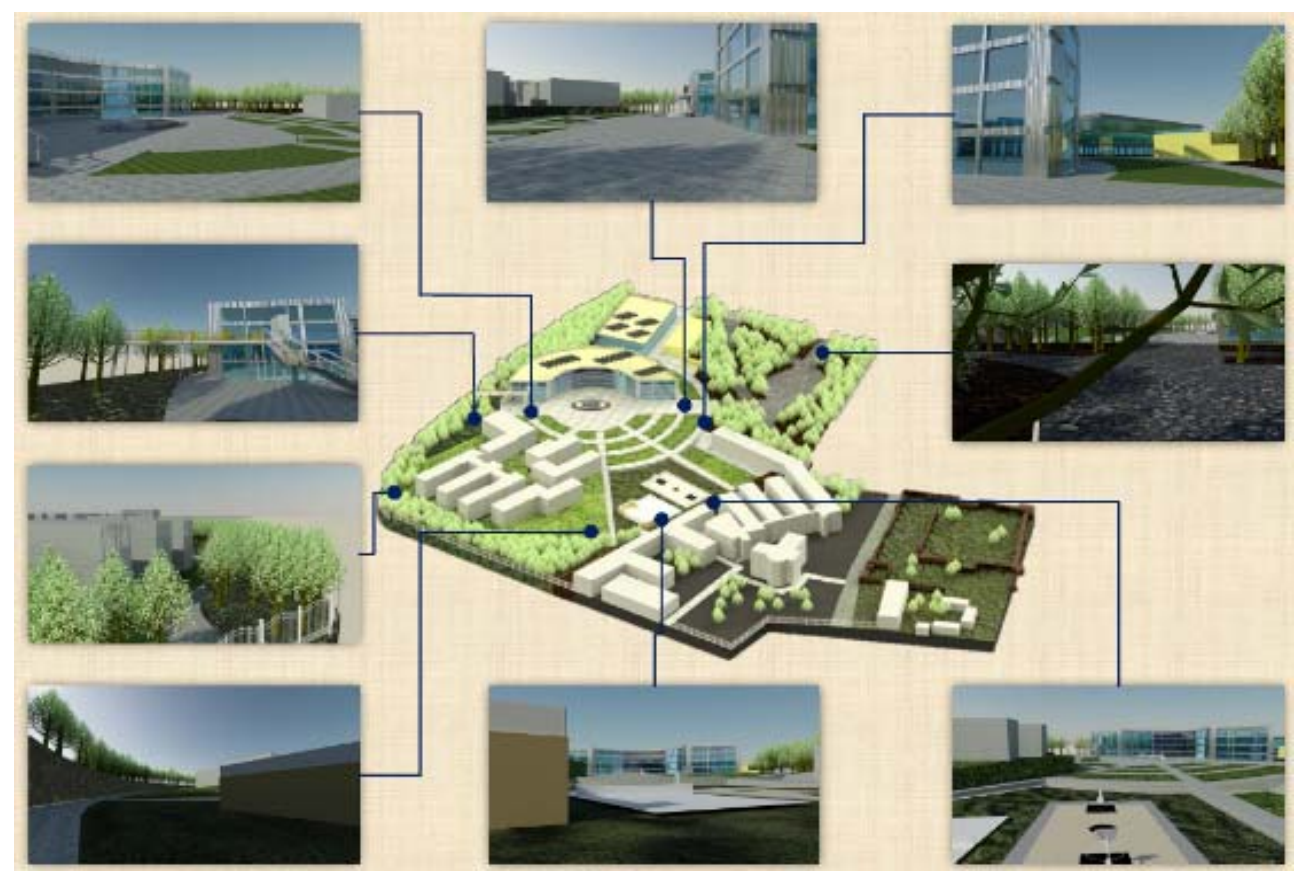

Fuente: Elaboración propia del curso

Fig. 3 Representación en 3D del análisis de una de las propuestas.

\subsubsection{Curso 19/20. Tema: La puesta en valor de la innovación tecnológica aplicada a la edificación}

Se presenta una gran oportunidad de aprovechar las nuevas tendencias del mercado, así como del campo de investigación sobre avances tecnológicos en la edificación y la obra civil. Algunas de las líneas en las tecnologías que están apareciendo ya en las edificaciones y procesos de construcción que nos rodean. La incorporación de procesos tecnológicos innovadores al sector de la edificación se ha dado gracias a la amplia utilidad y adaptación de estos.

Es a partir de esa premisa, donde se plantea como oportunidad la integración de esta temática como motivo principal del ejercicio académico del TFG, para tratarlo desde un enfoque especial, específico, técnico y cultural. La necesidad de integrar aspectos de nuevas tecnologías, sostenibilidad, usos, formas de entender, de vivir o disfrutar, y la implementación de nuevos elementos compatibles con la disposición de elementos construidos con otras 
técnicas y materiales (fig 4), es un reto para el que no hay una consideración profesional desarrollada.

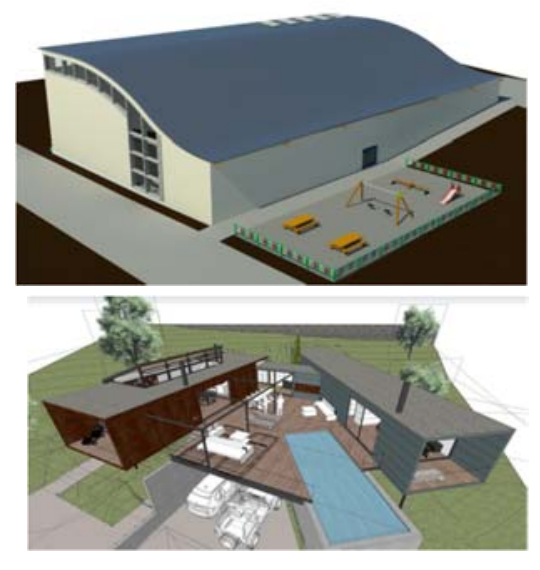

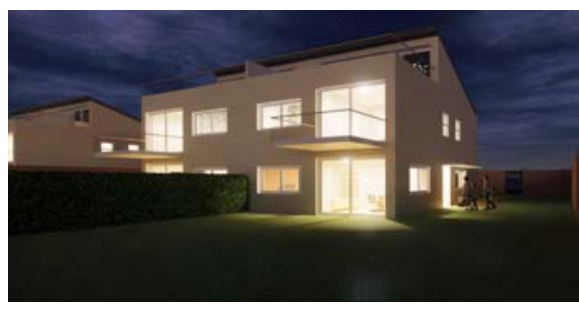

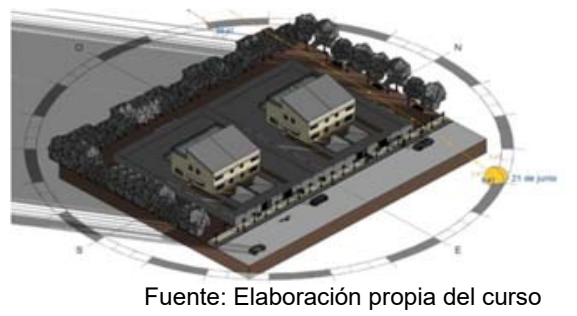

Fig. 4 Representación en 3D del análisis de varias de las propuestas. Fuente: Elaboración propia del curso.

\section{2. .- Respecto del estudiantado: participación y resultado}

La participación y seguimiento del estudiantado en los diferentes cursos ha sido muy alta, teniendo en cuenta el carácter presencial de las sesiones así establecidas. Plantear el curso de forma anual, y con el trabajo planificado de tal modo, permite que los estudiantes con materias pendientes puedan simultanearlo con el TFG y la coordinación con el profesorado, sin un gran esfuerzo adicional. El trabajo en equipo también favorece esta circunstancia.

El grado de eficiencia del resultado de los estudiantes del curso convencional es muy alto (no se consideran los datos del curso de adaptación por su situación de singularidad y no estar integrados en el modelo de estudio, ya que distorsionarían los resultados obtenidos del modelo propuesto).

Los estudiantes que desarrollan el curso, prácticamente la totalidad de los matriculados, superan el curso (92.9\%), en la totalidad de los cinco cursos solamente se ha suspendido a dos estudiantes (por no cumplir los requisitos de contenido en la documentación presentada al Tribunal). El dato del $6.5 \%$ de estudiantes que no presentaron sus trabajos es debido al no haber superado la totalidad de las materias de la titulación, por lo que no podían proceder a la Defensa ante Tribunal por norma.

Un aspecto relevante para conocer el nivel adquirido por los estudiantes es su propia opinión. Para ello podemos considerar las referencias que se obtienen de los trabajos finales, en sus valoraciones personales aportadas, que expresan de un modo claro el sentir al respecto. Por no ser extensivo, incorporamos algunas de estas referencias del pasado curso15/16, que resumen de un modo conciso este aspecto: 
La realización de este trabajo nos ha permitido desarrollar diferentes cualidades de trabajo en equipo, las cuales son muy importantes de cara a nuestro futuro personal y laboral.

La constante comunicación que ha existido en el desarrollo de la propuesta, ha facilitado el desarrollo de un espíritu de trabajo en equipo muy amplio, compartiendo una diversidad de opiniones, conocimientos y aptitudes.

La fluidez de esta comunicación y el apoyo constante entre los miembros del equipo, ha sido determinante para incentivar la motivación a lo largo del desarrollo del trabajo.

La motivación que se ha logrado desarrollar, ha sido la clave fundamental para alcanzar la perseverancia necesaria que requería la realización de esta propuesta, mejorando nuestra capacidad de respetar los plazos de entrega.

El conjunto de todas estas determinaciones, han sido la esencia fundamental del trabajo, las cuales nos han permitido avanzar en una misma dirección alcanzando los objetivos que nos habíamos propuesto. (García, 2016, p 98)

Desde otro punto de vista, se puede observar el nivel que los estudiantes muestran en su defensa ante el Tribunal, donde se llega a escuchar comentarios públicos en el debate por los miembros del Tribunal como "haber escuchado a un Grupo de profesionales".

\subsection{Respecto del profesorado participante}

Relevante es el interés mostrado por el profesorado. Su nivel de participación en el proceso evaluador ha sido muy alto. La participación es voluntaria, previa solicitud general, y siempre hay más candidatos que plazas, de hecho, en ocasiones se han configurado tribunales con más miembros de los tres requeridos. Se advierte la "ilusión" y motivación del profesorado, toda vez que la gran mayoría han sido estudiantes de sus materias y les permite ver la evolución de los mismos. Algunos profesores, han asistido a la sesión de Defensa, como público, al efecto de ver los resultados obtenidos. Es de agradecer dicha asistencia al mostrar el interés despertado por el modelo de trabajo.

Por otro lado, respecto del trabajo correspondiente a los tutores, el cambio del sistema obliga a una alta dedicación, si bien al tratarlo como una asignatura en equipo, y con la participación de varios profesores, este es más equilibrado. El cómputo de "carga docente" acordado con el Vicerrectorado, de $75 \mathrm{~h}$ por grupo (se ajusta a la docencia a impartir, e incluso incorpora las horas de Tribunal correspondientes. Este efecto se refuerza con el carácter voluntarista que caracteriza la Escuela, si bien el procedimiento descrito en este documento implica que queda poco margen para la "improvisación", o para la tutorización extemporánea y no organizada, más propia del proceso de tutorización del modelo anterior.

Un factor fundamental es que el profesorado participante dentro del proceso de esta materia, en su papel como "tutor o Director del trabajo" tenga un alto grado de coordinación, además de tener un gran compromiso con el proceso y metodología de trabajo. 


\subsection{Respecto del proceso evaluador: el Tribunal}

Los procesos de evaluación realizados hasta la fecha, han levantado un alto grado de expectación tanto entre el profesorado como en el alumnado, lo que se comprueba en la gran afluencia de público en las sesiones, además de familiares y amigos. Incluso se debe indicar que algunos profesores han manifestado su interés en participar en otras sesiones del mismo tipo de ejercicio de forma voluntaria.

Se debe indicar el alto grado de "efectividad" y "seriedad" que aporta al procedimiento el hecho que el Tribunal esté conformado por miembros del profesorado de la Escuela, pero que no formen parte del grupo de tutores, ya que de este modo los estudiantes consideran dicha evaluación, de mayor interés y con un grado de "neutralidad" ante el trabajo a presentar mucho mayor, favoreciendo el carácter profesional de la Defensa Pública del Trabajo, lo cual con posterioridad nos manifiestan los estudiantes que es de agradecer en su proceso de aprendizaje.

Los debates posteriores a la exposición tratan aspectos de gran profundidad, permitiendo a los alumnos desarrollar sus habilidades, consiguiendo transmitir su implicación y profesionalidad más allá de la exposición, aportando esto un aspecto diferencial muy positivo.

En todos los cursos se ha invitado a miembros del equipo rectoral a participar en alguna de las sesiones del Tribunal. Han asistido el Vicerrector del Campus de Guadalajara, el de Profesorado, el de Estudiantes, el Gerente de la Universidad, y la Directora de la Escuela de Arquitectura (antes de la fusión de centros), algunos de ellos han repetido. En el procedimiento de evaluación se ha visto con un alto grado de carácter positivo este hecho, con aporte de puntos de vista externos a la titulación.

\subsection{Respecto de la trascendencia del modelo de proceso para el TFG}

El modelo de TFG, en su fase inicial, fue propuesto para su desarrollo y aplicación de forma oficial en la Titulación de Ciencia y Tecnología de la Edificación, siendo aprobado en Junta de Centro de 13/12/2010. El resultado del Proyecto de innovación docente referido, en su informe recopilatorio del curso 2013/2014, (da Casa, 2014) fue utilizado como base para la redacción de la Normativa de Trabajos Fin de Grado de la UAH, aprobada en Consejo de Gobierno el 18/06/2015 (UAH 2016).

El Reglamento específico para el Grado de Ciencia y Tecnología de la Edificación, de la Escuela de Arquitectura, se modificó y fue aprobado en Junta de Escuela de Arquitectura de 19/10/2015, e informada favorablemente en Comisión de Docencia de la UAH el 4/12/2015. Siendo de aplicación desde el curso 2015/2016. Desde entonces se ha continuado con la implantación progresiva de los resultados del proceso de mejora, tras el análisis de los resultados de cada año, y el planteamiento del curso siguiente. 


\section{Conclusiones}

Se podría concluir que el TFG se debe considerar como el primer paso del aprendizaje continuado o aprendizaje permanente (Long Life Learning) como parte de la filosofía que fundamenta el EEES y que permite hacer que las personas puedan adaptarse mejor a los cambios continuos que se muestran en la sociedad y por tanto en el mundo laboral y empresarial, aspecto que además ya aparecía en el eje $n^{\circ} 9$ de la "Estrategia Universidad 2015" (Ministerio de Educación 2011).

La propuesta de metodología presentada y experimentada como experiencia de forma continuada desde 2011, presenta un modelo experimentado y aplicado, en base a criterios participativos y activos por parte del alumno, y relacionado con la resolución de problemas con una fuerte componente real, y en base al trabajo multidisciplinar, en equipos, y con una fuerte necesidad de exponer y defender las soluciones propuestas, con un resultado óptimo, que se muestra en los indicadores relativos del alumnado, favoreciendo la continuidad de los alumnos del curso, y con ello de superación de las materias. Además, en su proceso final, el alumno obtiene una serie de competencias trasversales como son: autonomía responsable, trabajo colaborativo, capacidad de resolver problemas complejos, y con capacidad de comunicar, transmitir y defender sus resultados. La calidad y profundidad técnica de los trabajos deja patente la evolución del alumnado. Todo ello redunda en una aproximación al mundo laboral.

Además, el método planteado es fácilmente exportable a cualquier tipo de titulación, independientemente de la Rama de Conocimiento, y entra dentro de los habituales procesos de cómputo de la dedicación docente del profesorado. El proceso de control y mejora continua desarrollado, permite disponer de un modelo más avanzado, y con mayor garantía de resultado para no caer en las dificultades ya consideradas, pudiendo optar por la solución que más se adapte a las características propias de cada titulación.

\section{Referencias}

ANECA (2012) Guía de Apoyo para la elaboración de la memoria de verificación de títulos oficiales universitarios (Grado y Máster) Agencia Nacional de Evaluación de la Calidad y Acreditación (ANECA) Recuperado de https://www.uchceu.es/docs/calidad/tramite-titulaciones/guia-ANECA.pdf

ARISTIZABAL, J.L.; RAMOS, A.; CHIRINO, V. (2018). Aprendizaje activo para el desarrollo de la psicomotricidad y el trabajo en equipo. Revista Electrónica Educare (Educare Electronic Journal) Vol. 22(1)

DA CASA, F., GARCíA, A., BAÑO, A., RODRÍGUEZ, F.J., MARÍN, A., CORIA, G., ... , DELGADO, I. (2008) "Sistema de evaluación y gestión del TFC. La comisión del tribunal final de carrera de la EUAT de Guadalajara de la UAH“. Actas del I Encuentro Internacional Profesores Proyecto Final de Carrera de Arquitectura Técnica. Ed Universidad Politécnica de Valencia.

DA CASA, F., (2012). "EI Trabajo Final de Grado. Una experiencia innovadora aplicada en las titulaciones Técnicas". VI Encuentro de Innovación en Docencia Universitaria Propuestas interdisciplinares e integradas. Universidad de Alcalá. 2012. 
DA CASA, F., GARCÍA, A., FERNÁNDEZ, E. (2014) "La implantación del Trabajo Final de Grado en las nuevas titulaciones. La situación concreta del grado de Ingeniería de Edificación (ciencia y tecnología en la edificación) como experiencia piloto en la Universidad de Alcalá (proyecto de innovación docente UAH/EV358)". XIII International Conference on Engineering and Technology Education. Guimarães - PORTUGAL.

GARCÍA, C., GARCÍA, F., ORTIZ, S. (2016) "La innovación aplicada a la edificación. Intervención en un nuevo campus universitario del siglo XXI en Guadalajara. Adecuación y multifuncionalidad del campus, sostenibilidad energética y gestión de la energía eléctrica" Trabajo de Fin de Grado Ciencia y Tecnología de la Edificación, Curso 2015/2016. Universidad de Alcalá.

MINISTERIO DE EDUCACIÓN (2011) Estrategia universidad 2015. Contribución de las universidades al progreso socioeconómico español 2010-2015. Octubre 2010. Secretaría General de Universidades. Ministerio de Educación. Madrid

OJEDA, J. (2019). Técnicas activas y su contribución al aprendizaje de la matemática en estudiantes de séptimo grado. CIENCIAMATRIA, 5(9), 517-535. https://doi.org/10.35381/cm.v5i9.211

PERRENOUD, P. (2004). Diez nuevas competencias para ensenar. Editorial Grao. Barcelona (España).

RULLÁN, M; FERNÁNDEZ, M, ESTAPE, G, MÁRQUEZ, M.D. (2010). "La evaluación de competencias transversales en la materia trabajos de fin de grado. Un estudio preliminar sobre la necesidad y oportunidad de establecer medios e instrumentos por ramas de conocimiento". Revista de Docencia Universitaria, Vol. 1. № 8: 74า100.

UAH (2016) Normativa sobre los Trabajos Fin de Grado de la Universidad de Alcalá. Recuperado de https://www.uah.es/export/sites/uah/es/conoce-la-uah/organizacion-y-gobierno/.galleries/GaleriaSecretaria-General/Normativa-Trabajos-Fin-Grado.pdf

UCM (2016) Instrucciones para elaboración de la Tesina. Facultad de Biología. Universidad Complutense de Madrid. Recuperado dehttp://biologicas.ucm.es/tesina_de_licenciatura_1

UNAV (2016) Instrucciones para elaboración de la Tesina. Facultad de Teología. UNAV. Recuperado de www.unav.edu/web 


\title{
EDIFICATE
}

I Congreso de Escuelas de Edificación y Arquitectura Técnica de España

València, 4 y 5 de noviembre de 2021

Escuela Técnica Superior de Ingeniería de Edificación

Universitat Politècnica de València

Doi: https://doi.org/10.4995/EDIFICATE2021.2021.13940

\section{Aplicación Ebrón para la gestión de los Trabajos Fin de Grado y Fin de Máster en la UPV}

\section{Ebrón Application for the management of End-of-Degree and End-of-Master Projects in UPV}

\author{
Pedro Gerardo Salinas Martínez \\ Escuela Técnica Superior de Ingeniería de Edificación, Universitat Politècnica de València.
} psalinas@csa.upv.es

\begin{abstract}
The Universitat Politècnica de Valéncia has developed the Ebrón application for the management of End-of-Degree and End-of-Master's Projects that simplifies all the processes that have to be carried out for their development. In these years its effectiveness has been proven and it has become an essential application.
\end{abstract}

Keywords: Undergraduate Thesis Project, End-of-degree project, Master's Thesis, Degree Management

\footnotetext{
Resumen

La Universitat Politècnica de Valéncia ha desarrollado la aplicación Ebrón para la gestión de los Trabajos Fin de Grado y Fin de Máster que simplifica todos los procesos que se tienen que llevar a cabo para su desarrollo. En estos años se ha comprobado su eficacia y se ha significado como una aplicación imprescindible.
}

Palabras clave: Trabajo Final Grado, Proyecto Final Grado, Trabajo final de Máster, Gestión Grado 


\section{Introducción}

La aplicación Ebrón, diseñada para la gestión de los Trabajos Fin de Grado (TFG) y Fin de Máster (TFM), según las directrices de la Normativa Marco de Trabajo Fin de Grado y Fin de Máster de la Universitat Politécnica de Valencia (UPV), aprobada por el Consejo de Gobierno en su sesión de 7 de marzo de 2013 y modificado posteriormente el 29 de enero de 2015, 28 de mayo de 2015, 21 de diciembre de 2017 y 13 de marzo de 2018 (NMTFG-M).

Está aplicación engloba todo el proceso de gestión desde la presentación de la propuestas de TFG y TFM por parte de los tutores hasta la realización de los tribunales encargados de las valoraciones de los TFG y TFM. Además tiene diferentes roles para que todos los intervinientes en el proceso puedan utilizarla.

Los roles que podemos encontrar entre otros, son:

- $\quad$ Entidad responsable del Título (ERT)

- Comisión Académica del Título (CAT)

- Departamento

- Tutor

- Tribunal

- Alumno

Cada ERT se rige por un marco de funcionamiento común pero, a la vez, por una normativa propia. Para acomodar esta variedad de comportamientos, ciertos parámetros de la aplicación son configurables para cada ERT, por lo que la aplicación ofrece la posibilidad de consultar y establecer dichos valores de una manera sencilla.

La opción de Configuración consta de dos secciones: Parámetros de configuración de la ERT y Ubicaciones de la ERT.

En la presente comunicación se van a desarrollar los apartados de presentación de propuestas de TFG/TFM y gestión de Defensa de TFG/TFM desde la ERT de la aplicación Ebrón.

\section{Objetivo}

El objetivo de la presente comunicación es dar a conocer el funcionamiento de la aplicación Ebrón, para que puede servir de referencia para otras Escuelas o Facultades para la gestión de los TFG y TFM.

\section{Presentación de propuestas de TFG/TFM}

El Tutor es el responsable de introducir los datos de su propuesta de TFG/TFM en Ebrón. Por otra parte, los roles Departamento, CAT y ERT disponen de un apartado de gestión de TFG/TFM que les permite validar o rechazar las distintas propuestas de TFG/TFM realizadas por los actores intervinientes en el proceso (ver Figura 1). Cada vez que hay un rechazo, la aplicación enviará una notificación al responsable del paso anterior de que debe subsanar los 
motivos del rechazo. Una vez que la ERT ha aceptado la propuesta de TFG/TFM, ésta es incorporada a la oferta de la ERT y los alumnos ya podrán solicitarla.

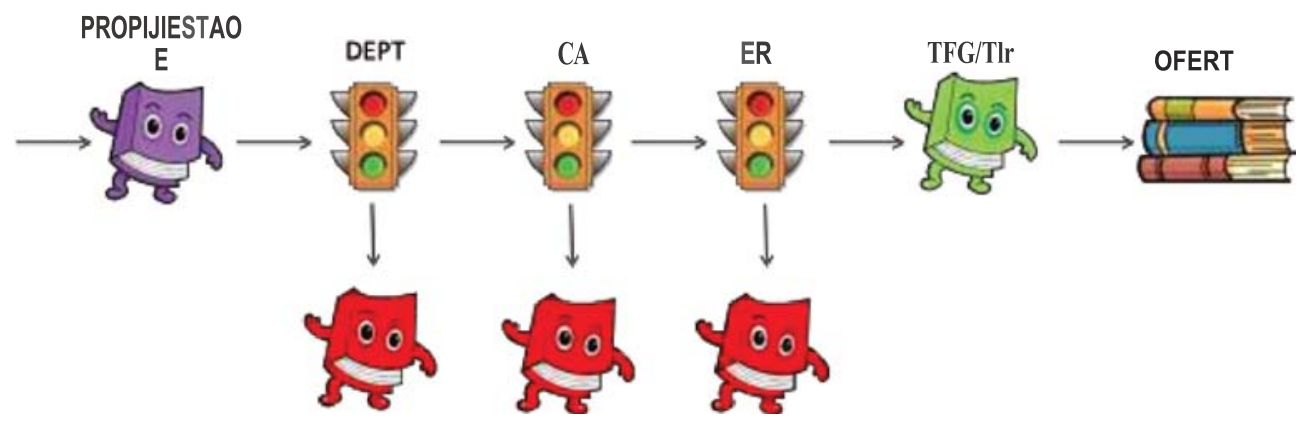

Fig. 1 Proceso de validación/rechazo de un TFG/TFM. UPV

Un requisito necesario para que sea posible introducir propuestas de TFG/TFM en Ebrón es que la ERT correspondiente haya publicado un Plazo de Oferta con sus correspondientes fechas . Por tanto, el proceso completo es el mostrado en la Figura 2

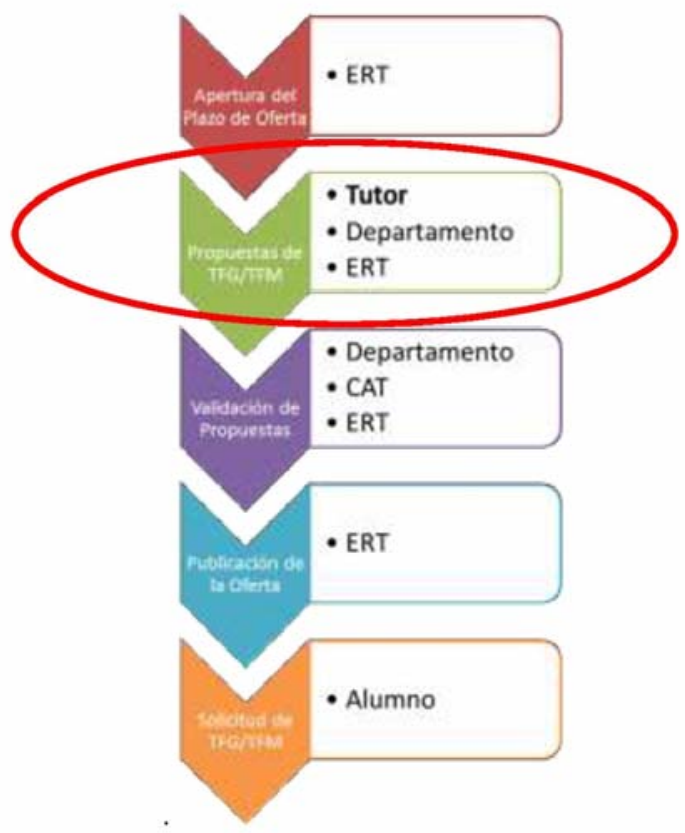

Fig. 2 Proceso de gestión de un TFG/TFM y el rol responsable. UPV 
EI Rol de ERT le dará acceso a las siguientes funcionalidades de gestión:

- Configuración: en esta opción se establecerán los parámetros de funcionamiento propios de una ERT.

- Gestión de Plazos de Oferta en base a lo indicado en el Artículo 7 de la NMTFG-M.

- Gestión de Peticiones de Oferta: según el Artículo 7 de la NMTFG-M, antes del comienzo de cada curso, la ERT requerirá a los departamentos implicados en la docencia del título la remisión de propuestas para ofertar TFG/TFM.

- Notificaciones: permitirá a la ERT definir los textos de cada tipo de notificación, así como parametrizar los envíos de las mismas.

- Grupos Temáticos: los grupos temáticos asociarán varios TFG/TFM que se ofertarán como un único bloque que, una vez asignados a un alumno, se gestionarán de manera independiente.

- Listados: para obtener información.

- Convocatorias de Defensa y Tribunales: según el Artículo 9 de la NMTFG-M, a lo largo del curso académico se realizarán, al menos, 4 convocatorias de defensa que establecerá la ERT al principio de cada curso. Se podrán gestionar las convocatorias de defensa, las solicitudes de defensa y los Tribunales.

- Propuestas de TFG/TFM: para ello, aparecerá una lista con todas las propuestas recibidas dentro del plazo de recepción vigente y que permitirá realizar filtrado por alumnos (interesados o asignados), departamento implicado en la docencia que ha enviado la propuesta, CAT implicadas en la revisión de las propuestas enviadas, tribunal que tiene asignadas las propuestas, tutor y cotutor.

- Gestión Documental: dónde la ERT definirá la estructura de los documentos a entregar por el alumno.

- Manuales: permite acceder a todos los manuales de la aplicación.

La oferta de TFG/TFM para los alumnos puede ser oferta pública, los tutores presentan propuesta sin alumno asignado y mediante un proceso de selección de la propia aplicación lo solicitan, o propuestas concertadas en las que el TFG/TFM ya tiene asignado el alumno en el momento que se presenta la propuesta..

Para dar de alta un TFG/TFM los datos que se tienen que incorporar a la aplicación son:

- Curso académico: curso al que está asignado el TFG/TFM .

- Titulación: ERT a la que se ha remitido la propuesta de TFG/TFM.

- Intensificación: En el caso que la ERT haya definido el plazo de oferta para una intensificación concreta .

- Área temática: lista de áreas a las que pertenece el trabajo .

- Departamento: departamento al que se adscribe el TFG/TFM .

- Tutores: lista de tutores y cotutores, con indicación del rol. En el desplegable de tutores aparecen los tutores del departamento que están en condiciones de tutelar un TFG/TFM (es decir, que han impartido docencia en el título en los dos últimos años) 
y, además, los que están adscritos a la ERT (pertenezcan al departamento o no). El campo departamento es necesario especificarlo porque indica el departamento responsable de validar el TFG/TFM.

- Cotutores externos: si ya existe podrá elegirse de la lista, en caso contrario habrá que darlo de alta. Suelen ser personas sin vinculación con la UPV. En caso de trabajos de modalidad Prácticas en empresa (SIE\} o Empresa, es necesario introducir alguno.

- Director experimental: si ya existe podrá elegirse de la lista, en caso contrario habrá que darlo de alta. Suelen ser personas con vinculación con la UPV.

- Tipo de proyecto: habrá que seleccionar entre las siguientes dos opciones :

- Trabajo dirigido a oferta pública: la propuesta de TFG/TFM es sugerida por alguno de los departamentos implicados en la docencia en la ERT. En estos casos, la asignación de alumnos será responsabilidad de la CAT.

- Trabajo concertado entre un alumno y avalado por tutor(es): la propuesta de TFG/TFM es solicitada por un alumno y avalada por un tutor o tutores. Al contrario de lo que sucedía en el caso anterior, la asignación de este tipo de proyectos será directa al alumno proponente. Si se selecciona esta casilla, se debe seleccionar el alumno al que se asigna el TFG/TFM en el desplegable de alumnos.

- Alumno asignado: para los TFG/TFM concertados entre alumnos y tutor, debe seleccionarse el alumno de la titulación al que se asigna el TFG/TFM .

- Modalidad de desarrollo del trabajo: según lo indicado en el Artículo 12 de la Normativa, será posible realizar el TFG/TFM en movilidad, en una empresa externa o en la propia universidad.

- Orientación: la orientación del TFG/TFM indicará si se trata de un trabajo de índole investigadora o profesional. Esta condición marcará la composición del tribunal de defensa ya que, en el primer caso, todos los miembros del tribunal deben ser doctores. (Solamente pueden ser de orientación investigadora los TFM).

- Títulos: título de la propuesta de TFG/TFM de que se trate (máximo 1.000 caracteres) . Es obligatorio introducirlos en los tres idiomas.

- Resumen: resumen del TFG/TFM en castellano o en valenciano (obligatorio) y en inglés (opcional).

- Palabras clave: palabras claves descriptivas del contenido del TFG/TFM en castellano o valenciano (obligatorio) y en inglés (opcional).

- Observaciones: el tutor podrá optar por completar un texto libre.

- Restricciones de tiempo :

- Fecha máxima de entrega: fecha establecida por el tutor para la entrega del trabajo.

○ Tiempo de dedicación estimado (horas): tiempo dedicación estimado para la realización del TFG/TFM en horas.

- Ofertado como confidencial: si lo marcamos como confidencial, al solicitar la defensa la documentación sólo será accesible por la ERT. 
- Validación de la propuesta de TFG/TFM: Por defecto está en Pendiente de revisión y crea la propuesta en estado Creado por ERT pendiente de revisión, para que puedan validarla el departamento, CAT y ERT, si procede. Si ponemos Aceptar la propuesta ya no queda validada por ERT.

- Fecha de validación de la propuesta de TFG/TFM: Fecha de validación si elegimos aceptar la propuesta en campo anterior.

- Comentarios anexos a la aceptación/validación: información adicional, que será obligatoria si rechazamos el trabajo.

- Documentación adjunta: se podrá optar por adjuntar un documento.

Cuando existan trabajos antiguos sin alumno asignado, pueden ser recuperados por el tutor o la ERT para los siguientes plazos de oferta que se abran. Podemos saber la procedencia de cada trabajo según su estado:

- Ofertado: son de una oferta pública anterior pero que no se asignaron.

- Aprobado por ERT: trabajos que no se llegaron a ofertar porque fueron validados por ERT después de publicar la oferta.

- Desvinculado: trabajo que tras estar asignado dos cursos y no haber defendido, la ERT o el tutor han decidido no renovar.

- Renuncia aceptada: la CAT ha aceptado la renuncia solicitada por el alumno.

La Normativa establece que, pasados dos años, la ERT podrá desvincular el trabajo y el alumno. En la aplicación hay una opción en donde aparecen los TFG/TFM pendientes de desvinculación. La ERT tiene la posibilidad de:

- Desvincular: el trabajo pasa a estado DESVINCULADO y se envía una notificación al alumno y al tutor informando del hecho. Los trabajos desvinculados se podrán reofertar (al hacerlo, cambiarán de estado a REOFERTADO).

- Renovar asignación: permite al alumno seguir con el trabajo durante un año más. El alumno debe solicitarlo mediante instancia.

La aplicación envía notificaciones informando sobre determinados eventos ocurridos durante el uso de la misma. Para todos los tipos de notificaciones, la ERT puede definir el asunto y el texto correspondiente.

Para aquellos alumnos que desarrollan su trabajo en otra universidad la aplicación tiene la opción de movilidad. El funcionamiento general respecto a la oferta es el siguiente:

- La ERT tiene que crear un plazo de oferta en movilidad, en el que sólo se pueden crear trabajos en movilidad

- En este plazo pueden crear trabajos la ERT, el tutor y el alumno. Todos los trabajos tienen que ser concertados, y los alumnos deben tener matricula en movilidad.

- Si el trabajo lo crea el alumno, el tutor lo puede revisar (aunque no podrá cambiar el alumno).

- Los trabajos pueden validarlos la CAT y la ERT. El departamento no tiene que validar, aunque si recibe las notificaciones si están habilitadas. 


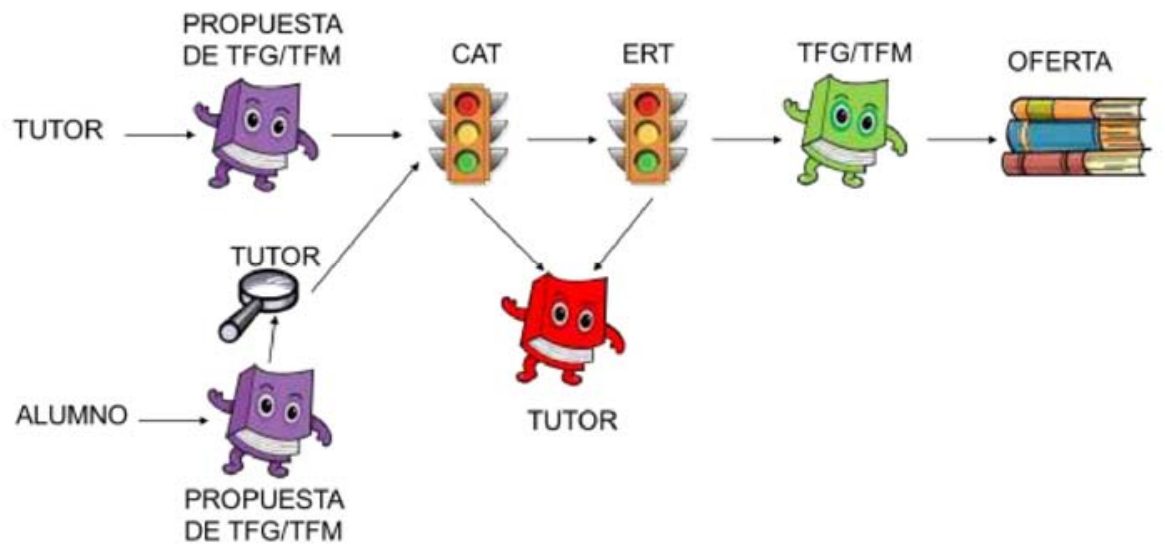

Fig. 3 Proceso de validación/rechazo de un TFG/TFM en Movilidad. UPV

\section{Defensa de TFG/TFM por ERT}

Los requisitos necesarios para defender los TFG/TFM es que la ERT haya definido los plazos de defensa, que haya solicitudes de defensa de TFG/TFM por parte de los estudiantes y que se hayan definido los tribunales correspondientes.

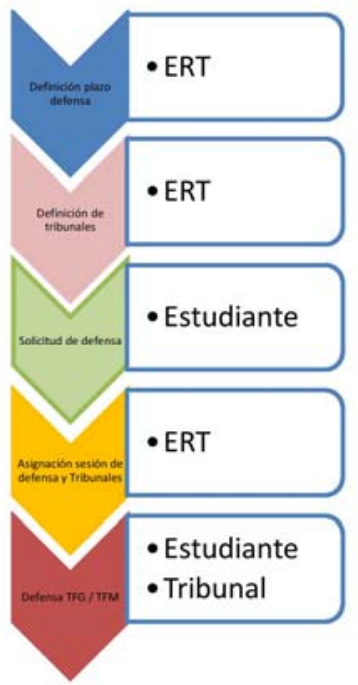

Fig. 4 Proceso completo para la defensa de un TFG/TFM. UPV

Para crear una convocatoria de defensa se deben indicar los siguientes datos:

- Nombre: nombre que se le da a la convocatoria de defensa. 
- Titulación: titulaciones, dentro de las que gestiona la ERT, a la que se asocia la convocatoria de defensa.

- Curso académico: curso académico al que pertenece la convocatoria de defensa.

- Estado: estado de la convocatoria de defensa. Podrá ser :

1. Borrador: se han introducido los datos pero no se ha publicado todavía.

2. Publicada: la convocatoria de defensa se ha publicado.

3. En curso : la convocatoria de defensa se ha publicado y ya ha comenzado.

4. Cerrada: la convocatoria de defensa ha expirado. En este estado ya no se pueden gestionar turnos de defensa ni sesiones

- Parámetros de la asignación: si hemos habilitado las áreas temáticas, podemos indicar el criterio usado para asignar las solicitudes a los tribunales. Las opciones son:

1. Asignación por Áreas Temáticas: a un tribunal de defensa únicamente se le podrán asignar trabajos de las áreas temáticas en las que se le haya autorizado.

2. Asignación por Titulación: a un tribunal de defensa se le podrá asignar cualquier trabajo de la titulación. Es el criterio usado cuando no están habilitadas las áreas temáticas.

3. Asignación por Área Temática y Titulación: inicialmente, al tribunal de defensa se le asignarán los trabajos de sus áreas temáticas. Si quedara un excedente de sesiones de defensa para el turno de defensa de la convocatoria al que se ha asignado el tribunal, éstas se podrán asignar al resto de trabajos de la convocatoria de defensa, coincidan o no las áreas temáticas.

- Tipo de convocatoria:

1. Individual: se citará a los estudiantes individualmente.

2. Colectiva: aunque cada estudiante defenderá su trabajo individualmente, se citará a todos los estudiantes a la vez.

3. Permanente: están abiertas todo el curso y sólo puede haber una.

- Fechas (si convocatoria no es permanente):

1. Fecha de inicio de presentación de trabajos: fecha de inicio de la convocatoria . A partir de esta fecha, los estudiantes podrán solicitar que se incluya la defensa de su TFG/TFM en esta convocatoria.

2. Fecha límite de presentación de trabajos: establece hasta cuándo tienen los estudiantes para la presentación de los trabajos previamente a su defensa. Según la Normativa, en ningún caso podrá ser menos de una semana desde la Fecha de inicio de la convocatoria de defensa.

- Solicitar informe al tutor: si esta casilla está marcada, cuando el estudiante solicite defender su TFG/TFM en la presente convocatoria, se enviará un correo al tutor indicándole el hecho y pidiéndole un informe de valoración que, posteriormente, será visible por el estudiante, por el tribunal y por la CAT. En caso de que la casilla no se 
marque, la petición de defensa del estudiante no desencadenará ninguna petición al tutor.

\section{- Duraciones:}

1. Tiempo de defensa del estudiante: duración, en minutos, del tiempo de exposición pública de que dispondrá el estudiante. Este parámetro no podrá ser mayor que el parámetro de configuración de la ERT llamado Duración estimada del tiempo de defensa y este parámetro, a su vez, nunca podrá ser mayor de $45^{\prime}$.

2. Tiempo de deliberación del tribunal: duración, en minutos, de la deliberación de los miembros del tribunal previa a la calificación de la defensa del estudiante.

- Defensa: en esta sección se establece las fechas y horas de los actos de defensa .

En la parte superior de la tabla, se mostrarán el número de total de solicitudes de defensa aprobadas por la ERT y el número de solicitudes de defensa que todavía no tienen un slot asignado. Además, si no es una convocatoria permanente, se incluirá la Fecha de comienzo de la convocatoria que marcará la fecha a partir de la cual es posible generar turnos de defensa. En ningún caso se podrán generar turnos de defensa antes de la fecha marcada por la Fecha de comienzo de la convocatoria. Además, la Fecha de comienzo de la convocatoria debe ser, como mínimo, 7 días mayor que la Fecha límite de presentación de trabajos .

Además, se pueden añadir turnos de defensa, cuyos parámetros son :

1 Turno: de mañana o de tarde.

2. Nombre: descripción la sesión de defensa .

3. Capacidad : número de estudiantes máximo que se puede evaluar en cada turno de defensa.

4. Inicio: día, mes y hora de inicio de la sesión de mañana o de tarde. 5 . Fin: día, mes y hora de fin de la sesión de mañana o de tarde.

6. Inicio de la pausa: día, mes y hora de la pausa en el turno.

7. Duración de la pausa: duración, en minutos, de la pausa.

8. Tribunal de calificación: tribunal asignado, entre los definidos en la gestión de tribunales. Si usamos la asignación por áreas temáticas, sólo podremos elegir tribunales con alguna en co- mún.

9. Ubicación : ubicación en que tendrá lugar los actos de defensa del turno.

10. Ubicación externa : para indicar otra ubicación.

11. Disponibles: es el número de slots de asignación disponible en cada turno de defensa. Se actualiza cada vez que se asigne un trabajo a un slot, ya sea automática o manualmente. 
Según estos parámetros se generarán los slots de asignación que, posteriormente (en la pantalla de gestión de asignaciones), se asocian a los estudiantes.

Una vez hayamos guardado el turno de defensa, tendremos opción de acceder a los botones Comunicar nombramiento y Convocar tribunal. Los turnos de defensa aparecen en formato tabular y con el botón Generar sesiones se generan los slots para cada turno de defensa .

La asignación automática se hace por orden de la solicitud de defensa del estudiante teniendo en cuenta las fechas de inicio y fin y la duración estimada de los actos de defensa.

Si al lanzar la generación automática no existieran solicitudes de defensa para esa convocatoria, la asignación se cancela y se mostrará, en su caso, un mensaje informativo a la ERT.

Cuando se lanza la generación automática, asigna sesión a todas las solicitudes que no la tengan. Puede lanzarse varias veces.

También se pueden asignar de forma manual. Para cada una de las sesiones disponibles, se muestra la fecha y la hora y la ERT selecciona una de las sesiones disponibles para asignarla al trabajo cuya información se está visualizando . Pulsando en el botón de Asignar selección, la sesión queda efectivamente asignada al trabajo.

Finalmente, al pinchar en Gestionar Tribunal, lleva la pantalla de gestión del tribunal para cada acto de defensa. Por defecto, el tribunal es el que se haya definido para el turno de defensa. Sin embargo, es posible modificarlo para cada acto defensa con el fin de reflejar cambios imprevistos.

Si la solicitud tiene restricción de publicidad, el alumno debe justificarlo, lo tiene que validar la CAT y aceptar derechos quien lo descarga. Sin embargo si el trabajo se ofertó como confidencial, no tiene que justificarlo el alumno ni validar la CAT.

Si solicita videoconferencia, el alumno debe justificarlo y tiene que validar la CAT.

Cuando tiene que validar la CAT, como ERT sólo podemos consultar la información. Tener en cuenta también que si el trabajo inicialmente se ofertó como confidencial, la solicitud tendrá restricción de publicidad obligatoriamente (el alumno no puede elegir otra cosa).

Si la solicitud tiene acceso cerrado al texto completo o restricción de publicidad, al descargarse el TFG/TFM, primero se tendrá que previsualizar un documento del acuerdo de confidencialidad, y una vez visualizado tendrá que firmar, teniendo que introducir su clave de UPVNet. Este procedimiento solo se realizará una vez por cada solicitud.

\subsection{Crear Tribunal}

La pantalla de gestión de un tribunal permite la introducción de los datos básicos del mismo. Se trata de un proceso en dos pasos: 
- Paso 1: Se indican los datos básicos del tribunal (nombre, curso académico de actuación, titulaciones y áreas temáticas (si están habilitadas). Una vez completados estos datos, se pulsa el botón de "Guardar como borrador".

- Paso 2: Introducción de los miembros del tribunal.

Los datos básicos del tribunal son:

- $\quad$ Nombre: nombre que se le dará al tribunal y aparecerá en el campo Tribunal de la tabla de la página principal de gestión de tribunales.

- Curso académico: curso académico de vigencia del tribunal.

- Titulación: se mostrarán todas las titulaciones que gestione la ERT.

- Área temática: si están habilitadas, se mostrarán todas las definidas por la ERT. Se tendrán en cuenta en la asignación de trabajos al tribunal.

- Estado: estado del tribunal. Un tribunal puede estar en modo borrador (provisional) o publicado (definitivo) .

- Miembros del tribunal: esta tabla recoge los miembros titulares del tribunal. Para añadirlos se abre la ventana de selección de miembro del tribunal, que permite realizar búsquedas en la base de datos de la universidad.

Los miembros disponible serán, según el Artículo 5.2 de la Normativa, "los miembros del PDI pertenecientes al cuerpo de funcionarios, o que tengan contrato indefinido, o formen parte del colectivo de profesores asociados. Entre estos miembros del tribunal de calificación podría incluirse un profesional externo de reconocido prestigio del ámbito profesional correspondiente al título".

En cuanto a los roles, el Artículo 5.6 de la Normativa indica que "salvo que la ERT establezca lo contrario, actuará como Presidente el PDI de mayor categoría docente y antigüedad y como Secretario el de menor categoría y antigüedad". Teniendo en cuenta estas dos restricciones, la aplicación generará una hoja de cálculo de MS-Excel que contendrá a los miembros del tribunal ordenados por categoría y antigüedad con el fin de que la ERT pueda asignar los roles manualmente.

La normativa también permite incluir a externos como miembros del tribunal (se habilita en la configuración de la ERT, parámetro Posibilidad de incluir a un profesional externo como miembro del tribunal). En estos casos el usuario no tendrá acceso a la aplicación.

\subsection{Gestión Documental}

En el apartado de Gestión documental se establece la estructura de la documentación que el alumno deberá adjuntar a través de la aplicación durante el proceso de depósito del TFG/TFM durante la presentación de una solicitud de defensa de su trabajo.

La ERT podrá definir la estructura por defecto de los TFG/TFM estableciendo el nombre y el número de ficheros que el alumno deberá adjuntar, así como indicar, de todos ellos, cuál es el que constituirá la memoria o documento principal del TFG/TFM. 
Para ello, dentro del menú Gestión documental existe una opción de Estructura documental de la ERT a través de la cual la ERT puede definir y ordenar los distintos bloques en que se divide la estructura de la documentación de los TFG/TFM.

Se introducirá el Nombre del bloque, la Descripción, se indicará si el contenido del bloque es el Documento principal del TFG/TFM, si no se envía a riunet, si es visible al tribunal y su carácter Opcional. El principal siempre se envía a riunet y no puede ser opcional.

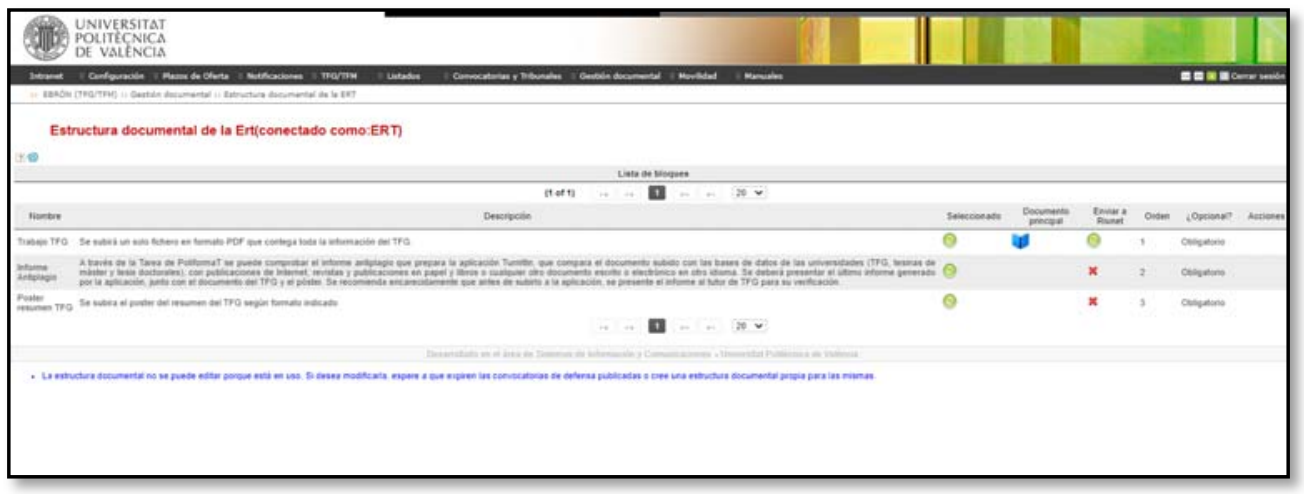

Fig. 5 Pantalla Estructura Documental de la ERT. UPV

La estructura documental de la ERT se cargará por defecto para todas las convocatorias gestionadas por una ERT. Sin embargo, puede haber casos en los que resulte más adecuado definir una estructura diferente para convocatorias concretas, por ejemplo, porque la naturaleza de las titulaciones así lo recomiende.

Para ello, la ERT tendrá una pantalla en la que podrá seleccionar, para cada curso académico, las convocatorias publicadas en dicho curso. Indicando la convocatoria cuya estructura documental se desea especificar, se cargará una pantalla para poder cambiar la documentación. La única restricción es que no se podrá editar una convocatoria de defensa en la que ya existan solicitudes de alumnos realizadas.

\section{Conclusiones}

La gestión de todo el proceso que conllevan los TFG y TFG es muy complicada y la aplicación Ebrón simplifica mucho el proceso. Se ajusta a la Normativa Marco de Trabajo Fin de Grado y Fin de Máster de la Universitat Politécnica de Valencia y permite la comunicación entre los diferentes departamentos para poder gestionar todo el proceso con una sola aplicación.

\section{Referencias}

España. NORMATIVA MARCO DE TRABAJO FIN DE GRADO Y FIN DE MÁSTER DE LA UNIVERSITAT POLITĖCNICA DE VALÉNCIA (Texto consolidado). BOUPV, 29 de marzo de 2018, núm. 110, p.14-35. 


\section{PLAN DE ESTUDIOS Y MODELOS DE GESTIÓN}

Experiencias y reflexiones del plan de estudios ante los nuevos retos y desafíos que se plantean en la profesión de la arquitectura técnica, así como modelos de gestión implementados en los centros en los que se imparte el grado conducente a su habilitación profesional con el objeto de mejorar la calidad de su formación. 


\title{
EDIFICATE
}

I Congreso de Escuelas de Edificación y Arquitectura Técnica de España València, 4 y 5 de noviembre de 2021

Escuela Técnica Superior de Ingeniería de Edificación

Universitat Politècnica de València

Doi: https://doi.org/10.4995/EDIFICATE2021.2021.13295

\section{Convergencia de Títulos de Grado conforme a la Orden ECI $3855 / 2015$}

\section{Convergence of Bachelor Degrees according to Order ECI $3855 / 2015$}

\author{
Juan Manuel Santiago Zaragozaa ${ }^{a}$ María Segarra Cañamares ${ }^{b}$, \\ (en representación de todas las Escuelas miembros de la CODATIE que han \\ participado en la elaboración de los reconocimientos) \\ aPresidente CODATIE, Escuela Técnica Superior de Ingeniería de Edificación, Universidad de \\ Granada, santi@ugr.es b Secretaria CODATIE. Escuela Politécnica de Cuenca, Universidad de \\ Castilla-La Mancha, maría.segarra@uclm.es
}

\begin{abstract}
Current legislation establishes the profession of Technical Architect as a regulated profession that requires an official Bachelor's Degree obtained in accordance with article 12.9 of Royal Decree 1393/2007, in accordance with the conditions established in the Agreement of the Council of Ministers of 14 December 2007.
\end{abstract}

This Agreement entrusts the Minister of Education and Science with the establishment of the requirements regarding the planning of the courses. ORDER ECI/3855/2007, of 27 December 2007, establishes the requirements for the verification of the official university degrees that enable the exercise of the profession of Technical Architect.

The ORDEN ECl establishes that the syllabuses will have a duration of 240 European credits containing at least a basic training module of 60 credits, a specific training module of 108 credits and a final degree project of 12 credits. The Conference of Directors of University Centres that offer degrees in the field of technical architecture and building has worked to reach a consensus on the subjects subject matter subject to the recognition of the 108 credits of specific training that allow for the Convergence of the Degree Degrees of the different Universities.

Keywords: Study plan, validations, regulated profession, Technical Architecture, Universities. 


\begin{abstract}
Resumen
La legislación vigente conforma la profesión de Arquitecto Técnico como profesión regulada que requiere de un título oficial de Grado obtenido de acuerdo con el artículo 12.9 del Real Decreto 1393/2007, conforme a las condiciones establecidas en el Acuerdo de Consejo de ministros de 14 de diciembre de 2007.

Dicho Acuerdo encomienda al ministro de Educación y Ciencia el establecimiento de los requisitos respecto a la planificación de las enseñanzas. Siendo la ORDEN ECI/3855/2007, de 27 de diciembre, la que establece los requisitos para la verificación de los títulos universitarios oficiales que habiliten para el ejercicio de la profesión de Arquitecto Técnico.

La ORDEN ECl establece que los planes de estudios tendrán una duración de 240 créditos europeos conteniendo como mínimo un módulo de formación básica de 60 créditos, uno de formación específica de 108 créditos y uno de proyecto fin de grado de 12 créditos. Desde la Conferencia de directores y directoras de centros universitarios que imparten titulaciones del ámbito de la arquitectura técnica y la edificación, se ha trabajado para consensuar las asignaturas sujetas al reconocimiento de los 108 créditos de formación específica que permiten la Convergencia de los Títulos de Grado de las distintas Universidades.
\end{abstract}

Palabras clave: Plan de estudios, convalidaciones, profesión regulada, Arquitectura Técnica, Universidades. 


\section{Introducción}

La Orden ECI/3855/2007, de 27 de diciembre, por la que se establecen los requisitos para la verificación de los títulos universitarios oficiales que habiliten para el ejercicio de la profesión de Arquitecto Técnico, establece como Objetivos en su Apartado 3, las competencias que el estudiante debe adquirir.

Dichas competencias se enumeran en 8 apartados los cuales contemplan:

1. Dirigir la ejecución material de las obras de edificación, de sus instalaciones y elementos, llevando a cabo el control cualitativo y cuantitativo de lo construido mediante el establecimiento y gestión de los planes de control de materiales, sistemas y ejecución de obra, elaborando los correspondientes registros para su incorporación al Libro del Edificio. Llevar el control económico de la obra elaborando las certificaciones y la liquidación de la obra ejecutada.

2. Redactar estudios y planes de seguridad y salud laboral y coordinar la actividad de las empresas en materia de seguridad y salud laboral en obras de construcción, tanto en fase de proyecto como de ejecución.

3. Llevar a cabo actividades técnicas de cálculo, mediciones, valoraciones, tasaciones y estudios de viabilidad económica; realizar peritaciones, inspecciones, análisis de patología y otros análogos y redactar los informes, dictámenes y documentos técnicos correspondientes; efectuar levantamientos de planos en solares y edificios.

4. Elaborar los proyectos técnicos y desempeñar la dirección de obras de edificación en el ámbito de su habilitación legal.

5. Gestionar las nuevas tecnologías edificatorias y participar en los procesos de gestión de la calidad en la edificación; realizar análisis, evaluaciones y certificaciones de eficiencia energética, así como estudios de sostenibilidad en los edificios.

6. Dirigir y gestionar el uso, conservación y mantenimiento de los edificios, redactando los documentos técnicos necesarios. Elaborar estudios del ciclo de vida útil de los materiales, sistemas constructivos y edificios. Gestionar el tratamiento de los residuos de demolición y de la construcción.

7. Asesorar técnicamente en los procesos de fabricación de materiales y elementos utilizados en la construcción de edificios.

8. Gestionar el proceso inmobiliario en su conjunto. Ostentar la representación técnica de las empresas constructoras en las obras de edificación.

Todas estas competencias deben de ser adquiridas conforme a los tres módulos que marca la Orden ECl/3855/2007 en su Apartado 5 sobre Planificación de las enseñanzas Introducción.

60 créditos de formación básica, 108 créditos de formación específica y 12 créditos de Proyecto Fin de Grado. 


\section{Objetivo}

Dar a conocer, a todas las Escuelas que imparten titulaciones que habilitan para el ejercicio de la profesión de Arquitecto Técnico, el trabajo llevado a cabo desde la Conferencia de directores y directoras de centros universitarios que imparten titulaciones del ámbito de la arquitectura técnica y la edificación (CODATIE) en relación a la Convergencia de los títulos de Grado conforme a la Orden ECI 3855/2007 de 27 de diciembre.

\section{Desarrollo}

En base al acuerdo alcanzado por los jefes de estudios, en su reunión mantenida el 17 de junio de 2016, en relación a la necesidad de buscar la Convergencia de los títulos de Grado de las distintas universidades tanto en créditos, como en módulos, materias y asignaturas que quedan incluidos en la Orden ECI 3855/2007 de 27 de diciembre, la CODATIE establece la necesidad de consensuar las asignaturas que estarían sujetas a los 108 créditos y se hace petición a todas las Escuelas de su estudio.

Con este objetivo y tras haber recopilado toda la información recibida por las Escuelas, se muestran las propuestas en la reunión mantenida por la CODATIE el 13 de diciembre de 2017, lo que motiva que se convoque a los jefes de estudios de las Escuelas con objeto de definir los criterios básicos sobre los que trabajar.

Con fecha 2 de marzo de 2018 se mantuvo la reunión de jefes de estudios en la Escuela Técnica Superior de Ingeniería de Edificación de la Universitat Politècnica de València, a la que asistieron representantes de 13 escuelas.

En el programa de la reunión se tomó como punto del orden del día para trabajar:

- ORDEN ECI 3855/2007 de 27 de diciembre: Estudios de las asignaturas sujetas a convalidación. Análisis de las propuestas recibidas, resumen, conclusiones y medidas a adoptar.

En la reunión se deliberó sobre los créditos y asignaturas que debían reconocerse en cada módulo de formación específica y los márgenes que iban a aceptarse, teniendo en cuenta que las asignaturas tienen diferentes créditos en cada Escuela y hay diferencias entre los planes de estudio. También se revisaron las competencias, y las propuestas que había enviado cada escuela. Cada jefe de estudios expuso los ajustes que tendría que hacer para encajar la propuesta. Se acordó que además del reconocimiento de 108 créditos totales con los 6 bloques, podía ser posible el reconocimiento por bloques individuales entre escuelas.

\subsection{Acuerdos adoptados para el reconocimiento de créditos}

En relación con las asignaturas básicas del grado: se reconocerán todas las asignaturas Básicas que pertenezcan a la Rama de Ingeniería Arquitectura, con un máximo de 60 créditos. 
En cuanto a las asignaturas específicas: Si un/a alumno/a tiene completado un módulo en la universidad origen, de los seis que componen el plan de estudios, se intentará reconocer dicho módulo en la universidad destino. A continuación, se expone los requerimientos de máximos y mínimos sobre los créditos de cada uno de los módulos que se podrán reconocer en Bloque:

- Módulo de Expresión Gráfica: Máximo 12 ECTS y mínimo 9 ECTS

- Módulo de Técnicas y Tecnologías de la Edificación: Máximo 36 ECTS y mínimo 30 ECTS. (Se intentará que la parte de Materiales sea un $40 \%$ y la parte de Construcción sea un 60\%)

- Módulo de Estructuras e Instalaciones de la Edificación: Máximo 18 ECTS y mínimo 15 ECTS (Se intentará que la parte de Instalaciones sea un $66,67 \%$ y la parte de Estructuras sea un $33,33 \%$ )

- Módulo de Gestión del Proceso: Máximo 18 ECTS y mínimo 16,5 ECTS

- Módulo de Gestión Urbanística y Economías aplicadas: Máximo 18 ECTS y mínimo 14 ECTS

- Módulo de Proyectos Técnicos: Máximo 12 ECTS y mínimo 9 ECTS

La suma de los créditos de todos los módulos de formación específica tiene que ser, si se puede por tema de créditos, de 108 ECTS. El margen por módulo y sobre el total será de +3 créditos. En total, entre básicas y obligatorias, se intentará llegar a 168 ECTS.

\section{Resultados}

A fecha septiembre del 2019 son doce las universidades que ya han elaborado y aprobado por los órganos competentes las tablas de reconocimiento en base a las cuales se facilita la movilidad de los alumnos.

Dichas tablas cumplen con todos y cada uno de los acuerdos adoptados, tanto en el número de créditos por materia, como en la suma total de créditos, recogiendo en ellas las asignaturas con las cuales se adquieren las competencias establecidas en la Orden ECl.

A continuación, se muestran las tablas con la distribución de créditos por módulos y asignaturas de las doce Universidades. 
Convergencia de Títulos de Grado conforme a la Orden ECI 3855/2015-

Convergence of Bachelor Degrees according to Order ECI 3855/2015

\begin{tabular}{|c|c|c|c|c|}
\hline \multicolumn{5}{|c|}{ BÁSICOS } \\
\hline & Créditos ECTS minimos & \multicolumn{2}{|c|}{ Total Básicos } & 60,0 \\
\hline \multicolumn{5}{|c|}{ ESPECIFICOS } \\
\hline MODULO & Asignatura & Código & ECTS & Total/Módulo \\
\hline \multirow{2}{*}{ Expresión Gráfica } & Dibujo arquitectónico III & 6456 & 6,0 & \multirow{2}{*}{12,0} \\
\hline & Topografia y replanteos & 6452 & 6,0 & \\
\hline \multirow{6}{*}{$\begin{array}{c}\text { Téenicas y Tecnología } \\
\text { de la } \\
\text { Edificación }\end{array}$} & Materiales I & 6438 & 6,0 & \multirow{6}{*}{33,0} \\
\hline & Materiales II & 6442 & 6,0 & \\
\hline & Construcción I & 6438 & 6,0 & \\
\hline & Construcción II & 6443 & 6,0 & \\
\hline & Construcción III & 6448 & 6,0 & \\
\hline & Eficiencia Energética & 6474 & 3,0 & \\
\hline \multirow{3}{*}{$\begin{array}{c}\text { Estructuras e } \\
\text { Instalaciones de la } \\
\text { Edificación }\end{array}$} & Instalaciones II & 6453 & 6,0 & \multirow{3}{*}{15,0} \\
\hline & Instalaciones III & 6462 & 3,0 & \\
\hline & $\begin{array}{l}\text { Análisis de estructuras } y \text { fundamentos de hormigón } \\
\text { armado }\end{array}$ & 6458 & 6,0 & \\
\hline \multirow{4}{*}{ Gestión del Proceso } & Organización de obra & 6466 & 6,0 & \multirow{4}{*}{18,0} \\
\hline & Prevención y seguridad & 6460 & 6,0 & \\
\hline & Técnicas en prevención de riesgos laborales & 6467 & 3,0 & \\
\hline & Equipos de Obra y Medios Auxiliares & 6461 & 3,0 & \\
\hline \multirow{3}{*}{$\begin{array}{l}\text { Gestión Urbanística y } \\
\text { Economia aplicadas }\end{array}$} & Presupuestos I & 6459 & 6,0 & \multirow{3}{*}{18,0} \\
\hline & Gestión Económica y Urbanística & 6471 & 6,0 & \\
\hline & Peritaciones y Tasaciones & 6470 & 6,0 & \\
\hline \multirow{2}{*}{ Proyectos Técnicos } & Proyectos técnicos I & 6464 & 6,0 & \multirow{2}{*}{12,0} \\
\hline & Proyectos técnicos II & 6468 & 6,0 & \\
\hline & & \multicolumn{2}{|c|}{ Total Específicas } & 108,0 \\
\hline & & \multicolumn{2}{|c|}{ TOTAL RECONOCIBLES } & 168,0 \\
\hline
\end{tabular}

Fig. 1 Universidad de Burgos 


\begin{tabular}{|c|c|c|c|c|}
\hline \multicolumn{5}{|c|}{ BÁSICOS } \\
\hline & Créditos ECTS mínimos & \multicolumn{2}{|c|}{ Total Básicos } & 60,0 \\
\hline \multicolumn{5}{|c|}{ ESPECIFICOS } \\
\hline MODULO & Asignatura & Código & ECTS & Total/Módulo \\
\hline Expresión Gráfica & $\begin{array}{c}\text { Dibujo II } \\
\text { Topografia y replanteos }\end{array}$ & $\begin{array}{l}59312 \\
59323\end{array}$ & $\begin{array}{l}6,0 \\
6,0\end{array}$ & 12,0 \\
\hline \multirow{5}{*}{$\begin{array}{c}\text { Técnicas y Tecnología } \\
\text { de la } \\
\text { Edificación }\end{array}$} & Materiales de Construcción I & 59306 & 6,0 & \multirow{5}{*}{33,0} \\
\hline & Construcción I & 59307 & 6,0 & \\
\hline & Construcción III & 59316 & 9,0 & \\
\hline & Construcción IV & 59324 & 6,0 & \\
\hline & Patología y Restauración & 59325 & 6,0 & \\
\hline \multirow{2}{*}{$\begin{array}{c}\text { Estructuras e } \\
\text { Instalaciones de la }\end{array}$} & Instalaciones de la Edificación | & 59313 & 9,0 & \multirow{2}{*}{18,0} \\
\hline & Estructuras de la Edificación I & 59314 & 9,0 & \\
\hline \multirow{3}{*}{ Gestión del Proceso } & Prevención y Seguridad en el Trabajo & 59319 & 6,0 & \multirow{3}{*}{18,0} \\
\hline & Planificación, Organización y Control de Obras & 59326 & 6,0 & \\
\hline & Calidad en la Edificación & 59327 & 6,0 & \\
\hline \multirow{3}{*}{$\begin{array}{l}\text { Gestión Urbanistica y } \\
\text { Economia aplicadas }\end{array}$} & Mediciones y Presupuestos & 59329 & 6,0 & \multirow{3}{*}{18,0} \\
\hline & $\begin{array}{l}\text { Peritaciones } \mathrm{y} \text { Tasaciones } \\
\end{array}$ & 59331 & 6,0 & \\
\hline & Gestión Urbanistica y Construcciones Urbanas & 59328 & 6,0 & \\
\hline \multirow{3}{*}{ Proyectos Técnicos } & Introducción a la Prevención y Seguridad y & & & \multirow{3}{*}{12,0} \\
\hline & Proyectos Técnicos & $\frac{59317}{50318}$ & $\frac{6,0}{60}$ & \\
\hline & Proyectos Técnicos & & 6,0 & \\
\hline & & \multicolumn{2}{|c|}{ Total Especificas } & 111,0 \\
\hline & & \multicolumn{2}{|c|}{ TOTAL RECONOCIBLES } & 171,0 \\
\hline
\end{tabular}

Fi g. 2 Universidad de Castilla-La Mancha

\begin{tabular}{|c|c|c|c|c|}
\hline \multicolumn{5}{|c|}{ BÁSICOS } \\
\hline & Créditos ECTS mínimos & \multicolumn{2}{|c|}{ Total Básicos } & 60,0 \\
\hline \multicolumn{5}{|c|}{ ESPECIFICOS } \\
\hline MODULO & Asignatura & Código & ECTS & Total/Módulo \\
\hline \multirow{2}{*}{ Expresión Gráfica } & Expresión Gráfica Arquitectónica I & 670601008 & 6,0 & \multirow{2}{*}{12,0} \\
\hline & Geometria Descriptiva & 670601004 & 6,0 & \\
\hline \multirow{5}{*}{$\begin{array}{c}\text { Téenicas y Tecnología } \\
\text { de la } \\
\text { Edificación }\end{array}$} & Materiales I & $670 \mathrm{G} 01003$ & 6,0 & \multirow{5}{*}{30,0} \\
\hline & Materiales II & $670 \mathrm{G} 01012$ & 6,0 & \\
\hline & Construcción I & 670601009 & 6,0 & \\
\hline & Construcción II & $670 G 01011$ & 6,0 & \\
\hline & Construcción IIII & $670 G 01017$ & 6,0 & \\
\hline \multirow{3}{*}{$\begin{array}{c}\text { Estructuras e } \\
\text { Instalaciones de la } \\
\text { Edificación }\end{array}$} & Instalaciones II & $670 G 01024$ & 6,0 & \multirow{3}{*}{18,0} \\
\hline & Instalaciones III & $670 G 01035$ & 6,0 & \\
\hline & Estructuras I & $670 G 01019$ & 6,0 & \\
\hline \multirow{3}{*}{ Gestión del Proceso } & Seguridad y Prevención & $670 G 01031$ & 6,0 & \multirow{3}{*}{18,0} \\
\hline & Gestión de Calidad, Seguridad y Medio Ambiente & 670601032 & 6,0 & \\
\hline & Organización, Programación y Control & $670 G 01021$ & 6,0 & \\
\hline \multirow{3}{*}{$\begin{array}{l}\text { Gestión Urbanistica y } \\
\text { Economia aplicadas }\end{array}$} & Mediciones, Presupuestos y Control económico & 670601030 & 6,0 & \multirow{3}{*}{18,0} \\
\hline & Gestión inmobiliaria, tasaciones y peritaciones & 670601033 & 6,0 & \\
\hline & Derecho público de la edificación & $670 \mathrm{G} 01015$ & 6,0 & \\
\hline \multirow{2}{*}{ Proyectos Técnicos } & Proyectos téenicos I & $670 G 01023$ & 6,0 & \multirow{2}{*}{12,0} \\
\hline & Proyectos técnicos II & 670601027 & 6,0 & \\
\hline & & \multicolumn{2}{|c|}{ Total Especificas } & 108,0 \\
\hline & & \multicolumn{2}{|c|}{ TOTAL RECONOCIBLES } & 168,0 \\
\hline
\end{tabular}

Fig. 3 Universidad de la Coruña 
Convergencia de Títulos de Grado conforme a la Orden ECI 3855/2015 -

Convergence of Bachelor Degrees according to Order ECI 3855/2015

\begin{tabular}{|c|c|c|c|c|}
\hline \multicolumn{5}{|c|}{ BÁSICOS } \\
\hline & Créditos ECTS mínimos & \multicolumn{2}{|c|}{ Total Básicos } & 60,0 \\
\hline \multicolumn{5}{|c|}{ ESPECIFICOS } \\
\hline MODULO & Asignatura & Código & ECTS & Total/Módulo \\
\hline \multirow{2}{*}{ Expresión Gráfica } & Dibujo \|I & 502309 & 6,0 & \multirow[b]{2}{*}{12,0} \\
\hline & Topografia & 500986 & 6,0 & \\
\hline \multirow{5}{*}{$\begin{array}{c}\text { Técnicas y Tecnología } \\
\text { de la } \\
\text { Edificación }\end{array}$} & Materiales I & 500985 & 6,0 & \multirow{5}{*}{30,0} \\
\hline & Materiales II & 500990 & 6,0 & \\
\hline & Construcción I & 500983 & 6,0 & \\
\hline & Construcción II & 500987 & 6,0 & \\
\hline & Construcción III y control de calidad I & 500991 & 6,0 & \\
\hline \multirow{3}{*}{$\begin{array}{c}\text { Estructuras e } \\
\text { Instalaciones de la } \\
\text { Edificación }\end{array}$} & Instalaciones I & 500984 & 6,0 & \multirow{3}{*}{18,0} \\
\hline & Instalaciones II & 500989 & 6,0 & \\
\hline & Estructuras 1 & 502306 & 6,0 & \\
\hline \multirow{3}{*}{ Gestión del Proceso } & Organización y equipos de obra & 500993 & 6,0 & \multirow{3}{*}{18,0} \\
\hline & Legislación y Prevención I & 500992 & 6,0 & \\
\hline & Mantenimimiento || y control de calidad & 501008 & 6,0 & \\
\hline \multirow{3}{*}{$\begin{array}{l}\text { Gestión Urbanistica y } \\
\text { Economía aplicadas }\end{array}$} & $\begin{array}{l}\text { Presupuestos I } \\
\end{array}$ & 500997 & 6,0 & \multirow{3}{*}{18,0} \\
\hline & Presupuestos II & 501005 & 6,0 & \\
\hline & Peritaciones y Gestión Urbanistica & 500996 & 6,0 & \\
\hline \multirow{2}{*}{ Proyectos Técnicos } & Proyectos & 501007 & 6,0 & \multirow{2}{*}{12,0} \\
\hline & Ofiçina técnica & 500995 & 6,0 & \\
\hline & & \multicolumn{2}{|c|}{ Total Especificas } & 108,0 \\
\hline & & \multicolumn{2}{|c|}{ TOTAL RECONOCIBLES } & 168,0 \\
\hline
\end{tabular}

Fig. 4 Universidad de Extremadura

\begin{tabular}{|c|c|c|c|c|}
\hline \multicolumn{5}{|c|}{ BÁSICOS } \\
\hline & Créditos ECTS minimos & \multicolumn{2}{|c|}{ Total Básicos } & 60,0 \\
\hline \multicolumn{5}{|c|}{ ESPECIFICOS } \\
\hline MODULO & Asignatura & Código & ECTS & Total/Módulo \\
\hline Expresión Gráfica & $\begin{array}{l}\text { Expresión gráfica de la Tecnologia de la } \\
\text { Edificación } \\
\end{array}$ & 25 & 6,0 & \multirow[t]{2}{*}{12,0} \\
\hline \multirow{5}{*}{$\begin{array}{c}\text { Técnicas y Tecnología } \\
\text { de la } \\
\text { Edificación }\end{array}$} & $\begin{array}{c}\text { Topografia } \\
\text { Materiales II: Tecnologia de los Materiales }\end{array}$ & $3 \mathrm{~A}$ & 6,0 & \\
\hline & $\frac{\text { Materiales II: Tecnologia de los Materiales }}{\text { Materiales III: Ensayos y Control }}$ & $\frac{22}{26}$ & 6,0 & \multirow{4}{*}{30,0} \\
\hline & Construcción l: Historia, Tipologias y fundamentos de & 15 & 6,0 & \\
\hline & Construcción II: Sistemas Estructurales & 23 & 6,0 & \\
\hline & Construcción III: Sistemas Complementarios & 27 & 6,0 & \\
\hline \multirow{3}{*}{$\begin{array}{c}\text { Estructuras e } \\
\text { Instalaciones de la } \\
\text { Edificación }\end{array}$} & Estructuras I & 24 & 6,0 & \multirow{3}{*}{18,0} \\
\hline & Instalaciones I & 28 & 6,0 & \\
\hline & Instalaciones II & 34 & 6,0 & \\
\hline \multirow{3}{*}{ Gestión del Proceso } & Organización y Programación en Edificación & 32 & 6,0 & \multirow{3}{*}{18,0} \\
\hline & Prevención y Seguridad & 43 & 6,0 & \\
\hline & Gestión de la Calidad & 42 & 6,0 & \\
\hline \multirow{3}{*}{$\begin{array}{l}\text { Gestión Urbanistica y } \\
\text { Economia aplicadas }\end{array}$} & Proyecto de Desarrollo Urbano & 37 & 6,0 & \multirow{3}{*}{18,0} \\
\hline & Mediciones y Presupuestos & 36 & 6,0 & \\
\hline & Valoraciones, Tasaciones y Peritaciones & 45 & 6,0 & \\
\hline \multirow{3}{*}{ Proyectos Técnicos } & Proyecto de Gestión del Proceso y Equipos de & & & \multirow{3}{*}{12,0} \\
\hline & Obras & 44 & 6,0 & \\
\hline & Proyectos I: Ingeniería de Edificación Elemental & 31 & 6,0 & \\
\hline & & \multicolumn{2}{|c|}{ Total Especificas } & 108,0 \\
\hline & & \multicolumn{2}{|c|}{ IOTAL RECONOCIBLES } & 168,0 \\
\hline
\end{tabular}

Fig. 5 Universidad de Granada 


\begin{tabular}{|c|c|c|c|c|}
\hline \multicolumn{5}{|c|}{ BÁSICOS } \\
\hline & Créditos ECTS mínimos & \multicolumn{2}{|c|}{ Total Básicos } & 60,0 \\
\hline \multicolumn{5}{|c|}{ ESPECIFICOS } \\
\hline MODULO & Asignatura & Código & ECTS & Total/Módulo \\
\hline \multirow{2}{*}{ Expresión Gráfica } & Replantejaments i Topografia & 20367 & 6,0 & \multirow[b]{2}{*}{12,0} \\
\hline & Dibuix Assistit per Ordinador & 20360 & 6,0 & \\
\hline \multirow{6}{*}{$\begin{array}{c}\text { Técnicas y Tecnología } \\
\text { de la } \\
\text { Edificación }\end{array}$} & Construcció I. Història de la Construcció & 20354 & 6,0 & \multirow{6}{*}{36,0} \\
\hline & Materials II & 20363 & 6,0 & \\
\hline & Construcció II & 20364 & 6,0 & \\
\hline & Materials III & 20368 & 6,0 & \\
\hline & Construcció III & 20365 & 6,0 & \\
\hline & Construcció IV & 20377 & 6,0 & \\
\hline \multirow{3}{*}{$\begin{array}{c}\text { Estructuras e } \\
\text { Instalaciones de la } \\
\text { Edificación } \\
\end{array}$} & Estructures I & 20361 & 6,0 & \multirow{3}{*}{18,0} \\
\hline & Estructures II & 20366 & 6,0 & \\
\hline & |nstal-lacions | & 20362 & 6,0 & \\
\hline \multirow{3}{*}{ Gestión del Proceso } & Organització i Equips d'Obra & 20370 & 6,0 & \multirow{3}{*}{21,0} \\
\hline & Prevenció i Seguretat & 20372 & 9,0 & \\
\hline & Control de Qualitat & 20379 & 6,0 & \\
\hline \multirow{2}{*}{$\begin{array}{l}\text { Gestión Urbanistica y } \\
\text { Economía aplicadas }\end{array}$} & Amidaments, Pressuposts i Valoracions I & 20371 & 6,0 & \multirow{2}{*}{12,0} \\
\hline & Amidaments, Pressuposts i Valoracions II & 20375 & 6,0 & \\
\hline Proyectos Técnicos & Projectes Tècnics & 20380 & 9,0 & 9,0 \\
\hline & & \multicolumn{2}{|c|}{ Total Especificas } & 108,0 \\
\hline & & \multicolumn{2}{|c|}{ TOTAL RECONOCIBIES } & 168,0 \\
\hline
\end{tabular}

Fig. 6 Universidad de las Islas Baleares

\begin{tabular}{|c|c|c|c|c|}
\hline \multicolumn{5}{|c|}{ BÁSICOS } \\
\hline & Créditos ECTS minimos & \multicolumn{2}{|c|}{ Total Básicos } & 60,0 \\
\hline \multicolumn{5}{|c|}{ ESPECIFICOS } \\
\hline MODULO & Asignatura & Código & ECTS & Total/Módulo \\
\hline \multirow{2}{*}{ Expresión Gráfica } & Expresión Gráfica II & 26537 & 6,0 & \multirow{2}{*}{12,0} \\
\hline & Replanteos y Topografia & 26542 & 6,0 & \\
\hline \multirow{4}{*}{$\begin{array}{c}\text { Técnicas y Tecnología } \\
\text { de la } \\
\text { Edificación }\end{array}$} & Historia de la Construcción & 26547 & 6,0 & \multirow{4}{*}{31,5} \\
\hline & Construcción I & 26540 & 7,5 & \\
\hline & Construcción II & 26543 & 9,0 & \\
\hline & Construcción III & 26544 & 9,0 & \\
\hline \multirow{3}{*}{$\begin{array}{c}\text { Estructuras e } \\
\text { Instalaciones de la } \\
\text { Edificación }\end{array}$} & Estructuras I & 26560 & 6,0 & \multirow{3}{*}{18,0} \\
\hline & Instalaciones II & 26559 & 6,0 & \\
\hline & Estructuras II & 26561 & 6,0 & \\
\hline \multirow{3}{*}{ Gestión del Proceso } & Calidad de la Edificación & 26552 & 6,0 & \multirow{3}{*}{18,0} \\
\hline & Planificación, Organización y Control de obras & 26553 & 6,0 & \\
\hline & $\begin{array}{l}\text { Thiroducción a la Prevención, Seguridad y Salud y } \\
\text { Proyectos Técnicos }\end{array}$ & 26555 & 6,0 & \\
\hline \multirow{2}{*}{$\begin{array}{l}\text { Gestión Urbanistica y } \\
\text { Economia aplicadas }\end{array}$} & Gestión Urbanistica & 26538 & 6,0 & \multirow{2}{*}{15,0} \\
\hline & Mediciones y Presupuestos & 26549 & 9,0 & \\
\hline \multirow{2}{*}{ Proyectos Técnicos } & Proyectos Técnicos & 26550 & 6,0 & \multirow{2}{*}{12,0} \\
\hline & Expresión Gráfica III & 26541 & 6,0 & \\
\hline & & \multicolumn{2}{|c|}{ Total Especificas } & 106,5 \\
\hline & & \multicolumn{2}{|c|}{ TOTAL RECONOCIBLES } & 166,5 \\
\hline
\end{tabular}

Fig. 7 Universidad del País Vasco 
Convergencia de Títulos de Grado conforme a la Orden ECI 3855/2015 -

Convergence of Bachelor Degrees according to Order ECI 3855/2015

\begin{tabular}{|c|c|c|c|c|}
\hline \multicolumn{5}{|c|}{ BÁSICOS } \\
\hline & Créditos ECTS mínimos & \multicolumn{2}{|c|}{ Total Básicos } & 60,0 \\
\hline \multicolumn{5}{|c|}{ ESPECIFICOS } \\
\hline MODULO & Asignatura & Código & ECTS & Total/Módulo \\
\hline \multirow{4}{*}{ Expresión Gráfica } & Técnicas avanzadas de expresión gráfica & 310731 & 3,0 & \multirow{4}{*}{10,0} \\
\hline & Levantamiento y replanteos en la edificación & 310719 & 4,5 & \\
\hline & Taller 3: Gestión I & 310718 & 1,0 & \\
\hline & Taller 4: Análisis del edificio & 310724 & 1,5 & \\
\hline \multirow{12}{*}{$\begin{array}{c}\text { Técnicas y Tecnología } \\
\text { de la } \\
\text { Edificación }\end{array}$} & Materiales pétreos & 310710 & 3,0 & \multirow{12}{*}{38,0} \\
\hline & Materiales no pétreos & 310716 & 6,0 & \\
\hline & Introducción a la construcción & 310704 & 4,5 & \\
\hline & Construcción de estructuras & 310714 & 4,5 & \\
\hline & Construcción bajo rasante & 310720 & 4,5 & \\
\hline & Construcción de envolventes y acabados & 310726 & 4,5 & \\
\hline & Taller 1: Aprender de la construcción tradicional & 310706 & 3,0 & \\
\hline & Taller 2: Modelizar conceptos (BIM) & 310712 & 1,0 & \\
\hline & Taller 3: Gestión I & 310718 & 1,0 & \\
\hline & Taller 4: Análisis del edificio & 310724 & 2,5 & \\
\hline & Taller 8: Proyectos & 310741 & 1,5 & \\
\hline & Taller 9: Modelo final & 310742 & 2,0 & \\
\hline \multirow{4}{*}{$\begin{array}{c}\text { Estructuras e } \\
\text { Instalaciones de la } \\
\text { Edificación }\end{array}$} & Instalaciones de fluidos & 310721 & 3,0 & \multirow{4}{*}{19,5} \\
\hline & Instalaciones electromecánicas & 310728 & 6,0 & \\
\hline & Introducción a las estructuras & 310709 & 6,0 & \\
\hline & Estructuras de acero y hormigón & 310715 & 4,5 & \\
\hline \multirow{6}{*}{ Gestión del Proceso } & Planificación y organización de obra & 310732 & 7,5 & \multirow{6}{*}{20,0} \\
\hline & Coordinación de seguridad y salud laboral & 310738 & 4,5 & \\
\hline & Prevención de riesgos laborales & 310722 & 4,5 & \\
\hline & Taller 4: Análisis del edificio & 310724 & 0,5 & \\
\hline & Taller 8: Proyectos & 310741 & 1,0 & \\
\hline & Taller 9: Modelo final & 310742 & 2,0 & \\
\hline \multirow{2}{*}{$\begin{array}{l}\text { Gestión Urbanistica y } \\
\text { Economía aplicadas }\end{array}$} & Presupuestos y control de costes & 310733 & 7,5 & \multirow{2}{*}{12,0} \\
\hline & Gestión urbanistica & 310729 & 4,5 & \\
\hline \multirow{2}{*}{ Proyectos Técnicos } & Taller 8: Proyectos & 310741 & 6,5 & \multirow{2}{*}{8,5} \\
\hline & Taller 9: Modelo final & 310742 & 2,0 & \\
\hline & & \multicolumn{2}{|c|}{ Total Especificas } & 108,0 \\
\hline & & \multicolumn{2}{|c|}{ TOTAL RECONOCIBLES } & 168,0 \\
\hline
\end{tabular}

Fig. 8 Universidad Politécnica de Cataluña 


\begin{tabular}{|c|c|c|c|c|}
\hline \multicolumn{5}{|c|}{ BÁSICOS } \\
\hline & Créditos ECTS minimos & \multicolumn{2}{|c|}{ Total Básicos } & 63,5 \\
\hline \multicolumn{5}{|c|}{ ESPECIFICOS } \\
\hline MODULO & Asignatura & Código & ECTS & Total/Módulo \\
\hline \multirow{2}{*}{ Expresión Gráfica } & Dibujo Arquitectónico II & 10010 & 4,5 & \multirow{2}{*}{ 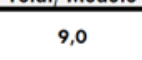 } \\
\hline & Topografia y Replanteos & 10011 & 4,5 & \\
\hline \multirow{6}{*}{$\begin{array}{c}\text { Técnicas y Tecnología } \\
\text { de la } \\
\text { Edificación }\end{array}$} & Materiales de Construcción II & 10012 & $\overline{4,5}$ & \multirow{6}{*}{36,0} \\
\hline & Materiales de Construcción IIII & 10013 & 9,0 & \\
\hline & Construcción I & 10014 & 9,0 & \\
\hline & Construcción II & 12484 & 4,5 & \\
\hline & Construcciones Históricas & 10019 & 4,5 & \\
\hline & Construcción IIII & 12485 & 4,5 & \\
\hline \multirow{3}{*}{$\begin{array}{c}\text { Estructuras e } \\
\text { Instalaciones de la } \\
\text { Edificación }\end{array}$} & Estructuras I & 10020 & 6,0 & \multirow{3}{*}{18,0} \\
\hline & Estructuras II & 10021 & 6,0 & \\
\hline & Instalaciones I| & 10022 & 6,0 & \\
\hline \multirow{4}{*}{ Gestión del Proceso } & Prevención y Seguridad I & 10024 & $\overline{4,5}$ & \multirow{4}{*}{21,0} \\
\hline & Prevención y Seguridad II & 10025 & 4,5 & \\
\hline & Organización, Programación y Control de Recursos & 10023 & 6,0 & \\
\hline & Calidad en la Edificación & 10026 & 6,0 & \\
\hline \multirow{3}{*}{$\begin{array}{l}\text { Gestión Urbanistica y } \\
\text { Economía aplicadas }\end{array}$} & Técnicas de Gestión Presupuestaria & 10030 & 6,0 & \multirow{3}{*}{15,0} \\
\hline & Peritaciones, Tasaciones y Valoraciones & 10029 & 4,5 & \\
\hline & Gestión Urbanistica & 10028 & 4,5 & \\
\hline \multirow{2}{*}{ Proyectos Técnicos } & Proyectos 1 & 10031 & 4,5 & \multirow{2}{*}{9,0} \\
\hline & Proyectos II & 10032 & 4,5 & \\
\hline & & \multicolumn{2}{|c|}{ Total Especificas } & 108,0 \\
\hline & & \multicolumn{2}{|c|}{ TOTAL RECONOCIBLES } & 171.5 \\
\hline
\end{tabular}

Fig. 9 Universitat Politècnica de València

\begin{tabular}{|c|c|c|c|c|}
\hline \multicolumn{5}{|c|}{ BÁSICOS } \\
\hline & Créditos ECTS mínimos & \multicolumn{2}{|c|}{ Total Básicos } & 60,0 \\
\hline \multicolumn{5}{|c|}{ ESPECIFICOS } \\
\hline MODULO & Asignatura & Código & ECTS & Total/Módulo \\
\hline \multirow{2}{*}{ Expresión Gráfica } & Topografia y replanteos & 28611 & 6,0 & \multirow{2}{*}{12,0} \\
\hline & Expresión gráfica de tecnologías constructivas & 28616 & 6,0 & \\
\hline \multirow{5}{*}{$\begin{array}{c}\text { Técnicas y Tecnología } \\
\text { de la } \\
\text { Edificación }\end{array}$} & Historia de la construcción & 28604 & 6,0 & \multirow{5}{*}{30,0} \\
\hline & Materiales I & 28607 & 6,0 & \\
\hline & Edificación I & 28609 & 6,0 & \\
\hline & Materiales II & 28613 & 6,0 & \\
\hline & Edificación II & 28614 & 6,0 & \\
\hline \multirow{3}{*}{$\begin{array}{c}\text { Estructuras e } \\
\text { Instalaciones de la } \\
\text { Edificación }\end{array}$} & Estructuras l: Introducción a las estructuras & 28612 & 6,0 & \multirow{3}{*}{18,0} \\
\hline & Instalaciones I & 28615 & 6,0 & \\
\hline & Instalaciones II & 28622 & 6,0 & \\
\hline \multirow{3}{*}{ Gestión del Proceso } & Organización, programación control obras & 28626 & 6,0 & \multirow{3}{*}{18,0} \\
\hline & Seguridad y salud laboral & 28627 & 6,0 & \\
\hline & Equipos de obra & 28620 & 6,0 & \\
\hline \multirow{3}{*}{$\begin{array}{l}\text { Gestión Urbanistica y } \\
\text { Economía aplicadas }\end{array}$} & Mediciones y presupuestos & 28624 & 6,0 & \multirow{3}{*}{18,0} \\
\hline & Gestión urbanistica e impacto ambiental & 28640 & 6,0 & \\
\hline & Valoraciones, peritaciones y tasaciones & 28630 & 6,0 & \\
\hline \multirow{2}{*}{ Proyectos Técnicos } & Proyectos técnicos I & 28633 & 6,0 & \multirow{2}{*}{12,0} \\
\hline & Proyectos técnicos II & 28634 & 6,0 & \\
\hline & & \multicolumn{2}{|c|}{ Total Especificas } & 108,0 \\
\hline & & \multicolumn{2}{|c|}{ TOTAL RECONOCIBLES } & 168,0 \\
\hline
\end{tabular}

Fig.10 Universidad de Zaragoza 
Convergencia de Títulos de Grado conforme a la Orden ECI 3855/2015 -

Convergence of Bachelor Degrees according to Order ECI 3855/2015

\begin{tabular}{|c|c|c|c|c|}
\hline \multicolumn{5}{|c|}{ BÁSICOS } \\
\hline & Créditos ECTS mínimos & \multicolumn{2}{|c|}{ Total Básicos } & 60,0 \\
\hline \multicolumn{5}{|c|}{ ESPECIFICOS } \\
\hline MODULO & Asignatura & Código & ECTS & Total/Módulo \\
\hline \multirow{3}{*}{ Expresión Gráfica } & Dibujo Arquitectónico II & 545000010 & 3,0 & \multirow{3}{*}{12,0} \\
\hline & Geometría Descriptiva II & 545000011 & 3,0 & \\
\hline & Topografia I & 545000019 & 6,0 & \\
\hline \multirow{8}{*}{$\begin{array}{c}\text { Técnicas y Tecnología } \\
\text { de la } \\
\text { Edificación }\end{array}$} & Materiales de Construcción I & 545000008 & 6,0 & \multirow{8}{*}{36,0} \\
\hline & Introducción a la Construcción & 545000009 & 6,0 & \\
\hline & Construcción de Estructuras de Acero & 545000022 & 3,0 & \\
\hline & Onstrucción de Cerramientos de Fachadas y Cubierta & 545000026 & 6,0 & \\
\hline & Construcción Sostenible & 545000036 & 3,0 & \\
\hline & Historia de la Construcción & 545000028 & 3,0 & \\
\hline & Patología y Rehabilitación & 545000039 & 6,0 & \\
\hline & Mantenimiento & 545000045 & 3,0 & \\
\hline \multirow{3}{*}{$\begin{array}{c}\text { Estructuras e } \\
\text { Instalaciones de la } \\
\text { Edificación }\end{array}$} & Resistencia de Materiales y Elasticidad & 545000020 & 6,0 & \multirow{3}{*}{18,0} \\
\hline & Análisis de Estructuras y Geotecnia & 545000024 & 6,0 & \\
\hline & Instalaciones $\mid$ & 545000021 & 6,0 & \\
\hline \multirow{4}{*}{ Gestión del Proceso } & Calidad de la Edificación & 545000044 & 6,0 & \multirow{4}{*}{21,0} \\
\hline & Planificación y Programación de Obras I & 545000033 & 6,0 & \\
\hline & Gestión del Proceso Edificatorio & 545000041 & 3,0 & \\
\hline & Prevención y Seguridad I & 545000034 & 6,0 & \\
\hline \multirow{3}{*}{$\begin{array}{l}\text { Gestión Urbanística y } \\
\text { Economía aplicadas }\end{array}$} & Legislación Urbanística & 545000046 & 3,0 & \multirow{3}{*}{12,0} \\
\hline & Mediciones y Presupuestos & 545000032 & 6,0 & \\
\hline & Valoraciones y Tasaciones. Peritaciones Judiciales & 545000042 & 3,0 & \\
\hline \multirow{2}{*}{ Proyectos Técnicos } & Proyectos Técnicos I & 545000030 & 3,0 & \multirow{2}{*}{9,0} \\
\hline & Proyectos Técnicos II & 545000037 & 6,0 & \\
\hline & & \multicolumn{2}{|c|}{ Total Especificas } & 108,0 \\
\hline & & \multicolumn{2}{|c|}{ TOTAL RECONOCIBLES } & 168,0 \\
\hline
\end{tabular}

Fig.11 Universidad Politécnica de Madrid 


\begin{tabular}{|c|c|c|c|c|}
\hline \multicolumn{5}{|c|}{ BÁSICOS } \\
\hline & Créditos ECTS mínimos & \multicolumn{2}{|c|}{ Total Básicos } & 60,0 \\
\hline \multicolumn{5}{|c|}{ ESPECIFICOS } \\
\hline MODULO & Asignatura & Código & ECTS & Total/Módulo \\
\hline \multirow{2}{*}{ Expresión Gráfica } & Análisis e interpretación del proy. arquitectónico & 12660 & 4,5 & \multirow{2}{*}{9,0} \\
\hline & Topografia y replanteos & 12652 & 4,5 & \\
\hline \multirow{8}{*}{$\begin{array}{c}\text { Técnicas y Tecnología } \\
\text { de la } \\
\text { Edificación }\end{array}$} & Materiales de construcción I & 12645 & 4,5 & \multirow{8}{*}{34,5} \\
\hline & Materiales de construcción II & 12650 & 3,0 & \\
\hline & Introducción a la construcción & 12677 & 4,5 & \\
\hline & Construcción I & 12651 & 4,5 & \\
\hline & Construcción II & 12659 & 4,5 & \\
\hline & Construcción III & 12663 & 4,5 & \\
\hline & Historia de la construcción & 12688 & 4,5 & \\
\hline & Construcción industrializada. Construcción sostenible & 12683 & 4,5 & \\
\hline \multirow{4}{*}{$\begin{array}{c}\text { Estructuras e } \\
\text { Instalaciones de la } \\
\text { Edificación }\end{array}$} & Introducción a las estructuras de edificación & 12654 & 4,5 & \multirow{4}{*}{18,0} \\
\hline & Estructuras de edificación I & 12661 & 4,5 & \\
\hline & Estructuras de edificación II & 12662 & 4,5 & \\
\hline & Instalaciones de edificación I & 12665 & 4,5 & \\
\hline \multirow{4}{*}{ Gestión del Proceso } & Seguridad, salud y prevención de riesgos laborales & 12669 & 4,5 & \multirow{4}{*}{18,0} \\
\hline & Técnicas de organización y programación de la edif. & 12681 & 4,5 & \\
\hline & Gestión y aseguramiento de la calidad & 12672 & 4,5 & \\
\hline & Deontologia, organización y ejercicio profesional & 12684 & 4,5 & \\
\hline \multirow{4}{*}{$\begin{array}{l}\text { Gestión Urbanistica y } \\
\text { Economia aplicadas }\end{array}$} & Valoraciones y tasaciones & 12674 & 4,5 & \multirow{4}{*}{16,5} \\
\hline & Mediciones y presupuestos & 12680 & 4,5 & \\
\hline & Análisis y control de costes durante el proceso constr. & 12687 & 4,5 & \\
\hline & Gestión medioambiental y urbanística & 12682 & 3,0 & \\
\hline \multirow{2}{*}{ Proyectos Técnicos } & Proyectos técnicos I & 12679 & 4,5 & \multirow{2}{*}{9,0} \\
\hline & Proyectos técnicos II & 12686 & 4,5 & \\
\hline & & \multicolumn{2}{|c|}{ Total Especificas } & 105,0 \\
\hline & & \multicolumn{2}{|c|}{ TOTAL RECONOCIBLES } & 165,0 \\
\hline
\end{tabular}

Fig.12 Universidad Católica San Antonio de Murcia

\section{Conclusiones}

Tras tres años de trabajo, en las que las distintas escuelas que conforman la CODATIE han podido hacer una puesta en común sobre las equivalencias entre los distintos planes de estudios, se consiguió finalmente llegar a un acuerdo sobre los créditos que podrían ser reconocidos.

Este acuerdo facilita la movilidad entre escuelas y la posibilidad de conformar planes de estudios comunes, a la vez que diferentes en su ámbito de especialización, lo que supone un gran avance a la vez que una oportunidad.

Dar a conocer este trabajo a todas las Escuelas, y que estas se sumen al acuerdo adoptado, se considera una labor más de la CODATIE que se suma al trabajo ya realizado. 


\section{Referencias}

España. Real Decreto 1393/2007, de 29 de octubre, por el que se establece la ordenación de las enseñanzas universitarias oficiales. BOE, 30 de octubre de 2007, núm. 260, p. 44037 a 44048.

España. Resolución de 17 de diciembre de 2007, de la Secretaría de Estado de Universidades e Investigación, por la que se publica el Acuerdo de Consejo de Ministros de 14 de diciembre de 2007, por el que se establecen las condiciones a las que deberán adecuarse los planes de estudios conducentes a la obtención de títulos que habiliten para el ejercicio de la profesión regulada de Arquitecto Técnico. BOE, 21 de diciembre de 2007, núm. 305, p. 52848 a 52849.

España. Orden ECI/3855/2007, de 27 de diciembre, por la que se establecen los requisitos para la verificación de los títulos universitarios oficiales que habiliten para el ejercicio de la profesión de Arquitecto Técnico. BOE, 29 de diciembre de 2007, núm. 312, p. 53739 a 53742. 


\title{
EDIFİCATE
}

I Congreso de Escuelas de Edificación y Arquitectura Técnica de España València, 4 y 5 de noviembre de 2021

Escuela Técnica Superior de Ingeniería de Edificación

Universitat Politècnica de València

Doi: https://doi.org/10.4995/EDIFICATE2021.2021.13515

Modificación del plan de estudios del grado en Arquitectura Técnica y Edificación de la UPC

\section{Curriculum modification for the degree in Technical Architecture and Building at the UPC}

\author{
Inmaculada Rodríguez Cantalapiedra ${ }^{a}$ y Juan Rodríguez Jordana ${ }^{b}$ \\ aEPSEB, UPC, inmaculada.rodriguez@upc.edu, 'bPSEB, UPC, juan.rodriguez@upc.edu.
}

\begin{abstract}
Within the framework of continuous improvement of the contents and teaching methodologies of university degrees, the Escola Politècnica Superior d'Edificació de Barcelona (EPSEB) of the Universitat Politècnica de Catalunya (UPC) decided to review and update the curriculum of the Degree in Technical Architecture and Building (GATE). As a previous step, a strategic plan for the degree was developed, involving internal and external agents, whose conclusions were binding in the aforementioned review. The modified curriculum defines the degree profile and introduces new teaching methodologies. On the other hand, its implementation has required significant strategies, commitments and efforts on the part of faculty, students and administrative and service personnel.
\end{abstract}

Keywords: Syllabus, teaching methodologies, competencies

\section{Resumen}

En el marco de la mejora continua de los contenidos y las metodologías docentes de las titulaciones universitarias, en la Escola Politècnica Superior d'Edificació de Barcelona (EPSEB) de la Universitat Politècnica de Catalunya (UPC), se decidió hacer una revisión y puesta al día del plan de estudios del Grado en Arquitectura Técnica y Edificación (GATE). Como paso previo se desarrolló un plan estratégico de la titulación, involucrando agentes internos y externos, cuyas conclusiones fueron vinculantes en la mencionada revisión. El plan de estudios modificado define el perfil de la titulación e introduce nuevas metodologías docentes. Por otra parte, su puesta en marcha ha requerido estrategias, compromisos y esfuerzos notables por parte de profesorado, estudiantado, y personal de administración y servicios.

Palabras clave: Plan de estudios, metodologías docentes, competencias, Grado en Arquitectura Técnica y Edificación, Escola Politècnica Superior d'Edificació de Barcelona (EPSEB). 


\section{Introducción}

Este artículo pretende explicar la experiencia de modificación del plan de estudios del Grado en Arquitectura Técnica y Edificación (GATE) llevada a cabo en la Escola Politècnica Superior d'Edificació de Barcelona (EPSEB). En primer lugar, se explicará el plan estratégico de la titulación, que se llevó a cabo a fin de hacer una revisión y puesta al día de ésta en profundidad. Luego se verá cómo sus conclusiones fueron vinculantes en la modificación del plan de estudios. Se expondrá el nuevo plan, sus principales características y se profundizará en los aspectos más relevantes. Finalmente, se compartirá la experiencia de su implementación en diferentes fases.

\subsection{Plan estratégico del GATE de la EPSEB en la UPC}

A fin de hacer una revisión en profundidad y puesta al día de los contenidos y metodologías docentes del GATE, en la EPSEB de la Universitat Politècnica de Catalunya (UPC) se llevó a cabo un plan estratégico, por parte de una comisión nombrada "ad hoc" desde la dirección del centro, y que se puede resumir en el siguiente esquema:

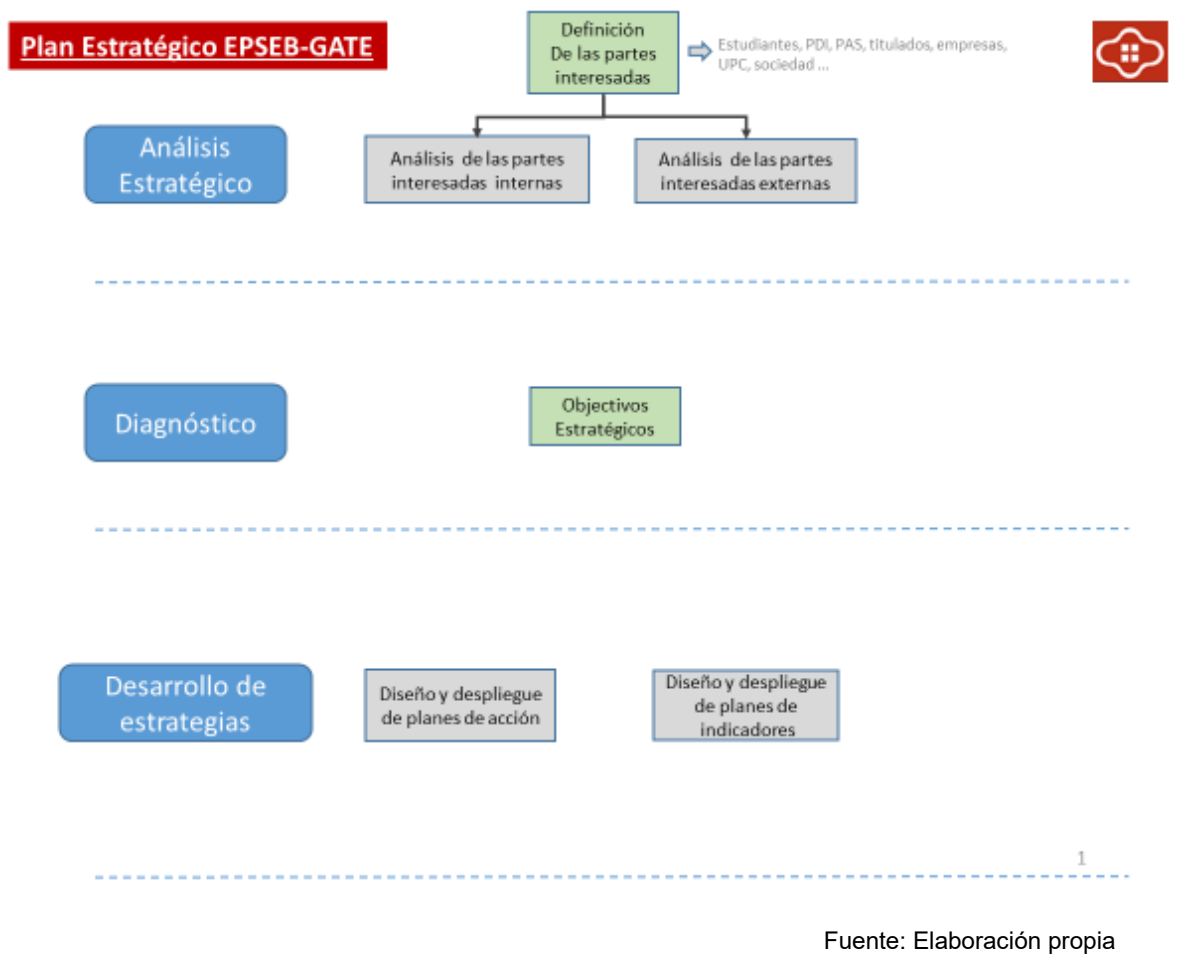

Fig. 1: Esquema de las fases del Plan Estratégico de la titulación del Grado en Arquitectura Técnica y Edificación (GATE) 


\subsubsection{Partes interesadas}

En el análisis estratégico se hicieron reuniones, se organizaron jornadas y se pasaron encuestas. Las partes interesadas que intervinieron fueron:

$\square \quad$ Internas

- Estudiantado

- Profesorado / Departamentos

$\square$ Externas

- Ex-alumnos

- Empresas y profesión

- Otras titulaciones españolas y europeas

\subsubsection{Diagnóstico}

Como resultado del análisis estratégico se llegó a un diagnóstico por conceptos o temas a introducir, reforzar o mejorar que se resume en la siguiente tabla según el análisis de las partes interesadas:

Tabla 1. Resumen del diagnóstico realizado por los diferentes agentes de los temas a mejorar

\begin{tabular}{|c|c|c|c|c|c|}
\hline $\begin{array}{l}\text { Conceptos o temas que } \\
\text { hay que introducir, reforzar } \\
\text { o mejorar: }\end{array}$ & $\begin{array}{l}\text { Estudiante } \\
\mathrm{s}\end{array}$ & Ex-alumnos & Departamentos & $\begin{array}{l}\text { Titulaciones } \\
\text { europeas }\end{array}$ & $\begin{array}{l}\text { Empresas- } \\
\text { profesión }\end{array}$ \\
\hline Metodologías docentes & $x$ & $\mathrm{x}$ & & $x$ & \\
\hline Práct. Ext. y visitas de obra & $\mathrm{x}$ & $\mathrm{x}$ & & $\mathrm{x}$ & $\mathrm{x}$ \\
\hline Motivación profesorado & $x$ & $\mathrm{x}$ & & & \\
\hline Coordinación horizontal & $\mathrm{x}$ & & & & \\
\hline Asignaturas mal valoradas & $x$ & & & & \\
\hline Comunicación & $x$ & & & & \\
\hline Espacios para estudiantes & $\mathrm{x}$ & & & & \\
\hline Software-BIM & $x$ & $\mathrm{X}$ & $\mathrm{X}$ & & $\mathrm{X}$ \\
\hline Plan de estudios & $x$ & & & & \\
\hline Competencias genéricas & & & & $x$ & $x$ \\
\hline Inglés técnico & & $\mathrm{X}$ & & & $\mathrm{X}$ \\
\hline Enfoque profesional & & $\mathrm{X}$ & & $\mathrm{X}$ & \\
\hline
\end{tabular}




\begin{tabular}{|l|l|l|l|l|l|}
\hline Estudios generalistas & & & & & $\mathrm{X}$ \\
\hline $\begin{array}{l}\text { Perfil experto en procesos } \\
\text { constructivos }\end{array}$ & & & & & $\mathrm{X}$ \\
\hline $\begin{array}{l}\text { Perfil en gestión en la } \\
\text { edificación }\end{array}$ & & & $\mathrm{X}$ & & $\mathrm{X}$ \\
\hline Perfil en rehabilitación & & & $\mathrm{X}$ & & $\mathrm{X}$ \\
\hline $\begin{array}{l}\text { Integración en equipos } \\
\text { multidisciplinarios / diseño }\end{array}$ & & & & & $\mathrm{X}$ \\
\hline $\begin{array}{l}\text { Perfil experto en } \\
\text { sostenibilidad y eficiencia } \\
\text { energética }\end{array}$ & $\mathrm{X}$ & $\mathrm{X}$ & & & $\mathrm{X}$ \\
\hline
\end{tabular}

\subsubsection{Objetivos}

Como consecuencia de este diagnóstico, se establecieron los siguientes objetivos:

- $\quad$ Nivel 1 (grandes ejes)

1. Actualización de los contenidos académicos y las metodologías docentes

2. Aumento de la motivación del estudiantado

3. Aumento de la implicación del profesorado

4. Aumento de la ocupabilidad del estudiantado egresado

5. Aumento del número de estudiantes

- $\quad$ Nivel 2

1. Introducción de nuevas metodologías docentes

2. Actualización de los contenidos de las asignaturas

3. Aumento de prácticas externas y visitas de obra

4. Introducción de software específico y BIM

5. Desarrollo de competencias genéricas

6. Definición de perfil de la titulación

\section{Plan de estudios}

El modelo de Educación Superior en España, ha experimentado un cambio sustancial que afecta tanto a la organización de los estudios como a los métodos aplicados por los docentes. 
Las técnicas de Aprendizaje Basado en Problemas (ABP) y la interdisciplinariedad forman parte de esa introducción de nuevas metodologías que, de forma creciente, se incorporan en el nivel universitario (Amo et al., 2014); (Amo et al., 2007); (De Miguel, 2005); (Jiménez, Lagos, Jareño, 2011).

La principal estrategia para conseguir muchos de los objetivos expuestos consistió en modificar el plan de estudios y modificar las metodologías docentes. Muchas asignaturas debían ceder créditos para permitir la aparición de nuevas asignaturas, la mayoría en forma de taller. Estos talleres prácticos, al menos uno por cuatrimestre, debían ser asignaturas de síntesis, basadas en proyectos, que recogieran los contenidos de las materias que se habían impartido hasta el momento de su aparición e impartidas por un grupo interdisciplinario de docentes.

En la siguiente tabla se comparan los dos planes de estudio, 2015 y 2019. Se resaltan las asignaturas que ceden créditos (coloreadas en amarillo) y las de nueva creación (coloreadas en verde), con especial énfasis en los talleres (coloreadas en azul). En letra roja el Trabajo final de grado que reduce sus créditos.

Tabla 2. Comparación de los planes de estudios. Coloreados en amarillo, aquellas asignaturas que a pesar de que se mantienen, ceden créditos; coloreados en verde nuevas asignaturas; coloreados en azul los Talleres de síntesis.

\begin{tabular}{|c|c|c|c|}
\hline \multirow{2}{*}{\multicolumn{2}{|c|}{$\begin{array}{c}\text { PLAN DE ESTUDIOS } 2015 \\
\text { 1A - Primer curso - Primer } \\
\text { cuadrimestre }\end{array}$}} & \multicolumn{2}{|l|}{ PLAN DE ESTUDIOS 2019} \\
\hline & & & \\
\hline Mecánica & 9 & Mecánica & 6 \\
\hline Expresión gráfica I & 9 & Introducción al dibujo arquitectónico & 6 \\
\hline Construcción I & 7,5 & Introducción a la Construcción & 4,5 \\
\hline \multirow[t]{3}{*}{ Fundamentos matemáticos } & 6 & Fundamentos matemáticos & 6 \\
\hline & & Fundamentos de Materiales, Química y Geología & 3 \\
\hline & & TALLER Aprender de la c. tradicional & 4,5 \\
\hline \multicolumn{4}{|c|}{$\begin{array}{c}\text { 1B - Primer curso - Segundo } \\
\text { cuadrimestre }\end{array}$} \\
\hline Economía & 7,5 & Materiales pétreos & 6 \\
\hline Seguridad y salud & 6 & Arquitectura, construcción y ciudad en la historia de Occidente. & 4,5 \\
\hline Materiales I & 9 & Dibujo arquitectónico & 6 \\
\hline \multirow[t]{3}{*}{ Estadística aplicada } & 6 & Introducción a las Estructuras & 6 \\
\hline & & Física de les Instalaciones y eficiencia energética & 4,5 \\
\hline & & TALLER Modelizar conceptos (BIM) & 3 \\
\hline \multicolumn{4}{|c|}{$\begin{array}{l}\text { 2A - Segundo curso - Primer } \\
\text { cuadrimestre }\end{array}$} \\
\hline Materiales II & 6 & Construcción de estructuras & 4,5 \\
\hline Construcción II & 3 & Estructuras de acero y hormigón & 4,5 \\
\hline
\end{tabular}




\begin{tabular}{|c|c|c|c|}
\hline Estructuras I & 6 & Materiales no pétreos & 6 \\
\hline Instalaciones I & 6 & Gestión empresarial & 4,5 \\
\hline \multirow[t]{2}{*}{ Expresión gráfica II } & 6 & Estadística aplicada & 6 \\
\hline & & TALLER de gestión I & 4,5 \\
\hline \multicolumn{4}{|c|}{$\begin{array}{c}\text { 2B - Segundo curso - Segundo } \\
\text { cuadrimestre }\end{array}$} \\
\hline $\begin{array}{l}\text { Levantamientos y } \\
\text { replanteamientos } \\
\text { Arquitectura construcción y } \\
\text { ciudad }\end{array}$ & 6 & $\begin{array}{l}\text { Levantamientos y replanteamientos en la edific. } \\
\text { Construcción bajo rasante }\end{array}$ & 4,5 \\
\hline Construcción III & 6 & Prevención de riesgos laborales & 4,5 \\
\hline Instalaciones II & 6 & Instalaciones de fluidos & 6 \\
\hline \multirow[t]{2}{*}{ Derecho } & 6 & Legislación aplicada a la edificación & 6 \\
\hline & & TALLER Análisis del edificio & 4,5 \\
\hline \multicolumn{4}{|c|}{$\begin{array}{c}\text { A - Tercer curso - Primer } \\
\text { cuadrimestre }\end{array}$} \\
\hline Prevención & 6 & Gestión urbanística & 4,5 \\
\hline Estructuras II & 6 & Construcción de envolventes y acabados & 4,5 \\
\hline Expresión gráfica III & 6 & Patología de la edificación & 3 \\
\hline Construcción IV & 6 & Instalaciones electromecánicas & 6 \\
\hline \multirow[t]{2}{*}{ Peritaciones y tasaciones } & 6 & Sistemas Estructurales & 6 \\
\hline & & TALLER Patología y Diagnosis & 6 \\
\hline \multicolumn{4}{|c|}{$\begin{array}{c}\text { 3B - Tercer curso - Segundo } \\
\text { cuadrimestre }\end{array}$} \\
\hline Calidad en la edificación & 6 & Técnicas avanzadas de Expresión Gráfica & 3 \\
\hline Gestión urbanística & 5 & Planificación y organización de obras & 7,5 \\
\hline $\begin{array}{l}\text { Presupuestos y control de } \\
\text { costes }\end{array}$ & 9 & Presupuestos y control de costes & 7,5 \\
\hline Construcción V & 4 & Calidad en la edificación & 4,5 \\
\hline Estructuras III & 6 & TALLER de Gestión II & 7,5 \\
\hline \multicolumn{4}{|c|}{$\begin{array}{c}\text { 4A - Cuarto curso - Primer } \\
\text { cuadrimestre }\end{array}$} \\
\hline Construcción VI & 5 & Conservación y Mantenimiento & 4,5 \\
\hline Construcción VII & 4 & Peritaciones y tasaciones & 4,5 \\
\hline Planificación & 9 & Coordinación de seguridad y salud laboral & 4,5 \\
\hline \multirow[t]{2}{*}{ Proyectos I } & 4,5 & TALLER Rehabilitación & 7,5 \\
\hline & & TALLER Proyectos & 9 \\
\hline \multicolumn{4}{|c|}{$\begin{array}{c}\text { 4B - Cuarto curso - Segundo } \\
\text { cuadrimestre }\end{array}$} \\
\hline Optativas & 9 & Optativas & 12 \\
\hline Proyectos II & 4,5 & TALLER Modelo final & 6 \\
\hline Proyecto final de grado & 24 & Proyecto final de grado & 12 \\
\hline
\end{tabular}


Mecánica, Expresión gráfica I, Expresión gráfica III, Levantamientos y replanteamientos, Arquitectura construcción y ciudad en la historia de occidente,

Como tecnológicas:

Materiales I, Materiales II, construcción I, construcción III, construcción IV, construcción V, construcción VI, Estructures II,

Y de gestión:

Economía, Peritaciones y tasaciones, Calidad en la edificación, Gestión urbanística, Presupuestos y control de costes, Seguridad y salud, Prevención, Planificación.

El proyecto fin de grado también cede créditos.

Las de nueva creación son:

Fundamentos de Materiales: Química y Geología y Física de las Instalaciones y Eficiencia Energética.

Y los 9 talleres que vertebran el plan de estudios:

TALLER 1 Aprender de la construcción tradicional

TALLER 2 Modelizar conceptos (BIM)

TALLER 3 Gestión I

TALLER 4 Análisis del edificio

TALLER 5 Patología y diagnosis.

TALLER 6 Gestión II

TALLER 7 Rehabilitación

TALLER 8 Proyectos

TALLER 9 Modelo final

En el taller 1, consistente en el estudio de un edificio existente a la luz de los conceptos que se van aprendiendo en la asignatura de introducción a la construcción, se pretende motivar y fidelizar al estudiantado de nuevo ingreso, que en los primeros cuatrimestres debe atender a muchas asignaturas de carácter básico, por las que, seguramente, no siente mucha atracción. En el taller 2 se introduce el software de soporte de la metodología BIM que deberá estar presente en la mayoría de las asignaturas. El taller 4 vuelve al análisis de un edificio desde un punto de vista más técnico, utilizando los conocimientos ya adquiridos. Los talleres 3 y 6 deben marcar el perfil de gestión de la titulación. En el primero se estudia la cadena de valor de una empresa en el ámbito de la construcción, mientras que, en el segundo, se introduce al estudiantado en el terreno de la gestión inmobiliaria. Los talleres 5 y 7 deben marcar el perfil de rehabilitación en edificación. El taller 8 resume las asignaturas de oficina técnica y el taller 9 es una reválida de las principales materias estudiadas en la titulación. 


\section{La implantación}

El nuevo plan tuvo que ser re-verificado y pasar por los filtros correspondientes: Servicio de Gestión Académica de la UPC, Agència de la Qualitat Universitària catalana y ANECA. Pero a la hora de ponerlo en marcha aparecieron graves problemas logísticos.

Un plan de estudios nuevo se puede implantar curso a curso, con el estudiantado de nuevo ingreso, mientras se va extinguiendo el plan de estudios "antiguo" con el estudiantado existente. Sin embargo, el plan de estudios que proponíamos no se consideraba como "nuevo" porque tenía las mismas competencias que el anterior. Se podría haber añadido alguna competencia para conseguir el estatus de "nuevo", pero ello alargaba considerablemente los plazos administrativos para su re-verificación. Por lo tanto, se trataba de un plan de estudios no "nuevo" sino "modificado", con lo que la implantación debía ser en bloque y para todo el estudiantado de la titulación.

Como ya se ha comentado, la modificación se basaba en la cesión de créditos de muchas asignaturas para la aparición de otras nuevas que debían dar respuesta a los objetivos del plan estratégico. Ello conllevaba que la mayoría del estudiantado de la titulación perdiera créditos en la adaptación. Se hizo una tabla de equivalencias pensada para evitar esta situación, pero ello requería una matriculación especial para cada situación.

A partir de las sesiones informativas que se organizaron con profesorado, personal de administración y estudiantado, este último colectivo se sintió gravemente perjudicado y organizó acciones de protesta y presión para evitar la implantación del nuevo plan. Todos los esfuerzos dedicados a la mejora de una titulación se interpretaban, por parte del colectivo al que estaba dirigida la mejora, como un método para recaudar dinero al hacerles pagar más por los créditos que perdían en la adaptación.

Debido a la situación de crisis en la que nos encontrábamos, el vicerrectorado y el servicio de gestión académica de la UPC nos permitió hacer una implantación en dos fases de modo que, al dar más oportunidades de matrícula, mediante el uso inteligente de la tabla de adaptaciones, se pudiera evitar la pérdida de créditos en el nuevo plan modificado. Se activó el sistema de tutorías y se diseñó un simulador que se puso a disposición en la web del centro para incentivar las matrículas de modo que se evitara la pérdida de créditos.

A pesar de todo ello, cuando se agotó el período transitorio y todo el estudiantado se tuvo que adaptar definitivamente, en muchos casos no se habian atendido las recomendaciones y el estudiantado que estaba afectado por la pérdida de créditos volvió a organizarse y a reclamar una solución, en la mayoría de los casos de carácter económico. La solución a la situación extremadamente complicada y tensa que se había generado vino a través de la opción del reconocimiento de créditos optativos que, si bien no contentaba a todo el mundo, sí que fue aceptada por la mayoría. También hay que tener en cuenta que todos estos procedimientos se pudieron llevar a cabo gracias a la abnegación de parte del personal de administración que tuvo que revisar los casos uno a uno, contestar un aluvión de instancias y atender un sinfín de quejas, no todas con buenos modos, en la ventanilla. 
Todo esto lo explicamos para llamar la atención sobre la rigidez del sistema universitario con la que tenemos que trabajar. Si las acciones de mejora se traducen, por problemas administrativos, en situaciones de crisis que son interpretadas como perjuicio para el colectivo destinatario de la mejora, se acabará optando por el inmovilismo.

\section{Conclusiones}

Transcurridos 10 años en la implantación de los planes de estudios basados en el modelo de Educación Superior Europea, estos precisan como poco, modificaciones: de ajustes a las nuevas situaciones sociales, de cambios de paradigmas, de cambios metodológicos de aprendizaje. Es un ejercicio higiénico, el ir realizando mejoras y re direccionamientos en los planes de estudios, a pesar de que la inercia del sistema entorpece la correcta adecuación.

El siguiente punto a analizar, es hacer un buen seguimiento de la puesta en marcha, mediante encuestas a los docentes, estudiantado y sociedad para comprobar que se han obtenido los resultados correctos y esperados.

\section{Referencias}

AMO, E., CÓRCOLES, C., PARDO, M. \& TEJADA, A. (2011). Implantación de Curso Piloto en ECTS en Primero de Economía y de ADE. En C. Vizcarro, J. R. Carrillo y J. J. Sobrino (coord.). Experiencias de Innovación docente en la UCLM. Ediciones de la Universidad de Castilla La Mancha, ISBN 978-84-8424-776-0, 133-150

AMO, E., JAREÑO, F., LAGOS, M., \& TOBARRA, M. (2014). "Las nuevas metodologías docentes y su repercusión en los planes de estudio" en Innovar: Revista De Ciencias Administrativas $Y$ Sociales, vol. 24, issue 54, p. 231-250. <Disponible en: http://www.jstor.org/stable/24329863> [Consulta: 31 Mayo de 2021]

DE MIGUEL, M. (2005). Modalidades de enseñanza centradas en el desarrollo de competencias. Orientaciones para promover el cambio metodológico en el Espacio Europeo de Educación Superior. Ministerio de Educación y Universidad de Oviedo. <Disponible en https://www2.ulpgc.es/hege/almacen/download/42/42376/modalidades_ensenanza_ competencias_mario_miguel2_documento.pdf> [Consulta: 25 de abril de 2021].

JIMÉNEZ, J. J., LAGOS, M. C. \& JAREÑO, F. (2011). Una experiencia interdisciplinar de Aprendizaje Basado en Problemas con estudiantes de Administración y Dirección de Empresas. Libro de Resúmenes del VIII Foro sobre la Evaluación de la Calidad de la Investigación y de la Educación Superior, 71. Granada: AEPC. <Disponible en http://www.ugr.es/ aepc/VIIIFORO/Documentos/Libros/libroresumenesviiiforo.PDF> [Consulta: 01 de junio de 2021] 


\title{
EDIFICATE
}

I Congreso de Escuelas de Edificación y Arquitectura Técnica de España València, 4 y 5 de noviembre de 2021

Escuela Técnica Superior de Ingeniería de Edificación

Universitat Politècnica de València

Doi: https://doi.org/10.4995/EDIFICATE2021.2021.13543

\section{La incorporación de los ODS en el plan de estudios de Arquitectura Técnica y Edificación (2021) de la Universidad de Alcalá \\ The incorporation of the SDGs in the Technical Architecture and Building plan (2021) of the University of Alcalá}

Fernando da Casa Martín ${ }^{a}$, Antonio Baño Nieva ${ }^{b}$, Juan Manuel Vega Ballesteros ${ }^{b}$, Ignacio Delgado Conde ${ }^{b}$, Francisco Maza Vázquez ${ }^{b}$, Enrique Fernández Tapia ${ }^{b}$, Javier

Temiño Vela ${ }^{b}$, Ernesto Echeverría Valiente, Flavio Celis D'Amico, Enrique Castaño

Perea, y Mónica Martinez Martinez ${ }^{\mathrm{b}}$

aEscuela de Arquitectura, Universidad de Alcalá. fernando.casa@uah, ${ }^{\mathrm{b} E s c u e l a ~ d e ~ A r q u i t e c t u r a, ~}$

Universidad de Alcalá

\begin{abstract}
The Bachelor's degrees of the first round of verifications (2008), have the obligation to review and renew their teaching approaches, since neither the ways of teaching, nor the ways of practicing the profession, nor the technologies are the same in 2021. There is an opportunity to update the contents and the interrelation between them. The Sustainable Development Goals (SDGs) can and should be part of this process of teaching innovation. This is the case of the evolution of the Degree in Science and Technology of Building, to the Degree in Technical Architecture and Building, recently approved (March 2021). The objective of the communication is to present the method followed for the integration of the SDGs in the verification process. The way practiced to determine the goals of each SDG to be incorporated is analyzed. The prioritization of the character of transversality in the planned approach, not as a specific subject but integrated, coordinated, and related between the different subjects in which it is progressively integrated into the degree. Finally, the definitive incorporation procedure to the Plan, its documentary and conceptual reflection, and the implementation forecast, the monitoring and control processes for the 2021/2022 academic year will be discussed.
\end{abstract}

Keywords: SDGs, University, Curriculum, Technical Architecture, transversality. 


\begin{abstract}
Resumen
Las titulaciones de Grado de la primera tanda de verificaciones (2008), tienen la obligación de revisar y renovar sus planteamientos docentes, ya que ni los modos de enseñar, ni los modos de ejercer la profesión, ni las tecnologías son las mismas en 2021. Se presenta una oportunidad de actualización de los contenidos y la interrelación entre ellos. Los Objetivos de Desarrollo Sostenible (ODS) pueden y deben formar parte de este proceso de innovación docente. Es el caso de la evolución del Grado en Ciencia y Tecnología de la Edificación, al Grado de Arquitectura Técnica y Edificación, aprobado recientemente (marzo 2021). El objetivo de la comunicación es presentar el método seguido para la integración de los ODS en el proceso de verificación. Se analiza el modo practicado para determinar las metas de cada ODS a incorporar. La priorización del carácter de transversalidad en el enfoque planificado, no como materia específica sino integrada, coordinada, y relacionada entre las diferentes asignaturas en las que se integra de forma progresiva en la titulación. Por último se comentará el procedimiento de incorporación definitiva al Plan, su reflejo documental y conceptual, y la previsión de implantación, los procesos de seguimientos y control para el curso 2021/2022.
\end{abstract}

Palabras clave: ODS, Universidad, Plan de estudios, Arquitectura Técnica, transversalidad. 


\section{Introducción}

Aprovechando la tramitación de verificación de la actualización del título de Grado de Ciencia y Tecnología en la Edificación, en su evolución al nuevo Grado de Arquitectura Técnica y Edificación, se ha considerado de interés la realización de un análisis más profundo de la situación actual para la realización de una actualización y modernización en los contenidos del Plan de estudios, teniendo en cuenta que el primer verifica ha cumplido ya más de diez años (la inicial es de 2008), y se ha pasado ya la primera renovación de la acreditación en 2017.

Dentro de dicha filosofía de acción se plantea, respecto de la titulación que se verifica, y como diferencia con el Grado que se extingue (Ciencia y Tecnología de la Edificación), la realización de las siguientes acciones, de forma generalizada:

- Revisar la situación actual de la docencia respecto del Sector profesional de la Arquitectura Técnica y de otros ámbitos de potencial trabajo de los titulados.

- Revisar los aspectos de obsolescencia del actual Plan de Estudios.

- Incorporar las temáticas de nueva oportunidad, así como las referidas a los nuevos campos de trabajo que puede abordar el Arquitecto Técnico fuera del ámbito de las atribuciones profesionales.

- Incorporar las temáticas de obligada evolución: Los Objetivos de Desarrollo Sostenible (ODS), las nuevas tecnologías aplicadas al sector de la Arquitectura y la Edificación y, la actualización de nuevas metodologías docentes.

Los ODS (objetivos de Desarrollo Sostenible), son un punto de referencia internacional, a iniciativa de Naciones Unidas. Su consideración es un punto de conexión y enlace con otras entidades, permiten trabajar de forma mancomunada, y en aspectos de actualidad social.

Su incorporación en el ámbito universitario es un reto actual (REDS, 2020). No es un tema baladí, ni simple ni de fácil implantación. No se trata de ampliar contenido de conocimientos en las materias, ni siquiera de incorporar acciones puntuales en la programación de las asignaturas. Es un proceso más complejo, que debe planificarse y verse afectado desde una visión de conjunto de cada titulación, con un carácter global y transversal.

Desde la propia ONU se manifiesta como una preocupación social, y sobre todo la necesidad de su integración en las Universidades, como acreditan los múltiples textos que ponen a disposición y difunden.

A este reto se ha sumado la Escuela de Arquitectura de la UAH, aceptando la invitación que en carta general de la Vicerrectora de Política de Responsabilidad Social y extensión universitaria solicita esta consideración a todos.

Las titulaciones de Edificación y Arquitectura, tienen un amplio abanico de alineaciones potenciales con algunas de las metas específicas de los ODS. Pero no podemos considerar que las competencias establecidas en la Orden ECI/3855/2007 dan cabida a los ODS, no olvidemos, que estos se establecen el 25 de septiembre de 2015, de forma muy posterior a la propia Orden ECI. 
Lo cierto es que en muchas de las titulaciones, se han ido incorporando de forma puntual estos criterios de sostenibilidad, bien por la creación de alguna asignatura optativa, o bien por la ampliación de los programas, con estos contenidos, de forma voluntarista por los profesores de algunas materias. Pero no se tiene conocimiento de ningún planteamiento de forma conjunta, global, y oficial desde el propio documento de Verificación.

Tras la experiencia realizada en la Universidad de Alcalá, la acogida muy favorable obtenida tanto interna como externamente, ha demostrado su interés, y de ahí el nuestro por hacer partícipe a nuestras titulaciones en el EDIFICATE de tal cuestión.

Se considera una oportunidad de motor de cambio con un gran carácter de transversalidad, si bien plantean cuestiones concretas, pero de ámbito multidisciplinar, y con una componente de conexión con el mundo real. Es una experiencia que permite la realización de intercambios, de análisis de las particularidades propias y de reflexiones internas de gran potencialidad en el ámbito docente, formativo, e investigador del alumno (SDSN, 2017).

\section{Objetivos}

El objetivo principal de esta comunicación es presentar el método seguido en el proceso de verificación de la nueva titulación de Arquitectura Técnica y Edificación, para la integración de los ODS, conocer el nivel de implantación y el modo de verificar el cumplimiento de los ODS, tras su implantación en el curso 2021/2022.

Para ello se consideran como objetivos secundarios pero necesarios, los siguientes:

- Elaborar el procedimiento y método de seguimiento y control, con la definición de los indicadores de medida para conocer su funcionamiento.

- Implantar el procedimiento, con la recopilación de los datos de los indicadores pertinentes

- Analizar los datos para conocer el nivel de obtención de los resultados buscados en el objetivo principal

- Establecer el correspondiente proceso para disponer de un Plan de mejora progresiva para poder implantar en el curso siguiente.

\section{Desarrollo de la innovación. La incorporación de los ODS en el nuevo Plan.}

El proceso de incorporación de los ODS al Plan de estudios de Arquitectura Técnica y Edificación, se ha planteado con una metodología con 3 fases previas a su concreción e implicación en el Plan de estudios. Un vez concretado el Plan, se complementa el método de trabajo con el proceso de implantación y el procedimiento de seguimiento y control. Se comentan cada una de ellas en los apartados siguientes. 


\subsection{Selección de ODS, y Metas de potencial aplicación en la titulación}

La ONU, en septiembre de 2015, establece 17 campos como ODS con carácter general, como un conjunto de objetivos globales. Cada uno de ellos desarrolla Metas específicas (ONU, 2015). Es inviable considerar abordar la totalidad de ellos, ya que en muchas ocasiones su relación con los Planes que habilitan para el ejercicio de la Arquitectura Técnica, es de mera tangencialidad, o incluso sin relación factible. En otros su carácter es muy generalista si viabilidad para aplicación concreta. Determinar en cuáles de ests metas, y Objobjetivos es de interés trabajar, se plantea como una necesidad prioritaria de abordar a la hora de su integración en el Plan.

Se han analizado la totalidad de las metas específicas de cada ODS (ONU, 2015), y se han podido discriminar aquellas en las que la actividad de la titulación podría tener una potencial aplicación. Se relacionan de forma resumida a continuación, en aras de poder establecer cuáles de ellas pueden o deben ser incorporadas en nuestro Plan de estudios.

ODS 4: Educación

- $\quad$ Meta 4.7: Alumnos con conocimientos para promover los ODS

- Meta 4.a: La Construcción de entornos docentes sostenibles y adecuados

ODS 6: Agua

- Meta 6.3: Saneamiento de aguas residuales, reciclado, reutilización

- Meta 6.4: Uso eficiente de los recursos hídricos

- Meta 6.5: Implantación de una gestión integrada del agua

ODS 7: Energía

- Meta 7.2: Implantación de Energías renovables

- Meta 7.3: Mejora de la eficiencia energética

- Meta 7.a: Investigación en tecnologías avanzadas, exportación a países menos desarrollados

ODS 8: Trabajo

- Meta 8.3: Emprendimiento, innovación en empresas, microempresas, pequeñas empresas

ODS 9: Industria

- Meta 9.3: investigación en innovación tecnológica, exportación a países menos desarrollados

ODS 11: ciudades

- Meta 11.1: Acceso a vivienda inclusiva, accesible y sostenible

- Meta 11.4: Salvaguardar el patrimonio cultural

- Meta 11.6: Mejorar la calidad del aire y reducir los desechos urbanos 
- Meta 11.7: Accesibilidad a zonas verdes, inclusivas y accesibles

- Meta 11.a: Planificación integral entre zonas urbanas y rurales

- Meta 11.b: Uso eficiente de los recursos, consideración del cambio climático y resiliencia ante desastres naturales.

- Meta 11.c: Proporcionar apoyo a los países menos adelantados, asistencia técnica, para que puedan construir edificios sostenibles y resilientes utilizando materiales locales

ODS 12: Consumo

- Meta 12.2: Gestión sostenibles y uso eficiente de los recursos

- Meta 12.5: Reducción de desechos

- Meta 12.b: Turismo sostenible

\subsection{Modo de la integración: Las alternativas de implantación: integración y transversalidad}

Con todo lo expuesto se observa que hay una serie de ámbitos de potencial incorporación a nuestra titulación. Serían: Eficiencia energética, Energías renovables, Eficiencia en los recursos, Accesibilidad, Inclusión, Resiliencia ante desastres, Patrimonio, Recursos hídricos, Reciclaje-Reutilización, Gestión de residuos, Innovación de materiales, Innovación de sistemas, Filosofía BIM, Conceptualización de la Gestión. Algunos de ellos ya forman parte de nuestra formación.

Ante esta situación, se plantea el modo de incorporación de las nuevas temáticas. Se debe buscar cómo poder hacerlo, e integrarlo en el Plan de estudios, que está condicionado por los requerimientos de la referida Orden ECl/3855/2007. Se plantean las siguientes alternativas factibles:

- Integración de las temáticas en las asignaturas actuales. Cada una de las materias indicadas tendría cabida en una o varias de las materias actuales del Plan de estudios.

- Creación de nuevas asignaturas específicas, tanto de carácter obligatorio como de optatividad.

- Incentivación al alumnado para la adquisición de los conocimientos en formatos o actividades docentes fuera del Plan de Estudios.

- Generación de actividades docentes (regladas), de integración de materias, tipo seminarios o talleres para tratar diversas temáticas de forma transversal y simultáneo con las materias clásicas.

\subsection{Procedimiento de incorporación al Plan}

Tras un amplio debate, tanto interno como con participación y referencias externas, en el proceso de elaboración del Plan de estudios, se planteó como opción más práctica generar una situación mixta de las diferentes alternativas anterores. Se propuso integrar en el nuevo Plan de estudios lo siguiente: 
- $\quad$ Generar una nueva materia iniciática en primer cuatrimestre de $1^{\circ}$. Que se plantea a modo de "inmersión iniciática en la Edificación", a modo de una "obertura", presentando lo que luego verán en modo "fogonazo", que sea muy activa y práctica para el alumno, y multidisciplinar interáreas de conocimiento (invitación a participar a todos los que quieran). El objetivo fundamental es generar la motivación e ilusión del alumno por la titulación, de hacer "que se enganchen" y "se diviertan". De este modo el alumno podrá conocer desde el inicio el significado de la titulación y lo que puede llegar a conseguir con su finalización (está en manos de nuestra capacidad transmitir dicha ilusión al alumno de primero). Así mismo, que comprenda el porqué, el para qué de estos estudios, que va a ver y casi cuando (a modo de guion de la titulación), y así se fomenta un menor abandono por el hecho de no comprender el que está estudiando (razón acreditada del abandono mayoritario). Es una oportunidad para incorporar los nuevos conceptos, su justificación y la necesidad de integración en la formación del alumno de un modo "iniciático" de modo que los alumnos los hagan suyos como filosofía integrada en su formación.

- Integrar las herramientas BIM, de sostenibilidad y eficiencia energética, y otras, en las materias específicas que lo precisen,con el aumento de dotación de ECTS, factible para ello.

- Integrar los conceptos y ámbitos de innovación (ODS, filosofía BIM, así como otros nuevos aspectos) en cada una de las asignaturas correspondientes, lo que implicará un enfoque particular y una revisión del total de las materias, pero sin la consideración de un aumento del contenido de conocimientos.

- Reconvertir una asignatura por curso, en materia de integración de los contenidos del resto de asignaturas de ese curso. De este modo, actuarán con un carácter transversal y de integración del conocimiento que el alumno debe adquirir con todas las materias de cada curso. Se trataría de dotarlas de un fuerte carácter práctico a dichas actividades con un formato por ejemplo tipo "taller". Se convertirán en materias dinamizadoras de la titulación.

- Modificar el enfoque de la optatividad, para redirigirlas hacia la aplicación práctica de diversas materias, que permitan la integración de los conocimientos y su desarrollo de ámbitos visto durante la titulación. Es junto con el TFG, el lugar de aplicación específica y desarrollo en casos concretos y reales, y de aplicación directa al ámbito de los ODS.

Estos planteamientos, y teniendo en cuenta las directrices para la elaboración de los planes de estudio de grado (FUNDACION MADRI+D, 2019), han sido de consideración a la hora de plantear la nueva estructura del Plan de rquitectura Técnica y Edficación de la Universidad de Alcalá. Esta integración, de forma simultánea, o puntual, ha sido necesaria acompañarla del consecuente análisis de las consecuencias, y beneficios de cada uno de ellas. El Plan fue aprobado en marzo de 2021 (UAH, 2021a) para su implantación de modo integral en el curso $2021 / 2022$. 


\section{Resultados}

\subsection{Las bases de partida de la estructura del Plan de estudios}

En el proceso de revisión de la acreditación de la titulación actual, se consideró como un punto fuerte la propia estructura del Plan de estudios. La filosofía implantada desde el inicio del grado, a extinguir, planteaba un primer y segundo curso de adquisición de herramientas básicas del conocimiento por el alumno, para en tercero desarrollar las asignaturas de integración de los mismos, y de ámbito profesional, para dejar el último curso libre al alumnado para el desarrollo de optatividad y TFG.

Siguiendo dicha filosofía se presenta la posibilidad de dar un paso más en este desarrollo, con el siguiente tenor:

- $\quad 1^{\circ}$ Curso: Adquisición de las herramientas básicas para el desarrollo de la titulación, incorporando el carácter de implicación, motivación, y comprensión del alumno de lo que puede obtener en el desarrollo de la titulación, de modo que pueda afrontarla de un modo más ilusionante, participar de forma más activa, e integrarse, en la vida de la Escuela.

- $\quad 2^{\circ}$ Curso: Desarrollo y aplicación de las herramientas, en los ámbitos generales de la edificación (construcción, materiales, estructuras, e instalaciones). Es obligado el modo de "cajones estancos" para su impartición, pero es de interés analizar el modo de poder generar la integrabilidad de los conocimientos en vías de adquisición (sobre todo en el $2^{\circ}$ cuatrimestre).

- $\quad 3^{\circ}$ Curso: Desarrollo de la especificidad técnica de la titulación, con el desarrollo de materias de integración de diferentes aspectos de carácter general (control económico, organización y planificación, seguridad, calidad), así como los más específicos (la sostenibilidad, la intervención en lo construido). También sería de interés analizar el modo de poder generar la integrabilidad de los conocimientos en vías de adquisición (sobre todo en el $2^{\circ}$ cuatrimestre).

- $\quad 4^{\circ}$ Curso: Desarrollo de las facetas de especialización y actividad profesional (optativas, empresa y legislación profesional). La faceta de integración se desarrolla en el TFG, en su carácter de materia anual, integradora y final.

De este modo el alumno, y los profesores, conocen el enfoque de cada una de las materias que se imparten, y la actitud general que se debe tener hacia cada asignatura, así como la relación de unas materias con otras, facilitando la coordinación de la titulación, y de su desarrollo.

Este aspecto será conocido por el alumno desde el inicio de su formación, siendo un aspecto fundamental para la organización de su trabajo y dedicación, sabiendo las implicaciones que supone el déficit de cualquier materia (por no haber sido superada, o interiorizada).

Respecto del tamaño de las asignaturas, en el actual Plan de estudios a extinguir, se dispone de un variado espectro de número de créditos, la mayoría son de 6 , si bien disponemos de asignaturas de $7.5,9,12$, y 18 (y la parcial de 4.5 de matemáticas del $2^{\circ}$ cuatrimestre). 
En otros planes de estudio se ha observado la incorporación de otros tamaños, como 2, 3, 8, o 10 ECTS. La Universidad de Alcalá, planteó desde el inicio que las asignaturas tuvieran un mínimo de 6 ECTS, si bien hay algunas salvedades puntuales en algunos planes.

La premisa básica del nuevo plan de estudios es disponer de 4 asignaturas por cuatrimestre, con un tamaño compatible entre sí, con capacidad de desarrollarse en el cronograma en suma de 30 por cuatrimestre (aspecto obligado para disponer de un equilibrio en la carga del alumno). Además, es importante no tener un tamaño excesivo (no mayor de 12 ECTS), para evitar que en caso de "repetición", implique un alto sobrecoste para el alumno (aspecto advertido desde el Vicerrectorado de estudiantes).

Analizadas las diversas opciones, se considera de interés la opción de trabajar en cuatro cuantías:

- 6 ECTS, con carácter general en las materias del Plan (tal y como se presenta en el actual Plan)

- $\quad$ 7.5 ECTS, en aquellas materias (actuales de 6) que deban ser incrementadas por hacerse cargo de nueva impartición.

- 9 ECTS, en las materias específicas que impliquen una mayor concentración de aspectos, y que permiten ser desarrolladas en un cuatrimestre.

- 12 ECTS, para asignaturas de mayor carácter práctico, como el TFG (obligado), y en su caso la optatividad por su propio carácter.

\subsection{Reflejo documental en el Plan (y relación conceptual)}

Con todo lo anterior, el resultado del Plan (UAH, 2021b) es el que se muestra en las tablas de la imagen siguiente (fig 1):

\begin{tabular}{|c|c|}
\hline \multicolumn{2}{|c|}{$\begin{array}{c}\text { PRIMER CURSO: } \\
\text { Adquisición de las herramientas básicas }\end{array}$} \\
\hline 19 CUATRIMESTRE & $2 \circ$ CUATRIMESTRE \\
\hline Fundamentos Matemáticos (9) & $\begin{array}{c}\text { Fundamentos Físicos de estructuras } \\
\text { e instalaciones (9) }\end{array}$ \\
\hline $\begin{array}{l}\text { Expresión Gráfica Edificación I } \\
\qquad(9)\end{array}$ & Expresión Gráfica Edificación II (9). \\
\hline $\begin{array}{l}\text { Fundamentos de Geología en la } \\
\text { Edificación (6) }\end{array}$ & $\begin{array}{l}\text { Expresión Gráfica de la Topografia } \\
\text { (6) }\end{array}$ \\
\hline Iniciación a la Edificación (6) & Fundamentos de Construcción (6) \\
\hline \multicolumn{2}{|c|}{$\begin{array}{c}\text { TERCER CURSO: } \\
\text { Desarrollo de la especificidad técnica de la titulación }\end{array}$} \\
\hline 19 CUATRIMESTRE & 29 CUATRIMESTRE \\
\hline $\begin{array}{l}\text { Presupuestos y Control } \\
\text { económico (6) }\end{array}$ & Valoraciones y Peritaciones (6) \\
\hline $\begin{array}{l}\text { Prevención, Seguridad y salud } \\
\text { (6) }\end{array}$ & Gestión en el proceso edificatorio (6) \\
\hline $\begin{array}{c}\text { Organización de obras y gestión } \\
\text { urbanistica (9) }\end{array}$ & Intervención en la edificación (9) \\
\hline Construcción Sostenible (9) & Proyectos Técnicos (9) \\
\hline
\end{tabular}

\begin{tabular}{|c|c|}
\hline \multicolumn{2}{|c|}{$\begin{array}{c}\text { SEGUNDO CURSO: } \\
\text { Desarrollo y aplicación de las herramientas }\end{array}$} \\
\hline 19 CUATRIMESTRE & 29 CUATRIMESTRE \\
\hline Estructuras I (9) & Estructuras II $(7,5)$ \\
\hline Materiales de construcción I (6) & Materiales de Construcción II (6) \\
\hline Instalaciones I $(7,5)$ & Instalaciones II $(7,5)$ \\
\hline $\begin{array}{l}\text { Sistemas y Tecnología } \\
\text { constructiva (7.5) }\end{array}$ & Taller de Edificación (9) \\
\hline \multicolumn{2}{|c|}{$\begin{array}{c}\text { CUARTO CURSO: } \\
\text { Desarrollo de las facetas de especialización y actividad profesional }\end{array}$} \\
\hline \begin{tabular}{l|l}
$1^{\circ}$ CUATRIMESTRE & $2^{\circ}$ CUATRIMESTRE
\end{tabular} & $2^{\circ}$ CUATRIMESTRE \\
\hline Empresa (6) & $\begin{array}{c}\text { Transversalidad: } \\
\text { Seminario Lab Materiales }\end{array}$ \\
\hline Derecho (6) & $\begin{array}{l}\text { Transversalidad: } \\
\text { Práctica Pericial Judicial }\end{array}$ \\
\hline \multicolumn{2}{|c|}{$\begin{array}{l}\text { Taller en Sostenibilidad } \\
\text { Taller ...en Construcción Avanzada }\end{array}$} \\
\hline TFG (12) c & arácter anual \\
\hline
\end{tabular}

Fuente: Elaboración propia

Fig. 1 Plan de estudios Arquitectura Técnica y Edificación de la Universidad de Alcalá 
Innovación docente en el Trabajo Final de Grado. La oportunidad del Aprendizaje participativo sobre casos reales - The incorporation of the SDGs in the Technical Architecture and Building plan (2021) of the University of Alcalá

La incorporación de las metas y objetivos ODS, se realiza en cada una de las asignaturas, de modo que estas tienen reflejadas en sus objetivos y competencias, aquellas que está, consideradas alineadas con ellas. De este modo se garantiza además una continuidad y progresividad en la aplicación de la filosofía ODS.

En el cuadro siguiente se puede observar esta aplicación en las materias que tienen un carácter principal en este ámbito. Sobre la estructura del Plan (fig 2) se han incorporado las metas de cada una de las materias, y se ha marcado en color las materias que tendrán principal atención en ello.

\begin{tabular}{|c|c|}
\hline \multicolumn{2}{|c|}{$\begin{array}{c}\text { PRIMER CURSO: } \\
\text { Adquisición de las herramientas básicas }\end{array}$} \\
\hline 12 CUATRIMESTRE & 22 CUATRIMESTRE \\
\hline Fundamentos Matemáticos (9) & $\begin{array}{l}\text { Fundamentos Físicos de estructuras } \\
\text { e instalaciones (9) }\end{array}$ \\
\hline Expresión Gráfica Edificación I (9) & Expresión Gráfica Edificación II (9). \\
\hline $\begin{array}{l}\text { Fundamentos de Geología en la } \\
\text { Edificación (6) }\end{array}$ & Expresión Gráfica Topografia (6) \\
\hline $\begin{array}{l}\text { Iniciación a la Edificación (6) } \\
4,7 / 11,6\end{array}$ & $\begin{array}{c}\text { Fundamentos de Construcción (6) } \\
\text { 4.a / 6.4 / 9.3/11.1/11.7/11.b / } \\
11 . c / 12.5 \\
\end{array}$ \\
\hline \multicolumn{2}{|c|}{$\begin{array}{c}\text { TERCER CURSO: } \\
\text { Desarrollo de la especificidad técnica de la titulación }\end{array}$} \\
\hline 12 CUATRIMESTRE & 29 CUATRIMESTRE \\
\hline $\begin{array}{l}\text { Presupuestos y Control económico } \\
\qquad(6)\end{array}$ & Valoraciones y Peritaciones (6) \\
\hline Prevención, Seguridad y salud (6) & $\begin{array}{l}\text { Gestión proceso edificatorio (6) } \\
6.3 / 6.4 / 6.5 / 12.2 / 12.5\end{array}$ \\
\hline $\begin{array}{l}\text { Organización de obras y gestión } \\
\text { urbanística (9) }\end{array}$ & $\begin{array}{l}\text { Intervención en la edificación (9) } \\
\qquad \mathbf{1 1 . 4 / 1 1 . c / 1 2 . b}\end{array}$ \\
\hline $\begin{array}{c}\text { Construcción Sostenible (9) } \\
6.4 / 7.2 / 7.3 / 7 . a / 11.6 / 11.7 \\
\text { /11.a / 11.b/11.c/12.2 }\end{array}$ & $\begin{array}{l}\text { Proyectos Técnicos (9) } \\
6.3 / 6.4 / 6.5 / 12.2 / 12.5\end{array}$ \\
\hline
\end{tabular}

\begin{tabular}{|c|c|}
\hline \multicolumn{2}{|c|}{$\begin{array}{l}\text { SEGUNDO CURSO: } \\
\text { Desarrollo y aplicación de las herramientas }\end{array}$} \\
\hline 1: CUATRIMESTRE & 2: CUATRIMESTRE \\
\hline Estructuras I (9) & Estructuras II $(7,5)$ \\
\hline Materiales de construcción I (6) & Materiales de Construcción II (6) \\
\hline $\begin{array}{c}\text { Instalaciones I }(7,5) \\
6.3 / 6.4 / 7.2 / 9.3 / 11.6 / 11 . b / 12.2 \\
\end{array}$ & $\begin{array}{c}\text { Instalaciones II }(7,5) \\
6.3 / 6.4 / 7.2 / 9.3 / 11.6 / 11 . b / 12.2 \\
\end{array}$ \\
\hline $\begin{array}{l}\text { Sistemas y Tecnología construc (7.5) } \\
\text { 4.a / } 6.4 / 9.3 / 11.1 / 11.7 / 11 . b / \\
\text { 11.c/12.5 }\end{array}$ & $\begin{array}{c}\text { Taller de Edificación (9) } \\
\text { 4.a /6.4/9.3/11.1/11.7/11.b/ } \\
\text { 11.c/12.5 }\end{array}$ \\
\hline \multicolumn{2}{|c|}{$\begin{array}{l}\text { CUARTO CURSO: } \\
\end{array}$} \\
\hline 19 CUATRIMESTRE & \begin{tabular}{|c|}
29 CUATRIMESTRE \\
\end{tabular} \\
\hline $\begin{array}{c}\text { Empresa (6) } \\
8,3 \\
\end{array}$ & $\begin{array}{c}\text { Transversalidad: } \\
\text { Seminario Lab Materiales }\end{array}$ \\
\hline Derecho (6) & $\begin{array}{c}\text { Transversalidad: } \\
\text { Práctica Pericial Judicial }\end{array}$ \\
\hline \multicolumn{2}{|c|}{$\begin{array}{c}6.4 / 7.2 / 7.3 / 7 . a / 11.6 / 11.7 / 11 . a / 11 . b / 11 . c / 12.2 \\
\text { Taller ... en Construcción Avanzada } \\
\text { 4.a } / 6.4 / 9.3 / 11.1 / 11.7 / 11 . b / 11 . c / 12.5\end{array}$} \\
\hline \multicolumn{2}{|c|}{ TFG (12) de carácter anual } \\
\hline
\end{tabular}

Fuente: Elaboración propia

Fig. 2 Plan de estudios, con indicación de las metas de los ODS en cada una de las asignaturas implicadas.

\subsection{La implantación}

La implantación del grado de Arquitectura Técnica y Edificación comenzará el curso 2021/22. Para facilitar la adaptación de los alumnos, se ha aprobado por unanimidad en todos los estamentos y colectivos consultados en el proceso de verificación, la implantación simultánea de los 4 cursos del nuevo grado. Esto lleva implícita la extinción del actual Grado en Ciencia y Tecnología de la Edificación.

Además de forma paralela a la implantación, se considera de interés comenzar con los siguientes procesos de trabajo:

- Establecer reuniones de Trabajo por grupos de materias interrelacionadas.

- Establecer un protocolo de comunicación y coordinación entre cursos, y bloques.

- Elaborar un protocolo de seguimiento y control (base en el Grupo Coordinadores). 


\subsection{Procedimiento y método de seguimiento y control de implantación y cumplimiento de los ODS en el nuevo grado de Arquitectura Técnica y Edificación en el curso $2021 / 2022$}

El proceso referido no puede quedar ahí, y se considera fundamental conocer la factibilidad de su implantación, y el nivel de consecución de los objetivos. Para ello es preciso disponer de un proceso de seguimiento y control, definirlo e implantarlo. Disponer de los indicadores precisos para conocer su funcionamiento, y establecer los procedimientos de análisis para conocer el correspondiente proceso de mejora progresivo (Alba, 2020).

Las acciones a desarrollar en el proceso de control y seguimiento se plantean en varias etapas de desarrollo, con el siguiente orden cronológico:

- Puesta en marcha del procedimiento. Explicación a todos los profesores implicados. Puesta en común para la participación global. Establecimiento del punto de partida, teniendo en cuenta las singularidades de cada materia.

- Aplicación en las materias del $1^{\circ}$ cuatrimestre. Recopilación de los datos de indicadores durante el curso según lo establecido en su protocolo.

- Análisis de los datos para la obtención de resultados,y detección de las singularidades acontecidas, los incidentes, conflictos, y particularidades. Conocimiento del nivel de consecución obtenido.

- Establecimiento de las medidas correctoras (al método inicial), para su aplicación en el $2^{\circ}$ cuatrimestre.

- Aplicación en las materias del $2^{\circ}$ cuatrimestre. Recopilación de los datos de indicadores durante el curso según lo establecido en su protocolo.

- Análisis de los datos para la obtención de resultados,y detección de las singularidades acontecidas, los incidentes, conflictos, y particularidades. Conocimiento del nivel de consecución obtenido en el $2^{\circ}$ cuatrimestre y la evolución respecto del $1^{\circ}$.

Para la evaluación de los resultados del curso, de forma conjunta en la titulación, se plantean al menos los siguientes aspectos:

- Análisis de las particularidades de la aplicación de los ODS en la docencia en los diferentes cursos, en función de la materia a impartir. Conocer las deficiencias, fortalezas y oportunidades que se deducen de la aplicación realizada en el curso.

- Determinar el margen de adaptabilidad del método de aplicación de los ODS en cada una de las materias, para futuros cursos.

- Determinar las dificultades de la aplicación y recopilación de datos de los indicadores. Revisar la situación y proponer alternativas de mejora.

- Análisis de los resultados en su conjunto. En su caso, tomar las medidas de modificación del método general. Obtención de las conclusiones parciales

- Establecimiento de las conclusiones globales del curso, y proponer las mejoras para nueva versión de la metodología estratégica, para su aplicación al curso siguiente. 
Se debe indicar que la viabilidad y factibilidad del desarrollo del proceso queda confirmada por la disponibilidad del profesorado involucrado. La participación colectiva de toda la titulación en el proceso de verificación de la titulación, facilita que el procedimiento que se plantea, tenga a priori garantizada la buena voluntad del resto de agentes de la titulación.

El seguimiento se realizará por parte del Grupo de Coordinación Docente de la Titulación, con el apoyo del equipo de Dirección, siendo esta una de las líneas de trabajo planificadas. Hay que tener en cuenta que las filosofías actuales en desarrollo son compatibles con la metodología que se plantea. Por lo tanto, se puede considerar que no se parte de cero, sino de un punto más avanzado y es factible llegar a conclusiones más desarrolladas y efectivas.

\section{Conclusiones}

Se puede concluir esta comunicación, indicando que la metodología de trabajo seguida, plantea la viabilidad de aplicar un nuevo enfoque de innovación docente en el ámbito de la Arquitectura Técnica y la Edificación, y por extrapolación a otras materias, ramas y modelos docentes.

Es una gran oportunidad la integración de los ODS en las titulaciones universitarias, no como una ampliación de contenidos y de las curriculas, sino su incorporación de un modo conceptual, transversal y filosófico, que forme parte del "modo de ser del alumno", teniendo en cuenta que solo es necesario variar el punto de vista para poder alinearse con las diferentes metas de cada ODS que puedan ser de aplicación.

La potencialidad de resultados en la formación docente es muy grande, si bien es preciso, no quedarse solo en su planteamiento y enunciado, sino integrarlo desde su base en la implantación del Plan de estudios. Y además, sin olvidar establecer los procesos de control y seguimiento adecuados para su comprobación y corrección en su caso.

En la Universidad de Alcalá, se ha apostado por ello, y aún sin haberse iniciado el curo de implantación, ya hay dos consecuencias iniciales: la creación del Grupo Agenda de Trabajo 2030 “Los ODS como innovación en la Edificación. Guadalajara.”; y, la concesión de un Proyecto de Innovación Docente (UAH/EV/1252) con título: "Implantación de los ODS en el plan de Arquitectura Técnica y Edificación. proceso de seguimiento y control en su curso inicial".

\section{Referencias}

ALBA HIDALGO, D., BENAYAS DEL ÁLAMO. J., Y BLANCO PORTELA, N. (2020). Cómo evaluar los ODS en las universidades. REDS. Recuperado de: www.reds-sdsn.es/documentos

FUNDACION PARA EL CONOCIMIENTO MADRI+D (2019) Guía para la verificación y modificación de los títulos oficiales de Grado y Máster. Recuperado de : https://www.madrimasd.org/uploads/guia_verificacion_v4_nov_2019.pdf 
ONU (2015) Objetivos de Desarrollo Sostenible. Recuperado de :

https://www.un.org/sustainabledevelopment/es/objetivos-de-desarrollo-sostenible/

REDS (2020) Dossier Implementando la Agenda 2030 en la universidad. MIÑANO, Rafael y GARCÍA HARO, Marta (Ed). Recuperado de: https://reds-sdsn.es/wp-content/uploads/2020/05/DosierREDS_Casos-ODS-Univ-2020_web.pdf

SDSN Australia/Pacific (2017): Getting started with the SDGs in universities: A guide for universities, higher education institutions, and the academic sector. Australia, New Zealand and Pacific Edition. Sustainable Development Solutions Network - Australia/Pacific, Melbourne.

UAH (2021 b) Plan de estudios G-257 Grado en Arquitectura Técnica y Edificación. Recuperado de: https://www.uah.es/export/sites/uah/es/estudios/.galleries/Archivosestudios/GR/Unico/AG257_2_6_1_E_G257.pdf

UAH (2021 a) Documento de Verificación del Grado en Arquitectura Técnica y Edificación de la Universidad de Alcalá. Recuperado de ;

https://arquitectura.uah.es/escuela/documentos/VE_ME_2504342_2021.pdf 


\title{
EDIFICATE
}

I Congreso de Escuelas de Edificación y Arquitectura Técnica de España

València, 4 y 5 de noviembre de 2021

Escuela Técnica Superior de Ingeniería de Edificación

Universitat Politècnica de València

Doi: https://doi.org/10.4995/EDIFICATE2021.2021.13550

\section{La ingeniería de edificación. Una apuesta de futuro Building engineering. Looking forward}

\author{
Juan M. Santiago Zaragoza ${ }^{a}$, Fabián García Carrillob y Joaquín Passolas Colmeneroc, \\ Emilio Gómez Cobos ${ }^{d}$ \\ apresidente CODATIE, Escuela Técnica Superior de Ingeniería de Edificación, Universidad de \\ Granada, santi@ugr.es, bFabián García Carrillo, Coodinador del Grado, Escuela Técnica Superior de \\ Ingeniería de Edificación, Universidad de Granada, fabian@ugr.es y ' Coordinador del Libro Blanco de \\ Ingeniería de Edificación, Escuela Técnica Superior de Ingeniería de Edficación, Universidad de \\ Granada, passolas@ugr.es. ${ }^{d}$ Escuela Técnica Superior de Ingeniería de Edficación, Universidad de \\ Granada, emiliog@ugr.es
}

\begin{abstract}
Building Engineering White Paper, was a turning point on the transformation of the study plan linked to Arquitecto Técnico profession that, in Spain is a regulated one. A simple search in the European catalog of University Titles that can be extended to the whole World, give a zero result about that professional name. So, analyzing that catalog, or this Title is included within Surveyors or Project Managers that means studies of Vocational Training, or is included within Building Engineers as a University Degree. The latter means an automatic recognition in most of the World countries that lead to the chosen designation of Building Engineering for the Study Plan.
\end{abstract}

It is well known the surprising Supreme Court Sentence (SCS) of 2010 that canceled this designation in some universities. That meant a helplessness situation for universities self-government established in the Spanish Constitution (art. 27).

Nevertheless under various names, that include Building Engineering, the different Study Plans (without doubt of the Engineering Field) are in force. The access to Postgraduates Studies with a wide offer of Masters in different universities (with no additional courses) and Doctorate Programs, was a milestone in the History of that Title that lead to a fundamental transformation of our Faculties.

In the field of Knowledge, the "Glass Ceiling", that required to study different careers to achieve a better academic and professional category, was broken. 
Many agreements with foreign universities and double Grade titles, mainly with European Universities certify our international recognition, most of the occasions easier than in our country universities.

Coming back to the designation of Building Engineering is looking forward to the future.

Keywords: white paper, building engineering, sustainable construction

\section{Resumen}

El Libro Blanco de Ingeniería de Edificación, supuso un antes y un después en la transformación de los estudios vinculados con la profesión, de actividad regulada en España, de Arquitecto Técnico. Una búsqueda simple, en el catálogo de titulaciones universitarias europeas y mundiales, arroja un resultado nulo, sobre la base de la denominación de este título español. Analizado dicho catálogo, o se incluye dicha titulación en el entorno de la agrimensura y la gestión de proyectos, lo que supondría una clara contracción del ámbito y nivel de formación, de su actividad real, y llevaría a la consiguiente degradación entre la Formación Profesional, en los Ciclos Superiores. O se incluye en el ámbito de la Ingeniería de Edificación, lo que supone un encaje real de la formación y la profesión desarrollada, y un reconocimiento automático en el resto del mundo. De ahí que en su momento, al albur de la construcción del EEES, desde la Universidad se optara por la denominación más cierta y reconocible de Ingeniería de Edificación.

De todos es conocida la sorprendentes y contradictorias STS de 2010, por las que, solo en determinadas universidades, se anulaba la denominación del título de Grado en Ingeniería de Edificación, no solo aumentando la presunta "confusión" que, se suponía resolver, generando incertidumbre para los antiguos y nuevos titulados europeos, y además, dejando a la Universidad española en situación de indefensión en lo que a su autonomía universitaria se refiere (art. 27 C.E.).

No obstante, esta es y será una profesión imprescindible, y hoy, con diversas denominaciones, que incluyen la de Ingeniería de Edificación, los planes de estudio del Libro Blanco de 2007, siguen vigentes y, sin lugar a dudas, formando a universitarios en el ámbito de la ingeniería, esto es, en la máxima capacitación para la resolución de problemas en el sector de la Edificación. El paso a la formación de posgrado, con numerosos másteres de especialización a los que se puede acceder (ya sin complementos de formación) y doctorados propios, suponen un reconocimiento de ello, un hito en la historia de la titulación renovada y una transformación radical de las Escuelas. 
En el ámbito del conocimiento, no hay límite que se circunscriba al de un ejercicio parcial y localmente regulado. Se rompió el famoso "techo de cristal" que obligaba a grandes esfuerzos personales para acceder a la formación en otras titulaciones, si se quería escalar en la categoría académica $y$ profesional.

Todo ello ha permitido alcanzar numerosos convenios con universidades extranjeras y acuerdos de doble titulación, sobre todo con universidades europeas, que valoran y acreditan ese reconocimiento y encaje internacional, tanto de la formación que ofrecen nuestras Escuelas, como de la profesión que ejercen nuestros titulados. Reconocimiento académico que, paradójicamente, en muchas ocasiones, es más fácil y directo que en nuestras propias y miopes universidades.

La vuelta a la denominación de la Ingeniería de Edificación es un reto de futuro por el que no se puede dejar de apostar.

Palabras clave: Libro Blanco. Ingeniería de Edificación. Construcción Sostenible.

\section{Introducción}

\subsection{EI Proceso de Bolonia. La nueva realidad del EEES}

En la década de los 80 del siglo XX se inició una reforma a nivel europeo que pretendía:

- Fomentar la competitividad internacional y

- Promover el empleo de los estudiantes europeos.

En 1988 se firmó la Carta Magna de las Universidades Europeas, suscrita por los rectores que se reunieron en Bolonia con motivo del 900 aniversario de su creación.

En Junio de 1999, once años después, se produce la Declaración de Bolonia, declaración conjunta de los Ministros Europeos de Educación reunidos en la citada capital italiana. Esta declaración tuvo su antecedente en la Declaración de la Sorbona, de mayo de 1998 que fue una declaración conjunta, en este caso para iniciar el proceso para la armonización del diseño del Sistema de Educación Superior Europeo (a cargo de los ministros de Francia, Alemania, Italia y Reino Unido).

El Proceso de Bolonia pretendió dar mayor coherencia a los sistemas de educación superior en Europa.

En una Europa unida en lo económico, la movilidad laboral se consideró como elemento imprescindible para conseguir la integración de los ciudadanos en cualquier país independientemente del país de procedencia. Para ello el Espacio Europeo de Educación Superior facilitó la movilidad de estudiantes y personal, haciendo que la educación superior 
fuera más inclusiva y accesible y, simultáneamente, con el objetivo de lograr que la educación superior en Europa fuera más atractiva y competitiva a escala mundial.

Como parte del Espacio Europeo de Educación Superior (EEES), todos los países participantes acordaron:

- Introducir un sistema de educación superior de tres ciclos, consistente en estudios de grado, máster y doctorado

- Garantizar el reconocimiento mutuo de las cualificaciones y los períodos de aprendizaje en el extranjero completados en otras universidades.

- Aplicar un sistema de garantía de la calidad, a fin de reforzar la calidad y pertinencia del aprendizaje y la enseñanza.

Ello dio lugar a un proceso de transformación de los modelos universitarios de los distintos países para adaptarse al EEES.

La adaptación al EEES generó un cambio de óptica que afectó no sólo el procedimiento de diseño de los nuevos planes y a la organización de los contenidos, sino que fue mucho más allá, e implicó cambios radicales en las metodologías de enseñanza y evaluación que se habían desarrollado hasta ese momento en el marco de la universidad española (Pallisera Díaz et al. 2010).

\subsection{El cambio en el sistema universitario español. Las nuevas titulaciones.}

Con objeto de proceder al cambio necesario de los distintos títulos del sistema universitario español, se produjo una convocatoria de la Agencia Nacional de Evaluación de la Calidad y Acreditación (ANECA) para la elaboración de los correspondientes Libros Blancos de los diferentes Títulos de Grado. El trabajo fue llevado a cabo por una red de universidades españolas, apoyadas por la ANECA, con objeto de realizar estudios y supuestos prácticos útiles en el diseño de las bases para un título de grado adaptado al EEES.

Por lo que a nuestra titulación respecta, la entonces Escuela Universitaria de Arquitectura Técnica, de la Universidad de Granada, con su director al frente, el profesor Joaquín Passolas Colmenero, coordinó el proyecto de Libro Blanco para el nuevo Título de Grado en Ingeniería de Edificación. En dicho proyecto participaron constituidas en Pleno, las 32 universidades que en aquel momento impartían la titulación de Arquitectura Técnica, y se invitó a un representante del Consejo General de la Arquitectura Técnica, el colectivo profesional.

Las 7 universidades coordinadoras-redactoras del Libro Blanco crearon cinco grupos de trabajo para dar contenido a los 14 puntos o secciones del proyecto:

1. Análisis de los estudios correspondientes o afines en Europa. Modelos y Centros contactados.

2. Los estudios en España. Planes de estudios vigentes. Estadísticas.

3. Los titulados y su inserción laboral. Perfiles profesionales.

4. Formación disciplinar y profesional. Competencias. 
5. El nuevo Título. Objetivos, estructura y créditos ECTS. Evaluación.

El proyecto así elaborado finalmente fue aprobado, por consenso general, en la última reunión del Plenario celebrada en la Escuela Universitaria de Arquitectura Técnica de la Universidad de Granada, el día 8 de junio de 2004.

A la estructura o bases académicas, se uniría el encaje administrativo. El 21 de diciembre de 2006, el Ministerio de Educación y Ciencia publicó un documento de trabajo de Propuesta de Directrices para la elaboración de títulos universitarios de grado y máster.

Finalmente, el Ministerio de Educación y Ciencia publicó el Real Decreto 1393/2007, de 29 de octubre, por el que se establece la ordenación de las enseñanzas universitarias oficiales. De acuerdo con dicha normativa las titulaciones en España se estructuraron de la siguiente forma (Pallisera Díaz et al 2010):

1. Los títulos de grado pasaron, con carácter general, a tener 240 créditos ECTS, con una duración de 4 años. Desaparecieron las licenciaturas y diplomaturas. En ese sentido la titulación de Arquitecto Técnico, de 3 cursos académicos más el Proyecto de Fin de Carrera, amplió su duración en un año suplementario.

2. Desapareció el catálogo de títulos, que era un listado limitado propuesto por los ministerios que tenían competencias universitarias, y se establecieron las competencias y contenidos de titulaciones con directrices europeas. Ello permitió a las universidades ejercer la autonomía en el sentido de definir nuevos títulos para dar respuesta a las nuevas necesidades sociales y del sistema productivo.

3. Otra de las características del nuevo modelo fue la formulación de nuevas titulaciones a partir de las competencias académicas, auténtica novedad en el sistema español, que tradicionalmente se basaba en las materias.

4. Por último se estableció un proceso riguroso de verificación y acreditación de los títulos universitarios, consistente en la aprobación inicial del título a través de la memoria de verificación, VERIFICA, y la posterior necesidad de renovación de la acreditación a los seis años de su aprobación, y renovaciones posteriores cada cuatro años

\section{Hacia una base común. La Ingeniería de Edificación en Europa}

Como se ha apuntado previamente, uno de los principales elementos estudiados por los grupos de trabajo del Libro Blanco de Ingeniería de Edificación, fue determinar la estructura de titulaciones y profesiones europeas relacionadas con la Arquitectura Técnica. Ante las preguntas, ¿Quién desempeña competencias análogas a nosotros en Europa?, ¿Cómo y dónde se forman?, y ¿Cómo se denominan dichas titulaciones y profesiones?, se acudió, actualizándolo a 2004, al anterior estudio "Las Profesiones del Sector de la Construcción en Europa”, elaborado, por el Centro de Documentación Josep Renart, del Colegio de Barcelona.

La respuesta, buscada en los principales países europeos, fue origen de los dos primeros capítulos del Libro Blanco: 1. Análisis de la situación de los estudios correspondientes o 
afines en Europa; y 2. Modelos de estudios europeos seleccionados y beneficios directos que aportará a los objetivos del Título la armonización que se propone.

En el primero de ellos se hizo un amplio recorrido por 15 países: Alemania, Austria, Bélgica, Dinamarca, Finlandia, Francia, Grecia, Irlanda, Italia, Luxemburgo, Noruega, Países Bajos, Portugal, Reino Unido y Suecia. De todos ellos se hizo un análisis de la formación académica y su denominación, el acceso al mundo profesional de los titulados, las funciones desempeñadas y la regulación legal del ejercicio profesional.

En el segundo capítulo, del análisis anterior, se identificaron algunas particularidades coincidentes, por sus tradiciones culturales, condiciones socio-económicas, peculiaridades geográficas, o simplemente criterios de homologación previamente adoptados, lo que permitió hacer una clasificación de índole territorial que llevaría a agruparlos, subdividiendo el espacio europeo estudiado (los países de Este aún no se habían incorporado) en cuatro áreas o zonas de influencia o de características comunes, que serían:

1. Zona escandinava, que agruparía a los países nórdicos, Dinamarca, Finlandia, Noruega y Suecia, de larga tradición compartida.

2. Zona anglosajona, que incluiría a los países que forman las Islas Británicas, Irlanda y Gran Bretaña, distinguiéndose entre Inglaterra, Gales y Escocia en el último caso.

3. Zona mediterránea, que además de España, incluiría a Portugal, Francia, Italia y Grecia. Aunque, desde un punto de vista educativo hay cierta divergencia.

4. Zona centroeuropea, que bajo la influencia de Alemania, incluiría también a Austria, Bélgica, Holanda y Luxemburgo.

Una primera conclusión fue comprobar que la formación y las funciones que desarrollaban los titulados europeos afines en el sector, en relación con lo que aquí tendría que ser una titulación homologable en el EEES, se enmarcaban en el campo común de actividad de la producción de la edificación, con bastante coincidencia entre ellos, por sectores culturales y áreas de influencia de los distintos países. $\mathrm{Y}$, asimismo, que las mayores correspondencias competenciales de nuestra formación se mantenían, y con un alto nivel de concurrencia, con determinadas titulaciones, ya asentadas en la mayoría de los países, en un ámbito de conocimiento y acción especifico, cual es la Ingeniería directamente vinculada con la construcción de edificios (Building Engineering, en su traducción común al inglés). Sólo en aspectos puntuales y en algunos países, se podría establecer una cierta relación con la Ingeniería de las Infraestructuras públicas y la Obra Civil, y menos aún con la Ingeniería Industrial. Con respecto al proceso de homologación se comprobó que los países de la zona mediterránea, aun con las mayores divergencias internas, serían los que deberían dar un mayor paso de acercamiento hacia los modelos ya implantados mayoritariamente en el resto de la Europa estudiada.

Finalmente, por lo que respecta a los centros de formación y a la denominación de los estudios afines, se pudo hacer el siguiente resumen de aquel estudio, del que surgió, mayoritariamente, la opción de "Ingeniería de Edificación" para equiparar a los nuevos 
estudios de grado españoles, y consecuentemente, identificar entre los ingenieros de edificación (building engineer), tanto a los titulados, como a los profesionales. A saber:

\subsection{Alemania}

Aquí, el título académico básico es de cuatro años, y se diferencia, claramente, según sea el tipo de establecimiento donde se cursan los estudios: bien sean las universidades científicas o Wissenschaftliche Hochschulen; bien sean las llamadas Fachhochschulen, término traducible, literalmente, por universidades de disciplinas, de orientación más profesionalizante. Si bien, el valor profesional de las titulaciones tiende a equipararse progresivamente, en base al ejercicio profesional desarrollado.

En Alemania se distinguen los siguientes títulos relacionados: Diplom-Ingenieur Architektur, o Ingeniero Diplomado en Arquitectura, procedente de una universidad científica, o bien Diplom-Ingenieur (FH) Fachrichtung Architektur, titulado en una Fachhochschule. Y más relacionados aún: Diplom-Ingenieur Fachrichtung Bauwesen, o Ingeniero Diplomado en Construcción, formado en una universidad científica, o bien Diplom-Ingenieur (FH) Fachrichtung o Ingeniero Graduado especializado, titulado en una Fachhochschule.

\subsection{Austria}

Los estudios universitarios relacionados con la edificación siguen la estela de Alemania, aunque su duración media suele ser algo superior y la formación es muy personalizada. Así, se ofertan titulaciones universitarias análogas, tanto en la distinción de centros de formación, como en la orientación profesional, distinguiéndose: Ingeniero Diplomado en Arquitectura por universidades técnicas, Diplom-Ingenieur Architektur (Technicche Hochschule); Y sobre todo: Ingeniero Diplomado de la Construcción por universidades técnicas, Diplom-Ingenieur Bauingenieurwesen (Technische Hochcchule). Existe una amplia oferta de especialidades, como: Ingeniería Constructiva - Konsfruktiver Ingenieurbau o Empresa Constructora y Economía de la Construcción - Baubetneb und Bauwirtschnft.

\subsection{Bélgica}

La Enseñanza Superior aquí tiene también dos orientaciones: la Enseñanza Superior universitaria, que incluye, en particular, los estudios de Ingeniería Civil ligados a la construcción; y la Enseñanza Superior no universitaria, que cubre otros títulos relacionados con dicho sector. Los estudios tienen una duración de 4 ó 5 años y se dividen en dos ciclos. El primero permite acceder al título de Candidato en la carrera considerada, pero solo el segundo da acceso a la profesión. Se pueden distinguir cuatro titulaciones de ciclo largo relacionadas: Arquitecto, Ingeniero Civil-Arquitecto, y, sobre todo, Ingeniero Civil de la Construcción, e Ingeniero Industrial de la Construcción.

\subsection{Dinamarca}

Las instituciones de Enseñanza Superior gozan de una gran autonomía para fijar los programas docentes, pero el ministerio competente establece las condiciones de acceso a 
los estudios y los requisitos para la obtención de los títulos. En la Enseñanza Superior universitaria se distinguen dos carreras relacionadas, de tipo largo, de 5 años o más: Arquitecto (que también puede ser diplomado de la Academia de Bellas Artes), e Ingeniero Civil. En la Enseñanza Superior de carácter no universitario, que se imparte en los llamados Hojere Loereanstalter, se icluyen otras carreras, de tipo intermedio 3 años y medio, entre las que se encuentra la que se puede traducir por Constructor o Arquitecto Constructor.

\subsection{Finlandia}

En Finlandia existen dos profesiones dedicadas a la construcción que se estudian en las universidades técnicas (Teknillinen Korkeakoulu), de una duración mínima de cuatro años y medio: Arquitecto - Aukkithefi, e Ingeniero Civil - Diploma Incinööri (Rakennustekniikka), título que se traduce literalmente por Ingeniero Diplomado (Técnica de la construcción). Existen otras dos profesiones, más próximas a la ejecución de las obras, que se forman en las Escuelas Politécnicas, asimismo son carreras de cuatro años de duración: Arquitecto Constructor - Rakennusarkkitehti, literalmente Arquitecto de la Construcción; e Ingeniero de la Construcción - Rakennusinsinööri. Aunque en Finlandia se emplea también la traducción inglesa Building Engineer, equiparando este título al nivel académico anglosajón Bachelor of Science.

\subsection{Francia}

En Francia la universidad ha mantenido, tradicionalmente, una fuerte independencia y una orientación esencialmente académica, no necesariamente vinculada a salidas profesionales concretas. Esto explica, en parte, el desarrollo, en paralelo a la enseñanza universitaria, de un complejo sistema de estudios y escuelas superiores especializadas, donde se forma a profesionales como ingeniero o arquitecto. Destacan las llamadas Grandes Ecoles (Escuelas Superiores de Ingeniería). En nuestro sector, aparte de otras titulaciones de menor duración y orientación profesionalizante, simplificadamente, se pueden distinguir dos carreras de tipo largo (5 años) relacionadas: Arquitecto, y sobre todo Ingeniero, donde existe la especialidad de Ingenieur de Travaux de la Construcción, orientado tanto a las obras públicas, como al sector de la construcción residencial.

\subsection{Grecia}

Se distingue entre la Enseñanza Superior que se imparte en universidades, institutos politécnicos y otras instituciones independientes, y la de carácter no universitario, que se imparte en los Institutos de Enseñanza Superior Técnica (TEI). En cuanto a los estudios superiores del sector de la edificación relacionados, existen dos carreras de tipo largo (5 años): Arquitecto, e Ingeniero con especialidades en Ingeniería Civil (Electricidad, Mecánica o Topografía). Asimismo existe una titulación traducible por Ingniero Técnico de 3,5 años.

\subsection{Irlanda}

Existe una gama relativamente amplia de formaciones especializadas relacionadas con el sector de la construcción. A nivel de graduados (Degree courses) se pueden destacar: 
Licenciado en Arquitectura - Bachelor of Architecture Degree, de cinco años reconocida profesionalmente en Irlanda y el Reino Unido; y Licenciado en Ingeniería Civil - Bachelor of Engineering (Civil), de cuatro años de duración.

En relación con la construcción, destacan las siguientes especializaciones: Ingeniería Estructural y Técnica Constructiva; Instalaciones y Control Ambiental en Edificios; Sistemas Informáticos y Gestión de la Construcción; y Diplomado Graduado en Economía y Gestión de la Construcción - Profesional Diploma / Degree in Construcción Economics and Management (Quantity Surveying). Se cursan en tres años de estudios académicos más un año de práctica. Por otro lado están: Diplomado / Graduado en Ingeniería Constructiva y Gestión de la Construcción - Professional Diploma/Degree in Building Engineering and Management. Y Licenciado en Gestión de la Construcción (Bachelor of Science in Construction Management).

\subsection{Italia}

La Enseñanza universitaria en Italia se estructura en dos ciclos o niveles. El primero, de tres años, permite acceder al título de Laurea, que faculta para la adquisición de competencias profesionales generales. El segundo ciclo, de dos años, conduce al título de Laurea Magistrale, y faculta para el ejercicio de actividades especializadas o de elevada cualificación.

Existe una amplia autonomía, pero se distinguen, básicamente, dos carreras universitarias relacionadas, con sus dos ciclos (en algún caso unificados), que intervienen en la construcción: Architettura, y , sobre todo, Ingegneria Edile (Ingeniería de Edificación), que, a veces, conforman una titulación doble. A ellas se puede añadir, con menor correspondencia, Ingegneria Civile. En muchas universidades, la orientación o especialización (diseño, paisaje, urbanismo, construcción, restauración, ...), se inicia desde el nivel de Laurea o grado. Los estudios de Arquitectura, en uno o dos ciclos, amplían la formación humanística, y están más vinculados al diseño, mientras que los de Ingeniería, más científicos, están más orientados a la tecnología y la producción.

\subsection{Luxemburgo}

Para poder llevar el título de Ingeniero en Luxemburgo se exige la homologación de un título superior correspondiente, adquirido en el extranjero en una carrera de al menos cuatro años y que, en el país donde se ha obtenido, dé derecho a cursar estudios de doctorado.

\subsection{Noruega}

Las formación universitaria se oferta en Noruega en dos modalidades básicas: por un lado están las carreras de ciclo largo, de, al menos, cuatro años y medio, que se estudian en los centros denominados Universitetet o Arkitelthogskolen; y, por otro, las carreras de ciclo corto, de orientación más práctica, y con una duración de dos o tres años, que, en el área técnica, se cursan en centros denominados Ingeniorhogskole. 
Son tres las formaciones universitarias, de tres años o más, que facultan en Noruega para un ejercicio profesional relacionado con la construcción: Arquitecto Civil (Sivilarkitekt), título de al menos cinco años, que se puede obtener, bien en una Escuela Superior de Arquitectura (Arkitekthogskolen), o bien en una Universidad Técnica (Norges Tekniske Hogskole); Ingeniero Civil - Facultad de la Construcción (Sivilingenior - Fakultet for Bygningsingeniorfag). Título de cuatro años y medio que se obtiene en una Universidad Técnica, y que incluye a todas las ramas de la Ingeniería, (mecánicos, químicos, eléctricos, etc.); y por último, Ingeniero de la Construcción (Ingenior, Avdeling Bygg og Anlegg). Literalmente "Ingeniero, Departamento de Construcción e Instalaciones", que se cursa en Escuelas de Ingeniería (Ingeniorhogskole).

\subsection{Países bajos}

El sistema neerlandés de Enseñanza Superior consta de cuatro tipos de establecimientos: las Universidades Técnicas, que forman a los ingenieros (especializados en Arquitectura o en Ingeniería Civil); las Escuelas Profesionales Superiores (Technische Hogescholen o Hogere Beroeps Onderwijs - HBO), que forman a los Ingenieros Técnicos (en Arquitectura o Ingeniería Civil); las Escuelas Técnicas Superiores (Hogere Technische Instituten - HTI), que permiten a los ingenieros técnicos acceder posteriormente al nivel de Ingeniero Civil; y las Academias de Bellas Artes (Academie van Bouwkunst), que permiten a los ingenieros técnicos acceder al título de Arquitecto.

Los titulados de las Escuelas Profesionales pueden acceder al nivel superior mientras están ejerciendo su profesión en el sector de la construcción, a condición de seguir los cursos de una Academia de Bellas Artes, para obtener el título de Arquitecto, o de una Escuela Técnica Superior, para obtener el título de Ingeniero. Vía de acceso esta tanto o mejor considerada que la vía directa de carácter universitario.

\subsection{Portugal}

En el sistema portugués los diferentes niveles de enseñanza están comunicados entre sí. De modo que la formación profesional y la formación politécnica, no universitaria, están comunicados con los estudios universitarios.

A nivel de estudios superiores en el sector de la construcción, se pueden distinguir dos carreras universitarias de tipo largo (5 años o más): Licenciado en Arquitectura y Licenciado en Ingeniería Civil; así como una carrera de tipo intermedio (3 años), de carácter politécnico: Ingeniero Técnico, en la especialidad de Ingeniería Civil, pero cuyos titulados pueden acceder a la Licenciatura universitaria mediante unos estudios complementarios de tres años. O pueden realizar un Diploma de Estudios Superiores Especializados (DESE), de una duración de dos años, que les permite obtener el título de Licenciado en Ingeniería Especializada (Dirección de Obras), que asimismo puede equipararse con el de Ingeniero Civil. 


\subsection{Reino unido}

El sistema educativo británico se distingue por la gran autonomía de los centros docentes para fijar sus programas y planes de estudios, y por la gran importancia que concede a los períodos de prácticas, previstos casi siempre como parte integrante de la formación. Esto permite una fácil adaptación a las necesidades del mercado de trabajo, pero provoca una gran dispersión de la oferta formativa, lo que dificulta la equiparación y homologación de los títulos académicos expedidos por las distintas universidades.

De este modo, los estudios relacionados son más diversos y especializados que en la mayoría de los países comunitarios. A ellos se puede acceder desde distintos títulos académicos de Bachelor of Science (BSc). Las carreras que representan, como mínimo, cuatro años de estudios superiores, incluidos los períodos de prácticas obligatorios, son: Arquitecto - Arquitect; Constructor - Builder; Experto en Construcción - Building Surveyor; Experto en Costes - Quantity Surveyor; Ingeniero de Estructuras - Civil and Structural Engineer; Ingeniero de Instalaciones - Building Services Engineer.

\subsection{Suecia}

En Suecia, los estudios superiores de ciclo largo en Ingeniería y Arquitectura, se realizan en la universidad y tienen una duración de cuatro años y medio o cinco años, incluyendo un periodos de prácticas de entre cuatro y seis meses. Las profesiones con formación universitaria relacionadas con la construcción son: Arquitecto (Arkitekt); Ingeniero Civil (Civilingenjör) que, aunque designa a todo tipo de ingenieros con formación de ciclo largo, suele aplicarse, por antonomasia, al Ingeniero de Caminos y Obras Hidráulicas (Väg- och vattenbyggnadsingenjör). Existe, no obstante, una amplia variedad de especializaciones (Ingeniería Estructural; Técnicas de Construcción de Edificios; Dirección de Proyectos de Edificación, o de Infraestructuras -Proyect Management-; Geotécnica; Ingeniería Hidráulica y Técnicas de Conservación del Agua; Construcción de Carreteras y Planificación del Tráfico; Planificación Territorial y Urbanismo; Ingeniería Ambiental). Por otra parte, la Escuela de Ingeniería (Ingenijörskola) de la Real Universidad Técnica de Estocolmo ofrece una carrera de tres años, que combina la ingeniería de la construcción con su gestión económica: Ingeniero en Técnica de Construcción y Economía (Ingenjör i Byggteknik och Ekonomi).

\section{La adaptación de los planes de estudio y la orden ECI}

Todas las universidades españolas, con mayor o menor premura, adaptaron sus planes de estudio a las nuevas determinaciones del Libro Blanco y del EEES. Del estudio anterior se infería directamente que el ámbito de estudio de los aquí denominados arquitectos técnicos era el de la ingeniería, sin que su ámbito de actuación y competencia fuera completamente ajeno a lo que había sido hasta ese momento. La titulación pasó a ser de grado, de nivel análogo al resto de titulaciones de grado, al margen de las pugnas profesionales, y dio acceso a estudios de segundo ciclo: másteres y doctorado de forma automática. 
Por tanto, lo que se aprobó en nuestras Escuelas fueron unos planes de estudios de Ingeniería, que preparan a profesionales perfectamente homologables en la esfera internacional. Pese a la desafortunada Sentencia que obligó al cambio de denominación del Título (aunque no en todos los Centros, no se olvide), los planes de estudios del Libro Blanco, cuyo contenido nunca ha sido cuestionado, siguen formando Ingenieros.

Es más, previamente a los recursos y a la Sentencia del Tribunal Supremo, que se verá más tarde, se había firmado un acuerdo entre el Consejo General de la Arquitectura Técnica CGATE, y el Consejo General de la Arquitectura CGA, con el visto bueno de los Ministerios de Educación y de Vivienda, aceptando todos, plenamente, la denominación de Ingeniero de Edificación para el título que se proponía en el Libro Blanco.

Con posterioridad se produce un hecho de gran trascendencia cual es la publicación de la Orden ECl-3855/2007, de 27 de diciembre, (que merecería más atención por sí sola), por la que se establecen los requisitos para la verificación de los títulos universitarios oficiales que habiliten para el ejercicio de la profesión de Arquitecto Técnico. Ello es, en lo que a su ejercicio regulado o habilitante, se refiere, claro está, que no al conjunto de su actividad profesional. Ha de tenerse en cuenta que, de acuerdo con datos de los Colegios, incluso durante el periodo en el que se desarrolló en España la burbuja inmobiliaria (1998-2007) que daría lugar a la crisis que finalmente se manifestó en toda su crudeza a partir de 2010 , el número de colegiados dedicados a la actividad profesional regulada no superó el $26 \%$ del total de egresados.

Como se ha dicho, las Escuelas de España invitaron a actuar, como un participante más, al CGATE en la elaboración del Libro Blanco. Sin embargo, sorprendentemente, en la discusión de dicha Orden, en la que sí intervino y activamente el CGATE, en ningún caso se invita a participar, ni se consulta a las universidades donde se impartían los títulos afectados. En otras titulaciones "habilitantes" fueron las universidades las que definieron las competencias reguladas de las titulaciones. No fue el caso para la Ingeniería de Edificación.

Y fue precisamente, un párrafo de esta Orden, el que establecía que el Ingeniero en Edificación era el único ingeniero habilitado para intervenir en edificación, el que provocó que los ingenieros en general, pero especialmente los Ingenieros Industriales y los Ingenieros Técnicos Industriales se opusieran frontalmente a dicha orden y la recurrieran. Aunque el resultado de su recurso tuvo otras consecuencias sobre la denominación.

\section{Y la sentencia del Supremo. Situación actual de la titulación y sus denominaciones en España}

Finalmente la conocida Sentencia del Tribunal Supremo (STS), haciendo una interpretación más allá de lo solicitado por las corporaciones recurrentes, determina que la denominación de la titulación induce a "confusión" al no corresponderse el título académico y profesional (el regulado o habilitante). Aunque no fue unánime, pues, como estableció el ex presidente del Tribunal Constitucional, D. Pascual Sala, en su voto particular a la Sentencia, son muy variadas las denominaciones académicas que no se corresponden con una titulación 
profesional. Sirva como ejemplo la denominación profesional de Abogado, cuya titulación académica era Licenciado en Derecho, o en la actualidad graduado/a en Derecho.

Ello condujo a las distintas universidades recurridas (que no fueron todas) y a algunas otras, en mayor o menor grado presionadas por sus rectores, algunos de ellos con la titulación de los recurrentes, a cambiar la denominación de las titulaciones de Ingeniería de Edificación. Y, paradójicamente, a un confuso conglomerado de nombres distintos para un mismo grado, que puede resumirse en:

- Graduado/a en Ingeniería de Edificación (mantenido en las universidades cuya denominación no fue recurrida)

- Graduado/a en Edificación

- Graduado/a en Arquitectura Técnica y Edificación

- Graduado/a en Arquitectura Técnica.

- Temporalmente, también hubo alguna denominación de Graduado/a en Ciencia y Tecnología de la Edificación.

Los planes de estudio de las distintas universidades, que siguieron el modelo del EEES a través del Libro Blanco, son, en todo caso, de ingeniería, nunca fueron recurridos en su contenido y nivel de formación que otorgan, por tanto, están plenamente vigentes, pese a la prohibición, para ciertas universidades del uso del término ingeniería. Por universidades y centros el catálogo de titulaciones vigente en la actualidad es el siguiente:

Tabla 1. Denominación de las titulaciones de grado por centro

\begin{tabular}{|c|c|c|}
\hline LOCALIDAD & CENTRO & $\begin{array}{c}\text { TITULACIONES QUE SE } \\
\text { IMPARTEN } \\
\end{array}$ \\
\hline ALICANTE & $\begin{array}{l}\text { Escuela Politécnica Superior de } \\
\text { ALICANTE }\end{array}$ & $\begin{array}{l}\text { GRADO EN } \\
\text { TECNICA }\end{array}$ \\
\hline BARCELONA & $\begin{array}{l}\text { Escuela Politécnica Superior de } \\
\text { Edificación } \quad \text { (EPSB) de } \\
\text { BARCELONA. }\end{array}$ & $\begin{array}{l}\text { GRADO EN ARQUITECTURA } \\
\text { TÉCNICA Y EDIFICACIÓN } \\
\end{array}$ \\
\hline $\begin{array}{l}\text { BARCELONA } \\
\text { PRIVADA }\end{array}$ & $\begin{array}{l}\text { UNIVERSIDAD RAMÓN } \\
\text { LLULL } \\
\text { Escuela Técnica Superior de } \\
\text { arquitectura }\end{array}$ & $\begin{array}{l}\text { GRADO EN ARQUITECTURA } \\
\text { TÉCNICA Y EDIFICACIÓN }\end{array}$ \\
\hline BURGOS & $\begin{array}{l}\text { Escuela Politécnica Superior de } \\
\text { BURGOS. }\end{array}$ & $\begin{array}{lll}\text { GRADO EN } & \text { ARQUITECTURA } \\
\text { TECNICA } & \\
\text { DOBLE GRADO EN INGENIERÍA } \\
\text { CIVIL Y Y ARQUITECTURA } \\
\text { TÉCNICA } & \\
\end{array}$ \\
\hline CACERES & $\begin{array}{l}\text { Escuela Politécnica Universidad } \\
\text { de EXTREMADURA }\end{array}$ & GRADO EN EDIFICACIÓN \\
\hline CARTAGENA & $\begin{array}{l}\text { Escuela de Arquitectura e } \\
\text { Ingeniería de Edificación } \\
\text { CARTAGENA } \\
\end{array}$ & $\begin{array}{lcc}\text { GRADO EN } & \text { INGENIERÍA } & \text { DE } \\
\text { EDIFICACIÓN } & & \\
\end{array}$ \\
\hline
\end{tabular}




\begin{tabular}{|c|c|c|}
\hline LOCALIDAD & CENTRO & $\begin{array}{l}\text { TITULACIONES QUE SE } \\
\text { IMPARTEN }\end{array}$ \\
\hline CASTELLÓN & $\begin{array}{l}\text { Escuela Superior de Tecnología } \\
\text { y Ciencias Experimentales. } \\
\text { CASTELLÓN PLANA }\end{array}$ & $\begin{array}{l}\text { GRADO EN ARQUITECTURA } \\
\text { TECNICA }\end{array}$ \\
\hline CUENCA & $\begin{array}{lll}\text { Escuela } & \text { Politécnica } & \text { de } \\
\text { CUENCA } & & \\
\end{array}$ & $\begin{array}{lcc}\text { GRADO EN } & \text { INGENIERÍA } & \text { DE } \\
\text { EDIFICACIÓN } & & \end{array}$ \\
\hline GIRONA & $\begin{array}{l}\text { Escuela Politécnica Superior } \\
\text { GERONA }\end{array}$ & $\begin{array}{l}\text { GRADO EN ARQUITECTURA } \\
\text { TÉCNICA Y EDIFICACIÓN }\end{array}$ \\
\hline GRANADA & $\begin{array}{l}\text { Escuela Técnica Superior de } \\
\text { Ingeniería de Edificación } \\
\text { GRANADA. }\end{array}$ & $\begin{array}{l}\text { GRADO EN EDIFICACIÓN } \\
\text { DOBLE GRADO GRADO } \\
\text { EDIFICACIÓN Y ADE }\end{array}$ \\
\hline GUADALAJARA & Escuela de Arquitectura & $\begin{array}{l}\text { GRADO EN ARQUITECTURA } \\
\text { TÉCNICA Y EDIFICACIÓN }\end{array}$ \\
\hline $\begin{array}{l}\text { ISLAS } \\
\text { BALEARES }\end{array}$ & $\begin{array}{l}\text { Escuela Politécnica Superior. } \\
\text { ISLAS BALEARES }\end{array}$ & GRADO EN EDIFICACIÓN \\
\hline LA CORUÑA & $\begin{array}{l}\text { Escuela Universitaria de } \\
\text { Arquitectura Técnica } \\
\text { LA CORUÑA }\end{array}$ & $\begin{array}{lll}\text { GRADO } & \text { EN ARQUITECTURA } \\
\text { TÉCNICA } & & \end{array}$ \\
\hline MADRID & $\begin{array}{l}\text { Escuela Técnica Superior de } \\
\text { Edificación } \\
\text { MADRID }\end{array}$ & $\begin{array}{l}\text { GRADO EN EDIFICACIÓN } \\
\text { GRADO EN EDIFICACIÓN + ADE }\end{array}$ \\
\hline $\begin{array}{l}\text { MADRID } \\
\text { PRIVADA }\end{array}$ & $\begin{array}{l}\text { UNIVERSIDAD ALFONSO X } \\
\text { EL SABIO } \\
\text { Escuela Politécnica Superior. }\end{array}$ & GRADO EN EDIFICACIÓN \\
\hline $\begin{array}{l}\text { MADRID } \\
\text { PRIVADA }\end{array}$ & $\begin{array}{l}\text { UNIVERSIDAD CAMILO JOSÉ } \\
\text { CELA } \\
\text { Escuela Supr. Arquitectura y } \\
\text { Tecnología (ESAT). }\end{array}$ & NO IMPARTE \\
\hline $\begin{array}{l}\text { MADRID } \\
\text { Villaviciosa de } \\
\text { Odón } \\
\text { PRIVADA }\end{array}$ & $\begin{array}{l}\text { UNIVERSIDAD EUROPEA DE } \\
\text { MADRID. } \\
\text { Escuela Superior de Arte y } \\
\text { Arquitectura. }\end{array}$ & NO IMPARTE \\
\hline $\begin{array}{l}\text { MURCIA } \\
\text { PRIVADA }\end{array}$ & $\begin{array}{l}\text { UNIVERSIDAD } r \text { CATÓLICA } \\
\text { SAN ANTONIO } \quad \text { Escuela } \\
\text { Universitaria Politécnica. }\end{array}$ & $\begin{array}{l}\text { GRADO EN INGENIERÍA DE } \\
\text { EDIFICACIÓN }\end{array}$ \\
\hline SEVILLA & $\begin{array}{l}\text { Escuela Técnica Superior de } \\
\text { Ingeniería de Edificación } \\
\text { SEVILLA }\end{array}$ & GRADO EN EDIFICACIÓN \\
\hline LA LAGUNA & $\begin{array}{l}\text { Escuela Politécnica Superior } \\
\text { Ingeniería de LA LAGUNA }\end{array}$ & $\begin{array}{l}\text { GRADO EN } \\
\text { TÉCNICA }\end{array}$ \\
\hline LLEIDA & $\begin{array}{l}\text { Escuela Politécnica Superior } \\
\text { LLEIDA }\end{array}$ & $\begin{array}{l}\text { GRADO EN ARQUITECTURA } \\
\text { TÉCNICA y EDIFICACIÓN }\end{array}$ \\
\hline SAN SEBASTIÁN & $\begin{array}{l}\text { Escuela Universitaria } \\
\text { Politécnica de Donostia }\end{array}$ & $\begin{array}{l}\text { GRADO EN } \\
\text { TÉCNICA }\end{array}$ \\
\hline
\end{tabular}


Juan M. Santiago Zaragoza, Fabián García Carrillo, Joaquín Passolas Colmenero, Emilio Gómez Cobos

\begin{tabular}{|c|c|c|}
\hline LOCALIDAD & CENTRO & $\begin{array}{l}\text { TITULACIONES QUE SE } \\
\text { IMPARTEN }\end{array}$ \\
\hline VALENCIA & $\begin{array}{l}\text { Escuela Técnica Superior de } \\
\text { Ingeniería de Edificación } \\
\text { VALENCIA }\end{array}$ & $\begin{array}{l}\text { GRADO EN ARQUITECTURA } \\
\text { TÉCNICA }\end{array}$ \\
\hline $\begin{array}{l}\text { VALLADOLID } \\
\text { PRIVADA }\end{array}$ & $\begin{array}{l}\text { UNIVERSIDAD } \quad \text { EUROPEA } \\
\text { MIGUEL DE CERVANTES } \\
\text { Escuela Politécnica Superior }\end{array}$ & $\begin{array}{l}\text { GRADO EN ARQUITECTURA } \\
\text { TÉCNICA }\end{array}$ \\
\hline ZAMORA & $\begin{array}{l}\text { Escuela Politécnica Superior de } \\
\text { ZAMORA. }\end{array}$ & $\begin{array}{l}\text { GRADO EN ARQUITECTURA } \\
\text { TÉCNICA }\end{array}$ \\
\hline ZARAGOZA & $\begin{array}{ll}\text { Escuela } & \text { Universitaria } \\
\text { Politécnica } & \\
\text { ZARAGOZA } & \end{array}$ & $\begin{array}{lll}\text { GRADO EN ARQUITECTURA } \\
\text { TÉCNICA }\end{array}$ \\
\hline
\end{tabular}

\section{La situación actual y el futuro de la titulación.}

\subsection{El incremento de competencias en los grados}

Al margen de las diferentes denominaciones de la titulación académica, es una realidad palpable que todas ellas habilitan para el ejercicio profesional regulado de la Arquitectura Técnica. $Y$ así debe seguir siendo mientras dichas reservas sigan existiendo en España. La situación en los diferentes países de la Unión Europea nos muestra una realidad completamente diferente, para la que habrá que estar preparado.

Sobre la base de los 240 créditos ECTS del Grado universitario, de los cuales la Orden ECI, fijó los créditos de carácter Básico en 60, los de Proyecto de Fin de Grado en 12, y limitó los de Formación Específica a 108, dejando pues, 60 créditos optativos para ser determinados, en sus contenidos y competencias, por las distintas Universidades. Esto acabaría permitiendo la intensificación de ciertas áreas o la especialización en cada Plan de Estudios concreto, es decir, la adquisición de nuevas competencias, complementarias a la formación contenida en los 180 créditos comunes de la Orden $\mathrm{ECl}$, que, en definitiva, son los que deben concentrar y otorgar las competencias establecidas para la parte regulada, o habilitante, para el ejercicio de la profesión de Arquitecto Técnico. Competencias que el Grado, con sus 240 créditos, lógicamente supera. Por tanto, con todos los respetos, no cabe una identificación como la que se alude en la sentencia.

\subsection{Y la formación de posgrado}

Prácticamente todas las universidades españolas han implantado un extenso catálogo de títulos de máster a los que (obviados los másteres habilitantes) tienen acceso los graduados de las titulaciones aquí mencionadas. Más aún, muchas de nuestras Escuelas han implantado programas de máster diseñados para la especialización de nuestros graduados. Dichos títulos oficiales, con reconocimiento inmediato a nivel europeo y, por extensión a nivel mundial, ofrecen nuevas competencias a nuestros egresados que deben trasladarse a su campo de actividad profesional. 
Los Másteres, antes inaccesibles, son una feliz realidad, y ofrecen a los nuevos titulados extraordinarias posibilidades para continuar y ampliar la formación regulada, por la vía de la especialización, otorgando nuevas competencias que, indudablemente, les sitúan en un nivel de cualificación avanzado, también en el ámbito de la Ingeniería. Los colegios profesionales, tradicionalmente, han apostado por los cursos de formación, como forma de mejorar en el ejercicio profesional, extendiéndolo así a nuevas facetas de actividad. No sería razonable que estos mismos colegios, ahora, estén dispuestos a cuestionar la formación de posgrado cuando, además, tiene carácter oficial y nivel universitario. Incluso las Escuelas de Arquitectura (cuyo título oficial es un Máster habilitante con atribuciones por encima de toda lógica), ofrecen Másteres de especialización que, evidentemente, aportan nuevas competencias y abren diversos campos al ejercicio de esa profesión.

El presente y el futuro, -desde la UE ya se nos viene avisando-, más que en las atribuciones reguladas, está en el ejercicio de las competencias reales, y en la asunción de las responsabilidades efectivas por cada cual. Y para ello hay que prepararse. La Universidad, nuestras Escuelas, van a seguir apostando por la ampliación de competencias a través de los Másteres, y los Colegios deben entenderlos como una vía para una ampliación cualitativa de su campo de actividad, además de como una oportunidad de colaboración más estrecha con la parte académica.

Las Escuelas generan, articulan o participan en una oferta variada y nada desdeñable de Másteres (Tabla 2) que ya están a disposición de los graduados y que, fundamentalmente, se sustentan en nuestras propias capacidades para proporcionar una oferta de formación atractiva. En estos Másteres suelen participar profesionales de reconocido prestigio ajenos a la Universidad, por tanto, pueden ser un extraordinario nexo de colaboración entre Academia y Profesión. De hecho, esa colaboración ya se está produciendo.

Tabla 2. Denominación de las titulaciones de máster por centro

\begin{tabular}{|l|l|l|}
\hline \multicolumn{1}{|c|}{ LOCALIDAD } & \multicolumn{1}{|c|}{ CENTRO } & \multicolumn{1}{|c|}{ MÁSTERES QUE SE IMPARTEN } \\
\hline \hline BARCELONA & $\begin{array}{l}\text { Escuela Politécnica Superior } \\
\text { de Edificación (EPSB) de } \\
\text { BARCELONA. }\end{array}$ & $\begin{array}{l}\text { Máster universitario en Construcción } \\
\text { Avanzada en la Edificación. } \\
\text { Máster universitario en Diagnosis y } \\
\text { Técnicas de Intervención en la } \\
\text { Edificación } \\
\text { Máster universitario en Gestión de la } \\
\text { Edificación }\end{array}$ \\
\hline
\end{tabular}




\begin{tabular}{|c|c|c|}
\hline LOCALIDAD & CENTRO & MÁSTERES QUE SE IMPARTEN \\
\hline $\begin{array}{l}\text { BARCELONA } \\
\text { PRIVADA }\end{array}$ & $\begin{array}{l}\text { UNIVERSIDAD RAMÓN } \\
\text { LLULL } \\
\text { Escuela Técnica Superior } \\
\text { de arquitectura }\end{array}$ & 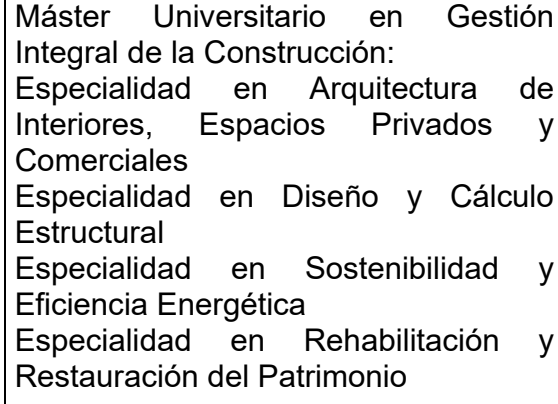 \\
\hline BURGOS & $\begin{array}{l}\text { Escuela Politécnica Superior } \\
\text { de BURGOS. }\end{array}$ & \begin{tabular}{|lrl} 
Máster Universitario en Inspección, \\
Rehabilitación y Eficiencia Energética \\
en la Edificación & \\
Máster Universitario en & Integridad y \\
Durabilidad de & Materiales, \\
Componentes y & Estructuras \\
(Interuniversitario; & \\
streaming/presencial) &
\end{tabular} \\
\hline CACERES & $\begin{array}{l}\text { Escuela Politécnica } \\
\text { Universidad de } \\
\text { EXTREMADURA }\end{array}$ & $\begin{array}{l}\text { Máster Universitario de Metodología } \\
\text { para Modelización de la Información } \\
\text { Construcción (Bim) }\end{array}$ \\
\hline CARTAGENA & $\begin{array}{l}\text { Escuela Arquitectura e } \\
\text { Ingeniería de Edificación } \\
\text { CARTAGENA }\end{array}$ & $\begin{array}{l}\text { Máster en Ciencia y Tecnología de la } \\
\text { Edificación en Arquitectura } \\
\text { Máster en Patrimonio Arquitectónico }\end{array}$ \\
\hline CASTELLÓN & $\begin{array}{l}\text { Escuela Superior de } \\
\text { Tecnología y Ciencias } \\
\text { Experimentales. } \\
\text { CASTELLÓN PLANA }\end{array}$ & $\begin{array}{l}\text { Máster en Eficiencia Energética y } \\
\text { Sostenibilidad }\end{array}$ \\
\hline GRANADA & $\begin{array}{l}\text { Escuela Técnica Superior } \\
\text { de Ingeniería de Edificación } \\
\text { GRANADA. }\end{array}$ & $\begin{array}{l}\text { Máster en Ciencia y Tecnología del } \\
\text { Patrimonio Arquitectónico (CITPA) } \\
\text { Máster en Rehabilitación } \\
\text { Arquitectónica } \\
\text { Máster en Estructuras } \\
\text { Máster en Prevención de Riesgos } \\
\text { Laborales } \\
\text { Doble Máster en Rehabilitación } \\
\text { Arquitectónica + Estructuras } \\
\text { Doble Máster en Rehabilitación } \\
\text { Arquitectónica y CITPA }\end{array}$ \\
\hline GUADALAJARA & Escuela de Arquitectura & $\begin{array}{l}\text { Máster Universitario en Gestión } \\
\text { Integral de Inmuebles y Servicios en el } \\
\text { Patrimonio Arquitectónico }\end{array}$ \\
\hline
\end{tabular}




\begin{tabular}{|c|c|c|}
\hline LOCALIDAD & CENTRO & MÁSTERES QUE SE IMPARTEN \\
\hline LA CORUÑA & $\begin{array}{l}\text { Escuela Universitaria de } \\
\text { Arquitectura Técnica } \\
\text { LA CORUÑA }\end{array}$ & $\begin{array}{l}\text { Máster Universitario en } \text { Dirección } \\
\text { integrada de proyectos } \\
\text { Máster Universitario en Edificación } \\
\text { Sostenible }\end{array}$ \\
\hline MADRID & $\begin{array}{l}\text { Escuela Técnica Superior } \\
\text { de Edificación } \\
\text { MADRID }\end{array}$ & $\begin{array}{l}\text { Máster en Innovación Tecnológica en } \\
\text { Edificación (MITE) } \\
\text { Máster en Gestión en Edificación } \\
\text { (MAGE) } \\
\text { Máster en Ejecución de Obras de } \\
\text { Rehabilitación y Restauración } \\
\text { (MEJORR) } \\
\text { Doble Máster en Innovación } \\
\text { Tecnológica en Edificación y Máster } \\
\text { en Ejecución de Obras de } \\
\text { Rehabilitación y Restauración }\end{array}$ \\
\hline $\begin{array}{l}\text { MURCIA } \\
\text { PRIVADA }\end{array}$ & $\begin{array}{l}\text { UNIVERSIDAD CATÓLICA } \\
\text { SAN ANTONIO Escuela } \\
\text { Universitaria Politécnica. }\end{array}$ & $\begin{array}{l}\text { Máster Universitario en Patología e } \\
\text { Intervención en Edificación }\end{array}$ \\
\hline SEVILLA & $\begin{array}{l}\text { Escuela Técnica Superior } \\
\text { de Ingeniería de Edificación } \\
\text { SEVILLA }\end{array}$ & $\begin{array}{l}\text { Máster Universitario en Seguridad } \\
\text { Integral en Edificación (Itinerarios) } \\
\text { Máster Universitario en Gestión } \\
\text { Integral en Edificación (Itinerarios) }\end{array}$ \\
\hline LA LAGUNA & $\begin{array}{l}\text { Escuela Politécnica Superior } \\
\text { Ingeniería de LA LAGUNA }\end{array}$ & $\begin{array}{l}\text { Máster Universitario en Gestión e } \\
\text { Innovación Tecnológica en la } \\
\text { Construcción }\end{array}$ \\
\hline SAN SEBASTIÁN & $\begin{array}{ll}\text { Escuela } & \text { Universitaria } \\
\text { Politécnica de Donostia }\end{array}$ & $\begin{array}{l}\text { Máster en Ingeniería de Materiales } \\
\text { Renovables }\end{array}$ \\
\hline VALENCIA & $\begin{array}{l}\text { Escuela Técnica Superior } \\
\text { de Ingeniería de Edificación } \\
\text { VALENCIA }\end{array}$ & Máster en Edificación \\
\hline ZAMORA & $\begin{array}{l}\text { Escuela Politécnica Superior } \\
\text { de ZAMORA. }\end{array}$ & $\begin{array}{l}\text { Máster en Dirección y Gestión de } \\
\text { Proyectos } \\
\text { Máster en gestión integrada de } \\
\text { edificación y obra civil } \\
\text { Máster en Energías Renovables y } \\
\text { Eficiencia Energética }\end{array}$ \\
\hline
\end{tabular}

Por otra parte, y viendo una oportunidad en cada problema, el terrible y extraordinario suceso de la pandemia del coronavirus Covid-19 ha provocado, también, la obligada y súbita inmersión de la universidad española en la docencia on line. Los estudiantes reciben clases y tutorías a través de video conferencia, o clases grabadas previamente, que el profesor imparte y gestiona con la ayuda de una serie de aplicaciones y plataformas en la web. Este sistema, asimismo, puede ser idóneo para acercar nuestra oferta formativa a los profesionales en ejercicio con dificultades de acceso directo a la Universidad, pero que 
desean adaptar su título o realizar un posgrado. Desde la Conferencia de Directores de Arquitectura Técnica e Ingeniería de Edificación, CODATIE, y con ese específico fin, se hace una apuesta decidida por extender la formación on line, y en lo posible, la oferta académica actual de nuestras Escuelas, ampliándola incluso con propuestas de Másteres Interuniversitarios, en áreas y ámbitos de especialización donde no haya oferta suficiente.

\subsection{Del Doctorado y la carrera académica.}

La oferta universitaria, aún escasa, de Programas de Doctorado vinculados a nuestro específico campo de acción, posibilita el acceso de titulados Máster al máximo nivel de formación académica, y por tanto de especialización, que existe en la Universidad. El Doctorado es hoy la vía imprescindible para iniciar una carrera académica universitaria, pero no sólo es eso. No se nos puede escapar que también abre las puertas a nuestros profesionales para que ocupen puestos de la máxima responsabilidad en instituciones y empresas. De hecho, aunque aún no son muy numerosos, algunos de ellos empiezan a ostentar cargos directivos relevantes, en unidades de I+D+i de centros de investigación, de grandes empresas y administraciones. Colegios profesionales y universidades debemos sentirnos orgullosos de ellos pues son los mejores heraldos de nuestra formación y nuestra profesión, los más dignos representantes de nuestro colectivo.

Este indiscutible avance desde el lado académico, con clara y directa repercusión en el mundo profesional tampoco puede estar lastrado por una denominación previa de Grado que nos retrotraería a un tiempo en que esto era imposible. Un nombre distintivo y homologable, que reconoce en él el acceso a un nivel máximo de formación y responsabilidad, facilitará, en el futuro, incrementar aún más nuestra presencia y nuestro nivel de participación en órganos de gestión y decisión, en cualquier parte del mundo, en la esfera pública y privada. $Y$ poder, por fin, actuar con criterio propio, representativo de un colectivo profesional independiente, que análogamente a nuestros colegas del resto del mundo, ejerce e impone su "superior", por mejor, criterio.

Respecto a la carrera académica, no cabe dudar de la importancia y trascendencia que tiene para el futuro de nuestras Escuelas y Colegios, el que nuestros egresados accedan al Doctorado. Hasta ahora, si nuestros propios titulados están presentes entre el profesorado estable de las Escuelas, es porque, con un esfuerzo encomiable, han realizado otros estudios y leído tesis doctorales, iniciando la larga carrera de obstáculos que supone la acreditación a los distintos cuerpos universitarios. En algunas universidades se ha llegado a los puestos de alta responsabilidad en las Escuelas y la propia Universidad.

Pero no hay que llevarse a engaño, este no es, ni mucho menos, el panorama general. Hoy día, hay Centros que imparten los grados aquí mencionados en los que sólo un profesor, de todo el claustro, tiene la titulación de Arquitecto Técnico o Ingeniero de Edificación. Es fácil comprender que la visión de nuestra profesión, el diseño de los planes de estudios, la defensa de nuestros intereses, y hasta el enfoque de asignaturas "clave" en la formación de los titulados, dependen de la formación previa del profesorado. Consecuentemente, los Colegios, que se nutren de las Escuelas, deben adoptar una posición común ¡de máxima alerta!, y con la participación directa del CGATE y la misma CODATIE, elaborar y poner en 
práctica un plan estratégico, para fomentar que nuestros mejores estudiantes y egresados, puedan hacer carrera universitaria. El futuro de esta profesión estará en sus manos. Pero hoy está en las nuestras el que eso sea posible: no nos atrincheremos esperando a que el pasado venga a rescatarnos.

\section{Conclusiones}

\subsection{Un presente indudablemente mejor y un futuro sin vuelta atrás}

A lo largo de toda nuestra historia, como colectivo, tanto la formación de los titulados como la actividad profesional desarrollada, es decir, las competencias adquiridas y acreditadas, han superado, con creces, al angosto límite de las atribuciones reguladas en España. La conquista de nuevos campos de actividad en el cada vez más complejo mundo de la Edificación nunca ha supuesto un problema para un profesional dedicado precisamente a resolverlos. Se ha de reconocer con orgullo que, sin nuestra participación, este sector no funcionaría. Sin embargo, cuando se ha intentado el reconocimiento oficial de la actividad realizada, el intento ha devenido en un proceso tortuoso que, casi siempre ha encallado por la voluntad y el poder corporativo de otros que han sentido amenazados unos privilegios, legales sin duda, fundamentados en la asunción de unas supuestas máximas responsabilidades que, en algún caso, no se corresponden ni con la formación recibida ni con el ejercicio desarrollado.

El colectivo académico, con la participación del CGATE, ha contemporizado o ha consentido este statu quo más allá de lo admisible. Se ha de provechar el cambio y el reto que ha supuesto contrastar nuestras capacidades o habilidades, a escala europea y mundial, para darle un impulso a esta extraordinaria e imprescindible profesión, con unos fundamentos sólidos, y que está recuperando la buena coyuntura en lo laboral y que, sin lugar a duda alguna, sí que es el mejor momento que nunca ha vivido en lo académico. Aprovechemos nuestras sinergias, ¡Ni un paso atrás!

La CODATIE ha comunicado formalmente a la Conferencia de Rectores de las Universidades Europeas y al Ministerio de Universidades, el sentir manifestado por las Escuelas y Universidades españolas que imparten la titulación, comprometidas en la construcción del EEES, en el sentido de apostar decididamente por unificar la denominación del título universitario como Grado en Ingeniería de Edificación, que asimismo da lugar a la profesión del igual nombre, ambos homologables tanto en el EEES como a nivel mundial.

El Título permitirá el acceso a distintos niveles de formación universitaria de posgrado, en dicho campo de especialidad propio. Todo ello, de acuerdo con los criterios y directrices del Libro Blanco del Título de Grado en Ingeniería de Edificación aprobado por la ANECA, incluyéndose entre las competencias -no exclusivas- otorgadas por el Grado, las que habilitan para el ejercicio regulado en España de la anterior profesión de Arquitecto Técnico.

\section{¡Larga vida a la Ingeniería de Edificación!}




\section{Referencias}

AA..VV. (2005). Libro Blanco del Título de Grado en Ingeniería de Edificación. Agencia Nacional de Evaluación de la Calidad y Acreditación. Desk impresores S.L. Madrid

MARIA PALLISERA DÍAZ, M., FULLANA NOELL, J., PLANAS LLADÓ, A. Y DEL VALLE GÓMEZ, A., (2010), "La adaptación al espacio europeo de educación superior en España. Los cambios/retos que implica la enseñanza basada en competencias y orientaciones para responder a ellos". Revista Iberoamericana de Educación / Revista Ibero-americana de Educação. n. ${ }^{\circ}$ 52/4 - 25/04/10 


\section{EDIFICATE}

I Congreso de Escuelas de Edificación y Arquitectura Técnica de España València, 4 y 5 de noviembre de 2021

Escuela Técnica Superior de Ingeniería de Edificación

Universitat Politècnica de València

Doi: https://doi.org/10.4995/EDIFICATE2021.2021.13564

\section{Radiografía del Grado en Arquitectura Técnica de la EPS de Zamora (Universidad de Salamanca)}

\section{Radiography of the technical architecture bachelor of Zamora EPS (Salamanca University)}

\section{Ascensión Rodríguez-Esteban¹, M. Almudena Frechilla-Alonso², Ana Belén González-Rogado 3 y Ana Belén Ramos-Gavilán ${ }^{4}$}

1Universidad de Salamanca, mare@usal.es, ${ }^{2}$ Universidad de Salamanca, almudena.frechilla@usal.es, ${ }^{3}$ Universidad de Salamanca, abg@usal.es, ㄴuniversidad de Salamanca, aramos@usal.es

\section{Abstract}

The Degree in Technical Architecture (GAT) of the Higher Polytechnic School of Zamora, of the University of Salamanca, is going through a difficult moment in terms of the number of enrollments, with a drastic reduction, which began in the 2009-2010 academic year and which It bottomed out in the 2014-2015 academic year, a situation from which, to date, it has not yet recovered. So much so, that in the current course does not reach $10 \%$ of which had its high points. This Degree, which replaced the Technical Architecture degree in the 2009-2010 academic year, began to be taught in 1998, in a modern and attractive University Campus that had just opened in Zamora, in which other Engineering Degrees were offered and that he had a great tug in his first ten years. There is no doubt that it was the crisis of the "brick" that caused that fall, but having recovered, the situation does not improve. Given this fact, we propose to make an X-ray of the current state of the GAT, putting white on black a series of parameters that can shed some light on the reasons why the number of registrations does not rebound.

Keywords: Technical Architecture Degree, Higher Polytechnic School of Zamora, University of Salamanca, current situation, number of enrollments, student satisfaction.

\section{Resumen}

El Grado de Arquitectura Técnica (GAT) de la Escuela Politécnica Superior de Zamora, de la Universidad de Salamanca, está pasando por un momento difícil en cuanto al número de matriculaciones, con una reducción drástica, que 
comenzó en el curso 2009-2010 y que tocó fondo en el curso 2014-2015, situación de la que, a día de hoy, todavía no se ha recuperado. Tal es así, que en el curso actual no llega al $10 \%$ de la que tuvo en sus momentos álgidos. Este Grado, que sustituyó a la titulación de Arquitectura Técnica en el curso 2009-2010, comenzó a impartirse en el año 1998, en un Campus Universitario que acababa de inaugurarse en Zamora, moderno y atractivo, en el que se ofertaban otros Grados de Ingeniería y que tuvo un gran tirón en sus primeros diez años. No cabe duda de que fue la crisis del "ladrillo" la que propició esa caída, pero habiéndose recuperado, la situación no mejora. Ante este hecho, nos proponemos hacer una radiografía del estado actual del GAT, poniendo blanco sobre negro a una serie de parámetros que puedan arrojar alguna luz sobre los motivos por los cuales el número de matriculaciones no repunta.

Palabras clave: Grado Arquitectura Técnica, Escuela Politécnica Superior de Zamora, Universidad de Salamanca, situación actual, número de matrículas, satisfacción estudiantes. 


\section{Introducción}

El Grado de Arquitectura Técnica (GAT) de la Universidad de Salamanca se imparte en la Escuela Politécnica Superior de Zamora (EPSZ), junto a otros 6 Grados y 2 Dobles Grados de ingenierías, que comparten profesorado e instalaciones. Se enclava en el Campus Viriato, que se construyó entre los años 1997 y 1999 sobre el antiguo Cuartel de Caballería homónimo, uno de los conjuntos edificatorios más emblemáticos de la ciudad (Ávila de la Torre, 2005) (Fig. 1).

La adaptación de las antiguas instalaciones castrenses para uso docente proporcionó unas magníficas infraestructuras en pleno ensanche urbano, cerca de las estaciones de autobuses y de ferrocarril y también de los dos hospitales. La proximidad a estos equipamientos y servicios no es una cuestión menor, puesto que puede influir en la cuestión que se pone sobre la mesa en esta comunicación, al igual que el hecho de que en el mismo Campus se encuentren la Escuela Universitaria de Magisterio y la Escuela Universitaria de Enfermería, ya que permite hacer una comparativa respecto a ítems comunes que se van a mostrar y que pueden ayudar a esclarecer el estudio.
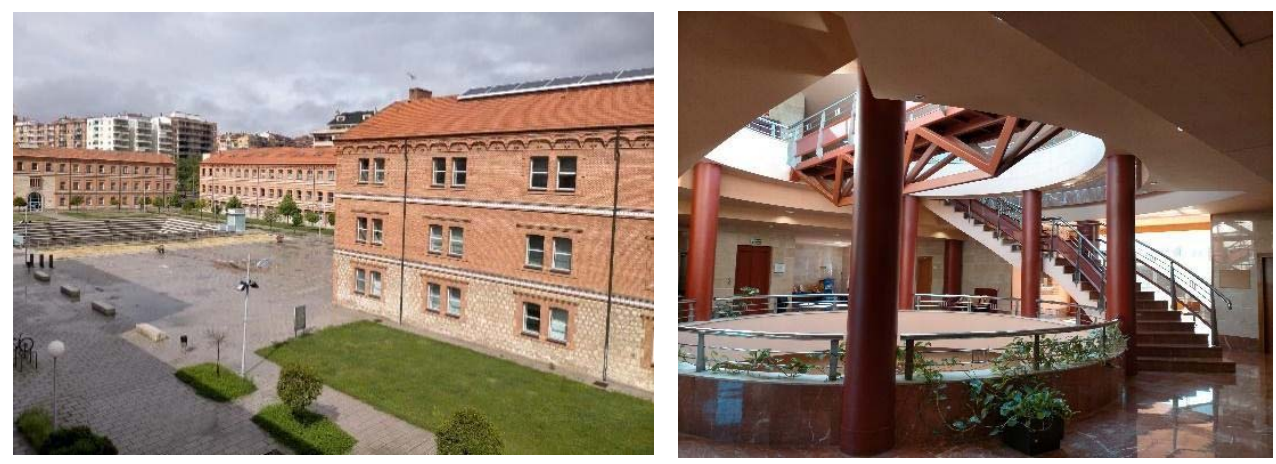

Fig. 1 Imágenes del Campus Viriato, vista general y espacio interior del edificio de la EPSZ

Desde que la titulación de Arquitectura Técnica se incorporó a la EPS de Zamora en 1998, y tras su transformación en Grado de Arquitectura Técnica en 2009, estos estudios gozaron de una demanda de estudiantes extraordinaria, hasta el punto de que en el curso 2005-2006 se amplió la oferta de matrículas en primer curso, de 90 a 120 (Fig. 2). Fue a partir de la crisis provocada por la burbuja inmobiliaria, cuando el número empezó a descender sin que, hasta el momento, haya llegado la recuperación esperada (Campos 2008). Este hecho resulta altamente preocupante para la comunidad universitaria y para Zamora en general, ya que el Campus Universitario es un revulsivo para atraer población y dinamizar la actividad a nivel local e, incluso, regional. Tal es así, que su promoción se lleva a cabo de forma conjunta entre la Universidad de Salamanca y el Ayuntamiento de la ciudad. 


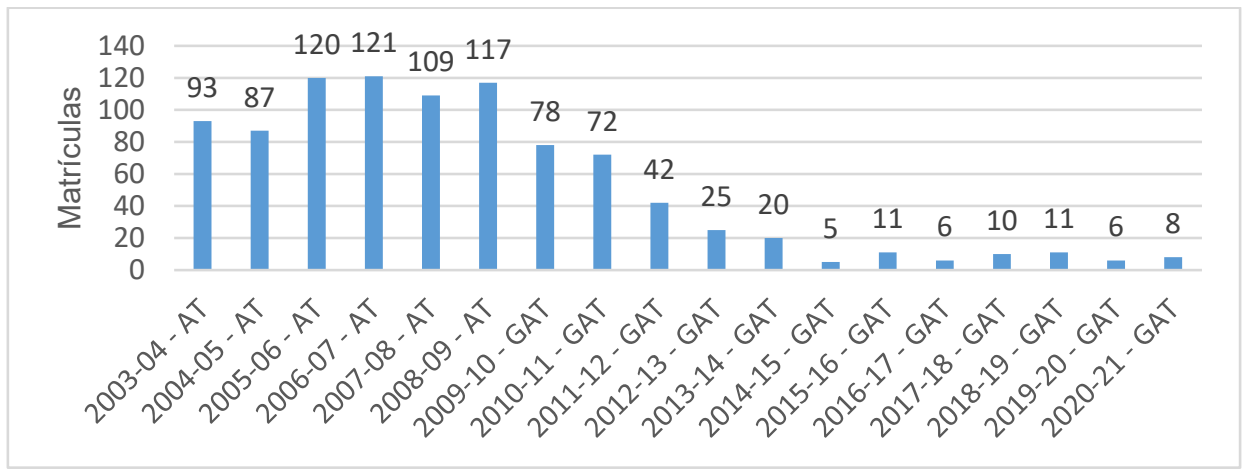

Fuente: Elaboración propia

Fig. 2 Estudiantes matriculados en primer curso de Arquitectura Técnica. Evolución

Los grados que se imparten en la EPS de Zamora tienen un comportamiento dispar frente a la demanda, siendo el Grado de Ingeniería Civil (GIC) el que se más se asemeja al GAT, incluso su declive es más pronunciado, frente al Grado de Ingeniería Mecánica (GIM) que se va manteniendo, aunque ha sufrido un ligero descenso (Fig. 3). Junto a estos Grados está el Grado de Ingeniería de Informática en Sistemas de Información (GIISI), el Grado de Ingeniería Agroalimentaria (GIA), el Grado de Ingeniería de Materiales (GIMAT), y los dobles Grados de Ingeniería de Materiales e Ingeniería Mecánica (GIMM) y de Ingeniería Informática en Sistemas de Información e Información y Documentación (GIID).

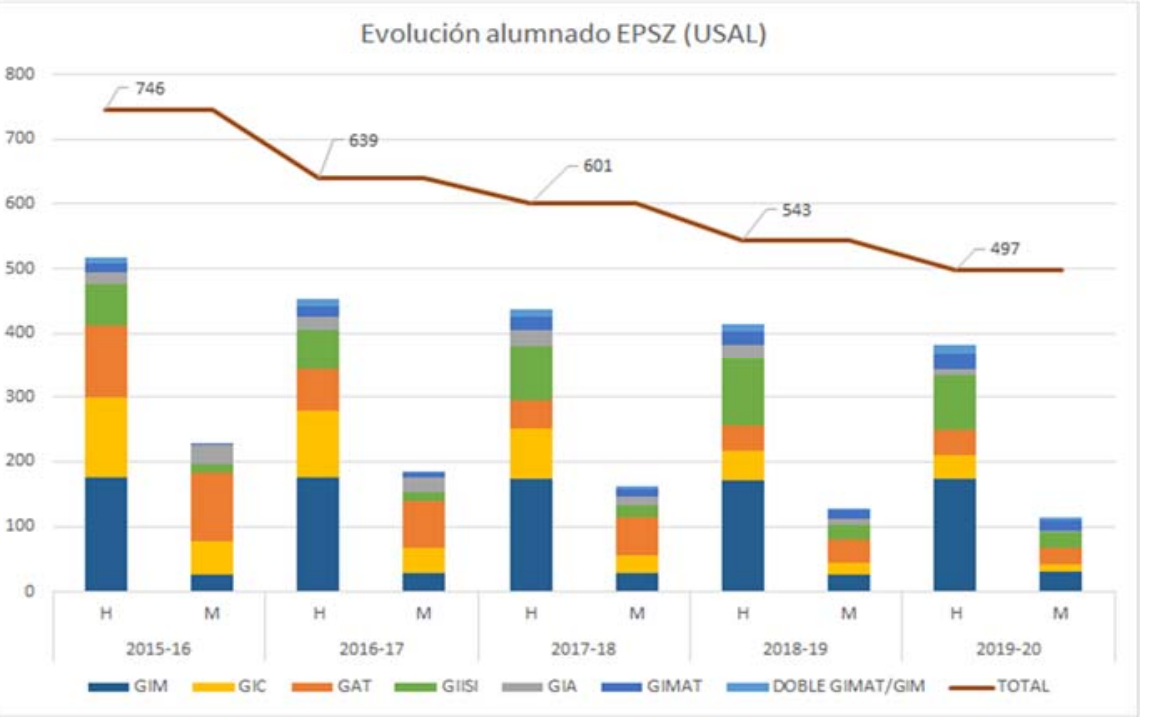

Fuente: Elaboración propia

Fig. 3 Evolución del alumnado por género y comparación del número de matrículas en la EPSZ entre Grados 
A esto se añaden los datos sobre matriculaciones en primer curso en diversos Grados del Campus Viriato y su evolución en los últimos 10 años, así como el número de plazas ofertadas. Para ello, extraemos los datos de tres Grados habilitantes representativos de la EPSZ (GIC, GAT, GIM), y los comparamos con los otros dos Grados que se imparten en las otras Escuelas del Campus: el Grado en Maestro en Educación Primaria (GMEP) y el Grado en Enfermería (GE) (Fig. 4).

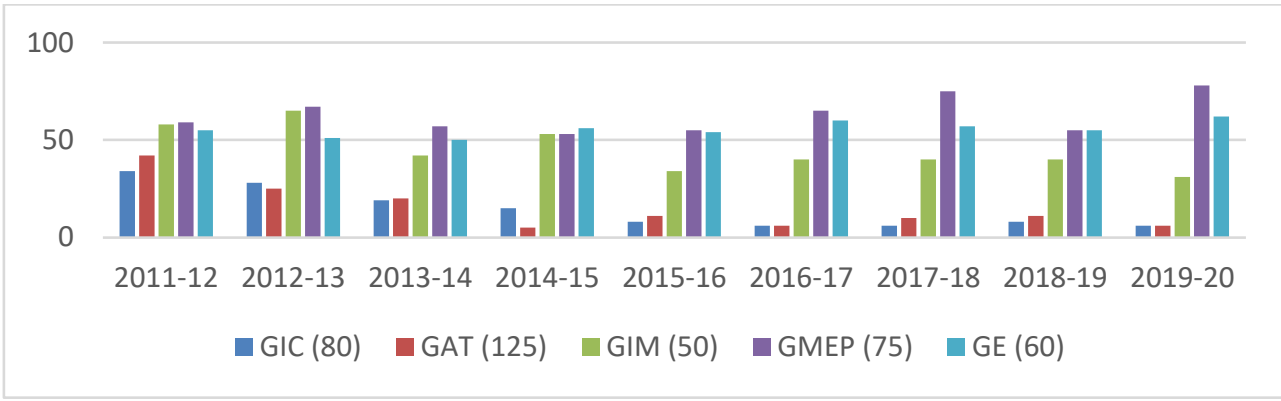

Fuente: Elaboración propia

Fig. 4 Comparación del número de matrículas del GAT, GIC, GIM, GMEP y GE. Entre paréntesis, el número de plazas ofertadas

Por otra parte, hay que destacar que, en el GAT, el porcentaje de mujeres es muy alto, máxime si lo comparamos con el GIM que se imparte en el Campus de Zamora (Fig. 5). Además, en los últimos cursos ha aumentado la presencia de estudiantes extranjeros que vienen de Marruecos y de China.

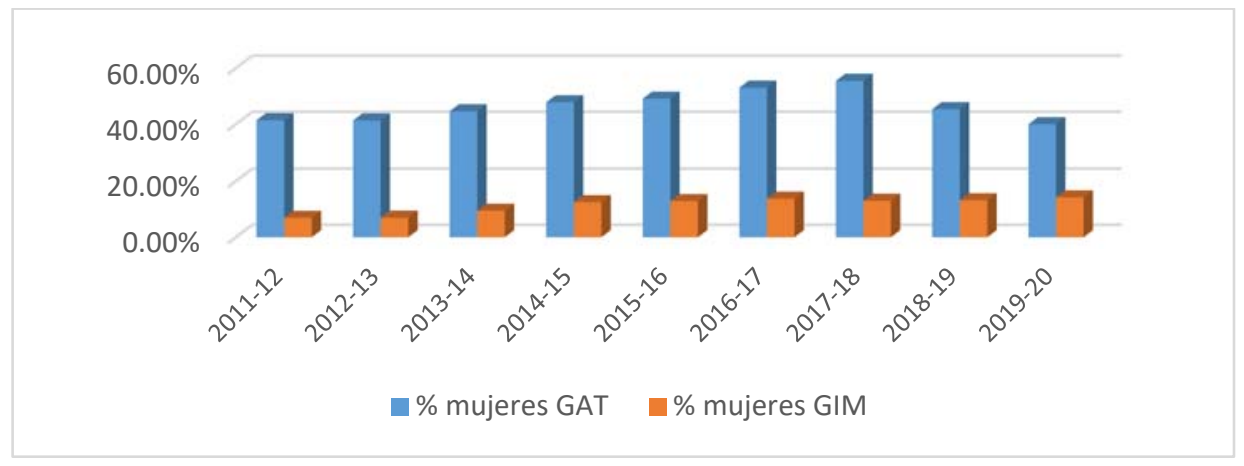

Fuente: Elaboración propia

Fig. 5 Comparación del porcentaje de mujeres matriculadas en el GAT y en el GIM

Con esta información de partida, se va a realizar una exposición de los resultados obtenidos en los ítems, que nos arrojan información sobre el estado de la cuestión y su evolución desde diez años atrás. Para ello, consideramos importante conocer el grado de satisfacción de los estudiantes con la Actividad Docente del profesorado y con el Programa Formativo, así como la inserción laboral de los egresados. 
Además, y considerando que el GAT es un Grado habilitante, es fundamental hacer un barrido por la categoría del personal docente, dado que hay muchas materias que necesitan un perfil profesional muy vinculado a ellas (COLIN 2018)

\section{Objetivos}

El objetivo de este estudio es hacer una radiografía general del Grado en Arquitectura Técnica de la EPSZ, para conocer, mediante el análisis de diversos datos y encuestas publicados, los aspectos que pudieran influir en la baja tasa de matrícula, comparándolos con ítems similares de otros Grados ubicados en el Campus de Zamora. Así mismo, aprovechando este foro, se pretende impulsar una mesa de conversación donde se exponga la situación de otros Centros de dimensiones similares.

\section{Desarrollo. Estado de la cuestión}

Consideramos que la información más importante es la que nos aportan los estudiantes, por ese motivo, es fundamental conocer su tasa de rendimiento, así como los resultados de las encuestas de satisfacción que han realizado sobre la Actividad Docente del Profesorado y sobre el Programa Formativo, sin olvidarnos de la opinión que tienen los egresados y su Inserción Laboral. Otros dos aspectos que pueden arrojar información y que también exponemos son las relaciones institucionales con las empresas y con otras universidades.

\subsection{Grado de satisfacción de los estudiantes con la Actividad Docente del Profesorado}

Cada dos años, los estudiantes responden anónimamente a una encuesta sobre el grado de satisfacción con la actividad docente del profesorado, atendiendo a las siguientes preguntas (tabla 1), donde se muestran los datos estadísticos descriptivos respecto al conjunto de ítems en porcentajes y cinco rangos de respuesta: TDA: totalmente de acuerdo, DA: de acuerdo, IN: indiferente, ED: en desacuerdo, TED: totalmente en desacuerdo.

Tabla 1. Preguntas a los estudiantes y respuestas en \% (curso 2018-2019)

\begin{tabular}{|c|c|c|c|c|c|}
\hline PREGUNTAS & TED & ED & IN & $\mathrm{DA}$ & TDA \\
\hline 1. El / la profesor/a explica con claridad & 1.11 & 2.77 & 11.51 & 42.66 & 37.95 \\
\hline 2. Resuelve las dudas plateadas y orienta a los estudiantes & 1.11 & 4.72 & 11.94 & 38.61 & 43.61 \\
\hline 3. Organiza y estructura bien las actividades que realizamos & 0.56 & 5.32 & 19.05 & 35.29 & 39.78 \\
\hline 4. Las actividades son provechosas para lograr los objetivos & 0.84 & 3.62 & 13.93 & 39.28 & 42.34 \\
\hline $\begin{array}{l}\text { 5.Favorece la participación del estudiante en el desarrollo de la } \\
\text { actividad }\end{array}$ & 1.96 & 6.98 & 18.16 & 35.47 & 37.43 \\
\hline 6.Está accesible para ser consultado por los estudiantes & 1.69 & 2.82 & 13.80 & 36.62 & 45.07 \\
\hline $\begin{array}{l}\text { 7. Ha facilitado mi aprendizaje, conocimientos habilidades y } \\
\text { destrezas }\end{array}$ & 1.39 & 5.29 & 17.55 & 38.44 & 37.33 \\
\hline 8. Los recursos didácticos utilizados son adecuados & 1.96 & 6.42 & 15.36 & 40.78 & 35.47 \\
\hline 9. La bibliografía y los materiales didácticos facilitados son útiles & 2.25 & 7.04 & 20.28 & 34.37 & 36.06 \\
\hline $\begin{array}{l}\text { 10.Los métodos de evaluación se corresponden con el desarrollo } \\
\text { docente }\end{array}$ & 1.53 & 2.14 & 11.93 & 41.59 & 42.81 \\
\hline
\end{tabular}




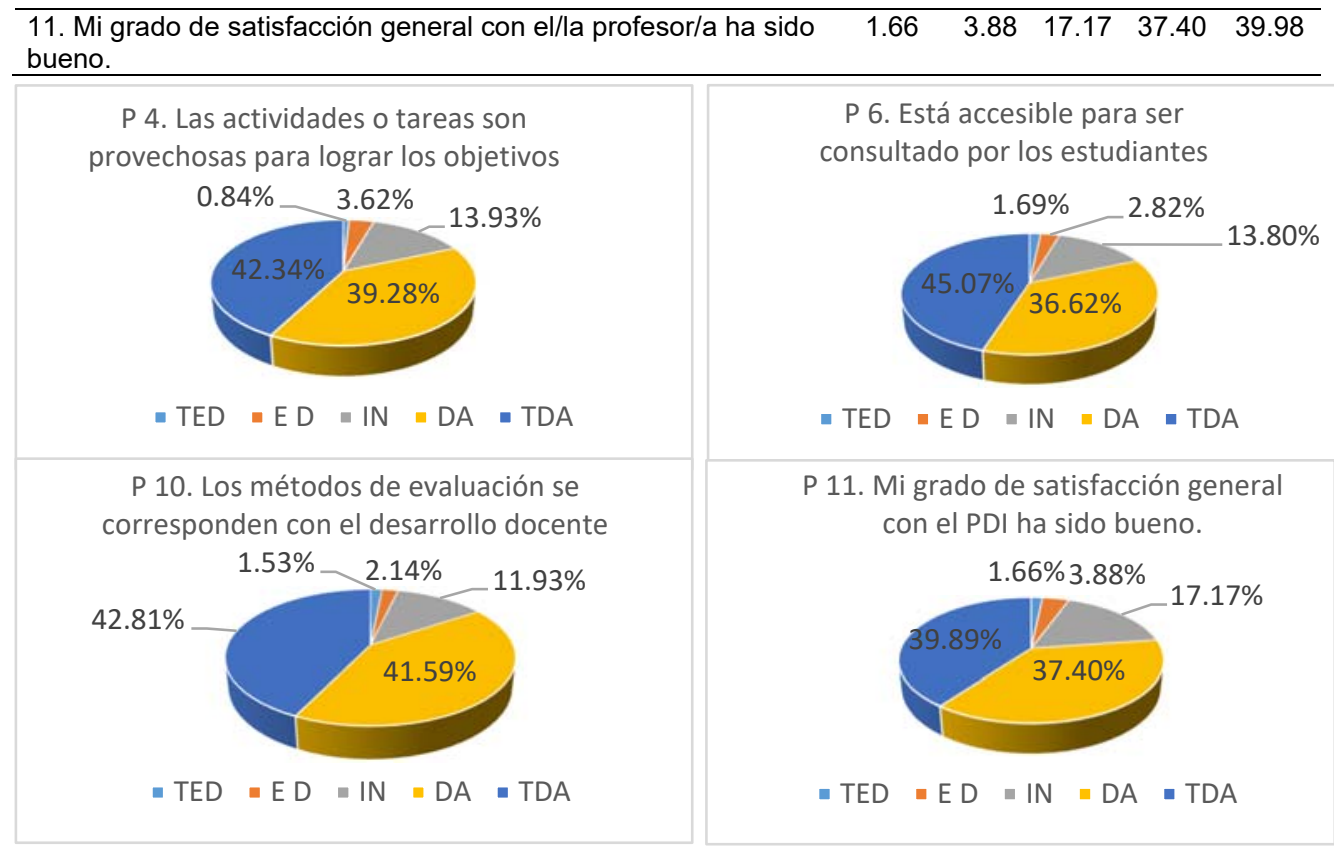

Fuente: Elaboración propia

Fig. 6 Respuestas a las preguntas 4, 6, 10 y 11

\subsection{Grado de satisfacción de los estudiantes con el Programa Formativo}

La opinión de los estudiantes respecto al Programa Formativo se extrae de una encuesta que se divide en cinco bloques: BLOQUE 1. Plan de Estudios y su Estructura; BLOQUE 2. Organización de la enseñanza; BLOQUE 3. Proceso de enseñanza - aprendizaje; BLOQUE 4. Instalaciones e infraestructuras y BLOQUE 5. Acceso y atención al alumno. (DOC USAL).

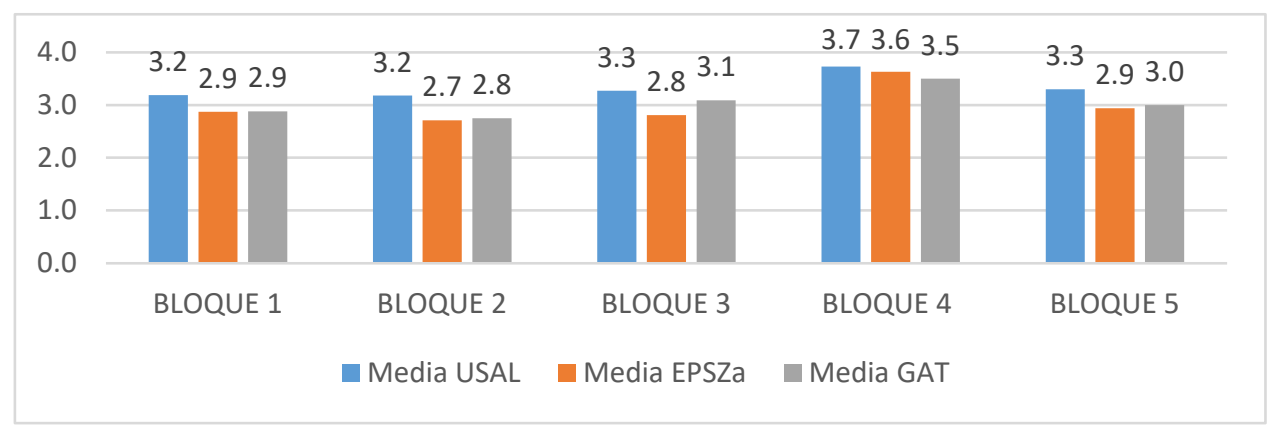

Fuente: Elaboración propia

Fig. 7 Respuestas de la encuesta de satisfacción de los estudiantes con el Programa Formativo, sobre 5 puntos. Curso 2019-2020 


\subsection{Tasa de rendimiento}

La Tasa de rendimiento, como relación porcentual entre el número de créditos superados y el número de créditos matriculados por titulación y curso académico, ofrece una lectura fundamental sobre el funcionamiento del Grado, informando sobre la facilidad o dificultad que tienen los estudiantes en aprobar las asignaturas de las que se matriculan. Con el fin de establecer el rango y comprobar si es un motivo del descenso de estudiantes, la comparamos con la tasa de rendimiento del GIM, que es el Grado habilitante de la EPSZ que mejor se mantiene (Fig. 8).

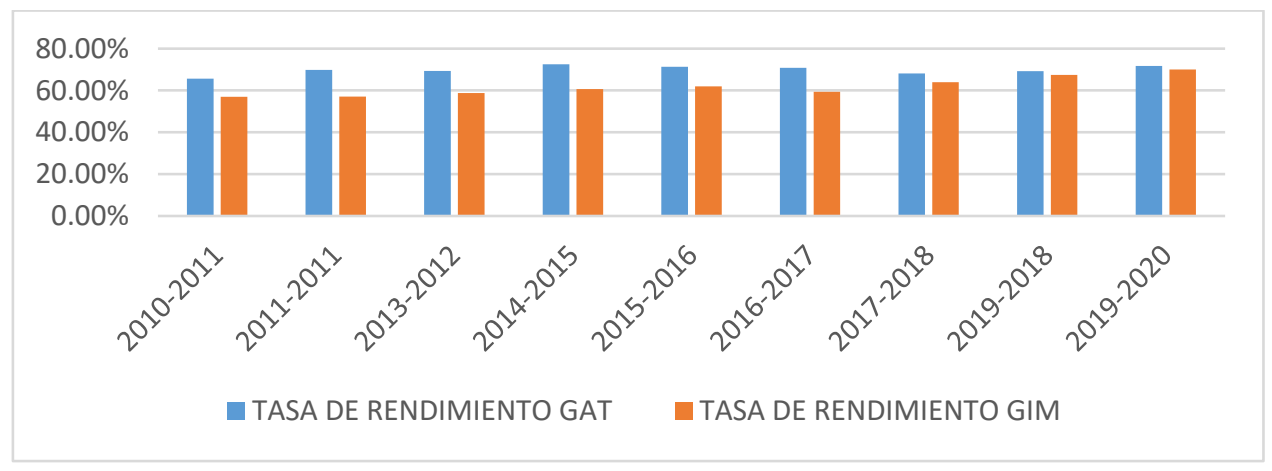

Fig. 8 Tasa de rendimiento del GAT y del GIM

Fuente: Elaboración propia

\subsection{Valoración de los egresados}

Sabiendo que la tendencia de los jóvenes a la hora de elegir el Grado depende en gran medida de las posibilidades que tenga para encontrar trabajo, las respuestas que nos interesan de los egresados son aquellas vinculadas con su satisfacción con el Grado que estudiaron (Fig. 8) y con su situación laboral (Fig. 9). (DOC EGRESADOS)

La encuesta corresponde a la promoción 2017-18 y se envió en el año 2021 a una población de 34 , participando el $26,47 \%$ de las personas a las que se les solicitó, porcentaje poco representativo pero que se acerca mucho al global de la Universidad, que está en un 27,49\%. 
M. A. Rodríguez-Esteban, M. A. Frechilla-Alonso, A. B. González-Rogado, A. B. Ramos-Gavilán
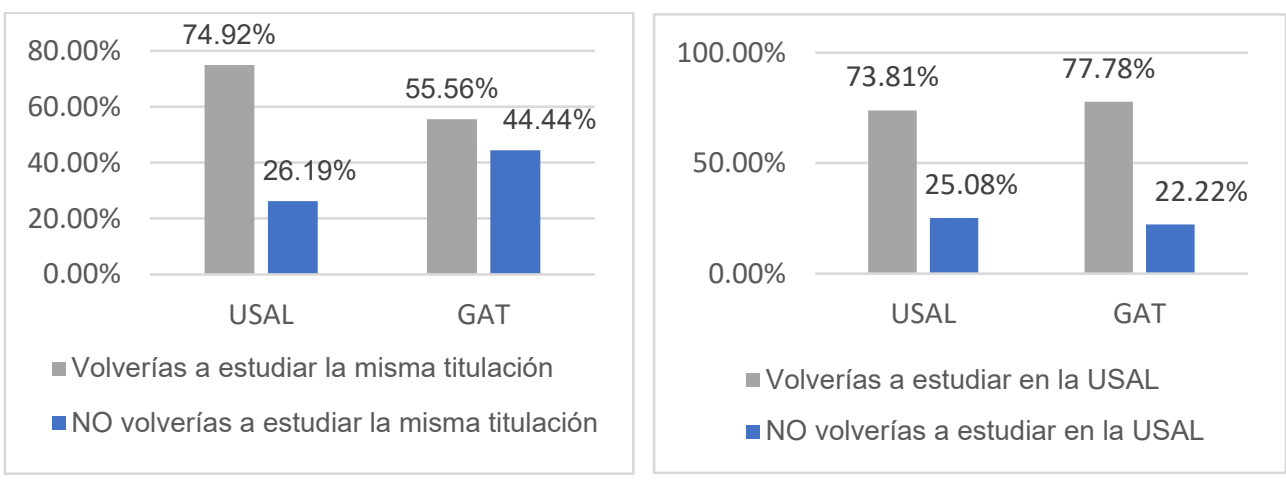

Fig. 9 Situación laboral de los egresados

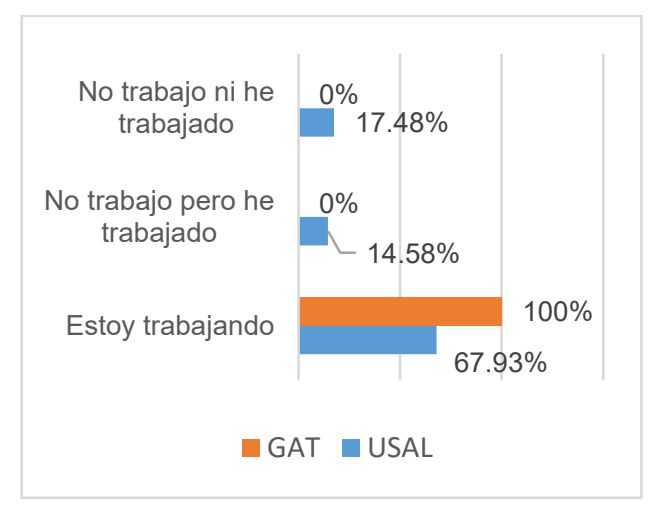

Fig. 10 Respuestas sobre la situación laboral de los egresados

\subsection{Perfil del Personal Docente}

Considerando que el Grado en Arquitectura a Técnica es un Grado habilitante, y que tiene un número importante de asignaturas que se pueden considerar profesionalizantes, llamadas así a aquellas que tienen aplicación directa en el campo profesional, cabe valorar la existencia de profesores asociados que pudieran acercar a las aulas el conocimiento que han adquirido y siguen adquiriendo por su experiencia laboral. 


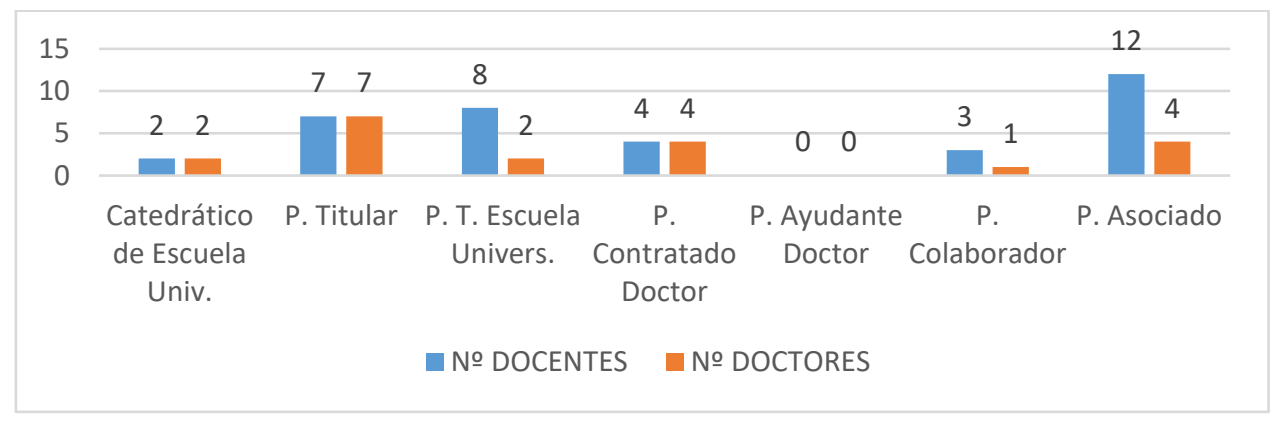

Fuente: Elaboración propia

Fig. 11 Número de docentes por su categoría profesional y $n^{\circ}$ de doctores. Curso 2019-20

\subsection{Relación con el sector empresarial}

Este ítem está relacionado directamente con la asignatura optativa Prácticas de Empresa (PE) (6 ECTS), en la cual, los estudiantes deben realizar prácticas curriculares en una empresa, durante 150 horas. Así mismo, aquellos que hayan superado esta asignatura y deseen continuar con prácticas, pueden realizar prácticas extracurriculares durante un máximo de 6 meses y 900 horas.

Para poder realizarse, la guía académica del GAT establece que: La Escuela Politécnica Superior de Zamora facilitará a los alumnos una serie de empresas del sector de la titulación con las que previamente el Centro habrá establecido un convenio de colaboración. Entre estas empresas los alumnos harán su elección. Todos los convenios llevan incorporados un tutor por parte de la Empresa y un tutor por parte de la Universidad. Para ello, los estudiantes que están matriculados de la asignatura PE tienen acceso a un listado en el que figuran 40 empresas, de las cuales 7 están vigentes en la fecha actual, 21 no están no vigentes y 11 en tramitación.

Cabe decir que la asignatura optativa "Prácticas de Empresa" es elegida por prácticamente el $100 \%$ de los estudiantes del GAT.

\subsection{Movilidad de estudiantes}

Este aspecto es relevante en la medida que se observan las relaciones que tiene la EPSZ con otros centros para el intercambio de estudiantes en todos los Grados que se imparten en Zamora, con el programa ERASMUS y el programa SICUE (Fig. 10). En concreto, para el GAT, hay convenios para dos estudiantes con la Universidad del Salento, en Lecce (Italia) y otros dos con la Universidad de Lisboa (Portugal). 


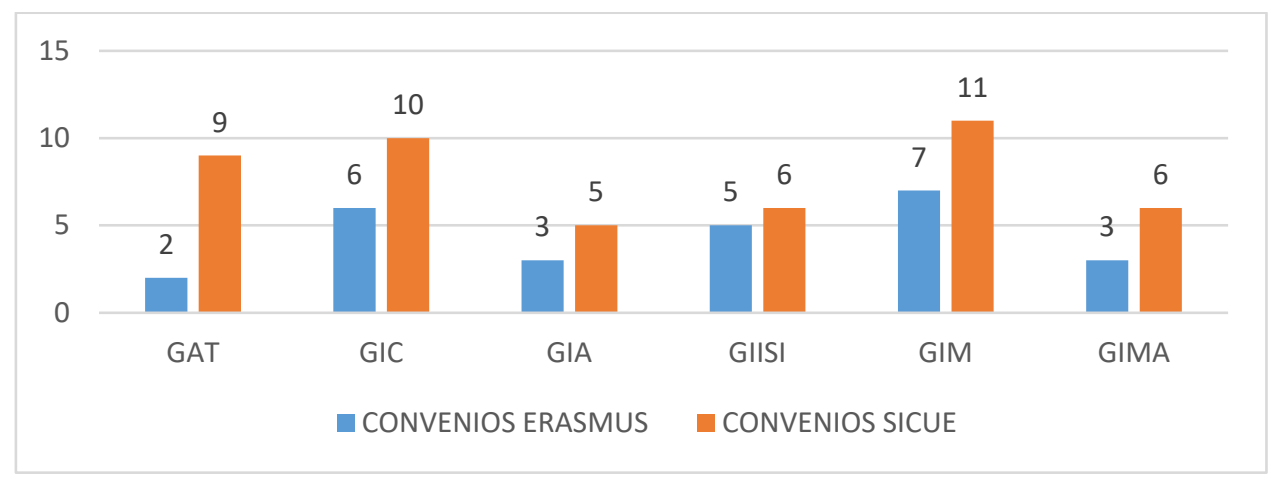

Fuente: Elaboración propia

Fig. 12 Número de Convenios ERASMUS + en los Grados de la EPSZ. Curso 2020-2021

\section{Resultados}

A tenor de la tendencia de números de matrículas en la EPSZ, los resultados arrojan datos poco optimistas en general y preocupantes, en particular para el GAT. Sin embargo, y comparado con el GIM, es un Grado atractivo para las mujeres, con una tasa de matrícula femenina entre el $40 \%$ y el $50 \%$.

Sin embargo, el descenso de matrículas contrasta con tres datos fundamentales: el grado de satisfacción del estudiante con la actividad docente del profesorado, la cual, en todos los ítems la puntuación supera el 3,5 sobre 5 puntos. De hecho, entre el $36 \%$ y el $42 \%$ están de acuerdo con la actividad y en ese mismo rango se mueven los que opinan que están totalmente de acuerdo. Esto frente a valores inferiores al $2 \%$ que opinan estar totalmente en desacuerdo.

Respecto al Programa Formativo, en todos los bloques preguntados, la valoración se encuentra entorno al 3,0, alcanzando 3,5 sobre 5,0 puntos, cuando valoran las instalaciones y son ligeramente inferiores a la media de puntuación de la USAL y de la EPSZ,

La Tasa de rendimiento del GAT lleva una tendencia más o menos constante durante los diez últimos años, con valores cercanos al 70\%, llegando a su mejor dato en el curso 2014-2015, que superó el $72 \%$. No obstante, estos porcentajes son mejores que los del GIM, que no han alcanzado el $70 \%$ en ningún curso de los analizados.

Otro aspecto que podría preocupar es la tasa de inserción laboral, pero que, a tenor de la encuesta realizada a los egresados, en el caso del GAT, está en el $100 \%$. Sin embargo, esto contrasta con su intención de volver a estudiar lo mismo, ya que un $22 \%$ no lo confiesa que no lo haría.

Respecto a las circunstancias propias del GAT, como Grado habilitante, es importante conocer la ratio de Profesorado Asociado con respecto al total. En este sentido, el 33\% de la plantilla tiene esta categoría, aunque es importante destacar que el $33 \%$ de ella es Doctor, mérito necesario para optar a otra categoría más académica que profesional. Aparte, en el 
GAT de la EPSZ, el profesorado con dedicación completa que imparte las materias relacionadas con la vida profesional del Arquitecto Técnico tiene relación laboral con la construcción, al amparo del art. 83 de la Ley Orgánica de Universidades (LOU).

En cuanto a las empresas, el número que tienen convenio con la USAL para acoger estudiantes en prácticas es muy limitado. Además, no se tiene conocimiento de que haya otro tipo de relación Universidad-Empresa en este campo como sucede en otras universidades, que han creado sinergias bidireccionales (Otero 2018).

Por último, las posibilidades sobre la movilidad del alumnado a otras universidades son muy reducidas, ya que solo existe convenio con dos, y ninguna es de lengua inglesa. Cabe decir que el número de estudiantes que solicitan movilidad SICUE y Erasmus representa un porcentaje muy elevado, respecto al total de matriculados.

Respecto a los aspectos donde hay debilidades, la Escuela contempla un Plan de Mejoras, en el autoinforme de renovación de la acreditación, de 2016, con propuestas concretas para solventarlas.

\section{Conclusiones}

De todo el estudio expuesto, se concluye que la actividad docente del profesorado y el Programa Formativo no son aspectos que, a priori, influyan en la baja tasa de matrícula. Tampoco lo es el perfil del profesorado, altamente relacionado con la construcción, ni tampoco, a día de hoy, la inserción laboral.

Así mismo, un aspecto tan importante como es la tasa de rendimiento, que se sitúa en valores superiores a los de otros Grados de la Escuela que tienen mayor matrícula, tampoco debería ser un hándicap para atraer estudiantes a la EPSZ.

En el lado opuesto están las relaciones institucionales con las empresas y con otras universidades, que se antojan escasas y poco atractivas para el alumnado.

De todo el análisis realizado no es posible extraer una conclusión certera sobre la problemática que se plantea, siendo posible que el foco de la cuestión gire en torno a otros aspectos ajenos al Grado que habría que analizar con detenimiento en otro estudio, además de observar e investigar las actuaciones de otros centros de tamaño similar al de Zamora, donde se imparta el Grado de Arquitectura Técnica o de Ingeniería de la Construcción, que tengan un mayor éxito en tasa de matrícula.

\section{Referencias}

ÁVILA DE LA TORRE, A (2010). Arquitectura y Urbanismo en Zamora (1850-1950). Zamora: Instituto de Estudios Zamoranos Florián de Ocampo.

CAMPOS ECHEVARRIA, J. L. (2008): La burbuja inmobiliaria española. Madrid: Marcial Pons.

COLIN RIVERA, M, I. (2018): “Importancia del perfil docente”. ACTA EDUCATIVA Universidad Abierta Revista. $\mathrm{N}^{\circ}$ 20. https://revista.universidadabierta.edu.mx/publicacion-20/ [Consulta: 16 de junio de 2021]. 
ESCUELA POLITÉCNICA SUPERIOR DE ZAMORA (2021). Grado en Arquitectura Técnica. $<$ https://www.usal.es/grado-en-arquitectura-tecnica > [Consulta: 18 de junio de 2021] [sin autoría reconocida].

ESCUELA POLITÉCNICA SUPERIOR DE ZAMORA (2021). Grado en Arquitectura Técnica. $<$ https://poliz.usal.es/politecnica/v1 r00/?m=Grados\&it=7\&doc=grados/Renovacion_acreditacion_GA T.pdf> [Consulta: 12 de junio de 2021] [sin autoría reconocida].

ESCUELA POLITÉCNICA SUPERIOR DE ZAMORA (2021). Prácticas externas, Programas de Movilidad, Normativas <https:// poliz.usal.es/politecnica/v1r00/> [Consulta: 8 de junio de 2021] [sin autoría reconocida].

ESCUELA POLITÉCNICA SUPERIOR DE ZAMORA (2021). Grado en Ingeniería Mecánica. $<$ https://www.usal.es/grado-en-ingenieria-mecanica-eps-de-zamora> [Consulta: 8 de junio de 2021] [sin autoría reconocida]

ESCUELA POLITÉCNICA SUPERIOR DE ZAMORA (2021). Grado en Ingeniería Agroalimentaria. <https://www.usal.es/grado-en-ingenieria-agroalimentaria-zamora> [Consulta: 8 de junio de 2021] [sin autoría reconocida]

ESCUELA POLITÉCNICA SUPERIOR DE ZAMORA (2021). Grado en Ingeniería Civil <https://www.usal.es/grado-en-ingenieria-civil-eps-de-zamora> [Consulta: 8 de junio de 2021] [sin autoría reconocida]

ESCUELA POLITÉCNICA SUPERIOR DE ZAMORA (2021). Grado en Ingeniería Informática en Sistemas de Información. <https://www.usal.es/grado-en-ingenieria-informatica-en-sistemas-deinformacion> [Consulta: 8 de junio de 2021] [sin autoría reconocida]

ESCUELA POLITÉCNICA SUPERIOR DE ZAMORA (2021). Grado en Ingeniería de Materiales <https://www.usal.es/grado-en-ingenieria-materiales> [Consulta: 8 de junio de 2021] [sin autoría reconocida]

ESCUELA UNIVERSITARIA DE MAGISTERIO DE ZAMORA (2021). <https://www.usal.es/escuelauniversitaria-de-magisterio-de-zamora> [Consulta: 9 de junio de 2021] [sin autoría reconocida]

ESCUELA UNIVERSITARIA DE ENFERMERÍA DE ZAMORA (2021) <https://www.usal.es/ grado-enenfermeria-eu-de-enfermeria-de-zamora-centro-adscrito> [Consulta: 9 de junio de 2021] [sin autoría reconocida].

OTERO-MOLINA, M. (2018): "Sinergia bidireccional Universidad-Empresa. Caso de estudio: Aula Universitaria de Arquitectura" en XXVI Congreso Universitario de Innovación Educativa de las Enseñanzas Técnicas. Oviedo. Disponible https://digibuo.uniovi.es/dspace/handle/10651/47930. [Consulta: 7 de junio de 2021].

UNIVERSIDAD DE SALAMANCA (2021) Relaciones internacionales <https://relint.usal.es/es/proyectos/erasmus> [Consulta: 9 de junio de 2021] [sin autoría reconocida]

UNIVERSIDAD MAYOR DE SAN ANDRÉS (2021) GRADO EN INGENIERÍA MECÁNICA <https:// mecanica.umsa.edu.bo/?page_id=131\#page-content> [Consulta: 15 de junio de 2021] [sin autoría reconocida]. 


\title{
EDIFİCATE
}

I Congreso de Escuelas de Edificación y Arquitectura Técnica de España València, 4 y 5 de noviembre de 2021

Escuela Técnica Superior de Ingeniería de Edificación

Universitat Politècnica de València

Doi: https://doi.org/10.4995/EDIFICATE2021.2021.13599

\section{Propuesta de modificación de las Competencias de la asignatura Construcción VI de la Escuela Técnica Superior de Ingeniería de Edificación de la Universitat Politècnica de València}

\section{Proposal to modify the Competences of the Construction VI course of the Higher Technical School of Building Engineering of the Polytechnic University of Valencia}

\begin{abstract}
Jaime Llinares Millán ${ }^{a}$, José Miguel Molines Cano ${ }^{b}$ y José María Bravo Plana-Salac
aUniversitat Politècnica de València, Departamento de Construcciones Arquitectónicas, jllinares@csa.upv.es, bUniversitat Politècnica de València, Departamento de Mecánica de los Medios Continuos y Teoríad e Estructuras, jomoca1@upv.es y 'Universitat Politècnica de València, Departamento de Física Aplicada, jpbrapla@fis.upv.es.
\end{abstract}

\begin{abstract}
In the following work a modification of the competences of the Construction VI subject is presented. The modification focuses on two fundamental aspects; redefine the specific competences of the subject; and divide these competencies into learning outcomes that make sense with the evolution of student learning.
\end{abstract}

Keywords: Construction VI; Building pathology; Transversal competences; Learning outcomes

\section{Resumen}

En el siguiente trabajo se presenta una modificación de las competencias de la asignatura Construcción VI. La modificación se centra en dos aspectos fundamentales; redefinir las competencias específicas de la asignatura; $y$ dividir estas competencias en resultados de aprendizaje que tengan sentido con la evolución del aprendizaje del alumno.

Palabras clave: Construcción VI; Patología de la edificación; Competencias transversales; Resultados del aprendizaje 


\section{Descripción general de la asignatura}

\subsection{Ubicación de la asignatura dentro de la titulación}

Entre las asignaturas que el alumno debe cursar para obtener el título de Grado de Arquitectura Técnica (G.A.T.) se encuentra la asignatura obligatoria "Construcción VI", con 4,5 créditos ECTs, adscrita al Departamento de Construcciones Arquitectónicas (ANECA, 2005).

Según el Plan de Estudios del G.A.T., la asignatura se ubica en el primer semestre del cuarto curso, lo que implica que los conocimientos de construcción que tienen los estudiantes cuando empiezan a cursarla son los adquiridos en los tres cursos anteriores en las asignaturas de Materiales de Construcción I, II y III y las de Construcción I, II-III y IV-V.

En relación con este aspecto, la asignatura Construcción $\mathrm{VI}$, pese a continuar la línea docente de las asignaturas de Construcción anteriores (I, II-III y IV-V), es la única cuya temática puede entenderse como "complementaria" o como "módulo adicional" ya que no cierra ningún proceso anterior, sino que prácticamente supone una competencia por si misma (a falta de ciertos resultados de aprendizaje correspondientes a la asignatura "Construcciones históricas") (ANECA, 2005).

No obstante, pese a ser un módulo diferenciado hay que señalar que para la comprensión de los contenidos de "Construcción VI", son necesarios, además de los conocimientos de construcción impartidos en las asignaturas de cursos precedentes, unos conocimientos básicos de Química, Física de los Materiales de Construcción, Estructuras y Seguridad y Salud. Estas materias son objeto de estudio en asignaturas anteriores del G.I.E. por lo que, en tanto no se modifique su ubicación, no habrá que incluirlos dentro del programa de "Construcción VI". También hay que señalar que la formación constructiva obligatoria del Grado en Arquitectura Técnica, finaliza con esta asignatura, pudiéndose completar con el área de intensificación "Intervención en construcciones históricas".

\subsection{Contenido y explicación general de la asignatura}

Tal como se puede observar en la figura 1, la disciplina de Construcción es uno de los pilares fundamentales de la titulación de Grado en Arquitectura Técnica, siendo la única de todas ellas que se encuentra presente en todos los semestres.

En la asignatura "Construcción I" se estudia el vocabulario y las soluciones básicas de la construcción. En la asignatura "Construcción II" el alumno aprende cómo funcionan estas soluciones al detalle, razonando para qué sirve cada uno de los componentes que las forman. La evolución lógica viene con la asignatura "Construcción III", en la cual, tras haber aprendido cómo funcionan y que misión tiene cada uno de los componentes que conformar una solución constructiva, el alumno tiene que aprender a formular soluciones constructivas nuevas, diseñadas o razonadas para una situación o problemática específica. 


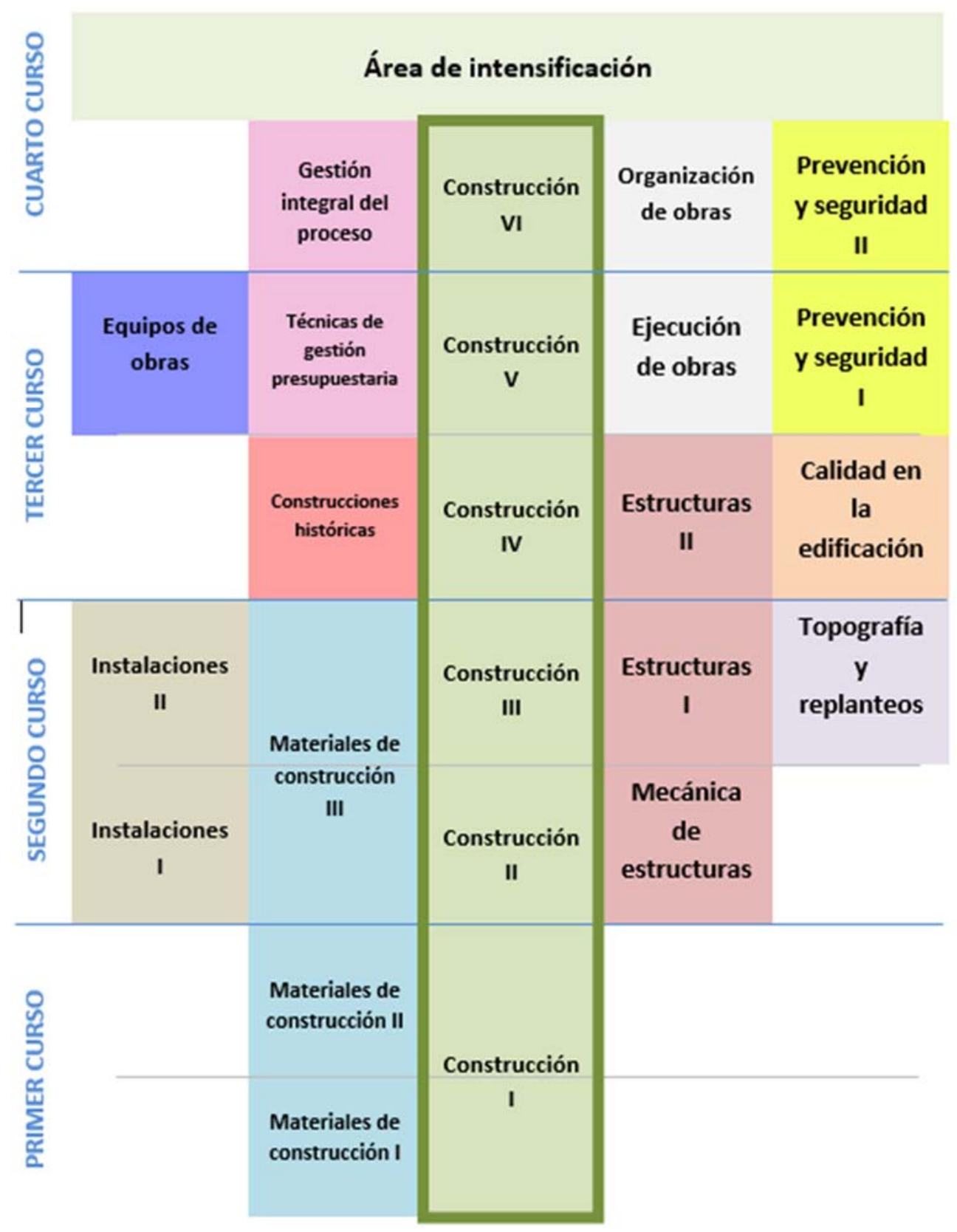

Fig. 1 Esquema de la distribución temporal de las asignaturas de Construcción, dentro del Área de intensificación en la titulación de Grado de Arquitectura Técnica en la ETSIE de la UPV.

Fuente: El autor 
Llegados a este punto, cuando el alumno ya comprende las diferentes soluciones y procesos constructivos ( $\mathrm{y}$ de forma detallada cómo funciona cada componente), en la asignatura "Construcción IV" se integran estos procesos dentro del funcionamiento global de la obra. Continuando con la visión de la obra como un proceso único compuesto por pequeños procesos relacionados entre sí, la asignatura "Construcción V" completa esta primera fase de la disciplina de la construcción introduciendo los medios secundarios y auxiliares de la obra (remates, grúas, seguridad y salud, etc...).

La asignatura "Construcción VI" tiene como objetivo principal abordar la temática referente al mantenimiento y restauración de los elementos construidos. En primer lugar se estudian las diferentes filosofías y sensibilidades en el campo de la intervención de elementos construidos, así como las técnicas de diagnosis más empleadas actualmente. En una segunda fase se estudian las diferentes lesiones que pueden encontrarse en los distintos elementos que componen un edificio (siempre que sea posible se intentarán agrupar por temática similar en cuanto a zonificación o elemento dañado). Finalmente, la asignatura se cierra con la redacción del libro de mantenimiento del edificio (ANECA, 2008).

Tal como puede observarse, pese a que es necesario tener los conocimientos y competencias adquiridas en el resto de las asignaturas de la disciplina (Construcción I, II, III, IV y V), la asignatura no sigue la linealidad que siguen el resto, siendo en sí misma un módulo independiente. Esta idea de independencia se acusa al comparar la asignatura y buscar sus homónimas en los planes de estudio de las diferentes escuelas técnicas de Ingeniería de Edificación de España.

En algunas escuelas, como en la Politécnica de Barcelona, se mantiene la misma nomenclatura, Construcción VI (primer cuatrimestre de cuarto curso), con un temario prácticamente idéntico. En otros casos se refuerza el concepto de mantenimiento del edificio, como es el caso de la Universidad Politécnica de Madrid, en la que dividen los contenidos en dos asignaturas distintas. Por una lado, la asignatura "Patología y Rehabilitación" (primer cuatrimestre de cuarto curso) y por otro, la asignatura "Mantenimiento" (segundo cuatrimestre de cuarto curso). Hay que señalar que la suma de los créditos de ambas asignaturas es muy similar a los que tiene "Construcción VI".

En otras escuelas se ha decidido eliminar el módulo de Mantenimiento para poder ahondar más en el módulo de Diagnosis y Patología. Este es el caso de la Universidad de Sevilla y su asignatura "Restauración y Patología de la Edificación (primer cuatrimestre de cuarto curso). Finalmente, en algunas escuelas se ha optado por darle un enfoque más humanístico, unificando la disciplina de la intervención con la historia de la arquitectura local. Un ejemplo de este último grupo es la Universidad de la Coruña con la asignatura "Patrimonio Arquitectónico Gallego", centrada, sobre todo, en las intervenciones realizadas en los monumentos más significativos de Galicia. 
Propuesta de modificación docente de la asignatura Construcción VI de la Escuela Técnica Superior de Ingeniería de Edificación de la Universitat Politècnica de València - Proposal for teaching modification of the Construction VI subject of the Higher Technical School of Building Engineering of the Polytechnic University of Valencia

\section{Competencias}

\subsection{Genéricas}

En el plan de estudios actual, se establecen las siguientes competencias genéricas para la asignatura:

- Poseer y comprender conocimientos en un área de estudio que parte de la base de la educación secundaria general, y se suelen impartir a un nivel, que si bien se apoya en libros de texto avanzados, incluye también algunos aspectos que implican conocimientos procedentes de la vanguardia de su campo de estudio.

- Saber aplicar sus conocimientos a su trabajo o vocación de una forma profesional y poseer las competencias que suelen demostrarse por medio de la elaboración y defensa de argumentos y resolución de problemas dentro del área de estudio.

- Capacidad de reunir e interpretar datos relevantes (normalmente dentro de su área de estudio) para emitir juicios que incluyan una reflexión sobre temas relevantes de índole social, científica o ética.

- Capacidad de transmitir información oral y escrita en la lengua nativa: ideas, problemas y soluciones a un público tanto especializado como no especializado.

- Poseer habilidades de aprendizaje necesarias para emprender estudios posteriores con un alto grado de autonomía.

- Conducta ética en ingeniería. Capacidad crítica y autocrítica. Conciencia de la necesidad de calidad y alto nivel profesional y de su aplicación al continuo perfeccionamiento.

Sin embargo, según las recomendaciones establecidas en el III Congreso Internacional sobre competencias docentes (Berna, 2012), es conveniente reformular las competencias de las asignaturas para que no superen las seis competencias genéricas, y una específica. Del mismo modo, se aconseja establecer títulos más globales para nombrar las competencias genéricas. Por ello, revisando las competencias actuales y los objetivos de la asignatura se decide reformularlas siendo el resultado el siguiente (Ausubel, 1990):

- Sostenibilidad y compromiso social. Tener en cuenta las dimensiones social, económica y ambiental al aplicar soluciones y llevar a cabo proyectos coherentes con el desarrollo humano y la sostenibilidad.

- Comunicación eficaz oral y escrita. Comunicarse de manera clara y eficiente en presentaciones orales y escritas adaptadas al tipo de público y a los objetivos de la comunicación utilizando las estrategias y los medios adecuados.

- Trabajo en equipo. Dirigir y dinamizar grupos de trabajo, resolviendo posibles conflictos, valorando el trabajo hecho con las otras personas y evaluando la efectividad del equipo así como la presentación de los resultados generados. 
- Aprendizaje autónomo. Aplicar los conocimientos alcanzados en la realización de una tarea en función de la pertinencia y la importancia, decidiendo la manera de llevarla a cabo y el tiempo que es necesario dedicarle y seleccionando las fuentes de información más adecuadas.

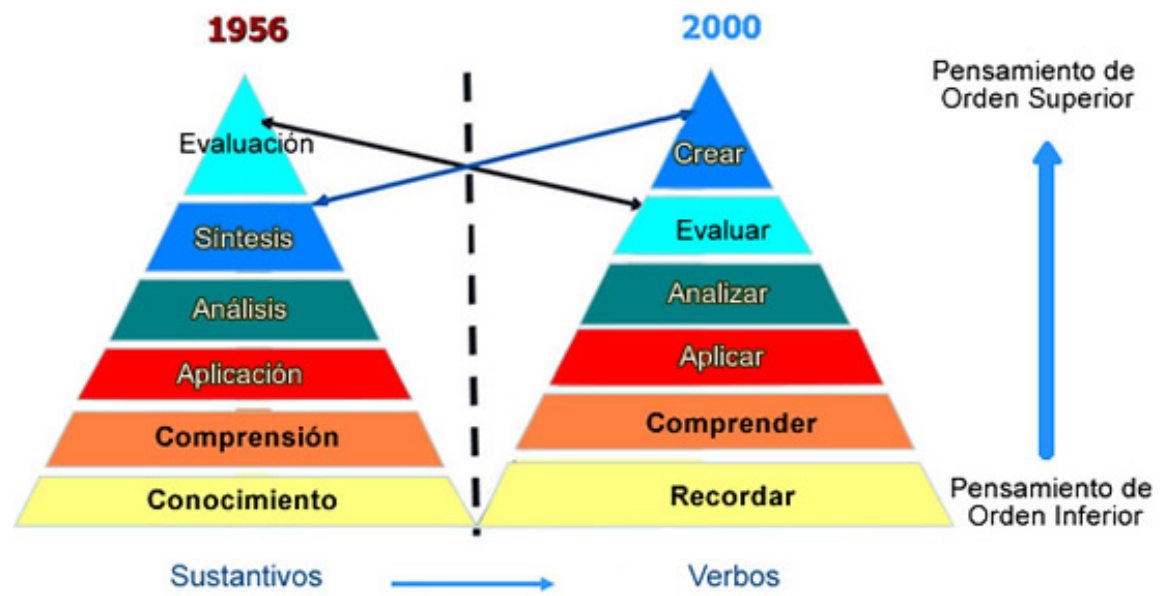

Fig. 2 Taxonomía de Bloom sobre los niveles de las habilidades del pensamiento. Se compara la taxonomía oficial de 1956 basada en sustantivos y su actualización del año 2000 basada en verbos. Fuente: Instituto de Ciencias de la Educación. UPV.

A la hora de reformularlas se tiene en cuenta el nivel de resultados de aprendizaje alcanzados en anteriores asignaturas, por lo que, aplicando la taxonomía de Bloom, todas las competencias se encuentran en el estadio 3 o 4 (Ausubel, 1990).

\subsection{Específicas}

En el bloque de las competencias específicas ocurre exactamente los mismo que con las competencias genéricas, que no se corresponden de forma coherente o precisa con las competencias propias de la asignatura.

Siguiendo el mismo esquema que en el apartado anterior, se listan las competencias específicas establecidas para la asignatura por el plan de estudios actual:

- Conocimiento de los elementos, sistemas y tipologías constructivas, tradicionales y prefabricados empleados en la edificación y sus variedades.

- Conocimiento de la evolución histórica de las técnicas, elementos y procedimientos constructivos y los sistemas estructurales que han dado origen a las formas estilísticas.

- Aptitud para identificar los elementos, sistemas y tipologías constructivas, definir su función, idoneidad relativa y compatibilidad en el proceso constructivo. Aptitud para plantear y resolver detalles constructivos. 
Propuesta de modificación docente de la asignatura Construcción VI de la Escuela Técnica Superior de Ingeniería de Edificación de la Universitat Politècnica de València - Proposal for teaching modification of the Construction VI subject of the Higher Technical School of Building Engineering of the Polytechnic University of Valencia

- Conocimiento de los procedimientos específicos de control de la ejecución material de obras de edificación.

- Capacidad para dictaminar sobre las causas y manifestaciones de las lesiones en los edificios, y proponer soluciones para evitar o subsanar su patología.

- Aptitud para evaluar e intervenir en la rehabilitación de edificios y en la conservación y restauración del patrimonio construido. Conocimiento del marco legislativo, normativa técnica y doctrina específica, de aplicación en el patrimonio construido.

- Capacidad para el análisis del ciclo de vida útil de los elementos y sistemas constructivos de los edificios.

- Capacidad para elaborar manuales y planes de mantenimiento de edificios y gestionar su implantación en el edificio.

- Conocimiento de la evaluación del impacto medioambiental de los procesos de edificación y demolición y de la sostenibilidad en la edificación.

- Conocimiento de los procedimientos y técnicas de evaluación de la eficiencia energética de los edificios. Aptitud para diseñar y materializar soluciones de acondicionamiento acústico, térmico y lumínico de los mismos.

- Capacidad para aplicar la normativa técnica al proceso de la edificación y generar documentos de especificación técnica que determinen los procedimientos y métodos constructivos de edificios.

- Conocimiento de los equipos, instalaciones provisionales y medios auxiliares empleados en las obras de edificación, sus características y normativa de aplicación. Capacidad para evaluar las necesidades y establecer criterios para la selección de los equipos, instalaciones provisionales y medios auxiliares.

Siguiendo las mismas pautas que en el apartado anterior, resulta necesario reformular las competencias, no sólo las referentes a la asignatura (pasaremos de 12 competencias específicas a 1, la cual la dividiremos a su vez en 5 resultados de aprendizaje). El resultado sería una única competencia específica principal, cuyos objetivos de aprendizaje prácticamente se vean abarcados en su totalidad por la asignatura (Fowler, 2002).

Para fijar la competencia específica principal, se buscan los dos elementos claves que definen la asignatura, el estudio del estado patológico, y el aprendizaje de métodos o técnicas para poder intervenir las lesiones diagnosticadas. En base a estos dos elementos, y aplicando el mismo proceso descriptivo basado en la taxonomía de Bloom se redacta una única competencia específica principal (que luego se dividirá en varios resultados de aprendizaje). (Elliot, 2000).

Competencia específica principal: Diagnosticar la patología de elementos edificados para su futura intervención. (Competencia adquirida en las asignaturas Construcción VI e Intervención en construcciones históricas).

El desglose en resultados de aprendizaje sería el siguiente: 
Tabla 1. Desglose de la competencia principal en sus respectivos resultados de aprendizaje, y su distribución dentro de las diferentes asignaturas que la componen. Fuente: El autor.

\begin{tabular}{l|c|c|}
\multicolumn{1}{|c|}{ Resultado de aprendizaje } & C. VI & I. en C.H. \\
\hline $\begin{array}{l}\text { Identificar las diferentes lesiones patentes en elementos construidos } \\
\text { Evaluar el daño/nivel de afección de cada lesión en elementos } \\
\text { construidos }\end{array}$ & $\checkmark$ & $\boldsymbol{X}$ \\
\hline $\begin{array}{l}\text { Realizar mapeados de lesiones aplicados sobre elementos } \\
\text { construidos }\end{array}$ & $\checkmark$ & $\boldsymbol{X}$ \\
\hline $\begin{array}{l}\text { Proponer posibles soluciones/intervenciones para las diferentes } \\
\text { lesiones }\end{array}$ & $\checkmark$ & $\boldsymbol{X}$ \\
\hline $\begin{array}{l}\text { Escoger y razonar entre las diferentes opciones de intervención } \\
\text { interpretando los datos obtenidos en estudios previos }\end{array}$ & $\boldsymbol{x}$ \\
\hline
\end{tabular}

\section{Indicadores de logro}

Para que los alumnos alcancen estas competencias, a continuación se exponen los objetivos específicos, o indicadores de logro, que han de superar los alumnos al cursar esta asignatura. Dichos indicadores servirán para evaluación el grado de conocimiento y habilidades adquiridos por los alumnos, así como la efectividad de la planificación docente (Elliot, 2000).

Tabla 2. Indicadores de logro definidos para la asignatura "Construcción Vl". Fuente: El autor.

\begin{tabular}{|l|l|l|}
\hline Código & \multicolumn{1}{|c|}{ Indicador de logro } & \multicolumn{1}{|c|}{ Recursos } \\
\hline IL 1 & $\begin{array}{l}\text { Introducir al alumno en las diferentes } \\
\text { filosofías de intervención existentes. }\end{array}$ & Clases teóricas \\
\hline IL 2 & $\begin{array}{l}\text { Conocimiento sobre las diferentes técnicas de } \\
\text { diagnosis existentes en la actualidad. Ensayos } \\
\text { no destructivos y semidestructivos }\end{array}$ & $\begin{array}{c}\text { Clases teóricas, sesiones en } \\
\text { el laboratorio, seminarios } \\
\text { específicos. }\end{array}$ \\
\hline
\end{tabular}


Propuesta de modificación docente de la asignatura Construcción VI de la Escuela Técnica Superior de Ingeniería de Edificación de la Universitat Politècnica de València - Proposal for teaching modification of the Construction VI subject of the Higher Technical School of Building Engineering of the Polytechnic University of Valencia

\begin{tabular}{|c|c|c|}
\hline Código & Indicador de logro & Recursos \\
\hline IL 3 & $\begin{array}{l}\text { Comprensión de la patología (conjunto de } \\
\text { lesiones) existente por causas estructurales }\end{array}$ & $\begin{array}{l}\text { Clases teóricas, prácticas de } \\
\text { campo, visitas temáticas }\end{array}$ \\
\hline IL 4 & $\begin{array}{l}\text { Comprensión de la patología (conjunto de } \\
\text { lesiones) existente por causas no estructurales }\end{array}$ & $\begin{array}{l}\text { Clases teóricas, prácticas de } \\
\text { campo, visitas temáticas }\end{array}$ \\
\hline IL 5 & $\begin{array}{l}\text { Conocimiento del alcance superficial de cada } \\
\text { lesión. Elementos que intervienen en una } \\
\text { lesión }\end{array}$ & $\begin{array}{l}\text { Clases teóricas, seminarios } \\
\text { específicos impartidos por } \\
\text { expertos del sector }\end{array}$ \\
\hline IL 6 & $\begin{array}{l}\text { Prevención de futuros daños en elementos } \\
\text { cercanos a una lesión no dañados }\end{array}$ & $\begin{array}{l}\text { Clases teóricas, prácticas de } \\
\text { campo }\end{array}$ \\
\hline IL 7 & $\begin{array}{l}\text { Detectar el origen y las causas de las } \\
\text { diferentes lesiones de un edificio. }\end{array}$ & $\begin{array}{l}\text { Clases teóricas, estudio de } \\
\text { casos, trabajo en grupo }\end{array}$ \\
\hline IL 8 & $\begin{array}{l}\text { Relacionar las diferentes lesiones de un } \\
\text { edificio, identificando las causas y efectos } \\
\text { secundarios comunes. }\end{array}$ & $\begin{array}{l}\text { Clases teóricas, estudio de } \\
\text { casos, trabajo en grupo }\end{array}$ \\
\hline IL 9 & $\begin{array}{l}\text { Proponer diferentes soluciones y realizar el } \\
\text { pertinente proyecto de intervención }\end{array}$ & $\begin{array}{l}\text { Clases teóricas, estudio de } \\
\text { caso. }\end{array}$ \\
\hline IL 10 & $\begin{array}{l}\text { Redactar el libro de mantenimiento de un } \\
\text { edificio }\end{array}$ & Clases teóricas \\
\hline
\end{tabular}

\section{Conclusión. Relación entre las Competencias y los Indicadores de logro.}

A continuación, se expone la relación entre las competencias (las cuatro competencias genéricas y la competencia específica anteriormente descritas) de la asignatura "Construcción Vl", y los objetivos específicos o indicadores de logro (Fowler, 2002).

Hay que destacar el hecho de que no existe ningún indicador de logro que esté sujeto o restringido a una única competencia (genérica o específica), por lo que se cumplen los 
preceptos de compatibilidad y complementariedad de competencias fijados en el III Congreso Internacional sobre competencias docentes (Berna, 2012).

Tabla 3. Relación entre los objetivos específicos (indicadores de logro) y las competencias de "Construcción Vl". Fuente: El autor.

\begin{tabular}{|c|c|c|c|c|c|}
\hline & CG 1 & CG 2 & CG 3 & CG 4 & $C E$ \\
\hline IL 1 & $\checkmark$ & $x$ & $x$ & $x$ & $\checkmark$ \\
\hline IL 2 & $\checkmark$ & $\checkmark$ & $\checkmark$ & $x$ & $\checkmark$ \\
\hline IL 3 & $x$ & $\checkmark$ & $x$ & $x$ & $\checkmark$ \\
\hline IL 4 & $x$ & $x$ & $x$ & $\checkmark$ & $\checkmark$ \\
\hline IL 5 & $x$ & $x$ & $x$ & $\checkmark$ & $\checkmark$ \\
\hline$I L 6$ & $x$ & $x$ & $x$ & $\checkmark$ & $\checkmark$ \\
\hline IL 7 & $x$ & $\checkmark$ & $\checkmark$ & $x$ & $\checkmark$ \\
\hline$I L 8$ & $x$ & $\checkmark$ & $\checkmark$ & $x$ & $\checkmark$ \\
\hline IL 9 & $\checkmark$ & $\checkmark$ & $\checkmark$ & $x$ & $\checkmark$ \\
\hline IL 10 & $x$ & $\checkmark$ & $x$ & $x$ & $\checkmark$ \\
\hline
\end{tabular}

\section{Referencias}

ANECA. (2008). Programa academia: principios y orientaciones para la aplicación de los criterios de evaluación. Madrid: Agencia Nacional de Evaluación del Profesorado.

ANECA. (2005). Libro blanco. Título de grado en ingeniería de edificación. Madrid: Agencia Nacional de Evaluación de la Calidad y Acreditación.

AUSUBEL D.P. (1990). Significado y aprendizaje significativo. In: Ausubel D.P., Novak J.D., Hanesian H. (eds) Psicología educativa: un punto de vista cognoscitivo. Trillas, Mexico, pp 55-107.

ELLIOT J. (2000). El cambio educativo desde la investigación-acción (traducción de P. Manzano). Madrid : Morata.

FOWLER B. (2002). La taxonomía de Bloom y el pensamiento crítico. http://www.eduteka.org/profeinvitad.php3?ProflnvID=0014 (acceso 15.01.2010) 


\section{TRANSVERSALIDAD}

Prácticas, recursos, experiencias e investigaciones de carácter transversal en el proceso de enseñanzaaprendizaje de la profesión regulada de arquitecto técnico. Recoge sinergias entre diferentes disciplinas y áreas, transferencia de conocimiento de la actividad investigadora y/o profesional al ámbito docente, y en general, cualquier actividad que potencie la formación transversal. 


\title{
EDIFICATE
}

I Congreso de Escuelas de Edificación y Arquitectura Técnica de España València, 4 y 5 de noviembre de 2021

Escuela Técnica Superior de Ingeniería de Edificación

Universitat Politècnica de València

Doi: https://doi.org/10.4995/EDIFICATE2021.2021.13251

\section{La Inteligencia Artificial y su contribución a la optimización de la atención y memoria de los estudiantes a través del diseño del aula}

\author{
Artificial Intelligence and its contribution to optimising \\ students' attention and memory through classroom design.
}

\begin{abstract}
Adrián Colomer Granero ${ }^{a}$, Juan Luis Higuera Trujillo ${ }^{b}$, Valeriana Naranjo Ornedoc y Carmen Llinares Millán ${ }^{d}$

anstituto de Investigación e Innovación en Bioingeniería, adcogra@i3b.upv.es, 'Escuela Técnica Superior de Ingeniería de la Edificación, jlhiguera@i3b.upv.es, 'Instituto de Investigación e Innovación en Bioingeniería, vnaranjo@dcom.upv.es y ${ }^{\mathrm{E} E s c u e l a ~ T e ́ c n i c a ~ S u p e r i o r ~ d e ~ I n g e n i e r i ́ a ~ d e ~ l a ~ E d i f i c a c i o ́ n, ~}$ cllinare@omp.upv.es
\end{abstract}

\begin{abstract}
The application of Artificial Intelligence to education has been studied for decades. However, despite its numerous contributions, there are hardly any studies focused on improving student performance through classroom design. The aim of this paper is to apply Artificial Intelligence to identify the optimal classroom design (based on colour, lighting and shape) to enhance the attention and memory performance of university students. To this end, a laboratory study was carried out in which 50 participants performed cognitive tests in virtual environments with different design configurations. The results show that the best performance in attention and memory is achieved with a similar design: smaller classrooms (ceiling height of $2.6 \mathrm{~m}$ and width of $7.6 \mathrm{~m}$ ), with cool colours and low saturations, and with lighting colour temperatures of $6500 \mathrm{~K}$. The only difference is in the illuminance: it requires lower levels (1001x) to enhance memory; and higher levels (500lx) for attention. The results may be useful for both researchers and professionals involved in the design of educational centres.
\end{abstract}

Keywords: classroom design, attention, memory, artificial Intelligence. 

and memory through classroom design.

\section{Resumen}

La aplicación de la Inteligencia Artificial en el sector de la educación ha sido objeto de estudio durante décadas. Sin embargo, y a pesar de sus numerosas contribuciones, apenas existen estudios centrados en mejorar el rendimiento de los estudiantes a través del diseño del aula. El objeto del presente trabajo es la aplicación de la Inteligencia Artificial para identificar el diseño óptimo del aula (atendiendo a su color, iluminación y forma), para potenciar el rendimiento en atención y memoria de los estudiantes universitarios. Para ello se llevó a cabo un estudio en laboratorio en el que 50 participantes realizaron pruebas cognitivas en entornos virtuales con diferentes configuraciones de diseño. Los resultados muestran que el mejor rendimiento en atención y memoria se consigue con un diseño similar: aulas de menores dimensiones (altura de techo de 2,6 $m$ y 7,6 $m$ de ancho), con colores fríos y de saturaciones bajas, y con temperaturas del color de la iluminación de 6500K. La única diferencia se detecta en la iluminancia: requiere niveles más bajos (100lx) para potenciar la memoria; y más altos (500lx) para la atención. Los resultados pueden ser de utilidad tanto para investigadores como profesionales relacionados con el diseño de centros docentes.

Palabras clave: diseño aulas, atención, memoria, inteligencia artificial 


\section{Introducción}

El término de Inteligencia Artificial no existía como tal hasta que en 1956 fue utilizado por primera vez en el congreso de Dartmounth, organizado por diversos investigadores interesados en desarrollar máquinas que imitaran el comportamiento humano. En dicha conferencia, el Profesor John McCarhty de la Universidad de Stanford utilizó el nombre de Inteligencia Artificial para referirse a "la ciencia y el ingenio de hacer máquinas inteligentes, especialmente programas de ordenador inteligentes".

Tras varios experimentos fallidos en torno a la Inteligencia Artificial a lo largo de las décadas de los 70 y 80 , se extrajo una conclusión clave: antes de crear ordenadores inteligentes, era necesario saber cómo proporcionarles la información requerida. Dado que este conocimiento no podía ser proporcionado enteramente por los seres humanos, las máquinas tenían que aprender por ellas mismas a partir del entorno, ya fuera utilizando bases de datos o motores de búsqueda. Capturar información del entorno es de vital importancia para la inteligencia artificial. Hoy en día, se genera diariamente una gran cantidad de información en todos los ámbitos (incluido el sector de la educación), haciendo del Big Data una técnica esencial en el siglo XXI (Henke, 2021; Reinsel et al., 2018).

En las últimas décadas, gracias al avance de la tecnología hardware se han creado sistemas revolucionarios de Inteligencia Artificial en diversos ámbitos. Muchas áreas de la vida cotidiana, tales como el sector educación, automovilístico, industrial, médico, aeronáutico y financiero entre otros piden asistentes digitales que permitan reducir costes. Esta demanda ha forzado la creación de los que se conoce como Inteligencia Artificial 2.0. En esta dirección, se proponen dos objetivos principales. El primero consiste en alcanzar sistemas inteligentes híbridos que combinen máquinas y humanos; el segundo supone crear sistemas inteligentes más complejos, conocidos comúnmente como sistemas supervisados (Pan, 2016).

La aplicación de la Inteligencia Artificial en el sector de la educación (también conocida como AIED, de sus siglas en inglés) ha sido objeto de estudio durante décadas (Rus et al., 2013). Uno de los objetivos principales es el de proporcionar una comprensión más profunda de como el aprendizaje del alumnado tiene lugar y de la influencia que en el ejercen otros factores tales como el contexto físico y socioeconómico de la persona.

Los Sistemas de Tutorización Inteligente (STI) tienen una serie de conocimientos, tanto de los contenidos y de los estudiantes como de las metodologías de aprendizaje, que les permiten ayudar al estudiante guiándolo a través del proceso de aprendizaje y la resolución de problemas. Los STI utilizan técnicas de IA para simular la tutorización individualizada, ofreciendo las actividades que mejor encajan con las necesidades de cada alumno y proporcionando retroalimentación (Roll et al., 2016). Algunos STI buscan motivar a los estudiantes a tomar el control de su propio aprendizaje, esperando desarrollar su responsabilidad y madurez. Los STI existentes hoy en día usan técnicas de aprendizaje automático, algoritmos de autoaprendizaje y redes neuronales para tomar las decisiones apropiadas sobre qué contenido proporcionar al alumno (Vanlehn, 2011). 
Otra alternativa a estos tutores inteligentes son los sistemas de evaluación automáticos (Lama et al. 2007), los cuales además de corregir al estudiante, le permiten conocer sus fortalezas y debilidades. Entre las alternativas a este modelo de aprendizaje están los ToL, basados en test online (Tartaglia et al. 2002), y CELLA, para el estudio del inglés (Lama et al. 2007).

Aparte de los sistemas mencionados previamente, hay otros que permiten aprender no en término de materias sino en términos de aptitudes. Éste es el caso del aprendizaje colaborativo, que enseña y guía a los estudiantes para desarrollar su capacidad de trabajo en grupo y mejorar la interacción entre ellos, como es el caso de DEGREE (Barros et al. 2000). Otra forma más dinámica de aprendizaje es aquella basada en los juegos (Lama et al. 2007). Con ellos, los estudiantes se ven motivados a desarrollar habilidades y conocimientos, e incluso les hacen estar más concienciados con problemáticas relacionadas con la sociedad y la ciudadanía, como en el caso del método de aprendizaje NetAid, cuyo objetivo es sensibilizar sobre la pobreza (Stokes, 2005).

Asimismo, parte de estos sistemas puede usarse tanto dentro de las aulas como fuera a través de Internet, permitiendo una educación continuada en cualquier momento y lugar.

Otra técnica implementada para apoyar el aprendizaje consiste en el uso de la realidad virtual, que puede proveer de experiencias inmersivas que simulan ciertos aspectos de la vida cotidiana. Esta función añadida a la Inteligencia Artificial permite al usuario interactuar y tomar decisiones en situaciones que podrían ser reales, registrando diferentes comportamientos. Dentro de estas experiencias, pueden asumir distintos roles. Por ejemplo, FearNot es un sistema de realidad virtual diseñado por escuelas y que presenta entornos relacionados con el acoso escolar. Este sistema busca ayudar a las personas que lo han sufrido dándoles consejos sobre que comportamientos adoptar en distintas situaciones (Vannini, 2011).

La AIED utilizada en las aulas ha evolucionado, y actualmente se persigue el objetivo de diseñar e implementar aulas inteligentes ("Smart classrooms en inglés"). Es posible combinar sistemas cognitivos con técnicas de minado de datos para hacer un seguimiento del comportamiento de los estudiantes y de su nivel de atención y concentración en clase, por ejemplo, a través de la recolección de información sobre su asistencia y publicando estudios para identificar y dar soporte a los estudiantes en riesgo de abandono escolar (Timmins, 2016). Otros investigadores están trabajando en nuevas interfaces, tales como el procesamiento del lenguaje natural, habla, reconocimiento de gestos y eye-tracking, entre otras, que podrían aplicarse al campo de la educación.

Sin embargo y a pesar de las numerosas aplicaciones que ha tenido esta técnica apenas existen estudios cuyo objetivo haya sido identificar elementos de diseño de un espacio para la mejora del rendimiento de los estudiantes. La contribución radica fundamentalmente en la posibilidad de identificar la combinación de diferentes elementos de diseño, y no el efecto de cada elemento de manera aislada o independiente como se ha realizado hasta el momento. 


\section{Objetivo}

El objeto del presente trabajo es la aplicación de la Inteligencia Artificial para identificar el diseño óptimo del aula (atendiendo a su color, iluminación y forma), capaz de potenciar las funciones cognitivas de atención y memoria de los estudiantes universitarios. Entre el conjunto de parámetros de diseño con capacidad de influir en las funciones cognitivas de los estudiantes en este trabajo nos centramos en el color (tono y saturación), forma (altura techo y anchura aula) e iluminación (iluminancia y temperatura del color).

\section{Material y Métodos}

La metodología se basó en un estudio en laboratorio, con las siguientes características.

\subsection{Muestra}

La muestra estaba formada por 50 participantes (55\% hombres- $45 \%$ mujeres), con una edad media de 20.06 años $(\sigma=3.122)$. Para formar parte de la muestra se marcaron cuatro criterios de inclusión: ser estudiante universitario, español (para evitar posibles efectos culturales), tener entre 18 y 23 años (edades más frecuentes en los grados universitarios de España) y no tener dificultades en la apreciación de los colores.

\subsection{Estímulos}

Como estímulo base se tomó la réplica virtual inmersiva de un aula física representativa. Concretamente, un aula de la Escuela Técnica Superior de Ingeniería de la Edificación (ETSIE) de la Universitat Politècnica de València. Sobre esta aula base se desarrollaron 34 configuraciones aisladas de diseño, atendiendo a las siguientes características:

- Variable forma. Con tres medidas para la altura del techo: $3.8 \mathrm{~m}, 3.2 \mathrm{~m}$ y $2.6 \mathrm{~m}$; y otras tres para la anchura: $8.8 \mathrm{~m}, 8.2 \mathrm{~m}$ y $7.6 \mathrm{~m}$.

- Variable iluminación. Con tres medidas para la iluminancia: $1001 x, 3001 x$ y 500lx; y otras tres para la temperatura del color: $3000 \mathrm{~K}, 4000 \mathrm{~K}$ y $6500 \mathrm{~K}$.

- Variable color. Con 8 tonos, divididos a su vez en fríos (5BG, 5PB, 5P, 5GY) y cálidos (5RP, 5R, 5YR, 5Y); y 2 saturaciones: alta (entre 10 y 16 unidades en Munsell chroma) y baja (entre 4 y 10 unidades).

Los participantes visualizaron las simulaciones mediante el dispositivo HTC Vive. Cada participante realizó 6 visualizaciones siguiendo una aleatorización automática; dando como resultado que cada estímulo fuese visto por al menos 8 participantes. La Figura 1 muestra una de las aulas evaluadas y una imagen de la experiencia. 

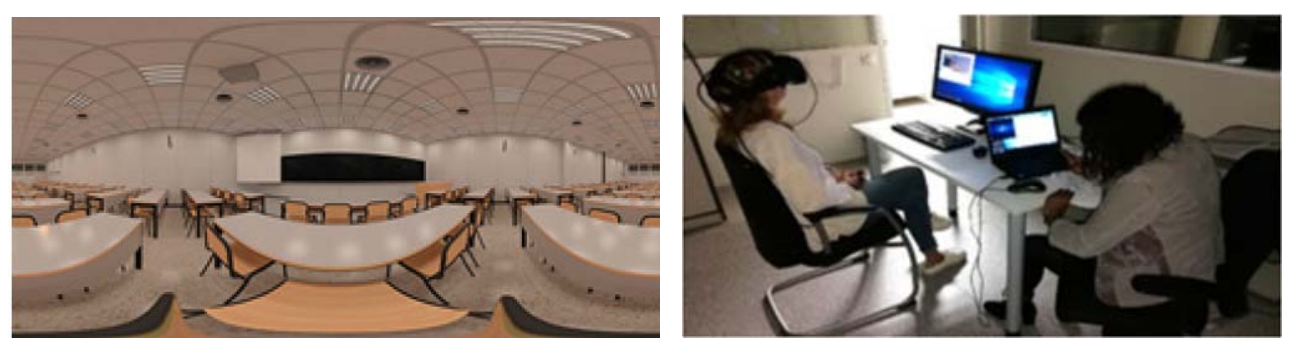

Fig. 1 Aula virtual y participante durante la experiencia

\subsection{Análisis de datos}

De cada participante se cuantificó el rendimiento en las tareas de atención y memoria.

Tarea de memoria. Esta tarea consistió en la memorización de un conjunto de palabras, basado en el estudio de Alonso y su equipo (2004). En concreto el participante debía escuchar 3 audios, cada uno de ellos con una lista de 15 palabras relacionadas entre sí. Las listas se presentaron contrabalanceadas. El participante debía escucharlas y repetirlas en un tiempo máximo de 30 segundos, antes de avanzar a la siguiente lista. Posteriormente se anotaba el número de aciertos de cada lista. El número de palabras recordadas fue corregido según la tasa de recuerdo propuesta por Alonso et al (2004).

Tarea de atención. Esta tarea consistía en reaccionar lo antes posible ante un estímulo auditivo concreto con un clic de ratón (objetivo) y evitar hacerlo ante otros cuatro (distractores), similar a las pruebas de rendimiento auditivo continuo (Seidman et al., 1998). En total la tarea contaba con 8 objetivos y 32 distractores, y el tiempo entre estímulos era de $800 \mathrm{~ms}$ a $1600 \mathrm{~ms}$. Los participantes tenían $750 \mathrm{~ms}$ para reaccionar a los estímulos, pasados los cuales se consideraba un error (al igual que reaccionar ante un estímulo distractor). Se registró el tiempo de reacción ante los estímulos objetivos y el número de errores cometidos. Esto se repetía en 3 ocasiones para cada entorno simulado, con 1500 ms entre sets.

\subsection{Inteligencia Artificial para identificar el diseño óptimo del aula}

Tal y como se ha comentado en la Sección 1, no existen estudios previos que focalicen en la identificación de elementos de diseño de un espacio para la mejora del rendimiento de los estudiantes mediante técnicas de Inteligencia Artificial. Para llevar a cabo el objetivo que se plantea en este trabajo, se siguió la metodología CRISP-DM para llevar a cabo proyectos de aprendizaje automático publicada por Shearer (2000), adaptándola al presente estudio (ver Figura 2)

En primer lugar, se realizó un proceso de comprensión de los datos adquiridos definido por varias tareas: descripción de los datos obtenidos, exploración de los mismos e identificación de su calidad. Tras esta primera etapa, se llevaron a cabo técnicas de selección y limpieza de datos para eliminar valores outliers, así como métodos de interpolación para imputar valores perdidos, garantizando así la construcción de una base de datos robusta y fiable. 
Posteriormente, y tomando como entrada la base de datos acondicionada, se dio comienzo a la fase del modelado del conocimiento a partir de dichos datos. Más concretamente, se emplearon técnicas de extracción manual de características y métodos estadísticos para el modelado. Tras esta etapa, se procedió a llevar a cabo una validación exhaustiva del modelo generado con un subconjunto de participantes cuyos datos no se emplearon en la etapa de construcción del modelo, garantizando así la habilidad de generalización y fiabilidad del mismo.

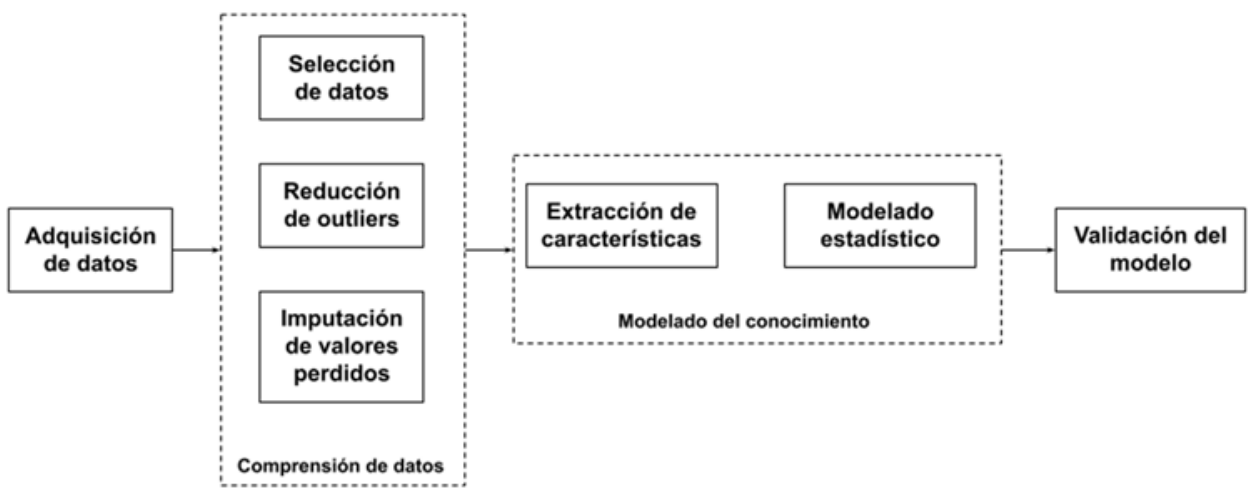

Fig. 2 Metodología CRISP-DM propuesta para la identificación de elementos de diseño de un espacio con el objetivo de mejorar el rendimiento de los estudiantes mediante técnicas de Inteligencia Artificial

\section{Resultados}

A partir de la aplicación de la Inteligencia Artificial se identificó la combinación de elementos de diseño que consigue maximizar las funciones cognitivas de atención y memoria. La Figura 3 recoge un esquema de los resultados.

Como se observa en el esquema siguiente el mejor rendimiento de la atención y de la memoria se consigue con un diseño similar: aulas de menores dimensiones (con una altura de techo de 2,6 $\mathrm{m}$ y 7,6 $\mathrm{m}$ de ancho), con colores fríos de saturaciones bajas, y con una temperatura del color de la iluminación de $6500 \mathrm{~K}$. La única diferencia se detecta en la iluminancia, que requiere niveles más bajos (100lx) para potenciar la memoria, y por el contrario el nivel más alto para potenciar la atención (500lx).

No existen trabajos previos que analicen la relación entre geometría del aula (altura-anchura) con respecto a las funciones cognitivas. Por el contrario, respecto al color existen trabajos previos como el de Mahnke (1996) que asocian los colores fríos a una mejora de la concentración de los estudiantes de más edad. También Stone (2003) y Xia et al. (2016) demostraron que los tonos azules mejoraban el desarrollo de tareas de gran dificultad. 
La Inteligencia Artificial y su contribución a la optimización de la atención y memoria de los estudiantes a través del diseño del aula- Artificial Intelligence and its contribution to optimising students' attention and memory through classroom design.

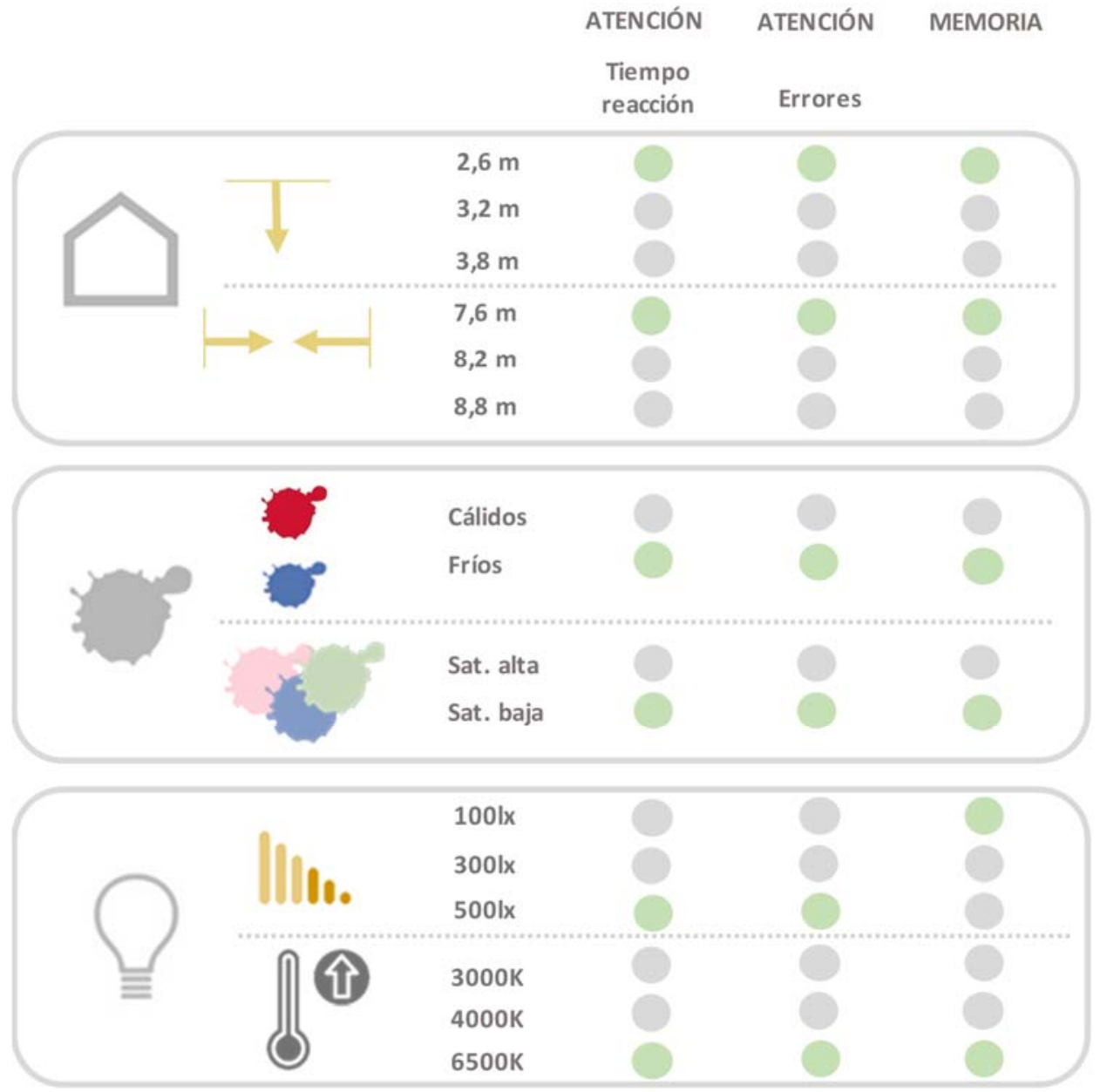

Fig. 3 Incidencia de la forma, el color y la iluminación en la atención y memoria de los estudiantes

La saturación del color ha sido también objeto de estudio. Así, por ejemplo, Kwallek et al. (1996) demostró que saturaciones similares a las etiquetadas como bajas en el presente estudio conseguían reducir errores en la ejecución de tareas intelectuales. En cuanto a la iluminación, son varios los trabajos que han observado una mejora de concentración con niveles elevados de temperatura del color (Viola et al., 2008; Keis et al., 2014). La discrepancia encontrada con la iluminancia es similar al resultado observado por Smolders y su equipo (2012), que ante un cambio del nivel de iluminación de 200lx a 1000lx mejoraron los niveles de atención sostenida y sin embargo, en algunas tareas de memoria el resultado era inverso, de forma que el mejor desempeño se producía con el nivel más bajo de iluminación (2001x). 


\section{Conclusiones}

La iluminación, el color y las dimensiones del aula son aspectos fundamentales a ser considerados en el diseño de los espacios arquitectónicos docentes. Son muchos los trabajos que han analizado la incidencia de un elemento de diseño, como la iluminación o el color, en el rendimiento de los estudiantes. Sin embargo, resulta fundamental analizar la incidencia de los elementos de diseño de manera combinada. Así por ejemplo la utilización de colores fríos en los revestimientos del aula potencia la atención y memoria del alumnado, pero siempre que éstos tengan saturaciones bajas. La Inteligencia Artificial permite realizar este análisis combinado. Los resultados pueden ser de utilidad tanto para investigadores como profesionales relacionados con el diseño de centros docentes.

\section{Agradecimientos}

Este trabajo ha sido financiado por el Ministerio de Economía, Industria y Competitividad de España (Proyecto BIA2017-86157-R; PRE2018-084051).

\section{Referencias}

ALONSO, M. Á., FERNANDEZ, Á., DIEZ, E., y BEATO, M. S. (2004). "Índices de producción de falso recuerdo y falso reconocimiento para 55 listas de palabras en castellano" en Psicothema, vol. $16, \mathrm{n}^{\circ}$ 3, pp. 357-362.

BARROS B., y FELISAVERDEJO, M. (2000). "Analysing student interaction processes in order to improve collaboration. The DEGREE approach" en International Journal of Artificial Intelligence in Education, vol. $11, n^{\circ} 3$, pp. 221-241.

HENKE, N. "The age of analytics: Competing in a data-driven world| McKinsey," [En línea]. Disponible: https://www.mckinsey.com/business-functions/mckinsey-analytics/our-insights/the-age-of-analyticscompeting-in-a-data-driven-world. [Último acceso: 11 Jun 2021].

KEIS, O., HELBIG, H., STREB, J., y HILLE, K. (2014). "Influence of blue-enriched classroom lighting on students ' cognitive performance" en Trends in Neuroscience and Education, vol. 3, no 3-4, pp. 8692.

KWALLEK, N., LEWIS, C. M., LIN-HSIAO, J. W. D., y WOODSON, H. (1996). "Effects of nine monochromatic office interior colors on clerical tasks and worker mood" en Color Research \& Application, vol. 21, n 6, pp.448-458.

LAMA M., SÁNCHEZ E. (2007). "Introducción a la monografía Técnicas de IA aplicadas a la Educación" en I. Artificial, Inteligencia artificial: revista iberoamericana de inteligencia artificial, vol. 11, $\mathrm{n}^{\circ} 33$.

MAHNKE, F. H. (1996). Color, environment, and human response: an interdisciplinary understanding of color and its use as a beneficial element in the design of the architectural environment. New York: Van Nostrad Reinhold.

PAN, Y. (2016). "Heading toward Artificial Intelligence 2.0" en Engineering, vol. 2, n 4, pp. 409-413. 
La Inteligencia Artificial y su contribución a la optimización de la atención y memoria de los estudiantes a través del diseño del aula- Artificial Intelligence and its contribution to optimising students' attention and memory through classroom design.

REINSEL, D., GANTZ J., y RYDNING J. (2018). "The Digitization of the World From Edge to Core".

ROLL, I., y WYLIE, R. (2016) "Evolution and Revolution in Artificial Intelligence in Education" en International Journal of Artificial Intelligence in Education, vol. 26, $\mathrm{n}^{\circ}$ 2, pp. 582-599.

RUS, V., D'MELLO, S., HU X., y GRAESSER, A. (2013). "Recent Advances in Conversational Intelligent Tutoring Systems" en Al Magazine, vol. 34, n 3, p. 42.

SEIDMAN, L. J., BREITER, H. C., GOODMAN, J. M., GOLDSTEIN, J. M., WOODRUFF, P. W., O'CRAVEN, K., ... ROSEN, B. R. (1998). "A functional magnetic resonance imaging study of auditory vigilance with low and high information processing demand" en Neuropsychology, vol. 12, $n^{\circ} 4, p$. 505-518.

SHEARER C. (2000). "El modelo CRISP-DM: el nuevo plan para la minería de datos, almacenamiento de los datos" en Journal of Data Warehousing, vol.5, $n^{\circ} 4$, pp. 13-22.

SMOLDERS, K. C., DE KORT, Y. A., y CLUITMANS, P. J. M. (2012). "A higher illuminance induces alertness even during office hours: findings on subjective measures, task performance and heart rate measures", en Physiology \& Behavior, vol. 107, $\mathrm{n}^{\circ}$ 1, pp. 7-16.

STOKES, B. (2005). "Videogames have changed: time to consider 'Serious Games'?", en The Development Education Journal, vol. 11, n 3, p. 12.

STONE, N. J. (2003). "Environmental view and color for a simulated telemarketing task", en Journal of Environmental Psychology, vol. 23, issue 1, pp. 63-78.

TARTAGLIA, A., y TRESSO, E. (2002). "An automatic evaluation system for technical education at the University level" en IEEE Transactions on Education, vol. 45, n 3, pp. 268-275.

TIMMINS, M.J. (2016). "Letting Artificial Intelligence in Education Out of the Box: Educational Cobots and Smart Classrooms" en International Journal of Artificial Intelligence in Education, vol. 26, $\mathrm{n}^{\circ} 2$, pp. 701-712.

VANLEHN, K. (2011). "The Relative Effectiveness of Human Tutoring, Intelligent Tutoring Systems, and Other Tutoring Systems" en Educational Psychology, vol. 46, nº 4, pp. 197-221.

VANNINI, N. (2011). "FearNot!': a computer-based anti-bullying-programme designed to foster peer intervention" en European Journal of Psychology of Education, vol. 26, $\mathrm{n}^{\circ}$ 1, pp. 21-44.

VIOLA, A. U., JAMES, L. M., SCHLANGEN, L. J., y DIJK, D. J. (2008). "Blue-enriched white light in the workplace improves self-reported alertness, performance and sleep quality" en Scandinavian Journal of Work, Environment \& Health, vol. 34, n 4, p. 297-306.

XIA, T., SONG, L., WANG, T. T., TAN, L., y MO, L. (2016). "Exploring the effect of red and blue on cognitive task performances" en Frontiers in Psychology, vol. 7, 784. 


\title{
EDIFICATE
}

I Congreso de Escuelas de Edificación y Arquitectura Técnica de España

València, 4 y 5 de noviembre de 2021

Escuela Técnica Superior de Ingeniería de Edificación

Universitat Politècnica de València

Doi: https://doi.org/10.4995/EDIFICATE2021.2021.13300

\section{La dificultad como oportunidad de cambio: mejoras docentes tras una experiencia íntegramente online}

\section{In difficulty lies opportunity: teaching improvements after an entirely online experience}

\author{
Lucía Reig-Cerdá a , María José Ruá-Aguilar a , Ángel Pitarch-Roig a y Joaquín \\ Martínez-Moyá b \\ a Universitat Jaume I, Departamento de Ingeniería Mecánica y Construcción, Ireig@uji.es, rua@uji.es \\ pitarch@uji.es, b Universitat Jaume I, Departamento de Ingeniería de Sistemas Industriales y Diseño, \\ jomoya@uji.es
}

\section{Abstract}

The global pandemic of Covid-19 forced to all educational levels to adapt in record time to an entirely online teaching. It was necessary to adapt content, materials and methodologies, maintaining the quality of teaching. Despite the fact that universities had various tools, such as their virtual platforms, which have improved student-teacher interaction and facilitate the management of resources and content, they were not prepared for such a drastic and significant change. However, the university community proved to be quickly adapted and moved on, and the update process entailed an opportunity to change towards a new, more active and student-centered teaching model. This communication presents the practical experience of a subject of construction materials of the degree in Technical Architecture of the Universitat Jaume I. It describes how the teaching was adapted during confinement and afterwards, how the experience improved the subject in a face-to-face or hybrid teaching model. The training in digital skills of the teaching staff, the new possibilities of communication with the students, or the new habits acquired have made it possible to improve the teaching-learning process, developing various activities to support face-to-face tasks, more attractive, interactive and motivating, which help students to improve their skills and learning outcomes.

Keywords: teaching methodologies, virtual resources, flexible learning, autonomous learning, H5P tools. 


\section{Resumen}

La pandemia mundial de la Covid-19 obligó a adaptar en tiempo récord una docencia íntegramente online en todos los niveles educativos. Fue necesario adaptar contenidos, materiales y metodologías, evitando perjudicar a la calidad de la enseñanza. Pese a que las universidades contaban con diversas herramientas, como sus plataformas virtuales, que mejoran la interacción alumno - profesor y facilitan la gestión de recursos, no estaban preparadas para un cambio tan drástico y significativo. No obstante, la comunidad universitaria se adaptó rápidamente y siguió adelante, actualizándose, lo que derivaría en una oportunidad de cambio hacia un nuevo modelo de enseñanza más activo y centrado en el estudiantado. Esta comunicación presenta la experiencia práctica de una asignatura de materiales de construcción del grado en Arquitectura Técnica de la Universitat Jaume I. Se describe cómo se adaptó la docencia durante el confinamiento para, posteriormente, incorporar mejoras en el modelo presencial o híbrido. La formación en competencias digitales del profesorado, las nuevas posibilidades de comunicación con el alumnado, o los nuevos hábitos adquiridos han permitido mejorar el proceso de enseñanzaaprendizaje, desarrollando diversas actividades de apoyo a las tareas presenciales, más atractivas, interactivas y motivadoras, que ayuden al alumnado a mejorar sus competencias y resultados de aprendizaje.

Palabras clave: metodologías docentes, recursos virtuales, flexibilidad en el aprendizaje, aprendizaje autónomo, herramientas H5P. 


\section{Introducción}

Los cursos académicos 2019-2020 y 2020-2021 han estado fuertemente condicionados por la pandemia mundial de la Covid-19. En marzo de 2020, se decretó en España un confinamiento obligatorio para la población, que afectó a todos los sectores de la Sociedad. La enseñanza no fue una excepción y, todos los niveles educativos tuvieron que adaptarse a las nuevas condiciones. Durante estos dos cursos se ha experimentado desde un confinamiento total, con una enseñanza totalmente virtual, a periodos de docenciaaprendizaje presenciales (guardando las preceptivas condiciones de seguridad: aforos, distancias, mascarillas...) y, en algunos casos, situaciones híbridas.

Docentes y alumnado han tenido que responder a las circunstancias cambiantes, siendo especialmente duro el periodo en el que, bajo una situación de emergencia, la docencia fue $100 \%$ online. Dicho periodo puso a prueba la capacidad de resiliencia a nivel personal y fue una oportunidad para testar el potencial de las herramientas para una enseñanza a distancia. A nivel universitario, las plataformas virtuales facilitaron mucho dicha adaptación, permitiendo compartir contenidos, impartir clases por videoconferencia y/o evaluar las asignaturas. A diferencia de lo que ocurrió en otros ámbitos y sectores de la sociedad, dichas herramientas permitieron mantener y adaptar la actividad universitaria. No obstante, tal como apuntan Adell y Andrés (Adell y Andrés, 2020), en aquel momento pasamos rápidamente a una educación en línea de emergencia, diferente de una educación a distancia, que requiere pedagogía y planificación.

La Universitat Jaume I, como la mayoría de las universidades públicas españolas, siempre ha apostado por una docencia presencial. Dentro de ella, una característica diferencial del grado en Arquitectura Técnica es que incorporó desde sus inicios la docencia por proyectos (Reig et al., 2017). Bajo la denominación de Proyecto Dirigido el alumnado, organizado por equipos, desarrolla un trabajo sobre un edificio real, lo que les permite tanto aplicar los conocimientos teóricos adquiridos en las diferentes asignaturas de cada curso, como trabajar otras competencias, como el trabajo en equipo, el análisis de documentación, la síntesis de información o la presentación de resultados ante un tribunal formado por profesores de las diferentes asignaturas (Reig et al., 2017; Martínez-Moya et al., 2020). Por tanto, dicha metodología eminentemente práctica, requiere interacción, tanto entre estudiantes para llevar a cabo el desarrollo del trabajo, como con el profesorado, que realiza su seguimiento. Fue necesario desarrollar nuevos hábitos, nuevas formas de comunicación y relacionarse y, pese a que la presencialidad permite un contacto personal que es difícil de suplir desde las pantallas, el uso de determinadas herramientas permitió comunicarse y trabajar de manera remota, síncrona y/o asíncrona, lo que permitió alcanzar las habilidades y competencias previstas, aunque siguiendo procedimientos distintos a los tradicionalmente empleados.

Tras la experiencia vivida, (Pitarch-Roig et al., 2020) era necesario reflexionar y aprender de lo vivido, tratando de optimizar el esfuerzo realizado para mejorar el proceso de enseñanzaaprendizaje. 


\section{Objetivos}

El objetivo de la presente comunicación es describir cómo se ha modificado la docencia en la asignatura 'Materiales de Construcción III' (Mdc3) del grado en Arquitectura Técnica de la Universitat Jaume I el curso 2020-21, tras su adaptación de emergencia para una docencia totalmente online en periodo de confinamiento.

\section{Metodología para mejorar la docencia de la asignatura Materiales de Construcción III}

La Figura 1 recoge la metodología seguida para mejorar el proceso enseñanza-aprendizaje en la asignatura Mdc3 del grado en Arquitectura Técnica de la Universitat Jaume I de Castellón. La presente comunicación se ha organizado en los mismos apartados, describiendo en primer lugar como se adaptó la docencia online durante la situación de emergencia sanitaria, para posteriormente reflexionar sobre los cambios que implicó, las oportunidades para rediseñar el proceso de docencia-aprendizaje universitarios y las necesidades de formación que ello implicaba. Se describirán la formación y apoyo recibidos, tanto durante la adaptación de emergencia a una docencia $100 \%$ online, como para el posterior desarrollo de una docencia presencial y/o híbrida. Se recogerán los cambios introducidos en la asignatura que, utilizando herramientas virtuales como soporte a la docencia presencial, facilitan la tarea docente y hacen más atractiva y dinámica la participación del alumnado, promoviendo también su capacidad de aprendizaje autónomo. Finalmente, se realizarán propuestas que permitan continuar mejorando la asignatura.

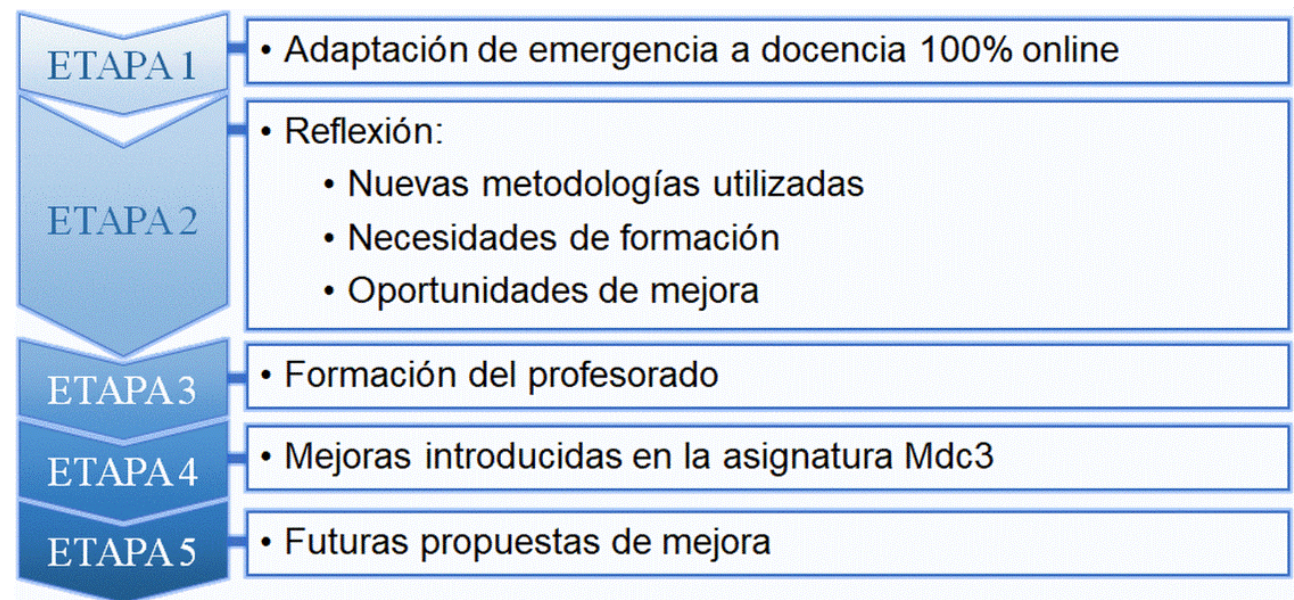

Fig. 1 Metodología seguida para mejorar el proceso enseñanza-aprendizaje en la asignatura Mdc3 


\section{Resultados. Mejora de la asignatura Materiales de Construcción III del grado en Arquitectura Técnica de la Universitat Jaume I}

En el siguiente apartado se describirá la asignatura objeto de mejora, para posteriormente describir cómo se adaptó su docencia durante el periodo de confinamiento, analizar las posibilidades de mejora que de ello derivaron, las necesidades de formación del profesorado, y las mejoras introducidas al volver a impartir la asignatura de forma presencial. Finalmente, tras reflexionar sobre este proceso de cambio, se realizarán nuevas propuestas de mejora para la asignatura, extrapolables a otras asignaturas del ámbito de la edificación.

\subsection{La asignatura}

Tal como recoge la Tabla 1, la asignatura Mdc3 impartida en el grado en Arquitectura Técnica de la Universitat Jaume I es obligatoria de 6 créditos, impartida en el segundo semestre de segundo curso. Se ha elegido esta asignatura para describir el proceso de modificación de la enseñanza-aprendizaje porque, cuando se decretó el estado de alarma en marzo de 2020, estaba siendo impartida de forma presencial y tuvo que ser adaptada de urgencia para una docencia totalmente online.

Tabla 1. Principales descriptores de la asignatura Mdc3

\begin{tabular}{ccccccc}
\hline Código & Nombre & Curso & Semestre & Créditos & $\begin{array}{c}\text { Horas } \\
\text { presenciales }\end{array}$ & $\begin{array}{c}\text { Horas no } \\
\text { presenciales }\end{array}$ \\
\hline ED0919 & $\begin{array}{c}\text { Materiales de } \\
\text { Construcción III }\end{array}$ & 2 & 2 & 6 & 57 & 93 \\
\hline
\end{tabular}

\subsection{Adaptación a la docencia en línea de emergencia}

La situación sanitaria del momento obligó a adaptar urgentemente la docencia a un modelo totalmente online: había que adaptarse de forma rápida y continuar. Era un nuevo modelo para el que fue necesaria una adaptación inmediata sin precedentes.

Para ello, el apoyo de la universidad fue clave, la cual fue flexible y trató de responder de la mejor forma posible a las necesidades de alumnado y profesorado; el apoyo de compañeros que compartían sus experiencias, dificultades y soluciones; así como del Centre d'Educació i Noves Tecnologies de la Universitat Jaume I (CENT, 2021), quien trató de resolver las diferentes dudas e inquietudes con gran eficiencia y profesionalidad. Así, en tiempo récord se generaron diversas guías de apoyo, procedimientos y mejoras tecnológicas que permitieron adaptar la docencia a las exigencias del momento.

En el caso concreto de Mdc3 se adaptaron las actividades, que tradicionalmente habían sido mayoritariamente presenciales y, tal como recoge la Tabla 2, se diferenció entre tareas que debían realizarse antes de la sesión virtual síncrona (a la hora de la clase), durante o después. 
La dificultad como oportunidad de cambio: mejoras docentes tras una experiencia íntegramente online In difficulty lies opportunity: teaching improvements after an entirely online experience

Tabla 2. Adaptación de actividades la asignatura Mdc3 durante el periodo de confinamiento

\begin{tabular}{|c|c|c|c|}
\hline \multirow{3}{*}{ 올 } & \multicolumn{3}{|c|}{ REALIZACIÓN } \\
\hline & ANTES & DURANTE & DESPUÉS \\
\hline & \multicolumn{2}{|c|}{ De la sesión Online Síncrona } & \\
\hline 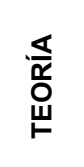 & - & $\begin{array}{l}\text { - Explicación de conocimientos } \\
\text { teóricos mediante Google Meet, } \\
\text { compartiendo presentación con los } \\
\text { alumnos. Y actividades de } \\
\text { autoevaluación de forma síncrona. }\end{array}$ & - \\
\hline
\end{tabular}

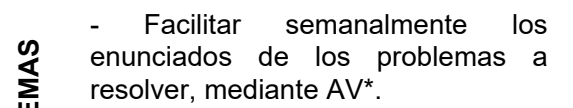

- Alumnado resuelve los problemas de forma autónoma.

- Entregan los problemas mediante tarea creada en AV.
- Resolución de problemas, compartiendo pantalla con los

alumnos mediante Google Meet

- Adaptar la práctica presencial a un formato online, en el que se sustituyeron las actividades de

of laboratorio por videos, fotografías... que les permitiesen trabajar los mismos conocimientos y habilidades. - Facilitar el enunciado de la práctica de laboratorio mediante AV.

- Conexión mediante Google Meet para dudas y aclaraciones - Alumnado completa el enunciado de forma autónoma.

- Entregan mediante tarea creada en AV.
- El alumnado resuelve el cuestionario de autoevaluación de la práctica de laboratorio correspondiente, mediante AV
음 - Desarrollo de forma autónoma por 을 parte del estudiantado.

음 - Directrices por parte de los (丆 profesores sobre como comunicarse 으 entre ellos: trabajando de forma U. colaborativa mediante Google Drive, щ reuniéndose telemáticamente con Google Meet, comunicación por 㩊 teléfono o WhatsApp...
- Tutorías mediante Google Meet para dudas y aclaraciones
- Desarrollo de forma autónoma por parte del estudiantado tras revisión y aclaración de dudas.
- Evaluación del contenido del trabajo desarrollado en Proyecto Dirigido.

- Modelo de examen, facilitado a través del AV. Resolución de dudas mediante tutoría online síncrona por Google Meet.
- Valoración, por parte de un tribunal de la defensa del trabajo desarrollado en Proyecto Dirigido.

- Realización del examen de la asignatura mediante un cuestionario realizado en $\mathrm{AV}$. Con cuestiones tipo test, cuestiones cortas y problemas. Con control del tiempo en cada una de las partes.
- Revisión de la calificación obtenida mediante foro de tutorías privadas del aula virtual, y mediante videoconferencia por Google Meet.

\footnotetext{
* AV: Aula Virtual (plataforma Moodle en la UJI)
} 
La mayor dificultad a la que se vieron sometidos estudiantes y profesores en este periodo fue no tener un contacto personal, lo cual se vio especialmente reflejado en las prácticas de laboratorio y la realización del Proyecto Dirigido, pues éste requería trabajo en equipo para su desarrollo y comunicación con los profesores para su revisión y defensa (Reig et al., 2017; Martínez-Moya et al., 2020). Por otra parte, la realización del examen de forma virtual, con el alumnado en sus casas y frente a un ordenador, fue también todo un reto, tanto para el estudiantado como para el profesorado (Pitarch-Roig et al., 2020). Para los primeros, por la inseguridad que les generaba pensar que no contaban con la presencia física del profesorado (aunque estuviesen conectados por videoconferencia), un posible fallo de conexión a internet, o el hecho de realizar un examen frente a un ordenador, cada uno con los condicionantes de sus propias viviendas. Para los segundos, por el reto que suponía diseñar un examen para su realización completamente online, con las incertidumbres legales sobre las posibles limitaciones para controlar el fraude durante la realización de las pruebas y la dificultad en acotar el tiempo sin limitarlo en exceso...

A pesar de todo, la experiencia vivida demostró que, tanto estudiantes como profesores realizaron un gran esfuerzo de adaptación y, pese a las dificultades, fue posible alcanzar los resultados de aprendizaje establecidos en la guía docente de la asignatura. Como es habitual, no todo el alumnado se implicó del mismo modo, resultando una tasa de rendimiento del $75 \%$ (aprobados / presentados) similar a la de cursos anteriores. Sin embargo, la tasa de éxito (aprobados / presentados) fue del $100 \%$, mientras que en cursos anteriores estaba en_torno del $90 \%$, lo que atribuimos fundamentalmente a una mayor dedicación del alumnado.

Los nuevos materiales desarrollados, las nuevas tecnologías utilizadas, el uso de diferentes metodologías didácticas... abrieron un mundo de posibilidades sobre el que resultaba necesario reflexionar. Surgió una oportunidad de transformar progresivamente la docencia tradicionalmente impartida en un proceso más dinámico y activo, que incorporase diversas actividades para reforzar y completar las sesiones presenciales. La oportunidad de diseñar un proceso más motivador, que facilite además el seguimiento de la asignatura en aquellos casos en los que los alumnos que, por motivos justificados, no pudiesen asistir a clase en un modelo presencial.

\subsection{Reflexión y aprendizaje}

La experiencia vivida durante el confinamiento y la rápida adaptación a un modelo de docencia totalmente online permitió dar un salto en las metodologías docentes. Surgió la oportunidad de aprovechar los nuevos materiales desarrollados y el conocimiento adquirido para rediseñar el proceso de enseñanza - aprendizaje, dotándolo de muchos más recursos para que cualquier estudiante tuviese múltiples oportunidades de asimilar y poner en práctica los conocimientos adquiridos, de una forma activa, visual y motivadora. Un cambio progresivo 
y constante, impulsado por el apoyo a la formación del profesorado en nuevas tecnologías, pedagogía o metodologías docentes.

El objetivo ahora era desarrollar un nuevo modelo, presencial o semipresencial, que tratase de incrementar: motivación, implicación, aprendizaje activo, clase invertida (trabajar conceptos antes y aprovechar más las horas de clase) (Marqués, 2016), flexibilidad, disponibilidad de materiales para afianzar contenidos, autoevaluación. De igual modo, tratar que el nuevo modelo permitiese, cuando no fuese posible la presencia física del alumnado, comunicarse utilizando otros medios, como videoconferencia, correo electrónico o tutorías virtuales.

Para ello, resultaba necesario:

- Modificar los hábitos y rutinas tradicionalmente adquiridos.

- Rediseñar la docencia, para incorporar actividades a desarrollar antes, durante y después de las sesiones presenciales.

- Desarrollar materiales complementarios a los apuntes de la asignatura, que fuesen visuales y prácticos, capaces de enlazar información directamente accesible desde internet, como videos, documentos, esquemas, imágenes...

- Reemplazar las clases tradicionalmente expositivas por otras más dinámicas, con una participación más activa por parte del estudiantado.

- Apoyar a los estudiantes que, de forma justificada, no pudiesen asistir a clase.

\subsection{Formación del profesorado}

Tanto para adaptarse a una docencia $100 \%$ online como para rediseñar la docencia presencial o semipresencial, resultó fundamental mejorar la competencia virtual del profesorado. La universidad respondió de forma eficiente y puso a disposición de la comunidad universitaria multitud de cursos, diseñados de forma que pudiesen ser seguidos por el mayor número de usuarios posible, incluso en modalidad de autoformación. Así, se ofertaron diversos cursos específicos, flexibles, con materiales audiovisuales que permitieron recibir la formación al propio ritmo y según las posibilidades y disponibilidad particulares. $A$ modo de ejemplo, cabe citar que, en el caso concreto de la asignatura de Mdc3, el profesorado atendió cursos relacionados con las siguientes materias:

- Herramientas audiovisuales para la docencia online.

- Blended learning (Salinas, 2018).

- Diseño de actividades para la docencia y evaluación en línea e invertida.

- Clases dinámicas y participativas mediante el uso de herramientas de Google Workspace.

- $\quad$ Creación de contenido multimedia interactivo utilizando el módulo H5P del Aula Virtual.

- Diseño de cuestionarios mediante Aula Virtual. 


\subsection{Mejoras introducidas en la asignatura Materiales de Construcción III}

La formación recibida resultó esencial para mejorar la transmisión de conocimiento, rediseñar la docencia y facilitar al alumnado materiales que les permitan poner en práctica los conocimientos teóricos adquiridos, mejorando sus competencias y resultados de aprendizaje. Así, se diseñaron y desarrollaron diferentes tipos de actividades, a realizar:

- Antes de las prácticas de laboratorio: cuyo objetivo era que los alumnos revisaran y trabajaran los conceptos teóricos que serían posteriormente desarrollados en la sesión presencial.

- Durante las prácticas de laboratorio: Se rediseñó el trabajo a desarrollar, adaptándolo a las circunstancias sanitarias del momento y a las actividades a realizar antes y después.

- Después de las sesiones presenciales de teoría, problemas y laboratorios: se prepararon cuestionarios de autoevaluación a través del aula virtual, que les permitiesen comprobar el grado de conocimiento adquirido.

Las figuras 2 y 3 muestran ejemplos de actividades desarrolladas utilizando el módulo H5P (CEDEC, 2021), recientemente integrado en al aula virtual (AV). En la Universitat Jaume I el AV utiliza la plataforma moodle y, de forma sencilla e intuitiva, resulta un gran apoyo complementario a las sesiones presenciales. La incorporación del entorno de creación de contenido H5P resulta verdaderamente útil y abre un gran abanico de posibilidades para integrar actividades dinámicas, motivadoras e interactivas en el aula virtual. La presentación interactiva (figura 2) es una herramienta que permite combinar la presentación de información (mediante introducción de texto, enlaces a videos, figuras, páginas web...), con cuestiones de diversos tipos (respuesta múltiple, verdadero / falso, rellenar espacios en blanco (figura $2 a$ ), arrastrar palabras sobre huecos (figura $2 b$ )...), tratando así de fomentar una lectura activa y comprensiva.

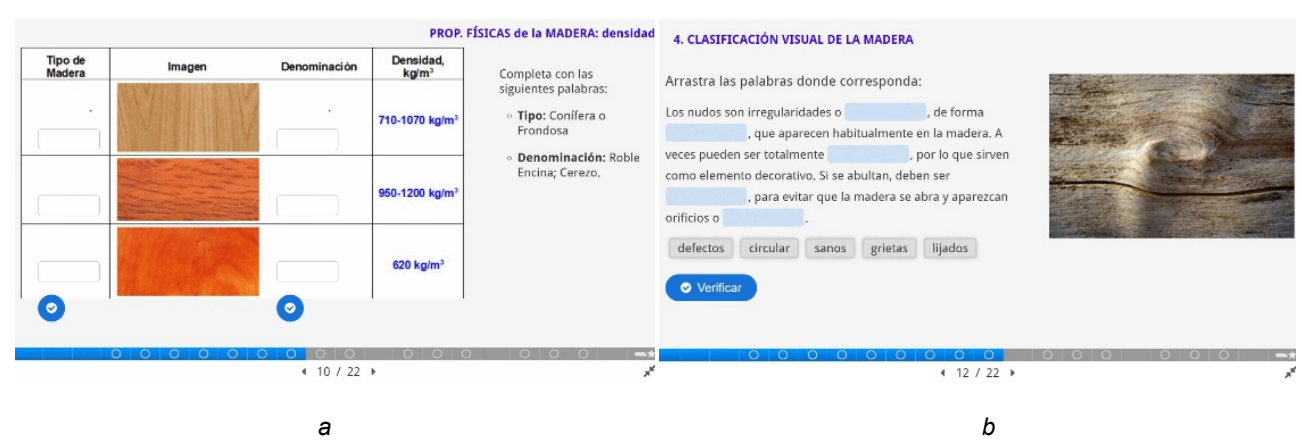

Fig. 2 Presentación interactiva diseñada con el módulo H5P para la asignatura Mdc3 
El video interactivo (figura 3) resulta también una herramienta excelente para completar las actividades presenciales pues, partiendo de un video (vinculado mediante enlace o desarrollado por nosotros a partir de fotos o video) permite intercalar actividades interactivas: como preguntas relacionadas con información que aparecerá en el video (figura 3a, pueden incorporarse antes o después de que aparezca dicha información), resumen del video a partir de cuestiones creadas por el profesorado (figura $3 b$ )...

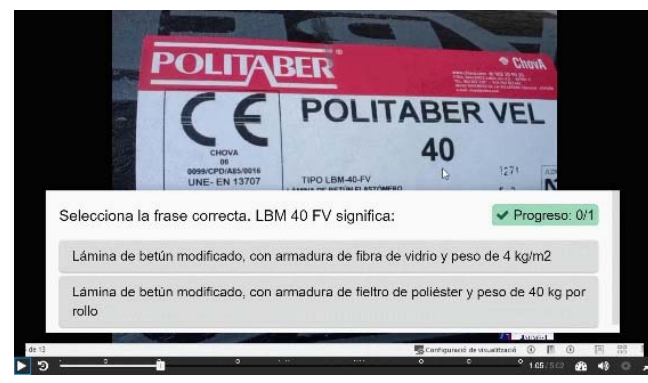

a

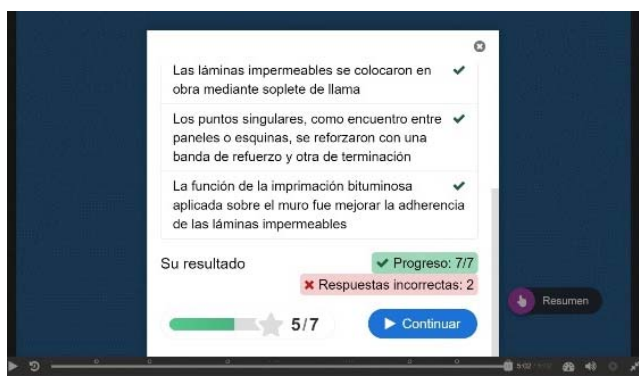

Fig. 3 Video interactivo diseñado con el módulo H5P para la asignatura Mdc3

La figura 4 presenta un cuestionario de autoevaluación propuesto para uno de los temas de la asignatura. El alumnado debe completarlo al finalizar el desarrollo del tema correspondiente, y les permite autoevaluar el nivel de conocimiento adquirido.
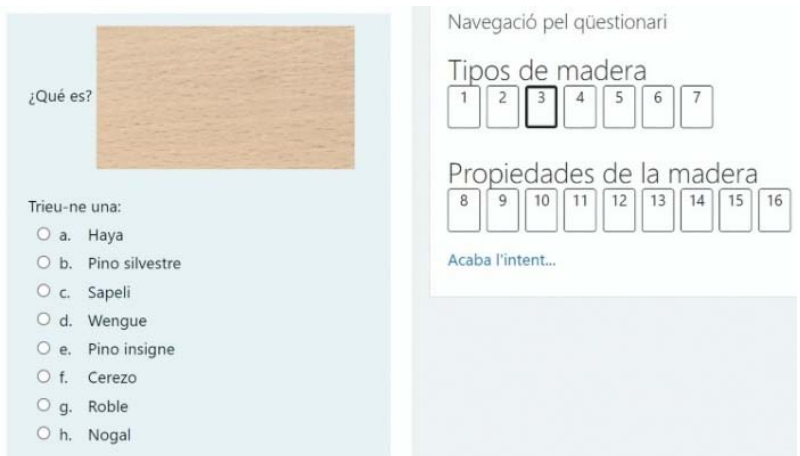

Fig. 4 Cuestionario de autoevaluación diseñado mediante el AV para la asignatura $M d c 3$

En definitiva, se ha tratado de aprovechar los materiales desarrollados y el conocimiento adquirido derivados de la situación sanitaria vivida para rediseñar la docencia y proponer actividades más atractivas, interactivas y motivadoras, que fomenten la participación e implicación del estudiantado en su propio proceso de aprendizaje. Combinar la docencia presencial con actividades online, de forma síncrona o asíncrona, permite reforzar y ampliar significativamente las oportunidades de las que dispone el alumnado para comprender y trabajar los conceptos teóricos, ponerlos en práctica y mejorar los resultados de aprendizaje. 


\subsection{Futuras propuestas de mejora}

Las diferentes actividades diseñadas para la asignatura Mdc3 han permitido una mayor implicación y motivación por parte del alumnado. No obstante, todavía queda mucho camino por recorrer:

- En ocasiones los estudiantes muestran poca disposición a realizar las actividades antes de la clase, pues no están habituados a ello. Introducir estas actividades de forma cada vez más sistemática les ayudaría a integrar una nueva forma de trabajo.

- Se pueden rediseñar más actividades complementarias, de refuerzo a las sesiones presenciales.

- Se pueden rediseñar más sesiones presenciales para invertir la clase (flipped clasroom), con el fin de aprovechar al máximo el tiempo presencial para el trabajo en actividades más complejas, como la resolución de problemas y ejercicios de aplicación práctica.

Los cambios propuestos pueden ser progresivos, pues el diseño de nuevas actividades complementarias y modificar las sesiones presenciales para invertir el orden de la clase requieren tiempo; además de un cambio de hábitos y rutinas, por parte de alumnado y profesores. No obstante, el esfuerzo vale la pena, pues una participación más activa del estudiantado en su propio proceso de aprendizaje derivará en una mayor motivación y un aprendizaje más duradero y significativo.

\section{Conclusiones}

La situación sobrevenida originada por la pandemia mundial de la COVID-19, la inseguridad y falta de comunicación presencial vividas durante el confinamiento, o la formación insuficiente en nuevas tecnologías generaron una fuerte necesidad y motivación. El esfuerzo realizado por la comunidad universitaria permitió transformar el proceso de enseñanzaaprendizaje, mejorándolo en muchos sentidos:

- Desde la universidad se ha dado un fuerte impulso a la formación del profesorado en nuevas tecnologías de la educación, con el desarrollo de guías, el apoyo de personal especializado, cursos de formación para el desarrollo de materiales multimedia o el uso de herramientas para la comunicación online.

- Gracias a una oferta de formación flexible, con materiales dinámicos y audiovisuales, el profesorado hemos podido mejorar significativamente nuestras competencias digitales.

- Fruto de la experiencia vivida, se ha logrado mejorar el proceso de enseñanzaaprendizaje, desarrollando nuevos materiales de apoyo y refuerzo de las actividades presenciales, que permiten y refuerzan el autoaprendizaje; así como facilitando el seguimiento de la asignatura cuando los alumnos no pueden asistir a las clases.

En definitiva, las dificultades vividas impulsaron un cambio hacia un proceso de enseñanzaaprendizaje más flexible, dinámico, activo y motivador; un proceso más centrado en el estudiantado. 


\section{Referencias}

ADELL SEGURA, J.; ANDRÉS CEBRIÁN, P. (2020). "Luces y sombras de la experiencia del confinamiento y el paso a la "Enseñanza en línea de emergencia» (CENT)". En IV Jornadas de innovación educativa DIMEU. Camino hacia la Virtualidad en la Universitat Jaume I. Castelló de la Plana: Publicacions de la Universitat Jaume I. Servei de Comunicació i Publicacions.

CEDEC, CENTRO NACIONAL DE DESARROLLO CURRICULAR EN SISTEMAS NO PROPIETARIOS. ¿Qué puede hacer H5p por mis alumnos?. < https://cedec.intef.es/que-puede-hacer-h5p-por-misalumnos/ > [Consulta: 13 de mayo de 2021] [personal o institucional]

CENT, CENTRE D'EDUCACIÓ I NOVES TECNOLOGIES DE LA UNIVERSITAT JAUME I. $<$ https://cent.uji.es/pub/> [Consulta: 13 de mayo de 2021]

MARQUÉS, M. (2016). "Qué hay detrás de la clase al revés (flipped classroom)". En Actas de las XXII Jornadas sobre la Enseñanza Universitaria de la Informática, 6-8 de julio, Almería. 77-84.

MARTÍNEZ-MOYA, J.A.; PITARCH-ROIG, A.; GARCÍA-ESPARZA, J.A.; RUÁ-AGUILAR, M.J. y CABEZA GONZÁLEZ, M. (2020) "Implementation of coordinated vertical project at technical architecture bachelor's degree, En ICERI 2020, 13th annual International Conference of Education, Research and Innovation, 9-10 November, Sevilla: IATED. 966-975.

PITARCH-ROIG, A.M.; MARTíNEZ-MOYÁ, J.A.; SÁEZ-RIQUELME, B.; REIG-CERDÁ, L.; MÁNEZPITARCH, M.J. "Analysis of non face-to-face teaching of the technical architecture bachelor's degree during the covid-19 state of alarm. Learned lessons." En ICERI 2020, 13th annual International Conference of Education, Research and Innovation, 9-10 November, Sevilla: IATED. 1785-1793.

REIG, L., RUÁ, M.J., BRAUliO, M., LeCHA, A., HUEDO, P. GALlego, T., PITARCH, A., SÁEZ, B., BABILONI, J. (2017). "Learning by doing in the bachelor's degree of technical architecture at the Universitat Jaume I". En EDULEARN 17, 9th annual International Conference on education and New Learning Technologies, 3-5 de julio, Barcelona: IATED. 7312-7321.

SALINAS, J., DE BENITO, B., PÉREZ, A., GISBERT, M. (2018). “¿Qué es el Blended Learning? Una revisión desde la investigación educativa" en RIED. Revista Iberoamericana de Educación a Distancia, 21, 1, 195-213. https://doi.org/10.5944/ried.21.1.18859. 


\title{
EDIFICATE
}

I Congreso de Escuelas de Edificación y Arquitectura Técnica de España

València, 4 y 5 de noviembre de 2021

Escuela Técnica Superior de Ingeniería de Edificación

Universitat Politècnica de València

Doi: https://doi.org/10.4995/EDIFICATE2021.2021.13374

\section{RIARTE. EI repositorio científico y profesional de la Arquitectura e Ingeniería. Contenidos y avances}

\section{RIARTE. The scientific and professional repository of Architecture and Engineering. Contents and advances}

\author{
Joaquín Manuel Durán Álvarez ${ }^{\mathrm{a}}$, Juan López-Asiain Martínez ${ }^{\mathrm{b}}$, Alejandro Payán de \\ Tejada Alonsoc

\begin{abstract}
aUniversidad de Granada. jdaeuat@ugr.es, '•Universidad Politécnica de Madrid. apayan@arquitectura-tecnica.com
\end{abstract} \\ juan.lopezasiain@upm.es, ${ }^{\circ}$ Consejo General de la Arquitectura Técnica de España.
}

\begin{abstract}
Just 3 years ago, the Research Repository of Technical Architecture in Spain (RIARTE) was launched, promoted by the CGATE, with the idea of identifying, recording, visualising and making use of the scientific-technical production of Technical Architecture.
\end{abstract}

At present, almost 2,000 documents, including doctoral theses, scientific production documents, collegiate articles and technical reports, make up a very important documentary corpus of the profession. It has emerged as something completely new in Spain and has established itself as a first-rate tool for both the dissemination of research and professional work in TA and for the recognition of authors.

The study of the typology of the documents, the journals where they are published, the most prolific authors, the areas of importance and the more than 3,100 free descriptors, is a global overview of the research and work of Technical Architects and its transmission to the construction sector and society in general.

For this reason, a transversal and longitudinal analysis will be carried out on the areas of work and the most used journals.

Keywords: Scientific production, Technical Architecture, Building Engineering, Research areas, Spain, RIARTE, professional journal, keywords, institutional repository. 


\section{Resumen}

Apenas hace 3 años, se inició el Repositorio de Investigación de la Arquitectura Técnica de España (RIARTE), promovido por el CGATE, con la idea de identificar, registrar, visualizar y dar uso a la producción científico-técnica de la Arquitectura Técnica.

En la actualidad, casi 2.000 documentos entre tesis doctorales, documentos de producción científica, artículos e informes técnicos, configuran un Corpus documental de la profesión muy importante. Ha surgido como algo completamente nuevo en España y se ha establecido como una herramienta de primer orden para, tanto la difusión de la investigación y el trabajo profesional de la AT, como para el reconocimiento de los autores.

El estudio de la tipología de los documentos, las revistas donde se publica, los autores más prolíficos, las áreas de importancia y los más de 3.100 descriptores libres, es un recorrido global sobre la investigación y el trabajo de los Arquitectos Técnicos y su transmisión al sector de la construcción y a la sociedad en general.

Por ello se realizará un análisis transversal y longitudinal sobre las áreas de trabajo y las revistas más usadas.

Palabras clave: se incluirá una lista corta, como máximo diez palabras clave. Por ejemplo: plan de estudios, metodologías docentes, competencias, formación online, recursos tecnológicos, evaluación, prácticas de empresa, Proyecto Final de Grado, etc. 


\section{Introducción}

El repositorio RIARTE ${ }^{1}$ surgió como idea por parte del CGATE$^{2}$ en el año 2017, para estar plenamente operativo en el año 2018. En la actualidad, y después de tres años de funcionamiento y con casi 2.000 documentos técnico-científicos se configura como una herramienta de primer orden para la búsqueda de información en el sector de la construcción.

Con más de 20.000 visualizaciones en el año 2019, se está convirtiendo en una base de datos de referencia para cualquier agente de la construcción (técnicos de proyecto y ejecución de obras, especialistas en mantenimiento, en eficiencia energética, en instalaciones o materiales, constructores, investigadores, usuarios, etc.) y, además, recopila el corpus de investigación y técnico de la Arquitectura Técnica $\left(\mathrm{AT}^{3}\right)$.

Los repositorios, surgen como herramienta de la filosofía Open Access. Ésta surgió como "un nuevo modelo de difusión de la investigación científica" (Björk, Laakso, Welling, y Paeatau, 2014, p.237). El Movimiento Open Access emerge así, con fuerza, en el mundo de la publicación científica.

Como dice la Guía para la evaluación de repositorios institucionales de investigación (Azorín, et al, 2021, p. 4):

El acceso abierto (Open Access) consiste en proveer de acceso on-line a toda la información científica disponible (artículos, monografías, datos de investigación...) de forma gratuita para el lector y bajo licencia para que pueda ser usada y explotada por los investigadores, las empresas y los ciudadanos. La idea que subyace bajo el acceso abierto es que los resultados y los datos utilizados en investigaciones financiadas públicamente deberían estar disponibles para todos y tener licencias que permitan su reutilización.

La investigación se hace más efectiva y sus resultados más visibles cuando se eliminan las barreras legales, comerciales y tecnológicas de acceso a la información científica. Además, el acceso abierto previene la duplicación de esfuerzos en investigación, fomenta la transferencia tecnológica y de conocimiento y promueve la innovación. Todos los actores implicados en el sistema de comunicación de la información científica se benefician del acceso abierto a la investigación y a los datos generados por ésta.

Además (Ferreras y Merlo, 2015, p. 98) comentan que:

\footnotetext{
${ }^{1}$ Repositorio de Investigación en Arquitectura Técnica

${ }^{2}$ Consejo General de la Arquitectura Técnica de España

3 AT.- Arquitectura Técnica; Aparejadores; Grado en Ingeniería de Edificación; Grado en Edificación; Grado en Arquitectura Técnica; Grado en Ciencia y Tecnología de la Edificación; Grado en Arquitectura Técnica y Edificación
} 
el acceso abierto es una forma de amortizar la inversión en investigación de un país, al poner a disposición de los usuarios, la documentación derivada de la misma, además de ayudar a la inclusión digital de los ciudadanos al ofrecer los contenidos a texto completo a los investigadores, los docentes, los estudiantes, las instituciones y a toda la ciudadanía.

Desde la Declaración de Budapest (Chan et al, 2002), dos son las estrategias seguidas para la implantación y el desarrollo del Movimiento Open Access: la publicación de revistas en Open Access o el traspaso del modelo antiguo a la edición en abierto; y, por otro lado, "la creación de los denominados hasta ahora "Repositorios Institucionales (IR) en Open Access. Ambas estrategias de trabajo son denominadas ahora como "Ruta oro" y "Ruta verde" respectivamente" (Sánchez y Melero, 2007, p. 2).

La denominación de repositorio institucional si bien al principio tenía connotaciones de ser sólo para instituciones de investigación o universitarias se ha ampliado, estableciendo una definición mucho más amplia como señala (MacColl, Jones y Andrew, 2006, p. 1): "Los repositorios institucionales han surgido de las universidades, pero también se están extendiendo a otros tipos de organizaciones educativas, como los colegios e institutos de investigación".

Así, los repositorios institucionales han derivado en repositorios temáticos en donde se recopila documentos digitales de investigación de una institución o de una temática.

En la idea inicial de creación del repositorio RIARTE surgieron varias justificaciones del por qué realizarlo y aparecen en la génesis de éste (Consejo General de la Arquitectura Técnica de España, 2018):

- Unidad de todos los documentos almacenados que actualmente se encuentran dispersos en distintas bases de datos, repositorios o bibliotecas, lo cual permite una fácil recuperación.

- Recuperación de aquellos documentos que, o bien porque sus registros han desaparecido o nunca han sido registrados en bases en red, no estaban visibles.

- Preservación a largo plazo de los registros y/o los documentos.

- Visibilidad universal de los trabajos.

- Una comunicación a la sociedad en general y al mundo profesional y docente de la producción científica realizada por los AT.

- Una identificación del corpus documental de la profesión, con verificación de las áreas de mayor interés, evolución y perspectivas.

- Un registro que permite el análisis y futuras investigaciones desde diversos ámbitos de nuestra producción científico-técnica.

- Un interés mucho más creciente de toda la comunidad científica sobre nuestra profesión y la investigación generada.

- Una interoperatibilidad entre distintas bases de datos que facilita la recuperación de contenidos desde distintos repositorios y la incorporación a redes nacionales e internacionales de repositorios. 
- Una evaluación de los contenidos registrados respecto a su uso por los usuarios del repositorio. Esto también produce una mayor difusión del trabajo de los autores.

- El fortalecimiento del prestigio y reconocimiento de aquellos trabajos de calidad contrastada y con gran interés por los usuarios, anexo a los autores.

- Una convergencia de esfuerzos desde el Consejo y los Colegios, con la Universidad, e intercambio de criterios e iniciativas de proyectos futuros.

Hay también seis funciones consecuencia de la anteriores:

- la recuperación y puesta en valor de aquellos documentos que, por la escasa difusión del soporte o por su no registro, tenían alta obsolescencia.

- La difusión a través de redes nacionales e internaciones de portales y bases de datos de los documentos depositados en RIARTE.

- El tener una base de estudio de las áreas de investigación de la AT y, por ende, de la construcción en general, transversalmente en el estado de la cuestión y longitudinalmente a lo largo del tiempo.

- El reconocimiento a los investigadores a través de los índices de impacto inherentes al repositorio en donde su usabilidad a través de los accesos queda visible.

- El poder usar para la docencia una base de datos con información contrastada y actual de múltiples temas que, en la mayoría de los casos están dispersos.

- El aunar el mundo profesional, (revistas y congresos colegiales) con el investigador (investigadores docentes) con las connotaciones positivas que tiene la unificación del corpus documental.

El repositorio RIARTE es parte esencial también de la producción científica de la AT que se va incorporando año tras año, con la información de la base de datos que se realiza para el Observatorio de la AT (Durán, 2020), complementándose uno con otro.

Es una iniciativa única en España en donde cada día crece la cantidad y calidad de los documentos aportados. Y crece el uso de su base de datos como fuente de información de primer orden del mundo de investigación y profesional alrededor del sector de la construcción.

Además, y dada su interoperatibilidad y calidad, ya ha sido aceptada en redes nacionales e internacionales. Así, cualquier documento registrado en RIARTE, pasa a esas redes:

- $\quad$ RECOLECTA (FECYT. Ministerio de Ciencia e Innovación, 2021):

Recolecta, o Recolector de Ciencia Abierta, es el agregador nacional de repositorios de acceso abierto. En esta plataforma se agrupan a todas las infraestructuras digitales españolas en las que se publican y/o depositan resultados de investigación en acceso abierto.

Recolecta nació en el año 2007 fruto de la colaboración entre la Fundación Española para la Ciencia y la Tecnología (FECYT) y la Red de Bibliotecas Universitarias (REBIUN) de la CRUE. 
- HISPANA (Gobierno de España. Ministerio de Cultura y Deporte, 2021): Hispana es el portal de acceso al patrimonio digital y el agregador nacional de contenidos a Europeana.

Reúne las colecciones digitales de archivos, bibliotecas y museos españoles.

- $\quad$ EUROPEANA (Comisión Europea. European Digital Library Network, 2021): Europeana (Biblioteca Digital Europea) fue lanzada por la Comisión Europea en noviembre de 2008 , con dos millones de volúmenes, iniciando un proyecto que pretende crear un portal de la cultura europea digitalizada y de fácil acceso para el usuario. En la actualidad tiene ya más de 50 millones de documentos.

- GOOGLE ACADÉmico (Google Inc., 2021): Google Académico (Google Scholar) es un buscador que permite localizar documentos de carácter académico como artículos, tesis, libros, patentes, documentos relativos a congresos y resúmenes. Se alimenta de información procedente de diversas fuentes: editoriales universitarias, asociaciones profesionales, repositorios de preprints, universidades y otras organizaciones académicas.

Por ello cualquier documento indizado en RIARTE pasa a esta disponible en cualquier ordenador del mundo con los servidores de búsquedas en estos portales.

Así, RIARTE se transforma, también, en una herramienta muy útil para la docencia. Los materiales digitales recopilados son elementos de contenido con acceso fácil e intuitivo por parte de los alumnos y recopilan información normalmente diseminada y sin visibilidad.

Por lo tanto (Gewerc et al, 2006) no se trata sólo de localizar los recursos existentes en sus lugares de depósito (repositorios), sino de entender que la utilización pertinente de éstos requiere de apoyos formativos potentes para ayudar al profesorado universitario a realizar el cambio de paradigma de enseñanza para el aprendizaje demandado. Estos apoyos formativos deben ir dirigidos a que los docentes adquieran herramientas metacognitivas para posibilitar su aprendizaje permanente y a considerar y proporcionar oportunidades para la investigación sobre su práctica docente.

\section{Objetivos}

El objetivo general es el análisis del repositorio RIARTE desde el punto de vista documental y de usabilidad.

Los específicos son:

1. Analizar el número de documentos totales en RIARTE y evolución.

2. Clasificar la tipología de documentos registrados.

3. Estudiar el acceso por parte de los usuarios a RIARTE.

4. Determinar los documentos con mayor acceso.

5. Identificar a los autores con más impacto 


\section{Metodología}

Se ha tomado como origen de datos los que recoge el repositorio RIARTE y los sucesivos informes que se han venido elaborando sobre su funcionamiento. El espacio temporal ha sido desde Abril 2018 a Junio 2021.

Se usarán variables bibliométricas cuantitativas respecto a número de documentos y cualitativas respecto a la tipología de documentos.

Y variables altmétricas con el número de visualizaciones registradas.

Respecto a los datos del repositorio se han registrado con la siguiente metodología:

- Las tesis doctorales contemplan el total de las registradas por AT desde el inicio de la carrera (año 1.978).

- Los artículos técnicos dimanan de los registros de los artículos de revistas colegiales desde el año 2010.

- Las comunicaciones técnicas de las realizas en los Congresos CONTART 20062009-2010-2016-2018-2020.

- Los artículos y comunicaciones científicas de la producción de investigación en los años 2018-2019 de la AT.

Según la técnica de recogida de datos es una investigación descriptiva, dado que se pretende dar una visión general sobre RIARTE y sus contenidos.

La orientación de la investigación es aplicada, para el uso del repositorio y como herramienta docente.

La finalidad es descriptiva, dado que se representa RIARTE el fin último de esta comunicación es mostrarlo como herramienta docente y de visualización de contenidos.

Las variables que se han usado son cuantitativas (número de documentos, autores, descriptores) y cualitativas (visualizaciones).

El marco temporal es todos los documentos registrados en RIARTE desde su inicio hasta Junio de 2021. La investigación es tanto sincrónica porque se analiza el repositorio en el estado actual como diacrónica, dado que se estudia su evolución desde la creación.

\section{Desarrollo de la innovación y Resultados}

\subsection{Documentos}

El número total de documentos registrados hasta Junio de 2021 es de 1.811. La evolución a lo largo del tiempo ha sido la siguiente: 


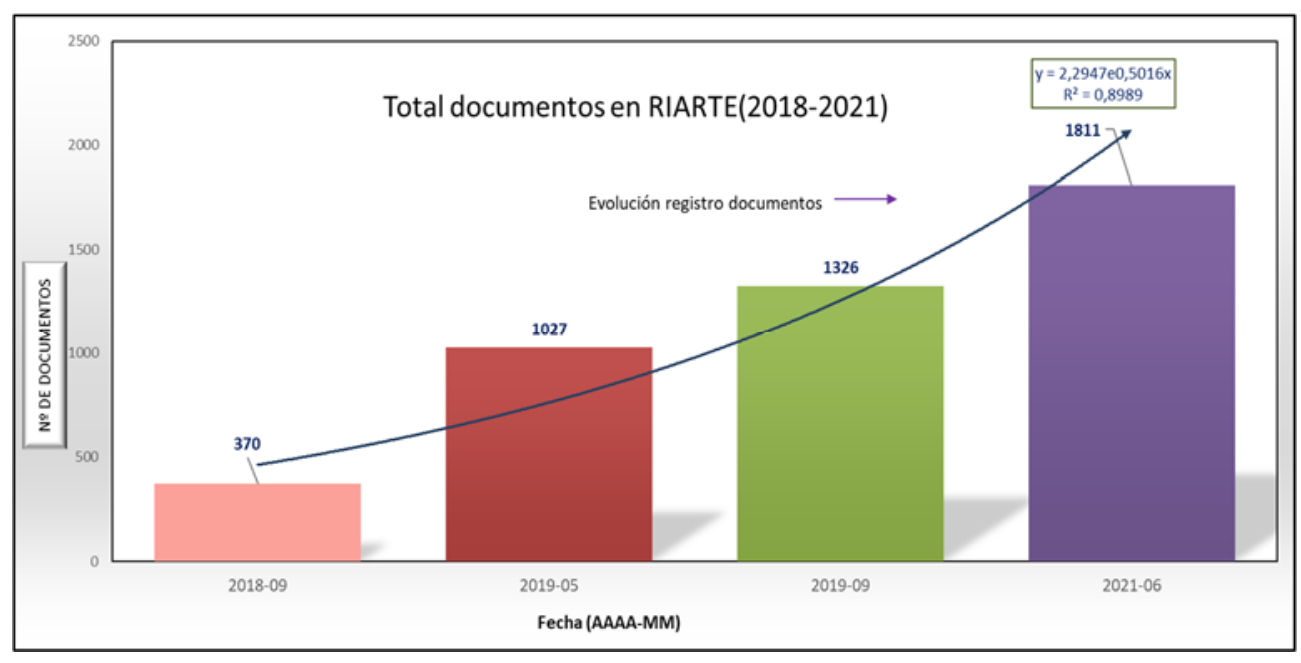

Figura 1. Total documentos en RIARTE (2018-2021). Origen: Elaboración propia

Como se observa, el ritmo de crecimiento de documentos es constante a lo largo del tiempo. En la actualidad se está registrando tanto la producción científica de 2020, como las actualizaciones de las revistas. Además, los autores cada vez más, piden la inclusión de toda su producción científica en RIARTE, dada su visibilidad y facilidad de acceso.

\subsection{Tipología de documentos}

El análisis actual de los documentos en RIARTE es:

Tabla 1. Total documentos en RIARTE por tipología. Origen: Elaboración propia

\begin{tabular}{lcc}
\multicolumn{1}{c}{ Tipos de documentos } & Totales & $\%$ \\
\hline TESIS DOCTORALES & 383 & $21,63 \%$ \\
\hline ARTÍCULOS CIENTÍFICOS & 192 & $10,84 \%$ \\
\hline ARTÍCULOS TÉCNICOS & 836 & $47,20 \%$ \\
\hline COMUNICACIONES CIENTÍFICAS & 45 & $2,54 \%$ \\
\hline COMUNICACIONES TÉCNICAS & 315 & $17,79 \%$ \\
\hline
\end{tabular}

Como se comprueba el porcentaje mayor es artículos técnicos. Son los registrados de las revistas colegiales dado que se han recogido todos los realizados desde el 2010 al 2021. Las tesis doctorales están en su totalidad y las comunicaciones técnicas, las existentes desde el año 2009 hasta el último CONTART 2020. 
Los artículos y comunicaciones científicas sólo se han registrado las del 2018-2019. Se está actualizando la base para incorporar las del 2020 y años anteriores.

Para el estudio del análisis temporal se han tomado los registros por tipología documental.

La evolución a lo largo del tiempo ha sido la siguiente:

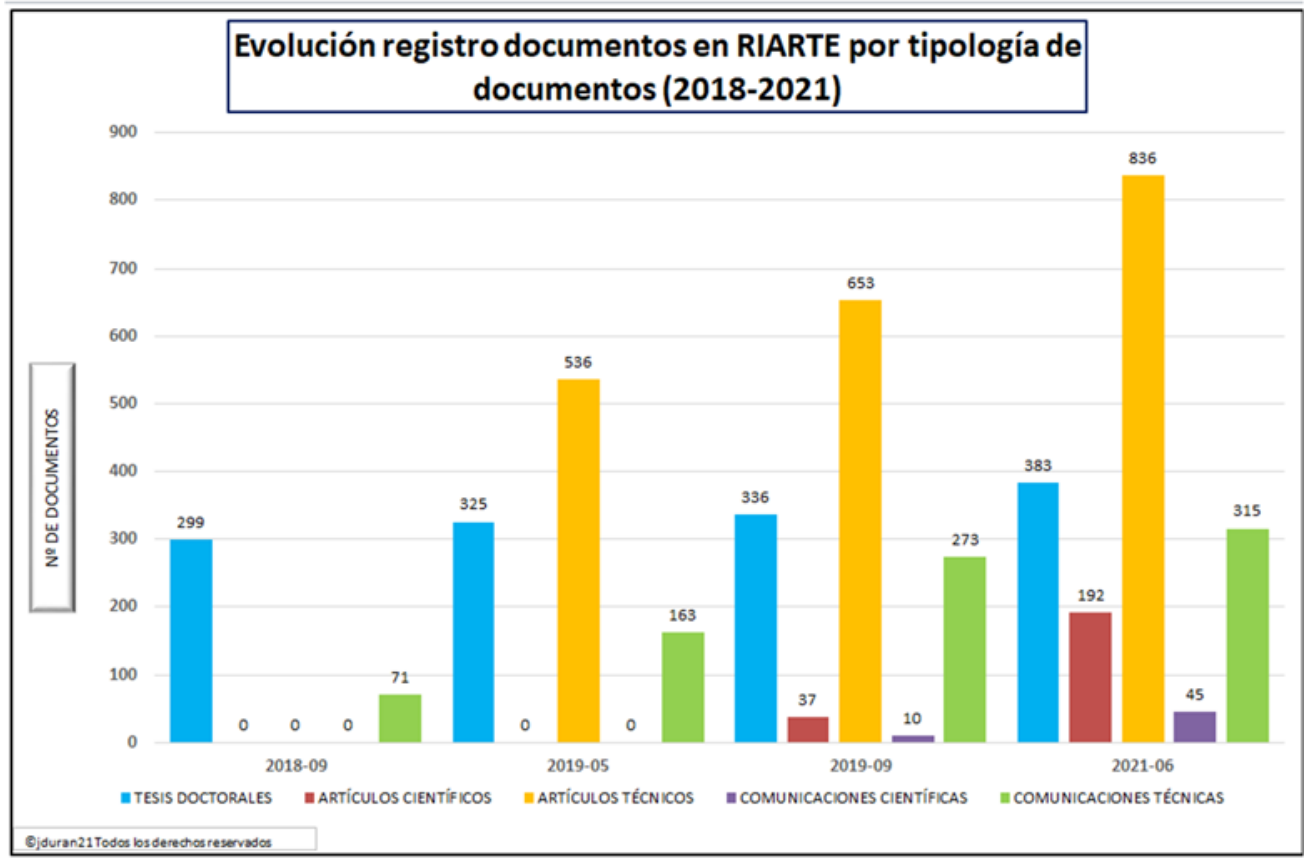

Figura 2. Evolución registro documentos en RIARTE por tipología documentos 2018-2021. Origen: Elaboración propia

\subsection{Autores}

El total de autores registrados ha sido de 426.

Las razones por tener más documentos pueden ser varias. Una es que en algunas revistas colegiales todos los artículos los firman autores de la misma revista y otra que algunos investigadores han pedido registrar toda su producción científica.

Tabla 2. Autores con más documentos registrados en RIARTE. Origen: Elaboración propia

\begin{tabular}{|lc|}
\hline \multicolumn{1}{|c}{ Autor } & $\begin{array}{c}\mathbf{N}^{\circ} \\
\text { Documentos }\end{array}$ \\
\hline Macías Bernal, Juan Manuel & 19 \\
Río Merino, Mercedes del & 15
\end{tabular}


RIARTE. El repositorio científico y profesional de la Arquitectura e Ingeniería. Contenidos y avances RIARTE. The scientific and professional repository of Architecture and Engineering. Contents and advances

\begin{tabular}{ll} 
Bienvenido Huertas, David & 13 \\
\hline Alejandre Sánchez, Francisco Javier & 11 \\
\hline Moyano Campos, Juan José & 11 \\
\hline Prieto Ibáñez, Andrés José & 10 \\
\hline Vidales Barriguete, Alejandra & 9 \\
\hline Piña Ramírez, Carolina & 9 \\
\hline Rodríguez Sáiz, Ángel & 8 \\
\hline Silva, Ana Catarina Ferrereira da & 8 \\
\hline González García, María de las Nieves & 6 \\
\hline
\end{tabular}

\subsection{Impacto}

Como impacto ha medido el número de visualizaciones de los documentos. El ranking creado es el siguiente:

Tabla 3. Documentos con más visualizaciones en RIARTE. Origen: Elaboración propia

\section{Título del documento}

Identificación de hogares vulnerables a partir del concepto pobreza energética. Indicador y modelo de evaluación
Visualizaciones

4.322

1.094

959

930

Lean Construction y la planificación colaborativa. Metodología del Last

Planner® System

El rol de las buenas prácticas educativas en los centros docentes :

821

organización, funcionamiento y docencia

Nueva metodología de evaluación de riesgos laborales adaptada a obras

800

de edificación: Nivel de la acción preventiva

Análisis cualitativo y cuantitativo de los fallos de diseño y ejecución en los

768

proyectos de cubiertas y fachadas y de su incidencia patológica en los

edificios de España

Intervención de los Arquitectos Técnicos en cálculos de estructuras

709

Sistema de gestión de residuos de construcción y demolición en obras de

682

edificación residencial. Buenas prácticas en la ejecución de obra

Aplicación del $8 \mathrm{~d}$ y de los principios Lean para la mejora de la seguridad y

674

prevención de obras de edificación 


\subsection{Descriptores}

En este repositorio el valor fundamental, aparte de lo mencionado es el registro de cada documento con descriptores libres y descriptores de un tesauro normalizado de la UNESCO, SKOS de Ciencia y Tecnología.

Con ello se parte de una base muy importante para análisis de redes, temas preferentes, clúster más relacionados, etc.

El total de descriptores libres que ahora mismo se ha registrado es de 3.192 y su análisis se presta a múltiples estudios.

Por ejemplo, respecto a tipologías de obras se han registrado los siguientes datos:

Tabla 4. Tipos de obra registrados en RIARTE. Origen: Elaboración propia

\begin{tabular}{|cc|}
\hline Descriptor tipo de obra & Documentos \\
\hline Obras de rehabilitación & 174 \\
\hline Obra nueva & 118 \\
\hline Obras de restauración & 68 \\
\hline Obras de reforma & 20 \\
\hline Obras de ampliación & 17 \\
\hline Obras de reparación & 17 \\
\hline Obras de consolidación & 9 \\
\hline Obras de reconstrucción & 4 \\
\hline
\end{tabular}

Como se comprueba, los documentos en su mayor parte están centrados en rehabilitación, después en obra nueva y finalmente en restauración. Es sintomático que la tendencia es la misma en el sector de la construcción según distintos informes (CESCE, 2020) y la rehabilitación aumenta su porcentaje años tras año, frente a la obra nueva en edificación.

\subsection{Factor de impacto}

Se han recogido los datos sobre el uso de RIARTE, por parte de los usuarios. Partíamos de 20.000 visualizaciones en el año 2019 , después de un año de funcionamiento.

A día de hoy, 30 de junio de 2021, los datos son: 
- Visitas a ítems (visualizaciones humanos):

- Visitas robots (tipo Google o buscadores portales): 2.140 .031

- Descargas de documentos:

El crecimiento ha sido exponencial y denota el interés del sector de la construcción en esta base de datos y que es una herramienta formidable para la transferencia de conocimiento desde la Arquitectura Técnica a la sociedad en general.

\section{Conclusiones}

Las conclusiones más importantes del presente trabajo son las siguientes:

1. El número de documentos en RIARTE en tres años ha aumentado de forma progresiva incorporando documentos técnicos y científicos.

2. Los documentos más registrados son artículos técnicos, tesis doctorales y comunicaciones técnicas.

3. El número de visualizaciones se ha multiplicado pasando el primer año de 8.000 a las casi 300.000 de la actualidad. Y las descargas también han sido muy importantes (95.631), lo que denota la usabilidad y visibilidad para los autores y usuarios.

4. Los documentos con mayor número de visualizaciones están relacionados con los temas más emergentes en la construcción: pobreza energética, bioconstrucción, programación y seguimiento de control de calidad, Lean Construction, Prevención de riesgos, patologías, cálculo de estructuras y $8 \mathrm{~d}$.

5. Los autores con mayor registro en RIARTE son Juan Manuel Macías Bernal, Mercedes del Río Merino y David Bienvenido Huertas. Los tres con gran producción científica y que, a su vez, publican tanto en revistas colegiales como en CONTART.

6. Respecto a los descriptores, éstos pueden reflejar la realidad de la Construcción en cuanto a distintos parámetros, como por ejemplo la tipología de obras que se realizan.

\section{Referencias}

AZORÍN, C., BERNAL, I., GOMEZ CASTAÑO, J., GUZMAN PEREZ, C., LOSADA YAÑEZ, M., MARIN DEL CAMPO, R., MARTINEZ GALINDO, F., MARTÍNEZ POUSA, C., MORILLO MORENO, J. C. y PRATS PRAT, J. (2021). Guía para la evaluación de repositorios institucionales de investigación. Fundación Española para la Ciencia y la Tecnología, FECYT.

BJÖRK, B., WELLINLAAKSO, M., WELLING, P., y PAEATAU, P. (2014). Anatomy of Green Open Access. Journal of the American Society for Information Science and Technology, vol. 65, issue 2, p. 237-250. doi:10.1002/asi.22963 
CESCE (2020). Construcción. Informe sectorial de la economía española. Madrid : Unidad de riesgos de CESCE.

CHAN, L., CUPLINSKAS, D., EISEN, M., FRIEND, F., GENOVA, Y., GUEDON, J.-C. y VELTEROP, J. (2002). The Budapest Open Access Initiative. Budapest.

COMISION EUROPEA. EUROPEAN DIGITAL LIBRARY NETWORK. (2021). EUROPEANA. $<$ https://www.europeana.eu/es > [Consulta: 28 de junio de 2021]

CONSEJO GENERAL DE LA ARQUITECTURA TECNICA DE ESPAÑA. (2018). Repositorio de investigación RIARTE. <http://www.riarte.es/page/about> [Consulta: 28 de junio de 2021]

DURAN ÁLVAREZ, J. (2020). Observatorio de la producción científica de la Arquitectura Técnica de España 2019. Granada: Unidad de Evaluación de la Actividad Científica. Vicerrectorado de Investigación y Transferencia. Universidad de Granada. doi:10.5281/zenodo.3902619

FECYT. MINISTERIO DE CIENCIA E INNOVACION. (2021). RECOLECTA. Recolector de ciencia abierta. https://recolecta.fecyt.es/portada?language=es [Consulta: 28 de junio de 2021]

FERRERAS FERNANDEZ, T., y MERLO VEGA, J. (2015). "Repositorios de acceso abierto: un nuevo modelo de comunicación científica. La Revista de la Sociedad ORL CLCR en el repositorio Gredos" en Revista de la Sociedad Otorrinolaringológica de Castilla y León, Cantabria y La Rioja, vol. 6, issue 12, p. 94-113.

GEWERC BARUJEL, A., PERNAS MORADO, E., RODRIGUEZ RODRIGUEZ, J., VIDAL PUGA, M., VILA SOBRINO, X., y AGRA PARDIÑAS, M. (2006). "La construcción de un repositorio de materiales abiertos reutilizables para apoyo a la docencia universitaria: MOREA" en Revista Lationamericana de tecnología educativa, vol. 5, issue 2, p.55-75.

GOBIERNO DE ESPAÑA. MINISTERIO DE CULTURA Y DEPORTE. (2021). HISPANA. Acceso en línea al patrimonio cultural. <https://hispana.mcu.es/es/inicio/inicio.do> [Consulta: 28 de junio de 2021]

GOOGLE INC. (2021). Google Académico. <https://scholar.google.es/schhp?hl=es> [Consulta: 28 de junio de 2021]

MACCOLL, J., JONES, R., y ANDREW, T. (2006). The institutional repository in the digital library. Chandos (Oxford) Publishing Ltd.

SANCHEZ, S., y MELERO, R. (2007). La denominación y el contenido de los Repositorios Institucionales en Acceso Abierto : base teórica para la "Ruta Verde". http://hdl.handle.net/10261/1487 


\title{
EDIFICATE
}

I Congreso de Escuelas de Edificación y Arquitectura Técnica de España

València, 4 y 5 de noviembre de 2021

Escuela Técnica Superior de Ingeniería de Edificación

Universitat Politècnica de València

Doi: https://doi.org/10.4995/EDIFICATE2021.2021.13457

\section{Innovación tecnológica de productos de la construcción en las enseñanzas técnicas de la Edificación}

\section{Technological innovation of construction products in the technical education of building}

\author{
María Fernández-Alconchel ${ }^{\mathrm{a}}$, José David Bienvenido-Huertas ${ }^{\mathrm{b}}$ y Juan José Moyano- \\ Campos $^{a}$ \\ ${ }^{a}$ Departamento de Expresión Gráfica e Ingeniería en la Edificación, Escuela Técnica Superior de \\ Ingeniería de Edificación, Universidad de Sevilla, mfalconchel@us.es, jmoyano@us.es b Departamento \\ de Construcciones Arquitectónicas II, Universidad de Sevilla, Sevilla, España, jbienvenido@us.es
}

\begin{abstract}
The generation of new patents and utility models in building is an area of innovation that Technical Architects can cover.

It isn't usual to find Technical Architects who are creators of technological advances in building. At present, thanks to new materials and production technologies in buildings, numerous patents can be generated with great repercussions on the economy and the quality of the built product. It is important to promote this issue in the field of construction, promoting the role of the Technical Architect in the production of technologies.

There are several scientific and technological discoveries that are proof of the need to encourage a professional activity aimed at creation through patents, such as the creation of new systems of implementation, equipment, tools, new materials, among others.
\end{abstract}

Keywords: patents, BIM, teacher education methodologies, construction products, learning

\section{Resumen}

La generación de nuevas patentes y modelos de utilidad en edificación es un ámbito de innovación que pueden abarcar los Arquitectos Técnicos. 
No es habitual que se encuentren Arquitectos Técnicos creadores de avances tecnológicos en edificación. En la actualidad, gracias a los nuevos materiales y tecnologías de producción en edificación, se pueden generar numerosas patentes de gran repercusión en la economía y la calidad del producto construido (Debe et al., 2016). Es importante promover esta cuestión en el ámbito de la edificación, impulsando el protagonismo del Arquitecto Técnico en la producción de tecnologías.

Existen varios descubrimientos científicos y tecnológicos que son la prueba de la necesidad de incentivar una actividad profesional dirigida a la creación mediante patentes, como pueden ser la creación de nuevos sistemas de puesta en obra, equipos, herramientas, nuevos materiales, entre otros.

Palabras clave: patentes, BIM, metodologías docentes, productos de construcción, aprendizaje 


\section{Introducción}

En la actualidad las patentes como elementos de producción e innovación están recibiendo una atención especial en las Escuelas Técnicas Superiores, tanto en las ramas de Ingeniería como de Arquitectura. En este sentido están constituyendo una vía de transferencia del conocimiento, a partir de la revisión de la literatura internacional (Calderón-Martínez, 2014). En algunos países como Estados Unidos e Inglaterra, el marco institucional por excelencia son las universidades.

Las universidades deben cumplir la función de impulsar, ejecutar y apoyar las propuestas para el desarrollo tecnológico de las diferentes empresas de sus países. En ellas, se crea un esquema regulatorio destinado a:

a) Apoyar la creación y afianzamiento de una cultura para patentar las nuevas innovaciones

b) Promover la transferencia tecnológica

c) Apoyar a la mediana y pequeña industria en el desarrollo de competencias tecnológicas

El conjunto de estas tareas debe convertirse en una política universitaria de largo alcance (Del et al., 2009). Las actividades científicas y tecnológicas forman parte de la difusión de los resultados de las investigaciones universitarias. Los resultados de estas actividades deben tener una aplicación para la sociedad y constituir un medio visible de transferencia tecnológica. Por ello, han generado un gran interés desde el punto de vista de la investigación académica. De hecho, la Universidad de Sevilla tiene en su estructura del VII Plan Propio de Investigación y Transferencia ayudas que fomentan la calidad de la protección y títulos de propiedad industrial e intelectual. La financiación llega alcanzar en ocasiones hasta los tres mil euros.

Un enfoque importante es la relación universidad-empresa, en el sentido de que la universidad se incluye entre los agentes que forman parte de una red que transfiere conocimiento y tecnología hacia este sector. La aceleración del cambio tecnológico y el interés por el crecimiento de la investigación han dado como resultado un incremento del desarrollo industrial. Este aumento se puede detectar en el siguiente gráfico (Fig 1) distribuido por comunidades autónomas y en las que puede apreciarse el número de patentes, las 
marcas comerciales y los diseños industriales, siendo la CC.AA. con diferencia la Comunidad de Madrid.

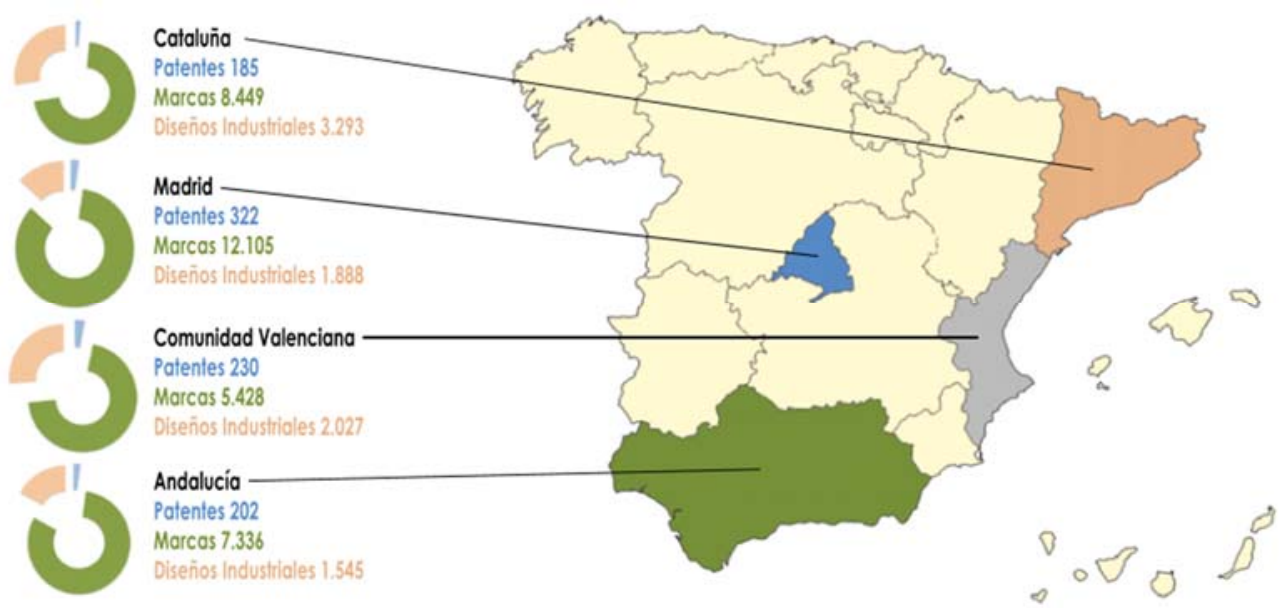

Fuente: OEPM (2020)

Fig. 1 CC.AA. con mayor número de solicitudes de Marcas, Patentes y Diseños Industriales nacionales

\section{Objetivos}

- Implementación del desarrollo de prototipos de patentes en las Escuelas de Ingeniería de Edificación y Arquitectura. Para implementar el desarrollo de prototipos de patentes en todas las escuelas debe de haber una integración entre los grupos de investigación y los trabajos que llevan a cabo los investigadores de la universidad. Debe de existir una base investigadora básica de calidad para que se puede llevar a cabo.

- Impulso de nuevas tecnologías. La utilización de software como BIM, THERM, modelado $3 d$, etc... hacen posible obtener un producto con resultados eficaces y en un periodo corto de tiempo. La utilización de estos softwares para la realización de los prototipos hace que estos tengan mayores niveles de desarrollo y detalles y poder visualizarlos en 3D.

- Implementación de los productos existentes Architecture Engineering and Construction (AEC). El conocimiento de los productos existentes y de la experiencia en el sector de la construcción nos hacen determinar errores y 
deficiencias que tienen algunos productos. Este hecho, nos hace pensar, en prototipos que se pueden realizar para mejorar sus características y eficiencia a la hora de su utilización.

\section{Desarrollo de la innovación}

\subsection{Aplicabilidad de una patente en las enseñanzas técnicas}

En el ámbito del desarrollo de productos de la construcción, quizás el más antiguos y utilizado ha sido el hormigón armado. La primera patente que llega a España de hormigón armado es el sistema Monier, realizada a finales del siglo XIX, concretamente en agosto de 1884. Éste se considera el método más antiguo de construcción con el nuevo material. Con este método se realizaron tuberías, vigas, pavimentos, cubiertas, entre otros objetos. Se ejecutaron a partir de un esqueleto metálico formado por una malla de barras de sección circular que se adapta a la forma del elemento a construir y se protege con revestimiento de cemento.

Como ejemplo de la aplicabilidad de los productos citados y tras realizar una búsqueda de aquellas patentes en el ámbito de la edificación, se han encontrado las siguientes:

- Nuevo elemento de encofrado reutilizable, ligero y económico. Este elemento ha sido desarrollado por el grupo de investigación Materiales y Sistemas Constructivos de la Edificación, perteneciente al Departamento de Edificación y Urbanismo de la Universidad de Alicante (Alicante, 2007).

- Mortero de cal termoaislante, su preparación y su uso en edificación. Universitat de les Illes Balears, 2019 (Patentes - Producción Científica Construcciones Arquitectónicas e Ingeniería de Edificación - Información Del Grupo - Grupos de Investigación - Estructuras - I+D+I - Universitat de Les Illes Balear>, n.d.).

- Estructura prefabrica para construcción mediante sistemas plegables. Universidad Nacional de Colombia. (Estructura Prefabricada Para Construcción Recibe Patente de La SIC - UNIMEDIOS: Universidad Nacional de Colombi>, n.d.) 
El sector de los materiales es uno de los ámbitos donde se desarrolla un incremento de las patentes, con fuertes inversiones apoyadas por proyectos de investigación donde además cuenta con experimentados centros y laboratorios que hacen óptimo la producción de nuevos productos. Sin embargo, a nivel de diseño de prototipos las patentes están más limitadas, porque necesitan de unos componentes de invención que no siempre las universidades son las más adecuadas. Un ejemplo claro es la Escuela Técnica Superior de Ingeniería de Edificación de la Universidad de Sevilla, que cuenta con el grupo de investigación TEP970 (Innovación tecnológica, sistemas de modelado 3D y diagnosis energética en patrimonio y edificación), creado por un grupo de 8 profesores doctores. Tiene por objetivo impulsar la investigación y la transferencia en empresas en el ámbito de la arquitectura e la ingeniería. Presenta evaluación positiva de la Agencia Andaluza del Conocimiento y, ha logrado en apenas unos años ser uno de los grupos referentes a nivel internacional en Modelado 3D del patrimonio histórico mediante técnicas de escaneo y en Análisis de medidas de rehabilitación energética en edificios y patrimonio.

Este grupo de investigación que colabora con el grupo de investigación TEP156 ingeniería gráfica y cartográfica, es uno de los grupos más consolidados en estudios cartográficos, recreación virtual de arqueología, representación del relieve terrestre. El potencial de ambos grupos de investigación supone tener una gran enorme experiencia en trabajos de levantamiento e infografía 3D en excavaciones arqueológicas y patrimonio arquitectónico, lo que se demuestra en los contratos de transferencia tecnológicas de los distintos miembros que componen el equipo. Esta interdisciplinariedad supone un nuevo reto en la conexión entre el desarrollo de la innovación tecnológica de prototipos y la recreación de la construcción de un modelo.

La transversalidad de la investigación del grupo TEP-970 conlleva una relación muy íntima con las Ciencias Naturales, las ciencias tecnológicas y las ciencias en áreas de arqueología de la arquitectura y el patrimonio cultural en general. La creación de plataformas de modelado $3 \mathrm{D}$ de alta precisión es una de las cuestiones más trascendentales en la comunidad científica para la gestión histórica y espacial en el patrimonio cultural. Las técnicas de adquisición de datos precisos requieren de tecnología puntera en equipos de medición. Para la implementación de equipos multidisciplinares especializados en la protección, conservación y difusión del Patrimonio Histórico comprendido distintos campos de conocimiento como la Arqueología, Arquitectura, Conservación, Arte, Historia, Informática y Matemáticas, se hace 
necesario contar con una cantera de equipos disponibles para los investigadores. Trabajar tanto en el ámbito de la nueva planta de la construcción en arquitectura e ingeniería civil, así como en el patrimonio arquitectónico, es abarcar dos facetas para poder crear productos nuevos y desarrollos de patentes.

En el campo de la seguridad y salud en el trabajo, existe un gran número de soluciones que pueden ser útiles para proteger la salud y vida de los trabajadores y prevenir numerosos accidentes de trabajos y enfermedades. Todas ellas se desarrollan en el área del sector de la construcción y la mejora de la eficiencia energética como otro ámbito de explotación. En este sentido el grupo de investigación TEP-970 ha realizado diversas patentes y modelos entre los que destacan el sistema AFF2 en fachada para revestir. La patente diseña un sistema constructivo para evitar el puente térmico en frente de forjados. La disposición de una estructura metálica de barras con un aislamiento fijo adosado a las vigas perimetrales antes del hormigonado hace que el sistema evite la transmisión térmica al forjado. Bienvenido et al.(Bienvenido-Huertas et al., 2018) demostró una reducción del $18 \%$ en la demanda global de energía. El sistema propuesto se describe gráficamente en la figura 2 y mediante un prototipo la fotografía 3 .

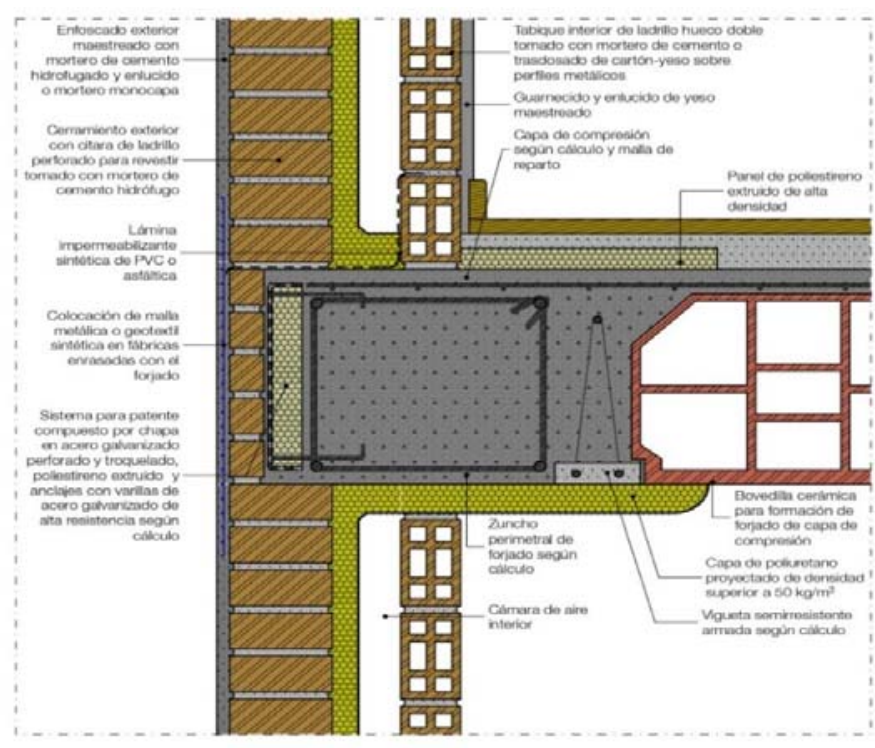

Fuente: Departamento Expresión Gráfica. ETSIE (2013)

Fig. 2 Sistema AFF2 en fachada para revestir 


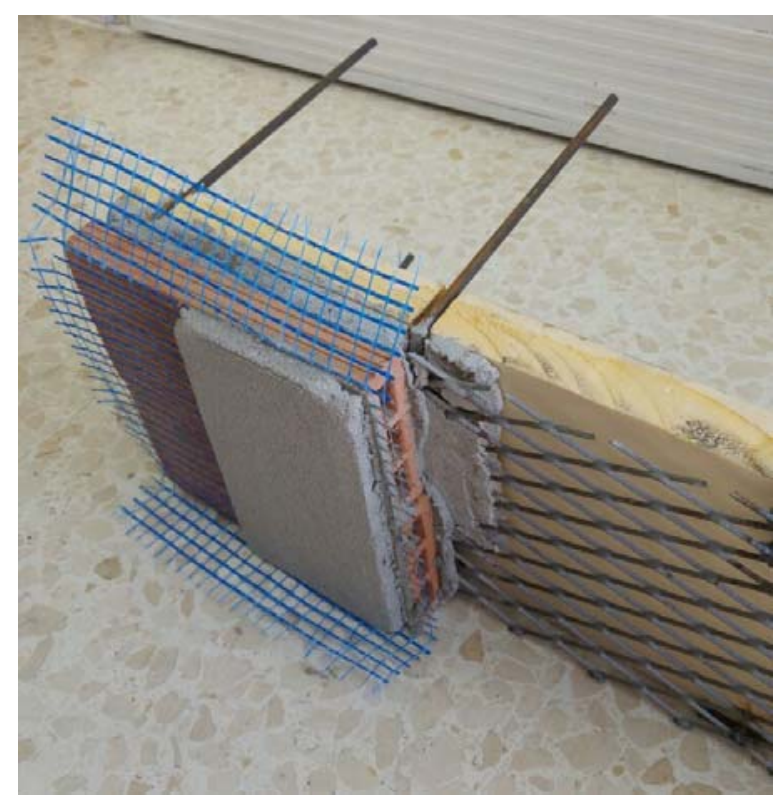

Fuente: Departamento Expresión Gráfica. ETSIE (2013)

Fig. 3 Prototipo sistema AFF2 en fachada para revestir

Para desarrollar la innovación tecnológica en las enseñanzas técnicas de la Edificación, es necesario conocer cuáles son los problemas técnicos que aparecen en el ciclo de vida del proyecto. Aunque existen términos más amplios según los tipos de componentes de la innovación tecnológica (Castro Hermida, 2003). La innovación como significado de crear cosas nuevas y distintas tiene aquí el sentido de creatividad o invención, sean productos fabricados en serie o exprofeso. La naturaleza de la innovación en edificación recae en la invención de productos y procesos. Planear y producir productos nuevos que generen una respuesta a problemas que se generan en el proceso de construcción y de la arquitectura. Para este proceso a nivel educativo tiene que haber un estimulador de problemas y un tutor que dirija estas enseñanzas técnicas. El primer paso es plantear distintas opciones a un problema técnico. Existe un taller de trabajo entre pequeños grupos de alumnos que van discutiendo distintos planteamientos. A continuación, se invita a trabajar en detalles y croquis sobre las diversas soluciones y se fomenta la participación del grupo de trabajo donde el aprendizaje del software es un aliciente para el trabajo innovativo. Diríamos en este sentido que el "gancho" que motiva a los estudiantes en la participación de nuevos productos creativos es la aplicabilidad del software. 
Este trabajo en las enseñanzas técnicas de arquitectura y edificación se está implantando en pequeños grupos de Trabajo Fin de Grado, a un nivel de cuarto curso de carrera en la rama de la arquitectura y la edificación. Concretamente en la Escuela Técnica Superior de Ingeniería de Edificación de la Universidad de Sevilla, el Departamento de Expresión gráfica e Ingeniería en la Edificación está con estas nuevas propuestas de las enseñanzas técnicas.

La dificultad que conlleva compartir docencia entre distintos departamentos limita la transversalidad de los dos grupos de investigación. Pero en la actualidad se está trabajando para poner en marcha una idea de conectividad de competencias para poder explorar a través de trabajos de levantamiento e infografía 3D en excavaciones arqueológicas, patrimonio arquitectónico y nueva construcción, donde las técnicas de adquisición de datos masivos tienen un papel fundamental de recreación en la situación geográfica y la creación de modelos de patentes e innovación de productos y procesos. Esta interdisciplinariedad supone un nuevo reto en la conexión entre el desarrollo de la innovación tecnológica de prototipos y la recreación de la construcción de un modelo. Este sería el gran reto que debemos afrontar a corto plazo.

\subsection{Software de aprendizaje para la funcionalidad de la patente}

Los criterios pedagógicos tradiciones resultan hoy en día de poca eficacia, ya que no motivan a los estudiantes y se han quedado anticuados con las nuevas tecnologías. Por ello, resulta interesante dotar a los estudiantes con nuevos programas informáticos para que puedan desarrollar de una forma más precisa y actual las actividades que quieran desarrollar.

De este modo, la utilización de tecnologías BIM supone un impulso profesional indispensable para poder llevar a cabo todos los proyectos. Esta herramienta de trabajo está implantada en muchas empresas de construcción y arquitectura. Gracias a esta herramienta, los profesionales pueden mejorar la eficiencia y perfeccionar sus trabajos de construcción.

La metodología de trabajo que se utiliza en BIM agiliza y facilita todos los procesos constructivos en el diseño y documentación de edificios (Woo, n.d.). Esto permite que toda la información de construcción, tanto gráfica como no gráfica, la tengamos a nuestra disposición en bases de datos, a la que podemos acceder y recuperar en un momento dado. El resultado nos permite obtener un modelo 3D, en el que podemos representar digitalmente de forma rápida y eficaz nuestro proyecto de construcción. 
Las ventajas de la metodología BIM respecto al trabajo tradicional, son las siguientes:

- Se actualiza automáticamente la información que se edita en cualquier parte del modelo, y ésta directamente se modifica en plantas, alzados, secciones y vistas 3D.

- Se trabaja sobre un único modelo, por tanto, no hay pérdidas de información

- Existe un entorno colaborativo en el que se trabaja de forma coordinada

- Acceso en cualquier momento a toda la información que se requiera

La metodología BIM puede y debe ser utilizada en los años de formación de los alumnos como una herramienta de aprendizaje (Roig et al., 2017). Estas sesiones están basadas en una exposición objetiva de los sistemas, procedimientos y técnicas constructivas de las diferentes fases de obra por parte del docente. La disciplina BIM tiene un carácter práctico que requiere un conocimiento teórico anterior para adquirir las habilidades de representaciones constructivas.

Otro software utilizado es THERM, es el programa informático para el análisis de la transmisión del calor bidimensional a través de elementos constructivos y que permite realizar el cálculo del U-factor, isotermas, vectores de flujo y temperaturas. En la simulación de las patentes, THERM permitió comprobar las mejoras realizadas por las diferentes soluciones constructivas y se obtuvo los resultados de transmitancia térmica de las diferentes patentes (Bienvenido-Huertas et al., 2018).

Existen diferentes softwares para el diseño de productos entre los que podemos destacar dos tipos:

1. Plataformas BIM: se utiliza para crear y organizar datos durante el proceso de diseño, construcción y operaciones. Algunos programas utilizados son: ArchiCAD (Archicad - GRAPHISOF>, n.d.), Revit (Software Revit | Obtener Precios y Comprar Software de Revit 2022 Oficial| Autodesk, n.d.) y Allplan (Software BIM - CAD - 3D - Allplan - ALLPLAN Systems España S.A, n.d.)

2. Programas de modelado: con estos programas se pueden generar escenas, modelar y simular productos. Algunos programas utilizados son: Solidworks (SOLIDWORK>, n.d.), CATIA (CAD Product Design and Engineering Cloud Solutions | Dassault Systèmes, n.d.), Rhino (Rhino - Rhinoceros 3D, n.d.) y Autodesk 
Inventor (Software Inventor | Obtener Precios y Comprar Software Oficial de Inventor 2022 | Autodesk, n.d.)

\section{Resultados}

Los procesos para llevar a cabo las innovaciones tecnológicas han ocasionado un gran aprendizaje hacia nuevos investigadores que forman parte de los grupos de investigación. Parte del proceso en la producción de patentes se relaciona con el tamaño de los grupos de investigación y la capacidad de coordinar el trabajo multidisciplinar. Dependiendo del área de especialidad puede ser más complicado la generación de una patente, aunque si se trabaja de forma multidisciplinar y se dedica tiempo, se obtiene el resultado esperado. Lo cierto es que, muy pocas patentes llegan a ser aceptadas en el ámbito industrial. Un obstáculo puede ser que no hay un vínculo de confianza entre universidad-empresa. Este hecho, nos hace pensar, en prototipos diseñados para tener en cuenta la demanda de las empresas y poder realizarlos para cubrir esas necesidades. Como resultado obtendremos un producto útil y eficaz que sea práctico. Para ello contamos con tres áreas de conocimientos, una es la construcción que nos hace determinar los errores y deficiencias que tienen algunos productos, otra los materiales, que nos muestran sus características y, por último, el conocimiento gráfico en el que disponemos de softwares para realizar prototipos de productos que sean útiles y no tengan la deficiencia que nos encontramos y así mejorarlos para que cumplan con su función.

\section{Conclusiones}

La docencia universitaria está encaminada a la formación de los mejores profesionales en cada escuela. La innovación de impartir clases de BIM en las escuelas esta cada día más presentes debido a la gran demanda en el mundo laboral. Gracias a estos programas, se ahorra tiempo ya que no es necesario convertir desde varios tipos de archivos y se reduce el número de errores al ser menor la necesidad de intercambios de información. Además, estos programas motivan a los alumnos a la hora de realizar los prototipos, ya que cuentan con herramientas en las que se puede diseñar cualquier objeto, pudiendo hacer una vista en $3 d$ de cómo quedaría el prototipo y poder visualizarlo con las texturas de los materiales, cosa que en el método tradicional no se podía hacer. Esto permite, despertar el grado de participación e interés por parte del alumnado. Todo esto no sería posible si las universidades no apoyaran las propuestas para el desarrollo tecnológico. Las patentes están sirviendo como 
modelo de aprendizaje y conocimiento en las escuelas, gracias a ellas, alumnos y profesores investigan sobre un tema y lo llevan a cabo, suponiendo esto, el aprendizaje de programas informáticos, nuevos conocimientos, trabajo en equipo, empleabilidad de nuevos softwares para diseñar y probar los prototipos.

\section{Referencias}

Alicante, U. de. (2007). Listado de patentes. MSCE - Materiales y Sistemas Constructivos de la Edificación. Grupo de Investigación-Materiales y Sistemas Constructivos de La Edificación. https://web.ua.es/es/msce/31-patentes/listado-de-patentes.html

Archicad - GRAPHISOFT. (n.d.). Retrieved June 17, 2021, from https://graphisoft.com/es/solutions/products/archicad

Bienvenido-Huertas, D., Quiñones, J. A. F., Moyano, J., \& Rodríguez-Jiménez, C. E. (2018). Patents analysis of thermal bridges in slab fronts and their effect on energy demand. Energies, 11(9), 2222. https://doi.org/10.3390/en11092222

CAD Product Design and Engineering Cloud Solutions | Dassault Systèmes. (n.d.). Retrieved June 17, 2021, from https://www.3ds.com/es/3dexperience/cloud/catia-product-designand-

experience?utm_medium=cpc\&utm_source=google\&utm_campaign=202101_glo_sea _es_op51508_labl_tt1brand_ewe_exact\&utm_term=catiaexact\&utm_content=search\&gclid=CjOKCQjw5auGBhDEARIsAFyNm9E5TKAepHGm gi9oryzxuQxg5PX8US44A0XJyVE4MKkampXcmzEyLDQaAq1bEALw_wcB

Calderón-Martínez, G. (2014). Patentes en Instituciones de Educación Superior en México. Revista de La Educacion Superior, 43(170), 37-56. https://doi.org/10.1016/j.resu.2014.06.001

Castro Hermida, M. A. (2003). La innovación tecnológica y la gestión de las limitaciones. Innovación Tecnológica En Las Organizaciones, 89-96.

Debe, E. L. A., El, C. E. N., De, C., \& Paralela, F. (2016). Un ámbito idóneo para los arquitectos técnicos. Cercha, 34-35.

Del, M., López Gómez, S., Simón, R. S., Cabrales Gómez, F., \& Tobón, C. G. (2009). The processes involved in a management model for university patents. In AGOSTO DE (Vol. 29, Issue 2). Universidad Nacional de Colombia - Facultad de Ingeniería. 
Estructura prefabricada para construcción recibe patente de la SIC-UNIMEDIOS: Universidad Nacional de Colombia. (n.d.). Retrieved June 14, 2021, from https://agenciadenoticias.unal.edu.co/detalle/article/estructura-prefabricada-paraconstruccion-recibe-patente-de-la-sic.html

Patentes - Producción científica - Construcciones arquitectónicas e ingeniería de edificación - Información del grupo - Grupos de investigación - Estructuras - 1+D+I - Universitat de les Illes Balears. (n.d.). Retrieved June 14, 2021, from https://www.uib.es/es/recerca/estructures/grups/grup/CONSTARQ/produccio/patents/ 2019.html

Rhino - Rhinoceros 3D. (n.d.). Retrieved June 17, 2021, from https://www.rhino3d.com/es/

Roig, R., Antolí, J. M., Blasco, J. E., Lledó, A., \& Pellín, N. (2017). Redes colaborativas en torno a la docencia universitaria. Instituto de Ciencias de La Educación. Universidad de Alicante, 2017, 290-301. https://rua.ua.es/dspace/bitstream/10045/71048/1/Redescolaborativas-en-torno-a-la-docencia-

universitaria_29.pdf\%0Ahttp://rua.ua.es/dspace/handle/10045/70977

Software BIM - CAD - 3D - Allplan - ALLPLAN Systems España S.A. (n.d.). Retrieved June 17, 2021, from https://www.allplan.com/es/

Software Inventor | Obtener precios y comprar software oficial de Inventor 2022 | Autodesk. (n.d.). Retrieved June 17, 2021, from https://www.autodesk.es/products/inventor/overview?term=1-YEAR

Software Revit | Obtener precios y comprar software de Revit 2022 oficial | Autodesk. (n.d.). Retrieved June 17, 2021, from https://www.autodesk.es/products/revit/overview?term=1-YEAR

SOLIDWORKS. (n.d.). Retrieved June 17, 2021, from https://www.solidworks.com/es

Woo, J. H. (n.d.). BIM (Building Information Modeling) and Pedagogical Challenges. 


\title{
EDIFICATE
}

I Congreso de Escuelas de Edificación y Arquitectura Técnica de España

València, 4 y 5 de noviembre de 2021

Escuela Técnica Superior de Ingeniería de Edificación

Universitat Politècnica de València

Doi: https://doi.org/10.4995/EDIFICATE2021.2021.13513

\section{Equipo docente para la Docencia Digital y la Coordinación Transversal de las asignaturas del Módulo de Gestión del Proceso del Grado de Edificación. Universidad de Granada}

\section{Teaching Team for Digital Teaching and Transversal Coordination of the subjects of the Process Management Module of the Degree in Building. University of Granada}

\begin{abstract}
Antonio J. Aguilar ${ }^{\mathrm{a}}$, Carlos Benavides de la Fuente ${ }^{\mathrm{b}}$ Gloria Cuenca-Moyanoc ${ }^{\mathrm{c}}$, Lourdes Gutiérrez-Carrillo $^{d}$, María L. de la Hoz-Torres ${ }^{e}$, María Martín-Morales ${ }^{f}$, M. Dolores Martínez-Aires $^{\mathrm{g}}$, Manuel Martínez Carrillo $^{\mathrm{h}}$ y Raquel Nieto-Álvarez

aDpto. Física Aplicada, Universidad de Granada (UGR), antojes@ugr.es, 'Estudiante del Grado de Edficación (UGR), carlosbf@correo.ugr.es, 'Dpto. Construcciones Arquitectónicas (DCA) (UGR), gloriacuenca@ugr.es, dDCA (UGR), mlgutier@ugr.es, eDpto. Física Aplicada (UGR), mlhoz@ugr.es,

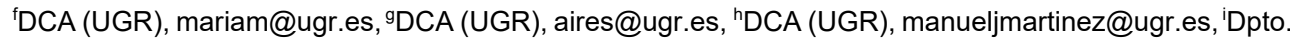
Expresión Gráfica Arquitectónica y en la Ingeniería, rnieto@ugr.es
\end{abstract}

\begin{abstract}
The healthcare crisis caused by COVID-19 has had an enormous impact on the development of academic activity, requiring the adaptation of traditional teaching methodology (mainly face-to-face) to blended or virtual scenarios. These circumstances have highlighted the need to implement new methodologies and tools, as well as the use of different platforms which are not acquainted for the teaching staff.

In this context, the Teaching Team for Digital Teaching and Transversal Coordination on the subjects of the Process Management Module of the Degree in Building at the University of Granada has been created. The objective of the project has been to empower the teaching staff through the training in digital tools that improve the available resources for the development of teaching in an online scenario; in adition to coordinating the process between different subjects, improving the teaching-learning experience and making the subject more attractive for the students.
\end{abstract}

This paper presents the specific objectives set, the structure of the sessions, and the methodology and materials used, which have helped the participating 
teachers to develop fundamental digital competences for the implementation of new teaching tools and methodologies.

Keywords: teaching team, digital training, project management model, BIM, advanced Moodle tools, good teaching practices

\section{Resumen}

La crisis sanitaria provocada por la COVID-19 ha tenido un enorme impacto en el desarrollo de la actividad académica, requiriendo la adaptación de la metodología de docencia tradicional (principalmente presencial) a escenarios semipresenciales o virtuales. Estas circunstancias han puesto de manifiesto la necesidad de implementar nuevas metodologías y herramientas, así como el uso de distintas plataformas con las que el profesorado no está familiarizado.

En este contexto se ha creado el Equipo docente para la Docencia Digital y la Coordinación Transversal de las asignaturas del Módulo de Gestión del Proceso del Grado de Edificación de la Universidad de Granada. El objetivo ha sido capacitar al profesorado a través de formación en herramientas digitales que permiten mejorar los recursos disponibles para el desarrollo de la docencia en un escenario online, coordinar el proceso entre diferentes asignaturas, mejorando la experiencia de enseñanza-aprendizaje y haciendo más atractiva la asignatura al alumnado.

En este trabajo se presenta los objetivos específicos planteados, las estructura de las sesiones, metodología y materiales utilizados, que han contribuido a que el profesorado participante desarrolle competencias digitales fundamentales para la implementación de nuevas herramientas y metodologías docentes.

Palabras clave: equipo docente, capacitación digital, modelo de gestión de proyectos, BIM, herramientas avanzadas Moodle, buenas prácticas docentes 
Antonio J. Aguilar, Carlos Benavides de la Fuente, Gloria Cuenca-Moyano, Lourdes Gutiérrez-Carrillo, María L. de la Hoz-Torres, María Martín-Morales, M. Dolores Martínez-Aires, Manuel Martínez Carrillo y Raquel Nieto-Álvarez

\section{Introducción}

La pandemia de la COVID-19 ha tenido una gran impacto en todos los sectores, tanto económico como social (Sarkodie \& Owusu, 2021). La docencia universitaria no se ha mantenido ajena, requiriendo de un gran esfuezo de adaptación de las metodologías de docencia tradicional (principalmente presencial) a escenarios semipresenciales o virtuales. En los últimos años, la Universidad de Granada (UGR), principalmente a través de sus Planes de Formación e Innovación Docente (FIDO) (UGR, 2016), ha formentado la creación de los equipos docentes multidisciplinares de formación continua del profesorado como herramienta para favorecer la colaboración entre profesorado experto y principiante, con la mejora continua de la práctica docente, el intercambio de experiencias y el establecimiento de compromisos.

La urgente necesidad de enseñanza online creada por la situación sanitaria, ha hecho que se hayan diseñado un amplio abanico de programas de formación para el profesorado, cursos intensivos, webinar, etc. (UGR, 2020a), con el fin de facilitar el proceso de adaptación, ayudando y acompañando en la difícil tarea de mantener una docencia y atención al alumnado con los estándares de calidad deseados.

Dentro de la estrategias de formación de la UGR se engloba el programa de presentación de solicitudes para la I Convocatoria de Formación de Equipos Docentes para la Docencia Digital con los siguientes objtivos (UGR, 2020b):

- $\quad$ el desarrollo de competencias docentes digitales,

- la implementación de metodologías activas y participativas a través de las plataformas digitales para la docencia,

- la incorporación y el uso didáctico de herramientas y plataformas digitales en los procesos de seguimiento, orientación, tutorización y evaluación del estudiantado,

- la diversificación de los procedimientos de evaluación continua y final mediante herramientas y plataformas digitales,

- $\quad$ el diseño de materiales o recursos docentes digitales, y

- $\quad$ el diseño y la puesta en marcha de cualquier iniciativa de innovación docente ligada a la digitalización de la docencia.

Englobado en esta convocatoria se ha creado el grupo docente denominado Equipo docente para la Docencia Digital y la Coordinación Transversal de las asignaturas del Módulo de Gestión del Proceso del Grado de Edificación. La acción formativa se definió tras el análisis de las herramientas disponibles para el profesorado diseñadas por el Centro de Producción de Recursos para la Universidad Digital (CEPRUD) de la UGR (CEPRUD, 2021), con el objetivo de no repetir contenidos generales, centrándose en herramientas avanzadas.

Por ello, se ha optado por el uso de herramientas digitales específicas para las asignaturas del módulo y, en general, del Grado de Edificación. Todas ellas tienen el objetivo de acercar al alumnado a las obras y profundizar en conceptos curriculares, destacando la creación de recursos digitales interactivos, el uso de la metodología Building Information Modelling (BIM) y la realidad virtual y videos $360^{\circ}$. Además, se han incorporado sesiones para mostrar 
estrategias para asistencia activa y buenas prácticas docentes, usando, entre otras herramientas, Moodle como plataforma para la gestión de aprendizaje.

\section{Objetivo}

En este trabajo se presenta la inciativa de un grupo de profesores del Grado de Edificación de la UGR para crear un Equipo docente para la Docencia Digital y la Coordinación Transversal de las asignaturas del Módulo de Gestión del Proceso del Grado de Edificación.

Se presentarán los objetivos propuestos, la estructura de la acción formativa y los resultados obtenidos.

\section{Desarrollo de la innovación docente}

\subsection{Objetivos del Equipo docente}

El Módulo Gestión del Proceso incluye cinco asignaturas:

- Organización y Programación en Edificación (asignatura obligatoria de 3er curso)

- Gestión de la Calidad (asignatura obligatoria de $4^{\circ}$ curso)

- Prevención y Seguridad (asignatura obligatoria de $4^{\circ}$ curso)

- Proyecto de Gestión del Proceso y Equipos de Obras (asignatura obligatoria de $4^{\circ}$ curso)

- $\quad$ Gestor de proyectos, de producción y de mantenimiento (asignatura optativa de $4^{\circ}$ curso)

El objetivo principal del equipo docente ha sido capacitar al profesorado de dicho módulo en herramientas digitales que permitan mejorar los recursos disponibles para el desarrollo de la docencia en un escenario online, coordinar el proceso entre diferentes asignaturas y mejorar la experiencia de enseñanza-aprendizaje.

Los objetivos específicos del equipo docente han sido los siguientes:

- $\quad$ 01. Coordinar las asignaturas del Módulo Gestión del Proceso en la adaptación a un escenario semipresencial, así como las necesidades en otras asignaturas del los departamentos con más docencia en el grado: Construcciones Arquitectónicas y Expresión Gráfica Arquitectónicas y en la Ingeniería.

- O2. Dotar al profesorado de nuevas herramientas para el diseño de nuevos materiales didácticos digitales y recursos docentes.

- O3. Proporcionar recursos que faciliten el seguimiento y tutorización del estudiantado. 
Antonio J. Aguilar, Carlos Benavides de la Fuente, Gloria Cuenca-Moyano, Lourdes Gutiérrez-Carrillo, María L. de la Hoz-Torres, María Martín-Morales, M. Dolores Martínez-Aires, Manuel Martínez Carrillo y Raquel Nieto-Álvarez

También se han analizado las necesidades de coordinación en el uso de herramientas docentes con otras asignaturas del grado.

\subsection{Componentes}

El equipo docente ha contado con once componentes. Dado que la convocatoria permitía la inclusión de estudiantes, se ha contado con la participación de dos alumnos de cuarto curso. El profesorado incialmente era el siguiente:

- Seis docentes adscritos al Módulo de Gestión de Proyectos

- La Directora de Dpto. de Construcciones Arquitectónicas

- La Secretaria del Dpto. de Expresión Gráfica Arquitectónicas y en la Ingeniería

A este grupo, dado que se envió la infomación a todo el profesorado del Grado de Edificación, se unieron dos nuevas integrantes pertenecientes al Dpto. de Construcciones Arquitectónicas.

Por otro lado, distinto profesorado se ha ido conectando puntualmente a alguna de las sesiones programadas.

\subsection{Estructura}

Para alcanzar los objetivos definidos, se han planificado sesiones agrupadas en tres módulos:

Módulo A. Coordinación de la adaptación de la docencia en los escenarios semipresencial y virtual de las asignaturas del Módulo de Gestión del Proceso, así como con otras asignaturas del Dpto. Construcciones Arquitectónicas y del Dpto. de Expresión Gráfica Arquitectónica y en la Ingeniería. Debate sobre las competencias, herramientas y recursos necesarios para la docencia digital en ambos escenarios. Las sesiones del Módulo A contribuyen a alcanzar el objetivo 01.

Módulo B. Herramientas de creación de contenidos digitales interactivos (desarrollo de contenido web, software Wimba Create, modelos digitales 3D interactivos, metodología Building Information Modelling aplicada a la docencia, Videos $360^{\circ}$, etc.) Las sesiones del Módulo B contribuyen a alcanzar el objetivo $\mathrm{O} 2$.

Módulo C. Herramientas digitales para el seguimiento, planificación y tutorización en la docencia digital (uso de software y plataformas: Kaltura, Miro, Prado, Kahoot, Telegram, etc.) Las sesiones del Módulo C contribuyen a alcanzar el objetivo O3.

\subsection{Metodología, planificación y materiales}

Las sesiones se han estructurado en tres módulos (A, B y C) que desarrollan los objetivos O1, O2 y O3 respectivamente, además de una sesión inicial ( $\mathrm{SI}$ ) y una final (SF). Todos los contenidos se planificaron para ser trabajados en quince sesiones según se recoge en la Tabla 1. 
Cada sesión ha tenido una duración de dos horas: una teórica y la otra de tipo Taller. Al final de cada sesión se ha planificado quince minutos de debate. Esto ha permitido exponer dudas relacionadas con la sesión y otros problemas identificados al implementar recursos digitales en el aula. Se ha fomentado la participación activa, con la utilización de distintas herramientas (por ejemplo, Kahoot, Miro, etc.) y con el diseño de distintas actividades que debían realizarse entre las sesiones (normalmente una semana).

Tabla 1. Contenidos de las sesiones

\begin{tabular}{|c|c|}
\hline $\begin{array}{l}\mathrm{N}^{\circ} \\
\text { Taller }\end{array}$ & Resumen de la sesión \\
\hline SI & $\begin{array}{l}\text { Sesión Inicial de constitución del equipo docente. Presentación del equipo } \\
\text { docente. Planificación y organización de sesiones. }\end{array}$ \\
\hline A3 & $\begin{array}{l}\text { Análisis de las necesidades y competencias transversales de las asignaturas } \\
\text { del Módulo de Gestión de Proyectos con las adquiridas en otras asignaturas } \\
\text { del Departamento de Expresión Gráfica Arquitectónica y en la Ingeniería. }\end{array}$ \\
\hline A1 & $\begin{array}{l}\text { Herramientas del estudiantado durante la docencia virtual: antecedentes, } \\
\text { plataformas y aplicaciones. }\end{array}$ \\
\hline A2 & $\begin{array}{l}\text { Sesión de coordinación transversal de asignaturas del Módulo Gestión del } \\
\text { Proceso del grado Ingeniería en Edificación. Participación de todo el equipo } \\
\text { docente. Creación de Matriz DAFO }\end{array}$ \\
\hline B1 & $\begin{array}{l}\text { Creación de recursos digitales. Introducción: Herramientas de desarrollo de } \\
\text { contenidos digitales: software Wimbra Create. }\end{array}$ \\
\hline B2 & Creación de recursos digitales. Integración en la plataforma PRADO. \\
\hline B3 & $\begin{array}{l}\text { Uso de la metodología Building Information Modelling (BIM) para la mejora de } \\
\text { la docencia. Introducción. }\end{array}$ \\
\hline B4 & $\begin{array}{l}\text { Uso de la metodología Building Information Modelling (BIM) para la mejora de } \\
\text { la docencia. Ejemplo de desarrollo de modelos. }\end{array}$ \\
\hline B5 & $\begin{array}{l}\text { Uso de la metodología Building Information Modelling (BIM) para la mejora de } \\
\text { la docencia. Integración en la plataforma de docencia: Sketchfab e Integración } \\
\text { en la plataforma PRADO. }\end{array}$ \\
\hline B6 & $\begin{array}{l}\text { Uso de realidad virtual y videos } 360^{\circ} \text { para el desarrollo de prácticas en un } \\
\text { escenario no presencial. }\end{array}$ \\
\hline B7 & $\begin{array}{l}\text { Creación de recursos digitales. Integración en la plataforma PRADO: Recursos } \\
\text { interactivos digitales H5P. }\end{array}$ \\
\hline $\mathrm{C} 1$ & $\begin{array}{l}\text { 1.- Herramientas digitales para la Asistencia activa. } \\
\text { 2.- Kaltura como herramienta de grabación y edición de contenido digital. }\end{array}$ \\
\hline $\mathrm{C} 2$ & $\begin{array}{l}\text { Autoevaluación y evaluación por pares del trabajo del alumnado: uso de la } \\
\text { herramienta TALLER de PRADO }\end{array}$ \\
\hline C3 & $\begin{array}{l}\text { Uso de plataformas digitales para el seguimiento y comunicación con el } \\
\text { alumnado: Telegram. }\end{array}$ \\
\hline
\end{tabular}


Antonio J. Aguilar, Carlos Benavides de la Fuente, Gloria Cuenca-Moyano, Lourdes Gutiérrez-Carrillo, María L. de la Hoz-Torres, María Martín-Morales, M. Dolores Martínez-Aires, Manuel Martínez Carrillo y Raquel Nieto-Álvarez

SF Sesión Final y cierre del equipo docente. Definición de puntos fuertes y débiles del proyecto docente. Definición de futuras acciones.

Dado que la UGR cuenta con un acuerdo con Google Apps, en el proyecto se ha hecho uso de las distintas Apps, algunas poco utilizadas por el profesorado. Además, el uso de estas herramientas ha permitido mostrar las ventajas de su implementación en la actividad docente, así como su potencial. Se han utilizado las siguientes:

- Google Meet

- Google Drive

- Google Site

- Google Formulario

- Google Calendar

- Google Doodle

Las sesiones se han realizado a través de Google Meet. Los recursos Google Calendar y Google Doodle han sido utilizados para programar las sesiones. Además, se ha elaborado en Google Drive un repositorio donde se ha puesto a disposición de todos los participantes los recursos y materiales generados en el equipo docente, así como facilitar la colaboración y el trabajo en equipo. Por otro, se ha elaborado una página web en la plataforma Google Site en la que se han publicado las sesiones actualizadas y enlaces a los recursos generados.

Por último, se ha diseñado un cuestionario final en Google Formulario para valorar la satisfacción de los miembros del equipo docente a la finalización del mismo.

\section{Resultados}

En la sesión inicial se realizó la presentación del equipo docente y la dinámica a seguir durante el desarrollo del proyecto, así como las herramientas que se iban a utilizar distintas a las disponibles en Google Apps y que implicaban que cada componente del equipo creará una cuenta (por ejemplo Kahoot y Miro). 


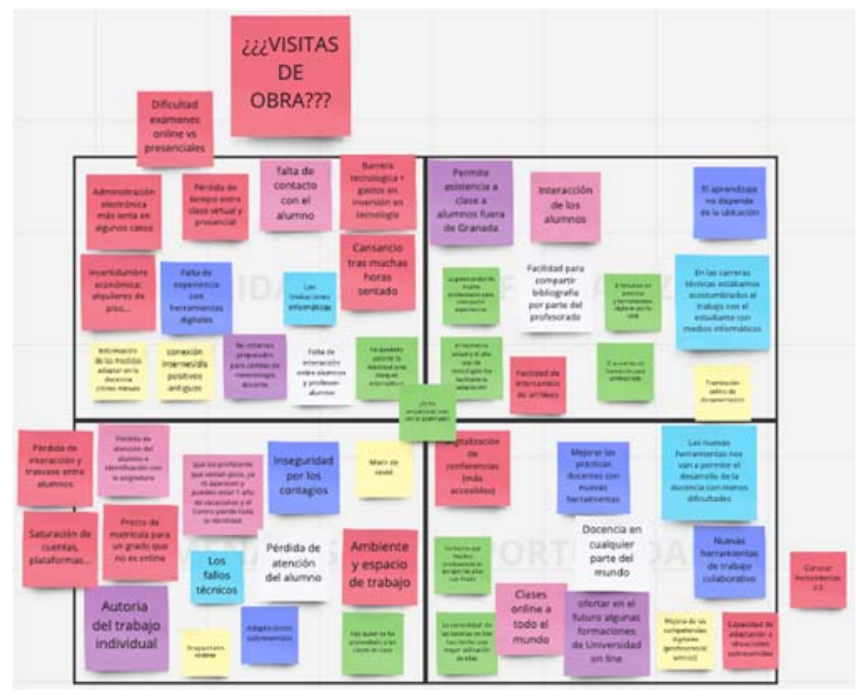

Fuente: Elaboración propia

Fig. 1 Matriz DAFO: docencia en la pandemia.

En la siguiente sesión de trabajo realizó una matriz DAFO sobre la adaptación de la docencia a un entorno online. Para ello se ha utilizado la pizarra colaborativa Miro (Fig. 1). En la Web creada con Google Site (Fig. 2) se fueron incorporando la infomación general e incluyendo la programación que estaba vinculada con un documento de Google Drive que se iba actualizado cada semana.

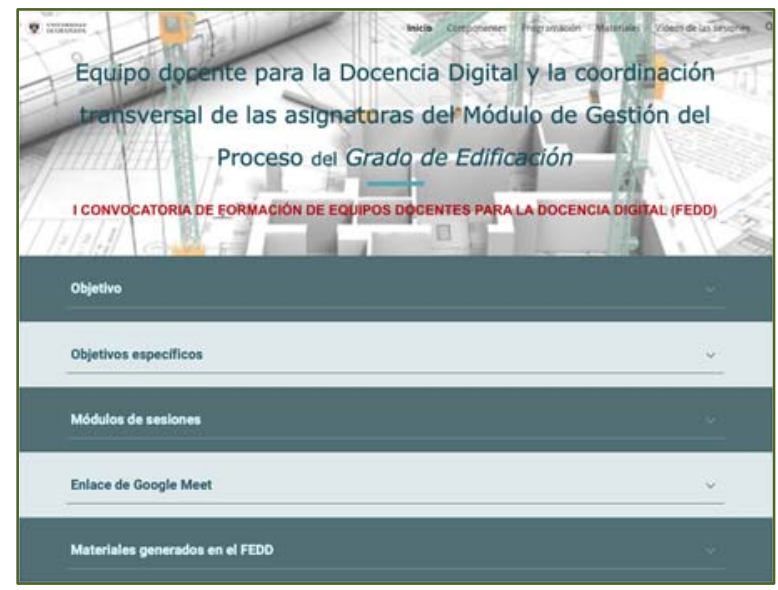

Fuente: Elaboración propia

Fig. 2 Web del Equipo docente. 


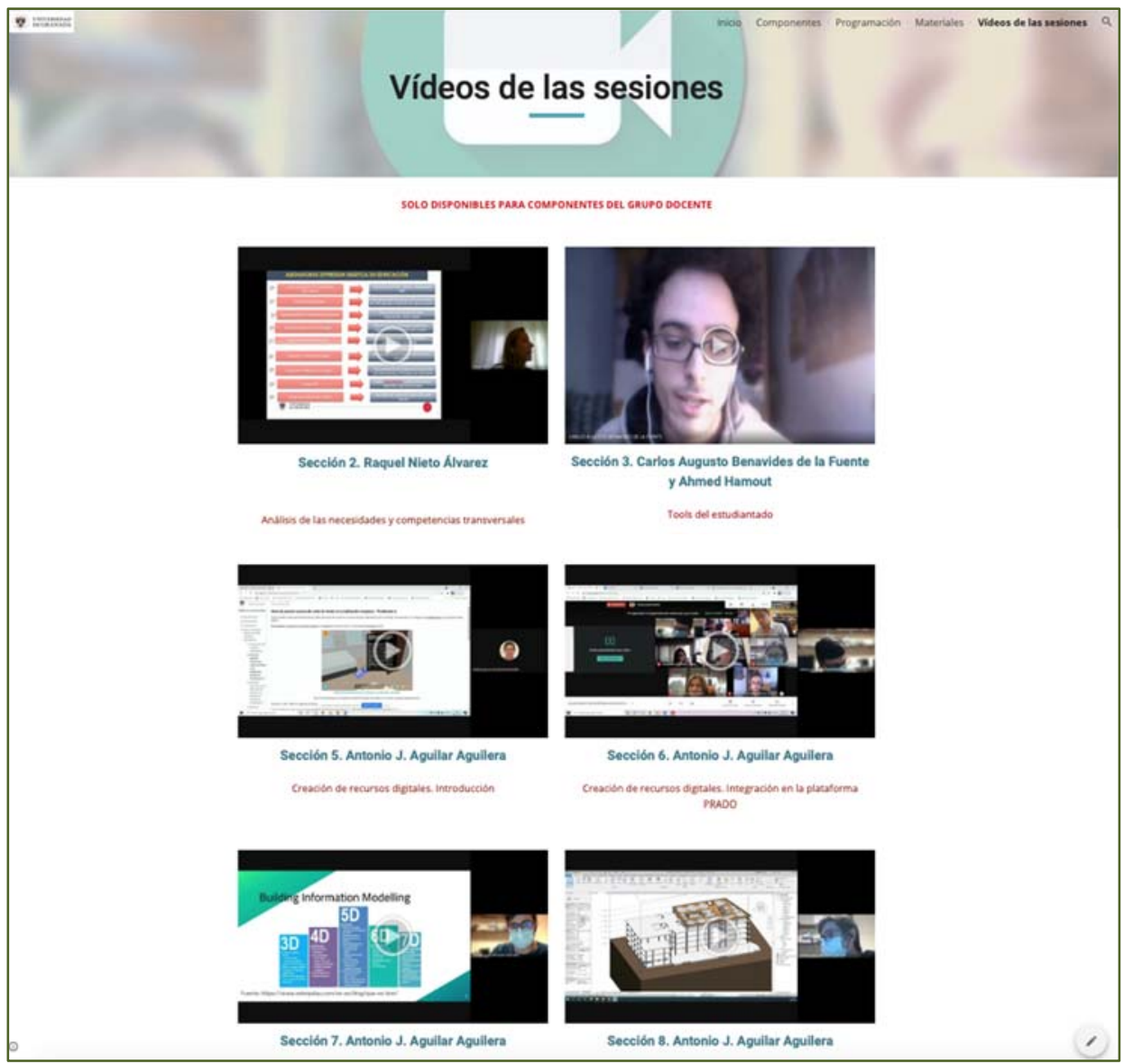

Fuente: Elaboración propia

Fig. 3 Vídeos de la sesiones disponibles en la Web.

También se añadieron los materiales utilizados o que eran necesarios para trabajar y/o seguir correctamente los contenidos. Dado que todas sesiones fueron grabadas, tras terminar las clases los vídeos estaban disponibles para faciliar la consulta de dudas sobre puntos concretos explicados (ver Fig. 3).

La metodología BIM ha tenido un gran peso en las sesiones desarrolladas en el marco del equipo docente. Las herramientas que proporciona esta metodología pueden utilizarse como un excelente recurso en el proceso de enseñanza-aprendizaje. Concretamente, en las sesiones se ha examinado el potencial uso de los modelos 3D BIM con el objetivo de analizar las características y configuraciones de las soluciones constructivas (ver Fig. 4) y la elaboración de entornos digitales interactivos que permitan su visualización mediante realidad virtual (ver Fig 5). 
Equipo docente para la Docencia Digital y la Coordinación Transversal de las asignaturas del Módulo de Gestión del Proceso del Grado de Edificación. Universidad de Granada - Teaching Team for Digital Teaching and Transversal Coordination of the subjects of the Process Management Module of the Degree in Building. University of Granada

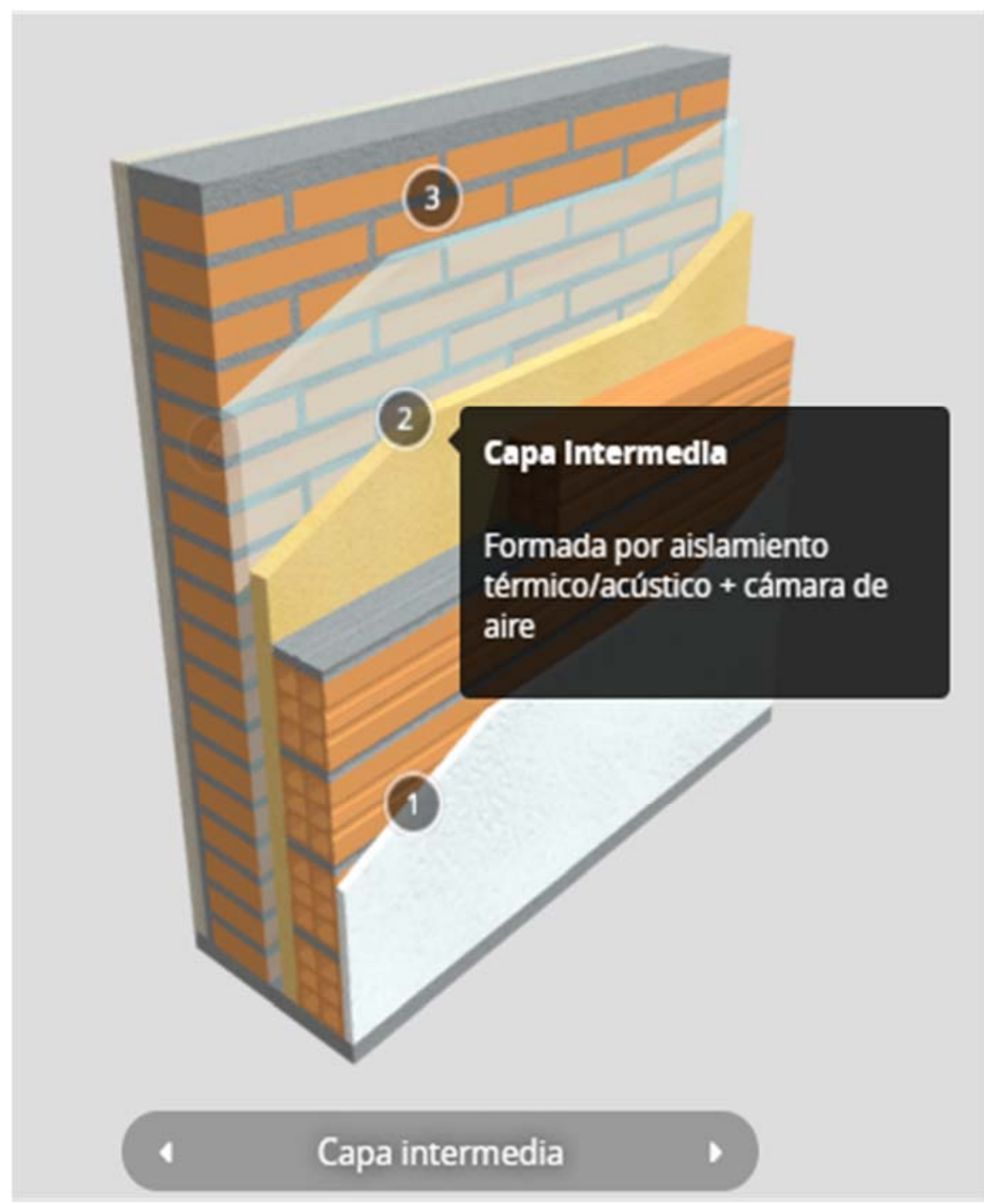

Fig. 4. Modelo digital de una solución constructiva tipo.

Fuente: Elaboración propia 
Antonio J. Aguilar, Carlos Benavides de la Fuente, Gloria Cuenca-Moyano, Lourdes Gutiérrez-Carrillo, María L. de la Hoz-Torres, María Martín-Morales, M. Dolores Martínez-Aires, Manuel Martínez Carrillo y Raquel Nieto-Álvarez

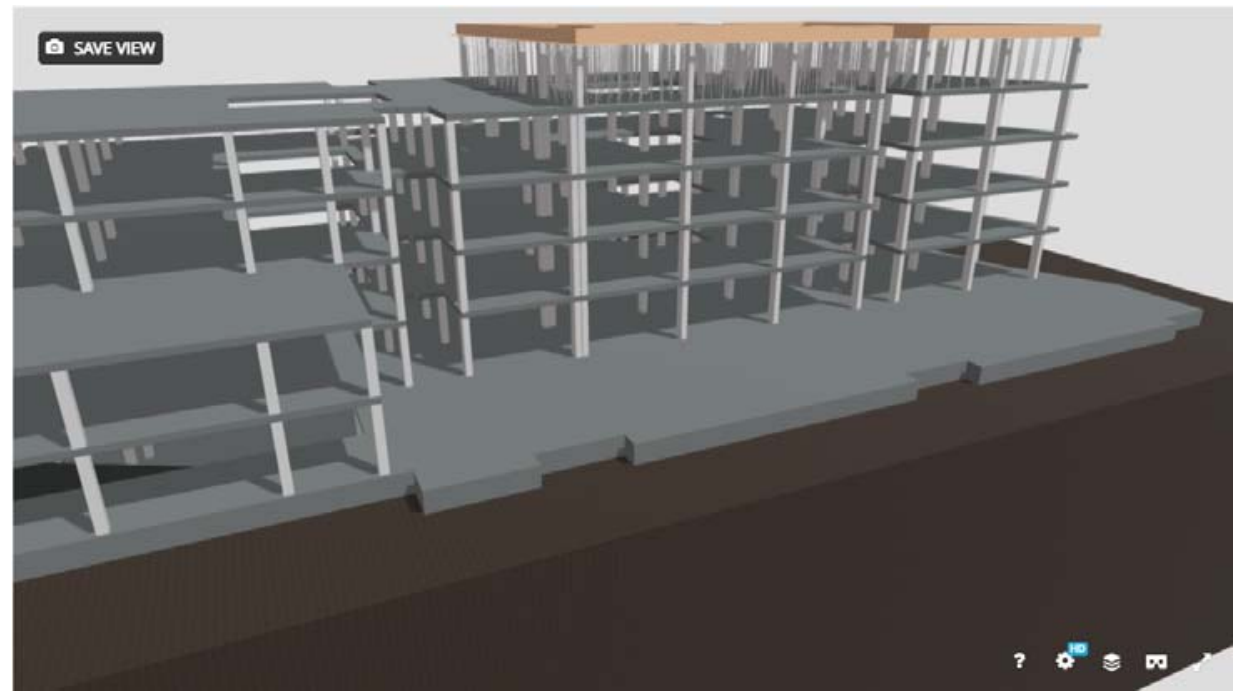

Fig. 5. Entorno de realidad virtual generado a partir de un modelo BIM.

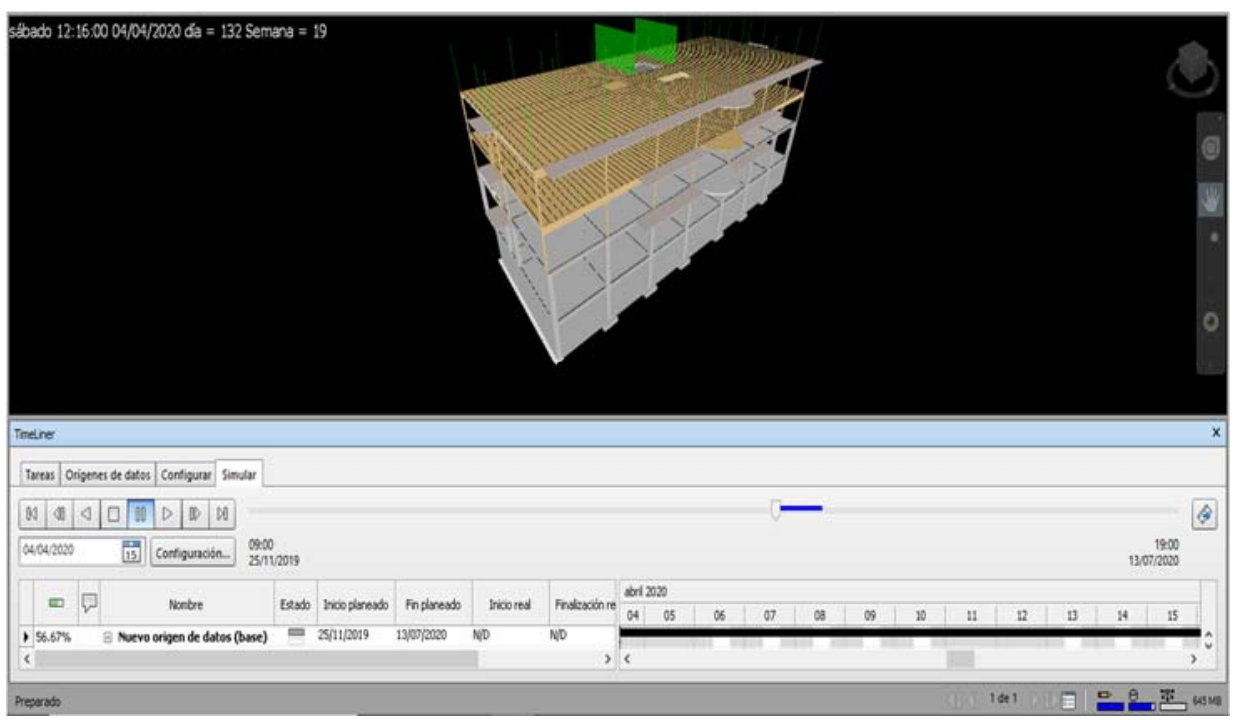

Fig. 6 Simulación de la planificación del proceso constructivo.

Fuente: Elaboración propia

Por otro lado, se profundizó en el uso de programas informáticos y herramientas BIM 4D para el análisis y gestión de la organización y programación de procesos de ejecución en obra, 
Equipo docente para la Docencia Digital y la Coordinación Transversal de las asignaturas del Módulo de Gestión del Proceso del Grado de Edificación. Universidad de Granada - Teaching Team for Digital

Teaching and Transversal Coordination of the subjects of the Process Management Module of the

Degree in Building. University of Granada

destacando su capacidad para facilitar la adquisición de conocimiento en relación a la interacción de los distintos procesos a partir de simulaciones (ver Fig. 6).

En este contexto, se realizó una introducción al uso de videos e imágenes $360^{\circ}$ para acercar al alumnado la experiencia de visitar una obra, facilitando la interacción con el contenido y pudiendo utilizarse para generar una experiencia inmersiva (ver Fig. 7). La incorporación de este tipo de recursos, unidos a los proporcionados por la metodología BIM, permiten la digitalización y creacción de nuevos recursos para la adquisición de competencias relacionadas con la docencia de las asignaturas del Módulo de Gestión del Proceso del Grado en Edificación.

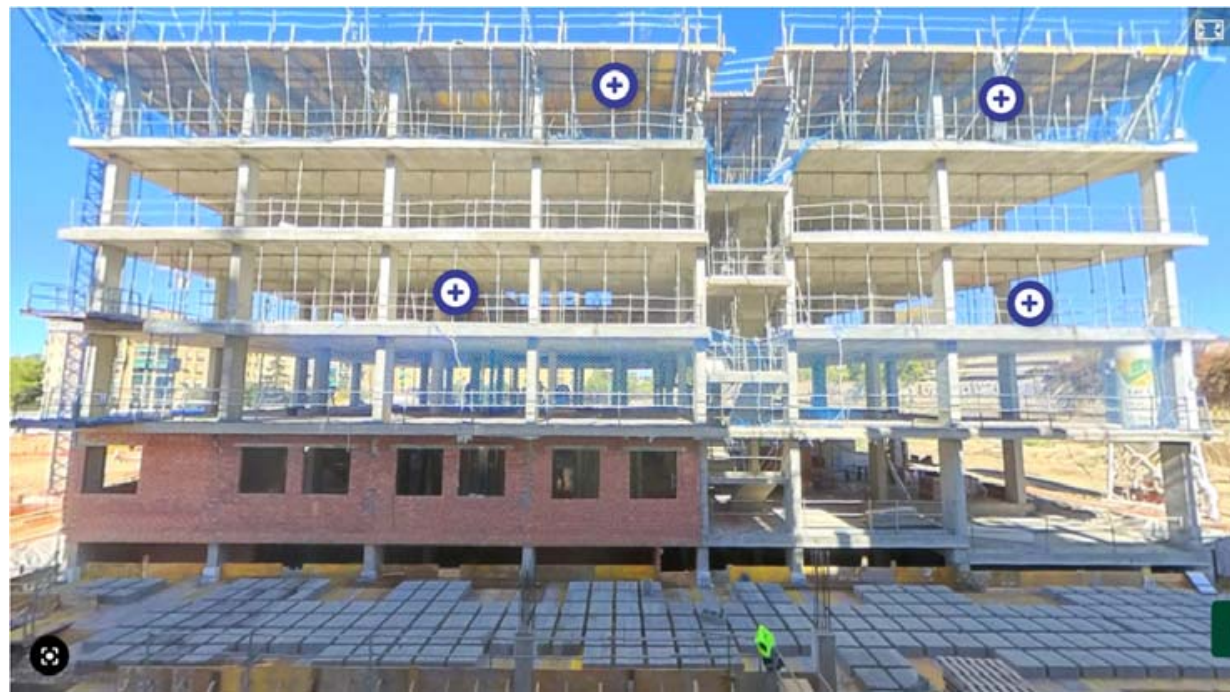

Fuente: Elaboración propia

Fig. 7. Imagen $360^{\circ}$ con contenido interactivo.

En la sesión final se ha realizado una Gráfica de Plus - Delta también utilizando la herramienta Miro. En esta gráfica en una columna se ha anotado lo positivo, o las cuestiones que se desarrollaron con un resultado positivo, y en la otra las áreas que necesitan mejorar (Ver Fig, 8).

Cabe destacar que uno de los puntos fuertes del equipo ha sido la participación de los estudiantes. Ellos han aportado un punto de vista enriquecedor y que como docentes es necesario conocer. 
Antonio J. Aguilar, Carlos Benavides de la Fuente, Gloria Cuenca-Moyano, Lourdes Gutiérrez-Carrillo, María L. de la Hoz-Torres, María Martín-Morales, M. Dolores Martínez-Aires, Manuel Martínez Carrillo y Raquel Nieto-Álvarez

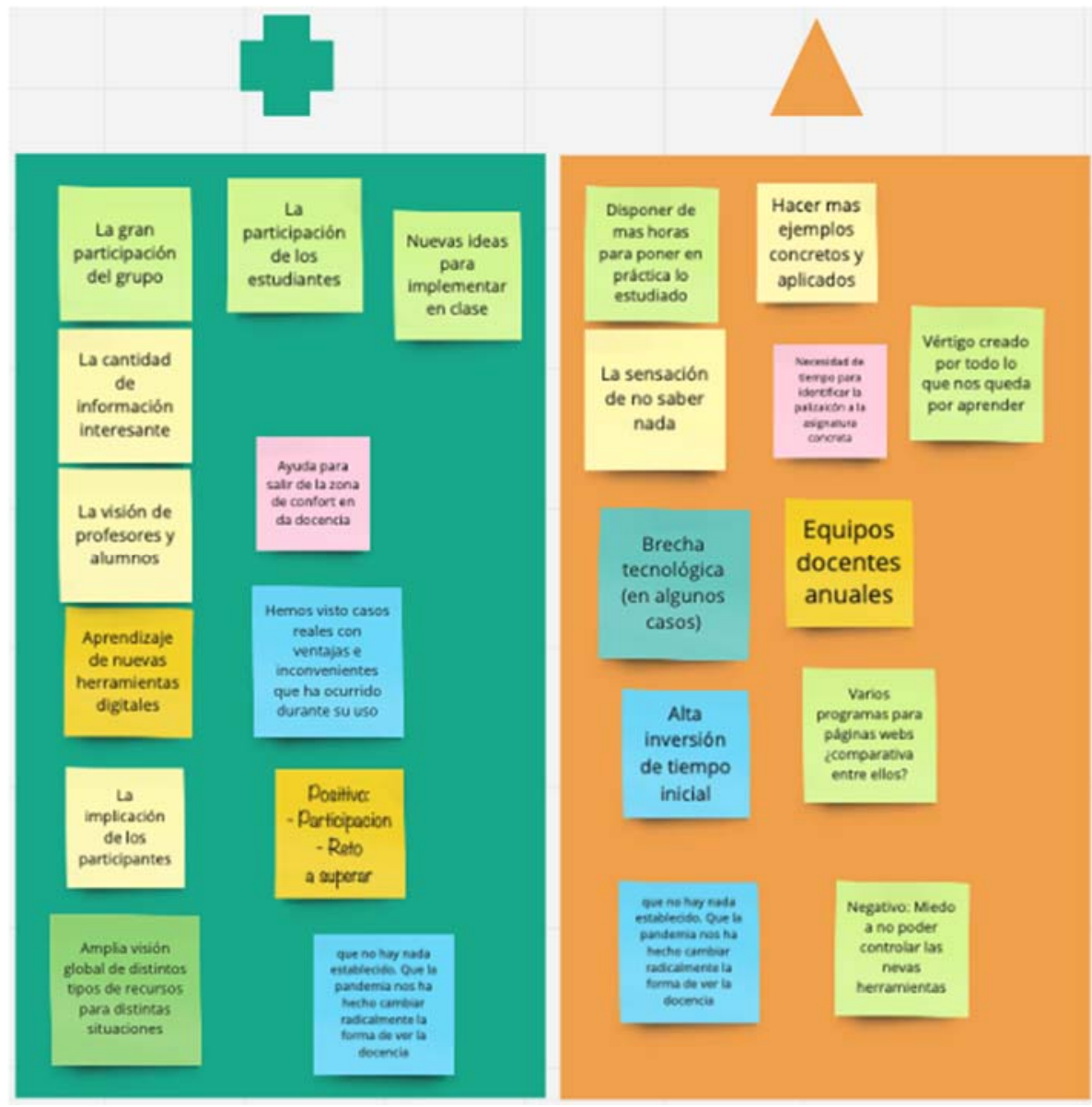

Fuente: Elaboración propia

Fig. 8 Gráfica de Plus - Delta.

Para cerrar la experiencia, se ha realizado la encuesta de satisfacción de valoración numérica de 1 a 5. Los resultados, recogidos en la Tabla 2, han dejado patente la satisfacción general con el equipo docente, así como la destacable participación. Así mismo, hay que destacar como resultado de la misma que, dada la gran cantidad de información y herramientas suministradas, se demanda una formación continuada que permite profundizar en su estudio y en el diseño de distinto material curricular para las asignaturas. 
Tabla 2. Resultado de la encuesta final

\begin{tabular}{|l|c|}
\hline \multicolumn{1}{|c|}{ Item } & Valoración \\
\hline INFORMACIÓN RELATIVA A LA ACCIÓN FORMATIVA & \\
\hline Los objetivos de la acción formativa han sido & 5 \\
\hline formulados de manera clara y concreta & 4,8 \\
\hline adecuados a las prácticas desarrolladas en el aula & 4,7 \\
\hline \begin{tabular}{l} 
Los contenidos de la acción formativa \\
\hline han sido claros y ha existido un orden lógico en su exposición
\end{tabular} & 4,8 \\
\hline han permitido desarrollar los temas tratados con un nivel adecuado & 4,9 \\
\hline La metodología & 4,7 \\
\hline ha favorecido la motivación y participación & 5 \\
\hline ha favorecido el desarrollo de actividades grupales & 4,9 \\
\hline Las actividades realizadas & \\
\hline han repercutido en mejorar mi conocimiento sobre la temática & 4,8 \\
\hline han sido las adecuadas para mejorar mis destrezas docentes & 4,8 \\
\hline La organización temporal & \\
\hline ha facilitado que las tareas teóricas y prácticas se realicen en los momentos \\
\hline adecuados & 4,9 \\
\hline ha facilitado el desarrollo total del curso & 4,9 \\
\hline La información facilitada ha sido adecuada respecto a & \\
\hline la posibilidad de aplicación de los conocimientos a la práctica docente & 4,8 \\
\hline lo necesario para hacer un seguimiento del curso & \\
\hline REFLEXIÓN PERSONAL SOBRE LA ACCIÓN FORMATIVA & \\
\hline $\begin{array}{l}\text { Mi implicación en la acción formativa como alumnado ha sido adecuada en } \\
\text { cuanto a }\end{array}$ & \\
\hline asistencia & \\
\hline participación activa & \\
\hline
\end{tabular}

\section{Conclusiones}

Dentro de los Planes de Formación e Innovación Docente de la UGR, los equipos docentes son una buena herramienta de formación, de colaboración e intercambio de experiencias entre profesorado experto y principiante con el objetivo de la mejora continua de la práctica docente.

La pandemia ha demandado una rápida adaptación del profesorado y de las metodologías docentes a la enseñanza online, lo que ha hecho necesario reforzar la formación en herramientas digitales. Con este objetivo, la UGR ha fomentado la creación de Equipos Docentes para la docencia digital. En este contexto surge el Equipo docente para la Docencia 
Antonio J. Aguilar, Carlos Benavides de la Fuente, Gloria Cuenca-Moyano, Lourdes Gutiérrez-Carrillo, María L. de la Hoz-Torres, María Martín-Morales, M. Dolores Martínez-Aires, Manuel Martínez Carrillo y Raquel Nieto-Álvarez

Digital y la Coordinación Transversal de las asignaturas del Módulo de Gestión del Proceso del Grado de Edificación. Su objetivo principal ha sido contribuir al desarrollo de competencias docentes digitales particularmente en el profesorado del Dpto. de Construcciones Arquitectónicas con docencia en las asignaturas del Módulo de Gestión de Proyectos y, de forma general, del Grado en Edificación.

A lo largo de las sesiones programadas, quienes integraban el grupo han ido conociendo las posibilidades de herramientas de creación de recursos digitales interactivos, el uso de la metodología Building Information Modelling (BIM), de la realidad virtual y videos $360^{\circ}$, que pueden acercar al alumnado a las obras y profundizar en conceptos específicos del grado.

Además, se han incorporado diferentes sesiones para mostrar herramientas de asistencia activa, tan necesaria en la situación de la pandemia, pero que pueden utilizarse en la docencia presencial.

Durante las primeras sesiones se ha comprobado que otro de los puntos fuertes de de la propusta ha sido contar en el equipo con dos estudiantes. Ellos han aportado una visión distinta de la adaptación de la docencia provocada por la crisis sanitaria de la COVID-19. La sesión que han impartido, así como su activa participación, han enriquecido los objetivos inicialmente planteados.

Este primer contacto ha permitido un acercamiento a una gran cantidad de contenidos desconocidos para la mayoría del profesorado que integra el equipo. Los resultados globales de la experiencia han sido muy positivos y enriquecedores, lo que se ha ido reflejando en una asistencia continuada de quienes integran el grupo docente así como por una insistente demanda de proseguir con una formación continua en estas herramientas avanzadas.

\section{Referencias}

CEPRUD (2021). Centro de Producción de Recursos para la Universidad Digital de la Universdiad de Granada <https://ceprud.ugr.es> [Consulta: 15 de junio de 2021].

UGR (2016). Planes de formación docente de la Universidad de Granada. $<$ https://calidad.ugr.es/areas/formacion-innovacion-docente/fomacion/cursos/acciones-formativas18-20> [Consulta: 15 de junio 2021].

UGR 2020a (2020). Plan de actuación COVID-19 de la Universidad de Granada. <https://covid19.ugr.es/informacion/docencia-virtual> [Consulta: 16 de junio 2021].

UGR 2020b (2020). Formación de Equipos para la Docencia Digital de la Universidad de Granada. $<$ https://calidad.ugr.es/areas/formacion-innovacion-docente/formacion/docencia-digital> [Consulta: 15 de junio 2021].

Sarkodie, S. A., y Owusu, P. A. (2021). "Global assessment of environment, health and economic impact of the novel coronavirus (COVID-19)" en Environment, Development and Sustainability, 23, p. 50055015 . 


\title{
EDIFICATE
}

I Congreso de Escuelas de Edificación y Arquitectura Técnica de España València, 4 y 5 de noviembre de 2021

Escuela Técnica Superior de Ingeniería de Edificación

Universitat Politècnica de València

Doi: https://doi.org/10.4995/EDIFICATE2021.2021.13526

\section{Ingeniería para las nuevas generaciones: contruyendo con bambú}

\section{Engineering for next generations: building with bamboo}

\author{
Alba Fernández Sáncheza , Ana María Cruz Valdivieso ${ }^{b}$ y Juan Manuel Santiago \\ Zaragozac \\ ${ }^{a}$ Escuela Técnica Superior de Ingeniería de Edificación de la Universidad de Granada,

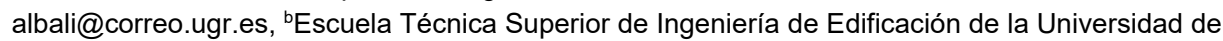

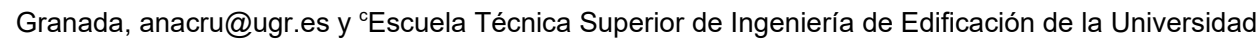 \\ de Granada, santi@ugr.es.
}

\begin{abstract}
Today, the most important duty for Human Being is leaving a safety environment for future generations without depleting natural resources. Housing is a primary need: it makes us safe and comfortable. Nevertheless cities can not gowth forever. Rehabilitation and soustainable buildings are securing the future. The study of new materials and their resistance is one of the most passionate faces of Building Engineering. To achieve soustainable buildings using that materials is an insurance for of small and medium enterprises of the construction sector.
\end{abstract}

The universities have the challenge of transferring knowledge to society. In this case the School of Building of the University of Granada tries to promote vocation for STEM studies between girls of Secondary participating in the program: I want to be an [Building] Engineer showing them the existence of sustainable materials, their handling, characterization and use on a day-to-day basis.

Finally it was made a summer camp were the girls students participate in workshops using one of the most sustainable material for building engineering: Bamboo.

Keywords: sustainability, materials, bamboo, building engineering 


\section{Resumen}

En la actualidad, dejar a las futuras generaciones un medio ambiente saludable, no agotando los recursos naturales, se ha convertido en una de las principales preocupaciones de la humanidad. La vivienda es una de las necesidades primarias del ser humano. Nos hace sentirnos seguros y a refugio. Sin embargo las ciudades no pueden seguir creciendo indefinidamente. La rehabilitación y la edificación sostenible son un seguro para el futuro.

El estudio de nuevos materiales y su resistencia, es una de las facetas apasionantes de la Ingeniería de Edificación. Conseguir la regeneración de edificios sostenibles con el uso de éstos es un seguro a largo plazo para las pequeñas y medianas empresas del sector de la construcción.

Uno de los grandes retos de la universidad es dar a conocer a alumnos de etapas escolares y pre-universitarios, los futuros profesionales, la existencia de otros materiales sostenibles, su manejo, caracterización e implementación en el dia a dia. Uno de los objetivos del trabajo que aquí se presenta es fomentar y alentar vocaciones en Ingeniería de Edificación en las chicas preuniversitarias con la participación en talleres donde van a conocer y trabajar con unos de los materiales más sostenibles en la actualidad: el Bambú.

Palabras clave: bambú, edificación, ingeniería, materiales, sostenibilidad. 


\section{Introducción}

El origen de la palabra sostenibilidad se remonta al 4 de agosto de 1987, cuando la Organización de las Naciones Unidas (ONU) publicó el "Informe Brundtlan", denominado así por haber sido realizado por la Comisión Brundtlan, liderada a su vez por la doctora y exprimera ministra noruega Gro Harlem Brundtland (Slow Fashion Next, 2020).

En el informe se enfrentan y contrastan el desarrollo económico actual y la sostenibilidad ambiental, analizando, criticando y replanteando las políticas de desarrollo económico globalizador y reconociendo que el actual avance social se está llevando a cabo a un costo medioambiental alto (Sysop, 2012).

El término desarrollo sostenible (o desarrollo sustentable), definido como "satisfacer las necesidades de la generación presente sin comprometer las posibilidades de las generaciones futuras para atender sus propias necesidades", fue utilizado por primera vez en el Informe Brundtland, e implica un cambio muy importante en cuanto a la idea de sustentabilidad, principalmente ecológica, dando énfasis al contexto económico y social del desarrollo. Se trata de un concepto que incluye el componente ético en las actividades humanas, considerando los aspectos social y medioambiental, además del económico, para que el desarrollo sea adecuado (Acciona, s.f.).

Hay que tener en cuenta que el origen de todos los bienes materiales son los recursos naturales y que el uso global de recursos por cápita aumenta continuamente de forma muy desigual, pues el $20 \%$ de la población mundial usa el $80 \%$ de los recursos de la Tierra. El crecimiento de la población, el aumento del uso individual y la mala gestión llevan al agotamiento prematuro de los recursos naturales y a la generalización de sus impactos (González Yebra, 2014).

La sostenibilidad, como criterio principal en la elección de materiales para el desarrollo de todo tipo de proyectos de diseño, re-diseño, construcción y fabricación, resulta fundamental. Esto se debe, entre otras razones, al cambio que ha tenido lugar en las últimas décadas en la concepción social de la población. Por ello, resulta imprescindible estudiar/investigar la carga ambiental de los materiales que tradicionalmente se emplean. Ya en 1990, tanto el matrimonio Ehrlich (Paul R. y Anne H.) como James Gustave Speth, introdujeron la relación entre sostenibilidad y bienestar mundial (demográfico) con respecto al impacto medioambiental de las materias primas, demostrando la necesidad de alcanzar una sustancial mejora ambiental (González Yebra, 2014).

En términos cuantitativos, es sencillo medir el bienestar de un país mediante el crecimiento económico (aumento del Producto Interior Bruto). Sin embargo, este indicador no contempla aspectos sociales de carácter cualitativo que determinan el bienestar de los ciudadanos, por lo que, en la actualidad, factores como la salud o la huella ecológica deben contemplarse también. Es cierto que son muchas las organizaciones e instituciones que han empezado a incluir entre sus objetivos la reducción de los impactos ambientales, pero aún queda un largo camino de concienciación que recorrer para hacer entre todos un mundo más sostenible (Grupo PSN, 2016). 
Para ello, resulta de vital importancia el estudio de nuevas soluciones que empleen recursos renovables, que integren una producción sostenible de los productos y que busquen nuevos usos para materiales naturales existentes, como el bambú. Por lo tanto, se acentúa la importancia del estudio de los materiales como fuente para generar soluciones innovadoras.

\subsection{El Bambú en la Costa Tropical de Granada}

Fuera de España, principalmente en América del Sur y Asia, la arquitectura vernácula de cada región ha empleado tradicionalmente el bambú como material de construcción. No obstante, actualmente su uso se ha extendido hasta convertirlo en el material principal en obras magistrales internacionalmente reconocidas y galardonadas.

Sin embargo, en España la construcción con bambú aún no se ha desarrollado en su plenitud, pues no existe ninguna obra en la que emplee el bambú con carácter estructural, siendo precisamente su elevada resistencia mecánica una de sus mejores características. Las construcciones más famosas en las que se ha aplicado el bambú en nuestro país son el techo curvo de la T4 del aeropuerto Adolfo Suárez Madrid-Barajas y el bloque de viviendas sociales diseñado y construido por el arquitecto Alejandro Zaera en el barrio de Carabanchel (Madrid), siendo en ambos casos empleado el bambú como material de acabado.

El bambú es un material de construcción con excelentes propiedades mecánicas, gran rapidez de crecimiento y alto valor ecológico. Éstas características hacen interesante el estudio de la posibilidad de establecer cultivos de bambú en la Costa Tropical de Granada, ya que ésta disfruta de un clima subtropical único en Europa que hace posible el cultivo de numerosas especies tropicales, así como de la caña de azúcar, cuyas características y requisitos de cultivo son similares a los del bambú (Torreón Arquitectura, s.f.).

Otro motivo que incentivó este estudio fue el cierre del que fuera el ingenio fabril azucarero más antiguo de Granada y de todo el sur de España, la azucarera del Guadalfeo (conocida también como azucarera de Nuestra Señora del Rosario), cuya construcción se remonta a mediados del siglo XIX, teniendo lugar la última cosecha y elaboración de azúcar de caña en el año 2005 (Turism12-CA, 2018).

Un gran porcentaje de la vega de la comarca estaba dedicado al cultivo de la caña de azúcar. Tras el cierre de la fábrica en el año 2006, fueron muchos los terrenos que quedaron desaprovechados, sin producir ningún tipo de cultivo en ellos. Por lo tanto, si es posible demostrar que el cultivo de bambú en la Costa Tropical granadina es viable, los propietarios de los terrenos tendrán una alternativa de cultivo económica y rentable, por lo que podrán apostar por el bambú, con la consiguiente reactivación económica de la zona. En este aspecto, otro de los objetivos a largo plazo es establecer una red de productores que aglutine agricultores, empresarios e instituciones locales para la puesta en marcha del cultivo de bambú.

Para demostrar que el cultivo del bambú es factible en la zona, se procedió en primer lugar a la lozalización de especies de bambú no autóctonas, pero que sí se encontraban ya en el 
municipio de Motril, empleadas como ornamentación en zonas ajardinadas o en pequeños cultivos asilvestrados. La primera plantación experimental se realizó en mayo de 2018, mediante un convenio de colaboración entre la Universidad de Granada y la entidad Caja Rural de Granada, con la cesión por parte de ésta última de una finca experimental. En ella se procedió, en un principio, a la plantación y cultivo de dos especies de bambú: Bambusa vulgaris Vulgaris y Bambusa vulgaris Vittata. A día de hoy, se han incorporado a la finca nuevas especies y ya se encuentran en producción.

En la actualidad, y gracias a varios convenios con organismos oficiales y empresas privadas, se está trabajando en tres plantaciones experimentales diferentes, donde se están cultivando 8 especies distintas de bambú.

Desde abril de 2013, profesores de la Escuela Técnica Superior de Ingeniería de Edificación de la Universidad de Granada, han realizado estudios de caracterización de varias especies de bambú, tanto importadas de diferentes productores de bambú, como del existente en el municipio de Motril. Esto ha permitido que numerosos estudiantes de la titulación de Grado en Edificación hayan realizado Proyectos Fin de Grado relacionados con el bambú. Además, ha dado lugar a colaboraciones con universidades extranjeras, así como a la continuación de la caracterización del bambú.

\subsection{La Mujer y la Ingeniería}

Los datos del Ministerio de Educación reflejan que las mujeres representan un $54 \%$ de la población universitaria española. Sin embargo, cuando se observan las carreras técnicas (ingenierías y arquitectura) la representación de mujeres baja hasta un $25 \%$. Un análisis más detallado, que tenga en cuenta que en arquitectura actualmente existe paridad, implica que las ingenierías son estudios copados por hombres -no todas pero sí las que pueden ser consideradas como las que proporcionarán las salidas profesionales del futuro. Concretamente en las llamadas TIC (Tecnologías de la Información y la Comunicación) el porcentaje de mujeres entre el alumnado supone un 10\%. (Quiero Ser Ingeniera, 2019).

La poca presencia de las mujeres en el sector tecnológico, motor del presente y futuro de la sociedad actual, es un problema de carácter global y para abordarlo es necesaria la implicación de todos los agentes sociales que puedan estar implicados. La sociedad no debe permitir que las mujeres, más de la mitad de la población mundial, representen apenas un $20 \%$ del sector líder de la economía del planeta. Las mujeres no se pueden quedar fuera de las profesiones con proyección de futuro, pues esto aumentaría la brecha de género en las posibilidades de empleo, aumentando la desigualdad social (Canal UGR, 2018).

Los estudios más recientes sobre la baja matriculación femenina en ingeniería sugieren que existen numerosos condicionantes externos que empujan a las jóvenes a no elegir una ingeniería aunque ésta les parezca una carrera atractiva. Entre estos motivos se encuentran numerosos tópicos con un arraigo muy fuerte en la sociedad (I.E.S. Padre Manjón, 2019).

El proyecto Quiero ser Ingeniera (2019) es un proyecto del Instituto de la Mujer y para la Igualdad de Oportunidades con el que se pretende romper con los estereotipos, dar una visión más equitativa y justa socialmente del talento femenino y sus oportunidades de participación 
en las profesiones del futuro y, fundamentalmente, fomentar y alentar vocaciones en Ingeniería en las chicas preuniversitarias. En el proyecto participaron, junto a la Universidad de Granada, la Universidad Politécnica de Madrid, la Universidad de Burgos, la Universidad Autónoma de Madrid, la Escuela Politécnica Superior de la Universidad de Alicante y la Universidad Politécnica de Cartagena.

\section{Objetivos}

El objetivo general del proyecto es fomentar y alentar vocaciones en Ingeniería en las chicas preuniversitarias, para aumentar su participación en las profesiones del futuro.

Los objetivos específicos son:

- Incentivar la participación en las actividades que se realizan en las distintas Escuelas de Ingeniería.

- Incentivar el trabajo en equipo de estudiantes preuniversitarias junto a profesores y estudiantes de la universidad.

- Dar a conocer nuevos materiales de naturaleza más sostenible, sus formas de utilización y sus posibilidades, así como realizar diversos trabajos manuales con ellos. En este caso concreto, la especie de bambú Guadua angustifolia Kunth.

\section{Desarrollo de la innovación}

La Escuela Técnica Superior de Ingeniería de Edificación (ETSIE) de la Universidad de Granada, junto a la Escuela Técnica Superior de Ingenierías Informática y de Telecomunicación, la Facultad de Ciencias y la Escuela Técnica Superior de Ingeniería de Caminos, Canales y Puertos, participaron en el año 2019 en el proyecto Quiero Ser Ingeniera, que constaba de 3 fases.

En la primera fase se realizaron visitas a distintos centros de Enseñanza Secundaria Obligatoria de la provincia de Granada, donde se presentó el proyecto a los padres y madres de los escolares, así como a los docentes y al personal a cargo de la orientación de los escolares, para facilitar que los agentes implicados en el entorno escolar fomenten en las chicas el estudio de carreras de ingeniería.

Un segunda fase donde durante tres días, las alumnas previa solicitud, participaron en los diferentes talleres de ingeniería ofertados. El desarrollado en la ETSIE de Granada, denominado "La madera como material de construcción", se realizó en grupos reducidos, donde las alumnas pudieron conocer los diferentes materiales naturales con los que se está trabajando en las investigaciones actuales de la Escuela (Figura 1). 


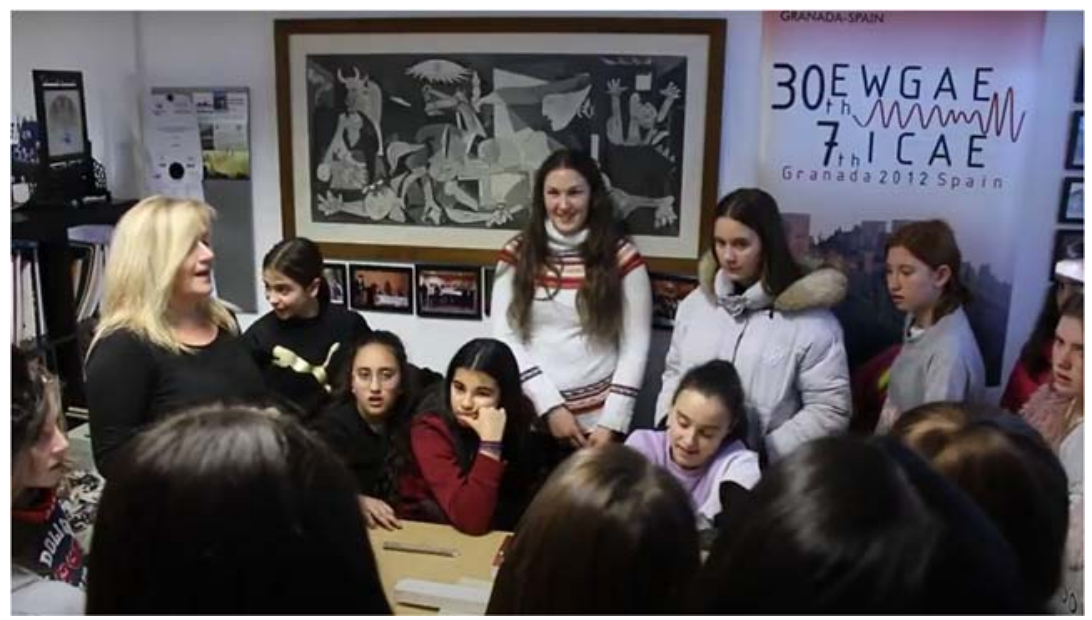

Fuente: Quiero Ser Ingeniera (2019)

Fig. 1 Estudiantes preuniversitarias conociendo los distintos materiales naturales que están siendo estudiados en la ETSIE

Una vez presentados los estudios en desarrollo en los que se analizan y emplean maderas tradicionales como el chopo o el pino, las estudiantes tuvieron la oportunidad de conocer el material con el que desarrollarían la tercera fase del proyecto: el bambú (Figura 2).

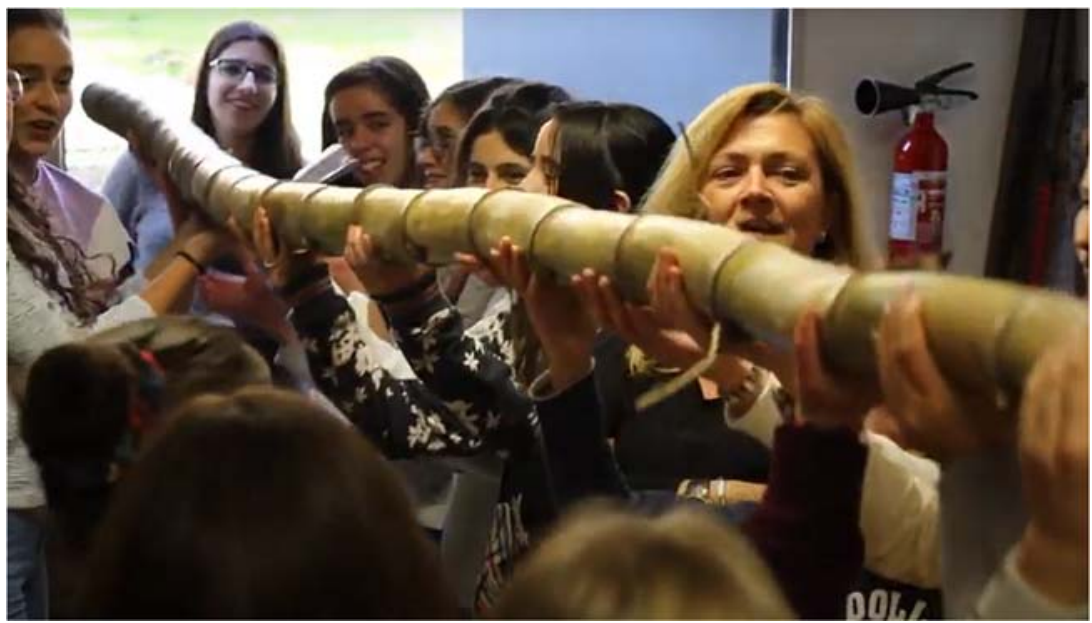

Fuente: Quiero Ser Ingeniera (2019)

Fig. 2 Estudiantes preuniversitarias sujetando una caña de bambú

En primer lugar, dos investigadoras de la ETSIE impartieron una conferencia introductoria en las que explicaron las excelentes características del bambú, sus principales usos en el sector 
de la Construcción, el papel tan importante que juega en relación a la sostenibilidad y las diferentes líneas de investigación en las que se está trabajando desde la Escuela con respecto a este material tan antiguo pero a la vez desconocido en nuestra sociedad.

Finalizada la exposición, se les mostraron a las estudiantes preuniversitarias los diferentes tipos de uniones que pueden emplearse en las construcciones con bambú: desde las tradicionales y sencillas cuerdas, hasta las más modernas y complejas estructuras articuladas de acero, pasando por la solución más empleada en la actualidad debido a su eficacia: varillas roscadas y pernos de acero.

Una vez conocidas todas las opciones, se les suministraron a las estudiantes los materiales necesarios para que pusieran en práctica las distintas uniones que acababan de aprender (Figura 3), para lo que se les pidió que se dividieran por parejas, animándolas a elegir como compañera a alguna estudiante que no conociesen de antemano.

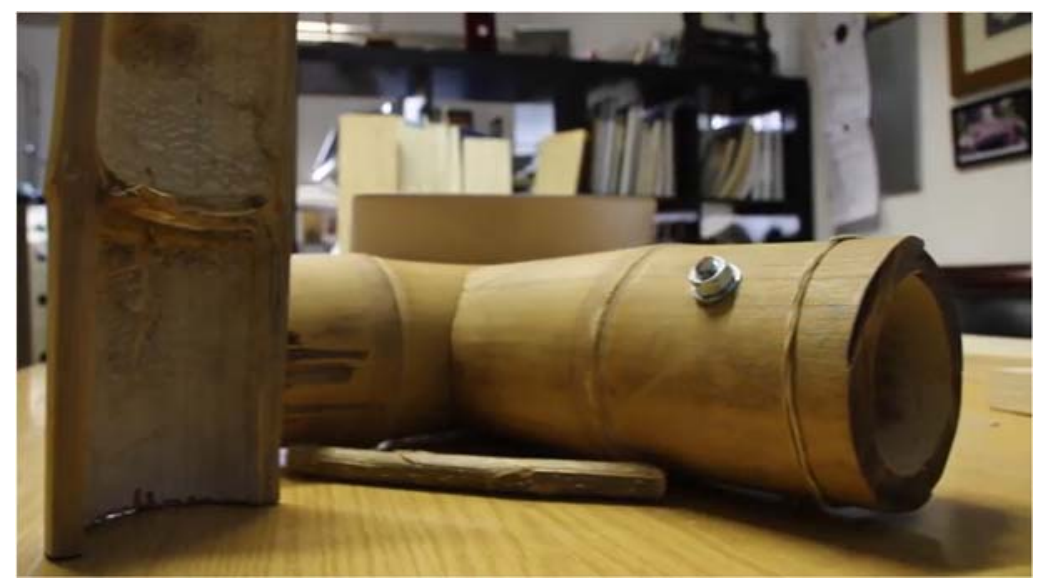

Fuente: Quiero Ser Ingeniera (2019)

Fig. 3 Cañas de bambú con las que las estudiantes preuniversitarias practicaron las uniones

En la tercer fase del proyecto, que tuvo una duración de una semana, las estudiantes participaron en el diseño y construcción de un modelo experimental fabricado con bambú, que sería ubicado en los jardines de la ETSIE y que debía incluir una pequeña cimentación y algunos de los tipos de uniones que habían aprendido en la fase anterior.

El modelo elegido consistía inicialmente en una pequeña caseta apoyada en 4 enanos de hormigón. La estructura principal estaría compuesta por cañas de bambú Guadua angustifolia Kunth, por ser ésta la especie más resistente y, por tanto, más empleada en el sector de la Construcción. Las paredes se compondrían mediante latillas (listones o tiras longitudinales con respecto al eje de la caña) de bambú de la misma especie, sujetas a la estructura con puntillas y tornillos. Para el suelo se emplearía un tablero de chopo al que se le añadirían 
latillas de bambú para obtener un acabado homogéneo. Partiendo de este diseño, se realizó un plano de despiece que se entregó a las estudiantes (Figura 4).

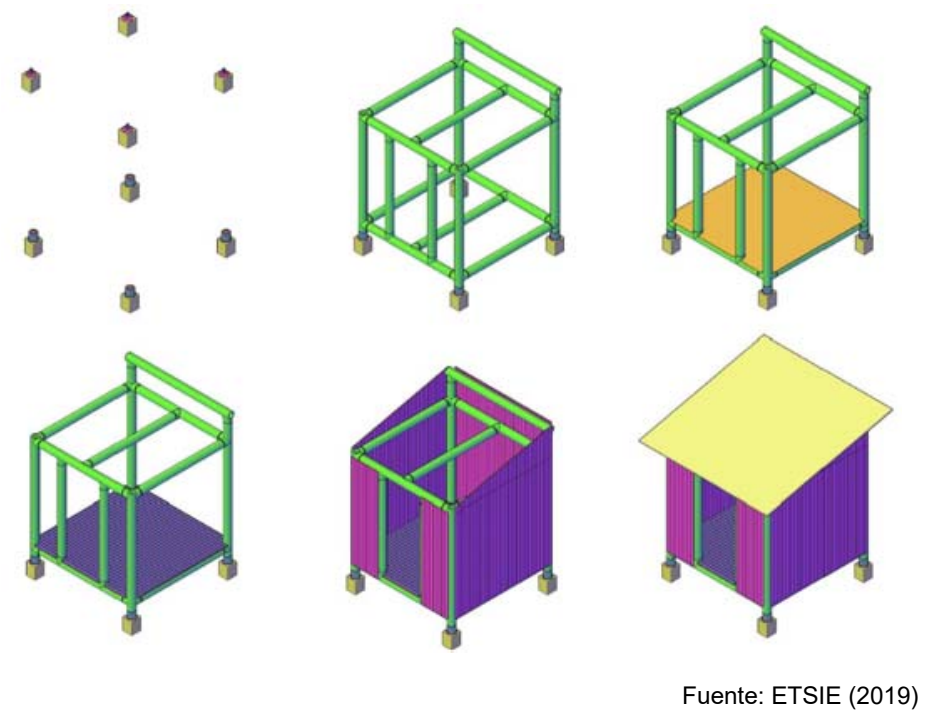

Fig. 4 Plano de despiece entregado a las estudiantes preuniversitarias

Con todo preparado, parte de las estudiantes comenzaron realizando el replanteo y ubicando los enanos que servirían como soporte de la estructura (Figura 5).

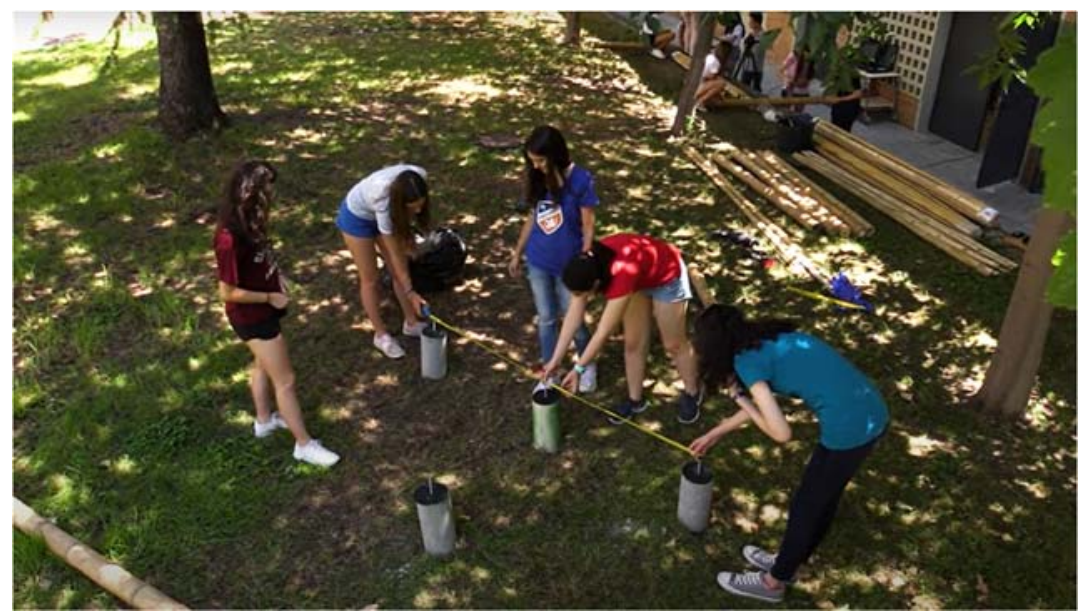

Fuente: UGRmedia (2019)

Fig. 5 Estudiantes preuniversitarias realizando el replanteo 
Al mismo tiempo, el resto de sus compañeras se encontraba cortando y lijando las cañas que servirían para construir la estructura del modelo experimental. Este paso incluía la complejidad de tener que decidir dónde ubicar cada caña (ya que no todas tenían la misma longitud ni grosor) y calcular por dónde cortarlas y qué longitud final debían obtener para poder componer la estructura éxitosamente.

Bajo la supervisión de las monitoras, las estudiantes se valieron de sierras de calar y manuales para dar el tamaño y la forma adecuada a cada caña (Figura 6), pues, para poder construir las uniones, era necesario realizar un rebaje simple o doble (denominado habitualmente como "boca de pez") en el extremo de la caña, ajustándolo para que encaje exactamente en la caña receptora a la que debe unirse. Para garantizar la perfección de las uniones, las estudiantes emplearon lijas y escofinas en los rebajes realizados, evitando de paso que quedasen astillas en ellos.

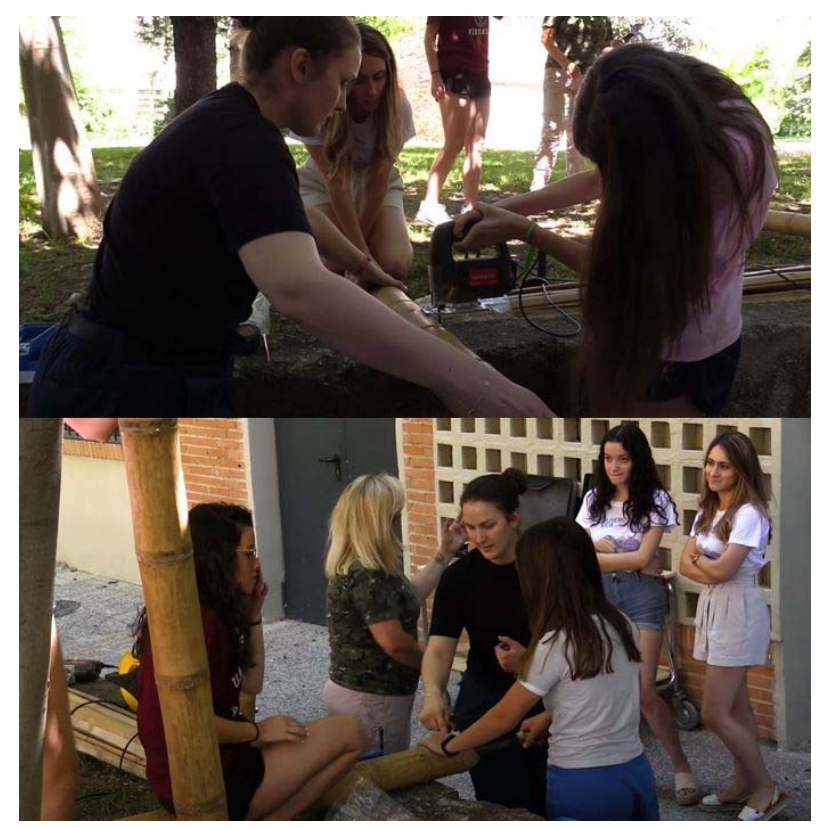

Fuente: UGRmedia (2019)

Fig. 6 Estudiantes preuniversitarias cortando y lijando las cañas de bambú

Cuando las cañas estuvieron listas, se procedió a montar la estructura (Figura 7). Para ello, las estudiantes emplearon la técnica que ya habían practicado en la fase anterior del proyecto, por lo que utilizaron varillas roscadas y pernos para realizar las uniones.

En el caso de que el extremo de una caña no terminara de encajar con naturalidad en su receptora, las chicas repetían el proceso de lijado para ajustar la boca de pez y asegurar una buena unión entre los elementos. 


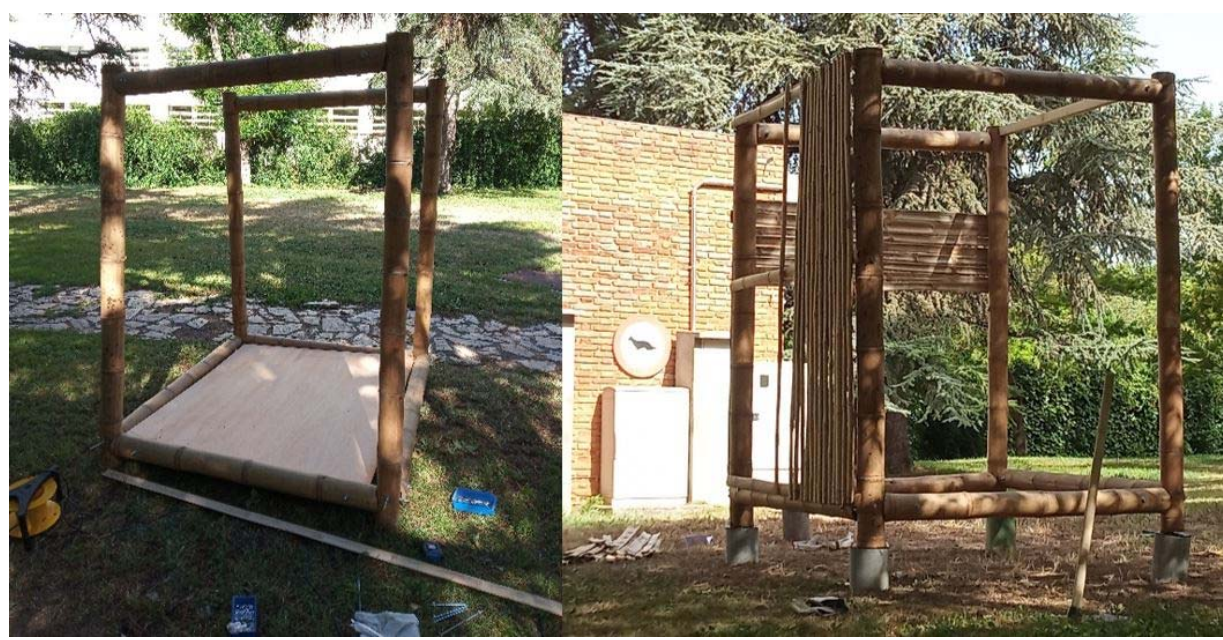

Fuente: ETSIE (2019)

Fig. 7 Estructura del modelo experimental de bambú

El siguiente paso fue componer las paredes. Para ello, lo primero que tuvieron que hacer fue medir la longitud necesaria que debía tener cada latilla en función de la posición en la que ésta fuese a ser colocada. Hecho esto, procedían a cortar la latilla y lijar sus extremos. Mientras un grupo se encargaba de esta tarea, otro las iba fijando en la estructura mediante tornillos y clavos, ubicando un listón en el centro de cada pared como refuerzo.

Poco a poco, las paredes fueron tomando forma (Figura 8). Para añadirle un toque personalizado, las estudiantes optaron por no colocar las latillas en la misma posición en todas las paredes, sino que decidieron colocar 2 caras en vertical y 2 en horizontal.

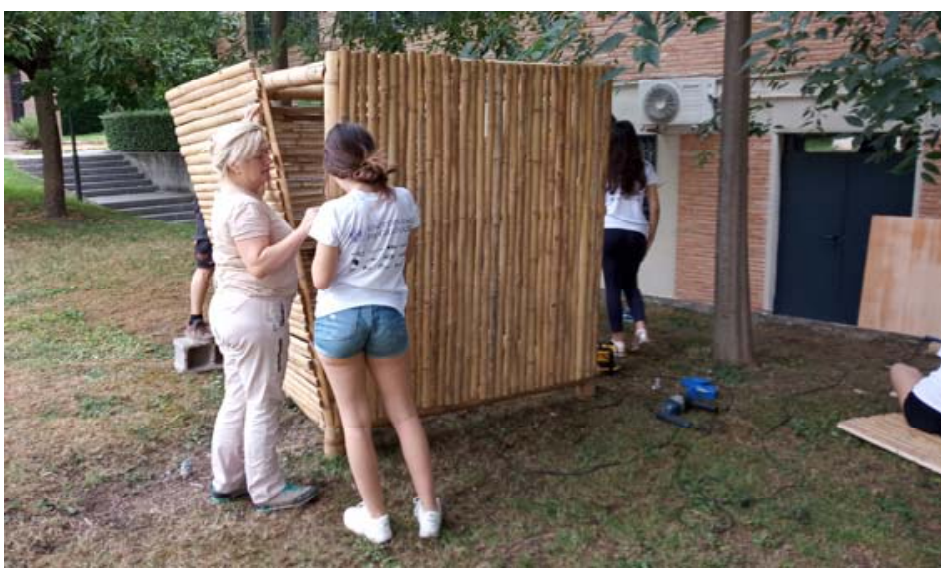

Fuente: ETSIE (2019)

Fig. 8 Estudiante preuniversitaria y monitora finalizando la pared posterior del modelo 
Paralelamente a este proceso, se realizó el diseño y composición del suelo (Figura 9). En este proceso, consistente en algo tan sencillo como clavar latillas a un tablero de chopo, se pudo ver la gran imaginación de las estudiantes preuniversitarias.

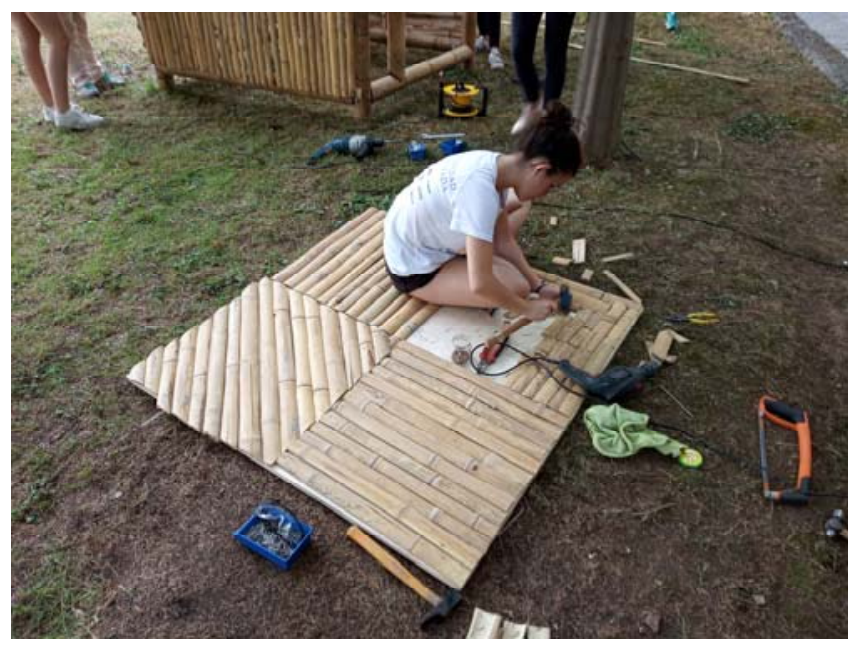

Fuente: ETSIE (2019)

Fig. 9 Estudiante preuniversitaria componiendo el suelo del modelo experimental de bambú

En lugar de hacer un único patrón para el suelo, las chicas decidieron dividir el tablero en 4 cuadrados iguales y hacer en cada uno un diseño diferente, creando una composición más original que la inicialmente planteada.

Pero no sólo eso, sino que compusieron el suelo empleando los restos de las latillas usadas en las paredes del modelo experimental, lo que demuestra que conocen la importancia de aprovechar al máximo los materiales y tratar de desperdiciar lo menos posible.

Conforme las paredes y el suelo fueron terminados, se procedió a introducir el tablero del suelo en el interior del modelo, fijándolo apropiadamente a la estructura y dando por terminado el taller (Figura 10).

Para que quedase constancia de su participación en el proyecto, todas las estudiantes firmaron el modelo experimental, dejando su nombre grabado en él.

Como punto a destacar de esta experiencia, hay que señalar que, aunque la segunda fase permitió que trabajasen por parejas, la tercera fase del proyecto supuso un auténtico y muy destacable trabajo en equipo por parte de las estudiantes preuniversitarias. Trabajaron coordinadamente, intercambiando información constantemente para garantizar que todo saliese bien y ayudándose las unas a las otras en la realización de los distintos procesos (Figura 11). 


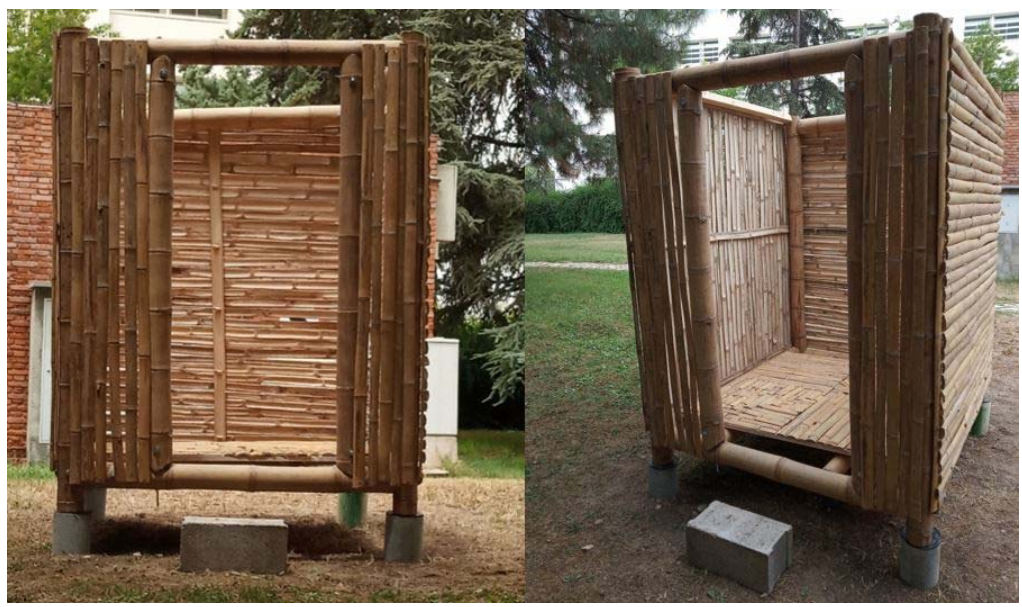

Fuente: ETSIE (2019)

Fig. 10 Modelo experimental finalizado

Además, las chicas rotaban entre las tareas disponibles, de modo que todas pudiesen participar en todo el proceso; e incluso las que ya habían realizado una determinada tarea aconsejaban a las siguientes y les enseñaban cómo debían hacerla.

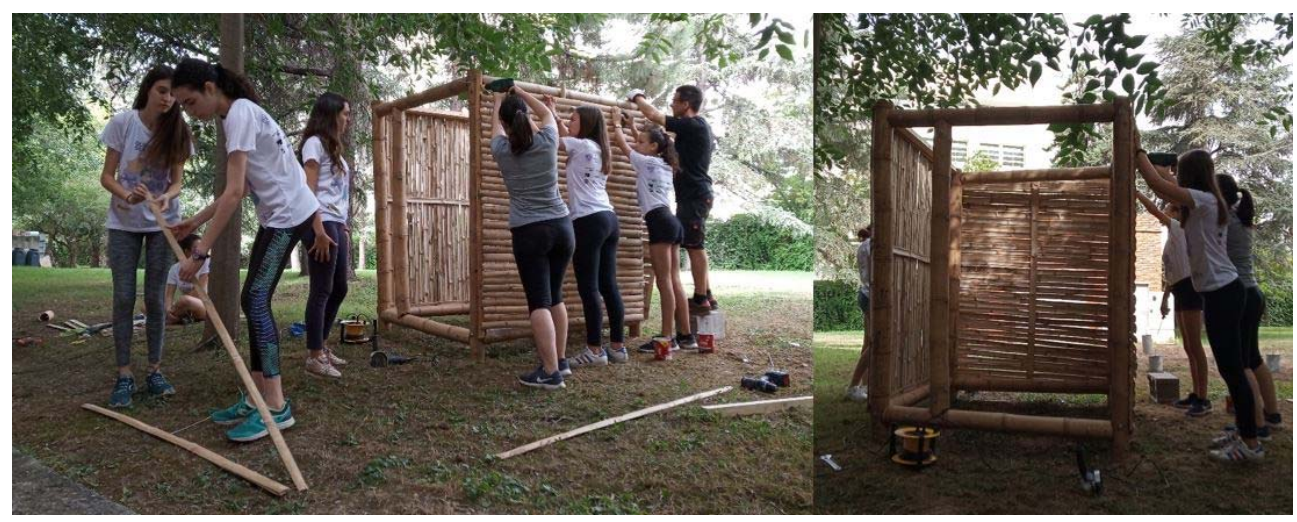

Fuente: ETSIE (2019)

Fig. 11 Estudiantes preuniversitarias colaborando en la realización del modelo experimental

Por todo ello, se puede concluir que la impartición de talleres y la realización de proyectos como el de Quiero Ser Ingeniera no sólo son beneficiosos para las estudiantes preuniversitarias, sino que también son necesarios y pueden ser, a la vez, interesantes y divertidos. 
Para las estudiantes de enseñanzas medias supone una forma amena y entretenida de acercarse al entorno universitario y al ámbito de la ingeniería, ambos prácticamente desconocidos para ellas muchas veces.

Iniciativas como esta son las que marcan la diferencia y permiten que las jóvenes de hoy sean las líderes del mañana, pues las animan a formar parte de las carreras y profesiones del futuro y fomentan en ellas el desarrollo de excelentes capacidades como la resolución de problemas, el trabajo en equipo y el interés por la investigación.

\section{Resultados}

El proyecto acercó la experiencia universitaria a las estudiantes de instituto que participaron en él, permitiéndoles conocer de primera mano las líneas de investigación que se encuentran abiertas en la Escuela Técnica Superior de Ingeniería de Edificación de la Universidad de Granada, así como los materiales que se están estudiando actualmente.

El proceso fomentó el trabajo en equipo de todos los participantes, que tuvieron que colaborar para realizar tareas complejas difíciles de realizar de forma individual. Asimismo, las estudiantes desarrollaron su imaginación y capacidad de resolución de problemas, pues tuvieron que solventar dificultades inesperadas que surgieron durante el desarrollo del taller, lo que no sólo permitió que éste se concluyera con éxito, sino que además les permitió incorporar su aportación personal al resultado.

Tanto las estudiantes como el personal docente y auxiliar implicado en el proyecto llevaron a cabo exitosamente la construcción del modelo de bambú propuesto, lo que ha servido posteriormente para analizar y ampliar la investigación sobre el bambú, determinando cómo han variado sus propiedades físico-mecánicas al verse expuesto a la intemperie granadina durante 2 años.

\section{Conclusiones}

Además de resultar una experiencia muy divertida para todos los participantes, el proyecto incentivó la vocación de las jóvenes estudiantes como futura opción por una ingeniería como carrera y profesión pues, además de permitirles experimentar por ellas mismas, les permitió interactuar con el profesorado de la Escuela, así como con actuales alumnas del grado y de doctorado, quienes les hablaron de su experiencia durante sus estudios universitarios, animándolas a escoger una carrera del futuro.

Se concluye por tanto que las experiencias y talleres como el desarrollado son beneficiosos y necesarios para dar a conocer el mundo universitario y sus posibilidades a los estudiantes de ESO y Bachillerato, incentivándolos a escoger su futuro con base en sus vocaciones y no en los prejuicios que puedan existir en su entorno y en la sociedad en general.

Crear puentes que unan los ámbitos académicos de enseñanza secundaria y universitario es un compromiso que todos los educadores y agentes implicados deberían asumir, pues sólo 
así se puede garantizar una educación de calidad y un futuro bueno e igualitario para los estudiantes.

\section{Referencias}

ACCIONA. ¿Sabes cuándo nace la sostenibilidad? <https://www.sostenibilidad.com/desarrollosostenible/sabes-cuando-nace-la-sostenibilidad/> [Consulta: 22 de junio de 2021]

CANAL UGR (2018) "Presentando el proyecto "Quiero ser ingeniera"” en Canal UGR, 3 de diciembre. $<$ https://canal.ugr.es/noticia/proyecto-quiero-ser-ingeniera/> [Consulta: 30 de mayo 2021]

GONZÁLEZ YEBRA, O. (2014). Caracterización del bambú Guadua (Guadua Angustifolia) para el Diseño e Industrialización en España. Almería: Editorial Universidad de Almería.

GRUPO PSN (2016) "Indicadores del bienestar alrededor del mundo" en PSN, 23 de marzo. $<$ https://enconfianza.psn.es/-/indicadores-del-bienestar-alrededor-del-mundo> [Consulta: 19 de junio 2021]

I.E.S. PADRE MANJÓN (2019) "Quiero ser ingeniera (4 ESO)" en I.E.S. Padre Manjón, 24 de abril. $<$ https://iespm.es/index.php/noticias/item/134-quiero-ser-ingeniera> [Consulta: 16 de junio 2021]

QUIERO SER INGENIERA. Objetivos. <https://quieroseringeniera.ugr.es/objetivos.html> [Consulta: 28 de mayo de 2021]

SLOW FASHION NEXT (2020) “¿Qué es el Informe Brundtland?” en Slow Fashion Next, 1 de noviembre. $<$ https://www.slowfashionnext.com/blog/que-es-el-informe-brundtland/> [Consulta: 20 de junio 2021]

SYSOP (2012) "El informe Brundtland - Nuestro futuro en común" en Cambio Climático .org, 22 de julio. <https://www.cambioclimatico.org/contenido/el-informe-brundtland-nuestro-futuro-en-comun> [Consulta: 16 de junio 2021]

TORREÓN ARQUITECTURA. Estudio de la viabilidad del cultivo de Bambúes Leñosos (Bambuseae) en la Costa Tropical de Granada. <http://torreonarquitectura.es/proyectos-archive/bambu/> [Consulta: 22 de junio de 2021]

TURISM12-CA (2018) "Salobreña: El último ingenio azucarero de Europa" en Turismo Salobreña, 11 de octubre. <https://turismosalobrena.com/es/salobrena-el-ultimo-ingenio-azucarero-de-europa/> [Consulta: 25 de mayo 2021] 


\title{
EDIFICATE
}

I Congreso de Escuelas de Edificación y Arquitectura Técnica de España

València, 4 y 5 de noviembre de 2021

Escuela Técnica Superior de Ingeniería de Edificación

Universitat Politècnica de València

Doi: https://doi.org/10.4995/EDIFICATE2021.2021.13530

\section{Internacionalización en el Grado de Arquitectura Técnica Internationalization in the Technical Architecture Degree}

\author{
Juan Villarroya Gaudóa, Rafael Adé Beltrán ${ }^{\mathrm{b}}$ e Inmaculada Urriés Ortizc \\ aProfesor Titular, Grado en Arquitectura Técnica en EUPLA, juanvi@unizar.es, bProfesor Titular y \\ Coordinador de Grado en Arquitectura Técnica en EUPLA, rade@unizar.es, 'Profesora Titular, Grado en \\ Arquitectura Técnica en EUPLA, inmaurri@unizar.es.
}

\begin{abstract}
There is a lot of talk about globalization, interconnectivity, multinational companies... We are part of Europe, in a world that is becoming more and more competitive, where we can see that, more and more often, our building companies have to go abroad and offer public tender in different countries in Europe or other more distant places such as South America, The Middle East, etc.
\end{abstract}

However, do we find it relevant enough, during our academic training, to acquire, within the cross-curricular competences, the ability and skills required in this field of internationalization?

We are talking about foreign language training, teamwork, multidisciplinary and international environment, leadership ability and many more.

Teaching has to adapt to the current needs and demands of society, integrate new technologies and reinforce those competences which we consider to be more relevant and valued by companies. In The La Almunia Polytechnical Engineering College we strongly believe in the necessity of improving the training of our students so as to enable them to perform tasks in international working settings to a high level of competence.

With these goals in mind, the cross-border project EUPLA-ISABTP (Institut Supérieur d'Aquitaine du Bâtiment et des Travaux Publics. UPPA, PAU UNIVERSITY) was set up.

Keywords: Internationalization, cross-border, transversality, skills, teaching methodologies, construction, architecture, building, mobility. 


\section{Resumen}

Son muchas las ocasiones en las que hablamos de globalización, interconectividad, multinacionales... Estamos dentro de Europa, en un mundo cada vez más competitivo, donde vemos que nuestras empresas constructoras cada vez en más ocasiones tienen que salir al extranjero y ofertar licitaciones públicas en otros países, de Europa, u otros continentes más lejanos, como América del Sur, Oriente Medio, etc.

Pero ¿nos preocupamos lo suficiente durante nuestra formación académica por adquirir, dentro de las competencias transversales, destreza y habilidad en este campo de internacionalización? Serían tales como formación en idiomas, lenguas extranjeras, trabajo en equipo, ambiente multidisciplinar e internacional, capacidad de liderazgo, y un largo etcétera.

La docencia tiene que adaptarse a las necesidades y demandas actuales de la sociedad. Incorporar las nuevas tecnologías y reforzar aquellas competencias que creemos que son más interesantes y cada vez más valoradas por las empresas. Desde la Escuela Universitaria Politécnica de La Almunia (EUPLA) creemos firmemente en la necesidad de mejorar la formación de nuestro alumnado y capacitarles para desempeñar un trabajo en ambientes internacionales de trabajo de manera notable.

Con estos objetivos, nació el proyecto transfronterizo EUPLA-ISABTP, (Instituto Superior de Aquitania de Edificación y Trabajos Públicos) de la UPPA (Universidad de Pau)

Palabras clave: Internacionalización, transfronterizo, transversalidad, competencias, metodologías docentes, construcción, arquitectura, edificación, movilidad. 


\section{Introducción}

El presente proyecto surge tras disfrutar de una beca de movilidad para PDI Erasmus ${ }^{1}$ en ISABTP, en Anglet, de la UPPA en noviembre de 2.016. Dada la relativa proximidad de ISABTP en Anglet y EUPLA en La Almunia de Doña Godina, centros de la Universidad de Pau y de Zaragoza respectivamente, se propone buscar actividades comunes con las que establecer relaciones entre el alumnado y profesorado de ambas escuelas, en las que se imparten las titulaciones de Arquitectura técnica e Ingeniería Civil, con una fuerte coincidencia en materias, asignaturas y temarios.

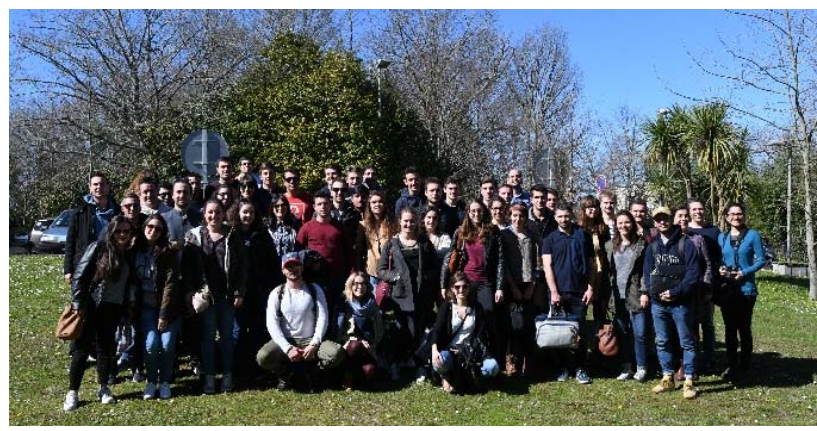

Fuente: Villarroya, J (2017)

Fig. 1 Foto de grupo en ISABTP Marzo 2017

Así surge la idea de desarrollar un proyecto cuyo enunciado sea común para distintas materias y asignaturas de una y otra escuela y se pueda desarrollar en un periodo de tiempo y espacio común. Desarrollando y estudiando los planes de estudios de las distintas carreras universitarias de ambos centros, se encontraron puntos comunes en asignaturas del segundo semestre de segundo curso.

La propuesta se materializa, en aquellas asignaturas que en los planes de estudios sean compatibles, con el desarrollo de un proyecto común, donde se trabajará por equipos internacionales, transfronterizos concretamente, estudiando, comparando y debatiendo las distintas propuestas y soluciones, justificándolas siempre de manera adecuada.

El proyecto transfronterizo ISABTP - EUPLA desde sus orígenes, tuvo la inquietud de ser algo práctico y eficiente, que se pudiera llevar a cabo de manera ágil y con recursos económicos limitados. Es un proyecto enfocado a la docencia, teniendo como protagonistas principales a las alumnas y los alumnos de los grados de Edificación de ambas escuelas. Tenía que ser un proyecto atractivo para el alumnado, para conseguir que sea un proyecto que perdure en el tiempo y que garantice el éxito del mismo. Con esta premisa se decidió ponerlo en marcha con premura, durante el curso 2016-17, para que el impulso inicial de la idea siguiese vivo y se materializase en una realidad. El proyecto sigue vigente, y en el

\footnotetext{
${ }^{1}$ Erasmus
} 
pasado curso 2019-20 se sumó a este proyecto transfronterizo la escuela de Arquitectura Técnica de la Universidad del País Vasco (UPV) de la escuela de San Sebastián.

\section{2. Ámbito de actuación}

Este proyecto está dirigido al alumnado del Grado Universitario de Arquitectura Técnica que se imparte en la EUPLA, concretamente en segundo curso, durante el segundo semestre. Igualmente, para la escuela francesa ISABTP, va dirigido al alumnado de segundo curso de Ingeniería Civil. Para UPV centran el proyecto en una asignatura de $4^{\circ}$ curso del $2^{\circ}$ semestre.

En el caso concreto de la EUPLA ${ }^{2}$, en este proyecto participa el alumnado y profesorado de hasta 4 asignaturas distintas, concretamente

1. Expresión Gráfica de Tecnologías Constructivas,

2. Instalaciones I,

3. Edificación III y

4. Estructuras II.

Igualmente, en las titulaciones que se imparten en ISABTP ${ }^{3}$ y UPV ${ }^{4}$ participan asignaturas análogas. La participación y seguimiento del proyecto transfronterizo ISABTP - EUPLA -UPV se establece como una premisa obligatoria para poder optar a la evaluación continua de las distintas asignaturas que están implicadas en el mismo. Esta condición garantiza la viabilidad y éxito del mismo, en tanto en cuanto el alumnado, si no se siente recompensado o premiado, lastimosamente, podría dejar de participar de manera activa en el mismo.

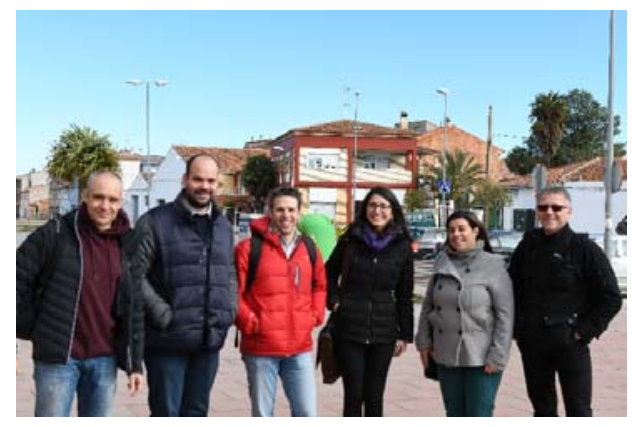

Fuente: Villarroya, J (2017)

Fig. 2 Los profesores y profesoras Olivier Maurel, Juan Villarroya, Rafael Adé, Inmaculada Urries, Mirentxu Forgeot y Philippe Maron en La Almunia, febrero 2017

\footnotetext{
${ }^{2}$ ESCUELA UNIVERSITARIA POLITÉCNICA LA ALMUNIA

${ }^{3}$ INSTITUT SUPÉRIEUR AQUITAIN DU BÂTIMENT ET DES TRAVAUX PUBLICS

${ }^{4}$ UNIVERSIDAD DEL PAÍS VASCO
} 
Se concreta un alcance de actuación: Un proyecto de edificación, de tipología destinada a vivienda principalmente, con estructura de hormigón. Ese será el tema principal, común para todos los participantes. Organizados por grupos de trabajo transfronterizos, cada componente del grupo desarrollará las partes que atañen a sus asignaturas. El reto es poner en común las distintas soluciones, y optimizarlas en un único proyecto.

\section{Desarrollo del proyecto}

El proyecto se desarrolla íntegramente en todo el segundo semestre. Se inicia la primera semana del segundo semestre, en febrero, y se extiende hasta el mes de mayo, intentando concluir unas semanas antes de las fechas de fin de semestre para no interferir con el desarrollo del curso. Existen un total de tres encuentros físicos, al inicio, mediados y final de semestre. Estos encuentros suelen ser de dos noches y tres días.

El primer encuentro tratamos de buscar un punto intermedio a las tres escuelas, y que todos los alumnos estén desplazados en un lugar neutro. Así se determinó como inicio del programa, la Residencia Universitaria de Jaca, perteneciente a UNIZAR. Los siguientes encuetros se realizan en las otras escuelas (Anglet, San Sebastián o La Almunia de Doña Godina) sin orden preestablecido. Las fechas y lugares vienen marcados cada curso por los distintos calendarios académicos de las tres escuelas, así como las festividades.

\section{Objetivos}

Los objetivos que persigue esta actividad son:

- Fomentar y fortalecer las relaciones ISABTP - EUPLA - UPV, tanto de alumnado como de PDI.

- Conocer otra cultura, próxima en distancia, pero con sustanciales diferencias (no nos adaptamos al horario francés, y viceversa...) máxime en un entorno de trabajo profesional, conociendo la tradición constructiva y otros sistemas actuales.

- Desarrollar un trabajo de manera autónoma, con equipos de trabajo organizados.

- Trabajar en un ambiente internacional y transfronterizo, desarrollando el uso de la lengua materna, y segundas o terceras lenguas extranjeras (además del español, el francés y el vasco, es habitual que hablen en inglés o incluso en alemán o rumano).

\section{Desarrollo de la innovación}

Debemos tener en cuenta que el alumnado se conoce dentro de la escuela a la que pertenece pero no entre las distintas escuelas, y que existe una barrera difícil de sortear, el idioma. Pocos alumnos de España tienen conocimiento de idioma francés. Sin embargo, a nuestro favor juega el papel de la escuela ISABTP, en la que el alumnado tienen como segundo idioma el castellano, debido a la cercanía con la frontera española, y algunas de sus asignaturas deben desarrollarlas en nuestro idioma. 
La barrera del idioma es uno de los motivos por el cual el primer encuentro se realiza en un lugar externo a ambas escuelas, con el objetivo de crear una nueva burbuja donde el alumnado de las tres escuelas puedan conocerse y descubran juntos el entorno.

Tal y como está concebido y planteado el proyecto transfronterizo ISABTP - EUPLA - UPV, permite trabajar y consolidar competencias transversales a adquirir por los y las estudiantes. Creemos firmemente en esta tipología de trabajo, y aquí está el punto fuerte de este proyecto. Explicaremos a continuación por qué.

\subsection{Trabajo por proyectos 5}

El proyecto en sí consiste en definir y solucionar un proyecto de un edificio residencial desde un anteproyecto, como si se tratase de un caso real. Los alumnos y alumnas de los distintos cursos de los grados deberán definir la volumetría, materiales, acabados, distribución, estructura y cálculo, instalaciones, detalles constructivos o puesta en obra de las soluciones, justificándolas en todo caso, adaptándolas a la normativa, con el hándicap de las distintas soluciones constructivas a uno y otro lado de la frontera.

\subsection{Aprendizaje cooperativo ${ }^{6,7}$}

El proyecto se tiene que resolver en equipo. Los equipos son multidisciplinares e internacionales. El objetivo es dar una respuesta conjunta y común a los distintos problemas y soluciones posibles. Cada miembro del grupo es responsable principal de una de las fases o capítulos del proyecto, pero todos son conocedores y autores del proyecto, pues deben incorporar las distintas soluciones de los demás compañeros y compañeras en su propio trabajo. Tiene que existir una coordinación y organigrama establecidos para garantizar el éxito del proyecto.

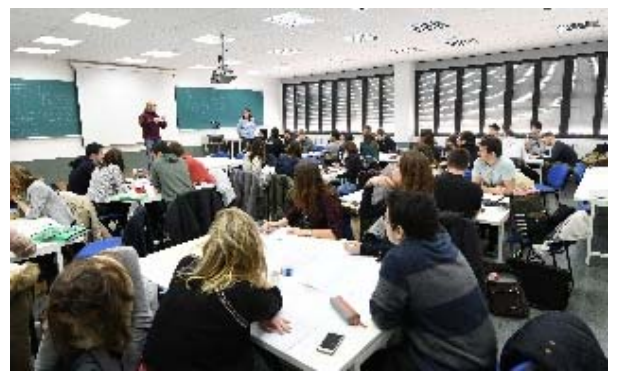

Fuente: Villarroya, J (2017)

Fig. 3 Grupos de trabajo, La Almunia, Febrero 2017

\footnotetext{
5 (Álvarez, 2010)

${ }^{6}$ (Domingo, 2008)

${ }^{7}$ (García, 2019)
} 


\subsection{Concepto de flipped classroom ${ }^{8}$}

El trabajo autónomo y la capacidad de autocrítica son la base de un profesional de éxito. Saber conducir al alumnado y motivarle en la investigación autosuficiente y en el aprendizaje individual, en la búsqueda de soluciones y mantener la inquietud por la formación viva, es una tarea del profesorado.

En los tres encuentros que se organizan a lo largo del semestre, la actividad principal es el trabajo autónomo, a modo de taller de proyectos, donde los grupos ponen en común sus ideas, proyectos, soluciones... y entre ellos va surgiendo y se va definiendo el proyecto. Además, dada la diferencia de soluciones constructivas o de diferencia de interpretación de normativa, aparece una competitividad sana entre el alumnado, que les motiva a superarse y buscar justificaciones a sus propuestas o soluciones finales.

\subsection{Aprendizaje por competencias ${ }^{9}$}

Decíamos al principio de este apartado que el punto fuerte de este proyecto era la transversalidad de la propuesta, y todos los participantes y responsables del mismo estamos convencidos de ello. Muchas veces en las asignaturas más convencionales estos aspectos quedan de lado, o se ven de manera casi anecdótica, pero en este proyecto son constantes. Detallaremos las más representativas ${ }^{10}$ :

\section{Instrumentales}

- Capacidad de análisis y síntesis

- Capacidad de organizar y planificar

- Conocimientos básicos de la profesión

- Comunicación oral y escrita en la propia lengua

- Conocimiento de una segunda lengua

- Habilidades básicas en el manejo de ordenadores

- Habilidades de gestión de la información

- Resolución de problemas

- Toma de decisiones

\section{Interpersonales}

- Capacidad de crítica y autocrítica

- Trabajo en equipo

- Habilidades interpersonales

- Capacidad de trabajar en un equipo interdisciplinar

- Capacidad para comunicarse con expertos de otras áreas

\footnotetext{
${ }^{8}$ (Berenguer-Albaladejo, 2016)

${ }^{9}$ (Aguado, 2017)

${ }^{10}$ (Sepúlveda, 2019)
} 
- Apreciación de la diversidad y la multiculturalidad

- Habilidad para trabajar en un contexto internacional

\section{Sistémicas}

- Capacidad de aplicar los conocimientos en la práctica

- Habilidades de investigación

- Capacidad de aprender

- Capacidad de adaptarse a nuevas situaciones

- Capacidad para generar nuevas ideas (creatividad)

- Liderazgo

- Conocimiento de culturas y costumbres de otros países

- Habilidad para trabajar de forma autónoma

- Diseño y gestión de proyectos

- Iniciativa y espíritu emprendedor

- Preocupación por la calidad

- Motivación de logro

\subsection{Uso de TIC's y plataformas online ${ }^{11}$}

Huelga decir que, dada la naturaleza del proyecto transfronterizo, es indispensable recurrir a herramientas de comunicación on-line para el desarrollo continuo del trabajo del alumnado. En una primera etapa este punto no se desarrolló lo suficiente y se dejó su elección y uso de manera libre. Para esta segunda edición, se solicitó la apertura de un curso en el Anillo Digital Docente de Unizar, concretamente en MOODLE, donde poder disponer de la documentación necesaria, así como la información referente al proyecto, fechas claves, etc. Y crear foros de debate compartidos, o controlar entregas parciales para el seguimiento, corrección y desarrollo de los trabajos de los distintos grupos.

En las distintas asignaturas, se trabaja con herramientas informáticas y Software de última generación, siendo la metodología BIM (Building Information Modeling) una premisa para la definición final del proyecto y las soluciones constructivas.

\section{Organización de los encuentros}

\section{Primer encuentro}

El primer encuentro tiene ditintos objetivos:

- Presentar el proyecto

- Crear los grupos de trabajo

- Conocer al alumnado y profesorado de las otras escuelas

- Comenzar el trabajo

\footnotetext{
${ }^{11}$ (Salinas, 2004)
} 


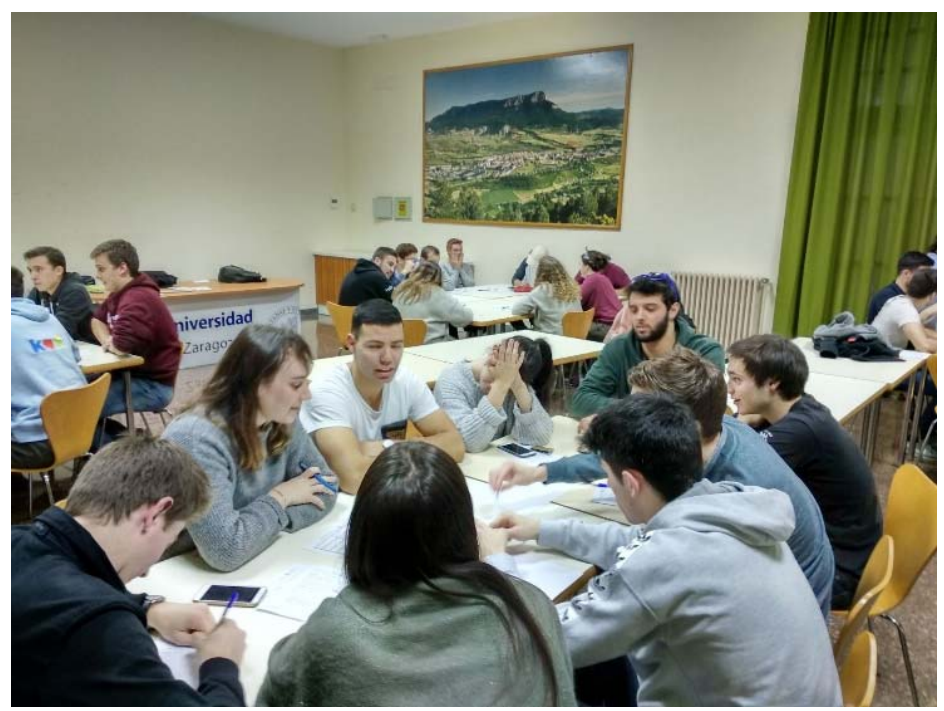

Fuente: Villarroya, J (2018)

Fig. 4 Inicio de la actividad del Team Building, Residencia Universitaria de Jaca, febrero de 2018

Para ello se llevan distintas actividades, que varían en función de la experiencia de años anteriores y de las distintas necesidades de cada curso. Principalmente se llevan acabo:

- Dinámicas de grupo

- $\quad$ Ejercicios de teambuilding

- Trabajos de resolución de problemas/conflictos de manera cooperativa

- Exposición oral de las presentaciones y de las distintas soluciones

- Visitas técnicas

- Encuentros culturales: comida, tradiciones, folclore...

Una vez hechos los grupos de cinco alumnos, se mantendrán hasta el final del semestre. Se plantean los objetivos generales del proyecto, el alcance del trabajo a realizar para cada asignatura, así como la definición de objetivos y organización de los dos encuentros restantes.

El último día del primer encuentro se reparten tareas, y se organizan los grupos para ir desarrollando el trabajo a lo largo del semestre.

\section{Segundo encuentro}

El segundo encuentro se desarrolla indistintamente en una de las escuelas de ISABTP , UPV o EUPLA. 
En este encuentro ponen en común el trabajo realizado hasta la fecha los grupos, y van perfilando los objetivos.

Es en este momento donde se aprecia un avance máximo, surgen todas las dudas de las diferencias en técnicas de construcción de ambos países.

Otra de las actividades que se realiza en los encuentros es una visita de obra. Los profesores de las respectivas escuelas buscan una obra en construcción a la que poder asistir con los alumnos de las escuelas, para que vean los distintos sistemas constructivos in situ.

\section{Tercer encuentro}

En el último encuentro tras perfilar los últimos detalles y preparar las presentaciones finales, se trata de realizar una exposición de cada grupo al resto de participantes de su proyecto realizado, con las distintas soluciones adoptadas en relación a las asignaturas involucradas en el proyecto.

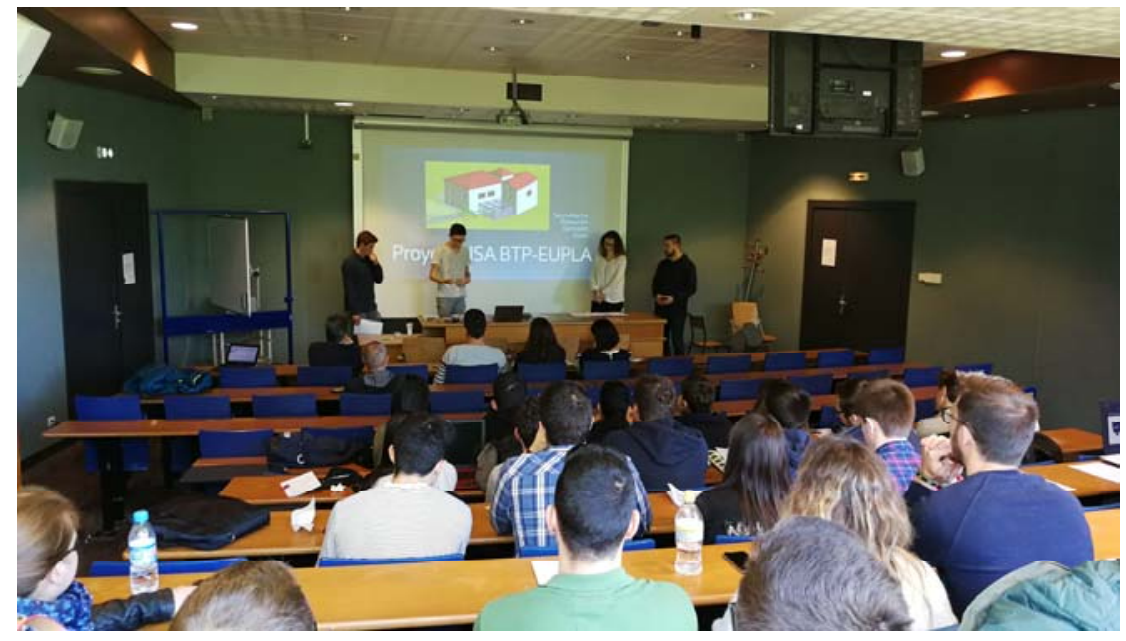

Fuente: Inmaculada U., A (2018)

Fig. 5 Presentaciones finales, Universidad ISABTP - Anglet (Francia), mayo de 2018

\section{Contribución real de estas experiencias desarrolladas en la mejora de la docencia y en la labor de tutoría.}

Transcurrido el primer curso de la titulación, enmarcar esta actividad en el segundo curso ofrece la posibilidad de conocer un ambiente internacional al alumnado, trabajar en otra escuela europea, quitarse miedos a salir al extranjero, y fomentar el ánimo de conocer otras culturas y formas de trabajo. Viajar y salir aumentan el conocimiento, la cultura y crean personalidades más solidarias y abiertas, sin prejuicios. Igualmente sirve de trampolín para animar a solicitar becas de movilidad internacionales en cursos superiores de la titulación.

Además, el desarrollo de este proyecto y el trabajo que se lleva en él, mejora el seguimiento de las asignaturas ordinarias. Se ha conseguido que, con un único enunciado de trabajo, con 
un proyecto tipo, se pueda desarrollar íntegramente las soluciones técnicas y constructivas en cada materia. Esto ha requerido consensar temarios y acompasar tiempos en las distintas asignaturas. Requiere una COORDINACIÓN total entre el profesorado de las distintas asignaturas que están involucradas en el proyecto. Este hecho es muy bien valorado por el alumnado, que en un mismo proyecto puede desarrollar las distintas prácticas de distintas asignaturas.

Dado el alto grado de trabajo autónomo e independiente, es necesaria además una predisposición mayor del profesorado de cara al mejor seguimiento de los trabajos desarrollados. Por lo tanto, hay un espacio en las asignaturas para corregir y valorar ese trabajo autónomo, así como para asesorar sobre otras cuestiones más transversales del proyecto en sí mismo.

El hecho de coordinar hasta 4 asignaturas, en el caso de la EUPLA, en un mismo semestre, donde el tema central del proyecto es el mismo, consensuado y trabajado por el profesorado en sus materias, motiva al alumnado a desarrollar ese proyecto, dedicándole más trabajo, entendiendo que el esfuerzo que se hace se ve integrado en las distintas asignaturas en las que participa. Muchos alumnos y alumnas han modificado las matrículas del segundo semestre para participar en este proyecto.

\section{Evaluación de la experiencia}

La Evaluación de la experiencia es de éxito. Esto se refrenda en que, tras la primera edición llevada a cabo el curso 2016-17, hasta el pasado curso 2019-2020, todo el PDI implicado confía en que esta actividad perdure y se consolide en el tiempo, acabando por ser un referente.

El curso pasado se realizó una encuesta de evaluación mediante formulario GOOGLE FORMS a todo el alumnado participante al finalizar la actividad. Para este curso se prevé realizar igualmente una encuesta, más extensa, recogiendo los comentarios de la experiencia anterior, con el fin de mejorar el proyecto y las actividades. De entre las respuestas, cabría destacar:

- A la pregunta ¿Repetirías esta actividad? La respuesta era Sí de manera unánime.

- En los comentarios generales, muchos invitaban a extender y repetir esta actividad en otros cursos y materias.

- Había alguna crítica en cuanto a la información; al ser un proyecto pionero, había alguna situación no contemplada que debíamos improvisar.

- Igualmente había una única crítica por haber creado un grupo de whatsapp para organizar los encuentros y coordinar las visitas. Nos llamó la atención porque entendíamos que era un sistema muy ágil para estar todos los participantes en contacto. 


\section{Resultados}

Participar en este proyecto permite trabajar y desarrollar:

- Coordinación entre distintas asignaturas del grado

- Trabajo en equipo

- Ambiente internacional de trabajo

$$
\begin{array}{ll}
\circ & \text { Metodologías } \\
\circ & \text { Cultura } \\
\circ & \text { Nuevas tecnologías y técnicas }
\end{array}
$$

- Expresión oral
- Lengua materna
- Lenguas extranjeras

- Liderazgo

- Visitas

$$
\begin{array}{ll}
\circ & \text { de obra } \\
\circ & \text { culturales }
\end{array}
$$

\section{Participantes}

Tabla 1. Alumnado

\begin{tabular}{|c|c|c|c|c|}
\hline Curso & N $^{\circ}$ participanes & EUPLA & ISABTP & UPV \\
\hline 2020 & 68 & 9 & 43 & 16 \\
\hline 2019 & 53 & 19 & 34 & - \\
\hline 2018 & 36 & 9 & 27 & - \\
\hline 2017 & 48 & 24 & 24 & \\
\hline
\end{tabular}


Tabla 2. Profesorado

\begin{tabular}{|c|c|c|c|c|}
\hline Curso & No participanes & EUPLA & ISABTP & UPV \\
\hline 2020 & 8 & 3 & 4 & 1 \\
\hline 2019 & 7 & 3 & 4 & - \\
\hline 2018 & 7 & 3 & 4 & - \\
\hline 2017 & 7 & 3 & 4 & \\
\hline
\end{tabular}

\section{Conclusiones}

Con las distintas experiencias, propias y las conocidas por nuestros estudiantes, creemos que es más que conveniente trabajar en la internacionalización del grado de Arquitectura técnica, por distintos factores y motivos.

Con la experiencia en las ediciones llevadas a cabo las conclusiones sólo son positivas.

Un proyecto de este tipo posibilita adquirir y desarrollar las siguientes competencias:

1. Capacidad de adaptación a nuevas situaciones

2. Amplitud de visión, trabajar en otro centro, con distinta metodología

3. Conocer otras costumbres, culturas, forma de vida

4. Quizá el más importante, aprender otras formas de construir, de trabajar, de organización... Ser críticos con los sistemas constructivos que trabajamos de manera habitual, así como con la normativa y legislación aplicables en unos y otros sitios.

En resumen, salir de nuestra forma de confort para adquirir capacidades de resolver problemas de manera autónoma en situaciones nuevas, desconocidas, y en entornos igualmente distintos al habitual. Además es una oportunidad para desarrollar el enriquecimiento personal del alumnado participante. 


\section{Referencias}

AGUADO D., GONZÁlEZ A., ANTÚNEZ M., DE DIOS T. (2017) "Evaluación de Competencias Transversales en Universitarios. Propiedades Psicométricas Iniciales del Cuestionario de Competencias Transversales" REICE. Revista Iberoamericana sobre Calidad, Eficacia y Cambio en Educación, , 15(2), 129-152. doi:10.15366/reice2017.15.2.007

ALVAREZ BORREGO V., HERREJÓN OTERO V,C., MORELOS FLORES M., RUBIO GONZÁLEZ M.T., (2010) "Trabajo por proyectos; aprendizaje con sentido" Revista Iberoamericana de Educación, ISSN-e 1681-5653, ISSN 1022-6508, Vol. 52, Nº. Extra 5,

BERENGUER-ALBALADEJO, C. (2016) "Acerca de la utilidad del aula invertida o flipped classroom" XIV Jornadas de Redes de Investigación en Docencia Universitaria. Investigación, innovación y enseñanza universitaria: enfoques pluridisciplinares. Alacant: Universitat d'Alacant, Institut de Ciències de I'Educació, 2016. ISBN 978-84-608-7976-3, pp. $1466-1480$

DOMINGO J. (2008) "El aprendizaje cooperativo”. Cuadernos de Trabajo Social Vol. 21231 246

ERASMUS +. https://ec.europa.eu/programmes/erasmus-plus/node_es

ESCUELA UNIVERSITARIA POLITÉCNICA LA ALMUNIA. Grado en Arquitectura Técnica. https://eupla.unizar.es/sites/eupla.unizar.es/files/archivos/Grados/plan_at.pdf

GARCÍA ARETIO, L. (2013) "Flipped classroom, ¿b-learning o EaD?" Contextos Universitarios Mediados, $\mathrm{n}^{\circ}$ 13,9 (ISSN: 2340-552X)

GARCÍA R., TRAVER J.A., CANDELA I. (2019) Aprendizaje cooperativo Fundamentos, características y técnicas. Madrid, Publicaciones ICCE

INSTITUT SUPERIEUR AQUITAIN DU BATIMENT ET DES TRAVAUX PUBLICS. Grado en Ingeniería Civli y Trabajos Públicos. https://isabtp.univ-pau.fr/en/home.html

SALINAS J. "Innovación docente y uso de las TIC en la enseñanza universitaria" (2004). Revista universidad y sociedad del conocimiento. ISSN 1658-580X. https://rusc.uoc.edu/

SEPULVEDA OBREQUE, A; OPAZO SALVATIERRA, M; DIAZ-LEVICOY, D. (2019). "Promoción de competencias transversales en la formación docente: actividades y

evaluación" Revista Cubana de Educación Superior. Versión On-line ISSN 0257-4314

UNIVERSIDAD DEL PAÍS VASCO. Grado en Arquitectura Técnica. https://www.ehu.eus/es/grado-arquitectura-tecnica/creditos-y-asignaturas-por-curso 


\title{
EDIFICATE
}

I Congreso de Escuelas de Edificación y Arquitectura Técnica de España

València, 4 y 5 de noviembre de 2021

Escuela Técnica Superior de Ingeniería de Edificación

Universitat Politècnica de València

Doi: https://doi.org/10.4995/EDIFICATE2021.2021.13534

\section{Competencias digitales, sí o sí Digital skills, no matter what}

\author{
Montserrat Bosch González ${ }^{\mathrm{a}}$ y Blas Echebarría Domínguez \\ ${ }^{a}$ Dep. Tecnologia de la Arquitectura, Escola Politècnica Superior Edificació de Barcelona EPSEB-UPC, \\ montserrat.bosch@upc.edu

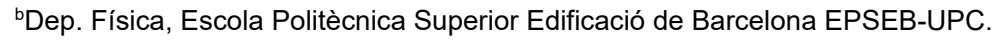 \\ blas.echebarria@upc.edu
}

\begin{abstract}
Even if we may consider that young university students are digital natives, it is not clear that they posses the skills corresponding to the level demanded as professionals with a university degree.
\end{abstract}

To assess the level of digital skills of the student body and also of the teaching staff in the Bachelor's degree in Architectural Technology and Building Construction at the Barcelona School of Building Construction (EPSEB-UPC), a study was carried out connected to a Final Degree Project in these studies.

Based on the results obtained, an implementation strategy and improvement of the level of skills in digital, information and communication technologies (ICT) was defined. For this, we took advantage of a change in the Degree's curriculum and the implementation of the Workshop subjects, taught in every semester and designed with the key objective of promoting transversality among the different disciplines of the Degree.

The COVID-19 situation has somewhat hindered the work planned for the 2020/21 academic year, but without any doubt it has shown us, in a forceful way, that digital skills are essential in university education and that the appropriate mechanisms must be established to guarantee their assimilation throughout the entire learning process.

Keywords: digital skills, transversality, evaluation, technological resources, $T I C$, learning platforms 


\section{Resumen}

Aunque podamos considerar que los jóvenes universitarios son nativos digitales, quedaría por demostrar que dispusieran de las habilidades correspondientes al nivel que precisan como profesionales con titulación de grado superior.

Para evaluar el nivel en competencias digitales del estudiantado y también del profesorado que imparte docencia en el Grado en Arquitectura Técnica y Edificación de la Escuela Politécnica Superior de la Edificación de Barcelona (EPSEB-UPC) se realizó un estudio vinculado a un Trabajo Final de Grado de la propia titulación.

A partir de los resultados obtenidos, se definió una estrategia de implementación y mejora del nivel en competencias digitales que incluyen las técnologías de la información y la comunicación (TIC) aprovechando la circunstancia de un cambio de Plan de Estudios y la aparición de las asignaturas Taller, ubicadas en cada cuatrimestre y diseñadas con el objetivo clave de promover la transversalidad entre las diferentes disciplinas del Grado.

Las circunstancias COVID-19 han dificultado en cierta manera los trabajos previstos para el curso 2020/21, pero sin ninguna duda nos han demostrado, de manera contundente, que las competencias digitales son imprescindibles en la docencia universitaria y que deben establecerse los mecanismos adecuados para garantizar su asunción a lo largo de todo el proceso de aprendizaje.

Palabras clave: competencias digitales, transversalidad, evaluación, TIC, recursos tecnológicos, plataformas aprendizaje 


\section{Introducción}

En 2010 dio inicio el proyecto "DIGCOMP: A Framework for Developing and Understanding Digital Competence in Europe" (Ferrari 2013), que definía una propuesta de Competencias Digitales Básicas para los ciudadanos europeos, que quedaban definidas en 5 bloques: la información y el tratamiento de datos; la comunicación y la colaboración; la creación de contenidos digitales; la seguridad; y la resolución de problemas. Diversos autores han analizado el uso de DigComp en ámbitos académicos y han detectado carencias en la impartición de contenidos que incluyan estas competencias, así como en su evaluación (Balula, 2016; Guzmán-Simón et al., 2017). Por este motivo se está trabajando en el desarrollo de propuestas que faciliten la adquisición de competencias digitales en entornos universitarios (J.L. Martín et al., 2017).

En este contexto, en 2019 se realizó, en la Escuela Politécnica Superior de Edificación de Barcelona EPSEB-UPC, como Trabajo Final del Grado en Arquitectura Técnica y Edificación (GATE), un estudio de análisis y evaluación del nivel de competencias digitales, en la que participaron tanto estudiantado como profesorado del centro, mediante una encuesta normalizada (Rosell Pursalls, 2019). La encuesta fue enviada a las/los 191 profesoras/res del centro y respondieron $28(15 \%)$, mientras que del total de estudiantado al que se envió la encuesta (690) respondieron 105 (16\%). Aunque puede parecer una muestra pequeña se consideró suficientemente representativa, ya que son resultados de respuesta similares a otras encuestas que se realizan habitualmente desde el centro. Los resultados pusieron de manifiesto que había un amplio margen de mejora para alcanzar un buen nivel de competencias digitales.

\subsection{Resultados de las encuestas sobre Competencias digitales}

A continuación, se presenta un breve extracto del análisis de las respuestas del estudiantado. La relevancia del número de respuestas se podría considerar válida en relación a la población, pero los datos que se muestran deben considerarse con prudencia: el grupo de estudiantado encuestado era de todos los niveles; la encuesta se había respondido de manera voluntaria; y cuando se habla de estudiantado estamos refiriéndonos exclusivamente a aquellos que han respondido la encuesta.

\subsubsection{Bloque Información y tratamiento de datos:}

Más de la mitad del estudiantado que ha respondido al cuestionario, utiliza Google y Wikipedia como bases de datos para identificar, localizar, obtener, almacenar y analizar la información digital. Muy pocos utilizan bases de datos especializadas, ni siquiera la Bibliotécnica de la UPC (Biblioteca digital especializada y temática). Sólo un $25 \%$ del estudiantado realiza una evaluación crítica de la información que obtiene vía digital. Un $25 \%$ del estudiantado no realiza copias de seguridad de la información que cree relevante almacenar. Sólo un $8 \%$ del estudiantado dice conocer algún programa de gestión bibliográfica. 


\subsubsection{Bloque Comunicación y colaboración:}

Este es el apartado en el que el estudiantado muestra mejor nivel de competencias: utilizan mayoritariamente entornos de trabajo y sistemas de comunicación digitales y se reconocen respetuosos en el lenguaje que utilizan, pero sólo un $20 \%$ comprueba derechos de propiedad o derechos de uso de contenidos digitales; más del $70 \%$ no utilizan las redes sociales para difundir los resultados de su trabajo; y sólo la mitad utilizan las redes sociales y las comunidades virtuales con fines de desarrollo académico y / o profesional.

\subsubsection{Bloque Creación de contenido digital:}

Más del $65 \%$ del estudiantado del centro no crea ni comparte contenidos digitales; sólo un $6 \%$ sabe cómo licenciar su producción digital y menos del $20 \%$ conoce la licencia Creative Commons; y más del $65 \%$ del estudiantado no conoce ningún sistema de verificación de plagio.

\subsubsection{Bloque Seguridad:}

Aproximadamente un $70 \%$ del estudiantado que ha respondido la encuesta no cambia ni actualiza las contraseñas de acceso frecuentemente; y más del $60 \%$ no leen las políticas de privacidad de los sitios web donde registran sus datos.

\subsubsection{Bloque Resolución de problemas:}

Más de la mitad de las/los estudiantes busca ayuda externa cuando tiene problemas técnicos en un dispositivo y, aunque la mayoría saben localizar, utilizar entornos virtuales de aprendizaje y seguir cursos on line, más del $30 \%$ no buscan tecnologías emergentes para mantenerse actualizados.

\subsection{La oportunidad de un nuevo plan de estudios}

Ante esta situación, consideramos que era necesario establecer un plan de mejora del nivel de competencias digitales del estudiantado de la EPSEB, aprovechando la circunstancia de la implantación de un nuevo Plan de Estudios, de modo que pudiésemos incorporar la formación en competencias digitales a lo largo de todo el grado, de forma gradual, hasta llegar a incidir en todas las asignaturas de la titulación.

Para realizar dicho plan era necesario implicar también al propio profesorado del centro, con las dificultades que todo ello podía conllevar dada la realidad general de la universidad pública española: plantillas envejecidas y falta de renovación con profesorado joven a dedicación completa, lógicamente más diestro en competencias digitales.

Se contempló por tanto una estrategia específica para el colectivo profesorado y, aprovechando que se iniciaba el nuevo Plan de Estudios del GATE, un grupo de profesoras y profesores que estábamos impartiendo una nueva asignatura en formato Taller consideramos que podíamos aprovechar la inercia del trabajo en equipo para impulsar una mejora docente en competencias digitales. 
La pandemia COVID 19 trastocó por completo el plan de trabajo, pero nos ha permitido adquirir algunas competencias digitales de manera acelerada para adaptar la docencia universitaria a formatos on line; nos ha permitido intensificar el análisis y la implementación de herramientas digitales; nos ha animado a seguir trabajando en la mejora de las competencias digitales; $y$, aunque de manera traumática, ha impulsado en la universidad la incorporación de nuevas formas docentes.

\section{Objetivos}

El primer objetivo (01) consistía en evaluar de manera detallada el nivel de competencias digitales de profesorado y estudiantado. La labor realizada hasta ahora ha consistido en unas sesiones informativas del proyecto al profesorado del centro y posteriormente reuniones más reducidas con un grupo de coordinadores de asignaturas clave. Este ha sido un primer paso, pero se debe continuar recabando información para realizar un diagnóstico ajustado de las necesidades y carencias en las competencias digitales dictadas por el Departament d'Educació de la Generalitat de Catalunya.

Con la información recabada, se ha podido planificar un plan de formación constante en el ámbito de las competencias digitales del profesorado, que se ha visto acelerado en algunos aspectos debido a la situación COVID, pero que necesita aún ser implementado de manera constante. Es evidente que, si el profesorado no dispone de los suficientes conocimientos en competencias digitales, tampoco los puede transmitir al estudiantado del centro. Cabe decir que, durante la etapa de estudio realizada, el profesorado ha mostrado una gran predisposición a mejorar en el ámbito tecnológico, y que la dirección del centro ha colaborado en todo momento.

Un segundo objetivo (02) era determinar estrategias adecuadas para incluir de manera efectiva una mejora en competencias digitales en la formación de manera reglada y constante a lo largo de los estudios. Una vía para asegurar la adquisición de las competencias digitales del estudiantado, podía ser destinar unos créditos, en forma de una asignatura completa, a las competencias digitales, en el primer cuatrimestre del grado, de tal manera que durante su trayectoria universitaria las pueda aplicar y mejorar a medida que progresa en la adquisición de otras competencias propias de la titulación.

En el momento de redactar este documento, esta estrategia no se ha implementado, pero se han identificado otras posibles acciones que se detallaran en el capítulo resultados.

$\mathrm{Y}$ un tercer objetivo (O3) era promover entre el profesorado del centro la realización de cursos como los que ya ofrece el Instituto de Ciencias de la Educación (ICE-UPC) y más adelante la realización de los cursos ACTIC (Acreditación de Competencias en las Tecnologías de la Información y la Comunicación). EI ACTIC es la certificación acreditativa de la competencia digital que las personas desarrollan en situaciones reales para alcanzar objetivos. Esta prueba se realiza telemáticamente a través de un centro colaborador reconocido de la Generalitat de Catalunya. Las personas que superan la prueba obtienen un certificado con uno de los tres niveles (básico, intermedio o avanzado) de las competencias 
digitales. Este certificado aporta el acceso a herramientas de aprendizaje virtual y la obtención de una certificación profesional.

El objetivo final de todo el proyecto era mejorar el nivel de competencias digitales de estudiantado y profesorado.

\section{Desarrollo de la innovación}

A partir de la concesión de una ayuda solicitada en la "Convocatòria d'ajuts a la millora docent de la UPC 2019/20", se han realizado una serie de acciones para dar respuesta a los Objetivos marcados (O1, O2 y O3) a los que se añadió un cuarto objetivo (O4): incorporar gradualmente en todas las asignaturas del nuevo plan de estudios actividades y formación en competencias digitales. Este $\mathrm{O} 4$ ha dado pie a un nuevo proyecto de innovación docente que hemos iniciado este año 2021.

Como primer paso, hicimos un estudio detallado de las competencias digitales que se encuentran actualmente incorporadas a una asignatura específica del grado, el Taller 1, donde se trabajan diversos aspectos de la construcción tradicional de un edificio elegido al principio del curso. En un taller multidisciplinar, donde se trabajan diversos aspectos: contexto histórico del edificio, materiales y métodos de construcción, estructura y estado de cargas del edificio, comportamiento térmico, etc. Dentro de la asignatura no existen directivas específicas de utilización de herramientas digitales con lo que, aquellas que se han incorporado, ha sido a criterio de cada profesor, atendiendo a las necesidades de la materia impartida. El objetivo de nuestra evaluación era, por tanto, analizar qué herramientas se utilizaban dentro de la asignatura para conseguir determinadas competencias, detectar posibles carencias y estudiar si la incorporación de alguna herramienta digital adicional podía ser de ayuda en alguna de las sesiones de la asignatura.

Tabla 1. Evaluación de competencias digitales en el Taller 1A (curso 2020-21 1Q)

\begin{tabular}{|c|c|c|c|c|c|c|c|c|c|c|c|c|}
\hline & & & \multicolumn{10}{|c|}{ SEMANAS } \\
\hline & & & 1 & 2 & 3 & 4 & 5 & 6 & 7 & 8 & 9 & 10 \\
\hline \multirow{5}{*}{$\begin{array}{l}1 . \\
\text { Diseño, } \\
\text { planificación e } \\
\text { implementación } \\
\text { didáctica } \\
\text { (Uso de } \\
\text { instrumentos y } \\
\text { aplicaciones) }\end{array}$} & $\begin{array}{l}\text { Utilizar las aplicaciones } \\
\text { de edición de textos y } \\
\text { presentaciones } \\
\text { multimedia para la } \\
\text { producción de } \\
\text { documentos digitales }\end{array}$ & $\begin{array}{l}\text { Uso de procesadores } \\
\text { de texto y de } \\
\text { presentación (Word, } \\
\text { powerpoint) }\end{array}$ & & & & & & & & & & \\
\hline & $\begin{array}{l}\text { Utilizar las aplicaciones } \\
\text { de tratamiento de datos } \\
\text { numéricos para la } \\
\text { producción de } \\
\text { documentos digitales }\end{array}$ & $\begin{array}{l}\text { Uso de hojas de } \\
\text { cálculo (excel) }\end{array}$ & & & & & & & & & & \\
\hline & \multirow{3}{*}{$\begin{array}{l}\text { Utilizar las aplicaciones } \\
\text { básicas de edición de } \\
\text { imagen fija, sonido e } \\
\text { imagen en movimiento } \\
\text { para la producción de } \\
\text { documentos digitales }\end{array}$} & $\begin{array}{l}\text { Uso y manipulación de } \\
\text { material fotográfico }\end{array}$ & & & & & & & & & & \\
\hline & & $\begin{array}{l}\text { Utilización de } \\
\text { Photoshop }\end{array}$ & & & & & & & & & & \\
\hline & & $\begin{array}{l}\text { Generación de } \\
\text { material multimedia } \\
\text { (video) }\end{array}$ & & & & & & & & & & \\
\hline
\end{tabular}




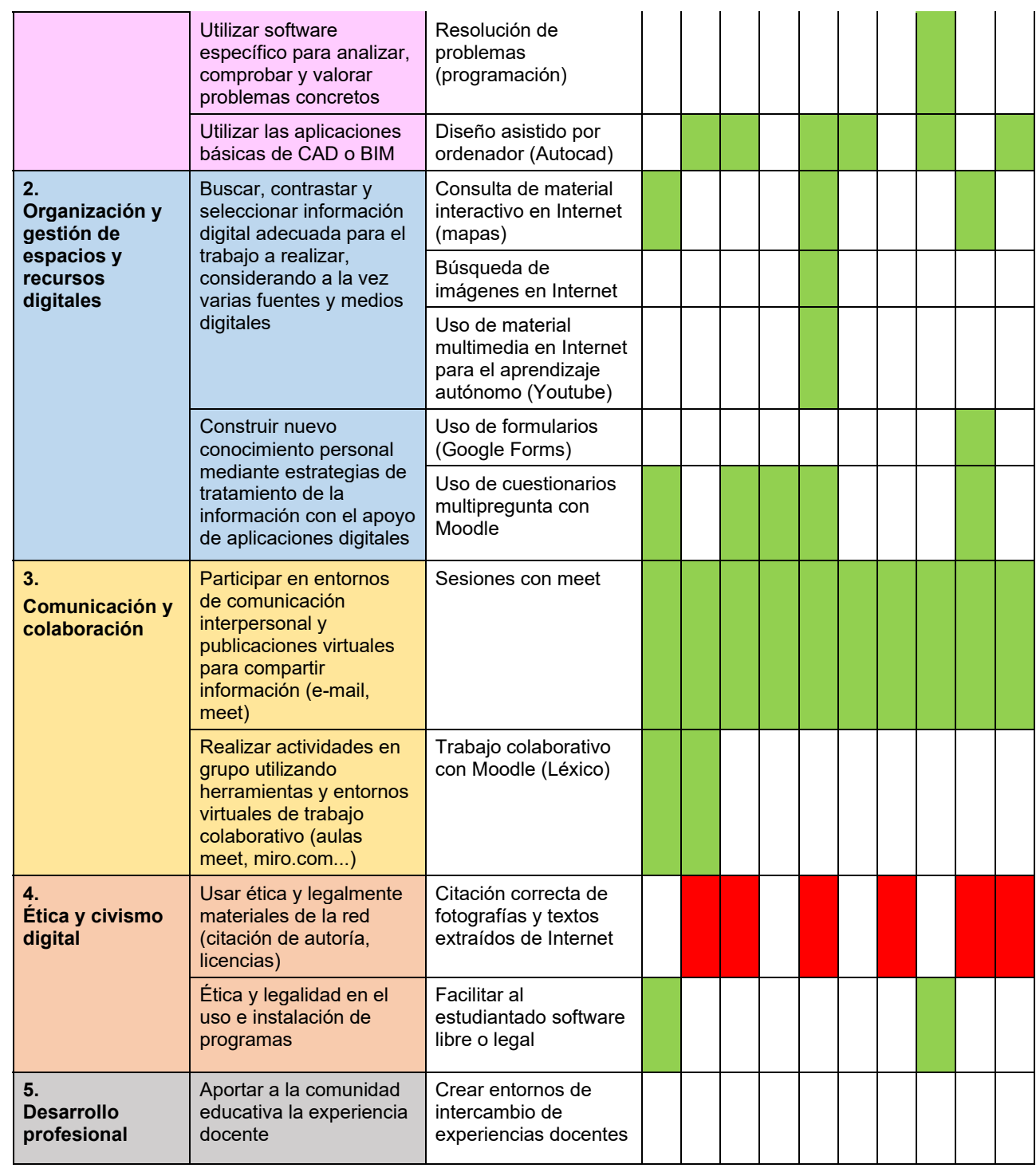

Los resultados principales del estudio se exponen en la Tabla 1, donde en color se indica el grado de implementación de cada competencia (verde=implementada, naranja=parcialmente implementada, rojo=no realizada). Las herramientas y competencias digitales se agruparon en 5 áreas principales, dentro de las que se definieron subáreas. Es de destacar que, de forma natural, en este curso ya se trabajan la mayoría de técnicas digitales. Existen algunas carencias un tanto llamativas, como por ejemplo el uso de hojas de cálculo, que fácilmente se podría incorporar a varias sesiones del curso, u otras que se podrían potenciar, como el tratamiento de imágenes, la programación o la generación de material multimedia. En 
cualquier caso, este estudio ha sido enormemente útil como una radiografía de la situación actual, de cara a desarrollar un plan de mejora.

Estos resultados se presentaron en una jornada realizada en el centro, en la que se trató de la evaluación de las asignaturas de Talleres. Dado el interés de los resultados obtenidos en el Taller 1, se decidió realizar una encuesta a los coordinadores de las demás asignaturas de Taller (hay un total de 9), para, si no de forma tan detallada, sí conocer las principales carencias, o incluso reiteraciones excesivas, en el uso de herramientas digitales. Al igual que en el Taller 1, esto constituirá la base de próximas acciones de mejora en este campo.

\section{Resultados}

En relación al objetivo O1. Evaluación de competencias digitales de profesorado y estudiantado:

Se ha analizado en detalle una asignatura taller de primer Curso y se han identificado todas las actividades docentes realizadas durante el Curso 2019/20 relacionadas con las competencias digitales. Este análisis ha permitido comprobar que

- Se están usando, de manera semanal, instrumentos y aplicaciones como procesadores de texto, hojas de cálculo, uso y manipulación de material fotográfico, programas de edición de imágenes, resolución de problemas mediante programación y diseño asistido por ordenador.

- Se han promovido, y el estudiantado ha adquirido, de manera semanal, competencias en organización y uso de recursos digitales: consulta de material interactivo en Internet, búsqueda autorizada de imágenes en redes, uso de material multimedia disponible en redes para aprendizaje autónomo, uso de formularios (en red) y de cuestionarios multipregunta en la plataforma Moodle.

- Se han usado entornos de comunicación y colaboración virtuales mediante el uso de la plataforma Google Meet y el trabajo colaborativo mediante la plataforma Moodle semanalmente.

- Aunque se ha insistido y se ha intentado incorporar la competencia en ética y civismo digital, hay que reforzar, tal vez en cursos próximos, actividades en esta temática. Con todo, se ha insistido en citar correctamente el material utilizado y se ha facilitado al estudiantado software libre y legal.

- Concluimos que, aun habiendo recorrido de mejora, en esta asignatura en concreto, el nivel de asunción de competencias digitales es correcto y fácilmente exportable a otras asignaturas 
Tabla 2. Evaluación de competencias digitales en las asignaturas de Taller (curso 2020-21 1Q)

\begin{tabular}{|c|c|c|c|c|c|c|c|c|c|c|c|}
\hline & \multicolumn{9}{|c|}{$\begin{array}{c}\text { Número de asignaturas en las que se } \\
\text { ha implementado }\end{array}$} \\
\hline & & & 1 & 2 & 3 & 4 & 5 & 6 & 7 & 8 & 9 \\
\hline \multirow{5}{*}{$\begin{array}{l}1 . \\
\text { Diseño, } \\
\text { planificación e } \\
\text { implementación } \\
\text { didáctica } \\
\text { (Uso de } \\
\text { instrumentos y } \\
\text { aplicaciones) }\end{array}$} & \multirow[t]{5}{*}{$\begin{array}{l}\text { De la guía } \\
\text { docente, se } \\
\text { desprende } \\
\text { que }\end{array}$} & $\begin{array}{l}\text { se han seleccionado y priorizado } \\
\text { los recursos y las herramientas } \\
\text { más adecuadas para las diferentes } \\
\text { actividades. }\end{array}$ & & & & & & & & & \\
\hline & & $\begin{array}{l}\text { se utilizarán los recursos y los } \\
\text { espacios con tecnologías digitales } \\
\text { del centro de forma habitual }\end{array}$ & & & & & & & & & \\
\hline & & $\begin{array}{l}\text { se han diseñado las actividades de } \\
\text { enseñanza-aprendizaje, de } \\
\text { acuerdo con el desarrollo curricular } \\
\text { sobre las "Competencias básicas } \\
\text { en el ámbito digital". }\end{array}$ & & & & & & & & & \\
\hline & & $\begin{array}{l}\text { se han elaborado materiales y } \\
\text { recursos personalizados para } \\
\text { atender las Necesidades } \\
\text { Específicas de Apoyo Educativo } \\
\text { (NESE) del estudiantado y para } \\
\text { compensar las desigualdades de } \\
\text { acceso a la tecnología }\end{array}$ & & & & & & & & & \\
\hline & & $\begin{array}{l}\text { el PDI de la asignatura utilizará } \\
\text { recursos digitales para tutoría y } \\
\text { seguimiento del estudiantado } \\
\text { (reuniones, asistencia, evaluación, } \\
\text { expediente, etc.) }\end{array}$ & & & & & & & & & \\
\hline \multirow{3}{*}{$\begin{array}{l}2 . \\
\text { Organización y } \\
\text { gestión de } \\
\text { espacios y } \\
\text { recursos } \\
\text { digitales }\end{array}$} & \multirow[t]{3}{*}{$\begin{array}{l}\text { Está } \\
\text { contemplado } \\
\text { en la } \\
\text { planificación } \\
\text { docente }\end{array}$} & $\begin{array}{l}\text { velar porque el estudiantado haga } \\
\text { un uso responsable de las } \\
\text { tecnologías digitales del centro y } \\
\text { aplique las normas de utilización }\end{array}$ & & & & & & & & & \\
\hline & & $\begin{array}{l}\text { utilizar los programas informáticos } \\
\text { generales del centro (software } \\
\text { GSuite, Atenea, e-secretaria) }\end{array}$ & & & & & & & & & \\
\hline & & $\begin{array}{l}\text { utilizar software específico de la } \\
\text { asignatura. }\end{array}$ & & & & & & & & & \\
\hline \multirow[t]{3}{*}{$\begin{array}{l}3 . \\
\text { Comunicación y } \\
\text { colaboración }\end{array}$} & \multirow[t]{3}{*}{$\begin{array}{l}\text { EI PDI de la } \\
\text { asignatura }\end{array}$} & $\begin{array}{l}\text { utiliza tecnologías digitales para } \\
\text { comunicarse con el estudiantado y } \\
\text { para coordinarse con otros } \\
\text { docentes. }\end{array}$ & & & & & & & & & \\
\hline & & $\begin{array}{l}\text { utiliza recursos tecnológicos para } \\
\text { publicar y compartir el contenido } \\
\text { de la asignatura. }\end{array}$ & & & & & & & & & \\
\hline & & $\begin{array}{l}\text { fomenta el uso activo de los } \\
\text { medios y recursos digitales para } \\
\text { llevar a término trabajo } \\
\text { colaborativo entre estudiantado y } \\
\text { profesorado }\end{array}$ & & & & & & & & & \\
\hline \multirow[t]{3}{*}{$\begin{array}{l}\text { E. } \\
\text { Ética y civismo } \\
\text { digital }\end{array}$} & \multirow[t]{3}{*}{$\begin{array}{l}\text { Las } \\
\text { actividades de } \\
\text { enseñanza- } \\
\text { aprendizaje }\end{array}$} & $\begin{array}{l}\text { asesoran al estudiantado sobre } \\
\text { medidas para garantizar la } \\
\text { privacidad de los datos personales } \\
\text { en el uso de las tecnologías } \\
\text { digitales }\end{array}$ & & & & & & & & & \\
\hline & & $\begin{array}{l}\text { promueven la construcción de una } \\
\text { identidad digital adecuada y } \\
\text { responsable a los estudiantes }\end{array}$ & & & & & & & & & \\
\hline & & $\begin{array}{l}\text { respetan los derechos de autor en } \\
\text { los materiales docentes que se } \\
\text { reproducen o que elaboran } \\
\text { haciendo uso de las tecnologías } \\
\text { digitales }\end{array}$ & & & & & & & & & \\
\hline
\end{tabular}




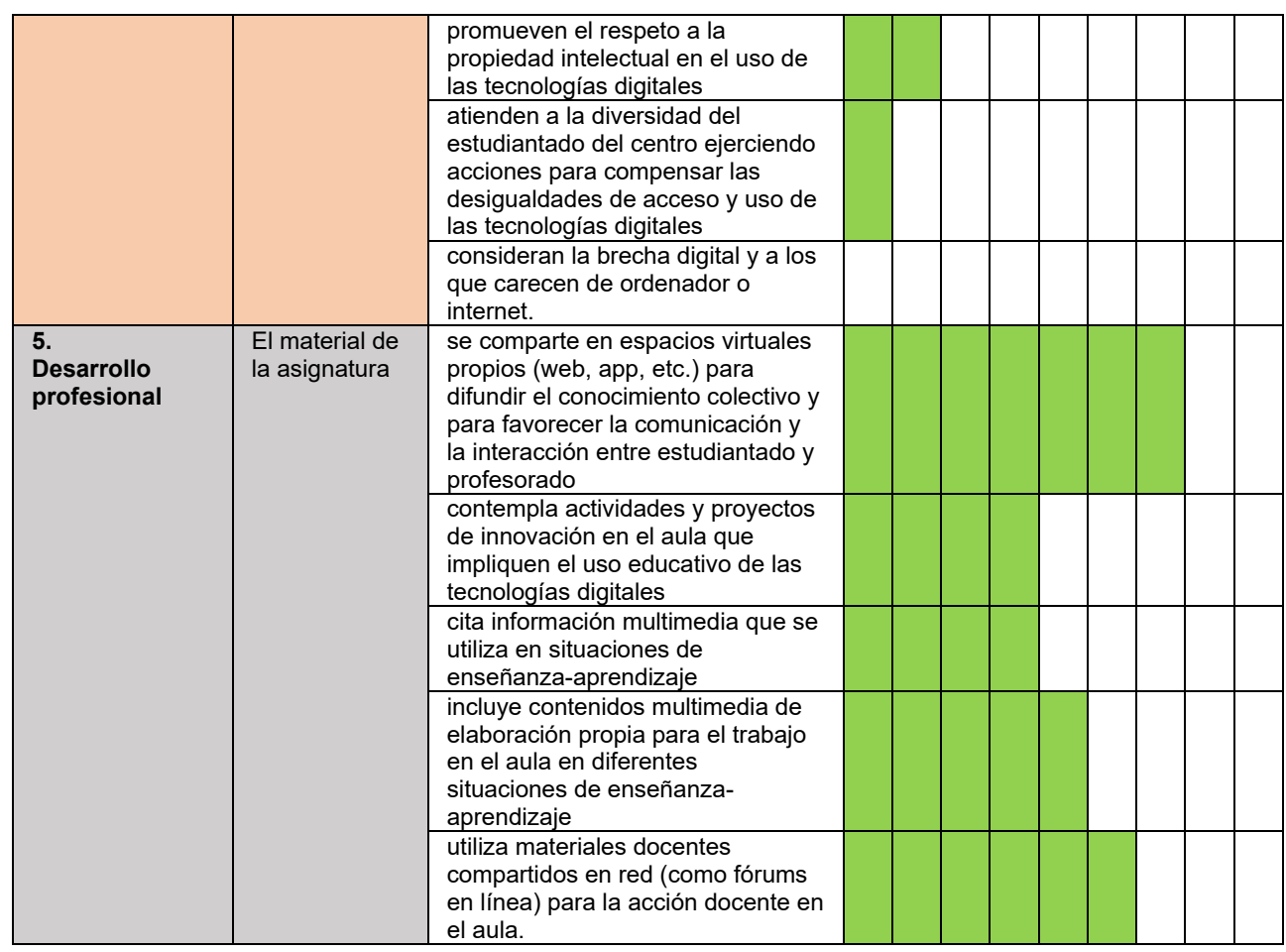

En cuanto al objetivo O2. Determinar estrategias adecuadas para incluir de manera efectiva la mejora en competencias digitales

A partir de la autoevaluación de la asignatura Taller 1, se han realizado diversas actividades con los coordinadores de las asignaturas Taller, todas ellas nuevas a partir de la implantación del Plan de Estudios vigente: encuestas de autoevaluación de los talleres por parte del profesorado, talleres participativos, reuniones de trabajo e intercambio de experiencias. Un resumen de los resultados se presenta en la Tabla 2. Esta encuesta nos indica que:

- Se utilizan de forma habitual recursos informáticos, en la medida en que las diferentes sesiones del Taller lo requieren. Habría que dar una mayor difusión a las directrices sobre el desarrollo curricular de las "Competencias básicas en el ámbito digital”, para que se implementen de forma coordinada. $Y$ hay que poner especial énfasis en implementar actividades orientadas a las Necesidades Específicas de Apoyo Educativo (NESE) del estudiantado y para compensar las desigualdades de acceso a la tecnología, que, a día de hoy, no se han implementado en ninguna de las asignaturas de Taller.

- Se utilizan de forma muy mayoritaria herramientas digitales de comunicación, tanto entre el profesorado, el alumnado, como en la comunicación profesorado-alumnado. Esto es claramente debido al proceso acelerado de digitalización derivada de la situación de pandemia y la adaptación a la no-presencialidad. 
- Hay que poner un mayor énfasis en el buen uso de las herramientas digitales: privacidad de los datos, respeto a la propiedad intelectual y los derechos de autor. $\mathrm{Y}$, relacionado con lo comentado en un punto anterior, se deben implementar acciones encaminadas a atender a la diversidad del estudiantado y las posibles carencias en el acceso a la información digital.

- Finalmente, existe una buena implementación de mecanismos de desarrollo profesional, tales como la elaboración de contenidos multimedia, proyectos de innovación utilizando herramientas digitales, o la utilización de espacios virtuales para compartir los conocimientos adquiridos.

Sobre el objetivo O3. Promover, entre el profesorado la Acreditación de Competencias en las Tecnologías de la Información y la Comunicación.

En este objetivo hay que reconocer que la situación COVID ha acelerado el nivel de competencias digitales del profesorado. Con todo, consideramos que es muy interesante acreditar el nivel de competencias, por lo que, en colaboración con la Biblioteca del Centro, se han iniciado una serie de actividades píldora, se ha adquirido material docente, cuestionarios de autoevaluación para el profesorado, se han realizado las gestiones y consultas de calendarios de las pruebas de acreditación y se han identificado los docentes interesados en acreditar su nivel de competencias.

\section{Conclusiones}

La mejora de competencias digitales en la vida universitaria depende de múltiples factores, pero, básicamente, recae en la responsabilidad docente. Es imprescindible fomentar la formación del profesorado.

El estudiantado dispone de habilidades y competencias, pero a menudo no es consciente de ello. En algunos aspectos de las competencias digitales está muy poco formado y es responsabilidad del sistema universitario, implementar y mejorar el nivel de competencias (ética y civismo digital, desarrollo profesional, aportes a la comunidad educativa).

La implementación de competencias transversales como las digitales debería ser estratégica de las titulaciones de grado y máster universitario. Es imprescindible generar acciones de mejora activas, regladas, y promovidas desde los diferentes estamentos que conforman el tejido universitario.

\section{Agradecimientos}

Los trabajos aquí presentados son el resultado del Proyecto "Incorporación y mejora de las competencias digitales en el Nuevo Plan de Estudios GATE-EPSEB-UPC", financiado en la Convocatoria de Ayudas a la Mejora y la Innovación Docente de la UPC 2019 (Acuerdo CG/2019/04/14, de 4 de julio de 2019). Queremos agradecer asimismo la ayuda del profesor Ramon Graus en la elaboración de parte del material que se presenta, así como sus ideas y comentarios al texto. 


\section{Referencias}

BALULA, A. (2016) The use of DIGCOMP in teaching and learning strategies: a roadmap towards inclusion. In: Proceedings of the 7th International Conference on Software Development and Technologies for Enhancing Accessibility and Fighting Info-exclusion, ACM. 275-282.

FERRARI, A. (2013). DIGCOMP: A Framework for Developing and Understanding Digital Competence in Europe. Sevilla: European Commission, Joint Research Centre, Institute for Prospective Technological Studies <http://publications.jrc.ec.europa.eu/repository/bitstream/JRC83167/lb-na26035-enn.pdf> [Consulta: 23 de junio 2021].

GUZMÁN-SIMÓN, F., GARCÍA-JIMÉNEZ, E. y LÓPEZ-COBO, I. (2017). “Undergraduate students' perspectives on digital competence and academic literacy in a Spanish University" en Computers in Human Behavior, 74, 196-204.

Martín, J.L., Frias, Z. y Pérez MartíneZ, J. (2017). "Can learning methodologies contribute to develop digital competences in telecommunication engineering education?" en FITCE Congress, 56th, 45-49 $<$ https://56thfitcecongress.aeit.es/wp-

content/uploads/2017/09/56th_FITCE_Congress_Spain_2017_paper_12.pdf> [Consulta: 23 de junio 2021].

Rosell PuRsals, C. (2019). Competències digitals adaptades als estudis d'Arquitectura Tècnica i Edificació. Trabajo Final de Grado de Arquitectura Técnica y Edificación, dirigido por Montserrat Bosch González. Barcelona: Universitat Politècnica de Catalunya, <http://hdl.handle.net/2117/175622> [Consulta: 23 de junio 2021]. 


\title{
EDIFICATE
}

I Congreso de Escuelas de Edificación y Arquitectura Técnica de España València, 4 y 5 de noviembre de 2021

Escuela Técnica Superior de Ingeniería de Edificación

Universitat Politècnica de València

Doi: https://doi.org/10.4995/EDIFICATE2021.2021.13546

\section{Formación e investigación en rehabilitación: un campo para la colaboración interuniversitaria}

\section{Training and research in rehabilitation: a field for inter- university collaboration}

\author{
Montserrat Bosch González ${ }^{1}$, Joan Ramón Rosell Amigó \\ ${ }^{1}$ Sub.dir Política Científica, Responsabilitat Social i Promoció EPSEB-UPC, \\ montserrat.bosch@upc.edu; \\ ${ }^{2}$ Responsable del Máster MUDIATEC, EPSEB-UPC, joan.ramon.rosell@upc.edu
}

\begin{abstract}
The recent Master's degree in Diagnosis and Intervention Techniques in Building Construction (MUDIATEC), which is offered at the Barcelona School of Building Construction (EPSEB-UPC), provides complementary training to the degrees of Architecture, Technical Architecture and Civil Engineering. The teaching program incorporates fundamental aspects of rehabilitation and restoration, without forgetting the necessary skills to understand and delve into construction processes.
\end{abstract}

We are presenting the Master MUDIATEC at the 1st Congress of Schools of Building and Technical Architecture of Spain with the following objectives:

- Encourage collaboration and the exchange of successful experiences in the field of diagnosis and rehabilitation in building among the faculty of the different schools, incorporating invited sessions in online format and participation in teaching activities such as the co-tutoring of Master's Final Projects.

- To promote research in such a strategic area as rehabilitation, identifying the lines demanded by the economic, social, and environmental situation related to the building sector.

- Share the field of action of the Building Construction Schools' own master's degrees in order to identify the map of strengths and generate synergies for exchange and consolidation.

Keywords: mobility, interuniversity collaboration, diagnosis, innovation 


\section{Resumen}

El reciente Máster Universitario en Diagnosis y Técnicas de Intervención en la Edificación MUDIATEC (Máster Oficial), que se imparte en la Escuela Politécnica Superior de Edificación de Barcelona (EPSEB-UPC), ofrece una formación complementaria a los grados de Arquitectura, Arquitectura Técnica e Ingeniería Civil. El Programa docente incorpora aspectos fundamentales de la rehabilitación y la restauración, sin olvidar las competencias necesarias para entender los procesos constructivos y ahondar en ellos.

Presentamos el Máster MUDIATEC en el 1 Congreso de Escuelas de Edificación y Arquitectura Técnica de España con los siguientes objetivos:

- Favorecer la colaboración y el intercambio de experiencias exitosas, en el ámbito de la diagnosis y la rehabilitación en edificación, entre el profesorado de las distintas escuelas, incorporando sesiones invitadas en formato on line y la participación en actividades docentes como la co-tutoría de Trabajos Finales de Máster

- Fomentar la investigación en un ámbito tan estratégico como la rehabilitación, con la identificación de las líneas que demanda la situación económica, social y ambiental relacionada con el sector de la edificación

- Compartir el campo de acción de los másters propios de las escuelas de edificación para identificar el mapa de fortalezas y generar sinergias de intercambio y consolidación.

Palabras clave: movilidad, colaboración interuniversitaria, diagnosis, innovación 


\section{Introducción}

El sector de la edificación y la construcción en Europa sigue siendo un potente vector de crecimiento económico. El subsector de la rehabilitación y el mantenimiento de edificios se muestra cada día más importante y, en momentos de crisis, se ha revalorizado e impulsado estratégicamente.

La intervención en edificios existentes es un sector muy dinámico en todos los países europeos, con una actividad media superior al $50 \%$ de todo el sector. Sin embargo, se observa que los datos no son iguales para cada país: en algunos casos las cifras alcanzan el $20 \%$ mientras que otras superan el $70 \%$ de la actividad total (Diagnosis Project , 2020).

La rehabilitación se había orientado, tradicionalmente, hacia los aspectos estructurales de los edificios y su seguridad. Hoy en día, múltiples acuerdos internacionales, como la última Cumbre Climática COP21 de París (Climate Summit COP21 of Paris) o la actualización de la Directiva Europea sobre eficiencia energética de los edificios 2018/844 (Unión Europea, 2018), han optado por acelerar la renovación de los edificios existentes para reducir los consumos energéticos y alcanzar un sistema energético sostenible, competitivo, seguro y descarbonizado.

Pero el empujón definitivo hacia la rehabilitación del parque edificado la ha dado, paradójicamente, la pandemia COVID 19 (Ver Figura 1), que ha funcionado como palanca para el impulso del sector, mediante el Pacto Verde Europeo y la publicación de la Oleada de Renovación, que se propone reducir las emisiones de gases de efecto invernadero en al menos el 55\% para 2030 y que Europa sea climáticamente neutra de aquí a 2050 (Comisión Europea, 2020).

Las prioridades para alcanzar los objetivos son:

- Dar respuesta a la pobreza energética, que reducirá las facturas de los ciudadanos

- De ahora a 2030, podrían renovarse 35 millones de edificios y crearse 160.000 empleos verdes en el sector de la construcción

- Reducir las emisiones y el uso de energía

- Mejorar la calidad de vida, la salud y el bienestar

- Hogares descarbonizados, digitalizados y más inteligentes

- Diseño sostenible asequible 


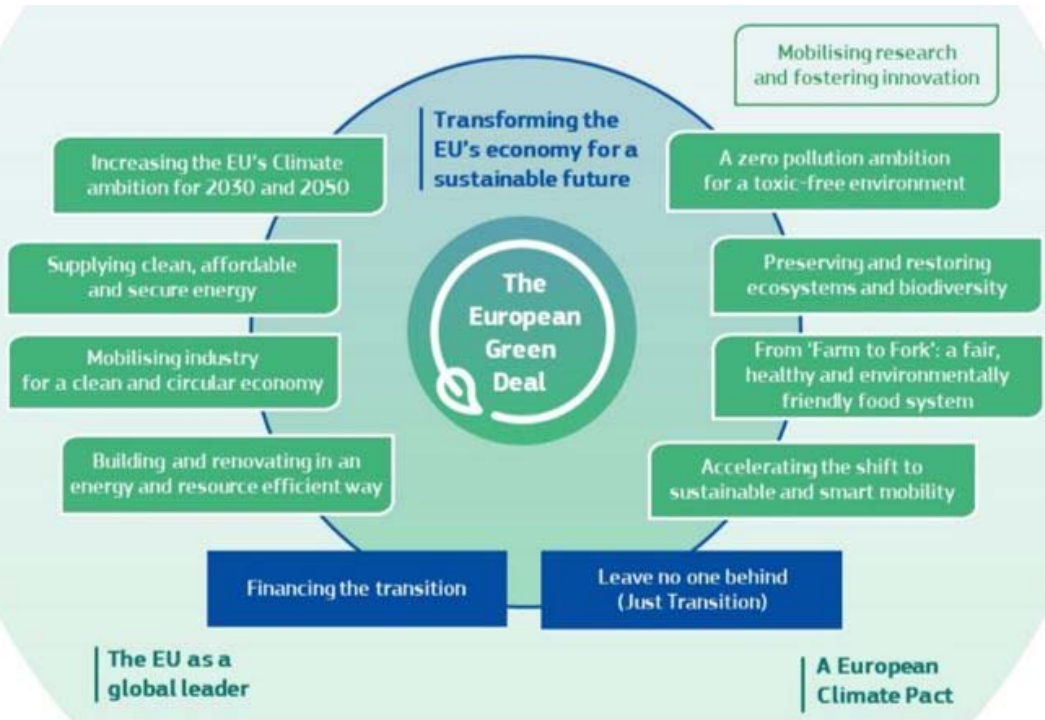

Figura 1 Elementos de la Euroepan Green Deal: Fuente: Comisión Europea

En estas circunstancias hay que añadir, a la cuestión energética, nuevas exigencias en cuanto a confort, accesibilidad y muchos otros parámetros que los edificios del siglo XXI deben ofrecer. Estos cambios indispensables son una excelente oportunidad para incorporar mejoras en los sistemas de gestión del sector e introducir, por ejemplo, el BIM (Building Information Modelling) como un modelo de trabajo estándar de gran utilidad, o la Metodología Lean para mejorar la productividad del proceso constructivo y reducir residuos, desperdicios, tiempo, materiales y recursos.

En este contexto, parece evidente que hay que ofrecer formación especializada a los profesionales del sector de la edificación en rehabilitación y que las escuelas de Arquitectura Técnica deben liderar estratégicamente y a poder ser de manera conjunta estas líneas de futuro que consoliden la profesión.

\section{Objetivos}

Esta presentación tiene un objetivo principal: aprovechar este encuentro para presentar el Máster Universitario en Diagnosis y Técnicas de Intervención en la Edificación, MUDIATEC (EPSEB, 2021), que se imparte desde el curso 2020/21 en la Escola Politècnica Superior d'Edificació de Barcelona EPSEB (Universitat Politècnica de Catalunya-Barcelona Tech), y que ofrece una formación complementaria a los grados de Arquitectura, de Arquitectura Técnica y/o a los estudios del ámbito de la Ingeniería Civil.

También tiene otros tres objetivos más concretos: 


\subsection{Favorecer la colaboración y el intercambio}

Favorecer la colaboración entre escuelas y profesorado del ámbito de la rehabilitación y la restauración y compartir, por ejemplo, experiencias exitosas, en el ámbito de la diagnosis y la rehabilitación en edificación.

Desde la Coordinación del Máster MUDIATEC, nos gustaría invitar al profesorado de las distintas escuelas a mostrar intervenciones singulares, que sirvan de ejemplo de buenas prácticas, e incorporarlas en sesiones invitadas en formato on line, al modo que está haciendo, por ejemplo, el Foro Cerámico Hyspalit con sus "LECCIONES APRENDIDAS: EL ARQUITECTO CUENTA SU OBRA" en colaboración con la Universidad de Sevilla (Foro Cerámico Hispalyt, 2021).

Otra posible colaboración podría consistir en la cotutoría de Trabajos Finales de Máster que pueden desarrollarse en formatos diversos y que, en relación a la investigación, podrían favorecer las relaciones entre grupos de investigación.

\subsection{Fomentar la investigación}

En un ámbito tan estratégico como la rehabilitación, se hace imprescindible identificar las líneas de investigación que demanda la situación económica, social y ambiental relacionada con el sector de la edificación. Evidentemente, hay líneas claramente identificadas en las que los distintos grupos de investigación consolidados de las diversas escuelas trabajan desde hace años y con éxito evidente: la caracterización y el desarrollo de nuevos materiales y todo el ámbito relacionado con la eficiencia energética y los mecanismos y sistemas para reducir los consumos o mejorar las prestaciones de los edificios.

La investigación en temas relacionados con la rehabilitación, tiene un largo recorrido evidente en nuevas temáticas como la monitorización, las simulaciones y los gemelos digitales para detectar, por ejemplo, los problemas asociados a los Sistemas de Aislamiento Térmico por el Exterior (SATE) frente al riesgo de incendios; o el metabolismo de los edificios y su optimización; y los nuevos campos de investigación en neuroarquitectura e inteligencia artificial entre otros.

Para acometer estos nuevos retos es necesaria la colaboración y la comunicación académica. Y los másters son una excelente oportunidad para identificar aquellos profesionales que están haciendo el esfuerzo de realizar un segundo ciclo, para incorporarlos a la investigación universitaria, y promover la realización de tesis doctorales.

\subsection{Compartir el campo de acción}

La proliferación de Másters desde las diversas escuelas es una excelente oportunidad para dar continuidad a la formación en Arquitectura Técnica y sería muy interesante disponer de un mapa de titulaciones y una puesta en común para que, respetando la independencia de los distintos centros, se pudiese promover la movilidad de profesorado y estudiantado según los intereses personales y profesionales de cada uno.

Una breve búsqueda en las páginas web de las distintas escuelas en las que se imparte Arquitectura Técnica muestra que estamos ofreciendo: Máster Universitario en Gestión 
Integral de la Edificación y Máster Universitario en Seguridad Integral en Edificación (Sevilla), Máster en Edificación (Valencia); Máster en Ciencia y Tecnología del Patrimonio Arquitectónico, Máster en Estructuras, Máster en Ingeniería Acústica, Máster en Prevención de Riesgos Laborales, Máster en Rehabilitación Arquitectónica, más los dobles másters (Granada); Máster en Innovación Tecnológica en Edificación, Máster en Gestión en Edificación, Máster en Ejecución de Obras de Rehabilitación y Restauración (Madrid), y el Máster universitario en Construcción Avanzada en la Edificación más el Máster Universitario en Diagnosis y Técnicas de Intervención en la Edificación (Barcelona).

Sería deseable favorecer y promover la movilidad de profesorado y estudiantado de manera que se puedan cursar asignaturas o participar en actividades conjuntas en aquellos másters que tengan objetivos y contenidos similares. Aprovechando las tecnologías de la Información y la Comunicación, y lo mucho aprendido durante la pandemia, se debería promover la posibilidad de cursar los másters con algún cuatrimestre a distancia, lo que permitiría al estudiantado un menor esfuerzo económico y personal.

También para el estudiantado de máster que proviene de los países de habla hispana, puede ser un interesante aliciente realizar el Máster en una ciudad como Barcelona y luego realizar su Trabajo Final de Máster en otra ciudad como Sevilla o Granada, por poner dos ejemplos suficientemente lejanos y diversos, con una cotutoría desde las dos universidades.

\section{Desarrollo de la investigación}

El máster MUDIATEC se ha gestado a partir de la experiencia previa en diagnosis y rehabilitación en edificación y pensando em el futuro inmediato del sector de la arquitectura y la construcción.

Responder al amplio y complejo espectro de exigencias que debe afrontar una correcta rehabilitación no es una tarea fácil y la mayoría de los profesionales del sector tienen dificultades para hacerlo. El aspecto clave, a la hora de hablar de edificios existentes, es llegar a un buen conocimiento de estos edificios y de sus componentes, por lo que una necesidad importante de este sector está relacionada con la falta de un perfil profesional específico: un experto en diagnosis y en técnicas de intervención que se ajusten y den respuesta a las necesidades de los proyectos de rehabilitación y/o restauración.

El máster MUDIATEC es la consecuencia final de un largo recorrido que arranca, si no antes, el curso 89/90 (hace más de 30 años) con la oferta del "Máster en patología, diagnosis y técnicas de rehabilitación del patrimonio construido", con carácter bianual y que se impartió durante 7 ediciones. Mientras que las técnicas y la metodología de análisis para la intervención en el patrimonio arquitectónico y la restauración de monumentos encontraban su "hábitat" en las escuelas de arquitectura, las cuestiones más tecnológicas, relacionadas con la diagnosis, la patología o la rehabilitación y el mantenimiento de la arquitectura doméstica se centralizaron en las escuelas de arquitectura técnica, o como mínimo, así ocurrió en la Politècnica de Catalunya. 
A pesar de las fluctuaciones y las idas y venidas en los contenidos de los planes de estudios, en la EPSEB se ha mantenido siempre una línea de investigación y de docencia muy vinculada a la diagnosis en edificios, por diversas circunstancias, que en los últimos años se ha consolidado con las líneas de especialización y los Diplomas de Ampliación de Competencias en Rehabilitación en el anterior Plan de Estudios del Grado en Arquitectura Técnica y Edificación (GATE), o el desgajo de las asignaturas del Máster Universitario en Construcción Avanzada en Edificación centradas en la rehabilitación, en el nuevo Máster MUDIATEC

EI MUDIATEC, incorpora aspectos fundamentales de la diagnosis, la rehabilitación y la restauración, sin olvidar las competencias necesarias para entender los procesos constructivos, ahondar en ellos y mejorar la capacitación profesional. También proporciona, como es de esperar en un Máster Universitario, formación dirigida hacia la investigación, lo que permite, a los titulados en Arquitectura Técnica y/o Ingeniería de la Edificación progresar en la carrera académica mediante un segundo ciclo específico y propio de la profesión (Ver Figura 2).

\begin{tabular}{|c|c|c|}
\hline Asignaturas & $\begin{array}{l}\text { créditos } \\
\text { ECTS }\end{array}$ & Tipo \\
\hline \multicolumn{3}{|l|}{ Primer cuatrimestre } \\
\hline Análisis Histórico-Arquitectónico-Constructivo de la Edificación Existente $\mathbf{\boldsymbol { \Delta }}$ & 5 & Obligatoria \\
\hline Evaluación Integral del Edificio Existente. Análisis Estructural $\mathbf{\Delta}$ & 5 & Obligatoria \\
\hline Levantamiento Gráfico de la Edificación Existente $\mathbf{\Delta}$ & 5 & Obligatoria \\
\hline Procesos Patológicos y de Diagnosis $\mathbf{\Delta}$ & 5 & Obligatoria \\
\hline Rehabilitación Energética $\mathbf{凶}$ & 5 & Obligatoria \\
\hline Técnicas de Diagnosis y Caracterización de Materiales $\boldsymbol{\Omega}$ & 5 & Obligatoria \\
\hline \multicolumn{3}{|l|}{ Segundo cuatrimestre } \\
\hline Proyecto de Intervención 四 & 6 & Obligatoria \\
\hline Técnicas de Intervención en la Edificación Existente (1) $\mathbf{\Xi}$ & 6 & Obligatoria \\
\hline Técnicas de Intervención en la Edificación Existente (2) 쪼 & 3 & Obligatoria \\
\hline Trabajo de Fin de Máster & 15 & Proyecto \\
\hline
\end{tabular}

Fuente: Elaboración propia

Figura 2 Plan de Estudios del Máster MUDIATEC. Fuente EPSEB

\section{Resultados}

La larga experiencia en el campo de la rehabilitación, la diagnosis y las técnicas de intervención nos han permitido acceder y conseguir dos proyectos Erasmus+: el proyecto "DIAGNOSIS Innovating a crucial profession in Building and construction sector" (2017/2019) (RehabiMed, 2019) cuyo objetivo era definir el perfil professional de un experto en diagnosis de edificios; y actualmente el proyecto "SMART Rehabilitation 3.0" (2019/2022) (Rehabimed, 2020), planteado como una segunda etapa y orientado a la fase de proyecto y ejecución de la rehabilitación, y con la novedad de la producción de cursos on line en abierto (Massive On Line Open Courses, MOOCs). La proyección europea también debe ser un objetivo colectivo en el que trabajar conjuntamente. 
Pero también el recorrido personal del profesorado de la EPSEB, y en especial el vinculado al Laboratori de Materials, es un resultado académico que ha consistido en más de 30 años de transferencia de tecnología y, en consecuencia, en experiencia y conocimiento muy estrechamente vinculados a la profesión.

Desde el Laboratorio de Materiales se han estado ofreciendo servicios en relación al estudio, determinación, diagnóstico o caracterización de materiales y sistemas constructivos. Por ejemplo, se han realizado estudios para evaluar el comportamiento estructural de los sistemas de construcción tradicionales como las paredes de carga de ladrillo y mampostería o las estructuras porticadas de hormigón y hormigón armado. También se han desarrollado metodologías de diagnósis y ensayos para forjados unidireccionales, estudios del comportamiento higrotérmico de distintas soluciones de cubiertas o fachadas y sus causas, caracterización de los hormigones y su patología, o problemas de deterioro e incluso colapso de elementos de madera.

Estos tipos de trabajos también son el fundamento para establecer líneas específicas de investigación que, a partir de los casos puntuales, permiten desarrollar herramientas de diagnóstico que sirven para nuevos proyectos, y en algunos casos incluso son lo suficientemente innovadores como para hacer una publicación de carácter técnico o científico, que deberá servir a los profesionales del sector en el desarrollo de sus tareas.

Y el Laboratorio de Materiales, junto con otros laboratorios de la EPSEB (Laboratorio de Acústica y ahorro energético, o Laboratorio del fuego, entre otros) son también laboratorios docentes que dan soporte y permiten, al estudiantado de máster y doctorado, desarrollar sus etapas investigadoras en el propio centro, con el acompañamiento del Personal Docente e Investigador (PDI) y el Personal de Administración y Servicios (PAS), lo que facilita la investigación en los temas estratégicos definidos por el centro.

Los resultados de la primera edición del Máster MUDIATEC aún no son suficientemente completos, ya que el estudiantado matriculado ha superado las asignaturas del primer curso pero aún está por entregar el Trabajo Final de Máster (TFM), a excepción de uno de los estudiantes que ya ha entregado el documento, con una buena cualificación, y que ha consistido en una investigación sobre nuevos materiales para aislamiento térmcio a partir de residuos agrícolas. Este TFM es un buen ejemplo del uso que hace el estudiantado de los Laboratorios universitarios.

Sí podemos constatar, a partir de las diversas reuniones formales e informales que hemos mantenido con el estudiantado, que el grado de satisfacción con lo aprendido es muy elevado. El estudiantado procedente de titulaciones universitarias españolas de Arquitectura Técnica, considera que la formación recibida complementa muy adecuadamente sus conocimientos en diagnosis y rehabilitación de edificios. El estudiantado extranjero (latinoamericano, la mayoría arquitectos) han descubierto un campo profesional que desconocían y han valorado muy positivamente toda la parte experimental y aplicada de la formación. 
Por nuestra parte, como docentes nos sentimos satisfechos con lo conseguido, implicados en la mejora y trabajando en la actualización constante de contenidos debido a las situaciones cambiantes propias de los tiempos. Y el hecho de trabajar sobre un edificio durante todo el curso, aplicando lo aprendido en un caso real, y concluyendo con un documento formal, también ha dado un excelente resultado con una presentación final de los trabajos a los técnicos municipales responsables de patrimonio.

\section{Conclusiones}

Muy probablemente, el mayor reto al que deberán enfrentarse los profesionales de la arquitectura y la edificación en los próximos 30 años sea combatir el cambio climático mediante todas las estrategias posibles que reduzcan los impactos ambientales y, entre ellas, la necesidad de reducir la actividad extractiva. La realidad demográfica de Europa nos sugiere, además, que tal vez ya esté casi todo construido y lo que necesitamos es mantener, mejorar y adaptar el parque edificado a las nuevas y mayores necesidades y exigencias de habitabilidad, confort y salubridad.

La rehabilitación es un sector en el que somos clave. Aunemos esfuerzos, capacidades, diversidades y pongamos el conocimiento al alcance de nuestro estudiantado y del profesorado, de manera imaginativa, cooperativa, con todos los medios que tengamos al alcance y divirtámonos aprendiendo y enseñando.

\section{Referencias}

Climate Summit COP21 of Paris. [En línea] https://unfccc.int/process-and-meetings/the-parisagreement/the-paris-agreement https://www.gouvernement.fr/en/paris-climate-conference.

Comisión Europea. 2020. Oleada de renovación: duplicar la tasa de renovación para reducir las emisiones, impulsar la recuperación y disminuir la pobreza energética. 2020.

Diagnosis Project . 2020. Un nuevo perfil profesional para el sector de la edificación y la construcción en Europa. Barcelona : Diagnosis Project 2017-1-ES01-KA203-038254, 2020.

EPSEB. 2021. Escola Politècnica Superior d'Edificació de Barcelona, Universitat Politècnica de $\begin{array}{llll}\text { Catalunya. } & \text { [En línea] } & \end{array}$ https://epseb.upc.edu/es/estudios/mudiatec/mudiatec?set_language=es.

Foro Cerámico Hispalyt. 2021. Foro cerámico Hispalyt. Lecciones Aprendidas. [En línea] Forocerámico, 2021. https://www.foroceramico.es/leccionesaprendidas/calendario?utm_campaign=lecciones-aprendidas-febrero-marzo2020\&utm_medium=email\&utm_source=acumbamail.

RehabiMed. 2019. DIAGNOSIS PROJECT. Programa Erasmus+ de la Union Europea. Cooperación para la innovación y el intercambio de buenas prácticas y cooperación estratégica. [En línea] 2019. http://www.erasmus-diagnosis.eu/. 
Formación e investigación en rehabilitación: un campo para la colaboración interuniversitariaTraining and research in rehabilitation: a field for inter-university collaboration

Rehabimed. 2020. SMART REHABILITACION 3.0. PROJECT. Programa Erasmust de la Union Europea. Asociación estratégica para la educación superior. [En línea] 2020. https://smartrehabilitation.eu/.

Unión Europea. 2018. Directiva (UE) 2018/844 del Parlamento Europeo y del Consejo. Directiva relativa a la eficiencia energética de los edificios. s.I. : Boletín Oficial de la Unión Europea, 2018. 


\title{
EDIFICATE
}

I Congreso de Escuelas de Edificación y Arquitectura Técnica de España

València, 4 y 5 de noviembre de 2021

Escuela Técnica Superior de Ingeniería de Edificación

Universitat Politècnica de València

Doi: https://doi.org/10.4995/EDIFICATE2021.2021.13570

Implantación de la evaluación de Competencias Transversales en la titulación de Grado en Arquitectura Técnica de la Escuela Técnica Superior de Ingeniería de Edificación de la Universitat Politècnica de València

Transversal Competences evaluation implementation in the Bachelor's Degree in Technical Architecture of the Higher Technical School of Building Engineering of the Polytechnic University of Valencia

\author{
M. Luisa Collado López ${ }^{\mathrm{a}}$ y Paloma Arrué Burillob \\ aUniversitat Poliltècnica de València. mcollado@csa.upv.e, \\ bUniversitat Poliltècnica de València. paarbu@csa.upv.es
}

\begin{abstract}
In 2014, the Polytechnic University of Valencia launched a project for the evaluation of transversal competences in students. Over the years it has been consolidated as a supplement to the academic record of people who complete their university studies at the UPV. This document shows the degree of transversal competences implementation in the Bachelor's degree in Technical Architecture in the 2020-2021 academic year.
\end{abstract}

Keywords: transversal competences, evaluation, competence level.

\section{Resumen}

La Universitat Politècnica de València puso en marcha en 2014 un proyecto para la evaluación de competencias transversales en el alumnado. A lo largo de los años se ha consolidado como complemento al expediente académico de las personas que finalizan sus estudios universitarios en la UPV. Este documento muestra el grado de implantación de las competencias transversales en la titulación de Grado en Arquitectura Técnica en el curso 2020-2021.

Palabras clave: competencias transversales, evaluación, nivel competencial.. 


\section{Introducción}

El proyecto de competencias transversales de la Universitat Politècnica de València (UPV) partió por iniciativa del Vicerrectorado de Estudios, Calidad y Acreditación y el plan estratégico UPV2020, que lo definía en el primero de sus retos:

... la Universitat Politècnica de València tiene como objetivo avanzar hacia modelos de formación que logren que sus estudiantes adquieran las competencias necesarias para poder tener una adecuada inserción laboral. Esta formación debe verse desde una perspectiva amplia, ligada al ciclo formativo integral de las personas, que abarca tanto el grado como el posgrado...

Con el objeto de revisar la definición de las competencias de los títulos y garantizar y medir la adquisición de las mismas, la UPV elaboró un listado de las competencias generales, las competencias recogidas en las normas CIN (en el caso de las profesiones que habilitan para el ejercicio de una actividad profesional regulada en España) y las competencias recogidas en referentes internacionales considerados relevantes por los diferentes títulos de la UPV.

El objetivo que plantea la UPV con la puesta en marcha de este proyecto es proporcionar a sus egresados un valor añadido diferenciador respecto a otros egresados y, por tanto, hacer más atractivos los estudios ofertados frente a ofertas similares de otras universidades. Además, se pone en valor la capacitación de nuestros egresados de cara a los empleadores y se detalla la adquisición de las competencias de cara a posibles acreditaciones o reconocimientos internacionales.

\section{Objetivos}

Los objetivos de la presente comunicación son:

a) Dar a conocer el proyecto de competencias transversales de la UPV.

b) Exponer los criterios para la evaluación de las competencias transversales en el Grado en Arquitectura Técnica de la ETSIE-UPV.

c) Conocer los resultados de la implantación del modelo.

\section{Las competencias transversales en la Universitat Politècnica de València}

Como resultado del proceso de estudio elaborado por la Universitat Politècnica de València se definieron trece dimensiones competenciales, a partir de ahora CT, que cumplían con el cometido previsto. (UPV 2020) 
Evaluación de Competencias Transversales en la Titulación de Grado en Arquitectura Técnica de la Escuela Técnica Superior de Ingeniería de Edificación de la Universitat Politècnica de València-

Transversal Competences evaluation implementation in the Bachelor's Degree in Technical Architecture of the Higher Technical School of Building Engineering of the Polytechnic University of Valencia

Tabla 1. Relación de Competencias Transversales-UPV. Fuente UPV

\begin{tabular}{|c|c|}
\hline CT1 Comprensión e integración & $\begin{array}{l}\text { Demostrar la comprensión e integración del conocimiento tanto } \\
\text { de la propia especialización como en otros contextos más } \\
\text { amplios. }\end{array}$ \\
\hline $\begin{array}{l}\text { CT2 Aplicación pensamiento } \\
\text { práctico }\end{array}$ & $\begin{array}{l}\text { Aplicar los conocimientos a la práctica, atendiendo a la } \\
\text { información disponible, y estableciendo el proceso a seguir para } \\
\text { alcanzar los objetivos con eficacia y eficiencia. }\end{array}$ \\
\hline $\begin{array}{l}\text { CT3 Análisis y resolución de } \\
\text { problemas }\end{array}$ & $\begin{array}{l}\text { Analizar y resolver problemas de forma efectiva, identificando y } \\
\text { definiendo los elementos significativos que lo constituyen. }\end{array}$ \\
\hline $\begin{array}{l}\text { CT4 Innovación, creatividad y } \\
\text { emprendimiento }\end{array}$ & $\begin{array}{l}\text { Innovar para responder satisfactoriamente y de forma original a } \\
\text { las necesidades y demandas personales, organizativas y } \\
\text { sociales con una actitud emprendedora. }\end{array}$ \\
\hline CT5 Diseño y proyecto & $\begin{array}{l}\text { Diseñar, dirigir y evaluar una idea de manera eficaz hasta } \\
\text { concretarla en un proyecto. }\end{array}$ \\
\hline $\begin{array}{l}\text { CT6 Trabajo en equipo y } \\
\text { liderazgo }\end{array}$ & $\begin{array}{l}\text { Trabajar y liderar equipos de forma efectiva para la consecución } \\
\text { de objetivos comunes, contribuyendo al desarrollo personal y } \\
\text { profesional de los mismos. }\end{array}$ \\
\hline $\begin{array}{l}\text { CT7 Responsabilidad ética, } \\
\text { medioambiental y profesional }\end{array}$ & $\begin{array}{l}\text { Actuar con responsabilidad ética y profesional ante uno mismo y } \\
\text { los demás. }\end{array}$ \\
\hline CT8 Comunicación efectiva & $\begin{array}{l}\text { Comunicarse de manera efectiva, tanto de forma oral como } \\
\text { escrita, utilizando adecuadamente los recursos necesarios y } \\
\text { adaptándose a las características de la situación y de la } \\
\text { audiencia }\end{array}$ \\
\hline CT9 Pensamiento crítico & $\begin{array}{l}\text { Desarrollar un pensamiento crítico interesándose por los } \\
\text { fundamentos en los que se asientan las ideas, acciones y } \\
\text { juicios, tanto propios como ajenos }\end{array}$ \\
\hline $\begin{array}{l}\text { CT10 Conocimiento de los } \\
\text { problemas contemporáneos }\end{array}$ & Conocimiento de los problemas contemporáneos \\
\hline CT11 Aprendizaje permanente & $\begin{array}{l}\text { Utilizar el aprendizaje de manera estratégica, autónoma y } \\
\text { flexible, a lo largo de toda la vida, en función del objetivo } \\
\text { perseguido }\end{array}$ \\
\hline $\begin{array}{l}\text { CT12 Planificación y gestión del } \\
\text { tiempo }\end{array}$ & $\begin{array}{l}\text { Planificar adecuadamente el tiempo disponible y programar las } \\
\text { actividades necesarias para alcanzar los objetivos, tanto } \\
\text { académico-profesionales como personales }\end{array}$ \\
\hline CT13 Instrumental específica & $\begin{array}{l}\text { Capacidad para utilizar las técnicas, las habilidades y las } \\
\text { herramientas actualizadas necesarias }\end{array}$ \\
\hline
\end{tabular}

Fuente: UPV (2015)

\subsection{La evaluación de las competencias transversales}

El modelo de evaluación de las competencias transversales en la UPV se realiza a través de tres vías:

Vía 1. Planes de Estudio. A lo largo del período de formación universitaria, se establecen puntos de control en determinadas asignaturas. 
Vía 2. Elaboración de Trabajo Fin de Grado o Trabajo Fin de Máster. Una vez superadas las materias de la titulación, en la evaluación del TFG o TFM

Vía 3. Actividades Extracurriculares. A través de actividades específicas que sean objeto de evaluación de las competencias transversales.

Dentro de la vía 1 se establecen además, tres niveles de dominio:

- Dominio I: corresponde a los dos primeros cursos de grado.

- Dominio II: corresponde a los dos segundos cursos de grado.

- Dominio III: corresponde a master universitario.

A partir de este modelo se establecen las asignaturas que se constituyen como puntos de control para valorar el grado de alcance de la competencia.

El concepto "punto de control" hace referencia a las asignaturas que son seleccionadas para encargarse de "medir" el grado de adquisición de la competencia que se le ha asignado. Puesto que las competencias transversales se adquieren en un proceso evolutivo largo, la UPV ha establecido al menos tres veces en los que realizar una evaluación del nivel de adquisición de cada una de las competencias durante el proceso formativo, (UPV 2015).

Partiendo de la duración de los grados en la UPV (cuatro cursos académicos) y de los másteres (uno/dos curso/s académico/s), se establece que el alumno debe ser evaluado de todas las CT de la forma siguiente:

a. al menos una vez durante los dos primeros cursos del grado (nivel de dominio I);

b. una segunda vez en asignaturas punto de control de la franja de tercero y cuarto curso del grado (nivel de dominio II);

c. durante la formación del máster (nivel de dominio III).

El baremo para la evaluación de las competencias transversales se ha establecido con una escala de cuatro valores que acompañan a la calificación del alumno:

D: nivel de desarrollo no alcanzado

C: en desarrollo

B: adecuado

A: excelente

Las CT se evalúan de forma independiente en cada una de las titulaciones de grado y máster que cursa un estudiante a través de la vía y dominio que le corresponde. Junto a las calificaciones obtenidas en los actos de evaluación ordinarios de cada asignatura se documenta el nivel de adquisición de la CT en los puntos de control, conforme a la escala indicada en el párrafo anterior. Durante su periodo formativo, el estudiante puede visualizar en su expediente la valoración obtenida en las CT en cada punto de control. El nivel de adquisición de una misma CT puede variar de una asignatura a otra, pudiendo obtener distinto valor de la escala en función de la materia que es punto de control. Al finalizar los 
Evaluación de Competencias Transversales en la Titulación de Grado en Arquitectura Técnica de la Escuela Técnica Superior de Ingeniería de Edificación de la Universitat Politècnica de València-

Transversal Competences evaluation implementation in the Bachelor's Degree in Technical Architecture of the Higher Technical School of Building Engineering of the Polytechnic University of Valencia

estudios de la titulación, el estudiante obtiene un valor promedio de la adquisición de las CT evaluadas.

Esta comunicación se centra en exponer los resultados de la implementación en los estudios de Grado en Arquitectura Técnica a través de las Vías 1 y 2, Dominios I y II.

\section{Las Competencias Transversales en Grado en Arquitectura Técnica. ETSIE-UPV}

El plan de estudios de Grado en Arquitectura Técnica está compuesto de 40 asignaturas entre las materias de formación básica, obligatorias y optativas, de acuerdo con el plan de estudios vigente publicado en Resolución de 26 de julio de 2010, de la Universidad Politécnica de Valencia, por la que se publica el plan de estudios de Graduado en Ingeniería de Edificación ${ }^{1}$.

Tabla 2. Resumen de la distribución de créditos del plan de estudios de Grado en Arquitectura Técnica. ETSIE-UPV. Fuente BOE n⿳0192.

\begin{tabular}{|c|c|}
\hline Tipo de materia & Créditos ECTS \\
\hline Formación básica. . & 63 \\
\hline Obligatorias .... & 141 \\
\hline Optativas ....... & 18 \\
\hline Prácticas externas & 6 \\
\hline Trabajo de fin de grado & 12 \\
\hline Total. & 240 \\
\hline
\end{tabular}

De entre estas asignaturas se seleccionan aquellas que se constituyen como punto de control de la evaluación de alguna competencia transversal, de forma que si una asignatura es punto de control se definen unas actividades de aprendizaje que quedan reflejadas en la guía docente y servirán de evidencia de nivel de adquisición de la CT. Así el alumnado conoce la CT asociada al punto de control y la forma en la que va a ser evaluado. Además, el profesorado documenta las evidencias recogidas de la evaluación para justificar el nivel de adquisición de la competencia.

\footnotetext{
${ }^{1}$ El Consejo de Gobierno de la Universitat Politècnica de València acordó el 26 de septiembre de 2012 el cambio en la denominación del Grado en Ingeniería de Edificación por la de Grado en Arquitectura Técnica, sin modificar ningún otro punto de la memoria de verificación tal y como fue aprobada por el Consejo de Universidades, por orden del Tribunal Superior de Justicia de la Comunidad Valenciana que dictaminó (auto $n^{\circ} 68$ de 9 de febrero de 2012) la anulación cautelar de la denominación de Grado en Ingeniería de Edificación.
} 
El Grado en Arquitectura Técnica en la ETSIE tiene todas las competencias transversales implantadas a lo largo de toda la titulación, en 39 asignaturas con un total de 108 puntos de control. El profesorado responsable de cada asignatura propone en la Guía Docente de la misma, qué CT trabaja, se indica si es punto de control y las evidencias que sirven para la evaluación. La Dirección Académica de la titulación es la encargada de coordinar estas actuaciones y velar porque todas las CT tengan al menos un punto de control en cada vía y dominio correspondiente.

La figura 1 muestra la relación de asignaturas de la titulación, en tono claro se representa la competencia transversal que se trabaja en cada una de ellas, y en color verde las que se constituyen como puntos de control. La forma en la que se recogen las evidencias de la evaluación de las competencias queda documentada en la guía docente de cada asignatura.

En el curso 2020-2021 las competencias transversales están implantadas como punto de control a lo largo de toda la titulación en un $95.93 \%$ de los créditos ofertados.

En la parte inferior de figura 1 aparece un resumen del número de puntos de control que tiene cada competencia transversal a lo largo de las asignaturas de la titulación.

Se puede apreciar que la mayor parte de los puntos de control se concentran en evaluar las siguientes competencias:

CT2 Aplicación pensamiento práctico.

CT3 Análisis y resolución de problemas.

CT6 Trabajo en equipo y liderazgo.

CT8 Comunicación efectiva.

En segundo lugar, aparecen:

CT1 Comprensión e integración.

CT5 Diseño y proyecto.

CT7 Responsabilidad ética, medioambiental y profesional.

CT12 Planificación y gestión del tiempo.

CT13 Instrumental específica.

Y finalmente las que se evalúan en un menor número de asignaturas.

CT4 Innovación, creatividad y emprendimiento

CT9 Pensamiento crítico.

CT10 Conocimiento de los problemas contemporáneos

CT11 Aprendizaje permanente 
Evaluación de Competencias Transversales en la Titulación de Grado en Arquitectura Técnica de la

Escuela Técnica Superior de Ingeniería de Edificación de la Universitat Politècnica de València-

Transversal Competences evaluation implementation in the Bachelor's Degree in Technical Architecture of the Higher Technical School of Building Engineering of the Polytechnic University of Valencia

No obstante, todas las competencias son evaluadas como mínimo en tres asignaturas como punto de control y que la UPV exige al menos una vez en los dos primeros cursos (Dominio I) y al menos una vez en los cursos tercero y cuarto (Dominio II).

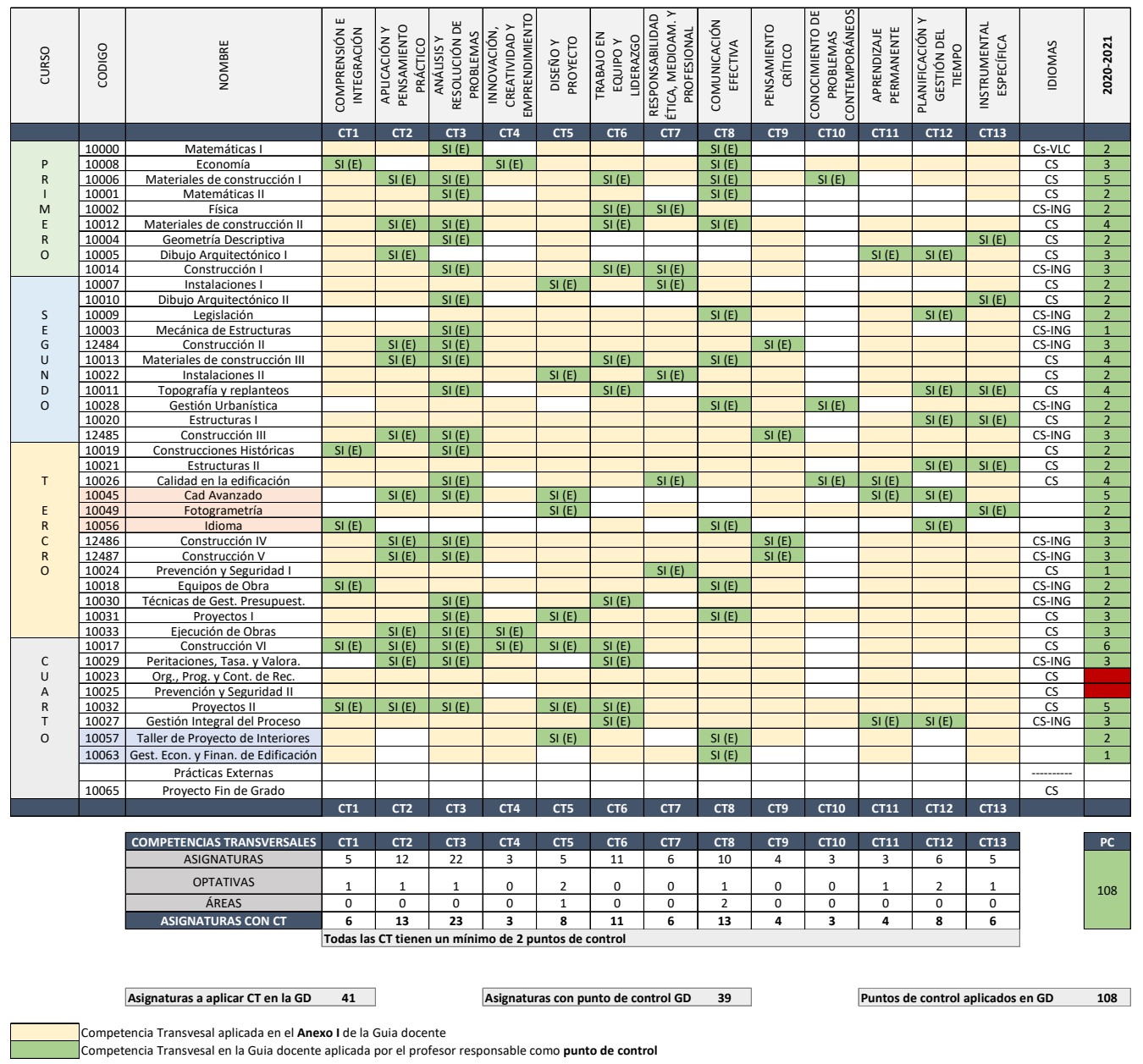

Fig 1. Distribución de asignaturas del grado y competencia transversal que se evalúa. Curso 2020-2021. Elaboración propia.

\section{Resultados de la evaluación de las competencias transversales}

A continuación, se muestran los resultados de la implementación de la evaluación de las competencias transversales en el curso 2020-2021 de Grado en Arquitectura Técnica a través de la Vía 1, correspondiente a las asignaturas de plan de estudios y Dominios I y II, 
que abarca los cuatro cursos de la titulación. En primer lugar, se muestran los datos globales de la titulación y seguidamente el detalle por cursos.

En el caso de Vía 2 (Elaboración del Trabajo Final de Grado) hay dos puntos de control, uno desde el punto de vista del tutor académico y otro por parte del Tribunal de evaluación al finalizar el acto de defensa donde se evalúan todas las CT.

En cuanto a la Vía 1, en la figura 2 se observa que cada competencia transversal está contemplada en un promedio de 8.3 asignaturas como punto de control, cuando la UPV recomienda al menos una asignatura cada dos cursos como punto de control. La competencia más extendida corresponde a la CT3 Análisis y resolución de problemas, aplicada en un total de 23 asignaturas equivalente a 129 créditos y las menores la CT10 Conocimiento de los problemas contemporáneos en 3 asignaturas equivalente a 16.50 créditos y la CT4 Innovación, creatividad y emprendimiento. Cabe pensar que la CT3 está muy relacionada con el carácter científico-técnico de la titulación de Grado en Arquitectura Técnica y, por tanto, es motivo de varios puntos de control. Si embargo, las que menos repercusión tienen como punto de control, adquieren mayor repercusión en la titulación de Máster en Edificación dentro de la Via1 Dominio III del proyecto de evaluación de las competencias.

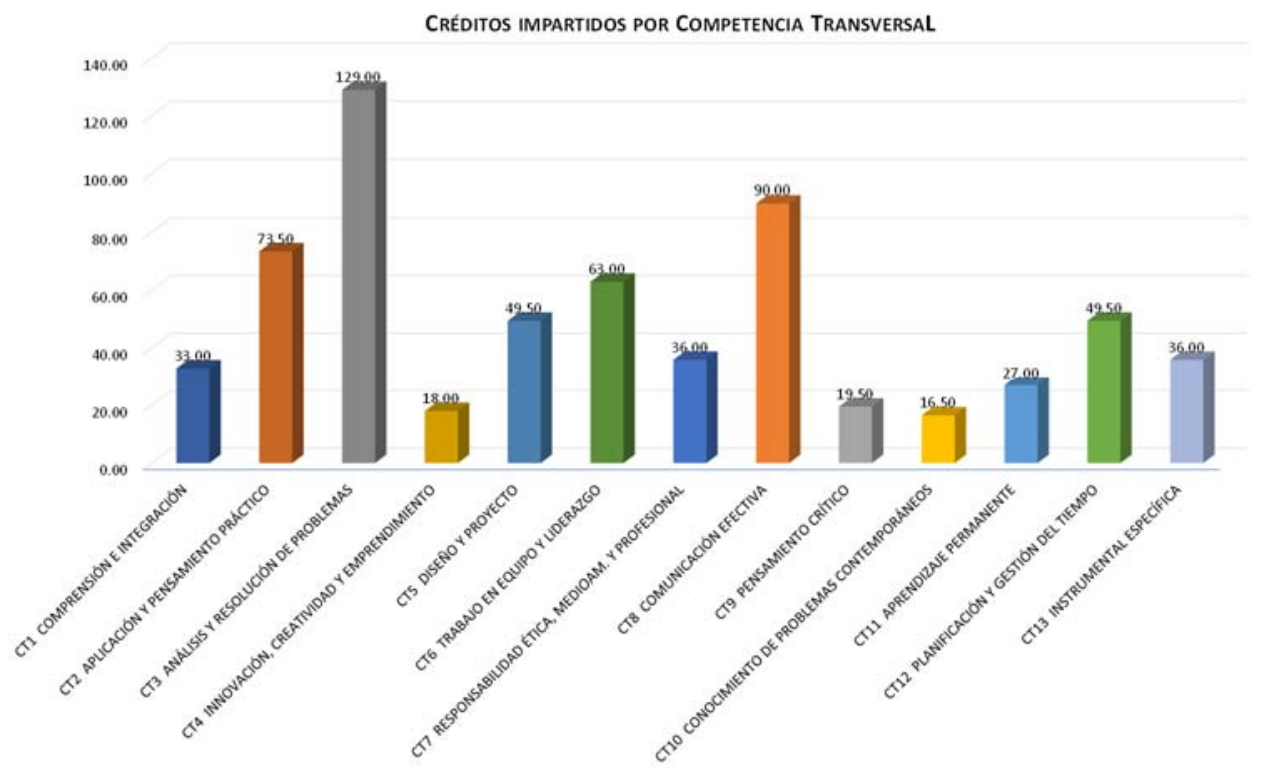

Fig 2. Créditos totales impartidos por cada competencia transversal en la titulación de Grado en Arquitectura Técnica de la UPV en el curso 2020/2021. Elaboración propia. 
Evaluación de Competencias Transversales en la Titulación de Grado en Arquitectura Técnica de la

Escuela Técnica Superior de Ingeniería de Edificación de la Universitat Politècnica de València-

Transversal Competences evaluation implementation in the Bachelor's Degree in Technical Architecture of the Higher Technical School of Building Engineering of the Polytechnic University of Valencia

En términos porcentuales, como muestra la figura $3 \mathrm{y}$, analizando cada competencia de forma individual, teniendo en cuenta que los créditos totales ofertados, en el curso 20202021, por la titulación son 258 créditos, las competencias transversales con mayor implantación son la CT3 Análisis y resolución de problemas $(50.00 \%)$, CT8 Comunicación efectiva (34.88\%), CT2 Aplicación y pensamiento práctico (28.49\%), CT6 Trabajo en equipo y liderazgo (24.42\%) y CT5 Diseño y proyecto y CT12 Planificación y gestión del tiempo $(19.19 \%)$, más directamente relacionadas con la profesión de Arquitecto Técnico, y por tanto, con el desarrollo de proyectos, liderando equipos y aportando soluciones prácticas. En cambio, las de menor implantación están asociadas al pensamiento crítico, innovación y problemas contemporáneos, menores del $10 \%$.

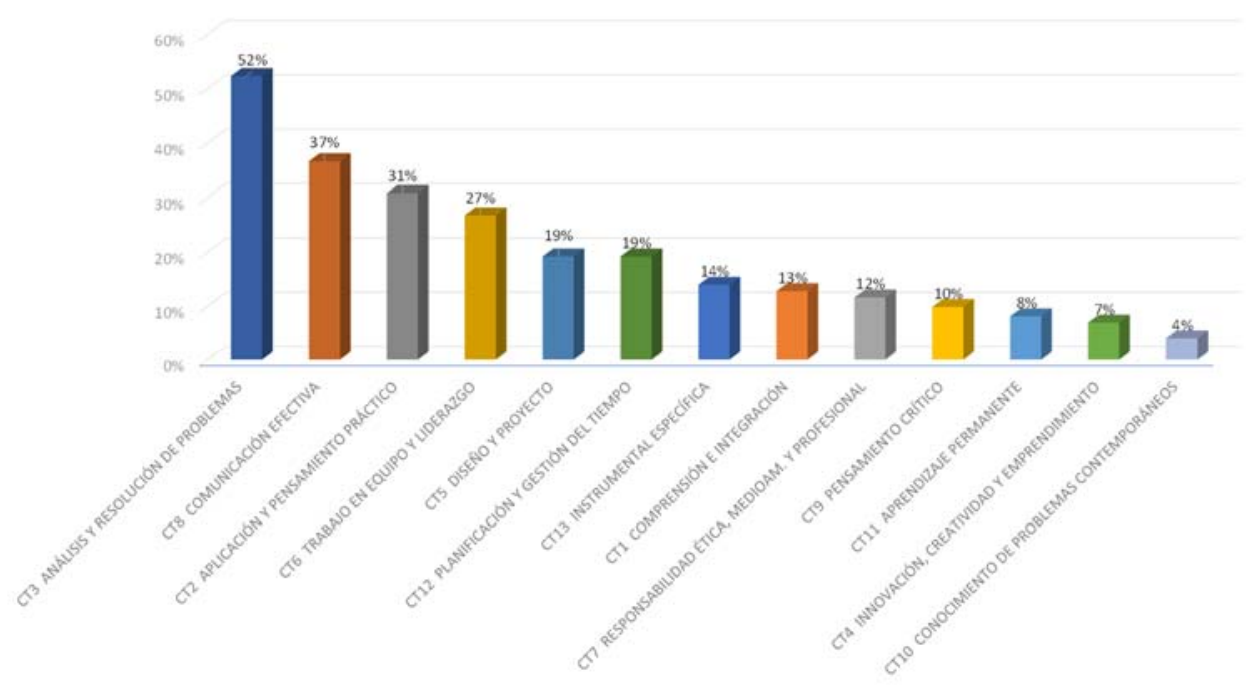

Fig 3. Porcentaje de créditos impartidos de cada Competencia Transversal en la Titulación de Grado en Arquitectura Técnica de la UPV en el curso 2020/2021. Elaboración propia.

La evaluación de las competencias distribuidas por curso académico refleja la evolución del aprendizaje del alumno a lo largo de sus estudios. En primer curso, que corresponde al Dominio I de Vía 1, de acuerdo con el proyecto UPV, la CT de mayor importancia es la CT3 impartida en 6 asignaturas con un total 19.5 créditos equivalente al $65.00 \%$ del primer curso (60 créditos). Y le siguen en importancia las competencias CT8 $(47.50 \%)$, CT6 $(40.00 \%)$ y CT2 $(32.50 \%)$. Este hecho inicia al estudiante recién llegado a la universidad en la adquisición de destrezas y habilidades de resolución de problemas, trabajo en equipo y liderazgo y comunicación efectiva que fomenta la interactuación con el resto de los estudiantes y profesores facilitando su integración en el ámbito universitario, favoreciendo las relaciones sociales, (Figura 4). 


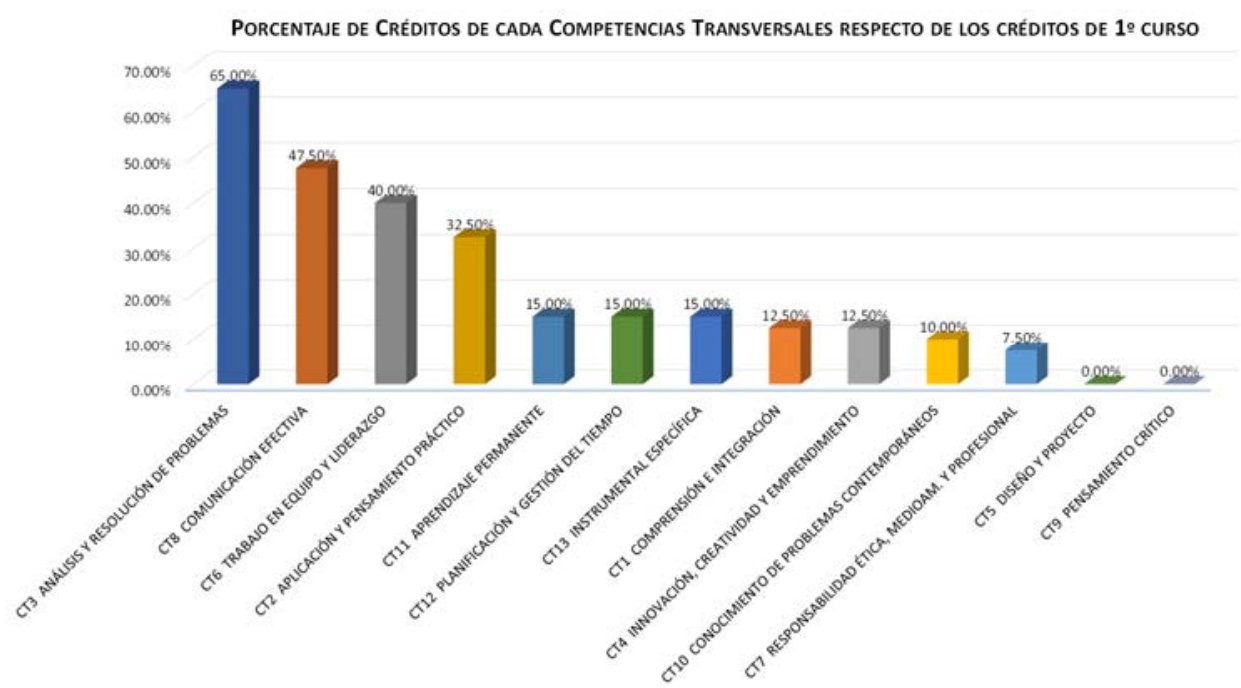

Fig 4. Porcentaje de créditos de la Titulación por Competencias Transversal en 1er Curso. Elaboración propia.

En segundo curso se refuerza la CT12 Planificación y gestión del tiempo, CT13 Instrumentación específica y CT5 Diseño y proyecto (figura 5). En este curso ya se comienzan a impartir asignaturas específicas de carácter tecnológico que requiere abordar el estudio de proyectos de edificación. Sin embargo, no hay puntos de control para la CT1 Compresión e Integración, CT4 Innovación, creatividad y emprendimiento y CT11 Aprendizaje permanente.

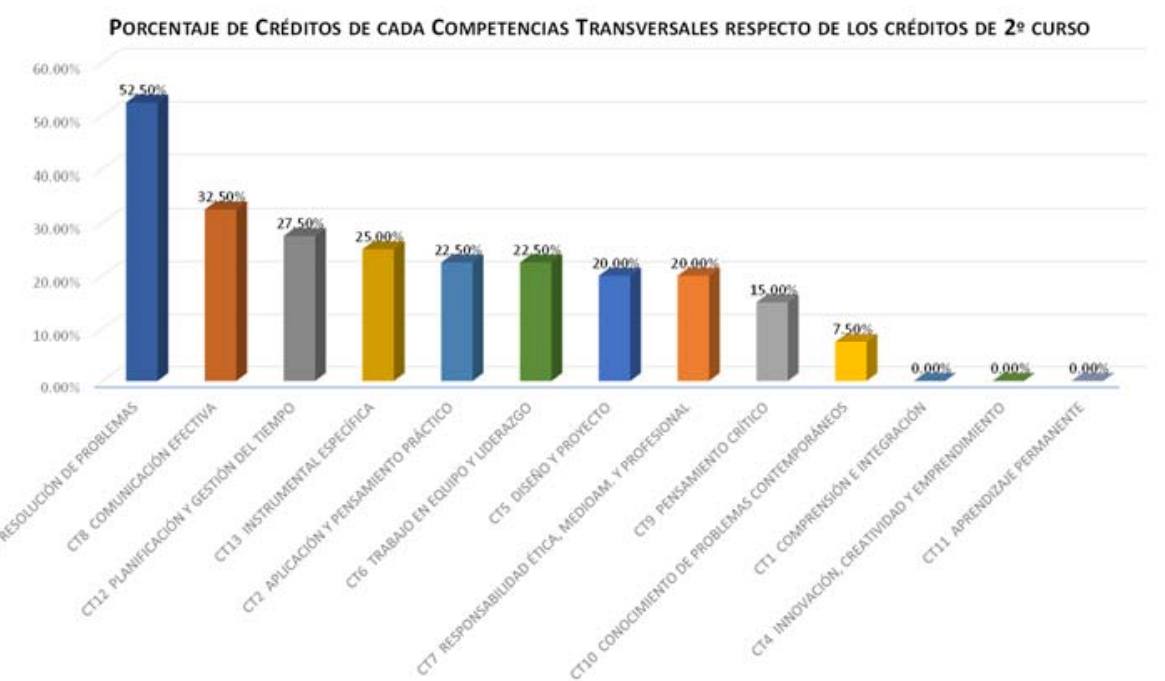

Fig 5. Porcentaje de créditos de la Titulación por Competencias Transversal en $2^{\circ}$ Curso. Elaboración propia. 
Evaluación de Competencias Transversales en la Titulación de Grado en Arquitectura Técnica de la Escuela Técnica Superior de Ingeniería de Edificación de la Universitat Politècnica de València-

Transversal Competences evaluation implementation in the Bachelor's Degree in Technical Architecture of the Higher Technical School of Building Engineering of the Polytechnic University of Valencia

En tercer curso (figura 6), dentro de la Via1 y Dominio II, se incorpora la CT9 Pensamiento crítico, CT4 Innovación, CT11 Aprendizaje permanente.

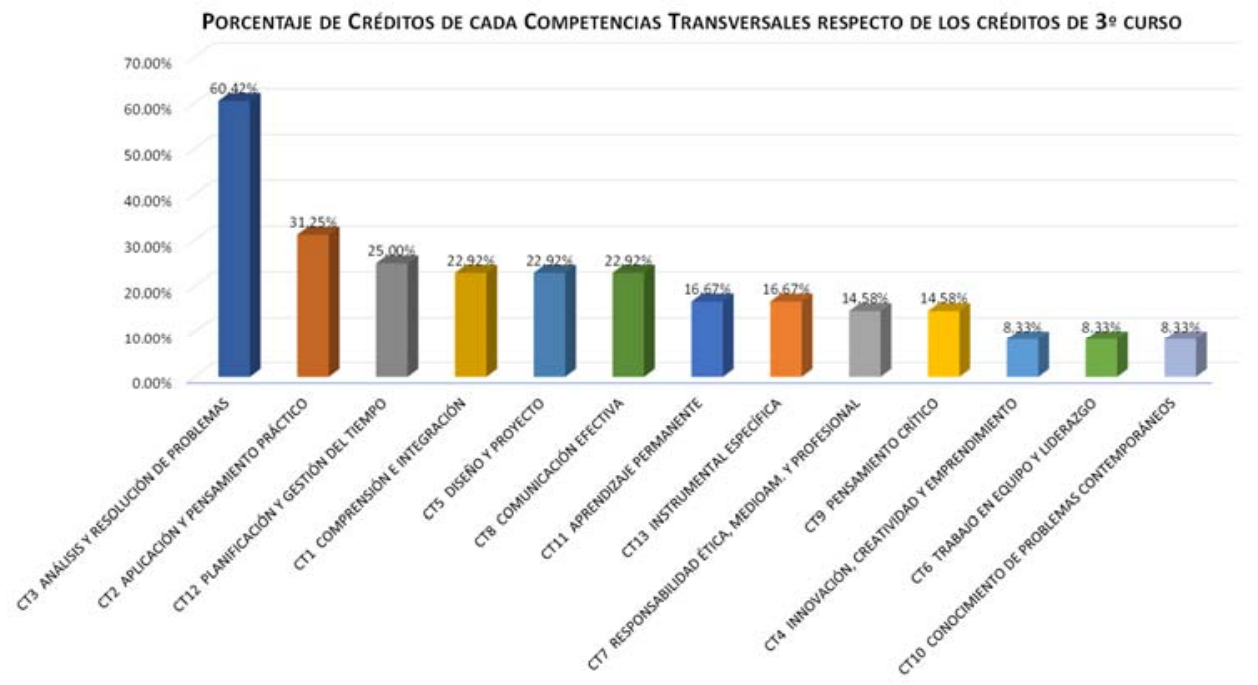

Fig 6. Porcentaje de créditos de la Titulación por Competencias Transversal en $3^{\circ}$ Curso. Elaboración propia.

En cuarto curso toma mayor importancia la CT8 Comunicación efectiva (36.36\%), CT5 Diseño y proyecto (31.28\%) y CT6 Trabajo en equipo y liderazgo (29.55\%), (figura 7).

Sería una opción de mejora que las competencias que fortalecen el contacto con el mundo laboral y potencian los conocimientos de la últimas tecnologías y desarrollos empresariales contemporáneos tuvieran una mayor implantación en el último curso de la titulación. Es destacable que no se desarrollen en este curso la CT7 Responsabilidad ética, medioambiental y profesional, CT9 Pensamiento crítico, CT10 Problemas contemporáneos y CT13 Instrumentación específica. Y la CT4 asociada al emprendimiento solo equivale al $6.82 \%$ del curso.

Se plantea como acción de mejora la incorporación de alguna de estas competencias en la adquisición por la Vía 3 como actividades extracurriculares. 


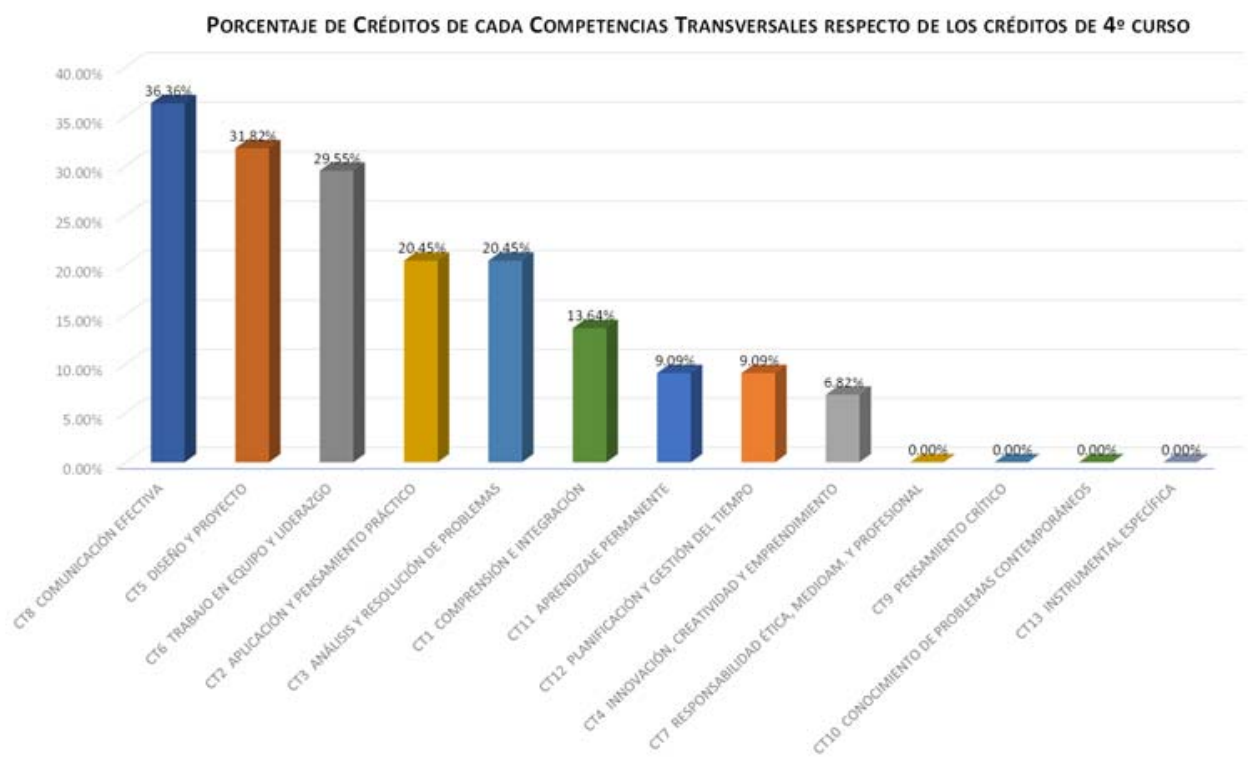

Fig 7. Porcentaje de créditos de la Titulación por Competencias Transversal en $4^{\circ}$ Curso. Elaboración propia.

No obstante, es importante destacar que en cuarto curso estas asignaturas corresponden únicamente al primer semestre, puesto que el segundo semestre se destina a las prácticas en empresa, áreas de intensificación y el desarrollo del Trabajo Fin de Grado, el cual incorpora la evaluación de las competencias en función del objeto del Trabajo Fin de Grado que ha realizado el estudiante. La evaluación de las competencias transversales en este caso corresponde a la Vía 2.

Durante este último periodo de formación universitaria del grado, comienza el contacto con el mundo laboral, donde el alumno es mucho más capaz de valorar y adquirir las habilidades asociadas a las CT de emprendimiento, pensamiento crítico, conocimiento de problemas contemporáneos y por supuesto instrumentación específica con el aprendizaje de tecnología, software y equipos técnicos de los que disponen las empresas del mundo de la edificación.

El nivel de adquisición de las CT en la UPV queda reflejado mediante dos modos complementarios, a través del expediente académico del estudiante, como suplemento al diploma, y mediante el portafolio de las CT de cada estudiante. Al igual que se genera el expediente, se genera un anexo en el que consta una relación de las valoraciones de las CT UPV en cada uno de los niveles (vías 1 y 2). Cabe indicar que este anexo se emite a petición expresa del estudiante. Con respecto a las CT obtenidas por la Vía 3, tras la aportación de las evidencias por parte del estudiante y su validación y gestión por parte de la UPV, quedan reflejadas en su expediente personal. 
Evaluación de Competencias Transversales en la Titulación de Grado en Arquitectura Técnica de la Escuela Técnica Superior de Ingeniería de Edificación de la Universitat Politècnica de València-

Transversal Competences evaluation implementation in the Bachelor's Degree in Technical Architecture of the Higher Technical School of Building Engineering of the Polytechnic University of Valencia

\section{Conclusiones}

La implementación de las Competencias Transversales en el Grado de Arquitectura Técnica en el curso 2002-2021 se ha producido en el $95.93 \%$ de los créditos ofertados, estando cada competencia reconocida como punto de control entre 3 y 23 asignaturas ofertadas de la titulación, lo que permite ser reconocido en el currículum del estudiante.

La profesión de Arquitecto Técnico necesita abordar un proyecto desde su planteamiento hasta su materialización en un edificio, teniendo capacidad para la resolución de problemas constructivos y tecnológicos, liderar equipos y programación de tiempos tanto en el diseño de un proyecto edificatorio como en sus fases de ejecución. Esta característica se encuentra alineada con las competencias transversales adquiridas en la titulación más implantadas como son la CT3 Análisis y resolución de problemas $(50.00 \%)$, CT8 Comunicación efectiva (34.88\%), CT2 Aplicación y pensamiento práctico (28.49\%), CT6 Trabajo en equipo y liderazgo (24.42\%) y CT5 Diseño y proyecto y CT12 Planificación y gestión del tiempo (19.19\%).

El diseño de la adquisición de las competencias por parte del estudiante en su aprendizaje evolutivo por cursos permite que vaya adquiriendo de forma paulatina las habilidades y destrezas, en la Vía 1, potenciando en los primeros cursos, con una formación de carácter básico, las competencias de análisis y resolución de problemas $(65 \%)$, comunicación efectiva $(47.50 \%)$ y trabajo en equipo $(40 \%)$, fomentando la interactuación con el resto de los estudiantes y profesores su integración en el ámbito universitario. En segundo curso asociados a una formación más tecnológica y especializada adquieren importancia competencias orientadas a la planificación y gestión del tiempo e instrumentación específica en más del $25 \%$. Y en tercer curso la competencia de aplicación y pensamiento práctico en más del $30 \%$.

El cuarto curso, en el segundo semestre, destinado a las prácticas de empresa, áreas de intensificación y Trabajo Fin de Grado permite la adquisición de competencias transversales por la Vía 2, con una formación más específica asociada al tipo de trabajo a desarrollar elegido por el estudiante.

Durante el curso 2020-2021 se han realizado las gestiones para implantar competencias transversales por la Vía 3 en actividades extracurriculares, reconocimiento la competencia CT10 Conocimiento de problemas contemporáneos, mediante la asistencia a conferencias, seminarios o exposiciones organizadas por la ETSIE, con motivo de la conmemoración del 50 aniversario y focalizadas en fomentar el contacto del estudiante de último curso con las empresas especializadas en el sector de la edificación.

Las perspectivas de la ETSIE para el próximo curso son potenciar y consolidar la implantación de las competencias transversales en sus tres vías con el objetivo de que el estudiante adquiera habilidades y destrezas que complementen y potencien su formación. $\mathrm{Y}$, por otro lado, continúen mejorando las encuestas de satisfacción del estudiante con respecto a la docencia impartida (7.95) y con la formación recibida a los tres años (6.94), 
indicados en el informe de Gestión del Grado en Arquitectura Técnica del curso 2019/2020, (UPV, 2020).

\section{Referencias}

UNIVERSITAT POLITĖCNICA DE VALĖNCIA (2020). Proyecto Competencias Transversales de la UPV.

https://poliformat.upv.es/access/content/group/ESP 0 2254/PROYECTO\%20COMPETENC IAS\%20TRANSVERSALES\%20DE\%20LA\%20UPV \%2027.07.18.pdf.[Consulta: 15 de junio de 2021].

UNIVERSITAT POLITĖCNICA DE VALĖNCIA (2020). Informe de gestión del Grado en Arquitectura Técnica. http://www.upv.es/titulaciones/GIE/info/memoria_informesc.html. [Consulta: 15 de junio de 2021].

UNIVERSITAT POLITĖCNICA DE VALĖNCIA (2015). Proyecto Competencias Transversales de la UPV. Rúbricas.

https://poliformat.upv.es/access/content/group/ESP 0 2254/R\%C3\%BAbricas\%20CT\%20U PV/CT-UPV\%20C\%C3\%B3mo\%20usar\%20las\%20r\%C3\%BAbricas.pdf. [Consulta: 20 de junio de 2021].

España. RESOLUCIÓN 12871 de 26 de julio de 2010, de la Universidad Politécnica de Valencia, por la que se publica el plan de estudios de Graduado en Ingeniería de Edificación. BOE, 9 de agosto de 2010, núm. 192, p.69927-69928. 


\title{
EDIFİCATE
}

I Congreso de Escuelas de Edificación y Arquitectura Técnica de España València, 4 y 5 de noviembre de 2021

Escuela Técnica Superior de Ingeniería de Edificación

Universitat Politècnica de València

Doi: https://doi.org/10.4995/EDIFICATE2021.2021.13573

\section{Prácticas curriculares de estudiantes en empresas y despachos profesionales en el Grado en Ingeniería de Edificación. \\ Curricular practices of students in companies and professional offices in the Building Engineering Degree}

\author{
Julián Pérez-Navarro ${ }^{a}$, Josefa Ros Torres ${ }^{a}$ \\ aDepartamento de Arquitectura y Tecnología de Edificación de la Universidad Politécnica de Cartagena \\ julian.perez@upct.es; josefa.ros@upct.es
}

\begin{abstract}
The profession of Technical Architect has a component linked to the indisputable practice and the inclusion of the subject of internships in the study plans allows the students to approach the occupations that they may develop in the future.

This study is based on surveys and interviews carried out with students and companies that have participated in the curricular practices during three academic years in the Building Engineering Degree of the UPCT.

The segmentation of the type of companies that students of this Degree have demanded, as well as the type of tasks that have been demanded of them, is also part of this communication.

Finally, we will highlight the contributions that our students can make to companies, within the framework of the digitization and sustainability objectives that pose a challenge for the construction sector in the coming years.
\end{abstract}

Keywords: Study plan, companies demanding students, tasks in internships, graduate opportunities. 


\section{Resumen}

La profesión de Arquitecto Técnico tiene una componente ligada a la práctica indiscutible y la inclusión de la asignatura de prácticas en empresa en los planes de estudio permite el acercamiento de los estudiantes a las ocupaciones que puedan desarrollar en el futuro.

Este estudio se basa en encuestas y entrevistas realizadas a los estudiantes y las empresas que han participado en las prácticas curriculares durante tres años académicos en el Grado en Ingeniería de Edificación de la UPCT.

La segmentación de la tipología de empresas que han demandado estudiantes de este grado, así como la tipología de tareas que les han demandado, también forma parte de esta comunicación.

Finalmente se destacarán las contribuciones que pueden realizar los estudiantes a las empresas, en el marco de los objetivos de digitalización y sostenibilidad que suponen un reto para el sector de la construcción en los próximos años

Palabras clave: Plan de estudios, empresas demandantes estudiantes, tareas en prácticas, oportunidades egresados. 


\section{Introducción}

La Universidad Politécnica de Cartagena viene impartiendo estudios para la obtención del título de Arquitecto Técnico desde el curso 2000-2001 y el año 2009 se adaptó el plan de estudios al Grado en Ingeniería de Edificación. A partir de ese momento, la asignatura de Prácticas en empresa forma parte de la materia curricular de los estudiantes.

La profesión de Arquitecto Técnico tiene una componente ligada a la práctica indiscutible, que precisa de su soporte en los planes de estudios.

Esta comunicación aborda la experiencia de estos últimos años, usando como metodología las encuestas realizadas a los estudiantes y las empresas, así como las memorias que realizan los estudiantes para su evaluación.

\section{Objetivos}

Esta comunicación tiene como objetivo principal segmentar la tipología de empresas que han demandado en los últimos cursos académicos estudiantes de este grado, así como la tipología de tareas que les han demandado, en contraposición con las fortalezas y debilidades que han comentado los estudiantes en relación a las competencias recibidas.

Como objetivos secundarios, se pretende detectar las contribuciones que pueden realizar los estudiantes a las empresas, que en muchos casos están poco tecnificadas y cuentan con una digitalización escasa.

\section{Desarrollo de la innovación}

Este estudio se basa en encuestas y entrevistas realizadas a los estudiantes y las empresas que han participado en las prácticas curriculares durante tres años académicos en el Grado en Ingeniería de Edificación de la UPCT. Además los estudiantes redactan una memoria que recoge una descripción de las tareas y trabajos desarrollados, valoración de las tareas desarrolladas con los conocimientos adquiridos en relación con los estudios universitarios, relación de problemas planteados e identificación de las aportaciones que en materia de aprendizaje han supuesto las prácticas.

Para el desarrollo de los objetivos pretendidos, en primer lugar se establecerá el perfil de las actividades de las empresas que demandan estudiantes de este grado. Después se comentarán las tareas que desarrollan los estudiantes en función de la empresa. Posteriormente se tratará la valoración de las tareas con los conocimientos adquiridos durante las prácticas y finalmente se verán las aportaciones que les han supuesto las prácticas.

Las empresas y profesionales que suscriben convenio de prácticas con la universidad, para contar con estudiantes del Grado en Ingeniería de Edificación, se pueden clasificar en los siguientes grupos: 
- constructoras

- promotoras

- empresas fabricantes

- entidades

- administración

- estudios de arquitectura

- $\quad$ estudios de arquitectura técnica

- $\quad$ estudios de ingeniería

- consultoras

En esta clasificación de tipologías de actividades (ver Fig. 1), destacan las empresas constructoras (53.42\%) como las principales demandantes de los estudiantes de este grado. Le siguen los estudios de técnicos (27.40\%), que se dividen en estudios de arquitectura, arquitectura técnica, ingeniería y consultoras. Sobre este grupo indicar que los estudios de arquitectura son los principales receptores (13.17\%) y sorprende la anecdótica presencia de estudios de arquitectura técnica o profesionales liberales de la titulación. A mejorar para el futuro, sería fomentar que los estudios de arquitectura técnica o profesionales liberales soliciten estudiantes del grado. Esta cuestión ya está en marcha, gracias a un convenio especifico que se ha firmado con el colegio profesional.

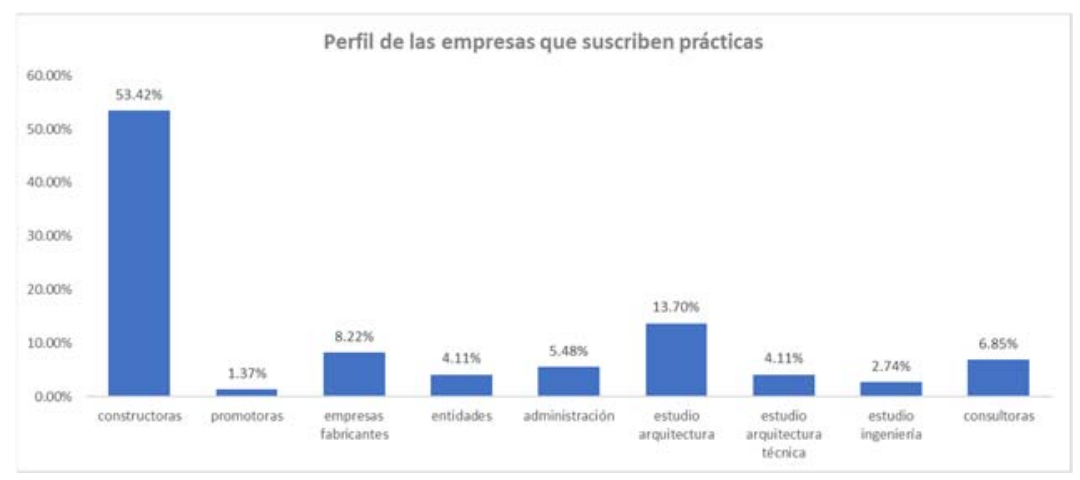

Fig. 1 (Elaboración propia) Perfil de las empresas que suscriben prácticas en empresa

En un segundo punto, interesa conocer las tareas desarrolladas en alguno de estos perfiles de empresas. Para ello se va a analizar por su representatividad la constructora, empresa fabricante, el estudio de arquitectura y estudio de arquitectura técnica.

En el caso de las prácticas desarrolladas en empresas constructoras (ver Fig. 2) destaca en primer lugar el apoyo al jefe de obra (31.40\%) con el desarrollo de tareas de contratación, planificación, costes y certificaciones. El seguimiento de obra $(24.60 \%)$ ocupa el segundo lugar y está muy relacionado con el control de la planificación y gestión de subcontratas. Finalmente, los estudiantes destacan como habitual, tareas relacionadas con la realización de mediciones y presupuestos (18.40\%) y dibujo en CAD (11.70\%). 


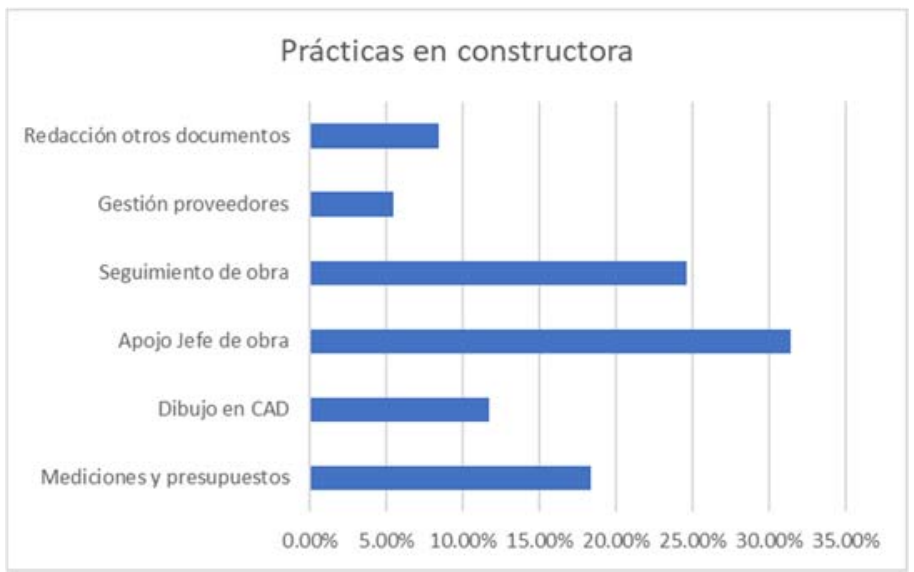

Fig. 2 (Elaboración propia) Tareas desarrolladas por los estudiantes en empresa constructora

En empresas de fabricación (ver Fig. 3) también han sido demandados estudiantes del grado. En estas empresas se han requerido conocimientos sobre modelado en BIM $(42.50 \%)$ o en programas como Sketchup (14.20\%). A diferencia de las empresas constructoras, en empresas auxiliares ya trabajan con metodología BIM. La realización de mediciones y presupuestos (28.20\%) sigue manteniéndose como una tarea frecuente.

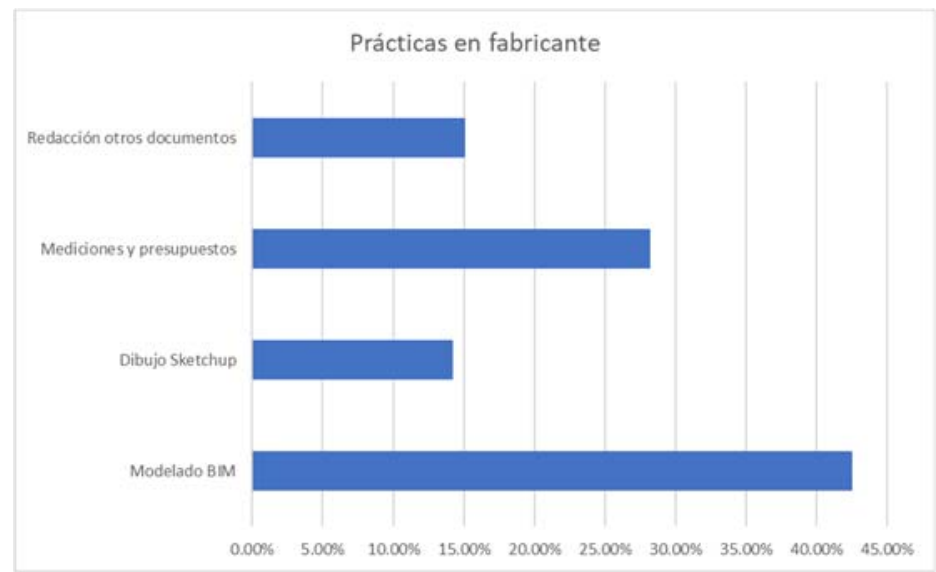

Fig. 3 (Elaboración propia) Tareas desarrolladas por los estudiantes en empresa fabricante

En los estudios de arquitectura (ver Fig. 4), la realización de mediciones y presupuestos (32.20\%) es la principal tarea para la que demandan a los estudiantes del grado, seguido por el dibujo de planos en CAD (22.40\%) y redacción de Memorias (16.10\%). Sorprende que no son demandadas competencias en BIM. 


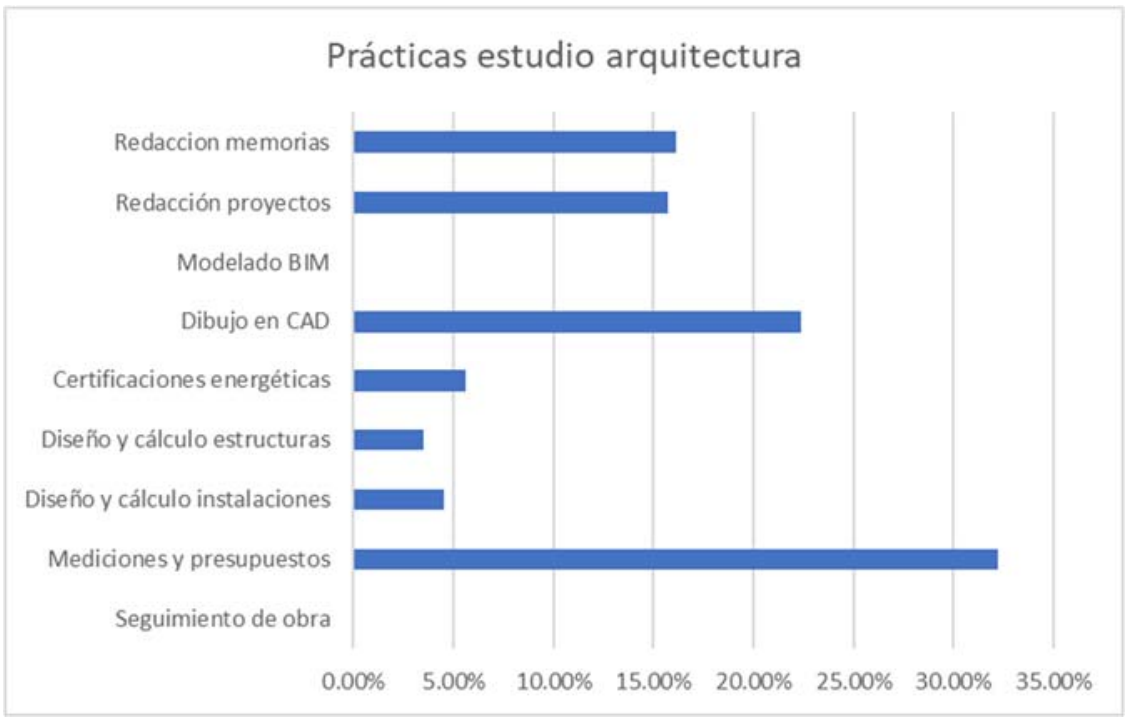

Fig. 4 (Elaboración propia) Tareas desarrolladas por los estudiantes en estudio de arquitectura

Finalmente respecto a los estudios de arquitectura técnica (ver Fig. 5), los estudiantes realizan principalmente tareas de apoyo a la Dirección de Ejecución de Obra y Coordinación de Seguridad y Salud $(40.70 \%)$, lo que implica una experiencia directa con las especialidades del ejercicio de la profesión liberal. En segundo lugar los estudiantes realizan tareas de mediciones y presupuestos (19.10\%), dejando para un tercer puesto tres apartados muy equilibrados, dibujo de planos en CAD (11.10\%), redacción memorias técnicas $(9.40 \%)$ y certificaciones energéticas $(8.90 \%)$. También recalcar que en ninguno de los casos se han mencionado ninguna tarea relacionada con BIM.

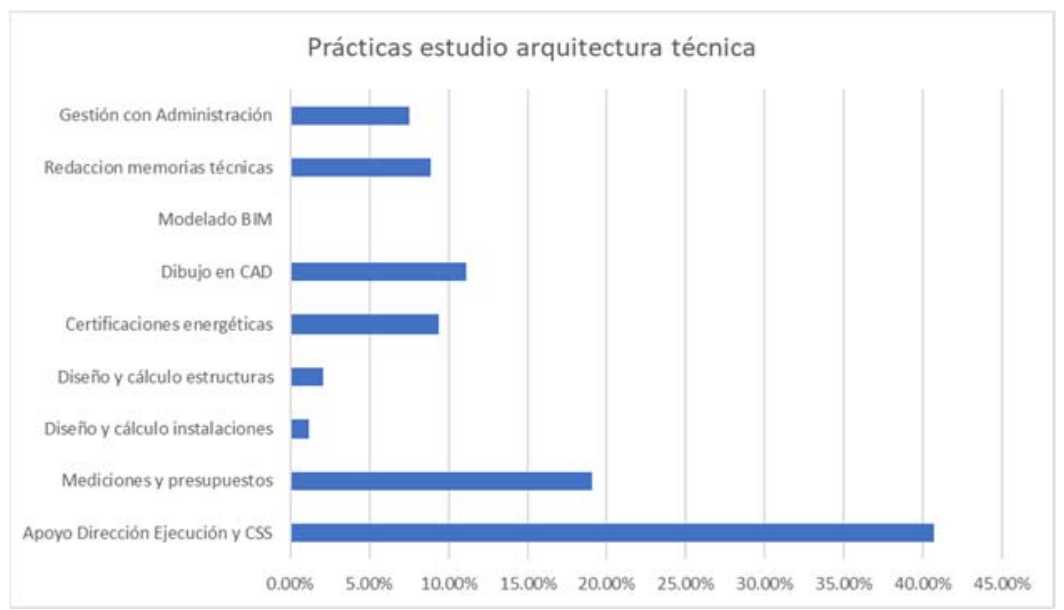

Fig. 5 (Elaboración propia) Tareas desarrolladas por los estudiantes en estudio arquitectura técnica 
Llegado a este punto, se va a comentar la valoración de las tareas desarrolladas con los conocimientos adquiridos en relación con los estudios universitarios. Dada la heterogeneidad de opiniones al respecto, se dividirán estas valoraciones en las que suponen fortalezas y debilidades.

\section{Fortalezas}

De las memorias examinadas se destacan a continuación algunas afirmaciones que realizan los estudiantes en las que muestran seguridad a la hora de enfrentarse a nuevos retos y al mercado profesional.

"Cabe destacar que prácticamente todo lo aprendido en la carrera y que es necesario para estas prácticas ha sido de muchísima utilidad, demostrándose que lo aprendido en el aula resulta muy útil como base para afrontar las situaciones reales y que no se aleja demasiado de la realidad que encontramos en el mundo laboral, salvo alguna que otra situación que por su naturaleza es complicada llevar desde la teoría hasta la práctica. Algo comprensible y perfectamente entendible"

"Las prácticas me dieron una seguridad de mi misma que anteriormente no tenía. Me di cuenta que podía realizar el trabajo sin problemas y desde que finalicé mi primera práctica me sentí preparada para trabajar"

"Estas prácticas han sido muy positivas y adecuadas para la formación del Grado en

Ingeniería de la Edificación, ya que han puesto a prueba todos los conocimientos adquiridos en cada una de las asignaturas vistas a lo largo del grado"

"Destreza a la hora de realizar presupuestos de reformas y soltura para realizar diferentes posibilidades de reforma y plasmarlo en planos en CAD"

"Conocimiento de normativas como el CTE, EHE, etc"

"Conocimientos de construcción, instalaciones, estructuras"

"Conocimiento avanzado de CAD"

"Preparación de planos, interpretación y análisis de los mismos, visión espacial. Preparación de proyectos"

\section{Debilidades}

En el mismo sentido, se resaltan a continuación algunos comentarios que han realizado los estudiantes en los que reconocen sus aspectos a mejorar.

"He descubierto mis debilidades durante la realización de las prácticas, por lo que han sido fundamentales en mi formación universitaria"

"El 3D hasta ahora para mi era una incógnita, sin embargo, por las tareas que me han sido otorgadas, me han permitido lograr un pequeño conocimiento sobre el 3D" 
Prácticas curriculares de estudiantes en empresas y despachos profesionales en el Grado en Ingeniería de Edificación- Curricular practices of students in companies and professional offices in the Building Engineering Degree

"Tengo algunas debilidades que me van a dificultar la integración en el mundo laboral pero podré superarlas"

"Trato con los clientes"

"Trabajo en equipo"

Otro de los apartados que se incluyen en la memoria que realizan los estudiantes consiste en identificar las aportaciones que en materia de aprendizaje han supuesto las prácticas y de las cuales se transcriben a continuación algunas.

"Es una oportunidad para dar a conocer todo lo que has aprendido y ponerlo en práctica" "Logras darte cuenta de lo que en realidad sabes y de lo que eres capaz"

"Un factor importante que valoro positivamente son las materias vistas en la universidad, que han llegado a ser muy teóricas, pero con esos conocimientos, he podido relacionarlos con la ejecución de los trabajos en obra"

"Aprender a desenvolverme en el entorno de una empresa. Sobre todo, me ha sido de gran ayuda en lo que se refiere a la comunicación con otras personas a la hora de resolver dudas"

"Me satisface mucho estar trabajando en esta empresa, ya que considero que un Ingeniero de Edificación tiene un amplio abanico de posibilidades en el mundo laboral"

"Mi experiencia hasta día de hoy está siendo más que satisfactoria, ya que estoy aprendiendo mucho, incluso más de lo esperado"

"He podido ver la gran diferencia de estudiar las obras en los apuntes a verlas in situ enfrentándose a los diferentes problemas que se pueden plantear día a día en ella"

\section{Oportunidades}

En este punto y después de los mensajes positivos y de satisfacción de los estudiantes, se dedicará este espacio a insistir en la capacidad de adaptación de la profesión de Arquitecto Técnico, cuyos egresados se integran con facilidad en la estructura de empresas del sector de la construcción.

Así el estudio Pespectiva Profesión 2020 que es una iniciativa del Col·legi d'Aparelladors, Arquitectes Tècnics i Enginyers d'Edificació de Barcelona, con la colaboración del Consejo Catalán de Aparejadores, con el objetivo de conocer el día a día de la realidad de la profesión de Arquitecto Técnico y las posibles tendencias de futuro, obtiene como una de las conclusiones que más del $70 \%$ de los egresados trabajan directamente en el sector de la construcción. La distribución principal de ocupaciones se basa en: profesión liberal, estudio profesional, empresas construcción y empresas diversas (ver Fig. 6). También se obtiene de este estudio que solamente el $\mathbf{5 \%}$ de los encuestados reconoce no está trabajando, lo que supone un índice muy bajo. 


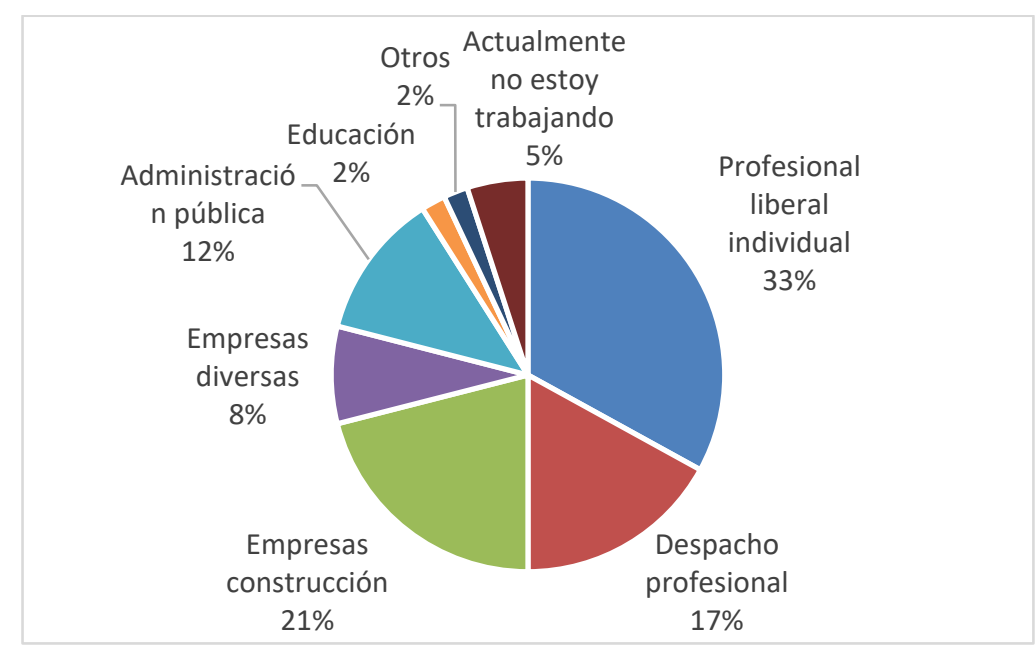

Fig. 6 (Elaboración propia en base a los datos del estudio "Perspectiva profesión 2020") Dedicación principal de los arquitectos técnicos

En este estudio, se analizan las principales tareas que desarrollan los arquitectos técnicos en el desarrollo de su profesión (ver Fig. 7). Así las principales ocupaciones son la dirección de ejecución de obra, el control económico y la gestión. Se puede encontrar cierta similitud entre estas ocupaciones y las tareas que han desarrollado los estudiantes en sus prácticas curriculares.

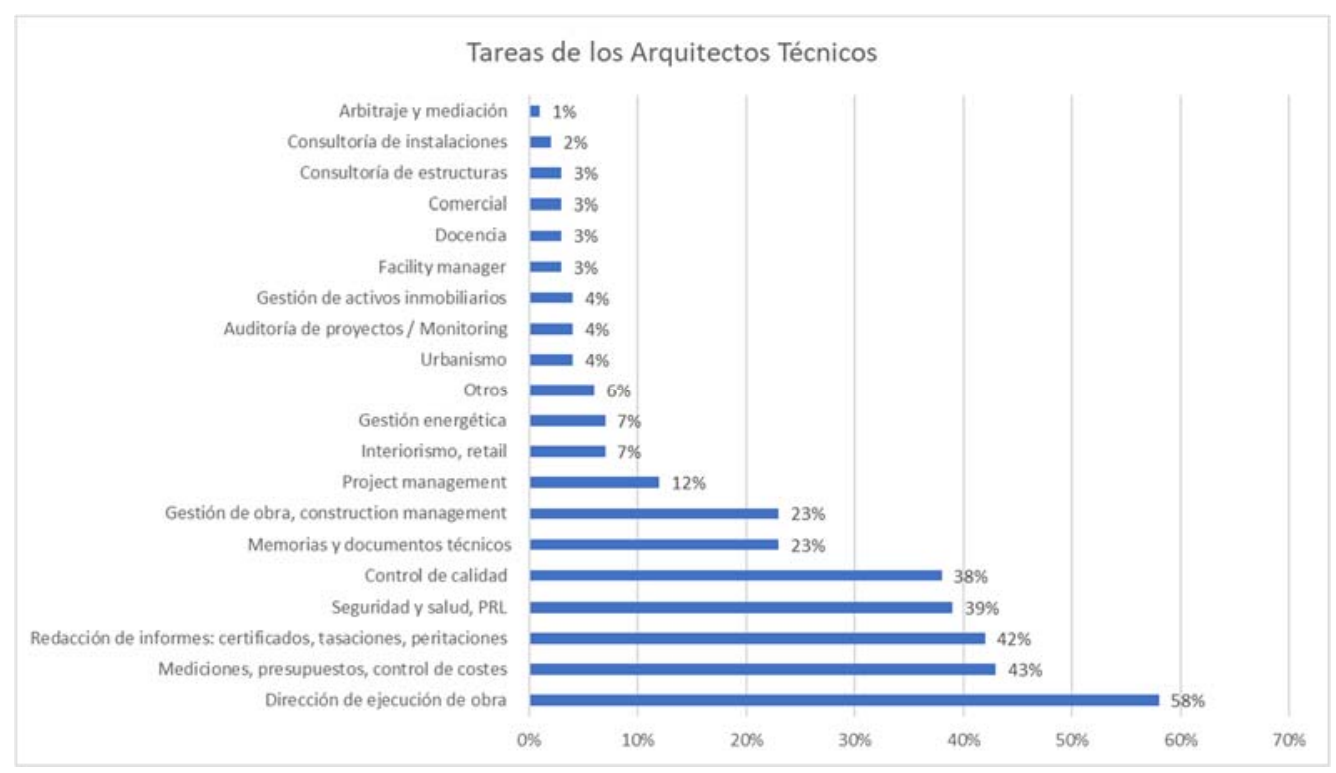

Fig. 7 (Elaboración propia en base a los datos del estudio "Perspectiva profesión 2020") Tareas realizadas por los arquitectos técnicos 


\section{Resultados}

Para dar cumplimiento del objetivo principal, hemos obtenido que las empresas constructoras $(53.42 \%)$ han sido las principales demandantes, ocupando el segundo lugar los estudios o despachos de técnicos (27.40\%).

Las tareas desarrolladas se han tratado monográficamente por su representatividad según la constructora, empresa fabricante, el estudio de arquitectura y estudio de arquitectura técnica. En el caso de la constructora, el apoyo al jefe de obra (31.40\%) con el desarrollo de tareas de contratación, planificación, costes y certificaciones, ha sido la principal ocupación de los estudiantes. En empresas de fabricación, a diferencia de las constructoras, se han requerido conocimientos sobre modelado en BIM (42.50\%) o en programas como Sketchup $(14.20 \%)$. En estudios de arquitectura, la realización de mediciones y presupuestos $(32.20 \%)$ es la principal tarea, mientras que en el caso de los estudios de arquitectura técnica, los estudiantes realizan principalmente tareas de apoyo a la Dirección de Ejecución de Obra y Coordinación de Seguridad y Salud (40.70\%). Ni en los estudios de arquitectura, ni en los de arquitectura técnica se han demandado competencias sobre metodología BIM.

Sobre la valoración de las tareas desarrolladas con los conocimientos adquiridos en relación con los estudios universitarios, subrayar como fortaleza, la seguridad con la que se han enfrentado a los retos que les han planteado las empresas y la capacidad de aprender y adaptación. Como debilidades, han puesto de manifiesto competencias que sería conveniente estudiar para su posible incorporación a los planes de estudio, como gestión de equipos y metodología BIM.

Para dar respuesta al segundo objetivo propuesto, sobre las contribuciones que pueden realizar nuestros estudiantes a las empresas, destacaría el esfuerzo que se debería realizar desde las universidades para adaptarse a las demandas de digitalización (implementación de metodología BIM) y sostenibilidad del sector (reto de reducción emisiones CO2 y eficiencia energética). Asegurar que los egresados tengan un nivel adecuado en las nuevas exigencias del mercado es asegurar el futuro de la titulación.

\section{Conclusiones}

La profesión de Arquitecto Técnico tiene una componente ligada a la práctica indiscutible y la inclusión de la asignatura de prácticas en empresa en los planes de estudio, permite el acercamiento de los estudiantes a las ocupaciones que puedan desarrollar en el futuro. La firma de convenios con colegios profesionales y asociaciones sectoriales puede fomentar el acercamiento de los estudiantes al sector en el que trabajarán.

Es posible afirmar que la satisfacción de los estudiantes con las prácticas realizadas es muy alta.

El sector está en plena transformación hacia la digitalización y no se debe perder de vista el potencial de los egresados, por lo que es conveniente potenciar estas competencias, no solo en la parte de desarrollo de proyecto sino en aspectos de gestión, planificación, costes, 
sostenibilidad. En el ámbito BIM, se podría equiparar a las dimensiones: 4D (planificación), 5D (costes), 6D (sostenibilidad) y 7D (gestión vida útil)

De otra parte, y en ámbito de la sostenibilidad que se le requiere al sector de la edificación, la Comisión Europea ha fijado el ambicioso objetivo europeo de neutralidad climática para 2050 en el marco del Pacto Verde de la UE. Los edificios son responsables del $40 \%$ del consumo de energía en la Unión Europea. Dado que el $90 \%$ de los edificios que existen en la actualidad seguirán en pie dentro de 30 años, la renovación del parque de edificios existente es clave para lograr los objetivos de descarbonización. Así la rehabilitación energética y la descarbonización se han convertido en pilares básicos del sector, de desarrollo profesional y de la actividad que se desarrollará en los próximos años.

En este escenario, en el que las empresas requerirán egresados altamente preparados y volviendo a la necesaria práctica de los estudiantes de este grado, es necesario seguir trabajando, en favorecer desde la universidad, un modelo formativo híbrido, entre los conocimientos académicos y los conocimientos prácticos vinculados a la profesión o ámbito laboral.

Más allá de una asignatura en el plan de estudios, se podría tomar como referencia una posible formación universitaria dual o el ejemplo que supone el Doctorado Industrial, por el que la tesis es desarrollada en el seno de una empresa. Éstas u otras herramientas deben permitir una mayor preparación de los estudiantes, elevar sus competencias y mejorar la visibilidad y empleabilidad de los egresados.

\section{Referencias}

UNIVERSIDAD POLITÉCNICA DE CARTAGENA (2021). Plan de Estudios del Grado en Ingeniería de Edificación < https://www.upct.es/estudios/grado/5021/plan_estudios.php> [Consulta: 24 de junio de 2021] [UPCT]

UNIVERSIDAD POLITÉCNICA DE CARTAGENA (2021). Aplicación de gestión de prácticas en empresa < https://pem.upct.es/practicas> [Consulta: 24 de junio de 2021] [UPCT]

[COL·LEGI D'APARELLADORS, ARQUITECTES TECNICS I ENGINYERS D'EDIFCACIO DE BARCELONA (2020). Estudi Perspectiva Professió 2020. <https://www.apabcn.cat/ca_es/colegi/laprofessio/perspectiva/Pagines/estudi-perspectivaprofessio-2020.aspx> [Consulta: 24 de junio de 2021] [CAATEEB] 


\title{
EDIFİCATE
}

I Congreso de Escuelas de Edificación y Arquitectura Técnica de España València, 4 y 5 de noviembre de 2021

Escuela Técnica Superior de Ingeniería de Edificación

Universitat Politècnica de València

Doi: https://doi.org/10.4995/EDIFICATE2021.2021.13578

\section{Una aproximación al desarrollo de un índice neurofisiológico capaz de predecir el rendimiento cognitivo de un alumno a partir del diseño del aula}

\section{An approach to developing a neurophysiological index capable of predicting a student's cognitive performance from classroom design}

\author{
Juan Luis Higuera Trujilloa ${ }^{a}$ Adrián Colomer Granerob ${ }^{b}$ Valeriana Naranjo Ornedoc y \\ Carmen Llinares Millán ${ }^{d}$ \\ ${ }^{a}$ Escuela Técnica Superior de Ingeniería de la Edificación, jlhiguera@i3b.upv.es, 'Instituto de \\ Investigación e Innovación en Bioingeniería, adcogra@i3b.upv.es, 'Instituto de Investigación e \\ Innovación en Bioingeniería, vnaranjo@dcom.upv.es y đEscuela Técnica Superior de Ingeniería de la \\ Edificación, cllinare@omp.upv.es
}

\begin{abstract}
Classroom design influences cognitive functions such as memory and attention. This relationship between environment and performance is complex, and the cognitive and neurophysiological effects are closely intertwined. The aim of this paper is to lay the foundations for a methodology capable of assessing the impact of classroom design on students' attention and memory, using automated cognitive indices based on neurophysiological measures. To this end, a laboratory study was carried out in which 50 subjects performed cognitive tests in virtual environments with different design configurations. During the tests, their psychological responses (attention and memory performance) and neurophysiological responses (electrocardiogram, electroencephalogram, and electrodermal response) were recorded. After processing the signals and extracting different metrics, correlations between the two types of responses were studied. This provided a basis of relationships for the future choice of metrics with which to train predictive models. The use of Artificial Intelligence will make it possible to automatically quantify the impact of classroom design on students' attention and memory, using indices based on neurophysiological measures.
\end{abstract}

Keywords: design, psychological response, neurophysiological response, artificial intelligence. 


\section{Resumen}

El diseño del aula influye en las funciones cognitivas, como la memoria y la atención. Esta relación entre entorno y rendimiento es compleja, y los efectos cognitivos y neurofisiológicos están estrechamente entrelazados. El objetivo del presente trabajo es centrar las bases de una metodología capaz de evaluar el impacto del diseño del aula en la atención y memoria de los alumnos, a partir de índices cognitivos automatizados basados en medidas neurofisiológicas. Para ello se llevó a cabo un estudio en laboratorio, en el que 50 sujetos realizaron pruebas cognitivas en entornos virtuales con diferentes configuraciones de diseño. Durante estas se registraron sus respuestas psicológicas (relativas al rendimiento en atención y memoria) y respuestas neurofisiológicas (electrocardiograma, electroencefalograma, y respuesta electrodérmica). Tras el tratamiento de las señales y la extracción de distintas métricas, se estudiaron las correlaciones entre ambos tipos de respuestas. Esto ofreció una base de relaciones para la futura elección de métricas con las que entrenar modelos predictivos. El uso de Inteligencia Artificial permitirá cuantificar de manera automática el impacto del diseño del aula en la atención y memoria de los alumnos, a partir de índices basados en medidas neurofisiológicas.

Palabras clave: diseño, respuesta psicológica, respuesta neurofisiológica, inteligencia artificial 


\section{Introducción}

Son muchos los estudios que han demostrado que los estímulos físicos del aula pueden influir en las funciones cognitivas determinantes del aprendizaje, la memoria y la atención (Choi et al., 2015). Estos importantes efectos han dado lugar a un creciente interés por analizar la relación entorno físico-aprendizaje.

Una gran parte de estos trabajos se ha centrado en los atributos ambientales, como la temperatura, la calidad del aire, o la acústica. Con respecto a la acústica del aula, Crandell y Smaldino (2000) y Picard y Bradley (2001) identificaron varias variables, como el ruido, la reverberación y la distancia entre el hablante y el oyente, que afectaban negativamente al proceso de aprendizaje. Por lo que se refiere a la iluminación, Tanner (2009) y Heschong et al. (2002) identificaron la influencia significativa de la luz natural en actividades de lectura y de ciencias, así como que las ventanas grandes estaban asociadas con mejores resultados de aprendizaje. Otra variable visual muy estudiada ha sido el color, por su impacto en el desempeño de las actividades de los estudiantes (Küller et al., 2009). Así, se ha demostrado que en tareas de lectura y escritura se cometen más errores en los espacios blancos que en aquellos coloreados (Kwallek et al., 1996). Esta relación entre el entorno y el rendimiento cognitivo es compleja debido a su carácter multidimensional (Higgins et al. 2005), y a que los efectos cognitivos, fisiológicos y afectivos que genera el entorno físico pueden estar estrechamente entrelazados (Evans y Stecker 2004).

En este sentido, resulta complejo medir el rendimiento cognitivo y no existe una metodología universalmente aceptada. El sistema tradicional de medición de estas funciones cognitivas es mediante el empleo de tests psicométricos. Sin embargo, este sistema resulta incompleto ya que no recoge el componente involuntario del sujeto. Hay que tener en cuenta que los estados cognitivo-emocionales se caracterizan por respuestas tanto psicológicas como fisiológicas (Izar, 1992). La medición neurofisiológica permite registrar datos no manipulables conscientemente por los sujetos (Dimoka et al., 2012), y en tiempo real mientras el sujeto ejecuta una tarea o responde a un estímulo específico.

Se sabe por ejemplo que las oscilaciones cerebrales pueden correlacionarse con múltiples funciones que incluyen registro y seguimiento sensorial, percepción, movimiento y procesos cognitivos relacionados con la atención, el aprendizaje y la memoria (Basar, 1999). Así, Cho et al., (2002) desarrollaron un sistema de mejora de la atención y concentración utilizando el electroencefalograma (EEG) en un aula virtual en la que se eliminaban distractores. Ko et al. (2017) encontraron una relación entre las variaciones de las señales de EEG y el nivel de atención sostenida en el aula, medida con los tiempos de respuesta realizando una tarea. Otros autores como Shah et al. (2011) encontraron una relación positiva entre las medidas de variabilidad del ritmo cardiaco (HRV) y el aprendizaje y la memoria verbal, pero no con la memoria visual. Hansen et al. (2003) observaron mejor desempeño de las tareas de memoria y atención con mayores niveles de HRV. 


\section{Objetivo}

El objetivo del presente trabajo es centrar las bases de una metodología capaz de evaluar el impacto del diseño del aula en la atención y memoria del alumnado, a partir de índices cognitivos automatizados basados en medidas neurofisiológicas. Estos índices serán capaces de caracterizar el rendimiento cognitivo de un sujeto ante un espacio concreto. Esto es: ante un determinado diseño de aula (real o virtual), se podría predecir el rendimiento cognitivo de los estudiantes en base a la respuesta neurofisiológica. Dada la magnitud del objetivo general del trabajo, se plantea un estudio piloto como prueba inicial.

\section{Material y Métodos}

La metodología se basó en un estudio en laboratorio, con las siguientes características:

\subsection{Muestra}

La muestra estaba formada por 50 sujetos ( $55 \%$ hombres- $45 \%$ mujeres), con una edad media de 20.06 años $(\sigma=3.122)$. Para formar parte de la muestra se marcaron cuatro criterios de inclusión: ser estudiante universitario, español (para evitar posibles efectos culturales), tener entre 18 y 23 años (edades más frecuentes en los grados universitarios de España) y no tener dificultades en la apreciación de los colores.

\subsection{Estímulos}

Como estímulo base se tomó la réplica virtual inmersiva de un aula física representativa. Concretamente, un aula de la Escuela Técnica Superior de Ingeniería de la Edificación (ETSIE) de la Universitat Politècnica de València. Sobre esta aula base se desarrollaron 34 configuraciones de diseño, con la siguiente clasificación:

- Variable forma. Con tres medidas para la altura del techo: $3.8 \mathrm{~m}, 3.2 \mathrm{~m}$ y $2.6 \mathrm{~m}$; y otras tres para la anchura: $8.8 \mathrm{~m}, 8.2 \mathrm{~m}$ y $7.6 \mathrm{~m}$.

- Variable iluminación. Con tres medidas para la iluminancia: $1001 x, 3001 x$ y 500lx; y otras tres para la temperatura del color: $3000 \mathrm{~K}, 4000 \mathrm{~K}$ y $6500 \mathrm{~K}$.

- Variable color. Con 8 tonos, divididos a su vez en fríos (5BG, 5PB, 5P, 5GY) y cálidos (5RP, 5R, 5YR, 5Y); y 2 saturaciones: alta (entre 10 y 16 unidades en Munsell chroma) y baja (entre 4 y 10 unidades).

Los sujetos experimentaron los espacios visualizando las simulaciones mediante el dispositivo HTC Vive.

\subsection{Análisis de datos}

De cada sujeto se registraron datos psicológicos y neurofisiológicos, además de un cuestionario demográfico básico. 


\section{Datos psicológicos}

Tarea de memoria. Esta tarea consistió en la memorización de un conjunto de palabras, basado en el estudio de Alonso y su equipo (2004). En concreto el sujeto debía escuchar 3 audios, cada uno de ellos con una lista de 15 palabras relacionadas entre sí. Las listas se presentaron contrabalanceadas. El sujeto debía escucharlas y repetirlas en un tiempo máximo de $30 \mathrm{seg}$, antes de avanzar a la siguiente lista. Posteriormente se anotaba el número de aciertos de cada lista. El número de palabras recordadas fue corregido según la tasa de recuerdo propuesta por Alonso et al (2004).

Tarea de atención. Esta tarea consistía en reaccionar lo antes posible ante un estímulo auditivo concreto con un clic de ratón (objetivo) y evitar hacerlo ante otros cuatro (distractores), similar a las pruebas de rendimiento auditivo continuo (Seidman et al., 1998). En total la tarea contaba con 8 objetivos y 32 distractores, y el tiempo entre estímulos era de $800 \mathrm{~ms}$ a $1600 \mathrm{~ms}$. Los sujetos tenían $750 \mathrm{~ms}$ para reaccionar a los estímulos, pasados los cuales se consideraba un error (al igual que reaccionar ante un estímulo distractor). Se registró el tiempo de reacción ante los estímulos objetivos y el número de errores cometidos. Esto se repetía en 3 ocasiones para cada entorno simulado, con 1500 ms entre sets.

\section{Datos neurofisiológicos}

Variabilidad del ritmo cardiaco (HRV). Mide variaciones en los intervalos entre latidos (Goldman, 1976). La variación del ritmo cardiaco a lo largo del tiempo (HRV) ha demostrado en diversos estudios tener una relación con los sistemas simpático y parasimpático y, a través de ellos, con la actividad cognitiva (Mann et al., 2015) y el control atencional (Ramírez et al., 2015). Para el registro de los datos HRV se utilizó un dispositivo b-Alert X10 (Figura 1).

Electroencefalograma (EEG). Mide variaciones en la actividad eléctrica de la superficie del cuero cabelludo (Niedermeyer y da Silva, 2005). Su análisis generalmente implica la clasificación de la señal dentro de bandas de frecuencia definidas, sobre la base de que el cerebro está formado por diferentes redes que operan en su frecuencia (Mohammadi et al., 2017). El EEG se ha utilizado para estudiar, por ejemplo, la carga de trabajo mental (Lotte et al., 2018). Para el registro del electroencefalograma se utilizó el dispositivo b-Alert x10 (ver Figura 1).

Actividad electrodérmica (EDA). Mide variaciones en la sudoración de la piel (Boucsein, 2012). Estos datos se obtienen a partir de las propiedades eléctricas de la piel del sujeto ya que varían con la actividad de las glándulas sudoríparas debido al estrés o la excitación emocional. Cuando una persona suda, la conductividad de su piel cambia y la activación de las glándulas sudoríparas ecrinas es un indicador de activación del sistema simpático. El dispositivo Shimmer 3GSR+ se utilizó para registrar la señal (Figura 1.). 

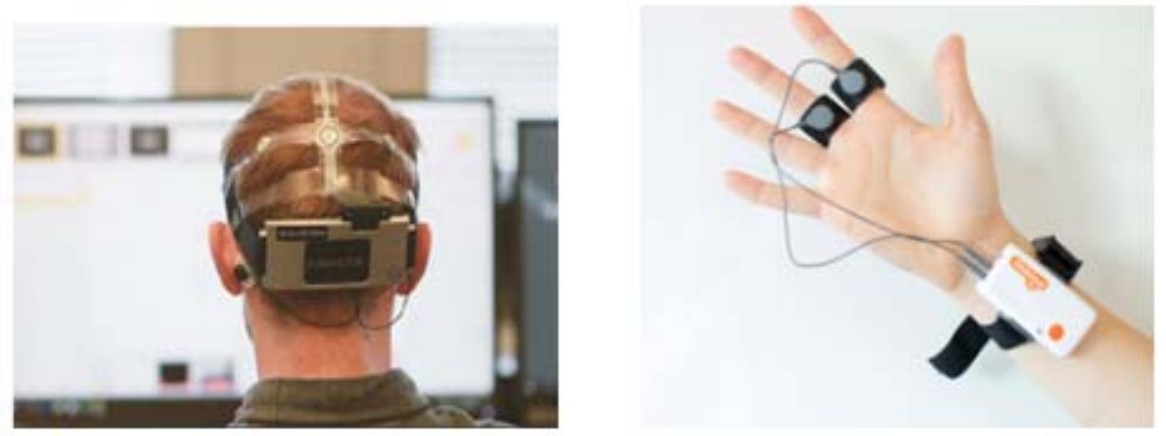

Fig. 1 Dispositivos b-Alert (izquierda) y Shimmer 3 GSR+ (derecha)

\section{Análisis de señales neurofisiológicas}

La metodología se puede dividir en dos grandes fases. La primera de ellas tiene como objetivo la reducción de ruido y artefactos que incluyen los registros fisiológicos adquiridos. La segunda es la responsable de extraer las características más relevantes de las bioseñales que puedan cuantificar de manera automática las capacidades bajo estudio del alumnado.

\subsection{Acondicionamiento de los registros neurofisiológicos}

Por lo que respecta a la señal electrocardiográfica, en este trabajo se aplicaron una serie de procesos de filtrado de las señales cardíacas encargados de reducir el ruido debido al movimiento del electrodo, el producido por el contacto electrodo-piel, el desplazamiento de la línea base del registro, las posibles contribuciones indeseadas por contracciones musculares y la interferencia de la red eléctrica.

Debido a la naturaleza de la señal electroencefalográfica, el proceso de reducción de ruido y eliminación de artefactos de esta es un proceso complejo que no solo requiere de un banco de filtros. Se hace necesaria una descomposición de componentes de señal independientes (ICA de sus siglas en inglés) (Hyvärinen, 2000) para poder aislar con éxito la señal cerebral útil del resto de señal indeseada.

Por último, cabe mencionar que la morfología del registro electrodérmico hace que tan sólo se precise de un filtro paso bajo que elimine las altas frecuencias.

\subsection{Extracción de métricas neurofisiológicas basadas en}

Variabilidad del ritmo cardiaco (HRV). En este trabajo se extrajeron métricas en el rango de la alta frecuencia de la señal (HF) $(0.15-0.4 \mathrm{~Hz})$ relacionada con la activación del sistema parasimpático o incremento de la relajación, y la baja frecuencia (LF) $(0.05-0.15 \mathrm{~Hz})$ relacionada con la activación del sistema simpático o incremento de la excitación. Más concretamente, se extraen diversos descriptores de señal en cuatro dimensiones o dominios (tiempo, frecuencia, tiempo-frecuencia y análisis no lineal), que se recogen en la 
guía acerca de la medición clínica del HRV que realizó la Sociedad Americana de Cardiología (1996).

Electroencefalograma (EEG). En este estudio se calcularon varias métricas: la banda Beta (13-30 Hz) de los electrodos $\mathrm{C} 3$ y Cz relacionados con la atención (Egner y Gruzelier, 2011), la banda Highbeta $(21-30 \mathrm{~Hz})$ relacionada a su vez con el estado de alerta (Choi et al., 2015) de los electrodos F3, Fz y Cz, que podrían ser indicadores de la memoria de trabajo y de la atención (Marzbani et al., 2016). Más concretamente se extraen índices de atención y memoria cuantificando el nivel de actividad cerebral en cada banda de frecuencia mediante la métrica Global Field Power propuesta por Lehmann (1980), ampliamente extendida en el ámbito de la neurociencia. Se cuantificaron las medias durante cada experiencia.

Actividad electrodémica (EDA). En este estudio el análisis permitió discernir la componente fásica de la señal, relacionada con la atención a estímulos (Raskin, 1973).

\subsection{Análisis estadístico}

De manera complementaria, y previamente al futuro desarrollo del modelo predictivo, se estudió mediante análisis estadístico la relación entre las métricas neurofisiológicas extraídas y el rendimiento cognitivo en atención y memoria. Para ello, se aplicó el coeficiente de correlación de Spearman entre los datos neurofisiológicos y las variables de atención y memoria.

\section{Resultados}

Las siguientes métricas neurofisiológicas permitirian registrar datos sin posibilidad de manipulación por parte del sujeto y en tiempo real.

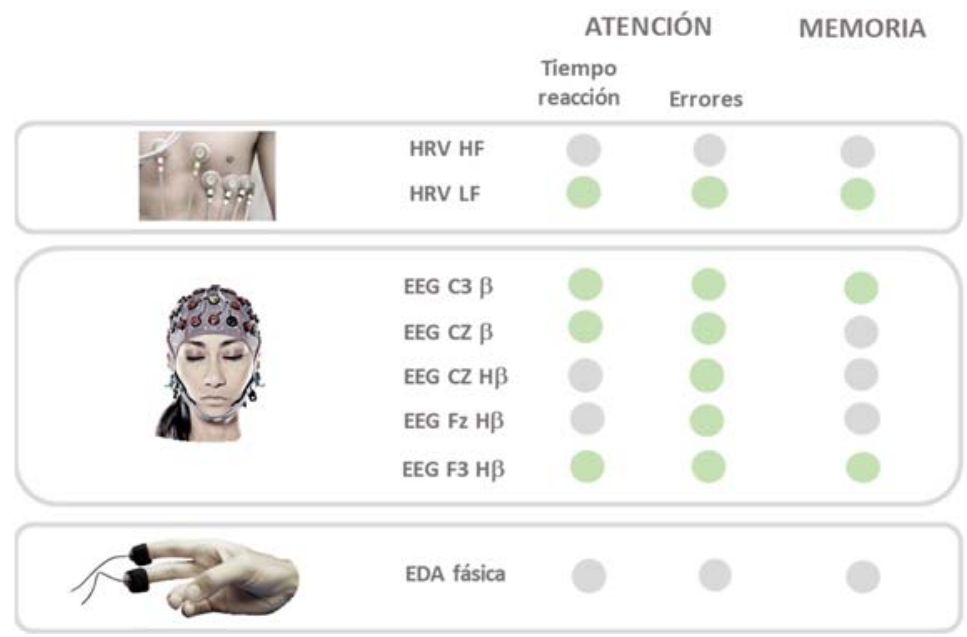

Fig. 2. Combinación de métricas neurofisiológicas integrantes de los índices cognitivos de atención y memoria 
Una aproximación al desarrollo de un índice neurofisiológico capaz de predecir el rendimiento cognitivo de un alumno a partir del diseño del aula - An approach to developing a neurophysiological index capable of predicting a student's cognitive performance from classroom design

\section{Conclusiones}

Existe un creciente interés en otros campos de investigación en obtener datos objetivos directamente del cuerpo humano para medir la respuesta del sujeto cuando las personas participan en diversas actividades o reaccionan a diferentes estímulos, integrando bases neurofisiológicas con diseño y tecnología. La medición neurofisiológica permite registrar datos confiables que son difíciles o imposibles de obtener con herramientas tradicionales, como las pruebas psicométricas. Por una parte, los sujetos no pueden manipular conscientemente sus respuestas, y además permite la medición continúa registrando datos en tiempo real mientras el sujeto ejecuta una tarea o responde a un estímulo específico.

\section{Agradecimientos}

Este trabajo ha sido financiado por el Ministerio de Economía, Industria y Competitividad de España (Proyecto BIA2017-86157-R; PRE2018-084051).

\section{Referencias}

ALONSO, M. Á., FERNANDEZ, Á., DIEZ, E., y BEATO, M. S. (2004). "Índices de producción de falso recuerdo y falso reconocimiento para 55 listas de palabras en castellano" en Psicothema, vol. $16, \mathrm{n}^{\circ}$ 3, p. 357-362.

BASAR, E., (1999). Brain function and oscillations. II. Integrative brain function. Neurophysiology and cognitive processes, Berlin Heidelberg: Springer.

BOUCSEIN, W. (2012). Electrodermal activity, 2nd ed. Newsbury Park, London, New Dehli: Springer Science \& Business Media.

CRANDELL, C. C., y SMALDINO, J. J. (2000). "Classroom acoustics for children with normal hearing and with hearing impairment" en Language, Speech \& Hearing services in schools, vol. 31, $\mathrm{n}^{\circ} 4, \mathrm{p}$. 362-370.

CHO, B. H., LEE, J. M., KU, J. H., JANG, D. P., KIM, J. S., KIM, I. Y., ... y KIM, S. I. (2002b). "Attention enhancement system using virtual reality and EEG biofeedback" en Proceedings IEEE Virtual Reality (156-163). Orlando, USA.

CHOI, Y., KIM, M., y CHUN, C. (2015). "Measurement of occupants' stress based on electroencephalograms (EEG) in twelve combined environments" en Building \& Environment, vol. 88, p. 65-72.

DIMOKA, A., DAVIS, F. D., GUPTA, A., PAVLOU, P. A., BANKER, R. D., DENNIS, A. R., ...y KENNING, P. H. (2012). "On the use of neurophysiological tools in IS research: Developing a research agenda for NeurolS" en MIS quarterly, vol. 36, n 3, p. 679-702.

EGNER, T., y GRUZELIER, J. H. (2011). "Learned self-regulation of EEG frequency components affects attention and event-related brain potentials in humans" en Neuroreport, vol. 12, $\mathrm{n}^{\circ} 18, \mathrm{p}$. 415 . 
EVANS, G. W., y STECKER, R. (2004). "Motivational consequences of environmental stress" en Journal of Environmental Psychology, vol. 24, n² 2, p. 143-165.

GOLDMAN, M. (1976). Principles of clinical electrocardiography. Los Altos, USA: LANGE.

HANSEN, A. L., JOHNSEN, B. H., y THAYER, J. F. (2003). "Vagal influence on working memory and attention" en International Journal of Psychophysiology, vol. 48, n 3, p. 263-274.

HESCHONG, L., WRIGHT, R. y OKURA, S. (2002). "Daylighting impacts on human performance in school" en Journal of the Illuminating Engineering Society, vol. 31, $n^{\circ} 2$, p. 101-114.

HIGGINS, S., HALL, E., WALL, K., WOOLNER, P., y MCCAUGHEY, C. (2005). The impact of school environments: a literature review, London: Design Council.

HYVÄRINEN A. y OJA E. (2000). "Independent component analysis: Algorithms and applications" en Neural Networks, vol. 13, n 4-5, pp. 411-430.

IZARD, C. E. (1992). "Basic emotions, relations among emotions, and emotion cognition relations" en Psychological Review, vol. 99, n³, p. 561-565.

KO, L. W., KOMAROV, O., HAIRSTON, W. D., JUNG, T. P., y LIN, C. T. (2017). "Sustained attention in real classroom settings: An EEG study" en Frontiers in Human Neuroscience, vol 11, p. 388.

KÜLLER, R., MIKELLIDES, B., y JANSSENS, J. (2009). "Color, arousal, and performance-A comparison of three experiments" en Color Research \& Application, vol. 34, n² 2, p. 141-152.

KWALLEK, N., LEWIS, C. M., LIN-HSIAO, J. W. D., y WOODSON, H. (1996). "Effects of nine monochromatic office interior colors on clerical tasks and worker mood" en Color Research \& Application, vol. 21, $\mathrm{n}^{\circ}$ 6, p. 448-458.

LEHMANN, W. S. D. (1980). "Reference-free identification of components of checkerboard-evoked multichannel potential fields" en Electroencephalography and clinical neurophysiology, vol. 48, $\mathrm{n}^{\circ} 6$, pp. 609-621.

LOTTE, F., BOUGRAIN, L., CICHOCKI, A., CLERC, M., CONGEDO, M., RAKOTOMAMONJY, A., y YGER, F. (2018). "A review of classification algorithms for EEG-based brain-computer interfaces: a 10 year update" en Journal of Neural Engineering, vol. 15, n 3, p. 31005.

MANN, S. L., SELBY, E. A., BATES, M. E., y CONTRADA, R. J. (2015). "Integrating affective and cognitive correlates of heart rate variability: A structural equation modeling approach" en International Journal of Psychophysiology, vol. 98, $\mathrm{n}^{\circ}$ 1, p. 76-86.

MARZBANI, H., MARATEB, H. R., y MANSOURIAN, M. (2016). "Neurofeedback: a comprehensive review on system design, methodology and clinical applications" en Basic and Clinical Neuroscience, vol. 7, $\mathrm{n}^{\circ} 2$, p.143-158.

MOHAMMADI, Z., FROUNCHI, J., \& AMIRI, M. (2017). "Wavelet-based emotion recognition system using EEG signal" en Neural Computing, vol. 28, nº 8, p. 1985-1990.

NIEDERMEYER, E., y DA SILVA, F. L. (2005). Electroencephalography: basic principles, clinical applications, and related fields. Philadelphia, USA: Lippincott Williams \& Wilkins. 
Una aproximación al desarrollo de un índice neurofisiológico capaz de predecir el rendimiento cognitivo de un alumno a partir del diseño del aula - An approach to developing a neurophysiological index capable of predicting a student's cognitive performance from classroom design

PICARD, M., Y BRADLEY, J. S. (2001). "Revisiting speech Interference in classrooms: revisando la interferencia en el habla dentro del salón de clases" en Audiology, vol. 40, n 5, p. 221-244.

RAMIREZ, E., ORTEGA, A. R., y DEL PASO, G. A. R. (2015). "Anxiety, attention, and decision making: The moderating role of heart rate variability" en International Journal of Psychophysiology, vol. 98, $n^{\circ} 3$, p. 490-496.

RASKIN, D.C. (1973). Attention and arousal. En W. F. Prokasy \& D. C. Raskin (Eds.), Electrodermal activity in psychological research (pp. 123-156), London, UK: Academic Press.

SHAH, A. J., SU, S., VELEDAR, E., BREMNER, J. D., GOLDSTEIN, F. C., LAMPERT, R., ... y VACCARINO, V. (2011). "Is heart rate variability related to memory performance in middle aged men?" en Psychosomatic Medicine, vol. 3, n 6, p. 475.

SEIDMAN, L. J., BREITER, H. C., GOODMAN, J. M., GOLDSTEIN, J. M., WOODRUFF, P. W., O'CRAVEN, K., ... ROSEN, B. R. (1998). "A functional magnetic resonance imaging study of auditory vigilance with low and high information processing demand" en Neuropsychology, vol. 12, $n^{\circ} 4$, p. 505-518.

SOCIEDAD AMERICANA DE CARDIOLOGÍA. (1996). "Task force of the european society of cardiology and the north american society of pacing and electrophysiology" en European Heart Journal, vol. 17, pp. 354-381.

TANNER, C. K. (2000). "The influence of school architecture on academic achievement" en Journal of Educational Administration, vol. 38, n 4, p. 309-330. 


\title{
EDIFICATE
}

I Congreso de Escuelas de Edificación y Arquitectura Técnica de España València, 4 y 5 de noviembre de 2021

Escuela Técnica Superior de Ingeniería de Edificación

Universitat Politècnica de València

Doi: https://doi.org/10.4995/EDIFICATE2021.2021.13588

\section{Observatorio 2020 de la producción científica de la Arquitectura} Técnica en España. Análisis de la evolución de la Investigación en Arquitectura Técnica en la Universidad española

\section{Spanish Technical Architecture and Building Engineering Monitoring Center of Scientific Output (2020 Edition). Analysis of the evolution of Research in Technical Architecture at the Spanish University.}

\author{
Joaquín Manuel Durán Álvarez ${ }^{a}$ \\ aUniversidad de Granada. jdaeuat@ugr.es
}

\begin{abstract}
For the last 6 years the Observatory of the Scientific Production of Technical Architecture has been compiled, analysing Universities, teachers and researchers of Technical Architects. In these years there has been an evolution of both the type of teaching staff and researchers and of the scientific production in $T A$.
\end{abstract}

The 2020 Observatory presents the situation of each University and the chronological evolution of professor, doctors, researchers and scientific production.

The aim of this paper is to analyze this evolution through the types of hiring of professors, the number of PhDs and their impact on scientific production. The strengths and weaknesses of Technical Architecture in teaching and research, through the bibliometric indexes of the Universities.

Keywords: Bibliometrics, Bibliometrics, Almetrics, Scientific production, Technical Architecture, Building Engineering, University, Research, Spain

\section{Resumen}

Desde hace 6 años se elabora el Observatorio de la Producción Científica de la Arquitectura Técnica (AT), que analiza a docentes e investigadores Arquitectos Técnicos de las universidades españolas. En estos años ha habido una evolución del tipo de docente, así como de los investigadores y su producción científica en la $A T$. 
El Observatorio 2020 es la última actualización, recogiendo la la situación de actual cada universidad, así como la evolución cronológica de las características curriculares de su profesorado y de la producción científica de sus investigadores.

En este trabajo se pretende analizar dicha evolución a través de los tipos de contratatación en los docentes, el número de doctores y su repercusión en la producción científica. Por otro lado, a través de los índices bibliométricos de las universidades españolas, se indentifican las fortalezas y debilidades de la AT en docencia e investigación.

Palabras clave: Bibliometría, Almetrics, Producción científica, Arquitectura Técnica, Ingeniería de Edificación, Universidad, Investigación, España 


\section{Introducción}

La Arquitectura Técnica $\left(\mathrm{AT}^{1}\right)$ es una profesión con largo recorrido, teniendo sus orígenes en la figura del aparejador. Las primeras referencias datan de hace más de 600 años, y a lo largo de su historia ha sufrido diferenes avatares de competencias, denominación y mercado de trabajo, pero siempre con una identificación única. Esta disciplina forma parte de la rama Ingeniería y Arquitectura de la Agencia Nacional de Evaluación de la Acreditación y Acreditación (ANECA) y, durante mucho tiempo, su corpus documental se ha ceñido sobre todo a informes técnicos, artículos de divulgación y proyectos. En los últimos, y desde dentro de la universidad, los docentes AT han ido obteniendo el doctorado, se han establecido en grupos de investigación con producción científica y su carrera como investigadores ha aumentado exponencialmente.

A lo largo de estos últimos 6 años, se ha ido recogiendo y analizando la producción científica de la AT (Durán, 2020), recogiendo en índices bibliométricos y Altmétricos, y en rankings la evolución de la investigación realizada por AT por universidades e investigadores. Además, se han registrado los docentes AT en activo en las universidades en el año 2020.

Partiendo de este banco de datos, se puede establer las correlaciones entre número de docentes, tipos de contratos, producción científica y tesis doctorales, para así realizar un estudio de una disciplina como la AT, a caballo entre Ingeniería y Arquitectura.

El análisis de una disciplina a través de su corpus documental es una línea de investigación que se ha utilizado a lo largo del tiempo. Así, a través de las tesis doctorales se ha analizado en el ámbito de la Biblioteconomía (Whitbeck, 1991), o a través de producción científica en general como Marketíng y Psicología (Donthu, Kumar, Pattnaik, y Lim, 2021), Odontología (Castro, 2019), Trabajo Social (Cubillos, 2017), etc.

Aunque el análisis de las instituciones de investigación a través de métodos bibliométricos es una herramienta inadecuada para la evaluación del rendimiento en investigación (Van Raan, 2005), si se utilizan correctamente, son un dispositivo de control de la gestión de la investigación universitaria y la política científica (Moed, Burger, Frankfort, y Van Raan, 1985).

Además, estas medidas de productividad en número de documentos publicados, son utilizadas ampliamente por los administradores para los criterios específicos de evaluación (Abbott, et al, 2010). Por otro lado, la productividad es el indicador por excelencia de la eficiencia en cualquier sistema de producción, incluída la investigación (Abramo \& DÁngelo, 2014)

En un estudio realizado sobre esta área en Wos of Science (WOS) (Rojas y San Antonio, 2010), se analizó cuantitativa y cualitativamente la producción científica de las universidades en el área de Construction y Building Tecnology entre 1997-2008. En la Tabla 1, se observa

\footnotetext{
${ }^{1}$ AT.- Arquitectura Técnica; Aparejadores; Grado en Ingeniería de Edificación; Grado en Edificación; Grado en Arquitectura Técnica; Grado en Ciencia y Tecnología de la Edificación; Grado en Arquitectura Técnica y Edificación
} 
los resultados de las universidades que tienen AT y con las variables cuantitativas de número de documentos publicados en WOS y porcentaje sobre el total:

Tabla 1. Ranking de Universidades por Producción en A de WOS

\begin{tabular}{|c|c|c|c|}
\hline \multirow{2}{*}{ Posición } & Institución & Ndoc & $\%$ Ndoc \\
\hline & Total Serie & 760 & 100 \\
\hline 2 & Universidad Politécnica de Madrid & 108 & 14,21 \\
\hline 4 & Universidad Politécnica de Valencia & 46 & 6,05 \\
\hline 5 & Universidad de Alicante & 41 & 5,39 \\
\hline 6 & Universidad de Sevilla & 30 & 3,95 \\
\hline 8 & Universidad de Granada & 26 & 3,42 \\
\hline 11 & Universidad del País Vasco & 18 & 2,37 \\
\hline 12 & Universidad de Castilla-La Mancha & 17 & 2,24 \\
\hline 13 & Universidad de La Coruña & 17 & 2,24 \\
\hline 20 & Universidad Politécnica de Cartagena & 10 & 1,32 \\
\hline 23 & Universidad de Salamanca & 8 & 1,05 \\
\hline 27 & Universidad Jaume I de Castellón & 6 & 0,79 \\
\hline 29 & Universidad de Zaragoza & 6 & 0,79 \\
\hline
\end{tabular}

Como se comprueba entre las 10 primeras están, la UPM, UPV, UAL, USE y UGR.

Este trabajo completa y actualiza el trabajo de Rojas, contrastando este ranking con la producción real de documentos en las distintas universidades de AT.

\section{Objetivos}

El objetivo general es el análisis de las Universidades de AT a través de indicadores cualitativos bibliométricos y la posible correlación entre distintas variables.

Los específicos son:

1. Comprobar las semejanzas de publicación del área de Arquitectura/Ingeniería de la Universidad española con las Universidades de AT

2. Analizar el tipo de estatus docente de los profesores AT en la Universidad española

3. Estudiar el ratio de docentes a tiempo parcial frente a los docentes a tiempo completo

4. Verificar la producción total de documentos científicos por Universidad AT y el ratio por docente 
5. Establecer el ratio doctor/docente en las Universidades de AT y su influencia en la producción científica

\section{Metodología}

Se ha tomado como origen de datos los que recoge el Observatorio AT (2020), eliminando las universidades privadas y las extranjeras, dado que las escalas docentes son distintas a las de la universidad pública. Estos datos han sido obtenidos, primero identificando los docentes AT de toda la Universidad española, registrando su producción científica en WOS, SCOPUS, CSCIC, Researchgate, Google Academic, bases de tesis doctorales, registros de patentes y repositorios universitarios. Después se ha elaborado el informe, estableciendo análisis pormenorizados tanto de Universidad como de investigador.

De dicho Observatorio se han seleccionado los siguientes datos:

$1^{\text {a }}$ Número de docentes en el año 2020 (ver Tabla 2):

Tabla 2. Número de docentes At por Universidad. 2020

\begin{tabular}{|c|c|c|c|}
\hline $\mathbf{N}^{0}$ & UNIVERSIDAD & UNIV. & Num. Docentes \\
\hline 1 & Universidad de Sevilla & USE & 76 \\
\hline 2 & Universidad Politécnica de Madrid & UPM & 56 \\
\hline 3 & Universidad de Granada & UGR & 42 \\
\hline 4 & Universidad Politécnica de Valencia & UPV & 33 \\
\hline 5 & Universidad de la Laguna & ULL & 26 \\
\hline 6 & Universidad de Burgos & UBU & 20 \\
\hline 7 & Universidad de A Coruña & UDC & 19 \\
\hline 8 & Universidad de Alicante & UAL & 18 \\
\hline 9 & Universidad de Girona & UDG & 16 \\
\hline 10 & Universidad Politécnica de Cartagena & UPCT & 14 \\
\hline 11 & Universidad de Alcalá de Henares & $\mathrm{UAH}$ & 11 \\
\hline 12 & Universidad de Castilla-La Mancha & UCLM & 10 \\
\hline 13 & Universidad Jaume I & UJI & 9 \\
\hline 14 & Universidad de las Islas Baleares & UIB & 8 \\
\hline 15 & Universidad de Lleida & UDL & 7 \\
\hline 16 & Universidad de Extremadura & UNEX & 6 \\
\hline 17 & Universidad de Zaragoza & UZAR & 6 \\
\hline 18 & Universidad de Salamanca & USAL & 6 \\
\hline 19 & Universidad del País Vasco & UPVA & 4 \\
\hline
\end{tabular}

$2^{\mathrm{a}}$ Docentes AT con tesis doctoral: número de doctores por universidad y por porcentaje Doctores/Docentes (ver Tabla 3): 
Observatorio 2020 de la producción científica de la Arquitectura Técnica en España. Análisis y evolución de la investigación - Spanish Technical Architecture and Building Engineering Monitoring Center of Scientific Output (2020 Edition). Analysis and evolution of research

Tabla 3. Número de doctores y docentes AT por Universidad AT. 2020

\begin{tabular}{|llcccc}
\hline$N^{\circ}$ & \multicolumn{1}{c}{ UNIVERSIDAD } & UNIV. & $\begin{array}{c}\text { Docentes } \\
\text { Doctores }\end{array}$ & Docentes & $\begin{array}{c}\% \\
\text { Doct/Docentes }\end{array}$ \\
\hline 1 & Universidad de Alicante & UAL & 14 & 18 & $77,78 \%$ \\
2 & Universidad del País Vasco & UPVA & 3 & 4 & $75,00 \%$ \\
3 & Universidad de Sevilla & USE & 50 & 76 & $65,79 \%$ \\
4 & Universidad Politécnica de Valencia & UPV & 21 & 33 & $63,64 \%$ \\
5 & Universidad de Granada & UGR & 24 & 42 & $57,14 \%$ \\
6 & Universidad Jaume I & UJI & 5 & 9 & $55,56 \%$ \\
7 & Universidad Politécnica de Madrid & UPM & 28 & 56 & $50,00 \%$ \\
8 & Universidad de Burgos & UBU & 10 & 20 & $50,00 \%$ \\
9 & Universidad de las Islas Baleares & UIB & 4 & 8 & $50,00 \%$ \\
10 & Universidad de la Laguna & ULL & 11 & 26 & $42,31 \%$ \\
11 & Universidad da Coruña & UDC & 8 & 19 & $42,11 \%$ \\
12 & Universidad de Castilla-La Mancha & UCLM & 4 & 10 & $40,00 \%$ \\
13 & Universidad de Girona & UDG & 6 & 16 & $37,50 \%$ \\
14 & Universidad de Extremadura & UNEX & 2 & 6 & $33,33 \%$ \\
15 & Universidad de Salamanca & USAL & 2 & 6 & $33,33 \%$ \\
16 & Universidad de Zaragoza & UZAR & 2 & 6 & $33,33 \%$ \\
17 & Universidad Politécnica de Cartagena & UPCT & 4 & 14 & $28,57 \%$ \\
18 & Universidad de Alcalá & UAH & 2 & 11 & $18,18 \%$ \\
19 & Universidad de Lleida & UDL & 1 & 7 & $14,29 \%$ \\
\hline
\end{tabular}

$3^{a}$ Presenta el número de documentos de investigación por docente, así como la universidad a la que pertenecen (Tabla4):

Tabla 4. Documentos de investigación e investigadores AT por Universidad. Histórico

\begin{tabular}{|clcccc}
\hline$N^{\circ}$ & UNIVERSIDAD & UNIV. & $\begin{array}{c}\text { Núm. } \\
\text { Documentos } \\
\text { Total }\end{array}$ & $\begin{array}{c}\text { Núm. } \\
\text { Autor. } \\
\text { Investig }\end{array}$ & $\begin{array}{c}\text { Docum / } \\
\text { Autor }\end{array}$ \\
\hline 1 & Universidad de Burgos & UBU & 379 & 14 & 27,07 \\
\hline 2 & Universidad Jaume I & UJI & 172 & 10 & 17,20 \\
\hline 3 & Universidad de Extremadura & UNEX & 63 & 5 & 12,60 \\
\hline 4 & Universidad de Lleida & UDL & 47 & 4 & 11,75 \\
\hline 5 & Universidad Politécnica de Madrid & UPM & 560 & 51 & 10,98 \\
\hline 6 & Universidad de Alicante & UAL & 218 & 22 & 9,91 \\
\hline 7 & Universidad de Granada & UGR & 323 & 38 & 8,50 \\
\hline 8 & Universidad de Sevilla & USE & 521 & 68 & 7,66 \\
\hline 9 & Universidad Politécnica de Valencia & UPV & 199 & 31 & 6,42 \\
\hline 10 & Universidad de la Laguna & ULL & 102 & 17 & 6,00 \\
\hline 11 & Universidad Politécnica de Cartagena & UPCT & 46 & 8 & 5,75 \\
\hline 12 & Universidad del País Vasco & UPVA & 14 & 3 & 4,67 \\
\hline
\end{tabular}




\begin{tabular}{|llcccc}
13 & Universidad de Zaragoza & UZAR & 20 & 5 & 4,00 \\
\hline 14 & Universidad de Alcalá & UAH & 7 & 2 & 3,50 \\
\hline 15 & Universidad da Coruña & UDC & 40 & 12 & 3,33 \\
16 & Universidad de Girona & UDG & 32 & 10 & 3,20 \\
17 & Universidad de las Islas Baleares & UIB & 16 & 5 & 3,20 \\
18 & Universidad de Castilla-La Mancha & UCLM & 22 & 7 & 3,14 \\
\hline 19 & Universidad de Salamanca & USAL & 12 & 4 & 3,00 \\
\hline
\end{tabular}

Tomando como punto de partida los datos recogidos en las tablas anteriores, se van a correlacionar con los obtenidos por Rojas y San Antonio (Rojas Sola \& San Antonio Gómez, 2010) con el fin de analizar la producción científica según tipo de contrato de docentes por universidad, doctores y producción científica.

\section{Resultados}

Inicialmente se ha cotejado la información sobre la variable cuantitativa de producción científica en el área de Construction y Building Tecnology, publicada por José Carlos San Antonio y José Ignacio R. (2010) y los datos extraídos del Observatorio AT 2020.

En la comparativa, las seis primeras universidades con mayor producción científica en AT aparecen también como las primeras en el ranking de documentos en WOS en el área de Construction y Building Tecnology. En la Tabla 5 se observa como la correlación se pierde, siendo el comportamiento de las universidades con AT muy diferentes a los datos generales englobando los documentos de Ingeniería y Arquitectura en WOS.

Tabla 5. Correlación Producción científica Universidades AT y Universidades "Construction y Building" en WOS

\begin{tabular}{|rcc|ccc|}
\hline N $^{\circ}$ & UNIVERSIDAD & AT & No $^{\circ}$ & UNIVERSIDAD & $\begin{array}{l}\text { Construction } \\
\text { y Building }\end{array}$ \\
\hline 1 & UPM & 560 & 1 & UPM & 108 \\
\hline 2 & USE & 521 & 6 & UPVA & 46 \\
\hline 3 & UBU & 379 & 5 & UAL & 41 \\
\hline 4 & UGR & 323 & 2 & USE & 30 \\
\hline 5 & UAL & 218 & 4 & UGR & 26 \\
\hline 6 & UPVA & 199 & - & UPVA & 18 \\
\hline 7 & UJI & 172 & - & UCLM & 17 \\
8 & ULL & 102 & 12 & UDC & 17 \\
9 & UNEX & 63 & - & UPCT & 10 \\
10 & UDL & 47 & - & USAL & 8 \\
\hline
\end{tabular}


Center of Scientific Output (2020 Edition). Analysis and evolution of research

\begin{tabular}{lll|lcl}
11 & UPCT & 46 & 7 & UJI & 6 \\
12 & UDC & 40 & - & UZAR & 6 \\
\hline
\end{tabular}

Posteriormente, se constrastó la información sobre los docentes AT de la universidad Española en el año 2020 respecto al tipo de contrato, obteniéndose las siguientes tipologías:

- Catedrático de Universidad

- Catedrático de Escuela Universitaria

- Titular de Universidad

- Titular de Escuela Universitaria

- Contratado Doctor

- Ayudante Doctor

- Colaborador

- Ayudante

- Contratado interino

- Asociado

- Investigador

En la Figura 1 se recoge la distribución de los docentes según tipo de categoría o contrato.

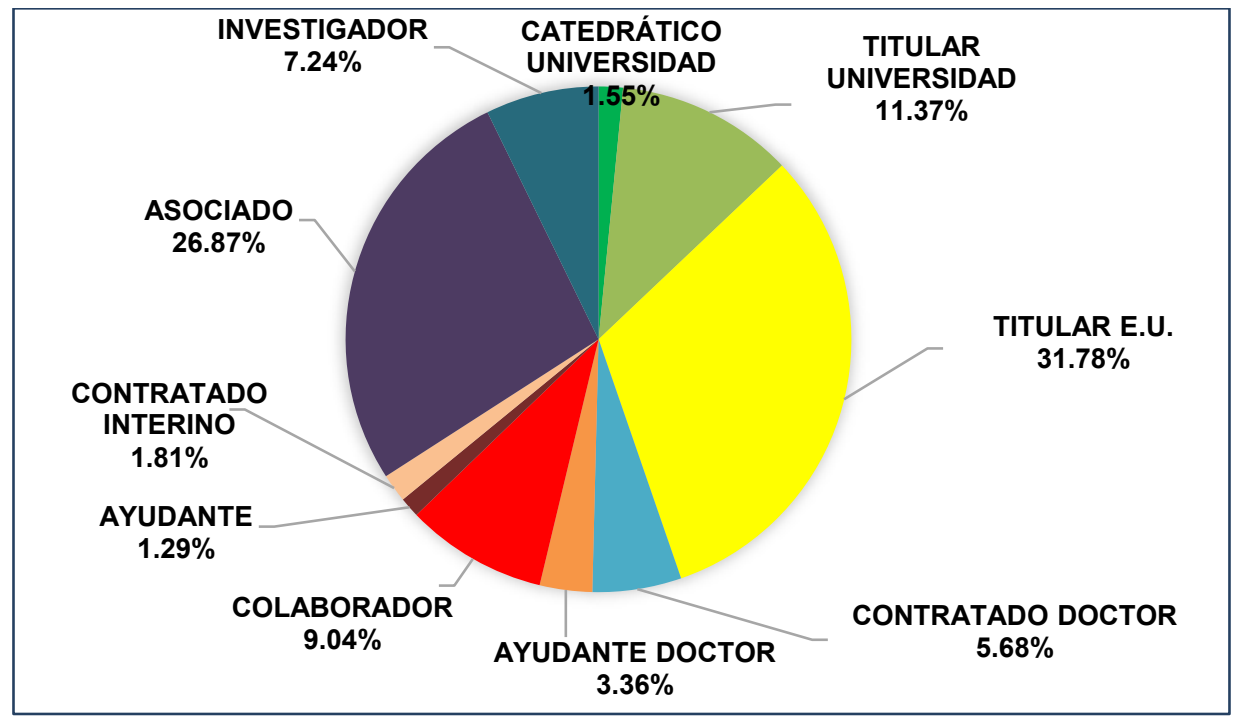

Figura 1. Tipología de contrado de docentes AT en la universidad española. 2020

Como se observa, la categoría con más profesorado es la de Titular de Escuela Universitaria, seguida por la de Asociado. Es sintomático el porcentaje de asociados en esta carrera $(26,87 \%)$, por la necesidad de docentes con un perfil profesional y que aportan el lado técnico a la docencia. 
La Tabla 6 muestra el análisis del personal a tiempo completo y a tiempo parcial por universidades, ordenados por el porcentaje de los docentes a tiempo completo.

Tabla 6. Porcentaje Docentes AT tiempo parcial/Tiempo completo por Universidad. 2020

\begin{tabular}{lccccc}
\hline & \multicolumn{2}{c}{ Totales } & \multicolumn{2}{c}{ Porcentajes } \\
UNIVERSIDAD & $\begin{array}{l}\text { tiempo } \\
\text { parcial }\end{array}$ & $\begin{array}{c}\text { tiempo } \\
\text { completo }\end{array}$ & $\begin{array}{c}\text { tiempo } \\
\text { parcial }\end{array}$ & $\begin{array}{c}\text { tiempo } \\
\text { completo }\end{array}$ \\
\hline Universidad de Burgos & 0 & 20 & $0,00 \%$ & $100,00 \%$ \\
\hline Universidad de Zaragoza & 0 & 6 & $0,00 \%$ & $100,00 \%$ \\
\hline Universidad da Coruña & 2 & 17 & $10,53 \%$ & $89,47 \%$ \\
\hline Universidad de La Laguna & 3 & 23 & $11,54 \%$ & $88,46 \%$ \\
\hline Universidad de Extremadura & 1 & 7 & $12,50 \%$ & $87,50 \%$ \\
\hline Universidad Politécnica de Valencia & 5 & 28 & $15,15 \%$ & $84,85 \%$ \\
\hline Universidad de Alicante & 3 & 15 & $16,67 \%$ & $83,33 \%$ \\
\hline Universidad de Granada & 7 & 35 & $16,67 \%$ & $83,33 \%$ \\
\hline Universidad Jaume I & 2 & 7 & $22,22 \%$ & $77,78 \%$ \\
\hline Universidad Politénica de Madrid & 14 & 42 & $25,00 \%$ & $75,00 \%$ \\
\hline Universidad de Castilla - La Mancha & 3 & 7 & $30,00 \%$ & $70,00 \%$ \\
\hline Universidad del País Vasco & 1 & 2 & $33,33 \%$ & $66,67 \%$ \\
\hline Universidad de Sevilla & 28 & 48 & $36,84 \%$ & $63,16 \%$ \\
\hline Universidad de Girona & 7 & 9 & $43,75 \%$ & $56,25 \%$ \\
\hline Universidad de las Islas Baleares & 4 & 4 & $50,00 \%$ & $50,00 \%$ \\
\hline Universidad de Lleida & 4 & 3 & $57,14 \%$ & $42,86 \%$ \\
\hline Universidad Politécnica de & 8 & 6 & $57,14 \%$ & $42,86 \%$ \\
Cartagena & 4 & 2 & $66,67 \%$ & $33,33 \%$ \\
\hline Universidad de Salamanca & 3 & 3 & $72,73 \%$ & $27,27 \%$ \\
\hline Universidad de Alcalá & & & &
\end{tabular}

La pregunta que nos hacemos es si el tipo de dedicación, tiene relación con la producción científica, dado que en el Observatorio (2020) se verificó que los investigadores con mayor producción, todos era doctores y a tiempo completo.

En la Tabla 7 se realiza la comparación en el porcentaje de doctores con el de producción científica por autores/as. Como se observa, no existe correlación entre porcentaje de docentes a tiempor parcial respecto al total de docentes y la producción científica por autor/universidad. Aunque la Universidad de Burgos encabeza las dos tablas, la correlación no existe en el resto de la serie. 
Tabla 7. Correlación Tiempo Parcial/Completo y Producción científica por Autor AT. Universidades AT

\begin{tabular}{|c|c|c|c|c|c|}
\hline $\mathbf{N}^{\circ}$ de orden & UNIVERSIDAD & $\begin{array}{l}\% \text { tiempo } \\
\text { completo / } \\
\text { Parcial }\end{array}$ & UNIVERSIDAD & $\begin{array}{c}\text { Docum / } \\
\text { Autor }\end{array}$ & $\begin{array}{l}\mathbf{N}^{\circ} \text { de } \\
\text { orden }\end{array}$ \\
\hline 1 & UBU & $100,00 \%$ & UBU & 27,07 & 1 \\
\hline 2 & UZAR & $100,00 \%$ & UJI & 17,20 & 9 \\
\hline 3 & UDC & $89,47 \%$ & UNEX & 12,60 & 5 \\
\hline 4 & ULL & $88,46 \%$ & UDL & 11,75 & 16 \\
\hline 5 & UNEX & $87,50 \%$ & UPM & 10,98 & 10 \\
\hline 6 & UPV & $84,85 \%$ & UAL & 9,91 & 7 \\
\hline 7 & UAL & $83,33 \%$ & UGR & 8,50 & 8 \\
\hline 8 & UGR & $83,33 \%$ & USE & 7,66 & 13 \\
\hline 9 & UJI & $77,78 \%$ & UPV & 6,42 & 6 \\
\hline 10 & UPM & $75,00 \%$ & ULL & 6,00 & 4 \\
\hline 11 & UCLM & $70,00 \%$ & UPCT & 5,75 & 17 \\
\hline 12 & UPVA & $66,67 \%$ & UPVA & 4,67 & 12 \\
\hline 13 & USE & $63,16 \%$ & UZAR & 4,00 & 2 \\
\hline 14 & UDG & $56,25 \%$ & UAH & 3,50 & 19 \\
\hline 15 & UIB & $50,00 \%$ & UDC & 3,33 & 3 \\
\hline 16 & UDL & $42,86 \%$ & UDG & 3,20 & 14 \\
\hline 17 & UPCT & $42,86 \%$ & UIB & 3,20 & 15 \\
\hline 18 & USAL & $33,33 \%$ & UCLM & 3,14 & 11 \\
\hline
\end{tabular}

Posteriormente se analizó el porcentaje de producción científica por autor/universidad con el número de doctores/docentes por universidad (Tabla 8). Como se ha comentado anteriormente, esa relación es muy directa en numerosos análisis realizados en otras áreas. No obtante, en este caso concreto, se observa que tampoco existe correlación entre porcentaje de doctores y cantidad de producción científica por autor/a.

Pero, ¿cuál puede ser la causa? Para dar respuesta a esta pregunta, se ha analizado el total de doctores con producción científica, distinguiendo los que tienen más de una publicación o solo una o ninguna (Ver Figura 2) Se observa que aproximadamente el $45 \%$ de los docentes doctores sólo han publicado uno o ningún artículo. Esto explicaría porqué en AT, la producción científica se realiza por investigadores que son doctores, pero son un gran número de doctores sin producción científica sostenida.

Esta es también la causa de la disintonía entre número de doctores en la universidades y la producción científica por autor/a. Lógicamente exisnten otras causas que incentivan la producción científica en determinadas universidades que no tiene que ver solo el número de 
doctores, por ejemplo, la la vigencia y actividad de los grupos de investigación a los que están asociados, los proyectos de investigación en los que participan, etc.

Tabla 8. Correlación Universidades AT \% Doct/Doc y Docum/Autor.

\begin{tabular}{|c|c|c|c|c|c|}
\hline $\mathbf{N}^{\circ}$ de orden & UNIVERSIDAD & $\begin{array}{l}\% \text { Doctores } \\
\text { / Docentes }\end{array}$ & $\begin{array}{l}\text { Docum I } \\
\text { Autor }\end{array}$ & UNIVERSIDAD & $\begin{array}{l}\mathrm{N}^{0} \text { de } \\
\text { orden }\end{array}$ \\
\hline 1 & UPVA & $75,00 \%$ & 27,07 & UBU & 15 \\
\hline 2 & UPV & $51,72 \%$ & 17,20 & UJI & 5 \\
\hline 3 & USE & $50,41 \%$ & 12,60 & UNEX & 8 \\
\hline 4 & UAL & $46,67 \%$ & 11,75 & UDL & 19 \\
\hline 5 & UJI & $42,86 \%$ & 10,98 & UPM & 9 \\
\hline 6 & USAL & $42,86 \%$ & 9,91 & UAL & 4 \\
\hline 7 & UGR & $38,03 \%$ & 8,50 & UGR & 7 \\
\hline 8 & UNEX & $36,36 \%$ & 7,66 & USE & 3 \\
\hline 9 & UPM & $35,78 \%$ & 6,42 & UPV & 2 \\
\hline 10 & UCLM & $33,33 \%$ & 6,00 & ULL & 12 \\
\hline 11 & UIB & $31,25 \%$ & 5,75 & UPCT & 13 \\
\hline 12 & ULL & $30,23 \%$ & 4,67 & UPVA & 1 \\
\hline 13 & UPCT & $29,41 \%$ & 4,00 & UZAR & 17 \\
\hline 14 & UDG & $27,78 \%$ & 3,50 & $\mathrm{UAH}$ & 16 \\
\hline 15 & UBU & $26,09 \%$ & 3,33 & UDC & 18 \\
\hline 16 & UAH & $23,08 \%$ & 3,20 & UDG & 14 \\
\hline 17 & UZAR & $23,08 \%$ & 3,20 & UIB & 11 \\
\hline 18 & UDC & $21,95 \%$ & 3,14 & UCLM & 10 \\
\hline 19 & UDL & $8,33 \%$ & 3,00 & USAL & 6 \\
\hline
\end{tabular}

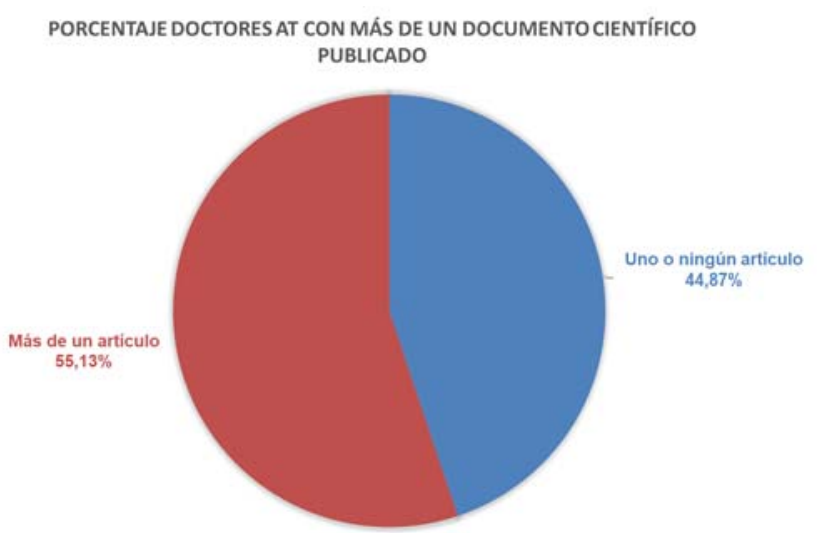

Figura 2. Porcentaje publicación artículos docentes doctores AT. Histórico 


\section{Conclusiones}

Las conclusiones más importantes del presente trabajo son las siguientes:

1. Las universidades con mayor producción científica en Construction y Building Tecnology, coinciden con las de mayor producción científica en AT.

2. El mayor porcentaje de tipo de docente AT es Titular de Escuela Universitaria, en 2020.

3. El porcentaje de asociados es del $26,87 \%$, superior al existente a otras titulaciones.

4. La Universidad de Burgos y Zaragoza son las que mayor procentaje de profesores a tiempo completo tienen.

5. El porcentaje de profesores a tiempo parcial influye de manera escasa en la cantidad de producción científica por autor/a en las universidades

6. El porcentaje de doctores docentes no es proporcional a la producción científica por autor/a.

7. El número de doctores docentes con muy poca producción científica es alto (45\%)

\section{Referencias}

ABBOtT, A., CYRANOSKI, D., JONES, N., MAHER, B., SCHIERMEIER, Q., y VAN NOORDEN, R. (2010). "Metrics: Do metrics matter?" en Nature, vol. 465, issue 7300, p. 860-862.

ABRAMO, G., y DÁNGELO, C. (2014). "How do you define and measure research productivity?" en Scientometrics, vol.101, issue 2, p. 1129-1144. doi:10.1007/s11192-014-1269-8

AKSNES, D., y TAXT, R. (2004). "Peer reviews and bibliometric indicators: A comparative study at a Norwegian university" en Research Evaluation, vol. 13, issue 1, p. 33-41. doi: $10.3152 / 147154404781776563$

CASTRO RODRÍGUEZ, Y. (2019). "Factors contributing to the student scientific production. The case of Dentistry in the National University of San Marcos, Peru" en Educacion Medica, issue 20, p. 49-58. doi:10.1016/j.edumed.2017.10.002

CUBILLOS VEGA, C. (2017). "Analisys of the scientific output on human rights within social work: an international perspective (2000-2015)" en Revista Española de Documentación Científica, vol. 40, issue1. doi:10.3989/redc.2017.1.1387

DONTHU, N., KUMAR, S., PATTNAIK, D., y LIM, W. (2021). "A bibliometric retrospection of marketing from the lens of psychology: Insights from Psychology y Marketing" en Psychology and Marketing, vol. 38, issue 5, p. 834-865. doi:10.1002/mar.21472

DURÁN ÁLVAREZ, J. (2021). Observatorio de la producción cientifica de la Arquitectura Técnica de España 2020. Granada: Unidad de Evaluación de la Actividad Científica. Vicerrectorado de Investigación y Transferencia. Universidad de Granada. doi:10.5281/zenodo.3902619 
MOED, H., BURGER, W., FRANKFORT, J., y VAN RAAN, A. (1985). "The use of bibliometric data for the measurement of university research performance" en Research Policy, vol. 14, issue 3, p. 131-149. doi:10.1016/0048-7333(85)90012-5

ROJAS SOLA, J., y SAN ANTONIO GÓMEZ, C. (2010). "Análisis bibliométrico de las publicaciones científicas españolas en la categoría Construction y Building Technology de la base de datos Web of Science (1997-2008)" en Materiales de Construcción, vol. 60, issue 300, p. 143-149. doi:0.3989/mc.2010.59810

VAN RAAN, A. (2005). "Fatal attraction: Conceptual and methodological problems in the ranking of universities by bibliometric methods" en Scientometrics, vol. 62, issue1, p. 133-143. doi:10.1007/s11192-005-0008-6

WHITBECK, G. (1991). "Doctoral Programs in Library and Information Science: A descriptive Study" en Journal of Education for Library and information Science, vol. 31, issue 4, p. 314-328. doi: $10.2307 / 40323367$ 


\title{
EDIFİCATE
}

I Congreso de Escuelas de Edificación y Arquitectura Técnica de España València, 4 y 5 de noviembre de 2021

Escuela Técnica Superior de Ingeniería de Edificación

Universitat Politècnica de València

Doi: https://doi.org/10.4995/EDIFICATE2021.2021.13591

\section{Proyecto Tetuán como espacio de aprendizaje. Investigación y docencia en Conservación del Patrimonio Edificado.}

\section{Tetouan Project as a learning space. Research and teaching in Conservation of Built Heritage.}

\author{
Lorenzo Jurina ${ }^{a}$, Carlo Manfredi ${ }^{b}$, Carmen Campra García de Viguera y \\ Antonio Jiménez-Delgado \\ aPolitecnico di Milano, Lorenzo.jurina@polimi.it; ${ }^{b}$ Ministero della Cultura, carlo.manfredi@beniculturali.it; \\ 'Universidad de Alicante, Carmen.campra@ua.es; dUniversidad de Alicante, \\ antonio.jimenez@gcloud.ua.es
}

\begin{abstract}
Tetouan Project forms a research and teaching strategy in the field of Conservation of Built Heritage. The physical space of the project is contextualized in the Medina declared in 1997 world heritage by UNESCO that together with the Muslim Cemetery and the Spanish Ensanche draw some of the most beautiful and best preserved landscapes in Morocco.

The project "designs" a series of activities and "develops" them in the space of the Historic Center with the aim of combining the fieldwork of the research group AEDIFICATIO and the teaching of different subjects with undergraduate students in Technical Architecture.
\end{abstract}

Keywords: Tetuán, Tetouan, Medina, preservation, heritage, education, cultural asset, research teaching space, educational project, interdisciplinary work, teaching by research

\section{Resumen}

Proyecto Tetuán configura una estrategia de investigación y docencia en el ámbito de la Conservación del Patrimonio Edificado. El espacio físico del proyecto se contextualiza en la Medina declarada en 1997 patrimonio mundial por la UNESCO que junto al Cemeterio musulmán y el Ensanche español dibujan unos de los paisajes más bellos y mejor conservados de Marruecos. El proyecto "diseña" una serie de actividades y las "desarrolla" en el espacio 
Proyecto Tetuán como espacio de aprendizaje - Tetuan Project as a learning space

del Centro Histórico con el objetivo de combinar el trabajo de campo del grupo de investigación AEDIFICATIO y la docencia de diferentes materias con estudiantes de grado en Arquitectura Técnica.

Palabras clave: Tetuán, Medina, Patrimonio, conservación, educación, bien cultural, espacio docente investigador, proyecto educativo, trabajo interdisciplinar, enseñanza por investigación. 


\section{Introducción}

"Proyecto Tetuán" constituye una estrategia de investigación en herramientas educativas para estudiantes universitarios aplicada a la Conservación del Patrimonio Edificado y su puesta en valor, tanto en exponentes tangibles como en elementos inmateriales del patrimonio cultural.

Desde el ámbito académico, ha sido una oportunidad poder disponer de la Medina de Tetuán como un espacio de investigación para sensibilizar al estudiantado y al profesorado de la UA de la importancia del patrimonio urbano como vehículo de la transmisión cultural y como herramienta educativa para la cooperación internacional.

En 2009 se realiza el "diseño curricular" del proyecto en materia de gestión del patrimonio cultural como línea de investigación experimental dentro del área de conocimiento de Construcciones Arquitectónicas de la UA que serviría para investigar en los sucesivos años hasta la actualidad. La investigación se coordina desde el Grupo de Investigación AEDIFICATIO (Edificación, tecnología, investigación y desarrollo) de la UA. EI "diseño" contempla como principal objetivo definir un modelo de trabajo de investigación donde el/la estudiante participe activamente en el centro histórico de una ciudad que sirve como espacio de aprendizaje e investigación y el/la docente-investigador/a realice el "desarrollo curricular" en el espacio elegido y centre su investigación en dos elementos que conforman un mismo escenario, estudiante y patrimonio cultural utilizando la docencia como objeto de investigación. La ciudad seleccionada es Tetuán, su Medina (declarada en 1997 Patrimonio Mundial por la UNESCO), Cementerio Musulmán y Ensanche Español.

La Medina de Tetuán posee un valor inherente a sus construcciones de gran riqueza arquitectónica. A todo ello se le une de forma inseparable las tradiciones y costumbres de sus habitantes que recorren sus calles a diario.

El análisis de los exponentes constructivos más significativos supone la dinamización de procesos de conservación necesarios en todos los ámbitos de la ciudad. En concreto el caso que se expone sirve como referente para el aprendizaje de un proyecto actual que contemple los objetivos de desarrollo sostenible establecidos por las Naciones Unidas. El proyecto establece las siguientes líneas de trabajo:

- Intervención y conservación en el patrimonio.

- Participación ciudadana.

- Metodología BIM aplicada al patrimonio.

Para una adecuada intervención y conservación del patrimonio se concibe el espacio de la Medina como contenedor de la cultura materializada en sus construcciones en las que reconocemos valores históricos-artísticos.

La participación ciudadana y la inclusión de los datos obtenidos en el proyecto estructura una nueva forma de documento con elementos sociológicos. Las técnicas participativas son nucleares en el proceso. La estratégia metodológica que se plantea es conocida como bottom-up, la cual permite abordar la colectividad desde las diversas y plurales individualidades.

La Medina ha constituido el "espacio docente-investigador" donde desarrollar el trabajo de campo de varias decenas de estudiantes y profesores del área de conocimiento de 
Construcciones Arquitectónicas de la UA en coordinación con expertos y académicos de Tetuán, Granada, Alicante y Milán. La actividad de docencia-investigación supone un modelo cuyos resultados son evaluados en periodos sucesivos.

\section{Objetivos}

Objetivo general: Capacitar de forma integral al estudiante para el trabajo en equipo interdisciplinar, interinstitucional e intergeneracional en materia de "gestión y conservación del patrimonio arquitectónico".

Objetivos particulares:

- Valorar el trabajo en equipo interdisciplinar, interuniversitario e intergeneracional.

- Desarrollar la capacidad de trabajo en un entorno socio-cultural nuevo para el estudiante.

- $\quad$ Poner en valor el análisis de la documentación histórica y sociológica.

- Capacitar en la toma de datos, diagnosis y dictamen en un edificio histórico.

- Desarrollar habilidades en el estudiante para el estudio del patrimonio inmaterial que forma parte del patrimonio arquitectónico y urbano.

- Propiciar el conocimiento del estudiante de las diferentes vías de formación e investigación en el ámbito del patrimonio arquitectónico.

- Desarrollar la capacidad de trabajar en red, finalizado el "workshop", utilizando el capital humano y material del "Proyecto Tetuán" en su futuro profesional y personal.

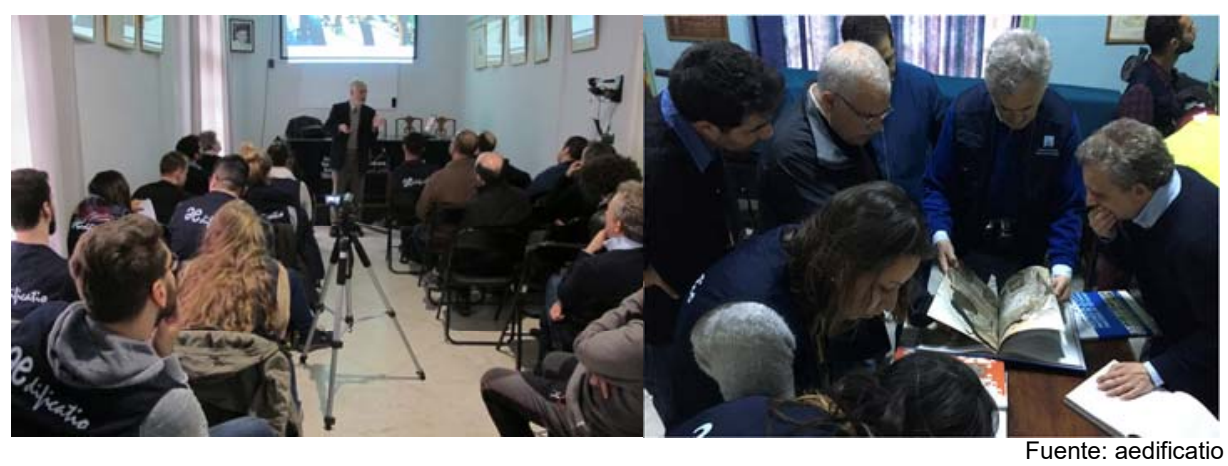

Fig. 1 Actividades de formación e investigación en la sede de la Asociación Tetuán Asmir 


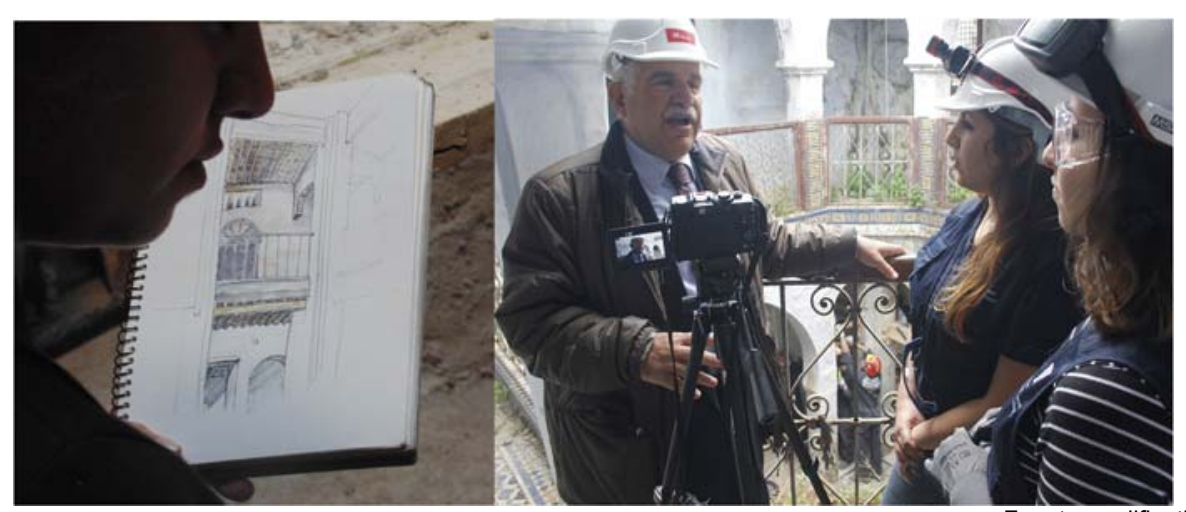

Fig. 2 Trabajo de campo y entrevista a Mohamed Benaboud

Fuente: aedificatio

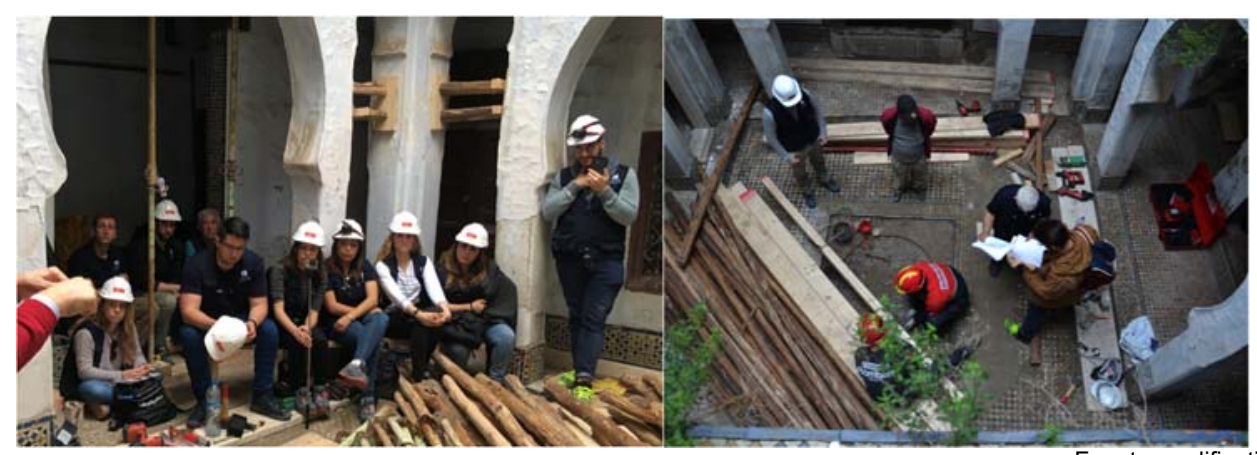

Fig. 3 Clases prácticas in situ e intervención en Casa Ben Marzuk y Mazmorras

\section{Desarrollo de la innovación}

El desarrollo curricular definido en el Proyecto Tetuán establece el método de trabajo y las estrategias para alcanzar los objetivos diseñados con anterioridad. Así, el planteamiento de un "desarrollo" llevado a cabo en los esquemas convencionales del sistema universitario europeo quedan excluidas y se hace necesaria una reflexión profunda de la definición del "espacio" que trasgreda y abra un método adecuado a las necesidades de formación e investigación que la sociedad actual reclama.

En el caso que nos ocupa es necesario establecer un único "método" que responda al desarrollo curricular aglutinando los objetivos diseñados para ambos ejes del Proyecto Tetuán, por un lado la "docencia para el desarrollo del proceso enseñanza-aprendizaje" y por el otro la "investigación sobre el proceso de enseñanza-aprendizaje". Se establece por tanto el siguiente desarrollo:

- Se estudia y se decide un lugar de trabajo que conforma el "espacio" de aprendizaje e investigación con un entorno socio-cultural nuevo para el estudiante.

- Se seleccionan equipos de trabajo interdisciplinar, interuniversitario e intergeneracional. 
- Se busca la documentación histórica y sociológica publicada.

- Se desarrollan actividades de toma de datos, diagnosis y dictamen de edificios históricos y del espacio urbano.

- Se desarrolla una estrategia para el estudio del patrimonio inmaterial que forma parte del patrimonio arquitectónico y urbano.

- Organización de cursos y charlas donde se aborden las vías de formación e investigación en el ámbito del patrimonio arquitectónico.

- Se realiza, para el posterior análisis, material escrito y audiovisual de los diferentes edificios, espacios urbanos y temas abordados del patrimonio tangible e inmaterial.

- Se trabaja en red, finalizado el "workshop", y se realiza un seguimiento de los estudiantes durante los años sucesivos para conocer sus actividades profesionales y personales.

\section{Resultados}

Durante el periodo de trabajo del Proyecto Tetuán se han obtenido numerosos resultados que quedan reflejados en las actividades y documentos generados en los diferentes años de trabajo. En definitiva se han intensificado las relaciones internacionales, los/as estudiantes han desarrollado habilidades y destrezas pluridisciplinares en un ámbito multicultural. Las investigaciones generadas han dado como resultado un riguroso conocimiento del patrimonio construido en la Medina de Tetuán e información inédita de las Mazmorras de la ciudad.

\section{9}

- Trabajo de Campo y toma de datos en la Medina de Tetuán.

- Primera intervención de emergencia en viviendas de La Medina.

- Realización del video: https://www.youtube.com/watch?v=9_-OzYiG6AE.

\section{0-13}

- Trabajo de Campo en la Medina de Tetuán.

- Trabajo de Campo en el Cementerio de Tetuán.

- International Workshop NYC, Milano, Granada y Alicante.

- Sáez Mentxakatorre, I. y Ortega Ortega, L.C. (2012). Guía práctica de Apuntalamientos de emergencia. Alicante: Alarifes.

- Libro: Líndez Vílchez, B. (coord.) (2014). Tetuán, herencia viva. Reflexiones y trabajos resultado de la colaboración de instituciones tetuaníes y la Universidad de Granada.

\section{4-2016}

- $\quad$ Trabajo de campo e investigación en viviendas y espacios de la Medina.

- Trabajo de Campo e investigación en las Mazmorras.

- Intervención de Emergencia en la Casa Ben Marzuk.

- Curso de formación a expertos de Marruecos y España. 


\section{7-18}

- $\quad$ Artículo de investigación: Jiménez Delgado, A., Travaglio, P. y Jurina, L. (2017). Interventi di consolidamento strutturale: il caso delle mazmorras e la casa Ben Marzuk nella Medina di Tétouan. En N. Augenti y L. Jurina (coord.), Atti del convegno IF CRASC'17 (14-16 settembre 2017, Milano) (pp. 543-556). Palermo: Dario Flaccovio Editore.

- Tesis doctoral: Hussey, R.A. (2017). A collaborative rescue archaeological and historical investigation of Tétouan's mazmorras, Morocco (Tesis doctoral). University of Florida. Disponible en http://jurina.it/wp-content/uploads/2013/11/111_Jimenez_A. pdf.

- Producción de vídeos de divulgación científica: ejemplo: http://rua.ua.es/dspace/handle/10045/65309.

\section{9-2021}

- Proyecto Tetuán. Retrospectiva 10 (2009-2019). Exposición retrospectiva fotográfica y audio visual de la actividad investigadora y de intervención en el patrimonio de la Ciudad de Tetuán.

- Libro: Jiménez Delgado, A. (2019). Revoltijo educativo. Pensando la educación. Alicante: Universidad de Alicante.

- $\quad$ Libro: Jiménez Delgado, A., y Lloret, J. (2019). Healt, Wellbeing and Sustainability in the Mediterranean City: Interdisciplinary Perspectives. New York-London: Routledge.

\section{Conclusiones}

El Proyecto Tetuán, al igual que otros proyectos realizados con anterioridad, han servido de base para establecer un método de trabajo en el denominado "Proyecto Aedificatio" que se centra en la construcción y conservación del patrimonio arquitectónico. Se desarrolla de forma interdisciplinar, tomando al ser humano y el bienestar social como centro y con un objetivo didáctico y cultural. Es un proyecto sostenible que une la arquitectura contemporánea y la tecnología con la tradición y el saber vernáculo, teniendo en cuenta la historia y el genius loci.

Los miembros del grupo de investigación "Aedificatio" están unidos por el interés hacia un trabajo profesional, de investigación y reflexión cultural basado en los siguientes valores compartidos. El grupo hace participe en sus actividades a estudiantes para formentar la docencia de calidad junto a la investigación.

Una vez desarrollado el "Proyecto Aedificatio" llevado a cabo en el contexto de la ciudad de Tetúan enumeramos las siguientes conclusiones de la actividad de aprendizajeinvestigación: 
Se basa en la interdisciplina, creyendo en la necesidad de superar los límites de un saber monodisciplinar, anclado en la singularidad de cada disciplina, en favor de la cooperación entre especialistas procedentes de distintos ramos del saber: arquitectura, ingeniería, sociología, historia, historia del arte, tecnología...

Propicia el encuentro y debate constructivo y formativo por parte de los diferentes miembros del grupo de investigación, el compromiso activo e intercambio de ideas.

Tiene como centro al ser humano, ententidiendolo como singularidad y colectividad. Hoy en día, frente a un mundo nuevo, cada vez más multicultural, multiétnico y multireligioso, se hace necesario un "Nuevo Humanismo" como redescubrimiento del hombre y de su relación con la realidad en la cual vive, como reafirmación del valor de la persona.

Otro eje es el bienestar social. El proyecto se basa en dar respuestas a las necesidades de la colectividad. Para ello es imprescindible el contacto directo con la población, propiciando la participación ciudadana y analizando la información recibida para un adecuado diagnóstico.

Tiene como objetivo generar y fomentar la cultura, produciendo un contenido que favorezca un pensamiento critico y reflexivo. Es un proyecto global e intercultural en cuanto a visión, expertos y metodología.

Otro objetivo es la educación. El "Proyecto Aedificatio" tiene una dimensión didáctica, propiciando la explicación y la difusión de contenidos dirigidos a la educación primaria, secundaria y universitaria. La misma palabra "Aedificatio" contiene en si este concepto fundamental: del lat. aedificare, con el significado de construir y fundar, si no también de educar, instruir, iluminar. El "Proyecto Aedificatio" tiene en cuenta la misión de la UNESCO en cuanto a Educación, Ciencia y Cultura. La educación y difusión, junto con el pensamiento crítico y reflexivo que se pretende alcanzar, llevan al empleo de un método de enseñanza por investigación o "problematizado"; basado en la sucesión de preguntas presentadas como problemas que el alumno debe ir cuestionándose y resolviendo por sí mismo mediante la autoreflexión.

Pretende fomentar la curiosidad y creatividad del observador así como propiciar la belleza y armonía del mismo diseño del proyecto arquitectónico y de su contenido, activando cada uno de los puntos desarrollados en el presente manifiesto.

Contempla los 17 objetivos de desarrollo sostenible de la ONU.

Une la contemporaneidad y la tecnología más avanzada con la tradición y saber vernáculo, enfatizando los elementos locales así como los globales y visiones intergeneracionales.

Contempla como objetivo último la preservación de los elementos indentitarios del lugar en el cual se interviene y la puesta en valor el genius loci. 
Lorenzo Jurina, Carlo Manfredi, Carmen Campra García de Viguera y Antonio Jiménez-Delgado

\section{Referencias}

ABDERRAHMAN (2015), El Fathi: Marruecos en Cervantes. Antología de textos. Patio de Monipodio, Tetuán.

BENABOUD, M. (coord.) (2004) Tétouan, capitale méditerranéenne, Asociación Tétouan-Asmir, Tétouan.

ERZINI, N. (2015), La influencia renacentista y mudejár en la arquitectura doméstica de Tetuán en los siglos XVI y XVII. Los Moriscos-Andalusies en Marruecos. Estado de la cuestión. Actas del Coloquio Internacional, Asociación Marroquí de Estudios Andalusies, pp. 41-64.

GÓMEZ MORENO, M. (1922) Descubrimientos y antigüedades en Tetuán. Boletín Oficial de la Zona de Protectorado Español en Marruecos, suplemento 10.

GOZALBES BUSTO, G. (1984) Las mazmorras de Tetuán. Estudios de Historia y Arqueología Medievales, 3-4, pp. 247-264.

GOZALBES BUSTO, G (1992) Los moriscos en Marruecos. Guillermo Gozalbes Busto, Granada.

GOZALBES, E. (2012) Tetuán: arqueología, historia y patrimonio. Asociación Tetuán-Asmir, Tetuán.

MIEGE, J.L., BENABOUD, M., ERZINI, N. (1996) Tétouan: ville andalouse marocaine, CNRS-Paris, Kalila Wa Dimna-Rabat.

MONTALBÁN Y MAZAS, C.S. (1939) Las mazmorras de Tetuán, su limpieza y exploración, Editorial Mundo Latino, Madrid.

Primo volume delle navigationi et viaggi nel qual si contiene la Descrittione dell'Africa (1550) Heredi di Lucantonio Giunti, Venezia, 1550.

SORINO, G., JIMÉNEZ-DELGADO, A., MANFREDI,C. (2019) BIM Methodology Applied To Architectural Heritage Preservation: Case Study Of The Medina And Dungeons Of Tetuán, Morocco, in "Building Information Modelling (BIM) in Design, Construction and Operations III", Edited By: De Wilde, P., Mahdjoubi, L., Garrigós Garrigos, A. Wit Press, Ashurst, pp. 157-168

TORRES LÓPEZ, R. (2011) La Medina di Tetuán. Guía de arquitectura, Conserjeria de Obras Públicas y Vivienda-Sevilla,Consejo Municipal de Tetuán-Tetuán, 3a edizione. 


\title{
EDIFİCATE
}

I Congreso de Escuelas de Edificación y Arquitectura Técnica de España València, 4 y 5 de noviembre de 2021

Escuela Técnica Superior de Ingeniería de Edificación

Universitat Politècnica de València

Doi: https://doi.org/10.4995/EDIFICATE2021.2021.13606

\section{Movilidad de los estudiantes de Arquitectura Técnica y Edificación: diagnóstico y oportunidades}

\section{Mobility of Architectural Technology and Building Construction students: diagnosis and opportunities}

\author{
Laia Haurie Ibarra ${ }^{a}$, Chantal Alastruey Martin ${ }^{a}$ \\ aEscola Politècnica Superior d'Edificació de Barcelona, Universitat Politècnica de Catalunya \\ (laia.haurie@upc.edu), (chantal.alastruey@upc.edu)
}

\begin{abstract}
Internationalization of higher education programmes is a goal pursued by most universities and their corresponding faculties and schools. One of the main indicators to evaluate internationalization is the number of students who complete a mobility program. In this work we carry out an analysis of the evolution of the mobility of Architectural Technology and Building Construction students from the Barcelona School of Building Construction (EPSEB) since 2010 and we compare it with the evolution of mobility in the university. We analyze the main causes that limit the mobility of ATE students and we suggest actions to increase the internationalization of our studies and students.
\end{abstract}

Keywords: internationalization, mobility, Erasmus+, outgoing student.

\begin{abstract}
Resumen
La internacionalización de los estudios universitarios es una meta que persiguen la mayoría de las universidades y sus correspondientes facultades y escuelas. Uno de los principales indicadores para evaluar la internacionalización de los estudios es el número de estudiantes que realizan un programa de movilidad. En este trabajo realizamos un análisis de la evolución de la movilidad de los estudiantes de Arquitectura Técnica y Edificación (ATE) de la Escuela Politécnica Superior de Edificación de Barcelona (EPSEB) desde el año 2010 y la comparamos con la media de la universidad. Se evalúan las principales causas que limitan la movilidad de los estudiantes de ATE y se proponen actuaciones para incrementar la internacionalización de nuestros estudios y estudiantes.
\end{abstract}

Palabras clave: internacionalización, movilidad, Erasmus+, estudiante outgoing. 


\section{Introducción}

La internacionalización de los estudios universitarios es una meta que persiguen la mayoría de universidades y sus correspondientes facultades y escuelas. A nivel de las escuelas uno de los principales indicadores que se utilizan para evaluar la internacionalización es el número de estudiantes que siguen un programa de movilidad. La encuesta realizada a 1325 empresas por parte de la Agencia de la Calidad Universitaria de Catalunya (AQU), entre 2014 y 2016, revela que, junto con las prácticas en empresas, las titulaciones y estancias en el extranjero son aspectos relevantes a la hora de contratar a un titulado (AQU, 2015). En este trabajo analizamos la evolución de la movilidad de los estudiantes de Arquitectura Técnica y Edificación de la Escuela Politécnica Superior de Edificación de Barcelona (EPSEB) desde el año 2010 y la comparamos con la media de la Universitat Politècnica de Catalunya. A partir del diagnóstico inicial intentaremos proponer actuaciones para fomentar la movilidad entre nuestros estudiantes

\section{Objetivos}

En los últimos cursos desde la EPSEB hemos detectado una disminución de las solicitudes de nuestros estudiantes para realizar una estancia de movilidad. En este estudio pretendemos analizar la evolución de la movilidad de ATE desde 2010 en relación a la movilidad en la UPC y detectar las posibles causas que conllevan esta reducción. El objetivo final es tener herramientas para plantear acciones que nos permitan incrementar la internacionalización de nuestros estudiantes.

\section{Desarrollo de la innovación}

Los datos del número de estudiantes que han cursado un programa de movilidad en la EPSEB y en la UPC, así como el número de estudiantes matriculados en el grado de ATE y el total de estudiantes de grado de la UPC, se han obtenido a partir de los datos estadísticos y de gestión que publica la UPC en su web: https://gpaq.upc.edu/lldades/.

Las autoras hemos estado vinculadas durante diferentes períodos con la elaboración y gestión del plan de movilidad de la EPSEB y en este trabajo queremos compartir nuestra percepción sobre posibles causas que dificultan la internacionalización del estudiantado del grado de ATE. Asimismo, proponemos algunas ideas para promover la movilidad entre el alumnado.

Por último, hemos realizado una encuesta entre el estudiantado para conocer cómo perciben el programa de movilidad de la escuela y detectar las principales barreras que les impiden llevar a cabo una estancia en el extranjero. 


\section{Resultados}

La tabla 1 muestra la evolución del número de estudiantes en el grado de ATE y en el global de la UPC, así como el porcentaje de estudiantes que realizó una estancia de movilidad desde el curso 2010/11 hasta el curso 2020/21. Respecto al número de estudiantes podemos observar que se ha ido produciendo una reducción de estudiantes en cada curso académico, tanto en la UPC como en el grado de ATE. Esta disminución es más pronunciada en el grado de ATE, aproximadamente un $75 \%$ menos estudiantes en el curso 2020/21 respecto al curso 2010/11. En el global de la UPC el número de estudiantes se mantiene aproximadamente en un $80 \%$ de los estudiantes que había en el curso 2010/11. Es conocido que las carreras vinculadas con el sector de la construcción arrastran el efecto sobre la demanda de plazas que tuvo la crisis económica que se inició en 2008 y afectó duramente al sector de la construcción (Torre, 2014). Sin embargo, el porcentaje de estudiantes de ATE realizaron una estancia de movilidad en el extranjero (estudiantes outgoing) creció coincidiendo con los años de crisis económica, situándose en el curso $2014 / 15$ en $5,6 \%$ por encima del global de la UPC (4,1\%). A partir de ese momento hemos ido observando una disminución del interés del estudiantado por la movilidad con una reducción hasta el $1,2 \%$ de estudiantes outgoing en el curso $2018 / 19$, todavía no afectado por la pandemia.

Tabla 1. Evolución del número de estudiantes que han realizado una estancia de movilidad, en el grado de ATE y en el global de la UPC.

\begin{tabular}{|c|c|c|c|c|c|c|}
\hline \multirow{2}{*}{$\begin{array}{c}\text { Curso } \\
\text { académico }\end{array}$} & \multicolumn{2}{|c|}{ Estudiantes grado } & \multicolumn{2}{|c|}{ Estudiantes outgoing } & \multicolumn{2}{|c|}{$\begin{array}{l}\% \text { Estudiantes } \\
\text { outgoing }\end{array}$} \\
\hline & ATE & UPC & ATE & UPC & ATE & UPC \\
\hline $2020 / 21$ & 577 & 25901 & 2 & 787 & 0,3 & 3,0 \\
\hline $2019 / 20$ & 677 & 25378 & 4 & 1328 & 0,6 & 5,2 \\
\hline $2018 / 19$ & 657 & 27951 & 8 & 1337 & 1,2 & 4,8 \\
\hline $2017 / 18$ & 736 & 27966 & 20 & 1507 & 2,7 & 5,4 \\
\hline $2016 / 17$ & 794 & 28707 & 24 & 1401 & 3,0 & 4,9 \\
\hline $2015 / 16$ & 1019 & 28902 & 34 & 1353 & 3,3 & 4,7 \\
\hline $2014 / 15$ & 1241 & 30387 & 69 & 1249 & 5,6 & 4,1 \\
\hline $2013 / 14$ & 1526 & 30681 & 68 & 1646 & 4,5 & 5,4 \\
\hline $2012 / 13$ & 1837 & 31214 & 92 & 2613 & 5,0 & 8,4 \\
\hline $2011 / 12$ & 2165 & 31882 & 71 & 2150 & 3,3 & 6,7 \\
\hline $2010 / 11$ & 2330 & 32698 & 75 & 2243 & 3,2 & 6,9 \\
\hline
\end{tabular}

A continuación, analizaremos las principales razones que pueden explicar esa falta de interés por la movilidad y qué acciones podemos llevar a cabo para intentar revertir esa tendencia. 


\section{Percepción de la movilidad}

Como se ha podido ver en la evolución de la movilidad en los últimos 10 años, esta ha ido empeorando, en número, conforme la crisis económica iba remitiendo. Es decir, durante los primeros años, la movilidad se percibía como una oportunidad que tenían nuestros estudiantes para poder abrirse paso en otros mercados laborales menos perjudicados por la crisis del sector. El estudiantado se iba de Erasmus con la idea, en muchos casos, de no volver y aprovechar su estancia para encontrar un futuro que en nuestro país se veía, laboralmente hablando, complicado.

Sin embargo, curiosamente esto no dio valor a la movilidad en sí, el período de estancia en el extranjero no se percibió como una oportunidad de adquirir nuevas competencias, que fuesen un valor diferencial en el momento de entrar en el mercado laboral como arquitectos técnicos y arquitectas técnicas.

¿A qué se debe esto? Por una parte, a la imagen que tiene la propia movilidad Erasmus, lamentablemente más famosa por su componente lúdico que por los logros académicos de los que participan en este programa. Por otra parte, parece que el sector de la construcción históricamente siempre ha sido un sector fuertemente vinculado al territorio. Así, en la mayoría de los casos y exceptuando multinacionales, que en muchas ocasiones son de origen extranjero, las empresas constructoras trabajan principalmente en territorio nacional.

Esta fuerte relación de la territorialidad de las empresas constructoras ha provocado que nuestro estudiantado no vea la necesidad, ni siquiera la utilidad, de realizar una estancia de movilidad en el extranjero, puesto que la experiencia internacional no se percibe como algo que será valorado en el momento de entrar en el mercado laboral.

Si nuestro estudiantado percibe que en la mayoría de los casos no va a necesitar la experiencia internacional y, es más, que esa experiencia no se va a valorar en su currículo como una adquisición de competencias, sino más bien como una estancia lúdica, ¿querrá participar en una movilidad cuando tiene a su alcance otras posibilidades que se perciben cómo más útiles?

Por ello y tras ver que la realización de prácticas en empresa, que además en la UPC están remuneradas, se percibe como algo más útil y que interesa más a nuestro estudiantado, se ha planteado la posibilidad de facilitar al estudiantado la realización de Erasmus prácticas. Se pretende tener una bolsa de prácticas internacionales a la que el estudiantado interesado pueda acceder para presentar su candidatura.

\section{Coste económico de la movilidad}

Cómo bien sabemos el coste de vida en otros países es superior al nuestro, aunque hay que decir que Barcelona, ciudad donde está situada nuestra escuela, es considerada una ciudad cara con respecto a otras. Aún así, tradicionalmente el estudiantado no abandona el hogar familiar durante sus estudios, lo que permite que, en la mayoría de casos, aunque el coste de vida sea elevado, la vivienda y manutención del estudiante no sea un factor que impida la realización de una carrera universitaria. 
Sin embargo, esa ventaja se pierde al realizar una movilidad y el coste de vida del estudiante, durante su estancia en el extranjero, en muchos casos se convierte en un coste inasumible para las familias.

Hay que decir que las movilidades Erasmus van asociadas a una ayuda económica mensual, pero esta ayuda no cubre el coste de vida de la mayoría de países europeos.

Este es un problema al que difícilmente se le pueda encontrar solución por parte de la Escuela o la Universidad. Pero sí se ha observado en los grupos de trabajo con estudiantado, que estos desconocen que además de la ayuda económica Erasmus, puede solicitar otras becas compatibles con este tipo de movilidades (de la Generalitat de Catalunya y de otras entidades privadas).

Es por ello que se realizará una campaña de comunicación para hacer llegar esta información al estudiantado, no sólo la información debe estar disponible en el apartado de movilidad de la web, puesto que sólo la verían aquellos que entrasen en ese apartado, sino que es imprescindible que todos nuestros estudiantes matriculados sepan qué es una movilidad, qué tipos de movilidades hay, a qué países, qué requisitos hay para poder realizarlas y qué ayudas económicas pueden conseguir en cada caso. Además, también hay que difundir los beneficios que realizar una estancia en extranjero puede aportar, tanto en lo que se refiere a la adquisición de competencias, al aprendizaje de una tercera lengua y a la formación de una red de contactos internacional que puede ser muy beneficiosa para el futuro laboral de nuestro estudiantado.

Esta campaña debería ir también acompañada de la presentación de casos de antiguos alumnos que nos hablen de su experiencia durante la movilidad $y$, sobre todo, de qué beneficios le ha aportado una vez finalizados sus estudios.

\section{Oferta de movilidad}

La UPC es una universidad donde la gestión de los acuerdos de movilidad Erasmus europeos está totalmente descentralizada, es decir, cada escuela o facultad gestiona sus propios acuerdos bilaterales. Si a esto le sumamos que en la UPC ya existen grados como el de Ingeniería Civil y Arquitectura, vemos como en muchas ocasiones se nos complica el poder realizar acuerdos con universidades de prestigio, sobre todo en países donde no hay una correspondencia directa con el grado en Arquitectura Técnica y Edificación.

¿Qué necesidad tiene una universidad europea de prestigio en hacer un acuerdo bilateral de movilidad con nuestro grado, si ya los tiene con Arquitectura e Ingeniería Civil?, ¿Es más qué sentido tiene para ellos hacer ese acuerdo si en su país no existe un grado de building engineering o similar? $Y$ ¿qué podemos hacer con esos países donde sí existe una carrera similar pero es una carrera técnica de 2 o 3 años, una minor?

No hay que olvidar que nuestro grado es habilitante y que no podemos aceptar que la realización de una estancia en el extranjero perjudique a nuestro estudiantado no permitiendo que adquieran las competencias necesarias para acabar de forma adecuada en tiempo y forma sus estudios. Este es un compromiso adquirido no sólo con nuestro 
estudiantado, sino también, como universidad pública que somos, con la sociedad a la que prestamos servicio.

Todas estas consideraciones nos han hecho replantearnos nuestra oferta de movilidad y buscar qué podemos ofrecer para ser más atractivos ante futuros partners. Partners que deben ser universidades de reconocido prestigio, que sepamos que pueden aportar a nuestro estudiantado una experiencia académica rica, que le sirva para su futuro profesional.

Tras trabajar con grupos de estudiantes propios y también con estudiantes de movilidad incoming vimos que nuestros principales puntos fuertes eran, por una parte el prestigio de la escuela y la universidad, por otra nuestra cada vez más amplia oferta de asignaturas en inglés, además el prestigio de algunos de nuestros laboratorios, referentes en investigación en ámbitos como la prevención contra incendios, los materiales de construcción, la eficiencia energética y la rehabilitación de patrimonio construido y, finalmente, la ciudad, Barcelona.

Teniendo estas ventajas presentes se ha trabajado en ampliar la oferta de asignaturas en inglés de modo que actualmente ya se puede hacer 60 ECTS en ese idioma. Esto nos ha hecho crecer en los últimos años, dado que hemos pasado de recibir 40 alumnos de movilidad de procedencia internacional en el curso 2012/2013 a 74 en el curso 2018/2019, siendo 52 en el 2019/2020 curso en que la pandemia impidió seguir creciendo (GPAQUPC,2021).

También se está trabajando para dar mayor visibilidad a actividades que, si bien ya se llevaban a cabo, nunca habían tenido protagonismo en nuestra web y redes sociales. Así cada vez que se hacen visitas a edificios de alto valor arquitectónico, como el recinto modernista del Hospital de la Santa Creu i Sant Pau o la Sagrada familia entre muchos otros, se hacen sus correspondientes publicaciones.

Hay que reconocer que tenemos una gran ventaja respecto otros países y poblaciones al estar en una ciudad con un patrimonio arquitectónico de gran valor, que atrae cada año a miles de turistas, ese es uno de los principales motivos por lo que resultamos atractivos a nuestro estudiantado internacional. Así que podemos sacarle provecho haciendo que ese patrimonio forme parte de la experiencia del estudiantado internacional. Curiosamente era algo que ya hacíamos, pero de nuevo no habíamos sido conscientes de la necesidad de dar visibilidad a este tipo de actividades.

Y como ya se ha dicho también están nuestros laboratorios, referente en ámbitos de investigación y transferencia de tecnología y que hasta ahora no han tenido el protagonismo debido. Estos laboratorios no están desvinculados de la docencia, al contrario, todos ellos participan de forma directa en la docencia del grado, haciendo diversas clases, a lo largo del curso, en sus instalaciones. Esto nos permite no tener que cambiar la forma como trabajamos, sino simplemente, tener que dar visibilidad a algo que, si bien para nosotros forma parte de la normalidad, para otros estudiantes de otras procedencias resulta tremendamente atractivo. Además, a esto hay que añadir, que nuestro profesorado, 
muchos de ellos y ellas vinculados a estos laboratorios, participa en proyectos europeos de investigación y fomento de la docencia, con lo que tiene socios en distintas instituciones.

Finalmente hay un último punto que también nos puede ayudar a mejorar nuestra oferta de movilidad, y es las redes internacionales en las que participa la UPC, como se puede ver en esta imagen, pertenecemos a una universidad muy activa en el ámbito de la internacionalización.

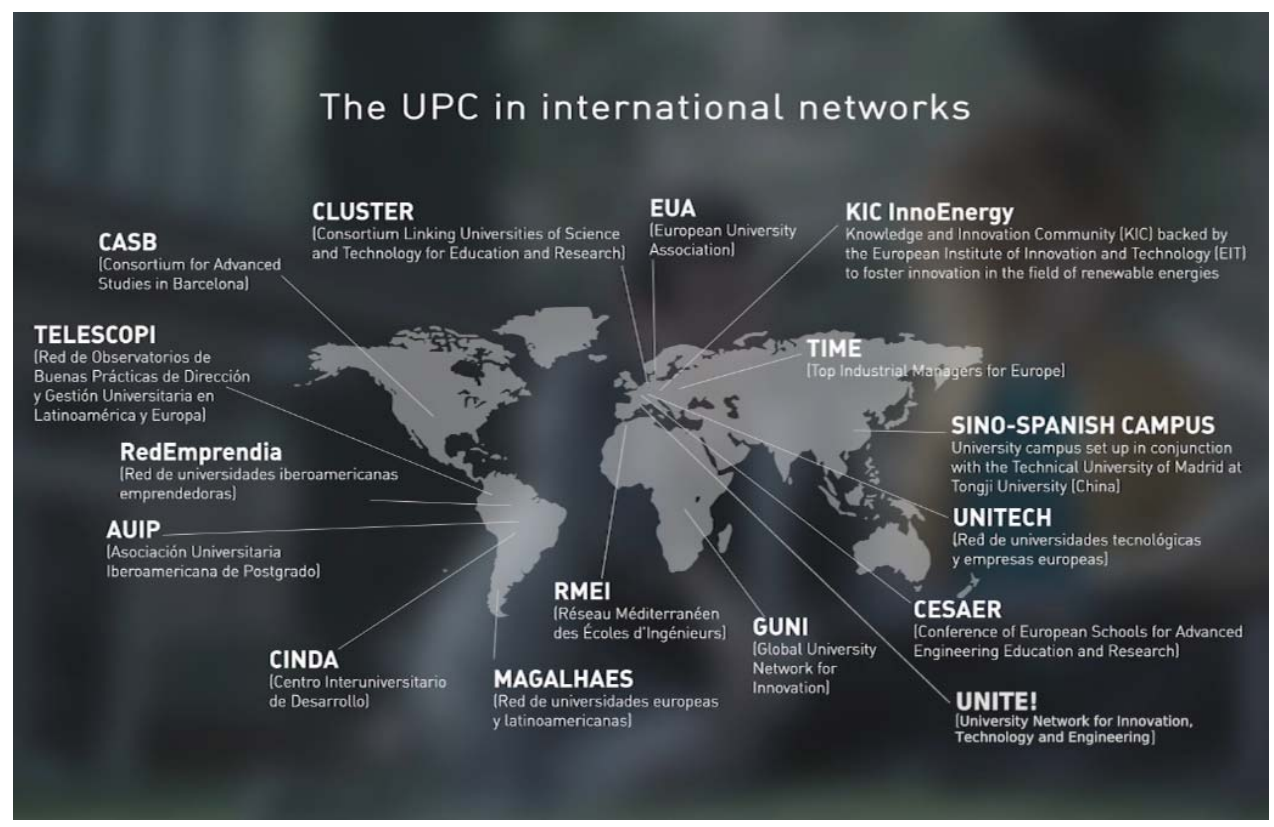

Fig. 1 Redes internacionales en las que participa la UPC (GRI-UPC, 2021)

Ahora que sabemos qué podemos aportar a nuestros futuros partners, ha llegado el momento de, con la ayuda del gabinete de relaciones internacionales de la UPC, contactar con universidades que ya son socias y que pueden ver en nosotros, una escuela más pequeña que las que ofrecen los grados de arquitectura e ingeniería civil, un espacio que cuida mucho su oferta de estudios en inglés y donde además sus estudiantes podrán participar en actividades altamente enriquecedoras, tanto aprendiendo del patrimonio arquitectónico de la ciudad, como de las actividades de experimentación en laboratorios que están vinculadas a distintas asignaturas y talleres del grado.

\section{Conclusiones}

Tras el análisis realizado hemos identificado diversos factores que dificultan el acceso a la movilidad del estudiantado de ATE y planteamos las siguientes líneas de actuación para fomentar la internacionalización del alumnado: 
- Ampliar la oferta de movilidad a estancias cortas pensadas para ser realizadas fuera del período lectivo y que tengan como objetivo la adquisición de competencias concretas muy relacionadas con el temario del plan de estudios.

Para poder ofrecer estas estancias cortas tenemos previsto aprovechar que el nuevo programa Erasmus ya contempla este tipo de estancias, que la Universitat Politècnica de Catalunya (UPC) pertenece a la red de universidades europea Unite! que organiza, entre otras muchas cosas, la oferta de cursos de varias semanas, y también la participación de profesorado de la escuela en proyectos Erasmus+ dentro de las Key Action 2 que contemplan y permiten financiar la movilidad de estudiantes para realizar cursos intensivos.

- Mejorar la oferta de movilidad. Ahora mismo tenemos una oferta variada, pero según nos han notificado representantes de los estudiantes en distintos grupos de trabajo, esta oferta no es lo suficientemente atractiva.

- Potenciar el Erasmus prácticas. Según hemos podido constatar las prácticas en empresas sí están muy bien valoradas por nuestro estudiantado y, de hecho, exceptuando los dos años de pandemia, el número total de convenios por curso, estaba subiendo cada año. Sin embargo, nuestro estudiantado no realiza ningún Erasmus prácticas, puesto que, según nos han expresado, ven muy complicado conseguir esas prácticas en el extranjero sin tener contactos previos a los que poder acudir. Por ello, aprovechando los contactos que tiene la escuela y su profesorado, queremos facilitar una oferta de prácticas en otros países que ayude a nuestro estudiantado a adquirir más experiencia en un mundo cada vez más globalizado.

- Hacer una campaña de comunicación para acercar todas las posibilidades para realizar una movilidad y sus beneficios al estudiantado. No solo hay que facilitar la información a aquellos que la busquen, ahora mismo es necesario acercar esta información a toda la comunidad, puesto que hemos detectado mucho desconocimiento respecto a qué posibilidades tienen y cómo realizar las distintas posibilidades de movilidad que ofrece la universidad.

\section{Referencias}

AGÈNCIA PER A LA QUALITAT DEL SISTEMA UNIVERSITARI DE CATALUNYA (AQU) (2015). Ocupabilitat i competències dels graduats recents: l'opinió d'empreses i institucions. Barecelona: AQU. <https://www.aqu.cat/doc/doc_69192241_1.pdf> [Consulta: 30 de junio de 2021]

GABINET DE PLANIFICACIÓ, AVALUACIÓ I QUALITAT (GPAQ) - UPC. Dades estadístiques i de gestió. <https://gpaq.upc.edu/lldades/indicador.asp?index=1_6_1> [Consulta: 30 de junio de 2021]

GABINETE DE RELACIONES INTERNACIONALES (GRI) - UPC. Alianzas internacionales. $<$ https://www.upc.edu/sri/es/alianzas> [Consulta: 30 de junio de 2021] 
Movilidad de los estudiantes de Arquitectura Técnica y Edificación: diagnóstico y oportunidades Mobility of Architectural Technology and Building Construction students: diagnosis and opportunities

(TORRE, 2014) TORRE, N (2014). "Las carreras ligadas a la crisis de la construcción se hunden en las aulas" en El Mundo.

https://www.elmundo.es/comunidad-valenciana/2014/07/19/53ca2073e2704efb4c8b456e.html [Consulta: 30 de junio de 2021] 
ISBN: 978-84-9048-409-8

||||||||||||||||||||||||||||||||
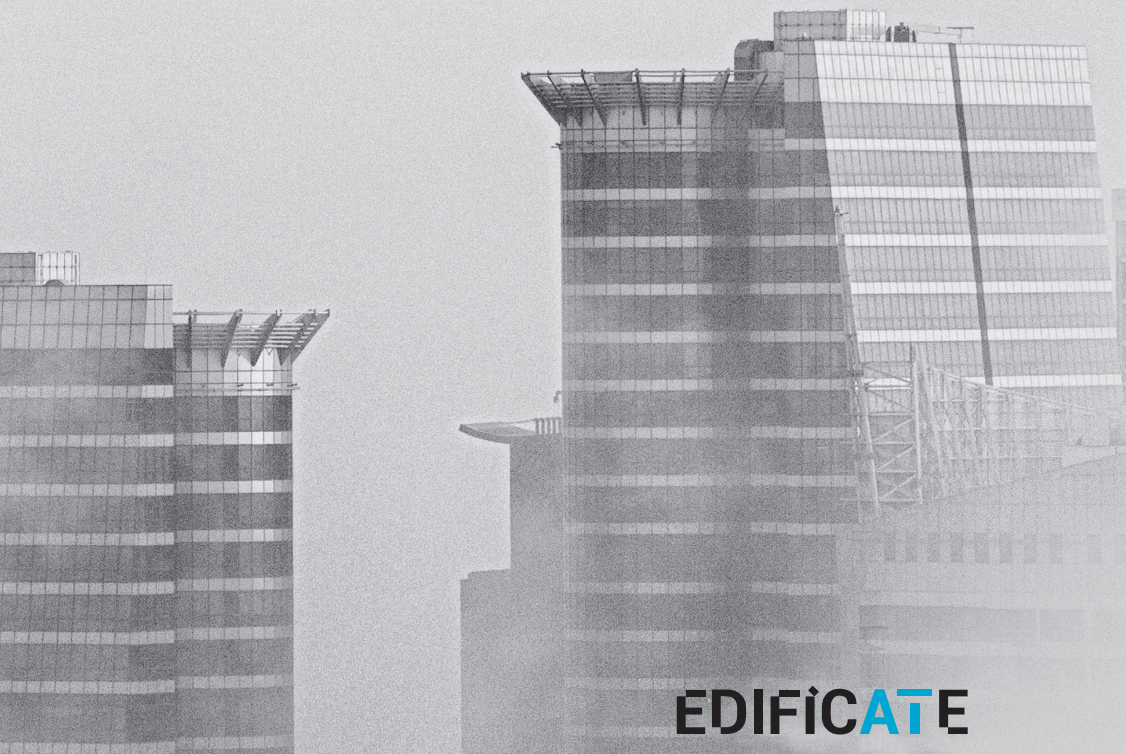